DOE/ID-10521/3

SAND96-0721/3 - UC-2020

Unlimited Release

\title{
Performance Evaluation of the Technical Capabilities of DOE Sites for Disposal of Mixed Low-Level Waste
}

Volume 3: Site Evaluations

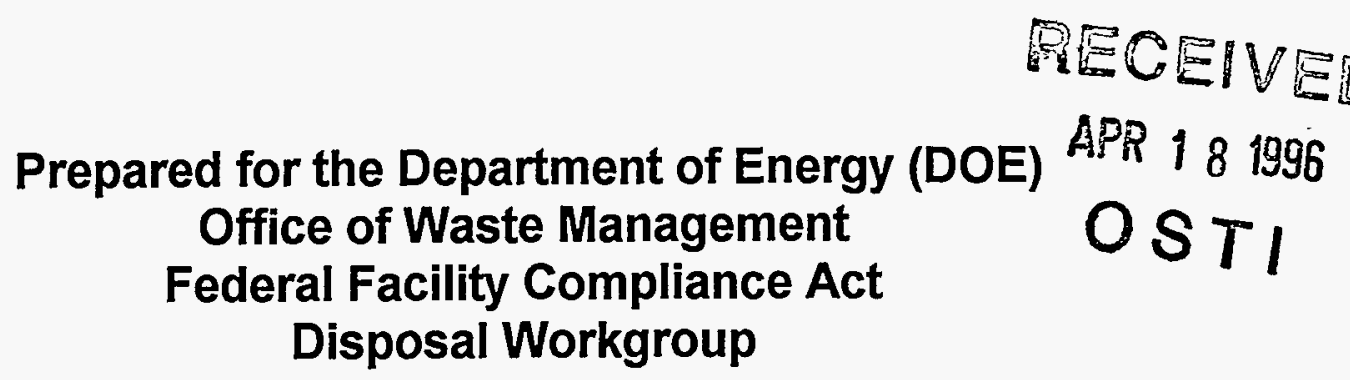

by

Robert D. Waters and Marilyn M. Gruebel, Editors

Sandia National Laboratories

March 1996

Sandia National Laboratories

Albuquerque, New Mexico

Prepared by

Sandia National Laboratories

Albuquerque, New Mexico 87185 and Livermore, California 94550

for the United States Department of Energy

under Contract DE-AC04-AL85000

Approved for public release; distribution is unlimited. 
Issued by Sandia National Laboratories, operated for the United States Department of Energy by Sandia Corporation.

NOTICE: This report was prepared as an account of work sponsored by an agency of the United States Government. Neither the United States Govern-ment nor any agency thereof, nor any of their employees, nor any of their contractors, subcontractors, or their employees, makes any warranty, express or implied, or assumes any legal liability or responsibility for the accuracy, completeness, or usefulness of any information, apparatus, product, or process disclosed, or represents that its use would not infringe privately owned rights. Reference herein to any specific commercial product, process, or service by trade name, trademark, manufacturer, or otherwise, does not necessarily constitute or imply its endorsement, recommendation, or favoring by the United States Government, any agency thereof or any of their contractors or subcontractors. The views and opinions expressed herein do not necessarily state or reflect those of the United States Government, any agency thereof or any of their contractors.

Printed in the United States of America. This report has been reproduced directly from the best available copy.

Available to DOE and DOE contractors from

Office of Scientific and Technical Information

PO Box 62

Oak Ridge, TN 37831

Prices available from (615) 576-8401, FTS 626-8401

Available to the public from

National Technical Information Service

US Department of Commerce

5285 Port Royal Rd

Springfield, VA 22161

NTIS price codes

Printed copy: A99

Microfiche copy: A01 
DOE/ID-10521/3

SAND96-0721/3 • UC-2020

Unlimited Release

\title{
Performance Evaluation of the Technical Capabilities of DOE Sites for Disposal of Mixed Low-Level Waste
}

\author{
Volume 3: Site Evaluations
}

\section{Prepared for the Department of Energy (DOE) Office of Waste Management Federal Facility Compliance Act Disposal Workgroup}

\author{
by \\ Robert D. Waters and Marilyn M. Gruebel, Editors \\ Sandia National Laboratories
}

March 1996

Sandia National Laboratories

Albuquerque, New Mexico

\begin{abstract}
A team of analysts designed and conducted a performance evaluation to estimate the technical capabilities of fifteen Department of Energy sites for disposal of mixed low-level waste (i.e., waste that contains both low-level radioactive materials and hazardous constituents). Volume 1 summarizes the process for selecting the fifteen sites, the methodology used in the evaluation, and the conclusions derived from the evaluation. Volume 2 provides details about the site-selection process, the performance-evaluation methodology, and the overall results of the analysis. Volume 3 contains detailed evaluations of the fifteen sites and discussions of the results for each site.
\end{abstract}



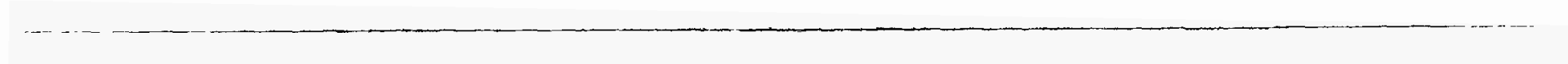


\section{PREFACE}

This report documents the performance evaluation of facilities at various Department of Energy (DOE) sites relative to their capabilities for the disposal of mixed low-level waste (MLLW). The principal goal in developing the performance evaluation (PE) was to estimate the limiting concentrations of radionuclides in residuals resulting from treatment of MLLW for disposal at these sites. The report consists of three volumes:

Volume 1 is an executive summary both of the PE methodology and of the results obtained from the PEs. While this volume briefly reviews the scope and method of analyses, its main objective is to emphasize the important insights and conclusions derived from the conduct of the PEs.

Volume 2 first describes the screening process used to determine the sites to be considered in the PEs. This volume then provides the technical details of the methodology for conducting the performance evaluations. It also provides a comparison and analysis of the overall results for all sites that were evaluated.

Volume 3 presents the results of the PEs for the 15 sites considered in the process. This presentation includes a discussion of the conceptual models and data used in the PE for each site.

The $\mathrm{PE}$ is not a substitute for the detailed analyses provided by performance assessments required by DOE Order 5820.2A; rather, it is a means for the DOE and the States to begin evaluating options for disposal of MLLW treatment residuals. The ultimate identification of sites that may host MLLW disposal activities will follow state and federal regulations for siting and permitting and will include public involvement in the decision-making process. The appropriate site-specific performance or risk assessments and environmental impact analyses in accordance with the National Environmental Policy Act will be required in determining limits on quantities of radionuclides that may be acceptable for disposal at any site. 


\section{ACKNOWLEDGMENTS}

The contributors to this report thank the technical staff of the sites included in the performance evaluations. Their input to and thorough review of the data and conceptual models contained in their respective site chapters added greatly to the quality of the results presented in this report. The site personnel involved in the project are acknowledged individually at the end of each site chapter.

The DOE FFCAct Disposal Workgroup, whose members are listed in the front of Volume 1 of this report, contributed significant technical input to the report and oversight for both the report and the entire project. Joel Case (DOE/Idaho) and Martin Letourneau (DOE/EM-33) provided managerial and technical oversight; other members of this Steering Committee were Lance Mezga (Lockheed Martin Energy Systems/Oak Ridge) and Linda Suttora (DOE/EM-431).

The Senior Review Panel provided independent review of the performance evaluation. The panel consisted of the following members:

Dade W. Moeller [Chairman]

Randall J. Charbeneau

William P. Dornsife

Frank L. Parker

Vern C. Rogers

Kristin Shrader-Frechette
President, Dade Moeller \& Associates, Inc.

Center for Research in Water Resources, University of Texas at Austin

Department of Environmental Resources, Commonwealth of Pennsylvania

Environmental and Water Resources Engineering, Vanderbilt University

President, Rogers \& Associates Engineering Corp.

Environmental Sciences and Policy Program, University of South Florida

The Review Team was responsible for the overall quality and consistency of the analysis. Members of the team were Margaret S.Y. Chu (Sandia National Laboratories [SNL]), Donald W. Lee and David C. Kocher (Oak Ridge National Laboratory [ORNL]), Elmer Wilhite (Westinghouse Savannah River Company), Rob Shuman (Rogers \& Associates Engineering Corp.), and John Starmer (ERM).

Evaluation of the sites considered in the performance evaluation was conducted by two Core Teams: one from Sandia National Laboratories and one from the Oak Ridge National Laboratory. Although only the primary Core Team contact is listed at the beginning of each site chapter, many people contributed to the overall methodology of the performance evaluation and to the information included in each of the site chapters. Other contributors to the compilation of the site chapters are the following:

Calculation of results (water pathway)

Calculation of results (atmospheric pathway)

Calculation of results (intruder pathway)

\author{
Maryann B. Hospelhom (SNL) \\ John D. Tauxe (ORNL) \\ Douglas A. Lombardi (ORNL) \\ Maria L. Socolof (ORNL)
}

Judy Campbell (Gram, Inc.) and Angela Guerin and Diana Dobias (SNL) provided key assistance in handling all the production details. 


\section{CONTENTS}

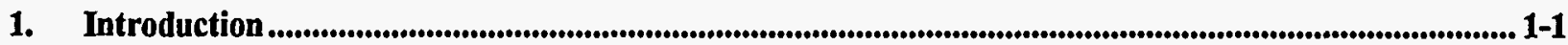

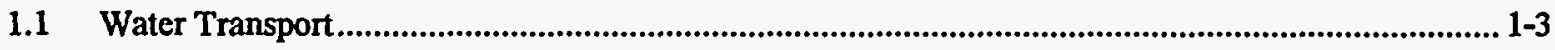

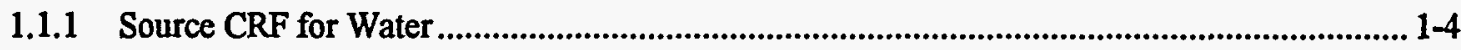

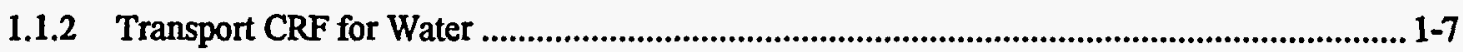

1.1.3 Radionuclide Travel Times in the Water Pathway ................................................................ 1-10

1.1.4 Decay Term for the Water Pathway ...................................................................... 1-11

1.2 Atmospheric Transport..................................................................................................11

1.2.1 Transport CRF for the Atmospheric Pathway ............................................................... 1-12

1.2.2 Radionuclide Travel Times in the Atmospheric Pathway .................................................. 1-14

1.2.3 Decay Term for the Atmospheric Pathway .................................................................1-14

1.3 Inadvertent Intruder Exposures ....................................................................................................... 1-14

2. California: Lawrence Livermore National Laboratory Site 300 (LLNL)................................................ 2-1

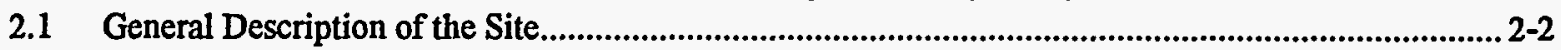

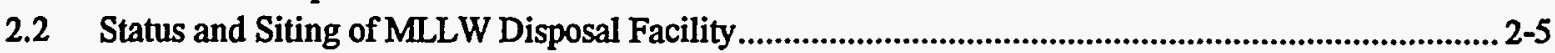

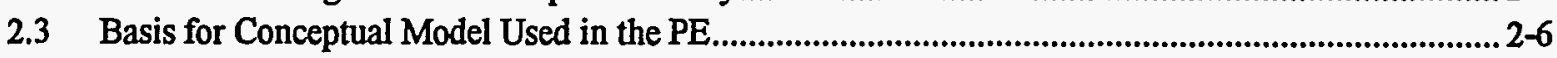

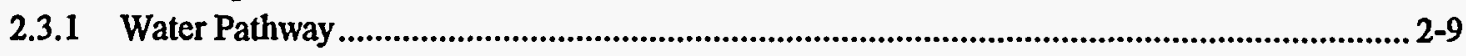

2.3.1.1 Current Understanding of Relevant Hydrogeology.......................................... 2-10

2.3.1.2 Conceptual Model Used in the PE................................................................ 2-11

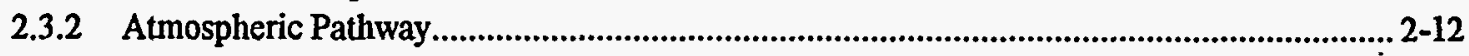

2.3.2.1 Current Understanding of Relevant Meteorology................................................ 2-12

2.3.2.2 Conceptual Model Used in the PE................................................................... 2-14

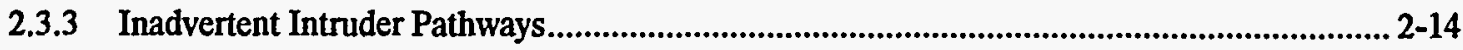

2.3.3.1 Current Understanding of Potential Modes of Inadvertent Intrusion .................... 2-16

2.3.3.2 Intruder Scenarios Used in the PE......................................................................... 2-16

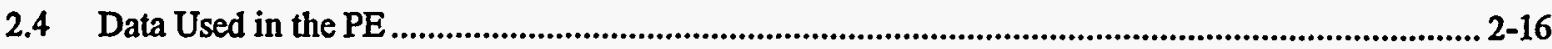

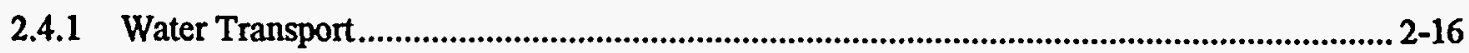

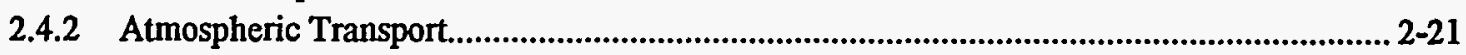

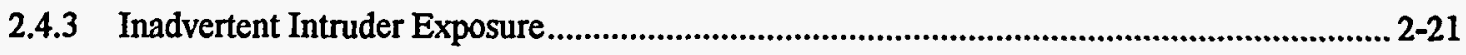

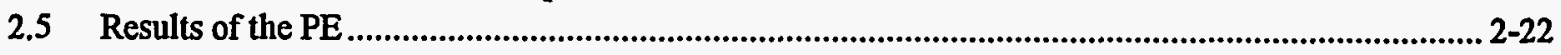

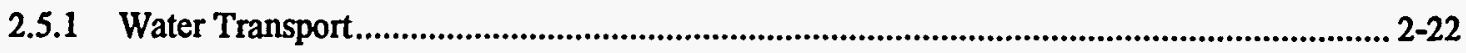

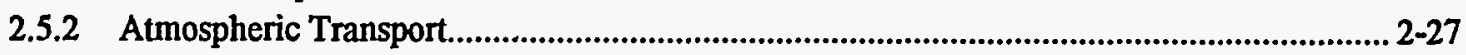

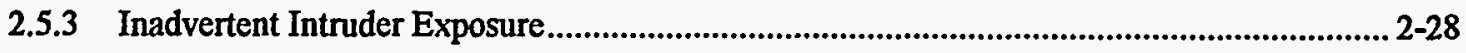

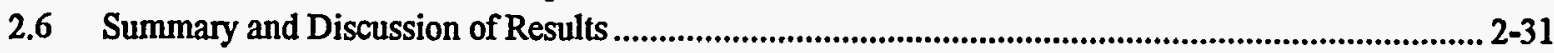

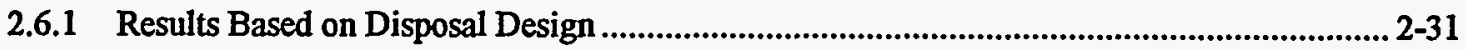

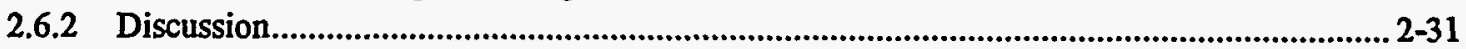

2.6.2.1 Parameter Sensitivity Analysis.................................................................... 2-34

2.6.2.2 Physical Constraints on Sensitivity Analysis Values............................................ 2-37

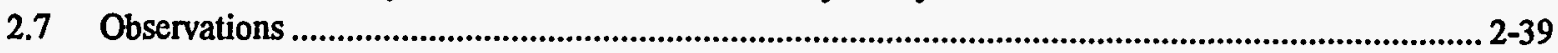

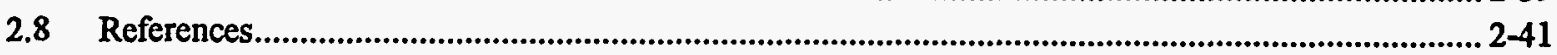

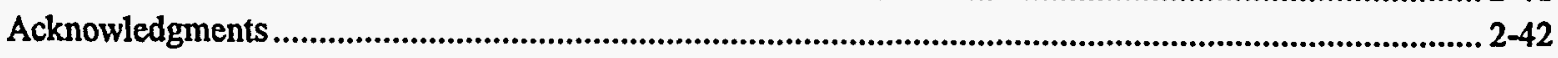

3. Colorado: Rocky Flats Environmental Technology Site (RFETS) ........................................................ 3-1

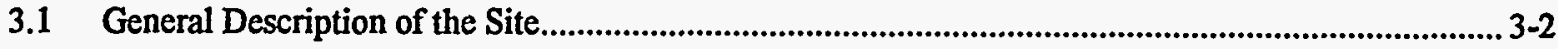

3.2 Status and Siting of MLLW Disposal Facility .......................................................................... 3-8 
3.3 Basis for Conceptual Model Used in the PE............................................................................... 3-9

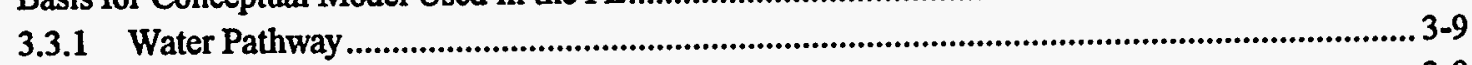

3.3.1.1 Current Understanding of Relevant Hydrogeology ................................................ 3-9

3.3.1.2 Conceptual Model Used in the PE ...................................................................... 3-12

3.3.2 Atmospheric Pathway................................................................................................ 3-14

3.3.2.1 Current Understanding of Relevant Meteorology ................................................ 3-14

3.3.2.2 Conceptual Model Used in the PE................................................................... 3-14

3.3.3 Inadvertent Intruder Pathways......................................................................................... 3-16

3.3.3.1 Current Understanding of Potential Modes of Inadvertent Intrusion ..................... 3-16

3.3.3.2 Intruder Scenarios Used in the PE.................................................................... 3-16

3.4 Data Used in the PE ............................................................................................................. 3-17

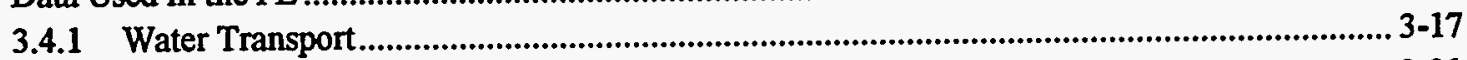

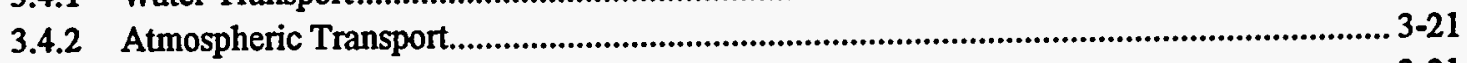

3.4.3 Inadvertent Intruder Exposure.................................................................................. 3-21

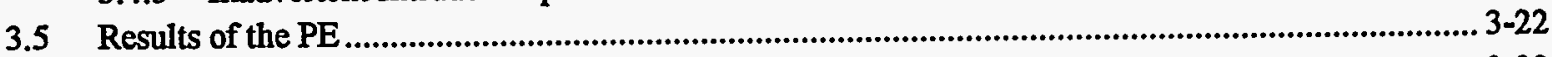

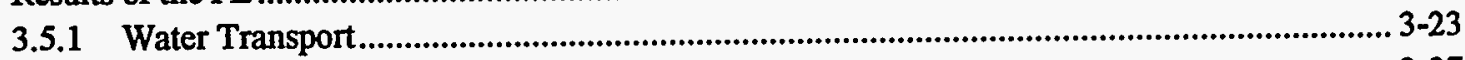

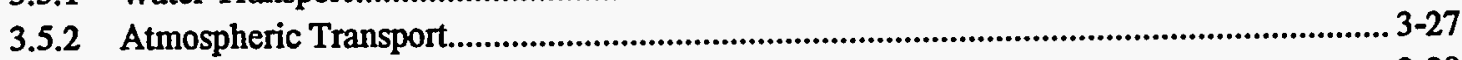

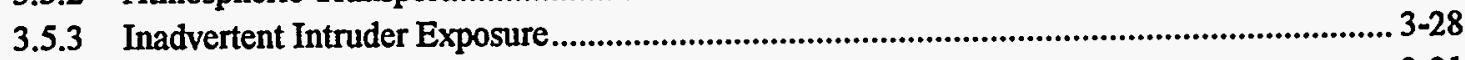

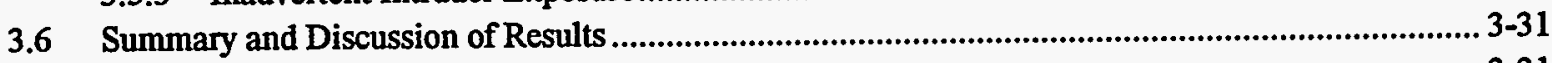

3.6.1 Results Based on Disposal Design ................................................................................ 3-31

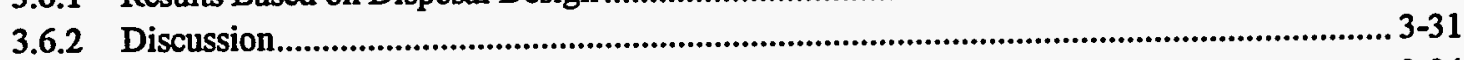

3.6.2.1 Parameter Sensitivity Analysis....................................................................... 3-34

3.6.2.2 Physical Constraints on Sensitivity Analysis Values.......................................... 3-38

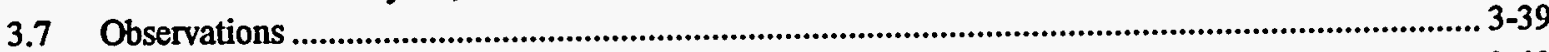

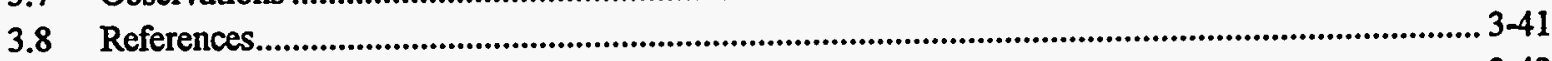

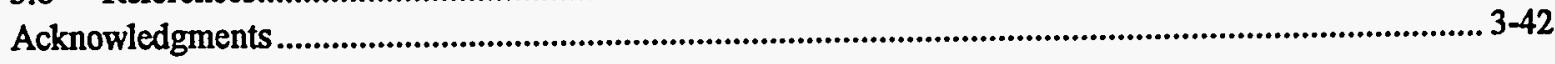

4. Idaho: Idaho National Engineering Laboratory (INEL) ........................................................................... 4-1

4.1 General Description of the Site................................................................................................... 4-2

4.2 Status and Siting of MLLW Disposal Facility................................................................................. 4-6

4.3 Basis for Conceptual Model Used in the PE.................................................................................. 4-7

4.3.1 Water Pathway ............................................................................................................ 4-7

4.3.1.1 Current Understanding of Relevant Hydrogeology ................................................ 4-7

4.3.1.2 Conceptual Model Used in the PE ......................................................................... 4-9

4.3.2 Atmospheric Pathway......................................................................................................... 4-10

4.3.2.1 Current Understanding of Relevant Meteorology ................................................ 4-10

4.3.2.2 Conceptual Model Used in the PE.................................................................... 4-12

4.3.3 Inadvertent Intruder Pathways..................................................................................... 4-12

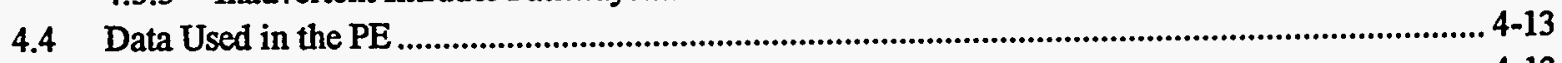

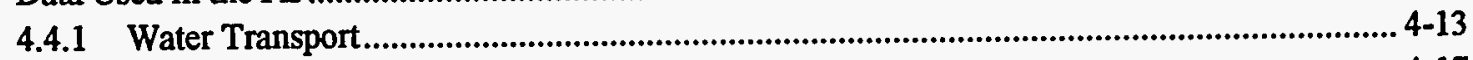

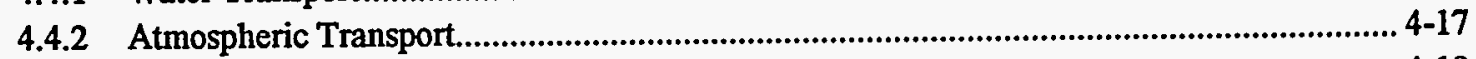

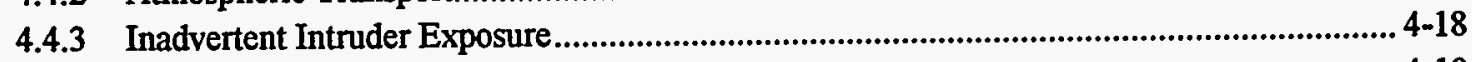

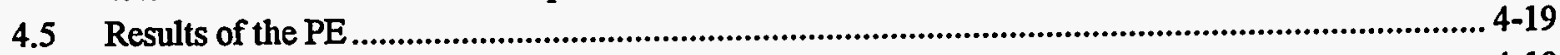

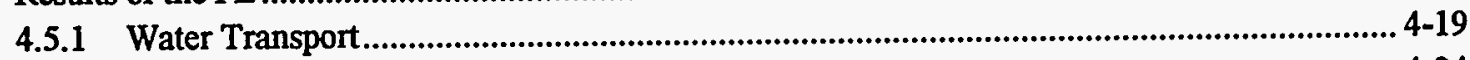

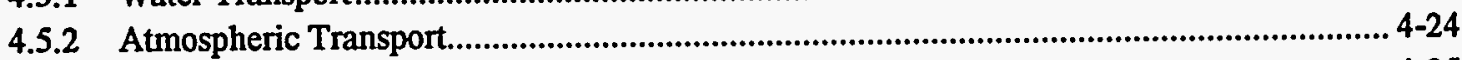

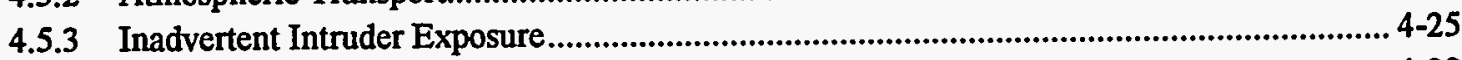

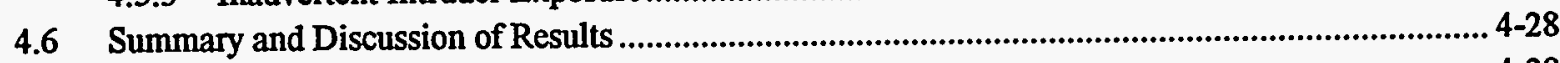

4.6.1 Results Based on Disposal Design ............................................................................... 4-28

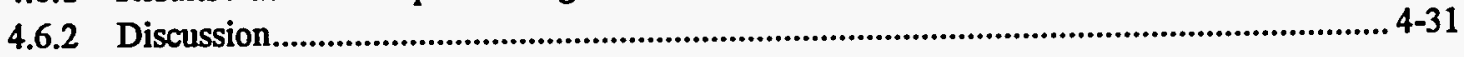


4.6.2.1 Parameter Sensitivity Analysis......................................................................... 4-31

4.6.2.2 Physical Constraints on Sensitivity Analysis Values ........................................... 4-36

4.6.2.3 Comparison of Conceptual Models and Results between the PE and the INEL Performance Assessment ............................................................................ 4-37

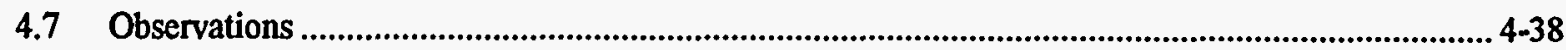

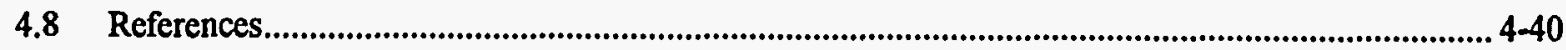

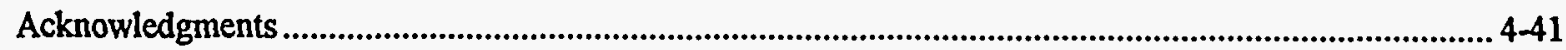

5. Ilinois: Argonne National Laboratory - East (ANLE)...................................................................................5 5-1

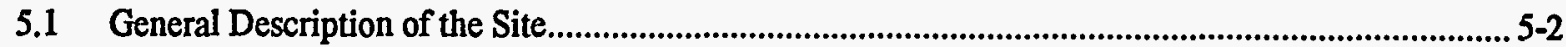

5.2 Status and Siting of MLLW Disposal Facility ............................................................................ $5-5$

5.3 Basis for Conceptual Model Used in the PE.............................................................................. 5-7

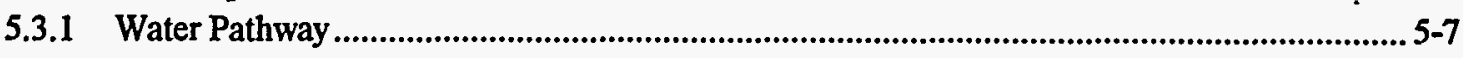

5.3.1.1 Current Understanding of Relevant Hydrogeology..............................................5 5-7

5.3.1.2 Conceptual Model Used in the PE .................................................................. 5

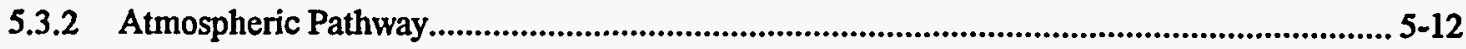

5.3.2.1 Current Understanding of Relevant Meteorology.............................................. 5-12

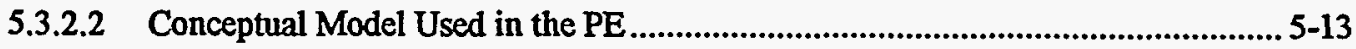

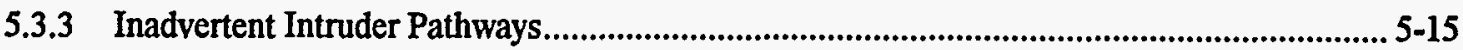

5.3.3.1 Current Understanding of Potential Modes of Inadvertent Intrusion ..................... 5-15

5.3.3.2 Intruder Scenarios Used in the PE..................................................................... 5-16

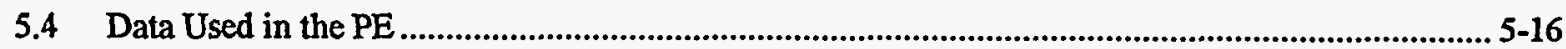

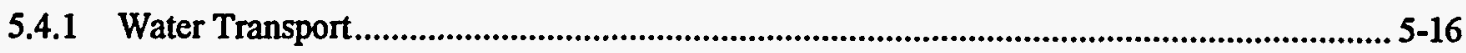

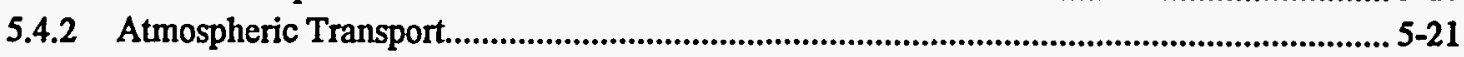

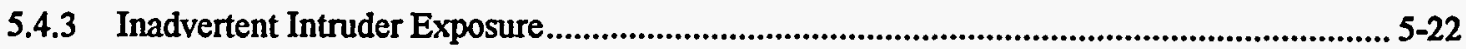

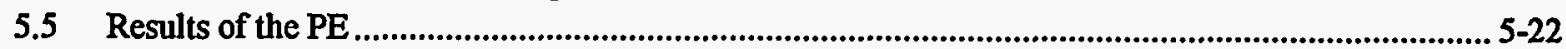

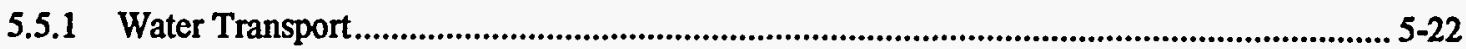

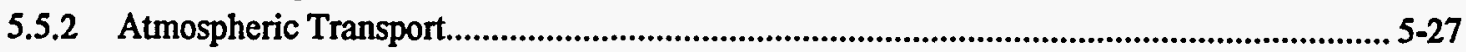

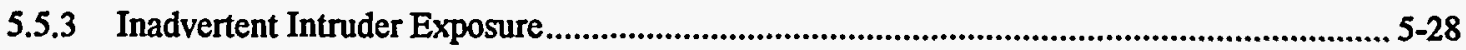

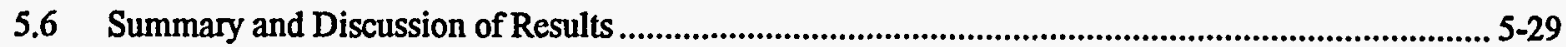

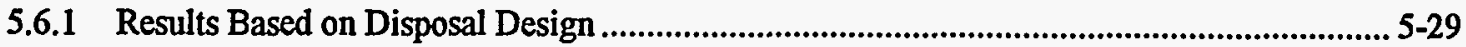

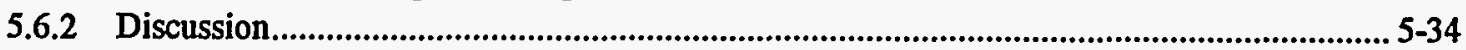

5.6.2.1 Parameter Sensitivity Analysis...................................................................... 5-35

5.6.2.2 Physical Constraints on Sensitivity Analysis Values............................................ 5-38

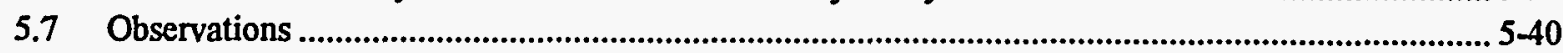

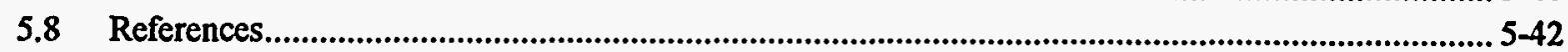

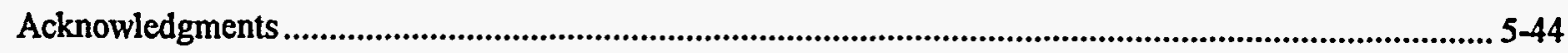

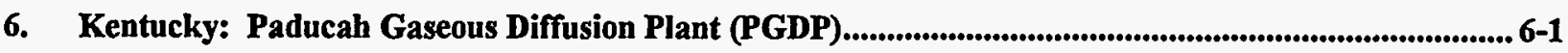

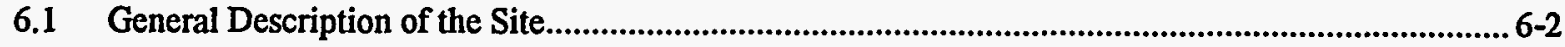

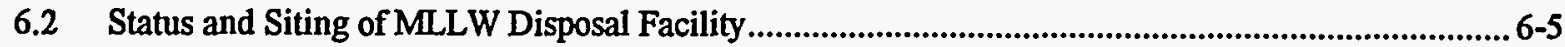

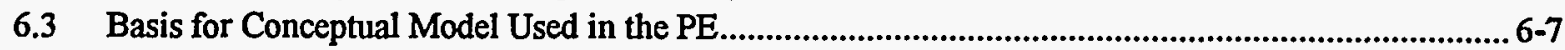

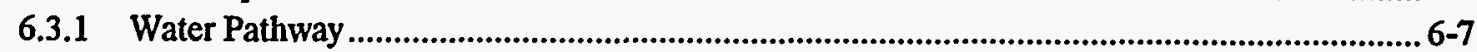

6.3.1.1 Current Understanding of Relevant Hydrogeology...............................................6-7

6.3.1.2 Conceptual Model Used in the PE ................................................................... 6-9

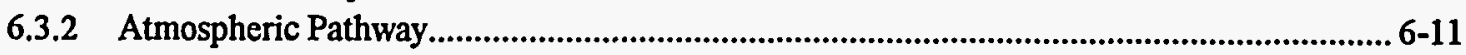

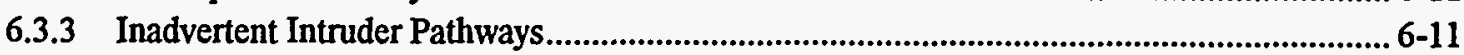

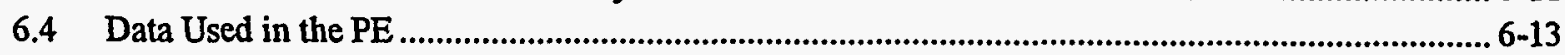

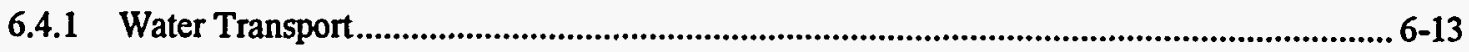




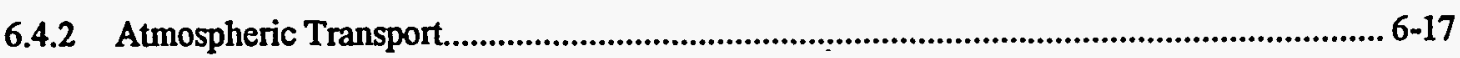

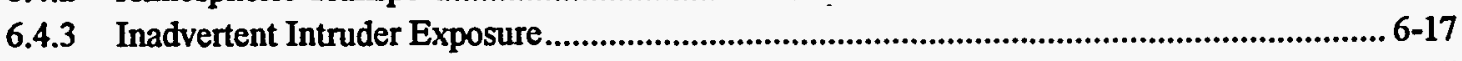

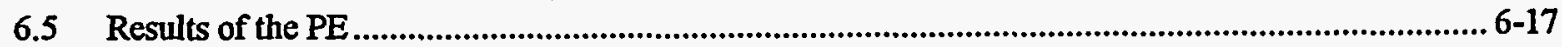

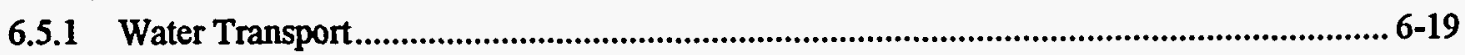

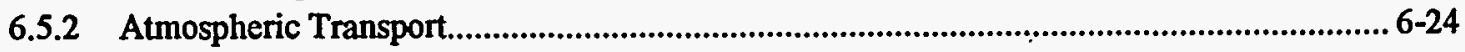

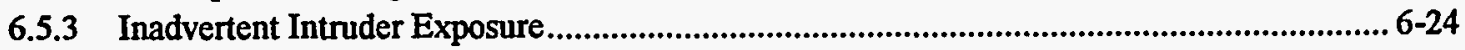

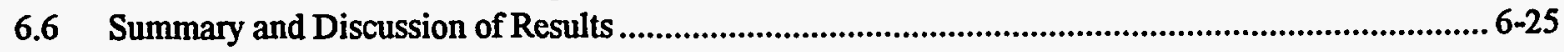

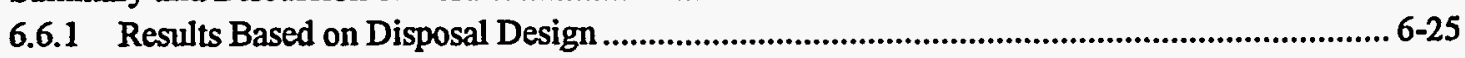

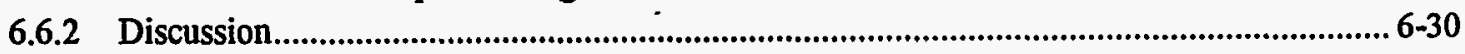

6.6.2.1 Parameter Sensitivity Analysis..................................................................6-31

6.6.2.2 Physical Constraints on Sensitivity Analysis Values......................................... 6-35

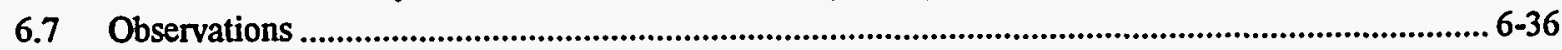

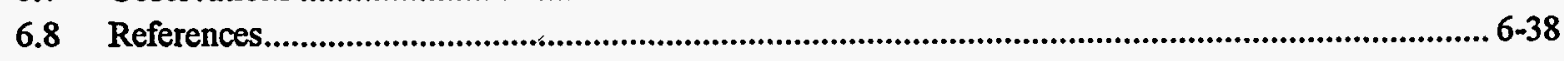

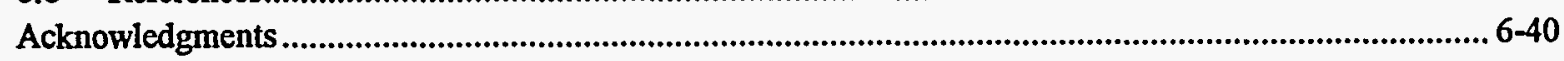

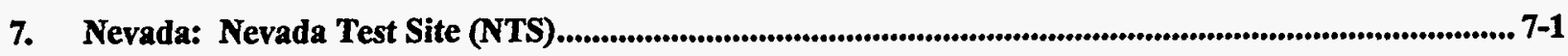

7.1 General Description of the Site................................................................................................... 7-2

7.2 Status and Siting of MLLW Disposal Facility .................................................................................. 7-5

7.3 Basis for Conceptual Model Used in the PE................................................................................. 7-7

7.3.1 Water Pathway ..................................................................................................................... 7-7

7.3.1.1 Current Understanding of Relevant Hydrogeology .................................................. 7-7

7.3.1.2 Conceptual Model Used in the PE ............................................................. 7-12

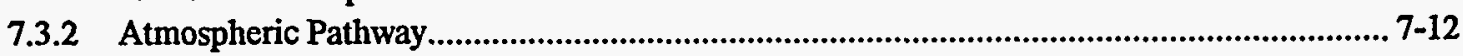

7.3.2.1 Current Understanding of Relevant Meteorology ................................................ 7-12

7.3.2.2 Conceptual Model Used in the PE ................................................................ 7-13

7.3.3 Inadvertent Intruder Pathways............................................................................................ 7-15

7.3.3.1 Current Understanding of Potential Modes of Inadvertent Intrusion .................... 7-15

7.3.3.2 Intruder Scenarios Used in the PE............................................................. 7-15

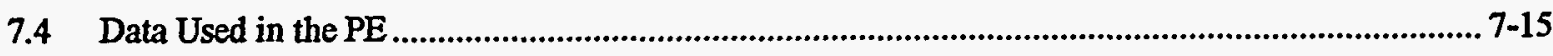

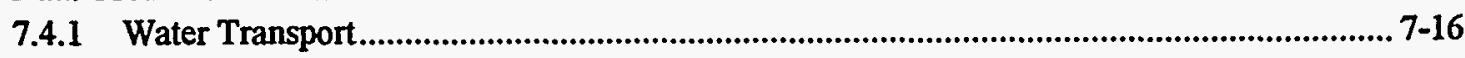

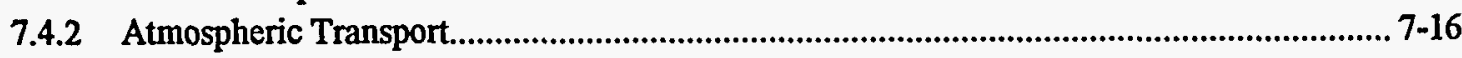

7.4.3 Inadvertent Intruder Exposure ................................................................................... 7-17

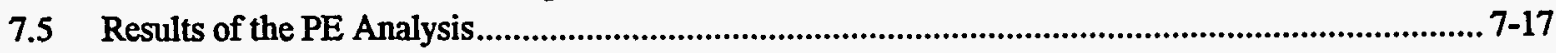

7.5.1 Water Transport.................................................................................................................... 7-17

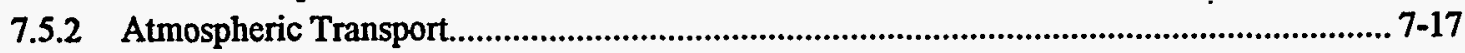

7.5.3 Inadvertent Intruder Exposure ......................................................................................... 7-18

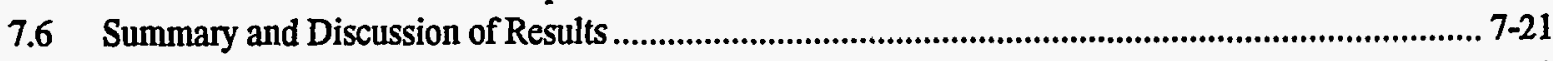

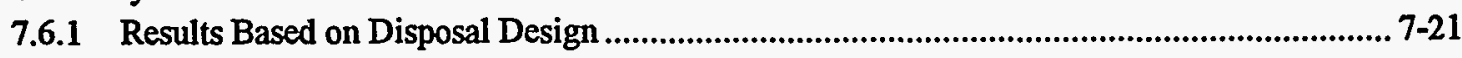

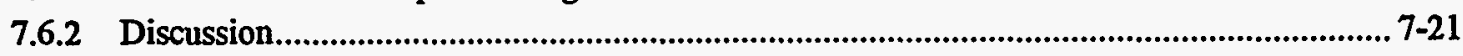

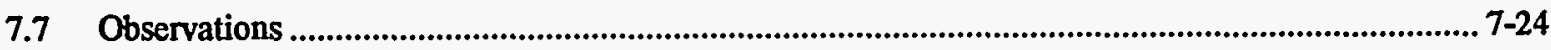

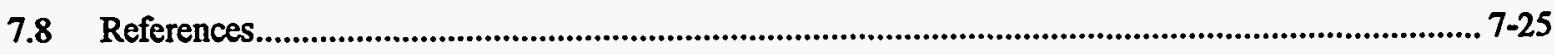

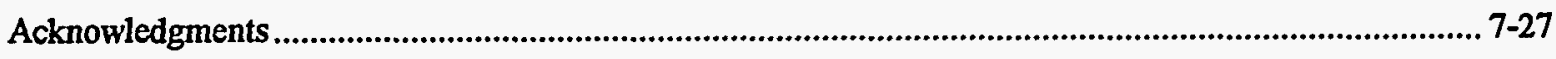

8. New Mexico: Los Alamos National Laboratory (LANL)............................................................................ 8-1

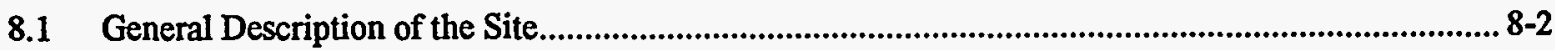

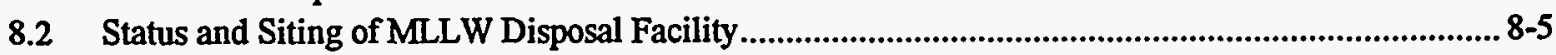

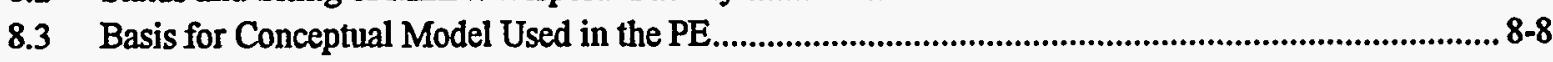

8.3.1 Water Pathway ........................................................................................................................ 8-8

8.3.1.1 Current Understanding of Relevant Hydrogeology ................................................. 8-9

viii 
8.3.1.2 Conceptual Model Used in the PE.................................................................. 8-13

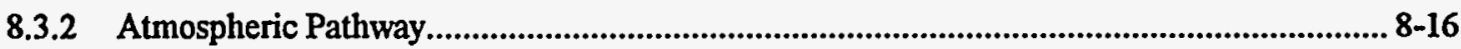

8.3.2.1 Current Understanding of Relevant Meteorology................................................. 8-16

8.3.2.2 Conceptual Model Used in the PE ........................................................................ 8-18

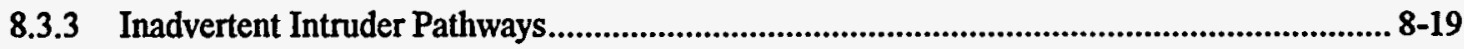

8.3.3.1 Current Understanding of Potential Modes of Inadvertent Intrusion .................... 8-19

8.3.3.2 Intruder Scenarios Used in the PE................................................................. 8-19

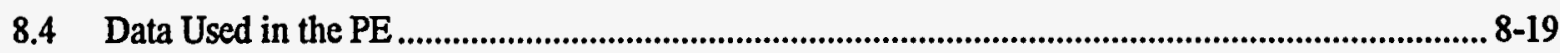

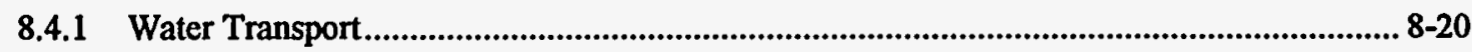

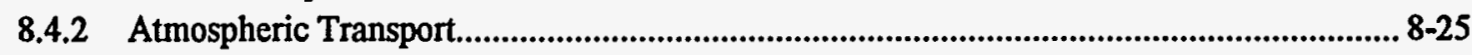

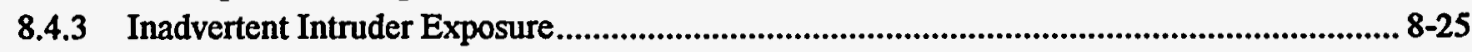

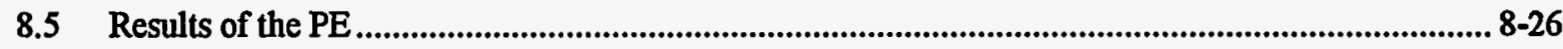

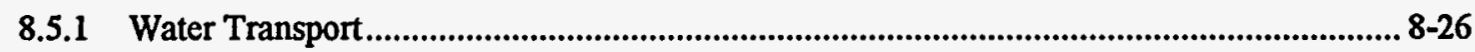

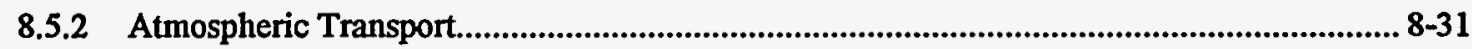

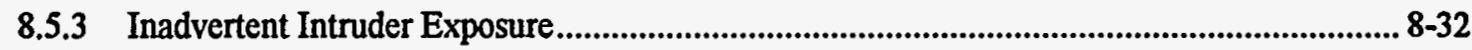

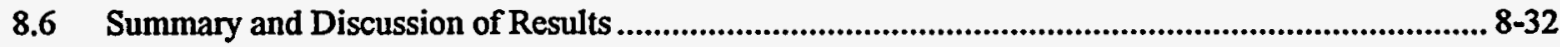

8.6.1 Results Based on Disposal Design ............................................................................ 8-37

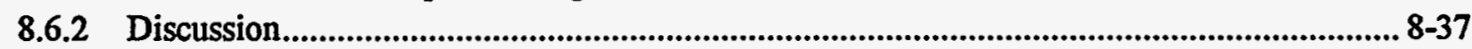

8.6.2.1 Parameter Sensitivity Analysis...................................................................... 8-38

8.6.2.2 Physical Constraints on Sensitivity Analysis Values.......................................... 8-41

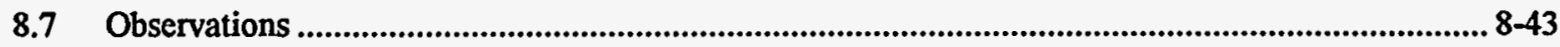

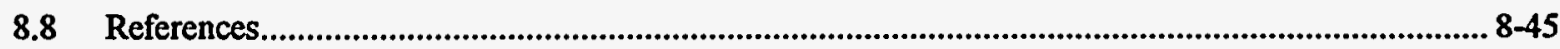

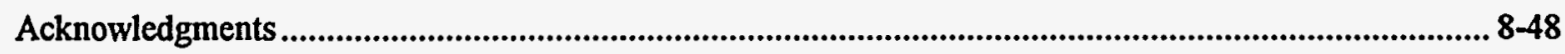

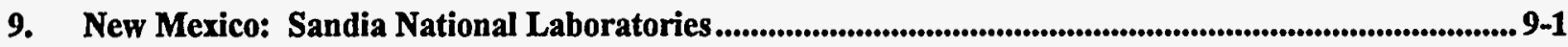

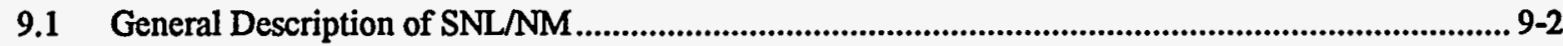

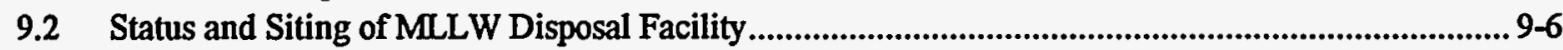

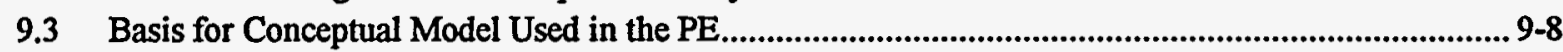

9.3.1 Water Pathway ......................................................................................................... 9-8

9.3.1.1 Current Understanding of Relevant Hydrogeology................................................ 9-8

9.3.1.2 Conceptual Model Used in the PE...................................................................... 9-9

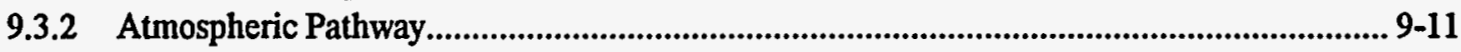

9.3.2.1 Current Understanding of Relevant Meteorology................................................. 9-11

9.3.2.2 Conceptual Model Used in the PE ................................................................... 9-11

9.3.3 Inadvertent Intruder Pathways......................................................................................13

9.3.3.1 Current Understanding of Potential Modes of Inadvertent Intrusion ................... 9-13

9.3.3.2 Intruder Scenarios Used in the PE.......................................................................... 9-13

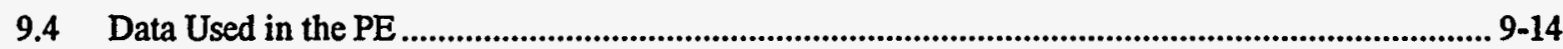

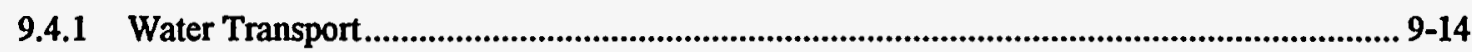

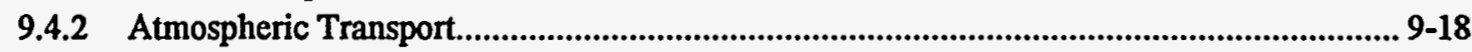

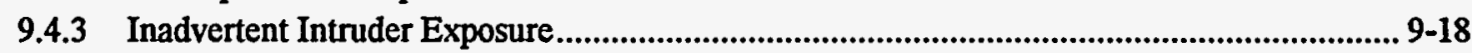

9.5 Results of the PE

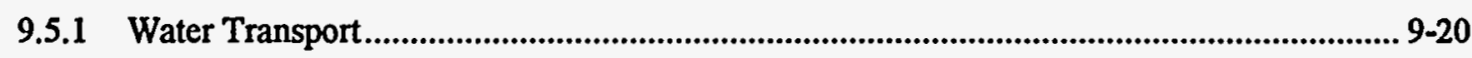

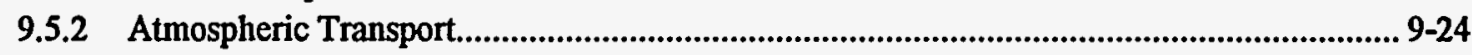

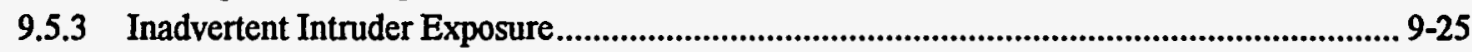

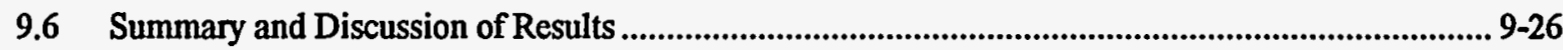

9.6.1 Results Based on Disposal Design .............................................................................. 9-26

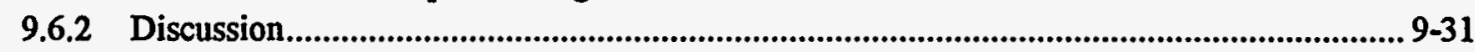

9.6.2.1 Parameter Sensitivity Analysis........................................................................ 9-31 
9.6.2.2 Physical Constraints on Sensitivity Analysis Values........................................... 9-33

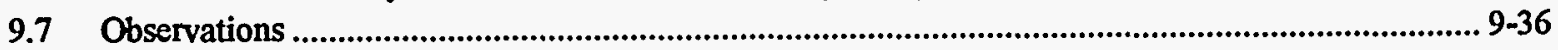

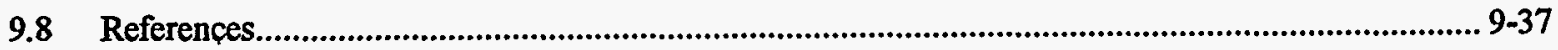

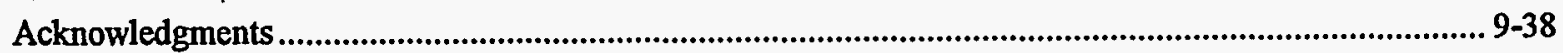

10. New York: West Valley Demonstration Project (WVDP).................................................................... 10-1

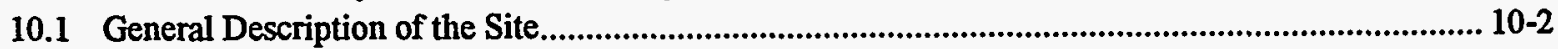

10.2 Status and Siting of MLLW Disposal Facility ........................................................................ 10-6

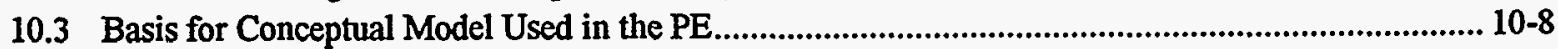

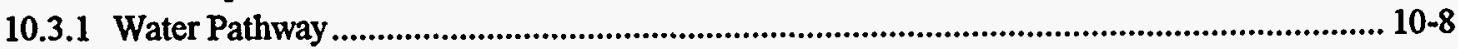

10.3.1.1 Current Understanding of Relevant Hydrogeology................................................ 10-8

10.3.1.2 Conceptual Model Used in the PE ................................................................. 10-11

10.3.2 Atmospheric Pathway................................................................................................... 10-14

10.3.2.1 Current Understanding of Relevant Meteorology.............................................. 10-14

10.3.2.2 Conceptual Model Used in the PE................................................................ 10-15

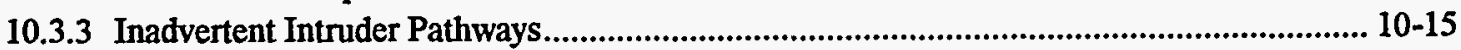

10.3.3.1 Current Understanding of Potential Modes of Inadvertent Intrusion .................. 10-17

10.3.3.2 Intruder Scenarios Used in the PE................................................................. 10-17

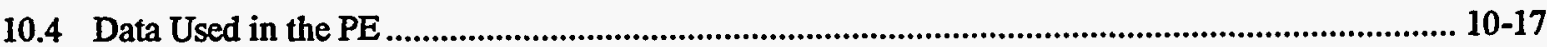

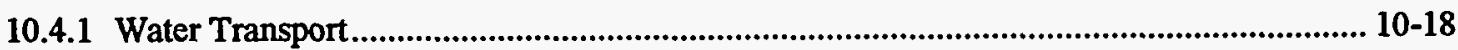

10.4.2 Atmospheric Transport............................................................................................ 10-23

10.4.3 Inadvertent Intruder Exposure .............................................................................. 10-23

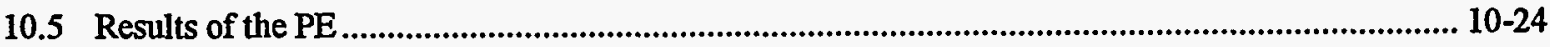

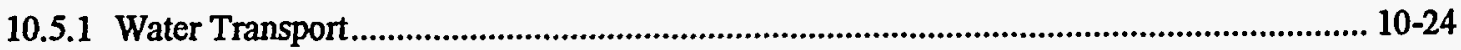

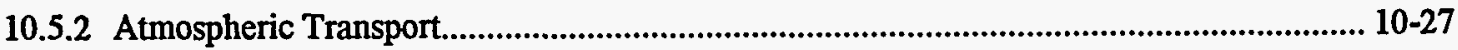

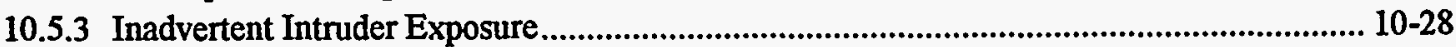

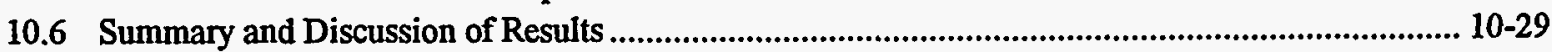

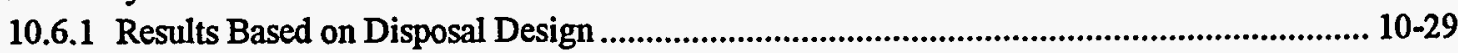

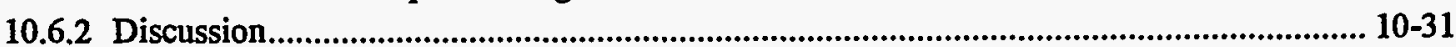

10.6.2.1 Parameter Sensitivity Analysis ............................................................... 10-31

10.6.2.2 Physical Constraints on Sensitivity Analysis Values........................................ 10-34

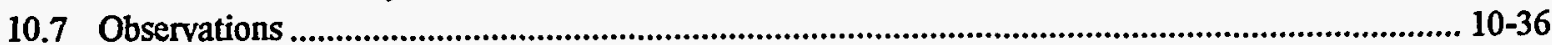

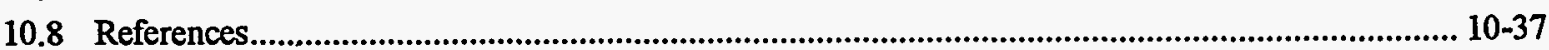

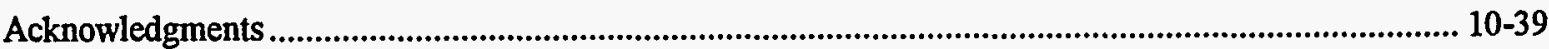

11. Ohio: Fernald Environmental Management Project (FEMP)................................................................. 11-1

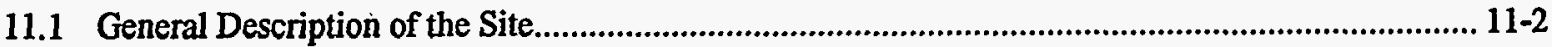

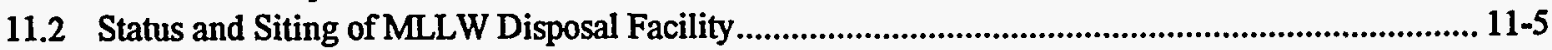

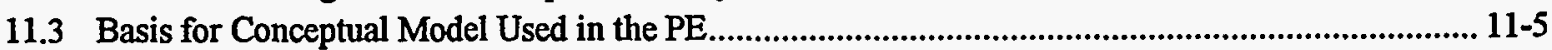

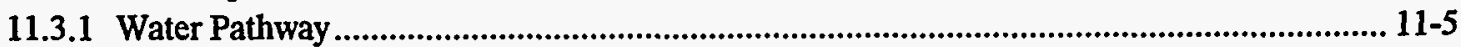

11.3.1.1 Current Understanding of Relevant Hydrogeology...........................................11-6

11.3.1.2 Conceptual Model Used in the PE ...............................................................11-6

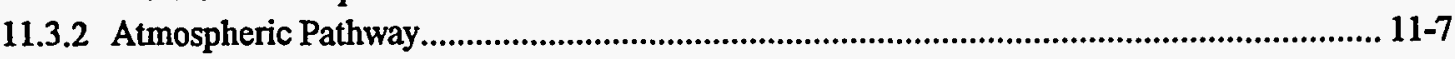

11.3.2.1 Current Understanding of Relevant Meteorology ............................................ 11-7

11.3.2.2 Conceptual Model Used in the PE................................................................. 11-9

11.3.3 Inadvertent Intruder Pathways...................................................................................... 11-9

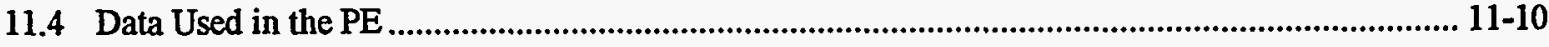

11.4.1 Water Transport........................................................................................................ 11-10

11.4.2 Atmospheric Transport......................................................................................... 11-14 


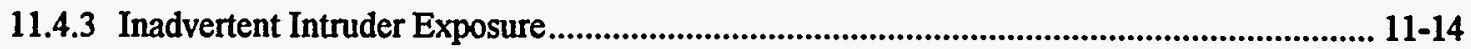

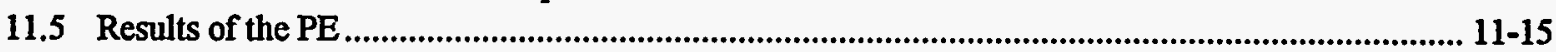

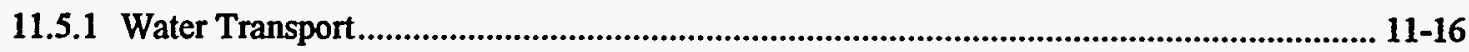

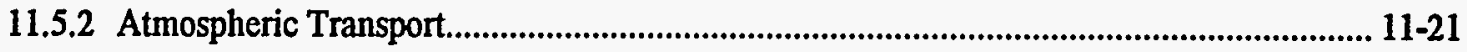

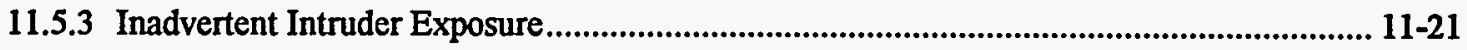

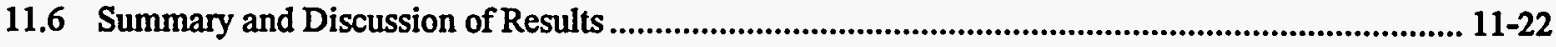

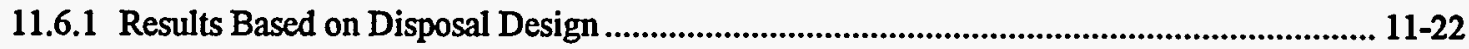

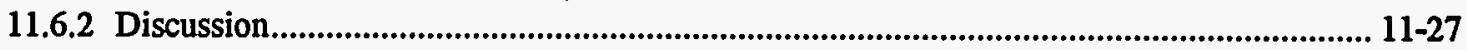

11.6.2.1 Parameter Sensitivity Analysis.............................................................. 11-28

11.6.2.2 Physical Constraints on Sensitivity Analysis Values....................................... 11-31

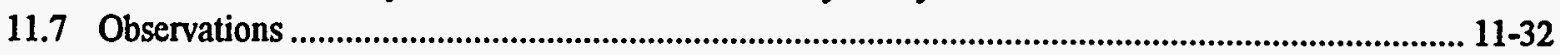

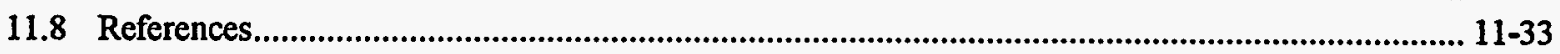

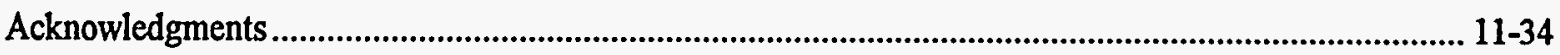

12. Ohio: Portsmouth Gaseous Diffusion Plant (PORTS) .................................................................................. 12-1

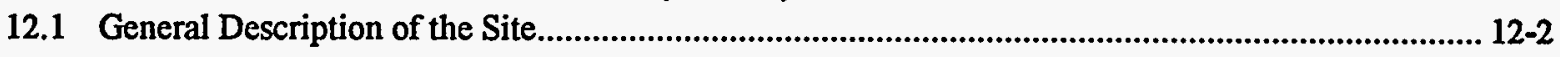

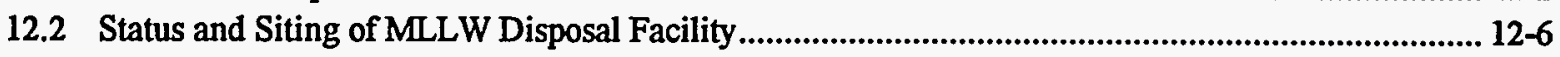

12.3 Basis for Conceptual Model Used in the PE........................................................................... 12-6

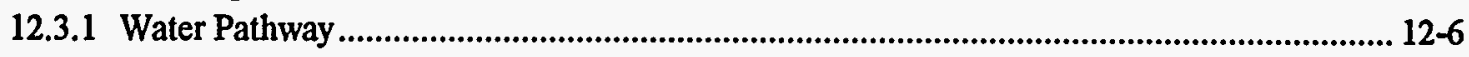

12.3.1.1 Current Understanding of Relevant Hydrogeology ............................................ 12-6

12.3.1.2 Conceptual Model Used in the PE.............................................................. 12-9

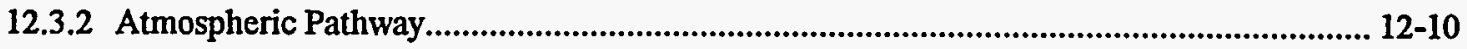

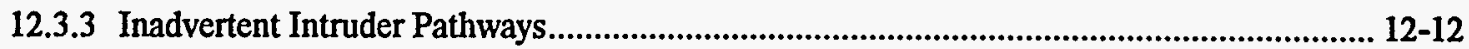

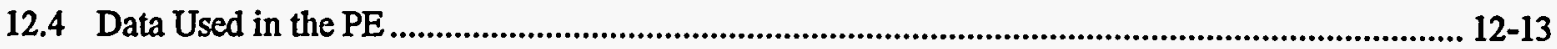

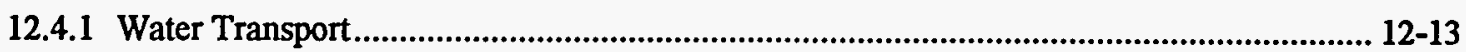

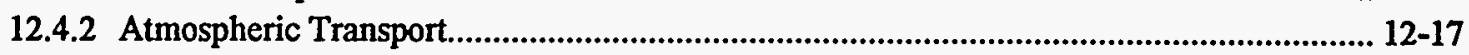

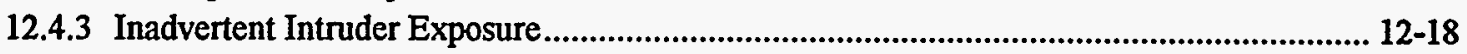

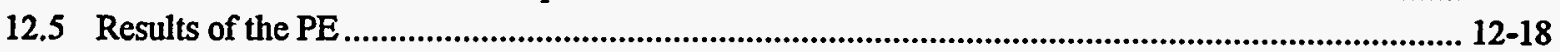

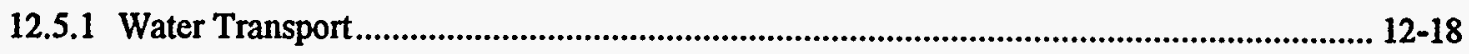

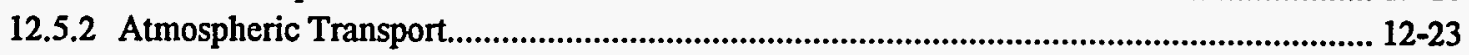

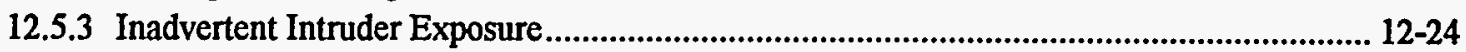

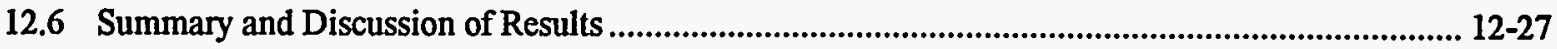

12.6.1 Results Based on Disposal Design ......................................................................... 12-27

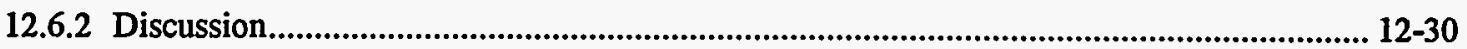

12.6.2.1 Parameter Sensitivity Analysis .................................................................. 12-30

12.6.2.2 Physical Constraints on Sensitivity Analysis Values.......................................... 12-33

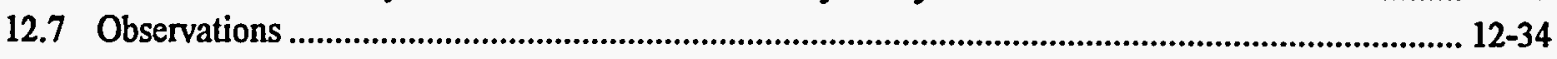

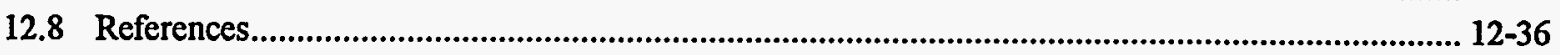

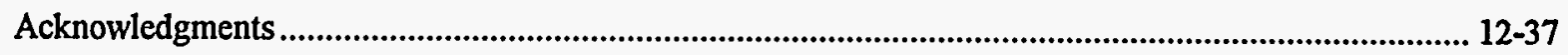

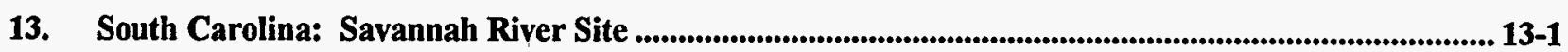

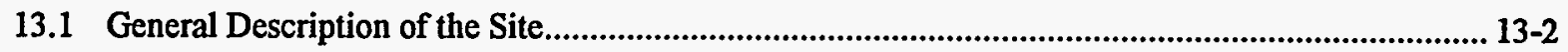

13.2 Status and Siting of MLLW Disposal Facility .................................................................... 13-6

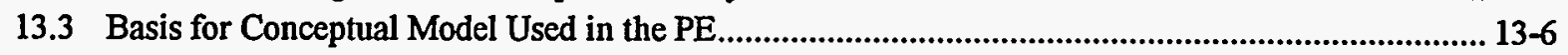

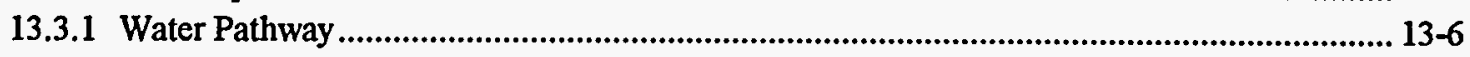

13.3.1.1 Current Understanding of Relevant Hydrogeology.......................................... 13-8

13.3.1.2 Conceptual Model Used in the PE ............................................................. 13-8

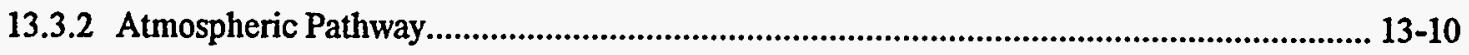

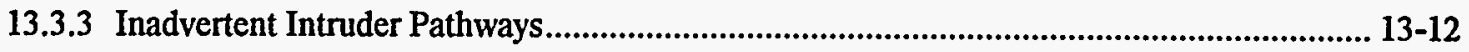


13.3.3.1 Current Understanding of Potential Modes of Inadvertent Intrusion. $13-12$

13.3.3.2 Intruder Scenarios Used in the PE

13.4 Data Used in the PE

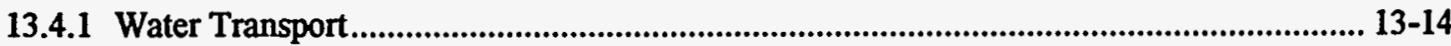

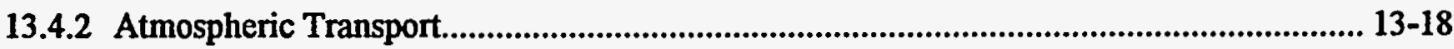

13.4.3 Inadvertent Intruder Exposure...................................................................................... 13-19

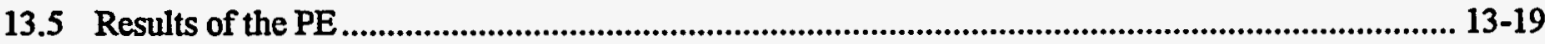

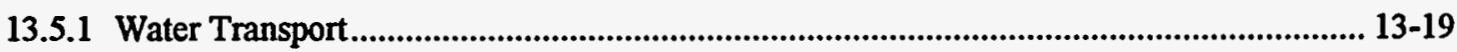

13.5.2 Atmospheric Transport............................................................................................... 13-24

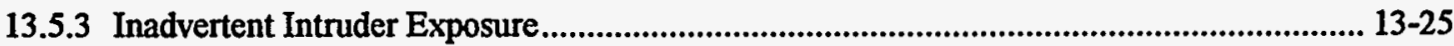

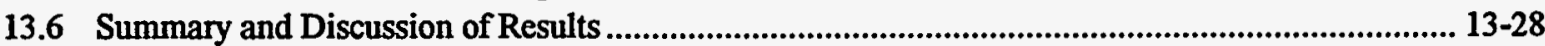

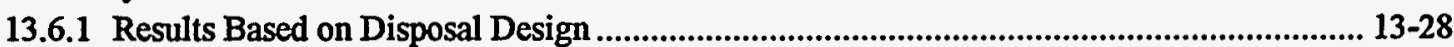

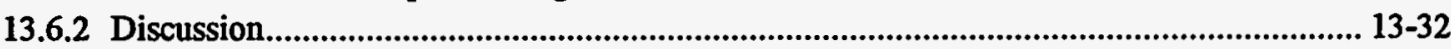

13.6.2.1 Parameter Sensitivity Analysis .............................................................. 13-32

13.6.2.2 Physical Constraints on Sensitivity Analysis Values........................................ 13-36

13.6.2.3 Comparison of Conceptual Models and Results between the PE and the Savannah River Site (E-Area Vaults) Performance Assessment......................... 13-37

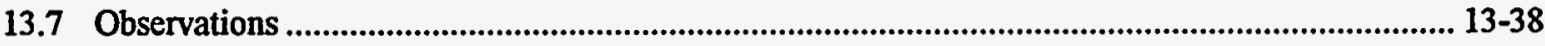

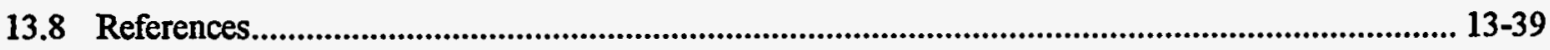

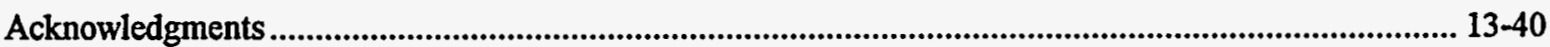

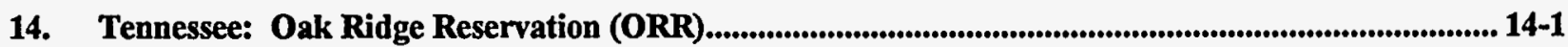

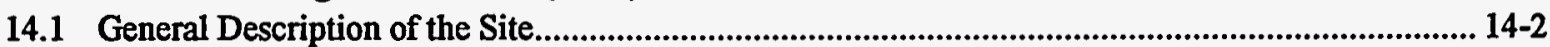

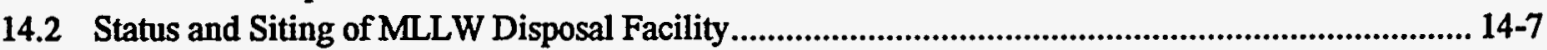

14.3 Basis for Conceptual Model Used in the PE........................................................................... 14-7

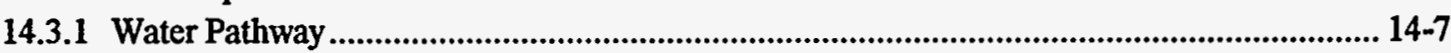

14.3.1.1 Current Understanding of Relevant Hydrogeology ............................................. 14-9

14.3.1.2 Conceptual Model Used in the PE ...............................................................14-11

14.3.2 Atmospheric Pathway............................................................................................................ 14-14

14.3.2.1 Current Understanding of Relevant Meteorology ............................................ 14-14

14.3.2.2 Conceptual Model Used in the PE ................................................................. 14-14

14.3.3 Inadvertent Intruder Pathways........................................................................................... 14-16

14.3.3.1 Current Understanding of Potential Modes of Inadvertent Intrusion .................. 14-16

14.3.3.2 Intruder Scenarios Used in the PE................................................................ 14-16

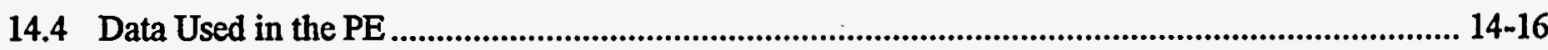

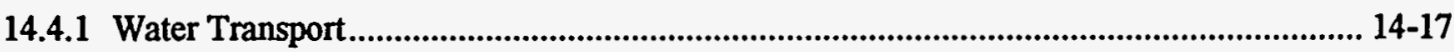

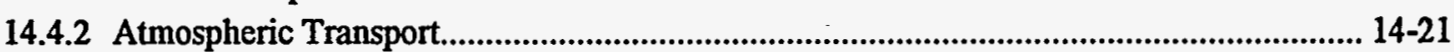

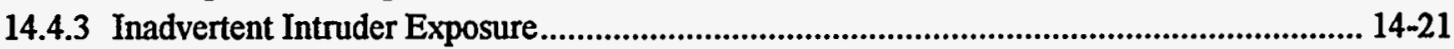

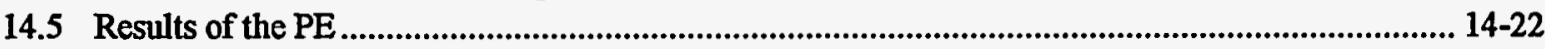

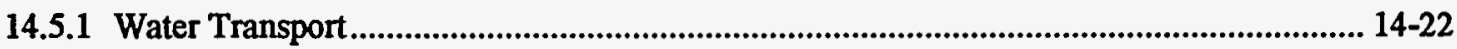

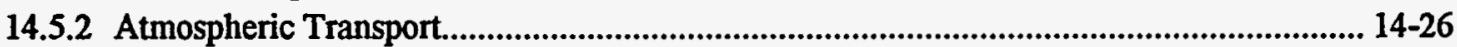

14.5.3 Inadvertent Intruder Exposure...................................................................................... 14-27

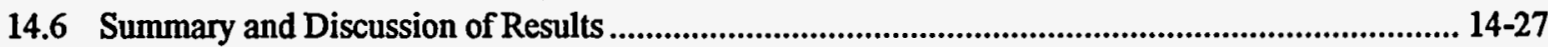

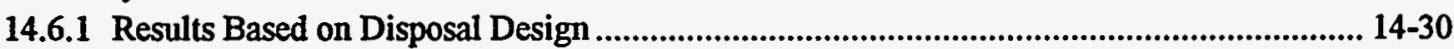

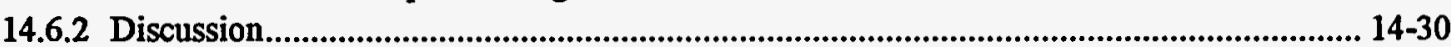

14.6.2.1 Parameter Sensitivity Analysis................................................................ 14-33

14.6.2.2 Physical Constraints on Sensitivity Analysis Values........................................... 14-36

14.6.2.3 Comparison of Conceptual Models and Results between the PE and the SWSA 6 Performance Assessment . 


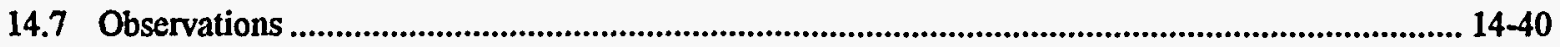

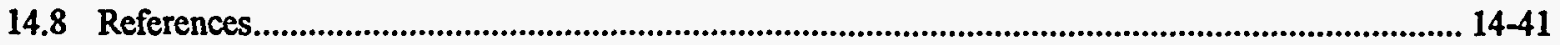

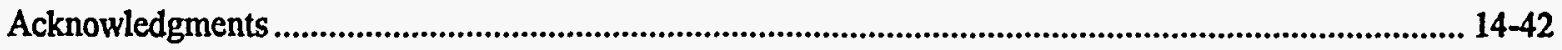

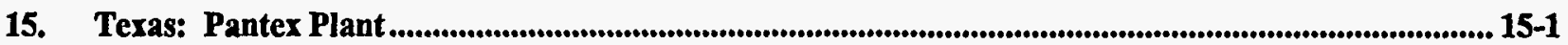

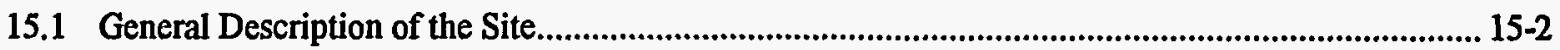

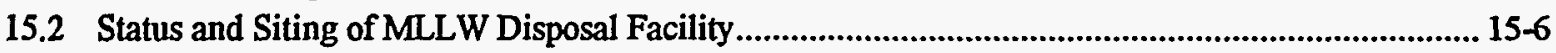

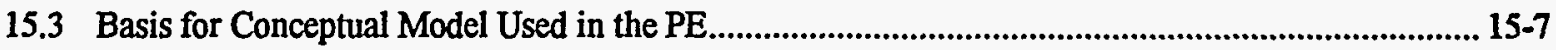

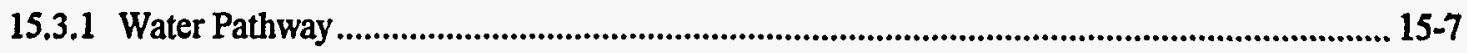

15.3.1.1 Current Understanding of Relevant Hydrogeology .............................................. 15-7

15.3.1.2 Conceptual Model Used in the PE .................................................................... 15-11

15.3.2 Atmospheric Pathway....................................................................................................... 15-14

15.3.2.1 Current Understanding of Relevant Meteorology............................................ 15-14

15.3.2.2 Conceptual Model Used in the PE ............................................................15-14

15.3.3 Inadvertent Intruder Pathways............................................................................................ 15-16

15.3.3.1 Current Understanding of Potential Modes of Inadvertent Intrusion .................. 15-16

15.3.3.2 Intruder Scenarios Used in the PE..................................................................... 15-16

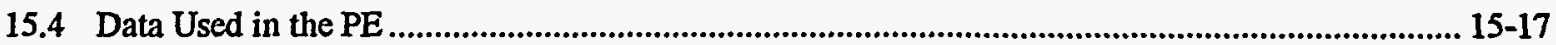

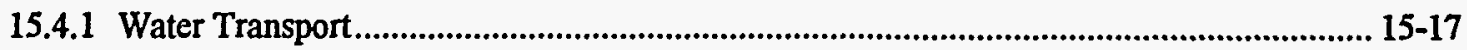

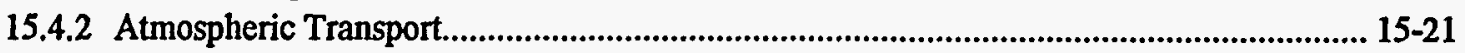

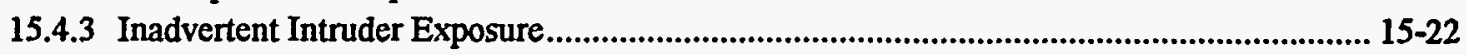

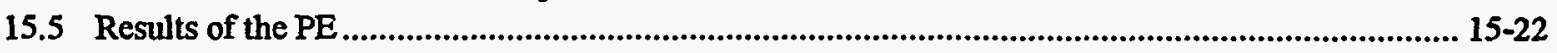

15.5.1 Water Transport......................................................................................................... 15-23

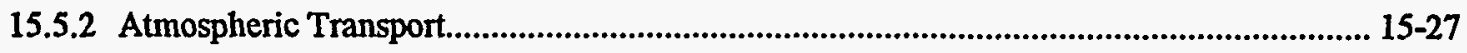

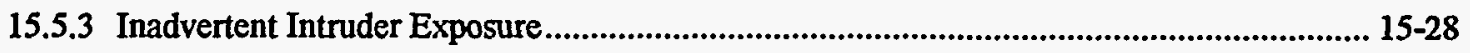

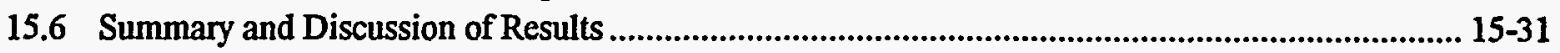

15.6.1 Results Based on Disposal Design ................................................................................. 15-31

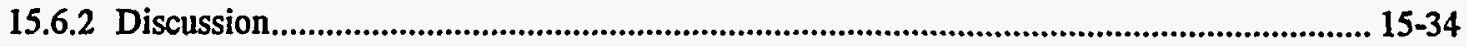

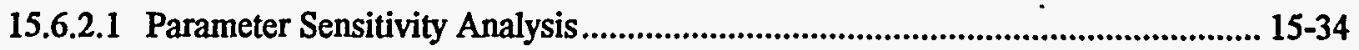

15.6.2.2 Physical Constraints on Sensitivity Analysis Values.......................................... 15-38

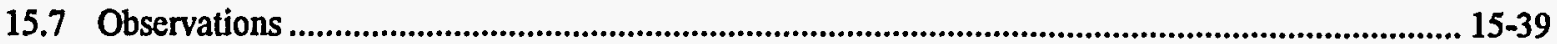

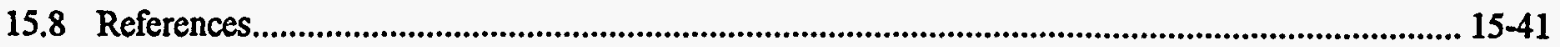

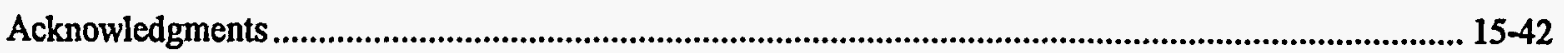

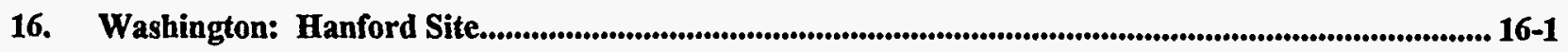

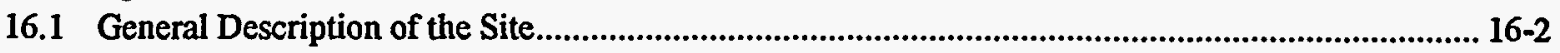

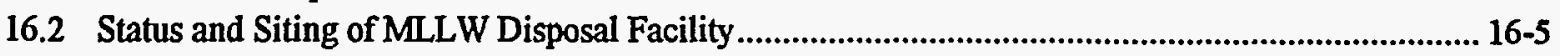

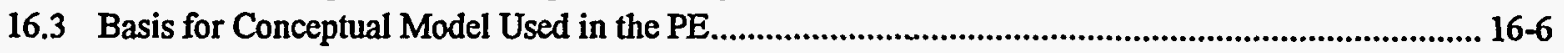

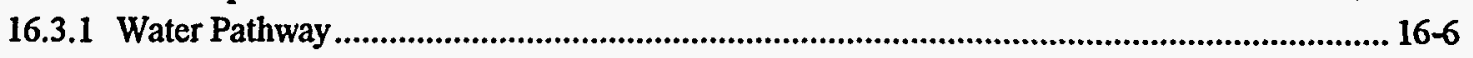

16.3.1.1 Current Understanding of Relevant Hydrogeology............................................. 16-6

16.3.1.2 Conceptual Model Used in the PE............................................................. 16-9

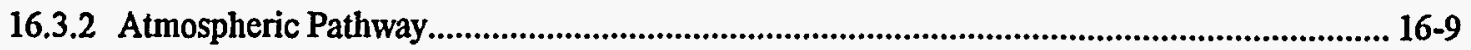

16.3.3 Inadvertent Intruder Pathways..................................................................................16-12

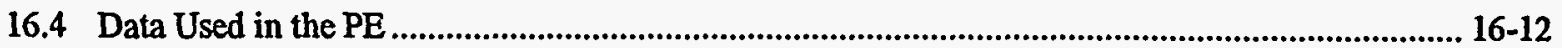

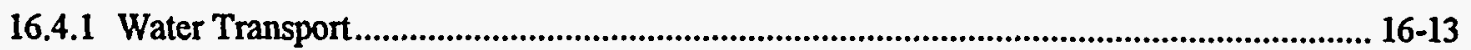

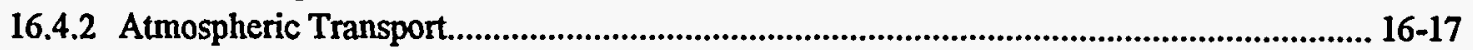

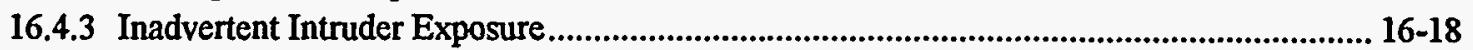

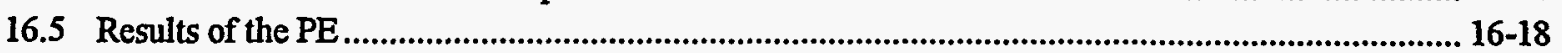

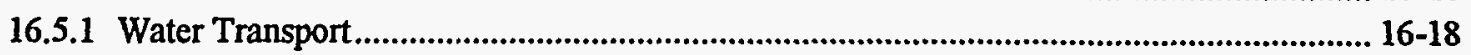




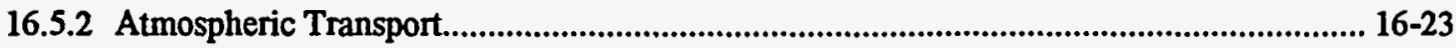

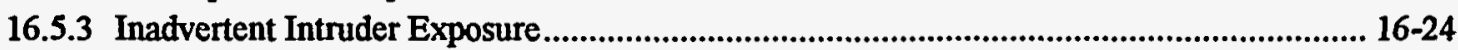

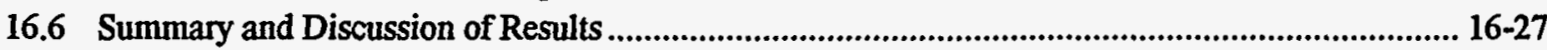

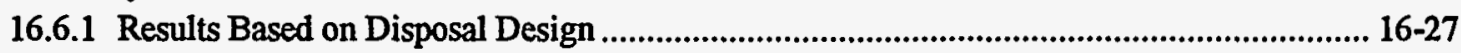

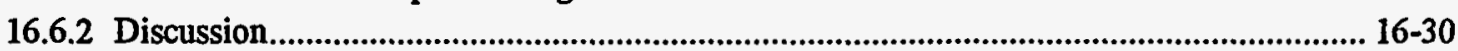

16.6.2.1 Parameter Sensitivity Analysis................................................................. 16-31

16.6.2.2 Physical Constraints on Sensitivity Analysis Values....................................... 16-34

16.6.2.3 Comparison of Conceptual Models and Results between the PE and the Hanford Performance Assessment ...................................................................... 16-35

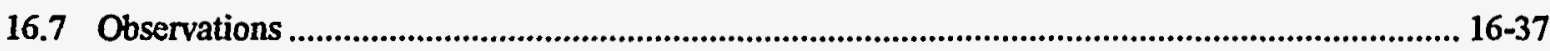

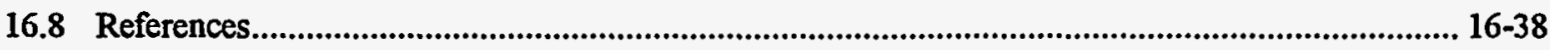

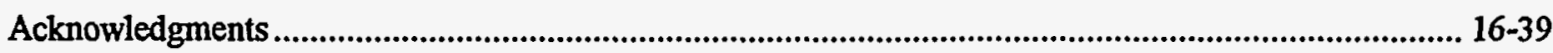

Appendix A: Comparison of PE Results with Performance Assessment Results for Sites with LLW

Performance Assessments

A.1 Idaho National Engineering Laboratory ...............................................................................A-INEL-1

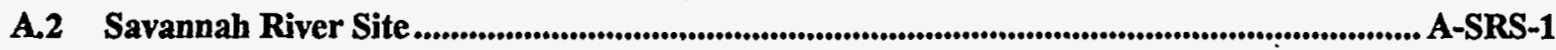

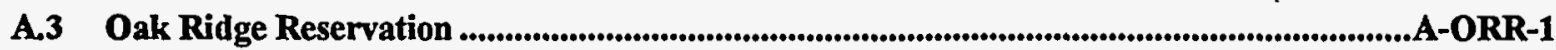

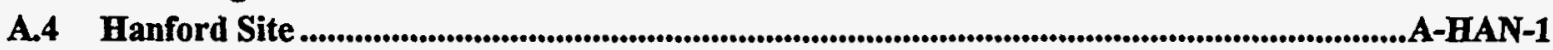




\section{TABLE OF FIGURES}

1-1

$1-2$

$1-3$

$1-4$

2-1

2-2

2-3

$2-4$

2-5

3-1

3-2

3-3

3-4

$3-5$

3-6

3-7

4-1

4-2

4-3

4-4

5-1

5-2

5-3

5-4

5-5

5-6

6-1

$6-2$

6-3

6-4

6-5

6-6

7-1

$7-2$

7-3

Assumed performance of engineered barriers for the two generic facilities....................................... 1-7

Generic conceptual model for the water pathway ......................................................................... 1-9

Conceptual model for the atmospheric pathway ....................................................................... 1-13

Exposure pathways in the PE for (a) homesteader and (b) post-drilling intruder scenarios ............. 1-16

Location map for Lawrence Livermore National Laboratory Site 300 ............................................. 2-3

Site map for Lawrence Livermore National Laboratory Site 300 ....................................................2 2-4

General location of the generic MLLW disposal facilities evaluated in the PE at LLNL Site 300 .... 2-7

Conceptual model for water transport at LLNL Site 300 .............................................................. 2-13

Windrose for Lawrence Livermore National Laboratory for the period 1987 to 1991 ..................... 2-15

Location map for Rocky Flats Environmental Technology Site ...................................................... 3-3

Site map for Rocky Flats Environmental Technology Site.............................................................. 3-4

Erosional surfaces and alluvial deposits east of the Front Range, Colorado ...................................... 3-5

West to east geologic cross section in the Rocky Flats area ......................................................... 3-6

Generalized stratigraphic column for the Rocky Flats area........................................................ 3-10

Conceptual model for water transport at RFETS ....................................................................... 3-13

Windrose for RFETS for the period 1986 to 1993 .................................................................... 3-15

Location map for the Idaho National Engineering Laboratory........................................................... 4-3

Site map for the Idaho National Engineering Laboratory ............................................................. 4-4

Conceptual model for water transport at INEL ...................................................................... 4-10

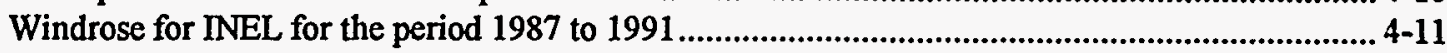

Location map for Argonne National Laboratory-East .................................................................. 5-3

Site map for Argonne National Laboratory-East...................................................................... 5-4

General location near the 800 Area Landfill for the generic MLLW disposal facilities

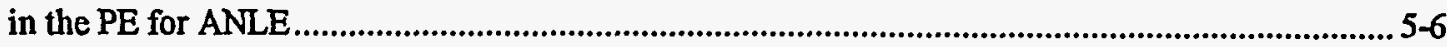

Generalized stratigraphy of rock units and aquifers in the ANLE area ........................................5 5-8

Conceptual model for water transport at ANLE ...................................................................... 5-11

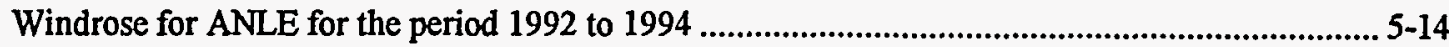

Location map for Paducah Gaseous Diffusion Plant ....................................................................6-3

Location of the Paducah Gaseous Diffusion Plant in relation to the geographic region..................... 6-4

Possible MLLW disposal sites identified by the site technical staff.................................................6-6

North-south geologic cross section through the Paducah Gaseous Diffusion Plant area .................... 6-8

Conceptual model for water transport at the Paducah Gaseous Diffusion Plant ............................... 6-10

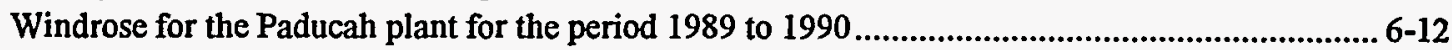

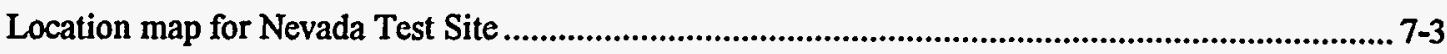

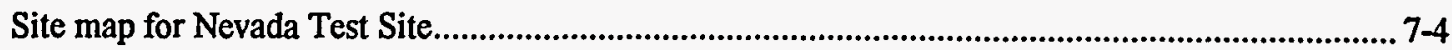

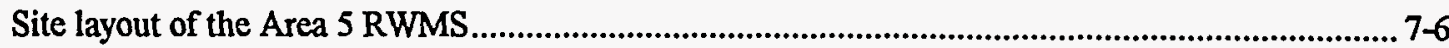

Generalized groundwater flow beneath Frenchman Flat and Yucca Flat .......................................... 7-9

Groundwater subbasins of the Death Valley groundwater basin ................................................. 7-10

Windrose for NTS for the period 1987 to 1991 ....................................................................... 7-14 
Current understanding of groundwater movement at the WVDP site ........................................... 10-10

Conceptual model for flow and transport at the WVDP site

Location of the proposed Mixed Waste Disposal Facility (MWDF) within the E-Area at the Savannah River Site. 
14-5 Schematic profile showing subsurface flow zones and intervals, general thickness ranges, estimated relative annual water flux, and change in water type with depth.

14-6 Conceptual model for groundwater and shallow stormflow zone transport at ORR.

14-7 Windrose for Oak Ridge Reservation for the period 1989 to 1993

15-1 Location map for Pantex Plant.

15-3 North-south stratigraphic cross section across Pantex Plant through the Ogallala Formation 


\section{TABLE OF TABLES}

Table

Page

1-1

1-2

1-3

2-1

2-2

2-3

2-4

2-5

2-6

2-7

2-8
Pathway Dose Conversion Factors for Water $\left(P C D F_{\text {Hater }}\right)$............................................................ 1-5

Source Concentration Reduction Factors $\left(C R F_{\text {Source }}\right)$ for the Tumulus and Trench Designs .............. 1-6

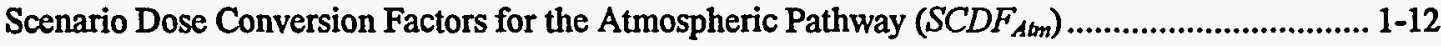

Parameters and Values Used in the PE for the Water Pathway at LLNL....................................... 2-18

Solid/Liquid Distribution Coefficients $\left(K_{d} s\right)$ Used in the PE at LLNL ....................................... 2-20

Parameters and Values Used in the PE for the Atmospheric Pathway at LLNL ............................ 2-21

Results of Calculations for the Water Pathway at LLNL.........................................................2-25

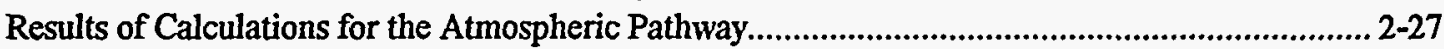

Permissible Waste Concentrations for the Standard Intrusion Scenarios ........................................ 2-29

Permissible Concentrations for the Generic Disposal Designs at LLNL......................................... 2-32

Parameter Values Used in the PE for LLNL Site 300 with Potential Variability

That Could Affect the Results.......................................................................................... 2-34

Parameter Values That Caused the Permissible Concentrations for the Water and

Intruder Pathways to Be Equal for Indicator Radionuclides at LLNL .......................................... 2-36

Variation of $K_{d}$ Values for the Geologic Media at LLNL............................................................... 2-37

Parameters and Values Used in the PE for the Water Pathway at RFETS..................................... 3-18

Solid/Liquid Distribution Coefficients $\left(K_{d} s\right)$ Used in the PE at RFETS.........................................3-20

Parameters and Values Used in the PE for the Atmospheric Pathway at RFETS .......................... 3-22

Results of Calculations for the Water Pathway at RFETS...................................................... 3-25

Results of Calculations for the Atmospheric Pathway............................................................... 3-28

Permissible Waste Concentrations for the Standard Intrusion Scenarios ....................................... 3-29

Permissible Concentrations for the Generic Disposal Designs at Rocky Flats ................................. 3-32

Parameter Values Used in the PE for RFETS with Potential Variability

That Could Affect the Results.................................................................................................. 3-34

Parameter Values That Caused the Permissible Concentrations for the Water and

Intruder Pathways to Be Equal for Indicator Radionuclides at RFETS ....................................... 3-36

Variation of $K_{d}$ Values for the Geologic Media at RFETS.................................................. 3-37

Parameters and Values Used in the PE for the Water Pathway at INEL........................................ 4-14

Solid/Liquid Distribution Coefficients $\left(K_{d} \delta\right)$ Used in the PE at INEL ......................................... 4-16

Parameters and Values Used in the PE for the Atmospheric Pathway at INEL ............................. 4-18

Results of Calculations for the Water Pathway at INEL .............................................................. 4-22

Results of Calculations for the Atmospheric Pathway..................................................................25

Permissible Waste Concentrations for the Standard Intrusion Scenarios ...................................... 4-26

Permissible Concentrations for the Generic Disposal Designs at INEL ........................................ 4-29

Parameter Values Used in the PE for INEL with Potential Variability

That Could Affect the Results............................................................................................... 4-32

Parameter Values That Caused the Permissible Concentrations for the Water and

Intruder Pathways to Be Equal for Indicator Radionuclides at INEL ......................................... 4-34

Variation of $K_{d}$ Values for the Unsaturated Zone at INEL .......................................................... 4-35

Parameters and Values Used in the PE for the Water Pathway at ANLE .....................................5-18

Solid/Liquid Distribution Coefficients $\left(K_{d} s\right)$ Used in the PE at ANLE ...................................... 5-20 
Permissible Waste Concentrations for the Standard Intrusion Scenarios .

5-30

Permissible Concentrations for the Generic Disposal Designs at ANLE.

5-9 Parameter Values That Caused the Permissible Concentrations for the Water and Intruder Pathways to Be Equal for Indicator Radionuclides at ANLE .................................... 5-36

5-10 Variation of $K_{d}$ Values for the Unsaturated Zone at ANLE ....................................................... 5-38

6-1 Parameters and Values Used in the PE for the Water Pathway at the Paducah Plant ..................... 6-14

Parameters and Values Used in the PE for the Atmospheric Pathway at the Paducah Plant........... 6-18

Results of Calculations for the Water Pathway at Paducah ....................................................... 6-21

Permissible Waste Concentrations for the Standard Intrusion Scenarios ....................................... 6-26

Permissible Concentrations for the Generic Disposal Designs at Paducah ........................................ 6-28

Parameter Values Used in the PE for Paducah with Potential Variability

Parameters and Values Used in the PE for the Water Pathway at LANL

Parameters and Values Used in the PE for the Atmospheric Pathway at LANL.............................. 8-25

Results of Calculations for the Water Pathway at LANL ............................................................ 8-29

Results of Calculations for the Atmospheric Pathway........................................................... 8-31

Permissible Waste Concentrations for the Standard Intrusion Scenarios ..................................... 8-33

Permissible Concentrations for the Generic Disposal Designs at LANL ........................................ 8-35

Parameter Values Used in the PE for LANL with Potential Variability

That Could Affect the Results.

8-9 Parameter Values That Caused the Permissible Concentrations for the Water and Intruder Pathways to Be Equal for Indicator Radionuclides at LANL............................................. 8-40

8-10 Variation of $K_{d}$ Values for the Unsaturated Zone at LANL ...................................................... 8-41

9-1 Parameters and Values Used in the PE for the Water Pathway at SNL/NM................................. 9-15 
9-9 Parameter Values That Caused the Permissible Concentrations for the Water and Intruder Pathways to Be Equal for Indicator Radionuclides at SNL/NM....................................... 9-34

9-10 Variation of $K_{d}$ Values for the Geologic Media at SNL/NM .......................................................... 9-35

10-1 Parameters and Values Used in the PE for the Water Pathway at WVDP ................................... 10-19

10-2 Solid/Liquid Distribution Coefficients $\left(K_{d} s\right)$ Used in the PE at WVDP.................................... 10-22

10-3 Parameters and Values Used in the PE for the Atmospheric Pathway at WVDP........................ 10-23

10-4 Results of Calculations for the Water Pathway at West Valley .................................................... 10-26

10-5 Results of Calculations for the Atmospheric Pathway............................................................. 10-28

10-6 Permissible Waste Concentrations for the Standard Intrusion Scenarios ..................................... 10-29

10-7 Permissible Concentrations for the Generic Disposal Designs at West Valley ............................. 10-30

10-8 Parameter Values Used in the PE for WVDP with Potential Variability

That Could Affect the Results......................................................................................................... 10-32

10-9 Parameter Values That Caused the Permissible Concentrations for the Water and Intruder Pathways to Be Equal for Indicator Radionuclides at WVDP......................................... 10-33

10-10 Variation of $K_{d}$ Values for the Geologic Media at WVDP .................................................... 10-34

11-1 Parameters and Values Used in the PE for the Water Pathway at FEMP .................................... 11-11

11-2 Solid/Liquid Distribution Coefficients $\left(K_{d} s\right)$ Used in the PE at FEMP ...................................... 11-13

11-3 Parameters and Values Used in the PE for the Atmospheric Pathway at FEMP.......................... 11-15

11-4 Results of Calculations for the Water Pathway at FEMP .......................................................... 11-18

11-5 Results of Calculations for the Atmospheric Pathway................................................................ 11-21

11-6 Permissible Waste Concentrations for the Standard Intrusion Scenarios .................................. 11-23

11-7 Permissible Concentrations for the Generic Disposal Designs at FEMP ...................................... 11-25

11-8 Parameter Values Used in the PE for FEMP with Potential Variability

11-9 Parameter Values That Caused the Permissible Concentrations for the Water and

11-10 Variation of $K_{d}$ Values at FEMP ..................................................................................... 11-30

12-1 Parameters and Values Used in the PE for the Water Pathway at Portsmouth................................ 12-14

12-2 Solid/Liquid Distribution Coefficients $\left(K_{d} s\right)$ Used in the PE at PORTS .................................... 12-16

12-3 Parameters and Values Used in the PE for the Atmospheric Pathway at Portsmouth .................... 12-17

12-4 Results of Calculations for the Water Pathway at Portsmouth ...................................................... 12-21

12-5 Results of Calculations for the Atmospheric Pathway......................................................... 12-24

12-6 Permissible Waste Concentrations for the Standard Intrusion Scenarios ...................................... 12-25

12-7 Permissible Concentrations for the Generic Disposal Designs at Portsmouth ............................... 12-28

12-8 Parameter Values Used in the PE for PORTS with Potential Variability

That Could Affect the Results................................................................................................ 12-31

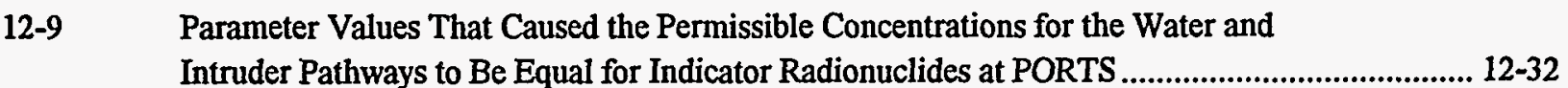

12-10 Variation of $K_{d}$ Values for the Geologic Media at PORTS...................................................... 12-33

13-1 Parameters and Values Used in the PE for the Water Pathway at SRS......................................... 13-15

13-2 Solid/Liquid Distribution Coefficients $\left(K_{d} s\right)$ Used in the PE at SRS ........................................... 13-17

13-3 Parameters and Values Used in the PE for the Atmospheric Pathway at SRS ............................ 13-18

13-4 Results of Calculations for the Water Pathway at SRS ................................................................. 13-22 
13-5 Results of Calculations for the Atmospheric Pathway........................................................... 13-24

13-6 Permissible Waste Concentrations for the Standard Intrusion Scenarios .................................... 13-26

13-7 Permissible Concentrations for the Generic Disposal Designs at SRS ....................................... 13-29

13-8 Parameter Values Used in the PE for SRS with Potential Variability

13-9 Parameter Values That Caused the Permissible Concentrations for the Water and

Intruder Pathways to Be Equal for Indicator Radionuclides at SRS ............................................ 13-34

13-10 Variation of $K_{d}$ Values at SRS ............................................................................................... 13-35

14-1 Parameters and Values Used in the PE for the Water Pathway at ORR

14-2 Solid/Liquid Distribution Coefficients $\left(K_{d} s\right)$ Used in the PE at ORR ........................................ 14-20

14-3 Parameters and Values Used in the PE for the Atmospheric Pathway at ORR ............................ 14-21

14-4 Results of Calculations for the Water Pathway at ORR ............................................................ 14-24

14-5 Results of Calculations for the Atmospheric Pathway.................................................................. 14-26

14-6 Permissible Waste Concentrations for the Standard Intrusion Scenarios .................................... 14-28

14-7 Permissible Concentrations for the Generic Disposal Designs at ORR ......................................... 14-31

14-8 Parameter Values Used in the PE for ORR with Potential Variability

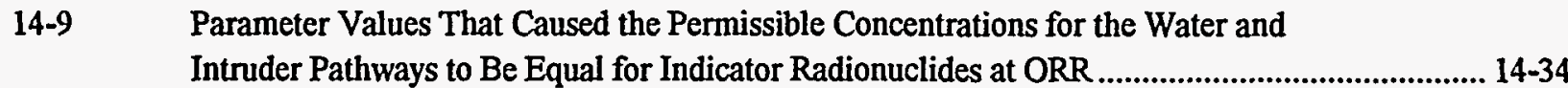

14-10 Variation of $K_{d}$ Values for the Saturated Zone at ORR .......................................................... 14-35

14-11 Comparison of Assumptions Used in the SWSA 6 Performance Assessment and ORR PE Groundwater Transport Analyses ............................................................................ 14-38

14-12 Comparison of the Individual Impacts of the SWSA 6 Performance Assessment and

ORR PE Transport Assumptions for the Radionuclides in the SWSA 6 IWMF .......................... 14-39

15-1 Parameters and Values Used in the PE for the Water Pathway at Pantex................................... 15-18

15-2 Solid/Liquid Distribution Coefficients $\left(K_{d} s\right)$ Used in the PE at Pantex ....................................... 15-20

15-3 Parameters and Values Used in the PE for the Atmospheric Pathway at the Pantex Plant............ 15-22

15-4 Results of Calculations for the Water Pathway at Pantex........................................................ 15-25

15-5 Results of Calculations for the Atmospheric Pathway..............................................................15-28

15-6 Permissible Waste Concentrations for the Standard Intrusion Scenarios ..................................... 15-29

15-7 Permissible Concentrations for the Generic Disposal Designs at Pantex...................................... 15-32

15-8 Parameter Values Used in the PE for Pantex Plant with Potential Variability

15-9 Parameter Values That Caused the Permissible Concentrations for the Water and

15-10 Variation of $K_{d}$ Values for the Geologic Media at Pantex.......................................................... 15-38

16-1 Parameters and Values Used in the PE for the Water Pathway at Hanford.................................. 16-14

16-2 Solid/Liquid Distribution Coefficients $\left(K_{d} s\right)$ Used in the PE at Hanford ...................................... 16-16

16-3 Parameters and Values Used in the PE for the Atmospheric Pathway at Hanford ........................ 16-17

16-4 Results of Calculations for the Water Pathway at Hanford .....................................................16-21

16-5 Results of Calculations for the Atmospheric Pathway........................................................... 16-24

16-6 Permissible Waste Concentrations for the Standard Intrusion Scenarios ...................................... 16-25

16-7 Permissible Concentrations for the Generic Disposal Designs at Hanford .................................... 16-28

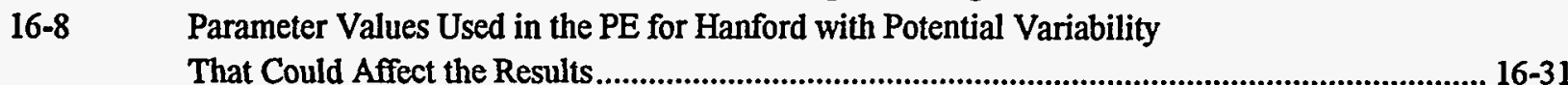




\section{NOMENCLATURE}

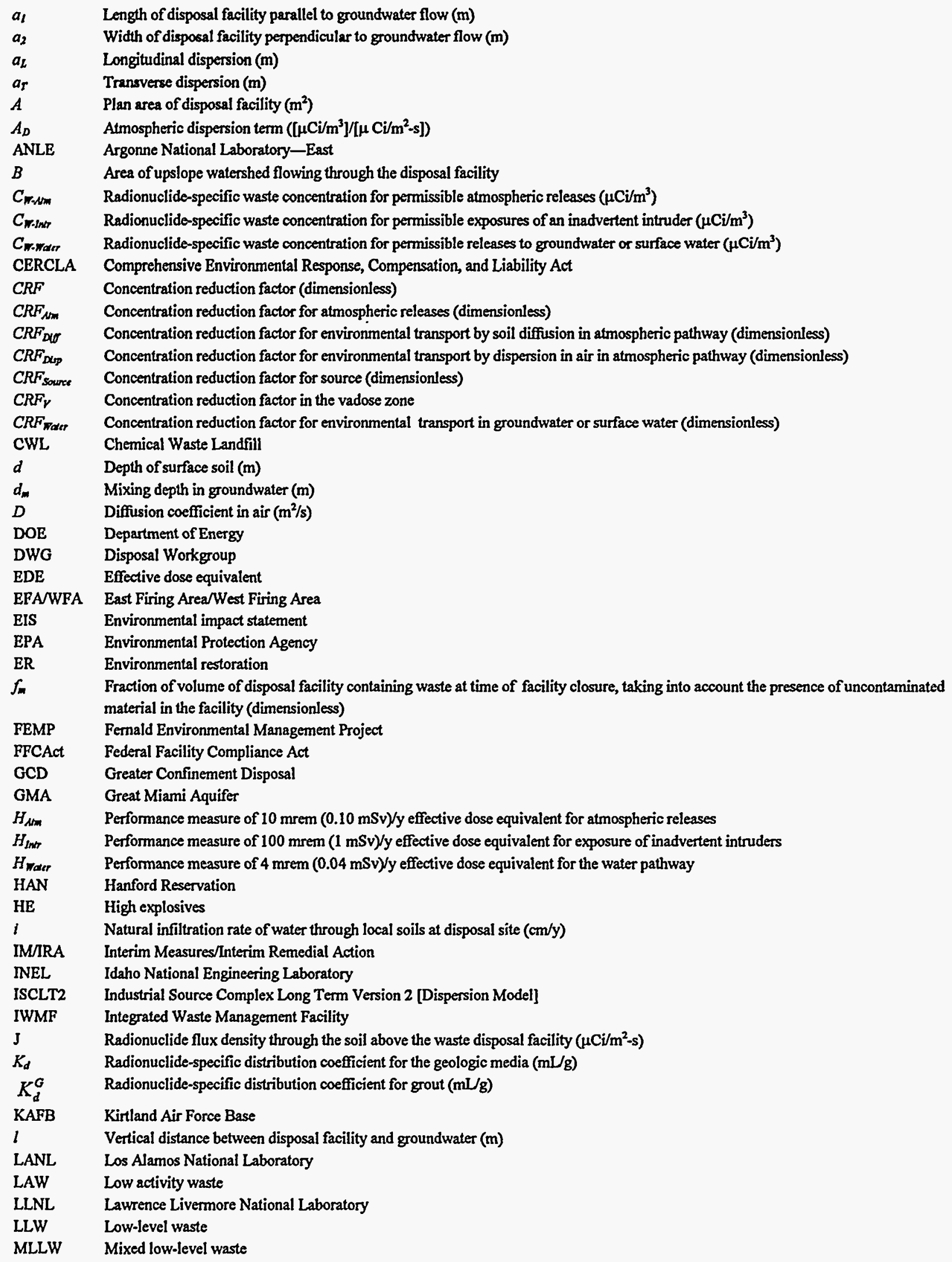




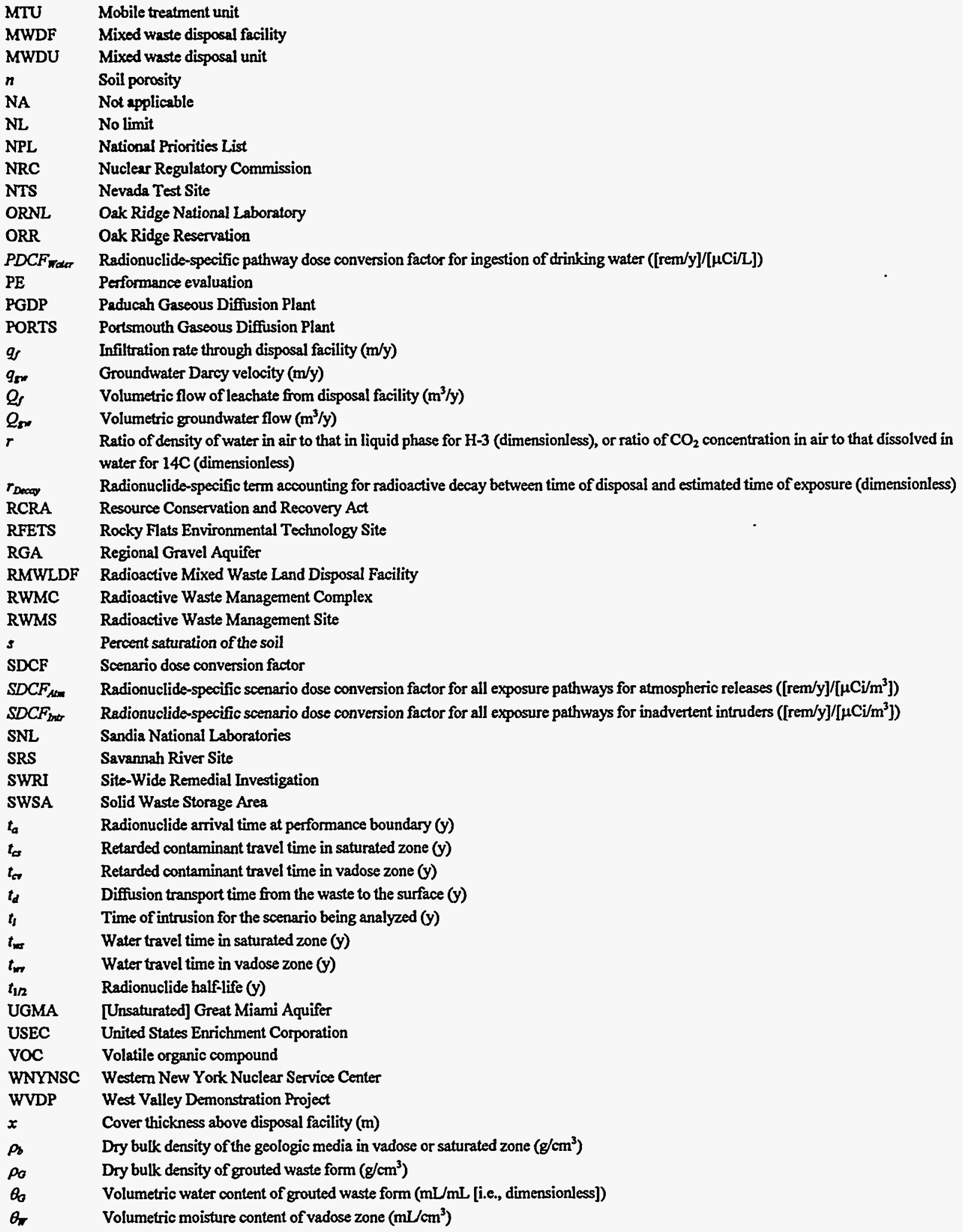




\section{INTRODUCTION}

Volume 3 of Performance Evaluation of the Technical Capabilities of DOE Sites for Disposal of Mixed Low-Level Waste contains the results of the performance evaluation (PE) for each of 15 Department of Energy (DOE) sites. Volume 1 of the report is an overall summary of the performance evaluation. Volume 2 provides background information about the PE process and details about the methodology used in the PE. It also contains a summary of the results for the 15 sites.

The objective of the PE is to estimate permissible concentrations of radionuclides in disposal facilities for mixed low-level waste (MLLW) such that releases of radionuclides to the environment would not result in exposures to humans in excess of some pre-determined performance measures. The PE does not address any ethical, social, or policy considerations relevant to siting such facilities. Calculations of releases for three pathways-water, atmospheric, and inadvertent intruder-form the foundation of the PE. The remainder of this chapter summarizes the key assumptions and equations used in these calculations; additional details about the PE methodology are contained in Chapter 5 of Volume 2. Chapters 2 through 16 of this volume provide the $\mathrm{PE}$ results for the 15 sites being evaluated. Most of the chapters follow the format listed below:

Section 1: brief, general description of the site

Section 2: plans for MLLW disposal, if any, and the location being evaluated in the PE

Section 3: current understanding of radionuclide movement at the selected location based on available information, and the conceptual model used for each of the three pathways

Section 4: site-specific and generic values used in the PE calculations and their sources

Section 5: estimates of permissible concentrations of radionuclides in waste ("permissible waste concentrations") determined in the PE calculations for each of the three pathways, along with values of the input parameters used in determining the results

Section 6: summary of results based on disposal-facility design; discussion with respect to such issues as uncertainty and sensitivity

Section 7: observations based on the results of the PE and the parameter sensitivity analysis

Section 8: references

An overall discussion of the results for all 15 sites is presented in Volume 2, Chapter 7 of this report.

Performance Measures and Human Exposure to Releases

The following assumptions are made in the PE about performance measures and human exposure to radionuclide releases: 
- The PE was based solely on a radiological assessment. The PE provided estimates of permissible concentrations of radionuclides in disposed waste using the performance objectives specified in DOE Order 5820.2A as "performance measures." Performance measures were used to relate radionuclide concentrations in disposed waste to permissible doses to individuals for three exposure pathways. The following performance measures are considered the more restrictive and were used in the PE:

- $4 \mathrm{mrem}(0.04 \mathrm{mSv})$ per year from consumption of drinking water resulting from releases to groundwater;

- $10 \mathrm{mrem}(0.1 \mathrm{mSv})$ per year from all exposure pathways resulting from atmospheric releases; and

- $100 \mathrm{mrem}(1 \mathrm{mSv})$ per year from all exposure pathways resulting from long-term, chronic exposure of inadvertent intruders (chronic exposures are assumed to cause more restrictive concentration limits than acute exposures) after loss of active institutional controls at $100 \mathrm{y}$ after disposal.

- The period for consideration was $10,000 \mathrm{y}$ from the time the disposal facility was closed. This time limit is the same as that specified in EPA standards for disposal of spent fuel, high level waste, and transuranic waste in 40 CFR Part 191, and it acknowledges that predictions of disposal facility performance for much longer times are highly speculative. For information purposes, the maximum radionuclide concentrations and arrival times for the water pathway that exceeded the 10,000-y period were calculated and reported. However, these estimates were not considered in determining the most restrictive waste concentrations for any of the three pathways. For inadvertent intrusion by the homesteader scenario, the performance measure was applied at the earliest time that intrusion was assumed to occur with two exceptions. In the assessments for six radionuclides (U-233, U-234, U-235, U-238, Pu-244, and Cm-247), the time of intrusion was assumed to occur at $10,000 \mathrm{y}$, the end of the performance period. This was done because ingrowth of decay products for these radionuclides yields scenario doses that increase over time and peak beyond the 10,000-y performance period. This approach was considered to be conservative. Changes were also made in the cases of Th-230 and $\mathrm{Cm}-245$, in which the ingrowth of decay products produces a scenario dose that increases over time and peaks within the 10,000-y performance period. Again, to be conservative the time of intrusion for these two radionuclides (Th-230 and Cm-245) were assumed to be the time of maximum dose, $9000 \mathrm{y}$ for Th-230 and $1000 \mathrm{y}$ for $\mathrm{Cm}-245$.

- Active institutional controls were considered effective for $100 \mathrm{y}$ after disposal; no active or passive institutional controls were considered effective after $100 \mathrm{y}$, although some credit was taken for the ability of the engineered barriers to preclude inadvertent intrusion beyond $100 \mathrm{y}$ after disposal.

- For the water and atmospheric pathways, the performance boundary (i.e., point of compliance) was $100 \mathrm{~m}$ (328 ft) from the edge of the disposal facility. For the inadvertent intruder pathway, the exposure was assumed to occur where an intruder dug or drilled into the disposal facility. 
- Three different types of parent/progeny relationships were considered. These were (1) decay relationships in which the progeny reach secular equilibrium with the parent radionuclide before the time frame of interest; (2) radionuclides who have progeny that do not reach equilibrium in less than the time frame of interest and whose half-lives are less than that of the parent; and (3) radionuclides who have progeny that do not reach secular equilibrium in less than the time frame of interest and whose half-lives are longer than that of the parent. These relationships are discussed in detail in Appendix E of Volume 2.

\section{Waste and Disposal Facility Characteristics}

The following assumptions were made in the PE about the waste and the disposal facility:

- The waste form was grouted treatment residuals.

- The same list of 58 radionuclides was used for 14 sites. At West Valley the list was confined to the 18 radionuclides specified in their consent decree with the state of New York.

- Two generic disposal facilities were considered: a Resource Conservation and Recovery Act (RCRA) compliant, below-ground trench and a RCRA-compliant, above-ground tumulus. Both facilities were square with a plan area of $2500 \mathrm{~m}^{2}$.

As discussed earlier, three pathways formed the basis of the PE, including the water pathway, the atmospheric pathway, and the inadvertent intruder pathway. The methods used to calculate radionuclide concentration limits for each of these pathways are summarized in Sections $1.1,1.2$, and 1.3 , respectively. These methods were generally applicable to all sites being evaluated. However, site characteristics may have caused variations from these methods. Such variations are noted in the site-evaluation chapters.

\subsection{WATER TRANSPORT}

The permissible radionuclide concentrations for the water pathway were calculated using

$$
C_{W-\text { Water }}=H_{\text {Water }} \times \frac{1}{P D C F_{\text {Water }}} \times C R F_{\text {Source }} \times C R F_{\text {Water }} \times r_{\text {Decay }} \times 1000
$$

where

$C_{W-W a t e r}$ is the concentration of a specific radionuclide in the disposed waste corresponding to the permissible drinking water dose at the performance boundary $\left(\mu \mathrm{Ci} / \mathrm{m}^{3}\right)$;

$H_{\text {Water }}$ is the performance measure of $0.004 \mathrm{rem}(0.04 \mathrm{mSv})$ per year effective dose equivalent for consumption of water;

$P D C F_{\text {Water }}$ is the dose conversion factor for the water ingestion pathway represented by the annual effective dose equivalent per unit concentration for drinking water for each nuclide $([\mathrm{rem} / \mathrm{y}] /[\mu \mathrm{Ci} / \mathrm{L}])$;

$C R F_{\text {Source }}$ is the concentration reduction factor for the source $(\mu \mathrm{Ci} / \mathrm{L} / \mu \mathrm{Ci} / \mathrm{L})$;

$C R F_{\text {Water }}$ is the concentration reduction factor for environmental transport in the groundwater or surface water $(\mu \mathrm{Ci} / \mathrm{L} / \mu \mathrm{Ci} / \mathrm{L})$; 
$r_{\text {Decay }}$ is the term accounting for radioactive decay during detention time in the waste plus retarded travel time via environmental transport in the water pathway to the performance boundary (dimensionless); and 1000 is a factor for converting $\mathrm{L}$ to $\mathrm{m}^{3}$.

The PE methodology for calculating permissible waste concentrations based on the water pathway is discussed in more detail in Chapter 5 and Appendix B of Volume 2.

The performance measure, $H_{\text {Water }}$ was $0.004 \mathrm{rem}(0.04 \mathrm{mSv})$ per year and was specific to the water pathway. The effects of the ingrowth of radionuclide decay products on the radionuclide concentration limits were accounted for by using the appropriate values for $P D C F_{\text {Water }}$ which were radionuclide-specific and the same for all sites. These values are listed in Table 1-1 along with the concentration-based performance measure for each radionuclide. $C R F_{\text {Source }}$ accounted for the attenuation between the original waste and the leachate exiting the bottom of the disposal facility. Estimates of $C R F_{\text {Source }}$ values were the same for all 15 sites, and the method for estimating $C R F_{\text {Source }}$ is summarized in this section. $C R F_{\text {Water }}$ accounted for the attenuation between the leachate exiting the disposal facility and the resulting concentration in water at the performance boundary. $C R F_{\text {Water }}$ values represented concentration reductions for undecayed radionuclides. Radionuclide decay, based on the detention and travel time, was accounted for separately using $r_{\text {Decay. }}$. The method for estimating $C R F_{\text {Water }}$ and $r_{\text {Decay }}$ is also summarized in this section. Values for $C R F_{W a t e r}$ and $r_{D e c a y}$ were site-specific and are reported in the site-evaluation chapters.

\subsubsection{Source CRF for Water}

Equilibrium partitioning between the solid and liquid phases described the relationship between the grouted waste form and the pore water. $C R F_{\text {Source }}$ was determined by

where

$$
C R F_{\text {Source }}=\frac{\left(\theta_{G}+K_{d}^{G} \rho_{G}\right)}{f_{m}}
$$

$\theta_{G}$ is the volumetric water content of the grouted waste form $(\mathrm{mL} / \mathrm{mL})$;

$K_{d}^{G}$ is the distribution coefficient (i.e., solid/liquid partition coefficient) of the radionuclide in the grout $(\mathrm{mL} / \mathrm{g})$;

$\rho_{G}$ is the dry bulk density of the grouted waste form $\left(\mathrm{g} / \mathrm{cm}^{3}\right)$; and

$f_{m}$ is the mixing fraction, defined as the ratio of the volume of waste disposed in a unit volume of the facility.

Values for these parameters are radionuclide-specific and facility-design-specific; thus, the values for $C R F_{\text {Source }}$ used in the PE were the same for all 15 sites. The values for $f_{m}$ were specific to the disposal facility design. The values for $K_{d}^{G}$ are listed with the $K_{d}$ values for the geologic media in the site-evaluation chapters; the values for $\theta_{G}, \rho_{G}$, and $f_{m}$ are reported with the site-specific data in the site-evaluation chapters; and values for $C R F_{\text {Source }}$ are listed in Table 1-2. 
Table 1-1. Pathway Dose Conversion Factors for Water ( $\left.P D C F_{\text {Water }}\right)$

\begin{tabular}{|c|c|}
\hline Radionuclide & $\begin{array}{c}\text { PDCF Ingestion } \\
(\mathrm{rem} / \mathrm{y}) /(\mu \mathrm{Ci} / \mathrm{L})\end{array}$ \\
\hline $\mathrm{H}-3$ & 4.67E-02 \\
\hline$C-14$ & $1.52 E+00$ \\
\hline$A \mid-26$ & $1.06 \mathrm{E}+01$ \\
\hline Si-32 & $7.99 E+00$ \\
\hline $\mathrm{Cl}-36$ & $2.21 \mathrm{E}+00$ \\
\hline $\mathrm{K}-40$ & $1.36 \mathrm{E}+01$ \\
\hline Co-60 & $1.97 \mathrm{E}+01$ \\
\hline Ni-59 & $1.53 \mathrm{E}-01$ \\
\hline $\mathrm{Ni}-63$ & 4.21E-01 \\
\hline Se-79 & $6.35 E+00$ \\
\hline Sr-90 & $1.12 E+02$ \\
\hline Zr-93 & $1.59 E+00$ \\
\hline $\mathrm{Nb}-93 \mathrm{~m}$ & 3.81E-01 \\
\hline $\mathrm{Nb}-94$ & $5.21 \mathrm{E}+00$ \\
\hline TC-99 & $1.07 \mathrm{E}+00$ \\
\hline $\mathrm{Pd}-107$ & 1.09E-01 \\
\hline $\mathrm{Ag}-108 \mathrm{~m}$ & $5.56 \mathrm{E}+00$ \\
\hline $\mathrm{Cd}-113 \mathrm{~m}$ & 1.17E+02 \\
\hline$S n-121 m$ & $1.28 E+00$ \\
\hline$S n-126$ & $1.53 E+01$ \\
\hline $1-129$ & $2.01 E+02$ \\
\hline Cs-135 & $5.16 \mathrm{E}+00$ \\
\hline Cs-137 & $3.65 E+01$ \\
\hline $\mathrm{Ba}-133$ & $2.48 \mathrm{E}+00$ \\
\hline $5 m-151$ & 2.84E-01 \\
\hline Eu-152 & $4.73 E+00$ \\
\hline Eu-154 & $6.97 \mathrm{E}+00$ \\
\hline $\mathrm{Pb}-210$ & $5.30 \mathrm{E}+03$ \\
\hline Ra-226 & $6.27 \mathrm{E}+03$ \\
\hline Ra-228 & $1.64 E+03$ \\
\hline Th-229 & $2.94 E+03$ \\
\hline
\end{tabular}

\begin{tabular}{|c|c|}
\hline Radionuclide & $\begin{array}{c}\text { PDCF Ingestion } \\
(\mathrm{rem} / \mathrm{y}) /(\mu \mathrm{Ci} / \mathrm{L})\end{array}$ \\
\hline Th-230 & b \\
\hline Th-232 & $3.63 E+03$ \\
\hline Pa-231 & $1.85 E+04$ \\
\hline U-232 & $1.55 \mathrm{E}+03$ \\
\hline U-233 & $b$ \\
\hline U-234 & $\mathrm{b}$ \\
\hline U-235 & $\mathrm{b}$ \\
\hline U-236 & $1.96 E+02$ \\
\hline U-238 & $2.07 E+02$ \\
\hline $\mathrm{Np}-237$ & $3.24 E+03$ \\
\hline Pu-238 & $2.34 \mathrm{E}+03$ \\
\hline Pu-239 & $2.58 E+03$ \\
\hline $\mathrm{Pu}-240$ & $2.58 E+03$ \\
\hline Pu-241 & $4.82 E+08$ \\
\hline $\mathrm{Pu}-242$ & $2.45 E+03$ \\
\hline Pu-244 & $4.11 E+03$ \\
\hline Am-241 & $2.66 \mathrm{E}+03$ \\
\hline Am-243 & $2.64 E+03$ \\
\hline $\mathrm{Cm}-243$ & $1.83 \mathrm{E}+03$ \\
\hline $\mathrm{Cm}-244$ & $1.47 \mathrm{E}+03$ \\
\hline $\mathrm{Cm}-245$ & $4.56 E+03$ \\
\hline $\mathrm{Cm}-246$ & $2.70 E+03$ \\
\hline $\mathrm{Cm}-247$ & $2.70 E+03$ \\
\hline $\mathrm{Cm}-248$ & $9.94 E+03$ \\
\hline Cf-249 & $3.46 \mathrm{E}+03$ \\
\hline Cf-250 & $2.64 E+08$ \\
\hline Cf-251 & $3.54 E+03$ \\
\hline
\end{tabular}

a PDCF is based on a $2 \mathrm{~L} / \mathrm{d}$ water consumption rate.

b PDCF is based on curve-fit equations for PDCFs (see Appendix E of Volume 2):

Th-230 PDCF $=343.6+2.644^{*} \mathrm{~T}-4.9 \mathrm{E}-4^{*} \mathrm{~T}^{2}+4.274 \mathrm{E}-08^{*} \mathrm{~T}^{3}-1.44 \mathrm{E}-12^{*} \mathrm{~T}^{4}$

$U-233$ PDCF $=217.3+0.26013^{*} \mathrm{~T}-8.656 \mathrm{E}-6^{*} \mathrm{~T}^{2}$

$U-234$ PDCF $=206.2+5.612 E-3^{*} T+8.032 E-06^{*} T^{2}-4.175 E-10 * T^{3}$

$\mathrm{U}-235$ PDCF $=188.6+0.3909^{*} \mathrm{~T}-3.728 \mathrm{E}-06^{*} \mathrm{~T}^{2}$

These curve it equations are for arrival times of the radionuclides at the performance boundary between 100 and $10,000 \mathrm{y}$. If arrival time exceeds $10,000 \mathrm{y}$, the calculation is made for $T=10,000 \mathrm{y}$. 
Table 1-2. Source Concentration Reduction Factors $\left(C R F_{\text {Source }}\right)$ for the Tumulus and Trench Designs

\begin{tabular}{|l|c|c|}
\hline Radionuclide & $\begin{array}{c}\text { Trench } \\
\text { CRF }_{\text {Source }}\end{array}$ & $\begin{array}{c}\text { Tumulus } \\
\text { CRF }_{\text {Source }}\end{array}$ \\
\hline H-3 & 0.45 & 0.90 \\
\hline $\mathrm{C}-14$ & 27 & 54 \\
\hline Al-26 & 270 & 540 \\
\hline Si-32 & 270 & 540 \\
\hline Cl-36 & 0.45 & 0.91 \\
\hline K-40 & 3.1 & 6.2 \\
\hline Co-60 & 270 & 540 \\
\hline Ni-59 & 27 & 54 \\
\hline Ni-63 & 27 & 54 \\
\hline Se-79 & 3.1 & 6.2 \\
\hline Sr-90 & 270 & 540 \\
\hline $\mathrm{Zr}-93$ & 27 & 54 \\
\hline Nb-93m & 27 & 54 \\
\hline Nb-94 & 27 & 54 \\
\hline Tc-99 & 3.1 & 6.2 \\
\hline Pd-107 & 270 & 540 \\
\hline Ag-108m & 270 & 540 \\
\hline Cd-113m & 270 & 540 \\
\hline Sn-121m & 27 & 54 \\
\hline Sn-126 & 27 & 54 \\
\hline l-129 & 3.1 & 6.2 \\
\hline Cs-135 & 27 & 54 \\
\hline Cs-137 & 27 & 54 \\
\hline Ba-133 & 27 & 54 \\
\hline Sm-151 & 27 & 54 \\
\hline Eu-152 & 27 & 54 \\
\hline Eu-154 & 27 & 54 \\
\hline Pb-210 & 270 & 540 \\
\hline Ra-226 & 27 & 54 \\
\hline Ra-228 & 27 & 54 \\
\hline Th-229 & 540 \\
\hline Th-230 & 540 \\
\hline Th-232 & 540 \\
\hline Pa-231 & 270 \\
\hline
\end{tabular}

\begin{tabular}{|l|c|c|}
\hline Radionuclide & $\begin{array}{c}\text { Trench } \\
\text { CRF }_{\text {Source }}\end{array}$ & $\begin{array}{c}\text { Tumulus } \\
\text { CRF }_{\text {source }}\end{array}$ \\
\hline U-232 & 270 & 540 \\
\hline U-233 & 270 & 540 \\
\hline U-234 & 270 & 540 \\
\hline U-235 & 270 & 540 \\
\hline U-236 & 270 & 540 \\
\hline U-238 & 270 & 540 \\
\hline Np-237 & 270 & 540 \\
\hline Pu-238 & 270 & 540 \\
\hline Pu-239 & 270 & 540 \\
\hline Pu-240 & 270 & 540 \\
\hline Pu-241 & 270 & 540 \\
\hline Pu-242 & 270 & 540 \\
\hline Pu-244 & 270 & 540 \\
\hline Am-241 & 270 & 540 \\
\hline Am-243 & 270 & 540 \\
\hline Cm-243 & 270 & 540 \\
\hline Cm-244 & 270 & 540 \\
\hline Cm-245 & 270 & 540 \\
\hline Cm-246 & 270 & 540 \\
\hline Cm-247 & 270 & 540 \\
\hline Cm-248 & 270 & 540 \\
\hline Cf-249 & 270 & 540 \\
\hline Cf-250 & 270 & 540 \\
\hline Cf-251 & 270 & 540 \\
\hline & & \\
\hline & 270 & \\
\hline
\end{tabular}




\subsubsection{Transport CRF for Water}

The analysis of water flow and radionuclide transport in the water pathway to determine $C R F_{\text {Water }}$ values used site-specific information whenever possible, with conceptual model development relying heavily on interaction with site personnel. For sites that had performance assessments for low-level waste (LLW) disposal, the flow and transport assumptions used in the performance assessment were incorporated into the PE conceptual model, and site-specific data were used in the calculations. For sites that did not have performance assessments, a generic conceptual model was used that incorporated site-specific water flow paths into a simple transport analysis. Site-specific data were used in the calculations as well as information from any characterization studies that might have been performed on the sites. Both the generic and sitespecific data used in the PE are listed in the site-evaluation chapters.

Analysis of radionuclide movement through water consisted of two parts: (1) estimating the concentration reduction factor, $C R F_{\text {Water }}$; and (2) estimating the radionuclide travel time from the facility to the performance boundary.

The major assumptions for flow and transport that were used in the generic conceptual model are the following:

- The rate of water flowing through the generic disposal facilities were based on the performance of the engineered barriers (Figure 1-1);

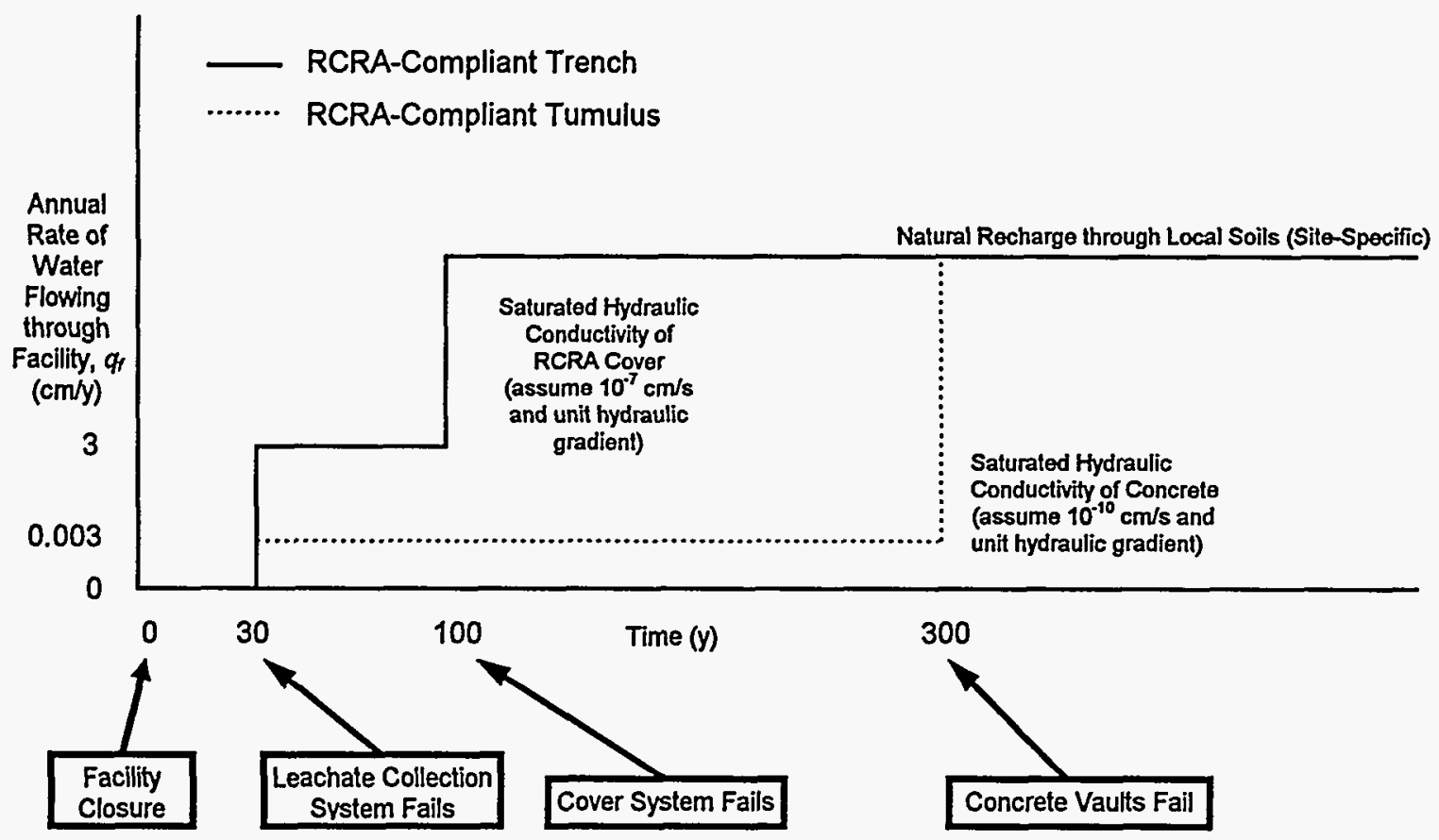

Figure 1-1. Assumed performance of engineered barriers for the two generic facilities. 
- Flow in the unsaturated and saturated zones was steady state;

- Source release from the disposal facility was continuous and constant with step increases at the engineered barrier failure times;

- Flow and transport in the unsaturated zone was one-dimensional with no lateral spreading from diffusion or dispersion (thus, the concentration reduction factor (CRF) for transport through the unsaturated zone was unity);

- When the relevant geologic formations in the vadose zone at a site were known to contain fractures, these fractured sections were eliminated from the analysis and the resulting thickness of the vadose zone was reduced;

- Flow and transport in the saturated zone was one-dimensional with no diffusion or hydrodynamic dispersion in the longitudinal or transverse directions;

- When the relevant geologic formations in the saturated zone at a site were known to contain fractures, matrix porosity and the fractured porosity were combined as an effective porosity;

- Complete mixing across an appropriate mixing depth was used to represent dilution in the saturated zone; and

- Sorption of dissolved radionuclides on the porous media provided only retardation in the unsaturated and saturated zones.

Estimates of the transport $\mathrm{CRF}$ for the water pathway, $C R F_{\text {Water }}$ relied on analyses of the unsaturated and saturated zones.

\section{Generic Conceptual Model for Flow and Transport in the Unsaturated Zone}

As shown in Figure 1-2, in the conceptual model leachate was generated by water flowing through the disposal facility at the rate, $q_{f}$ which was controlled by the assumed performance of the disposal facility. When all engineered barriers had failed, $q_{f}$ was assumed to be equal to the natural recharge through local soils, $i$. A disposal facility with plan area, $A$, was assumed to be oriented perpendicular to the groundwater flow direction.

The volumetric flow of water through the facility that generated leachate was based on the assumed performance and size of the disposal facility. It was defined as

$$
Q_{f}=q_{f} A
$$

where

$Q_{f}$ is the volumetric flow rate of leachate from the facility $\left(\mathrm{m}^{3} / \mathrm{y}\right)$;

$q_{f}$ is the rate of water flowing through the facility $(\mathrm{m} / \mathrm{y})$; and

$A$ is the facility plan area $\left(\mathrm{m}^{2}\right)$ with length, $a_{1}$, and width, $a_{2}(\mathrm{~m})$.

It was assumed that no dilution occurred in the unsaturated zone; therefore, the concentration that reached groundwater eventually equaled the leachate concentration. No lateral spreading was assumed, so the leachate flux through the unsaturated zone was confined to the soil column directly below the plan area of the facility. 


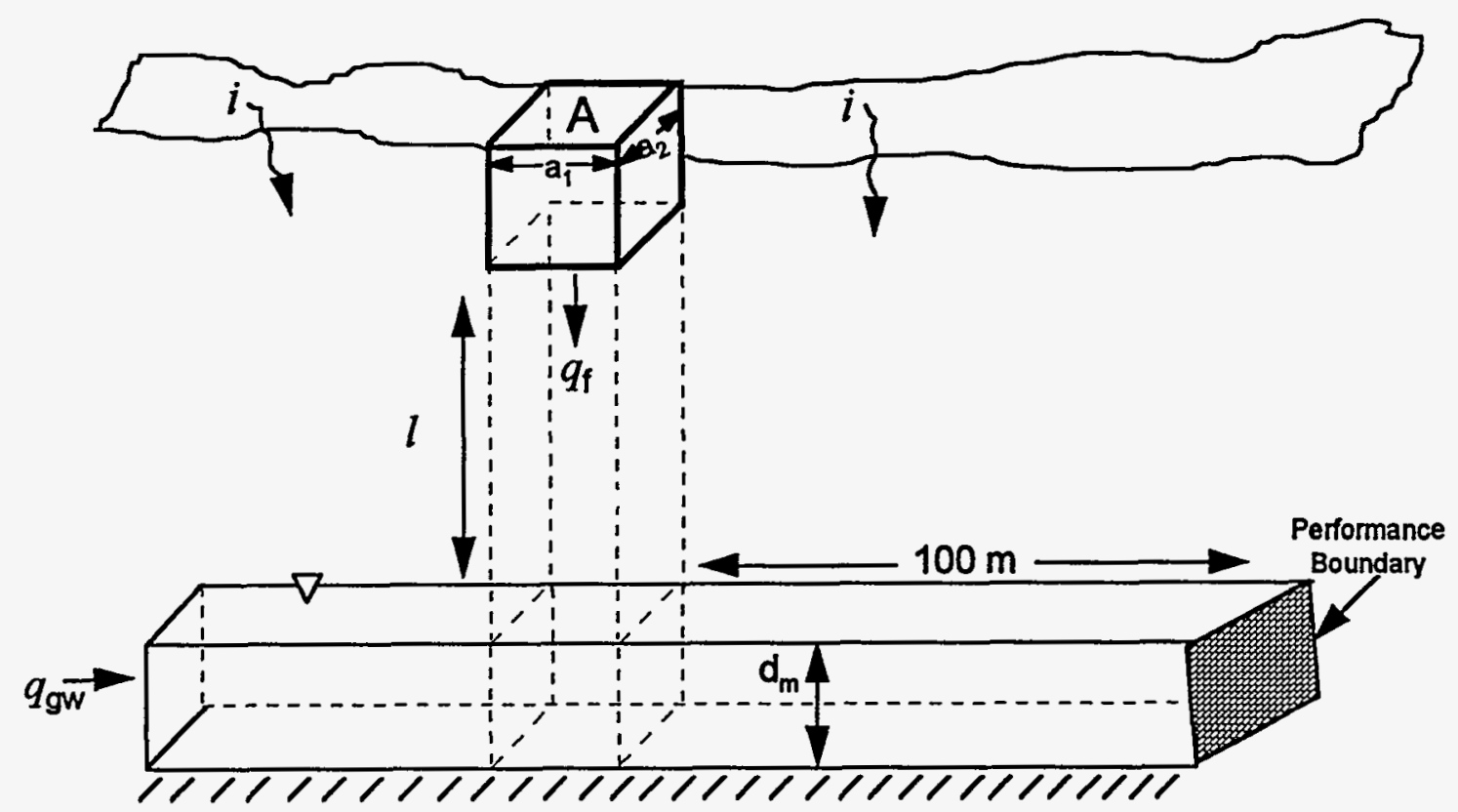

Figure 1-2. Generic conceptual model for the water pathway.

\section{Generic Conceptual Model for Flow and Transport in the Saturated Zone}

In the conceptual model, as contaminated water entered the aquifer, the contaminant mixed with clean groundwater, forming a plume with a shape controlled by aquifer and contaminant properties. The generic conceptual model assumed that instantaneous and complete mixing within the aquifer occurred directly below the facility. Mixing in the vertical direction occurred by hydrodynamic dispersion, and the contaminant mixing depth was determined by the thickness of an actual plume at the $100-\mathrm{m}(328-\mathrm{ft})$ performance boundary.

Dilution by mixing caused the only CRF in the water pathway and, therefore, the CRF became

$$
C R F_{\text {water }}=\left(Q_{f}+Q_{g w}\right) / Q_{f}
$$

where $Q_{g w}$ was the volumetric groundwater flow $\left(\mathrm{m}^{3} / \mathrm{y}\right)$, defined as

$$
Q_{g w}=q_{z w} d_{m} a_{2}
$$

where

$q_{g w}$ is the groundwater Darcy velocity, the volume discharge per unit bulk area $(\mathrm{m} / \mathrm{y})$;

$d_{m}$ is the contaminant mixing depth in the groundwater (m); and

$a_{2}$ is the width of the facility (m). 
The contaminant mixing depth in the groundwater, $d_{m}$, was determined according to aquifer properties. For thin aquifers, mixing over the entire aquifer thickness was assumed. For thicker aquifers, the mixing depth was estimated by the plume thickness due to vertical dispersion at $100 \mathrm{~m}$ from the facility.

\subsubsection{Radionuclide Travel Times in the Water Pathway}

The total retarded radionuclide travel time was the sum of the retarded travel times in the unsaturated and saturated zones.

\section{Unsaturated Zone}

The water travel time in the unsaturated zone, $t_{w w}$ for steady-state, one-dimensional flow under unit gradient conditions was defined as

$$
t_{w v}=\frac{l \theta_{w}}{q_{f}}
$$

where

$l$ is the distance between the disposal facility and the groundwater $(\mathrm{m})$; and

$\theta_{w}$ is the volumetric moisture content in the unsaturated zone $\left(\mathrm{mL} / \mathrm{cm}^{3}\right)$.

Retarded contaminant travel time in the unsaturated zone, $t_{c w}$ was

$$
t_{c v}=t_{w v}\left(1+K_{d} \rho_{b} / \theta_{w}\right)
$$

where

$K_{d}$ is the distribution coefficient for the radionuclide in the unsaturated zone $(\mathrm{mL} / \mathrm{g})$; and

$\rho_{b}$ is the dry bulk density of the soil in the unsaturated zone $\left(\mathrm{g} / \mathrm{cm}^{3}\right)$.

\section{Safurated Zone}

The water travel time in the saturated zone, $t_{w s,}$ assuming steady-state, one-dimensional flow, was defined as

$$
t_{w s}=\frac{100 n}{q_{g w}}
$$

where

$n$ is the porosity of the saturated zone.

Retarded contaminant travel time in the saturated zone, $t_{c s}$, was defined as

$$
t_{c s}=t_{w s}\left(1+K_{d} \rho_{b} / n\right)
$$

where

$K_{d}$ is the distribution coefficient for the radionuclide in the saturated zone $(\mathrm{mL} / \mathrm{g})$; and $\rho_{b}$ is the dry bulk density of the soil in the saturated zone $\left(\mathrm{g} / \mathrm{cm}^{3}\right)$. 


\subsubsection{Decay Term for the Water Pathway}

For releases to water, the decay term, $r_{\text {Decay, }}$ accounted for radioactive decay during detention time in the disposal facility plus retarded travel to the performance boundary. The decay term was defined as

$$
r_{\text {Decay }}=\exp \left[\frac{\ln (2)\left(t_{a}\right)}{t_{1 / 2}}\right]
$$

where

$t_{a}$ is the radionuclide arrival time at the performance boundary, calculated as the detention time in the disposal facility plus retarded travel time (y); and

$t_{1 / 2}$ is the radionuclide half-life $(\mathrm{y})$.

\subsection{ATMOSPHERIC TRANSPORT}

The radionuclide concentration limits for the atmospheric pathway were calculated using

$$
C_{W-A t m}=H_{A t m} \times \frac{1}{S D C F_{A t m}} \times C R F_{D i f f} \times C R F_{D i s p} \times r_{D e a x y} \times 1000
$$

where

$C_{W-A t m}$ is the annual average concentration of a specific radionuclide in the disposed waste corresponding to the permissible dose from atmospheric releases at the performance boundary $\left(\mu \mathrm{Ci} / \mathrm{m}^{3}\right)$;

$H_{A t m}$ is the performance measure of $0.01 \mathrm{rem}(0.1 \mathrm{mSv})$ per year for all pathways for atmospheric releases;

$S D C F_{A t m}$ is the scenario dose conversion factor represented as the annual effective dose equivalent per unit concentration for all pathways from atmospheric releases for each radionuclide $\left([\mathrm{rem} / \mathrm{y}] /\left[\mu \mathrm{Ci} / \mathrm{m}^{3}\right]\right)$;

$C R F_{\text {Diff }}$ is the concentration reduction that occurs from the top of the disposal facility to the soil surface as the radionuclide diffuses upward $\left[\left(\mu \mathrm{Ci} / \mathrm{m}^{3}\right) /\left(\mu \mathrm{mi} / \mathrm{m}^{3}\right)\right]$;

$C R F_{\text {Disp }}$ is the concentration reduction that occurs as the radionuclide is emitted to the atmosphere, mixed with the ambient air, and dispersed downwind to the performance boundary $\left[\left(\mu \mathrm{Ci} / \mathrm{m}^{3}\right) /\left(\mu \mathrm{Ci} / \mathrm{m}^{3}\right)\right]$; and

$r_{\text {Decay }}$ is the term accounting for radioactive decay during detention time in the waste plus travel time via environmental transport in the atmospheric pathway to the performance boundary (dimensionless).

The PE methodology for calculating permissible waste concentrations for the atmospheric pathway is discussed in more detail in Chapter 5 and Appendix $\mathrm{C}$ of Volume 2.

Only the volatile radionuclides $\mathrm{H}-3$ and $\mathrm{C}-14$ were considered in the $\mathrm{PE}$ for atmospheric releases. Based on regulatory precedents for controlling radiation exposures of the public, radon was excluded from consideration in the PE. The performance measure, $H_{A t m}$, was 0.01 rem $(0.1 \mathrm{mSv})$ and was specific to the atmospheric pathway. Scenario dose conversion factors $\left(S D C F_{A t m}\right)$ were radionuclide-specific and the same for all sites. Values for $S D C F_{A t m}$ are listed in 
Table 1-3. Two environmental transport $C R F$ s were used for the atmospheric pathway: $C R F_{D i f f}$ which defined the concentration reduction that occurred from the top of the disposal facility to the soil surface from the upward radionuclide diffusion profile and $C R F_{D i s p}$, which defined the concentration reduction that occurred as the radionuclide was emitted to the atmosphere, mixed with the ambient air, and dispersed downwind to the performance boundary. The method for estimating the two components of $C R F_{A t m}$ are described in this section. $C R F_{A t m}$ values represented concentration reductions for undecayed radionuclides. Radioactive decay, based on the detention and travel time, was accounted for separately using $r_{\text {Decay }}$. The method for estimating $r_{\text {Decay }}$ is also described in this section. $C R F_{A t m}$ and $r_{\text {Decay }}$ values were radionuclidespecific and site-specific and are reported in the site-evaluation chapters.

Table 1-3. Scenario Dose Conversion Factors for the Atmospheric Pathway $\left(S D C F_{A t m}\right)$

\begin{tabular}{|l|c|}
\hline \multicolumn{1}{|c|}{ Radionuclide } & $\begin{array}{c}\mathrm{SDCF}_{\text {Atm }}{ }^{2} \\
(\mathrm{rem} / \mathrm{y}) /(\mu \mathrm{Ci} / \mathrm{L})\end{array}$ \\
\hline $\mathrm{H}-3$ & $8.33 \mathrm{E}+02$ \\
\hline $\mathrm{C}-14$ & $2.20 \mathrm{E}+05$ \\
\hline
\end{tabular}

a Based on an average adult breathing rate of $8000 \mathrm{~m}^{3} / \mathrm{y}$

\subsubsection{Transport CRF for the Atmospheric Pathway}

The conceptual model for atmospheric transport is illustrated in Figure 1-3. The atmospheric transport CRF consisted of two components. The product of the components provided estimates of total $C R F_{A m}$ values. The analysis used both generic and site-specific data. These data are provided in the site-evaluation chapters.

\section{Diffusion}

The major assumptions for diffusion in the atmospheric pathway that were used in the generic conceptual model are the following:

- The waste was completely mixed into the soil and, therefore, no credit was taken for the waste disposal facility.

- An upper bound diffusion coefficient was used in the calculation.

- All diffusion was upward.

- Diffusive flux was approximated as first order, linear, and steady state. 


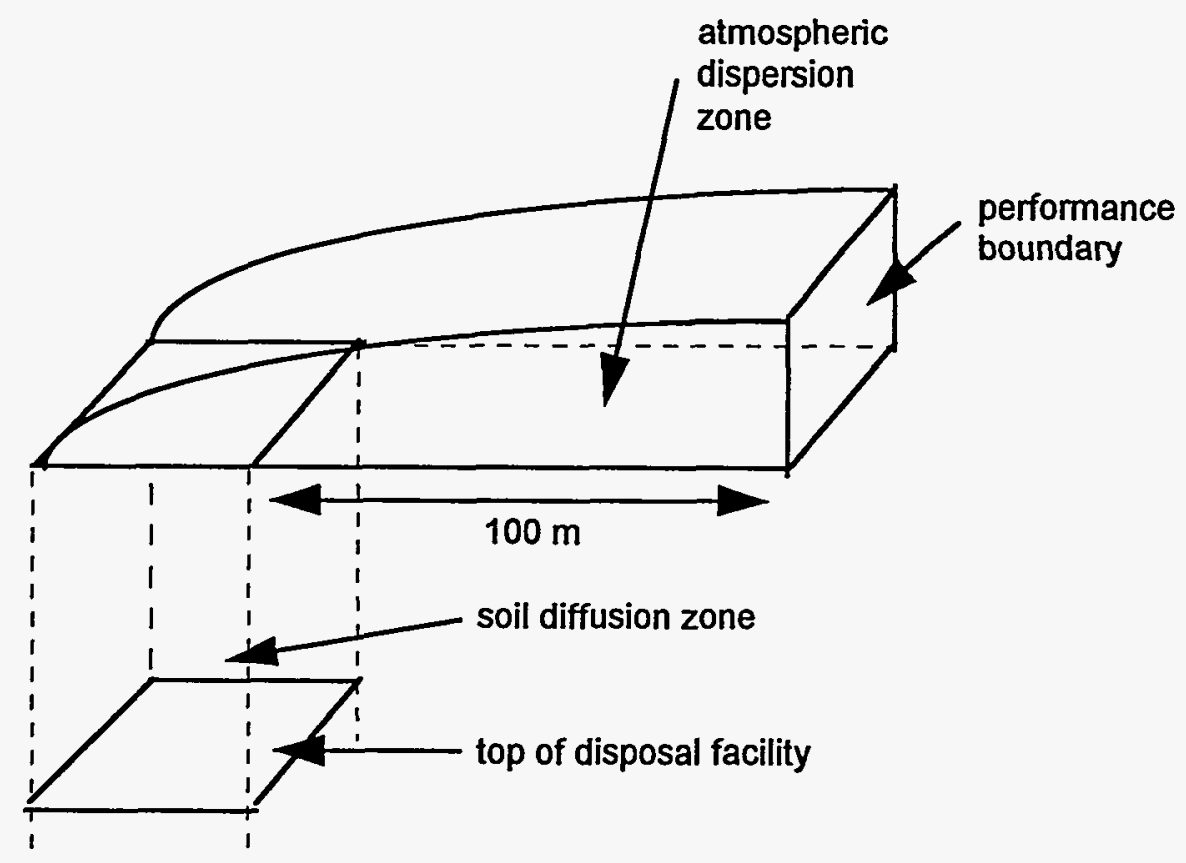

Figure 1-3. Conceptual model for the atmospheric pathway.

$C R F_{D i f f}$ was calculated using the following equation:

$$
C R F_{D i f f}=\frac{x n s}{r d}
$$

where

$x$ is the cover thickness above the disposal facility (m);

$n$ is the soil porosity;

$s$ is the percent saturation of the soil (dimensionless);

$r$ is the ratio of the density of water in air to that in the liquid phase, for $\mathrm{H}-3$, or the ratio of the $\mathrm{CO}_{2}$ concentration in the air to that in dissolved water, for C-14 (dimensionless); and

$d$ is the depth of the surface soil (m).

\section{Dispersion}

$C R F_{D i s p}$ was calculated using the following equation:

$$
C R F_{\text {Disp }}=\frac{D}{A D}
$$

where

$D$ is the $\mathrm{H}-3$ or $\mathrm{C}-14\left(\right.$ as $\left.{ }^{14} \mathrm{CO}_{2}\right)$ diffusion coefficient in air $\left(\mathrm{m}^{2} / \mathrm{s}\right)$; and 
$A_{D}$ is the atmospheric dispersion term $\left(\mu \mathrm{Ci} / \mathrm{m}^{3} / \mu \mathrm{Ci} / \mathrm{m}^{2}-\mathrm{s}\right)$.

The atmospheric dispersion term, $A_{D}$, was estimated using a Gaussian air dispersion model.

\subsubsection{Radionuclide Travel Times in the Atmospheric Pathway}

To estimate transport time of the radionuclide to the soil surface, the diffusion velocity, $v_{d}$ was approximated as a one-dimensional, first-order, linear expression. Assuming $v_{d}$ was uniform, the transport time, $t_{d}$, was given by

$$
t_{d}=\frac{x^{2}}{D}
$$

Once airborne, the transport time to receptors located at the performance boundary downwind was on the order of seconds. Therefore, appreciable radionuclide decay did not occur during the dispersion phase of transport.

\subsubsection{Decay Term for the Atmospheric Pathway}

For releases to the atmosphere, $r_{\text {Decay }}$ accounted for radioactive decay during detention in the disposal facility and retarded travel to the soil surface. The decay term was defined as

$$
r_{\text {Decay }}=\exp \left[\frac{\ln (2)\left(t_{a}\right)}{t_{1 / 2}}\right]
$$

where

$t_{a}$ is the radionuclide arrival time at the performance boundary, calculated as the detention time in the disposal facility plus retarded travel time (y); and

$t_{1 / 2}$ is the radionuclide half-life (y).

\section{$1.3 \quad$ INADVERTENT INTRUDER EXPOSURES}

The radionuclide concentration limits for the inadvertent intruder pathway were calculated using

where

$$
C_{W-\text { Intr }}=H_{J n t r} \times \frac{1}{S D C F_{\text {Intr }}} \times r_{\text {Decay }}
$$

$C_{W-I n t r}$ is the concentration of a specific radionuclide in the disposed waste corresponding to the permissible dose to an inadvertent intruder $\left(\mu \mathrm{Ci} / \mathrm{m}^{3}\right)$;

$H_{\text {Intr }}$ is the performance measure of $100 \mathrm{mrem}(1 \mathrm{mSv})$ per year effective dose equivalent for inadvertent intrusion;

$S D C F_{\text {Intr }}$ is the annual effective dose equivalent per unit concentration for an intrusion scenario for each specific nuclide $\left([\mathrm{mrem} / \mathrm{y}] /\left[\mu \mathrm{Ci} / \mathrm{m}^{3}\right]\right)$; and

$r_{\text {Decay }}$ is the decay term accounting for radioactive decay prior to the assumed intrusion (dimensionless). 
The PE methodology for calculating permissible waste concentrations based on inadvertent intruder exposures is discussed in more detail in Chapter 5 and Appendix D of Volume 2. Implicit in this discussion is the understanding that the long-term living havits of future inadvertent intruders are difficult to predict with any certainty and that this certainty presumably increases with time.

The performance measure, $H_{\text {Intr }}$ was $100 \mathrm{mrem}(1 \mathrm{mSv})$ per year and was specific to the inadvertent intruder pathway. The calculation of permissible waste concentrations for inadvertent intruder exposures did not utilize CRFs. Instead, the total dose resulting from an intrusion scenario (the sum of the doses from all exposure pathways involved in that intrusion) was modified by scenario dose conversion factors $(S D C F$ s) that were applied to specific exposure pathways. These values were radionuclide-specific and facility-design-specific and were the same for all sites. Values for $S D C F_{\text {Intr }}$ are listed in Appendix E of Volume 2. Values for $r_{\text {Decay }}$ were based on time of intrusion into the disposal facility. The method for estimating $r_{\text {Decay }}$ values is described in this section.

The analysis of the inadvertent intruder pathway considered two chronic scenarios: homesteader and post-drilling. The homesteader scenario included establishment by an intruder of a permanent homestead directly above a disposal facility with the foundation of the home extending into the waste; some of the waste exhumed from the disposal facility was mixed with native soil in the intruder's vegetable garden. The post-drilling scenario considered the construction of a well for a domestic water supply by an intruder who resided permanently near a disposal facility; the well was drilled through the disposal facility. The exposure pathways for the intruder scenarios are shown in Figure 1-4.

The major assumptions related to the inadvertent intruder scenarios are the following:

- Only chronic exposure was considered (associated with $100 \mathrm{mrem}[1 \mathrm{mSv}]$ per year performance measure).

- Intrusion occurred only beyond the period of active institutional controls (100 y), depending on intrusion scenario and site-specific factors. Benefits from passive institutional controls (e.g., permanent marker system, public records of prior land use) after active institutional control were not considered.

- Only pathways related to direct intrusion into the waste were considered (no water pathways).

- Inhalation exposure to radon was not considered (see Chapter 5 of Volume 2).

- The performance measures applied for 10,000 y for radionuclides with significant longlived decay products (i.e., U-234, U-235, U-238, and Np-237).

- Depletion of radionuclide inventory from the waste disposal facility by leaching through water pathways was not considered. 


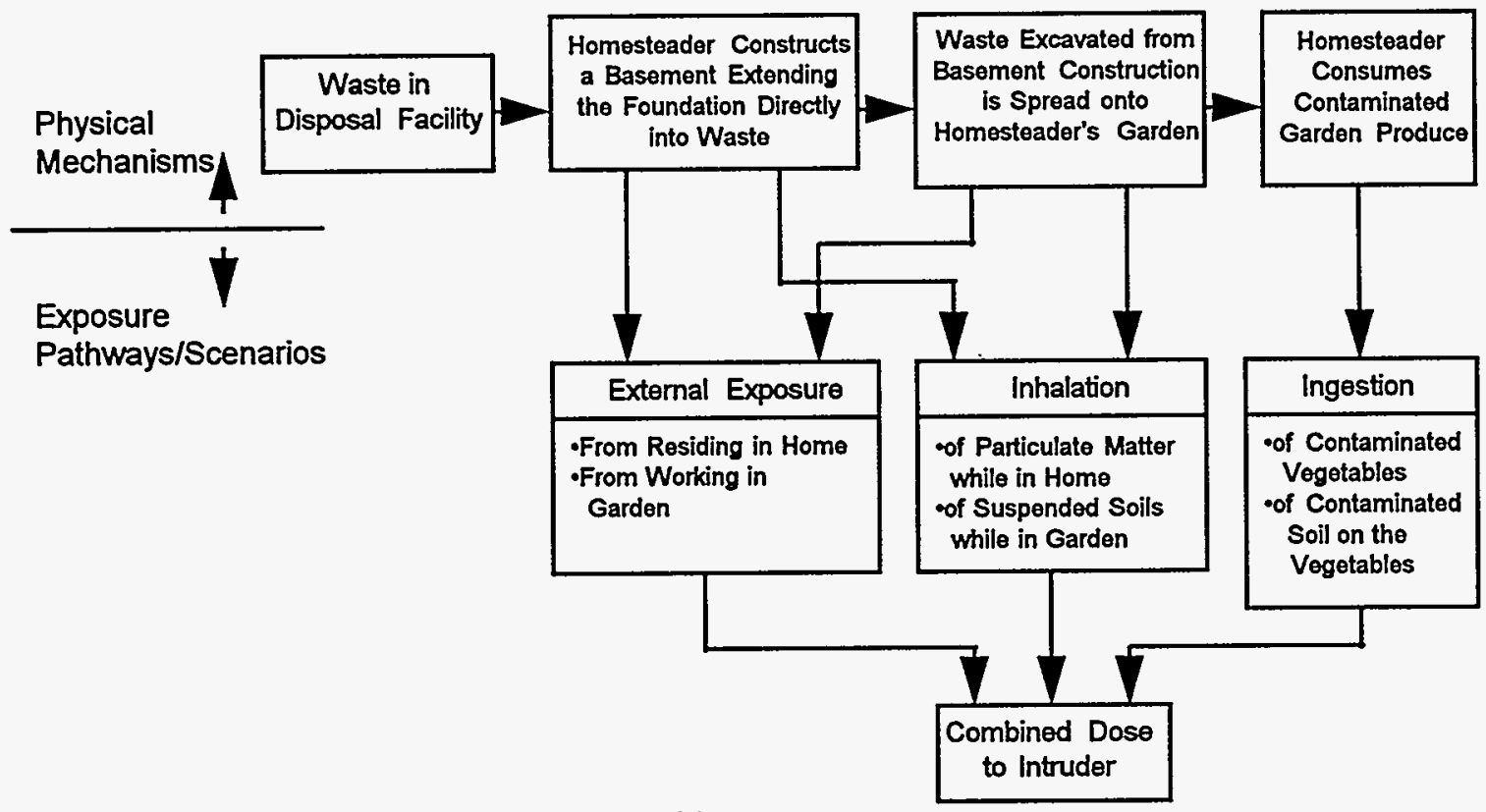

(a)

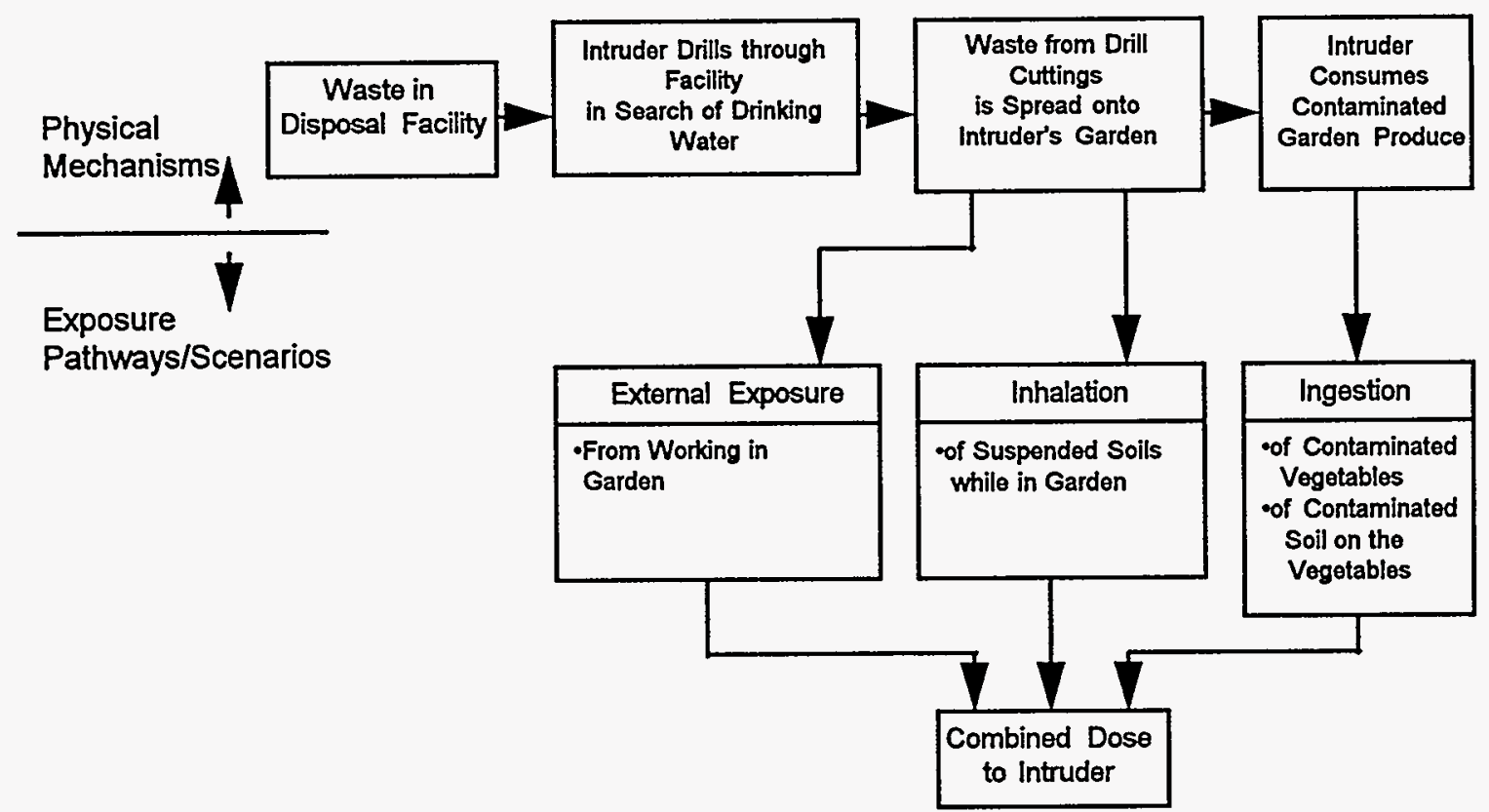

(b)

Figure 1-4. Exposure pathways in the PE for (a) homesteader and (b) post-drilling intruder scenarios. 
The decay term for the inadvertent intrusion scenarios accounted for radioactive decay prior to an assumed intrusion. The decay term was defined as

$$
r_{\text {Decay }}=\exp \left[\frac{\ln (2)\left(t_{i}\right)}{t_{1 / 2}}\right]
$$

where

$t_{i}$ is the time of intrusion for the intruder scenario being analyzed $(y)$; and

$t_{1 / 2}$ is the radionuclide half-life $(y)$.

Unless modified by site-specific conditions, the time of intrusion, $t_{i}$, for the homesteader scenario was $500 \mathrm{y}$ for the generic above-ground tumulus and $300 \mathrm{y}$ for the generic shallow trench. The time of intrusion for the post-drilling scenario was $100 \mathrm{y}$ for both the trench and tumulus designs in hard-rock drilling regions. The exceptions for the generic intruder scenarios were radionuclides with significant long-lived decay products (i.e., U-234, U-235, U-238, and Np-237) for which $t_{i}$ was $10,000 \mathrm{y}$. The intrusion scenarios are discussed in Appendix D of Volume 2. 



\section{California: LAWRENCE LIVERMORE NATIONAL LABORATORY SITE 300 (LLNL) \\ Core Team Contact: Bruce M. Thomson}

The Federal Facility Compliance Act (FFCAct, 1992) requires the Department of Energy (DOE) to establish plans in conjunction with its regulators and with members of the public for the treatment of DOE's mixed low-level waste (MLLW). Although the FFCAct did not specifically address disposal of treated MLLW, both DOE and the States recognized that disposal issues were an integral part of treatment discussions. Since 1992, DOE has worked with the States to define and develop an evaluation process for disposal options. Preliminary activities of this joint DOEState process have narrowed the sites for further evaluation from 49 to 15 .

The Disposal Workgroup (DWG), which was established by DOE to develop a process for evaluating disposal options, designed a performance evaluation (PE) to quantify and compare the limitations of the remaining $15 \mathrm{DOE}$ sites for MLLW disposal. The principal goal of the PE was to estimate, for grouted residuals resulting from the treatment of MLLW, permissible concentrations of radionuclides in waste for disposal at each site. These "permissible waste concentrations" were based solely on long-term physical performance of the disposal facility and did not take into account any operational waste acceptance criteria that a site might have developed. The PE did not address any ethical, social, or policy considerations relevant to siting such facilities.

The PE used analyses that are consistent with the approach used in many low-level waste (LLW) performance assessments. The objective was to use a set of modeling assumptions of sufficient detail to capture major site-specific characteristics and yet be general enough for consistent application at all sites. Additionally, the analyses were designed to ensure that the sites were analyzed consistently and that all major assumptions were clearly stated.

The remainder of this chapter provides the PE results for Lawrence Livermore National Laboratory (LLNL) Site 300, one of the 15 sites being evaluated. The chapter contains the following information:

Section 2.1: brief, general description of the site, based on previous work done by the DWG (Gruebel et al., 1994)

Section 2.2: plans for MLLW disposal, if any, and the location evaluated in the PE

Section 2.3: current understanding of radionuclide movement at the selected location based on available information, and the conceptual model used for the evaluation of each of three pathways (water, atmospheric, and inadvertent intruder)

Section 2.4: site-specific and generic values used in the PE calculations and their sources

Section 2.5: estimates of maximum waste concentrations determined in the PE calculations for each of the three pathways, along with calculated values used in determining these results 
Section 2.6: summary of results based on disposal-facility design; discussion with respect to such issues as uncertainty and sensitivity

Section 2.7: observations based on the results of the $\mathrm{PE}$ and the parameter sensitivity analysis

Section 2.8 references

The general assumptions and methodology used in the PE are summarized in Chapter 1 of this volume and explained in more detail in Volume 2 of this report. Overall results for all the sites are discussed in Chapter 7 of Volume 2.

\subsection{GENERAL DESCRIPTION OF THE SITE}

Lawrence Livermore National Laboratory (LLNL) Site 300 is located approximately $24 \mathrm{~km}$ (15 mi) southeast of Livermore, California (Figure 2-1), in the sparsely populated hills of the Diablo Range. Land use surrounding Site 300 is predominately agricultural. The Carnegie State Vehicular Recreation Area is located south of the site. South and east of the site, a corridor along Corral Hollow Road is designated as an ecological preserve. Two other smaller, privately operated defense-related research and testing facilities are located near Site 300.

The nearest urban area is the city of Tracy (population 42,000), approximately $12 \mathrm{~km}$ $(8 \mathrm{mi})$ northeast of Site 300 . Population within a $10-\mathrm{km}(6.2-\mathrm{mi})$ radius of LLNL Site 300 is less than 1000; estimated population within a $50-\mathrm{km}(31-\mathrm{mi})$ radius is 1.9 million.

The University of California has managed and operated LLNL for DOE since 1952. The primary mission of LLNL has been weapons research and development, with additional work in energy, biomedical, and environmental programs. The laboratory currently does not operate a LLW disposal facility and has no plans for either a LLW or MLLW disposal facility. Site 300, which covers approximately $28 \mathrm{~km}^{2}\left(11 \mathrm{mi}^{2}\right.$ ) owned by DOE (Figure 2-2), was established in 1953 to provide a high explosives (HE) test site in support of laboratory activities. Additional activities at Site 300 include dynamic and environmental testing of prototype components and environmental restoration operations. The site includes two remote firing areas and 25 magazines to store $\mathrm{HE}$, supported by a chemistry processing area and an administrative complex.

Mild winters and warm, dry summers characterize the climate of Site 300 . The average annual temperature for the region ranges from $7.7^{\circ} \mathrm{C}\left(46^{\circ} \mathrm{F}\right)$ in January to $21.7^{\circ} \mathrm{C}\left(71^{\circ} \mathrm{F}\right)$ in July. The average annual rainfall at Site 300 is $25 \mathrm{~cm}$ (10 in.). Evapotranspiration in the area is estimated at $85 \%$ of the annual rainfall or about 20 to $23 \mathrm{~cm}(8$ to $9 \mathrm{in}$.). However, potential evapotranspiration for the year is approximately $152 \mathrm{~cm}(60 \mathrm{in}$.). For approximately $45 \%$ of the year, prevailing winds are from the west and southwest.

The topography of Site 300 consists of rugged, hilly terrain. The hills and canyons are generally oriented northwest-southeast. Elevations range from $500 \mathrm{ft}$ to $1,750 \mathrm{ft}$ above sea level. The primary drainage in the vicinity of Site 300 is Corral Hollow Creek, which is ephemeral and flows to the east. A tributary to this creek is Elk Ravine, which drains most of the Site 300 property. There are about 25 springs in the Site 300 area, 19 of which are perennial. 


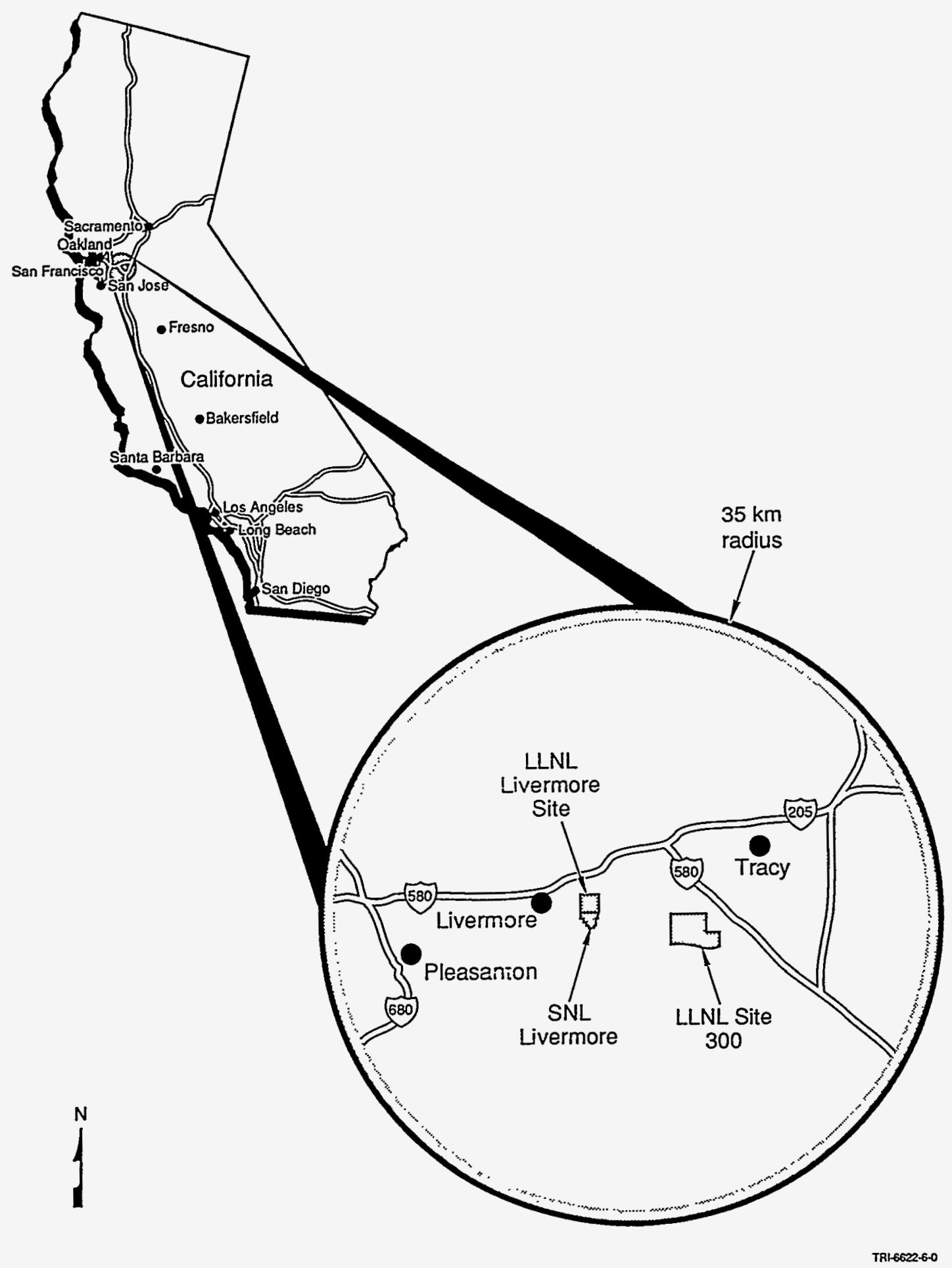

Figure 2-1. Location map for Lawrence Livermore National Laboratory Site 300. 


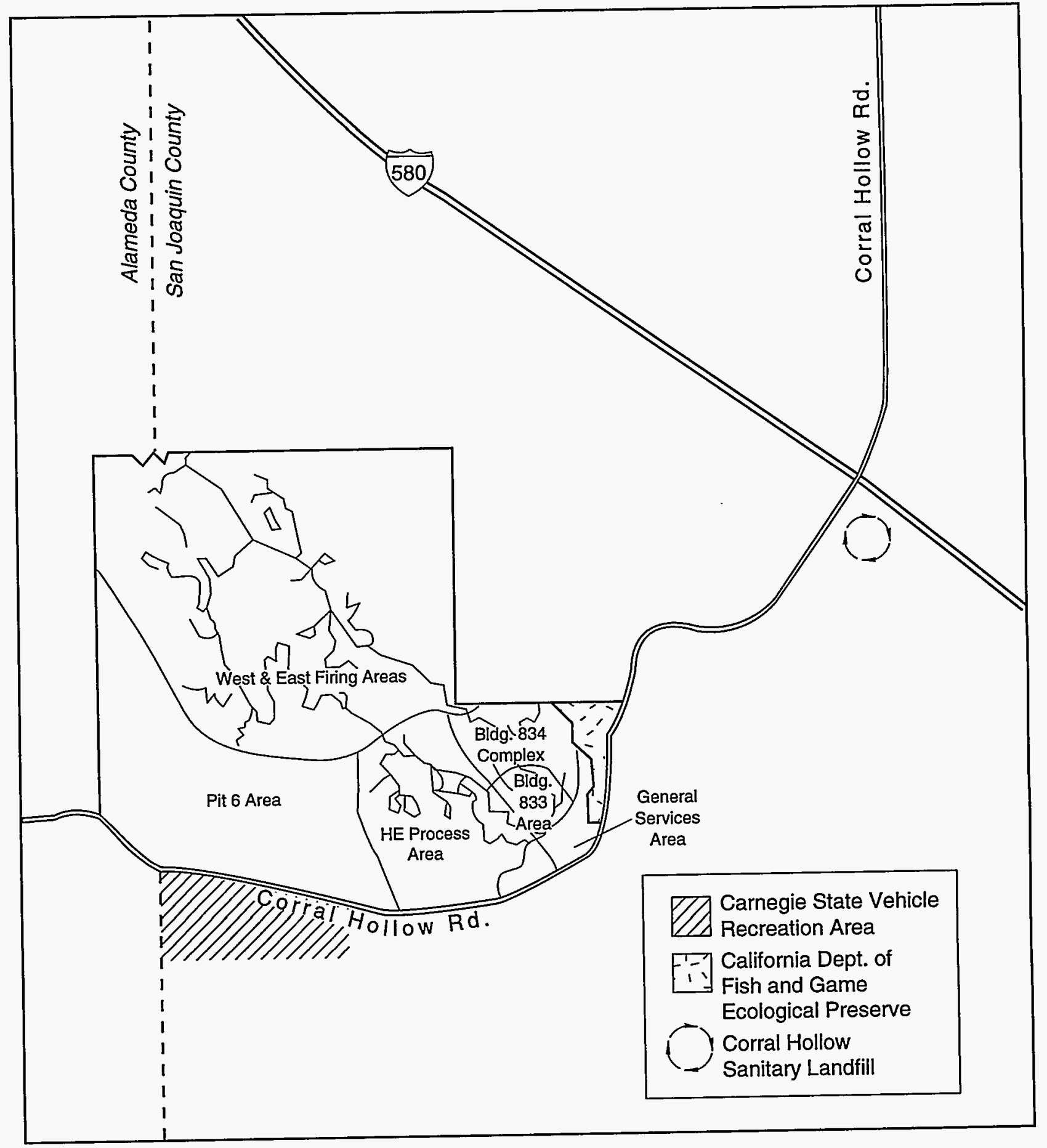

TRI-6622-32-1

Figure 2-2. Site map for Lawrence Livermore National Laboratory Site 300. 
Site 300 is located in the southeastern portion of the Altamont Hills, which are part of the Coast Ranges Physiographic Province that separates the Livermore Valley to the west from the San Joaquin Valley to the east. The Coast Ranges Physiographic Province is dominated by northnorthwest trending, fault-bounded antiformal mountain ranges and synformal valleys. Bedrock consists of igneous, metamorphic, and sedimentary rocks ranging in age from Jurassic to Pleistocene. The present physiography and geology are the result of deformation and depositional processes along an active continental plate margin. Seismic activity and geodetic measurements indicate that deformation is continuing. Five mappable bedrock units are found within Site 300: the Great Valley sequence, the Tesla Formation, the Cierbo Formation, the Neroly Formation, and the Pliocene nonmarine unit. These bedrock units are locally overlain by terrace remnants, floodplain, ravine fill, landslide, and alluvial and colluvial deposits.

The general hydrogeologic setting consists of gently dipping sedimentary bedrock deposits dissected by steep ravines. The upper blue and lower blue sandstones of the Neroly Formation are the major regional aquifers. Alluvial valley fill deposits represent locally important sources of groundwater as well. No aquifer(s) in the LLNL area have been designated by the U.S. Environmental Protection Agency (EPA) as sole source aquifers as defined in 40 CFR 149.2.

\subsection{STATUS AND SITING OF MLLW DISPOSAL FACILITY}

At the time of the PE, personnel at LLNL Site 300 had no plans for on-site MLLW disposal. However, in preparation for the PE, site technical staff at LLNL independently established a set of simple site selection criteria that were used in identifying possible locations of an MLLW disposal facility at Site 300 . These selection criteria are summarized as follows:

\section{Operational Criteria}

1. Provide a safe distance from $\mathrm{HE}$ firing zones

2. Provide a safe distance from pistol and rifle ranges

3. Provide a safe distance from $\mathrm{HE}$ handling and storage facilities (referred to as "quantity-distance criteria" by Site 300 staff)

4. Assure access to the site during HE firing tests

\section{Hydrogeological Criteria}

5. Eliminate currently contaminated areas from consideration

6. Avoid proximity to the Elk Ravine and Corral Hollow Faults

7. Eliminate areas within the flood plain from consideration

8. Eliminate areas with shallow groundwater from consideration

9. Consider geotechnical construction characteristics

Other Considerations

10. Give priority to areas with available data 
The purpose of the first three selection criteria is that an MLLW disposal facility should not interfere with the primary mission of the Site 300 facility, which consists of development and testing of $\mathrm{HE}$ materials. Emphasis is placed on the safety of personnel employed at the location; thus, the fourth criterion recognizes that during testing activities many of the Site 300 roads are closed, which could preclude access to or operations in a disposal facility. Criteria five through nine deal with the basic stability, integrity, and long-term performance of any type of disposal facility. Eliminating from consideration areas within Site 300 that are already contaminated (criteria eight) is based both on the perceived difficulty of detecting failure of a disposal facility at such a location and on the observation that existing groundwater contamination is indicative of a formation with little natural ability to attenuate pollutants. The last criterion is primarily one of expediency: a PE is easiest to perform and defend if site-specific data are available rather than use of speculative information extrapolated from off-site studies.

Using these criteria, the LLNL site technical staff narrowed the potential locations to two: a location along the northern boundary of Site 300 and the 829 Site (Figure 2-3). The northern location would likely be the preferred of the two locations because of minimal interference with site operation, even though a new road and access would be required. However, the location chosen for the analysis was the 829 Site primarily because some site characterization data were available. This site is near some $\mathrm{HE}$ burn pits but is otherwise undeveloped. A considerable amount of hydrogeological information is available for this site as a result of groundwater contamination at nearby locations and subsequent investigations.

Two generic disposal facilities were considered in the PE: a RCRA-compliant, belowground trench and a RCRA-compliant, above-ground tumulus. The generic facilities were selected to provide consistency in analysis of the performance of the 15 sites. Both generic facilities were assumed to be square with a plan area of $2500 \mathrm{~m}^{2}\left(26,910 \mathrm{ft}^{2}\right)$.

\subsection{BASIS FOR CONCEPTUAL MODEL USED IN THE PE}

Site 300 was placed on the National Priorities List (NPL) in 1990 due to the presence of a variety of soil and groundwater contaminants, and all investigations since then have been conducted in accordance with the Comprehensive Environmental Response, Compensation, and Liability Act (CERCLA) under the oversight of the EPA, the California Regional Water Quality Control Board, and the California Department of Toxic Substances Control. The primary contaminants of concern at Site 300 are volatile organic compounds (VOCs), HE compounds, and tritium. Investigations of potential groundwater contamination by uranium-238 are in progress.

An extensive 15-volume report, "Final Site-Wide Remedial Investigation Report, Lawrence Livermore National Laboratory Site 300" (Webster-Scholten, 1994), has been prepared by LLNL. The report, referred to as the Site-Wide Remedial Investigation (SWRI) report, summarizes the characteristics and environmental contamination at Site 300. The SWRI report is a compilation and synthesis of all environmental and remedial investigations that have been conducted at Site 300 . This report had five objectives: 


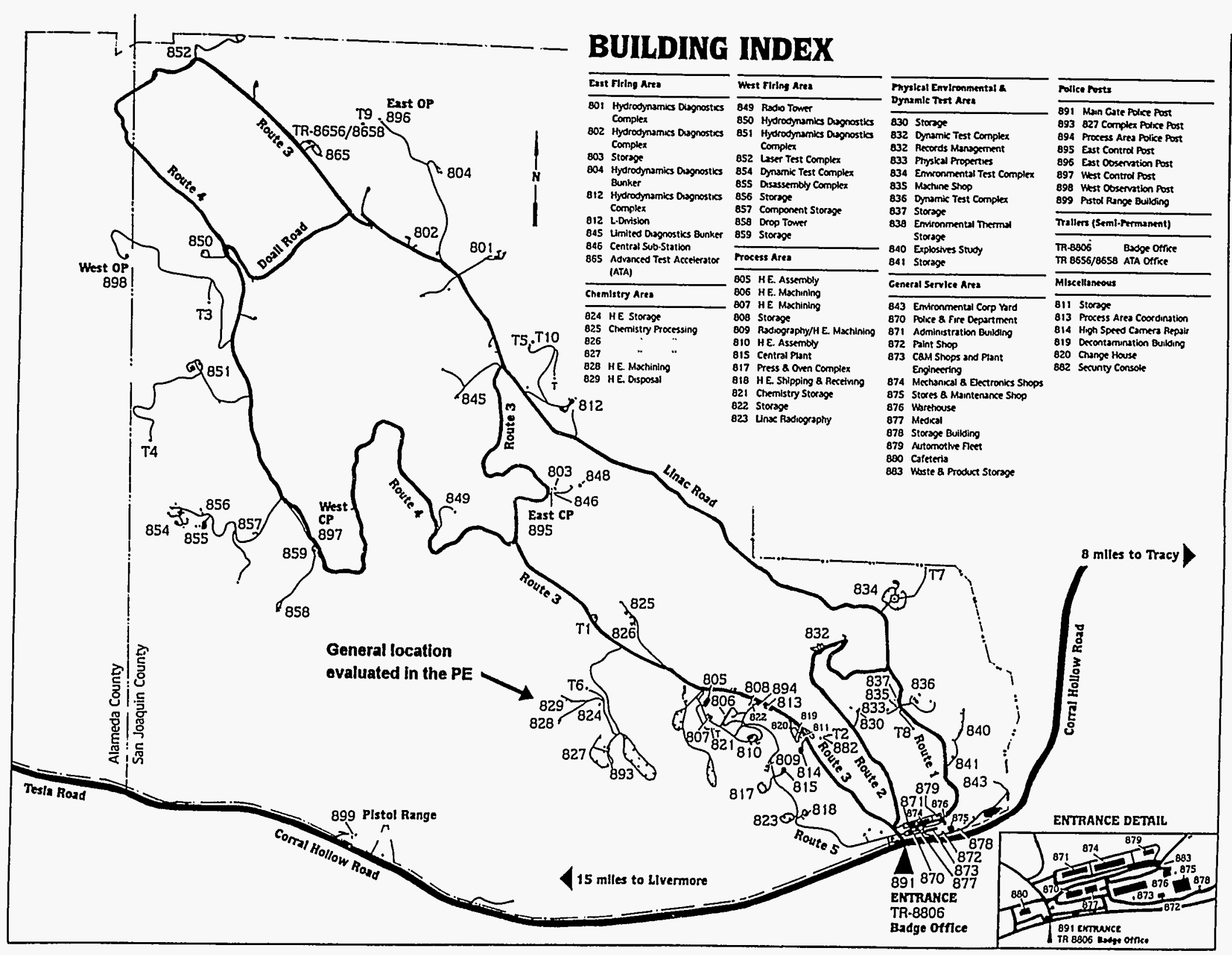

Figure 2-3. General location of the generic MLLW disposal facilities evaluated in the PE at LLNL Site 300. 
1. Characterize the geology and hydrogeology of the site;

2. Identify the nature and extent of contaminants released to the environment in each study area at the site;

3. Evaluate the potential routes of migration of these contaminants and estimate exposure of all potential human and ecological exposure points;

4. Estimate health risks and noncancer health effects (hazard index) for each potential exposure point based on the potential exposure-point concentrations or activities of contaminants; and

5. Present the results of the previous remedial investigations in a site-wide perspective.

Due to the diversity of activities that have been conducted at Site 300 , there are a wide variety of contaminant sources. These include surface spills; leakage from transfer pumps, landfills and pits, and underground fuel tanks; disposal lagoon discharges; disposal dry well discharges; leaching from contaminated gravel; and septic tank discharges. Six study areas have been identified in Site 300: the General Services Area study area, Building 833 study area, Building 834 study area, East Firing Area/West Firing Area (EFA/WFA) study area, the Pit 6 Area study area, and the HE Process Area study area. To date nearly 5,000 soil and rock samples from several stratigraphic units in these study areas have been collected, and more than 400 groundwater monitor wells have been installed, most of which are sampled quarterly or biannually. In addition, surface water and air quality sampling programs are continuing, and soil vapor surveys have been used as reconnaissance and field screening techniques during study area environmental investigations. The results of these sampling and analysis programs to December 31, 1991, are summarized in the SWRI (Webster-Scholten, 1994).

Contaminant release screening and fate analyses have been conducted for Site 300 using methods recommended by the EPA for Superfund sites. This process included identification of each potential release scenario and the environmental media affected by the release, followed by development of conceptual models to identify probable migration processes to selected exposure points. A listing of the conceptual models for migration processes at Site 300 follows:

1. Contaminants bind to resuspended soil particles with subsequent exposure through inhalation, dermal contact, and incidental ingestion.

2. Volatile organic contaminants present in subsurface soil/rock volatilize into the atmosphere with subsequent inhalation.

3. Volatile organic compounds present in subsurface soil volatilize and diffuse into buildings with subsequent inhalation.

4. Volatile organic contaminants present in surface water volatilize into the atmosphere with subsequent inhalation.

5. Tritium present in soil moisture volatilizes into the atmosphere with subsequent inhalation.

6. Contaminants that have migrated from soil become present in groundwater. Exposure occurs where contaminated groundwater reaches the land surface, such as at a spring or well, or where groundwater is produced from water supply wells.

7. Contaminants introduced into groundwater are transported. Exposure occurs where contaminated groundwater reaches the land surface, such as at a spring or well, or where groundwater is produced from water supply wells. 
Most of the models used in the fate and transport modeling studies for Site 300 are analytical models and are described in the SWRI report (Webster-Scholten, 1994). These include use of analytical models for groundwater flow and transport calculations, although the numerical VLEACH code (US EPA, 1990) was used to simulate the downward migration of VOCs through the vadose zone. A site-wide groundwater model has not been developed at Site 300 . Analytical solutions of the two dimensional contaminant transport equation have been used to model pollutant transport in individual study areas.

A Baseline Risk Assessment has been developed for Site 300 to estimate potential present and future public health and ecological risks associated with environmental contamination based on the condition that no cleanup or remediation activities would take place. This assessment will be used in the future to assist in evaluating the effectiveness of remediation alternatives for reducing potential public health and ecological risks. The Baseline Risk Assessment for Site 300 was divided into two major categories: (1) public health/human exposure and risk assessment and (2) ecological exposure and risk assessment.

Two scenarios were used to evaluate potential human exposure to environmental contaminants at Site 300. The first scenario pertained to exposure of adult employees at Site 300 and estimated health risks attributable to contaminants in surface soil, surface water, and subsurface soil. Consumption of contaminated water was not considered because off-site sources of water supply are used. The second dealt with exposure of nearby residents and was associated with use of contaminated groundwater. Contamination of groundwater beyond the Site 300 boundary has already occurred, and increasing urbanization of surrounding property makes this latter scenario a reasonable concern. Groundwater supplies in the vicinity of Site $\mathbf{3 0 0}$ are limited and are not sufficient to support irrigation-dependent agriculture.

Based on past operations at Site 300 , only two radioactive substances, tritium and uranium-238, are of potential concern, and environmental contamination attributable to these radionuclides is limited to the EFA/WFA area. Calculations presented in the SWRI report estimate an individual total excess lifetime cancer risk ranging from $1 \times 10^{-7}$ to $3 \times 10^{-7}$ for inhalation of resuspended particulates, and a total risk ranging from $2 \times 10^{-6}$ to $6 \times 10^{-6}$ for ingestion and dermal absorption of contaminated surface soil for on-site employees. Summing the risks associated with direct ingestion of tritium containing water, inhalation of tritiated water vapor, dermal absorption of tritiated water, and ingestion of home-grown agricultural products by off-site residents gave an estimated individual excess lifetime cancer risk of from $7 \times 10^{-7}$ to $3 \times 10^{-6}$.

\subsubsection{Water Pathway}

Knowledge of groundwater flow and radionuclide movement in the water pathway at LLNL provided the basis for the conceptual model considered in the PE. The conceptual model encompasses the site technical staff's current understanding of site-specific geology, hydrology, water-table and aquifer characteristics, and transport pathways. 


\subsubsection{Current Understanding of Relevant Hydrogeology}

Groundwater recharge to bedrock aquifers is thought to be local in extent and is controlled by structure and topography. Factors that limit recharge include the low precipitation (approximately $25 \mathrm{~cm}$ [10 in.] per year), high potential evapotranspiration (approximately $152 \mathrm{~cm}$ [60 in.] per year), intervening aquitards, and steep topography that facilitates rapid runoff of precipitation. Recharge to the regional aquifer in the Neroly Formation is thought to occur principally along outcrops in Elk Ravine as well as other alluvium-filled valleys in the area. There is no evidence of direct vertical recharge through higher stratigraphic formations. Perched waterbearing zones at several locations within Site 300 have been identified where fine-grained siltstone and siltstone horizons limit vertical groundwater flow to the underlying regional aquifer as well as interaquifer communication.

The groundwater at Site 300 is generally of potable quality, although it is relatively high in total dissolved solids and sulfate concentration. During 1996, off-site water will replace groundwater as the source of potable supply for Site 300; therefore, groundwater is not used for human consumption. However, groundwater will continue to be used for potable supply at some neighboring locations.

Both surface and subsurface investigations have identified the presence of extensive fracturing and joint sets in bedrock formations at Site 300. Investigations have been conducted to characterize this phenomenon and determine its impact on groundwater flow and contaminant transport. These studies, summarized in the SWRI report, suggest that, although the claystone of the upper part of the upper aquitard contains horizontal fractures, the lower part of the unit is devoid of fractures. These and other field data indicate that the aquitard is an effective hydrologic barrier (Webster-Scholten, 1994, p. 3-44).

A perched groundwater zone has been identified near the 829 Site, possibly caused by surface activities at Site 300 . This perched water zone appears to be of very limited extent in that it has been detected only in two closely spaced monitoring wells. Furthermore, LLNL technical staff note that no seeps or springs have been observed along outcroppings at the elevation of this perched groundwater in the vicinity of the 829 Site. Site technical staff at LLNL are confident that perched water zones at Site 300 would be considered a groundwater resource by regulatory agencies in the State of California and have proposed that groundwater in this formation be considered in the PE analysis. However, as the perched water zone appears to be the result of human activities at the surface, it is probable that siting a mixed waste disposal facility (MWDF) at this location would result in its disappearance. Therefore, due to the transient nature of the perched water zone, the Senior Review Panel (see Chapter 3 of Volume 2) provided guidance that anthropogenic groundwater not be considered as an aquifer in the PE analysis. Accordingly, the regional aquifer in the Neroly formation was used to establish the maximum radionuclide waste concentrations for the groundwater pathway. This decision approximately doubles the estimated groundwater travel time because the perched zone is roughly half the depth of the regional aquifer at the 829 Site. 
According to the SWRI report, few data are available on evapotranspiration rates at Site 300. The estimated average potential evaporation rate (excluding transpiration by plants) is 152 $\mathrm{cm}$ (60 in.) per year for Site 300 and adjacent areas, and evaporation occurs primarily during the hot, windy summer months. Little site-wide transpiration by vegetation occurs in the summer, as evidenced by dying grasses during the late spring and localized controlled burns of vegetation by the Site 300 Fire Department. A conservative estimate of recharge used perviously at LLNL is $10 \%$ of the average annual precipitation. It is likely that most of this recharge occurs in the valleys where flat slopes allow ponding of water and well sorted alluvial materials have higher vertical hydraulic conductivities than the silt and claystone formations at higher elevations.

\subsubsection{Conceptual Model Used in the PE}

The PE used a generic conceptual model to describe the water pathway (summarized in Section 1.1.2 of this volume and described in detail in Chapter 5 of Volume 2). In the unsaturated zone, leachate was generated by constant flow of water through the disposal facility at a rate that was controlled by the assumed performance of the disposal facility. When all engineered barriers had failed, flow rate was assumed to be equal to the natural recharge through local soils. The volumetric flow of water through the facility that generated leachate was based on the assumed performance and size of the disposal facility. No dilution was assumed to occur in the unsaturated zone; so at steady state, the concentration that reached groundwater equaled the leachate concentration. No lateral spreading was assumed, so the leachate flux through the unsaturated zone was confined to the soil column directly below the plan area of the facility.

As contaminated water entered the saturated zone, the contaminant mixed with clean groundwater, forming a plume with a shape controlled by aquifer and contaminant properties. The generic conceptual model assumed that instantaneous and complete mixing within the aquifer occurred directly below the facility. Mixing in the vertical direction occurred by hydrodynamic dispersion, and the contaminant mixing depth was an estimated value.

The generic conceptual model was adapted to conditions at LLNL Site 300 based on sitespecific knowledge of the geology and water flow paths. Site technical staff at LLNL Site 300 participated in the development of the conceptual model for groundwater contaminant transport of the 829 Site. The following description represents the conceptual model of the water pathway that was used in the PE for LLNL. The site is located on a hilltop at an elevation of approximately $365 \mathrm{~m}(1200 \mathrm{ft})$ above mean sea level. The regional water table is located in the Neroly formation at an elevation of approximately $207 \mathrm{~m}(680 \mathrm{ft})$ above mean sea level. Groundwater investigations identified the presence of perched groundwater in a monitoring well near the site, with water located at an elevation of $300 \mathrm{~m}(976 \mathrm{ft})$ above mean sea level. The conceptual model for the water pathway incorporates movement of radionuclides through the vadose zone to the regional water table and subsequent transport through this saturated zone to the performance boundary. 
Due to very low natural recharge at Site 300 , the water flow profile through the disposal facility differs from that presented in both Figure 5-3 and Section 5.2.2.2 of Volume 2. Because natural groundwater recharge rates at Site $300(2.7 \mathrm{~cm} / \mathrm{y}[1.05 \mathrm{in} . / \mathrm{y}])$ are less than the rate assumed for an intact RCRA cover $\left(1 \times 10^{-7} \mathrm{~cm} / \mathrm{s}\right.$ or $\left.3.2 \mathrm{~cm} / \mathrm{y}[1.2 \mathrm{in} . / \mathrm{y}]\right)$, the natural rate is assumed to commence $30 \mathrm{y}$ after closure of the site when the leachate collection system fails, and then will continue in perpetuity. For the tumulus design, the water flow profile is the generic one assumed in the PE in which a rate of $1 \times 10^{-10} \mathrm{~cm} / \mathrm{s}$ or $0.003 \mathrm{~cm} / \mathrm{y}(0.001 \mathrm{in} . / \mathrm{y})$ begins $30 \mathrm{y}$ after closure and continues for $270 \mathrm{y}$, followed by the natural recharge of $2.7 \mathrm{~cm} / \mathrm{y}(1.05 \mathrm{in} . / \mathrm{y})$.

At the 829 Site, the regional groundwater formation has a hydraulic gradient of 0.017 $\mathrm{m} / \mathrm{m}$, and the hydraulic conductivity is estimated at $1.85 \times 10^{-3} \mathrm{~cm} / \mathrm{s}$ (Webster-Scholten, 1994, pg. 13-5-43). The conceptual model for the water transport pathway is presented in Figure 2-4. This model was developed from data in the SWRI report (Webster-Scholten, 1994) in cooperation with LLNL Site 300 technical staff. The time for water to travel to the performance boundary in the regional aquifer is calculated to be $2.5 \mathrm{y}$.

Groundwater migration through the vadose zone is calculated using the estimated recharge and the volumetric water content of the unsaturated formation as described in Chapter 5 of Volume 2.

All other assumptions for the water pathway are consistent with the generic conceptual model for water transport described in Section 5.3.1 of Volume 2. These assumptions include (1) equilibrium between the grouted waste form and leachate from the repository; (2) a continuous source term for each of the radionuclides; (3) one-dimensional contaminant transport through the vadose zone to the water table, followed by one-dimensional horizontal transport in groundwater; (4) no longitudinal dispersion; and (5) equilibrium distribution between soluble and sorbed pollutants as described by a linear distribution coefficient.

\subsubsection{Atmospheric Pathway}

The conceptual model used in the PE for evaluating the atmospheric pathway was derived from performance assessments for LLW disposal facilities at Hanford (Kincaid et al., 1993), INEL (Maheras et al., 1994), NTS (Baer et al., 1994), ORR (ORNL, 1994), and SRS (MMES et al., 1994). The model was generalized for the PE but used site-specific values for many of the parameters.

\subsubsection{Current Understanding of Relevant Meteorology}

Historical air monitoring data (1972-1991) collected at sampling locations at Site 300 for airborne lead, beryllium, radionuclides, and particulates do not indicate that airborne contaminants pose a threat to public health or the environment (Webster-Scholten, 1994). The climate of Site 300 is characterized by mild, rainy winters, and hot, dry summers. Based on data collected at the Site 300 weather station from 1965 to 1992, the average annual rainfall was $25.5 \mathrm{~cm}(10.03 \mathrm{in}$.), with a maximum of $53.1 \mathrm{~cm}$ (20.90 in.) in 1982-83 and a minimum of $10.4 \mathrm{~cm}$ (4.09 in.) during 1975-76. The Site 300 region rarely experiences severe weather. The predominant wind direction is from the west-southwest. 


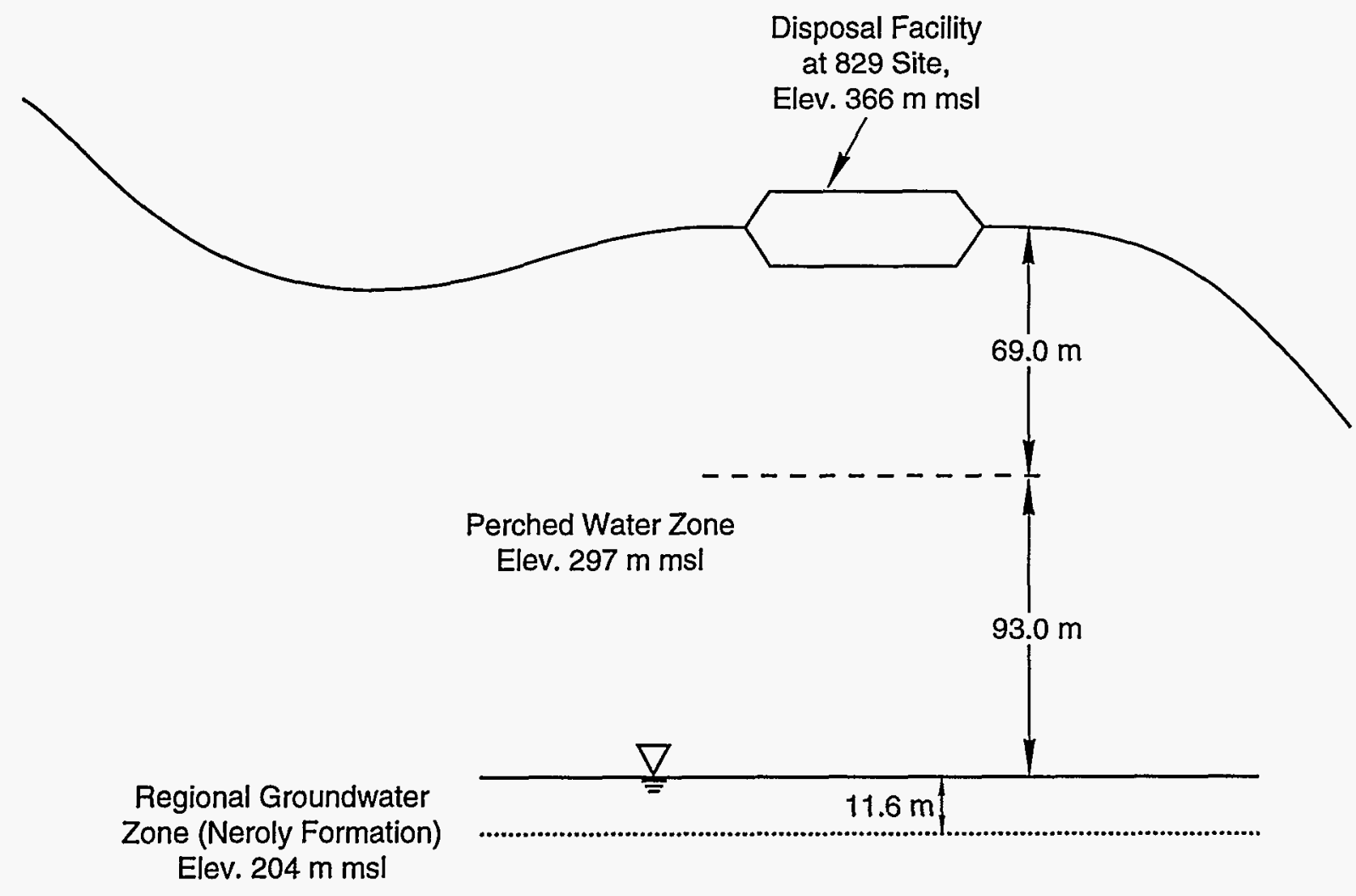

TRI-6622-36-1

Figure 2-4. Conceptual model for water transport at LLNL Site 300. 
Meteorological data are based on STAR data files summarized by the windrose in Figure 2-5. These data were obtained from hourly average meteorological readings taken at a height of $10 \mathrm{~m}(33 \mathrm{ft})$ at the meteorological tower at LLNL Site 300 during the period 1987 to 1991.

\subsubsection{Conceptual Model Used in the PE}

The PE used a generic conceptual model to describe the atmospheric pathway (summarized in Section 1.2 of this volume and described in detail in Chapter 5 of Volume 2). Only H-3 (tritium) and C-14 were expected to be volatile for the disposal facility conditions and thus were the only radionuclides considered for atmospheric transport in the PE. In the model, radionuclides were transported from the disposal facility to the soil surface by vapor (tritium) and gaseous (carbon dioxide carrying the $\mathrm{C}-14$ isotope) diffusion. When the radionuclides reached the soil surface, they were entrained in the air in vapor form as volatiles. Once airborne, these radionuclides were transported via atmospheric dispersion to a receptor located at the performance boundary.

Two components of the atmospheric pathway were evaluated separately: (1) the zone from the top of the disposal facility to the soil surface as indicated by the upward radionuclide diffusion profile; and (2) the zone in which a radionuclide was emitted to the atmosphere, mixed with the ambient air, and dispersed downwind from the waste disposal facility boundary to the $100-\mathrm{m}(328-\mathrm{ft})$ performance boundary.

The arrival time of radionuclides at the performance boundary was assumed to be $100 \mathrm{y}$ based on the following generic assumptions of the PE:

- The waste form was grouted MLLW treatment residuals. Based on this assumption, tritium as vapor was bound in the pore water of the hydrophilic grout, and carbon dioxide as a gas carrying the $\mathrm{C}-14$ isotope was limited by the high $\mathrm{pH}$ of the grout, so that the waste form provided retention of these volatile radionuclides in the disposal facility.

- The disposal facility was capped by a RCRA-compliant cover system. Based on this assumption, the cover system was maintained to provide low permeability for $100 \mathrm{y}$.

\subsubsection{Inadvertent Intruder Pathways}

Standard intrusion scenarios were used in the PE, with information derived from performance assessments of LLW disposal facilities at SRS (MMES et al., 1994) and ORR (ORNL, 1994) indicating that only two chronic-exposure scenarios needed to be considered for most sites and facility designs. Any variations in these scenarios were based on discussions with site technical staff about such factors as the types of activities that reasonably could result in exposure to buried waste at the site and the effectiveness of active or passive institutional controls and engineered barriers in precluding access to the waste. 


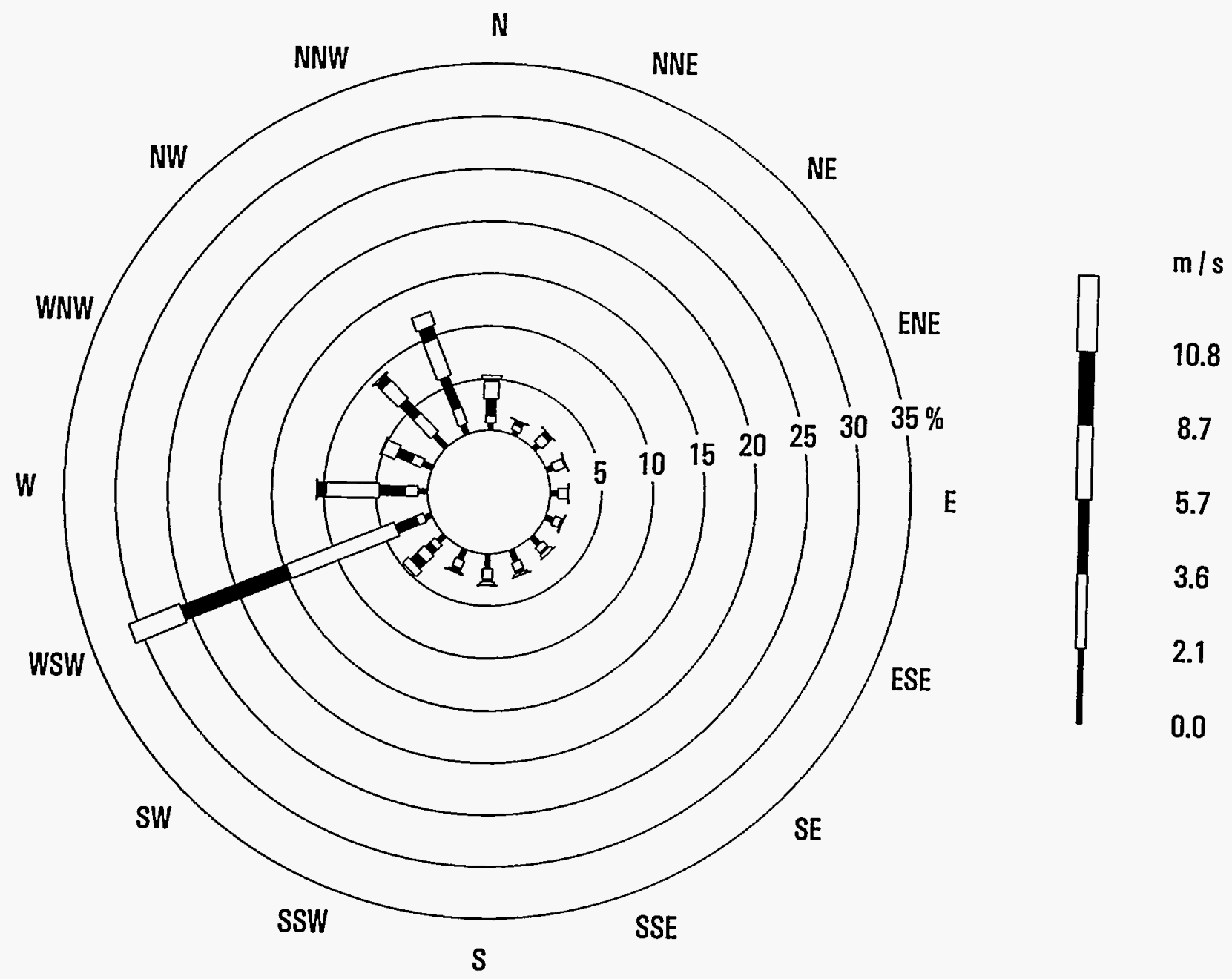

Figure 2-5. Windrose for Lawrence Livermore National Laboratory for the period 1987 to 1991. The frequency of winds from each direction is plotted as a series of connected bars that extend from the center of the circular diagram toward the direction from which the winds originate. Wind speed categories are denoted by bar widths and shadings. The frequency of winds in each wind speed category is indicated by the length of the corresponding bar. 


\subsubsection{Current Understanding of Potential Modes of Inadvertent Intrusion}

The city of Tracy is located approximately $12 \mathrm{~km}(8 \mathrm{mi})$ northeast of Site 300 . Proposals being evaluated by the city could allow expansion and residential construction (i.e., homes with basements) along the Site 300 boundary. Site 300 is located in the southeastern portion of the Altamont Hills where windmills for producing electricity are scattered throughout the area. Foundations for these windmills require substantial excavation.

\subsubsection{Intruder Scenarios Used in the PE}

The PE used two standard intrusion scenarios that could be modified for site-specific conditions to describe potential modes of inadvertent intrusion (summarized in Section 1.3 of this volume and described in detail in Chapter 5 of Volume 2). The first scenario, the agriculture (homesteader) scenario, included establishment by an intruder of a permanent homestead directly above a disposal facility with the foundation of the home extending into the waste; some of the waste exhumed from the disposal facility was mixed with native soil in the intruder's vegetable garden. The second scenario, the post-drilling scenario, considered the construction of a well for a domestic water supply by an intruder. The well was drilled through the disposal facility, and the cuttings were mixed with soil in the intruder's vegetable garden. The intruder gardened in some of the exhumed waste but did not reside permanently above the disposal facility. In both scenarios, exposure occurred where an intruder dug or drilled into the disposal facility.

For the generic intruder scenarios, the time of intrusion for the homesteader scenario was assumed to be $300 \mathrm{y}$ for the trench design and $500 \mathrm{y}$ for the tumulus design. The time of intrusion for the post-drilling scenario was assumed to be $100 \mathrm{y}$.

\subsection{DATA USED IN THE PE}

The data presented in this section apply to the PE conceptual models described in Section 2.3. The calculations for determining permissible waste concentrations for the radionuclides considered in the PE are discussed in more detail in Chapter 5 of Volume 2 and summarized in Chapter 1 of this volume. The results of the calculations for LLNL are presented in Section 2.5 and discussed in Section 2.6 of this volume.

\subsubsection{Water Transport}

Site-specific values required to perform the water pathway analysis were selected by site technical staff from site-specific characterizations and reports, from site-specific modeling results, or from general literature. For the unsaturated zone, the site-specific data that were required for the PE were distance between the disposal facility and groundwater; ambient moisture content; dry bulk density of the geologic medium; distribution coefficients $\left(K_{d} s\right)$ of the radionuclides in the geologic medium; and natural recharge. For the saturated zone, the site-specific data that were required were porosity; dry bulk density of the geologic medium; distribution coefficients $\left(K_{d} s\right)$ of the radionuclides in the geologic medium; groundwater Darcy flow rates; and mixing depth in the aquifer. 
These values for LLNL are listed in Table 2-1 along with generic values that were used in the PE. Also indicated in the table is a designation of the type of data the value represents and the source of the value. The values were determined from one or more of four data sources:

(A) measurement performed by the site, state, or federal agency; (B) result of a numerical analysis performed by the site, state, or federal agency; (C) general literature value selected by site technical staff; and (D) generic value of the PE.

Of the parameters in the $\mathrm{PE}$ that depended on site-specific values, only three potentially encompassed enough variability in values to significantly affect the results: recharge, $i$; distribution coefficients $\left(K_{d} \mathrm{~s}\right)$ for the geologic media; and groundwater Darcy velocity $\left(q_{g^{w}}\right)$. The sources of these values are discussed in this section. The sensitivity of the results to changes in the values of these parameters is discussed in Section 2.6 of this volume and in Chapter 6 of Volume 2.

The recharge at LLNL Site 300 was cited as a regional annual average in a report by Raber and Carpenter (1983). Although most recharge is expected to occur along the stream channels, the regional rate of $2.5 \mathrm{~cm} / \mathrm{y}$ was used in the $\mathrm{PE}$ to introduce conservatism in the analysis.

Values for distribution coefficients $\left(K_{d} \mathrm{~s}\right)$ are listed in Table 2-2 for the 58 radionuclides (32 elements) considered in the PE. Because no radioactive contaminants other than tritium and uranium-238 are present at Site 300, no independent information has been developed regarding adsorption of specific radionuclides onto native soils at this location. Therefore, equilibrium distribution coefficients $\left(K_{d} s\right)$ for sandy soils compiled by Thibault et al. (1990) were used in the $\mathrm{PE}$ analysis. These distribution coefficients are used to calculate retarded travel time for each element. The generic distribution coefficients for grout encapsulated radionuclides are used to describe partitioning between grout and leachate in the repository itself.

The groundwater Darcy velocity was calculated based on information in the SWRI (Webster-Scholten, 1994) and information provided by site technical staff (Carpenter, 1994). A high value of $1.85 \times 10^{3} \mathrm{~cm} / \mathrm{y}$ was used for the hydraulic conductivity to reflect groundwater flow through interbedded sandstone lenses. In the absence of sufficient data to estimate the hydraulic gradient, the slope of the water table was assumed to be the same as the dip of the strata.

Most of the site-specific values for parameters used in the LLNL PE are based on references and analyses contained in the SWRI report. The values referenced in the SWRI report are recommended by site technical staff for this analysis. As noted in Table 2-1, some of the values were provided by LLNL technical staff from other LLNL-produced documents (recharge, bulk density and volumetric water content of vadose zone soils, and characteristics of the regional aquifer at the 829 Site). In addition, the $K_{d}$ values in Table 2-2 from the compilation of Thibault et al. (1990) were reviewed by Site 300 technical staff and determined to be appropriate for use in the PE analysis. 
Table 2-1. Parameters and Values Used in the PE for the Water Pathway at LLNL (generic PE values are in bold; these values and the standard PE method for applying them are summarized in Chapter 1 of this volume and discussed in more detail in Chapter 5 of Volume 2) (Part 1 of 2)

\begin{tabular}{|c|c|c|c|}
\hline Parameter & Value & $\begin{array}{l}\text { Data } \\
\text { Type }\end{array}$ & Comments \\
\hline \multicolumn{4}{|l|}{ SOURCE TERM } \\
\hline $\begin{array}{l}\text { Volumetric water } \\
\text { content of the waste, } \theta_{G}\end{array}$ & 0.3 & D & Standard PE value \\
\hline $\begin{array}{l}\text { Bulk density of grouted } \\
\text { waste, } \rho_{b}\end{array}$ & $1.76 \mathrm{~g} / \mathrm{ml}$ & D & Standard PE value \\
\hline $\begin{array}{l}\text { Distribution coefficients } \\
\text { for grouted waste, } K_{d}^{G}\end{array}$ & various & D & $\begin{array}{l}\text { Standard PE value; see Table } 2-2 \text { in this } \\
\text { chapter }\end{array}$ \\
\hline $\begin{array}{l}\text { Disposal facility plan } \\
\text { area, } A\end{array}$ & $2500 \mathrm{~m}^{2}$ & D & $\begin{array}{l}\text { Standard PE value; } A=a_{1} * a_{2} \text {, where } \\
a_{1}=a_{2}=50 \mathrm{~m}\end{array}$ \\
\hline $\begin{array}{l}\text { Waste mixing fraction } \\
\text { for trench, } f_{m}\end{array}$ & 0.67 & D & Standard PE value \\
\hline $\begin{array}{l}\text { Waste mixing fraction } \\
\text { for tumulus, } f_{m}\end{array}$ & 0.33 & D & Standard PE value \\
\hline $\begin{array}{l}\text { Annual rate of water flowing } \\
\text { through intact trench facility, } \\
g_{f}\end{array}$ & $0.025 \mathrm{~m} / \mathrm{y}$ & A & $\begin{array}{l}\text { Standard PE value is } 3 \mathrm{~cm} / \mathrm{y} \text {. Natural recharge } \\
\text { is lower for this site. }\end{array}$ \\
\hline $\begin{array}{l}\text { Annual rate of water } \\
\text { flowing through intact } \\
\text { tumulus facility, } q_{f}\end{array}$ & $\begin{array}{c}0.00003 \\
\mathrm{~m} / \mathrm{y}\end{array}$ & $\mathbf{D}$ & Standard PE value \\
\hline $\begin{array}{l}\text { Time to failure of } \\
\text { leachate collection } \\
\text { system }\end{array}$ & $30 y$ & D & Standard PE value \\
\hline $\begin{array}{l}\text { Time to failure of trench } \\
\text { facility }\end{array}$ & $100 y$ & $\mathbf{D}$ & Standard PE value \\
\hline $\begin{array}{l}\text { Time to failure of } \\
\text { tumulus facility }\end{array}$ & $300 y$ & D & Standard PE value \\
\hline $\begin{array}{l}\text { Natural recharge through } \\
\text { local soils, } i\end{array}$ & $0.025 \mathrm{~m} / \mathrm{y}$ & A & Raber and Carpenter, 1983 \\
\hline
\end{tabular}

* $A=$ site measurement; $B=$ result of site numerical analysis; $C=$ literature value selected by site technical staff; $D=$ generic $P E$ value 
Table 2-1. Parameters and Values Used in the PE for the Water Pathway at LLNL (generic PE values are in bold; these values and the standard PE method for applying them are summarized in Chapter 1 of this volume and discussed in more detail in Chapter 5 of Volume 2) (Part 2 of 2)

\begin{tabular}{|c|c|c|c|}
\hline Parameter & Value & $\begin{array}{l}\text { Data } \\
\text { Type }\end{array}$ & Comments \\
\hline \multicolumn{4}{|l|}{ UNSATURATED ZONE } \\
\hline Moisture content, $\theta_{w}$ & 0.17 & A & Madrid, 1992 \\
\hline Bulk density, $\rho_{b}$ & $2.0 \mathrm{~g} / \mathrm{cm}^{3}$ & C & $\begin{array}{l}\text { Dry bulk density of quartz at } 25 \% \\
\text { porosity }\end{array}$ \\
\hline $\begin{array}{l}\text { Distribution coefficients for } \\
\text { geologic media, } K_{d}\end{array}$ & various & c & See Table 2-2 in this chapter \\
\hline $\begin{array}{l}\text { Thickness between trench and } \\
\text { saturated zone, } l\end{array}$ & $153.2 \mathrm{~m}$ & A & $\begin{array}{l}\text { Monitoring wells W-829-06 and W- } \\
\text { 829-08; Table } 13-17 \text { in Webster- } \\
\text { Scholten, } 1994\end{array}$ \\
\hline $\begin{array}{l}\text { Thickness between tumulus and } \\
\text { saturated zone, } l\end{array}$ & $162 \mathrm{~m}$ & A & $\begin{array}{l}\text { Monitoring wells W-829-06 and W- } \\
\text { 829-08; Table 13-17 in Webster- } \\
\text { Scholten, } 1994\end{array}$ \\
\hline \multicolumn{4}{|l|}{ SATURATED ZONE } \\
\hline Porosity, $n$ & 0.25 & $A$ & $\begin{array}{l}\text { Personal communication with R. } \\
\text { Ferry, Weiss Assoc., 10/27/94 }\end{array}$ \\
\hline Bulk density, $\rho_{b}$ & $2.0 \mathrm{~g} / \mathrm{cm}^{3}$ & C & $\begin{array}{l}\text { Dry bulk density of quartz at } 25 \% \\
\text { porosity }\end{array}$ \\
\hline $\begin{array}{l}\text { Distribution coefficients for } \\
\text { geologic media, } K_{d}\end{array}$ & various & C & See Table 2-2 in this chapter \\
\hline Mixing depth, $d_{m}$ & $11 \mathrm{~m}$ & $A$ & $\begin{array}{l}\text { Calculated by Sandia National } \\
\text { Laboratories }\end{array}$ \\
\hline $\begin{array}{l}\text { Hydraulic gradient of regional } \\
\text { aquifer }\end{array}$ & 0.017 & $A$ & $\begin{array}{l}\text { D. Carpenter, LLNL, 10/18/94 (based } \\
\text { on dip of formation) }\end{array}$ \\
\hline $\begin{array}{l}\text { Hydraulic conductivity of regional } \\
\text { aquifer }\end{array}$ & $\begin{array}{c}1.85 \times 10^{-3} \mathrm{~cm} / \mathrm{s} \\
(583.4 \mathrm{~m} / \mathrm{y})\end{array}$ & $A$ & $\begin{array}{l}\text { Webster-Scholten, 1994; D. } \\
\text { Carpenter, LLNL, 10/18/94 }\end{array}$ \\
\hline Darcy velocity, $q_{\text {ow }}$ & $9.9 \mathrm{~m} / \mathrm{y}$ & B & $\begin{array}{l}\text { Product of hydraulic conductivity and } \\
\text { hydraulic gradient }\end{array}$ \\
\hline $\begin{array}{l}\text { Distance to performance } \\
\text { boundary from facility } \\
\text { boundary }\end{array}$ & $100 \mathrm{~m}$ & D & Standard PE value \\
\hline
\end{tabular}

* $A=$ site measurement; $B=$ result of site numerical analysis; $C=$ literature value selected by site technical staff; $D=$ generic $P E$ value 
Table 2-2. Solid/Liquid Distribution Coefficients $\left(K_{d} \mathrm{~s}\right)$ Used in the PE at LLNL

\begin{tabular}{|c|c|c|}
\hline Element & $\begin{array}{c}\text { Waste } K_{d}^{G} \\
(\mathrm{~mL} / \mathrm{g})^{a}\end{array}$ & $\begin{array}{c}K_{d} \text { for Geologic Media } \\
(\mathrm{mL} / \mathrm{g})^{b}\end{array}$ \\
\hline $\mathrm{H}$ & 0 & 0.1 \\
\hline$C$ & 10 & 5 \\
\hline $\mathrm{Al}$ & 100 & $35^{c}$ \\
\hline $\mathrm{Si}$ & 100 & 35 \\
\hline $\mathrm{Cl}$ & 0 & $15^{d}$ \\
\hline $\mathrm{K}$ & 1 & 15 \\
\hline Co & 100 & 60 \\
\hline $\mathrm{Ni}$ & 10 & 400 \\
\hline $\mathrm{Se}$ & 1 & 150 \\
\hline $\mathrm{Sr}$ & 100 & 15 \\
\hline $\mathrm{Zr}$ & 10 & 600 \\
\hline $\mathrm{Nb}$ & 10 & 160 \\
\hline TC & 1 & 0.1 \\
\hline $\mathrm{Pd}$ & 100 & 55 \\
\hline $\mathrm{Ag}$ & 100 & 90 \\
\hline $\mathrm{Cd}$ & 100 & 80 \\
\hline $\mathrm{Sn}$ & 10 & 130 \\
\hline 1 & 1 & 1 \\
\hline Cs & 10 & 280 \\
\hline $\mathrm{Ba}$ & 10 & $15^{e}$ \\
\hline $\mathrm{Sm}$ & 10 & 245 \\
\hline $\mathrm{Eu}$ & 10 & $245^{f}$ \\
\hline $\mathrm{Pb}$ & 100 & 270 \\
\hline $\mathrm{Ra}$ & 10 & 500 \\
\hline Th & 100 & 3200 \\
\hline $\mathrm{Pa}$ & 100 & 550 \\
\hline $\mathrm{U}$ & 100 & 35 \\
\hline $\mathrm{Np}$ & 100 & 5 \\
\hline $\mathrm{Pu}$ & 100 & 550 \\
\hline $\mathrm{Am}$ & 100 & 1900 \\
\hline $\mathrm{Cm}$ & 100 & 4000 \\
\hline Cf & 100 & $4000^{\circ}$ \\
\hline
\end{tabular}

Standard PE values; see Chapter 5 of Volume 2

Values for sand from Thibault et al., 1990

Based on similarity to $\mathrm{Si}$

Based on similarity to $\mathrm{Br}$

Based on similarity to $\mathrm{Sr}$

Based on similarity to $\mathrm{Sm}$

Based on similarity to $\mathrm{Cm}$ 


\subsubsection{Atmospheric Transport}

Site-specific data required to perform the atmospheric pathway analysis came from site personnel as data either from site characterizations and reports or from general literature. The site-specific data required for the soil diffusion calculation were the same as some of those required for the water transport analysis (Section 2.4.1). These values are shown in Table 2-3. Necessary atmospheric dispersion data included wind speed and direction and stability class, which are summarized in Section 2.3.2.1.

Table 2-3. Parameters and Values Used in the PE for the Atmospheric Pathway at LLNL (generic PE values are in bold; these values and the standard PE method for applying them are summarized in Chapter 1 of this volume and discussed in more detail in Chapter 5 of Volume 2)

\begin{tabular}{|c|c|c|c|}
\hline Parameter & Value & $\begin{array}{l}\text { Data } \\
\text { Type }\end{array}$ & Comments \\
\hline $\begin{array}{l}\text { Disposal facility cover } \\
\text { thickness, } x\end{array}$ & $1.0 \mathrm{~m}$ & $\mathbf{D}$ & Standard PE value \\
\hline $\begin{array}{l}\text { Depth of the soil surface, } \\
d\end{array}$ & $0.01 \mathrm{~m}$ & D & $\begin{array}{l}\text { Standard PE value based on } \\
\text { Maheras et al., } 1994\end{array}$ \\
\hline Porosity, $n$ & 0.25 & A & R. Ferry, Weiss Assoc., 10/27/94 \\
\hline Percent saturation, $s$ & 0.17 & A & Value based on Madrid, 1992 \\
\hline $\begin{array}{l}\text { Ratio of water density in } \\
\text { air to liquid, } r\end{array}$ & $9.2 E-06$ & D & $\begin{array}{l}\text { Standard PE value based on MMES } \\
\text { et al., } 1994\end{array}$ \\
\hline $\begin{array}{l}\text { Ratio of } \mathrm{CO}_{2} \\
\text { concentration in air to } \\
\text { dissolved in water, } r\end{array}$ & 4.3E-04 & D & $\begin{array}{l}\text { Standard PE value based on Foust } \\
\text { et al. (as cited in Cooper and Alley, } \\
\text { 1986) }\end{array}$ \\
\hline $\begin{array}{l}\text { Tritium diffusion } \\
\text { coefficient in air, } D\end{array}$ & $2.39 E-05 \mathrm{~m}^{2} / \mathrm{s}$ & D & $\begin{array}{l}\text { Standard PE value based on CRC, } \\
1981\end{array}$ \\
\hline $\begin{array}{l}\text { Carbon diffusion } \\
\text { coefficient in air, } D\end{array}$ & $1.4 E-05 \mathrm{~m}^{2} / \mathrm{s}$ & D & $\begin{array}{l}\text { Standard PE value based on CRC, } \\
1981\end{array}$ \\
\hline $\begin{array}{l}\text { Atmospheric dispersion term, } \\
A_{D}\end{array}$ & $\begin{array}{c}0.6 \\
\left(\mu \mathrm{Ci} / \mathrm{m}^{3}\right) /\left(\mu \mathrm{Ci} / \mathrm{m}^{2}-\mathrm{s}\right)\end{array}$ & B & $\begin{array}{l}\text { Value is estimated using the Industrial } \\
\text { Source Complex-Version } 2 \text { Long Term Air } \\
\text { Dispersion Model (ISCLT2) (EPA, 1992) } \\
\text { based on site-specific STAR data. }\end{array}$ \\
\hline
\end{tabular}

- $A=$ site measurement; $B=$ result of site numerical analysis; $C=$ literature value selected by the site; $D=g$ eneric $P E$ value

\subsubsection{Inadvertent Intruder Exposure}

As explained in Section 2.3.3, the PE used two standard intrusion scenarios to describe potential modes of inadvertent intrusion at all the sites. Because these intrusion scenarios were considered applicable to all sites, no values specific to LLNL are used in the calculation of exposures to inadvertent intruders. 


\subsection{RESULTS OF THE PE}

The performance evaluation provided estimates of permissible concentrations in disposed MLLW. The three calculations that formed the foundation of the PE-for the water, atmospheric, and inadvertent intruder pathways-are summarized in Sections 1.1, 1.2, and 1.3, respectively, of this volume and discussed in detail in Chapter 5 of Volume 2.

For each pathway, the maximum permissible waste concentration at the performance boundary was determined for each radionuclide by using the performance measures: $4 \mathrm{mrem}$ $(0.04 \mathrm{mSv})$ per year from the water pathway for releases to drinking water; $10 \mathrm{mrem}(0.1 \mathrm{mSv})$ per year from all pathways for atmospheric releases; and $100 \mathrm{mrem}(1 \mathrm{mSv})$ per year from all exposure pathways for chronic exposure of inadvertent intruders; and the appropriate pathway or scenario dose conversion factors (annual effective dose equivalent per unit concentration) based on EPA dose conversion factors. The basis for the performance measures used in the PE is discussed in more detail in Chapter 5 of Volume 2. For the water and atmospheric pathways, the concentration reduction provided by the environment (i.e., the CRF) was estimated using results of site analyses and data. For the intruder analyses, concentration reduction was estimated for appropriate exposure pathways for two intrusion scenarios that, in general, were the same for all the sites. The results of the calculations for the pathways that were analyzed at LLNL are provided in this section and discussed in Section 2.6.

\subsubsection{Water Transport}

Two CRFs were calculated for the water pathway: the source $\mathrm{CRF}, C R F_{\text {Source, }}$ and the environmental transport $\mathrm{CRF}$ for water, $C R F_{\text {Water }}$. The source $\mathrm{CRF}$ represents the concentration attenuation between the disposed waste and leachate exiting the bottom of the disposal facility and was defined as the dimensionless ratio of the waste concentration to the resulting leachate concentration. Desorption with infiltrating water was the mechanism used to describe the leaching of radionuclides from the grout. Because a generic method was used to determine the $C R F_{\text {Source }}$ for the 58 radionuclides considered in the PE (summarized in Section 1.1 of this volume and discussed in more detail in Chapter 5 of Volume 2), the radionuclide-specific values for the source CRF for each type of generic facility were the same for all 15 sites.

The environmental transport $\mathrm{CRF}$ for water was defined as the ratio of the concentration of the leachate exiting the disposal facility to the resulting concentration in water at the performance boundary. The concentration attenuation represented by $C R F_{\text {Water }}$ consisted of dilution due to mixing with uncontaminated groundwater. Effects of radioactive decay and decay product ingrowth were also included in the $\mathrm{PE}$.

In the PE, water travel time from the facility location to the performance boundary was calculated as a basis for comparison with retarded travel time of the radionuclides. For LLNL, water travel time from the land surface to the performance boundary (i.e., without consideration of a disposal facility) was estimated at about $1,100 \mathrm{y}$. 
The calculation of travel time through the vadose zone for a radionuclide, on the other hand, accounts both for what is usually a lower infiltration rate because of the facility's RCRA cover (and because of the concrete vaults for the tumulus design) and for the retardation defined by the distribution coefficient for the geologic media. In the PE, the calculation for travel time in the vadose zone usually first determined the distance a radionuclide traveled at the lower rate. Then, if the radionuclide had not fully traversed the vadose zone, the additional time required to complete travel in the vadose zone under a higher, infiltration rate based on natural recharge through local soils was calculated and added to the time determined at the lower infiltration rate.

At LLNL, this procedure was used for calculations of travel time through the vadose zone for a tumulus facility because the assumed rate of water flowing through the concrete vaults was less than the natural recharge. However, for a trench facility at Site 300 , the natural recharge was less than the assumed rate of water flowing through a RCRA cover; calculations through the vadose zone for a trench facility were based entirely on the natural recharge.

In the PE, the detention time in the facility for a radionuclide was the time during which water flowing through the facility was assumed to be caught by the leachate collection system. Specifically, the calculation of travel time for a radionuclide accounted for the following:

- For the trench design at LLNL, the leachate collection system was assumed to catch water flowing through the facility for the first $30 \mathrm{y}$. After $30 \mathrm{y}$, the liner and leachate collection system failed, and the rate of water flowing through the facility was assumed to be 0.025 $\mathrm{m} / \mathrm{y}$, which was the lesser of the natural recharge for local soils and the rate based on a unit hydraulic gradient and the saturated hydraulic conductivity of the RCRA cover system $(0.03 \mathrm{~m} / \mathrm{y}[0.1 \mathrm{ft} / \mathrm{y}])$.

- For the tumulus design, the leachate collection system was assumed to catch water flowing through the facility for the first $30 \mathrm{y}$. After $30 \mathrm{y}$, the liner and leachate collection system was assumed to fail, and the rate of water flowing through the facility for the next $270 \mathrm{y}$ was assumed to be $0.00003 \mathrm{~m} / \mathrm{y}(0.0001 \mathrm{ft} / \mathrm{y})$ based on a unit hydraulic gradient and the saturated hydraulic conductivity of the concrete vaults. After a total of $300 \mathrm{y}$ of reduced flow because of engineered barriers ( $30 \mathrm{y}$ detention plus $270 \mathrm{y}$ limited by the concrete vaults), the rate of water flowing through the facility was assumed to be the natural recharge for local soils, $0.025 \mathrm{~m} / \mathrm{y}(0.08 \mathrm{ft} / \mathrm{y})$.

Travel time through the aquifer was independent of facility design and was about $2.5 \mathrm{y}$, based on groundwater Darcy velocity and a 100-m distance to the performance boundary (see Section 1.1.2 of this volume for a summary of these assumptions and Chapter 5 of Volume 2 for additional details).

Retardation of radionuclides by interaction with soils and rock in the vadose and saturated zones increased travel times for individual radionuclides. This effect was particularly important for short-lived radionuclides because of radioactive decay. For short-lived radionuclides, the effects of radioactive decay combined with long travel times increased the permissible concentrations in the disposal facility. 
Application of the PE methodology for water transport of the 58 radionuclides considered in the PE produced the results shown in Table 2-4 for the generic trench and tumulus designs at LLNL. The table shows permissible waste concentrations based on transport through the water pathway $\left(C_{\text {W-Water }}\right)$ as well as the values used in calculating the permissible waste concentrations for this pathway.

Some radionuclides listed in Table 2-4 have no limit (NL) on their permissible waste concentrations, the result of the combined effects of relatively short half-lives and sufficiently long travel time to the performance boundary. "No limit" is defined as a permissible waste concentration that is greater than the specific activity of the pure elemental radionuclide. For disposal of the maximum possible waste concentration of these relatively short-lived radionuclides, the water pathway produces a dose at the performance boundary of less than $4 \mathrm{mrem}(0.04 \mathrm{mSv})$ per year, and therefore, the permissible waste concentration was unlimited based on exposures from this pathway.

For some radionuclides, no value is listed in Table 2-4 for the radioactive decay term, $r_{\text {Decay. }}$. These radionuclides had radioactive decay terms that were very large (e.g., greater than $\left.1 \times 10^{50}\right)$. Any radionuclide with a radioactive decay term greater than $1 \times 10^{50}$ was ensured a calculated permissible waste concentration greater than the specific activity of the pure elemental radionuclide, which, as described previously, resulted in no limit (NL) on permissible waste concentrations for disposal.

Arrival times for some radionuclides listed in Table 2-4 were beyond the 10,000-y performance period. For those radionuclides, the estimated waste concentrations are presented in Table 2-4 for information purposes only. Consistent with the approach used in LLW performance assessments, these values were not considered in determining the most restrictive disposal limit from among the evaluated pathways.

For most radionuclides in Table 2-4, the rate of water flowing through the facility at the time of failure of the tumulus facility determines the subsurface aqueous transport. Even though there is a relatively high water content associated with the grouted waste, the very low hydraulic conductivity of the concrete $\left(1 \times 10^{-10} \mathrm{~cm} / \mathrm{s}\right)$ effectively prevents vertical migration of contaminants through the vault until failure occurs. Therefore, the subsurface movement of most of the 58 radionuclides is controlled by the rate of flow through the facility beginning at $300 \mathrm{y}$ after closure when the concrete vaults that constitute the tumulus are assumed to fail. The shortlived radionuclides decay to insignificant activities prior to failure of the vault; thus, their maximum permissible concentrations are not limited by this exposure pathway. 
Table 2-4. Results of Calculations for the Water Pathway at LLNL (water travel time from land surface to performance boundary [excluding facility detention] $=1,100 \mathrm{y}$ ) (Part 1 of 2 )

\begin{tabular}{|c|c|c|c|c|c|c|c|c|c|c|c|c|}
\hline \multirow[t]{2}{*}{ Nuclide } & \multirow[b]{2}{*}{$\begin{array}{c}\text { PDCF } \\
\text { remly per } \mu \mathrm{Cl}\end{array}$} & \multicolumn{5}{|c|}{ Trench } & \multicolumn{5}{|c|}{ Tumulus } & \multirow[t]{2}{*}{ Nuclide } \\
\hline & & $\begin{array}{l}\text { CRF source } \\
\text { (dimensionless) }\end{array}$ & $\begin{array}{l}\text { CRF } \\
\text { (dimentionless) }\end{array}$ & \begin{tabular}{|l|} 
Arrival \\
Time $(y)$ \\
\end{tabular} & $\begin{array}{c}r_{\text {Dercay }}{ }^{2} \\
\text { (dimonsionloss) }\end{array}$ & $\begin{array}{c}C_{w-W m a r}^{b} \\
\left(\mu \mathrm{Ci} / m^{2}\right)\end{array}$ & $\begin{array}{l}\text { CRF source } \\
\text { (dimonsionless) }\end{array}$ & $\begin{array}{c}\text { CRF water } \\
\text { (dimensionless) }\end{array}$ & \begin{tabular}{|l|} 
Arrival \\
Time (y)
\end{tabular} & $\underset{\text { (dimensionless) }}{r_{\text {Decayy }}}$ & $\begin{array}{c}C_{\text {w.Worer }}{ }^{b} \\
\left.(\mu \mathrm{Cim})^{3}\right)\end{array}$ & \\
\hline $\mathrm{H}-3$ & 4.67E-02 & 0.45 & 88 & $2.3 E+03$ & e & $\mathrm{NL}$ & 0.9 & 88 & $2.7 E+03$ & e & NL & $\mathrm{H}-3$ \\
\hline$C-14$ & $1.52 E+00$ & 27 & 88 & $6.2 E+04$ & $1.9 E+03$ & $1 E+07$ & 54 & 88 & $6.6 \mathrm{E}+04$ & $3.0 E+03$ & $4 \mathrm{E}+07$ & c-14 \\
\hline Al-26 & $1.06 E+01$ & 270 & 88 & $4.3 E+05$ & $1.5 E+\infty 0$ & $1 E+04$ & 540 & 88 & $4.6 E+05$ & $1.5 E+\infty$ & $3 E+04 c$ & Al-26 \\
\hline Si-32 & $7.99 E+00$ & 270 & 88 & $4.3 E+05$ & e & $\mathrm{NL}$ & 540 & 88 & $4.6 \mathrm{E}+05$ & e & $\mathrm{NL}$ & Si-32 \\
\hline $\mathrm{Cl}-36$ & $2.21 E+\infty 0$ & 0.45 & 88 & $1.9 E+05$ & $1.5 E+00$ & $1 E+02$ & 0.9 & 88 & $2.0 E+05$ & $1.6 E+00$ & $2 E+02$ & $\mathrm{Cl}-36$ \\
\hline$K-40$ & $1.36 \mathrm{E}+01$ & 3.1 & 88 & $1.9 E+05$ & $1.0 \mathrm{E}+00$ & $8 E+01$ & 6.2 & 88 & $2.0 E+05$ & $1.0 E+\infty 0$ & $2 E+02^{c}$ & $K-40$ \\
\hline Co-60 & $1.97 E+01$ & 270 & 88 & $7.4 E+05$ & e & $N L$ & 540 & 88 & $7.8 \mathrm{E}+05$ & e & NL & Co-60 \\
\hline Ni-59 & $1.53 \mathrm{E}-01$ & 27 & 88 & $4.9 E+06$ & $2.8 E+19$ & NL & 54 & 88 & $5.2 E+06$ & $3.7 \mathrm{E}+20$ & NL & $\mathrm{Ni}-59$ \\
\hline $\mathrm{Ni}-63$ & $4.21 E-01$ & 27 & 88 & $4.9 E+06$ & e & NL & 54 & 88 & $5.2 E+06$ & e & $\mathbf{N L}$ & Ni-63 \\
\hline Se-79 & $6.35 E+\infty 0$ & 3.1 & 88 & $1.8 \mathrm{E}+06$ & $3.4 E+0.8$ & $6 E+10$ & 6.2 & 88 & $1.9 \mathrm{E}+06$ & $1.1 E+09$ & $\mathrm{NL}$ & Se-79 \\
\hline Sr-90 & $1.12 E+02$ & 270 & 88 & $1.9 \mathrm{E}+05$ & e & NL & 540 & 88 & $2.0 \mathrm{E}+05$ & e & $\mathrm{NL}$ & Sr-90 \\
\hline $2 r-93$ & $1.59 \mathrm{E}+\infty 0$ & 27 & 88 & $7.4 \mathrm{E}+06$ & $3.0 E+01$ & $2 E+05$ & 54 & 88 & $7.8 E+06$ & 3.7E+01 & $4 E+05^{\circ}$ & $2 \mathrm{r}-93$ \\
\hline $\mathrm{Nb}-93 \mathrm{~m}$ & $3.81 E-01$ & 27 & 88 & $2.0 E+06$ & $e$ & NL & 54 & 88 & $2.1 E+06$ & $\bar{e}$ & $\mathrm{NL}$ & $\mathrm{Nb}-93 \mathrm{~m}$ \\
\hline $\mathrm{Nb}-94$ & $5.21 E+\infty 0$ & 27 & 88 & $2.0 E+06$ & $3.8 E+29$ & $\mathrm{NL}$ & 54 & 88 & $2.1 \mathrm{E}+06$ & $1.9 \mathrm{E}+31$ & $\mathrm{NL}$ & $\mathrm{Nb}-94$ \\
\hline Tc-99 & $1.07 E+00$ & 3.1 & 88 & $2.3 E+03$ & $1.0 E+00$ & $1 E+03$ & 6.2 & 88 & $2.7 E+03$ & $1.0 E+00$ & $2 E+03$ & Tc-99 \\
\hline$P d-107$ & $1.09 E-01$ & 270 & 88 & $6.8 E+05$ & $1.1 E+00$ & $9 E+05$ & 540 & 88 & $7.2 \mathrm{E}+05$ & $1.1 \mathrm{E}+\infty$ & $2 E+06$ & Pd-107 \\
\hline $\mathrm{Ag}-108 \mathrm{~m}$ & $5.56 \mathrm{E}+00$ & 270 & 88 & $1.1 E+06$ & e & NL. & 540 & 88 & $1.2 E+06$ & $e$ & $\overline{N L}$ & $\mathrm{Ag}-108 \mathrm{~m}$ \\
\hline $\mathrm{Cd}-113 \mathrm{~m}$ & $1.17 E+02$ & 270 & 88 & $9.8 E+05$ & e & $\mathrm{NL}$ & 540 & 88 & $1.0 E+06$ & e & $\mathrm{NL}$ & Cd-113m \\
\hline Sn-121m & $1.28 E+\infty 0$ & 27 & 88 & $1.6 \mathrm{E}+06$ & e & $N L$ & 54 & 88 & 1.7E+06 & e & $\mathrm{NL}$ & Sn-121m \\
\hline $5 n-126$ & $1.53 E+01$ & 27 & 88 & $1.6 \mathrm{E}+06$ & $6.4 E+04$ & $4 E+07$ & 54 & 88 & $1.7 E+06$ & $1.2 E+05$ & $2 \mathrm{E}+08^{\circ}$ & $5 n-126$ \\
\hline $1-129$ & $2.01 E+02$ & 3.1 & 88 & $1.3 E+04$ & $1.0 E+00$ & $5 E+\infty 0$ & 6.2 & 88 & $1.4 E+04$ & $1.0 E+00$ & $1 E+01^{\circ}$ & $\mid-129$ \\
\hline$C_{s-135}$ & $5.16 \mathrm{E}+00$ & 27 & 88 & $3.4 E+06$ & $2.8 E+\infty 0$ & $5 E+03$ & 54 & 88 & $3.6 \mathrm{E}+06$ & $3.0 \mathrm{E}+00$ & $1 E+04^{c}$ & Cs-135 \\
\hline Cs-137 & $3.65 E+01$ & 27 & 88 & $3.4 \mathrm{E}+06$ & e & NL & 54 & 88 & $3.6 E+06$ & $e$ & $N L \quad{ }^{\circ}$ & Cs-137 \\
\hline $8 a-133$ & $2.48 E+00$ & 27 & 88 & $1.9 \mathrm{E}+05$ & e & NL & 54 & 88 & $2.0 E+05$ & $\bar{e}$ & NL & $\mathrm{Ba}-133$ \\
\hline$S m-151$ & $2.84 \mathrm{E}-01$ & 27 & 88 & $3.0 \mathrm{E}+06$ & e & $\mathrm{NL}$ & 54 & 88 & $3.2 \mathrm{E}+06$ & e & NL & $5 m-151$ \\
\hline Eu-152 & $4.73 E+00$ & 27 & 88 & $3.0 \mathrm{E}+06$ & e & $N L$ & 54 & 88 & $3.2 E+06$ & e & NL & Eu-152 \\
\hline Eu-154 & $6.97 E+00$ & 27 & 88 & $3.0 \mathrm{E}+06$ & e & NL & 54 & 88 & $3.2 \mathrm{E}+06$ & e & NL & Eu-154 \\
\hline $\mathrm{Pb}-210$ & $5.30 E+03$ & 270 & 88 & $3.3 \mathrm{E}+06$ & $e$ & NL & 540 & 88 & $3.5 E+06$ & e & NL & $\mathrm{Pb}-210$ \\
\hline Ra-226 & $6.27 E+03$ & 27 & 88 & $6.1 E+06$ & e & $\mathrm{NL}$ & 54 & 88 & $6.5 \mathrm{E}+06$ & e & $N L$ & Ra-226 \\
\hline Ra-228 & $1.64 E+03$ & 27 & 88 & $6.1 E+06$ & e & $\mathrm{NL}$ & 54 & 88 & $6.5 E+06$ & e & $\mathrm{NL}$ & Ra-228 \\
\hline Th-229 & $2.94 E+03$ & 270 & 88 & $3.9 E+07$ & e & $\mathrm{NL}$ & 540 & 88 & $4.2 E+07$ & e & $\mathrm{NL}$ & Th-229 \\
\hline Th-230 & $6.12 \mathrm{E}+03$ d & 270 & 88 & $3.9 E+07$ & NA & $2 E+01$ & 540 & 88 & $4.2 E+07$ & NA & $3 E+01^{c}$ & Th-230 \\
\hline Th-232 & $3.63 E+03$ & 270 & 88 & $3.9 E+07$ & 1.0E+00 & $3 E+01$ & 540 & 88 & $4.2 E+07$ & $1.0 E+\infty$ & $5 E+01 c$ & Th-232 \\
\hline Pa-231 & $1.85 E+04$ & 270 & 88 & $6.8 \mathrm{E}+06$ & $\mathrm{e}$ & $N L$ & 540 & 88 & $7.1 \mathrm{E}+06$ & $\mathrm{e}$ & NL ${ }^{\circ}$ & $\mathrm{Pa}-231$ \\
\hline
\end{tabular}


Table 2-4. Results of Calculations for the Water Pathway at LLNL (water travel time from land surface to performance boundary [excluding facility detention] $=1,100 \mathrm{y})($ Part 2 of 2$)$

\begin{tabular}{|c|c|c|c|c|c|c|c|c|c|c|c|c|c|}
\hline \multirow[t]{2}{*}{ Nuclide } & \multirow[b]{2}{*}{$\begin{array}{c}\text { PDCF } \\
\text { remly per } \mu \mathrm{CI}\end{array}$} & \multicolumn{6}{|c|}{ Trench } & \multicolumn{5}{|c|}{ Tumulus } & \multirow[t]{2}{*}{ Nuclide } \\
\hline & & $\begin{array}{l}\text { CRF source } \\
\text { (dimenalonless) }\end{array}$ & $\begin{array}{l}\text { CRF What } \\
\text { (dimensionlest) }\end{array}$ & $\begin{array}{l}\text { Arrival } \\
\text { Time (y) }\end{array}$ & \begin{tabular}{|c|}
$r_{\text {Dencay }}$ \\
(dimensionless)
\end{tabular} & $\begin{array}{r}C_{\text {w.Watw }} \\
\left(\mu \mathrm{Cl} / \mathrm{m}^{3}\right)\end{array}$ & & $\begin{array}{l}\text { CRF source } \\
\text { (dimenstonless) }\end{array}$ & $\begin{array}{l}\text { CRF Woter } \\
\text { (dimensionloss) }\end{array}$ & \begin{tabular}{|l|} 
Arrival \\
Time (y)
\end{tabular} & $\begin{array}{c}\text { rovayy } \\
\text { (dimenzionloss) }\end{array}$ & $\begin{array}{c}C_{\text {w.wamer }} \\
\left(\mu \mathrm{Ci} / \mathrm{m}^{2}\right)\end{array}$ & \\
\hline$U-232$ & $1.55 E+03$ & 270 & 88 & $4.3 E+05$ & e & NL & $c$ & 540 & 88 & $4.6 E+05$ & e & $N L$ & $\mathrm{U}-232$ \\
\hline U-233 & $1.95 E+03 d$ & 270 & 88 & $4.3 E+05$ & NA & $5 E+01$ & c & 540 & 88 & $4.6 E+05$ & NA & $1 E+02^{\circ}$ & U.233 \\
\hline U-234 & $6.48 E+02$ & 270 & 88 & $4.3 E+05$ & NA & $1 E+02$ & $\div$ & 540 & 88 & $4.6 \mathrm{E}+05$ & NA & $3 E+02$ & $U-234$ \\
\hline U-235 & $3.73 E+03$ & 270 & 88 & $4.3 E+05$ & NA & $2 E+01$ & c & 540 & 88 & $4.6 \mathrm{E}+05$ & NA & $5 E+01$ & U-235 \\
\hline$U-236$ & $1.96 E+02$ & 270 & 88 & $4.3 E+05$ & $1.0 \mathrm{E}+00$ & $5 E+02$ & 6 & 540 & 88 & $4.6 \mathrm{E}+05$ & $1.0 E+00$ & $1 E+03=$ & $u-236$ \\
\hline U-238 & $2.07 E+02$ & 270 & 88 & $4.3 E+05$ & NA & $4 E+02$ & 5 & 540 & 88 & $4.6 E+05$ & NA & $9 E+02$ & U-238 \\
\hline$N p-237$ & $3.24 E+03$ & 270 & 88 & $6.2 E+04$ & $1.0 \mathrm{E}+00$ & $3 E+01$ & 6 & 540 & 88 & $6.6 E+04$ & $1.0 E+00$ & $6 \mathrm{E}+01^{\circ}$ & Np-237 \\
\hline Pu-238 & $2.34 E+03$ & 270 & 88 & $6.8 \mathrm{E}+06$ & e & $4 E+05$ & 6 & 540 & 88 & $7.1 E+06$ & $e$ & $8 E+05 \div$ & Pu-238 \\
\hline $\mathrm{Pu}-239$ & $2.58 E+03$ & 270 & 88 & $6.8 \mathrm{E}+06$ & e & $\mathrm{NL}$ & $c$ & 540 & 88 & $7.1 E+06$ & e & $\mathrm{NL}$ & Pu-239 \\
\hline Pu-240 & $2.58 E+03$ & 270 & 88 & $6.8 E+06$ & e & $\mathrm{NL}$ & 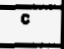 & 540 & 88 & $7.1 E+06$ & e & $\mathrm{NL}$ & Pu-240 \\
\hline Pu-241 & $4.82 E+08$ & 270 & 88 & $6.8 E+06$ & e & $4 E+06$ & .1 & 540 & 88 & $7.1 E+06$ & $e$ & $9 \mathrm{E}+06$ & Pu-241 \\
\hline$P u-242$ & $2.45 E+03$ & 270 & 88 & $6.8 E+06$ & $2.6 \mathrm{E}+05$ & $1 E+07$ & ${ }^{\circ}$ & 540 & 88 & 7.1E+06 & $5.4 E+0.5$ & $4 E+07$ & Pu-242 \\
\hline $\mathrm{Pu}-244$ & $4.11 E+03$ & 270 & 88 & $6.8 E+06$ & $\mathrm{NA}$ & $2 E+01$ & 5 & 540 & 88 & $7.1 \mathrm{E}+06$ & NA & $5 E+01$ & Pu-244 \\
\hline$A m-241$ & $2.66 E+03$ & 270 & 88 & $2.3 \mathrm{E}+07$ & e & $1 E+05$ & CT & 540 & 88 & $2.5 E+07$ & $e$ & $3 E+05$ & Am-241 \\
\hline$A m-243$ & $2.64 E+03$ & 270 & 88 & $2.3 E+07$ & e & $\mathrm{NL}$ & 5 & 540 & 88 & $2.5 E+07$ & $e$ & $\mathrm{NL}$ & $\mathrm{Am}-243$ \\
\hline $\mathrm{Cm}-243$ & $1.83 E+03$ & 270 & 88 & $4.9 E+07$ & e & $\mathrm{NL}$ & 5 & 540 & 88 & $5.2 E+07$ & e & $N L$ & $\mathrm{Cm}-243$ \\
\hline $\mathrm{Cm}-244$ & $1.47 E+03$ & 270 & 88 & $4.9 \mathrm{E}+07$ & e & $\mathrm{NL}$ & $\therefore$ & 540 & 88 & $5.2 E+07$ & e & $\overline{N L}$ & $\mathrm{Cm}-244$ \\
\hline $\mathrm{C}_{\mathrm{m}-245}$ & $4.56 \mathrm{E}+03$ & 270 & 88 & $4.9 E+07$ & $\overline{N A}$ & $2 E+01$ & $i$ & 540 & 88 & $5.2 \mathrm{E}+07$ & NA & $4 E+01^{\circ}$ & $\mathrm{Cm}-245$ \\
\hline $\mathrm{Cm}-246$ & $2.70 E+03$ & 270 & 88 & $4.9 E+07$ & e & $\mathrm{NL}$ & 6 & 540 & 88 & $5.2 \mathrm{E}+07$ & e & $\mathrm{NL}$ & $\mathrm{Cm}-246$ \\
\hline $\mathrm{Cm}-247$ & $4.34 E+03$ & 270 & 88 & $4.9 E+07$ & NA & $2 E+01$ & 7 & 540 & 88 & $5.2 E+07$ & NA & $4 E+01 \div$ & $\mathrm{Cm}-247$ \\
\hline $\mathrm{Cm}-248$ & $9.94 E+03$ & 270 & 88 & $4.9 \mathrm{E}+07$ & $3.0 \mathrm{E}+42$ & $\mathrm{NL}$ & 5 & 540 & 88 & $5.2 E+07$ & $8.2 E+44$ & $N L$ & $\mathrm{Cm}-248$ \\
\hline Cf-249 & $3.46 E+03$ & 270 & 88 & $4.9 \mathrm{E}+07$ & e & $5 E+02$ & .1 & 540 & 88 & $5.2 \mathrm{E}+07$ & e & $1 E+03$ & Cf-249 \\
\hline Cf-250 & $2.64 E+08$ & 270 & 88 & $4.9 E+07$ & e & $\mathrm{NL}$ & c & 540 & 88 & $5.2 E+07$ & e & $\mathrm{NL}$ & Cf-250 \\
\hline Cf-251 & $3.54 E+03$ & 270 & 88 & $4.9 E+07$ & $e$ & $\mathrm{NL}$ & 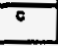 & 540 & 88 & $5.2 E+07$ & e & $N L$ & Cf-251 \\
\hline
\end{tabular}

a "NA" means Not Applicable - decay factor is implicit in the PDCF for this radionuclide.

b "NL" means No Limit - estimated permissible concentration is greater than the specific activity of the pure elemental radionuclide.

c Radionuclide concentration is based on arrival time at the performance boundary beyond 10,000y.

d PDCF is a function of arrival time. See Chapter 1 of this volume for equation.

e racay $\geq 1 E+50$

Contribution of decay product(s) is significant to determination of this value (see Table E-3 in Volume 2). Listed arrival time is that of the parent radionuclide. Antival time of the

significant decay product(s) is greater than $10,000 \mathrm{y}$. 
For the generic trench at LLNL, the $C R F_{\text {Water }}$ for the water pathway is 88 , and the arrival times at the performance boundary (i.e., $100 \mathrm{~m}$ from the edge of the disposal facility) range from 2,300 to 49 million years, including the detention time in the facility. For the generic tumulus at LLNL, the $C R F_{\text {Water }}$ for the water pathway is 88 , and the arrival times at the performance boundary range from 2,700 to 52 million years. The early arrival times of 2,300 and $2,700 \mathrm{y}$ for the trench and tumulus represent highly mobile radionuclides. The similarities between the results for the two different repository designs are principally due to the low natural recharge at Site 300. Failure of the RCRA-compliant trench cover $200 \mathrm{y}$ before failure of the tumulus vault results in a maximum groundwater travel distance of $5.4 \mathrm{~m}$ compared to a total depth to groundwater of $162 \mathrm{~m}$.

\subsubsection{Atmospheric Transport}

Two CRFs were used to account for the attenuation encompassing diffusion to the ground surface, mixing in air, and dispersion in the atmosphere to the performance boundary. The CRF for diffusion in soil, $C R F_{D i f}$, was defined as the ratio of the radionuclide concentration in the waste to its resulting concentration in the upper one centimeter of soil. The CRF for dispersion in air, $C R F_{D i s p}$, was defined as the ratio of the radionuclide concentration in the upper one centimeter of soil to its resulting concentration in air at the performance boundary. The effect of radioactive decay was also included in the PE.

Application of the PE methodology for atmospheric transport of the two volatile radionuclides considered in the $\mathrm{PE}$ (H-3 and $\mathrm{C}$-14) produced the results shown in Table 2-5 for both the generic trench and tumulus designs; there was no assumed difference in these two disposal technologies with respect to permissible waste limits based on the atmospheric pathway at LLNL. The table shows permissible waste concentrations based on transport in the atmospheric pathway $\left(C_{W-A t m}\right)$ as well as the values used in calculating the permissible waste concentrations. For both $\mathrm{H}-3$ and $\mathrm{C}-14$, the greatest concentration reduction was assumed to occur as the radionuclides diffused from the top of the disposal facility to the soil surface.

Table 2-5. Results of Calculations for the Atmospheric Pathway

\begin{tabular}{|c|c|c|c|c|c|c|c|}
\hline \multirow[t]{2}{*}{ Nuclide } & \multirow[b]{2}{*}{$\begin{array}{c}S D C F_{\text {Atm }} \\
(\mathrm{rem} / \mathrm{y}) /(\mu \mathrm{Cin})\end{array}$} & \multicolumn{6}{|c|}{ Generic Trench and Tumulus } \\
\hline & & $\underset{\text { (dimensionless) }}{C R F_{D I H 7}}$ & $\begin{array}{c}C_{\text {dimenslonless) }} \\
\text { (disp }\end{array}$ & $\begin{array}{c}\mathrm{CRF}_{\text {Atm }} \\
\text { (dimensionless) }\end{array}$ & $\begin{array}{l}\text { Arrival } \\
\text { Time (y) }\end{array}$ & $\begin{array}{c}\text { roecay } \\
\text { (dimenslonless) }\end{array}$ & $\begin{array}{c}C_{W-A t m} \\
\left(\mu \mathrm{Ci} / \mathrm{m}^{3}\right)\end{array}$ \\
\hline $\mathrm{H}-3$ & 8.33E+02 & $2 E+06$ & $1 E+03$ & $2 E+09$ & 100 & 280 & $7 E+09$ \\
\hline C-14 & $2.20 E+05$ & $4 E+04$ & $2 E+03$ & $8 \mathrm{E}+07$ & 100 & 1 & $4 E+03$ \\
\hline
\end{tabular}


The time of arrival at the performance boundary for both radionuclides is shown in Table 2-5 as $100 \mathrm{y}$. However, the actual migration of H-3 and C-14 from the disposal facility to the surface and downwind to the performance boundary was calculated to be on the order of hours, not years. As discussed in Section 2.3.2.2, the waste form and RCRA cover are assumed to retain these volatile radionuclides in the disposal facility for at least $100 \mathrm{y}$.

\subsubsection{Inadvertent Intruder Exposure}

The calculation of permissible waste concentrations for inadvertent intruder exposures did not utilize CRFs. Instead, the total dose resulting from an intrusion scenario (the sum of the doses from all exposure pathways involved in that intrusion) was modified by scenario dose conversion factors (SDCFs) that were applied to specific exposure pathways. The important exposure pathways for each radionuclide are listed in Appendix D of Volume 2. These values were radionuclide-specific and facility-design-specific and were the same for all sites. Values for the radioactive decay term were based on time of intrusion into the disposal facility (for the homesteader scenario, $300 \mathrm{y}$ for the trench design and $500 \mathrm{y}$ for the tumulus design; for the postdrilling scenario, $100 \mathrm{y}$ for both disposal designs). However, results based on intruder scenarios should be evaluated carefully because future social behavior, and intrusion scenarios, are difficult to predict.

The permissible waste concentrations for the two generic facility designs for each of the 58 radionuclides based on the standard PE intrusion scenarios are listed in Table 2-6. The most restrictive radionuclide concentration limits for each generic facility are indicated with bold type.

For six radionuclides in the table (U-233, U-234, U-235, U-238, Pu-244, and Cm-247), the time of homesteader intrusion was changed to $10,000 \mathrm{y}$, the end of the performance period. For these six radionuclides, ingrowth of decay products yields scenario doses that increase over time. The doses at $10,000 \mathrm{y}$, therefore, represent the maximum that could be encountered during the performance period. Also, for Th-230 and $\mathrm{Cm}-245$, ingrowth of decay products likewise produces a scenario dose that increases over time and peaks within the 10,000-y performance period. The times of homesteader intrusion for these two radionuclides (Th-230 and Cm-245) were taken as the time of maximum dose, 9000 and $1000 \mathrm{y}$, respectively.

For the trench design, the post-drilling scenario generally yielded more restrictive waste limits than the homesteader scenario for those radionuclides with half-lives shorter than about $30 \mathrm{y}$. For the tumulus design, the post-drilling scenario generally yielded more restrictive limits than the homesteader scenario for those radionuclides with half-lives shorter than about $130 \mathrm{y}$. 
Table 2-6. Permissible Waste Concentrations for the Standard Intrusion Scenarios (most limiting radionuclide concentrations for each facility design is highlighted in bold italic)

(Part 1 of 2)

\begin{tabular}{|c|c|c|c|c|c|}
\hline \multirow[t]{2}{*}{ Nuclide } & \multicolumn{2}{|c|}{ Trench } & \multicolumn{2}{|c|}{ Tumulus } & \multirow[t]{2}{*}{ Nuclide } \\
\hline & $\begin{array}{c}C_{W / m t^{\prime}} \\
\text { Homesteader } \\
(\mu \mathrm{Cim}) \\
\end{array}$ & $\begin{array}{c}C_{W-1 n t} \\
\text { Post-Drilling } \\
\left(\mu \mathrm{Cimm}^{3}\right) \\
\end{array}$ & $\begin{array}{c}C_{W-n t^{\prime}} \\
\text { Homesteader } \\
\left(\mu \mathrm{Ci} / \mathrm{m}^{3}\right)\end{array}$ & $\begin{array}{c}C_{W / n t r} \\
\text { Post-Drilling } \\
\left(\mu \mathrm{Ci} / \mathrm{m}^{3}\right) \\
\end{array}$ & \\
\hline $\mathrm{H}-3$ & $1 E+12$ & $7 E+07$ & NL & $7 E+07$ & $\mathrm{H}-3$ \\
\hline$c-14$ & $1 E+04$ & $7 E+04$ & $1 E+04$ & $7 E+04$ & C-14 \\
\hline Al-26 & $5 E+01$ & $5 E+04$ & $5 E+01$ & $5 E+04$ & $\mathrm{Al}-26$ \\
\hline Si-32 & $9 E+03$ & $1 \mathrm{E}+04$ & $4 E+04$ & $1 E+04$ & Si-32 \\
\hline $\mathrm{Cl}-36$ & $2 E+02$ & $9 E+02$ & $2 E+02$ & $9 \mathrm{E}+02$ & $\mathrm{Cl}-36$ \\
\hline$K-40$ & $7 E+02$ & $2 E+04$ & $7 E+02$ & $2 E+04$ & $K-40$ \\
\hline Co-60 & $\mathrm{NL}$ & $3 E+10$ & NL & $3 E+10$ & Co-60 \\
\hline Ni-59 & $3 E+06$ & $1 E+07$ & $3 E+06$ & $1 \mathrm{E}+07$ & Ni-59 \\
\hline Ni-63 & $8 E+06$ & $1 E+07$ & $3 E+07$ & $1 E+07$ & $\mathrm{Ni}-63$ \\
\hline Se-79 & $2 E+05$ & $8 E+05$ & $2 E+05$ & $8 E+05$ & Se-79 \\
\hline Sr-90 & $1 E+06$ & $6 E+04$ & $1 E+08$ & $5 E+04$ & Sr-90 \\
\hline Zr-93 & $5 E+06$ & $3 E+07$ & $5 E+06$ & $3 E+07$ & $Z r-93$ \\
\hline $\mathrm{Nb}-93 \mathrm{~m}$ & $5 E+12$ & $4 E+09$ & $\mathrm{NL}$ & $4 E+09$ & $\mathrm{Nb}-93 \mathrm{~m}$ \\
\hline $\mathrm{Nb}-94$ & $9 E+01$ & $9 E+04$ & $1 E+02$ & $9 E+04$ & $\mathrm{Nb}-94$ \\
\hline TC-99 & $2 E+04$ & $8 E+04$ & $2 E+04$ & $8 E+04$ & Tc-99 \\
\hline Pd-107 & $6 E+06$ & $3 E+07$ & $6 E+06$ & $3 E+07$ & Pd-107 \\
\hline $\mathrm{Ag}-108 \mathrm{~m}$ & $6 E+02$ & $1 E+05$ & $1 E+03$ & $1 E+05$ & $\mathrm{Ag}-108 \mathrm{~m}$ \\
\hline Cd-113m & $4 E+09$ & $1 E+06$ & $7 E+13$ & $1 E+06$ & $C d-113 m$ \\
\hline Sn-121m & $2 E+07$ & $5 E+07$ & $2 E+08$ & $5 E+07$ & sn-121m \\
\hline $\mathrm{Sn}-126$ & $8 E+01$ & $7 E+04$ & $8 E+01$ & $7 E+04$ & Sn-126 \\
\hline $\mid-129$ & $2 E+03$ & $1 E+04$ & $2 E+03$ & $1 E+04$ & |-129 \\
\hline Cs-135 & $2 E+05$ & $8 E+05$ & $2 E+05$ & $8 E+05$ & Cs-135 \\
\hline Cs-137 & $3 E+05$ & $8 E+05$ & $3 E+07$ & $8 E+05$ & Cs-137 \\
\hline $\mathrm{Ba}-133$ & $2 E+11$ & $3 E+08$ & NL & $3 E+08$ & Ba-133 \\
\hline sm-151 & $2 E+08$ & $2 E+08$ & $8 E+08$ & $2 E+08$ & Sm-151 \\
\hline Eu-152 & $6 \mathrm{E}+08$ & $2 E+07$ & $2 E+13$ & $2 E+07$ & Eu-152 \\
\hline Eu-154 & $4 E+12$ & $4 E+08$ & NL & $4 E+08$ & Eu-154 \\
\hline $\mathrm{Pb}-210$ & $7 E+06$ & $7 E+04$ & $4 E+09$ & $7 E+04$ & $\mathrm{~Pb}-210$ \\
\hline Ra-226 & $8 E+01$ & $3 E+03$ & $9 E+01$ & $3 E+03$ & Ra-226 \\
\hline $\mathrm{Ra}-228$ & $\mathrm{NL}$ & $4 E+09$ & NL & $4 E+09$ & Ra-228 \\
\hline Th-229 & $5 E+02$ & $3 E+04$ & $5 E+02$ & $3 E+04$ & Th-229 \\
\hline Th-230 & $8 E+01$ & $7 E+04$ & $8 E+01$ & $7 E+04$ & Th-230 \\
\hline Th-232 & $6 E+01$ & $2 E+04$ & $6 E+01$ & $2 E+04$ & Th-232 \\
\hline $\mathrm{Pa}-231$ & $2 E+02$ & $5 E+03$ & $2 E+02$ & $5 E+03$ & $\mathrm{~Pa}-231$ \\
\hline
\end{tabular}


Table 2-6. Permissible Waste Concentrations for the Standard Intrusion Scenarios (most limiting radionuclide concentrations for each facility design is highlighted in bold italic) (Part 2 of 2)

\begin{tabular}{|c|c|c|c|c|c|}
\hline \multirow[t]{2}{*}{ Nuclide } & \multicolumn{2}{|c|}{ Trench } & \multicolumn{2}{|c|}{ Tumulus } & \multirow[t]{2}{*}{ Nuclide } \\
\hline & $\begin{array}{c}C_{\text {W-1ntr }} \\
\text { Homesteader } \\
\left(\mu \mathrm{Ci} / \mathrm{m}^{3}\right)\end{array}$ & $\begin{array}{c}C_{W / n t r} \\
\text { Post-Drilling } \\
\left(\mu \mathrm{C} / \mathrm{m}^{3}\right)\end{array}$ & $\begin{array}{c}C_{w+n t r} \\
\text { Homesteader } \\
\left(\mu \mathrm{Ci} / \mathrm{m}^{3}\right)\end{array}$ & $\begin{array}{c}C_{w-1 n t r} \\
\text { Post-Drilling } \\
\left(\mu \mathrm{Ci} / \mathrm{m}^{3}\right) \\
\end{array}$ & \\
\hline U-232 & $2 E+03$ & $5 E+04$ & $1 E+04$ & $5 E+04$ & U-232 \\
\hline U-233 & $7 E+02$ & $1 E+05$ & $7 E+02$ & $1 E+05$ & U-233 \\
\hline U-234 & $1 E+03$ & $1 E+05$ & $1 E+03$ & $1 E+05$ & U-234 \\
\hline U-235 & $6 E+02$ & $1 E+05$ & $6 E+02$ & $1 E+05$ & U-235 \\
\hline U-236 & $2 E+04$ & $1 E+05$ & $2 E+04$ & $1 E+05$ & $\mathrm{U}-236$ \\
\hline U-238 & $5 E+03$ & $1 E+05$ & $5 E+03$ & $1 E+05$ & $U-238$ \\
\hline $\mathrm{Np}-237$ & $4 E+02$ & $4 E+03$ & $4 E+02$ & $4 E+03$ & Np-237 \\
\hline $\mathrm{Pu}-238$ & $7 E+04$ & $1 E+05$ & $4 E+05$ & $1 E+05$ & Pu-238 \\
\hline Pu-239 & $6 E+03$ & $5 E+04$ & $6 E+03$ & $5 E+04$ & Pu-239 \\
\hline $\mathrm{Pu}-240$ & $6 E+03$ & $5 E+04$ & $7 E+03$ & $5 E+04$ & Pu-240 \\
\hline Pu-241 & $2 E+05$ & $1 E+06$ & $3 E+05$ & $1 E+06$ & Pu-241 \\
\hline Pu-242 & $6 E+03$ & $5 E+04$ & $6 E+03$ & $5 E+04$ & Pu-242 \\
\hline Pu-244 & $4 E+02$ & $5 E+04$ & $4 E+02$ & $5 E+04$ & Pu-244 \\
\hline Am-241 & $7 E+03$ & $5 E+04$ & $9 E+03$ & $5 E+04$ & Am-241 \\
\hline Am-243 & $9 E+02$ & $4 E+04$ & $9 E+02$ & $4 E+04$ & Am-243 \\
\hline $\mathrm{Cm}-243$ & $1 E+06$ & $8 E+05$ & $5 E+06$ & $8 E+05$ & $\mathrm{Cm}-243$ \\
\hline Cm-244 & $2 E+06$ & $3 E+06$ & $2 E+06$ & $3 E+06$ & Cm-244 \\
\hline Cm-245 & $1 E+03$ & $4 E+04$ & $1 E+03$ & $4 \mathrm{E}+04$ & $\mathrm{Cm}-245$ \\
\hline $\mathrm{Cm}-246$ & $6 E+03$ & $5 E+04$ & $6 E+03$ & $5 E+04$ & $\mathrm{Cm}-246$ \\
\hline $\mathrm{Cm}-247$ & $3 E+02$ & $5 E+04$ & $3 E+02$ & $5 E+04$ & $\mathrm{Cm}-247$ \\
\hline Cm-248 & $2 E+03$ & $1 E+04$ & $2 E+03$ & $1 E+04$ & $\mathrm{Cm}-248$ \\
\hline Cf-249 & $8 E+02$ & $4 E+04$ & $1 E+03$ & $4 E+04$ & Cf-249 \\
\hline Cf-250 & $2 E+06$ & $9 E+06$ & $2 E+06$ & $9 E+06$ & Cf-250 \\
\hline Cf-251 & $2 E+03$ & $4 E+04$ & $2 E+03$ & $4 E+04$ & Cf-251 \\
\hline
\end{tabular}

a "NL" means No Limit - estimated permissible concentration is greater than the specific activity of the pure elemental radionuclide. 


\subsection{SUMMARY AND DISCUSSION OF RESULTS}

The limiting radionuclide concentrations in disposed MLLW for the water, atmospheric, and intruder analyses for the generic trench and tumulus designs are summarized in Section 2.6.1. An overall discussion of the results of the PE for LLNL Site 300 is contained in Section 2.6.2.

\subsubsection{Results Based on Disposal Design}

For both the generic trench and tumulus designs at LLNL Site 300, one radionuclide (Tc -99) was limited by the water pathway, one radionuclide (C-14) was limited by the atmospheric pathway, and 56 radionuclides were limited by intrusion scenarios, as shown in Table 2-7. The radionuclide limited by the water pathway, Tc-99, is highly mobile and long-lived.

For both the trench and tumulus designs in the water pathway analysis, concentrations for one radionuclide (H-3) that arrived at the performance boundary before 10,000 y had no limit. As discussed in Section 2.5.1, the calculated concentrations for radionuclides reported as NL were above the specific activity of the pure elemental radionuclide, implying that the performance measure of $4 \mathrm{mrem}(0.04 \mathrm{mSv})$ per year would not be reached under the given release and transport assumptions.

As also discussed in Section 2.5.1, values for some radionuclides are not reported in Table 2-7 for the water pathway analysis. Arrival times for these radionuclides were beyond the 10,000 -y performance period. Consistent with the approach used in LLW performance assessments, these values were not considered in determining the most restrictive disposal limit from among the evaluated pathways because arrival times for these radionuclides were beyond $10,000 \mathrm{y}$.

\subsubsection{Discussion}

The results of the PE are based on the framework of assumptions summarized in Chapter 1 of this volume and discussed in detail in Volume 2 of this report and on the site-specific conceptual model for contaminant transport discussed in this chapter. Using alternative assumptions about the conceptual model has the potential to affect the results. Changes in the conceptual model could include alternative assumptions about the disposal facility, the source term, and radionuclide movement in the three pathways. Depending on the degree of possible variation and the relative importance of the parameters used in the calculation of estimated permissible waste concentrations, variability in parameter values can also affect the results. For parameters, results could vary depending on potential changes in values of both the generic and the site-specific parameters used in the PE analysis. 
Table 2-7. Permissible Concentrations for Generic Disposal Designs at LLNL (permissible concentration related to the most limiting pathway for each facility design is highlighted in bold italic) (Part 1 of 2)

\begin{tabular}{|c|c|c|c|c|c|c|c|}
\hline \multirow[t]{2}{*}{ Nuclide } & \multicolumn{3}{|c|}{ Trench } & \multicolumn{3}{|c|}{ Tumulus } & \multirow[t]{2}{*}{ Nuclide } \\
\hline & $\begin{array}{c}C_{\text {w-Water }}{ }^{2, b} \\
\left(\mu \mathrm{Ci} / \mathrm{m}^{3}\right) \\
\end{array}$ & $\begin{array}{l}C_{W-A t m}{ }^{c} \\
\left(\mu \mathrm{Ci} / \mathrm{m}^{3}\right) \\
\end{array}$ & $\begin{array}{l}C_{W / n t t^{d}} \\
\left(\mu \mathrm{Ci} / \mathrm{m}^{3}\right)\end{array}$ & $\begin{array}{c}C_{\text {W-Water }}{ }^{2, b} \\
\left(\mu \mathrm{Ci} / \mathrm{m}^{3}\right)\end{array}$ & $\begin{array}{l}C_{W-A t m}{ }^{c} \\
\left(\mu \mathrm{Ci} / \mathrm{m}^{3}\right)\end{array}$ & $\begin{array}{l}C_{W / n t r}{ }^{d} \\
\left(\mu \mathrm{Ci} / m^{3}\right)\end{array}$ & \\
\hline $\mathrm{H}-3$ & NL & $7 E+09$ & $7 E+07$ & $\mathrm{NL}$ & $7 E+09$ & $7 E+07$ & $\mathrm{H}-3$ \\
\hline C-14 & - & $4 E+03$ & $1 E+04$ & - & $4 E+03$ & $1 E+04$ & C-14 \\
\hline Al-26 & - & & $5 E+01$ & - & & $5 E+01$ & Al-26 \\
\hline Si-32 & - & & $9 E+03$ & - & & $1 E+04$ & Si-32 \\
\hline $\mathrm{Cl}-36$ & - & & $2 E+02$ & - & & $2 E+02$ & $\mathrm{Cl}-36$ \\
\hline$K-40$ & - & & $7 E+02$ & - & & $7 E+02$ & $\mathrm{~K}-40$ \\
\hline Co-60 & - & & $3 E+10$ & - & & $3 E+10$ & Co-60 \\
\hline $\mathrm{Ni}-59$ & - & & $3 E+06$ & - & & $3 E+06$ & $\mathrm{Ni}-59$ \\
\hline $\mathrm{Ni}-63$ & - & & $8 E+06$ & - & & $1 E+07$ & $\mathrm{Ni}-63$ \\
\hline Se-79 & - & & $2 E+05$ & - & & $2 E+05$ & Se-79 \\
\hline Sr-90 & - & & $5 E+04$ & - & & $5 E+04$ & Sr-90 \\
\hline Zr-93 & - & & $5 E+06$ & - & & $5 E+06$ & Zr-93 \\
\hline $\mathrm{Nb}-93 \mathrm{~m}$ & - & & $4 E+09$ & - & & $4 E+09$ & $\mathrm{Nb}-93 \mathrm{~m}$ \\
\hline $\mathrm{Nb}-94$ & - & & $9 E+01$ & - & & $1 E+02$ & $\mathrm{Nb}-94$ \\
\hline Tc-99 & $1 E+03$ & & $2 E+04$ & $2 E+03$ & & $2 E+04$ & Tc-99 \\
\hline $\mathrm{Pd}-107$ & - & & $6 E+06$ & - & & $6 E+06$ & $P d-107$ \\
\hline $\mathrm{Ag}-108 \mathrm{~m}$ & - & & $5 E+02$ & - & & $1 E+03$ & $\mathrm{Ag}-108 \mathrm{~m}$ \\
\hline $\mathrm{cd}-113 \mathrm{~m}$ & - & & $1 E+06$ & $=$ & & $1 E+06$ & Cd-113m \\
\hline Sn-121m & - & & $2 E+07$ & - & & $5 E+07$ & Sn-121m \\
\hline Sn-126 & - & & $8 E+01$ & - & & $8 E+01$ & Sn-126 \\
\hline $1-129$ & - & & $2 E+03$ & - & & $2 E+03$ & |-129 \\
\hline Cs-135 & - & & $2 E+05$ & - & & $2 E+05$ & Cs-135 \\
\hline Cs-137 & - & & $3 E+05$ & - & & $8 E+05$ & Cs-137 \\
\hline $\mathrm{Ba}-133$ & - & & $3 E+08$ & - & & $3 E+08$ & $\mathrm{Ba}-133$ \\
\hline $\mathrm{Sm}-151$ & - & & $2 E+08$ & - & & $2 E+08$ & Sm-151 \\
\hline Eu-152 & - & & $2 E+07$ & - & & $2 E+07$ & Eu-152 \\
\hline Eu-154 & - & & $4 E+08$ & - & & $4 E+08$ & Eu-154 \\
\hline $\mathrm{Pb}-210$ & - & & $7 E+04$ & - & & $7 E+04$ & $\mathrm{~Pb}-210$ \\
\hline Ra-226 & - & & $8 E+01$ & - & & $9 E+01$ & Ra-226 \\
\hline $\mathrm{Ra}-228$ & - & & $4 E+09$ & - & & $4 E+09$ & Ra-228 \\
\hline Th-229 & - & & $5 E+02$ & - & & $5 E+02$ & Th-229 \\
\hline Th-230 & - & & $8 E+01$ & - & & $8 E+01$ & Th-230 \\
\hline Th-232 & - & & $6 E+01$ & - & & $6 E+01$ & Th-232 \\
\hline $\mathrm{Pa}-231$ & - & & $2 E+02$ & - & & $2 E+02$ & $\mathrm{~Pa}-231$ \\
\hline
\end{tabular}


Table 2-7. Permissible Concentrations for Generic Disposal Designs at LLNL (permissible concentration related to the most limiting pathway for each facility design is highlighted in bold italic) (Part 2 of 2)

\begin{tabular}{|c|c|c|c|c|c|c|c|}
\hline \multirow[t]{2}{*}{ Nuclide } & \multicolumn{3}{|c|}{ Trench } & \multicolumn{3}{|c|}{ Tumulus } & \multirow[t]{2}{*}{ Nuclide } \\
\hline & $\begin{array}{c}C_{\text {w.Water }}^{a, b} \\
\left(\mu \mathrm{CU} \mathrm{m}^{3}\right)\end{array}$ & $\begin{array}{l}C_{w a t m m}{ }^{c} \\
\left.(\mu \mathrm{Cim})^{3}\right)\end{array}$ & $\begin{array}{l}C_{w / n r^{d}}^{d} \\
\left(\mu \mathrm{Cl} / m^{3}\right)\end{array}$ & $\begin{array}{c}C_{\text {w.water }}{ }^{n, b} \\
\left(\mu \mathrm{Cu} \mathrm{m}^{3}\right)\end{array}$ & $\begin{array}{l}C_{W-A t m}{ }^{c} \\
\left(\mu \mathrm{Ci} / \mathrm{m}^{3}\right)\end{array}$ & $\begin{array}{l}C_{w / n r^{d}}{ }^{d} \\
\left(\mu \mathrm{Ci} / \mathrm{m}^{3}\right)\end{array}$ & \\
\hline U-232 & - & & $2 E+03$ & - & & $1 E+04$ & U-232 \\
\hline U-233 & - & & $7 E+02$ & - & & $7 E+02$ & U-233 \\
\hline U-234 & - & & $1 E+03$ & - & & $1 E+03$ & $U-234$ \\
\hline U-235 & - & & $6 E+02$ & - & & $6 E+02$ & U-235 \\
\hline$U-236$ & - & & $2 E+04$ & - & & $2 E+04$ & U-236 \\
\hline U-238 & - & & $5 E+03$ & - & & $5 E+03$ & U-238 \\
\hline $\mathrm{Np}-237$ & - & & $4 E+02$ & - & & $4 E+02$ & $\mathrm{~Np}-237$ \\
\hline Pu-238 & - & & $7 E+04$ & - & & $1 E+05$ & Pu-238 \\
\hline Pu-239 & - & & $6 E+03$ & - & & $6 E+03$ & Pu-239 \\
\hline Pu-240 & - & & $6 E+03$ & - & & $7 E+03$ & Pu-240 \\
\hline $\mathrm{Pu}-241$ & - & & $2 E+05$ & - & & $3 E+05$ & $\mathrm{Pu}-241$ \\
\hline $\mathrm{Pu}-242$ & - & & $6 E+03$ & - & & $6 E+03$ & Pu-242 \\
\hline Pu-244 & - & & $4 E+02$ & - & & $4 E+02$ & Pu-244 \\
\hline Am-241 & - & & $7 E+03$ & - & & $9 E+03$ & Am-241 \\
\hline $\mathrm{Am}-243$ & - & & $9 E+02$ & - & & $9 E+02$ & Am-243 \\
\hline $\mathrm{Cm}-243$ & - & & $8 E+05$ & - & & $8 E+05$ & $\mathrm{Cm}-243$ \\
\hline $\mathrm{Cm}-244$ & - & & $2 E+06$ & - & & $2 E+06$ & $\mathrm{Cm}-244$ \\
\hline $\mathrm{Cm}-245$ & - & & $1 E+03$ & - & & $1 E+03$ & $\mathrm{Cm}-245$ \\
\hline $\mathrm{Cm}-246$ & - & & $6 E+03$ & - & & $6 E+03$ & $\mathrm{Cm}-246$ \\
\hline $\mathrm{Cm}-247$ & - & & $3 E+02$ & - & & $3 E+02$ & $\mathrm{Cm}-247$ \\
\hline $\mathrm{Cm}-248$ & - & & $2 E+03$ & - & & $2 E+03$ & $\mathrm{Cm}-248$ \\
\hline Cf-249 & - & & $8 E+02$ & - & & $1 E+03$ & Cf-249 \\
\hline Cf-250 & - & & $2 E+06$ & - & & $2 E+06$ & Cf-250 \\
\hline Cf-251 & - & & $2 E+03$ & - & & $2 E+03$ & Cf-251 \\
\hline
\end{tabular}

- "NL" means No LImit - estimated permissible concentration factor is greater than the specific activity of the pure olemental radionuclide.

- ".," indicates that the radionuclide concentration is based on an arrival time beyond 10,000 $y_{\text {; }}$ see Table 2-4 for specific values.

- Results presented for radionclides expected to be volatile under disposal facility conditions.

- Concentration is based on the most restrictive intrusion scenario assumed for the site; see Table 2-6. 
The effect on results from using alternative generic assumptions and parameter values is discussed in Chapter 6 of Volume 2. In addition, a discussion is provided in that chapter about the effects of using alternative values for site-specific parameters. Based on this discussion, four parameters were identified (three site-specific and one generic, all used in the water pathway analysis) that could potentially influence the results to the degree that the calculated waste concentrations become limited by a pathway other than the one determined for the PE (Table 2-7). The impacts on the results of using alternative values for these four parameters for the water pathway in the PE for LLNL Site 300 are discussed in this section. The basis for and possible variation in the values used in the PE for these parameters are discussed in Section 2.6.2.2.

\subsubsection{Parameter Sensitivity Analysis}

The PE provided results for two disposal facility designs: a RCRA-compliant, belowground trench and a RCRA-compliant, above-ground tumulus. Similar assumptions about the integrity of engineered barriers were made in the PE for both facility designs. Because the factors used to estimate transport of radionuclides in the water pathway for both designs were similar, the discussion in this section focuses on examining the results for the indicator radionuclides reported for the tumulus design (indicator radionuclides are defined in Chapter 7 of Volume 2).

As discussed in Chapter 6 of Volume 2, only four parameters used in the PE were identified as having a potential range of values that might affect results: natural recharge $(i)$; groundwater Darcy velocity $\left(q_{g w}\right)$; area of the facility $(A)$; and distribution coefficients $\left(K_{d} \mathrm{~s}\right)$. These parameter values for LLNL Site 300 are summarized in Table 2-8.

Table 2-8. Parameter Values Used in the PE for LLNL Site 300 with Potential Variability That Could Affect the Results

\begin{tabular}{|l|l|}
\hline \multicolumn{1}{|c|}{ Parameter } & \multicolumn{1}{|c|}{ Value } \\
\hline Natural recharge through local soils, $i$ & $0.025 \mathrm{~m} / \mathrm{y}$ \\
\hline $\begin{array}{l}\text { Distribution coefficients for geologic } \\
\text { media, } K_{d}\end{array}$ & See Table 2-2 in this chapter for values \\
\hline Groundwater Darcy velocity, $q_{g w}$ & $\begin{array}{l}9.9 \mathrm{~m} / \mathrm{y} \text { (based on aquifer properties; see } \\
\text { Section 2.4.1 for discussion) }\end{array}$ \\
\hline Plan-view Area, $A$ & $2500 \mathrm{~m}^{2}$ (standard PE value) \\
\hline
\end{tabular}

The traditional procedure for performing a sensitivity analysis is to vary the parameters used in the calculations and observe the effect on the results. To be meaningful, this method requires some knowledge of the statistical distribution of each of the parameters considered, including their likely maximum and minimum values. For the PE calculations, the potential variability of the parameters used to calculate the permissible waste concentrations for the two different facility designs was not estimated. For most of the radionuclides considered in the PE, there were only two exposure pathways: the water pathway and intruder exposure scenarios (the 
atmospheric pathway is considered only for $\mathrm{H}-3$ and $\mathrm{C}-14$ ). The intruder pathway results provide a baseline that can be used for comparison with the water pathway results because the intruder scenarios used in the PE were relatively independent of the physical characteristics of the individual sites. For $\mathrm{H}-3$ and $\mathrm{C}-14$, the atmospheric pathway results present a baseline that can also be used for comparison with the water pathway because the atmospheric pathway results are not highly sensitive to any individual input parameter (see Chapter 6 of Volume 2).

The intruder and atmospheric baselines provided an alternative method of performing sensitivity analyses for the $\mathrm{PE}$. The input parameters for the water pathway were varied to determine if the limiting exposure pathway could be altered (e.g., the results could be changed from intruder-scenario-controlled [or atmospheric-pathway-controlled] to water-pathwaycontrolled). After new values for the water pathway parameters were determined, these values were examined for reasonableness based on physical constraints at the site.

To analyze the sensitivity of the results to changes in the parameter values for recharge, groundwater Darcy velocity, and area of the facility, the parameter values used in the PE for LLNL were varied. Only one parameter value was varied at a time for each indicator radionuclide, leaving the others equal to their PE values. In most instances, the parameter value was varied until the waste concentrations for the water and intruder (or atmospheric) pathways became equal, regardless of the likelihood (or physical impossibility) of the value to occur.

The parameter values that caused the permissible concentrations for the water and intruder pathways to become equal are listed in Table 2-9a for the 8 indicator radionuclides. For the indicator radionuclides $\mathrm{H}-3, \mathrm{Sr}-90$, and $\mathrm{Cs}-137$, no value variations of these parameters resulted in equal concentrations. For C-14, the limiting pathway is the atmospheric pathway, so the water versus intruder comparison is not applicable. For Tc-99, the value for recharge had to decrease by an order of magnitude or the groundwater velocity had to increase by an order of magnitude to change the limiting pathway from water to intruder. For U-238, all values that caused equal concentrations also caused arrival at the performance boundary beyond 10,000 y. For Pu-239, the value for recharge had to increase more than 3 orders of magnitude for the water pathway concentration to equal the intruder pathway concentration, although the arrival time remained beyond $10,000 \mathrm{y}$. No value variations in the groundwater velocity or facility area resulted in equal water pathway and intruder pathway concentrations for Pu-239. For Am-241, the value for recharge had to increase by almost two orders of magnitude, the groundwater velocity had to decrease by almost one order of magnitude, or the facility size had to increase by 3 orders of magnitude for the water and intruder pathway concentrations to be equal, although the variation in groundwater velocity resulted in an arrival time later than $10,000 \mathrm{y}$ for all parameters except recharge.

The parameter values that caused the permissible concentrations for the water and atmospheric pathways to become equal are listed in Table 2-9b for H-3 and C-14. For H-3, the limiting pathway is the intrusion scenario, so this comparison is not applicable. For C-14, the recharge had to decrease slightly in order for the limiting pathway to change from atmospheric to water. No variation in parameter values caused the limiting pathway to change for groundwater velocity or plan area of the facility. 
Table 2-9. Parameter Values That Caused the Permissible Concentrations for the Water and Intruder Pathways to Be Equal for Indicator Radionuclides at LLNL (tumulus design) (bold italic type indicates limiting pathway in the PE)

(a) Water/Intruder Pathways

\begin{tabular}{|c|c|c|c|c|c|c|}
\hline \multirow[t]{4}{*}{$\begin{array}{l}\text { Indicator } \\
\text { Nuclide }\end{array}$} & \multirow[t]{4}{*}{$\begin{array}{c}\text { PE } \\
c_{w-W a t e r}{ }^{2} \\
\left(\mu C i / m^{3}\right)\end{array}$} & \multirow[t]{4}{*}{$\begin{array}{c}\text { PE } \\
C_{W-\ln t} \\
\left(\mu \mathrm{Ci} / \mathrm{m}^{3}\right)\end{array}$} & \multirow[t]{4}{*}{$\begin{array}{c}\text { PE } \\
C_{W-\text { Intr }} \\
C_{W-W a t e r}\end{array}$} & $\begin{array}{c}\text { Natural } \\
\text { Recharge, } \\
\text { I } \\
\text { (m/y) }\end{array}$ & $\begin{array}{l}\text { Groundwater } \\
\text { Darcy } \\
\text { Velocity, } q_{g w} \\
(\mathrm{~m} / \mathrm{y})\end{array}$ & $\begin{array}{c}\text { Area, } \\
\text { A } \\
\left(\mathrm{m}^{2}\right)\end{array}$ \\
\hline & & & & \multicolumn{3}{|c|}{ PEValues } \\
\hline & & & & 0.025 & 9.9 & 2500 \\
\hline & & & & \multicolumn{3}{|c|}{$\begin{array}{c}\text { Value That Caused Equal } \\
\text { Concentrations }\end{array}$} \\
\hline $\mathrm{H}-3$ & NL & $7 E+07$ & - & $c$ & C & C \\
\hline C-14 & $4 E+07^{b}$ & $1 E+04$ & 0.0003 & $0.13^{b}$ & $c$ & c \\
\hline Sr-90 & $\mathrm{NL}^{\mathrm{b}}$ & $5 E+04$ & - & c & c & c \\
\hline Tc-99 & $2 E+03$ & $2 E+04$ & 10 & $0.0033^{b}$ & 80 & $<100$ \\
\hline Cs-137 & $N L^{b}$ & $8 E+05$ & - & c & $\mathrm{c}$ & c \\
\hline U-238 & $9 E+02^{b}$ & $5 E+03$ & 5.6 & $0.0048^{b}$ & $50^{b}$ & $<100^{b}$ \\
\hline $\mathrm{Pu}-239$ & $\mathrm{NL}^{\mathrm{b}}$ & $6 E+03$ & - & $72^{b}$ & $\mathrm{c}$ & $c$ \\
\hline $\begin{array}{l}\text { Am-241 } \\
(\mathrm{Np}-237)^{\mathrm{d}}\end{array}$ & $3 E+05^{b, 0}$ & $9 E+03$ & 0.03 & $1.2^{\circ}$ & $0.2^{b .0}$ & $6 E+06^{b, 0}$ \\
\hline
\end{tabular}

a "NL" means No Limit - estimated permissible concentration is greater than the specific activity of the pure elemental radionuclide.

b Arrival time at the performance boundary is greater than $10,000 \mathrm{y}$.

c No variation in values caused equal concentrations

d The dominant decay product for Am-241

e Based on the dominant decay product, Np-237

"." Value could not be calculated

(b) Water/Atmospheric Pathways

\begin{tabular}{|c|c|c|c|c|c|c|}
\hline \multirow[t]{4}{*}{$\begin{array}{l}\text { Indicator } \\
\text { Nuclide }\end{array}$} & \multirow[t]{4}{*}{$\begin{array}{c}\text { PE } \\
C_{W \cdot W a t e r} \\
\left(\mu \mathrm{Ci} / \mathrm{m}^{3}\right)\end{array}$} & \multirow[t]{4}{*}{$\begin{array}{c}\text { PE } \\
C_{W-A t m} \\
\left(\mu \mathrm{Ci} / \mathrm{m}^{3}\right)\end{array}$} & \multirow[t]{4}{*}{$\begin{array}{c}\text { PE } \\
\frac{C_{W-A t m}}{C_{W-W a t e r}}\end{array}$} & $\begin{array}{c}\text { Natural } \\
\text { Recharge, } \\
i \\
(\mathrm{~m} / \mathrm{y})\end{array}$ & $\begin{array}{c}\text { Groundwater } \\
\text { Darcy } \\
\text { Velocity, } q_{\text {ow }} \\
(\mathrm{m} / \mathrm{y})\end{array}$ & $\begin{array}{c}\text { Area, } \\
\text { A } \\
\left(\mathrm{m}^{2}\right)\end{array}$ \\
\hline & & & & \multicolumn{3}{|c|}{ PE Values } \\
\hline & & & & 0.025 & 9.9 & 2500 \\
\hline & & & & \multicolumn{3}{|c|}{$\begin{array}{c}\text { Value That Caused Equal } \\
\text { Concentrations }\end{array}$} \\
\hline $\mathrm{H}-3$ & NL & $7 E+09$ & - & a & $\mathbf{a}$ & a \\
\hline$C-14$ & $4 E+07^{b}$ & $4 E+03$ & 0.0001 & 0.22 & $a$ & $\mathbf{a}$ \\
\hline
\end{tabular}

a No variation in values caused equal concentrations.

b Arrival time at the performance boundary is greater than $10,000 \mathrm{y}$. 
The $K_{d}$ values for the geologic media that caused the permissible concentrations for the water and intruder pathways to be the same are listed in Table 2-10 for 5 of the indicator radionuclides. The indicator radionuclides $\mathrm{H}-3, \mathrm{C}-14$, and Tc-99 were not considered in this analysis because general consensus is that the $K_{d}$ values for these radionuclides are small. A $K_{d}$ value of $0.7 \mathrm{~mL} / \mathrm{g}$ resulted in an arrival time at the performance boundary equal to $10,000 \mathrm{y}$.

Table 2-10. Variation of $K_{d}$ Values for the Geologic Media at LLNL (tumulus design) (a $K_{d}$ value of about $0.7 \mathrm{~mL} / \mathrm{g}$ caused radionuclide arrival at the performance boundary equal to $10,000 \mathrm{y}$ )

\begin{tabular}{|c|c|c|c|c|c|}
\hline $\begin{array}{l}\text { Indicator } \\
\text { Nuclide }\end{array}$ & $\begin{array}{c}P E \\
K_{d} \\
(\mathrm{~mL} / \mathrm{g}) \\
\end{array}$ & $\begin{array}{c}\text { PE } \\
C_{W-W a t e r} \\
\left(\mu \mathrm{Ci} / \mathrm{m}^{3}\right) \\
\end{array}$ & $\begin{array}{c}\text { PE } \\
\begin{array}{c}C_{W / n t r} \\
\left(\mu \mathrm{Ci} / \mathrm{m}^{3}\right)\end{array} \\
\end{array}$ & $\begin{array}{c}\text { PE } \\
C_{\text {w-lnte }} \\
C_{W-\text { Water }}\end{array}$ & $\begin{array}{l}K_{d} \text { Value That } \\
\text { Caused Equal } \\
\text { Concentrations }\end{array}$ \\
\hline Sr-90 & 15 & $\mathrm{NL}^{b}$ & $5 E+04$ & - & $c$ \\
\hline Cs-137 & 280 & $\mathrm{NL}^{\mathrm{b}}$ & $8 E+05$ & - & c \\
\hline U-238 & 35 & $9 E+02^{b}$ & $5 E+03$ & 5.6 & $c, d$ \\
\hline $\mathrm{Pu}-239$ & 550 & $\mathrm{NL}^{\mathrm{b}}$ & $6 E+03$ & - & $12^{b, d}$ \\
\hline $\begin{array}{l}A m-241 \\
(\mathrm{~Np}-237)^{\circ}\end{array}$ & $\begin{array}{l}1900 \\
(5)\end{array}$ & $3 E+05^{b, f}$ & $9 E+03$ & 0.03 & 0.13 \\
\hline
\end{tabular}

a "NL" means No Limit - the estimated permissible waste concentration is greater than the specifis activity of the pure elemental radionuclide.

b Radionuclide arrival time at the performance boundary is greater than $10,000 \mathrm{y}$.

c No variation in value caused equal concentrations.

Value less than $0.7 \mathrm{~mL} g$ caused arrival at the performance boundary before $10,000 \mathrm{y}$, which changed the limiting pathway.

e The dominant decay product for Am-241

1 Concentration determined by Np-237 (see Appendix E in Volume 2)

"-" Value could not be calculated.

For Sr-90 and Cs-137, no $K_{d}$ value caused the water and intruder permissible waste concentrations to become equal. A $K_{d}$ value less than $0.7 \mathrm{~mL} / \mathrm{g}$ for $\mathrm{U}-238$ caused the arrival time at the performance boundary to be less than 10,000 y and therefore changed the limiting pathway from intruder to water. For Pu-239, a $K_{d}$ value of $12 \mathrm{~mL} / \mathrm{g}$ caused the water pathway concentration to equal the intruder pathway concentration, although the arrival time still exceeded $10,000 \mathrm{y}$; the $K_{d}$ value had to be decreased to less than $0.7 \mathrm{~mL} / \mathrm{g}$ for the limiting pathway to change from intruder to water. The PE result for Am-241 is limited by the decay product $(\mathrm{Np}-237)$ contribution to the dose. However, if the $K_{d}$ value for Am-241 is reduced to $0.13 \mathrm{~mL} / \mathrm{g}$, then the water pathway waste concentration will be limited by the parent radionuclide $(\mathrm{Am}-241)$ and the water pathway will control. Due to the long half-life of Np-237, reduction of its $K_{d}$ has no effect on the resulting waste concentration.

\subsubsection{Physical Constraints on Sensitivity Analysis Values}

The PE results for LLNL Site 300 are based on values provided by the site's technical staff for site-specific parameters used in calculations. Descriptions and references for these values 
are provided in Sections 2.3 and 2.4. Ranges and statistical distributions are generally not known for all of the input parameter values; however, site-specific knowledge can be used to determine whether the values determined in the sensitivity analysis are reasonable and physically possible at LLNL Site 300.

\section{Natural Recharge}

For the two radionuclides controlled by the water pathway (Tc-99 and U-238), the natural recharge must be reduced about one order of magnitude to less than $4.8 \mathrm{~mm} / \mathrm{y}$ before the intruder scenarios become the controlling pathways. Although recharge is not known with certainty, a reduction of this magnitude may be possible at the 829 Site. Given the low annual precipitation at LLNL Site 300 , the high evaporation rates $(150 \mathrm{~cm} / \mathrm{y})$, and the proposed location at the 829 Site on top of a hill that is well removed from major recharge areas, a recharge this small may be realistic. In this event (i.e., a natural recharge of less than $4.8 \mathrm{~mm} / \mathrm{y}$ ), the intrusion scenario would limit the maximum waste concentrations for all of the 8 indicator radionuclides. By extension, the intrusion scenario would also limit the concentration for most of the other 58 radionuclides considered in the $\mathrm{PE}$. As noted previously, for the water pathway to control the waste concentration rather than the atmospheric pathway and intruder scenarios for C-14 and Am-241, respectively, the recharge would have to exceed the assumed precipitation rate, which is highly unlikely at this site.

\section{Groundwater Darcy Velocity}

The groundwater velocity for the two radionuclides limited by the water pathway (Tc-99 and $\mathrm{U}-238$ ) must be increased to high values before the maximum permissible waste concentrations determined by the intruder scenario become limiting. Given the relatively low permeability of the Neroly formation and the flat gradient, it does not appear that these values are likely. A high groundwater velocity for Tc-99 would cause it to reach the performance boundary prior to $10,000 \mathrm{y}$. A nearly two order of magnitude decrease in the groundwater velocity would result in the water pathway limiting the concentration of Am-241. Although unlikely, this may be possible at LLNL Site 300 and would be an appropriate objective of a more thorough analysis conducted in a performance assessment.

\section{Facility Area}

The values for the facility areas estimated by the sensitivity analysis range from less than $100 \mathrm{~m}^{2}\left(1075 \mathrm{ft}^{2}\right)$ to $1 \times 10^{6} \mathrm{~m}^{2}\left(1 \times 10^{7} \mathrm{ft}^{2}\right)$ (Table 2-9). The results for U-238, Pu-239, and Am-241 correspond to arrival times greater than $10,000 \mathrm{y}$. The sensitivity analyses show that reasonable variations in this parameter will not change the results of the $\mathrm{PE}$.

\section{Distribution Coefficients}

For the water pathway, a $K_{d}$ value of $0.7 \mathrm{~mL} / \mathrm{g}$ results in a contaminant arrival time at the performance boundary of $10,000 \mathrm{y}$. According to Table 2-4, all of the radionuclides either decay or arrive at the performance boundary beyond 10,000 y for a tumulus facility except Tc-99. Furthermore, all of these radionuclides except Tc-99 have $K_{d}$ values much greater than $0.7 \mathrm{~mL} / \mathrm{g}$. Changes in $K_{d}$ values would affect the PE results by changing travel times of the radionuclides through the soils in the upper hydrostratigraphic unit. The limiting pathway for a radionuclide could change from intruder to water not only because the permissible waste concentration changes but also because the arrival time decreases to less than $10,000 \mathrm{y}$. The $K_{d}$ values used in 
the PE analysis were conservative values for sand selected from the compilation by Thibault et al. (1990). In this discussion the term "conservative" refers to values that are likely to result in a relatively low sorption of radionuclides on soil particles, thus resulting in low values of maximum permissible waste concentrations by the water pathway $\left(C_{\text {W-Water }}\right)$. It is likely that soils found in the unsaturated zone at LLNL Site 300 may have much higher adsorptive capacity (i.e., higher $K_{d}$ values) for most of the radionuclides under consideration in the $\mathrm{PE}$, so that most of them will take more than $10,000 \mathrm{y}$ to reach the performance boundary by the water pathway. Therefore, reasonable values of $K_{d}$ will not affect the results of the PE analysis.

\subsection{OBSERVATIONS}

Based on the results of the PE and the parameter-sensitivity analysis, the following observations can be made about MLLW disposal at LLNL Site 300:

- The LLNL Site 300 has characteristics that are typical of an arid climate. The average natural recharge is low $(2.5 \mathrm{~cm} / \mathrm{y}$ [1 in./y]), and the depth to the regional water table is

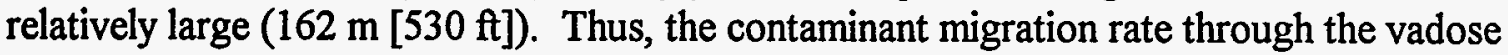
zone, combined with the large depth to groundwater, results in very long travel times to the performance boundary via the water pathway. For both disposal facility designs, the travel time to the performance boundary is predicted to be greater than $10,000 \mathrm{y}$ for all radionuclides except $\mathrm{H}-3$ and $\mathrm{Tc}-99$.

- For both the trench and tumulus designs at LLNL, the results indicate that 56 out of the 58 radionuclides evaluated in the $\mathrm{PE}$ would be limited by the intrusion scenarios. One radionuclide (Tc-99) would be limited by the water pathway, and one radionuclide (C-14) would be limited by the atmospheric pathway. These results reflect the dominant role of the selected human intrusion scenarios that is demonstrated for almost all the sites considered in the PE (see Sections 7.5 and 7.6 in Volume 2). This dominance indicates a need to be aware of the inability to predict the social behavior of populations far into the future.

The results also indicate that for the water pathway, 56 radionuclides for both the trench and tumulus designs would arrive at the performance boundary after the 10,000-y period of consideration in the $\mathrm{PE}$ analysis. Of the 2 radionuclides that would arrive before $10,000 \mathrm{y}$, one $(\mathrm{H}-3)$ had no limit on waste concentration.

Because almost all of the radionuclides at LLNL either are limited by the intrusion scenarios, arrive at the performance boundary after $10,000 \mathrm{y}$, or have no limit on waste concentration, this site may have flexibility in accepting a variety of radionuclides for disposal.

- Either a trench or tumulus facility design may be feasible for disposal of MLLW at LLNL Site 300 . Because of the low natural water recharge, the maximum permissible waste concentrations for both the trench and tumulus designs for almost all of the radionuclides considered in the PE are determined by intrusion scenarios. 
- Site 300 at LLNL has some surface physical constraints that could limit disposal activities. Although the site has a large amount of undeveloped land that could in principle be used for an MLLW disposal facility, much of it is either within the impact area of active firing sites or is too rugged for a disposal facility. However, in a cursory review site technical staff identified areas at LLNL Site 300 that may be suitable to locate a disposal facility.

- The sensitivity analysis for LLNL Site 300 indicates that reasonable changes in values for the natural recharge, groundwater Darcy velocity, and facility size would not change the controlling pathway. The PE values for these parameters could not be changed in a reasonable way to affect the results (i.e., change the controlling pathway) for any of the indicator radionuclides.

In flow and transport problems, the $K_{d}$ values are often the most uncertain site-specific input parameters. However, according to the sensitivity-analysis results, none of the $K_{d}$ values for the indicator radionuclides could be changed in a reasonable way to change the controlling pathway.

- The PE was a scoping analysis performed using assumptions that are conservative relative to most LLW performance assessments. There are no site-specific studies to compare with the PE results. A more detailed performance assessment would be required for permitting or other serious disposal planning. 


\subsection{REFERENCES}

Baer, T.A., L. L. Price, J. N. Emery, N. E. Olague, 1994. Second Performance Assessment Iteration of the Greater Confinement Disposal Facility at the Nevada Test Site. SAND930089. Albuquerque, NM: Sandia National Laboratories.

Carpenter, David. Personal communication, 10/7/94. Livermore, CA: Lawrence Livermore National Laboratory.

Cooper, C.D., and F.C. Alley, 1986. Air Pollution Control: A Design Approach. Prospect Heights, IL: Waveland Press, Inc.

CRC, 1981. CRC Handbook of Chemistry and Physics. Eds. Robert C. Weast and Melvin J. Astle. Boca Raton, FL: CRC Press, Inc.

EPA, 1992. User's Guide for the Industrial Source Complex (ISC2) Dispersion Models, Volume I: User Instructions. EPA Publication No. EPA-450/4-92-008a. Research Triangle, NC: U.S. Environmental Protection Agency.

FFCAct, 1992. Federal Facility Compliance Act of 1992. P.L. 102-386, October 1992.

Gruebel, M.M., R.D. Waters, M.B. Hospelhorn, and M.S.Y. Chu, eds., 1994. Framework for DOE Low-Level and Mixed Low-Level Waste Disposal: Site Fact Sheets. SAND94-2728. Albuquerque, NM: Sandia National Laboratories.

Kincaid, C.T., J.W. Shade, G.A. Whyatt, M.G. Piepho, K. Rhoads, J.A. Voogd, J.H. Westsik, Jr., M.D. Freshley, K.A. Blanchard, and B.G. Lauzon, eds., 1993. Performance Assessment of Grouted Double-Shell Tank Waste Disposal at Hanford. WHC-SD-WM-EE-004, Rev. 0. U.S. Department of Energy, Pacific Northwest Laboratory and Westinghouse Hanford Company.

Madrid, V., 1992. "Neutron Logging at Site 300," interdepartment memo to Site-Wide Remediation Investigation staff. Livermore, CA: Lawrence Livermore National Laboratory. $(10 / 16 / 92)$

Maheras, Steven J., Arthur S. Rood, Swen O. Magnuson, Mary E. Sussman, and Rajiv N. Bhatt, 1994. Radioactive Waste Management Complex Low-Level Waste Radiological Performance Assessment. EGG-WM-8773. Idaho Falls, ID: U.S. Department of Energy Office of Environmental Restoration and Waste Management, DOE Idaho Operations Office.

MMES (Martin Marietta Energy Systems), EG\&G Idaho, Inc., and Westinghouse Savannah River Company, 1994. Radiological Performance Assessment for the E-Area Vaults Disposal Facility (U). WSRC-RP-94-218, Rev. 0. Aiken, SC: Westinghouse Savannah River Company. 
ORNL, 1994. Performance Assessment for Continuing and Future Operations at Solid Waste Storage Area 6. ORNL-6783. Oak Ridge, TN: U.S. Department of Energy, Oak Ridge National Laboratory.

Raber, Ellen, and David W. Carpenter, eds., 1983. An Evaluation of the Hydrogeology and Groundwater Chemistry Associated with Landfills at LLNL's Site 300. UCRL-53416. Livermore, CA: Lawrence Livermore National Laboratory.

Thibault, D.H., M.I. Sheppard, and P.A. Smith, 1990. A Critical Compilation and Review of Default Soil Solid/Liquid Partition Coefficients, Kd, for Use in Environmental Assessments. AECL-10125. Pinawa, Manitoba, Canada: Whiteshell Nuclear Research Establishment, Atomic Energy of Canada Limited.

US EPA, (1990). VLEACH - A One Dimensional Finite Difference Vadose Zone Leaching Model. Washington, D.C.

Webster-Scholten, C.P., ed., 1994. Final Site-Wide Remedial Investigation Report, Lawrence Livermore National Laboratory Site 300. 15 volumes. UCRL-AR-108131. Livermore, CA: Environmental Restoration Division, Lawrence Livermore National Laboratory.

WSRC, 1994. Radiological Performance Assessment for the E-Area Vaults Disposal Facility (U). WSRC-RP-94-218, Rev. 0. Aiken, SC: EG\&G Idaho, Inc., and Westinghouse Savannah River Company.

\section{Acknowledgments}

The SNL Core Team acknowledges the contributions of Albert Lamarre, David Carpenter, and Michael Taffett of LLNL and Robert Ferry of Weiss Associates. 


\section{Colorado: ROCKY FLATS ENVIRONMENTAL TECHNOLOGY SITE (RFETS) Core Team Contact: Bruce M. Thomson}

The Federal Facility Compliance Act (FFCAct, 1992) requires the Department of Energy (DOE) to establish plans in conjunction with its regulators and with members of the public for the treatment of DOE's mixed low-level waste (MLLW). Although the FFCAct did not specifically address disposal of treated MLLW, both DOE and the States recognized that disposal issues were an integral part of treatment discussions. Since 1992, DOE has worked with the States to define and develop an evaluation process for disposal options. Preliminary activities of this joint DOEState process have narrowed the sites for further evaluation from 49 to 15 .

The Disposal Workgroup (DWG), which was established by DOE to develop a process for evaluating disposal options, designed a performance evaluation (PE) to quantify and compare the limitations of the remaining $15 \mathrm{DOE}$ sites for MLLW disposal. The principal goal of the PE was to estimate, for grouted treatment residuals resulting from the treatment of MLLW, permissible concentrations of radionuclides in waste for disposal at each site. These "permissible waste concentrations" were based solely on long-term physical performance of the disposal facility and did not take into account any operational waste acceptance criteria that a site might have developed. The PE did not address any ethical, social, or policy considerations relevant to siting such facilities.

The PE used analyses that are consistent with the approach used in many low-level waste (LLW) performance assessments. The objective was to use a set of modeling assumptions of sufficient detail to capture major site-specific characteristics and yet be general enough for consistent application at all sites. Additionally, the analyses were designed to ensure that the sites were analyzed consistently and that all major assumptions were clearly stated.

The remainder of this chapter provides the PE results for Rocky Flats Environmental Technology Site (RFETS), one of the 15 sites being evaluated. The chapter contains the following information:

Section 3.1: brief, general description of the site based on previous work done by the DWG (Gruebel et al., 1994)

Section 3.2: plans for MLLW disposal, and the location evaluated in the PE

Section 3.3: current understanding of radionuclide movement at the selected location based on available information, and the conceptual model used for the evaluation of each of three pathways (water, atmospheric, and inadvertent intruder)

Section 3.4: site-specific and generic values used in the PE calculations and their sources

Section 3.5: estimates of maximum waste concentrations determined in the PE calculations for each of the three pathways, along with calculated values used in determining these results 
Section 3.6: summary of results based on disposal-facility design; discussion with respect to such issues as uncertainty and sensitivity

Section 3.7: observations based on the results of the PE and the parameter sensitivity analysis

Section 3.8: references

The general assumptions and methodology used in the PE are summarized in Chapter 1 of this volume and explained in more detail in Volume 2 of this report. Overall results for all the sites are discussed in Chapter 7 of Volume 2.

\subsection{GENERAL DESCRIPTION OF THE SITE}

The Rocky Flats Environmental Technology Site (RFETS) is a US DOE facility located near Denver, Colorado (Figure 3-1). The area adjacent to RFETS includes a mixture of agricultural activities, open space, light industry, and low-density residential housing. However, the area is rapidly becoming urbanized and had approximately 2.1 million people living within $50 \mathrm{mi}(80 \mathrm{~km})$ of the site in 1992 . The site is approximately $16 \mathrm{mi}(26 \mathrm{~km})$ northwest of downtown Denver, Colorado, and 9 to $12 \mathrm{mi}(14$ to $19 \mathrm{~km})$ from the communities of Boulder, Golden, and Arvada.

The plant is currently operated by Kaiser-Hill Company $(\mathrm{K}-\mathrm{H})$, which took over operations of the plant from EG\&G on July 1, 1995. The plant's original mission was to produce components for nuclear weapons from materials such as plutonium, uranium, beryllium, and alloys of stainless steel. Parts made at RFETS were shipped elsewhere for final assembly. Other activities included processing of obsolete weapons and scrap materials to recover transuranic radionuclides including plutonium and americium. Formerly referred to as the Rocky Flats Plant, the site was selected in 1951 and limited production operations began in 1952. The mission of producing weapons components was discontinued in 1992, and current activities focus on safe storage of special nuclear materials, environmental restoration, waste management, decontamination and decommissioning of facilities, and economic development.

Over the past five decades RFETS has increased in size from an initial controlled area of $2,520 \mathrm{ac}$ (1010 ha) to the present 6,550 ac (2620 ha) (Figure 3-2). Primary facilities are located on approximately $384 \mathrm{ac}$ (154 ha) near the center of the site, while the remaining area serves as a buffer zone and contains limited support facilities. Major sources of information about the RFETS site, its environmental characteristics, and the environmental monitoring programs are contained in the Final Environmental Impact Statement (US DOE, 1980) and the Rocky Flats Plant Site Environmental Report for 1992 (EG\&G Rocky Flats, Inc., 1992a).

The climate at RFETS is temperate and semiarid and is characterized as continental in that temperatures are largely determined by air masses that form over the North American continent. The site has an active meteorological monitoring program with records extending back to 1953 . Summer temperatures typically range from mid $-80^{\circ} \mathrm{F}$ to $60^{\circ} \mathrm{F}\left(27^{\circ} \mathrm{C}\right.$ to $\left.16^{\circ} \mathrm{C}\right)$, while average winter high and low temperatures range from about $45^{\circ} \mathrm{F}$ to $20^{\circ} \mathrm{F}\left(7^{\circ} \mathrm{C}\right.$ to $\left.-7^{\circ} \mathrm{C}\right)$, respectively. 


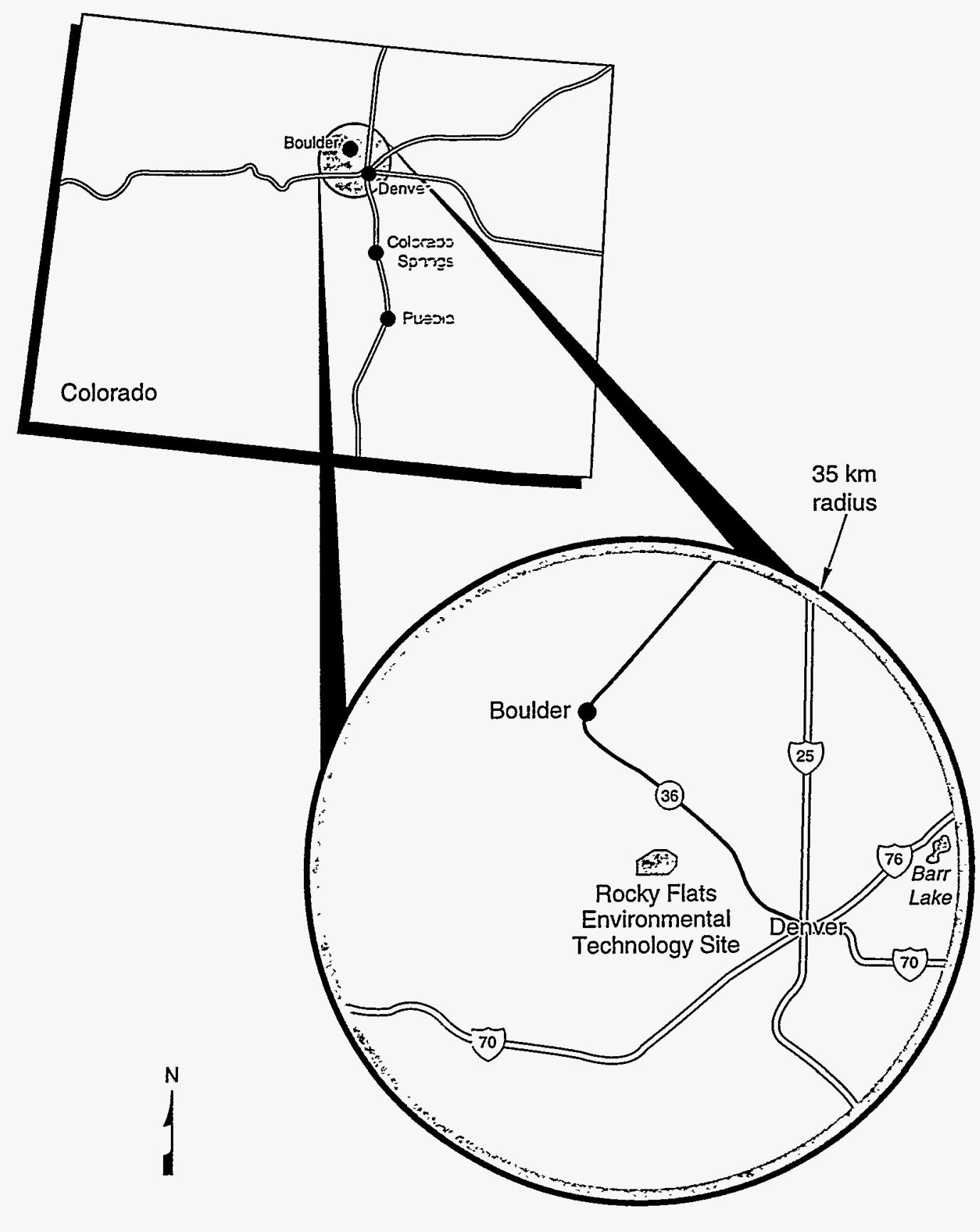

Figure 3-1. Location map for Rocky Flats Environmental Technology Site. 


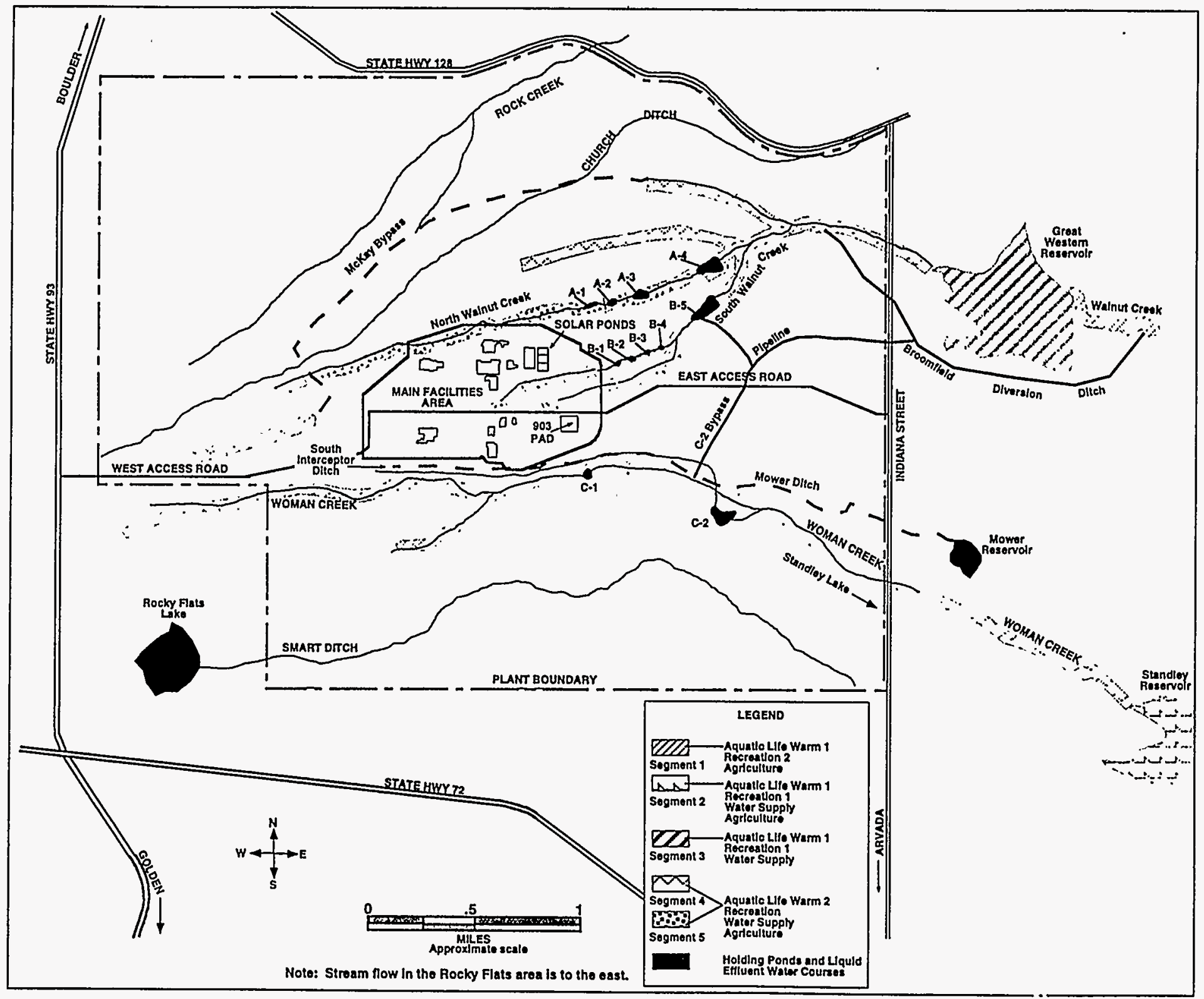

Figure 3-2: Site map for Rocky Flats Environmental Technology Site (EG\&G Rocky Flats, Inc., 1993b, Figure 2.3.3-2). 
The average annual precipitation at RFETS is just under $40 \mathrm{~cm} / \mathrm{y}$ (15 in./y). About $42 \%$ of the annual precipitation occurs from April through June. Thunderstorms occur about 50 days per year in the area. Their maximum occurrence is during the summer and results from convective heating. High winds are common along the Front Range during winter and spring months. Known as "Chinook" winds, these result from winds being forced over the Rocky Mountains and accelerating as they cross the Continental Divide. The air warms and dries as it sinks, and compresses on the eastern side of the mountains. RFETS normally experiences several days a year with wind velocities exceeding $60 \mathrm{mph}(96 \mathrm{~km} / \mathrm{hr})$, with gusts of $80 \mathrm{mph}(128 \mathrm{~km} / \mathrm{hr})$ or more occurring less frequently.

RFETS is located on the eastern edge of an alluvium-covered pediment known locally as Rocky Flats at an elevation of about $6,000 \mathrm{ft}(1830 \mathrm{~m})$. This terrace, which extends north and south and is about $5 \mathrm{mi}(8 \mathrm{~km})$ wide at RFETS, is on the western margin of the Colorado Piedmont section of the Plains Physiographic Province. Immediately to the west are abruptly rising foothills that constitute the flanks of the Front Range of the Rocky Mountains. The pediment slopes gradually to the east at an average gradient of $95 \mathrm{ft} / \mathrm{mi}(18 \mathrm{~m} / \mathrm{km})$. The land surface is covered by a stony soil formed from alluvial fan deposits due to flows from a canyon located to the west.

An extended cross section of the pediment that illustrates the general characteristics of the area is shown in Figure 3-3. The Rocky Flats pediment is the most extensive of the pediments. The surface of this pediment consists of alluvial sediments that are 10 to $50 \mathrm{ft}$ ( 3 to $5 \mathrm{~m}$ ) thick. The pediment dips to the east at a slope of from $0.7 \%$ to $2 \%$.

WH

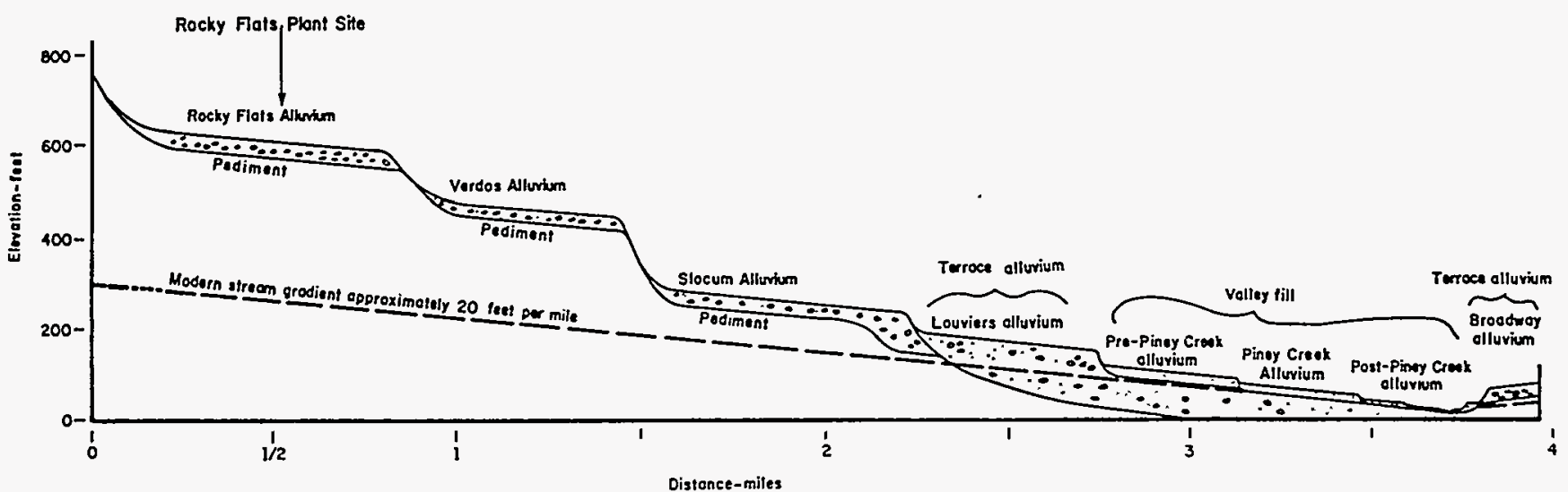

Figure 3-3. Erosional surfaces and alluvial deposits east of the Front Range, Colorado (US DOE, 1980, Figure 2.3.4-1). 
A geologic cross section of RFETS is presented in Figure 3-4. Faulting in the area of RFETS is not well documented, although a projection of the Eggleston Fault appears to cross the northeast corner of the site. A more complete discussion of faulting in the vicinity of RFETS is presented in the EIS. Historically, Colorado has been an area of relatively low seismic activity. With the possible exception of an earthquake in 1882 northwest of RFETS, there have been no large earthquakes in the State of Colorado in recorded history. No active faults have been identified at RFETS, although an investigation is underway to locate faults and/or fractures in the shallow subsurface through a site-wide borehole correlation study (EG\&G, 1994).

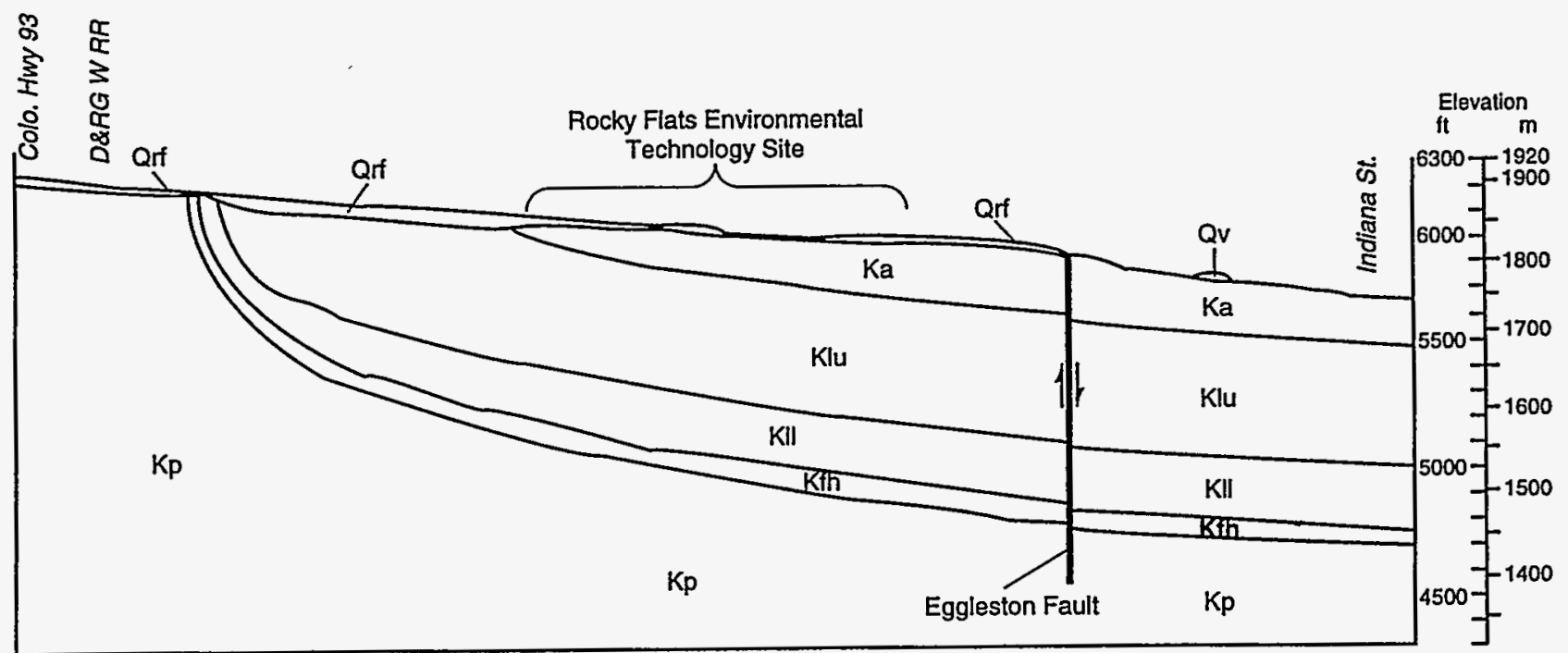

Vertical Exaggeration $\times 4$

Legend

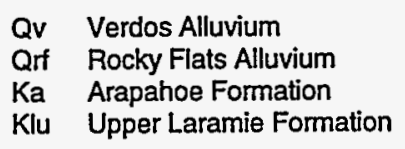

KII Lower Laramie Formation

Kfh Fox Hills Sandstone

Kp Pierre Shale

Klu Upper Laramie Formation

TRI-6622-45-0

Figure 3-4. West to east geologic cross section in the Rocky Flats area (US DOE, 1980, Figure 2.3.4-6).

The surficial features of RFETS appear to be principally the result of episodes of erosion, alluvial terrace formation, and soil development related to glacial and interglacial epochs. Terrace alluvium was deposited from flood discharges that were probably as great as $1400 \mathrm{~m}^{3} / \mathrm{s}(50,000$ $\mathrm{ft}^{3} / \mathrm{s}$ ) from Ralston and Clear creeks south of the site (cited in US DOE, 1980). 
Surface water drainage from RFETS flows into one of three ephemeral streams, which in turn supply water to two reservoirs used for municipal water supply. One of these, Great Western Reservoir, has been isolated from Rocky Flats drainage by construction of a diversion ditch. These streams also provide groundwater recharge for near-surface aquifers that are subsequently used for domestic and agricultural uses. Five streams occur on or near RFETS: North Walnut Creek, South Walnut Creek, and Woman Creek drain RFETS; Rock Creek drains the northwest corner of the buffer zone and is a tributary to Coal Creek, which lies to the north of the site (see Figure 3-2). All of the streams generally drain to the east. North Walnut Creek and South Walnut Creek flow into a diversion ditch that carries the water around Great Western Reservoir, which provides the water supply for the city of Broomfield. Woman Creek flows into Standley Lake, which provides irrigation water and the municipal water supply for the city of Westminster. A series of 11 detention ponds have been constructed along North and South Walnut Creeks and Woman Creek to facilitate control of runoff and wastewater from the site. Water from detention pond C-2, located in the Woman Creek drainage, is transferred via pipe and discharged into the Great Western Reservoir diversion ditch. Water in the streams at RFETS results from surface runoff following periods of precipitation, baseflow supplied by seeps and springs, and diversions and wastewater from plant operations, including discharge of treated sanitary wastewater.

Six drainage ditches also convey water through the area. The South Boulder Diversion Canal carries water southward to Ralston Reservoir, which is part of the water supply for the City of Denver and also supplies water for RFETS. The ditches for the Last Chance, Church, McKay, and Kinnear Ditch and Reservoir Company divert water from Coal Creek and cross RFETS property. Outflow from Rocky Flats Lake is transported out of the area by the Smart Ditch, which also crosses the site.

Because of the proximity of RFETS to a major population center, the facility operates an aggressive site-wide monitoring program. The site routinely measures all air and water emissions and monitors atmospheric conditions and surface and groundwater quality. In addition, soil monitoring and ecological studies are continuing at the site to determine the impact of plant activities on the environment. The results of these monitoring programs are summarized annually in a report entitled "Rocky Flats Plant Site Environmental Report."

Two types of liquid effluent are produced at RFETS, treated sanitary wastewater and surface water runoff. These are collected, controlled, and monitored in a series of ponds prior to discharge. Wastewater is tested prior to release to document compliance with Colorado Water Quality Control Commission standards. In addition to sampling plant discharges, an extensive site-wide surface water sampling and analysis program has been developed to evaluate potential contaminant releases and to characterize baseline water quality. Details of the monitoring programs and a summary of their results are contained in the annual Rocky Flats Plant Site Environmental Reports.

The RFETS groundwater monitoring program has the dual objectives of both monitoring groundwater contaminant transport at the site and developing additional information regarding site characterization. This latter objective is of particular value to the PE process as this 
information is needed to develop a conceptual model of the groundwater transport pathway for MLLW. Characterization objectives at RFETS include identifying hydrostratigraphic units, evaluating groundwater pathways and migration characteristics, qualifying and quantifying the relationships between groundwater and surface water at RFETS, establishing background analyte concentrations, and characterizing background geochemical interactions. This information has been developed through an extensive hydrogeological investigation program and includes information collected from approximately 500 groundwater monitoring wells. A description of the hydrogeological characteristics of RFETS developed from this monitoring program is contained in Section 3.3.

\subsection{STATUS AND SITING OF MLLW DISPOSAL FACILITY}

At the time of the PE, RFETS was preparing and had submitted a Draft Interim Measures/Interim Remedial Action (IM/IRA) report to the Colorado Department of Health and Environment and the Environmental Protection Agency, Region VIII for OU-4 solar evaporation pond closure. This project includes disposal of two LLW forms, approximately $1100 \mathrm{~m}^{3}(38,830$ $\left.\mathrm{f}^{3}\right)$ of solar pond sludge and $5700 \mathrm{~m}^{3}\left(201,210 \mathrm{ft}^{3}\right)$ of solar pond sludge that has been mixed with cement, referred to as pondcrete, in a corrective action management unit located at the solar evaporation ponds. The Draft IM/IRA is presently under review. A proposed Site Treatment Plan for mixed waste generated at RFETS has recently been prepared by DOE (US DOE, 1995). The Site Treatment Plan addresses the treatment of solid and liquid MLLW, and solid and liquid transuranic wastes in storage at the site. Additional stored MLLW referred to as pondcrete and solar pond sludge may require treatment and disposal, depending on subsequent plant operational decisions. The Site Treatment Plan focuses on treatment and storage of waste materials and does not address final disposal alternatives.

RFETS personnel are in the preliminary stages of evaluating an MWDF at a site that is expected to be located close to the new solid waste landfill, which is near the northwestern edge of the plant boundary. This site was selected because it offers a greater depth to groundwater and is a considerable distance from any surface water channels.

Two generic disposal facilities were considered in the PE: a RCRA-compliant, belowground trench and a RCRA-compliant, above-ground tumulus (described in more detail in Chapter 5 of Volume 2). The generic facilities were selected to provide consistency in analysis of the performance of the 15 sites. Both generic facilities were assumed to be square with a plan area of $2500 \mathrm{~m}^{2}\left(26,910 \mathrm{ft}^{2}\right)$. The PE assumed that an MWDF would be located near the new solid waste landfill, which is consistent with the area under consideration by RFETS staff. A nearby monitoring well provided much of the hydrogeologic information needed for the PE calculations. 


\subsection{BASIS FOR CONCEPTUAL MODEL USED IN THE PE}

Because there are no current plans for constructing an MLLW disposal facility at RFETS, a formal performance assessment for such a facility has not been conducted. Therefore, the information needed to evaluate each of the three exposure routes considered in the PE process was developed from other sources. Major sources of data used in the PE analysis are described below. The following section summarizes the conditions at RFETS that are relevant to the PE process.

\subsubsection{Water Pathway}

Knowledge of groundwater flow and radionuclide movement in the water pathway at RFETS provided the basis for the conceptual model considered in the PE. The conceptual model encompasses the site technical staff's current understanding of site-specific geology, hydrology, water table and water bearing unit characteristics, and transport pathways.

\subsubsection{Current Understanding of Relevant Hydrogeology}

The present understanding of RFETS site hydrogeology is summarized in documents prepared for the RFETS groundwater monitoring program. These include the "Draft Final Hydrogeologic Characterization Report" (EG\&G, 1995), "RFP Site Environmental Report for 1992" (EG\&G, 1992a), "Groundwater Protection and Monitoring Program Plan: DOE Order 5400.1" (EG\&G, 1993b), and "Geologic Characterization of the Rocky Flats Plant" (EG\&G, 1992b).

Underlying RFETS is a series of stratigraphic units consisting of (in descending order of stratigraphic position) surface deposits (recent valley fill and loose rock debris), the Rocky Flats Alluvium, Arapaho Formation, Laramie Formation, Fox Hills Sandstone and the Pierre Shale. A generalized stratigraphic column is presented in Figure 3-5. The Rocky Flats Alluvium, hillslope colluvium, and Arapaho Sandstone Formation comprise the uppermost hydrologic unit where potential groundwater contamination might occur at RFETS (EG\&G, 1992b). The Rocky Flats Alluvium and the weathered subcropping Arapaho Sandstones are in hydraulic connection in some cases and together represent the water bearing unit. This uppermost water bearing unit diminishes in thickness from west to east, ranging from approximately $100 \mathrm{ft}(30 \mathrm{~m})$ to less than one foot $(0.3 \mathrm{~m})$. In the central portion of the RFETS, the unit is approximately 15 to $25 \mathrm{ft}$ ( 5 to $8 \mathrm{~m}$ ) thick (EG\&G, 1994). The Verdos Alluvium is stratigraphically younger but at a lower elevation than the Rocky Flats Alluvium and has been identified in the eastern part of RFETS. Its thickness ranges up to $12 \mathrm{ft}(14 \mathrm{~m})$.

There is evidence that the alluvial formations experience recharge from precipitation. The bedrock sandstones of the Laramie Formation are isolated within intervals of claystone. Groundwater contained in those bedrock sandstones is confined and represents a lower elevation flow system. It is believed that there are no bedrock pathways through which contaminated groundwater can transport pollutants offsite from RFETS to a confined aquifer system (EG\&G, 1995b). 


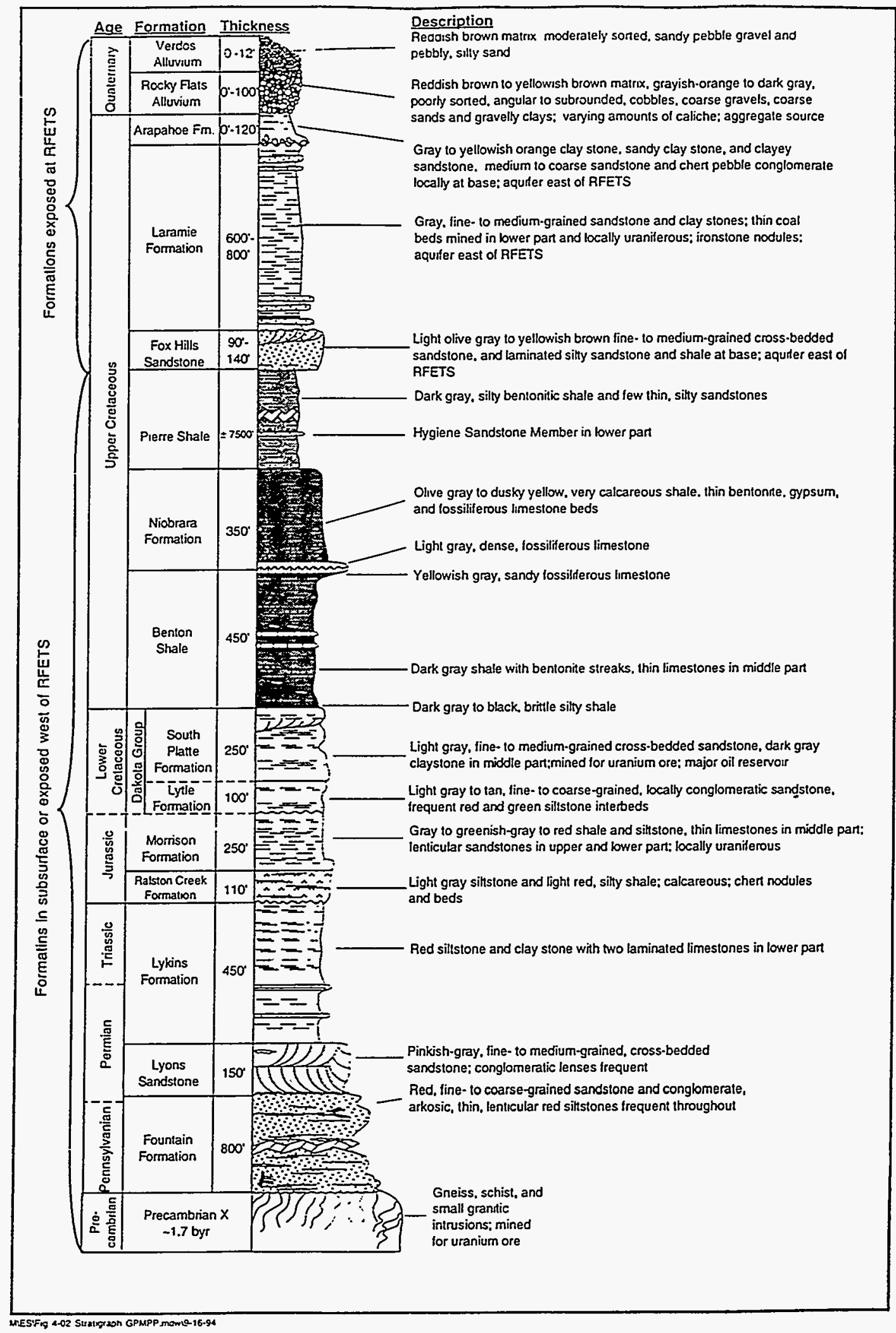

Figure 3-5. Generalized stratigraphic column for the Rocky Flats area (EG\&G Rocky Flats, Inc., 1993b, Figure 2.1.2-1). 
Six major geologic parameters influence groundwater flow at RFETS (EG\&G, 1994):

1. Topography controls the surface waters of the upslope drainage basin, which in part recharges groundwater and the three principal streams draining RFETS.

2. The lithology and permeability of the unconsolidated surficial deposits permit meteoric waters to recharge the water table.

3. Paleotopography of the bedrock pediment, which is generally less permeable than the overlying unconsolidated surficial deposits, serves to focus groundwater movement along bedrock lows.

4. Paleoweathering of the bedrock surface enhances bedrock hydraulic conductivity to groundwater.

5. The bedrock lithology, composed primarily of claystone with lesser amounts of siltstone and sandstone, is generally less permeable than the unconsolidated surficial deposits.

6. Fracturing and possible faulting of the bedrock may allow preferential groundwater flow along local trends.

Considerable effort has been devoted in recent years to developing a quantitative understanding of the hydrogeology at RFETS. The most current summary of groundwater occurrence and flow is presented in the "Groundwater Protection and Monitoring Program Plan" (EG\&G, 1994). Individual studies related to RFETS include new and continuing investigations in

- Site-wide spring and seep inventory and characterization;

- Historical aquifer test data compilation and validation;

- Geologic characterization;

- Physical hydrogeologic characterization;

- Groundwater geochemistry; and

- Site-wide groundwater flow modeling.

The uppermost hydrostratigraphic unit at RFETS consists of the following geologic units: Rocky Flats Alluvium, valley-fill alluvium, colluvium, landslide deposits, weathered Arapaho and Laramie Formation bedrock, and the sandstones within the Arapaho and upper Laramie Formations in hydraulic communication with the overlying unconsolidated surficial deposits (EG\&G, 1994). Lower hydrostratigraphic units consist of the consolidated, unweathered bedrock zone of the Arapaho and upper Laramie Formations not in hydraulic communication with the overlying strata. Interbedded siltstones and claystones with hydraulic conductivity on the order of $1 \times 10^{-7} \mathrm{~cm} / \mathrm{s}\left(4 \times 10^{-8} \mathrm{in} . / \mathrm{s}\right)$ behave as aquitards and limit vertical groundwater flow even though large vertical hydraulic gradients have been measured. Groundwater geochemical characteristics also support the distinction between the upper and lower hydrostratigraphic units. 
The depth to the water table at RFETS is highly variable. In general it becomes shallower from west to east as the alluvial material thins and the confining claystones approach the surface. Groundwater seeps from the Rocky Flats Alluvium are common where it is incised by stream channels. It should be noted that the contours of the potentiometric surface generally reflect the influence of bedrock geology except where stream channels have incised the alluvium.

A discussion of the hydrostratigraphic unit considered in establishing the location of the performance boundary in the PE is appropriate. Due to the limited extent of saturated material in the Rocky Flats Alluvium and its very slow rate of recharge, this formation is not properly referred to as an aquifer because it is not capable of yielding significant and usable quantities of groundwater. Thus, it is referred to in RFETS reports as the water bearing zone located in the upper hydrostratigraphic unit rather than as the water table aquifer. This situation has been described by EG\&G (1995b). However, because discharge from the Rocky Flats Alluvium recharges hillside colluvium and subsequently valley-fill colluvium, the upper hydrostratigraphic unit is subject to groundwater monitoring under RCRA and CERCLA. Discharge from this formation also produces a number of seep springs, several of which have been used in the past for watering livestock. Although these seeps are a potential surface water exposure pathway, they are located beyond the $100-\mathrm{m}$ (328-ft) distance from the edge of a hypothetical disposal facility so that groundwater remains the water exposure pathway considered in the PE. Unweathered bedrock of the Arapaho and Laramie Formations are not considered part of the upper hydrostratigraphic unit because of their markedly lower hydraulic conductivities; in this hydrogeologic system they generally function as an aquitard, although preferential flow through fractures may occur to a limited degree. Because groundwater in the upper hydrostratigraphic unit is naturally occurring, and to maintain consistency with current regulatory programs, the Rocky Flats Alluvium is considered to be the water bearing unit in the PE analysis.

\subsubsection{Conceptual Model Used in the PE}

The PE used a generic conceptual model to describe the water pathway (summarized in Section 1.1.2 of this volume and described in detail in Chapter 5 of Volume 2). In the unsaturated zone, leachate was generated by constant rate of flow through the disposal facility at a rate that was controlled by the assumed performance of the disposal facility. When all engineered barriers had failed, the rate of flow was assumed to be equal to the natural recharge through local soils. The volumetric flow of water through the facility that generated leachate was based on the assumed performance and size of the disposal facility. No dilution was assumed to occur in the unsaturated zone, so at steady state, the concentration that reached groundwater equaled the leachate concentration. No lateral spreading was assumed, so the leachate flux through the unsaturated zone was confined to the soil column directly below the plan area of the facility.

As contaminated water entered the saturated zone, the contaminant mixed with clean groundwater, forming a plume with a shape controlled by hydraulic and contaminant properties. The generic conceptual model assumed that instantaneous and complete mixing within the water bearing unit occurred directly below the facility. Vertical mixing occurred by hydrodynamic dispersion, and the contaminant mixing depth was an estimated value. 
The generic conceptual model was adapted to conditions at RFETS based on site-specific knowledge of the geology and water flow paths. Site technical staff at RFETS participated in the development of the conceptual model for groundwater contaminant transport. The following description represents the conceptual model of the water pathway that was used in the PE for RFETS. The conceptual model for the water pathway at RFETS is illustrated in Figure 3-6.

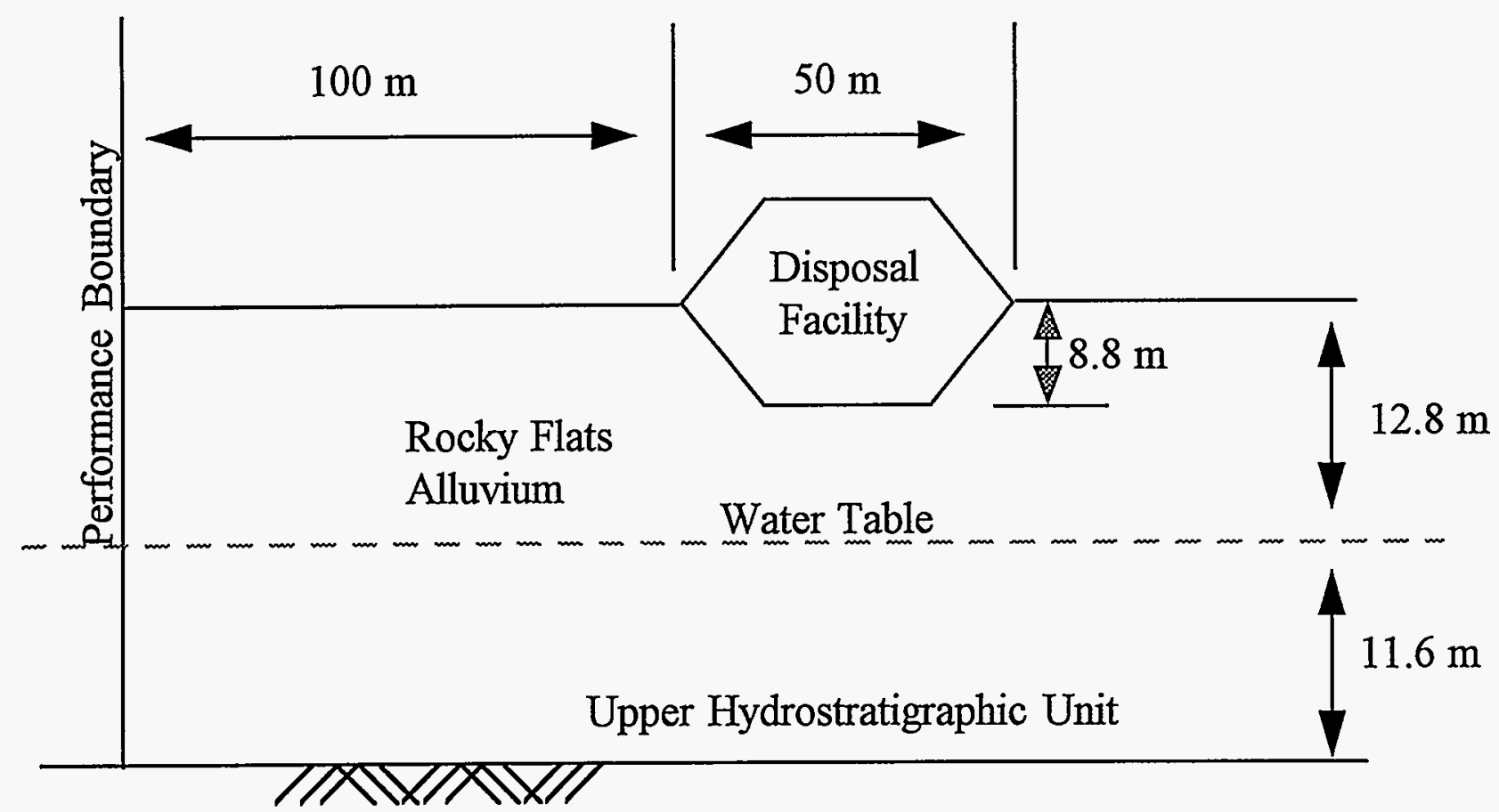

rfp.ppt

Figure 3-6. Conceptual model for water transport at RFETS.

Few data are available on recharge for the pediments at RFETS. A study of groundwater recharge rates was initiated in 1993 (ASI, 1993); however, it did not assess recharge near the prospective MWDF site. Rocky Flats personnel are developing a site-wide groundwater flow model and have generated estimates of recharge through model calibration studies (EG\&G, 1993a). These values are reported in Section 3.4.1. 


\subsubsection{Atmospheric Pathway}

The conceptual model used in the PE for evaluating the atmospheric pathway was derived from performance assessments for LLW disposal facilities at Hanford (Kincaid et al., 1993), INEL (Maheras et al., 1994), NTS (Baer et al., 1994), ORR (ORNL, 1994), and SRS (MMES et al., 1994). The model was generalized for the $P E$ but used site-specific values for many of the parameters.

\subsubsection{Current Understanding of Relevant Meteorology}

Atmospheric conditions at RFETS needed for PE calculations are summarized in the EIS (US DOE, 1980). Winds at RFETS are predominantly westerly, with stronger winds occurring during the winter. Extreme wind events are associated with local chinook conditions. The EIS notes that peak gusts of $105 \mathrm{mph}(169 \mathrm{~km} / \mathrm{hr})$ have been recorded on four occasions through 1979 and that gusts up to $150 \mathrm{mph}(242 \mathrm{~km} / \mathrm{hr})$ have been recorded at a meteorological station $7 \mathrm{mi}(11 \mathrm{~km})$ north-northwest of the RFETS.

The site continuously monitors radionuclide air emissions at 63 locations in 17 buildings using selective alpha air monitors, total long-lived alpha screening of air duct emission filters, and radiochemical analysis of isotopes collected from air duct emission samples. In addition, a meteorological monitoring program has been in place at RFETS since 1952. This program includes an ambient air monitoring program with samplers at 23 locations on the plant site, 14 locations around the plant boundary, and 11 locations in neighboring communities.

Meteorological data are based on STAR data files summarized by the windrose in Figure 3-7. These data were obtained from hourly average meteorological readings taken at a

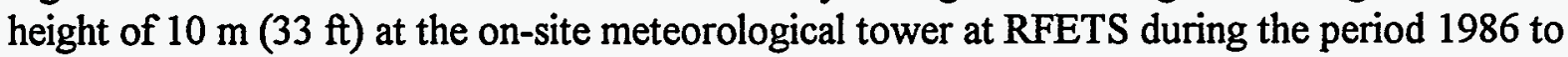
1993.

The dispersive characteristics of the atmosphere also depend on its stability. The most commonly used classification scheme is the Pasquill system. This system consists of six stability categories where Pasquill Category A represents extremely unstable conditions and Pasquill Category F indicates moderately stable conditions. Data presented in the EIS (DOE, 1980) show a relatively high incidence of neutral to stable conditions (Categories $D$ through $F$ ). These conditions occur from $70 \%$ to $90 \%$ of the time.

\subsubsection{Conceptual Model Used in the PE}

The PE used a generic conceptual model to describe the atmospheric pathway (summarized in Section 1.2 of this volume and described in detail in Chapter 5 of Volume 2). Only H-3 (tritium) and C-14 were expected to be volatile for the disposal facility conditions and thus were the only radionuclides considered for atmospheric transport in the PE. In the model, radionuclides were transported from the disposal facility to the soil surface by vapor (tritium) and gaseous (carbon dioxide carrying the $\mathrm{C}$ - 14 isotope) diffusion. When the radionuclides reached the soil surface, they were entrained in the air in vapor form as volatiles. Once airborne, these radionuclides were transported via atmospheric dispersion to a receptor located at the performance boundary. 


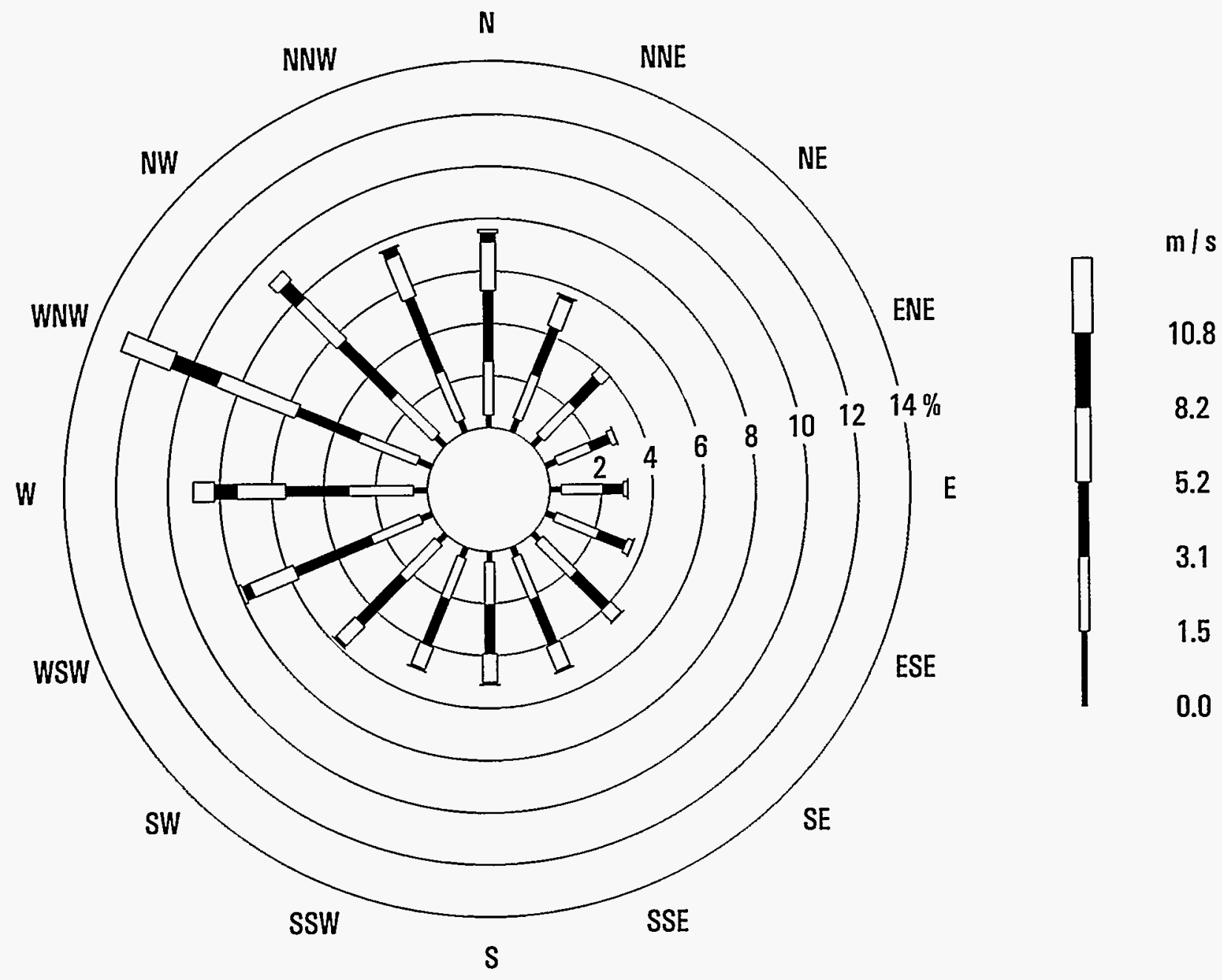

Figure 3-7. Windrose for RFETS for the period 1986 to 1993 . The frequency of winds from each direction is plotted as a series of connected bars that extend from the center of the circular diagram toward the direction from which the winds originate. Wind speed categories are denoted by bar widths and shadings. The frequency of winds in each wind speed category is indicated by the length of the corresponding bar. 
Two components of the atmospheric pathway were evaluated separately: (1) the zone from the top of the disposal facility to the soil surface as indicated by the upward radionuclide diffusion profile; and (2) the zone in which a radionuclide was emitted to the atmosphere, mixed with the ambient air, and dispersed downwind from the waste disposal facility boundary to the $100-\mathrm{m}(328-\mathrm{ft})$ performance boundary.

The arrival time of radionuclides at the performance boundary was assumed to be $100 \mathrm{y}$ based on the following generic assumptions of the PE:

- The waste form was grouted MLLW treatment residuals. Based on this assumption, tritium as vapor was bound in the pore water of the hydrophilic grout, and carbon dioxide as a gas carrying the $\mathrm{C}-14$ isotope was limited by the high $\mathrm{pH}$ of the grout, so that the waste form provided retention of these volatile radionuclides in the disposal facility.

- The disposal facility was capped by a RCRA-compliant cover system. Based on this assumption, the cover system was maintained to provide low permeability for $100 \mathrm{y}$.

\subsubsection{Inadvertent Intruder Pathways}

Standard intrusion scenarios were used in the PE, with information derived from performance assessments of LLW disposal facilities at SRS (MMES et al., 1994) and ORR (ORNL, 1994) indicating that only two chronic-exposure scenarios needed to be considered for most sites and facility designs. Any variations in these scenarios were based on discussions with site technical staff about such factors as the types of activities that reasonably could result in exposure to buried waste at the site and the effectiveness of active or passive institutional controls and engineered barriers in precluding access to the waste.

\subsubsection{Current Understanding of Potential Modes of Inadvertent Intrusion}

The area adjacent to RFETS includes a mixture of agricultural activities, open space, light industry, and low-density residential housing. However, the area is rapidly becoming urbanized and had approximately 2.1 million people living within $50 \mathrm{mi}(80 \mathrm{~km})$ of the site in 1992 . The site is approximately $16 \mathrm{mi}(26 \mathrm{~km})$ northwest of downtown Denver, Colorado, and 9 to $12 \mathrm{mi}$ (14 to $19 \mathrm{~km}$ ) from the communities of Boulder, Golden, and Arvada. Much of the land associated with RFETS and its buffer zone was historically used for grazing and was originally homesteaded in the late 19th century. The site includes a number of old dwellings.

\subsubsection{Intruder Scenarios Used in the PE}

The PE used two standard intrusion scenarios that could be modified for site-specific conditions to describe potential modes of inadvertent intrusion (summarized in Section 1.3 of this volume and described in detail in Chapter 5 of Volume 2). The first scenario, the agriculture (homesteader) scenario, included establishment of a permanent homestead directly above a disposal facility with the foundation of the home extending into the waste; some of the waste exhumed from the disposal facility was mixed with native soil in the intruder's vegetable garden. The second scenario, the post-drilling scenario, considered the construction of a well for a domestic water supply by an intruder. The well was drilled through the disposal facility, and the 
cuttings were mixed with soil in the intruder's vegetable garden. The intruder gardened in some of the exhumed waste but did not reside permanently above the disposal facility. In both scenarios, exposure occurred where an intruder dug or drilled into the disposal facility.

For the generic intruder scenarios, the time of intrusion for the homesteader scenario was assumed to be $300 \mathrm{y}$ for the trench design and $500 \mathrm{y}$ for the tumulus design. The time of intrusion for the post-drilling scenario was assumed to be $100 \mathrm{y}$.

\subsection{DATA USED IN THE PE}

The data presented in this section apply to the PE conceptual models described in Section 3.3. The calculations for determining permissible waste concentrations for the radionuclides considered in the PE are discussed in more detail in Chapter 5 of Volume 2 and summarized in Chapter 1 of this volume. The results of the calculations for RFETS are presented in Section 3.5 and discussed in Section 3.6 of this volume.

\subsubsection{Water Transport}

Site-specific values required to perform the water pathway analysis were selected by site technical staff either from site characterizations and reports, from site-specific modeling results, or from general literature. For the unsaturated zone, the site-specific data that were required for the PE were the distance between the disposal facility and groundwater; ambient moisture content; dry bulk density of the geologic medium; distribution coefficients $\left(K_{d} s\right)$ of the radionuclides in the geologic medium; and natural recharge. For the saturated zone, the site-specific data that were required were porosity; dry bulk density of the geologic medium; distribution coefficients $\left(K_{d} \mathrm{~S}\right)$ of the radionuclides in the geologic medium; groundwater Darcy flow rates; and mixing depth in the aquifer.

These values for RFETS are listed in Table 3-1 along with generic values that were used in the PE. Also indicated in the table is a designation of the type of data the value represents and the source of the value. The values were determined from one or more of four data sources: (A) measurement performed by the site, state, or federal agency; (B) result of a numerical analysis performed by the site, state, or federal agency; (C) general literature value selected by the site; and (D) generic value of the PE.

Of the parameters in the PE that depended on site-specific values, only three potentially encompassed enough variability in values to significantly affect the results: natural recharge, $i$; distribution coefficients $\left(K_{d} \mathrm{~s}\right)$ for the geologic media; and groundwater Darcy velocity $\left(q_{g w}\right)$. The sources of these values are discussed in this section. The sensitivity of the results to changes in the values of these parameters is discussed in Section 3.6.2 of this volume and Chapter 6 of Volume 2. 
Table 3-1. Parameters and Values Used in the PE for the Water Pathway at RFETS (generic PE values are in bold; these values and the standard PE method for applying them are summarized in Chapter 1 of this volume and discussed in more detail in Chapter 5 of Volume 2) (Part 1 of 2)

\begin{tabular}{|c|c|c|c|}
\hline Parameter & Value & $\begin{array}{l}\text { Data } \\
\text { Type }\end{array}$ & Comments \\
\hline \multicolumn{4}{|l|}{ SOURCE TERM } \\
\hline $\begin{array}{l}\text { Volumetric water } \\
\text { content of the grouted } \\
\text { waste, } \theta_{G}\end{array}$ & 0.3 & D & Standard PE value \\
\hline $\begin{array}{l}\text { Bulk density of grouted } \\
\text { waste, } \rho_{6}\end{array}$ & $1.76 \mathrm{~g} / \mathrm{ml}$ & D & Standard PE value \\
\hline $\begin{array}{l}\text { Distribution coefficients } \\
\text { for grouted waste, } K_{d}^{G}\end{array}$ & various & D & $\begin{array}{l}\text { Standard PE value; see Table 3-2 in } \\
\text { this chapter }\end{array}$ \\
\hline $\begin{array}{l}\text { Disposal facility plan } \\
\text { area, } A\end{array}$ & $2500 \mathrm{~m}^{2}$ & D & $\begin{array}{l}\text { Standard PE value; } A=a_{1} * a_{2} \text {, where } \\
a_{1}=a_{2}=50 \mathrm{~m}\end{array}$ \\
\hline $\begin{array}{l}\text { Waste mixing fraction } \\
\text { for trench, } f_{m}\end{array}$ & 0.67 & $\dot{D}$ & Standard PE value \\
\hline $\begin{array}{l}\text { Waste mixing fraction } \\
\text { for tumulus, } f_{m}\end{array}$ & 0.33 & D & Standard PE value \\
\hline $\begin{array}{l}\text { Annual rate of water } \\
\text { flowing through intact } \\
\text { trench facility, } q_{f}\end{array}$ & $0.03 \mathrm{~m} / \mathrm{y}$ & D & Standard PE value \\
\hline $\begin{array}{l}\text { Annual rate of water } \\
\text { flowing through intact } \\
\text { tumulus facility, } q_{f}\end{array}$ & $\begin{array}{l}0.00003 \\
\mathrm{~m} / \mathrm{y}\end{array}$ & D & Standard PE value \\
\hline $\begin{array}{l}\text { Time to failure of } \\
\text { leachate collection and } \\
\text { liner systems }\end{array}$ & $30 y$ & D & Standard PE value \\
\hline $\begin{array}{l}\text { Time to failure of trench } \\
\text { facility }\end{array}$ & $100 y$ & D & Standard PE value \\
\hline $\begin{array}{l}\text { Time to failure of } \\
\text { tumulus facility }\end{array}$ & $300 y$ & D & Standard PE value \\
\hline $\begin{array}{l}\text { Natural recharge through } \\
\text { local soils, } i\end{array}$ & $\begin{array}{l}0.05 \\
\mathrm{~m} / \mathrm{y}\end{array}$ & B & EG\&G, 1993a \\
\hline
\end{tabular}

* $A=$ site measurement; $B=$ result of site numerical analysis; $C=$ =literature value selected by the site; $D=g$ eneric $P E$ value 
Table 3-1. Parameters and Values Used in the PE for the Water Pathway at RFETS (generic PE values are in bold; these values and the standard PE method for applying them are summarized in Chapter 1 of this volume and discussed in more detail in Chapter 5 of Volume 2) (Part 2 of 2)

\begin{tabular}{|c|c|c|c|}
\hline Parameter & Value & $\begin{array}{l}\text { Data } \\
\text { Type }^{*}\end{array}$ & Comments \\
\hline \multicolumn{4}{|l|}{ UNSATURATED ZONE } \\
\hline Moisture content, $\theta_{w}$ & 0.12 & $\mathrm{~B}$ & ASI, 1993 \\
\hline Bulk density, $\rho_{b}$ & $\begin{array}{l}1.34 \\
\mathrm{~g} / \mathrm{cm}^{3}\end{array}$ & C & Fedors \& Warner, 1993 \\
\hline $\begin{array}{l}\text { Distribution coefficients of } \\
\text { geologic medla, } K_{d}\end{array}$ & Various & AVC & See Table 3-2 in this chapter \\
\hline $\begin{array}{l}\text { Thickness between trench } \\
\text { and saturated zone }\end{array}$ & $4.0 \mathrm{~m}$ & A & EG\&G, 1995b \\
\hline $\begin{array}{l}\text { Thickness between tumulus } \\
\text { and saturated zone, } l\end{array}$ & $\begin{array}{l}12.8 \mathrm{~m} \\
(42 \mathrm{ft}) \\
\end{array}$ & A & $E G \& G, 1995 b$ \\
\hline Thickness of RF Alluvium & $\begin{array}{l}24.4 \mathrm{~m} \\
(80 \mathrm{ft})\end{array}$ & A & Plate 4-2, EG\&G, 1995a \\
\hline Bedrock Lithofacies & Claystone & A & Plate 5-1, EG\&G, 1995a \\
\hline Soil Above Bedrock ${ }^{1}$ & $\begin{array}{l}\text { GW, GP, } \\
\text { GM, GC }\end{array}$ & A & Plate 4-5, EG\&G, 1995a \\
\hline Hydraulic conductivity & $\begin{array}{l}0.134 \mathrm{~m} / \mathrm{d} \\
(0.44 \mathrm{ft} / \mathrm{d})\end{array}$ & $B$ & EG\&G, 1993a \\
\hline Effective porosity & 0.1 & $\mathrm{C}$ & Hurr, 1976 \\
\hline Hydraulic gradient & 0.012 & A & Plate 1, EG\&G, 1995b \\
\hline \multicolumn{4}{|l|}{ SATURATED ZONE } \\
\hline Effective porosity, $n$ & 0.1 & C & Hurr, 1976 \\
\hline Bulk density, $p_{b}$ & 1.34 & c & Fedors \& Warner, 1993 \\
\hline $\begin{array}{l}\text { Distribution coefficients of } \\
\text { geologic media, } K_{d}\end{array}$ & Various & AVC & See Table 3-2 in this chapter \\
\hline Mixing depth, $d_{m}$ & $11.6 \mathrm{~m}$ & & Predicted by PAGAN code (Chu et al., 1991) \\
\hline Darcy velocity, $q_{g w}$ & $\begin{array}{l}0.59 \mathrm{~m} / \mathrm{y} \\
(1.9 \mathrm{ft} / \mathrm{y})\end{array}$ & B & Calculated from data in EG\&G, 1995b \\
\hline Thickness of saturated zone & $\begin{array}{l}11.6 \mathrm{~m} \\
(38 \mathrm{ft})\end{array}$ & A & $E G \& G, 1995 b$ \\
\hline Groundwater travel time & $17 y$ & B & Calculated from data in EG\&G, 1995b \\
\hline $\begin{array}{l}\text { Distance to } \\
\text { performance boundary } \\
\text { from facility boundary }\end{array}$ & $100 \mathrm{~m}$ & D & Standard PE value \\
\hline
\end{tabular}

$1 \mathrm{GW}=$ well graded gravel, GP = poorty graded gravel, GM = silty gravels, gravel-sand-silt, GC = clayey gravels, gravel-sand-clay. - $A=$ site measurement; $B=$ result of site numerical analysis; $C=$ =literature value selected by the site; $D=g$ eneric $P E$ value 
Table 3-2. Solid/Liquid Distribution Coefficients $\left(K_{d} \mathrm{~S}\right)$ Used in the PE at RFETS

\begin{tabular}{|c|c|c|}
\hline Element & $\begin{array}{c}\text { Waste } K_{d}^{G} \\
(\mathrm{~mL} / \mathrm{g})^{a}\end{array}$ & $\begin{array}{c}K_{d} \text { for Geologic Media } \\
(\mathrm{mL} /)^{b}\end{array}$ \\
\hline $\mathrm{H}$ & 0 & 0.1 \\
\hline C & 10 & 5 \\
\hline $\mathrm{Al}$ & 100 & $35^{c}$ \\
\hline $\mathrm{Si}$ & 100 & 35 \\
\hline $\mathrm{Cl}$ & 0 & $15^{d}$ \\
\hline $\mathrm{K}$ & 1 & 15 \\
\hline Co & 100 & 60 \\
\hline $\mathrm{Ni}$ & 10 & 400 \\
\hline $\mathrm{Se}$ & 1 & 150 \\
\hline $\mathrm{Sr}$ & 100 & 15 \\
\hline $\mathrm{Zr}$ & 10 & 600 \\
\hline $\mathrm{Nb}$ & 10 & 160 \\
\hline TC & 1 & 0.1 \\
\hline$P d$ & 100 & 55 \\
\hline $\mathrm{Ag}$ & 100 & 90 \\
\hline $\mathrm{Cd}$ & 100 & 80 \\
\hline sn & 10 & 130 \\
\hline 1 & 1 & 1 \\
\hline Cs & 10 & 280 \\
\hline $\mathrm{Ba}$ & 10 & $15^{\mathrm{e}}$ \\
\hline $\mathrm{Sm}$ & 10 & 245 \\
\hline $\mathrm{Eu}$ & 10 & $245^{\prime}$ \\
\hline $\mathrm{Pb}$ & 100 & 270 \\
\hline $\mathrm{Ra}$ & 10 & 500 \\
\hline Th & 100 & 3200 \\
\hline $\mathrm{Pa}$ & 100 & 550 \\
\hline $\bar{U}$ & 100 & 35 \\
\hline $\mathrm{Np}$ & 100 & 5 \\
\hline $\mathrm{Pu}$ & 100 & 550 \\
\hline $\mathrm{Am}$ & 100 & 1900 \\
\hline $\mathrm{Cm}$ & 100 & 4000 \\
\hline Cf & 100 & $4000^{\circ}$ \\
\hline
\end{tabular}

\footnotetext{
a Standard PE values; see Chapter 5 of Volume 2

b Values for sand from Thibault et al., 1990, except where noted

c Based on similarity to $\mathrm{Si}$

d Based on similarity to $\mathrm{Br}$

e Based on similarity to $\mathrm{Sr}$

f Based on similarity to Sm

g Based on similarity to $\mathrm{cm}$
} 
Values for distribution coefficients $\left(K_{d} \mathrm{~s}\right)$ are listed in Table 3-2 for the 58 radionuclides (32 elements) considered in the PE. In addition to the $K_{d}$ values for the geologic media, grout $K_{d}$ values are listed for determining the desorption from the source term resulting from the grouted waste form.

Due to the presence of only a few specific radionuclides at RFETS, no site-specific $K_{d}$ values have been developed. Therefore, $K_{d}$ values for sandy soils compiled by Thibault et al. (1990) were used in the PE analysis. The values used for each of the elements are shown in Table 3-2. These distribution coefficients were used to calculate retarded travel times for each element. The generic distribution coefficients for grout encapsulated radionuclides are used to describe partitioning between grout and leachate in the repository itself.

Most of the site-specific values for parameters used in the RFETS PE are based on the "Draft Final Hydrogeologic Characterization Report" (EG\&Gं, 1995) and on the references and data used to develop that report. The values identified in that report were recommended by site technical staff for the PE analysis. As noted in Table 3-1, some of the values were provided by RFETS site technical staff from other RFETS-produced documents, in particular the "Site-Wide Groundwater Flow Modeling at the Rocky Flats Plant" (EG\&G, 1993a). This report describes a project to develop a comprehensive groundwater flow model at the RFETS site. A major component of this effort was the development of estimates of hydraulic parameters for each of the water bearing formations and the overlying unsaturated zone. The values used in the PE for recharge $(i)$ and hydraulic conductivity $(K)$ were taken from this study. The Darcy groundwater velocity $\left(q_{g^{w}}\right)$ was calculated using the hydraulic gradient published in the Hydrogeological Characterization Report (EG\&G, 1994). In addition, the $K_{d}$ values in Table 3-2 from the compilation by Thibault et al. (1990) were reviewed by RFETS technical staff and determined to be appropriate for use in the $\mathrm{PE}$ analysis.

\subsubsection{Atmospheric Transport}

Site-specific data required to perform the atmospheric pathway analysis came from site personnel as data either from site characterizations and reports or from general literature. The site-specific data required for the soil diffusion calculation were the same as some of those required for the water transport analysis (Section 3.4.1). These values are shown in Table 3-3. Necessary atmospheric dispersion data included wind speed and direction and stability class, which are summarized in Section 3.3.2.1.

\subsubsection{Inadvertent Intruder Exposure}

As explained in Section 3.3.3, the PE used two standard intrusion scenarios to describe potential modes of inadvertent intrusion at all the sites. Because these intrusion scenarios were considered applicable to all sites, no values specific to RFETS are used in the calculation of exposures to inadvertent intruders. 
Table 3-3. Parameters and Values Used in the PE for the Atmospheric Pathway at RFETS (generic PE values are in bold; these values and the standard PE method for applying them are summarized in Chapter 1 of this volume and discussed in more detail in Chapter 5 of Volume 2)

\begin{tabular}{|l|c|c|l|}
\hline Parameter & Value & $\begin{array}{c}\text { Data } \\
\text { Type }\end{array}$ & \multicolumn{1}{|c|}{ Comments } \\
\hline $\begin{array}{l}\text { Disposal facility cover } \\
\text { thickness, } x\end{array}$ & $1.0 \mathrm{~m}$ & D & Standard PE value \\
\hline $\begin{array}{l}\text { Depth of the soil surface, } \\
d\end{array}$ & $0.01 \mathrm{~m}$ & D & $\begin{array}{l}\text { Standard PE value based on Maheras } \\
\text { et al. (1994) }\end{array}$ \\
\hline Porosity, $n$ & 0.35 & B & ASI, 1993 \\
\hline Percent saturation, $s$ & 0.34 & B & ASI, 1993 \\
\hline $\begin{array}{l}\text { Ratio of water density in } \\
\text { air to liquid, } r\end{array}$ & $9.2 E-06$ & D & $\begin{array}{l}\text { Standard PE value based on MMES et } \\
\text { al. (1994) }\end{array}$ \\
\hline $\begin{array}{l}\text { Ratio of CO, } \\
\text { concentration in air to } \\
\text { dissolved in water, } r\end{array}$ & $4.3 E-04$ & D & $\begin{array}{l}\text { Standard PE value based on Foust et } \\
\text { al. (as cited in Cooper and Alley, } \\
1986)\end{array}$ \\
\hline $\begin{array}{l}\text { Tritium diffusion } \\
\text { Coefficient in air, } D\end{array}$ & $2.39 E-05 \mathrm{~m}^{2} / \mathrm{s}$ & D & $\begin{array}{l}\text { Standard PE value based on CRC } \\
(1981)\end{array}$ \\
\hline $\begin{array}{l}\text { Carbon diffusion } \\
\text { coefficient in air, } D\end{array}$ & $1.4 \mathrm{E}+05 \mathrm{~m}^{2} / \mathrm{s}$ & D & $\begin{array}{l}\text { Standard PE value based on CRC } \\
\text { (1981) }\end{array}$ \\
\hline $\begin{array}{l}\text { Atmospheric dispersion term, } \\
A_{D}\end{array}$ & $\begin{array}{l}0.31 \\
\left(\mu \mathrm{C} / \mathrm{m}^{3}\right) /\left(\mu \mathrm{CV}^{2}-\mathrm{s}\right)\end{array}$ & B & $\begin{array}{l}\text { Value is estimated using the Industrial } \\
\text { Source Complex-Version } 2 \text { Long Term Air } \\
\text { Dispersion Model (ISCLT2) (EPA, 1992) } \\
\text { based on site-specific STAR data }\end{array}$ \\
\hline
\end{tabular}

* $A=$ site measurement; $B=$ result of site numerical analysis; $C=$ literature value selected by the site; $D=g e n e r i c ~ P E$ value

\subsection{RESULTS OF THE PE}

The performance evaluation provided estimates of permissible waste concentrations in disposed MLLW. The three calculations that formed the foundation of the PE-for the water, atmospheric, and inadvertent intruder pathways-are summarized in Sections 1.1, 1.2, and 1.3, respectively, of this volume and discussed in detail in Chapter 5 of Volume 2.

For each pathway the maximum permissible waste concentration at the performance boundary was determined for each radionuclide by using the performance measures: $4 \mathrm{mrem}$ $(0.04 \mathrm{mSv})$ per year from the water pathway for releases to drinking water; $10 \mathrm{mrem}(0.1 \mathrm{mSv})$ per year from all pathways for atmospheric releases; and $100 \mathrm{mrem}(1 \mathrm{mSv})$ per year from all exposure pathways for chronic exposure of inadvertent intruders; and the appropriate pathway or scenario dose conversion factors (annual effective dose equivalent per unit concentration) based on EPA dose conversion factors. The basis for the performance measures used in the PE is discussed in more dciail in Chapter 5 of Volume 2. For the water and atmospheric pathways, the concentration reduction provided by the environment (i.e., the CRF) was estimated using results of site analyses and data. For the intruder analyses, concentration reduction was estimated for 
appropriate exposure pathways for two intrusion scenarios that, in general, were the same for all the sites. The results of the calculations for the pathways that were analyzed at RFETS are provided in this section and discussed in Section 3.6.

\subsubsection{Water Transport}

Two CRFs were calculated for the water pathway: the source CRF, $C R F_{\text {source, }}$ and the environmental transport $\mathrm{CRF}$ for water, $C R F_{\text {Water. }}$. The source $\mathrm{CRF}$ represents the concentration attenuation between the disposed waste and leachate exiting the bottom of the disposal facility and was defined as the dimensionless ratio of the waste concentration to the resulting leachate concentration. Desorption with infiltrating water was the mechanism used to describe the leaching of radionuclides from the grout. Because a generic method was used to determine the $C R F_{\text {Source }}$ for the 58 radionuclides considered in the PE (summarized in Section 1.1 of this volume and discussed in more detail in Chapter 5 of Volume 2), the radionuclide-specific values for the source CRF for each type of generic facility were the same for all 15 sites.

The environmental transport $\mathrm{CRF}$ for water was defined as the ratio of the concentration of the leachate exiting the disposal facility to the resulting concentration in water at the performance boundary. The concentration attenuation represented by $C R F_{\text {Water }}$ consisted of dilution due to mixing with uncontaminated groundwater. Effects of radioactive decay and decay product ingrowth were also included in the PE.

In the PE, water travel time to the performance boundary was calculated as a basis for estimating retarded travel time of the radionuclides. For RFETS, water travel time from the land surface to the performance boundary (i.e., without consideration of a disposal facility) was estimated at about $48 \mathrm{y}$.

The calculation of travel time through the vadose zone for a radionuclide, on the other hand, must account both for the lower infiltration rate because of the facility's RCRA cover and for the retardation defined by the distribution coefficient for the geologic media. In the PE, the calculation for travel time in the vadose zone first determined the distance a radionuclide traveled at the lower infiltration rate. Then, if the radionuclide had not fully traversed the vadose zone, the additional time required to complete travel in the vadose zone under the higher, infiltration rate was calculated based on the natural recharge through local soils and added to the time determined at the lower infiltration rate.

In the PE, the detention time in the facility for a radionuclide was the time during which water flowing through the facility was assumed to be caught by the leachate collection system. Specifically, the calculation of travel time for a radionuclide accounted for the following:

- For the trench design, the leachate collection system was assumed to catch water flowing through the facility for the first $30 \mathrm{y}$. After $30 \mathrm{y}$, the liner and leachate collection system failed, and water flowing through the facility for the next $70 \mathrm{y}$ was assumed to the $0.03 \mathrm{~m} / \mathrm{y}(0.1 \mathrm{ft} / \mathrm{y})$ based on a unit hydraulic gradient and the saturated hydraulic conductivity of the RCRA cover system. After a total of $100 \mathrm{y}$ of reduced water flowing 
because of engineered barriers ( $30 \mathrm{y}$ of detention plus $70 \mathrm{y}$ limited by the RCRA cover system), the rate was assumed to be the natural recharge through local soils, $0.05 \mathrm{~m} / \mathrm{y}$ $(0.16 \mathrm{ft} / \mathrm{y})$.

- For the tumulus design, the leachate collection system was assumed to catch water flowing through the facility for the first $30 \mathrm{y}$. After $30 \mathrm{y}$, the liner and leachate collection system was assumed to fail, and the rate of water flowing through the facility for the next $270 \mathrm{y}$ was assumed to be $0.00003 \mathrm{~m} / \mathrm{y}(0.0001 \mathrm{ft} / \mathrm{y})$ based on a unit hydraulic gradient and the saturated hydraulic conductivity of the concrete vaults. After a total of $300 \mathrm{y}$ of reduced flow because of engineered barriers ( $30 \mathrm{y}$ detention plus $270 \mathrm{y}$ limited by the concrete vaults), the rate was assumed to be the natural recharge through local soils, $0.05 \mathrm{~m} / \mathrm{y}(0.16 \mathrm{ft} / \mathrm{y})$.

Travel time through the aquifer was independent of facility design and was about $0.5 \mathrm{y}$, based on groundwater Darcy velocity and a $100-\mathrm{m}$ (328-ft) distance to the performance boundary (see Section 1.1.2 of this volume for a summary of these assumptions and Chapter 5 of Volume 2 for additional details). The arrival time of a radionuclide at the performance boundary is the sum of the detention time in the facility, travel time through the vadose zone, and travel time through the aquifer.

Retardation of radionuclides by interaction with soils and rock in the vadose and saturated zones increased travel times for individual radionuclides. This effect was particularly important for short-lived radionuclides because of radioactive decay. For short-lived radionuclides, the effects of radioactive decay combined with long travel times increased the permissible concentrations in the disposal facility.

Application of the PE methodology for water transport of the 58 radionuclides considered in the PE produced the results shown in Table 3-4 for the generic trench and tumulus designs at RFETS. The table shows permissible waste concentrations based on transport through the water pathway $\left(C_{\text {W-Water }}\right)$ as well as the values used in calculating the permissible waste concentrations.

Some radionuclides listed in Table 3-4 have no limit (NL) on their permissible waste concentrations, the result of the combined effects of relatively short half-lives and sufficiently long travel time to the performance boundary. "No limit" is defined as a permissible waste concentration that is greater than the specific activity of the pure elemental radionuclide. For disposal of the maximum possible waste concentration of these relatively short-lived radionuclides, the water pathway produced a dose at the performance boundary of less than 4 mrem $(0.04 \mathrm{mSv})$ per year and, therefore, the permissible waste concentration was unlimited based on exposures from this pathway.

For some radionuclides, no value is listed in Table 3-4 for the radioactive decay term, $r_{\text {Decay. }}$. These radionuclides had radioactive decay terms that were very large (e.g., greater than $\left.1 \times 10^{50}\right)$. Any radionuclide with a radioactive decay term greater than $1 \times 10^{50}$ ensured a calculated permissible waste concentration greater than the specific activity of the pure elemental radionuclide, which, as described previously, resulted in no limit (NL) on permissible waste concentrations for disposal. 
Table 3-4. Results of Calculations for the Water Pathway at RFETS (water travel time from land surface to performance boundary [excluding facility detention] $=48 \mathrm{y})$ (Part 1 of 2$)$

\begin{tabular}{|c|c|c|c|c|c|c|c|c|c|c|c|c|}
\hline \multirow[t]{2}{*}{ Nuclide } & \multirow[b]{2}{*}{$\begin{array}{c}\text { PDCF } \\
\text { remly per } \mu \mathrm{Cr}\end{array}$} & \multicolumn{5}{|c|}{ Trench } & \multicolumn{5}{|c|}{ Tumulus } & \multirow[t]{2}{*}{ Nuclide } \\
\hline & & $\begin{array}{l}\text { CRF source } \\
\text { (dimentionlese) }\end{array}$ & $\begin{array}{c}\text { CRF wher } \\
\text { (dimentionless) }\end{array}$ & \begin{tabular}{|c|} 
Arrival \\
Time (y) \\
\end{tabular} & $\begin{array}{c}\text { rovery }^{a} \\
\text { (dimensionleass) }\end{array}$ & $\begin{array}{c}C_{\text {whwater }}{ }^{b} \\
\left(\mu \mathrm{CL} / \mathrm{m}^{3}\right) \\
\end{array}$ & $\begin{array}{l}\text { CRF source } \\
\text { (dimentionless) }\end{array}$ & \begin{tabular}{|c|} 
CRF waser \\
(dimentionleas)
\end{tabular} & \begin{tabular}{|l|} 
Arrival \\
Time (y)
\end{tabular} & \begin{tabular}{|c|} 
roveny $^{2}$ \\
(dimensioniouse)
\end{tabular} & $\begin{array}{c}C_{\text {wWmar }}{ }^{b} \\
\left.(\mu \mathrm{Clm})^{2}\right)\end{array}$ & \\
\hline $\mathrm{H}-3$ & 4.67E-02 & 0.45 & 6.0 & $1.0 \mathrm{E}+02$ & $3.4 E+02$ & $7 E+04$ & 0.9 & 4.0 & $4.0 \mathrm{E}+02$ & $7.6 \mathrm{E}+09$ & $2 E+12$ & $\mathrm{H}-3$ \\
\hline C-14 & $1.52 E+00$ & 27 & 4.0 & $1.8 E+03$ & $1.2 \mathrm{E}+\infty 0$ & $3 E+02$ & 54 & 4.0 & $3.2 E+03$ & $1.5 E+\infty$ & $8 E+02$ & C-14 \\
\hline$A 1-26$ & $1.06 E+01$ & 270 & 4.0 & $1.2 E+04$ & $1.0 \mathrm{E}+00$ & $4 E+02$ & 540 & 4.0 & $2.0 E+04$ & $1.0 \mathrm{E}+00$ & $8 E+02$ & Al-26 \\
\hline Si-32 & $7.99 E+\infty 0$ & 270 & 4.0 & $1.2 E+04$ & $3.8 \mathrm{E}+35$ & $\mathrm{NL}$ & 540 & 4.0 & $2.0 E+04$ & e & NL & Si-32 \\
\hline $\mathrm{Cl}-36$ & $2.21 E+\infty 0$ & 0.45 & 4.0 & $5.1 E+03$ & $1.0 \mathrm{E}+\infty$ & $3 E+\infty 0$ & 0.9 & 4.0 & $8.9 E+03$ & $1.0 E+\infty$ & $6 \mathrm{E}+\infty 0$ & Cl-36 \\
\hline$K-40$ & $1.36 E+01$ & 3.1 & 4.0 & $5.1 E+03$ & $1.0 \mathrm{E}+\infty 0$ & $3 E+\infty$ & 6.2 & 4.0 & $8.9 E+03$ & $1.0 \mathrm{E}+00$ & $7 E+\infty 0$ & $\mathrm{~K}-40$ \\
\hline Co-60 & $1.97 E+01$ & 270 & 4.0 & $2.0 E+04$ & e & $\mathrm{NL}$ & 540 & 4.0 & $3.5 E+04$ & e & $\mathrm{NL}$ & Co-60 \\
\hline Ni-59 & 1.53E-01 & 27 & 4.0 & $1.3 \mathrm{E}+05$ & $3.4 \mathrm{E}+\infty$ & $9 E+03$ & 54 & 4.0 & $2.3 E+05$ & $8.1 E+\infty 0$ & $4 E+04$ & N1-59 \\
\hline $\mathrm{Ni}-63$ & 4.21E-01 & 27 & 4.0 & $1.3 E+05$ & $e$ & $\mathrm{NL}$ & 54 & 4.0 & $2.3 \mathrm{E}+05$ & e & NL & NI-63 \\
\hline Se-79 & $6.35 E+\infty 0$ & 3.1 & 4.0 & $5.0 E+04$ & $1.7 \mathrm{E}+\infty$ & $1 E+01$ & 6.2 & 4.0 & $8.6 \mathrm{E}+04$ & $2.5 E+\infty 0$ & $4 E+01$ & Se-79 \\
\hline ST-90 & $1.12 E+02$ & 270 & 4.0 & $5.1 E+03$ & $e$ & NL & 540 & 4.0 & $8.9 E+03$ & e & $\mathrm{NL}$ & Sr-90 \\
\hline $2 r-93$ & $1.59 E+00$ & 27 & 4.0 & $2.0 \mathrm{E}+05$ & $1.1 E+00$ & $3 E+02$ & 54 & 4.0 & $3.4 E+05$ & $1.2 \mathrm{E}+\infty 0$ & $6 E+02$ & Zr-93 \\
\hline Nb-93m & 3.81E-01 & 27 & 4.0 & $5.4 E+04$ & e & NL & 54 & 4.0 & $9.2 \mathrm{E}+04$ & e & NL & Nb-93m \\
\hline $\mathrm{Nb}-94$ & $5.21 E+\infty 0$ & 27 & 4.0 & $5.4 E+04$ & $6.4 E+\infty$ & $5 E+02$ & 54 & 4.0 & $9.2 E+04$ & $2.4 E+01$ & $4 E+03$ & $\mathrm{Nb}-94$ \\
\hline Tc-99 & $1.07 \mathrm{E}+\infty 0$ & 3.1 & 4.0 & $1.4 E+02$ & $1.0 \mathrm{E}+\infty 0$ & $4 E+01$ & 6.2 & 4.0 & $4.0 \mathrm{E}+02$ & $1.0 E+\infty$ & $9 E+01$ & Tc-99 \\
\hline Pd-107 & $1.09 \mathrm{E}-01$ & 270 & 4.0 & $1.9 \mathrm{E}+04$ & $1.0 \mathrm{E}+00$ & $4 E+04$ & 540 & 4.0 & $3.2 E+04$ & $1.0 E+\infty$ & $7 E+04$ & Pd-107 \\
\hline $\mathrm{Ag}-108 \mathrm{~m}$ & $5.56 E+00$ & 270 & 4.0 & $3.0 \mathrm{E}+04$ & e & NL & 540 & 4.0 & $5.2 E+04$ & $e$ & $\mathrm{NL}$ & Ag-108m \\
\hline $\mathrm{Cd}-113 \mathrm{~m}$ & $1.17 E+02$ & 270 & 4.0 & $2.7 E+04$ & e & NL & 540 & 4.0 & $4.6 E+04$ & e & NL & $\mathrm{Cd}-113 \mathrm{~m}$ \\
\hline Sn-121m & $1.28 E+\infty 0$ & 27 & 4.0 & $4.4 E+04$ & e & NL & 54 & 4.0 & $7.5 E+04$ & e & NL & Sn-12im \\
\hline Sn-126 & $1.53 \mathrm{E}+01$ & 27 & 4.0 & $4.4 E+04$ & $1.4 E+00$ & $4 E+01$ & 54 & 4.0 & $7.5 E+04$ & $1.7 E+\infty$ & $9 \mathrm{E}+01$ & Sn-126 \\
\hline $1-129$ & $2.01 E+02$ & 3.1 & 4.0 & $4.2 E+02$ & $1.0 \mathrm{E}+00$ & $2 E-01$ & 6.2 & 4.0 & $9.2 E+02$ & $1.0 \mathrm{E}+00$ & $5 E-01$ & $1-129$ \\
\hline Cs-135 & $5.16 E+\infty$ & 27 & 4.0 & $9.4 E+04$ & $1.0 E+00$ & $8 E+01$ & 54 & 4.0 & $1.6 \mathrm{E}+05$ & $1.0 \mathrm{E}+\infty$ & $2 \mathrm{E}+02$ & Cs-135 \\
\hline Cs-137 & $3.65 E+01$ & 27 & 4.0 & $9.4 \mathrm{E}+0.4$ & e & NL & 54 & 4.0 & $1.6 \mathrm{E}+05$ & e & $\mathrm{NL}$ & Cs-137 \\
\hline $8 a-133$ & $2.48 E+\infty 0$ & 27 & 4.0 & $5.1 E+03$ & e & NL & 54 & 4.0 & $8.9 \mathrm{E}+03$ & $e$ & $\mathrm{NL}$ & $\mathrm{Ba}-133$ \\
\hline Sm-151 & 2.84E-01 & 27 & 4.0 & $8.2 E+04$ & e & $\mathrm{NL}$ & 54 & 4.0 & $1.4 \mathrm{E}+05$ & $\bar{e}$ & $\mathrm{NL}$ & $\mathrm{sm-151}$ \\
\hline Eu-152 & $4.73 \mathrm{E}+\infty 0$ & 27 & 4.0 & $8.2 E+0.4$ & $\bar{e}$ & $\mathrm{NL}$ & 54 & 4.0 & $1.4 E+05$ & e & NL & Eu-152 \\
\hline Eu-154 & $6.97 \mathrm{E}+\infty 0$ & 27 & 4.0 & $8.2 E+04$ & e & $\mathrm{NL}$ & 54 & 4.0 & $1.4 E+05$ & e & $\mathrm{NL}$ & Eu-154 \\
\hline $\mathrm{Pb}-210$ & $5.30 \mathrm{E}+03$ & 270 & 4.0 & $9.1 E+04$ & e & $\mathrm{NL}$ & 540 & 4.0 & $1.5 \mathrm{E}+05$ & e & NL & $\mathrm{Pb}-210$ \\
\hline Ra-226 & $6.27 E+03$ & 27 & 4.0 & $1.7 \mathrm{E}+05$ & $3.6 \mathrm{E}+31$ & $\mathrm{NL}$ & 54 & 4.0 & $2.9 E+05$ & e & NL & $\operatorname{Ra} a-226$ \\
\hline Ra-228 & $1.64 E+03$ & 27 & 4.0 & $1.7 \mathrm{E}+05$ & e & NL & 54 & 4.0 & $2.9 E+05$ & e & $\mathrm{NL}$ & Ra-228 \\
\hline Th-229 & $2.94 E+03$ & 270 & 4.0 & $1.1 \mathrm{E}+06$ & $1.8 \mathrm{E}+44$ & $\mathrm{NL}$ & 540 & 4.0 & $1.8 E+06$ & $e$ & $\mathrm{NL}$ & Th-229 \\
\hline Th-230 & $6.12 E+03$ & 270 & 4.0 & $1.1 \mathrm{E}+06$ & NA & $6 E-01$ & 540 & 4.0 & $1.8 E+06$ & NA & $1 E+\infty$ & Th-230 \\
\hline Th-232 & $3.63 \mathrm{E}+03$ & 270 & 4.0 & $1.1 E+06$ & $1.0 E+\infty 0$ & $1 E+\infty 0$ & 540 & 4.0 & $1.8 E+06$ & $1.0 E+\infty$ & $2 E+\infty 0$ & Th-232 \\
\hline Pa-231 & $1.85 E+04$ & 270 & 4.0 & $1.8 E+05$ & $4.9 E+01$ & $1 E+01$ & 540 & 4.0 & $3.1 E+05$ & $7.7 E+02$ & $3 E+02$ & Pa-231 \\
\hline
\end{tabular}


$\stackrel{\sim}{\tilde{N}}$ Table 3-4. Results of Calculations for the Water Pathway at RFETS (water travel time from land surface to performance boundary [excluding facility detention] $=48 \mathrm{y})$ (Part 2 of 2$)$

\begin{tabular}{|c|c|c|c|c|c|c|c|c|c|c|c|c|}
\hline \multirow[t]{2}{*}{ Nuclide } & \multirow[b]{2}{*}{$\begin{array}{c}\text { PDCF } \\
\text { rem/y per } \mu \mathrm{Cl}\end{array}$} & \multicolumn{5}{|c|}{ Trench } & \multicolumn{5}{|c|}{ Tumulus } & \multirow[t]{2}{*}{ Nuclide } \\
\hline & & $\begin{array}{l}\text { CRF Source } \\
\text { (dimensionloss) }\end{array}$ & \begin{tabular}{|c|} 
CRF wator \\
(dimensioniess)
\end{tabular} & $\begin{array}{l}\text { Arrival } \\
\text { Time }(y)\end{array}$ & $\underset{\text { (dimensionioss) }}{r_{\text {Decay }} a}$ & $\begin{array}{c}C_{\text {w.Water }}{ }^{b} \\
\left(\mu \mathrm{Cl} / \mathrm{m}^{3}\right)\end{array}$ & $\begin{array}{l}\text { CRF source } \\
\text { (dimensionless) }\end{array}$ & \begin{tabular}{|c|} 
CRF water \\
(dimensiontess)
\end{tabular} & $\begin{array}{c}\text { Arrival } \\
\text { Time }(y)\end{array}$ & $\begin{array}{c}r_{\text {Decay }} \\
\text { (dimensionioss) }\end{array}$ & $\begin{array}{c}C_{\text {w-Water }}^{b} \\
\left(\mu \mathrm{Cl} / \mathrm{m}^{3}\right)\end{array}$ & \\
\hline$U-232$ & $1.55 E+03$ & 270 & 4.0 & $1.2 E+04$ & e & NL & 540 & 4.0 & $2.0 E+04$ & e & NL. & U-232 \\
\hline U-233 & $1.95 E+03$ & 270 & 4.0 & $1.2 E+04$ & NA & $2 E+\infty$ & 540 & 4.0 & $2.0 E+04$ & NA & $4 E+00$ & U-233 \\
\hline U-234 & $6.48 E+02$ & 270 & 4.0 & $1.2 \mathrm{E}+04$ & NA & $6 E+00$ & 540 & 4.0 & $2.0 E+04$ & NA & $1 E+01$ & U-234 \\
\hline U-235 & $3.73 E+03$ & 270 & 4.0 & $1.2 E+04$ & $\overline{N A}$ & $1 E+\infty$ & 540 & 4.0 & $2.0 \mathrm{E}+04$ & NA & $2 E+\infty$ & U-235 \\
\hline U-236 & $1.96 \mathrm{E}+02$ & 270 & 4.0 & $1.2 \mathrm{E}+04$ & $1.0 E+\infty 0$ & $2 E+01$ & 540 & 4.0 & $2.0 E+04$ & $1.0 E+00$ & $4 E+01$ & U-236 \\
\hline$U-238$ & $2.07 E+02$ & 270 & 4.0 & $1.2 E+04$ & $\mathrm{NA}$ & $2 E+01$ & 540 & 4.0 & $2.0 E+04$ & NA & $4 E+01$ & U-238 \\
\hline Np-237 & $3.24 \mathrm{E}+03$ & 270 & 4.0 & $1.8 \mathrm{E}+03$ & $1.0 E+\infty 0$ & $1 E+\infty$ & 540 & 4.0 & $3.2 \mathrm{E}+03$ & $1.0 \mathrm{E}+00$ & $2 E+\infty$ & Np-237 \\
\hline $\mathrm{Pu}-238$ & $2.34 \mathrm{E}+03$ & 270 & 4.0 & $1.8 E+05$ & e & $2 E+04$ & 540 & 4.0 & $3.1 E+05$ & $e$ & $3 E+04$ & $\mathrm{Pu}-238$ \\
\hline Pu-239 & $2.58 E+03$ & 270 & 4.0 & $1.8 E+05$ & $2.0 E+02$ & $3 E+02$ & 540 & 4.0 & $3.1 E+05$ & $8.5 E+03$ & $3 E+04$ & Pu-239 \\
\hline Pu-240 & $2.58 E+03$ & 270 & 4.0 & $1.8 E+05$ & $2.9 E+08$ & $4 E+08$ & 540 & 4.0 & $3.1 E+05$ & $2.7 E+14$ & $\mathrm{NL}$ & $\mathrm{Pu}-240$ \\
\hline Pu-241 & $4.82 E+08$ & 270 & 4.0 & $1.8 E+05$ & e & $2 E+05$ & 540 & 4.0 & $3.1 E+05$ & e & $4 E+05$ & Pu-241 \\
\hline $\mathrm{Pu}-242$ & $2.45 E+03$ & 270 & 4.0 & $1.8 \mathrm{E}+05$ & $1.4 E+00$ & $2 E+\infty 0$ & 540 & 4.0 & $3.1 E+05$ & $1.8 E+\infty 0$ & $6 E+00$ & Pu-242 \\
\hline Pu-244 & $4.11 E+03$ & 270 & 4.0 & $1.8 \mathrm{E}+05$ & NA & $1 E+00$ & 540 & 4.0 & $3.1 E+05$ & NA & $2 E+00$ & Pu-244 \\
\hline Am-241 & $2.66 \mathrm{E}+03$ & 270 & 4.0 & $6.4 \mathrm{E}+05$ & e & $6 E+03$ & 540 & 4.0 & $1.1 E+06$ & $e$ & $1 \mathrm{E}+04$ & Am-241 \\
\hline Am-243 & $2.64 E+03$ & 270 & 4.0 & $6.4 E+05$ & $1.1 E+26$ & $\mathrm{NL}$ & 540 & 4.0 & $1.1 E+06$ & $2.2 E+44$ & $\mathrm{NL}$ & Am-243 \\
\hline $\mathrm{Cm}-243$ & $1.83 E+03$ & 270 & 4.0 & $1.3 E+06$ & e & $3 E+05$ & 540 & 4.0 & $2.3 E+06$ & e & $2 E+07$ & $\mathrm{Cm}-243$ \\
\hline $\mathrm{Cm}-244$ & 1.47E+03 & 270 & 4.0 & $1.3 E+06$ & $e$ & $2 E+11$ & 540 & 4.0 & $2.3 E+06$ & $e$ & $\mathrm{NL}$ & $\mathrm{Cm}-244$ \\
\hline $\mathrm{Cm}-245$ & $4.56 \mathrm{E}+03$ & 270 & 4.0 & $1.3 E+06$ & NA & 9E-01 & 540 & 4.0 & $2.3 \mathrm{E}+06$ & NA & $2 E+\infty$ & $\mathrm{Cm}-245$ \\
\hline $\mathrm{Cm}-246$ & $2.70 E+03$ & 270 & 4.0 & $1.3 E+06$ & e & $\mathrm{NL}$ & 540 & 4.0 & $2.3 E+06$ & $e$ & NL & $\mathrm{Cm}-246$ \\
\hline $\mathrm{Cm}-247$ & $4.34 E+03$ & 270 & 4.0 & $1.3 E+06$ & NA & $9 \mathrm{E}-01$ & 540 & 4.0 & $2.3 E+06$ & NA & $2 E+\infty$ & $C m-247$ \\
\hline $\mathrm{Cm}-248$ & $9.94 E+03$ & 270 & 4.0 & 1.3E+06 & $1.4 \mathrm{E}+01$ & $6 E+00$ & 540 & 4.0 & $2.3 E+06$ & $9.5 \mathrm{E}+01$ & $8 E+01$ & $\mathrm{Cm}-248$ \\
\hline Cf-249 & $3.46 \mathrm{E}+03$ & 270 & 4.0 & $1.3 E+06$ & $e$ & $2 E+01$ & 540 & 4.0 & $2.3 E+06$ & $e$ & $4 E+01$ & Cf-249 \\
\hline Cf-250 & $2.64 \mathrm{E}+08$ & 270 & 4.0 & $1.3 E+06$ & $e$ & $\mathrm{NL}$ & 540 & 4.0 & $2.3 E+06$ & e & $\mathrm{NL}$ & Cf-250 \\
\hline $\mathrm{Cf}-251$ & $3.54 E+03$ & 270 & 4.0 & $1.3 \mathrm{E}+06$ & $e$ & NL & 540 & 4.0 & $2.3 E+06$ & $\mathrm{e}$ & NL & Cf-251 \\
\hline
\end{tabular}

a "NA" means Not Applicable - decay factor is implicit in the PDCF for this radionuclide.

b "NL" means No Limit - estimated permissible concentration is greater than the specific activity of the pure elemental radionucllde.

c Radionuclide concentration is based on arrival time at the performance boundary beyond $10,000 \mathrm{y}$.

d PDCF is a function of arrival time. See Chapter 1 of this volume for equation.

e roway $\geq 1 E+50$

f Contribution of decay product(s) is significant to determination of this value (see Table E-3 in Volume 2). Listed arrival time is that of the parent radionuclide. If this footnote does not appear in combination with footnote $c$, the arrival time of the significant decay product(s) is less than $10,000 \mathrm{y}$. 
Arrival times for some radionuclides listed in Table 3-4 were beyond the 10,000-y performance period. For those radionuclides, the estimated waste concentrations are presented in Table 3-4 for information purposes only. Consistent with the approach used in LLW performance assessments, these values were not considered in determining the most restrictive disposal limit from among the evaluated pathways.

For the trench design at RFETS, the total undecayed CRFs (the product of the $C R F_{\text {Source }}$ and the $C R F_{\text {Water }}$ ) for the water pathway ranged from about 2 to 1080 . For the tumulus design, the total undecayed CRF values ranged from about 4 to 2160 , reflecting the reduced amount of waste able to occupy the tumulus facility. Travel times to the performance boundary via the water pathway for the trench design varied from $100 \mathrm{y}$ for $\mathrm{H}-3$ to more than one million years for a number of the heavy radionuclides. Travel times for nuclides escaping the tumulus ranged from $400 \mathrm{y}$ for H-3 to more than two million years for many of the heavy nuclides. The relatively short arrival time for some of the radionuclides released from the trench result in small permissible concentrations in the waste $\left(C_{\text {W-Water }}\right)$; however, 22 of the 58 radionuclides considered still have maximum permissible concentrations that exceed those of the pure component (reported as "NL"). The tumulus design has "NL" values for 24 of the 58 nuclides considered. Differences in the arrival times between the trench and tumulus designs were attributable to (1) the assumed later failure of the tumulus facility ( $300 \mathrm{y}$ after closure rather than $100 \mathrm{y}$ for the trench); (2) the increased rate of flow at the time of failure of the liner and leachate collections system at $30 \mathrm{y}$ for the trench facility $\left(1 \times 10^{-7} \mathrm{~cm} / \mathrm{s}\right.$ or $3 \mathrm{~cm} / \mathrm{y}\left[4 \times 10^{-8} \mathrm{in} . / \mathrm{s}\right.$ or $\left.\left.1.2 \mathrm{in} . / \mathrm{y}\right]\right)$ compared to that through the tumulus $\left(1 \times 10^{-10} \mathrm{~cm} / \mathrm{s}\right.$ or $0.03 \mathrm{~cm} / \mathrm{y}\left[4 \times 10^{-11} \mathrm{in} . / \mathrm{s}\right.$ or $\left.\left.0.01 \mathrm{in} . / \mathrm{y}\right]\right)$; and (3) the increased travel distance through the vadose zone for the tumulus (the bottom of the trench is $8.8 \mathrm{~m}$ $(28.9 \mathrm{ft})$ below grade and therefore only $4 \mathrm{~m}(13 \mathrm{ft})$ above the water table).

\subsubsection{Atmospheric Transport}

Two CRFs were used to account for the attenuation encompassing diffusion to the ground surface, mixing in air, and dispersion in the atmosphere to the performance boundary. The CRF for diffusion in soil, $C R F_{D i f}$, was defined as the ratio of the radionuclide concentration in the waste to its resulting concentration in the upper one centimeter of soil. The CRF for dispersion in air, $C R F_{D i s p}$, was defined as the ratio of the radionuclide concentration in the upper one centimeter of soil to its resulting concentration in air at the performance boundary. The effect of radioactive decay was also included in the PE.

Application of the PE methodology for atmospheric transport of the two volatile radionuclides considered in the $\mathrm{PE}(\mathrm{H}-3$ and $\mathrm{C}-14)$ produced the results shown in Table 3-5 for both the generic trench and tumulus designs; there was no assumed difference in these two disposal technologies with respect to permissible waste limits based on the atmospheric pathway at RFETS. The table shows permissible waste concentrations based on transport in the atmospheric pathway $\left(C_{W-A t m}\right)$ as well as the values used in calculating the permissible waste concentrations. For both $\mathrm{H}-3$ and $\mathrm{C}-14$, the greatest concentration reduction occurred as the radionuclides diffuse from the top of the disposal facility to the soil surface. 
Table 3-5. Results of Calculations for the Atmospheric Pathway

\begin{tabular}{|c|c|c|c|c|c|c|c|}
\hline \multirow[t]{2}{*}{ Nuclide } & \multirow[b]{2}{*}{$\begin{array}{c}S D C F_{A t m} \\
(\mathrm{rem} / \mathrm{y}) /(\mu \mathrm{Cin})\end{array}$} & \multicolumn{6}{|c|}{ Generic Trench and Tumulus } \\
\hline & & $\begin{array}{c}C R F_{\text {Diff }} \\
\text { (dilmenslonless) }\end{array}$ & $\begin{array}{c}C R F_{\text {Disp }} \\
\text { (dlmensionloss) }\end{array}$ & $\begin{array}{c}C R F_{\text {Atm }} \\
\text { (dimenslontess) }\end{array}$ & $\begin{array}{l}\text { Arrival } \\
\text { Time (y) }\end{array}$ & $\begin{array}{c}\text { roecay } \\
\text { (dilmensionless) }\end{array}$ & $\begin{array}{l}C_{W-A t m} \\
\left(\mu \mathrm{Ci} / \mathrm{m}^{3}\right)\end{array}$ \\
\hline $\mathrm{H}-3$ & $8.33 E+02$ & $2 E+06$ & $1 E+03$ & $2 E+09$ & 100 & 300 & $7 E+09$ \\
\hline C-14 & $2.20 E+05$ & $4 E+04$ & $2 E+03$ & $8 E+07$ & 100 & 1 & $4 E+03$ \\
\hline
\end{tabular}

The time of arrival at the performance boundary for both radionuclides is shown in Table 3-5 as $100 \mathrm{y}$. However, the actual migration of H-3 and C-14 from the disposal facility to the surface and downwind to the performance boundary was calculated to be on the order of hours, not years. As discussed in Section 3.3.2.2, the waste form and RCRA cover are assumed to retain these volatile radionuclides in the disposal facility for at least $100 \mathrm{y}$.

\subsubsection{Inadvertent Intruder Exposure}

The calculation of permissible waste concentrations for inadvertent intruder exposures did not utilize CRFs. Instead, the total dose resulting from an intrusion scenario (the sum of the doses from all exposure pathways involved in that intrusion) was modified by scenario dose conversion factors (SDCFs) that were applied to specific exposure pathways. The important exposure pathways for each radionuclide are listed in Appendix D of Volume 2. These values were radionuclide-specific and facility-design-specific and were the same for all sites. Values for the radioactive decay term were based on time of intrusion into the disposal facility (for the homesteader scenario, $300 \mathrm{y}$ for the trench design and $500 \mathrm{y}$ for the tumulus design; for the postdrilling scenario, $100 \mathrm{y}$ for both disposal designs). However, results based on intruder scenarios should be evaluated carefully because future social behavior, and intrusion scenarios, are difficult to predict.

The permissible waste concentrations for the two generic facility designs for each of the 58 radionuclides based on the standard PE intrusion scenarios are listed in Table 3-6. The most restrictive waste concentration limits for each generic facility are indicated with bold type.

For six radionuclides in the table (U-233, U-234, U-235, U-238, Pu-244, and Cm-247), the time of homesteader intrusion was changed to $10,000 \mathrm{y}$, the end of the performance period. For these six radionuclides, ingrowth of decay products yields scenario doses that increase over time. The doses at 10,000 y, therefore, represent the maximum that could be encountered during the performance period. Also, for Th-230 and $\mathrm{Cm}-245$, ingrowth of decay products likewise produces a scenario dose that increases over time and peaks within the 10,000 -y performance period. The times of homesteader intrusion for these two radionuclides (Th-230 and $\mathrm{Cm}-245$ ) were taken as the time of maximum dose, 9000 and $1000 \mathrm{y}$, respectively.

For the trench design, the post-drilling scenario generally yielded more restrictive waste limits than the homesteader scenario for those radionuclides with half-lives shorter than about 30 y. For the tumulus design, the post-drilling scenario generally yielded more restrictive limits than the homesteader scenario for those radionuclides with half-lives shorter than about $130 \mathrm{y}$. 
Table 3-6. Permissible Waste Concentrations for the Standard Intrusion Scenarios (most limiting radionuclide concentration for each facility design is highlighted in bold italic) (Part 1 of 2)

\begin{tabular}{|c|c|c|c|c|c|}
\hline \multirow[t]{2}{*}{ Nuclide } & \multicolumn{2}{|c|}{ Trench } & \multicolumn{2}{|c|}{ Tumulus } & \multirow[t]{2}{*}{ Nuclide } \\
\hline & $\begin{array}{c}C_{w+h \sigma^{2}} \\
\text { Homesteader } \\
\left(\mu \mathrm{C} / \mathrm{m}^{3}\right) \\
\end{array}$ & $\begin{array}{c}C_{\text {w/ntr }} \\
\text { Post-Drilling } \\
\left(\mu \mathrm{C} / \mathrm{m}^{3}\right) \\
\end{array}$ & $\begin{array}{c}\boldsymbol{C}_{\text {w-lntr }} \\
\text { Homesteader } \\
\left(\mu \mathrm{Ci} / \mathrm{m}^{3}\right) \\
\end{array}$ & $\begin{array}{c}C_{W-1 n t} \\
\text { Post-Drilling } \\
\left(\mu \mathrm{Ci} / \mathrm{m}^{3}\right) \\
\end{array}$ & \\
\hline $\mathrm{H}-3$ & $1 E+12$ & $7 E+07$ & NL & $7 E+07$ & $\mathrm{H}-3$ \\
\hline$c-14$ & $1 E+04$ & $7 E+04$ & $1 E+04$ & $7 E+04$ & C-14 \\
\hline Al-26 & $5 E+01$ & $5 E+04$ & $5 E+01$ & $5 E+04$ & Al-26 \\
\hline Si-32 & $9 E+03$ & $1 E+04$ & $4 E+04$ & $1 E+04$ & Si-32 \\
\hline $\mathrm{Cl}-36$ & $2 E+02$ & $9 E+02$ & $2 E+02$ & $9 E+02$ & $\mathrm{Cl}-36$ \\
\hline$K-40$ & $7 E+02$ & $2 E+04$ & $7 E+02$ & $2 E+04$ & $K-40$ \\
\hline Co-60 & $\mathrm{NL}$ & $3 E+10$ & NL & $3 E+10$ & $\mathrm{Co}-60$ \\
\hline Ni-59 & $3 E+06$ & $1 E+07$ & $3 E+06$ & $1 E+07$ & $\mathrm{Ni}-59$ \\
\hline Ni-63 & $8 E+06$ & $1 E+07$ & $3 E+07$ & $1 E+07$ & $\mathrm{Ni}-63$ \\
\hline Se-79 & $2 E+05$ & $8 E+05$ & $2 E+05$ & $8 E+05$ & Se-79 \\
\hline Sr-90 & $1 E+06$ & $5 E+04$ & $1 E+08$ & $5 E+04$ & Sr-90 \\
\hline$Z r-93$ & $5 E+06$ & $3 E+07$ & $5 E+06$ & $3 E+07$ & $\mathrm{Zr}-93$ \\
\hline $\mathrm{Nb}-93 \mathrm{~m}$ & $5 E+12$ & $4 E+09$ & NL & $4 E+09$ & $\mathrm{Nb}-93 \mathrm{~m}$ \\
\hline $\mathrm{Nb}-94$ & $9 E+01$ & $9 E+04$ & $1 E+02$ & $9 E+04$ & $\mathrm{Nb}-94$ \\
\hline Tc-99 & $2 E+04$ & $8 E+04$ & $2 E+04$ & $8 E+04$ & Tc-99 \\
\hline $\mathrm{Pd}-107$ & $6 E+06$ & $3 E+07$ & $6 E+06$ & $3 E+07$ & Pd-107 \\
\hline $\mathrm{Ag}-108 \mathrm{~m}$ & $5 E+02$ & $1 E+05$ & $1 E+03$ & $1 E+05$ & $\mathrm{Ag}-108 \mathrm{~m}$ \\
\hline $\mathrm{Cd}-113 \mathrm{~m}$ & $4 E+09$ & $1 E+06$ & $7 E+13$ & $1 E+06$ & Cd-113m \\
\hline $\mathrm{Sn-121m}$ & $2 E+07$ & $5 E+07$ & $2 E+08$ & $5 E+07$ & Sn-121m \\
\hline$S n-126$ & $8 E+01$ & $7 E+04$ & $8 E+01$ & $7 E+04$ & Sn-126 \\
\hline l-129 & $2 E+03$ & $1 E+04$ & $2 E+03$ & $1 E+04$ & 1-129 \\
\hline Cs-135 & $2 E+05$ & $8 E+05$ & $2 E+05$ & $8 E+05$ & Cs-135 \\
\hline Cs-137 & $3 E+05$ & $8 E+05$ & $3 E+07$ & $8 E+05$ & Cs-137 \\
\hline Ba-133 & $2 E+11$ & $3 E+08$ & $\mathrm{NL}$ & $3 E+08$ & $\mathrm{Ba}-133$ \\
\hline$S m-151$ & $2 E+08$ & $2 E+08$ & $8 E+08$ & $2 E+08$ & Sm-151 \\
\hline Eu-152 & $6 E+08$ & $2 E+07$ & $2 E+13$ & $2 E+07$ & Eu-152 \\
\hline Eu-154 & $4 E+12$ & $4 E+08$ & NL & $4 E+08$ & Eu-154 \\
\hline $\mathrm{Pb}-210$ & $7 E+06$ & $7 E+04$ & $4 E+09$ & $7 E+04$ & $\mathrm{~Pb}-210$ \\
\hline Ra-226 & $8 E+01$ & $3 E+03$ & $9 E+01$ & $3 E+03$ & Ra-226 \\
\hline Ra-228 & $\mathrm{NL}$ & $4 E+09$ & NL & $4 E+09$ & Ra-228 \\
\hline Th-229 & $6 E+02$ & $3 E+04$ & $5 E+02$ & $3 E+04$ & Th-229 \\
\hline Th-230 & $8 E+01$ & $7 E+04$ & $8 E+01$ & $7 E+04$ & Th-230 \\
\hline Th-232 & $6 E+01$ & $2 E+04$ & $6 E+01$ & $2 E+04$ & Th-232 \\
\hline $\mathrm{Pa}-231$ & $2 E+02$ & $5 E+03$ & $2 E+02$ & $5 E+03$ & $\mathrm{~Pa}-231$ \\
\hline
\end{tabular}


Table 3-6. Permissible Waste Concentrations for the Standard Intrusion Scenarios (most limiting radionuclide concentration for each facility design is highlighted in bold italic)

(Part 2 of 2)

\begin{tabular}{|c|c|c|c|c|c|}
\hline \multirow[t]{2}{*}{ Nuclide } & \multicolumn{2}{|c|}{ Trench } & \multicolumn{2}{|c|}{ Tumulus } & \multirow[t]{2}{*}{ Nuclide } \\
\hline & $\begin{array}{c}C_{W-\operatorname{mat}}{ }^{a} \\
\text { Homesteader } \\
\left(\mu \mathrm{Ci} / \mathrm{m}^{3}\right)\end{array}$ & $\begin{array}{c}C_{w-1 n t r} \\
\text { Post-Drilling } \\
\left.\left(\mu \mathrm{Ci}^{3}\right)^{3}\right) \\
\end{array}$ & $\begin{array}{c}\text { C }_{\text {W-Imtr }} \\
\text { Homesteader } \\
\left(\mu \mathrm{Ci} \mathrm{m}^{3}\right)\end{array}$ & $\begin{array}{c}C_{W \text { dntr }} \\
\text { Post-Drilling } \\
\left(\mu \mathrm{Ci} / \mathrm{m}^{3}\right)\end{array}$ & \\
\hline U-232 & $2 E+03$ & $5 E+04$ & $1 E+04$ & $5 E+04$ & $\mathrm{u}-232$ \\
\hline U-233 & $7 E+02$ & $1 E+05$ & $7 E+02$ & $1 E+05$ & U-233 \\
\hline U-234 & $1 E+03$ & $1 E+05$ & $1 E+03$ & $1 E+05$ & U-234 \\
\hline U-235 & $6 E+02$ & $1 E+05$ & $6 E+02$ & $1 E+05$ & U-235 \\
\hline U-236 & $2 E+04$ & $1 E+05$ & $2 E+04$ & $1 E+05$ & U-236 \\
\hline U-238 & $5 E+03$ & $1 E+05$ & $5 E+03$ & $1 E+05$ & U-238 \\
\hline Np-237 & $4 E+02$ & $4 E+03$ & $4 E+02$ & $4 E+03$ & Np-237 \\
\hline $\mathrm{Pu}-238$ & $7 E+04$ & $1 E+05$ & $4 E+05$ & $1 E+05$ & Pu-238 \\
\hline $\mathrm{Pu}-239$ & $6 E+03$ & $5 E+04$ & $6 E+03$ & $5 E+04$ & Pu-239 \\
\hline Pu-240 & $6 E+03$ & $5 E+04$ & $7 E+03$ & $5 E+04$ & Pu-240 \\
\hline Pu-241 & $2 E+05$ & $1 E+06$ & $3 E+05$ & $1 \mathrm{E}+06$ & Pu-241 \\
\hline $\mathrm{Pu}-242$ & $6 E+03$ & $5 E+04$ & $6 E+03$ & $5 \mathrm{E}+04$ & Pu-242 \\
\hline $\mathrm{Pu}-244$ & $4 E+02$ & $5 E+04$ & $4 E+02$ & $5 E+04$ & Pu-244 \\
\hline Am-241 & $7 E+03$ & $5 E+04$ & $9 E+03$ & $5 E+04$ & Am-241 \\
\hline Am-243 & $9 E+02$ & $4 E+04$ & $9 E+02$ & $4 E+04$ & Am-243 \\
\hline $\mathrm{Cm}-243$ & $1 E+06$ & $8 E+05$ & $5 E+06$ & $8 E+05$ & $\mathrm{Cm}-243$ \\
\hline $\mathrm{Cm}-244$ & $2 E+06$ & $3 E+06$ & $2 E+06$ & $3 E+06$ & $\mathrm{Cm}-244$ \\
\hline $\mathrm{Cm}-245$ & $1 E+03$ & $4 E+04$ & $1 E+03$ & $4 E+04$ & $\mathrm{Cm}-245$ \\
\hline $\mathrm{Cm}-246$ & $6 E+03$ & $5 E+04$ & $6 E+03$ & $5 E+04$ & $\mathrm{Cm}-246$ \\
\hline $\mathrm{Cm}-247$ & $3 E+02$ & $5 E+04$ & $3 E+02$ & $5 E+04$ & $\mathrm{Cm}-247$ \\
\hline $\mathrm{Cm}-248$ & $2 E+03$ & $1 E+04$ & $2 E+03$ & $1 E+04$ & $\mathrm{Cm}-248$ \\
\hline Cf-249 & $8 E+02$ & $4 E+04$ & $1 E+03$ & $4 \mathrm{E}+04$ & Cf-249 \\
\hline Cf-250 & $2 E+06$ & $9 E+06$ & $2 E+06$ & $9 E+06$ & $C f-250$ \\
\hline Cf-251 & $2 E+03$ & $4 E+04$ & $2 E+03$ & $4 E+04$ & $C f-251$ \\
\hline
\end{tabular}

a "NL" means No Limit - estimated permissible concentration is greater than the specific activity of the pure elemental radionuclide. 


\subsection{SUMMARY AND DISCUSSION OF RESULTS}

The limiting radionuclide concentrations in disposed waste for the water, atmospheric, and intruder analysis for the generic trench and tumulus designs are summarized in Table 3-7 and discussed in Section 3.6.1. An overall discussion of the results of the PE for RFETS is contained in Section 3.6.2.

\subsubsection{Results Based on Disposal Design}

For the generic trench design at RFETS, 8 radionuclides were limited by the water pathway, no radionuclides were limited by the atmospheric pathway, 49 radionuclides were limited by intrusion scenarios, and 1 radionuclide was limited by both the water pathway and the intrusion scenarios, as shown in Table 3-7. For the generic tumulus design, 6 radionuclides were limited by the water pathway, no radionuclides were limited by the atmospheric pathway, and 52 radionuclides were limited by intrusion scenarios.

For both the trench and tumulus designs, concentrations for 2 radionuclides that arrived at the performance boundary before 10,000 y reported in Table 3-7 for the water pathway analysis had no limit. As discussed in Section 3.5.1, the calculated concentrations for those radionuclides reported as NL (No Limit) were above the specific activity of the pure elemental radionuclide, implying that the performance measure of $4 \mathrm{mrem}$ per year $(0.04 \mathrm{mSv}$ per year) would not be reached under the given release and transport assumptions.

As also discussed in Section 3.5.1, values for some radionuclides are not reported in Table 3-7 for the water pathway analysis. Arrival times for these radionuclides were beyond the 10,000-y performance period. For these radionuclides, the estimated waste concentrations are presented in Table 3-4 for information purposes but are not listed in Table 3-7. Consistent with the approach used in LLW performance assessments, these values were not considered in determining the most restrictive disposal limit from among the evaluated pathways because arrival times for these radionuclides were beyond $10,000 \mathrm{y}$.

\subsubsection{Discussion}

The results of the PE are based on the framework of assumptions summarized in Chapter 1 of this volume and discussed in detail in Volume 2 of this report and on the site-specific conceptual model for contaminant transport discussed in this chapter. Using alternative assumptions about the conceptual model has the potential to affect the results. Changes in the conceptual model could include alternative assumptions about the disposal facility, the source term, and radionuclide movement in the three pathways. Depending on the degree of possible variation and the relative importance of the parameters used in the calculation of estimated permissible radionuclide concentrations, variability in parameter values can also affect the results. For parameters, results could vary depending on potential changes in values of both the generic and the site-specific parameters used in the PE analysis. 
Table 3-7. Permissible Concentrations for the Generic Disposal Designs at Rocky Flats (permissible concentration related to the most limiting pathway for each facility design is highlighted in bold italic) (Part 1 of 2)

\begin{tabular}{|c|c|c|c|c|c|c|c|}
\hline \multirow[t]{2}{*}{ Nuclide } & \multicolumn{3}{|c|}{ Trench } & \multicolumn{3}{|c|}{ Tumulus } & \multirow[t]{2}{*}{ Nuclide } \\
\hline & $\begin{array}{c}C_{\text {w.water }}{ }^{a, b} \\
\left(\mu \mathrm{Ci} / \mathrm{m}^{3}\right)\end{array}$ & $\begin{array}{l}C_{W-A t m}^{c} \\
\left(\mu \mathrm{Ci} / m^{3}\right)\end{array}$ & $\begin{array}{l}C_{W-\ln { }^{2}}{ }^{d} \\
\left(\mu \mathrm{Ci} / \mathrm{m}^{3}\right)\end{array}$ & $\begin{array}{c}C_{\text {w-water }}{ }^{a, b} \\
\left(\mu \mathrm{Ci} / \mathrm{m}^{3}\right) \\
\end{array}$ & $\begin{array}{l}C_{W-A t m}{ }^{c} \\
\left(\mu \mathrm{Ci} / m^{3}\right)\end{array}$ & $\begin{array}{l}C_{w d i n t r}^{d} \\
\left(\mu \mathrm{Ci} / \mathrm{m}^{3}\right)\end{array}$ & \\
\hline $\mathrm{H}-3$ & $7 E+04$ & $7 E+09$ & $7 E+07$ & $2 E+12$ & $7 E+09$ & $7 E+07$ & $\mathrm{H}-3$ \\
\hline$c-14$ & $3 E+02$ & $4 E+03$ & $1 E+04$ & $8 E+02$ & $4 E+03$ & $1 E+04$ & $C-14$ \\
\hline Al-26 & - & & $5 E+01$ & - & & $5 E+01$ & Al-26 \\
\hline Si-32 & - & & $9 E+03$ & - & & $1 E+04$ & Si-32 \\
\hline Cl-36 & $3 E+00$ & & $2 E+02$ & $6 E+00$ & & $2 E+02$ & $\mathrm{Cl}-36$ \\
\hline$K-40$ & $3 E+00$ & & $7 E+02$ & $7 E+00$ & & $7 E+02$ & $K-40$ \\
\hline Co-60 & - & & $3 E+10$ & $-\quad 1$ & & $3 E+10$ & Co-60 \\
\hline Ni-59 & $=$ & & $3 E+06$ & - & & $3 E+06$ & $\mathrm{Ni}-59$ \\
\hline $\mathrm{Ni}-63$ & - & & $8 E+06$ & - & & $1 E+07$ & $\mathrm{Ni}-63$ \\
\hline Se-79 & - & & $2 E+05$ & - & & $2 E+05$ & Se-79 \\
\hline Sr-90 & $\mathrm{NL}$ & & $5 E+04$ & $\mathrm{NL}$ & & $5 E+04$ & Sr-90 \\
\hline $2 r-93$ & - & & $5 E+06$ & - & & $5 E+06$ & Zr-93 \\
\hline $\mathrm{Nb}-93 \mathrm{~m}$ & - & & $4 E+09$ & - & & $4 E+09$ & $\mathrm{Nb}-93 \mathrm{~m}$ \\
\hline $\mathrm{Nb}-94$ & - & & $9 E+01$ & 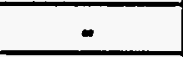 & & $1 E+02$ & $\mathrm{Nb}-94$ \\
\hline Tc-99 & $4 E+01$ & & $2 E+04$ & $9 E+01$ & & $2 E+04$ & Tc-99 \\
\hline$P d-107$ & - & & $6 E+06$ & - & & $6 E+06$ & Pd-107 \\
\hline $\mathrm{Ag}-108 \mathrm{~m}$ & - & & $5 E+02$ & - & & $1 E+03$ & $\mathrm{Ag}-108 \mathrm{~m}$ \\
\hline $\mathrm{Cd}-113 \mathrm{~m}$ & - & & $1 E+06$ & - & & $1 E+06$ & $\mathrm{Cd}-113 \mathrm{~m}$ \\
\hline Sn-121m & - & & $2 E+07$ & - & & $5 E+07$ & $S n-121 m$ \\
\hline Sn-126 & - & & $8 E+01$ & - & & $8 E+01$ & $5 n-126$ \\
\hline $1-129$ & $2 E-01$ & & $2 E+03$ & 5E-01 & & $2 E+03$ & I-129 \\
\hline Cs-135 & - & & $2 E+05$ & - & & $2 E+05$ & Cs-135 \\
\hline Cs-137 & - & & $3 E+05$ & - & & $8 E+05$ & Cs-137 \\
\hline Ba-133 & $\mathrm{NL}$ & & $3 E+08$ & $\mathrm{NL}$ & & $3 E+08$ & $\mathrm{Ba}-133$ \\
\hline$S m-151$ & $=$ & & $2 E+08$ & - & & $2 E+08$ & $S m-151$ \\
\hline Eu-152 & - & & $2 E+07$ & - & & $2 E+07$ & Eu-152 \\
\hline Eu-154 & - & & $4 E+08$ & - & & $4 E+08$ & Eu-154 \\
\hline $\mathrm{Pb}-210$ & - & & $7 E+04$ & - & & $7 E+04$ & $\mathrm{~Pb}-210$ \\
\hline Ra-226 & - & & $8 E+01$ & - & & $9 E+01$ & Ra-226 \\
\hline Ra-228 & - & & $4 E+09$ & - & & $4 E+09$ & Ra-228 \\
\hline Th-229 & - & & $5 E+02$ & - & & $5 E+02$ & Th-229 \\
\hline Th-230 & $=$ & & $8 E+01$ & - & & $8 E+01$ & Th-230 \\
\hline Th-232 & - & & $6 E+01$ & - & & $6 E+01$ & Th-232 \\
\hline Pa-231 & - & & $2 E+02$ & - & & $2 E+02$ & $\mathrm{~Pa}-231$ \\
\hline
\end{tabular}


Table 3-7. Permissible Concentrations for the Generic Disposal Designs at Rocky Flats (permissible concentration related to the most limiting pathway for each facility design is highlighted in bold italic) (Part 2 of 2)

\begin{tabular}{|c|c|c|c|c|c|c|c|}
\hline \multirow[t]{2}{*}{ Nuclide } & \multicolumn{3}{|c|}{ Trench } & \multicolumn{3}{|c|}{ Tumulus } & \multirow[t]{2}{*}{ Nuclide } \\
\hline & $\begin{array}{c}C_{\text {w.water }}{ }^{a, b} \\
\left(\mu \mathrm{Ci} / \mathrm{m}^{3}\right)\end{array}$ & $\begin{array}{c}C_{W-A t m}{ }^{c} \\
\left(\mu \mathrm{Ci} / \mathrm{m}^{3}\right)\end{array}$ & $\begin{array}{l}C_{W d / n r^{d}}{ }^{d} \\
\left(\mu \mathrm{Ci} / \mathrm{m}^{3}\right)\end{array}$ & $\begin{array}{c}C_{\text {w.water }}{ }^{a, b} \\
\left(\mu \mathrm{Ci} / \mathrm{m}^{3}\right)\end{array}$ & $\begin{array}{l}C_{\text {W-Atm }}{ }^{c} \\
\left(\mu \mathrm{Ci} / \mathrm{m}^{3}\right)\end{array}$ & $\begin{array}{l}C_{w / n t r}{ }^{d} \\
\left(\mu \mathrm{Ci} / \mathrm{m}^{3}\right) \\
\end{array}$ & \\
\hline$U-232$ & - & & $2 E+03$ & - & & $1 E+04$ & U-232 \\
\hline U-233 & - & & $7 E+02$ & - & & $7 E+02$ & $\mathrm{U}-233$ \\
\hline U-234 & - & & $1 E+03$ & - & & $1 E+03$ & U-234 \\
\hline U-235 & - & & $6 E+02$ & - & & $6 E+02$ & U-235 \\
\hline$\cup-236$ & - & & $2 E+04$ & - & & $2 E+04$ & U-236 \\
\hline U-238 & - & & $5 E+03$ & - & & $5 E+03$ & $\mathrm{U}-238$ \\
\hline Np-237 & $1 E+00$ & & $4 E+02$ & $2 E+00$ & & $4 \mathrm{E}+02$ & $\mathrm{~Np}-237$ \\
\hline Pu-238 & - & & $7 E+04$ & - & & $1 E+05$ & Pu-238 \\
\hline Pu-239 & - & & $6 E+03$ & - & & $6 E+03$ & Pu-239 \\
\hline Pu-240 & $=$ & & $6 E+03$ & - & & $7 E+03$ & Pu-240 \\
\hline Pu-241 & $2 E+05$ & & $2 E+05$ & $4 E+05$ & & $3 E+05$ & Pu-241 \\
\hline Pu-242 & - & & $6 E+03$ & $=$ & & $6 E+03$ & Pu-242 \\
\hline $\mathrm{Pu}-244$ & - & & $4 E+02$ & - & & $4 E+02$ & Pu-244 \\
\hline $\mathrm{Am}-241$ & $6 E+03$ & & $7 E+03$ & $1 E+04$ & & $9 E+03$ & Am-241 \\
\hline Am-243 & - & & $9 E+02$ & $=$ & & $9 E+02$ & Am-243 \\
\hline $\mathrm{Cm}-243$ & $=$ & & $8 E+05$ & - & & $8 E+05$ & $\mathrm{Cm}-243$ \\
\hline Cm-244 & - & & $2 E+06$ & - & & $2 E+06$ & $\mathrm{Cm}-244$ \\
\hline $\mathrm{Cm}-245$ & - & & $1 E+03$ & - & & $1 E+03$ & $\mathrm{Cm}-245$ \\
\hline $\mathrm{Cm}-246$ & - & & $6 E+03$ & - & & $6 E+03$ & $\mathrm{Cm}-246$ \\
\hline Cm-247 & - & & $3 E+02$ & - & & $3 E+02$ & $\mathrm{Cm}-247$ \\
\hline Cm-248 & - & & $2 E+03$ & - & & $2 E+03$ & $\mathrm{Cm}-248$ \\
\hline Cf-249 & - & & $8 E+02$ & - & & $1 E+03$ & Cf-249 \\
\hline Cf-250 & - & & $2 E+06$ & $=$ & & $2 E+06$ & Cf-250 \\
\hline Cf-251 & - & & $2 E+03$ & - & & $2 E+03$ & Cf-251 \\
\hline
\end{tabular}

a "NL" means No Limit - estimated permissible concentration factor is greater than the specific activity of the pure elemental radionuclide.

b "-" Indicates that the radionuclide concentration is based on an arrival time beyond $10,000 \mathrm{y}$; see Table 3-4

for specific values.

c Results presented for radionclides expected to be volatile under disposal facility conditions.

d Concentration is based on the most restrictive intrusion scenario assumed for the site; see Table 3-6. 
The variation in results from using alternative generic assumptions and parameter values is discussed in Chapter 6 of Volume 2. In addition, a discussion is provided in that chapter about the effects of using alternative values for site-specific parameters. Based on this discussion, four parameters were identified (three site-specific and one generic, all used in the water pathway analysis) that could potentially influence the results to the degree that the calculated waste concentrations become limited by a pathway other than the one determined for the PE (Table 3-7). The impacts on the results of using alternative values for these four parameters for the water pathway in the PE for RFETS are discussed in this section. The basis for and possible variation in the values used in the $\mathrm{PE}$ for these parameters are discussed in Section 3.6.2.2.

\subsubsection{Parameter Sensitivity Analysis}

The PE provided results for two disposal facility designs: a RCRA-compliant, belowground trench and a RCRA-compliant, above-ground tumulus. Similar assumptions about the integrity of engineered barriers were made in the PE for both facility designs. Because the factors used to estimate transport of radionuclides in the water pathway for both designs were similar, the discussion in this section focuses on examining the results for the indicator radionuclides reported for the tumulus design (indicator radionuclides are defined in Chapter 7 of Volume 2).

As discussed in Chapter 6 of Volume 2, only four parameters used in the PE were identified as having a potential range of values that might affect results: natural recharge $(i)$; groundwater Darcy velocity $\left(q_{g_{w}}\right)$; area of the facility $(A)$; and distribution coefficients $\left(K_{d} S\right)$. These parameter values for RFETS are summarized in Table 3-8.

Table 3-8. Parameter Values Used in the PE for RFETS with Potential Variability That Could Affect the Results

\begin{tabular}{|l|l|}
\hline \multicolumn{1}{|c|}{ Parameter } & \multicolumn{1}{|c|}{ Value } \\
\hline Natural recharge through local soils, $i$ & $\begin{array}{l}\text { 0.05 m/y (based on EG\&G, 1993a; see } \\
\text { Section 3.4.1) }\end{array}$ \\
\hline Distribution coefficients for geologic & $\begin{array}{l}\text { Sandy soil values from Thibault et al. (1990); } \\
\text { see Table 3-2 in this chapter for values }\end{array}$ \\
media, $K_{d}$ & $\begin{array}{l}0.59 \mathrm{~m} / \mathrm{y} \text { (based on EG\&G, 1995b; see } \\
\text { Section 3.4.1) }\end{array}$ \\
\hline Groundwater Darcy velocity, $q_{g w}$ & $2500 \mathrm{~m}^{2}$ (standard PE value) \\
\hline Plan-view Area, $A$ & \\
\hline
\end{tabular}

The traditional procedure for performing a sensitivity analysis is to vary the parameters used in the calculations and observe the effect on the results. To be meaningful, this method requires some knowledge of the statistical distribution of each of the parameters considered, including their likely maximum and minimum values. For the PE calculations, the potential variability of the parameters used to calculate the permissible waste concentrations for the two different facility designs was not estimated. For most of the radionuclides considered in the PE, there were only two limiting exposure pathways: the water pathway and intruder exposure scenarios (the atmospheric pathway was considered only for $\mathrm{H}-3$ and $\mathrm{C}-14$ ). The intruder- 
pathway results provide a baseline that can be used for comparison with the water-pathway results because the intruder scenarios used in the PE were relatively independent of the physical characteristics of the individual sites.

This baseline provided an alternative method of performing sensitivity analyses for the $\mathrm{PE}$. The input parameters for the water pathway were varied to determine if the controlling exposure pathway could be altered (e.g., the results could be changed from intruder-scenario controlled to water-pathway controlled). After new values for the water pathway parameters were determined, these values were examined for reasonableness based on physical constraints at the site.

The sensitivity analysis was limited to a comparison of the water and intruder exposure pathways. A comparison between the water and atmospheric pathways was not conducted because only two radionuclides analyzed in the $\mathrm{PE}(\mathrm{H}-3$ and $\mathrm{C}-14)$ may potentially be limited by the atmospheric pathway. This pathway is not a controlling pathway for either $\mathrm{H}-3$ or $\mathrm{C}-14$ at RFETS.

To analyze the sensitivity of the results to changes in the parameter values for recharge, groundwater Darcy velocity, and area of the facility, the parameter values used in the PE for RFETS were varied. Only one parameter value was varied at a time for each indicator radionuclide, leaving the others equal to their PE values. In most instances, the parameter value was varied until the waste concentrations for the water and intruder pathways became equal, regardless of the likelihood (or physical impossibility) of the value to occur.

The parameter values that caused the permissible concentrations for the water and intruder pathways to become equal are listed in Table 3-9 for the 8 indicator radionuclides. Due to the shallow depth of the upper hydrostratigraphic unit at RFETS, 2 of the 8 indicator radionuclides (C-14 and Tc-99) are limited by the water pathway for a tumulus facility. Furthermore, the maximum permissible concentrations of Am-241 and Pu-239 are approximately the same for both the intruder and water pathways. The fact that 4 of the 8 indicator nuclides may be limited by the water pathway clearly illustrates the importance of this potential exposure scenario at the RFETS.

For a tumulus disposal facility, the parameter values that caused the maximum permissible concentrations for the water and the intruder pathways are listed in Table 3-9 for the 8 indicator radionuclides. Recharge is considered first in discussing the results of the sensitivity analysis. The water pathway limits the maximum permissible waste concentration for C-14, Tc-99, and U-238, although U-238 arrives at the performance boundary beyond $10,000 \mathrm{y}$. For the maximum concentration to become controlled by the intruder pathway, the natural recharge would have to be reduced 1 to 2 orders of magnitude to less than $1 \mathrm{~cm} / \mathrm{y}(0.4 \mathrm{in} / \mathrm{y})$. Given the precipitation rate of nearly $40 \mathrm{~cm} / \mathrm{y}$ ( $16 \mathrm{in} / \mathrm{y}$ ) at RFETS, it is not believed that a recharge this small is realistic. The $\mathrm{PE}$ analysis for Pu-239 and Am-241 suggests that their concentrations are limited by the intruder scenario; however, a slight increase in natural recharge from $5 \mathrm{~cm} / \mathrm{y}(2 \mathrm{in} . / \mathrm{y})$ to $6 \mathrm{~cm} / \mathrm{y}(2.3 \mathrm{in} . / \mathrm{y})$ and $7 \mathrm{~cm} / \mathrm{y}(2.7 \mathrm{in} . / \mathrm{y})$, respectively, would result in the maximum permissible waste concentration becoming limited by the water pathway. Sr-90 and Cs-137 remain limited by the intruder scenario regardless of the recharge used in the PE calculations. 
Table 3-9. Parameter Values That Caused the Permissible Concentrations for the Water and Intruder Pathways to Be Equal for Indicator Radionuclides at RFETS (tumulus design) (bold italic type indicates limiting pathway in the PE)

\begin{tabular}{|c|c|c|c|c|c|c|}
\hline \multirow[t]{4}{*}{$\begin{array}{l}\text { Indicator } \\
\text { Nuclide }\end{array}$} & \multirow[t]{4}{*}{$\begin{array}{c}\mathrm{PE} \\
\mathrm{C}_{\mathrm{W} \cdot \mathrm{watar}^{2}} \\
\left(\mu \mathrm{Ci} / \mathrm{m}^{3}\right)\end{array}$} & \multirow[t]{4}{*}{$\begin{array}{c}\text { PE } \\
C_{W / n \pi} \\
\left(\mu \mathrm{Ci} / m^{3}\right)\end{array}$} & \multirow[t]{4}{*}{$\begin{array}{c}\text { PE } \\
\frac{C_{W-\text { Int }}}{C_{W-W a t e r}}\end{array}$} & $\begin{array}{c}\text { Natural } \\
\text { Recharge, } \\
i \\
(\mathrm{~m} / \mathrm{y})\end{array}$ & $\begin{array}{l}\text { Groundwater } \\
\text { Darcy } \\
\text { Velocity, } q_{g w} \\
\text { (m/y) }\end{array}$ & $\begin{array}{c}\text { Area, } \\
\text { A } \\
\left(\mathrm{m}^{2}\right)\end{array}$ \\
\hline & & & & \multicolumn{3}{|c|}{ PE Values } \\
\hline & & & & .05 & 0.59 & 2500 \\
\hline & & & & \multicolumn{3}{|c|}{$\begin{array}{c}\text { Value That Caused Equal } \\
\text { Concentrations }\end{array}$} \\
\hline $\mathrm{H}-3$ & $2 E+12$ & $7 E+07$ & 3E-05 & c & $c$ & c \\
\hline$c-14$ & $8 E+02$ & $1 E+04$ & 10 & $0.007^{b}$ & 16 & $<100$ \\
\hline Sr-90 & NL & $5 E+04$ & - & c & c & $c$ \\
\hline Tc-99 & $9 E+01$ & $2 E+04$ & 200 & 2E-04 & 150 & $<100$ \\
\hline Cs-137 & $N L^{b}$ & $8 E+05$ & - & c & $c$ & $c$ \\
\hline U-238 & $4 E+01^{b}$ & $5 E+03$ & 100 & $3 E-04$ & $100^{b}$ & $<100^{b}$ \\
\hline Pu-239 & $3 E+04^{b}$ & $6 E+03$ & 0.2 & $0.065^{b}$ & $1.5^{\mathrm{b}}$ & $c$ \\
\hline $\begin{array}{l}\mathrm{Am}-241 \\
(\mathrm{~Np}-237)^{d}\end{array}$ & $1 E+04^{\circ}$ & $9 E+03$ & 0.9 & $0.075^{\circ}$ & $0.4^{\circ}$ & $6 E+03^{\circ}$ \\
\hline
\end{tabular}

a "NL" means No Limit - estimated permissible concentration is greater than the specific activity of the pure elemental radionuclide.

b Radionuclide arrival time at the performance boundary is greater than $10,000 \mathrm{y}$.

c No variation in values caused equal concentrations.

d The dominant decay product for Am-241

e Based on the dominant decay product, Np-237

"-" Value could not be calculated.

A similar situation exists for groundwater velocity $\left(q_{g w}\right)$; the value used in the PE analysis must increase by over 2 to 3 orders of magnitude for the intruder scenario to become limiting for C-14, Tc-99, and U-238. A 50\% increase in groundwater velocity would cause the intruder scenario to control the Pu-239 concentration. A slight decrease in the groundwater velocity would cause Am-241 to be limited by the water pathway. No variation in groundwater velocity would affect the limiting pathways for $\mathrm{H}-3, \mathrm{Sr}-90$, or $\mathrm{Cs}-137$.

As with the other parameter values, the facility area must be reduced to very low values $\left(A<100 \mathrm{~m}^{2}\right)$ for the three indicator radionuclides that are limited by the water pathway to change the controlling pathway. An increase in the area to $6000 \mathrm{~m}^{2}\left(64,565 \mathrm{ft}^{2}\right)$ for Am-241 would cause the water pathway and intrusion scenario concentrations to be the same. Even though the maximum permissible concentration for $\mathrm{Pu}-239$ as determined by the two exposure scenarios is approximately equal, the disposal facility area could not be increased to change the limiting pathway.

At RFETS, the low recharge $(5 \mathrm{~cm} / \mathrm{y}[2 \mathrm{in} / \mathrm{y}])$ and the relatively shallow groundwater $(12.8 \mathrm{~m}$ [42 $\mathrm{ft}])$ conioine to make the travel time for the water pathway very dependent on the

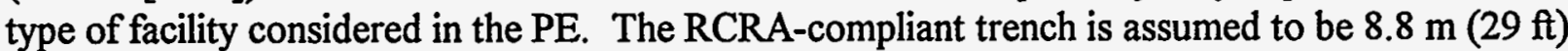

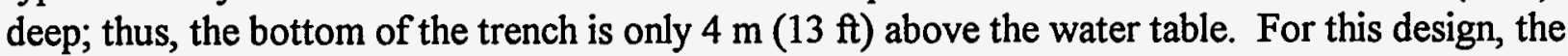
water travel time to the performance boundary is estimated at $27 \mathrm{y}: 10 \mathrm{y}$ to travel through the 
unsaturated zone based on the natural recharge, and $17 \mathrm{y}$ to migrate $100 \mathrm{~m}$ (328 ft) horizontally through the upper hydrostratigraphic unit. In contrast, the generic tumulus design considered in the $\mathrm{PE}$ is assumed to be placed at the surface; therefore, leachate from a disposal facility must migrate through the entire $12.8 \mathrm{~m}(42 \mathrm{ft})$ thick vadose zone. Thus, the water travel time to the performance boundary would be approximately $48 \mathrm{y}$, consisting of $31 \mathrm{y}$ to travel through the unsaturated zone based on the natural recharge, and $17 \mathrm{y}$ to migrate $100 \mathrm{~m}(328 \mathrm{ft})$ horizontally through the upper hydrostratigraphic unit.

Because site-specific $K_{d}$ values for the geologic media were not available for RFETS, generic $K_{d}$ values were used in the PE. The same values were used for both the saturated and unsaturated soils at the site because there are no significant differences in the soil characteristics in these two zones. A $K_{d}$ value of $17 \mathrm{~mL} / \mathrm{g}$ applied to the subsurface soils at RFETS would cause an arrival time at the performance boundary of 10,000 y for the tumulus design. The $K_{d}$ values that caused the permissible concentrations for the water and intruder pathways to be the same are listed in Table 3-10 for 5 of the indicator radionuclides. The indicator radionuclides $\mathrm{H}-3, \mathrm{C}-14$, and Tc-99 are not considered in this analysis because general consensus is that the $K_{d}$ values for these radionuclides are small.

Table 3-10. Variation of $K_{d}$ Values for the Geologic Media at RFETS (tumulus design) (a $K_{d}$ value of about $17 \mathrm{~mL} / \mathrm{g}$ caused radionuclide arrival at the performance boundary equal to $10,000 \mathrm{y}$ )

\begin{tabular}{|c|c|c|c|c|c|}
\hline $\begin{array}{l}\text { Indicator } \\
\text { Nuclide }\end{array}$ & $\begin{array}{c}P E \\
K_{d} \\
(\mathrm{~mL} / \mathrm{g}) \\
\end{array}$ & $\begin{array}{c}\text { PE } \\
C_{w-w a t e r} \\
\left(\mu \mathrm{Ci} / \mathrm{m}^{3}\right)\end{array}$ & $\begin{array}{c}P E \\
C_{W-\operatorname{lntr}} \\
\left(\mu \mathrm{Ci} / \mathrm{m}^{3}\right)\end{array}$ & $\begin{array}{c}P E \\
C_{W-\text { Intr }} \\
C_{\text {W-Water }}\end{array}$ & $\begin{array}{l}K_{d} \text { Value that } \\
\text { Caused Equal } \\
\text { Concentrations }\end{array}$ \\
\hline Sr-90 & 15 & NL & $5 E+04$ & - & c \\
\hline Cs-137 & 280 & $\mathrm{NL}^{\mathrm{b}}$ & $8 E+05$ & - & 0.1 \\
\hline U-238 & 35 & $4 E+01^{b}$ & $5 E+03$ & 100 & $c, d$ \\
\hline Pu-239 & 550 & $3 E+04^{b}$ & $6 E+03$ & 0.2 & $460^{b, d}$ \\
\hline $\begin{array}{l}\mathrm{Am}-241 \\
(\mathrm{~Np}-237)^{\circ}\end{array}$ & $\begin{array}{c}1900 \\
(5)\end{array}$ & $1 E+04$ & $9 E+03$ & 0.9 & 8 \\
\hline
\end{tabular}

a "NL" means No Lmit - the estimated permissible waste concentration is greater than the specific activity of the pure elemental radionuclide.

b Radlonuclide arrival time at the performance boundary is greater than $10,000 \mathrm{y}$.

c No variation in value caused equal concentrations.

d Value less than $17 \mathrm{~mL} / \mathrm{g}$ caused arrival at the performance boundary before 10,000 y which changed the limiting pathway.

- The dominant decay product of Am-241

"-" Value could not be calculated.

The results in Table 3-10 show that, except for U-238, the variability in $K_{d}$ values required to alter the exposure pathways is much greater than would likely occur. The radionuclide U-238 is limited by intrusion scenarios; however, a relatively small decrease in $K_{d}$ from $35 \mathrm{~mL} / \mathrm{g}$ to 17 $\mathrm{mL} / \mathrm{g}$ would change the limiting pathway from intruder to water. The PE permissible waste concentration for Am-241 was limited by the decay product (Np-237) contribution to the dose. If 
the $K_{d}$ value for Am-241 was reduced to $8 \mathrm{~mL} / \mathrm{g}$, then the water pathway concentration was limited by the parent radionuclide (Am-241) and the water pathway controlled. Due to the long half-life of Np-237, reduction of its $K_{d}$ had no effect on the resulting waste concentration.

\subsubsection{Physical Constraints on Sensitivity Analysis Values}

The PE results for RFETS are based on parameter values provided by the RFETS technical staff for site-specific parameters used in calculations. Descriptions and technical justifications of these values are provided in Sections 3.3 and 3.4. Ranges and statistical distributions may not have been known for all of the input parameter values; however, sitespecific knowledge can be used to determine whether the values determined in the sensitivity analysis are reasonable and physically possible at RFETS.

\section{Natural Recharge}

For the three radionuclides controlled by the water pathway (C-14, Tc-99, and U-238), the average recharge must be reduced from 1 to 2 orders of magnitude below the value of $5 \mathrm{~cm} / \mathrm{y}$ ( 2 in./y) estimated by site technical staff before the intruder scenario becomes the controlling pathway. Although the recharge is not known with certainty, a reduction of this magnitude seems highly unlikely. Reductions of the recharge would increase the travel time to the performance boundary for these nuclides to greater than 10,000 y. For Pu-239 and Am-241, the limiting waste concentrations for the two pathways are approximately equal, so that a slight increase in recharge would result in the water pathway controlling the waste concentrations, while a decrease would result in the intruder scenario limiting the maximum permissible waste concentration.

\section{Groundwater Darcy Velocity}

As with the natural recharge, the groundwater velocity for the three radionuclides controlled by the water pathway must be reduced to very low values before the maximum permissible waste concentrations determined by the intruder scenario become limiting. Given the relatively high permeability of the alluvial material in the upper hydrostratigraphic unit, it does not appear that these values are likely. Furthermore, as with the natural recharge, relatively small changes in the groundwater velocity will alter the potential exposure pathway for $\mathrm{Pu}-239$ and Am-241.

\section{Facility Area}

The values for the facility areas estimated by the sensitivity analysis are less than $100 \mathrm{~m}^{2}$ $\left(1076 \mathrm{ft}^{2}\right)$ or $6,000 \mathrm{~m}^{2}\left(64,565 \mathrm{ft}^{2}\right)$ (Table 3-9). The results for U-238 correspond to arrival times greater than $10,000 \mathrm{y}$.

\section{Distribution Coefficients}

In the $\mathrm{PE}$, a $K_{d}$ value of $17 \mathrm{~mL} / \mathrm{g}$ corresponds to an arrival time of 10,000 y (i.e., the $10,000-\mathrm{y} K_{d}$ ). According to Table 3-4, 49 radionuclides arrived beyond $10,000 \mathrm{y}$ for a tumulus facility. Of these radionuclides, 11 have $K_{d}$ values that are close to the $10,000-\mathrm{y} K_{d}$. Changes in $K_{d}$ values could affect the PE results by changing travel times of the radionuclides through the soils in the upper hydrostratigraphic unit. The limiting pathway for a radionuclide could change from intruder to water not only because the permissible waste concentration changes but also because the arrival time decreases to less than $10,000 \mathrm{y}$. The $K_{d}$ values used in the PE analysis 
were conservative values for sand selected from the compilation by Thibault et al. (1990). In this discussion the term "conservative" refers to values that are likely to result in a relatively low sorption of radionuclides on soil particles, thus resulting in low values of maximum permissible waste concentrations by the water pathway $\left(C_{\text {W-Water }}\right)$. It is likely that soils found in the alluvial deposits of the upper hydrostratigraphic unit at RFETS have much higher sorptive capacity (i.e., higher $K_{d}$ values) for most of the radionuclides under consideration in the PE, so that the most of them will take more than $10,000 \mathrm{y}$ to reach the performance boundary by the water pathway. However, for U-238, it could be reasonable to lower the $K_{d}$ from $35 \mathrm{~mL} / \mathrm{g}$ to less than $17 \mathrm{~mL} / \mathrm{g}$, thereby changing the limiting pathway from intruder to water.

\subsection{OBSERVATIONS}

Based on the results of the $\mathrm{PE}$ and the parameter-sensitivity analysis, the following observations can be made about MLLW disposal at RFETS:

- RFETS is unusual in comparison to other western sites evaluated in the PE. While the natural recharge is low $(5 \mathrm{~cm} / \mathrm{y}$ [ 2 in./y]), there is a groundwater formation present at a depth of less than $15 \mathrm{~m}$ ( $49 \mathrm{ft}$ ). Thus, while the migration rate through the vadose zone is slow, the shallow depth to groundwater results in short travel times to the performance boundary via the water pathway relative to other western sites. This condition is particularly true for the generic trench design considered in the PE, the floor of which is $8.8 \mathrm{~m}(29 \mathrm{ft})$ below grade.

- For RFETS, the results indicate that, of the 58 radionuclides evaluated in the PE, 50 for the trench design and 52 for the tumulus design would be limited by the intrusion scenarios. These results reflect the dominant role of the selected human intrusion scenarios that is demonstrated for almost all the sites considered in the PE (see Sections 7.5 and 7.6 in Volume 2). This dominance indicates a need to be aware of the inability to predict the social behavior of populations far into the future.

The results also indicate that for the water pathway, 47 of the 58 radionuclides for both the trench and tumulus designs would arrive at the performance boundary after the 10,000 -y period of consideration in the $\mathrm{PE}$ analysis of the water pathway. Of the radionuclides that would arrive before $10,000 \mathrm{y}$, two for both designs had no limit on waste concentration.

Because RFETS has many radionuclides that either are limited by the intrusion scenarios, arrive at the performance boundary after $10,000 \mathrm{y}$, or have no limit on waste concentration, this site may have flexibility in accepting a variety of radionuclides for disposal.

- Either a trench or tumulus facility design may be feasible for disposal of MLLW at RFETS. Due to the low natural recharge, most of the radionuclides evaluated in the PE are limited by intrusion scenarios for both the trench and tumulus designs. For either type 
of facility, the occurrence of significant adsorption of radionuclides onto subsurface soils is likely to significantly improve its performance as a waste repository.

- RFETS does not have significant surface physical constraints that could limit disposal activities. The site has a large amount of undeveloped land that could in principle be used for an MLLW disposal facility.

- The sensitivity analysis for RFETS indicates that reasonable changes in values for the natural recharge, groundwater Darcy velocity, and facility size would not significantly change the results. Values for these parameters could not be changed in a reasonable way for the 8 indicator radionuclides to change the controlling pathway from intruder to water for any of the indicator radionuclides except Pu-239 and Am-241. The maximum permissible concentrations for these two radionuclides were approximately the same for both the intruder and water pathways.

In flow and transport problems, the $K_{d}$ values are often the most uncertain site-specific input parameters. However, according to the results of the sensitivity analysis, none of the $K_{d}$ values for the 5 indicator radionuclides could be changed in a reasonable way to change the controlling pathway except for U-238. This result suggests that the maximum waste concentrations of other long-lived radionuclides or those with long-lived decay products might also be limited by the water pathway, although their arrival time at the performance boundary would likely be greater than $10,000 \mathrm{y}$.

- The PE was a scoping analysis performed using assumptions that are conservative relative to most LLW performance assessments. There are no site-specific studies to compare with the PE results. A more detailed performance assessment would be required for permitting or other disposal planning. 


\subsection{REFERENCES}

ASI, 1993. Final Interim Report, Ground-Water Recharge Study. Lakewood, CO.

Baer, T.A., L. L. Price, J. N. Emery, N. E. Olague, 1994. Second Performance Assessment Iteration of the Greater Confinement Disposal Facility at the Nevada Test Site. SAND930089. Albuquerque, NM: Sandia National Laboratories.

Chu, M.S.Y., M.W. Kozak, J.E. Campbell, and B.M. Thompson, 1991. A Self-Teaching Curriculum for the NRC/SNL Low-Level Waste Performance Assessment Methodology. SAND90-0585. Albuquerque, NM: Sandia National Laboratories.

Cooper, C.D., and F.C. Alley, 1986. Air Pollution Control: A Design Approach. Prospect Heights, IL: Waveland Press, Inc.

CRC, 1981. CRC Handbook of Chemistry and Physics. Eds. Robert C. Weast and Melvin J. Astle. Boca Raton, FL: CRC Press, Inc.

EG\&G Rocky Flats Inc., 1992a. Rocky Flats Plant Site Environmental Report. RFP-ENV-92. Golden, CO: Prepared for US DOE Rocky Flats Plant by EG\&G Rocky Flats Inc.

EG\&G Rocky Flats Inc., 1992b. Phase II Geologic Characterization: Data Acquisition: Surface Geologic Mapping of the Rocky Flats Plant and Vicinity, Jefferson and Boulder Counties, Colorado. Golden, CO: Prepared for US DOE Rocky Flats Plant by EG\&G Rocky Flats Inc.

EG\&G Rocky Flats Inc., 1993a. Site-Wide Groundwater Flow Modeling at the Rocky Flats Plant. Golden, CO.

EG\&G Rocky Flats Inc., 1993b. Groundwater Protection and Monitoring Plan. Prepared for US DOE Rocky Flats Area in compliance with DOE Order 5400.1, Golden CO.

EG\&G Rocky Flats Inc., 1994. Rocky Flats Plant Site Environmental Report.

EG\&G Rocky Flats Inc., 1995a. Draft Final Geologic Characterization Report for the Rocky Flats Environmental Technology Site. Volume I. Golden, CO.

EG\&G Rocky Flats Inc., 1995b. Draft Final Hydrogeologic Characterization Report. Volume II. Golden, $\mathrm{CO}$.

EPA (Environmental Protection Agency), 1992. User's Guide for the Industrial Source Complex (ISC2) Dispersion Models, Volume I: User Instructions. EPA Publication No. EPA-450/492-008a. Research Triangle, NC: U.S. Environmental Protection Agency.

Fedors, R., and J.W. Warner, 1993. Characterization of Physical and Hydraulic Properties of Surficial Materials and Groundwater/Surface Water Interaction Study at Rocky Flats Plant, Golden, CO. Groundwater Technical Report \#21. Ft. Collins, CO: Colorado State University. 
FFCAct, 1992. Federal Facility Compliance Act of 1992. P.L. 102-386. October 1992.

Gruebel, M.M., R.D. Waters, M.B. Hospelhorn, and M.S.Y. Chu, eds., 1994. Frameword for DOE Low-Level and Mixed Low-Level Waste Disposal: Site Fact Sheets. SAND94-2728. Albuquerque, NM: Sandia National Laboratories.

Hurr, R.T., 1976. Hydrology of a Nuclear-processing Plant Site, Jefferson County, Colorado. USGS Open File Report 76-268.

Kincaid, C.T., J.W. Shade, G.A. Whyatt, M.G. Piepho, K. Rhoads, J.A. Voogd, J.H. Westsik, Jr., M.D. Freshley, K.A. Blanchard, and B.G. Lauzon, eds., 1993. Performance Assessment of Grouted Double-Shell Tank Waste Disposal at Hanford. WHC-SD-WM-EE-004, Rev. 0. U.S. Department of Energy, Pacific Northwest Laboratory and Westinghouse Hanford Company.

Maheras, Steven J., Arthur S. Rood, Swen O. Magnuson, Mary E. Sussman, and Rajiv N. Bhatt, 1994. Radioactive Waste Management Complex Low-Level Waste Radiological Performance Assessment. EGG-WM-8773. Idaho Falls, ID: U.S. Department of Energy Office of Environmental Restoration and Waste Management, DOE Idaho Operations Office.

MMES (Martin Marietta Energy Systems), EG\&G Idaho, Inc., and Westinghouse Savannah River Company, 1994. Radiological Performance Assessment for the E-Area Vaults Disposal Facility (U). WSRC-RP-94-218, Rev. 0. Aiken, SC: Westinghouse Savannah River Company.

ORNL (Oak Ridge National Laboratory), 1994. Performance Assessment for Continuing and Future Operations at Solid Waste Storage Area 6. ORNL-6783. Oak Ridge, TN: U.S. Department of Energy, Oak Ridge National Laboratory.

Thibault, D.H., M.I. Sheppard, and P.A. Smith, 1990. A Critical Compilation and Review of Default Soil Solid/Liquid Partition Coefficients, $K_{d}$, for Use in Environmental Assessments. AECL-10125. Pinawa, Manitoba, Canada: Whiteshell Nuclear Research Establishment, Atomic Energy of Canada Limited.

US DOE, 1980. Final Environmental Impact Statement: Rocky Flats Plant Site, Golden, Jefferson County, Colorado. DOE/EIS-0064.

US DOE, 1995. Proposed Site Treatment Plan for Mixed Wastes, Rocky Flats Environmental Technology Site, Rev. 3/3/95. Golden, CO.

\section{Acknowledgments}

The SNL Core Team acknowledges the contributions of Robert Smith, Barry Roberts, and Steve Singer of EG\&G and Rick DiSalvo, Brandon Williamson, and William Prymak of US DOE Rocky Flats. 


\section{Idaho: IDAHO NATIONAL ENGINEERING LABORATORY (INEL) Core Team Contact: Gregory P. Zimmerman}

The Federal Facility Compliance Act (FFCAct, 1992) requires the Department of Energy (DOE) to establish plans in conjunction with its regulators and with members of the public for the treatment of DOE's mixed low-level waste (MLLW). Although the FFCAct did not specifically address disposal of treated MLLW, both DOE and the States recognized that disposal issues were an integral part of treatment discussions. Since 1992, DOE has worked with the States to define and develop an evaluation process for disposal options. Preliminary activities of this joint DOEState process have narrowed the sites for further evaluation from 49 to 15.

The Disposal Workgroup (DWG), which was established by DOE to develop a process for evaluating disposal options, designed a performance evaluation (PE) to quantify and compare the limitations of the remaining $15 \mathrm{DOE}$ sites for MLLW disposal. The principal goal of the PE was to estimate, for grouted residuals resulting from the treatment of MLLW, permissible concentrations of radionuclides in waste for disposal at each site. These "permissible waste concentrations" were based solely on long-term physical performance of the disposal facility and did not take into account any operational waste acceptance criteria that a site might have developed. The PE did not address any ethical, social, or policy considerations relevant to siting such facilities.

The PE used analyses that are consistent with the approach used in many low-level waste (LLW) performance assessments. The objective was to use a set of modeling assumptions of sufficient detail to capture major site-specific characteristics and yet be general enough for consistent application at all sites. Additionally, the analyses were designed to ensure that the sites were analyzed consistently and that all major assumptions were clearly stated.

The remainder of this chapter provides the PE results for Idaho National Engineering Laboratory (INEL), one of the 15 sites being evaluated. The chapter contains the following information:

Section 4.1: brief, general description of the site based on previous work done by the DWG (Gruebel et al., 1994)

Section 4.2: plans for MLLW disposal, if any, and the location evaluated in the PE

Section 4.3: current understanding of radionuclide movement at the selected location based on available information, and the conceptual model used for the evaluation of each of three pathways (water, atmospheric, and inadvertent intruder)

Section 4.4: site-specific and generic values used in the PE calculations and their sources

Section 4.5: estimates of maximum waste concentrations determined in the PE calculations for each of the three pathways, along with calculated values used in determining these results 
Section 4.6: summary of results based on disposal-facility design; discussion with respect to such issues as uncertainty and sensitivity

Section 4.7: observations based on the results of the PE and the parameter sensitivity analysis

Section 4.8: references

The general assumptions and methodology used in the PE are summarized in Chapter 1 of this volume and explained in more detail in Volume 2 of this report. Overall results for all the sites are discussed in Chapter 7 of Volume 2.

\subsection{GENERAL DESCRIPTION OF THE SITE}

The Idaho National Engineering Laboratory (INEL) is located along the northwestern edge of the Eastern Snake River Plain in southeastern Idaho, near the city of Idaho Falls (Figure 4-1). Most of INEL lies within Butte County, Idaho. The INEL site lies at the foot of three mountain ranges-the Lost River range, the Lemhi range, and the Bitterroot-Centennial range-and covers $2315 \mathrm{~km}^{2}$ (895 mi ${ }^{2}$ or 572,000 acres) of semiarid shrub steppe (Figure 4-2). Most of the land at INEL withdrawn from the public domain for use by DOE is undeveloped. The INEL site is located within Resource Areas administered by the Bureau of Land Management. The DOE manages INEL, with administration through three DOE operations offices: the Idaho operations office; the Idaho branch office of Pittsburgh Naval Reactors; and the Chicago operations office.

The town nearest to INEL is Atomic City (about 25 residents), which is less than $1.5 \mathrm{~km}$ (1 mi) from INEL's southern boundary. Arco, $11 \mathrm{~km}(7 \mathrm{mi})$ to the west, is the largest boundary community with 1100 residents. The largest population centers near INEL are Blackfoot $(9,700$ residents), $37 \mathrm{~km}$ ( $23 \mathrm{mi})$ to the southeast; Idaho Falls ( 44,000 residents), $35 \mathrm{~km}(21 \mathrm{mi})$ to the east; and Pocatello (46,000 residents), $71 \mathrm{~km}$ (44 mi) to the south. Approximately 121,000 people are estimated to reside within an $80-\mathrm{km}(50-\mathrm{mi})$ radius of the INEL operational center.

In 1949, INEL was formally established as the National Reactor Testing Station, where the Atomic Energy Commission built, tested, and operated various types of nuclear reactors. As of April 1991, 52 reactors had been built at INEL; of these, 13 were operating or operable. The INEL is currently a multi-program DOE laboratory; mission activities, including those associated with DOE's Environmental Restoration and Waste Management, occur primarily on nine major facility areas that were developed when INEL was established.

In 1975, INEL was designated as one of five DOE Environmental Research Parks to be used to study complex ecological relationships and the effects of human activities on natural systems. The physical aspects of INEL and its flora and fauna are typical of cold, high altitude, sagebrush ecosystems found in many parts of the western United States. INEL provides a unique setting for scientific investigation because the public has been excluded from much of the area for over 25 years. 


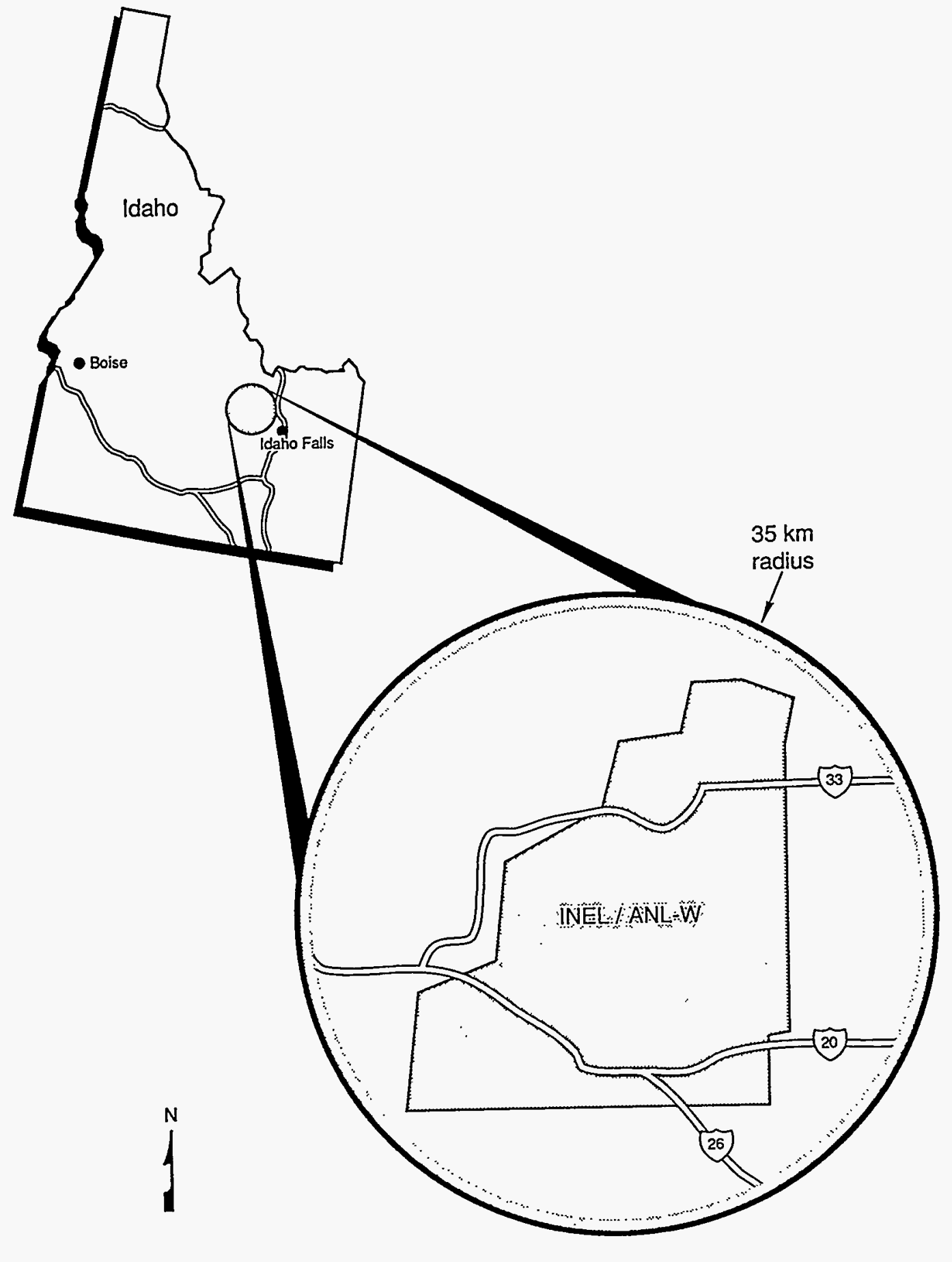

Figure 4-1. Location map for the Idaho National Engineering Laboratory. 


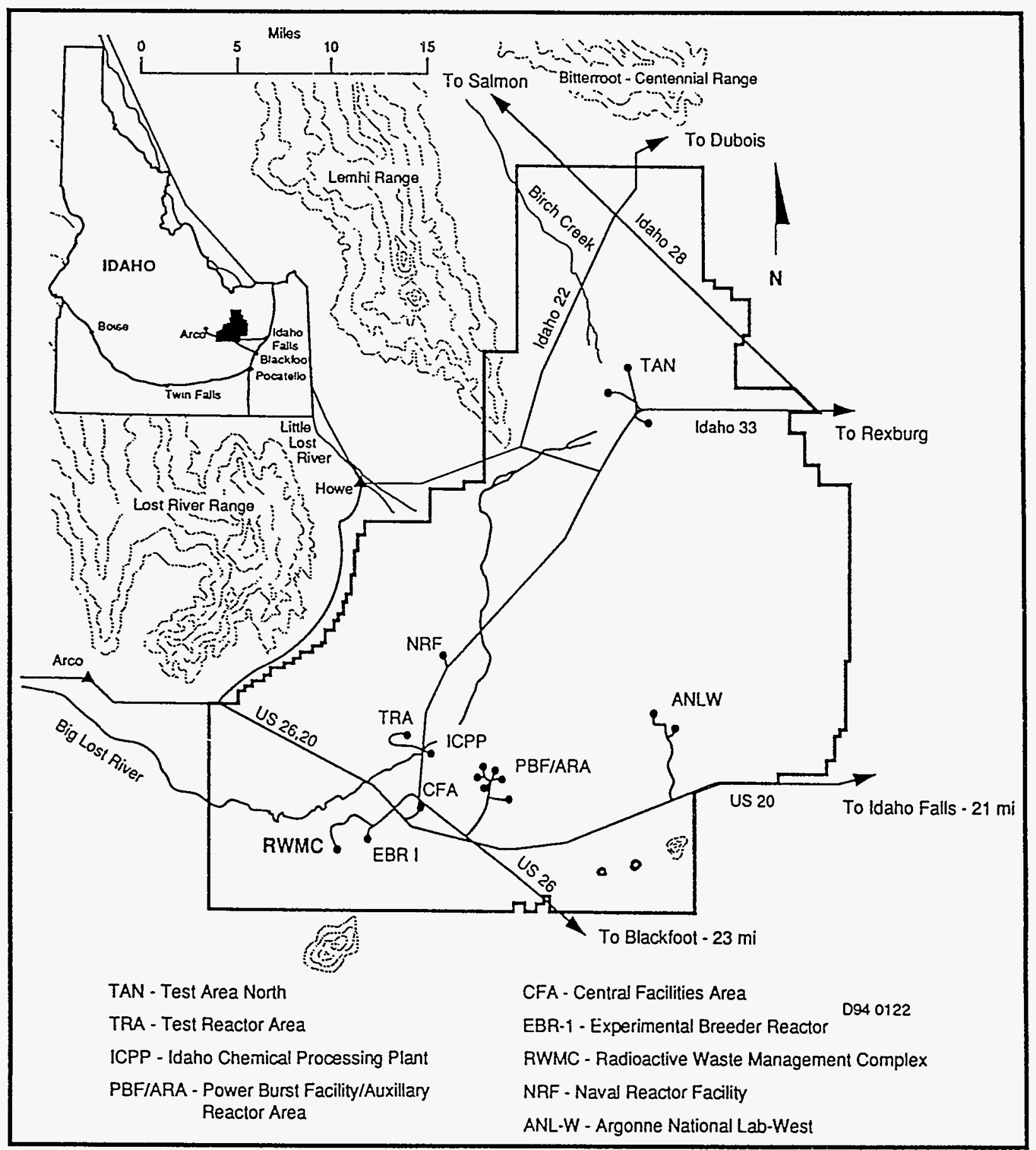

Figure 4-2. Site map for the Idaho National Engineering Laboratory. 
The climate at INEL is semiarid, with sagebrush-steppe characteristics. The temperature extremes recorded at INEL vary from $-42^{\circ} \mathrm{C}\left(-43^{\circ} \mathrm{F}\right)$ in January to $39^{\circ} \mathrm{C}\left(102^{\circ} \mathrm{F}\right)$ in July. The topographic features that affect local weather patterns are the northeast-southwest orientation of the Snake River Plain and the mountain ranges to the north and west. Air masses entering the Snake River Plain must first cross mountain barriers, where much of the air moisture is precipitated; thus, annual rainfall at INEL is light. The average annual precipitation at INEL is $22 \mathrm{~cm}$ ( $8.5 \mathrm{in}$.); the greatest rainfall recorded within a $24-\mathrm{hr}$ period at INEL was $4.2 \mathrm{~cm}$ (1.6 in.) in June 1969.

The INEL site is in a belt of prevailing westerly winds that is channeled within the Eastern Snake River Plain. The record of average wind speed shows a minimum of $8 \mathrm{~km} / \mathrm{h}(5 \mathrm{mph})$ in December and a maximum of $14.5 \mathrm{~km} / \mathrm{h}(9 \mathrm{mph})$ in April and May. The highest wind speed based on the maximum hourly average is $82 \mathrm{~km} / \mathrm{h}$ (51 mph) from the west-southwest. Strong gusts can occur in the immediate vicinity of thunderstorms.

The INEL is located near the northern margin of the Eastern Snake River Plain, a low-lying area of late Tertiary and Quaternary volcanism and sedimentation that extends from the Idaho-Oregon border to southeastern Idaho. In the vicinity of INEL, the elevation is approximately $1500 \mathrm{~m}(4920 \mathrm{ft})$ above mean sea level.

The Eastern Snake River Plain truncates basin and range structures on the northwest and southeast, with approximately 1200 to $1400 \mathrm{~m}$ (4000 to $4600 \mathrm{ft}$ ) of relief between the ranges and relatively flat plain. The Eastern Snake River Plain contains a substantial volume of silicic and basaltic volcanic rocks with relatively minor sediments, except along its margins where drainages emerge from the neighboring highlands. The basalts have displaced the Snake River southward to its present course. Although basalt covers three-quarters of INEL's surface, rhyolite and ash flow tuffs beneath the basalt are more voluminous.

The surface of much of the Eastern Snake River Plain is covered by waterborne and windborne soils derived primarily from Cenozoic (65 million years ago to recent) volcanic and Paleozoic (570 to 245 million years ago) sedimentary rocks from the three surrounding mountain ranges. Underlying the plain are layers of interbedded volcanic and sedimentary rocks, principally a $0-$ to $1-\mathrm{km}$ (0- to 3280-ft) thick sequence of basaltic lava with interbeds of sedimentary materials. A typical soil association occurring on a lava flow consists of three to four soil series differentiated from one another largely on the basis of soil depth. INEL landscapes are covered with a blanket (generally less than $2 \mathrm{~m}$ [7 ft] thick and commonly between 0.3 and $0.9 \mathrm{~m}$ [ 1 to $3 \mathrm{ft}$ thick) of windborne sediments that were deposited in episodes associated with climatic cycles.

Surface water on INEL originates from streams draining through intermountain valleys to the west and northwest, from localized snowmelt, and from rainfall. Streams entering INEL include the Big Lost River, Little Lost River, and Birch Creek. Little Lost River and Birch Creek 
descend southeast to the plain in a broad valley floored with alluvium. Big Lost River, which enters INEL from the west, also descends on a broad alluvial valley.

The groundwater underlying INEL is part of the Snake River Plain Aquifer, which became an EPA-designated sole source aquifer in 1991. The Snake River Plain Aquifer is a continuous body of groundwater that underlies nearly all of the Eastern Snake River Plain. It is approximately $320 \mathrm{~km}$ (200 mi) long, 50 to $100 \mathrm{~km}(30$ to $60 \mathrm{mi})$ wide, and $25,000 \mathrm{~km}^{2}(9,650$ $\mathrm{mi}^{2}$ ) in area. The aquifer may contain $2.5 \times 10^{12} \mathrm{~m}^{3}$ of water, $6.3 \times 10^{11} \mathrm{~m}^{3}$ of which might be recoverable. About $8 \times 10^{9} \mathrm{~m}^{3}$ of water is withdrawn annually from the aquifer through irrigation well pumpage.

Groundwater supplies all of the drinking water consumed within the Eastern Snake River Plain, and an alternative drinking water source or combination of sources is not available. The nearest community public water supply (i.e., with 15 or more connections servicing residents year-round) is located in Atomic City, $18 \mathrm{~km}$ (11 mi) upgradient from INEL's Radioactive Waste Management Complex.

\subsection{STATUS AND SITING OF MLLW DISPOSAL FACILITY}

The Radioactive Waste Management Complex (RWMC) (Figure 4-2) was established in 1952 as a controlled area for disposal of defense wastes (mostly transuranic), solid LLW, and mixed waste generated at INEL. Since 1970, transuranic waste has been stored above ground in specially designed storage facilities, and disposal of mixed waste has not occurred at the RWMC since April 1984. The RWMC is one of several waste management facilities at INEL but is the only operating LLW disposal area for solid radioactive wastes at INEL. The RWMC provides a near-surface disposal site for solid LLW generated almost exclusively by INEL activities.

The RWMC encompasses $0.5 \mathrm{~km}^{2}(144 \mathrm{ac}$ ) and consists of two main disposal and storage areas. Within these areas are smaller, specialized disposal and storage areas. INEL currently has no disposal facility available for MLLW.

Most of the MLLW currently stored at INEL is alpha MLLW shipped by off-site generators to INEL for storage and treatment under RCRA requirements. Sources of MLLW include environmental restoration, decontamination and decommissioning, production operations, laboratory activities, construction maintenance, and research and development activities. Currently, MLLW is accepted at INEL for storage and disposal from INEL contractors only.

At the time of the PE, personnel at NNEL had no plans for on-site disposal of MLLW, and no INEL-specific facility designs or locations had been developed or identified. However, this PE exercise requires the identification of a suitable location for a future MLLW disposal facility at INEL; and a subsequent discussion with site technical staff (Taylor, 1994) revealed that INEL has begun to consider some areas of the INEL for this purpose. Such a hypothetically proposed site is used for this PE analysis, as described below. 
Available land for any additional expansion of waste management activities is limited at present at the RWMC; however, alternate locations exist at INEL with vadose zone thicknesses greater than that below the RWMC and its adjacent property. For these reasons, an unnamed, alternate location was identified for this PE analysis in the north-central portion of INEL (see Figure 4-2; in the general vicinity of and, more likely, just south of the Test Area North). This location would also be more remote than the RWMC with respect to nearby population centers.

At this alternate INEL location, groundwater depths of 45 to $60 \mathrm{~m}(150$ to $200 \mathrm{ft})$, uninterrupted by basalt flows, have been indicated by core drillings. For this $\mathrm{PE}$ analysis, a vadose zone thickness of $50 \mathrm{~m}(164 \mathrm{ft})$ has been selected as applicable for subsurface transport calculations following consultation with INEL site technical staff (Taylor, 1994). While detailed core samples are not generally available for this portion of INEL, it can be reasonably assumed that the sedimentary layers at this location will have the same flow characteristics as those beneath the RWMC.

Two generic disposal facilities were considered in the PE: a RCRA-compliant, belowground trench and a RCRA-compliant, above-ground tumulus (described in more detail in Chapter 5 of Volume 2). The generic facilities were selected to provide consistency in analysis of the performance of the 15 sites. Both generic facilities were assumed to be square with a plan area of $2500 \mathrm{~m}^{2}\left(26,910 \mathrm{ft}^{2}\right)$.

\subsection{BASIS FOR CONCEPTUAL MODEL USED IN THE PE}

The current understanding of radionuclide transport from a disposal facility at INEL is based on referenced sources of information contained in the performance assessment (Maheras et al., 1994) for INEL's RWMC, which is currently in operation as a disposal site for LLW. The descriptions below summarize how this information was incorporated into the PE's conceptual model for INEL.

\subsubsection{Water Pathway}

Knowledge of groundwater flow and radionuclide movement in the water pathway at INEL provided the basis for the conceptual model considered in the PE. The conceptual model encompassed the site technical staff's current understanding of site-specific geology, hydrology, water table and aquifer characteristics, and transport pathways.

\subsubsection{Current Understanding of Relevant Hydrogeology}

Studies of LLW disposal at INEL have centered on the RWMC, located in the southwestern part of INEL. Surficial sediments over most of the RWMC site are loess and minor alluvial silts and sands, ranging in thickness from 1 to $7.5 \mathrm{~m}(3.3 \mathrm{to} 24.6 \mathrm{ft})$. The geology underlying the RWMC is typical of the Eastern Snake River Plain, consisting of a series of basalt flows with silty interbeds of sedimentary deposits extending to great depths. The basalt 
flows are strongly fractured and fissured, exhibit a classic structure of massive rock in the center grading to highly vesicular rubble at the top and bottom, and vary in thickness from 3 to $30 \mathrm{~m}$ (10 to $98 \mathrm{ft}$ ). The fine-grained interbeds have an average thickness on the order of a few meters. Surficial and subsurface geologic data indicate that the RWMC area has both subsided and accumulated basalt flows and sediments at an average rate of $0.3 \mathrm{~mm} / \mathrm{y}(0.01 \mathrm{in} . / \mathrm{y})$, uninterrupted by significant uplift or erosion.

Flows from streams are generally diverted for irrigation before reaching INEL. Thus, during dry years, water from these streams does not reach INEL. The Big Lost River, Little Lost River, and Birch Creek drainages are part of a closed basin with no outlet. The drainages terminate in four playas in the north-central part of INEL. As a result of the closed basin, when water does flow onto INEL, it either evaporates or infiltrates into the ground. The INEL site is not crossed by any perennial streams; all surface outflows are a result of localized runoff.

The vadose zone at INEL ranges in thickness from $45 \mathrm{~m}$ (150 ft) in the northern portion to over $270 \mathrm{~m}(900 \mathrm{ft})$ in the south. Recharge $n$ estimates for undisturbed locations with natural vegetation cover are generally low: less than $1 \mathrm{~cm} / \mathrm{y}(0.4 \mathrm{in} . / \mathrm{y})$. Estimates for disturbed locations are higher-up to $10 \mathrm{~cm} / \mathrm{y}(4 \mathrm{in} / \mathrm{y})$-and show a seasonal effect. The recharge occurs primarily in the early spring as the accumulated snowpack melts during periods of low potential evapotranspiration. Similar to the RWMC, the region identified by the INEL staff as a likely location for a future disposal site is in a low-lying area and will be disturbed by disposal operations. For these reasons, the recharge of $7 \mathrm{~cm} / \mathrm{y}$ ( 3 in./y) used in the RWMC performance assessment is also assumed for the PE.

The primary controls on the movement of water within the vadose zone are thought to be sedimentary interbeds (Maheras et al., 1994). The fractures in the basalt are large enough (1 to $3 \mathrm{~mm}$ [0.04 to $0.12 \mathrm{in}$.]) that water movement in them likely occurs without attaining equilibrium with the much lower permeability basalt matrix. Therefore, water travel times through the vadose zone are likely longer in the northern part of INEL where sedimentary interbeds are thicker. The vadose zone provides partial protection to the underlying regional aquifer by filtering out many contaminants by adsorption, buffering dissolved chemical waste, and allowing radioactive decay during water transport.

Not all of the vadose zone at INEL is unsaturated. Perched water exists when large amounts of infiltration occur during periods when the Big Lost River flows onto INEL. Perched water also occurs at several facilities where infiltration ponds have continuously supplied water at the surface. These perched water bodies can extend radially up to $600 \mathrm{~m}(2000 \mathrm{ft})$ within the vadose zone.

Most of the permeable zones in the Snake River Aquifer underlying INEL occur along the upper and lower densely fractured or rubbled edges of the basalt flows. Estimates of the permeable or effective thickness of the aquifer vary from 76 to $400 \mathrm{~m}$ ( 250 to $1300 \mathrm{ft}$ ). This effective thickness undoubtedly varies spatially beneath INEL. Water movement in the aquifer is 
generally from the northeast to the southwest. Similar to the effective thickness, the flow velocity varies spatially as well. Tracer studies at INEL indicated natural flow rates (seepage velocities) of 1.5 to $6.1 \mathrm{~m} / \mathrm{d}$ ( 5 to $20 \mathrm{ft} / \mathrm{d})$, with an average near $3 \mathrm{~m} / \mathrm{d}(10 \mathrm{ft} / \mathrm{d})$; however, these locally measured velocities are not necessarily representative of the entire aquifer.

\subsubsection{Conceptual Model Used in the PE}

The PE used a generic conceptual model to describe the water pathway (summarized in Section 1.1.2 of this volume and described in detail in Chapter 5 of Volume 2). In the unsaturated zone, leachate was generated by constant flow through the disposal facility at a rate that was controlled by the assumed performance of the disposal facility. When all engineered barriers had failed, the rate was assumed to be equal to the natural recharge through local soils. The volumetric flow of water through the facility that generated leachate was based on the assumed performance and size of the disposal facility. No dilution was assumed to occur in the unsaturated zone, so at steady state, the concentration that reached groundwater equaled the leachate concentration. No lateral spreading was assumed, so the leachate flux through the unsaturated zone was confined to the soil column directly below the plan area of the facility.

As contaminated water entered the saturated zone, the contaminant mixed with clean groundwater, forming a plume with a shape controlled by aquifer and contaminant properties. The generic conceptual model assumed that instantaneous and complete mixing within the aquifer occurred directly below the facility. Mixing in the vertical direction occurred by hydrodynamic dispersion, and the contaminant mixing depth was an estimated value.

The generic conceptual model was adapted to conditions at INEL based on site-specific knowledge of the geology and water flow paths. The following description represents the conceptual model of the water pathway that was used in the PE for INEL.

The conceptual model for the water pathway at INEL is illustrated in Figure 4-3. The vadose zone was modeled as a single unit of sedimentary deposits with properties identical to those underlying the RWMC but with a thickness of $50 \mathrm{~m}$ (164 ft), uninterrupted by basalt interbeds or other significant features.

The entire Eastern Snake River Plain is underlain by the Snake River Plain Aquifer. The aquifer is thick with rapid water flowrates-average horizontal pore water velocities estimated at several hundred meters per year. With this groundwater flow activity, INEL must rely principally on the unsaturated zone for attenuation of contaminant releases to the subsurface.

As was used for the RWMC performance assessment, a 12-m (39 ft) mixing depth was assumed for the aquifer, based upon the average well screen depth for drinking water wells drilled into the aquifer. 


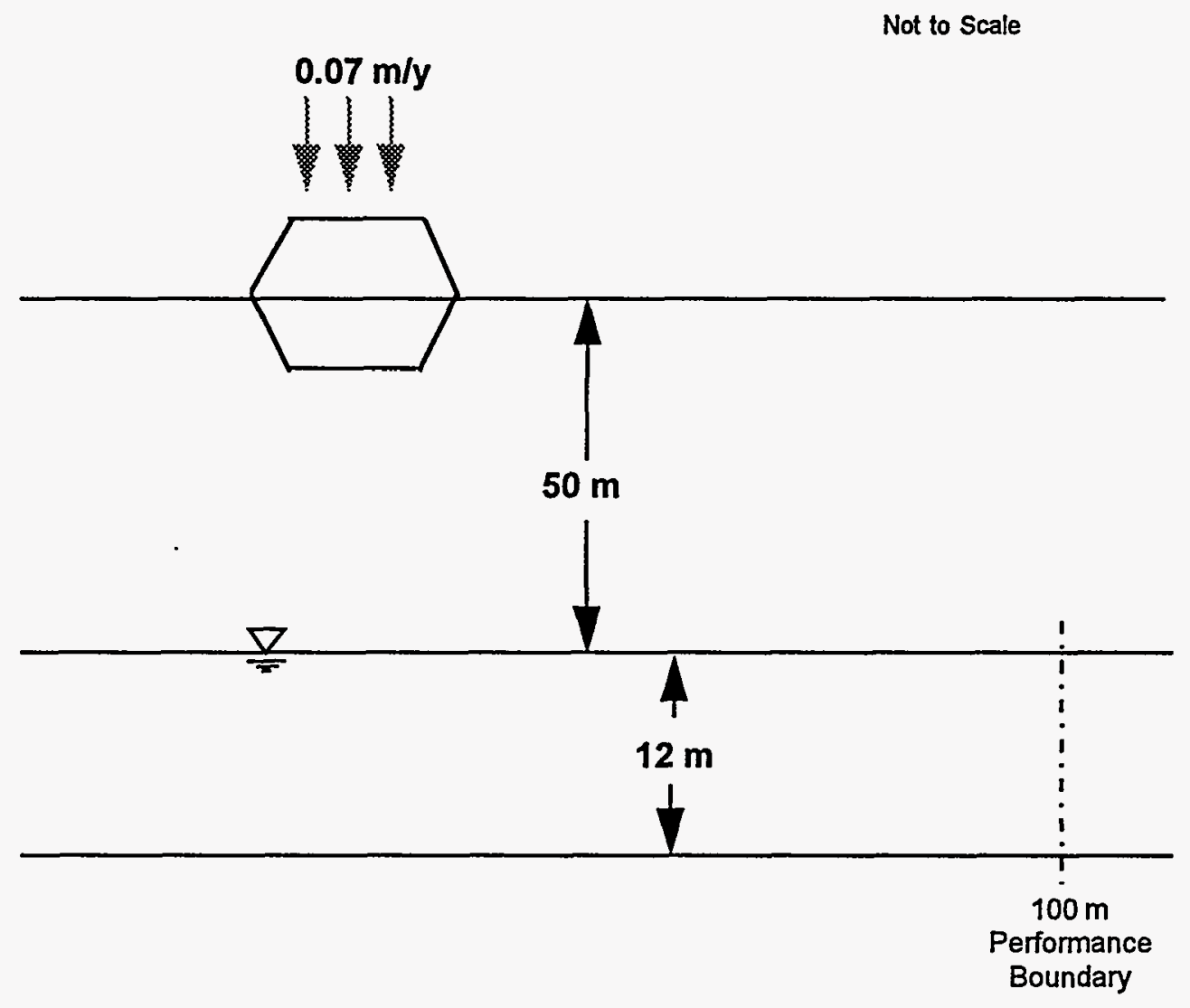

Figure 4-3. Conceptual model for water transport at INEL.

\subsubsection{Atmospheric Pathway}

The conceptual model used in the PE for evaluating the atmospheric pathway was derived from performance assessments for LLW disposal facilities at Hanford (Kincaid et al., 1993), INEL (Maheras et al., 1994), NTS (Baer et al., 1994), ORR (ORNL, 1994), and SRS (MMES et al., 1994). The model was generalized for the PE but used site-specific values for many of the parameters.

\subsubsection{Current Understanding of Relevant Meteorology}

Meteorological data are based on STAR data files summarized by the windrose in Figure 4-4. These data were obtained from hourly average meteorological readings taken at a height of $10 \mathrm{~m}(33 \mathrm{ft})$ at the meteorological tower in the Central Facilities Area at INEL during the period 1987 to 1991. 


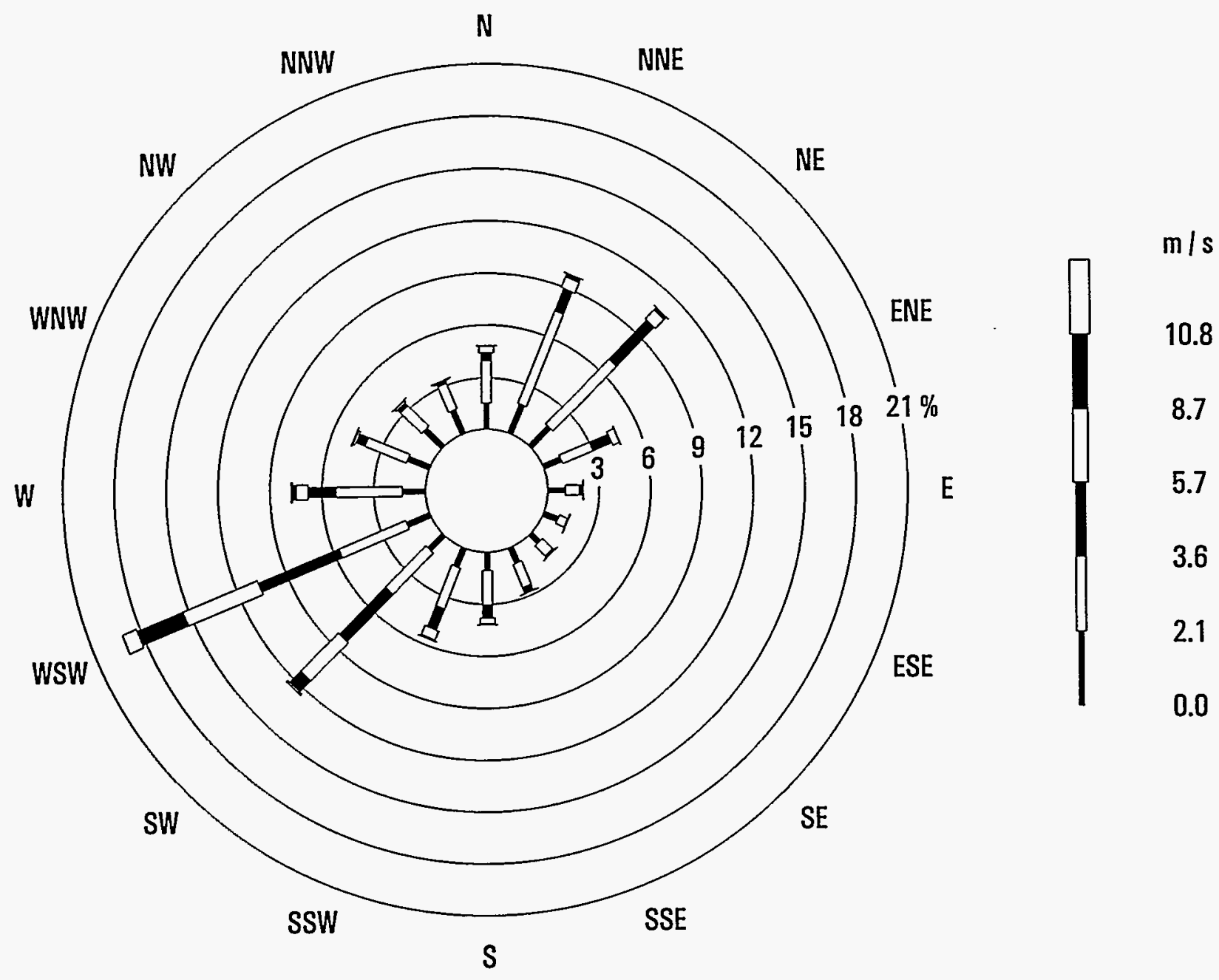

Figure 4-4. Windrose for INEL for the period 1987 to 1991 . The frequency of winds from each direction is plotted as a series of connected bars that extend from the center of the circular diagram toward the direction from which the winds originate. Wind speed categories are denoted by bar widths and shadings. The frequency of winds in each wind speed category is indicated by the length of the corresponding bar. 


\subsubsection{Conceptual Model Used in the PE}

The PE used a generic conceptual model to describe the atmospheric pathway (summarized in Section 1.2 of this volume and described in detail in Chapter 5 of Volume 2). Only $\mathrm{H}-3$ (tritium) and C-14 were expected to be volatile for the disposal facility conditions and thus were the only radionuclides considered for atmospheric transport in the PE. In the model, radionuclides were transported from the disposal facility to the soil surface by vapor (tritium) and gaseous (carbon dioxide carrying the $\mathrm{C}-14$ isotope) diffusion. When the radionuclides reached the soil surface, they were entrained in the air in vapor form as volatiles. Once airborne, these radionuclides were transported via atmospheric dispersion to a receptor located at the performance boundary.

Two components of the atmospheric pathway were evaluated separately: (1) the zone from the top of the disposal facility to the soil surface as indicated by the upward radionuclide diffusion profile; and (2) the zone in which a radionuclide was emitted to the atmosphere, mixed with the ambient air, and dispersed downwind from the waste disposal facility boundary to the $100-\mathrm{m}(328-\mathrm{ft})$ performance boundary.

The arrival time of radionuclides at the performance boundary was assumed to be $100 \mathrm{y}$ based on the following generic assumptions of the PE:

- The waste form was grouted MLLW treatment residuals. Based on this assumption, tritium as vapor was bound in the pore water of the hydrophilic grout, and carbon dioxide as a gas carrying the $\mathrm{C}-14$ isotope was limited by the high $\mathrm{pH}$ of the grout, so that the waste form provided retention of these volatile radionuclides in the disposal facility.

- The disposal facility was capped by a RCRA-compliant cover system. Based on this assumption, the cover system was maintained to provide low permeability for $100 \mathrm{y}$.

\subsubsection{Inadvertent Intruder Pathways}

Standard intrusion scenarios were used in the PE, with information derived from performance assessments of LLW disposal facilities at SRS (MMES et al., 1994) and ORR (ORNL, 1994) indicating that only two chronic-exposure scenarios needed to be considered for most sites and facility designs. Any variations in these scenarios were based on discussions with site technical staff about such factors as the types of activities that reasonably could result in exposure to buried waste at the site and the effectiveness of active or passive institutional controls and engineered barriers in precluding access to the waste.

The PE used two standard intrusion scenarios to describe potential modes of inadvertent intrusion (summarized in Section 1.3 of this volume and described in detail in Chapter 5 of Volume 2). The first scenario, the agriculture (homesteader) scenario, included establishment by an intruder of a permanent homestead directly above a disposal facility with the foundation of the home extending into the waste; some of the waste exhumed from the disposal facility was mixed 
with native soil in the intruder's vegetable garden. The second scenario, the post-drilling scenario, considered the construction of a well for a domestic water supply by an intruder. The well was drilled through the disposal facility and the cuttings were mixed with soil in the intruder's vegetable garden. The intruder gardened in some of the exhumed waste but did not reside permanently above the disposal facility. In both scenarios, exposure occurred where an intruder dug or drilled into the disposal facility.

For the generic intruder scenarios, the time of intrusion for the homesteader scenario was assumed to be $300 \mathrm{y}$ for the trench design and $500 \mathrm{y}$ for the tumulus design. The time of intrusion for the post-drilling scenario was assumed to be $100 \mathrm{y}$.

The two intrusion scenarios were discussed with INEL personnel, who concurred with the applicability and credibility of these scenarios at INEL.

\subsection{DATA USED IN THE PE}

The data presented in this section apply to the PE conceptual models described in Section 4.3. The calculations for determining permissible waste concentrations for the radionuclides considered in the PE are discussed in more detail in Chapter 5 of Volume 2 and summarized in Chapter 1 of this volume. The results of the calculations for INEL are presented in Section 4.5 and discussed in Section 4.6 of this volume.

\subsubsection{Water Transport}

Site-specific values required to perform the water pathway analysis were selected by site technical staff either from site characterizations and reports, from site-specific modeling results, or from general literature. For the unsaturated zone, the site-specific data that were required for the $\mathrm{PE}$ were distance between the disposal facility and groundwater; ambient moisture content; dry bulk density and distribution coefficients $\left(K_{d} \mathrm{~s}\right)$ of the geologic media; and natural recharge. For the saturated zone, the site-specific data that were required were porosity; dry bulk density of the geologic medium and distribution coefficients $\left(K_{d} \mathrm{~s}\right)$ of the radionuclides in the geologic medium; groundwater Darcy flow rates; and mixing depth in the aquifer.

These values for INEL are listed in Table 4-1 along with generic values that were used in the PE. Also indicated in the table is a designation of the type of data that the value represents and the source of the value. The values were determined from one or more of four data sources: (A) measurement performed by the site, state, or federal agency; (B) result of a numerical analysis performed by the site, state, or federal agency; (C) general literature value selected by the site; and (D) generic value of the PE. 
Table 4-1. Parameters and Values Used in the PE for the Water Pathway at INEL (generic PE values are in bold; these values and the standard PE method for applying them are summarized in Chapter 1 of this volume and discussed in more detail in Chapter 5 of Volume 2) (Part 1 of 2)

\begin{tabular}{|c|c|c|c|}
\hline Parameter & Value & $\begin{array}{l}\text { Data } \\
\text { Type* }\end{array}$ & Comments \\
\hline \multicolumn{4}{|l|}{ SOURCE TERM } \\
\hline $\begin{array}{l}\text { Volumetric water content } \\
\text { of the grouted waste, } \theta_{\theta}\end{array}$ & 0.3 & $\mathbf{D}$ & Standard PE value \\
\hline $\begin{array}{l}\text { Bulk density of grouted } \\
\text { waste, } \rho_{0}\end{array}$ & $1.76 \mathrm{~g} / \mathrm{cm}^{3}$ & $\bar{D}$ & Standard PE value \\
\hline $\begin{array}{l}\text { Distribution coefficients } \\
\text { for grouted waste, } K_{d}^{G}\end{array}$ & various & D & Standard PE value; see Table 4-2 \\
\hline $\begin{array}{l}\text { Disposal facility plan } \\
\text { area, } A\end{array}$ & $2500 \mathrm{~m}^{2}$ & $\overline{\mathbf{D}}$ & $\begin{array}{l}\text { Standard PE value; } A=a_{1} * a_{2}, \text { where } \\
a_{1}=a_{2}=50 \mathrm{~m}\end{array}$ \\
\hline $\begin{array}{l}\text { Waste mixing fraction for } \\
\text { trench, } f_{m}\end{array}$ & 0.67 & D & Standard PE value \\
\hline $\begin{array}{l}\text { Waste mixing fraction for } \\
\text { tumulus, } f_{m}\end{array}$ & 0.33 & D & Standard PE value \\
\hline $\begin{array}{l}\text { Annual rate of water } \\
\text { flowing through intact } \\
\text { trench facility }\end{array}$ & $0.03 \mathrm{~m} / \mathrm{y}$ & D & Standard PE value \\
\hline $\begin{array}{l}\text { Annual rate of water } \\
\text { flowing through intact } \\
\text { tumulus facility }\end{array}$ & $\begin{array}{c}0.00003 \\
\mathrm{~m} / \mathrm{y}\end{array}$ & D & Standard PE value \\
\hline $\begin{array}{l}\text { Time to failure of leachate } \\
\text { collection system }\end{array}$ & $30 y$ & D & Standard PE value \\
\hline $\begin{array}{l}\text { Time to failure of trench } \\
\text { facility }\end{array}$ & $100 y$ & D & Standard $P E$ value \\
\hline $\begin{array}{l}\text { Time to failure of tumulus } \\
\text { facility }\end{array}$ & $300 y$ & $\mathbf{D}$ & Standard PE value \\
\hline $\begin{array}{l}\text { Natural recharge through local } \\
\text { soils, } i\end{array}$ & $0.07 \mathrm{~m} / \mathrm{y}$ & A & Rood et al., 1994 \\
\hline
\end{tabular}

* $A=$ site measurement; $B=$ result of site numerical analysis; $C=$ literature value selected by the site; $D=$ generic $P E$ value 
Table 4-1. Parameters and Values Used in the PE for the Water Pathway at INEL (generic PE values are in bold; these values and the standard PE method for applying them are summarized in Chapter 1 of this volume and discussed in more detail in Chapter 5 of Volume 2) (Part 2 of 2)

\begin{tabular}{|c|c|c|c|}
\hline Parameter & Value & $\begin{array}{l}\text { Data } \\
\text { Type * }\end{array}$ & Comments \\
\hline \multicolumn{4}{|l|}{ UNSATURATED ZONE } \\
\hline Moisture content, $\theta_{w}$ & 0.17 & A & Rood et al., 1994 \\
\hline Bulk density, $\rho_{b}$ & $1.5 \mathrm{~g} / \mathrm{cm}^{3}$ & A & Rood et al., 1994 \\
\hline $\begin{array}{l}\text { Distribution coefficients for } \\
\text { geologic media, } K_{d}\end{array}$ & various & & See Table 4-2 \\
\hline $\begin{array}{l}\text { Thickness between trench and } \\
\text { saturated zone, } l\end{array}$ & $41.2 \mathrm{~m}$ & A & $\begin{array}{l}\text { Cumulative unsaturated sediment thickness } \\
\text { is } 50 \mathrm{~m} \text { (Taylor, 1994) and trench facility } \\
\text { bottom is } 8.8 \mathrm{~m} \text { below ground surface }\end{array}$ \\
\hline $\begin{array}{l}\text { Thickness between tumulus } \\
\text { and saturated zone, } l\end{array}$ & $50 \mathrm{~m}$ & A & $\begin{array}{l}\text { Cumulative unsaturated sediment thickness } \\
\text { is } 50 \mathrm{~m} \text { (Taylor, 1994) and tumulus facility } \\
\text { bottom is at ground surface }\end{array}$ \\
\hline \multicolumn{4}{|l|}{ SATURATED ZONE } \\
\hline Porosity, $n$ & 0.1 & $A$ & Rood et al., 1994 \\
\hline Bulk density, $\rho_{b}$ & $1.9 \mathrm{~g} / \mathrm{cm}^{3}$ & A & Rood et al., 1994 \\
\hline $\begin{array}{l}\text { Distribution coefficients for } \\
\text { geologic media, } K_{d}\end{array}$ & various & & See Table 4-2 \\
\hline Mixing depth, $d_{m}$ & $12 m$ & B & $\begin{array}{l}\text { This is actually the well screen depth used in } \\
\text { the performance assessment; it is less than } \\
\text { the predicted mixing depth and is therefore } \\
\text { conservative (Rood et al., 1994) }\end{array}$ \\
\hline Darcy velocity, $q_{g w}$ & $56 \mathrm{~m} / \mathrm{y}$ & A & Rood et al., 1994 \\
\hline $\begin{array}{l}\text { Distance to performance } \\
\text { boundary from facility } \\
\text { boundary }\end{array}$ & $100 \mathrm{~m}$ & $\mathbf{D}$ & Standard PE value \\
\hline
\end{tabular}

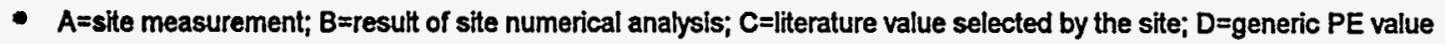


Table 4-2. Solid/Liquid Distribution Coefficients $\left(K_{d} \mathrm{~s}\right)$ Used in the PE at INEL

\begin{tabular}{|c|c|c|c|}
\hline \multirow[t]{2}{*}{ Element } & \multirow{2}{*}{$\begin{array}{c}\text { Waste } K_{d}^{G} \\
(\mathrm{~mL} / \mathrm{g})^{\mathrm{a}}\end{array}$} & \multicolumn{2}{|c|}{$K_{d}$ for Geologic Media $(\mathrm{mL} / \mathrm{g})^{b}$} \\
\hline & & Unsaturated Zone & Saturated Zone \\
\hline $\mathrm{H}$ & 0 & $0^{c}$ & $0^{\circ}$ \\
\hline C & 10 & $0^{c}$ & $0^{\circ}$ \\
\hline $\mathrm{Al}$ & 100 & 35 & 35 \\
\hline $\mathrm{Si}$ & 100 & 35 & 35 \\
\hline $\mathrm{Cl}$ & 0 & 15 & 15 \\
\hline $\mathrm{K}$ & 1 & $0.55^{\mathrm{c}}$ & $0.55^{\mathrm{c}}$ \\
\hline Co & 100 & $5^{c}$ & $5^{c}$ \\
\hline $\mathrm{Ni}$ & 10 & $100^{\circ}$ & $100^{\circ}$ \\
\hline $\mathrm{Se}$ & 1 & 150 & 150 \\
\hline $\mathrm{Sr}$ & 100 & $2^{c}$ & $2^{\mathrm{c}}$ \\
\hline $\mathrm{Zr}$ & 10 & 600 & 600 \\
\hline $\mathrm{Nb}$ & 10 & 160 & 160 \\
\hline Tc & 1 & $0.15^{\circ}$ & $0.15^{c}$ \\
\hline$P d$ & 100 & 55 & 55 \\
\hline $\mathrm{Ag}$ & 100 & $45^{c}$ & $45^{\circ}$ \\
\hline $\mathrm{Cd}$ & 100 & 80 & 80 \\
\hline $\mathrm{Sn}$ & 10 & 130 & 130 \\
\hline 1 & 1 & $0.05^{c}$ & $0.05^{c}$ \\
\hline Cs & 10 & $20^{\circ}$ & $20^{\circ}$ \\
\hline $\mathrm{Ba}$ & 10 & $60^{\circ}$ & $60^{\circ}$ \\
\hline $\mathrm{Sm}$ & 10 & 245 & 245 \\
\hline Eu & 10 & $65^{c}$ & $65^{\circ}$ \\
\hline $\mathrm{Pb}$ & 100 & $100^{d}$ & $10^{d}$ \\
\hline $\mathrm{Ra}$ & 10 & $50^{\circ}$ & $5^{c}$ \\
\hline Th & 100 & $1000^{c}$ & $100^{c}$ \\
\hline $\mathrm{Pa}$ & 100 & $1000^{d}$ & $100^{d}$ \\
\hline$U$ & 100 & $1000^{\circ}$ & $100^{c}$ \\
\hline $\mathrm{Np}$ & 100 & $50^{\circ}$ & $5^{c}$ \\
\hline $\mathrm{Pu}$ & 100 & $2000^{c}$ & $200^{\circ}$ \\
\hline $\mathrm{Am}$ & 100 & 1900 & $190^{\mathrm{e}}$ \\
\hline $\mathrm{Cm}$ & 100 & 4000 & $400^{e}$ \\
\hline $\mathrm{Cf}$ & 100 & 4000 & $400^{e}$ \\
\hline
\end{tabular}

a Standard PE values; see Chapter 5 of Volume 2

b Values for sand from Thibault et al., 1990, unless otherwise noted

C Maheras et al., 1994, Table 3-7

d Case et al., 1990

e Based on 10:1 ratio used by Maheras et al., 1994 
The values in Table 4-1 present the data used for calculations for the generic trench and tumulus design. The subsurface data for the assumed site for the proposed MLLW facility differ from the RWMC only in the cumulative thickness of sedimentary interbeds in the underlying stratigraphy, which is estimated at $50 \mathrm{~m}(164 \mathrm{ft})$. Otherwise, the hydrogeologic parameters are identical to those used in the performance assessment for the RWMC (Maheras et al., 1994); most have been derived from the Engineering Design File RWMC-760 (Rood et al., 1994), which documents the calculations presented in the performance assessment.

Of the parameters in the PE that depended on site-specific values, only three potentially encompassed enough variability in values to significantly affect the results: natural recharge, $i$; distribution coefficients $\left(K_{d} \mathrm{~s}\right)$ for the geologic media; and groundwater Darcy velocity $\left(q_{g w}\right)$. The sources of these values are discussed in this section. The sensitivity of the results to changes in the values of these parameters is discussed in Section 4.6.2 of this volume and Chapter 6 of Volume 2.

The natural recharge through the disposal facility and the groundwater velocity in the Snake River Plain Aquifer were determined by site staff for the RWMC performance assessment (Maheras et al., 1994). The range of values for recharge was estimated in studies performed at the USGS soil percolation site, adjacent to the RWMC, to be from 0.005 to $0.10 \mathrm{~m} / \mathrm{y}(0.016$ to $0.33 \mathrm{ft} / \mathrm{y})$. The highest recorded value is $0.30 \mathrm{~m}(0.98 \mathrm{ft})$ of recharge, measured near neutron access tube 6 on the RWMC. Groundwater Darcy velocities were given a range of $55 \mathrm{~m} / \mathrm{y}$ to $222 \mathrm{~m} / \mathrm{y}(180 \mathrm{ft} / \mathrm{y}$ to $728 \mathrm{ft} / \mathrm{y})$ in the performance assessment.

Values for distribution coefficients $\left(K_{d} s\right)$ are listed in Table 4-2 for the 58 radionuclides (32 elements) considered in the PE. In addition to the $K_{d}$ values for the geologic media, grout $K_{d}$ values are listed for determining the desorption from the source term resulting from the grouted waste form. The $K_{d}$ values for the unsaturated zone are standard PE values (Thibault et al., 1990), except where superseded by values obtained from the RWMC performance assessment. The RWMC performance assessment differentiates between $K_{d}$ values for the unsaturated and saturated zones: it assigns values to the saturated zone equal to one-tenth the value for the unsaturated zone for elements with atomic number 82 and higher $(\mathrm{Pb}-210$ and above on the $\mathrm{PE}$ list of radionuclides). Deferring to site expertise, this method was adopted for the $\mathrm{PE}$ analysis at INEL as well.

\subsubsection{Atmospheric Transport}

Site-specific data required to perform the atmospheric pathway analysis came from site personnel as data either from site characterizations and reports or from general literature. The site-specific data required for the soil diffusion calculation were the same as some of those required for the water transport analysis (Section 4.4.1). These values are shown in Table 4-3. Necessary atmospheric dispersion data included wind speed and direction and stability class, which are summarized in Section 4.3.2.1. 
Table 4-3. Parameters and Values Used in the PE for the Atmospheric Pathway at INEL (generic PE values are in bold; these values and the standard PE method for applying them are summarized in Chapter 1 of this volume and discussed in more detail in Chapter 5 of Volume 2)

\begin{tabular}{|c|c|c|c|}
\hline Parameter & Value & $\begin{array}{l}\text { Data } \\
\text { Type* }\end{array}$ & Comments \\
\hline $\begin{array}{l}\text { Disposal facility cover } \\
\text { thickness, } x\end{array}$ & $1.0 \mathrm{~m}$ & D & Standard PE value \\
\hline $\begin{array}{l}\text { Depth of the soil } \\
\text { surface, } d\end{array}$ & $0.01 \mathrm{~m}$ & D & $\begin{array}{l}\text { Standard PE value based on } \\
\text { Maheras et al. (1994) }\end{array}$ \\
\hline Porosity, $n$ & 0.487 & $c$ & $\begin{array}{l}\text { INEL Engineering Design File, RWMC-760, } \\
\text { p. C-1, provided to Core Leam during } \\
\text { September } 1994 \text { site visit. (Rood, et al., } \\
\text { 1994) }\end{array}$ \\
\hline Percent saturation, $s$ & 0.68 & c & $\begin{array}{l}\text { INEL Engineering Design File, RWMC-760, } \\
\text { p. C-1, provided to Core Leam during } \\
\text { September } 1994 \text { site visit. (Rood, et al., } \\
\text { 1994) }\end{array}$ \\
\hline $\begin{array}{l}\text { Ratio of water density } \\
\text { in air to liquid, } r\end{array}$ & 9.2E-06 & D & $\begin{array}{l}\text { Standard PE value based on MMES } \\
\text { et al. (1994) }\end{array}$ \\
\hline $\begin{array}{l}\text { Ratio of } \mathrm{CO}_{2} \\
\text { concentration in air to } \\
\text { dissolved in water, } r\end{array}$ & $4.3 E-04$ & D & $\begin{array}{l}\text { Standard PE value based on Foust et } \\
\text { al. (as cited in Cooper and Alley, } \\
\text { 1986) }\end{array}$ \\
\hline $\begin{array}{l}\text { Tritium diffusion } \\
\text { coefficient in air, } D\end{array}$ & $2.39 E-05 \mathrm{~m}^{2} / \mathrm{s}$ & D & $\begin{array}{l}\text { Standard PE value based on CRC } \\
(1981)\end{array}$ \\
\hline $\begin{array}{l}\text { Carbon diffusion } \\
\text { coefficient in air, } D\end{array}$ & $1.4 \mathrm{E}-05 \mathrm{~m}^{2} / \mathrm{s}$ & D & $\begin{array}{l}\text { Standard PE value based on CRC } \\
\text { (1981) }\end{array}$ \\
\hline $\begin{array}{l}\text { Atmospheric dispersion } \\
\text { term, } A_{D}\end{array}$ & $\begin{array}{c}0.24 \\
\left(\mu \mathrm{Ci} / \mathrm{m}^{3}\right) /\left(\mu \mathrm{Ci} / \mathrm{m}^{2}-\mathrm{s}\right)\end{array}$ & B & $\begin{array}{l}\text { Value is estimated using the Industrial } \\
\text { Source Complex-Version } 2 \text { Long Term Air } \\
\text { Dispersion Model (ISCLT2) (EPA, 1992) } \\
\text { based on site-specific STAR data }\end{array}$ \\
\hline
\end{tabular}

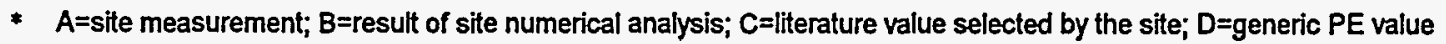

\subsubsection{Inadvertent Intruder Exposure}

As explained in Section 4.3.3, the PE used two standard intrusion scenarios to describe potential modes of inadvertent intrusion at all the sites. Because these intrusion scenarios were considered applicable to all sites, no values specific to INEL are used in the calculation of exposures to inadvertent intruders. 


\subsection{RESULTS OF THE PE}

The performance evaluation provided estimates of permissible concentrations in disposed MLLW. The three calculations that formed the foundation of the PE-for the water, atmospheric, and inadvertent intruder pathways-are summarized in Sections 1.1, 1.2, and 1.3, respectively, of this volume and discussed in detail in Chapter 5 of Volume 2.

For each pathway the maximum permissible waste concentration at the performance boundary was determined for each radionuclide by using the performance measures: $4 \mathrm{mrem}$ $(0.04 \mathrm{mSv})$ per year from the water pathway for releases to drinking water; $10 \mathrm{mrem}(0.1 \mathrm{mSv})$ per year from all pathways for atmospheric releases; and $100 \mathrm{mrem}(1 \mathrm{mSv})$ per year from all exposure pathways for chronic exposure of inadvertent intruders; and the appropriate pathway or scenario dose conversion factors (annual effective dose equivalent per unit concentration) based on EPA dose conversion factors. The basis for the performance measures used in the PE is discussed in more detail in Chapter 5 of Volume 2. For the water and atmospheric pathways, the concentration reduction provided by the environment (i.e., the CRF) was estimated using results of site analyses and data. For the intruder analyses, concentration reduction was estimated for appropriate exposure pathways for two intrusion scenarios that, in general, were the same for all the sites. The results of the calculations for the pathways that were analyzed at INEL are provided in this section and discussed in Section 4.6.

\subsubsection{Water Transport}

Two CRFs were calculated for the water pathway: the source CRF, $C R F_{\text {Source, }}$ and the environmental transport $\mathrm{CRF}$ for water, $C R F_{\text {Water. }}$. The source $\mathrm{CRF}$ represents the concentration attenuation between the disposed waste and leachate exiting the bottom of the disposal facility and was defined as the dimensionless ratio of the waste concentration to the resulting leachate concentration. Desorption with infiltrating water was the mechanism used to describe the leaching of radionuclides from the grout. Because a generic method was used to determine the $C R F_{\text {Source }}$ for the 58 radionuclides considered in the PE (summarized in Section 1.1 of this volume and discussed in more detail in Chapter 5 of Volume 2), the radionuclide-specific values for the source CRF for each type of generic facility were the same for all 15 sites.

The environmental transport CRF for water was defined as the ratio of the concentration of the leachate exiting the disposal facility to the resulting concentration in water at the performance boundary. The concentration attenuation represented by $C R F_{\text {Water }}$ consisted of dilution due to mixing with uncontaminated groundwater. Effects of radioactive decay and decay product ingrowth were also included in the PE.

In the PE, water travel time from the facility location to the performance boundary was calculated as a basis for comparison with the retarded travel time of the radionuclides. For INEL, water travel time from the land surface to the performance boundary (i.e., without consideration of a disposal facility) was estimated at about $120 \mathrm{y}$. 
The calculation of travel time through the vadose zone for a radionuclide, on the other hand, must account both for the lower infiltration rate because of the facility's RCRA cover and for the retardation defined by the distribution coefficient for the geologic media. In the PE, the calculation for travel time in the vadose zone first determined the distance a radionuclide traveled at the lower infiltration rate. Then, if the radionuclide had not fully traversed the vadose zone, the additional time required to complete travel in the vadose zone under the higher, infiltration rate based on the natural recharge through local soils was calculated and added to the time determined at the lower infiltration rate.

In the $\mathrm{PE}$, the detention time in the facility for a radionuclide was the time during which water flowing through the facility was assumed to be caught by the leachate collection system. Specifically, the calculation of travel time for a radionuclide accounted for the following:

- For the trench design, the leachate collection system was assumed to catch water flowing through the facility for the first $30 \mathrm{y}$. After $30 \mathrm{y}$, the liner and leachate collection system failed, and water flowing through the facility for the next $70 \mathrm{y}$ was assumed to be $0.03 \mathrm{~m} / \mathrm{y}$ $(0.1 \mathrm{ft} / \mathrm{y})$ based on a unit hydraulic gradient and the saturated hydraulic conductivity of the RCRA cover system. After a total of 100 y of reduced water flow because of engineered barriers ( $30 \mathrm{y}$ of detention plus $70 \mathrm{y}$ limited by the RCRA cover system), the rate was assumed to be the natural recharge through local soils, $0.07 \mathrm{~m} / \mathrm{y}(0.23 \mathrm{ft} / \mathrm{y})$.

- For the tumulus design, the leachate collection system was assumed to catch water flowing through the facility for the first $30 \mathrm{y}$. After $30 \mathrm{y}$, the liner and leachate collection system was assumed to fail, and flow of water through the facility for the next $270 \mathrm{y}$ was assumed to be $0.00003 \mathrm{~m} / \mathrm{y}(0.0001 \mathrm{ft} / \mathrm{y})$ based on a unit hydraulic gradient and the saturated hydraulic conductivity of the concrete vaults. After a total of $300 \mathrm{y}$ of reduced flow because of engineered barriers ( $30 \mathrm{y}$ detention plus $270 \mathrm{y}$ limited by the concrete vaults), the rate was assumed to be the natural recharge through local soils, $0.07 \mathrm{~m} / \mathrm{y}$ $(0.23 \mathrm{ft} / \mathrm{y})$.

Travel time through the aquifer was independent of facility design and was about $0.18 \mathrm{y}$, based on groundwater Darcy velocity and a 100-m (328-ft) distance to the performance boundary (see Section 1.1.2 of this volume for a summary of these assumptions and Chapter 5 of Volume 2 for additional details). The arrival time of a radionuclide at the performance boundary is the sum of the detention time in the facility, travel time through the vadose zone, and travel time through the aquifer.

Retardation of radionuclides by interaction with soils and rock in the vadose and saturated zones increased travel times for individual radionuclides. This effect was particularly important for short-lived radionuclides because of radioactive decay. For short-lived radionuclides, the effects of radioactive decay combined with long travel times increased the permissible concentrations in the disposal facility. 
Application of the PE methodology for water transport of the 58 radionuclides considered in the PE produced the results shown in Table 4-4 for the generic trench and generic tumulus designs at INEL. The table shows permissible waste concentrations based on transport through the water pathway $\left(C_{\text {w-Water }}\right)$ as well as the values used in calculating the permissible waste concentrations.

Some radionuclides listed in Table 4-4 have no limit (NL) on their permissible waste concentrations, the result of the combined effects of relatively short half-lives and sufficiently long travel time to the performance boundary. "No limit" is defined as a permissible waste concentration that is greater than the specific activity of the pure elemental radionuclide. For disposal of the maximum possible waste concentration of these relatively short-lived radionuclides, the water pathway produced a dose at the performance boundary of less than $4 \mathrm{mrem}(0.04 \mathrm{mSv})$ per year and, therefore, the permissible waste concentration was unlimited based on exposures from this pathway.

For some radionuclides, no value is listed in Table 4-4 for the radioactive decay term, $r_{\text {Decay. }}$. These radionuclides had radioactive decay terms that were very large (e.g., greater than $1 E+50)$. Any radionuclide with a radioactive decay term greater than $1 E+50$ was ensured a calculated permissible waste concentration greater than the specific activity of the pure elemental radionuclide, which, as described previously, resulted in no limit (NL) on permissible waste concentrations for disposal.

Arrival times for some radionuclides listed in Table 4-4 were beyond the 10,000-y performance period. For those radionuclides, the estimated waste concentrations are presented in Table 4-4 for information purposes only. Consistent with the approach used in LLW performance assessments, these values were not considered in determining the most restrictive disposal limit from among the evaluated pathways.

For all radionuclides in Table 4-4, the rate of water flow at the time of facility failure controlled the subsurface transport (i.e., the subsurface movement of the radionuclides in the trench and tumulus was controlled by the natural recharge at $100 \mathrm{y}$ after closure for the trench [when the cover failed] and at $300 \mathrm{y}$ for the tumulus [when the concrete vaults failed]). None of the radionuclides was controlled by flow rates at earlier times.

For the tumulus, the total undecayed $C R F$ (the product of the $C R F_{\text {Source }}$ and the $C R F_{\text {Water }}$ ) for the groundwater pathway were twice the total undecayed CRFs for the trench within roundoff error. This result was due to the difference in the volume fraction of waste (the ratio of waste material to total material in the disposal unit) between the two technologies - twice as much waste leached from the trench for a given rate of flow because a given volume of trench contained twice as much waste. 
Table 4-4. Results of Calculations for the Water Pathway at INEL (water travel time from land surface to performance boundary [excluding facility detention] $=120 \mathrm{y}$ ) (Part 1 of 2)

\begin{tabular}{|c|c|c|c|c|c|c|c|c|c|c|c|c|}
\hline \multirow[t]{2}{*}{ Nuclide } & \multirow[b]{2}{*}{$\begin{array}{c}\text { PDCF } \\
\text { rem/y per } \mu \mathrm{CI} L\end{array}$} & \multicolumn{5}{|c|}{ Trench } & \multicolumn{5}{|c|}{ Tumulus } & \multirow[t]{2}{*}{ Nuclide } \\
\hline & & $\begin{array}{l}\text { CRF } \\
\text { (olmensionloss) } \\
\end{array}$ & 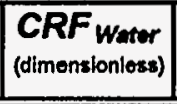 & $\begin{array}{c}\text { Arrival } \\
\text { Time }(y) \\
\end{array}$ & \begin{tabular}{|c|}
$\begin{array}{c}\text { roveny }^{2} \\
\text { (dimensionless) }\end{array}$ \\
\end{tabular} & $\begin{array}{c}C_{\text {wawater }}^{b} \\
\left(\mu \mathrm{Cl} / \mathrm{m}^{3}\right) \\
\end{array}$ & $\begin{array}{l}\text { CRF }_{\text {Source }} \\
\text { (dimensioniess) }\end{array}$ & \begin{tabular}{|c|} 
CRF Wetor \\
(dimensiontess)
\end{tabular} & $\begin{array}{c}\text { Arrival } \\
\text { Time }(y)\end{array}$ & \begin{tabular}{|c|}
$\begin{array}{c}\text { roccayy }^{\prime} \\
\text { (dimensionless) }\end{array}$ \\
\end{tabular} & $\begin{array}{c}C_{\text {w-warer }}{ }^{b} \\
\left(\mu \mathrm{Cl} / \mathrm{m}^{3}\right)\end{array}$ & \\
\hline $\mathrm{H}-3$ & 4.67E-02 & 0.45 & 190 & 1.7E+02 & $1.3 \mathrm{E}+04$ & $1 E+08$ & 0.9 & 190 & $4.2 E+02$ & $1.8 E+10$ & $3 E+14$ & $\mathrm{H}-3$ \\
\hline C-14 & $1.52 E+00$ & 27 & 190 & $1.7 E+02$ & $1.0 \mathrm{E}+00$ & $1 E+04$ & 54 & 190 & $4.2 E+02$ & $1.1 E+00$ & $3 E+04$ & C-14 \\
\hline$A 1-26$ & $1.06 \mathrm{E}+01$ & 270 & 190 & $3.1 E+04$ & $1.0 E+00$ & $2 E+04$ & 540 & 190 & $3.8 \mathrm{E}+04$ & $1.0 \mathrm{E}+00$ & $4 E+04$ & Al-26 \\
\hline Si-32 & $7.99 E+00$ & 270 & 190 & $3.1 E+04$ & $e$ & $\mathrm{NL}$ & 540 & 190 & $3.8 E+04$ & $e$ & $\mathrm{NL}$ & Si-32 \\
\hline Cl-36 & $2.21 \mathrm{E}+00$ & 0.45 & 190 & $1.3 E+04$ & $1.0 \mathrm{E}+00$ & $2 E+02$ & 0.9 & 190 & $1.7 \mathrm{E}+04$ & $1.0 E+00$ & $3 E+02$ & Cl 36 \\
\hline$K-40$ & $1.36 \mathrm{E}+01$ & 3.1 & 190 & $6.6 \mathrm{E}+02$ & $1.0 \mathrm{E}+00$ & $2 E+02$ & 6.2 & 190 & $1.0 \mathrm{E}+03$ & $1.0 E+00$ & $4 \mathrm{E}+02$ & $\mathrm{~K}-40$ \\
\hline Co-60 & $1.97 E+01$ & 270 & 190 & $4.6 \mathrm{E}+03$ & $\mathrm{e}$ & NL & 540 & 190 & $5.8 \mathrm{E}+03$ & e & $\mathrm{NL}$ & Co-60 \\
\hline Ni-59 & 1.53E-01 & 27 & 190 & $8.9 E+04$ & $2.2 E+00$ & $3 E+05 \quad c$ & 54 & 190 & $1.1 E+05$ & $2.7 E+00$ & $7 E+05$ & Ni-59 \\
\hline $\mathrm{Ni}-63$ & 4.21E-01 & 27 & 190 & $8.9 E+04$ & e & NL $\quad c$ & 54 & 190 & $1.1 E+05$ & e & $\mathrm{NL}$ & Ni-63 \\
\hline Se-79 & $6.35 E+00$ & 3.1 & 190 & $1.3 E+05$ & $4.1 \mathrm{E}+00$ & $2 E+03$ & 6.2 & 190 & $1.6 \mathrm{E}+05$ & $5.6 \mathrm{E}+00$ & $4 \mathrm{E}+03$ & se-79 \\
\hline Sr-90 & $1.12 E+02$ & 270 & 190 & $1.9 E+03$ & $1.2 \mathrm{E}+20$ & $\mathrm{NL}$ & 540 & 190 & $2.6 E+03$ & $3.8 E+26$ & $\mathrm{NL}$ & Sr-90 \\
\hline $2 r-93$ & $1.59 E+00$ & 27 & 190 & $5.3 E+05$ & $1.3 E+\infty 0$ & $2 \mathrm{E}+04{ }^{\circ}$ & 54 & 190 & $6.5 E+05$ & $1.3 E+00$ & $4 E+04$ & Zr-93 \\
\hline Nb-93m & $3.81 \mathrm{E}-01$ & 27 & 190 & $1.4 \mathrm{E}+05$ & $e$ & $\mathrm{NL}$ & 54 & 190 & 1.7E+05 & $e$ & $\mathrm{NL}$ & $\mathrm{Nb}-93 \mathrm{~m}$ \\
\hline $\mathrm{Nb}-94$ & $5.21 E+00$ & 27 & 190 & $1.4 \mathrm{E}+05$ & $1.4 E+02$ & $5 \mathrm{E}+05 \quad c$ & 54 & 190 & $1.7 E+05$ & $3.9 E+02$ & $3 E+06$ & $\mathrm{Nb}-94$ \\
\hline Tc-99 & $1.07 E+00$ & 3.1 & 190 & $3.0 \mathrm{E}+02$ & $1.0 \mathrm{E}+\infty 0$ & $2 E+03$ & 6.2 & 190 & $5.8 E+02$ & $1.0 E+00$ & $5 E+03$ & TC-99 \\
\hline Pd-107 & $1.09 \mathrm{E}-01$ & 270 & 190 & $4.9 E+04$ & $1.0 E+\infty$ & $2 E+06$ & 540 & 190 & $6.0 \mathrm{E}+04$ & $1.0 \mathrm{E}+\infty 0$ & $4 E+06$ & Pd-107 \\
\hline$A g-108 m$ & $5.56 \mathrm{E}+00$ & 270 & 190 & $4.0 E+04$ & e & $\mathrm{NL}$ & 540 & 190 & $4.9 E+0.4$ & e & NL & $\mathrm{Ag}-108 \mathrm{~m}$ \\
\hline Cd-113m & $1.17 \mathrm{E}+02$ & 270 & 190 & $7.1 E+04$ & e & NL & 540 & 190 & $8.6 E+04$ & e & $\mathrm{NL}$ & $\mathrm{Cd}-113 \mathrm{~m}$ \\
\hline Sn-121m & $1.28 \mathrm{E}+00$ & 27 & 190 & $1.2 E+05$ & e & $N L$ & 54 & 190 & $1.4 E+05$ & e & $\mathrm{NL}$ & $\mathrm{sn}-121 \mathrm{~m}$ \\
\hline Sn-126 & $1.53 \mathrm{E}+01$ & 27 & 190 & $1.2 \mathrm{E}+05$ & $2.2 E+00$ & $3 E+03$ & 54 & 190 & $1.4 E+05$ & $2.6 E+\infty 0$ & $7 E+03$ & $5 n-126$ \\
\hline $\mid-129$ & $2.01 E+02$ & 3.1 & 190 & $2.1 E+02$ & $1.0 E+\infty$ & $1 \mathrm{E}+01$ & 6.2 & 190 & $4.7 E+02$ & $1.0 E+\infty$ & $2 E+01$ & $1-129$ \\
\hline Cs-135 & $5.16 E+00$ & 27 & 190 & $1.8 E+04$ & $1.0 \mathrm{E}+\infty$ & $4 E+03$ & 54 & 190 & $2.2 E+04$ & $1.0 E+\infty$ & $8 E+03$ & Cs-135 \\
\hline$C_{s-137}$ & $3.65 E+01$ & 27 & 190 & $1.8 E+04$ & $e$ & NL ${ }^{\circ}$ & 54 & 190 & $2.2 E+04$ & $e$ & $\mathrm{NL}$ & Cs-137 \\
\hline $8 a-133$ & $2.48 \mathrm{E}+00$ & 27 & 190 & $5.3 E+04$ & $e$ & $\mathrm{NL}$ & 54 & 190 & $6.5 \mathrm{E}+04$ & e & $\mathrm{NL}$ & $B a-133$ \\
\hline$S m-151$ & 2.84E-01 & 27 & 190 & $2.2 E+05$ & e & $\mathrm{NL}$ & 54 & 190 & $2.6 \mathrm{E}+05$ & $e$ & $\mathrm{NL}$ & $S m-151$ \\
\hline Eu-152 & $4.73 E+00$ & 27 & 190 & $5.8 E+04$ & $\mathbf{e}$ & $\mathrm{NL}$ & 54 & 190 & $7.0 E+04$ & $e$ & $\mathrm{NL}$ & $E u-152$ \\
\hline Eu-154 & $6.97 \mathrm{E}+00$ & 27 & 190 & $5.8 \mathrm{E}+04$ & e & $\mathrm{NL}$ & 54 & 190 & $7.0 \mathrm{E}+04$ & $e$ & NL & $E u-154$ \\
\hline $\mathrm{Pb}-210$ & $5.30 \mathrm{E}+03$ & 270 & 190 & $8.8 E+04$ & $e$ & $\mathrm{NL}$ & 540 & 190 & $1.1 E+05$ & e & NL & $\mathrm{Pb}-210$ \\
\hline Ra-226 & $6.27 E+03$ & 27 & 190 & $4.4 E+04$ & $2.2 E+08$ & $7 E+08 \quad \circ$ & 54 & 190 & $5.4 \mathrm{E}+04$ & $1.4 \mathrm{E}+10$ & $1 \mathrm{E}+11$ & Ra-226 \\
\hline Ra-228 & $1.64 \mathrm{E}+03$ & 27 & 190 & $4.4 E+04$ & e & $\mathrm{NL}$ & 54 & 190 & $5.4 \mathrm{E}+04$ & $e$ & $N L$ & Ra-228 \\
\hline Th-229 & $2.94 E+03$ & 270 & 190 & $8.8 E+05$ & $2.7 E+36$ & $\mathrm{NL}$ & 540 & 190 & $1.1 \mathrm{E}+06$ & $1.6 E+44$ & NL & Th-229 \\
\hline Th-230 & $6.12 E+03$ & 270 & 190 & $8.8 E+05$ & NA & $3 E+01 \quad c$ & 540 & 190 & $1.1 E+06$ & NA & $7 E+01$ & Th-230 \\
\hline$T h-232$ & $3.63 E+03$ & 270 & 190 & $8.8 E+05$ & $1.0 E+00$ & $6 E+01 \quad c$ & 540 & 190 & $1.1 \mathrm{E}+06$ & $1.0 \mathrm{E}+\infty 0$ & $1 E+02$ & Th-232 \\
\hline $\mathrm{Pa}-231$ & $1.85 E+04$ & 270 & 190 & $8.8 E+05$ & $1.3 \mathrm{E}+08$ & $1 E+09 \quad c$ & 540 & 190 & $1.1 E+06$ & $6.9 E+09$ & $2 E+11$ & Pa-231 \\
\hline
\end{tabular}


Table 4-4. Results of Calculations for the Water Pathway at INEL (water travel time from land surface to performance boundary [excluding facility detention] $=120 \mathrm{y})($ Part 2 of 2$)$

\begin{tabular}{|c|c|c|c|c|c|c|c|c|c|c|c|c|}
\hline \multirow[t]{2}{*}{ Nuclide } & \multirow[b]{2}{*}{$\begin{array}{c}\text { PDCF } \\
\text { remly per } \mu \mathrm{Cl}\end{array}$} & \multicolumn{5}{|c|}{ Trench } & \multicolumn{5}{|c|}{ Tumulus } & \multirow[t]{2}{*}{ Nuclide } \\
\hline & & $\begin{array}{l}\text { CRF source } \\
\text { (dimensiontezs) }\end{array}$ & $\begin{array}{c}\text { CRF water } \\
\text { (dimencionloses) }\end{array}$ & $\begin{array}{l}\text { Arrival } \\
\text { Time (y) }\end{array}$ & $\begin{array}{c}\text { romayy }^{a} \\
\text { (dimonsionioss) }\end{array}$ & $\begin{array}{c}C_{\text {wwater }}{ }^{b} \\
\left(\mu \mathrm{Ci} / \mathrm{m}^{3}\right)\end{array}$ & $\begin{array}{l}\text { CRF source } \\
\text { (dimonsionloss) }\end{array}$ & 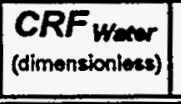 & $\begin{array}{l}\text { Arrival } \\
\text { Time }(y)\end{array}$ & $\begin{array}{c}r_{\text {Docasy }} \\
\text { (dimenzionlessos) }\end{array}$ & $\begin{array}{c}C_{\text {wwatar }} \\
\left(\mu \mathrm{C} / \mathrm{m}^{3}\right)\end{array}$ & \\
\hline $\mathrm{U}-232$ & $1.55 \mathrm{E}+03$ & 270 & 190 & $8.8 E+05$ & e & NL & 540 & 190 & $1.1 E+06$ & e & NL & U-232 \\
\hline U-233 & $1.95 E+03$ - & 270 & 190 & $8.8 E+05$ & NA & $1 E+02$ & 540 & 190 & 1.1E+06 & NA & $2 E+02$ & $U-233$ \\
\hline U-234 & $6.48 E+02 d$ & 270 & 190 & $8.8 E+05$ & NA & $3 E+02 c$ & 540 & 190 & $1.1 E+06$ & NA & $6 E+02$ & U-234 \\
\hline $\mathrm{U}-235$ & $3.73 E+03 d$ & 270 & 190 & $8.8 E+05$ & NA & $5 E+01 \quad c$ & 540 & 190 & $1.1 \mathrm{E}+06$ & NA & $1 E+02$ & $U-235$ \\
\hline U-236 & $1.96 E+02$ & 270 & 190 & $8.8 E+05$ & $1.0 E+\infty$ & $1 E+03$ & 540 & 190 & $1.1 \mathrm{E}+06$ & $1.0 E+\infty$ & $2 E+03$ & U-236 \\
\hline$U-238$ & $2.07 E+02$ & 270 & 190 & $8.8 E+05$ & NA & $1 E+03$ C & 540 & 190 & $1.1 \mathrm{E}+06$ & $\mathrm{NA}$ & $2 E+03$ & $U-238$ \\
\hline $\mathrm{Np}-237$ & $3.24 E+03$ & 270 & 190 & $4.4 E+04$ & $1.0 \mathrm{E}+\infty$ & $6 E+01 \quad c$ & 540 & 190 & $5.4 \mathrm{E}+04$ & $1.0 \mathrm{E}+\infty$ & $1 E+02$ & $\mathrm{~Np}-237$ \\
\hline Pu-238 & $2.34 E+03$ & 270 & 190 & $1.8 \mathrm{E}+06$ & e & $9 E+05 \div 1$ & 540 & 190 & $2.1 E+06$ & $e$ & $2 E+06$ & $\mathrm{Pu}-238$ \\
\hline Pu-239 & $2.58 E+03$ & 270 & 190 & $1.8 E+06$ & $1.2 \mathrm{E}+22$ & $\mathrm{NL} \quad \mathrm{c}$ & 540 & 190 & $2.1 E+06$ & $6.0 E+26$ & NL & Pu-239 \\
\hline$P u-240$ & $2.58 E+03$ & 270 & 190 & $1.8 E+06$ & $e$ & $\mathrm{NL}$ & 540 & 190 & $2.1 E+06$ & $e$ & NL & $P u-240$ \\
\hline Pu-241 & $4.82 E+08$ & 270 & 190 & $1.8 \mathrm{E}+06$ & $e$ & $9 E+06$ & 540 & 190 & $2.1 E+06$ & e & $2 E+07$ & Pu-241 \\
\hline Pu-242 & $2.45 E+03$ & 270 & 190 & $1.8 \mathrm{E}+06$ & $2.6 \mathrm{E}+01$ & $2 E+03$ & 540 & 190 & $2.1 E+06$ & $5.3 \mathrm{E}+01$ & $9 E+03$ & $\mathrm{Pu}-242$ \\
\hline Pu-244 & $4.11 E+03$ & 270 & 190 & $1.8 E+06$ & NA & $5 E+01 \div$ & 540 & 190 & $2.1 E+06$ & NA & $1 E+02$ & Pu-244 \\
\hline Am-241 & $2.66 E+03$ & 270 & 190 & $1.7 \mathrm{E}+06$ & e & $3 E+05 \quad c$ & 540 & 190 & $2.0 \mathrm{E}+06$ & e & $6 E+05$ & Am-241 \\
\hline$A m-243$ & $2.64 E+03$ & 270 & 190 & 1.7E+06 & $e$ & $N L$ & 540 & 190 & $2.0 \mathrm{E}+06$ & e & NL & Am-243 \\
\hline $\mathrm{Cm}-243$ & $1.83 E+03$ & 270 & 190 & $3.5 E+06$ & e & $\mathrm{NL}$ & 540 & 190 & 4.3E+06 & e & NL & $\mathrm{Cm}-243$ \\
\hline $\mathrm{Cm}-244$ & $1.47 \mathrm{E}+03$ & 270 & 190 & $3.5 \mathrm{E}+06$ & $\mathrm{e}$ & $\mathrm{NL}$ & 540 & 190 & $4.3 \mathrm{E}+06$ & $\mathbf{e}$ & $\mathrm{NL}$ & $\mathrm{Cm}-244$ \\
\hline $\mathrm{Cm}-245$ & $4.56 E+03$ & 270 & 190 & $3.5 E+06$ & NA & $4 E+01 \quad$ & 540 & 190 & $4.3 E+06$ & NA & $9 E+01$ & $\mathrm{Cm}-245$ \\
\hline $\mathrm{Cm}-246$ & $2.70 E+03$ & 270 & 190 & $3.5 E+06$ & $\mathbf{e}$ & $\mathrm{NL}$ & 540 & 190 & $4.3 E+06$ & $e$ & NL & $\mathrm{Cm}-246$ \\
\hline $\mathrm{Cm}-247$ & $4.34 \mathrm{E}+03$ & 270 & 190 & $3.5 E+06$ & NA & $5 E+01$ & 540 & 190 & $4.3 E+06$ & NA & $1 E+02$ & $\mathrm{Cm}-247$ \\
\hline $\mathrm{Cm}-248$ & $9.94 E+03$ & 270 & 190 & $3.5 E+06$ & $1.1 E+03$ & $2 E+04$ & 540 & 190 & $4.3 E+06$ & $5.1 E+03$ & $2 E+05$ & $\mathrm{Cm}-248$ \\
\hline Cf-249 & $3.46 E+03$ & 270 & 190 & $3.5 \mathrm{E}+06$ & e & $1 E+03=1$ & 540 & 190 & $4.3 E+06$ & e & $2 E+03$ & Cf-249 \\
\hline Cf-250 & $2.64 E+08$ & 270 & 190 & $3.5 \mathrm{E}+06$ & e & $\mathrm{NL} \quad \mathrm{c}$ & 540 & 190 & $4.3 E+06$ & e & $\mathrm{NL}$ & Cf-250 \\
\hline$C f-251$ & $3.54 E+03$ & 270 & 190 & $3.5 E+06$ & $e$ & $\mathrm{NL}$ & 540 & 190 & $4.3 \mathrm{E}+06$ & 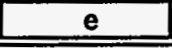 & $\mathrm{NL}$ & $\mathrm{Cf}-251$ \\
\hline
\end{tabular}

a "NA" means Not Applicable - decay factor is implictt in the PDCF for this radionuclide.

b "NL" means No Limit - estimated permissible concentration is greater than the specific activity of the pure elemental radionuclide.

c Radionuclide concentration is based on artival time at the performance boundary beyond $10,000 \mathrm{y}$.

d PDCF is a function of arrival time. See Chapter 1 of this volume for equation.

e rocary $\geq 1 E+50$

f Contribution of decay product(s) is significant to determination of this value (see Table E-3 in Volume 2). Listed arrival time is that of the parent radionuclide. Arrival time of the significant decay product(s) is greater than $10,000 \mathrm{y}$. 
For the PE trench design at INEL, the total undecayed CRFs for the groundwater pathway ranged from about 85 to 51,000 . Among the listed radionuclides, arrival times at the performance boundary ranged from $170 \mathrm{y}$ to 3.5 million $\mathrm{y}$, including the retention time in the facility before failure. The travel time through the unsaturated zone accounted for greater than $99 \%$ of the total subsurface travel time at INEL.

For the PE tumulus design at INEL, the total undecayed CRFs for the groundwater pathway ranged from about 170 to 100,000 . Among the listed radionuclides, arrival times at the performance boundary ranged from $420 \mathrm{y}$ to 4.3 million $y$, including the retention time in the facility before failure. Differences in these arrival times compared to the trench were attributable to (1) the assumed time of hydrologic failure of the facility (100 y for the trench and $300 \mathrm{y}$ for the tumulus); and (2) the increased travel distance through the vadose zone for the tumulus (the bottom of the tumulus was assumed to be at grade level, while the trench was assumed to be a shallow buried structure).

Appendix A.1 contains a comparison of the PE method for the water pathway and its results to the LLW performance assessment conducted for INEL's Radioactive Waste Management Complex (Maheras et al., 1994).

\subsubsection{Atmospheric Transport}

Two CRFs were used to account for the attenuation encompassing diffusion to the ground surface, mixing in air, and dispersion in the atmosphere to the performance boundary. The CRF for diffusion in soil, $C R F_{D i f f}$, was defined as the ratio of the radionuclide concentration in the waste to its resulting concentration in the upper one centimeter of soil. The CRF for dispersion in air, $C R F_{D i s p}$, was defined as the ratio of the radionuclide concentration in the upper one centimeter of soil to its resulting concentration in air at the performance boundary. The effect of radioactive decay was also included in the PE.

Application of the PE methodology for atmospheric transport of the two volatile radionuclides considered in the $\mathrm{PE}(\mathrm{H}-3$ and $\mathrm{C}-14)$ produced the results shown in Table 4-5 for both the generic trench and tumulus designs; there was no assumed difference in these two disposal technologies with respect to permissible waste limits based on the atmospheric pathway at INEL. The table shows permissible waste concentrations based on transport in the atmospheric pathway $\left(C_{W-A t m}\right)$, as well as the values used in calculating the permissible waste concentrations. For both $\mathrm{H}-3$ and $\mathrm{C}-14$, the greatest concentration reduction occurred as the radionuclides diffuse from the top of the disposal facility to the soil surface.

The time of arrival at the performance boundary for both radionuclides is shown in Table 4-5 as $100 \mathrm{y}$. However, the actual migration of $\mathrm{H}-3$ and $\mathrm{C}-14$ from the disposal facility to the surface and downwind to the performance boundary was calculated to be on the order of hours, not years. As discussed in Section 4.3.2.2, the waste form and RCRA cover are assumed to retain these volatile radionuclides in the disposal facility for at least $100 \mathrm{y}$. 
Table 4-5. Results of Calculations for the Atmospheric Pathway

\begin{tabular}{|c|c|c|c|c|c|c|c|}
\hline \multirow[t]{2}{*}{ Nuclide } & \multirow{2}{*}{$\begin{array}{c}S D C F_{A t m} \\
(\mathrm{rem} / \mathrm{y}) /(\mu \mathrm{Cj} / \mathrm{L})\end{array}$} & \multicolumn{6}{|c|}{ Generic Trench and Tumulus } \\
\hline & & $\begin{array}{c}C R F_{\text {Diff }} \\
\text { (dimensionless) }\end{array}$ & $\begin{array}{c}C R F_{\text {Disp }} \\
\text { (dimensionless) }\end{array}$ & $\begin{array}{c}\text { CRF }_{\text {Atm }} \\
\text { (dimensionless) }\end{array}$ & $\begin{array}{c}\text { Arrival } \\
\text { Time }(y)\end{array}$ & $\begin{array}{c}r_{\text {Docay }} \\
\text { (dimensionless) }\end{array}$ & $\begin{array}{r}C_{W-A t m} \\
\left(\mu \mathrm{Ci} / \mathrm{m}^{3}\right) \\
\end{array}$ \\
\hline $\mathrm{H}-3$ & $8.33 E+02$ & $4 E+06$ & $1 E+03$ & $4 E+09$ & 100 & $3 E+02$ & $1 E+10$ \\
\hline$C-14$ & $2.20 E+05$ & $8 E+04$ & $2 E+03$ & $2 E+08$ & 100 & $1 E+00$ & $7 E+03$ \\
\hline
\end{tabular}

Appendix A.1 contains a comparison of the PE method for the atmospheric pathway and its results to the LLW performance assessment conducted for INEL's Radioactive Waste Management Complex (Maheras et al., 1994).

\subsubsection{Inadvertent Intruder Exposure}

The calculation of permissible waste concentrations for inadvertent intruder exposures did not utilize CRFs. Instead, the total dose resulting from an intrusion scenario (the sum of the doses from all exposure pathways involved in that intrusion) was computed from scenario dose conversion factors (SDCFs) that were applied to specific exposure pathways. These SDCF values were radionuclide-specific and facility-design-specific and were the same for all sites. The exposure pathways evaluated for each radionuclide are listed in Appendix $\mathrm{D}$ of Volume 2. Values for the radioactive decay term were based on time of intrusion into the disposal facility (for the homesteader scenario: $300 \mathrm{y}$ for the trench design and $500 \mathrm{y}$ for the tumulus design; for the post-drilling scenario: $100 \mathrm{y}$ for both disposal designs).

The permissible waste concentrations for the two generic facility designs for each of the 58 radionuclides based on the standard PE intrusion scenarios are listed in Table 4-6. The most restrictive radionuclide concentration limits for each generic facility are indicated with boldface type.

For six radionuclides in the table (U-233, U-234, U-235, U-238, Pu-244, and Cm-247), the time of homesteader intrusion was changed to $10,000 \mathrm{y}$, the end of the performance period. For these six radionuclides, ingrowth of decay products yields scenario doses that increase over time. The doses at $10,000 \mathrm{y}$, therefore, represent the maximum that could be encountered during the performance period. Also, for Th-230 and $\mathrm{Cm}-245$, ingrowth of decay products likewise produces a scenario dose that increases over time and peaks within the 10,000-y performance period. The times of homesteader intrusion for these two radionuclides (Th-230 and Cm-245) were taken as the time of maximum dose, $9000 \mathrm{y}$ and $1000 \mathrm{y}$, respectively. 
Table 4-6. Permissible Waste Concentrations for the Standard Intrusion Scenarios (most limiting radionuclide concentration for each facility design is highlighted in bold italic) (Part 1 of 2)

\begin{tabular}{|c|c|c|c|c|c|}
\hline \multirow[t]{2}{*}{ Nuclide } & \multicolumn{2}{|c|}{ Trench } & \multicolumn{2}{|c|}{ Tumulus } & \multirow[t]{2}{*}{ Nuclide } \\
\hline & $\begin{array}{c}C_{w-\operatorname{mtr}}{ }^{2} \\
\text { Homesteader } \\
\left(\mu \mathrm{Ci} \mathrm{m}^{3}\right) \\
\end{array}$ & $\begin{array}{c}C_{\text {wdnt }} \\
\text { Post-Drilling } \\
\left(\mu \mathrm{C} / \mathrm{m}^{3}\right) \\
\end{array}$ & $\begin{array}{c}\mathbf{C}_{\text {w-Intr }} \\
\text { Homesteader } \\
\left(\mu \mathrm{Ci} / \mathrm{m}^{3}\right) \\
\end{array}$ & $\begin{array}{c}C_{w / n t r} \\
\text { Post-Drilling } \\
\left(\mu \mathrm{Ci} / \mathrm{m}^{3}\right) \\
\end{array}$ & \\
\hline $\mathrm{H}-3$ & $1 E+12$ & $7 E+07$ & $\mathrm{NL}$ & $7 E+07$ & $\mathrm{H}-3$ \\
\hline C-14 & $1 E+04$ & $7 E+04$ & $1 E+04$ & $7 E+04$ & $C-14$ \\
\hline Al-26 & $5 E+01$ & $5 E+04$ & $5 E+01$ & $5 E+04$ & Al-26 \\
\hline Si-32 & $9 E+03$ & $1 E+04$ & $4 E+04$ & $1 E+04$ & Si-32 \\
\hline $\mathrm{Cl}-36$ & $2 E+02$ & $9 E+02$ & $2 E+02$ & $9 E+02$ & $\mathrm{Cl}-36$ \\
\hline$K-40$ & $7 E+02$ & $2 E+04$ & $7 E+02$ & $2 E+04$ & $K-40$ \\
\hline Co-60 & $\mathrm{NL}$ & $3 E+10$ & $\mathrm{NL}$ & $3 E+10$ & Co-60 \\
\hline $\mathrm{Ni}-59$ & $3 E+06$ & $1 E+07$ & $3 E+06$ & $1 E+07$ & $\mathrm{Ni}-59$ \\
\hline $\mathrm{Ni}-63$ & $8 E+06$ & $1 E+07$ & $3 E+07$ & $1 E+07$ & $\mathrm{Ni}-63$ \\
\hline Se-79 & $2 E+05$ & $8 E+05$ & $2 E+05$ & $8 E+05$ & Se-79 \\
\hline$S_{r}-90$ & $1 E+06$ & $5 E+04$ & $1 E+08$ & $5 E+04$ & Sr-90 \\
\hline $\mathrm{Zr}-93$ & $5 E+06$ & $3 E+07$ & $6 E+06$ & $3 E+07$ & $\mathrm{Zr}-93$ \\
\hline $\mathrm{Nb}-93 \mathrm{~m}$ & $5 E+12$ & $4 E+09$ & NL & $4 E+09$ & $\mathrm{Nb}-93 \mathrm{~m}$ \\
\hline $\mathrm{Nb}-94$ & $9 E+01$ & $9 E+04$ & $1 E+02$ & $9 E+04$ & $\mathrm{Nb}-94$ \\
\hline TC-99 & $2 E+04$ & $8 E+04$ & $2 E+04$ & $8 E+04$ & Tc-99 \\
\hline Pd-107 & $6 E+06$ & $3 E+07$ & $6 E+06$ & $3 E+07$ & $\mathrm{Pd}-107$ \\
\hline $\mathrm{Ag}-108 \mathrm{~m}$ & $5 E+02$ & $1 E+05$ & $1 E+03$ & $1 E+05$ & $\mathrm{Ag}-108 \mathrm{~m}$ \\
\hline Cd-113m & $4 E+09$ & $1 E+06$ & $7 E+13$ & $1 E+06$ & $\mathrm{Cd}-113 \mathrm{~m}$ \\
\hline $\mathrm{Sn}-121 \mathrm{~m}$ & $2 E+07$ & $5 \mathrm{E}+07$ & $2 \mathrm{E}+08$ & $5 E+07$ & $\mathrm{Sn}-121 \mathrm{~m}$ \\
\hline Sn-126 & $8 E+01$ & $7 E+04$ & $8 E+01$ & $7 E+04$ & Sn-126 \\
\hline $1-129$ & $2 E+03$ & $1 E+04$ & $2 E+03$ & $1 E+04$ & $1-129$ \\
\hline Cs-135 & $2 E+05$ & $8 E+05$ & $2 E+05$ & $8 E+05$ & Cs-135 \\
\hline Cs-137 & $3 E+05$ & $8 E+05$ & $3 E+07$ & $8 E+05$ & Cs-137 \\
\hline $\mathrm{Ba}-133$ & $2 E+11$ & $3 E+08$ & NL & $3 E+08$ & $\mathrm{Ba}-133$ \\
\hline $\mathrm{Sm}-151$ & $2 E+08$ & $2 E+08$ & $8 E+08$ & $2 E+08$ & $\mathrm{Sm}-151$ \\
\hline Eu-152 & $6 E+08$ & $2 E+07$ & $2 E+13$ & $2 E+07$ & Eu-152 \\
\hline Eu-154 & $4 E+12$ & $4 E+08$ & NL & $4 E+08$ & Eu-154 \\
\hline $\mathrm{Pb}-210$ & $7 E+06$ & $7 E+04$ & $4 E+09$ & $7 E+04$ & $\mathrm{~Pb}-210$ \\
\hline Ra-226 & $8 E+01$ & $3 E+03$ & $9 E+01$ & $3 E+03$ & Ra-226 \\
\hline Ra-228 & $\mathrm{NL}$ & $4 E+09$ & $N L$ & $4 E+09$ & Ra-228 \\
\hline Th-229 & $5 E+02$ & $3 E+04$ & $5 E+02$ & $3 E+04$ & Th-229 \\
\hline Th-230 & $8 E+01$ & $7 E+04$ & $8 E+01$ & $7 E+04$ & Th-230 \\
\hline Th-232 & $6 E+01$ & $2 E+04$ & $6 E+01$ & $2 E+04$ & Th-232 \\
\hline $\mathrm{Pa}-231$ & $2 E+02$ & $5 E+03$ & $2 E+02$ & $5 E+03$ & $\mathrm{~Pa}-231$ \\
\hline
\end{tabular}


Table 4-6. Permissible Waste Concentrations for the Standard Intrusion Scenarios (most limiting radionuclide concentration for each facility design is highlighted in bold italic) (Part 2 of 2)

\begin{tabular}{|c|c|c|c|c|c|}
\hline \multirow[t]{2}{*}{ Nuclide } & \multicolumn{2}{|c|}{ Trench } & \multicolumn{2}{|c|}{ Tumulus } & \multirow[t]{2}{*}{ Nuclide } \\
\hline & $\begin{array}{c}\text { Cwrma } \\
\text { Homesteader } \\
\left.(\mu \mathrm{Clm})^{3}\right) \\
\end{array}$ & $\begin{array}{c}C_{\text {whth }} \\
\text { Post-Drilling } \\
\left(\mu \mathrm{C} / \mathrm{m}^{3}\right) \\
\end{array}$ & $\begin{array}{c}C_{w 4 n e r} \\
\text { Homesteader } \\
\left(\mu \mathrm{Ci} / \mathrm{m}^{3}\right) \\
\end{array}$ & $\begin{array}{c}C_{w-1 n t r} \\
\text { Post-Drilling } \\
\left(\mu \mathrm{Ci} / \mathrm{m}^{3}\right) \\
\end{array}$ & \\
\hline$U-232$ & $2 E+03$ & $5 E+04$ & $1 E+04$ & $5 E+04$ & U-232 \\
\hline U-233 & $7 E+02$ & $1 E+05$ & $7 E+02$ & $1 E+05$ & U-233 \\
\hline$U-234$ & $1 E+03$ & $1 E+05$ & $1 E+03$ & 1E+05 & U-234 \\
\hline$U-235$ & $6 E+02$ & $1 E+05$ & $6 E+02$ & $1 E+05$ & U-235 \\
\hline U-236 & $2 E+04$ & $1 E+05$ & $2 E+04$ & $1 E+05$ & U-236 \\
\hline$U-238$ & SE+03 & $1 E+05$ & $5 E+03$ & $1 E+05$ & U-238 \\
\hline $\mathrm{Np}-237$ & $4 E+02$ & $4 E+03$ & $4 E+02$ & $4 E+03$ & $\mathrm{~Np}-237$ \\
\hline Pu-238 & $7 E+04$ & $1 E+05$ & $4 E+05$ & $1 E+05$ & Pu-238 \\
\hline $\mathrm{Pu}-239$ & $6 E+03$ & $5 E+04$ & $6 E+03$ & $5 E+04$ & $\mathrm{Pu}-239$ \\
\hline$P u-240$ & $6 E+03$ & $5 E+04$ & $7 E+03$ & $5 E+04$ & Pu-240 \\
\hline Pu-241 & $2 E+05$ & $1 E+06$ & $3 E+05$ & $1 E+06$ & Pu-241 \\
\hline $\mathrm{Pu}-242$ & $6 E+03$ & $5 E+04$ & $6 E+03$ & $5 E+04$ & $\mathrm{Pu}-242$ \\
\hline$P u-244$ & $4 E+02$ & $5 E+04$ & $4 E+02$ & $5 E+04$ & Pu-244 \\
\hline Am-241 & $7 E+03$ & $5 E+04$ & $9 E+03$ & $5 E+04$ & Am-241 \\
\hline Am-243 & $9 E+02$ & $4 E+04$ & $9 E+02$ & $4 E+04$ & Am-243 \\
\hline $\mathrm{Cm}-243$ & $1 E+06$ & $8 E+05$ & $5 E+06$ & $8 E+05$ & $\mathrm{Cm}-243$ \\
\hline $\mathrm{Cm}-244$ & $2 E+06$ & $3 E+06$ & $2 E+06$ & $3 E+06$ & $\mathrm{Cm}-244$ \\
\hline $\mathrm{Cm}-245$ & $1 E+03$ & $4 E+04$ & $1 E+03$ & $4 E+04$ & Cm-245 \\
\hline $\mathrm{Cm}-246$ & $6 E+03$ & $5 E+04$ & $6 E+03$ & $5 E+04$ & Cm-246 \\
\hline $\mathrm{Cm}-247$ & $3 E+02$ & $5 E+04$ & $3 E+02$ & $5 E+04$ & $\mathrm{Cm}-247$ \\
\hline $\mathrm{Cm}-248$ & $2 E+03$ & $1 E+04$ & $2 E+03$ & 1E+04 & $\mathrm{Cm}-248$ \\
\hline Cf-249 & $8 E+02$ & $4 E+04$ & $1 E+03$ & $4 E+04$ & Cf-249 \\
\hline Cf-250 & $2 E+06$ & $9 E+06$ & $2 E+06$ & $9 E+06$ & C $f-250$ \\
\hline$C f-251$ & $2 E+03$ & $4 E+04$ & $2 E+03$ & $4 E+04$ & Cf-251 \\
\hline
\end{tabular}

a "NL" means No Limit - estimated permissible concentration is greater than the specific activity of the pure elemental radionuclide. 
For the trench design, the waste limits of 47 radionuclides were controlled by the homesteader scenario and 11 were controlled by the post-drilling scenario. For the trench design, the post-drilling scenario generally yielded more restrictive waste limits than the homesteader scenario for those radionuclides with half-lives shorter than about $30 \mathrm{y}$. For the tumulus design, the waste limits of 41 radionuclides were controlled by the homesteader scenario and 17 were controlled by the post-drilling scenario. For the tumulus design, the post-drilling scenario generally yielded more restrictive limits than the homesteader scenario for those radionuclides with half-lives shorter than about $130 \mathrm{y}$.

Appendix A.1 contains a comparison of the PE method for the intrusion scenarios and its results to the LLW performance assessment conducted for INEL's Radioactive Waste Management Complex (Maheras et al., 1994).

\subsection{SUMMARY AND DISCUSSION OF RESULTS}

The limiting waste concentrations in disposed MLLW for the water, air, and intruder analyses for the generic trench and tumulus designs are summarized in Table 4-7 and discussed in Section 4.6.1. An overall discussion of the results of the PE for INEL is contained in Section 4.6.2.

\subsubsection{Results Based on Disposal Design}

For both the generic trench and tumulus designs at $\mathrm{NEL}$, three radionuclides $(\mathrm{K}-40$, Tc-99, and I-129) were limited by the water pathway, one radionuclide (C-14) was limited by the atmospheric pathway, and 54 radionuclides were limited by intrusion scenarios, as shown in Table 4-7. Among the 54 radionuclides limited by intrusion for the trench design at INEL, 43 were controlled by homesteader intrusion, while 11 were controlled by post-drilling. Among the 54 radionuclides limited by intrusion for the tumulus design at INEL, 37 were controlled by homesteader intrusion, while 17 were controlled by post-drilling.

For both the trench design and the tumulus design at INEL, the concentrations for two radionuclides that arrive at the performance boundary before 10,000 y for the water pathway analysis have no limit (i.e., Co-60 and Sr-90). As discussed in Section 4.5.1, the calculated concentrations for those radionuclides reported as NL (No Limit) exceeded the specific activity of the pure elemental radionuclide, implying that the performance measure of 4 mrem $(0.04 \mathrm{mSv})$ per year would not be reached under the given release and transport assumptions.

As also discussed in Section 4.5.1, values for some radionuclides are not reported in Table 4-7 for the water pathway analysis. Arrival times for these radionuclides were beyond the $10,000-y$ performance period. For these radionuclides, the estimated waste concentrations are presented in Table 4-4 for information purposes but are not listed in Table 4-7. Consistent with the approach used in LLW performance assessments, these values were not considered in determining the most restrictive disposal limit from among the evaluated pathways because arrival times for these radionuclides were beyond $10,000 \mathrm{y}$. 
Table 4-7. Permissible Concentrations for the Generic Disposal Designs at INEL (permissible waste concentration related to the most limiting pathway for each disposal design is highlighted in bold italic) (Part 1 of 2)

\begin{tabular}{|c|c|c|c|c|c|c|c|}
\hline \multirow[t]{2}{*}{ Nuclide } & \multicolumn{3}{|c|}{ Trench } & \multicolumn{3}{|c|}{ Tumulus } & \multirow[t]{2}{*}{ Nuclide } \\
\hline & $\begin{array}{c}C_{\text {w-Water }}{ }^{a, b} \\
\left(\mu \mathrm{Ci} / \mathrm{m}^{3}\right)\end{array}$ & $C_{W-A t m}^{c}{ }_{\left(\mu \mathrm{Cl} / \mathrm{m}^{3}\right)}$ & $\begin{array}{l}C_{W-n n t r}^{d} \\
\left(\mu \mathrm{Ci} / m^{3}\right)\end{array}$ & $\begin{array}{c}C_{\text {W-Water }}{ }^{a, b} \\
\left(\mu \mathrm{Ci} \mathrm{m}^{3}\right)\end{array}$ & $C_{\left(\mu-A m^{3}\right.}{ }^{c}$ & $\begin{array}{l}C_{\text {W-Intr }}{ }^{d} \\
\left(\mu \mathrm{Ci} / \mathrm{m}^{3}\right)\end{array}$ & \\
\hline $\mathrm{H}-3$ & $1 E+08$ & $1 E+10$ & $7 E+07$ & $3 E+14$ & $1 E+10$ & $7 E+07$ & $\mathrm{H}-3$ \\
\hline$\overline{C-14}$ & $1 E+04$ & $7 E+03$ & $1 E+04$ & $3 E+04$ & $7 E+03$ & $1 \mathrm{E}+04$ & $c-14$ \\
\hline Al-26 & - & & $5 E+01$ & - & & $5 E+01$ & $\mathrm{Al}-26$ \\
\hline Si-32 & - & & $9 E+03$ & - & & $1 E+04$ & Si-32 \\
\hline $\mathrm{Cl}-36$ & - & & $2 E+02$ & - & & $2 E+02$ & $\mathrm{Cl}-36$ \\
\hline$K-40$ & $2 E+02$ & & $7 E+02$ & $4 E+02$ & & $7 E+02$ & $k-40$ \\
\hline Co-60 & NL & & $3 E+10$ & NL & & $3 E+10$ & Co-60 \\
\hline $\mathrm{Ni}-59$ & - & & $3 E+06$ & - & & $3 E+06$ & Ni-59 \\
\hline $\mathrm{Ni}-63$ & - & & $8 E+06$ & - & & $1 E+07$ & $\mathrm{Ni}-63$ \\
\hline Se-79 & - & & $2 E+05$ & - & & $2 E+05$ & Se-79 \\
\hline$S r-90$ & $\mathrm{NL}$ & & $5 E+04$ & $\mathrm{NL}$ & & $5 E+04$ & Sr-90 \\
\hline $2 r-93$ & - & & $5 E+06$ & - & & $5 E+06$ & $2 r-93$ \\
\hline $\mathrm{Nb}-93 \mathrm{~m}$ & - & & $4 E+09$ & - & & $4 E+09$ & $\mathrm{Nb}-93 \mathrm{~m}$ \\
\hline Nb-94 & - & & $9 E+01$ & - & & $1 E+02$ & $\mathrm{Nb}-94$ \\
\hline Tc-99 & $2 E+03$ & & $2 E+04$ & $5 E+03$ & & $2 E+04$ & TC-99 \\
\hline $\mathrm{Pd}-107$ & - & & $6 E+06$ & - & & $6 E+06$ & $P d-107$ \\
\hline $\mathrm{Ag}-108 \mathrm{~m}$ & - & & $5 E+02$ & - & & $1 E+03$ & $\mathrm{Ag}-108 \mathrm{~m}$ \\
\hline$c d-113 m$ & - & & $1 E+06$ & - & & $1 E+06$ & Cd-113m \\
\hline$S n-121 m$ & - & & $2 E+07$ & - & & $5 E+07$ & $5 n-121 m$ \\
\hline $5 n-126$ & - & & $8 E+01$ & - & & $8 E+01$ & $5 n-126$ \\
\hline $1-129$ & $1 E+01$ & & $2 E+03$ & $2 E+01$ & & $2 E+03$ & $1-129$ \\
\hline Cs-135 & - & & $2 E+05$ & $=$ & & $2 E+05$ & Cs-135 \\
\hline Cs-137 & - & & $3 E+05$ & - & & $8 E+05$ & Cs-137 \\
\hline $\mathrm{Ba}-133$ & - & & $3 E+08$ & - & & $3 E+08$ & $\mathrm{Ba}-133$ \\
\hline Sm-151 & - & & $2 E+08$ & - & & $2 E+08$ & $S m-151$ \\
\hline Eu-152 & - & & $2 E+07$ & - & & $2 E+07$ & Eu-152 \\
\hline Eu-154 & $=$ & & $4 E+08$ & - & & $4 E+08$ & Eu-154 \\
\hline $\mathrm{Pb}-210$ & - & & $7 E+04$ & - & & $7 E+04$ & $\mathrm{~Pb}-210$ \\
\hline Ra-226 & $=$ & & $8 E+01$ & - & & $9 E+01$ & Ra-226 \\
\hline $\mathrm{Ra}-228$ & - & & $4 E+09$ & - & & $4 E+09$ & Ra-228 \\
\hline Th-229 & - & & $5 E+02$ & - & & $5 E+02$ & Th-229 \\
\hline Th-230 & - & & $8 E+01$ & - & & $8 E+01$ & Th-230 \\
\hline Th-232 & - & & $6 E+01$ & - & & $6 E+01$ & Th-232 \\
\hline $\mathrm{Pa}-231$ & - & & $2 E+02$ & - & & $2 E+02$ & $\mathrm{~Pa}-231$ \\
\hline
\end{tabular}


Table 4-7. Permissible Concentrations for the Generic Disposal Designs at INEL (permissible waste concentration related to the most limiting pathway for each disposal design is highlighted in bold italic) (Part 2 of 2)

\begin{tabular}{|c|c|c|c|c|c|c|c|}
\hline \multirow[t]{2}{*}{ Nuclide } & \multicolumn{3}{|c|}{ Trench } & \multicolumn{3}{|c|}{ Tumulus } & \multirow[t]{2}{*}{ Nuclide } \\
\hline & $\begin{array}{c}C_{\text {W.Water }}{ }^{2, b} \\
\left(\mu \mathrm{Ci} / \mathrm{m}^{3}\right)\end{array}$ & $\begin{array}{c}C_{W-A t m}{ }^{c} \\
\left(\mu \mathrm{Ci} / m^{3}\right)\end{array}$ & $\begin{array}{l}C_{W-\operatorname{lnt} \pi^{d}} \\
\left(\mu \mathrm{Ci} / \mathrm{m}^{3}\right)\end{array}$ & $\begin{array}{c}C_{\text {W-Water }}{ }^{2, b} \\
\left(\mu \mathrm{Ci} \mathrm{m}^{3}\right)\end{array}$ & $\begin{array}{c}C_{W-A t m}{ }^{e} \\
\left(\mu \mathrm{Ci} / m^{3}\right)\end{array}$ & $\begin{array}{l}C_{W-n r^{d}} \\
\left(\mu \mathrm{Ci} / m^{3}\right)\end{array}$ & \\
\hline$U-232$ & - & & $2 E+03$ & - & & $1 E+04$ & U-232 \\
\hline$U-233$ & - & & $7 E+02$ & - & & $7 E+02$ & $U-233$ \\
\hline$U-234$ & - & & $1 E+03$ & - & & $1 E+03$ & U-234 \\
\hline$U-235$ & - & & $6 E+02$ & - & & $6 E+02$ & U-235 \\
\hline U-236 & - & & $2 E+04$ & - & & $2 E+04$ & U-236 \\
\hline U-238 & $=$ & & $5 E+03$ & - & & $5 E+03$ & U-238 \\
\hline $\mathrm{Np}-237$ & - & & $4 E+02$ & - & & $4 E+02$ & Np-237 \\
\hline $\mathrm{Pu}-238$ & - & & $7 E+04$ & - & & $1 E+05$ & Pu-238 \\
\hline $\mathrm{Pu}-239$ & $=$ & & $6 E+03$ & - & & $6 E+03$ & Pu-239 \\
\hline $\mathrm{Pu}-240$ & - & & $6 E+03$ & - & & $7 E+03$ & Pu-240 \\
\hline Pu-241 & - & & $2 E+05$ & - & & $3 E+05$ & Pu-241 \\
\hline $\mathrm{Pu}-242$ & - & & $6 E+03$ & - & & $6 E+03$ & $\mathrm{Pu}-242$ \\
\hline Pu-244 & - & & $4 E+02$ & - & & $4 E+02$ & Pu-244 \\
\hline$A m-241$ & - & & $7 E+03$ & $=$ & & $9 E+03$ & $\mathrm{Am}-241$ \\
\hline Am-243 & - & & $9 E+02$ & - & & $9 E+02$ & Am-243 \\
\hline $\mathrm{Cm}-243$ & - & & $8 E+05$ & - & & $8 E+05$ & $\mathrm{Cm}-243$ \\
\hline $\mathrm{Cm}-244$ & - & & $2 E+06$ & - & & $2 E+06$ & $\mathrm{Cm}-244$ \\
\hline $\mathrm{Cm}-245$ & - & & $1 E+03$ & - & & $1 E+03$ & $\mathrm{Cm}-245$ \\
\hline $\mathrm{Cm}-246$ & - & & $6 E+03$ & - & & $6 E+03$ & $\mathrm{Cm}-246$ \\
\hline $\mathrm{Cm}-247$ & - & & $3 E+02$ & - & & $3 E+02$ & $\mathrm{Cm}-247$ \\
\hline $\mathrm{Cm}-248$ & - & & $2 E+03$ & - & & $2 E+03$ & $\mathrm{Cm}-248$ \\
\hline Cf-249 & - & & $8 E+02$ & - & & $1 E+03$ & Cf-249 \\
\hline Cf-250 & - & & $2 E+06$ & - & & $2 E+06$ & Cf-250 \\
\hline Cf-251 & - & & $2 E+03$ & - & & $2 E+03$ & Cf-251 \\
\hline
\end{tabular}

a "NL" means No Limit - estimated permissible concentration factor is greater than the specific activity of the pure elemental radionuclide.

$b$ " "- indicates that the radionuclide concentration is based on an arrival time beyond 10,000 y; see Table $4-4$ for specific values.

c Results presented for radionclides expected to be volatile under disposal facility conditions.

d Concentration is based on the most restrictive intrusion scenario assumed for the site; see Table 4-6. 
For both the trench and the tumulus, radionuclides limited by the groundwater pathway at INEL were K-40, Tc-99, and I-129. These are highly mobile nuclides with sufficiently long half-lives so that subsurface arrival times in excess of $120 \mathrm{y}$ (the minimum groundwater pathway travel time at INEL) do not result in large amounts of radioactive decay. Only seven radionuclides had water pathway arrival times shorter than $10,000 \mathrm{y}$. These nuclides include Co-60, Sr-90, K-40, Tc-99, and I-129, which have been discussed above, as well as $\mathrm{H}-3$ and C-14. Tritium has significant radioactive decay during subsurface transport and is thus limited by the post-drilling scenario, which is assumed to occur at $100 \mathrm{y}$. Carbon-14 is controlled by the atmospheric pathway.

At INEL, there is no significant difference in the permissible waste concentrations computed for the trench as compared to the tumulus. That is, there is less than one order of magnitude difference in the waste limits between the two disposal facility designs.

\subsubsection{Discussion}

The results of the PE are based on the framework of assumptions summarized in Chapter 1 of this volume and discussed in detail in Volume 2 of this report and on the site-specific conceptual model for contaminant transport discussed in this chapter. Using alternative assumptions about the conceptual model has the potential to affect the results. Changes in the conceptual model could include alternative assumptions about the disposal facility, the source term, and radionuclide movement in the three pathways. Depending on the degree of possible variation and the relative importance of the parameters used in the calculation of estimated permissible radionuclide concentrations, variability in parameter values can also affect the results. For parameters, results could vary depending on potential changes in values of both the generic and the site-specific parameters used in the PE.

The effect on results from using alternative generic assumptions and parameter values is discussed in Chapter 6 of Volume 2. In addition, a discussion is provided in that chapter of the effects of using alternative values for site-specific parameters. Based on this discussion, four parameters were identified (three site-specific and one generic, all used in the water pathway analysis) that could potentially influence the results to the degree that the calculated waste concentrations become limited by a pathway other than the one determined for the PE (Table 4-7). The impacts on the results of using alternative values for these four parameters for the water pathway in the PE for INEL are discussed in this section. The basis for and possible variation in the values used in the PE for these parameters are discussed in Section 4.6.2.2.

\subsubsection{Parameter Sensitivity Analysis}

The PE provided results for two disposal facility designs: a RCRA-compliant, belowground trench and a RCRA-compliant, above-ground tumulus. Similar assumptions about the integrity of engineered barriers were made in the PE for both facility designs. Because the factors used to estimate transport of radionuclides in the water pathway for both designs were similar, the 
discussion in this section focuses on examining the results for the indicator radionuclides reported for the tumulus design (indicator radionuclides are defined in Chapter 7 of Volume 2).

As discussed in Chapter 6 of Volume 2, four parameters used in the PE were identified as having a potential range of values that might affect results: annual natural recharge $(i)$; groundwater Darcy velocity $\left(q_{g w}\right)$; plan-view area of the facility $(A)$; and distribution coefficients $\left(K_{d} s\right)$. These parameter values for $\mathbb{N E L}$ are summarized in Table 4-8.

Table 4-8. Parameter Values Used in the PE for INEL with Potential Variability That Could Affect the Results

\begin{tabular}{|l|l|}
\hline \multicolumn{1}{|c|}{ Parameter } & \multicolumn{1}{|c|}{ Value } \\
\hline Natural recharge through local soils, $i$ & $\begin{array}{l}0.07 \mathrm{~m} / \mathrm{y} \text { (Rood et al., 1994; see } \\
\text { Section 4.3.1.1) }\end{array}$ \\
\hline $\begin{array}{l}\text { Distribution coefficients for geologic } \\
\text { media, } K_{d}\end{array}$ & see Table 4-2 in this chapter for values \\
\hline Groundwater Darcy velocity, $q_{\text {gw }}$ & $\begin{array}{l}56 \mathrm{~m} / \mathrm{y} \text { (Rood et al., 1994; see Section } \\
4.4 .1 \text { for discussion) }\end{array}$ \\
\hline Plan-view Area, $A$ & $2500 \mathrm{~m}^{2}$ (standard PE value) \\
\hline
\end{tabular}

The traditional procedure for performing a sensitivity analysis is to vary the parameters used in the calculations and observe the effect on the results. To be meaningful, this method requires some knowledge of the statistical distribution of each of the parameters considered, including their likely maximum and minimum values. For the PE calculations, the potential variability of the parameters used to calculate the permissible waste concentrations for the two different facility designs was not estimated. For most of the radionuclides considered in the PE, there were only two exposure pathways: the water pathway and intruder exposure scenarios (the atmospheric pathway is considered only for $\mathrm{H}-3$ and $\mathrm{C}-14$ ). The intruder pathway results provide a baseline that can be used for comparison with the water pathway results because the intruder scenarios used in the PE were relatively independent of the physical characteristics of the individual sites. For $\mathrm{H}-3$ and $\mathrm{C}-14$, the atmospheric-pathway results provide a baseline that can also be used for comparison with the water pathway because the atmospheric-pathway results are not highly sensitive to any individual input parameter (see Chapter 6 of Volume 2).

The intruder and atmospheric baselines provided an alternative method of performing sensitivity analyses for the PE. The input parameters for the water pathway were varied to determine if the limiting exposure pathway could be altered (e.g., the results could be changed from intruder-scenario-controlled [or atmospheric-pathway-controlled] to water-pathwaycontrolled). After new values for the water pathway parameters were determined, these values were examined for reasonableness based on physical constraints at the site. 
To analyze the sensitivity of the results to changes in the parameter values for recharge, groundwater Darcy velocity, and area of the facility, the parameter values used in the PE for INEL were varied. Only one parameter value was varied at a time for each indicator radionuclide, leaving the others equal to their PE values. In most instances, the parameter value was varied until the waste concentrations for the water and intruder (or atmospheric) pathways became equal, regardless of the likelihood (or physical impossibility) of the value to occur.

The parameter values that caused the permissible concentrations for the water and intruder pathways to become equal are listed in Table 4-9a for the 8 indicator radionuclides. For the indicator radionuclide $\mathrm{H}-3$, no value variations of these parameters resulted in equal concentrations. For C-14, the limiting pathway is the atmospheric pathway, so the water versus intruder comparison is not applicable. For Sr-90 and Cs-137, increases in recharge of about 2 orders of magnitude were required to change the limiting pathway from intruder to water. No value variations in the groundwater velocity or facility area resulted in equal water pathway and intruder pathway concentrations for these two radionuclides. For Tc-99, the value for recharge had to decrease by more than 3 times, the groundwater velocity had to increase by a factor of about 3 , or the facility size had to decrease by an order of magnitude to change the limiting pathway from water to intruder. For U-238, all values that caused equal concentrations also arrived at the performance boundary beyond 10,000 y. For Pu-239, the value for recharge had to increase one order of magnitude for the water pathway concentration to equal the intruder pathway concentration, although the arrival time remains beyond $10,000 \mathrm{y}$. No value variations in the groundwater velocity or facility area resulted in equal water pathway and intruder pathway concentrations for Pu-239. For Am-241, the value for recharge had to increase by two orders of magnitude or the groundwater velocity had to decrease by two orders of magnitude for the water and intruder pathway concentrations to be equal, although the variation in groundwater velocity resulted in an arrival time later than $10,000 \mathrm{y}$.

The parameter values that caused the permissible concentrations for the water and atmospheric pathways to become equal are listed in Table 4-9b for H-3 and C-14. For H-3, the limiting pathway is the intrusion scenario, so this comparison is not applicable. For C-14, the recharge had to increase by a factor of 4 , the groundwater velocity had to decrease by a factor of 4 , or the plan area had to increase by a factor of 20 in order for the limiting pathway to change from atmospheric to water.

Two sets of $K_{d}$ values were used in the PE analysis, one for the unsaturated zone and one for the saturated zone. The unsaturated zone $K_{d}$ values dominated the PE concentration results due to long travel times in the unsaturated zone $(99 \%$ of the total water travel time occurred in the unsaturated zone). Therefore, the $K_{d}$ values for the unsaturated zone were varied for this sensitivity analysis. 
Table 4-9. Parameter Values That Caused the Permissible Concentrations for the Water and Intruder Pathways to Be Equal for Indicator Radionuclides at INEL (tumulus design) (bold italic type indicates limiting pathway in the PE)

(a) Water/Intruder Pathways

\begin{tabular}{|c|c|c|c|c|c|c|}
\hline \multirow[t]{4}{*}{$\begin{array}{l}\text { Indicator } \\
\text { Nuclide }\end{array}$} & \multirow[t]{4}{*}{$\begin{array}{c}\text { PE } \\
C_{W-W a t e r} \\
\left(\mu \mathrm{Ci} / \mathrm{m}^{3}\right)\end{array}$} & \multirow[t]{4}{*}{$\begin{array}{c}\text { PE } \\
C_{W-1 n t r} \\
\left(\mu \mathrm{Ci} / \mathrm{m}^{3}\right)\end{array}$} & \multirow[t]{4}{*}{$\begin{array}{c}P E \\
C_{W-\ln t} \\
C_{W-W a t e r}\end{array}$} & $\begin{array}{c}\text { Natural } \\
\text { Recharge, } \\
i \\
(\mathrm{~m} / \mathrm{y})\end{array}$ & $\begin{array}{l}\text { Groundwater } \\
\text { Darcy } \\
\text { Velocity, } q_{g w} \\
\text { (m/y) }\end{array}$ & $\begin{array}{c}\text { Area, } \\
\text { A } \\
\left(\mathrm{m}^{2}\right)\end{array}$ \\
\hline & & & & \multicolumn{3}{|c|}{ PE Values } \\
\hline & & & & 0.07 & 56 & 2500 \\
\hline & & & & \multicolumn{3}{|c|}{$\begin{array}{c}\text { Value That Caused Equal } \\
\text { Concentrations }\end{array}$} \\
\hline$\overline{H-3}$ & $3 E+14$ & $7 E+07$ & $2 \mathrm{E}-07$ & $\bar{b}$ & $\mathrm{~b}$ & b \\
\hline$C-14$ & $3 E+04$ & $1 E+04$ & 0.3 & 0.15 & 27 & $1.0 \mathrm{E}+04$ \\
\hline Sr-90 & NL & $5 E+04$ & - & 24 & $\mathrm{~b}$ & b \\
\hline Tc-99 & $5 E+03$ & $2 E+04$ & 4 & 0.02 & 200 & 200 \\
\hline Cs-137 & $\mathrm{NL}^{\mathrm{c}}$ & $8 E+05$ & - & 13 & $b$ & b \\
\hline $\mathrm{U}-238$ & $2 E+03^{c}$ & $5 E+03$ & 2.5 & $0.03^{c}$ & $135^{\circ}$ & $450^{\circ}$ \\
\hline Pu-239 & $\mathrm{NL}^{\mathrm{c}}$ & $6 E+03$ & - & $0.73^{c}$ & $b$ & $\mathrm{~b}$ \\
\hline $\begin{array}{l}\mathrm{Am}-241 \\
(\mathrm{~Np}-237)^{\mathrm{d}}\end{array}$ & $6 E+05^{c, 0}$ & $9 E+03$ & 0.015 & $7.5^{\circ}$ & $0.5^{6,0}$ & b \\
\hline
\end{tabular}

a "NL" means No Limit - estimated permissible concentration is greater than the specific activity of the pure elemental radionuclide.

b No variation in values caused equal concentrations

c Arrival time at the performance boundary is greater than $10,000 \mathrm{y}$.

d The dominant decay product for Am-241

e Based on the dominant decay product, Np-237

"- Value could not be calculated

(b) Water/Atmospheric Pathways

\begin{tabular}{|c|c|c|c|c|c|c|}
\hline \multirow[t]{4}{*}{$\begin{array}{l}\text { Indicator } \\
\text { Nuclide }\end{array}$} & \multirow[t]{4}{*}{$\begin{array}{c}\text { PE } \\
C_{W-W a t e r} \\
\left(\mu \mathrm{Ci} / \mathrm{m}^{3}\right)\end{array}$} & \multirow[t]{4}{*}{$\begin{array}{c}\text { PE } \\
C_{W \cdot A t m} \\
\left(\mu \mathrm{Ci} / \mathrm{m}^{3}\right)\end{array}$} & \multirow[t]{4}{*}{$\begin{array}{c}\text { PE } \\
C_{W-A t m} \\
C_{W-W a t e r}\end{array}$} & $\begin{array}{c}\text { Natural } \\
\text { Recharge, } \\
i \\
(\mathrm{~m} / \mathrm{y})\end{array}$ & $\begin{array}{l}\text { Groundwater } \\
\text { Darcy } \\
\text { Velocity, } q_{g w} \\
\text { (m/y) }\end{array}$ & $\begin{array}{c}\text { Area, } \\
\text { A } \\
\left(\mathrm{m}^{2}\right)\end{array}$ \\
\hline & & & & \multicolumn{3}{|c|}{ PE Values } \\
\hline & & & & 0.07 & 56 & 2500 \\
\hline & & & & \multicolumn{3}{|c|}{$\begin{array}{c}\text { Value That Caused Equal } \\
\text { Concentrations }\end{array}$} \\
\hline $\mathrm{H}-3$ & $3 E+14$ & $1 E+10$ & $3 E-05$ & 3.0 & a & $\bar{~} \bar{a}$ \\
\hline$c-14$ & $3 E+04$ & $7 E+03$ & $2 E-01$ & 0.3 & 13 & 50,000 \\
\hline
\end{tabular}

a No variation in values caused equal concentrations. 
A $K_{d}$ value of about $8 \mathrm{~mL} / \mathrm{g}$ resulted in an arrival time at the performance boundary equal to $10,000 \mathrm{y}$. The $K_{d}$ values that caused the permissible concentrations for the water and intruder pathways to be the same are listed in Table 4-10 for 5 of the indicator radionuclides. The indicator radionuclides $\mathrm{H}-3, \mathrm{C}-14$, and Tc-99 were not considered in this analysis because general consensus is that the $K_{d}$ values for these radionuclides are small.

Table 4-10. Variation of $K_{d}$ Values for the Unsaturated Zone at INEL (tumulus design) (a $K_{d}$ value of $8 \mathrm{~mL} / \mathrm{g}$ caused radionuclide arrival at the performance boundary equal to $10,000 \mathrm{y})$

\begin{tabular}{|c|c|c|c|c|c|}
\hline $\begin{array}{l}\text { Indicator } \\
\text { Nuclide }\end{array}$ & $\begin{array}{c}P E \\
K_{d} \\
(\mathrm{~mL} / g)\end{array}$ & $\begin{array}{c}\text { PE } \\
C_{\text {W-Water }}\end{array}$ & $\begin{array}{c}\text { PE } \\
C_{w-\ln t r}\end{array}$ & $\begin{array}{c}\text { PE } \\
C_{W-\text { Intr }} \\
c_{W-\text { Water }}\end{array}$ & $\begin{array}{l}\kappa_{d} \text { Value That } \\
\text { Caused Equal } \\
\text { Concentrations }\end{array}$ \\
\hline Sr-90 & 2 & NL & $5 E+04$ & - & c \\
\hline Cs-137 & 20 & $\mathrm{NL}^{\mathrm{b}}$ & $8 E+05$ & - & c \\
\hline$U-238$ & 1000 & $2 E+03^{b}$ & $5 E+03$ & 2.5 & $c, d$ \\
\hline Pu-239 & 2000 & $\mathrm{NL}^{\mathrm{b}}$ & $6 E+03$ & - & $115^{b, d}$ \\
\hline $\begin{array}{l}\mathrm{Am}-241 \\
(\mathrm{~Np}-237)^{\circ}\end{array}$ & $\begin{array}{l}1900 \\
(50)\end{array}$ & $6 E+05^{b, f}$ & $9 E+03$ & 0.015 & 2 \\
\hline
\end{tabular}

a "NL" means No Limit - the estimated permissible waste concentration is greater than the specific activity of the pure elemental radionuclide.

b Arrival time at the performance boundary is greater than $10,000 \mathrm{y}$.

c No variation in value caused equal concentrations.

d Value less than $8 \mathrm{~mL} / \mathrm{g}$ caused arrival at the performance boundary before $10,000 \mathrm{y}$, which changed the limiting pathway.

e The dominant decay product for Am-241

f Concentration determined by Np-237 (see Appendix E in Volume 2)

"." Value could not be calculated.

For Sr-90 and Cs-137, no $K_{d}$ value caused the water and intruder permissible waste concentrations to become equal. A $K_{d}$ value less than $8 \mathrm{~mL} / \mathrm{g}$ for U-238 caused the arrival time at the performance boundary to be less than $10,000 \mathrm{y}$, and therefore changed the limiting pathway from intruder to water. For Pu-239, a $K_{d}$ value of $115 \mathrm{~mL} / \mathrm{g}$ caused the water pathway concentration to equal the intruder pathway concentration, although the arrival time still exceeded $10,000 \mathrm{y}$; the $K_{d}$ value had to be decreased to less than $8 \mathrm{~mL} / \mathrm{g}$ for the limiting pathway to change from intruder to water. The PE result for Am-241 is limited by the decay product (Np-237) contribution to the dose. However, if the $K_{d}$ value for Am-241 is reduced to $2 \mathrm{~mL} / \mathrm{g}$, then the water pathway waste concentration will be limited by the parent radionuclide (Am-241) and the water pathway will control. Due to the long half-life of Np-237, reduction of its $K_{d}$ has no effect on the resulting waste concentration. 


\subsubsection{Physical Constraints on Sensitivity Analysis Values}

The PE results for INEL are based on parameter values provided by the INEL technical staff for site-specific parameters used in calculations. Descriptions and technical justifications of these values are provided in Sections 4.3 and 4.4. The range and statistical distribution may not be known for each input parameter value; however, site-specific knowledge can be used to determine whether the values determined in the sensitivity analysis are reasonable and physically possible at INEL.

\section{Natural Recharge}

The sensitivity analysis results indicate it was possible to change the limiting pathway for Tc-99 and C-14 by changing the recharge. The values for recharge estimated in the sensitivity analysis range from 0.02 to $24 \mathrm{~m} / \mathrm{y}(0.07$ to $79 \mathrm{ft} / \mathrm{y}$ ) (Table 4-9 [a] and [b]) compared to the PE value of $0.07 \mathrm{~m} / \mathrm{y}(0.23 \mathrm{ft} / \mathrm{y})$. The natural recharge at INEL is reported to vary from $0.005 \mathrm{~m} / \mathrm{y}$ to $0.3 \mathrm{~m} / \mathrm{y}$, based on percolation tests and neutron access tube measurements. The sensitivity analysis values for Tc-99, U-238 (Table 4-9[a]) and C-14 (Table 4-9[b]) all fall within the reported range, although $\mathrm{U}-238$ radionuclide travel times were greater than $10,000 \mathrm{y}$. The remaining indicator radionuclides (Sr-90, Cs-137, and Am-241) all had values which fell outside of the reported range for recharge at INEL and are not physically reasonable.

\section{Groundwater Darcy Velocity}

The sensitivity analysis results indicate it is possible to change the limiting pathway for Tc-99 by changing the groundwater velocity. The values for the groundwater Darcy velocity estimated by the sensitivity analysis vary from 0.5 to $200 \mathrm{~m} / \mathrm{y}(1.6$ to $656 \mathrm{ft} / \mathrm{y})$ (Table 4-9[a] and [b]) compared to the $\mathrm{PE}$ value of $56 \mathrm{~m} / \mathrm{y}(184 \mathrm{ft} / \mathrm{y})$. At INEL, the groundwater Darcy velocity varies from $55 \mathrm{~m} / \mathrm{y}$ to $222 \mathrm{~m} / \mathrm{y}$ (180 ft/y to $728 \mathrm{ft} / \mathrm{y})$. The Tc-99 and U-238 sensitivity analysis values are reasonable because they fall within the reported range for Darcy velocity at INEL, however, U-238 has an arrival time greater than 10,000 y. All other indicator radionuclide sensitivity analysis values (Am-241 and C-14) do not fall within the reported range and are not physically reasonable.

\section{Facility Area}

The sensitivity analysis results indicate it was possible to change the limiting pathway for C-14 by changing the facility size. The value for the facility area estimated in the sensitivity analysis ranged from $200 \mathrm{~m}^{2}$ to $50,000 \mathrm{~m}^{2}\left(2160 \mathrm{ft}^{2}\right.$ to $\left.540,000 \mathrm{ft}^{2}\right)$ (Table 4-9[a] and [b]). All of these values are possible because there are no particular physical constraints that limit the size of an MWDF at INEL. However, U-238 arrived at the performance boundary beyond 10,000 y. For Tc-99, a facility limited in plan view area to $200 \mathrm{~m}^{2}\left(2160 \mathrm{ft}^{2}\right.$ ) (about $14 \mathrm{~m}$ by $14 \mathrm{~m}$ square [ $46 \mathrm{ft}$ by $46 \mathrm{ft}$ ]) is probably not reasonable.

\section{Distribution Coefficients}

The results shown in Table 4-10 indicate that it was not possible to change the limiting exposure pathway by changing the $K_{d}$ value. The radionuclides $\mathrm{Pu}-239$ and Am-241 were the most sensitive of the indicator radionuclides; it was possible to change the limiting pathway from 
intruder to water when the $K_{d} \mathrm{~s}$ were changed to $8 \mathrm{~mL} / \mathrm{g}$ (the $K_{d}$ required to cause arrival at the performance boundary at $10,000 \mathrm{y}$ ) and $2 \mathrm{~mL} / \mathrm{g}$, respectively. These are probably not reasonable values for either radionuclide at INEL; Pu-239 had a PE value of $2000 \mathrm{~mL} / \mathrm{g}$ and Am-241 had a $\mathrm{PE}$ value of $1900 \mathrm{~mL} / \mathrm{g}$.

\subsubsection{Comparison of Conceptual Models and Results between the PE and the INEL Performance Assessment}

The conceptual model selected to represent a site can be considerably more important to the results than the parameter values selected for that particular model. The conceptual model for flow and transport used in the water pathway analysis for the INEL RWMC performance assessment (Maheras et al., 1994) is believed to be conservative with respect to actual site behavior because relatively few mechanisms are used to represent the environmental concentration that is known or believed to occur. The conceptual model used in this PE analysis is believed to be slightly more conservative than that used in the INEL performance assessment because fewer attenuation mechanisms have been used. The comparison of results and conceptual models between the INEL PE and the RWMC performance assessment provides an opportunity to determine the differences in conservatism used in these two analyses. The comparison of results and conceptual models is described in detail in Appendix A.1 and is summarized here.

The major differences between the conceptual models used in the RWMC performance assessment and in the PE, as well as their implications, are highlighted below.

- The PE method assumes that all inventories are emplaced at the time of facility closure, and that no releases to the environment occur before failure of the leachate collection system. In the RWMC, the time of closure was assumed to be the year 2020; however, emplacement into the facility of the radionuclides considered in the INEL performance assessment began in 1984. For a mobile and relatively short-lived isotope such as tritium, this means that a large fraction of the material will have decayed and escaped the facility before closure in 2020. This causes a significant over-prediction in concentrations by the $\mathrm{PE}$ method, resulting in lower CRFs and more restrictive waste concentration limits.

- In addition to the differences in emplacement of radionuclides into the facility, the RWMC performance assessment and the PE make different assumptions about the release of radionuclides at the source. The RWMC performance assessment uses a transient release, based on a complex calculation of degradation, decay, and ingrowth of the source material. The PE assumes a constant release rate and steady-state transport model. For INEL, this difference is most noticeable in the saturated zone, where the RWMC performance assessment allowed the contaminants to undergo time-variant releases and two-dimensional advection-dispersion. The PE assumes a constant release and no dispersion.

- Studying the effect of dispersion in the aquifer helps to clarify this difference. The end result is that the peak radionuclide concentration at the point of compliance (i.e., at the 
well) is reduced from that at its point of initial mixing (i.e., beneath the facility) by a factor of 0.83 ; that is, the well concentration is $83 \%$ of the initial aquifer concentration, due to horizontal dispersion. Alternatively, this may be thought of as a dispersion CRF:

$$
C R F_{\text {Dispersion }}=(0.83)^{-1}=1.2
$$

Superimposing this simple calculation upon the standard PE method reduces the source of the differences to the characterization of the source term alone because the environmental transport calculations match very well.

This discussion pertains only to comparison of the analyses contained in the RWMC performance assessment and the INEL PE. No quantitative statements can be made about the degree of conservatism of either analysis with respect to the actual behavior of any specific radionuclide at INEL over a 10,000-y time period.

\subsection{OBSERVATIONS}

Based on the results of the PE and the parameter-sensitivity analysis, the following observations can be made about MLLW disposal at INEL:

- The INEL site has characteristics that are typical of an arid climate. The annual rainfall and the natural recharge at INEL are relatively low $(0.22 \mathrm{~m} / \mathrm{y}$ and $0.07 \mathrm{~m} / \mathrm{y}[0.5 \mathrm{ft} / \mathrm{y}$ and $0.23 \mathrm{ft} / \mathrm{y}$ ], respectively). The thickness of the vadose zone at the evaluated site is about $50 \mathrm{~m}(165 \mathrm{ft})$.

- For both the trench and tumulus designs at INEL, the results indicate that of the 58 radionuclides evaluated in the $\mathrm{PE}, 54$ radionuclides would be limited by the intrusion scenarios. These results reflect the dominant role of the selected human intrusion scenarios that is demonstrated for almost all the sites considered in the PE (see Sections 7.5 and 7.6 in Volume 2). This dominance indicates a need to be aware of the inability to predict the social behavior of populations far into the future.

The results also indicate that for the water pathway, 51 radionuclides for both designs . would arrive at the performance boundary after the $10,000-y$ period of consideration in the PE analysis of the water pathway. Of the 7 that arrived before $10,000 \mathrm{y}$, two had no limit on waste concentration.

Because INEL has many radionuclides that either are limited by the intrusion scenarios, arrive at the performance boundary after $10,000 \mathrm{y}$, or have no limit on waste concentration, this site may have flexibility in accepting a variety of radionuclides for disposal. 
- Using either a trench or tumulus design is feasible at INEL. Current LLW disposal practices at INEL involve shallow-buried pit and vault designs. At INEL, there is no significant difference in the permissible waste concentrations estimated by the PE between the trench and tumulus designs for the longer-lived radionuclides.

- INEL does not have physical constraints that could limit disposal activities. While present LLW disposal activities at INEL occupy most of the currently available land area within the RWMC, there are other areas at INEL of adequate size and with sufficient depth to groundwater to accommodate future MLLW disposal.

- The sensitivity analysis for INEL indicates that reasonable changes in values for the natural recharge, groundwater Darcy velocity, and facility size for most radionuclides would not significantly change the results. Values for recharge for Tc-99 and C-14, the groundwater Darcy velocity for Tc-99, and the plan area of the disposal facility for C-14 could affect the limiting pathway.

In flow and transport problems, the $K_{d}$ values are often the most uncertain site-specific input parameters. Some of the $K_{d}$ values for the geologic media at INEL could have sufficient uncertainty to affect the results (i.e., change the limiting pathway) for several of the radionuclides considered in the PE by changing the arrival time at the performance boundary (Table 4-10).

- The conceptual model for water flow used in the INEL PE is based on the LLW performance assessment for INEL's RWMC. The conceptual model for radionuclide transport in the PE analysis is slightly more conservative than the one used in the performance assessment. The differences in the results of the two analyses have been identified and quantified (see Appendix A.1).

The conceptual model for intrusion scenarios used in the INEL PE is based on the LLW performance assessment for INEL's RWMC. The conceptual model for intrusion in the $\mathrm{PE}$ analysis is believed to produce results that are two to three orders of magnitude more restrictive than the one used in the performance assessment. The differences in the results of the two analyses have been identified and quantified (see Appendix A.1). 


\subsection{REFERENCES}

Baer, T.A., L. L. Price, J. N. Emery, N. E. Olague, 1994. Second Performance Assessment Iteration of the Greater Confinement Disposal Facility at the Nevada Test Site. SAND93-0089. Albuquerque, NM: Sandia National Laboratories.

Case, M.J., et al., 1990. Radioactive Waste Management Complex Performance Assessment. EGG-WM-8773.

Cooper, C.D., and F.C. Alley, 1986. Air Pollution Control: A Design Approach. Prospect Heights, IL: Waveland Press, Inc.

CRC, 1981. CRC Handbook of Chemistry and Physics. Eds. Robert C. Weast and Melvin J. Astle. Boca Raton, FL: CRC Press, Inc.

EPA, 1992. User's Guide for the Industrial Source Complex (ISC2) Dispersion Models, Volume I: User Instructions. EPA Publication No. EPA-450/4-92-008a. Research Triangle, NC:

U.S. Environmental Protection Agency.

FFCAct, 1992. Federal Facility Compliance Act of 1992. P.L. 102-386, October 1992.

Gruebel, Marilyn M., Robert D. Waters, Maryann B. Hospelhorn, and Margaret S. Y. Chu, eds., 1994. Framework for DOE Mixed Low-Level Waste Disposal: Site Fact Sheets. SAND942728. Albuquerque, NM: Sandia National Laboratories.

Kincaid, C.T., J.W. Shade, G.A. Whyatt, M.G. Piepho, K. Rhoads, J.A. Voogd, J.H. Westsik, Jr., M.D. Freshley, K.A. Blanchard, and B.G. Lauzon, eds., 1993. Performance Assessment of Grouted Double-Shell Tank Waste Disposal at Hanford. WHC-SD-WM-EE-004, Rev. 0. U.S. Department of Energy, Pacific Northwest Laboratory and Westinghouse Hanford Company.

Maheras, Steven J., Arthur S. Rood, Swen O. Magnuson, Mary E. Sussman, and Rajiv N. Bhatt, 1994. Radioactive Waste Management Complex Low-Level Waste Radiological Performance Assessment. EGG-WM-8773. Idaho Falls, ID: U.S. Department of Energy Office of Environmental Restoration and Waste Management, DOE Idaho Operations Office.

MMES (Martin Marietta Energy Systems), EG\&G Idaho, Inc., and Westinghouse Savannah River Company, 1994. Radiological Performance Assessment for the E-Area Vaults Disposal Facility (U). WSRC-RP-94-218, Rev. 0. Aiken, SC: Westinghouse Savannah River Company. 
ORNL (Oak Ridge National Laboratory), 1994. Performance Assessment for Continuing and Future Operations at Solid Waste Storage Area 6. ORNL-6783. Oak Ridge, TN: U.S.

Department of Energy, Oak Ridge National Laboratory.

Rood, A.S., 1994. GWSCREEN: A Semi-Analytical Model for Assessment of the Groundwater Pathway from Surface or Buried Contamination, Theory and User's Manual, Version 2.0, EGG-GEO-10797, Rev. 2, Idaho National Engineering Laboratory, EG\&G Idaho, Inc., Idaho Falls, ID.

Rood, A.S., et al. 1994. Engineering Design File, RWMC-760, Idaho National Engineering Laboratory, EG\&G Idaho, Inc., Idaho Falls, ID.

Taylor, D., 1994. Personal communication in meeting with INEL site technical staff, September 23, 1994.

Thibault, D.H., M.I. Sheppard, and P.A. Smith, 1990. A Critical Compilation and Review of Default Soil Solid/Liquid Partition Coefficients, Kd, for Use in Environmental Assessments. AECL-10125. Pinawa, Manitoba, Canada: Whiteshell Nuclear Research Establishment, Atomic Energy of Canada Limited.

\section{Acknowledgments}

The ORNL Core Team acknowledges the contributions of Swen Magnuson, Roger Piscatella, D. Taylor, and Arthur Rood of INEL. 


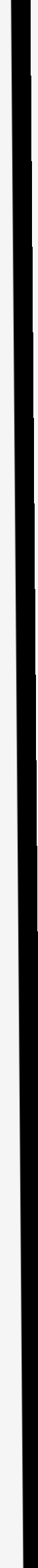




\section{Illinois: ARGONNE NATIONAL LABORATORY-EAST (ANLE) Core Team Contact: Marilyn M. Gruebel}

The Federal Facility Compliance Act (FFCAct, 1992) requires the Department of Energy (DOE) to establish plans in conjunction with its regulators and with members of the public for the treatment of DOE's mixed low-level waste (MLLW). Although the FFCAct does not specifically address disposal of treated MLLW, both DOE and the States recognized that disposal issues are an integral part of treatment discussions. Since 1992, DOE has worked with the States to define and develop an evaluation process for disposal options. Preliminary activities of this joint DOEState process have narrowed the sites for further evaluation from 49 to 15 .

The Disposal Workgroup (DWG), which was established by DOE to develop a process for evaluating disposal options, designed a performance evaluation (PE) to quantify and compare the limitations of the remaining 15 DOE sites for MLLW disposal. The principal goal of the PE was to estimate, for grouted residuals resulting from the treatment of MLLW, permissible concentrations of radionuclides in waste for disposal at each site. These "permissible waste concentrations" were based solely on long-term physical performance of the disposal facility and did not take into account any operational waste acceptance criteria that a site might have developed. The PE did not address any ethical, social, or policy considerations relevant to siting such facilities.

The PE used analyses that are consistent with the approach used in many low-level waste (LLW) performance assessments. The objective was to use a set of modeling assumptions of sufficient detail to capture major site-specific characteristics and yet be general enough for consistent application at all sites. Additionally, the analyses were designed to ensure that the sites were analyzed consistently and that all major assumptions were clearly stated.

The remainder of this chapter provides the PE results for Argonne National LaboratoryEast (ANLE), one of the 15 sites being evaluated. The chapter contains the following information:

Section 5.1: brief, general description of the site, based on previous work done by the DWG (Gruebel et al., 1994)

Section 5.2: plans for MLLW disposal, if any, and the location evaluated in the PE

Section 5.3: current understanding of radionuclide movement at the selected location based on available information, and the conceptual model used for the evaluation of each of three pathways (water, atmospheric, and inadvertent intruder)

Section 5.4: site-specific and generic values used in the PE calculations and their sources

Section 5.5: estimates of maximum waste concentrations determined in the PE calculations for each of the three pathways, along with calculated values used in determining these results 
Section 5.6: summary of results based on disposal-facility design; discussion with respect to such issues as uncertainty and sensitivity

Section 5.7: observations based on the results of the PE and the parameter sensitivity analysis

Section 5.8: references

The general assumptions and methodology used in the PE are summarized in Chapter 1 of this volume and explained in more detail in Volume 2 of this report. Overall results for all the sites are discussed in Chapter 6 of Volume 2.

\subsection{GENERAL DESCRIPTION OF THE SITE}

Argonne National Laboratory-East (ANLE) is located in DuPage County, Illinois, approximately $35 \mathrm{~km}$ (22 mi) southwest of downtown Chicago and $40 \mathrm{~km}$ ( $25 \mathrm{mi})$ west of Lake Michigan (Figure 5-1). The site is north of the Des Plaines River Valley, south of Interstate Highway 55, and west of Illinois Highway 83. Major features of the region include both the Des Plaines River channel, which contains the river and the Chicago Sanitary and Ship Canal, and Lake Michigan.

Urban developments associated with high concentrations of commercial, industrial, and residential usage are located near ANLE. The site is located within the western suburbs of Chicago between the communities of Woodridge and Lemont. Approximately 7 million people

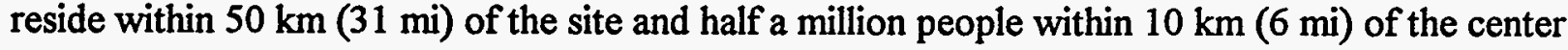
of the site.

The ANLE site contains a multiprogram research and development laboratory that conducts basic and applied research on advanced fission reactors and in the physical, life, and environmental sciences to support development of energy technologies. The site occupies the central $6.9 \mathrm{~km}^{2}(1,700 \mathrm{ac})$ of a $15.1-\mathrm{km}^{2}(3,740-\mathrm{ac})$ tract (Figure 5-2). The $8.3-\mathrm{km}^{2}(2,040-\mathrm{ac})$ Waterfall Glen Forest Preserve surrounding the site is mostly former ANLE property that was deeded to the DuPage County Forest Preserve District in 1973 for use as a public recreational area, nature preserve, and demonstration forest.

The climate of the area is representative of the upper Mississippi Valley, as moderated by Lake Michigan, and is characterized by cold winters and hot summers. January is the coldest month with an average temperature of $-6^{\circ} \mathrm{C}\left(21^{\circ} \mathrm{F}\right)$; July is the warmest month with an average temperature of $21^{\circ} \mathrm{C}\left(70^{\circ} \mathrm{F}\right)$. Precipitation averages about $84 \mathrm{~cm}(33$ in.) annually, with the largest rainfalls occurring between April and September. Evapotranspiration in the area is estimated at $80 \%$ of the annual rainfall or about $67 \mathrm{~cm}$ ( $26 \mathrm{in}$.). The annual average wind direction is generally variable, from the west to south, but with a significant northeast component. 


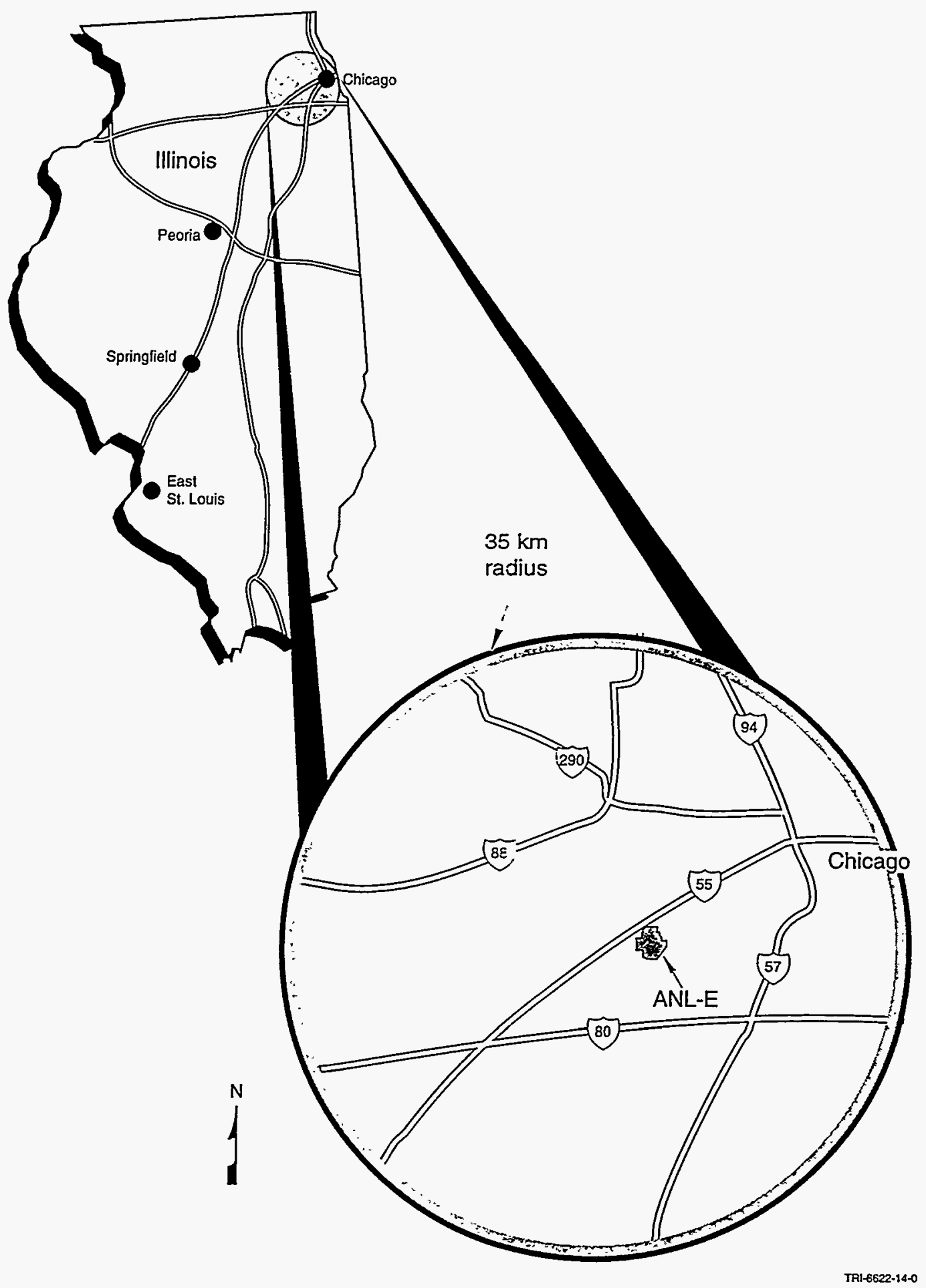

Figure 5-1. Location map for Argonne National Laboratory-East. 


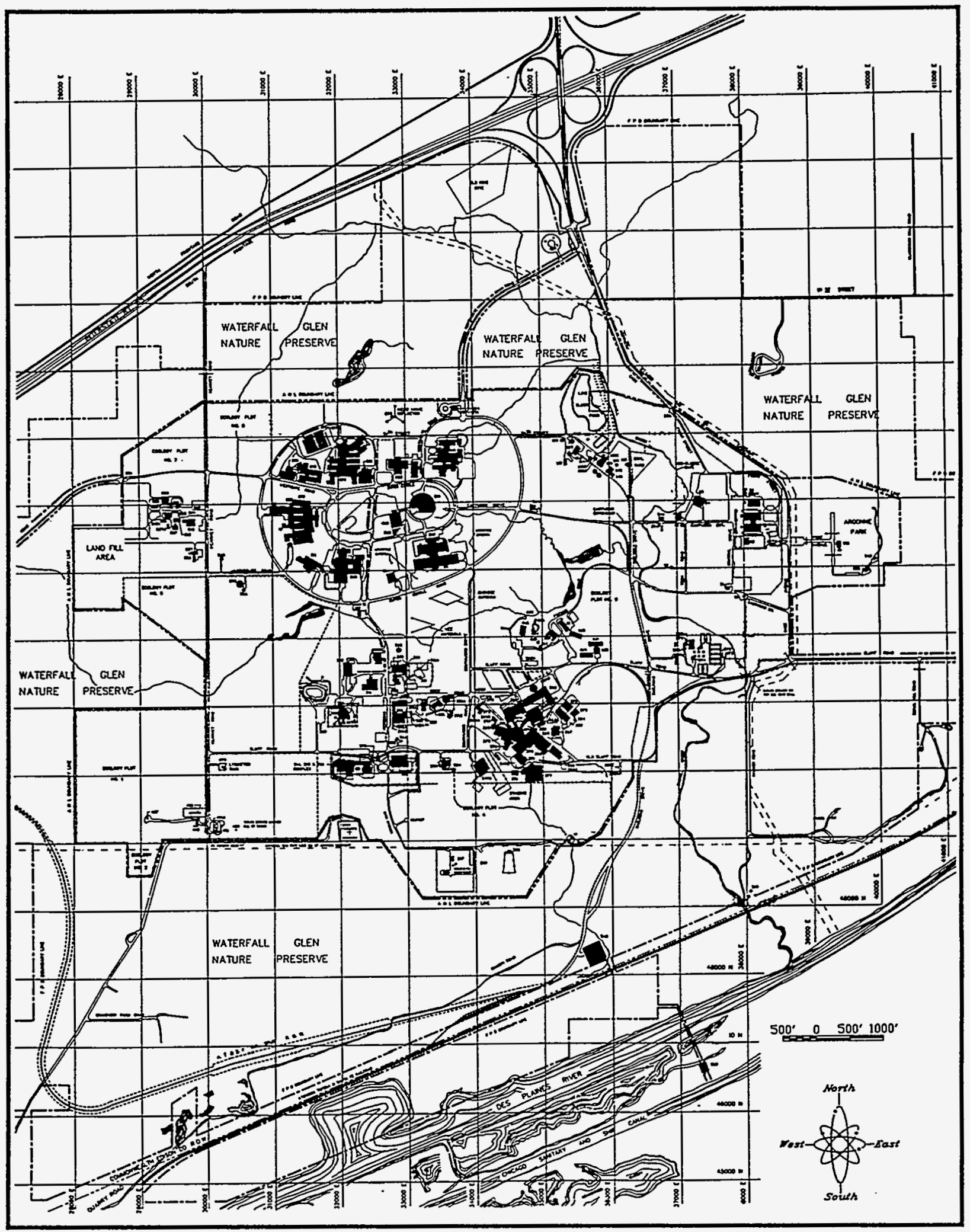

Figure 5-2. Site map for Argonne National Laboratory-East. The ANLE site is located on a $6.9-\mathrm{km}^{2}(1700-\mathrm{ac})$ tract near the center of a $15.1-\mathrm{km}^{2}(3,740-\mathrm{ac})$ tract of the Waterfall Glen Nature Preserve. 
The topography of the area is generally gently rolling. The average elevation is about $220 \mathrm{~m}(720 \mathrm{ft})$ above sea level. Slopes of consequence are found only adjacent to streams and along the banks of the Des Plaines River.

The stratigraphy of the ANLE area consists of about 10 to $50 \mathrm{~m}$ (33 to $160 \mathrm{ft}$ ) of glacial till on top of the bedrock, which is Silurian-age dolomite about 60 to $70 \mathrm{~m}$ (200 to $300 \mathrm{ft})$ thick. This dolomite is underlain by shale and older dolomites, sandstones, and Precambrian granite.

The ANLE site is located in the Des Plaines River drainage basin (Figure 5-2) about $40 \mathrm{~km}$ (25 mi) west of Lake Michigan and on the northern margin of the Des Plaines River valley. The Des Plaines River flows southwest about $48 \mathrm{~km}(30 \mathrm{mi})$ until it joins with the Kankakee River to form the Illinois River.

Two principal aquifers are used as water supplies in the vicinity of the laboratory. Most groundwater supplies in the ANLE area are derived from the Silurian-age dolomite. The lower aquifer is in the older Galesville Sandstone, which lies between 150 and $460 \mathrm{~m}$ (500 and $1500 \mathrm{ft}$ ) below the surface. The Maquoketa Shale separates the upper dolomite aquifer from the underlying sandstone aquifer and retards hydraulic connection between the two. The area around ANLE is becoming less dependent on groundwater as water piped from Lake Michigan becomes more accessible. No aquifers in the ANLE area have been designated by the U.S. Environmental Protection Agency (EPA) as sole source aquifers as defined in 40 CFR 149.2.

\subsection{STATUS AND SITING OF MLLW DISPOSAL FACILITY}

At the time of the PE, ANLE personnel had no plans for on-site disposal of MLLW. However, in preparation for the PE, site technical staff independently established a set of simple site-selection criteria that were used to identify more preferable locations for an MLLW disposal facility at ANLE. These selection criteria are summarized as follows:

- Avoid areas of standing water or in close proximity to running water.

- Consider areas with a near-maximum thickness of glacial till (unsaturated zone).

- Consider areas where groundwater flow predictably follows regional flow to the south and southeast.

- Avoid areas that have not already been disturbed by ANLE activities.

- Give priority to areas with available data.

Based on these criteria, ANLE technical staff indicated that a likely location to be evaluated in the PE would be in the western or northwestern portion of the site near the 800 Area (Figure 5-3). This general location was selected based on the five criteria described above; the selection does not take into account any possible future use of the area based on facility planning. However, site selection for ANLE's sanitary landfill, which is located in the 800 Area, likely was based on similar criteria. 


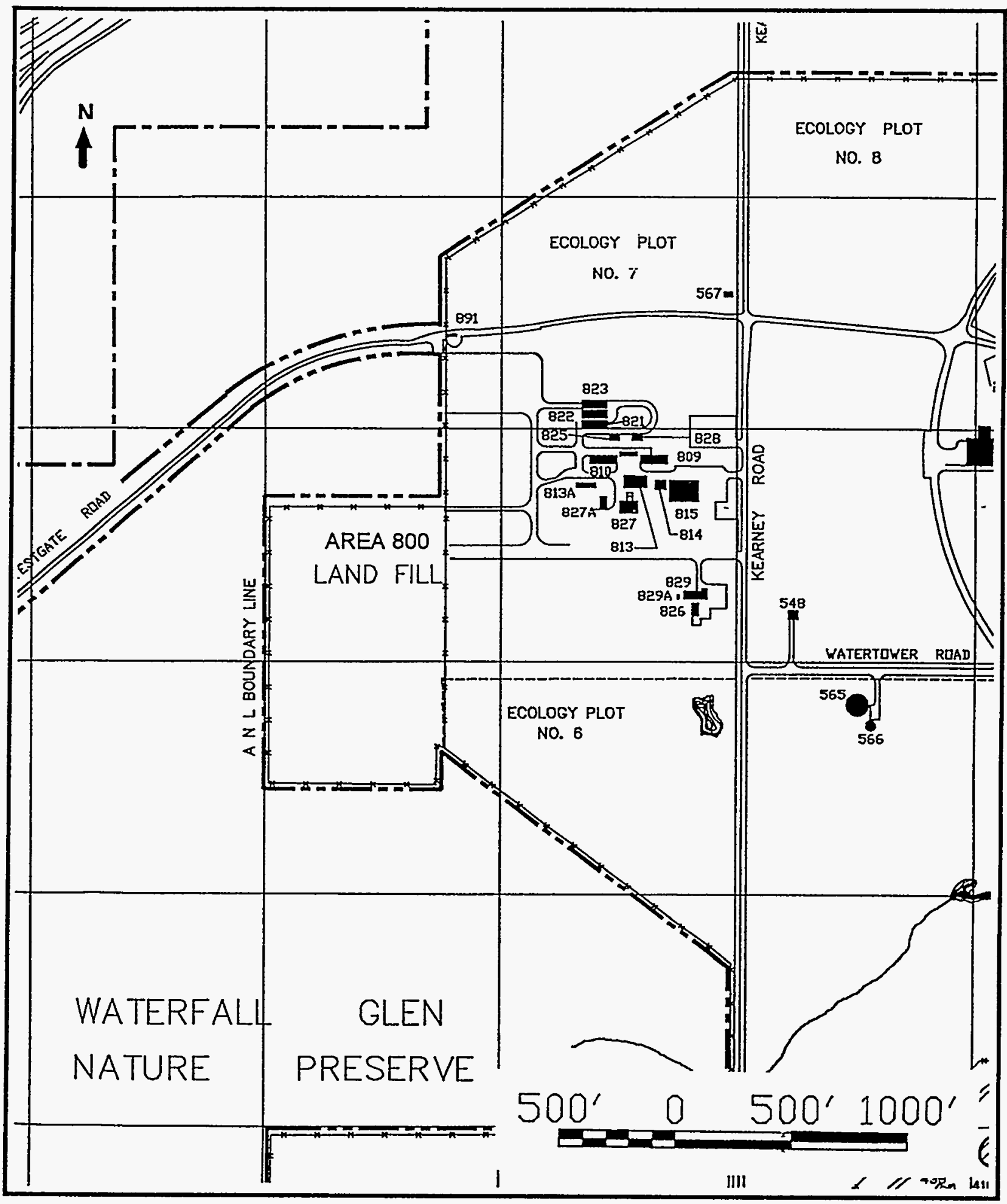

Figure 5-3. General location near the 800 Area Landfill for the generic MLLW disposal facilities in the PE for ANLE. 
Two generic disposal facilities were considered in the PE: a RCRA-compliant, belowground trench and a RCRA-compliant, above-ground tumulus (described in more detail in Chapter 5 of Volume 2). The generic facilities were selected to provide consistency in analysis of the performance of the 15 sites. Both generic facilities were assumed to be square with a plan area of $2500 \mathrm{~m}^{2}\left(26,910 \mathrm{ft}^{2}\right)$.

\subsection{BASIS FOR CONCEPTUAL MODEL USED IN THE PE}

The conceptual model used for the PE at ANLE was based on reports from the U.S. Geological Survey (Knowles et al., 1963) and the Illinois State Water Survey (Roadcap et al., 1993) as well as various published studies provided by ANLE. In addition, the site had undertaken a multiphase project to fully characterize the ANLE site. The Sitewide Hydrogeological Baseline Study was initiated for the purpose of determining the principal geological and hydrological characteristics of the soils and aquifers beneath ANLE (ANLE, 1993). Field work began in FY 1994 and was expected to continue through FY 1996. Preliminary data from Phase I of this baseline study were used in the PE when applicable.

\subsubsection{Water Pathway}

Knowledge of groundwater flow and radionuclide movement in the water pathway at ANLE provided the basis for the conceptual model considered in the PE. The conceptual model encompasses the site technical staff's current understanding of site-specific geology, hydrology, water table and aquifer characteristics, and transport pathways.

\subsubsection{Current Understanding of Relevant Hydrogeology}

The generalized stratigraphy of the rock units and aquifers in the ANLE area is shown in Figure 5-4. These units are discussed in this section from the surface to depth. In the area around ANLE, the Valparaiso Moraine consists of a prominent bedrock high that is covered by surficial deposits and two Pleistocene glacial units designated as the Wadsworth Till and the underlying Lemont Drift. The surficial deposits are wind-blown silts generally less than $1.5 \mathrm{~m}(5 \mathrm{ft})$ thick. The composition of the Wadsworth Till and the Lemont Drift is highly variable both horizontally and vertically over short distances. The Wadsworth Till is dominated by a thick silty clay to clayey silt. Thin discontinuous granular zones, usually less than 1.5 to $3 \mathrm{~m}$ (5 to $10 \mathrm{ft}$ ) thick, may occur within the Wadsworth. The Lemont Drift consists of sandy silt, silty sand, and clayey silt of various origins but also includes large volumes of glaciolacustrine and glaciofluvial materials. A

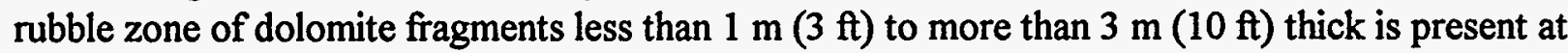
the base of the Lemont at several locations where ANLE staff have installed bedrock monitoring wells. At ANLE, the total thickness of the deposits overlying the bedrock ranges from about 12 to $49 \mathrm{~m}$ (40 to $160 \mathrm{ft}$ ) (ANLE, 1993). 


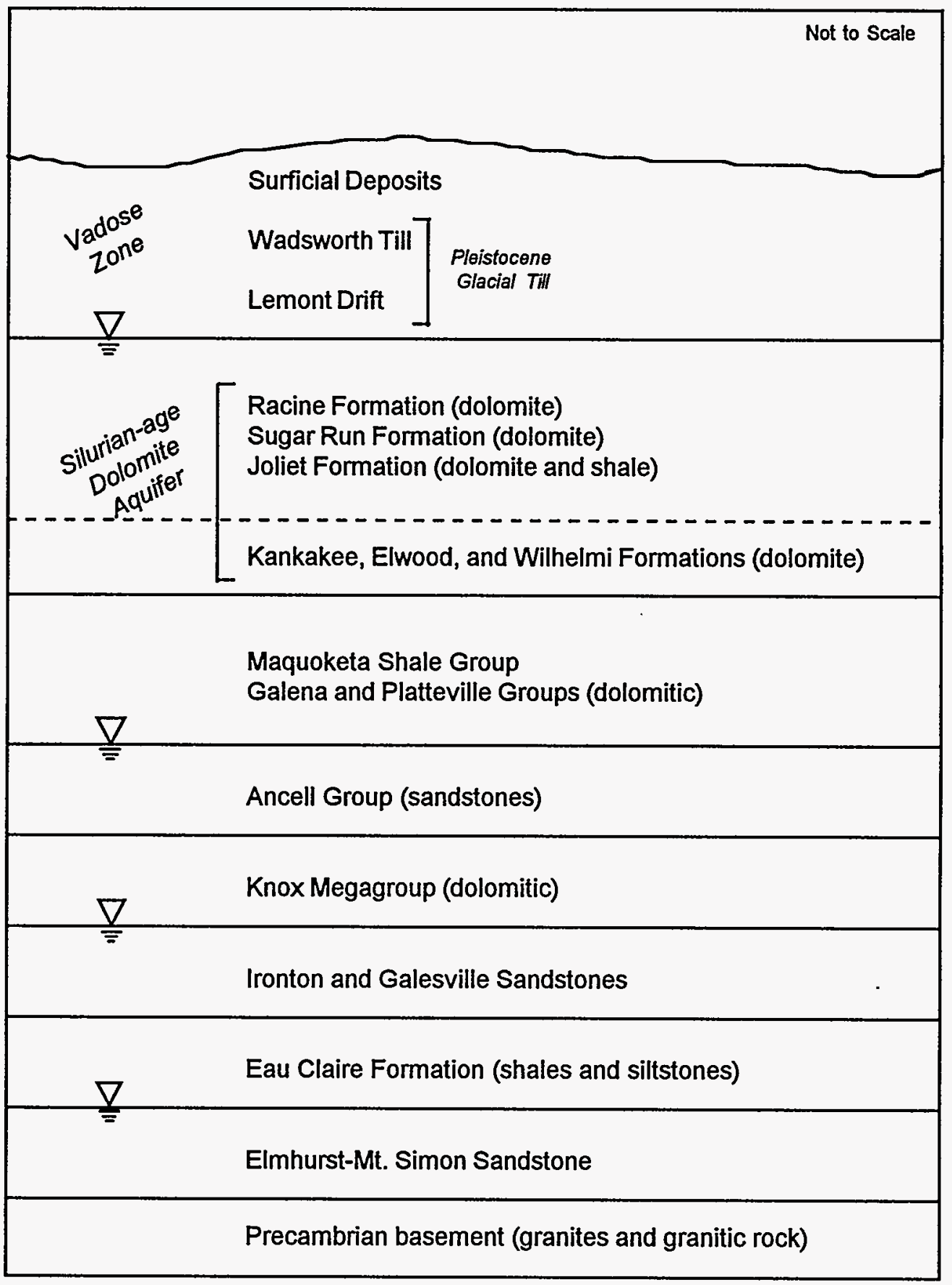

Figure 5-4. Generalized stratigraphy of rock units and aquifers in the ANLE area (based on Roadcap et al., 1993). 
The bedrock surface underlying ANLE consists of Silurian-age dolomite with fractures, joints, and bedding planes that have been enlarged by moderate solutioning. The dolomite is thinto massive-bedded, fine- to medium-grained, and calcareous, and contains some chert. The dolomite consists of several formations and ranges in thickness from 60 to $70 \mathrm{~m}$ (200 to $225 \mathrm{ft}$ ) at the ANLE site (Knowles et al., 1963).

Older units underlie the Silurian-age dolomite. The relatively impermeable Maquoketa Shale Group consists of about $50 \mathrm{~m}$ (165 ft) of compact, soft shale. Underlying the Maquoketa are carbonate rocks and a series of rock units containing water-bearing sandstones. Below these units is a sequence containing sandstone units that have been used as regional aquifers. The underlying Precambrian-age basement is composed of granites or granitic rock (Roadcap et al., 1993).

Surface drainage at ANLE is in a southerly direction toward the Des Plaines River, which is located approximately $610 \mathrm{~m}(2,000 \mathrm{ft})$ south of the site (Figure 5-2). Sawmill Creek flows through the eastern portion of the site. This stream originates north of the site, flows through the property in a southerly direction, and discharges into the Des Plaines River. Two small streams originate in the western portion of the site and combine to form Freund Brook, which discharges into Sawmill Creek. Along the southern margin of the property, the terrain slopes abruptly downward, forming forested bluffs. These bluffs are dissected by ravines containing intermittent streams that discharge some site drainage into the Des Plaines River (Golchert and Kolzow, 1994). Surface water from the area around ANLE is not used as a source of drinking water.

Groundwater in the area surrounding the ANLE site occurs within three hydrogeological groups. From the surface downward they are (1) glacial deposits of Pleistocene age, (2) shallow dolomite bedrock of Silurian age, and (3) deeper bedrock aquifers. The upper two groups are effectively separated from the deep bedrock system by a shale aquitard (ANLE, 1993). The Pleistocene-age glacial deposits form the vadose zone at ANLE.

Groundwater in the Wadsworth Till (the upper Pleistocene glacial unit) near the surface occurs mainly in the silty clay or sandy portions of the unit. About 25 active monitoring wells are completed in the Wadsworth in the western and southern portions of the ANLE site. In addition, six piezometers were installed in the southwestern portion of the site. Data on groundwater levels from 1988-1993 indicate seasonal fluctuations of up to several feet. Most of the monitoring wells contain water throughout the year, although a few are dry because of insufficient recharge and low hydraulic conductivity. Water level elevations are variable and do not indicate a consistent direction of lateral groundwater flow. A broad surface elevation control is indicated on the water level elevations by an approximately $20-\mathrm{m}(65-\mathrm{ft})$ difference in the ground surface and static water level elevations at the western and southern portions of the site. However, within each of these areas, the water level and surface elevations are poorly correlated, possibly indicating a lack of significant lateral flow. Water level elevations measured by piezometers in 1988 indicated a steady decline during the spring, summer, and fall, probably because of drought conditions. Some of this water level decrease was recovered during late fall and winter. "Slug" tests of the wells 
yielded hydraulic conductivity values of $4.2 \times 10^{-6}$ to $3.2 \times 10^{-7} \mathrm{~cm} / \mathrm{s}$ in the silty clay and $1.6 \times 10^{-4}$ to $4.2 \times 10^{-5} \mathrm{~cm} / \mathrm{s}$ in the sand (ANLE, 1993).

Little information is available on the Lemont Drift (the lower Pleistocene glacial unit) to evaluate the hydrogeological characteristics of the unit. The Lemont Drift has a clay content approximately one-half that of the Wadsworth Till and is probably more permeable than the overlying unit (ANLE, 1993).

Isopach maps of "upper" and "basal" sands within the.Wadsworth Till and the Lemont Dritt (Roadcap et al., 1993, Figures 6 and 7) from an area south of ANLE and the Des Plaines River indicate the possibility of groundwater-resource potential within these deposits. These units currently are minimally utilized in the area around ANLE because they are relatively thin and discontinuous. Based on field and laboratory tests, the downward rate of movement of water through the silty clay glacial deposits in the area has been calculated at $0.25 \mathrm{~cm}(0.1 \mathrm{in}$.) per day (Knowles et al., 1963).

The Silurian-age dolomite aquifer overlies the Maquoketa Shale. The Maquoketa acts as an aquitard between the dolomite and the underlying older aquifers. Significant permeability in the dolomite is primarily near the top of the unit from secondary structures such as bedding planes, joints, and fractures enhanced by solutioning. Recharge to the dolomite is chiefly from local precipitation that infiltrates through the overlying glacial deposits. Long-term aquifer tests conducted in the 1950s at ANLE resulted in transmissivity values in the range of 7000 to 9000 $\mathrm{gpd} / \mathrm{ft}(86,900$ to $111,700 \mathrm{Lpd} / \mathrm{m})$ for the dolomite. The upper portion of the dolomite forms the shallow bedrock aquifer for northeastern Illinois (ANLE, 1993). Almost all water wells in the area are completed in the Silurian-age dolomite aquifer (Knowles et al., 1963).

Approximately $90 \mathrm{~m}(300 \mathrm{ft})$ below the Maquoketa Shale aquitard is a sandstone aquifer in the Ancell Group (Figure 5-4). Below the Ancell Group, older rocks contain two waterbearing sandstone units. The uppermost of the two sandstone units (the Galesville Sandstone) is widely utilized as a source of groundwater in northern Illinois; the lower aquifer (the ElmhurstMt. Simon Sandstone) is no longer utilized as an aquifer but supplied groundwater to the Chicago region in the past (Roadcap et al., 1993).

The four domestic water supply wells now in use on the ANLE site are drilled about $90 \mathrm{~m}$ (300 ft) deep, terminating in the Silurian-age dolomite. A well drilled $490 \mathrm{~m}(1,600 \mathrm{ft})$ deep into Galesville Sandstone has been out of service for many years. The ANLE site expects to decrease its use of groundwater as water piped from Lake Michigan becomes accessible.

\subsubsection{Conceptual Model Used in the PE}

The PE used a generic conceptual model to describe the water pathway (summarized in Section 1.1.2 of this volume and described in detail in Chapter 5 of Volume 2). In the unsaturated zone, leachate was generated by constant flow of water through the disposal facility at a rate that 
was controlled by the assumed performance of the disposal facility. When all engineered barriers had failed, the rate was assumed to be equal to the natural recharge through local soils. The volumetric flow of water through the facility that generated leachate was based on the assumed performance and size of the disposal facility. No dilution was assumed to occur in the unsaturated zone, so at steady-state the concentration that reached groundwater equaled the leachate concentration. No lateral spreading was assumed, so the leachate flux through the unsaturated zone was confined to the soil column directly below the plan area of the facility.

As contaminated water entered the saturated zone, the contaminant mixed with clean groundwater, forming a plume with a shape controlled by aquifer and contaminant properties. The generic conceptual model assumed that instantaneous and complete mixing within the aquifer occurred directly below the facility. Mixing in the vertical direction occurred by hydrodynamic dispersion, and the contaminant mixing depth was an estimated value.

The generic conceptual model was adapted to conditions at ANLE based on site-specific knowledge of the geology and water flow paths. The following description represents the conceptual model of the water pathway that was used in the PE for ANLE.

The conceptual model for the water pathway at ANLE is illustrated in Figure 5-5. The conceptual model incorporated vertical movement of radionuclides through the unsaturated zone (glacial till) to the saturated zone (fractured dolomite aquifer) and subsequent lateral transport $100 \mathrm{~m}(328 \mathrm{ft})$ through the saturated zone to the performance boundary.

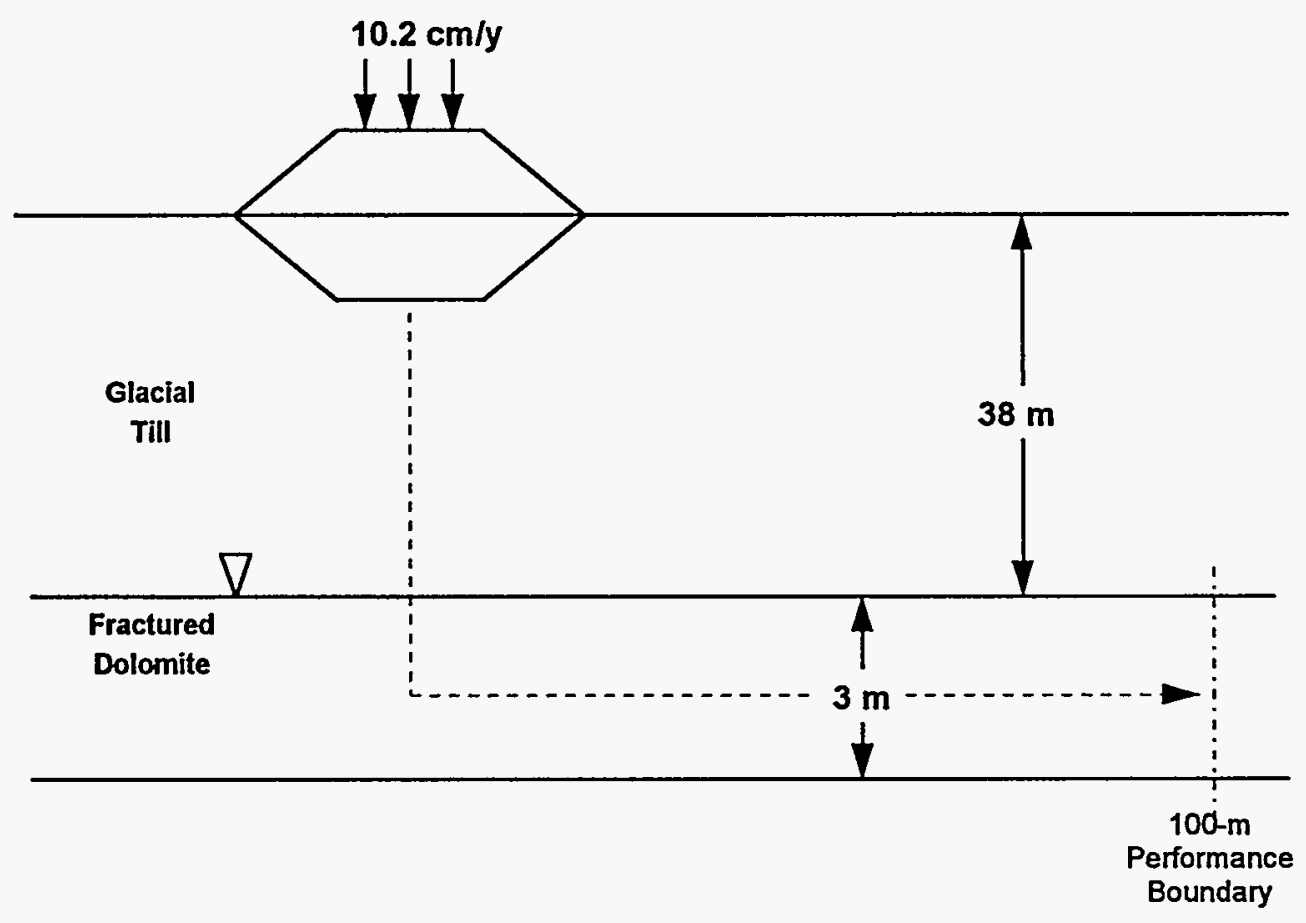

Figure 5-5. Conceptual model for water transport at ANLE. 
The unsaturated or vadose zone, consisting of surficial deposits and the Wadsworth Till and Lemont Drift, was simplified to one unit. The surficial deposits are relatively thin and variable and do not contribute significantly to the transport model. The glacial till is highly variable in composition, potentially consisting of zones ranging from clayey silt to sand and gravel. Sand lenses in the Wadsworth Till and Lemont Drift were not considered as potential aquifers because of data indicating extreme seasonal fluctuations, questionable lateral flow, and probable absence in the 800 Area.

In the PE model, the saturated zone in the upper fractured dolomite of the Silurian-age aquifer was assumed to be the shallowest viable source of drinking water. Contaminated water from the vadose zone was assumed to mix with the aquifer water; instantaneous and complete mixing was assumed throughout an aquifer mixing depth $\left(d_{m}\right)$ of $3 \mathrm{~m}(10 \mathrm{ft})$. Groundwater flow and radionuclide transport was assumed to occur in the fractures and bedding planes of the upper portion of the dolomite. Retardation because of sorption was also included in the saturated zone calculation.

\subsubsection{Atmospheric Pathway}

The conceptual model used in the PE for evaluating the atmospheric pathway was derived from performance assessments for LLW disposal facilities at Hanford (Kincaid et al., 1993), INEL (Maheras et al., 1994), NTS (Baer et al., 1994), ORR (ORNL, 1994), and SRS (MMES et al., 1994). The model was generalized for the $P E$ but used site-specific values for many of the parameters.

\subsubsection{Current Understanding of Relevant Meteorology}

The ANLE site provides yearly estimates of potential radiation doses from daily operations at the site, including doses due to atmospheric exposures. The most recent report (Golchert and Kolzow, 1994) presents estimates for 1993; the remainder of this section cites information from that report.

Continuously operating air samplers are used at ANLE to measure the concentrations of airborne particulate radioactivity. Non-radiological air contaminants in ambient air have not been monitored. Particulate samplers are placed at fifteen locations around the ANLE perimeter and at six off-site locations approximately five miles from ANLE to determine the ambient or background concentrations.

Airborne particulate samples for direct radiation measurement are collected continuously at thirteen perimeter locations and at five off-site locations. Additional air samples, used for radiochemical analysis of plutonium and other radionuclides, are collected at two perimeter locations and one off-site location. Stack monitoring is conducted continuously at those emission points that have a probability of releasing measurable radioactive effluents. The results of these measurements are used for calculating the theoretical annual off-site dose using the CAP-88 
version of the EPA-AIRDOSE/RADRISK atmospheric dispersion computer code (EPA, 1992a) and dose conversion.

The EPA-AIRDOSE/RADRISK computer code uses a modified Gaussian plume equation to estimate both horizontal and vertical dispersion of radionuclides released to the air from stacks or area sources. For 1993, doses were calculated for H-3, C-11, N-13, O-15, Ar-41, Kr-85, Ra-220 plus decay products, and a number of actinide radionuclides.

Meteorological data are based on STAR data files summarized by the windrose in Figure 5-6. These data were obtained from hourly average meteorological readings taken at a height of $10 \mathrm{~m}(33 \mathrm{ft})$ at the on-site meteorological tower at ANLE during the period 1992 to 1994.

\subsubsection{Conceptual Model Used in the PE}

The PE used a generic conceptual model to describe the atmospheric pathway (summarized in Section 1.2 of this volume and described in detail in Chapter 5 of Volume 2). Only H-3 (tritium) and C-14 were expected to be volatile for the disposal facility conditions and thus were the only radionuclides considered for atmospheric transport in the PE. In the model, radionuclides were transported from the disposal facility to the soil surface by vapor (tritium) and gaseous (carbon dioxide carrying the $\mathrm{C}-14$ isotope) diffusion. When the radionuclides reached the soil surface, they were entrained in the air in vapor form as volatiles. Once airborne, these radionuclides were transported via atmospheric dispersion to a receptor located at the performance boundary.

Two components of the atmospheric pathway were evaluated separately: (1) the zone from the top of the disposal facility to the soil surface as indicated by the upward radionuclide diffusion profile; and (2) the zone in which a radionuclide was emitted to the atmosphere and mixed with the ambient air, and dispersed downwind from the waste disposal facility boundary to the $100-\mathrm{m}(328-\mathrm{ft})$ performance boundary.

The arrival time of radionuclides at the performance boundary was assumed to be $100 \mathrm{y}$ based on the following generic assumptions of the PE:

- The waste form was grouted MLLW treatment residuals. Based on this assumption, tritium as vapor was bound in the pore water of the hydrophilic grout, and carbon dioxide as a gas carrying the $\mathrm{C}-14$ isotope was limited by the high $\mathrm{pH}$ of the grout, so that the waste form provided retention of these volatile radionuclides in the disposal facility.

- The disposal facility was capped by a RCRA-compliant cover system. Based on this assumption, the cover system was maintained to provide low permeability for $100 \mathrm{y}$. 


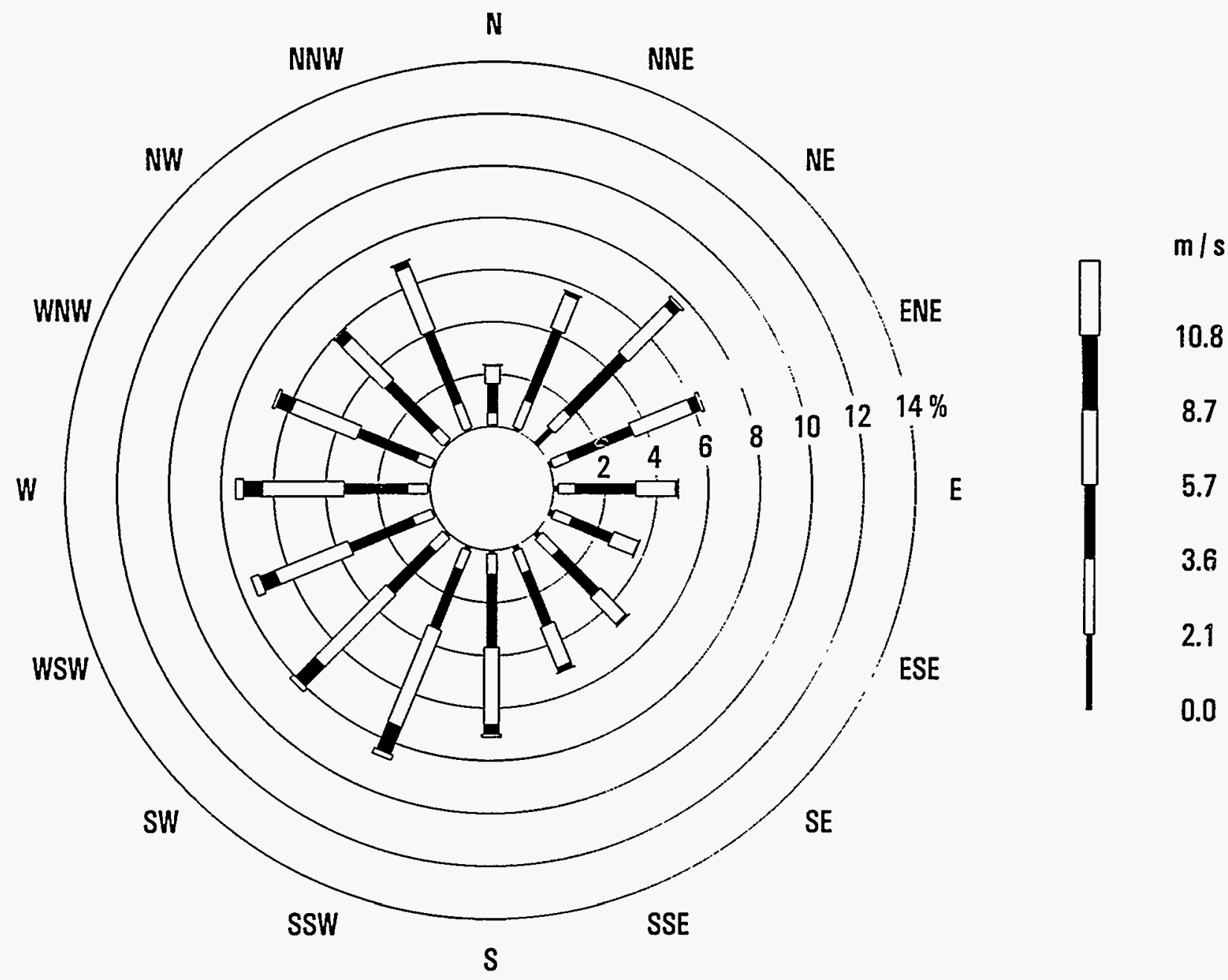

Figure 5-6. Windrose for ANLE for the period 1992 to 1994 . The frequency of winds from each direction is plotted as a series of connected bars that extend from the center of the circular diagram toward the direction from which the winds originate. Wind speed categories are denoted by bar widths and shadings. The frequency of winds in each wind speed category is indicated by the length of the corresponding bar. 


\subsubsection{Inadvertent Intruder Pathways}

Standard intrusion scenarios were used in the PE, with information derived from performance assessments of LLW disposal facilities at SRS (MMES et al., 1994) and ORR (ORNL, 1994) indicating that only two chronic-exposure scenarios needed to be considered for most sites and facility designs. Any variations in these scenarios were based on discussions with site technical staff about such factors as the types of activities that reasonably could result in exposure to buried waste at the site and the effectiveness of active or passive institutional controls and engineered barriers in precluding access to the waste.

\subsubsection{Current Understanding of Potential Modes of Inadvertent Intrusion}

A key factor in examining potential modes of inadvertent intrusion at ANLE is population. The area around ANLE experienced a large population growth beginning in the 1950s. The sixcounty area including the Chicago metropolitan area contains about 7.3 million people, making it by far the most populous inland area in the United States. DuPage County, where ANLE is located, is ranked as one of the fastest growing counties in the nation, with a population growth exceeding $120,000(18 \%)$ for the 1980 s. Office, research, and industrial development exists in the major highway corridors throughout the region. The growth of this commercial development and its ability to attract similar industries to the area are among the major forces behind DuPage County's rapid growth (ANLE, 1994).

From early photographs of the ANLE site, most of the land that the laboratory now occupies, as well as the surrounding acreage, appears to have been actively farmed in the past. With the rapid growth of the area, however, farming is no longer a significant occupation. Large areas of farmland around the ANLE site have been converted into housing (Golchert and Kolzow, 1994). According to site technical staff, current construction practices include building homes with basements.

The area around ANLE historically has relied on groundwater for its drinking water. According to staff in the Illinois State Water Survey (memo from Allen Wehrman, Acting Director, Office of Ground-Water Quality to Gordon Appel, Deputy Director, Illinois Department of Nuclear Safety, July 13, 1994), more than 10,000 water wells, most of which are domestic wells, are located within an approximately 6 to $9 \mathrm{mi}(9.5$ to $14.5 \mathrm{~km})$ radius of ANLE. According to ANLE technical staff, this dependence on groundwater should decrease as water piped from Lake Michigan becomes more accessible in the area.

Personnel at ANLE have conducted long-range planning activities for the next 15 to 20 years that indicate expansion of laboratory functions (ANLE, 1994). No plans are currently being considered for decommissioning of ANLE. 


\subsubsection{Intruder Scenarios Used in the PE}

The PE used two standard intrusion scenarios that could be modified for site-specific conditions to describe potential modes of inadvertent intrusion (summarized in Section 1.3 of this volume and described in detail in Chapter 5 of Volume 2). The first scenario, the agriculture (homesteader) scenario, included establishment of a permanent homestead directly above a disposal facility with the foundation of the home extending into the waste; some of the waste exhumed from the disposal facility was mixed with native soil in the intruder's vegetable garden. The second scenario, the post-drilling scenario, considered the construction of a well for a domestic water supply by an intruder. The well was drilled through the disposal facility, and the cuttings were mixed with soil in the intruder's vegetable garden. The intruder gardened in some of the exhumed waste but did not reside permanently above the disposal facility. In both scenarios, exposure occurred where an intruder dug or drilled into the disposal facility.

For the generic intruder scenarios, the time of intrusion for the homesteader scenario was assumed to be $300 \mathrm{y}$ for the trench design and $500 \mathrm{y}$ for the tumulus design. The time of intrusion for the post-drilling scenario was assumed to be $100 \mathrm{y}$.

Based on discussions with ANLE technical staff, the standard intrusion scenarios used in the PE were expected to bound any site-specific modes of intrusion that could access disposed waste in an MLLW disposal facility at the site.

\subsection{DATA USED IN THE PE}

The data presented in this section apply to the PE conceptual models described in Section 5.3. The calculations for determining permissible waste concentrations for the radionuclides considered in the PE are discussed in more detail in Chapter 5 of Volume 2 and summarized in Chapter 1 of this volume. The results of the calculations for ANLE are presented in Section 5.5 and discussed in Section 5.6 of this volume.

\subsubsection{Water Transport}

Site-specific values required to perform the water pathway analysis were selected by site technical staff either from site characterizations and reports, from site-specific modeling results, or from general literature. For the unsaturated zone, the site-specific data that were required for the PE were distance between the disposal facility and groundwater; ambient moisture content; dry bulk density of the geologic medium; distribution coefficients $\left(K_{d} s\right)$ of the radionuclides in the geologic medium; and natural recharge. For the saturated zone, the site-specific data that were required were porosity; dry bulk density of the geologic medium; distribution coefficients $\left(K_{d} s\right)$ of the radionuclides in the geologic medium; groundwater Darcy flow rates; and mixing depth in the aquifer. 
These values for ANLE are listed in Table 5-1 along with generic values that were used in the PE. Also indicated in the table is a designation of the type of data that the value represents and the source of the value. The values were determined from one or more of four data sources: (A) measurement performed by the site, state, or federal agency; (B) result of a numerical analysis performed by the site, state, or federal agency; (C) general literature value selected by the site; and (D) generic value of the PE.

Of the parameters in the PE that depended on site-specific values, only three potentially encompassed enough variability in values to significantly affect the results: natural recharge, $i$; distribution coefficients $\left(K_{d} \mathrm{~s}\right)$ for the geologic media; and groundwater Darcy velocity $\left(q_{g_{w}}\right)$. The sources of these values are discussed in this section. The sensitivity of the results to changes in the values of these parameters is discussed in Section 5.6.2 of this volume and Chapter 6 of Volume 2.

The natural recharge was determined from site-specific literature. A report published by the U.S. Geological Survey (Knowles et al., 1963) indicated that the computed recharge to the Silurian-age dolomite aquifer was about 4 in. $(10.2 \mathrm{~cm})$ per year, or about one-eighth of the average annual precipitation of 33 in. $(84 \mathrm{~cm})$. This number was based on calculations using measured averages of permeability of the glacial till $\left(0.01 \mathrm{gpd} / \mathrm{ft}^{2}\left[0.004 \mathrm{Lpd} / \mathrm{m}^{2}\right]\right)$ and of the hydraulic gradient (the piezometric surface of the water in the glacial till was about $75 \mathrm{ft}[23 \mathrm{~m}]$ higher than the piezometric surface in the Silurian-age dolomite; the saturated thickness of the overlying glacial till was about $100 \mathrm{ft}[30.5 \mathrm{~m}]$ ).

Values for distribution coefficients $\left(K_{d} s\right)$ are listed in Table 5-2 for the 58 radionuclides (32 elements) considered in the PE. In addition to the $K_{d}$ values for the geologic media, grout $K_{d}$ values are listed for determining the desorption from the source term resulting from the grouted waste form. Because the ANLE staff determined that the glacial till (unsaturated zone) could be treated as a single sand unit, $K_{d}$ values for sandy soil from the general literature were used (Thibault et al., 1990). The range of values from a study of adsorption on glacial deposits in southeastern Illinois for Sr-90, Am-241, Pu-239, Cs-237, and Ni-63 (Aggarwal et al., 1991) were within the range of $K_{d}$ values reported by Thibault et al. (1990); for consistency, the values from Thibault et al. (1990) were used for these radionuclides. Very little data are available about $K_{d} \mathrm{~s}$ for fractured dolomite. The ANLE technical staff recommended using available fresh-water, carbonate $K_{d}$ values for the saturated zone (fractured dolomite) for six elements (thorium, uranium, neptunium, plutonium, americium, and curium) that were listed in reports related to the performance assessment of the Waste Isolation Pilot Plant for disposal of transuranic waste (Tien et al., 1983, as cited in Trauth et al., 1992). Dolomite values for the remaining elements were not available; values used in the PE are general literature values for sandy soil (Thibault et al., 1990) because these values were, in general, the more conservative (i.e., lower) of available values in the general literature. For both the unsaturated and saturated zones, values were not available in the general literature for several elements (aluminum, chlorine, barium, europium, and californium); values for these elements were selected based on their similarity to other elements, as shown in the footnotes to Table 5-2. 
Table 5-1. Parameters and Values Used in the PE for the Water Pathway at ANLE (generic PE values are in bold; these values and the standard PE method for applying them are summarized in Chapter 1 of this volume and discussed in more detail in Chapter 5 of Volume 2) (Part 1 of 2)

\begin{tabular}{|c|c|c|c|}
\hline Parameter & Value & $\begin{array}{l}\text { Data } \\
\text { Type }\end{array}$ & Comments \\
\hline \multicolumn{4}{|l|}{ SOURCE TERM } \\
\hline $\begin{array}{l}\text { Volumetric water content } \\
\text { of the grouted waste, } \theta_{0}\end{array}$ & 0.3 & D & Standard PE value \\
\hline $\begin{array}{l}\text { Bulk density of grouted } \\
\text { waste, } \rho_{0}\end{array}$ & $\begin{array}{l}1.76 \\
\mathrm{~g} / \mathrm{cm}^{3}\end{array}$ & $\mathbf{D}$ & Standard PE value \\
\hline $\begin{array}{l}\text { Distribution coefficients } \\
\text { for grouted waste, } K_{d}^{G}\end{array}$ & various & D & $\begin{array}{l}\text { Standard PE value; see Table } 5-2 \text { in } \\
\text { this chapter }\end{array}$ \\
\hline $\begin{array}{l}\text { Disposal facility plan } \\
\text { area, } A\end{array}$ & $2500 \mathrm{~m}^{2}$ & D & $\begin{array}{l}\text { Standard PE value; } A=a_{1} * a_{2} \text {, where } \\
a_{1}=a_{2}=50 \mathrm{~m}\end{array}$ \\
\hline $\begin{array}{l}\text { Waste mixing fraction } \\
\text { for trench, } f_{m}\end{array}$ & 0.67 & D & Standard PE value \\
\hline $\begin{array}{l}\text { Waste mixing fraction } \\
\text { for tumulus, } f_{m}\end{array}$ & .033 & D & Standard PE value \\
\hline $\begin{array}{l}\text { Annual rate of water } \\
\text { flowing through intact } \\
\text { trench facility, } q_{f}\end{array}$ & $0.03 \mathrm{~m} / \mathrm{y}$ & $\mathbf{D}$ & Standard PE value \\
\hline $\begin{array}{l}\text { Annual rate of water } \\
\text { flowing through intact } \\
\text { tumulus facility, } q_{f}\end{array}$ & $\begin{array}{c}0.00003 \\
\mathrm{~m} / \mathrm{y}\end{array}$ & D & Standard PE value \\
\hline $\begin{array}{l}\text { Time to failure of } \\
\text { leachate collection and } \\
\text { liner systems }\end{array}$ & $30 y$ & D & Standard PE value \\
\hline $\begin{array}{l}\text { Time to failure of trench } \\
\text { facility }\end{array}$ & $100 y$ & $\mathbf{D}$ & Standard PE value \\
\hline $\begin{array}{l}\text { Time to failure of } \\
\text { tumulus facility }\end{array}$ & $300 y$ & $\mathbf{D}$ & Standard PE value \\
\hline $\begin{array}{l}\text { Natural recharge through } \\
\text { local soils, } i\end{array}$ & $\begin{array}{c}0.102 \\
\mathrm{~m} / \mathrm{y}\end{array}$ & A & Knowles et al., 1963, p. 21 \\
\hline
\end{tabular}

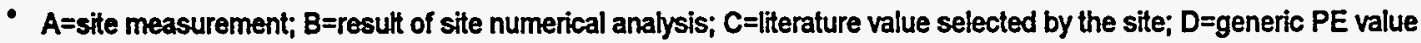


Table 5-1. Parameters and Values Used in the PE for the Water Pathway at ANLE (generic PE values are in bold; these values and the standard $P E$ method for applying them are summarized in Chapter 1 of this volume and discussed in more detail in Chapter 5 of Volume 2) (Part 2 of 2)

\begin{tabular}{|c|c|c|c|}
\hline Parameter & Value & $\begin{array}{l}\text { Data } \\
\text { Type* }\end{array}$ & Comments \\
\hline \multicolumn{4}{|c|}{ UNSATURATED ZONE (Glacial Till) } \\
\hline Moisture content, $\theta_{w}$ & 0.16 & $\mathrm{C}$ & $\begin{array}{l}\text { Computed based on a seepage velocity of } 0.1 \\
\text { in./day and coefficient of permeability of } 0.01 \\
\text { gal/day per } t^{2} \text { (Knowles et al., 1963, p. 20) }\end{array}$ \\
\hline Bulk density, $\rho_{b}$ & $1.8 \mathrm{~g} / \mathrm{cm}^{3}$ & A & $\begin{array}{l}\text { Unpublished analytical results from } 317 / 319 \\
\text { Area and } 800 \text { Area Landfill }\end{array}$ \\
\hline $\begin{array}{l}\text { Distribution coefficients for } \\
\text { geologic media, } K_{d}\end{array}$ & various & C & See Table 5-2 in this chapter \\
\hline $\begin{array}{l}\text { Thickness between trench } \\
\text { and saturated zone, } l\end{array}$ & $29.2 \mathrm{~m}$ & A & $\begin{array}{l}\text { Estimate based on well log depths to bedrock } \\
\text { (ANLE, 1993, Table 2.3); also unpublished } \\
\text { preliminary mapping of thickness of glacial till } \\
\text { (isopach) }\end{array}$ \\
\hline $\begin{array}{l}\text { Thickness between tumulus } \\
\text { and saturated zone, } l\end{array}$ & $38 \mathrm{~m}$ & A & $\begin{array}{l}\text { Estimate based on well log depths to bedrock } \\
\text { (ANLE, 1993, Table 2.3); also unpublished } \\
\text { preliminary mapping of thickness of glacial till } \\
\text { (isopach) }\end{array}$ \\
\hline \multicolumn{4}{|c|}{ SATURATED ZONE (Fractured Dolomite) } \\
\hline Porosity, $n$ & 0.03 & C & Krynine and Judd, 1957, p. 49 \\
\hline Bulk density, $\rho_{b}$ & $2.7 \mathrm{~g} / \mathrm{cm}^{3}$ & C & Krynine and Judd, 1957, p. 49 \\
\hline $\begin{array}{l}\text { Distribution coefficients for } \\
\text { geologic media, } K_{d}\end{array}$ & various & C & See Table 5-2 in this chapter \\
\hline Mixing depth, $d_{m}$ & $3 \mathrm{~m}$ & A & $\begin{array}{l}\text { Well logs indicating fracturing in upper } 10-12 \\
\text { ft (3-3.5 m) (G\&M, 1995); fractured flow zone } \\
\text { (Golchert, 1994, p. 29) }\end{array}$ \\
\hline Hydraulic conductivity, $K$ & $\begin{array}{c}3.8 \times 10^{-3} \\
\mathrm{~cm} / \mathrm{s}\end{array}$ & A & $\begin{array}{l}\text { Transmissivity }=8000 \mathrm{gpd} / \mathrm{ft} \text { (Knowles et al., } \\
1963 \text {, p. 32); slug tests for deep wells (RMT, } \\
1993, \text { p. 28) }\end{array}$ \\
\hline Hydraulic gradient & $0.005 \mathrm{ft} / \mathrm{ft}$ & A & $\begin{array}{l}0.009 \mathrm{ft} / \mathrm{ft} \max \text { (Knowles et al., 1963, p. 32); } \\
0.002 \mathrm{ft} / \mathrm{ft} \text { min (G\&M, 1995); unpublished } \\
\text { preliminary bedrock elevation map (flow } \\
\text { follows topography) }\end{array}$ \\
\hline Darcy velocity, $q_{g w}$ & $6 \mathrm{~m} / \mathrm{y}$ & B & $\begin{array}{l}\text { Product of hydraulic conductivity and hydraulic } \\
\text { gradient }\end{array}$ \\
\hline $\begin{array}{l}\text { Distance to } \\
\text { performance boundary } \\
\text { from facility boundary }\end{array}$ & $100 \mathrm{~m}$ & $\mathbf{D}$ & Standard PE value \\
\hline
\end{tabular}

- $A=$ site measurement; $B=$ result of site numerical analysis; $C=$ literature value selected by the site; $D=g e n e r i c ~ P E$ value 
Table 5-2. Solid/Liquid Distribution Coefficients $\left(K_{d} s\right)$ Used in the PE at ANLE

\begin{tabular}{|c|c|c|c|}
\hline \multirow[t]{2}{*}{ Element } & \multirow{2}{*}{$\begin{array}{c}\text { Waste } \\
K_{d}^{\sigma}(\mathrm{mL} / \mathrm{g})^{a}\end{array}$} & \multicolumn{2}{|c|}{$K_{d}$ for Geologic Media (mL/g) } \\
\hline & & $\begin{array}{l}\text { Unsaturated Zone } \\
\text { (Glacial Till) b }\end{array}$ & $\begin{array}{c}\text { Saturated Zone } \\
\text { (Dolomite Aquifer) }\end{array}$ \\
\hline $\mathrm{H}$ & 0 & 0.1 & 0.1 \\
\hline C & 10 & 5 & 5 \\
\hline $\mathbf{A l}$ & 100 & $35^{\mathrm{d}}$ & $35^{\mathrm{d}}$ \\
\hline Si & 100 & 35 & 35 \\
\hline $\mathrm{Cl}$ & 0 & $15^{\circ}$ & $15^{\mathrm{e}}$ \\
\hline $\mathrm{K}$ & 1 & 15 & 15 \\
\hline Co & 100 & 60 & 60 \\
\hline $\mathrm{Ni}$ & 10 & 400 & 400 \\
\hline $\mathrm{Se}$ & 1 & 150 & 150 \\
\hline $\mathrm{Sr}$ & 100 & 15 & 15 \\
\hline $\mathrm{Zr}$ & 10 & 600 & 600 \\
\hline $\mathrm{Nb}$ & 10 & 160 & 160 \\
\hline Tc & 1 & 0.1 & 0.1 \\
\hline $\mathrm{Pd}$ & 100 & 55 & 55 \\
\hline$\overline{\mathrm{Ag}}$ & 100 & 90 & 90 \\
\hline Cd & 100 & 80 & 80 \\
\hline $\mathrm{Sn}$ & 10 & 130 & 130 \\
\hline 1 & 1 & 1 & 1 \\
\hline Cs & 10 & 280 & 280 \\
\hline $\mathrm{Ba}$ & 10 & $15^{t}$ & $15^{1}$ \\
\hline $\mathrm{Sm}$ & 10 & 245 & 245 \\
\hline $\mathrm{Eu}$ & 10 & $245^{\circ}$ & $245^{\circ}$ \\
\hline $\mathrm{Pb}$ & 100 & 270 & 270 \\
\hline $\mathbf{R a}$ & 10 & 500 & 500 \\
\hline$T h$ & 100 & 3200 & $6000^{\mathrm{h}}$ \\
\hline $\mathrm{Pa}$ & 100 & 550 & 550 \\
\hline$U$ & 100 & 35 & $7^{h}$ \\
\hline $\mathrm{Np}$ & 100 & 5 & $20^{h}$ \\
\hline $\mathrm{Pu}$ & 100 & 550 & $500^{\mathrm{h}}$ \\
\hline $\mathrm{Am}$ & 100 & 1900 & $5000^{h}$ \\
\hline $\mathrm{Cm}$ & 100 & 4000 & $7000^{h}$ \\
\hline $\mathrm{Cf}$ & 100 & $4000^{\prime}$ & $7000^{i}$ \\
\hline
\end{tabular}

a Standard PE values; see Chapter 5 of Volume 2

b Values for sand from Thibault et al., 1990

c Values for sand from Thibault et al., 1990, unless otherwise noted

d Based on similarity to Si; value for sand from Thibault et al., 1990

- Based on similarity to Br; value for sand from Thibault et al., 1990

f Based on similarity to $\mathrm{Sr}$, value for sand from Thibault et al., 1990

g Based on similarity to $\mathrm{Sm}$; value for sand from Thibault et al., 1990

h Value for carbonates from Tien et al., 1983, as cited in Trauth et al., 1992

i Based on similarity to $\mathrm{Cm}$; value for sand from Thibault et al., 1990

j Based on similarity to $\mathrm{Cm}$; value for carbonates from Tien et al., 1983, as cited in Trauth et al., 1992 
Hydraulic conductivity of the saturated zone was determined based on an average coefficient of transmissibility of $8000 \mathrm{gpd} / \mathrm{ft}(99,409 \mathrm{Lpd} / \mathrm{m})$. This value was converted to hydraulic conductivity by assuming that only the upper $100 \mathrm{ft}(30.5 \mathrm{~m})$ of the fractured dolomite was saturated (Roadcap et al., 1993, p. 15). The groundwater Darcy velocity was determined from the product of the hydraulic conductivity and the hydraulic gradient.

\subsubsection{Atmospheric Transport}

Site-specific data required to perform the atmospheric pathway analysis came from site personnel as data either from site characterizations and reports or from general literature. The site-specific data required for the soil diffusion calculation were the same as some of those required for the water transport analysis (Section 5.4.1). These values are shown in Table 5-3. Necessary atmospheric dispersion data included wind speed and direction and stability class, which are summarized in Section 5.3.2.1.

Table 5-3. Parameters and Values Used in the PE for the Atmospheric Pathway at ANLE (generic PE values are in bold; these values and the standard PE method for applying them are summarized in Chapter 1 of this volume and discussed in more detail in Chapter 5 of Volume 2)

\begin{tabular}{|c|c|c|c|}
\hline Parameter & Value & $\begin{array}{l}\text { Data } \\
\text { Type* }\end{array}$ & Comments \\
\hline $\begin{array}{l}\text { Disposal facility cover } \\
\text { thickness, } x\end{array}$ & $1.0 \mathrm{~m}$ & $\mathbf{D}$ & Standard PE value \\
\hline $\begin{array}{l}\text { Depth of the soil } \\
\text { surface, } d\end{array}$ & $0.01 \mathrm{~m}$ & $\mathbf{D}$ & $\begin{array}{l}\text { Standard PE value based on Maheras } \\
\text { et al. (1994) }\end{array}$ \\
\hline Porosity, $n$ & 0.38 & $\mathrm{C}$ & Freeze and Cherry, 1979, p. 37 \\
\hline Percent saturation, $\mathbf{s}$ & $0.30 \mathrm{v} / \mathrm{v}$ & A & $\begin{array}{l}\text { Analytical results from } 317 / 319 \text { Area and } \\
800 \text { Area Landfill }(0.15 \mathrm{w} / \mathrm{w})\end{array}$ \\
\hline $\begin{array}{l}\text { Ratio of water density } \\
\text { in air to liquid, } r\end{array}$ & 9.2E-06 & $\mathbf{D}$ & $\begin{array}{l}\text { Standard PE value based on MMES et } \\
\text { al. (1994) }\end{array}$ \\
\hline $\begin{array}{l}\text { Ratio of } \mathrm{CO}_{2} \\
\text { concentration in air to } \\
\text { dissolved in water, } r\end{array}$ & 4.3E-04 & $\mathbf{D}$ & $\begin{array}{l}\text { Standard PE value based on Foust et } \\
\text { al. (as cited in Cooper and Alley, } \\
\text { 1986) }\end{array}$ \\
\hline $\begin{array}{l}\text { Tritium diffusion } \\
\text { coefficient in air, } D\end{array}$ & $2.39 \mathrm{E}-05 \mathrm{~m}^{2} / \mathrm{s}$ & D & $\begin{array}{l}\text { Standard PE value based on CRC } \\
\text { (1981) }\end{array}$ \\
\hline $\begin{array}{l}\text { Carbon diffusion } \\
\text { coefficient in air, } D\end{array}$ & 1.4E-05 $\mathrm{m}^{2} / \mathrm{s}$ & D & $\begin{array}{l}\text { Standard PE value based on CRC } \\
(1981)\end{array}$ \\
\hline $\begin{array}{l}\text { Atmospheric dispersion } \\
\text { term, } A_{D}\end{array}$ & $\begin{array}{c}0.17 \\
\left(\mu \mathrm{Cl} / \mathrm{m}^{3}\right) /\left(\mu \mathrm{Ci} / \mathrm{m}^{2}-\mathrm{s}\right)\end{array}$ & B & $\begin{array}{l}\text { Value is estimated using the industrial } \\
\text { Source Complex-Version } 2 \text { Long Term Air } \\
\text { Dispersion Model (ISCLT2) (EPA, 1992b) } \\
\text { based on site-specific STAR data }\end{array}$ \\
\hline
\end{tabular}

- $A=$ =site measurement; $B=$ result of site numerical analysis; $C=$ literature value selected by the site; $D=$ generic $P E$ value 


\subsubsection{Inadvertent Intruder Exposure}

As explained in Section 5.3.3, the PE used two standard intrusion scenarios to describe potential modes of inadvertent intrusion at all the sites. Because these intrusion scenarios were considered applicable to all sites, no values specific to ANLE are used in the calculation of exposures to inadvertent intruders.

\subsection{RESULTS OF THE PE}

The performance evaluation provided estimates of permissible waste concentrations in disposed MLLW. The three calculations that formed the foundation of the PE-for the water, atmospheric, and inadvertent intruder pathways-are summarized in Sections 1.1, 1.2, and 1.3, respectively, of this volume and discussed in detail in Chapter 5 of Volume 2.

For each pathway the maximum permissible waste concentration at the performance boundary was determined for each radionuclide by using the performance measures: $4 \mathrm{mrem}$ ( $0.04 \mathrm{mSv}$ ) per year from the water pathway for releases to drinking water; $10 \mathrm{mrem}(0.1 \mathrm{mSv})$ per year from all pathways for atmospheric releases; and $100 \mathrm{mrem}(1 \mathrm{mSv})$ per year from all exposure pathways for chronic exposure of inadvertent intruders; and the appropriate pathway or scenario dose conversion factors (annual effective dose equivalent per unit concentration) based on EPA dose conversion factors. The basis for the performance measures used in the PE is discussed in more detail in Chapter 5 of Volume 2. For the water and atmospheric pathways, the concentration reduction provided by the environment (i.e., the CRF) was estimated using results of site analyses and data. For the intruder analyses, concentration reduction was estimated for appropriate exposure pathways for two intrusion scenarios that, in general, were the same for all the sites. The results of the calculations for the pathways that were analyzed at ANLE are provided in this section and discussed in Section 5.6.

\subsubsection{Water Transport}

Two CRFs were calculated for the water pathway: the source CRF, $C R F_{\text {Source, }}$, and the environmental transport $\mathrm{CRF}$ for water, $C R F_{\text {Water. }}$. The source $\mathrm{CRF}$ represents the concentration attenuation between the disposed waste and leachate exiting the bottom of the disposal facility and was defined as the dimensionless ratio of the waste concentration to the resulting leachate concentration. Desorption with infiltrating water was the mechanism used to describe the leaching of radionuclides from the grout. Because a generic method was used to determine the $C R F_{\text {Source }}$ for the 58 radionuclides considered in the PE (summarized in Section 1.1 of this volume and discussed in more detail in Chapter 5 of Volume 2), the radionuclide-specific values for the source CRF for each type of generic facility were the same for all 15 sites.

The environmental transport CRF for water was defined as the ratio of the concentration of the leachate exiting the disposal facility to the resulting concentration in water at the performance boundary. The concentration attenuation represented by $C R F_{\text {Water }}$ consisted of 
dilution due to mixing with uncontaminated groundwater. Effects of radioactive decay and decay product ingrowth were also included in the PE.

In the PE, water travel time from the facility location to the performance boundary was calculated as a basis for comparison with the retarded travel time of the radionuclides. For ANLE, water travel time from the land surface to the performance boundary (i.e., without consideration of a disposal facility) was estimated at about $112 \mathrm{y}$.

The calculation of travel time through the vadose zone for a radionuclide, on the other hand, must account both for the lower flow rate because of the facility's RCRA cover and for the retardation defined by the distribution coefficient for the geologic media. In the PE, the calculation for travel time in the vadose zone first determined the distance a radionuclide traveled at the lower infiltration rate. Then, if the radionuclide had not fully traversed the vadose zone, the additional time required to complete travel in the vadose zone under the higher, infiltration rate based on the natural recharge through local soils was calculated and added to the time determined at the lower infiltration rate.

In the PE, the detention time in the facility for a radionuclide was the time during which water flowing through the facility was assumed to be caught by the leachate collection system. Specifically, the calculation of travel time for a radionuclide accounted for the following:

- For the trench design, the leachate collection system was assumed to catch water flowing through the facility for the first $30 \mathrm{y}$. After $30 \mathrm{y}$, the liner and leachate collection system failed, and water flowing through the facility for the next $70 \mathrm{y}$ was assumed to be $0.03 \mathrm{~m} / \mathrm{y}$ $(0.1 \mathrm{ft} / \mathrm{y})$ based on a unit hydraulic gradient and the saturated hydraulic conductivity of the RCRA cover system. After a total of $100 \mathrm{y}$ of reduced flow because of engineered barriers ( $30 \mathrm{y}$ of detention plus $70 \mathrm{y}$ limited by the RCRA cover system), the rate was assumed to be the average recharge through local soils, $0.102 \mathrm{~m} / \mathrm{y}(0.335 \mathrm{ft} / \mathrm{y})$.

- For the tumulus design, the leachate collection system was assumed to catch water flowing through the facility for the first $30 \mathrm{y}$. After $30 \mathrm{y}$, the liner and leachate collection system was assumed to fail, and water flowing through the facility for the next $270 \mathrm{y}$ was assumed to be $0.00003 \mathrm{~m} / \mathrm{y}(0.0001 \mathrm{ft} / \mathrm{y})$ based on a unit hydraulic gradient and the saturated hydraulic conductivity of the concrete vaults. After a total of $300 \mathrm{y}$ of reduced flow because of engineered barriers ( $30 \mathrm{y}$ detention plus $270 \mathrm{y}$ limited by the concrete vaults), the rate was assumed to be the average recharge through local soils, $0.102 \mathrm{~m} / \mathrm{y}$ $(0.335 \mathrm{ft} / \mathrm{y})$.

Travel time through the aquifer was independent of facility design and was about $0.5 \mathrm{y}$, based on groundwater Darcy velocity and a 100-m (328-ft) distance to the performance boundary (see Section 1.1.2 of this volume for a summary of these assumptions and Chapter 5 of Volume 2 for additional details). The arrival time of a radionuclide at the performance boundary is the sum of 
the detention time in the facility, travel time through the vadose zone, and travel time through the aquifer.

Retardation of radionuclides by interaction with soils and rock in the vadose and saturated zones increased travel times for individual radionuclides. This effect was particularly important for short-lived radionuclides because of radioactive decay. For short-lived radionuclides, the effects of radioactive decay combined with long travel times increased the permissible concentrations in the disposal facility.

Application of the PE methodology for water transport of the 58 radionuclides considered in the PE produced the results shown in Table 5-4 for the generic trench and tumulus designs at ANLE. The table shows permissible waste concentrations based on transport through the water pathway $\left(C_{\text {W-Water }}\right)$ as well as the values used in calculating the permissible waste concentrations.

Some radionuclides listed in Table 5-4 have no limit (NL) on their permissible waste concentrations, the result of the combined effects of relatively short half-lives and sufficiently long travel time to the performance boundary. "No limit" is defined as a permissible waste concentration that is greater than the specific activity of the pure elemental radionuclide. For disposal of the maximum possible waste concentration of these relatively short-lived radionuclides, the water pathway produced a dose at the performance boundary of less than $4 \mathrm{mrem}(0.04 \mathrm{mSv})$ per year and, therefore, the permissible waste concentration was unlimited based on exposures from this pathway.

For some radionuclides, no value is listed in Table 5-4 for the radioactive decay term, $r_{\text {Decay. }}$. These radionuclides had radioactive decay terms that were very large (i.e., greater than $1 \times 10^{50}$ ). Any radionuclide with a radioactive decay term greater than $1 \times 10^{50}$ was ensured calculated concentration greater than the specific activity of the pure elemental radionuclide, which, as described previously, resulted in no limit (NL) on permissible waste concentrations for disposal.

Arrival times for some radionuclides listed in Table 5-4 were beyond the 10,000-y performance period. For those radionuclides, the estimated waste concentrations are presented in Table 5-4 for information purposes only. Consistent with the approach used in LLW performance assessments, these values were not considered in determining the most restrictive disposal limit from among the evaluated pathways.

For all radionuclides in Table 5-4, the rate of water flow at the time of facility failure controlled the subsurface transport (i.e., the subsurface movement of the radionuclides in the trench and tumulus was controlled by the flow rate at $100 \mathrm{y}$ after closure for the trench [when the cover failed] and at $300 \mathrm{y}$ for the tumulus [when the concrete vaults failed]). 
Table 5-4. Results of Calculations for the Water Pathway at ANLE (water travel time from land surface to performance boundary [excluding facility detention] $=112 y)$ (Part 1 of 2)

\begin{tabular}{|c|c|c|c|c|c|c|c|c|c|c|c|c|}
\hline \multirow[t]{2}{*}{ Nuclide } & \multirow[b]{2}{*}{$\begin{array}{c}\text { PDCF } \\
\text { rem/y per } \mu \mathrm{C} n\end{array}$} & \multicolumn{5}{|c|}{ Trench } & \multicolumn{5}{|c|}{ Tumulus } & \multirow[t]{2}{*}{ Nuclide } \\
\hline & & $\begin{array}{l}\text { CRF } \text { source } \\
\text { (dimensionless) }\end{array}$ & \begin{tabular}{|c|} 
CRF Water \\
(dimenstonless)
\end{tabular} & $\begin{array}{l}\text { Arrival } \\
\text { Time (y) } \\
\end{array}$ & $\begin{array}{c}\text { PDeceny }^{a} \\
\text { (dimensionloss) }\end{array}$ & $\begin{array}{c}C_{W-W h t e r}^{b} \\
\left(\mu \mathrm{Ci} / \mathrm{m}^{3}\right)\end{array}$ & \begin{tabular}{|l|} 
CRF source \\
(dimensionless)
\end{tabular} & \begin{tabular}{|c|} 
CRF waser \\
(dimensionloss)
\end{tabular} & \begin{tabular}{|c|} 
Arrival \\
Time (y) \\
\end{tabular} & \begin{tabular}{|c|}
$r_{\text {Dacay }}{ }^{2}$ \\
(dimensionless)
\end{tabular} & $\begin{array}{c}C_{\text {w.water }}{ }^{b} \\
\left(\mu \mathrm{Cl} / \mathrm{m}^{3}\right)\end{array}$ & \\
\hline $\mathrm{H}-3$ & 4.67E-02 & 0.45 & 4.5 & $1.8 \mathrm{E}+02$ & 2.7E+04 & $5 E+06$ & 0.9 & 4.5 & $4.3 E+02$ & $3.4 E+10$ & $1 E+13$ & $\mathrm{H}-3$ \\
\hline C-14 & $1.52 \mathrm{E}+00$ & 27 & 4.5 & $2.9 E+03$ & $1.4 E+\infty$ & $5 E+02$ & 54 & 4.5 & $3.9 \mathrm{E}+03$ & $1.6 E+\infty$ & $1 E+03$ & C-14 \\
\hline Al-26 & $1.06 \mathrm{E}+01$ & 270 & 4.5 & $2.0 \mathrm{E}+04$ & $1.0 \mathrm{E}+\infty 0$ & $5 E+02$ & 540 & 4.5 & $2.5 E+04$ & $1.0 E+\infty$ & $9 \mathrm{E}+02$ & Al-26 \\
\hline Si-32 & $7.99 E+\infty 0$ & 270 & 4.5 & $2.0 E+04$ & e & $\mathrm{NL}$ & 540 & 4.5 & $2.5 E+04$ & e & $\mathrm{NL}$ & Si-32 \\
\hline Cl-36 & $2.21 E+\infty$ & 0.45 & 4.5 & $8.5 E+03$ & $1.0 \mathrm{E}+\infty$ & $4 \mathrm{E}+\infty 0$ & 0.9 & 4.5 & $1.1 \mathrm{E}+04$ & $1.0 E+00$ & $8 E+\infty 0$ & $\mathrm{Cl}-36$ \\
\hline$K-40$ & $1.36 \mathrm{E}+01$ & 3.1 & 4.5 & $8.5 E+03$ & $1.0 \mathrm{E}+\infty$ & $4 E+00$ & 6.2 & 4.5 & $1.1 E+04$ & $1.0 \mathrm{E}+00$ & $8 E+\infty 0$ & $K-40$ \\
\hline Co-60 & 1.97E+01 & 270 & 4.5 & $3.4 \mathrm{E}+0.4$ & e & $\mathrm{NL}$ & 540 & 4.5 & $4.3 E+04$ & $e$ & NL & Co-60 \\
\hline Ni-59 & $1.53 E-01$ & 27 & 4.5 & $2.2 E+05$ & $7.7 E+\infty$ & $2 E+04$ & 54 & 4.5 & $2.9 E+05$ & $1.4 \mathrm{E}+01$ & $9 \mathrm{E}+04$ & $\mathrm{Ni}-59$ \\
\hline Ni-63 & $4.21 E-01$ & 27 & 4.5 & $2.2 \mathrm{E}+05$ & e & $\mathrm{NL}$ & 54 & 4.5 & $2.9 E+05$ & e & $N L$ & $\mathrm{Ni}-63$ \\
\hline Se-79 & $6.35 E+\infty$ & 3.1 & 4.5 & $8.4 E+04$ & $2.5 E+\infty 0$ & $2 E+01$ & 6.2 & 4.5 & $1.1 E+05$ & $3.2 E+\infty$ & $6 \mathrm{E}+01$ & Se-79 \\
\hline Sr-90 & $1.12 E+02$ & 270 & 4.5 & $8.5 E+03$ & $e$ & $\mathrm{NL}$ & 540 & 4.5 & $1.1 E+04$ & $e$ & $\mathrm{NL}$ & Sr-90 \\
\hline $\mathrm{Zr}-93$ & $1.59 E+\infty$ & 27 & 4.5 & $3.4 E+05$ & $1.2 E+\infty$ & $4 E+02$ & 54 & 4.5 & $4.3 E+05$ & $1.2 E+00$ & $8 E+02$ & $\mathrm{Zr}-93$ \\
\hline $\mathrm{Nb}-93 \mathrm{~m}$ & 3.81E-01 & 27 & 4.5 & $9.0 \mathrm{E}+04$ & $e$ & $\mathrm{NL}$ & 54 & 4.5 & $1.1 \mathrm{E}+05$ & $e$ & $\mathrm{NL}$ & $\mathrm{Nb}-93 \mathrm{~m}$ \\
\hline Nb-94 & $5.21 E+00$ & 27 & 4.5 & $9.0 \mathrm{E}+04$ & $2.2 E+01$ & $2 E+03$ & 54 & 4.5 & $1.1 E+05$ & $5.4 \mathrm{E}+01$ & $1 E+04$ & $\mathrm{Nb}-94$ \\
\hline Tc-99 & $1.07 E+\infty 0$ & 3.1 & 4.5 & $1.8 \mathrm{E}+02$ & $1.0 E+00$ & $5 E+01$ & 6.2 & 4.5 & $4.3 E+02$ & $1.0 E+\infty$ & $1 E+02$ & Tc-99 \\
\hline$P d-107$ & 1.09E-01 & 270 & 4.5 & $3.1 E+04$ & $1.0 \mathrm{E}+00$ & $4 \mathrm{E}+04$ & 540 & 4.5 & $4.0 \mathrm{E}+04$ & $1.0 E+\infty 0$ & $9 E+04$ & $\mathrm{Pd}-107$ \\
\hline$A g-108 m$ & $5.56 \mathrm{E}+\infty 0$ & 270 & 4.5 & $5.1 \mathrm{E}+0.4$ & e & $\mathrm{NL}$ & 540 & 4.5 & $6.5 \mathrm{E}+04$ & $e$ & $\mathrm{NL}$ & $A g-108 m$ \\
\hline $\mathrm{Cd}-113 \mathrm{~m}$ & 1.17E+02 & 270 & 4.5 & $4.5 E+0.4$ & $e$ & $\mathrm{NL}$ & 540 & 4.5 & $5.8 \mathrm{E}+04$ & $e$ & $\mathrm{NL}$ & $\mathrm{Cd}-113 \mathrm{~m}$ \\
\hline $\mathrm{Sn}-121 \mathrm{~m}$ & $1.28 E+00$ & 27 & 4.5 & $7.3 E+04$ & e & $\mathrm{NL}$ & 54 & 4.5 & $9.3 E+04$ & $e$ & NL & $\mathrm{sn-121m}$ \\
\hline $5 n-126$ & $1.53 \mathrm{E}+01$ & 27 & 4.5 & $7.3 \mathrm{E}+04$ & $1.7 E+00$ & $5 E+01$ & 54 & 4.5 & $9.3 \mathrm{E}+04$ & $1.9 E+00$ & $1 E+02$ & $5 n-126$ \\
\hline $1-129$ & $2.01 E+02$ & 3.1 & 4.5 & $6.9 E+02$ & $1.0 E+00$ & $3 E-01$ & 6.2 & 4.5 & $1.1 E+03$ & $1.0 E+00$ & 6E-01 & $1-129$ \\
\hline Cs-135 & $5.16 \mathrm{E}+00$ & 27 & 4.5 & $1.6 \mathrm{E}+05$ & $1.0 E+00$ & $1 E+02$ & 54 & 4.5 & $2.0 \mathrm{E}+05$ & $1.1 E+\infty 0$ & $2 E+02$ & Cs-135 \\
\hline Cs-137 & $3.65 \mathrm{E}+01$ & 27 & 4.5 & $1.6 \mathrm{E}+05$ & e & $\mathrm{NL}$ & 54 & 4.5 & $2.0 E+05$ & e & $\overline{N L}$ & Cs-137 \\
\hline $\mathrm{Ba}-133$ & $2.48 E+00$ & 27 & 4.5 & $8.5 \mathrm{E}+03$ & e & $\mathrm{NL}$ & 54 & 4.5 & $1.1 E+04$ & $e$ & $\mathrm{NL}$ & $\mathrm{Ba}-133$ \\
\hline$S m-151$ & 2.84E-01 & 27 & 4.5 & $1.4 \mathrm{E}+05$ & e & $\mathrm{NL}$ & 54 & 4.5 & $1.8 \mathrm{E}+05$ & $e$ & $\mathrm{NL}$ & Sm-151 \\
\hline Eu-152 & $4.73 E+00$ & 27 & 4.5 & $1.4 E+05$ & $e$ & $\mathrm{NL}$ & 54 & 4.5 & $1.8 \mathrm{E}+05$ & $e$ & $N L$ & Eu-152 \\
\hline Eu-154 & $6.97 \mathrm{E}+00$ & 27 & 4.5 & $1.4 E+05$ & e & $\mathrm{NL}$ & 54 & 4.5 & $1.8 \mathrm{E}+05$ & $e$ & NL & Eu-154 \\
\hline $\mathrm{Pb}-210$ & $5.30 E+03$ & 270 & 4.5 & $1.5 E+05$ & e & NL & 540 & 4.5 & $1.9 E+05$ & $e$ & NL & $\mathrm{Pb}-210$ \\
\hline Ra-226 & $6.27 \mathrm{E}+03$ & 27 & 4.5 & $2.8 E+05$ & e & NL & 54 & 4.5 & $3.6 \mathrm{E}+05$ & $e$ & $\mathrm{NL}$ & $\mathrm{Ra}-226$ \\
\hline Ra-228 & $1.64 \mathrm{E}+03$ & 27 & 4.5 & $2.8 \mathrm{E}+05$ & $e$ & $N L$ & 54 & 4.5 & $3.6 \mathrm{E}+05$ & $e$ & $\mathrm{NL}$ & $\operatorname{Ra} 2228$ \\
\hline Th-229 & $2.94 E+03$ & 270 & 4.5 & $1.9 E+06$ & e & NL & 540 & 4.5 & $2.4 E+06$ & e & $\mathrm{NL}$ & Th-229 \\
\hline Th-230 & $6.12 \mathrm{E}+03$ & 270 & 4.5 & $1.9 \mathrm{E}+06$ & NA & $8 E-01$ & 540 & 4.5 & $2.4 E+06$ & NA & $2 E+00$ & Th-230 \\
\hline Th-232 & $3.63 \mathrm{E}+03$ & 270 & 4,5 & $1.9 \mathrm{E}+06$ & $1.0 \mathrm{E}+\infty 0$ & $1 E+\infty$ & 540 & 4.5 & $2.4 E+06$ & $1.0 E+00$ & $3 E+00$ & Th-232 \\
\hline Pa-231 & $1.85 \mathrm{E}+04$ & 270 & 4.5 & $3.1 \mathrm{E}+05$ & $6.8 \mathrm{E}+02$ & $2 E+02$ & 540 & 4.5 & $3.9 E+05$ & $4.1 E+03$ & $2 E+03$ & $\mathrm{Pa-231}$ \\
\hline
\end{tabular}


un Table 5-4. Results of Calculations for the Water Pathway at ANLE (water travel time from land surface to performance boundary [excluding facility detention] $=112 \mathrm{y})($ Part 2 of 2$)$

\begin{tabular}{|c|c|c|c|c|c|c|c|c|c|c|c|c|c|}
\hline \multirow[t]{2}{*}{ Nuclide } & \multirow{2}{*}{$\begin{array}{c}\text { PDCF } \\
\text { remly per } \mu \mathrm{Ch} \\
\end{array}$} & \multicolumn{5}{|c|}{ Trench } & \multicolumn{6}{|c|}{ Tumulus } & \multirow[t]{2}{*}{ Nuclide } \\
\hline & & $\begin{array}{l}\text { CRF source } \\
\text { (dimentiontess) }\end{array}$ & \begin{tabular}{|c|} 
CRF water \\
(dimenstonless)
\end{tabular} & \begin{tabular}{|c|} 
Arrival \\
Time $(y)$ \\
\end{tabular} & $\begin{array}{c}r_{\text {Decany }} \\
\text { (dimensionlosts) }\end{array}$ & $\begin{array}{c}C_{W-W m a r}^{b} \\
\left(\mu \mathrm{Ci} / \mathrm{m}^{3}\right)\end{array}$ & \begin{tabular}{l|} 
CRF source \\
(dimentionless)
\end{tabular} & $\begin{array}{c}\text { CRF wax } \\
\text { (dimensionlecs) }\end{array}$ & $\begin{array}{l}\text { Arrival } \\
\text { Time (y) }\end{array}$ & $\begin{array}{c}\text { PDocay }^{a} \\
\text { (dimentiontoas) }\end{array}$ & $\begin{array}{r}C_{\text {w.manur }} \\
\left(\mu \mathrm{Cl} / \mathrm{m}^{2}\right) \\
\end{array}$ & & \\
\hline U-232 & $1.55 E+03$ & 270 & 4.5 & $1.8 E+04$ & e & NL & 540 & 4.5 & $2.4 E+04$ & e & NL & c & U-232 \\
\hline U-233 & $1.95 \mathrm{E}+03$ d & 270 & 4.5 & $1.8 \mathrm{E}+04$ & NA & $2 E+\infty 0$ & 540 & 4.5 & $2.4 E+04$ & NA & $5 E+00$ & - & $U-233$ \\
\hline U-234 & $6.48 E+02$ & 270 & 4.5 & $1.8 E+04$ & NA & $7 E+\infty$ & 540 & 4.5 & $2.4 E+04$ & NA & $1 E+01$ & $\bar{c}$ & U-234 \\
\hline U-235 & $3.73 E+03$ वा & 270 & 4.5 & $1.8 \mathrm{E}+04$ & NA & $1 E+\infty$ & 540 & 4.5 & $2.4 E+04$ & NA & $3 E+\infty$ & $\bar{c}$ & U-235 \\
\hline U-236 & $1.96 \mathrm{E}+02$ & 270 & 4.5 & $1.8 E+04$ & $1.0 \mathrm{E}+\infty 0$ & $2 E+01$ & 540 & 4.5 & $2.4 E+04$ & $1.0 E+\infty 0$ & $5 E+01$ & 5 & U-236 \\
\hline $\mathrm{U}-238$ & $2.07 E+02$ & 270 & 4.5 & $1.8 \mathrm{E}+04$ & NA & $2 E+01$ & 540 & 4.5 & $2.4 E+04$ & NA & $5 E+01$ & $\bar{c}$ & U-238 \\
\hline Np-237 & $3.24 E+03$ & 270 & 4.5 & $3.6 \mathrm{E}+03$ & $1.0 E+\infty 0$ & $1 E+\infty 0$ & 540 & 4.5 & $4.6 E+03$ & $1.0 E+00$ & $3 E+\infty$ & & $\mathrm{Np}-237$ \\
\hline Pu-238 & $2.34 E+03$ & 270 & 4.5 & $3.1 E+05$ & e & $2 E+04 \quad c$ & 540 & 4.5 & $3.9 E+05$ & $\mathbf{e}$ & $4 E+04$ & c & $\mathrm{Pu}-238$ \\
\hline$P u-239$ & $2.58 E+03$ & 270 & 4.5 & $3.1 E+05$ & $6.6 \mathrm{E}+03$ & $1 E+04 \quad 6$ & 540 & 4.5 & $3.9 E+05$ & $7.8 E+04$ & $3 E+05$ & 5 & Pu-239 \\
\hline Pu-240 & $2.58 \mathrm{E}+03$ & 270 & 4.5 & $3.1 E+05$ & $1.1 E+14$ & $\mathrm{NL}$ & 540 & 4.5 & $3.9 \mathrm{E}+05$ & $9.4 E+17$ & NL & E & $\mathrm{Pu}-240$ \\
\hline Pu-241 & $4.82 E+08$ & 270 & 4.5 & $3.1 E+05$ & e & $2 E+05$ & 540 & 4.5 & $3.9 \mathrm{E}+05$ & $e$ & $4 E+05$ & & Pu-241 \\
\hline $\mathrm{Pu}-242$ & $2.45 E+03$ & 270 & 4.5 & $3.1 E+05$ & $1.8 E+00$ & $3 E+\infty 0$ & 540 & 4.5 & $3.9 E+05$ & $2.1 E+00$ & $8 E+\infty 0$ & 5 & Pu-242 \\
\hline Pu-244 & $4.11 E+03$ & 270 & 4.5 & $3.1 E+05$ & NA & $1 E+\infty$ & 540 & 4.5 & $3.9 E+05$ & NA & $2 E+\infty$ & 5 & $P u-244$ \\
\hline Am-241 & $2.66 E+03$ & 270 & 4.5 & $1.2 E+06$ & e & $7 E+03$ & 540 & 4.5 & $1.5 E+06$ & $e$ & $1 E+04$ & & Am-241 \\
\hline Am-243 & $2.64 E+03$ & 270 & 4.5 & $1.2 E+06$ & $1.5 E+49$ & $\mathrm{NL}$ & 540 & 4.5 & $1.5 E+06$ & $e$ & $\mathrm{NL}$ & c & $A m-243$ \\
\hline $\mathrm{Cm}-243$ & $1.83 E+03$ & 270 & 4.5 & $2.4 E+06$ & e & $1 E+07$ & 540 & 4.5 & $3.0 \mathrm{E}+06$ & e & $2 E+08$ & $\mathrm{c}$ & $\mathrm{Cm}-243$ \\
\hline $\mathrm{Cm}-244$ & $1.47 E+03$ & 270 & 4.5 & $2.4 E+06$ & e & $\mathrm{NL}$ & 540 & 4.5 & $3.0 \mathrm{E}+06$ & $e$ & $\mathrm{NL}$ & $\mathrm{c}$ & $\mathrm{Cm}-244$ \\
\hline $\mathrm{Cm}-245$ & $4.56 E+03$ & 270 & 4.5 & $2.4 E+06$ & NA & $1 E+\infty$ & 540 & 4.5 & $3.0 E+06$ & NA & $2 E+\infty 0$ & 5 & $\mathrm{Cm}-245$ \\
\hline $\mathrm{Cm}-246$ & $2.70 E+03$ & 270 & 4.5 & $2.4 E+06$ & e & $\mathrm{NL}$ & 540 & 4.5 & $3.0 \mathrm{E}+06$ & e & $\mathrm{NL}$ & c & $\mathrm{Cm}-246$ \\
\hline $\mathrm{Cm}-247$ & $4.34 E+03$ & 270 & 4.5 & $2.4 \mathrm{E}+06$ & NA & $1 E+00$ C & 540 & 4.5 & $3.0 \mathrm{E}+06$ & NA & $2 E+00$ & $\mathrm{c}$ & $\mathrm{Cm}-247$ \\
\hline $\mathrm{Cm}-248$ & $9.94 E+03$ & 270 & 4.5 & $2.4 E+06$ & $1.1 \mathrm{E}+02$ & $5 E+01 \quad c$ & 540 & 4.5 & $3.0 E+06$ & $3.9 E+02$ & $4 E+02$ & 5 & $\mathrm{Cm}-248$ \\
\hline CF-249 & $3.46 E+03$ & 270 & 4.5 & $2.4 E+06$ & e & $3 E+01$ & 540 & 4.5 & $3.0 E+06$ & $e$ & $5 E+01$ & 5 & Cf-249 \\
\hline Cf-250 & $2.64 E+08$ & 270 & 4.5 & $2.4 E+06$ & e & $\mathrm{NL}$ & 540 & 4.5 & $3.0 E+06$ & e & $\mathrm{NL}$ & e & Cf-250 \\
\hline Cf-251 & $3.54 E+03$ & 270 & 4.5 & $2.4 E+06$ & e & $\mathrm{NL}$ & 540 & 4.5 & $3.0 E+06$ & $e$ & $\mathrm{NL}$ & 5 & Cf-251 \\
\hline
\end{tabular}

"NA" means Not Applicable - decay factor is implicit in the PDCF for this radionuclide.

b "NL" means No Limit - estimated permissibte concentration is greater than the specific activity of the pure elemental radionuclide.

c Radionuclide concentration is based on arrival time at the performance boundary beyond $10,000 \mathrm{y}$.

d PDCF is a function of arrival time. See Chapter 1 of this volume for equation.

e roway $\geq 1 E+50$

$f$ Contribution of decay product(s) is significant to determination of this value (see Table E-3 in Volume 2). Listed arrival time is that of the parent radionuclide. If this footnote does not appear in combination with footnote $c$, the arrival time of the significant decay product(s) is less than $10,000 \mathrm{y}$. 
For the tumulus, the total undecayed CRFs (the product of the $C R F_{\text {Source }}$ and the $C R F_{\text {Water }}$ ) for the water pathway were about twice the total undecayed CRFs for the trench, given the same recharge (i.e., at the time of hydrologic failure of the facility). This result was due to the difference in the volume fraction of waste (the ratio of waste material to total material in the disposal unit) between the two technologies-twice as much waste leached from the trench for a given rate of flow because a given volume of trench contained twice as much waste as the tumulus.

For the trench design at ANLE, the total undecayed CRFs for the water pathway for the 58 radionuclides listed in Table 5-4 ranged from about 2 to 1200 . Among the radionuclides, arrival times at the performance boundary ranged from $180 \mathrm{y}$ to 2.4 million $\mathrm{y}$, including the retention time in the facility before failure. Travel time through the unsaturated zone accounted for almost all of the total subsurface travel time.

For the tumulus design, the total undecayed CRFs for the groundwater pathway for the radionuclides listed in Table 5-4 ranged from about 4 to 2400. Among the listed radionuclides, arrival times at the performance boundary ranged from 430 y to 3 million y, including the retention time in the facility before failure. Differences in these arrival times compared to the trench were attributable to (1) the assumed time of hydrologic failure of the facility (100 y for the trench and $300 \mathrm{y}$ for the tumulus); (2) the increased rate of flow at the time of failure of the facility compared to that when the leachate collection system failed $(0.03 \mathrm{~m} / \mathrm{y}[0.1 \mathrm{ft} / \mathrm{y}]$ for the trench and $0.00003 \mathrm{~m} / \mathrm{y}[0.0001 \mathrm{ft} / \mathrm{y}]$ for the tumulus); and (3) the increased travel distance through the vadose zone for the tumulus (the bottom of the tumulus was assumed to be at grade level, while the trench was assumed to be a shallowly buried structure).

The permissible waste concentrations for $\mathrm{H}-3$ for both designs are relatively large $\left(5 \times 10^{6} \mu \mathrm{Ci} / \mathrm{m}^{3}\right.$ for the trench design and $1 \times 10^{13} \mu \mathrm{Ci} / \mathrm{m}^{3}$ for the tumulus design). The half-life of $\mathrm{H}-3$ is about $12 \mathrm{y}$, so a considerable amount of radioactive decay occurs during the radionuclide's detention in the disposal facility and travel to the $100-\mathrm{m}(328-\mathrm{ft})$ performance boundary. The performance of $\mathrm{H}-3$ in the water pathway can be compared to Tc-99, which has the same total travel time as H-3 of $180 \mathrm{y}$ for the trench design and $430 \mathrm{y}$ for the tumulus design. The half-life of Tc- 99 is about $210,000 \mathrm{y}$, and the permissible waste concentrations for the trench and tumulus designs $\left(5 \times 10^{1} \mu \mathrm{Ci} / \mathrm{m}^{3}\right.$ and $1 \times 10^{2} \mu \mathrm{Ci} / \mathrm{m}^{3}$, respectively) are considerably smaller than those for $\mathrm{H}-3$.

\subsubsection{Atmospheric Transport}

Two CRFs were used to account for the attenuation encompassing diffusion to the ground surface, mixing in air, and dispersion in the atmosphere to the performance boundary. The CRF for diffusion in soil, $C R F_{D i f}$, was defined as the ratio of the radionuclide concentration in the waste to its resulting concentration in the upper one centimeter of soil. The CRF for dispersion in air, $C R F_{D i s p}$, was defined as the ratio of the radionuclide concentration in the upper one centimeter 
of soil to its resulting concentration in air at the performance boundary. The effect of radioactive decay was also included in the PE.

Application of the PE methodology for atmospheric transport of the two volatile radionuclides considered in the $\mathrm{PE}$ (H-3 and C-14) produced the results shown in Table 5-5 for both the generic trench and tumulus designs; there was no assumed difference in these two disposal technologies with respect to permissible waste limits based on the atmospheric pathway at ANLE. The table shows permissible waste concentrations based on transport in the atmospheric pathway $\left(C_{W r A t m}\right)$ as well as the values used in calculating the permissible waste concentrations. For both $\mathrm{H}-3$ and $\mathrm{C}-14$, the greatest concentration reduction was assumed to occur as the radionuclides diffused from the top of the disposal facility to the soil surface.

Table 5-5. Results of Calculations for the Atmospheric Pathway

\begin{tabular}{|c|c|c|c|c|c|c|c|}
\hline \multirow[t]{2}{*}{ Nuclide } & \multirow[b]{2}{*}{$\begin{array}{c}\text { SDCF } \\
(\mathrm{rem} / \mathrm{y}) /(\mu \mathrm{Ci})\end{array}$} & \multicolumn{6}{|c|}{ Generic Trench and Tumulus } \\
\hline & & $\begin{array}{c}C R F_{\text {Difr }} \\
\text { (dimensionless) }\end{array}$ & $\begin{array}{c}C R F_{\text {Disp }} \\
\text { (dilmensionless) }\end{array}$ & $\begin{array}{c}\mathrm{CRF}_{\text {Atm }} \\
\text { (dimensionless) }\end{array}$ & $\begin{array}{l}\text { Arrival } \\
\text { Time (y) }\end{array}$ & $\begin{array}{c}r_{\text {Decay }} \\
\text { (dimensionless) }\end{array}$ & $\begin{array}{r}C_{W \cdot A t m} \\
\left(\mu \mathrm{Ci} / \mathrm{m}^{3}\right)\end{array}$ \\
\hline $\mathrm{H}-3$ & $8.33 E+02$ & $3 E+06$ & $3 E+03$ & $9 E+09$ & 100 & 300 & $3 E+10$ \\
\hline C-14 & $2.20 \mathrm{E}+05$ & $7 E+04$ & $4 E+03$ & $3 E+08$ & 100 & 1 & $1 E+04$ \\
\hline
\end{tabular}

The time of arrival at the performance boundary for both radionuclides is shown in Table 5-5 as $100 \mathrm{y}$. However, the actual migration of H-3 and C-14 from the disposal facility to the surface and downwind to the performance boundary was calculated to be on the order of hours, not years. As discussed in Section 5.3.2.2, the waste form and RCRA cover are assumed to retain these volatile radionuclides in the disposal facility for at least $100 \mathrm{y}$.

\subsubsection{Inadvertent Intruder Exposure}

The calculation of permissible waste concentrations for inadvertent intruder exposures did not utilize CRFs. Instead, the total dose resulting from an intrusion scenario (the sum of the doses from all exposure pathways involved in that intrusion) was modified by scenario dose conversion factors (SDCFs) that were applied to specific exposure pathways. The important exposure pathways for each radionuclide are listed in Appendix D of Volume 2. These values were radionuclide-specific and facility-design-specific and were the same for all sites. Values for the radioactive decay term were based on time of intrusion into the disposal facility (for the homesteader scenario, $300 \mathrm{y}$ for the trench design and $500 \mathrm{y}$ for the tumulus design; for the postdrilling scenario, 100 y for both disposal designs). However, results based on intruder scenarios should be evaluated carefully because future social behavior, and intrusion scenarios, are difficult to predict. 
The permissible waste concentrations for the two generic facility designs for each of the 58 radionuclides based on the standard PE intrusion scenarios are listed in Table 5-6. The most restrictive waste concentration limits for each generic facility are indicated with bold type.

For six radionuclides in the table (U-233, U-234, U-235, U-238, Pu-244, and Cm-247), the time of homesteader intrusion was changed to $10,000 \mathrm{y}$, the end of the performance period. For these six radionuclides, ingrowth of decay products yields scenario doses that increase over time. The doses at $10,000 \mathrm{y}$, therefore, represent the maximum that could be encountered during the performance period. Also, for Th-230 and $\mathrm{Cm}-245$, ingrowth of decay products likewise produces a scenario dose that increases over time and peaks within the 10,000-y performance period. The times of homesteader intrusion for these two radionuclides (Th-230 and Cm-245) were taken as the time of maximum dose, 9000 and $1000 \mathrm{y}$, respectively.

For the trench design, the post-drilling scenario generally yielded more restrictive waste limits than the homesteader scenario for those radionuclides with half-lives shorter than about $30 \mathrm{y}$. For the tumulus design, the post-drilling scenario generally yielded more restrictive limits than the homesteader scenario for those radionuclides with half-lives shorter than about $130 \mathrm{y}$.

\subsection{SUMMARY AND DISCUSSION OF RESULTS}

The limiting waste concentrations in disposed MLLW for the water, atmospheric, and intruder analyses for the generic trench and tumulus designs are summarized in Table 5-7 and discussed in Section 5.6.1. An overall discussion of the results of the PE for ANLE is contained in Section 5.6.2.

\subsubsection{Results Based on Disposal Design}

For the generic trench design at ANLE, 7 radionuclides were limited by the water pathway, no radionuclides were limited by the atmospheric pathway, 49 radionuclides were limited by intrusion scenarios, and 2 radionuclides were limited by both the water pathway and the intrusion scenarios, as shown in Table 5-7. For the generic tumulus design, 4 radionuclides were limited by the water pathway, no radionuclides were limited by the atmospheric pathway, and 54 radionuclides were limited by intrusion scenarios.

For the trench design, concentrations for two radionuclides ( $\mathrm{Sr}-90$ and $\mathrm{Ba}-133$ ) that arrived at the performance boundary before 10,000 y reported in Table 5-7 for the water pathway analysis had no limit; for the tumulus design all reported waste concentrations for the water pathway had numerical limits. As discussed in Section 5.5.1, the calculated concentrations for those radionuclides reported as NL (No Limit) were above the specific activity of the pure elemental radionuclide, indicating that the performance measure of $4 \mathrm{mrem}(0.04 \mathrm{mSv})$ per y would not be reached under the given release and transport assumptions. 
Table 5-6. Permissible Waste Concentrations for the Standard Intrusion Scenarios (most limiting radionuclide concentration for each facility design is highlighted in bold italic) (Part 1 of 2)

\begin{tabular}{|c|c|c|c|c|c|}
\hline \multirow[t]{2}{*}{ Nuclide } & \multicolumn{2}{|c|}{ Trench } & \multicolumn{2}{|c|}{ Tumulus } & \multirow[t]{2}{*}{ Nuclide } \\
\hline & $\begin{array}{c}C_{w+m r^{a}} \\
\text { Homesteader } \\
\left(\mu \mathrm{Ci} m^{3}\right)\end{array}$ & $\begin{array}{c}C_{w-1 n t r} \\
\text { Post-Drilling } \\
\left(\mu \mathrm{Cim}^{3}\right)\end{array}$ & $\begin{array}{c}C_{w-1 m t^{2}} \\
\text { Homesteader } \\
\left(\mu \mathrm{C} / m^{3}\right)\end{array}$ & $\begin{array}{c}\text { Cw-lnt } \\
\text { Post-Drilling } \\
\left(\mu \mathrm{Ci} / \mathrm{m}^{3}\right)\end{array}$ & \\
\hline $\mathrm{H}-3$ & $1 E+12$ & $7 E+07$ & NL & $7 E+07$ & $\mathrm{H}-3$ \\
\hline$C-14$ & $1 E+04$ & $7 E+04$ & $1 E+04$ & $7 E+04$ & C-14 \\
\hline Al-26 & $5 E+01$ & $5 E+04$ & $5 E+01$ & $5 E+04$ & Al-26 \\
\hline Si-32 & $9 E+03$ & $1 E+04$ & $4 E+0.4$ & $1 E+04$ & Si-32 \\
\hline $\mathrm{Cl}-36$ & $2 E+02$ & $9 E+02$ & $2 E+02$ & $9 E+02$ & $\mathrm{Cl}-36$ \\
\hline$K-40$ & $7 E+02$ & $2 E+04$ & $7 E+02$ & $2 E+04$ & $K-40$ \\
\hline Co-60 & NL & $3 E+10$ & $\mathrm{NL}$ & $3 E+10$ & Co-60 \\
\hline $\mathrm{Ni}-59$ & $3 E+06$ & $1 E+07$ & $3 E+06$ & $1 E+07$ & $\mathrm{Ni}-59$ \\
\hline Ni-63 & $8 E+06$ & $1 E+07$ & $3 E+07$ & $1 E+07$ & $\mathrm{Ni}-63$ \\
\hline Se-79 & $2 E+05$ & $8 E+05$ & $2 E+05$ & $8 E+05$ & Se-79 \\
\hline Sr-90 & $1 E+06$ & $6 E+04$ & $1 E+08$ & $5 E+04$ & Sr-90 \\
\hline Zr-93 & $5 E+06$ & $3 E+07$ & $5 E+06$ & $3 E+07$ & Zr-93 \\
\hline $\mathrm{Nb}-93 \mathrm{~m}$ & $5 E+12$ & $4 E+09$ & $N L$ & $4 E+09$ & $\mathrm{Nb}-93 \mathrm{~m}$ \\
\hline $\mathrm{Nb}-94$ & $9 E+01$ & $9 E+04$ & $1 E+02$ & $9 E+04$ & $\mathrm{Nb}-94$ \\
\hline TC-99 & $2 E+04$ & $8 E+04$ & $2 E+04$ & $8 E+04$ & Tc-99 \\
\hline$P d-107$ & $6 E+06$ & $3 E+07$ & $6 E+06$ & $3 E+07$ & Pd-107 \\
\hline $\mathrm{Ag}-108 \mathrm{~m}$ & $5 E+02$ & $1 E+05$ & $1 E+03$ & $1 E+05$ & $\mathrm{Ag}-108 \mathrm{~m}$ \\
\hline$C d-113 m$ & $4 E+09$ & $1 E+06$ & $7 E+13$ & $1 E+06$ & Cd-113m \\
\hline $\mathrm{Sn}-121 \mathrm{~m}$ & $2 E+07$ & $5 E+07$ & $2 E+08$ & $5 E+07$ & Sn-121m \\
\hline Sn-126 & $8 E+01$ & $7 E+04$ & $8 E+01$ & $7 E+04$ & Sn-126 \\
\hline $\mid-129$ & $2 E+03$ & $1 E+04$ & $2 E+03$ & $1 E+04$ & $1-129$ \\
\hline Cs-135 & $2 E+05$ & $8 E+05$ & $2 E+05$ & $8 E+05$ & Cs-135 \\
\hline Cs-137 & $3 E+05$ & $8 E+05$ & $3 E+07$ & $8 E+05$ & Cs-137 \\
\hline $\mathrm{Ba}-133$ & $2 E+11$ & $3 E+08$ & $\mathrm{NL}$ & $3 E+08$ & $\mathrm{Ba}-133$ \\
\hline$S m-151$ & $2 E+08$ & $2 E+08$ & $8 E+08$ & $2 E+08$ & $\mathrm{sm}-151$ \\
\hline Eu-152 & $6 E+08$ & $2 E+07$ & $2 E+13$ & $2 E+07$ & Eu-152 \\
\hline Eu-154 & $4 E+12$ & $4 E+08$ & $\mathrm{NL}$ & $4 E+08$ & Eu-154 \\
\hline $\mathrm{Pb}-210$ & $7 E+06$ & $7 E+04$ & $4 E+09$ & $7 E+04$ & $\mathrm{~Pb}-210$ \\
\hline Ra-226 & $8 E+01$ & $3 E+03$ & $9 E+01$ & $3 E+03$ & Ra-226 \\
\hline Ra-228 & $\mathrm{NL}$ & $1 E+09$ & NL & $4 E+09$ & Ra-228 \\
\hline Th-229 & $5 E+02$ & $3 E+04$ & $5 E+02$ & $3 E+04$ & Th-229 \\
\hline Th-230 & $8 E+01$ & $7 E+04$ & $8 E+01$ & $7 E+04$ & Th-230 \\
\hline Th-232 & $6 E+01$ & $2 E+04$ & $6 E+01$ & $2 E+04$ & Th-232 \\
\hline $\mathrm{Pa}-231$ & $2 E+02$ & $5 E+03$ & $2 E+02$ & $5 E+03$ & $\mathrm{~Pa}-231$ \\
\hline
\end{tabular}


Table 5-6. Permissible Waste Concentrations for the Standard Intrusion Scenarios (most limiting radionuclide concentration for each facility design is highlighted in bold italic)

(Part 2 of 2)

\begin{tabular}{|c|c|c|c|c|c|}
\hline \multirow[t]{2}{*}{ Nuclide } & \multicolumn{2}{|c|}{ Trench } & \multicolumn{2}{|c|}{ Tumulus } & \multirow[t]{2}{*}{ Nuclide } \\
\hline & $\begin{array}{c}C_{W-1 m e r}{ }^{2} \\
\text { Homesteader } \\
\left(\mu \mathrm{C} / \mathrm{m}^{3}\right) \\
\end{array}$ & $\begin{array}{c}C_{\text {want }} \\
\text { Post-Drilling } \\
\left(\mu \mathrm{C} / \mathrm{m}^{3}\right) \\
\end{array}$ & $\begin{array}{c}C_{\text {wantr }}{ }^{2} \\
\text { Homesteader } \\
\left(\mu \mathrm{Ci} / \mathrm{m}^{3}\right) \\
\end{array}$ & $\begin{array}{c}C_{\text {wdntr }} \\
\text { Post-Drilling } \\
\left(\mu \mathrm{Ci} / \mathrm{m}^{3}\right) \\
\end{array}$ & \\
\hline U-232 & $2 E+03$ & $5 E+04$ & $1 E+04$ & $5 E+04$ & U-232 \\
\hline U-233 & $7 E+02$ & $1 E+05$ & $7 E+02$ & $1 E+05$ & U-233 \\
\hline U-234 & $1 E+03$ & $1 E+05$ & $1 E+03$ & $1 E+05$ & U-234 \\
\hline U-235 & $6 E+02$ & $1 E+05$ & $6 E+02$ & $1 E+05$ & $\mathrm{U}-235$ \\
\hline U-236 & $2 E+04$ & $1 E+05$ & $2 E+04$ & $1 E+05$ & $\mathrm{U}-236$ \\
\hline U-238 & $6 E+03$ & $1 E+05$ & $5 E+03$ & $1 E+05$ & $U-238$ \\
\hline $\mathrm{Np}-237$ & $4 E+02$ & $4 E+03$ & $4 E+02$ & $4 E+03$ & Np-237 \\
\hline Pu-238 & $7 E+04$ & $1 E+05$ & $4 E+05$ & $1 E+05$ & Pu-238 \\
\hline Pu-239 & $6 E+03$ & $5 E+04$ & $6 E+03$ & $5 E+04$ & Pu-239 \\
\hline $\mathrm{Pu}-240$ & $6 E+03$ & $5 E+04$ & $7 E+03$ & $5 E+04$ & Pu-240 \\
\hline Pu-241 & $2 E+05$ & $1 \mathrm{E}+06$ & $3 E+05$ & $1 E+06$ & Pu-241 \\
\hline Pu-242 & $6 E+03$ & $5 E+04$ & $6 E+03$ & $5 E+04$ & Pu-242 \\
\hline Pu-244 & $4 E+02$ & $5 E \div 04$ & $4 E+02$ & $5 E+04$ & Pu-244 \\
\hline Am-241 & $7 E+03$ & $5 E+04$ & $9 E+03$ & $5 E+04$ & Am-241 \\
\hline Am-243 & $9 E+02$ & $4 E+04$ & $9 E+02$ & $4 E+04$ & Am-243 \\
\hline $\mathrm{Cm}-243$ & $1 E+06$ & $8 E+05$ & $5 E+06$ & $8 E+05$ & $C_{m-243}$ \\
\hline $\mathrm{Cm}-244$ & $2 E+06$ & $3 E+06$ & $2 E+06$ & $3 E+06$ & $\mathrm{Cm}-244$ \\
\hline $\mathrm{Cm}-245$ & $1 E+03$ & $4 E+04$ & $1 E+03$ & $4 E+04$ & $\mathrm{Cm}-245$ \\
\hline $\mathrm{Cm}-246$ & $6 E+03$ & $5 E+04$ & $6 E+03$ & $5 E+04$ & $\mathrm{Cm}-246$ \\
\hline $\mathrm{Cm}-247$ & $3 E+02$ & $5 E+04$ & $3 E+02$ & $5 E+04$ & $\mathrm{Cm}_{\mathrm{m}-247}$ \\
\hline $\mathrm{Cm}-248$ & $2 E+03$ & $1 E+04$ & $2 E+03$ & $1 E+04$ & $\mathrm{Cm}-248$ \\
\hline Cf-249 & $8 E+02$ & $4 E+04$ & $1 E+03$ & $4 E+04$ & Cf-249 \\
\hline$C f-250$ & $2 E+06$ & $9 \mathrm{E}+06$ & $2 E+06$ & $9 E+\infty 6$ & Cf-250 \\
\hline$C f-251$ & $2 E+03$ & $4 E+04$ & $2 E+03$ & $4 E+04$ & $C f-251$ \\
\hline
\end{tabular}

a "NL" means No Limit - estimated permissible concentration is greater than the specific activity of the pure elemental radlonuclide. 
Table 5-7. Permissible Concentrations for the Generic Disposal Designs at ANLE (permissible concentration related to the most limiting pathway for each facility design is highlighted in bold italic) (Part 1 of 2)

\begin{tabular}{|c|c|c|c|c|c|c|c|}
\hline \multirow[t]{2}{*}{ Nuclide } & \multicolumn{3}{|c|}{ Trench } & \multicolumn{3}{|c|}{ Tumulus } & \multirow[t]{2}{*}{ Nuclide } \\
\hline & $\begin{array}{c}C_{\text {w.Wetwr }}{ }^{2, b} \\
\left(\mu \mathrm{Cu} \mathrm{m}^{3}\right)\end{array}$ & $\begin{array}{l}C_{W-A t m}{ }^{c} \\
\left(\mu \mathrm{Cl} / \mathrm{m}^{3}\right) \\
\end{array}$ & $\begin{array}{l}C_{w-1 n t^{d}} \\
\left(\mu \mathrm{CU} \mathrm{m}^{3}\right)\end{array}$ & $\begin{array}{c}C_{\text {w.Water }}{ }^{n, b} \\
\left(\mu \mathrm{Ci} / \mathrm{m}^{3}\right)\end{array}$ & $\begin{array}{l}C_{W-a t m}{ }^{c} \\
\left.(\mu \mathrm{Cilm})^{3}\right) \\
\end{array}$ & $\begin{array}{l}C_{w-1 m e r}{ }^{d} \\
\left(\mu \mathrm{Ci} / m^{3}\right) \\
\end{array}$ & \\
\hline $\mathrm{H}-3$ & $5 E+06$ & $3 E+10$ & $7 E+07$ & $1 E+13$ & $3 E+10$ & $7 E+07$ & $\mathrm{H}-3$ \\
\hline$C-14$ & $5 E+02$ & $1 E+04$ & $1 E+04$ & $1 E+03$ & $1 E+04$ & $1 E+04$ & C-14 \\
\hline$\overline{A l-26}$ & - & & $5 E+01$ & - & & $5 E+01$ & $\mathrm{Al}-26$ \\
\hline Si-32 & - & & $9 E+03$ & - & & $1 E+04$ & Si-32 \\
\hline $\mathrm{Cl}-36$ & $4 E+00$ & & $2 E+02$ & - & & $2 E+02$ & $\mathrm{Cl}-36$ \\
\hline$K-40$ & $4 E+00$ & & $7 E+02$ & - & & $7 E+02$ & $K-40$ \\
\hline Co-60 & - & & $3 E+10$ & - & & $3 E+10$ & $\mathrm{Co}-60$ \\
\hline $\mathrm{Ni}-59$ & - & & $3 E+06$ & - & & $3 E+06$ & $\mathrm{Ni}-59$ \\
\hline $\mathrm{Ni}-63$ & - & & $8 E+06$ & - & & $1 E+07$ & $\mathrm{Ni}-63$ \\
\hline Se-79 & - & & $2 E+05$ & - & & $2 E+05$ & Se-79 \\
\hline$S T-90$ & NL. & & $5 E+04$ & - & & $5 E+04$ & Sr-90 \\
\hline $2 r-93$ & - & & $5 E+06$ & - & & $5 E+06$ & $2 r-93$ \\
\hline $\mathrm{Nb}-93 \mathrm{~m}$ & - & & $4 E+09$ & - & & $4 E+09$ & $\mathrm{Nb}-93 \mathrm{~m}$ \\
\hline $\mathrm{Nb}-94$ & - & & $9 E+01$ & - & & $1 E+02$ & $\mathrm{Nb}-94$ \\
\hline Tc-99 & $5 E+01$ & & $2 E+04$ & $1 E+02$ & & $2 E+04$ & Tc-99 \\
\hline$P d-107$ & - & & $6 E+06$ & - & & $6 E+06$ & Pd-107 \\
\hline $\mathrm{Ag}-108 \mathrm{~m}$ & - & & $5 E+02$ & - & & $1 E+03$ & $\mathrm{Ag}-108 \mathrm{~m}$ \\
\hline$C d-113 m$ & - & & $1 E+06$ & - & & $1 E+06$ & $C d-113 m$ \\
\hline $5 n-121 m$ & - & & $2 E+07$ & - & & $5 E+07$ & $\mathrm{Sn-121m}$ \\
\hline$S n-126$ & - & & $8 E+01$ & - & & $8 E+01$ & Sn-126 \\
\hline $1-129$ & $3 E=01$ & & $2 E+03$ & $6 E-01$ & & $2 E+03$ & $1-129$ \\
\hline Cs-135 & - & & $2 E+05$ & - & & $2 E+05$ & Cs-135 \\
\hline Cs-137 & - & & $3 E+05$ & - & & $8 E+05$ & Cs-137 \\
\hline Ba-133 & NL & & $3 E+08$ & - & & $3 E+08$ & $\mathrm{Ba}-133$ \\
\hline$S m-151$ & - & & $2 E+08$ & - & & $2 E+08$ & Sm-151 \\
\hline Eu-152 & - & & $2 E+07$ & - & & $2 E+07$ & Eu-152 \\
\hline Eu-154 & - & & $4 E+08$ & - & & $4 E+08$ & Eu-154 \\
\hline $\mathrm{Pb}-210$ & - & & $7 E+04$ & - & & $7 E+04$ & $\mathrm{~Pb}-210$ \\
\hline Ra-226 & - & & $8 E+01$ & - & & $9 E+01$ & Ra-226 \\
\hline Ra-228 & - & & $4 E+09$ & - & & $4 E+09$ & Ra-228 \\
\hline Th-229 & - & & $5 E+02$ & - & & $5 E+02$ & Th-229 \\
\hline Th-230 & - & & $8 E+01$ & - & & $8 E+01$ & Th-230 \\
\hline Th-232 & - & & $6 E+01$ & - & & $6 E+01$ & Th-232 \\
\hline Pa-231 & - & & $2 E+02$ & - & & $2 E+02$ & $\mathrm{~Pa}-231$ \\
\hline
\end{tabular}


Table 5-7. Permissible Concentrations for the Generic Disposal Designs at ANLE (permissible concentration related to the most limiting pathway for each facility design is highlighted in bold italic) (Part 2 of 2)

\begin{tabular}{|c|c|c|c|c|c|c|c|}
\hline \multirow[t]{2}{*}{ Nuclide } & \multicolumn{3}{|c|}{ Trench } & \multicolumn{3}{|c|}{ Tumulus } & \multirow[t]{2}{*}{ Nuclide } \\
\hline & $\begin{array}{c}C_{\text {w-water }}{ }^{a, b} \\
\left(\mu \mathrm{Cl} / \mathrm{m}^{3}\right)\end{array}$ & $\begin{array}{c}C_{W-A t m}{ }^{c} \\
\left(\mu \mathrm{Ci} / m^{3}\right)\end{array}$ & $\begin{array}{l}C_{W / n r^{d}} \\
(\mu \mathrm{Ci/m})\end{array}$ & $\begin{array}{c}C_{\text {w-water }}{ }^{a, b} \\
\left(\mu \mathrm{Ci} / \mathrm{m}^{3}\right)\end{array}$ & $\begin{array}{c}C_{\text {watm }}{ }^{c} \\
\left(\mu \mathrm{Ci} / \mathrm{m}^{3}\right)\end{array}$ & $\begin{array}{l}C_{w+m r^{d}} \\
\left(\mu \mathrm{Ci} / m^{3}\right)\end{array}$ & \\
\hline U-232 & - & & $2 E+03$ & - & & $1 E+04$ & U-232 \\
\hline U-233 & - & & $7 E+02$ & - & & $7 E+02$ & U-233 \\
\hline U-234 & - & & $1 E+03$ & - & & $1 E+03$ & U-234 \\
\hline U-235 & - & & $6 E+02$ & - & & $6 E+02$ & U-235 \\
\hline U-236 & - & & $2 E+04$ & - & & $2 E+04$ & U-236 \\
\hline U-238 & - & & $6 E+03$ & - & & $5 E+03$ & U-238 \\
\hline$N p-237$ & $1 E+00$ & & $4 E+02$ & $3 E+00$ & & $4 E+02$ & $N p-237$ \\
\hline $\mathrm{Pu}-238$ & - & & $7 E+04$ & - & & $1 E+05$ & $\mathrm{Pu}-238$ \\
\hline Pu-239 & $=$ & & $6 E+03$ & - & & $6 E+03$ & Pu-239 \\
\hline $\mathrm{Pu}-240$ & - & & $6 E+03$ & - & & $7 E+03$ & Pu-240 \\
\hline Pu-241 & $2 E+05$ & & $2 E+05$ & $4 E+05$ & & $3 E+05$ & Pu-241 \\
\hline Pu-242 & - & & $6 E+03$ & - & & $6 E+03$ & Pu-242 \\
\hline Pu-244 & - & & $4 E+02$ & - & & $4 E+02$ & Pu-244 \\
\hline Am-241 & $7 E+03$ & & $7 E+03$ & $1 E+04$ & & $9 E+03$ & $A m-241$ \\
\hline Am-243 & - & & $9 E+02$ & - & & $9 E+02$ & Am-243 \\
\hline $\mathrm{Cm}-243$ & - & & $8 E+05$ & - & & $8 E+05$ & Cm-243 \\
\hline $\mathrm{Cm}-244$ & - & & $2 E+06$ & - & & $2 E+06$ & $\mathrm{Cm}-244$ \\
\hline $\mathrm{Cm}-245$ & - & & $1 E+03$ & - & & $1 E+03$ & $\mathrm{Cm}-245$ \\
\hline $\mathrm{Cm}-246$ & $=$ & & $6 E+03$ & - & & $6 E+03$ & $\mathrm{Cm}-246$ \\
\hline $\mathrm{Cm}-247$ & - & & $3 E+02$ & - & & $3 E+02$ & $\mathrm{Cm}-247$ \\
\hline $\mathrm{Cm}-248$ & - & & $2 E+03$ & - & & $2 E+03$ & $\mathrm{Cm}-248$ \\
\hline Cf-249 & - & & $8 E+02$ & - & & $1 E+03$ & Cf-249 \\
\hline Cf-250 & - & & $2 E+06$ & - & & $2 E+06$ & Cf- -250 \\
\hline Cf-251 & - & & $2 E+03$ & - & & $2 E+03$ & Cf-251 \\
\hline
\end{tabular}

" "NL" means No Limit - estimated permissible concentration factor is greater than the specific activity of the pure elemental radionuclide.

- "." indicates that the radionuclide concentration is based on an arrival time beyond 10,000y; see Table 5-4 for specific values.

- Results presented for radionclides expected to be volatile under disposal facility conditions.

d Concentration is based on the most restrictive intrusion scenario assumed for the site; see Table 5-6. 
As also discussed in Section 5.5.1, values for some radionuclides are not reported in Table 5-7 for the water pathway analysis. Arrival times for these radionuclides were beyond the 10,000-y performance period. For these radionuclides, the estimated waste concentrations are presented in Table 5-4 for information purposes but are not listed in Table 5-7. Consistent with the approach used in LLW performance assessments, these values were not considered in determining the most restrictive disposal limit from among the evaluated pathways because arrival times for these radionuclides were beyond $10,000 \mathrm{y}$.

For both the trench and tumulus designs, the radionuclides limited by the water pathway generally tended to be highly mobile (e.g., $\mathrm{H}-3, \mathrm{Cl}-36$, and $\mathrm{K}-40$ for the trench design and $\mathrm{C}-14$, Tc-99, and I-129 for both the trench and tumulus designs). The radionuclide $\mathrm{H}-3$ was limited by the intruder scenarios rather than by the water pathway for the tumulus design because the longer total retention time in the tumulus allowed considerably more radioactive decay than the trench design. The thoriums, uraniums, and most of the transuranics are not shown as being limited by the water pathway because their peak arrival times were beyond $10,000 \mathrm{y}$. For both the trench and tumulus designs, only one transuranic radionuclide was limited by the water pathway: Np-237 is long-lived and mobile.

\subsubsection{Discussion}

The results of the PE are based on the framework of assumptions summarized in Chapter 1 of this volume and discussed in detail in Volume 2 of this report and on the site-specific conceptual model for contaminant transport discussed in this chapter. Using alternative assumptions about the conceptual model has the potential to affect the results. Changes in the conceptual model could include alternative assumptions about the disposal facility, the source term, and radionuclide movement in the three pathways. Depending on the degree of possible variation and the relative importance of the parameters used in the calculation of estimated permissible waste concentrations, variability in parameter values can also affect the results. For parameters, results could vary depending on potential changes in values of both the generic and the site-specific parameters used in the PE analysis.

The effect on results from using alternative generic assumptions and parameter values is discussed in Chapter 6 of Volume 2. In addition, a discussion is provided in that chapter about the effects of using alternative values for site-specific parameters. Based on this discussion, four parameters were identified (three site-specific and one generic, all used in the water pathway analysis) that could potentially influence the results to the degree that the calculated waste concentrations become limited by a pathway other than the one determined for the PE (Table 5-7). The impacts on the results of using alternative values for these four parameters for the water pathway in the PE for ANLE are discussed in this section. The basis for and possible variation in the values used in the PE for these parameters are discussed in Section 5.6.2.2. 


\subsubsection{Parameter Sensitivity Analysis}

The PE provided results for two disposal facility designs: a RCRA-compliant, belowground trench and a RCRA-compliant, above-ground tumulus. Similar assumptions about the integrity of engineered barriers were made in the PE for both facility designs. Because the factors used to estimate transport of radionuclides in the water pathway for both designs were similar, the discussion in this section focuses on examining the results for the indicator radionuclides reported for the tumulus design (indicator radionuclides are defined in Chapter 7 of Volume 2).

As discussed in Chapter 6 of Volume 2, only four parameters used in the PE were identified as having a potential range of values that might affect results: natural recharge through the disposal facility $(i)$; groundwater Darcy velocity $\left(q_{g w}\right)$; area of the facility $(A)$; and distribution coefficients $\left(K_{d} \mathrm{~s}\right)$. These parameter values for ANLE are summarized in Table 5-8.

Table 5-8. Parameter Values Used in the PE for ANLE with Potential Variability That Could Affect the Results

\begin{tabular}{|l|l|}
\hline \multicolumn{1}{|c|}{ Parameter } & \multicolumn{1}{c|}{ Value } \\
\hline Natural recharge through local soils, $i$ & $0.102 \mathrm{~m} / \mathrm{y}$ (Knowles et al., 1963, p. 21) \\
\hline $\begin{array}{l}\text { Distribution coefficients for geologic } \\
\text { media, } K_{d}\end{array}$ & $\begin{array}{l}\text { Sandy soil values from Thibault et al. (1990); } \\
\text { see Table 5-2 in this chapter for values }\end{array}$ \\
\hline Groundwater Darcy velocity, $q_{\text {ow }}$ & $\begin{array}{l}6 \mathrm{~m} / \mathrm{y} \text { (calculation by PE analysts based on } \\
\text { sources provided by ANLE staff; see Section } \\
5.4 .1 \text { for discussion) }\end{array}$ \\
\hline Plan-view Area, $A$ & $2500 \mathrm{~m}^{2}$ (standard PE value) \\
\hline
\end{tabular}

The traditional procedure for performing a sensitivity analysis is to vary the parameters used in the calculations and observe the effect on the results. To be meaningful, this method requires some knowledge of the statistical distribution of each of the parameters considered, including their likely maximum and minimum values. For the PE calculations, the potential variability of the parameters used to calculate the permissible waste concentrations for the two different facility designs was not estimated. For most of the radionuclides considered in the PE, there were only two exposure pathways: the water pathway and intruder exposure scenarios (the atmospheric pathway was considered only for $\mathrm{H}-3$ and $\mathrm{C}-14$ ). The intruder-pathway results provide a baseline that can be used for comparison with the water-pathway results because the intruder scenarios used in the PE were relatively independent of the physical characteristics of the individual sites. This baseline provided an alternative method of performing sensitivity analyses for the PE. The input parameters for the water pathway were varied to determine if the controlling exposure pathway could be altered (e.g., the results could be changed from intruderscenario controlled to water-pathway controlled). After new values for the water pathway 
parameters were determined, these values were examined for reasonableness based on physical constraints at the site.

The sensitivity analysis was limited to a comparison of the water and intruder exposure pathways. A comparison between the water and atmospheric pathways was not conducted because the atmospheric pathway is not limiting.

To analyze the sensitivity of the results to changes in the parameter values for recharge, groundwater Darcy velocity, and area of the facility, the parameter values used in the PE for ANLE were varied. Only one parameter value was varied at a time for a radionuclide, leaving the others equal to their PE values. In most instances, the parameter value was varied until the waste concentrations for the water and intruder pathways became equal, regardless of the likelihood (or physical impossibility) of the value to occur.

The parameter values that caused the permissible concentrations for the water and intruder pathways to become equal are listed in Table 5-9 for the 8 indicator radionuclides.

Table 5-9. Parameter Values That Caused the Permissible Concentrations for the Water and Intruder Pathways to Be Equal for Indicator Radionuclides at ANLE (tumulus design) (bold italic type indicates limiting pathway in the PE)

\begin{tabular}{|c|c|c|c|c|c|c|}
\hline \multirow[t]{4}{*}{$\begin{array}{l}\text { Indicator } \\
\text { Nuclide }\end{array}$} & \multirow[t]{4}{*}{$\begin{array}{c}\text { PE } \\
C_{w-w a t e r}^{a} \\
\left(\mu \mathrm{Ci} / \mathrm{m}^{3}\right)\end{array}$} & \multirow[t]{4}{*}{$\begin{array}{c}\text { PE } \\
C_{W / \ln r} \\
\left(\mu \mathrm{Ci} / \mathrm{m}^{3}\right)\end{array}$} & \multirow[t]{4}{*}{$\begin{array}{c}\text { PE } \\
\frac{C_{W-\ln t r}}{C_{W-W a t e r}}\end{array}$} & $\begin{array}{c}\text { Natural } \\
\text { Recharge, } \\
i \\
(\mathrm{~m} / \mathrm{y})\end{array}$ & $\begin{array}{l}\text { Groundwater } \\
\text { (Aquifer) } \\
\text { Velocity, } q_{g w} \\
\text { (m/y) }\end{array}$ & $\begin{array}{c}\text { Area, } \\
\text { A } \\
\left(\mathrm{m}^{2}\right)\end{array}$ \\
\hline & & & & \multicolumn{3}{|c|}{ PE Values } \\
\hline & & & & 0.102 & 6 & 2500 \\
\hline & & & & \multicolumn{3}{|c|}{$\begin{array}{l}\text { Value That Caused Equal } \\
\text { Concentrations }\end{array}$} \\
\hline $\mathrm{H}-3$ & $1 E+13$ & $7 E+07$ & 0.000007 & c & $c$ & c \\
\hline$c-14$ & $1 E+03$ & $1 E+04$ & 10 & $0.025^{b}$ & 110 & $<100$ \\
\hline Sr-90 & $N^{b}{ }^{b}$ & $5 E+04$ & - & c & c & c \\
\hline Tc-99 & $1 E+02$ & $2 E+04$ & 200 & $0.0005^{b}$ & 1800 & $<100$ \\
\hline Cs-137 & $\mathrm{NL}^{b}$ & $8 E+05$ & - & c & c & c \\
\hline U-238 & $5 E+01^{b}$ & $5 E+03$ & 100 & $0.0007^{b}$ & $900^{b}$ & $<100$ \\
\hline Pu-239 & $3 E+05^{b}$ & $6 E+03$ & 0.02 & $0.16^{b}$ & c & c \\
\hline $\begin{array}{l}\text { Am-241 } \\
(\mathrm{Np}-237)^{\mathrm{d}}\end{array}$ & $1 E+04^{\circ}$ & $9 E+03$ & 0.9 & $0.2^{\circ}$ & $3^{\circ}$ & $10,000^{\circ}$ \\
\hline
\end{tabular}

a "NL" means No Limit - estimated permissible concentration is greater than the specific activity of the pure elemental radionuclide.

b Arrival time at the performance boundary is greater than $10,000 \mathrm{y}$.

c No variation in values caused equal concentrations.

d The dominant decay product for Am-241

"- Value could not be calculated. 
For the parameters listed in Table 5-9, significant variations in values for most of the indicator radionuclides are needed to change the limiting pathways based on the PE results. For instance, for the indicator radionuclides $\mathrm{C}-14, \mathrm{Tc}-99$, and U-238, values for recharge would need to decrease by at least an order of magnitude to cause the waste concentrations for the water and intruder pathways to become equal; however, all 3 radionuclides would arrive at the performance boundary after $10,000 \mathrm{y}$. For the same radionuclides, values for groundwater velocity would need to increase by more than an order of magnitude, and U-238 would arrive at the performance boundary after 10,000 y; values for the facility plan area would need to decrease by more than an order of magnitude to change the limiting pathway. For Am-241, the values for recharge and facility dimensions (length and width) would have to double and the value for groundwater velocity would have to decrease by $50 \%$ to change the limiting pathway from intruder to water. For Pu-239, the value for the recharge would need to increase by more than $25 \%$ to cause the water and intruder pathways to become equal, but the radionuclide would arrive at the performance boundary after $10,000 \mathrm{y}$.

At ANLE, the unsaturated zone travel time accounts for almost all of the water travel time from the disposal facility to the performance boundary. Therefore, only $K_{d}$ values for the unsaturated zone were varied.

A $K_{d}$ value of about $14 \mathrm{~mL} / \mathrm{g}$ applied to the unsaturated zone would cause an arrival time at the performance boundary of $10,000 \mathrm{y}$. The $K_{d}$ values that caused the permissible concentrations for the water and intruder pathways to be the same are listed in Table 5-10 for five of the indicator radionuclides. The indicator radionuclides $\mathrm{H}-3, \mathrm{C}-14$, and Tc-99 are not considered in this analysis because general consensus is that the $K_{d}$ values for these radionuclides are small.

For Sr-90, Cs-137, and Am-241, using very small $K_{d}$ values (i.e., 4 or 5 orders of magnitude less than the $K_{d}$ values used in the PE) did not cause the permissible waste concentrations for the water pathway to equal those of the intruder pathway. For U-238, any $K_{d}$ value less than $14 \mathrm{~mL} / \mathrm{g}$ caused the arrival time at the performance boundary to be less than $10,000 \mathrm{y}$, thereby changing the limiting pathway from intruder to water. Decreasing the $K_{d}$ value for $\mathrm{Pu}-239$ by about one-third allowed the permissible waste concentration in the water pathway to become equal to that in the intruder pathway; however, the arrival time at the performance boundary was still beyond $10,000 \mathrm{y}$. Reducing the $K_{d}$ to below $14 \mathrm{~mL} / \mathrm{g}$ allows arrival at the performance boundary before $10,000 \mathrm{y}$, which would change the limiting pathway from intruder to water for U-238. 
Table 5-10. Variation of $K_{d}$ Values for the Unsaturated Zone at ANLE (tumulus design) (a $K_{d}$ value of about $14 \mathrm{~mL} / \mathrm{g}$ caused radionuclide arrival at the performance boundary equal to $10,000 \mathrm{y})$

\begin{tabular}{|c|c|c|c|c|c|}
\hline $\begin{array}{l}\text { Indicator } \\
\text { Nuclide }\end{array}$ & $\begin{array}{c}\text { PE } \\
K_{d} \\
\text { (mUg) }\end{array}$ & $\begin{array}{c}\text { PE } \\
C_{W-W a s e r} \\
\left(\mu \mathrm{Ci} / \mathrm{m}^{3}\right)\end{array}$ & $\begin{array}{c}\text { PE } \\
C_{W / n t r} \\
\left(\mu \mathrm{Ci} / \mathrm{m}^{3}\right)\end{array}$ & $\begin{array}{c}\text { PE } \\
C_{\text {W-Intr }} \\
C_{W-\text { Water }}\end{array}$ & $\begin{array}{l}K_{d} \text { Value that } \\
\text { Caused Equal } \\
\text { Concentrations }\end{array}$ \\
\hline ST-90 & 15 & $\mathrm{NL}^{b}$ & $5 E+04$ & - & $c$ \\
\hline Cs-137 & 280 & $\mathrm{NL}^{\mathrm{b}}$ & $8 E+05$ & - & $c$ \\
\hline U-238 & 35 & $5 E+01^{b}$ & $5 E+03$ & 100 & $c, d$ \\
\hline Pu-239 & 550 & $3 E+05^{b}$ & $6 E+03$ & 0.02 & $350^{b, d}$ \\
\hline $\begin{array}{l}A m-241 \\
(\mathrm{~Np}-237)^{\circ}\end{array}$ & $\begin{array}{c}1900 \\
(5) \\
\end{array}$ & $1 E+04^{\prime}$ & $9 E+03$ & 0.9 & $c$ \\
\hline
\end{tabular}

a "NL" means No Limit - the estimated permissible waste concentration is greater than the specific activity of the pure elemental radionuclide.

b Permissible waste concentration is based on arrival time at the performance boundary beyond $10,000 \mathrm{y}$.

c No variation in value caused equal concentrations.

d Value less than $14 \mathrm{~m} \cup \mathrm{g}$ caused arrival at the performance boundary before $10,000 \mathrm{y}$, which changed the limiting pathway.

e The dominant decay product for Am-241

i Based on the dominant decay product, Np-237

"- Value could not be calculated.

\subsubsection{Physical Constraints on Sensitivity Analysis Values}

The PE results for ANLE are based on parameter values provided by the ANLE technical staff for site-specific parameters used in calculations. Descriptions and technical justifications of these values are provided in Sections 5.3 and 5.4. Ranges and statistical distributions were not known for most of the input parameter values; however, site-specific knowledge can be used to determine whether the values determined in the sensitivity analysis are reasonable and physically possible at ANLE.

\section{Natural Recharge}

The value used for the recharge $(0.102 \mathrm{~m} / \mathrm{y}[0.335 \mathrm{ft} / \mathrm{y}])$ was based on a 1963 compilation (Knowles et al., p. 21) and was a computed recharge to the Silurian-age dolomite aquifer. Another study cited in the 1963 compilation indicated that the amount of recharge to the Silurianage dolomite aquifer averaged about $0.076 \mathrm{~m} / \mathrm{y}(3 \mathrm{in} / \mathrm{y})$. Based on this value, the recharge at ANLE could be as much as $25 \%$ less than the value used in the PE. The sensitivity analysis described above suggests that a $25 \%$ decrease in the recharge would not affect any indicator radionuclide. A recharge that was about $25 \%$ or more greater (to $0.14 \mathrm{~m} / \mathrm{y}[0.46 \mathrm{ft} / \mathrm{y}]$ ) would change the numerical results for the indicator radionuclide $\mathrm{Pu}-239$, but the arrival time at the performance boundary would be greater than $10,000 \mathrm{y}$. The recharge would have to double (to $0.2 \mathrm{~m} / \mathrm{y}[0.7 \mathrm{ft} / \mathrm{y}])$ to change the limiting pathway for the indicator radionuclide Am-241. 
Precipitation in the ANLE area averages about $0.84 \mathrm{~m} / \mathrm{y}$ ( 33 in./y), so about $25 \%$ of the annual precipitation would have to recharge groundwater to cause the limiting pathway for Am-241 to change from intruder to water.

\section{Groundwater Darcy Velocity}

The value used in the PE for the groundwater Darcy velocity ( $6 \mathrm{~m} / \mathrm{y}$ [20 ft/y]) was calculated using values supplied by ANLE technical staff. A coefficient of transmissibility (Knowles et al., 1963, p. 32) was used to calculate the hydraulic conductivity based on the assumption that the aquifer was located in the upper $30.5 \mathrm{~m} \mathrm{(100} \mathrm{ft)} \mathrm{of} \mathrm{the} \mathrm{Silurian-age} \mathrm{dolomite}$ (Roadcap et al., 1993, p. 15). The coefficient of transmissibility was provided as a range of 7000 to $9000 \mathrm{gpd} / \mathrm{ft}$ (Knowles et al., 1963), which, using the same assumptions about aquifer thickness and hydraulic gradient, would yield a range of groundwater Darcy velocities of 5.3 to $6.7 \mathrm{~m} / \mathrm{y}$ $(17$ to $22 \mathrm{ft} / \mathrm{y})$. The groundwater Darcy velocity of $6 \mathrm{~m} / \mathrm{y}(20 \mathrm{ft} / \mathrm{y})$ used in the PE was the mean of the Knowles et al. range based on preliminary data from the Sitewide Hydrogeological Baseline Study. The sensitivity analysis indicates that the value would have to be at least $50 \%$ less (to 3 $\mathrm{m} / \mathrm{y}[10 \mathrm{ft} / \mathrm{y}]$ for Am-241) or more than an order of magnitude greater (to $110 \mathrm{~m} / \mathrm{y}$ [360 ft/y] for $\mathrm{C}-14$ ) to change the limiting pathway. If the coefficient of transmissibility were the only possible variable in determining the groundwater Darcy velocity at ANLE, then the value used in the PE would adequately represent current knowledge of site conditions. However, the values used for aquifer thickness and hydraulic gradient are not based on a large amount of data. A groundwater Darcy velocity of $110 \mathrm{~m} / \mathrm{y}(360 \mathrm{ft} / \mathrm{y})$ required to change the limiting pathway for C-14 is unrealistic. Given the assumptions used in determining the PE value for groundwater Darcy velocity, it is not possible to determine the lower bound value for this parameter. A $3 \mathrm{~m} / \mathrm{y}$ $(10 \mathrm{ft} / \mathrm{y})$ groundwater Darcy velocity could be in the lower end of the possible range at ANLE. This lower value of $3 \mathrm{~m} / \mathrm{y}(10 \mathrm{ft} / \mathrm{y})$ would change the limiting pathway for Am-241 from intruder to water.

\section{Facility Area}

The generic trench and tumulus designs used in the PE were a standard size $(50 \mathrm{~m}$ by $50 \mathrm{~m}\left[2500 \mathrm{~m}^{2}\right]$ ) and shape (square) for all sites. The ANLE staff had not considered a disposal facility for MLLW prior to the PE; therefore, no site-specific size for the facilities was considered in the PE. As shown by the sensitivity analysis, for the indicator radionuclides C-14, Tc-99, and U-238, a tumulus facility would need to be very small (less than $100 \mathrm{~m}^{2}\left[1080 \mathrm{ft}^{2}\right]$ ) to change the limiting pathway. For Am-241, doubling the facility dimensions to $100 \mathrm{~m}$ by $100 \mathrm{~m}(328 \mathrm{ft}$ by $328 \mathrm{ft})\left(10,000 \mathrm{~m}^{2}\left[108,000 \mathrm{ft}^{2}\right]\right)$ would change the limiting pathway. The area of the facility should be important only when evaluating the size of an actual facility, and sensitivity analysis indicates that the indicator radionuclide Am-241 could be affected.

\section{Distribution Coefficients}

The PE for ANLE used values for distribution coefficients $\left(K_{d} \mathrm{~s}\right)$ for the geologic media that, except for a few carbonate values in the saturated zone, were based on a compilation of $K_{d}$ values published in the open literature (Thibault et al., 1990). The vadose zone, although comprised of glacial till containing sand, silt, and clay, was treated as a single sand unit, and 
generic $K_{d}$ values for sandy soil were used for the vadose zone in the PE. This assumption is conservative because $K_{d}$ values for sandy soil are generally smaller than those for silt or clay (i.e., a radionuclide is generally more mobile in sand than in silt or clay and thus will arrive at the performance boundary faster). The sensitivity analysis indicated that changes in $K_{d}$ values have the ability to impact the results by changing travel times of the radionuclides in the geologic media.

According to Table 5-4, 5 radionuclides with concentration limits arrived at the performance boundary before $10,000 \mathrm{y}$; ten radionuclides with concentration limits (Al-26, Cl-36, K-40, Pd-107, Sn-126, U-233, U-234, U-235, U-236, and U-238) arrived between 10,000 and $100,000 \mathrm{y}$. For two of these radionuclides (Cl-36 and K-40, both of which arrived at $11,000 \mathrm{y}$ ), minor changes in their $K_{d}$ values (from 15 to about 14) would cause them to arrive before 10,000 y. For Al-26 and the uraniums $\left(K_{d}=35 \mathrm{~mL} / \mathrm{g}\right)$, which arrived at the performance boundary at about $25,000 \mathrm{y}$ in the $\mathrm{PE}$, a reduction in $K_{d}$ of about $2 / 3$ (from 35 to about 14) would cause them to arrive before $10,000 \mathrm{y}$. The $K_{d}$ value for $\mathrm{Pd}-107$ would have to decrease by about $3 / 4$ (from 55 to about 14), and the $K_{d}$ value for Sn-136 would have to decrease by an order of magnitude for these radionuclides to arrive before $10,000 \mathrm{y}$. Because waste concentrations in the water pathway were not considered in the PE results if the radionuclide arrived after $10,000 \mathrm{y}$, a decrease in arrival time to less than $10,000 \mathrm{y}$ could cause a change in limiting pathway if the waste concentration for a radionuclide in the water pathway is more restrictive than that in the intrusion pathway. The water pathway would limit the permissible waste concentrations for 8 of these 10 radionuclides if their arrival times were less than $10,000 \mathrm{y}$.

The PE results for ANLE are based on estimates of parameter values developed by the site technical staff for site-specific parameters used in calculations for the water pathway. In addition, the ANLE technical staff participated in the development of the site-specific conceptual model for the water pathway and have indicated that it represents their current understanding of actual site conditions.

\subsection{OBSERVATIONS}

Based on the results of the PE and the parameter-sensitivity analysis, the following observations can be made about MLLW disposal at ANLE:

- ANLE has characteristics of a moderate (i.e., neither strictly humid nor arid) climate. The natural recharge is more like that of a humid climate than an arid one, but the site has a relatively thick vadose zone compared to more humid sites, and water travel time in the vadose zone accounts for almost all the subsurface travel time.

- For ANLE, the results indicate that of the 58 radionuclides evaluated in the PE, 51 radionuclides for the trench design and 54 radionuclides for the tumulus design would be limited by the intrusion scenarios. These results reflect the dominant role of the selected human intrusion scenarios that is demonstrated for almost all the sites considered in the PE 
(see Sections 7.5 and 7.6 in Volume 2). This dominance indicates a need to be aware of the inability to predict the social behavior of populations far into the future.

The results also indicate that for the water pathway, 47 radionuclides for the trench design and 51 radionuclides for the tumulus design would arrive at the performance boundary after the 10,000-y period of consideration in the $\mathrm{PE}$ analysis of the water pathway. The primary reason for these arrival times is that ANLE has a thick unsaturated zone. Of the radionuclides that would arrive before $10,000 \mathrm{y}$, two for the trench design had no limit on waste concentration.

Because ANLE has many radionuclides that either are limited by the intrusion scenarios, arrive at the performance boundary after $10,000 \mathrm{y}$, or have no limit on waste concentration, this site may have flexibility in accepting a variety of radionuclides for disposal.

- Using either a trench or tumulus design appears feasible at ANLE, although a tumulus design would provide slightly better performance.

- The ANLE site may have physical constraints that could limit disposal activities. Because ANLE did not have plans for on-site MLLW disposal at the time of the PE, the evaluated location was determined on the basis of simple criteria and any possible future use of the area based on facility planning was not accounted for.

- The sensitivity analysis for ANLE indicates that reasonable changes in values for the natural recharge, groundwater Darcy velocity, and facility size for most radionuclides would not significantly change the results. Values for natural recharge and groundwater Darcy velocity would have to be at a relatively extreme end of their possible ranges to significantly affect the results (i.e., change the limiting pathway), and very few radionuclides would be affected (Table 5-9).

In flow and transport problems, the $K_{d}$ values are often the most uncertain site-specific input parameters. Some of the $K_{d}$ values of the geologic media at ANLE could have sufficient uncertainty to affect the results (i.e., change the limiting pathway) for several of the radionuclides considered in the $\mathrm{PE}$ by changing the arrival time at the performance boundary (Table 5-10).

- The PE was a scoping analysis performed using assumptions that are conservative relative to most LLW performance assessments. There are no site-specific studies to compare with the PE results. A more detailed performance assessment would be required for permitting or other disposal planning. 


\subsection{REFERENCES}

Aggarwal, Pradeep K., Thomas R. Powell, Gregory L. Headington, and Albert J. Pollock, 1991. An Experimental Study of Radionuclide Adsorption on Glacial Deposits from Southeastern Illinois. Final Report, Rev. 2. Columbus, OH: Battelle Columbus Laboratory.

ANLE (Argonne National Laboratory-East), 1993. "Statement of Work for a Sitewide Hydrogeological Baseline/ Characterization Study (Phases I and II)." Argonne, IL: Environment and Waste Management Program, Argonne National Laboratory. (unpublished)

ANLE (Argonne National Laboratory—East), 1994. Laboratory Integrated Facilities Plan, FY94. Document No. JOSTD-106-G-T006. Argonne, IL: Argonne National Laboratory.

Baer, T.A., L. L. Price, J. N. Emery, N. E. Olague, 1994. Second Performance Assessment Iteration of the Greater Confinement Disposal Facility at the Nevada Test Site. SAND930089. Albuquerque, NM: Sandia National Laboratories.

Cooper, C.D., and F.C. Alley, 1986. Air Pollution Control: A Design Approach. Prospect Heights, IL: Waveland Press, Inc.

CRC, 1981. CRC Handbook of Chemistry and Physics. Eds. Robert C. Weast and Melvin J. Astle. Boca Raton, FL: CRC Press, Inc.

EPA (Environmental Protection Agency), 1992a. Clean Air Act Assessment Package - 1988. CAP88-PC, Version 1.00. Washington, DC: U.S. Environmental Protection Agency.

EPA (Environmental Protection Agency), 1992b. User's Guide for the Industrial Source Complex (ISC2) Dispersion Models, Volume I: User Instructions. EPA Publication No. EPA-450/4-92-008a. Research Triangle, NC: U.S. Environmental Protection Agency.

FFCAct, 1992. Federal Facility Compliance Act of 1992. P.L. 102-386, October 1992.

Freeze, R. Allan, and John A. Cherry, 1979. Groundwater. Englewood Cliffs, NJ: Prentice-Hall, Inc.

G\&M, 1995. "Phase I Hydrogeological Assessment Report, Argonne, Illinois." Milwaukee, WI: Geraghty \& Miller, Inc. (unpublished)

Gruebel, M.M., R.D. Waters, M.B. Hospelhorn, and M.S.Y. Chu, eds., 1994. Framework for DOE Low-Level and Mixed Low-Level Waste Disposal: Site Fact Sheets. SAND94-2728. Albuquerque, NM: Sandia National Laboratories. 
Golchert, N.W., 1994. Surveillance of Site A and Plot M, Report for 1993. ANL-94/9. Argonne, IL: Argonne National Laboratory.

Golchert, N.W., and R.G. Kolzow, 1994. Argonne National Laboratory-East Site Environmental Report for Calendar Year 1993. ANL-94/10. Argonne, IL: Argonne National Laboratory.

Kincaid, C.T., J.W. Shade, G.A. Whyatt, M.G. Piepho, K. Rhoads, J.A. Voogd, J.H. Westsik, Jr., M.D. Freshley, K.A. Blanchard, and B.G. Lauzon, eds., 1993. Performance Assessment of Grouted Double-Shell Tank Waste Disposal at Hanford. WHC-SD-WM-EE-004, Rev. 0. U.S. Department of Energy, Pacific Northwest Laboratory and Westinghouse Hanford Company.

Knowles, Doyle B., W.J. Drescher, and E.F. LeRoux, 1963. Ground-Water Conditions at Argonne National Laboratory, Illinois, 1948-60. Geological Survey Water-Supply paper 1669-0. Washington, DC: U.S. Geological Survey.

Krynine, Dimitri, and William R. Judd, 1957. Principles of Engineering Geology and Geotechnics. New York, NY: McGraw-Hill Book Company.

Maheras, Steven J., Arthur S. Rood, Swen O. Magnuson, Mary E. Sussman, and Rajiv N. Bhatt, 1994. Radioactive Waste Management Complex Low-Level Waste Radiological Performance Assessment. EGG-WM-8773. Idaho Falls, ID: U.S. Department of Energy Office of Environmental Restoration and Waste Management, DOE Idaho Operations Office.

MMES (Martin Marietta Energy Systems), EG\&G Idaho, Inc., and Westinghouse Savannah River Company, 1994. Radiological Performance Assessment for the E-Area Vaults Disposal Facility (U). WSRC-RP-94-218, Rev. 0. Aiken, SC: Westinghouse Savannah River Company.

ORNL (Oak Ridge National Laboratory), 1994. Performance Assessment for Continuing and Future Operations at Solid Waste Storage Area 6. ORNL-6783. Oak Ridge, TN: U.S. Department of Energy, Oak Ridge National Laboratory.

RMT, 1993. "800 Area Landfill Groundwater Assessment Report." Schaumburg, IL: RMT, Inc. (unpublished)

Roadcap, George S., Stuart J. Cravens, and Edward C. Smith, 1993. Meeting the Growing Demand for Water: An Evaluation of the Shallow Ground-Water Resources in Will and Southern Cook Counties, Illinois. Research Report 123. Champaign, $\mathrm{K}$ : State Water Survey Division. 
Thibault, D.H., M.I. Sheppard, and P.A. Smith, 1990. A Critical Compilation and Review of Default Soil Solid/Liquid Partition Coefficients, $K_{d}$, for Use in Environmental Assessments. AECL-10125. Pinawa, Manitoba, Canada: Whiteshell Nuclear Research Establishment, Atomic Energy of Canada Limited.

Tien, P-L., F.B. Nimick, A.B. Muller, P.A. Davis, R.V. Guzowski, L.E. Duda, and R.L. Hunter, 1983. Repository Site Data and Information in Bedded Salt: Palo Duro Basin, Texas.

SAND82-2223, NUREG/CR-3129. Albuquerque, NM: Sandia National Laboratories. Cited in Trauth, Kathleen M., Stephen C. Hora, Rob P. Rechard, and D.R. Anderson, 1992. The Use of Expert Judgment to Quantify Uncertainty in Solubility and Sorption Parameters for Waste Isolation Pilot Plant Performance Assessment. SAND92-0479. Albuquerque, NM: Sandia National Laboratories.

\section{Acknowledgments}

The SNL Core Team acknowledges the contributions of Norbert Golchert, Glenn Wittman, and Dolores Ray of Argonne National Laboratory-East. 


\section{Kentucky: PADUCAH GASEOUS DIFFUSION PLANT (PGDP) Core Team Contact: Gregory P. Zimmerman}

The Federal Facility Compliance Act (FFCAct, 1992) requires the Department of Energy (DOE) to establish plans in conjunction with its regulators and with members of the public for the treatment of DOE's mixed low-level waste (MLLW). Although the FFCAct did not specifically address disposal of treated MLLW, both DOE and the States recognized that disposal issues were an integral part of treatment discussions. Since 1992, DOE has worked with the States to define and develop an evaluation process for disposal options. Preliminary activities of this joint DOEState process have narrowed the sites for further evaluation from 49 to 15.

The Disposal Workgroup (DWG), which was established by DOE to develop a process for evaluating disposal options, designed a performance evaluation (PE) to quantify and compare the limitations of the remaining $15 \mathrm{DOE}$ sites for MLLW disposal. The principal goal of the PE was to estimate, for grouted residuals resulting from the treatment of MLLW, permissible concentrations of radionuclides in waste for disposal at each site. These "permissible waste concentrations" were based solely on long-term physical performance of the disposal facility and did not take into account any operational waste acceptance criteria that a site might have developed. The PE did not address any ethical, social, or policy considerations relevant to siting such facilities.

The PE used analyses that are consistent with the approach used in many low-level waste (LLW) performance assessments. The objective was to use a set of modeling assumptions of sufficient detail to capture major site-specific characteristics and yet be general enough for consistent application at all sites. Additionally, the analyses were designed to ensure that the sites were analyzed consistently and that all major assumptions were clearly stated.

The remainder of this chapter provides the PE results for Paducah Gaseous Diffusion Plant, one of the 15 sites being evaluated. The chapter contains the following information:

Section 6.1: brief, general description of the site based on previous work done by the . DWG (Gruebel et al., 1994)

Section 6.2: plans for MLLW disposal, if any, and the location evaluated in the PE

Section 6.3: current understanding of radionuclide movement at the selected location based on available information, and the conceptual model used for the evaluation of each of three pathways (water, atmospheric, and inadvertent intruder)

Section 6.4: site-specific and generic values used in the PE calculations and their sources

Section 6.5: estimates of maximum waste concentrations determined in the PE calculations for each of the three pathways, along with calculated values used in determining these results 
Section 6.6: summary of results based on disposal-facility design; discussion with respect to such issues as uncertainty and sensitivity

Section 6.7: observations based on the results of the PE and the parameter sensitivity analysis

Section 6.8: references

The general assumptions and methodology used in the PE are summarized in Chapter 1 of this volume and explained in more detail in Volume 2 of this report. Overall results for all the sites are discussed in Chapter 7 of Volume 2.

\subsection{GENERAL DESCRIPTION OF THE SITE}

The Paducah Gaseous Diffusion Plant (PGDP) is located in the western portion of the Ohio River drainage basin, in the extreme western area of Kentucky (Figure 6-1). The plant resides within a 304-ha (750-acre) fenced area on a 1386-ha (3423-acre) federal reservation (Kornegay et al., 1994), about $14 \mathrm{~km}(9 \mathrm{mi})$ west of the city of Paducah, Kentucky and $5 \mathrm{~km}$ (3 mi) south of the Ohio River (Figure 6-2). PGDP is adjacent to the West Kentucky Wildife Management Area on the west and south, and adjacent to the Tennessee Valley Authority Shawnee Plant on the north. The nominal elevation in the main plant area is $116 \mathrm{~m}(380 \mathrm{ft})$ above the mean sea level, $22 \mathrm{~m}(73 \mathrm{ft})$ above the average pool level of the Ohio River near PGDP.

The two largest towns in the area are Metropolis, Illinois (population 6,800), about $8 \mathrm{~km}$ (5 mi) to the northeast, and Paducah, Kentucky (population 27,500). Estimated rural population within a $10 \mathrm{~km}(6 \mathrm{mi})$ radius of PGDP is 2,000 and estimated population within a $50 \mathrm{~km}$ (30 mi) radius is 106,500 .

The PGDP was completed in 1954 to operate in conjunction with the Oak Ridge Gaseous Diffusion Plant in Tennessee and the Portsmouth Gaseous Diffusion Plant in Ohio. The Oak Ridge plant is no longer in operation. The Energy Act of 1992 established the U.S. Enrichment Corporation (USEC) and gave it the responsibility of operating the Paducah and Portsmouth plants. The mission of the USEC at Paducah is the separation of uranium isotopes using a gaseous diffusion process, producing enriched uranium for nuclear fuel. The DOE mission at PGDP is to conduct investigations for identification and remediation of environmental contamination stemming from prior operations. The PGDP site is owned by DOE.

The climate of the PGDP area may be broadly classified as temperate continental. Because of the geographic location with reference to the center of the continent, the midwinter cold waves from the Canadian Northwest are usually considerably modified by the time they reach Kentucky (Ruffner, 1985). In summer when the high pressure off the Florida coast is displaced westward from its normal position, extended periods of hot, humid weather will occur. July is the hottest month, with an average monthly temperature of $26^{\circ} \mathrm{C}\left(79^{\circ} \mathrm{F}\right)$ and January is the coldest month with an average temperature of $1.1^{\circ} \mathrm{C}\left(34^{\circ} \mathrm{F}\right)$. Precipitation is well distributed throughout the year with an average of $116 \mathrm{~cm}$ (45.8 in.) (Ruffner, 1985). Snowfall is common from December through March with an annual average of $25 \mathrm{~cm}$ (10 in.). 


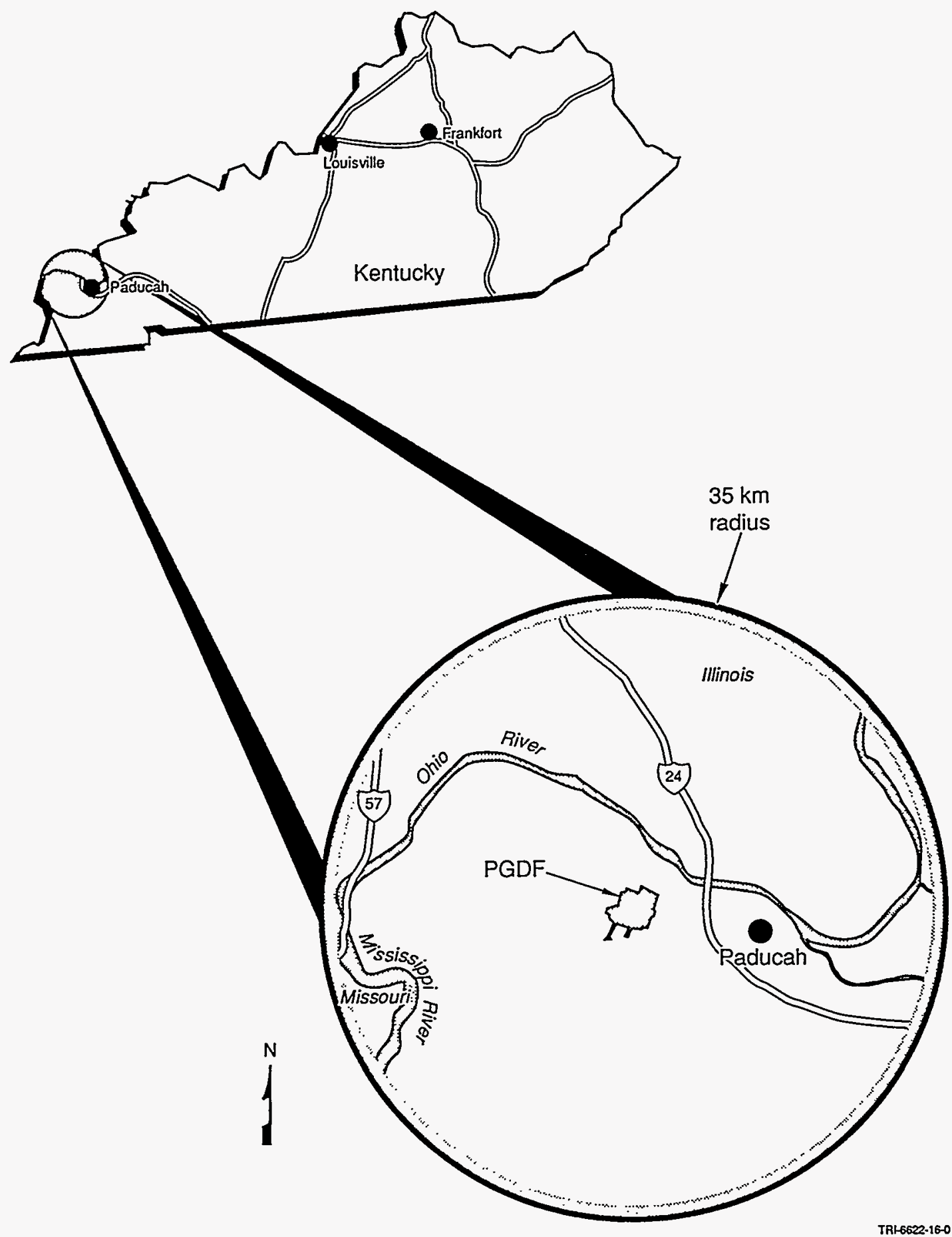

Figure 6-1. Location map for the Paducah Gaseous Diffusion Plant. 


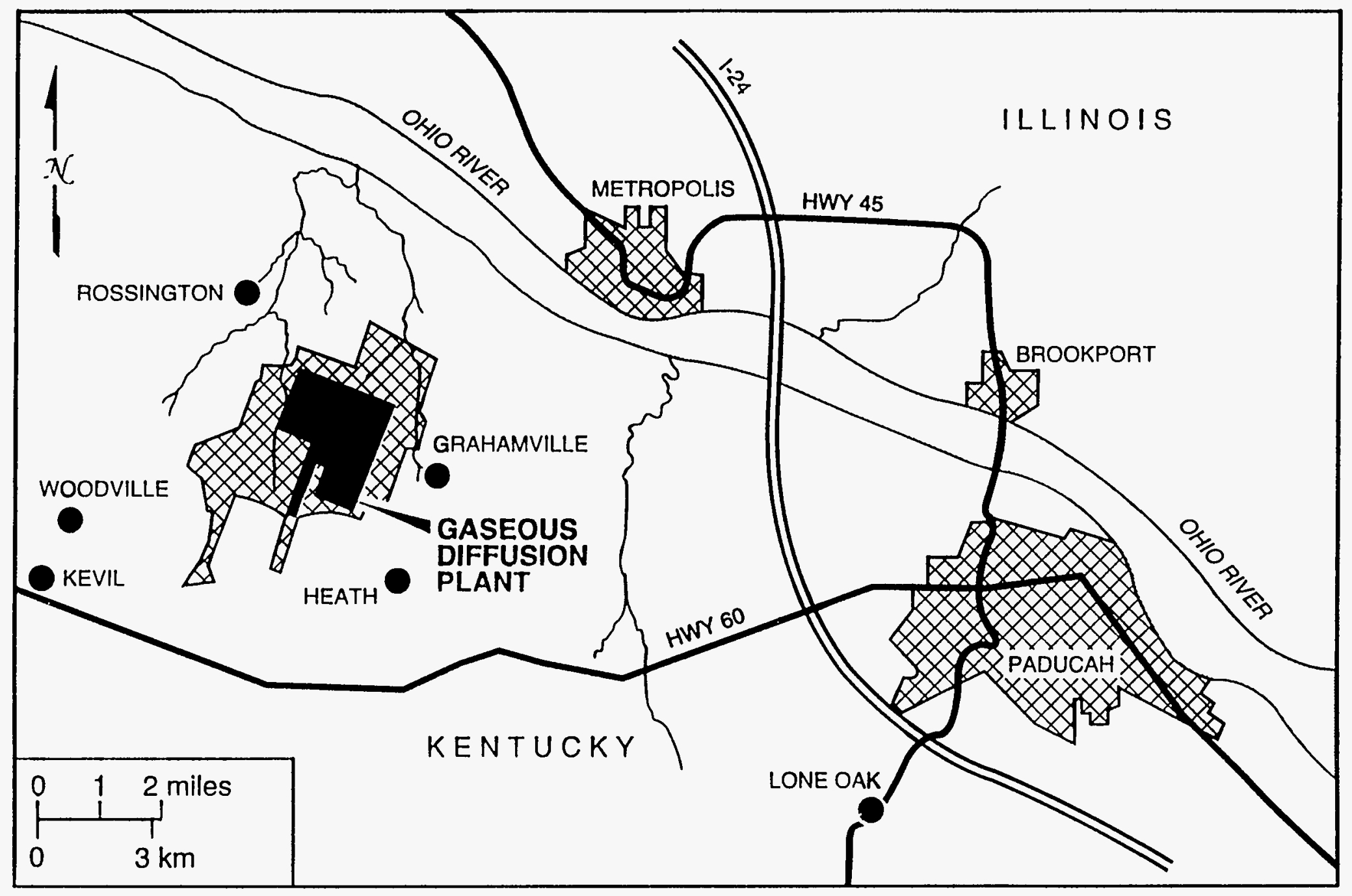

Figure 6-2. Location of the Paducah Gaseous Diffusion Plant in relation to the geographic region (Kornegay et al., 1994). 
PGDP is located within the drainage areas of Big and Little Bayou creeks, which meet about $5.6 \mathrm{~km}$ ( $3.5 \mathrm{mi})$ north of the site and discharge into the Ohio River near River Mile 948 (USGS, 1982). Big Bayou Creek is a perennial stream whose drainage extends from approximately $4 \mathrm{~km}(2.5 \mathrm{mi})$ south of PGDP to the Ohio River. It flows toward the river along a 14-km (9-mi) course that passes along the western boundary of the plant. Little Bayou Creek originates in the wildlife management area and flows north toward the Ohio River along a 10-km (6.5-mi) course that includes parts of the eastern boundary of the plant. As can be seen from Figure 6-2, in the main plant area, surface water drainage is to the east and northeast toward Little Bayou Creek, and to the west and northwest toward Big Bayou Creek. Effluents from PGDP operations constitute about $85 \%$ of the normal flow in Big Bayou Creek and $100 \%$ of the normal flow in Little Bayou Creek (Kornegay et al., 1991).

Although PGDP does not use groundwater for supply purposes, local residents within one kilometer $(0.6 \mathrm{mi})$ of the eastern site boundary use wells for their domestic needs (DOE, 1989). In August 1988, off-site groundwater contamination was discovered north of PGDP (Rogers and Jett, 1989). A community water line was extended to the residents with contaminated wells, at DOE's expense, for a long-term water supply. Although the underlying regional groundwater aquifer (RGA) is classified as a sole-source aquifer, it is not currently utilized north (downgradient) of the plant (Rogers et al., 1988).

\subsection{STATUS AND SITING OF MLLW DISPOSAL FACILITY}

At the time of the PE, personnel at the PGDP had no plans for on-site MLLW disposal. This PE project required the identification of a suitable location for a future MLLW disposal facility at PGDP. Three primary areas were identified by the site technical staff as possible sites for such facilities. They are the north, middle, and south sites, labeled by the letters $\mathrm{n}, \mathrm{m}$, and $\mathrm{s}$, respectively in Figure 6-3. All of these locations are just west of the fenced area. The south site overlies the northern edge of the Tertiary Porters Creek clay terrace, and the north area overlies the southern end of the underlying RGA (described in Section 6.3.1.1). The middle site overlies a transitional region. The north site was chosen for evaluation in the $\mathrm{PE}$ because it would provide the greatest amount of protection to the underlying aquifer. This site would therefore provide the largest permissible radionuclide concentrations in waste from among the three sites.

Two generic disposal facilities were considered in the PE: a RCRA-compliant, belowground trench and a RCRA-compliant, above-ground tumulus (described in more detail in Chapter 5 of Volume 2). The generic facilities were selected to provide consistency in analysis of the performance of the 15 sites. Both generic facilities were assumed to be square with a plan area of $2500 \mathrm{~m}^{2}\left(26,910 \mathrm{ft}^{2}\right)$. 


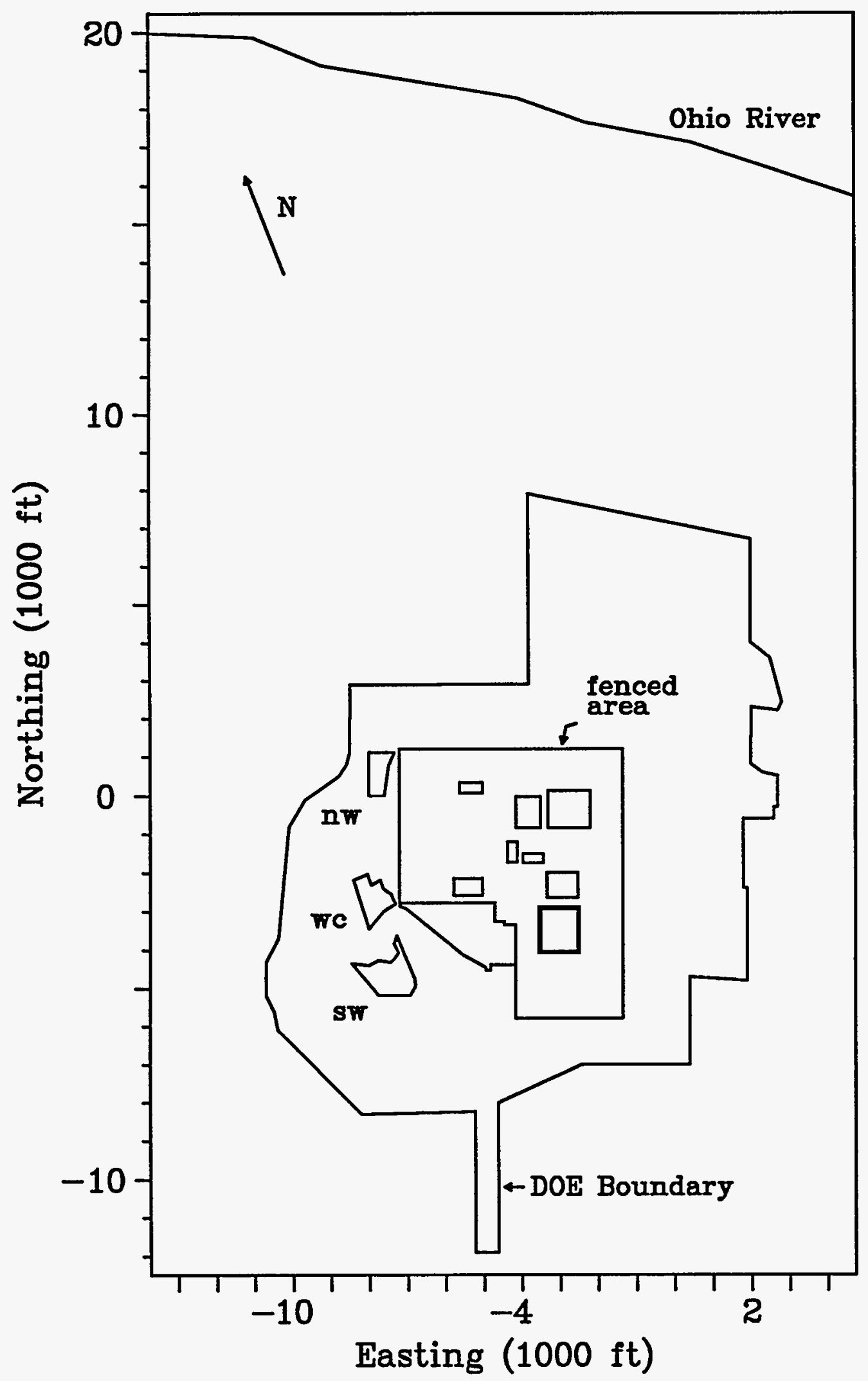

Figure 6-3. Possible MLLW disposal sites (n: north; m: middle; and s: south) identified by the site technical staff. 


\subsection{BASIS FOR CONCEPTUAL MODEL USED IN THE PE}

The current understanding of radionuclide transport from a disposal facility at PGDP is based on referenced sources of information contained in the assessment of waste limits for solid waste landfill at PGDP (Lee et al., 1995; Wang et al., 1994). In addition, groundwater studies have been conducted for PGDP (Clausen et al., 1992; GeoTrans, 1990). The descriptions below summarize how this information was incorporated into the PE's conceptual model for PGDP.

\subsubsection{Water Pathway}

Knowledge of groundwater flow and radionuclide movement in the water pathway at the Paducah plant provided the basis for the conceptual model considered in the PE. The conceptual model encompasses the site technical staff's current understanding of site-specific geology, hydrology, water table and aquifer characteristics, and transport pathways.

\subsubsection{Current Understanding of Relevant Hydrogeology}

Proceeding from the surface downward, the PGDP area is underlain by loess, PliocenePleistocene continental deposits, Tertiary and Cretaceous sediments (Porters Creek clay and McNairy formation), and Mississippian bedrock (Figure 6-4). The loess deposits range in thickness from 1.5 to $6 \mathrm{~m}(5$ to $25 \mathrm{ft})$ with an average of $4.6 \mathrm{~m}(15 \mathrm{ft})$. The continental deposits subdivide into different hydrogeologic units (Clausen et al., 1992). The upper continental system is formed by laterally discontinuous but correlatable sands with occasional pebbles and is referred to as the shallow sand. The shallow sand is underlain by a sedimentary unit which varies from all clay to all sand, but usually is predominantly clay, silt, or clayey silt. This unit forms a semiconfining layer separating the unconfined groundwater system in the shallow sand from the underlying regional gravel aquifer (RGA). The RGA is in the lower facies of continental deposits and is predominantly gravel with silt and sand, but sometimes it is found locally as all sand or as a cobbley gravel. The RGA has an average thickness of $9 \mathrm{~m} \mathrm{(30} \mathrm{ft)}$ and is the major aquifer in the area. It terminates at the slope formed by Porters Creek clay beneath the southern part of PGDP. The RGA is recharged by infiltration of precipitation through the shallow sand and upper clay layers, and discharges to the Ohio River (Figure 6-4).

Near PGDP, the continental deposits rest unconformably on the McNairy formation, which has a total thickness ranging from $69 \mathrm{~m}(225 \mathrm{ft})$ to $91 \mathrm{~m}(300 \mathrm{ft})$. The base of the Cretaceous sediments dips southward on the truncated subcrop of Mississippian bedrock, which dips moderately to the northeast toward the Illinois Basin. 


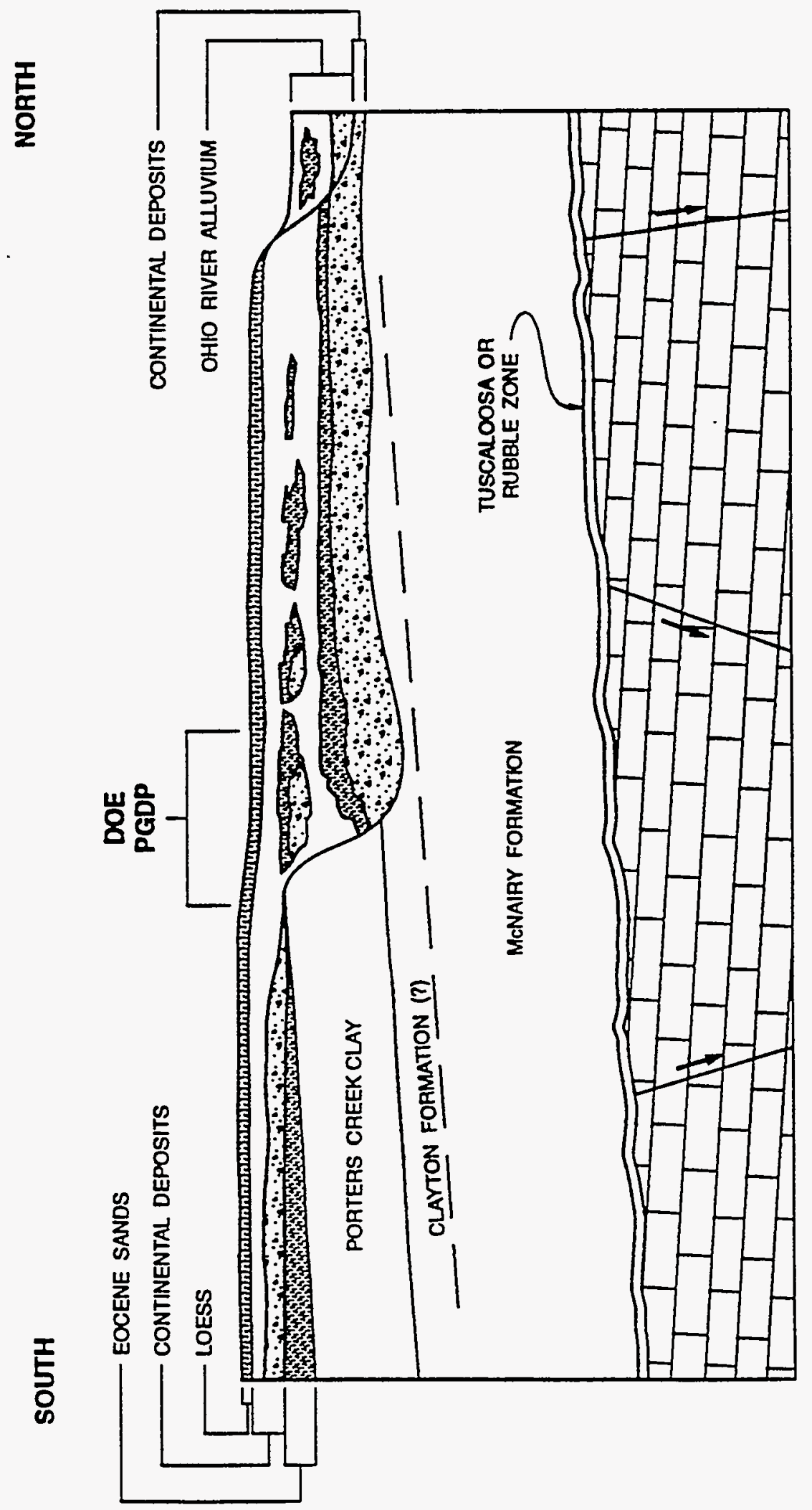

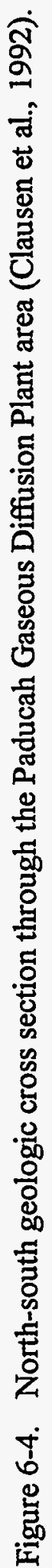


Site groundwater data indicate that the water table beneath PGDP is in the upper continental deposits (Figure 6-4) and has elevations of about 340 to $360 \mathrm{ft}$ (104 to $110 \mathrm{~m}$ ) (Clausen et al., 1992). This water table is about 30 to $50 \mathrm{ft}$ (9 to $15 \mathrm{~m}$ ) higher than the average pool elevation of the Ohio River. The water table south of the PGDP site has even higher elevations (greater than $370 \mathrm{ft}$ [110 m]) because of the higher ground surface and the presence of underlying Porters Creek clay. The hydraulic head in the RGA has values ranging from 325 to $330 \mathrm{ft}(99$ to $100 \mathrm{~m})$ beneath the plant and decreases to the average pool elevation at the Ohio River. These data suggest that radionuclides in the groundwater near PGDP basically move downward from the upper continental deposits to the RGA and transport northward from the plant area toward the Ohio River (Figure 6-4).

\subsubsection{Conceptual Model Used in the PE}

The PE used a generic conceptual model to describe the water pathway (summarized in Section 1.1.2 of this volume and described in detail in Chapter 5 of Volume 2). In the unsaturated zone, leachate was generated by constant flow through the disposal facility at a rate that was controlled by the assumed performance of the disposal facility. When all engineered barriers had failed, the rate was assumed to be equal to the natural recharge through local soils. The volumetric flow of water through the facility that generated leachate was based on the assumed performance and size of the disposal facility. No dilution was assumed to occur in the unsaturated zone, so at steady state, the concentration that reached groundwater equaled the leachate concentration. No lateral spreading was assumed, so the leachate flux through the unsaturated zone was confined to the soil column directly below the plan area of the facility.

As contaminated water entered the saturated zone, the contaminant mixed with clean groundwater, forming a plume with a shape controlled by aquifer and contaminant properties. The generic conceptual model assumed that instantaneous and complete mixing within the aquifer occurred directly below the facility. Mixing in the vertical direction occurred by hydrodynamic dispersion, and the contaminant mixing depth was an estimated value.

The generic conceptual model was adapted to conditions at PGDP based on site-specific knowledge of the geology and water flow paths. The conceptual model for the water pathway at PGDP is illustrated in Figure 6-5. Basically, the groundwater near the north site moves downward through the semi-confining upper continental deposits to the RGA and is transported in the RGA northward to the performance boundary. In order to bring this conceptual model in line with the generic PE model, the semi-confining layer ( $14.0 \mathrm{~m}$ [45.9 ft] thick) was added to the unsaturated zone (1.5 m [4.9 ft] thick) to make a zone of vertical transport which is $15.5 \mathrm{~m}$ [50.8 $\mathrm{ft}]$ thick (see Figure 6-5). These zones were given the hydrogeological properties of the semi-confining layer, since it is dominant in the travel time calculation. The PE's "saturated zone" consists of the RGA alone as a zone of horizontal transport. 


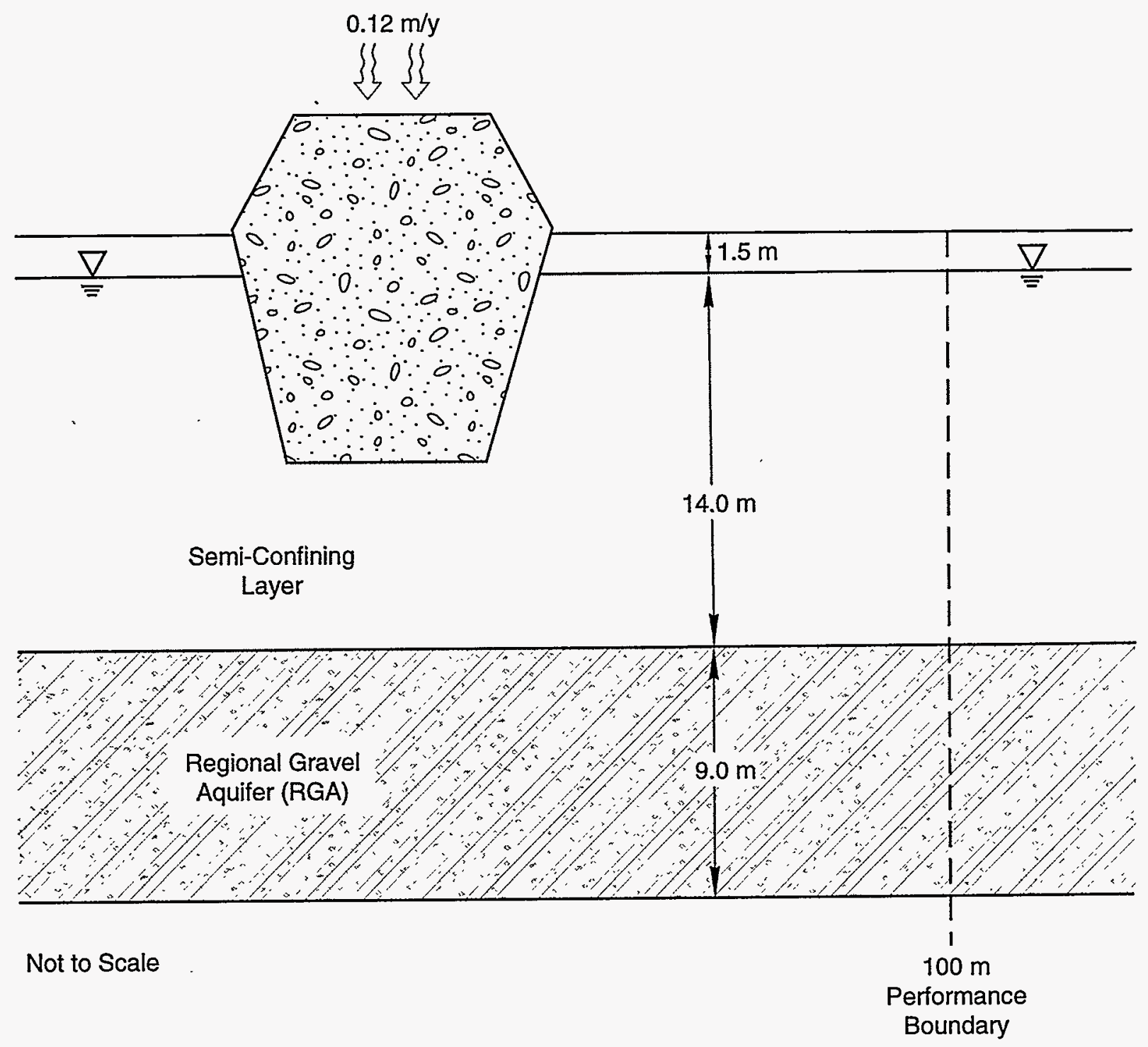

TRI-6622-43-0

Figure 6-5. Conceptual model for water transport at the Paducah Gaseous Diffusion Plant. 


\subsubsection{Atmospheric Pathway}

The conceptual model used in the PE for evaluating the atmospheric pathway was derived from performance assessments for LLW disposal facilities at Hanford (Kincaid et al., 1993), INEL (Maheras et al., 1994), NTS (Baer et al., 1994), ORR (ORNL, 1994), and SRS (MMES et al., 1994). The model was generalized for the PE but used site-specific values for many of the parameters. Meteorological data are based on STAR data files summarized by the windrose in Figure 6-6. These data were obtained from hourly average meteorological readings taken at a height of $60 \mathrm{~m}(197 \mathrm{ft})$ at the on-site meteorological tower at the Paducah plant during the period 1989 to 1990.

The PE used a generic conceptual model to describe the atmospheric pathway (summarized in Section 1.2 of this volume and described in detail in Chapter 5 of Volume 2). Only H-3 (tritium) and C-14 were expected to be volatile for the disposal facility conditions and thus were the only radionuclides considered for atmospheric transport in the PE. In the model, radionuclides were transported from the disposal facility to the soil surface by vapor (tritium) and gaseous (carbon dioxide carrying the $\mathrm{C}-14$ isotope) diffusion. When the radionuclides reached the soil surface, they were entrained in the air in vapor form as volatiles. Once airborne, these radionuclides were transported via atmospheric dispersion to a receptor located at the performance boundary.

Two components of the atmospheric pathway were evaluated separately: (1) the zone from the top of the disposal facility to the soil surface as indicated by the upward radionuclide diffusion profile; and (2) the zone in which a radionuclide was emitted to the atmosphere, mixed with the ambient air, and dispersed downwind from the waste disposal facility boundary to the $100-\mathrm{m}$ (328-ft) performance boundary.

The arrival time of radionuclides at the performance boundary was assumed to be $100 \mathrm{y}$ based on the following generic assumptions of the PE:

- The waste form was grouted MLLW treatment residuals. Based on this assumption, tritium as vapor was bound in the pore water of the hydrophilic grout, and carbon dioxide as a gas carrying the $\mathrm{C}-14$ isotope was limited by the high $\mathrm{pH}$ of the grout, so that the waste form provided retention of these volatile radionuclides in the disposal facility.

- The disposal facility was capped by a RCRA-compliant cover system. Based on this assumption, the cover system was maintained to provide low permeability for $100 \mathrm{y}$.

\subsubsection{Inadvertent Intruder Pathways}

Standard intrusion scenarios were used in the PE, with information derived from performance assessments of LLW disposal facilities at SRS (MMES et al., 1994) and ORR (ORNL, 1994) indicating that only two chronic-exposure scenarios needed to be considered for most sites and facility designs. Any variations in these scenarios were based on discussions with site technical staff about such factors as the types of activities that reasonably could result in exposure to buried waste at the site and the effectiveness of active or passive institutional controls and engineered barriers in precluding access to the waste. 


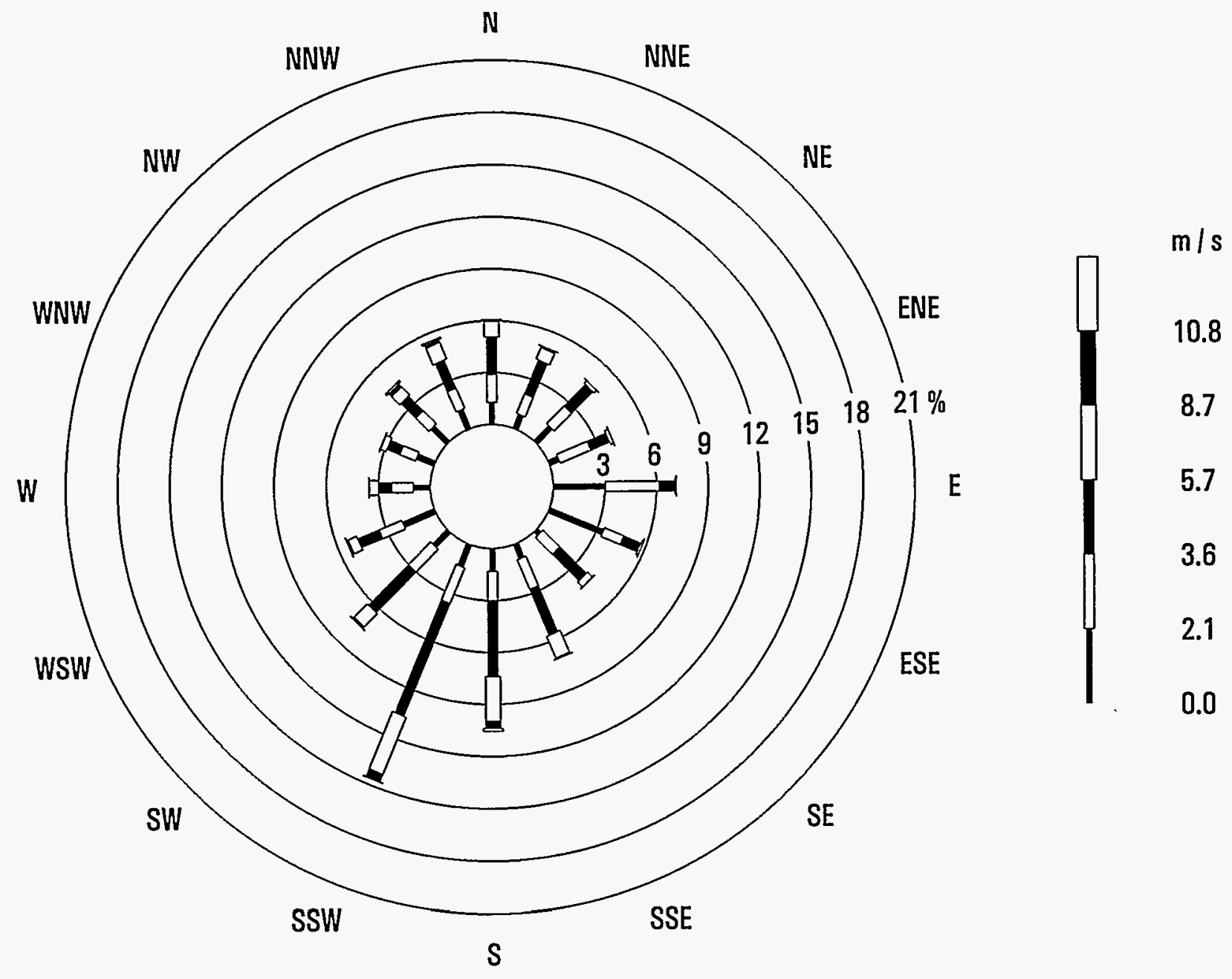

Figure 6-6. Windrose for the Paducah plant for the period 1989 to 1990 . The frequency of winds from each direction is plotted as a series of connected bars that extend from the center of the circular diagram toward the direction from which the winds originate. Wind speed categories are denoted by bar widths and shadings. The frequency of winds in each wind speed category is indicated by the length of the corresponding bar. 
The PE used two standard intrusion scenarios that could be modified for site-specific conditions to describe potential modes of inadvertent intrusion (summarized in Section 1.3 of this volume and described in detail in Chapter 5 of Volume 2). The first scenario, the agriculture (homesteader) scenario, included establishment by an intruder of a permanent homestead directly above a disposal facility with the foundation of the home extending into the waste; some of the waste exhumed from the disposal facility was mixed with native soil in the intruder's vegetable garden. The second scenario, the post-drilling scenario, considered the construction of a well for a domestic water supply by an intruder. The well was drilled through the disposal facility, and the cuttings were mixed with soil in the intruder's vegetable garden. The intruder gardened in some of the exhumed waste but did not reside permanently above the disposal facility. In both scenarios, exposure occurred where an intruder dug or drilled into the disposal facility.

For the generic intruder scenarios, the time of intrusion for the homesteader scenario was assumed to be $300 \mathrm{y}$ for the trench design and $500 \mathrm{y}$ for the tumulus design. The time of intrusion for the post-drilling scenario was assumed to be $100 \mathrm{y}$.

The two intrusion scenarios were discussed with PGDP personnel, who concurred with the applicability and credibility of these scenarios at PDGP.

\subsection{DATA USED IN THE PE}

The data presented in this section apply to the PE conceptual models described in Section 6.3. The calculations for determining permissible waste concentrations for the radionuclides considered in the PE are discussed in more detail in Chapter 5 of Volume 2 and summarized in Chapter 1 of this volume. The results of the calculations for the Paducah plant are presented in Section 6.5 and discussed in Section 6.6 of this volume.

\subsubsection{Water Transport}

Site-specific values required to perform the water pathway analysis were selected by site technical staff either from site characterizations and reports, from site-specific modeling results, or from general literature. For the unsaturated zone, the site-specific data that were required for the $\mathrm{PE}$ were distance between the disposal facility and groundwater; ambient moisture content; dry bulk density of the geologic medium; distribution coefficients $\left(K_{d} s\right)$ of the radionuclides in the . geologic medium; and natural recharge. For the saturated zone, the site-specific data that were required were porosity; dry bulk density of the geologic medium; distribution coefficients $\left(K_{d} s\right)$ of the radionuclides in the geologic medium; groundwater Darcy flow rates; and mixing depth in the aquifer.

These values for the Paducah plant are listed in Table 6-1 along with generic values that were used in the PE. Also indicated in the table is a designation of the type of data that the value represents and the source of the value. The values were determined from one or more of four data sources: (A) measurement performed by the site, state, or federal agency; (B) result of a numerical analysis performed by the site, state, or federal agency; (C) general literature value selected by the site; and (D) generic value of the PE. 
Table 6-1. Parameters and Values Used in the PE for the Water Pathway at the Paducah Plant (generic PE values are in bold; these values and the standard PE method for applying them are summarized in Chapter 1 of this volume and discussed in more detail in Chapter 5 of Volume 2) (Part 1 of 2)

\begin{tabular}{|c|c|c|c|}
\hline Parameter & Value & $\begin{array}{l}\text { Data } \\
\text { Type }\end{array}$ & Comments \\
\hline \multicolumn{4}{|l|}{ SOURCE TERM } \\
\hline $\begin{array}{l}\text { Volumetric water content } \\
\text { of the grouted waste, } \theta_{0}\end{array}$ & 0.3 & D & Standard PE value \\
\hline $\begin{array}{l}\text { Bulk density of grouted } \\
\text { waste, } p_{0}\end{array}$ & $\begin{array}{c}1.76 \\
\mathrm{~g} / \mathrm{cm}^{3}\end{array}$ & D & Standard PE value \\
\hline $\begin{array}{l}\text { Distribution coefficients } \\
\text { for grouted waste, } K_{d}^{G}\end{array}$ & various & $\mathbf{D}$ & Standard PE value; see Table 6-2 \\
\hline $\begin{array}{l}\text { Disposal facility plan } \\
\text { area, } A\end{array}$ & $2500 \mathrm{~m}^{2}$ & D & $\begin{array}{l}\text { Standard PE value; } A=a_{1} * a_{2} \text {, where } \\
a_{1}=a_{2}=50 \mathrm{~m}\end{array}$ \\
\hline $\begin{array}{l}\text { Waste mixing fraction } \\
\text { for trench, } f_{m}\end{array}$ & 0.67 & $\mathbf{D}$ & Standard PE value \\
\hline $\begin{array}{l}\text { Waste mixing fraction } \\
\text { for tumulus, } f_{m}\end{array}$ & 0.33 & $\mathbf{D}$ & Standard PE value \\
\hline $\begin{array}{l}\text { Annual rate of water } \\
\text { flowing through intact } \\
\text { trench facility, } q_{f}\end{array}$ & $0.03 \mathrm{~m} / \mathrm{y}$ & $\mathbf{D}$ & Standard PE value \\
\hline $\begin{array}{l}\text { Annual rate of water } \\
\text { flowing through intact } \\
\text { tumulus facility, } q_{f}\end{array}$ & $\begin{array}{c}0.00003 \\
\mathrm{~m} / \mathrm{y}\end{array}$ & D & Standard PE value \\
\hline $\begin{array}{l}\text { Time to failure of } \\
\text { leachate collection } \\
\text { system }\end{array}$ & $30 y$ & D & Standard PE value \\
\hline $\begin{array}{l}\text { Time to failure of trench } \\
\text { facility }\end{array}$ & $100 y$ & $\mathbf{D}$ & Standard $P E$ value \\
\hline $\begin{array}{l}\text { Time to failure of } \\
\text { tumulus facility }\end{array}$ & $300 y$ & D & Standard PE value \\
\hline $\begin{array}{l}\text { Natural recharge through } \\
\text { local soils, } i\end{array}$ & $0.12 \mathrm{~m} / \mathrm{y}$ & A & GeoTrans, Inc. (1990) \\
\hline
\end{tabular}

* $A=$ site measurement; $B=$ result of site numerical analysis; $C=$ literature value selected by the site; $D=g e n e r i c ~ P E$ value 
Table 6-1. Parameters and Values Used in the PE for the Water Pathway at the Paducah Plant (generic PE values are in bold; these values and the standard PE method for applying them are summarized in Chapter 1 of this volume and discussed in more detail in Chapter 5 of Volume 2) (Part 2 of 2)

\begin{tabular}{|c|c|c|c|}
\hline Parameter & Value & $\begin{array}{l}\text { Data } \\
\text { Type* }\end{array}$ & Comments \\
\hline \multicolumn{4}{|l|}{ UNSATURATED ZONE } \\
\hline Moisture content, $\theta_{w}$ & 0.2 & A & Shaia (1995) \\
\hline Bulk density, $\rho_{b}$ & $1.7 \mathrm{~g} / \mathrm{cm}^{3}$ & A & Shaia (1995) \\
\hline $\begin{array}{l}\text { Distribution coefficients for } \\
\text { geologic media, } K_{d}\end{array}$ & various & & See Table 6-2 \\
\hline $\begin{array}{l}\text { Thickness of unsaturated } \\
\text { zone }\end{array}$ & $1.5 \mathrm{~m}$ & A & Davis, 1995a \\
\hline \multicolumn{4}{|c|}{ SEMI-CONFINED ZONE (thicknesses added to UNSATURATED ZONE) } \\
\hline $\begin{array}{l}\text { Thickness of saturated semi- } \\
\text { confining layer for trench }\end{array}$ & $6.7 \mathrm{~m}$ & A & $\begin{array}{l}\text { Trench of } 8.8 \mathrm{~m} \text { depth is excavated through } \\
1.5 \mathrm{~m} \text { of unsaturated materials and } 7.3 \mathrm{~m} \text { of } \\
\text { the semi confining layer. }\end{array}$ \\
\hline $\begin{array}{l}\text { Thickness of saturated semi- } \\
\text { confining layer for tumulus }\end{array}$ & $14.0 \mathrm{~m}$ & A & $\begin{array}{l}\text { Semi-confining layer is } 14.0 \mathrm{~m} \text { thick, and } \\
\text { tumulus rests on ground surface. }\end{array}$ \\
\hline \multicolumn{4}{|l|}{ SATURATED ZONE } \\
\hline Porosity, $n$ & 0.25 & A & Davis, 1995b \\
\hline Bulk density, $\rho_{b}$ & $2.0 \mathrm{~g} / \mathrm{cm}^{3}$ & A & Shaia, 1995 \\
\hline $\begin{array}{l}\text { Distribution coefficients for } \\
\text { geologic media, } K_{d}\end{array}$ & various & & See Table 6-2 \\
\hline Mixing depth, $d_{m}$ & $9 \mathrm{~m}$ & $\mathrm{C}$ & Davis, 1995b \\
\hline Darcy velocity, $q_{g w}$ & $25 \mathrm{~m} / \mathrm{y}$ & $\mathrm{C}$ & Davis, $1995 b$ \\
\hline $\begin{array}{l}\text { Distance to } \\
\text { performance boundary } \\
\text { from facility boundary }\end{array}$ & $100 \mathrm{~m}$ & D & Standard PE value \\
\hline
\end{tabular}

* $A=$ site measurement; $B=$ result of site numerical analysis; $C=$ literature value selected by the site; $D=g e n e r i c ~ P E$ value 
Table 6-2. Solid/Liquid Distribution Coefficients $\left(K_{d} \mathrm{~s}\right)$ Used in the PE at the PGDP

\begin{tabular}{|c|c|c|}
\hline Element & $\begin{array}{c}\text { Waste } K_{d}^{G} \\
(\mathrm{~mL} / \mathrm{g})^{a}\end{array}$ & $\begin{array}{c}K_{d} \text { for Geologic Media } \\
(\mathrm{mL} / \mathrm{g})^{b}\end{array}$ \\
\hline $\mathrm{H}$ & 0 & 0.1 \\
\hline$c$ & 10 & 5 \\
\hline $\mathrm{Al}$ & 100 & 35 \\
\hline$\widehat{\mathrm{Si}}$ & 100 & 35 \\
\hline $\mathrm{Cl}$ & 0 & 15 \\
\hline$K$ & 1 & 15 \\
\hline$C_{0}$ & 100 & 60 \\
\hline$\overline{\mathrm{Ni}}$ & 10 & 400 \\
\hline $\mathrm{Se}$ & 1 & 150 \\
\hline $\mathrm{Sr}$ & 100 & 15 \\
\hline $\mathrm{Zr}$ & 10 & 600 \\
\hline $\mathrm{Nb}$ & 10 & 160 \\
\hline$T C$ & 1 & 0.1 \\
\hline$P d$ & 100 & 55 \\
\hline $\mathrm{Ag}$ & 100 & 90 \\
\hline$C d$ & 100 & 80 \\
\hline$S n$ & 10 & 130 \\
\hline 1 & 1 & 1 \\
\hline Cs & 10 & 280 \\
\hline $\mathrm{Ba}$ & 10 & 15 \\
\hline $\mathrm{Sm}$ & 10 & 245 \\
\hline $\mathrm{Eu}$ & 10 & 245 \\
\hline $\mathrm{Pb}$ & 100 & 270 \\
\hline $\mathrm{Ra}$ & 10 & 500 \\
\hline$T h$ & 100 & 3200 \\
\hline $\mathrm{Pa}$ & 100 & 550 \\
\hline$u$ & 100 & 35 \\
\hline $\mathrm{Np}$ & 100 & 5 \\
\hline $\mathrm{Pu}$ & 100 & 550 \\
\hline Am & 100 & 1900 \\
\hline $\mathrm{Cm}$ & 100 & 4000 \\
\hline $\mathrm{Cf}$ & 100 & 4000 \\
\hline
\end{tabular}

a Standard PE values; see Chapter 5 of Volume 2

b Values based on Thibault et al., 1990 
Of the parameters in the PE that depended on site-specific values, only three potentially encompassed enough variability in values to significantly affect the results: natural recharge, $i$; distribution coefficients $\left(K_{d} \mathrm{~s}\right)$ for the geologic media; and groundwater Darcy velocity $\left(q_{g w}\right)$. The sources of these values are discussed in this section. The sensitivity of the results to changes in the values of these parameters is discussed in Section 6.6.2 of this volume and Chapter 6 of Volume 2

The natural recharge for PGDP was provided by site staff, but the range and distribution are unknown. The groundwater Darcy velocity was assigned a base case value of $25 \mathrm{~m} / \mathrm{y}$ $(82 \mathrm{tt} / \mathrm{y})$, and Clausen (1994) estimates that this value has a range of a factor of 7 higher or lower than the base case.

Values for distribution coefficients $\left(K_{d} \mathrm{~s}\right)$ are listed in Table 6-2 for the 58 radionuclides (32 elements) considered in the PE. In addition to the $K_{d}$ values for the geologic media, grout $K_{d}$ values are listed for determining the desorption from the source term resulting from the grouted waste form. The $K_{d}$ values for the subsurface flow pathway (both for the unsaturated and saturated zones) are taken from the standard PE values for sandy soils (Thibault et al., 1990).

\subsubsection{Atmospheric Transport}

Site-specific data required to perform the atmospheric pathway analysis came from site personnel as data either from site characterizations and reports or from general literature. The site-specific data required for the soil diffusion calculation were the same as some of those required for the water transport analysis (Section 6.4.1). These values are shown in Table 6-3. Necessary atmospheric dispersion data included wind speed and direction and stability class, which are summarized in Section 6.3.2.

\subsubsection{Inadvertent Intruder Exposure}

As explained in Section 6.3.3, the PE used two standard intrusion scenarios to describe potential modes of inadvertent intrusion at all the sites. Because these intrusion scenarios were considered applicable to all sites, no values specific to the Paducah plant are used in the calculation of exposures to inadvertent intruders.

\subsection{RESULTS OF THE PE}

The performance evaluation provided estimates of permissible waste concentrations in disposed MLLW. The three calculations that formed the foundation of the PE-for the water, atmospheric, and inadvertent intruder pathways-are summarized in Sections 1.1, 1.2, and 1.3, respectively, of this volume and discussed in detail in Chapter 5 of Volume 2. 
Table 6-3. Parameters and Values Used in the PE for the Atmospheric Pathway at the Paducah Plant (generic PE values are in bold; these values and the standard PE method for applying them are summarized in Chapter 1 of this volume and discussed in more detail in Chapter 5 of Volume 2)

\begin{tabular}{|c|c|c|c|}
\hline Parameter & Value & $\begin{array}{l}\text { Data } \\
\text { Type* }\end{array}$ & Comments \\
\hline $\begin{array}{l}\text { Disposal facility cover } \\
\text { thickness, } x\end{array}$ & $1.0 \mathrm{~m}$ & $\mathbf{D}$ & Standard PE value \\
\hline $\begin{array}{l}\text { Depth of the soil } \\
\text { surface, } d\end{array}$ & $0.01 \mathrm{~m}$ & $\mathbf{D}$ & $\begin{array}{l}\text { Standard PE value based on Maheras et } \\
\text { al. (1994) }\end{array}$ \\
\hline Porosity, $n$ & 0.35 & $\mathrm{C}$ & $\begin{array}{l}\text { Facsimile communication from Ken Davis } \\
\text { (PGDP) to Jim Wang (ORNL), April 28, } 1995 . \\
\text { (Davis, K.R., 1995c) }\end{array}$ \\
\hline Percent saturation, $s$ & 0.57 & C & $\begin{array}{l}\text { Facsimile communication from Ken Davis } \\
\text { (PGDP) to Jim Wang (ORNL), April 28, } 1995 . \\
\text { (Davis, K.R., 1995c) }\end{array}$ \\
\hline $\begin{array}{l}\text { Ratio of water density } \\
\text { in air to liquid, } r\end{array}$ & 9.2E-06 & $\mathbf{D}$ & $\begin{array}{l}\text { Standard PE value based on MMES et al. } \\
\text { (1994) }\end{array}$ \\
\hline $\begin{array}{l}\text { Ratio of } \mathrm{CO}_{2} \\
\text { concentration in air to } \\
\text { dissolved in water, } r\end{array}$ & 4.3E-04 & $\mathbf{D}$ & $\begin{array}{l}\text { Standard PE value based on Foust et al. } \\
\text { (as cited in Cooper and Alley, 1986) }\end{array}$ \\
\hline $\begin{array}{l}\text { Tritium diffusion } \\
\text { coefficient in air, } D\end{array}$ & $\begin{array}{c}2.39 E-05 \\
\mathrm{~m}^{2} / \mathrm{s}\end{array}$ & $\mathbf{D}$ & Standard PE value based on CRC (1981) \\
\hline $\begin{array}{l}\text { Carbon diffusion } \\
\text { coefficient in air, } D\end{array}$ & $1.4 E-05 \mathrm{~m}^{2} / \mathrm{s}$ & $\mathbf{D}$ & Standard PE value based on CRC (1981) \\
\hline $\begin{array}{l}\text { Atmospheric dispersion } \\
\text { term, } A_{D}\end{array}$ & $\begin{array}{c}0.39 \\
\left(\mu \mathrm{CV} / \mathrm{m}^{2}\right) /\left(\mu \mathrm{CV} / \mathrm{m}^{2}-s\right)\end{array}$ & B & $\begin{array}{l}\text { Value is estimated using the Industrial Source } \\
\text { Complex-Version } 2 \text { Long Term Air Dispersion } \\
\text { Model (ISCLT2) (EPA, 1992) based on site- } \\
\text { specific STAR data }\end{array}$ \\
\hline
\end{tabular}

$A=$ site measurement; $B=$ result of site numerical analysis; $C=$ literature value selected by the site; $D=$ generic $P E$ value

For each pathway the maximum permissible waste concentration at the performance boundary was determined for each radionuclide by using the performance measures: $4 \mathrm{mrem}$ $(0.04 \mathrm{mSv})$ per year from the water pathway for releases to drinking water; 10 mrem $(0.1 \mathrm{mSv})$ per year from all pathways for atmospheric releases; and $100 \mathrm{mrem}(1 \mathrm{mSv})$ per year from all exposure pathways for chronic exposure of inadvertent intruders; and the appropriate pathway or scenario dose conversion factors (annual effective dose equivalent per unit concentration) based on EPA dose conversion factors. The basis for the performance measures used in the PE is discussed in more detail in Chapter 5 of Volume 2. For the water and atmospheric pathways, the concentration reduction provided by the environment (i.e., the CRF) was estimated using results of site analyses and data. For the intruder analyses, concentration reduction was estimated for 
appropriate exposure pathways for two intrusion scenarios that, in general, were the same for all the sites. The results of the calculations for the pathways that were analyzed at Paducah are provided in this section and discussed in Section 6.6.

\subsubsection{Water Transport}

Two CRFs were calculated for the water pathway: the source $C R F, C R F_{\text {Source, }}$ and the environmental transport $\mathrm{CRF}$ for water, $C R F_{\text {Water. }}$. The source $\mathrm{CRF}$ represents the concentration attenuation between the disposed waste and leachate exiting the bottom of the disposal facility and was defined as the dimensionless ratio of the waste concentration to the resulting leachate concentration. Desorption with infiltrating water was the mechanism used to describe the leaching of radionuclides from the grout. Because a generic method was used to determine the $C R F_{\text {Source }}$ for the 58 radionuclides considered in the $\mathrm{PE}$ (summarized in Section 1.1 of this volume and discussed in more detail in Chapter 5 of Volume 2), the radionuclide-specific values for the source CRF for each type of generic facility were the same for all 15 sites.

The environmental transport CRF for water was defined as the ratio of the concentration of the leachate exiting the disposal facility to the resulting concentration in water at the performance boundary. The concentration attenuation represented by $C R F_{\text {Water }}$ consisted of dilution due to mixing with uncontaminated groundwater. Effects of radioactive decay and decay product ingrowth were also included in the PE.

In the $\mathrm{PE}$, water travel time from the facility location to the performance boundary was calculated as a basis for comparison with the retarded travel time of the radionuclides: For: Paducah, water travel time from the land surface to the performance boundary (i.e., without consideration of a disposal facility) was estimated at about $27 \mathrm{y}$.

The calculation of travel time through the vadose zone for a radionuclide, on the other hand, must account both for the lower rate of flow because of the facility's RCRA cover and for the retardation defined by the distribution coefficient for the geologic media. In the PE, the calculation for travel time in the vadose zone first determined the distance a radionuclide traveled at the lower infiltration rate. Then, if the radionuclide had not fully traversed the vadose zone, the additional time required to complete travel in the vadose zone under the higher, infiltration rate based on the natural recharge through local soils was calculated and added to the time determined at the lower infiltration rate.

In the $\mathrm{PE}$, the detention time in the facility for a radionuclide was the time during which water flowing through the facility was assumed to be caught by the leachate collection system. Specifically, the calculation of travel time for a radionuclide accounted for the following: ;

- For the trench design, the leachate collection system was assumed to catch water flowing through the facility for the first $30 \mathrm{y}$. After $30 \mathrm{y}$, the liner and leachate collection-system failed, and water flowing through the facility for the next $70 \mathrm{y}$ was assumed to be $0.03 \mathrm{~m} / \mathrm{y}$ 
$(0.1 \mathrm{ft} / \mathrm{y})$ based on a unit hydraulic gradient and the saturated hydraulic conductivity of the RCRA cover system. After a total of $100 \mathrm{y}$ of reduced flow because of engineered barriers ( $30 \mathrm{y}$ of detention plus $70 \mathrm{y}$ limited by the RCRA cover system), the rate was assumed to be the average natural recharge through local soils, $0.12 \mathrm{~m} / \mathrm{y}(0.39 \mathrm{ft} / \mathrm{y})$.

- For the tumulus design, the leachate collection system was assumed to catch water flowing through the facility for the first $30 \mathrm{y}$. After $30 \mathrm{y}$, the liner and leachate collection system was assumed to fail, and water flowing through the facility for the next $270 \mathrm{y}$ was assumed to be $0.00003 \mathrm{~m} / \mathrm{y}(0.0001 \mathrm{ft} / \mathrm{y})$ based on a unit hydraulic gradient and the saturated hydraulic conductivity of the concrete vaults. After a total of $300 \mathrm{y}$ of reduced flow because of engineered barriers ( $30 \mathrm{y}$ detention plus $270 \mathrm{y}$ limited by the concrete vaults), the rate was assumed to be the average natural recharge through local soils, $0.12 \mathrm{~m} / \mathrm{y}(0.39 \mathrm{ft} / \mathrm{y})$.

Travel time through the aquifer was independent of facility design and was about $24 \mathrm{y}$, including vertical movement from the water table to the RGA and horizontal flow to the 100-m (328-ft) performance boundary (see Section 1.1.2 of this volume for a summary of these assumptions and Chapter 5 of Volume 2 for additional details). The arrival time of a radionuclide at the performance boundary is the sum of the detention time in the facility, travel time through the vadose zone, and travel time through the aquifer.

Retardation of radionuclides by interaction with soils and rock in the vadose and saturated zones increased travel times for individual radionuclides. This effect was particularly important for short-lived radionuclides because of radioactive decay. For short-lived radionuclides, the effects of radioactive decay combined with long travel times increased the permissible concentrations in the disposal facility.

Application of the PE methodology for water transport of the 58 radionuclides considered in the PE produced the results shown in Table 6-4 for the generic trench and tumulus designs at Paducah. The table shows permissible waste concentrations based on transport through the water pathway $\left(C_{\text {Wr-Water }}\right)$ as well as the values used in calculating the permissible waste concentrations.

Some radionuclides listed in Table 6-4 have no limit (NL) on their permissible waste concentrations, the result of the combined effects of relatively short half-lives and sufficiently long travel time to the performance boundary. "No limit" is defined as a permissible waste concentration that is greater than the specific activity of the pure elemental radionuclide. For disposal of the maximum possible waste concentration of these relatively short-lived radionuclides, the water pathway produced a dose at the performance boundary of less than $4 \mathrm{mrem}(0.04 \mathrm{mSv})$ per year and, therefore, the permissible waste concentration was unlimited based on exposures from this pathway. 
Table 6-4. Results of Calculations for the Water Pathway at Paducah (water travel time from land surface to performance boundary [excluding facility detention] $=27 \mathrm{y})($ Part 1 of 2$)$

\begin{tabular}{|c|c|c|c|c|c|c|c|c|c|c|c|c|}
\hline \multirow[t]{2}{*}{ Nuclide } & \multirow[b]{2}{*}{$\begin{array}{c}\text { PDCF } \\
\text { rem/y per } \mu \text { Cin } \\
\end{array}$} & \multicolumn{5}{|c|}{ Trench } & \multicolumn{5}{|c|}{ Tumulus } & \multirow[t]{2}{*}{ Nuclide } \\
\hline & & $\begin{array}{l}\text { CRF } \\
\text { (dimonsionlezs) }\end{array}$ & \begin{tabular}{|c|} 
CRF water \\
(dimonsionless)
\end{tabular} & \begin{tabular}{|c|} 
Arrival \\
Time (y)
\end{tabular} & $\begin{array}{c}r_{\text {Decay }} \\
\text { (dimensionioses) }\end{array}$ & $\begin{array}{c}C_{\text {w-water }}{ }^{b} \\
\left(\mu \mathrm{Ci} / \mathrm{m}^{3}\right)\end{array}$ & $\begin{array}{l}\text { CRF source } \\
\text { (dimentioniess) }\end{array}$ & \begin{tabular}{|c|} 
CRF Water $_{\text {(dimentionless) }}$ \\
\end{tabular} & \begin{tabular}{|c|} 
Arrival \\
Time (y)
\end{tabular} & $\begin{array}{c}r_{\text {Daceny }} \\
\text { (dimensionless) }\end{array}$ & $\begin{array}{c}C_{\text {whwater }}{ }^{b} \\
\left(\mu \mathrm{CU} \mathrm{m}^{3}\right)\end{array}$ & \\
\hline $\mathrm{H}-3$ & 4.67E-02 & 0.45 & 39 & $1.0 E+02$ & 3.7E+02 & $5 E+05$ & 0.9 & 39 & $3.5 E+02$ & $3.4 E+08$ & $1 E+12$ & $\mathrm{H}-3$ \\
\hline C-14 & $1.52 E+00$ & 27 & 39 & $6.1 E+02$ & $1.1 E+\infty 0$ & $3 E+03$ & 54 & 39 & $1.5 E+03$ & $1.2 E+00$ & $7 E+03$ & C-14 \\
\hline Al-26 & $1.06 E+01$ & 270 & 39 & $3.7 E+03$ & $1.0 E+\infty$ & $4 E+03$ & 540 & 39 & $8.3 E+03$ & $1.0 \mathrm{E}+00$ & $8 E+03$ & Al-26 \\
\hline Si-32 & $7.99 E+\infty 0$ & 270 & 39 & $3.7 E+03$ & $1.3 \mathrm{E}+11$ & $\mathrm{NL}$ & 540 & 39 & $8.3 E+03$ & $9.2 E+24$ & NL & Si-32 \\
\hline $\mathrm{Cl}-36$ & $2.21 E+00$ & 0.45 & 39 & $1.6 E+03$ & $1.0 \mathrm{E}+\infty 0$ & $3 E+01$ & 0.9 & 39 & $3.7 E+03$ & $1.0 E+\infty$ & $6 E+01$ & $\mathrm{Cl}-36$ \\
\hline$K-40$ & 1.36E+01 & 3.1 & 39 & $1.6 E+03$ & $1.0 \mathrm{E}+00$ & $3 E+01$ & 6.2 & 39 & $3.7 E+03$ & $1.0 \mathrm{E}+00$ & $7 E+01$ & $\mathrm{~K}-40$ \\
\hline Co-60 & $1.97 \mathrm{E}+01$ & 270 & 39 & $6.3 E+03$ & $e$ & NL & 540 & 39 & $1.4 E+04$ & e & NL & Co-60 \\
\hline Ni-59 & $1.53 \mathrm{E}-01$ & 27 & 39 & $4.1 E+04$ & $1.5 E+\infty$ & $4 E+04$ & 54 & 39 & $9.1 E+04$ & $2.3 E+00$ & $1 E+05$ & Ni-59 \\
\hline $\mathrm{Ni}-63$ & 4.21E-01 & 27 & 39 & $4.1 E+04$ & e & $\mathrm{NL}$ & 54 & 39 & $9.1 E+04$ & e & NL & N1-63 \\
\hline Se-79 & $6.35 E+00$ & 3.1 & 39 & $1.6 E+04$ & $1.2 E+\infty$ & $9 E+01$ & 6.2 & 39 & $3.4 E+04$ & $1.4 E+\infty 0$ & $2 E+02$ & Se-79 \\
\hline $5 r-90$ & $1.12 E+02$ & 270 & 39 & $1.6 E+03$ & $8.9 E+16$ & $\mathrm{NL}$ & 540 & 39 & $3.7 E+03$ & $4.9 E+38$ & $\mathrm{NL}$ & Sr-90 \\
\hline $2 \mathrm{r}-93$ & $1.59 \mathrm{E}+\infty 0$ & 27 & 39 & $6.2 E+0.4$ & $1.0 E+00$ & $3 E+03$ & 54 & 39 & $1.4 E+0.5$ & $1.1 E+\infty 0$ & $6 \mathrm{E}+03$ & $Z r-93$ \\
\hline $\mathrm{Nb}-93 \mathrm{~m}$ & 3.81E-01 & 27 & 39 & 1.7E+04 & e & NL & 54 & 39 & $3.7 E+04$ & e & $N L$ & Nb-93m \\
\hline $\mathrm{Nb}-94$ & $5.21 \mathrm{E}+\infty$ & 27 & 39 & $1.7 E+04$ & $1.8 E+00$ & $1 E+03$ & 54 & 39 & $3.7 E+04$ & $3.6 \mathrm{E}+\infty 0$ & $6 \mathrm{E}+03$ & $\mathrm{Nb}-94$ \\
\hline Tc-99 & $1.07 E+\infty 0$ & 3.1 & 39 & $1.0 \mathrm{E}+02$ & $1.0 E+\infty 0$ & $4 E+02$ & 6.2 & 39 & $3.5 E+02$ & $1.0 E+00$ & $9 \mathrm{E}+02$ & Tc-99 \\
\hline$P d-107$ & $1.09 E-01$ & 270 & 39 & $5.8 E+03$ & $1.0 E+00$ & $4 E+05$ & 540 & 39 & $1.3 \mathrm{E}+04$ & $1.0 E+\infty 0$ & $8 \mathrm{E}+05$ & Pd-107 \\
\hline $4 g-108 m$ & $5.56 \mathrm{E}+00$ & 270 & 39 & $9.4 \mathrm{E}+03$ & $4.7 E+21$ & $\mathrm{NL}$ & 540 & 39 & $2.1 E+04$ & $1.5 E+48$ & NL & $A g-108 m$ \\
\hline Cd-113m & $1.17 E+02$ & 270 & 39 & $8.3 E+03$ & e & NL & 540 & 39 & $1.9 E+04$ & e & NL & $\mathrm{Cd}-113 \mathrm{~m}$ \\
\hline $\mathrm{Sn-121m}$ & $1.28 \mathrm{E}+00$ & 27 & 39 & $1.3 E+04$ & e & NL & 54 & 39 & $3.0 \mathrm{E}+04$ & e & NL & Sn-121m \\
\hline $5 n-126$ & $1.53 E+01$ & 27 & 39 & $1.3 E+04$ & $1.1 E+\infty 0$ & $3 E+02$ & 54 & 39 & $3.0 \mathrm{E}+04$ & $1.2 E+\infty$ & $7 E+02$ & $5 n-126$ \\
\hline $1-129$ & $2.01 E+02$ & 3.1 & 39 & $2.0 E+02$ & $1.0 E+\infty 0$ & $2 E+00$ & 6.2 & 39 & $5.5 E+02$ & $1.0 \mathrm{E}+\infty 0$ & $5 E+\infty$ & $1-129$ \\
\hline Cs-135 & $5.16 \mathrm{E}+\infty 0$ & 27 & 39 & $2.9 E+04$ & $1.0 E+00$ & $8 E+02$ & 54 & 39 & $6.4 E+04$ & $1.0 E+\infty 0$ & $2 E+03$ & Cs-135 \\
\hline Cs-137 & $3.65 E+01$ & 27 & 39 & $2.9 E+04$ & e & $\mathrm{NL}$ & 54 & 39 & $6.4 E+04$ & e & NL & Cs-137 \\
\hline Ba-133 & $2.48 E+00$ & 27 & 39 & $1.6 \mathrm{E}+03$ & $9.4 E+46$ & NL & 54 & 39 & $3.7 E+03$ & e & NL & $B a-133$ \\
\hline$S m-151$ & $2.84 E-01$ & 27 & 39 & $2.5 E+04$ & e & NL & 54 & 39 & $5.6 E+04$ & $e$ & $\mathrm{NL}$ & Sm-151 \\
\hline Eu-152 & $4.73 E+00$ & 27 & 39 & $2.5 E+04$ & e & $\mathrm{NL}$ & 54 & 39 & $5.6 \mathrm{E}+04$ & e & $\mathrm{NL}$ & Eu-152 \\
\hline Eu-154 & $6.97 E+00$ & 27 & 39 & $2.5 E+04$ & e & NL & 54 & 39 & $5.6 \mathrm{E}+04$ & e & $\mathrm{NL}$ & Eu-154 \\
\hline $\mathrm{Pb}-210$ & $5.30 E+03$ & 270 & 39 & $2.8 E+04$ & e & $\mathrm{NL}$ & 540 & 39 & $6.2 E+04$ & e & $\mathrm{NL}$ & $\mathrm{Pb}-210$ \\
\hline Ra-226 & $6.27 E+03$ & 27 & 39 & $5.2 E+04$ & $5.0 E+09$ & $3 E+09$ & 54 & 39 & $1.1 E+05$ & $3.0 E+21$ & $\mathrm{NL}$ & $\operatorname{Ra} a-226$ \\
\hline Ra-228 & $1.64 E+03$ & 27 & 39 & $5.2 E+04$ & e & NL. & 54 & 39 & $1.1 E+05$ & $e$ & NL & $R a-228$ \\
\hline Th-2229 & $2.94 E+03$ & 270 & 39 & $3.3 E+05$ & $3.8 E+13$ & NL & 540 & 39 & $7.3 E+05$ & $1.1 E+30$ & $\mathrm{NL}$ & Th-229 \\
\hline Th-230 & $6.12 E+03$ & 270 & 39 & $3.3 E+05$ & $\mathrm{NA}$ & $7 E+\infty$ & 540 & 39 & $7.3 E+05$ & NA & $1 E+01$ & Th-230 \\
\hline Th-232 & $3.63 E+03$ & 270 & 39 & $3.3 E+05$ & $1.0 E+\infty 0$ & $1 E+01$ & 540 & 39 & $7.3 E+05$ & $1.0 E+00$ & $2 E+01$ & Th-232 \\
\hline $\mathrm{Pa}-231$ & $1.85 E+04$ & 270 & 39 & $5.7 E+04$ & $3.3 E+\infty 0$ & $7 E+\infty$ & 540 & 39 & $1.3 E+05$ & $1.4 E+01$ & $6 E+01$ & $\mathrm{~Pa}-231$ \\
\hline
\end{tabular}


ते Table 6-4. Results of Calculations for the Water Pathway at Paducah (water travel time from land surface to performance boundary [excluding facility detention] $=27 \mathrm{y})($ Part 2 of 2)

\begin{tabular}{|c|c|c|c|c|c|c|c|c|c|c|c|c|}
\hline \multirow[t]{2}{*}{ Nuclide } & \multirow[b]{2}{*}{$\begin{array}{l}\text { PDCF } \\
\text { rem/y per }\end{array}$} & \multicolumn{5}{|c|}{ Trench } & \multicolumn{5}{|c|}{ Tumulus } & \multirow[t]{2}{*}{ Nuclide } \\
\hline & & \begin{tabular}{|l|} 
CRF \\
(dimensionlouss)
\end{tabular} & $\begin{array}{l}C R F_{\text {Water }} \\
\text { (dimensionless) }\end{array}$ & \begin{tabular}{|c|} 
Arrival \\
Time $(y)$
\end{tabular} & $\begin{array}{c}\text { rDecay }^{\prime \prime} \\
\text { (dimensionless) }\end{array}$ & $\begin{array}{c}C_{w \cdot W a t o r}^{b} \\
\left(\mu \mathrm{Ci} / \mathrm{m}^{3}\right)\end{array}$ & $\begin{array}{l}\text { CRF } \\
\text { (dimentionless) }\end{array}$ & \begin{tabular}{|c|} 
(dimensionless) \\
(dimater
\end{tabular} & $\begin{array}{c}\text { Arrival } \\
\text { Time (y) }\end{array}$ & $\begin{array}{c}r_{\text {Decay }} \\
\text { (dimensionloss) }\end{array}$ & $\begin{array}{c}C_{\text {w-Water }}{ }^{b} \\
\left(\mu \mathrm{Ci} / m^{3}\right)\end{array}$ & \\
\hline U-232 & 1.55E+03 & 270 & 39 & 3.7E+03 & $7.9 E+15$ & NL & 540 & 39 & $8.3 E+03$ & $4.6 E+35$ & NL & u-232 \\
\hline U-233 & $1.78 E+03$ & 270 & 39 & $3.7 \mathrm{E}+03$ & NA & $4 E+01$ & 540 & 39 & $8.3 E+03$ & $\mathrm{NA}$ & $5 E+01$ & U-233 \\
\hline U-234 & $5.67 E+02$ & 270 & 39 & $3.7 E+03$ & $\mathrm{NA}$ & $1 E+02$ & 540 & 39 & $8.3 E+03$ & NA & $1 E+02$ & $U-234$ \\
\hline U-235 & $3.17 E+03$ & 270 & 39 & 3.7E+03 & NA & $3 E+01$ & 540 & 39 & $8.3 E+03$ & NA & $3 E+01$ & U-235 \\
\hline $\mathrm{U}-236$ & $1.96 E+02$ & 270 & 39 & $3.7 E+03$ & $1.0 \mathrm{E}+00$ & $2 E+02$ & 540 & 39 & $8.3 E+03$ & $1.0 E+00$ & $4 E+02$ & U.236 \\
\hline U-238 & $2.07 E+02$ & 270 & 39 & $3.7 E+03$ & $\mathrm{NA}$ & $2 E+02$ & 540 & 39 & $8.3 E+03$ & NA & $4 \mathrm{E}+02$ & U-238 \\
\hline Np-237 & $3.24 \mathrm{E}+03$ & 270 & 39 & $6.1 E+02$ & $1.0 E+\infty 0$ & $1 E+01$ & 540 & 39 & $1.5 \mathrm{E}+03$ & $1.0 E+00$ & $3 E+01$ & Np-237 \\
\hline Pu-238 & $2.34 E+03$ & 270 & 39 & $5.7 E+04$ & e & $4 E+05$ & 540 & 39 & $1.3 E+05$ & e & $4 E+05$ & Pu-238 \\
\hline $\mathrm{Pu}-239$ & $2.58 E+03$ & 270 & 39 & $5.7 E+04$ & $5.1 E+\infty$ & $8 E+01$ & 540 & 39 & $1.3 E+05$ & $3.7 E+01$ & $1 E+03$ & Pu-239 \\
\hline $\mathrm{Pu}-240$ & $2.58 \mathrm{E}+03$ & 270 & 39 & $5.7 E+04$ & $4.0 E+02$ & $6 E+03$ & 540 & 39 & $1.3 E+05$ & $5.7 E+05$ & $2 E+07$ & Pu-240 \\
\hline Pu-241 & $4.82 E+08$ & 270 & 39 & $5.7 E+04$ & e & $2 E+06$ & 540 & 39 & $1.3 E+05$ & e & $4 E+06$ & Pu-241 \\
\hline Pu-242 & $2.45 E+03$ & 270 & 39 & $5.7 E+04$ & $1.1 E+00$ & $2 E+01$ & 540 & 39 & $1.3 E+05$ & $1.3 \mathrm{E}+00$ & $4 E+01$ & Pu-242 \\
\hline Pu-244 & $4.11 E+03$ & 270 & 39 & $5.7 E+04$ & NA & $1 \mathrm{E}+01$ & 540 & 39 & $1.3 E+05$ & NA & $2 E+01$ & Pu-244 \\
\hline Am-241 & $2.66 \mathrm{E}+03$ & 270 & 39 & $2.0 E+05$ & e & $6 \mathrm{E}+04$ & 540 & 39 & $4.3 E+05$ & $e$ & $1 E+05$ & $A m-241$ \\
\hline$A m-243$ & $2.64 E+03$ & 270 & 39 & $2.0 E+05$ & $9.8 \mathrm{E}+07$ & $2 E+09$ & 540 & 39 & $4.3 E+05$ & $4.7 E+17$ & $\mathrm{NL}$ & Am-243 \\
\hline $\mathrm{Cm}-243$ & $1.83 E+03$ & 270 & 39 & $4.1 E+05$ & e & $7 E+04$ & 540 & 39 & $9.1 E+05$ & e & $1 \mathrm{E}+06$ & $\mathrm{Cm}-243$ \\
\hline $\mathrm{Cm}-244$ & $1.47 E+03$ & 270 & 39 & $4.1 E+05$ & e & $2 E+06$ & 540 & 39 & $9.1 E+05$ & e & $7 E+09$ & $\mathrm{Cm}-244$ \\
\hline $\mathrm{Cm}-245$ & $4.56 \mathrm{E}+03$ & 270 & 39 & $4.1 E+05$ & NA & $9 E+\infty$ & 540 & 39 & $9.1 E+05$ & NA & $2 E+01$ & $\mathrm{Cm}-245$ \\
\hline $\mathrm{Cm}-246$ & $2.70 E+03$ & 270 & 39 & $4.1 E+05$ & $1.1 E+26$ & $\mathrm{NL}$ & 540 & 39 & $9.1 E+05$ & $\mathrm{e}$ & $\mathrm{NL}$ & $\mathrm{Cm}-246$ \\
\hline $\mathrm{Cm}-247$ & $4.34 E+03$ & 270 & 39 & $4.1 E+05$ & $\mathrm{NA}$ & $9 \mathrm{E}+00$ & 540 & 39 & $9.1 E+05$ & NA & $2 E+01$ & $\mathrm{Cm}-247$ \\
\hline $\mathrm{Cm}-248$ & $9.94 E+03$ & 270 & 39 & $4.1 E+05$ & $2.3 E+00$ & $9 E+\infty$ & 540 & 39 & $9.1 E+05$ & $6.1 E+00$ & $5 E+01$ & $\mathrm{Cm}-248$ \\
\hline Ci-249 & $3.46 E+03$ & 270 & 39 & $4.1 E+05$ & e & $2 \mathrm{E}+02$ & 540 & 39 & $9.1 E+05$ & e & $4 E+02$ & $\mathrm{Cf}-249$ \\
\hline Cf-250 & $2.64 E+08$ & 270 & 39 & $4.1 E+05$ & e & $\mathrm{NL}$ & 540 & 39 & $9.1 E+05$ & e & NL & Cf-250 \\
\hline $\mathrm{Cf}-251$ & $3.54 E+03$ & 270 & 39 & $4.1 E+05$ & $\mathrm{e}$ & $\mathrm{NL}$ & 540 & 39 & $9.1 E+05$ & $\mathrm{e}$ & $\mathrm{NL}$ & $C f-251$ \\
\hline
\end{tabular}

a "NA" means Not Applicable - decay factor is implicit in the PDCF for this radionuclide.

b "NL" means No Limit - estimated permissible concentration is greater than the specific activity of the pure elemental radionuclide.

c Radionuclide concentration is based on arrival time at the performance boundary beyond $10,000 \mathrm{y}$.

d PDCF is a function of arrival time. See Chapter 1 of this volume for equation.

e $r_{\text {Docay }} \geq 1 E+50$

$f$ Contribution of decay product(s) is significant to determination of this value (see Table E-3 in Volume 2). Listed arrival time is that of the parent radionuclide. If this footnote does not appear in combination with footnote $c$, the arrival time of the significant decay product(s) is less than 10,000 $\mathrm{y}$. 
For some radionuclides, no value is listed in Table 6-4 for the radioactive decay term, $r_{\text {Decay. }}$. These radionuclides had radioactive decay terms that were very large (e.g., greater than $\left.1 \times 10^{50}\right)$. Any radionuclide with a radioactive decay term greater than $1 \times 10^{50}$ was ensured a calculated permissible waste concentration greater than the specific activity of the pure elemental radionuclide, which, as described previously, resulted in no limit (NL) on permissible waste concentrations for disposal.

Arrival times for some radionuclides listed in Table 6-4 were beyond the 10,000-y performance period. For those radionuclides, the estimated waste concentrations are presented in Table 6-4 for information purposes only. Consistent with the approach used in LLW performance assessments, these values were not considered in determining the most restrictive disposal limit from among the evaluated pathways.

For all radionuclides in Table 6-4, the rate of water flowing through the facility at the time of facility failure controlled the subsurface transport (i.e., the subsurface movement of the radionuclides in the trench and tumulus was controlled by the rate of water flow at $100 \mathrm{y}$ after closure for the trench [when the cover failed] and at $300 \mathrm{y}$ for the tumulus [when the concrete vaults failed]).

For the tumulus, the total undecayed CRFs (the product of the $C R F_{\text {Source }}$ and the $C R F_{\text {Water }}$ ) for the water pathway were about twice the total undecayed CRFs for the trench, given the same total rate of flow (i.e., at the time of hydrologic failure of the facility). This result was due to the difference in the volume fraction of waste (the ratio of waste material to total material in the disposal unit) between the two technologies - twice as much waste leached from the trench for a given rate of flow because a given volume of trench contained twice as much waste as the tumulus.

For the trench design at Paducah, the total undecayed CRFs for the water pathway ranged from about 18 to 11,000 . Among the listed radionuclides, arrival times at the performance boundary ranged from $100 \mathrm{y}$ to $410,000 \mathrm{y}$, including the retention time in the facility before failure. The radionuclide travel time of $100 \mathrm{y}$ applied to $\mathrm{H}-3$ and Tc-99 and was based on the slow release from the trench starting at $30 \mathrm{y}$. The travel time through the unsaturated zone accounted for about $10 \%$ of the total subsurface travel time.

For the tumulus design, the total undecayed CRFs for the water pathway ranged from about 35 to 21,000. Among the listed radionuclides, arrival times at the performance boundary ranged from $350 \mathrm{y}$ to $910,000 \mathrm{y}$, including the retention time in the facility before failure. Differences in these arrival times compared to the trench were attributable to (1) the assumed time of hydrologic failure of the facility (100 y for the trench and $300 \mathrm{y}$ for the tumulus); and (2) the increased travel distance through the vadose zone for the tumulus (the bottom of the tumulus was assumed to be at grade level, while the trench was assumed to be a shallow buried structure). 


\subsubsection{Atmospheric Transport}

Two CRFs were used to account for the attenuation encompassing diffusion to the ground surface, mixing in air, and dispersion in the atmosphere to the performance boundary. The CRF for diffusion in soil, $C R F_{D i f f}$, was defined as the ratio of the radionuclide concentration in the waste to its resulting concentration in the upper one centimeter of soil. The CRF for dispersion in air, $C R F_{\text {Disp, }}$ was defined as the ratio of the radionuclide concentration in the upper one centimeter of soil to its resulting concentration in air at the performance boundary. The effect of radioactive decay was also included in the PE. .

Application of the PE methodology for atmospheric transport of the two volatile radionuclides considered in the $\mathrm{PE}(\mathrm{H}-3$ and $\mathrm{C}-14)$ produced the results shown in Table 6-5 for both the generic trench and tumulus designs; there was no assumed difference in these two disposal technologies with respect to permissible waste limits based on the atmospheric pathway at Paducah. The table shows permissible waste concentrations based on transport in the atmospheric pathway $\left(C_{W-A t m}\right)$, as well as the values used in calculating the permissible waste concentrations. For both $\mathrm{H}-3$ and $\mathrm{C}-14$, the greatest concentration reduction occurred as the radionuclides diffuse from the top of the disposal facility to the soil surface.

Table 6-5. Results of Calculations for the Atmospheric Pathway

\begin{tabular}{|c|c|c|c|c|c|c|c|}
\hline \multirow[t]{2}{*}{ Nuclide } & \multirow{2}{*}{$\begin{array}{c}S D C F_{A t m} \\
(\mathrm{rem} / \mathrm{y}) /(\mu \mathrm{Ci} / \mathrm{L})\end{array}$} & \multicolumn{6}{|c|}{ Generic Trench and Tumulus } \\
\hline & & $\begin{array}{c}C R F_{D i f f} \\
\text { (dimenaionloss) }\end{array}$ & $\begin{array}{c}\text { CRF } \\
\text { (dimentiontese) }\end{array}$ & $\begin{array}{c}C R F_{A t m} \\
\text { (dimanationlose) }\end{array}$ & $\begin{array}{c}\text { Arrival } \\
\text { Time (y) }\end{array}$ & $\begin{array}{c}r_{\text {Docay }} \\
\text { (dimenslonless) }\end{array}$ & $\begin{array}{r}C_{W-A t m} \\
\left(\mu \mathrm{Ci} / \mathrm{m}^{3}\right) \\
\end{array}$ \\
\hline $\mathrm{H}-3$ & $8.33 E+02$ & $2 E+06$ & $1 E+03$ & $2 E+09$ & 100 & 300 & $7 E+09$ \\
\hline$C-14$ & $2.20 E+05$ & $5 E+04$ & $2 E+03$ & $1 E+08$ & 100 & 1 & $5 E+03$ \\
\hline
\end{tabular}

The time of arrival at the performance boundary for both radionuclides is shown in Table 6-5 as $100 \mathrm{y}$. However, the actual migration of $\mathrm{H}-3$ and $\mathrm{C}-14$ from the disposal facility to the surface and downwind to the performance boundary was calculated to be on the order of hours, not years. As discussed in Section 6.3.2, the waste form and RCRA cover are assumed to retain these volatile radionuclides in the disposal facility for at least $100 \mathrm{y}$.

\subsubsection{Inadvertent Intruder Exposure}

The calculation of permissible waste concentrations for inadvertent intruder exposures did not utilize CRFs. Instead, the total dose resulting from an intrusion scenario (the sum of the doses from all exposure pathways involved in that intrusion) was computed from scenario dose conversion factors (SDCFs) that were applied to specific exposure pathways. The important exposure pathways for each radionuclide are listed in Appendix D of Volume 2. These values were radionuclide-specific and facility-design-specific and were the same for all sites. Values for 
were radionuclide-specific and facility-design-specific and were the same for all sites. Values for the radioactive decay term were based on time of intrusion into the disposal facility (for the homesteader scenario, $300 \mathrm{y}$ for the trench design and $500 \mathrm{y}$ for the tumulus design; for the post-drilling scenario, $100 \mathrm{y}$ for both disposal designs). However, results based on intruder scenarios should be evaluated carefully because future social behavior, and intrusion scenarios, are difficult to predict.

The permissible waste concentrations for the two generic facility designs for each of the 58 radionuclides based on the standard PE intrusion scenarios are listed in Table 6-6. The most restrictive radionuclide concentration limits for each generic facility are indicated with boldface type.

For six radionuclides in the table (U-233, U-234, U-235, U-238, Pu-244, and Cm-247), the time of homesteader intrusion was changed to $10,000 \mathrm{y}$, the end of the performance period. For these six radionuclides, ingrowth of decay products yields scenario doses that increase over time. The doses at $10,000 \mathrm{y}$, therefore, represent the maximum that could be encountered during the performance period. Also, for Th-230 and $\mathrm{Cm}-245$, ingrowth of decay products likewise produces a scenario dose that increases over time and peaks within the 10,000-y performance period. The times of homesteader intrusion for these two radionuclides (Th-230 and Cm-245) were taken as the time of maximum dose, $9000 \mathrm{y}$ and $1000 \mathrm{y}$, respectively.

For the trench design, the waste concentrations of 47 radionuclides were controlled by the homesteader scenario and 11 were controlled by the post-drilling scenario. For the trench design, the post-drilling scenario generally yielded more restrictive waste limits than the homesteader scenario for those radionuclides with half-lives shorter than about $30 \mathrm{y}$. For the tumulus design, the waste limits of 41 radionuclides were controlled by the homesteader scenario and 17 were controlled by the post-drilling scenario. For the tumulus design, the post-drilling scenario generally yielded more restrictive limits than the homesteader scenario for those radionuclides with half-lives shorter than about $130 \mathrm{y}$.

\subsection{SUMMARY AND DISCUSSION OF RESULTS}

The limiting waste concentrations in disposed MLLW for the water, atmospheric, and intruder analyses for the generic trench and tumulus designs are summarized in Table 6-7 and discussed in Section 6.6.1. An overall discussion of the results of the PE for Paducah is contained in Section 6.6.2.

\subsubsection{Results Based on Disposal Design}

For the generic trench design at Paducah, 13 radionuclides were limited by the water pathway, no radionuclides were limited by the atmospheric pathway, and 45 radionuclides were limited by intrusion scenarios, as shown in Table 6-7. Among the 45 radionuclides limited by intrusion scenarios for the trench at Paducah, 35 were controlled by homesteader intrusion, while 10 were controlled by post-drilling. 
Table 6-6. Permissible Waste Concentrations for the Standard Intrusion Scenarios (most limiting radionuclide concentration for each facility design is highlighted in bold italic) (Part 1 of 2)

\begin{tabular}{|c|c|c|c|c|c|}
\hline \multirow[t]{2}{*}{ Nuclide } & \multicolumn{2}{|c|}{ Trench } & \multicolumn{2}{|c|}{ Tumulus } & \multirow[t]{2}{*}{ Nuclide } \\
\hline & $\begin{array}{c}C_{w \text { wntr }} \\
\text { Homesteader } \\
\left(\mu \mathrm{Ci} / \mathrm{m}^{3}\right) \\
\end{array}$ & $\begin{array}{c}C_{\text {whint }} \\
\text { Post-Drilling } \\
\left(\mu \mathrm{Ci} / \mathrm{m}^{3}\right) \\
\end{array}$ & $\begin{array}{c}C_{w-\operatorname{mer}} \\
\text { Homesteader } \\
\left(\mu \mathrm{Ci} / \mathrm{m}^{3}\right) \\
\end{array}$ & $\begin{array}{c}C_{\text {w-lntr }} \\
\text { Post-Drilling } \\
\left(\mu \mathrm{Ci} / \mathrm{m}^{3}\right) \\
\end{array}$ & \\
\hline $\mathrm{H}-3$ & $1 E+12$ & $7 E+07$ & NL & $7 E+07$ & $\mathrm{H}-3$ \\
\hline C-14 & $1 E+04$ & $7 E+04$ & $1 E+04$ & $7 E+04$ & C-14 \\
\hline Al-26 & $5 E+01$ & $5 E+04$ & $5 E+01$ & $5 E+04$ & $\mathrm{Al}-26$ \\
\hline Si-32 & $9 E+03$ & $1 \mathrm{E}+04$ & $4 E+04$ & $1 E+04$ & Si-32 \\
\hline $\mathrm{Cl}-36$ & $2 E+02$ & $9 E+02$ & $2 E+02$ & $9 E+02$ & $\mathrm{Cl}-36$ \\
\hline$K-40$ & $7 E+02$ & $2 E+04$ & $7 E+02$ & $2 E+04$ & $K-40$ \\
\hline Co-60 & NL & $3 E+10$ & NL & $3 E+10$ & Co-60 \\
\hline $\mathrm{Ni}-59$ & $3 E+06$ & $1 E+07$ & $3 E+06$ & $1 E+07$ & $\mathrm{Ni}-59$ \\
\hline $\mathrm{Ni}-63$ & $8 E+06$ & $1 E+07$ & $3 E+07$ & $1 E+07$ & $\mathrm{Ni}-63$ \\
\hline Se-79 & $2 E+05$ & $8 E+05$ & $2 E+05$ & $8 E+05$ & Se-79 \\
\hline Sr-90 & $1 E+06$ & $5 E+04$ & $1 E+08$ & $5 E+04$ & Sr-90 \\
\hline $2 r-93$ & $5 E+06$ & $3 E+07$ & $5 E+06$ & $3 E+07$ & $\mathrm{Zr}-93$ \\
\hline $\mathrm{Nb}-93 \mathrm{~m}$ & $5 E+12$ & $4 E+09$ & NL & $4 E+09$ & $\mathrm{Nb}-93 \mathrm{~m}$ \\
\hline $\mathrm{Nb}-94$ & $9 E+01$ & $9 E+04$ & $1 E+02$ & $9 E+04$ & $\mathrm{Nb}-94$ \\
\hline TC-99 & $2 E+04$ & $8 \mathrm{E}+04$ & $2 E+04$ & $8 E+04$ & TC-99 \\
\hline$P d-107$ & $6 E+06$ & $3 E+07$ & $6 E+06$ & $3 E+07$ & $\mathrm{Pd}-107$ \\
\hline $\mathrm{Ag}-108 \mathrm{~m}$ & $5 E+02$ & $1 E+05$ & $1 E+03$ & $1 \mathrm{E}+05$ & $\mathrm{Ag}-108 \mathrm{~m}$ \\
\hline Cd-113m & $4 E+09$ & $1 E+06$ & $7 E+13$ & $1 E+06$ & $\mathrm{Cd}-113 \mathrm{~m}$ \\
\hline Sn-121m & $2 E+07$ & $5 E+07$ & $2 E+08$ & $5 E+07$ & Sn-121m \\
\hline $5 n-126$ & $8 E+01$ & $7 E+04$ & $8 E+01$ & $7 E+04$ & Sn-126 \\
\hline $1-129$ & $2 E+03$ & $1 E+04$ & $2 E+03$ & $1 E+04$ & $\mid 1-129$ \\
\hline Cs-135 & $2 E+05$ & $8 E+05$ & $2 E+05$ & $8 E+05$ & Cs-135 \\
\hline Cs-137 & $3 E+05$ & $8 E+05$ & $3 E+07$ & $8 E+05$ & Cs-137 \\
\hline $\mathrm{Ba}-133$ & $2 E+11$ & $3 E+08$ & NL & $3 E+08$ & $\mathrm{Ba}-133$ \\
\hline$S m-151$ & $2 E+08$ & $2 E+08$ & $8 E+08$ & $2 E+08$ & $\mathrm{Sm}-151$ \\
\hline Eu-152 & $6 E+08$ & $2 E+07$ & $2 E+13$ & $2 E+07$ & Eu-152 \\
\hline Eu-154 & $4 E+12$ & $4 E+08$ & $\mathrm{NL}$ & $4 E+08$ & Eu-154 \\
\hline $\mathrm{Pb}-210$ & $7 E+06$ & $7 E+04$ & $4 E+09$ & $7 E+04$ & $\mathrm{~Pb}-210$ \\
\hline $\mathrm{Ra}-226$ & $8 E+01$ & $3 E+03$ & $9 E+01$ & $3 E+03$ & Ra-226 \\
\hline Ra-228 & $\mathrm{NL}$ & $4 E+09$ & NL & $4 E+09$ & Ra-228 \\
\hline Th-229 & $5 E+02$ & $3 E+04$ & $5 E+02$ & $3 E+04$ & Th-229 \\
\hline Th-230 & $8 E+01$ & $7 E+04$ & $8 E+01$ & $7 E+04$ & Th-230 \\
\hline Th-232 & $6 E+01$ & $2 E+04$ & $6 E+01$ & $2 E+04$ & Th-232 \\
\hline $\mathrm{Pa}-231$ & $2 E+02$ & $5 E+03$ & $2 E+02$ & $5 E+03$ & $\mathrm{~Pa}-231$ \\
\hline
\end{tabular}


Table 6-6. Permissible Waste Concentrations for the Standard Intrusion Scenarios (most limiting radionuclide concentration for each facility design is highlighted in bold italic) (Part 2 of 2)

\begin{tabular}{|c|c|c|c|c|c|}
\hline \multirow[t]{2}{*}{ Nuclide } & \multicolumn{2}{|c|}{ Trench } & \multicolumn{2}{|c|}{ Tumulus } & \multirow[t]{2}{*}{ Nuclide } \\
\hline & $\begin{array}{c}C_{w-1 n t r} \\
\text { Homesteader } \\
\left(\mu \mathrm{Cl} / \mathrm{m}^{3}\right)\end{array}$ & $\begin{array}{c}C_{\text {Whnt }} \\
\text { Post-Drilling } \\
\left(\mu \mathrm{C} / \mathrm{m}^{3}\right)\end{array}$ & $\begin{array}{c}C_{w-1 n t r} \\
\text { Homesteader } \\
\left(\mu \mathrm{Ci} / \mathrm{m}^{3}\right) \\
\end{array}$ & $\begin{array}{c}C_{w-\operatorname{mtr}} \\
\text { Post-Drilling } \\
\left(\mu \mathrm{Ci} / \mathrm{m}^{3}\right) \\
\end{array}$ & \\
\hline U-232 & $2 E+03$ & $5 E+04$ & $1 E+04$ & $5 E+04$ & U-232 \\
\hline U-233 & $7 E+02$ & $1 E+05$ & $7 E+02$ & $1 E+05$ & $U-233$ \\
\hline U-234 & $1 E+03$ & $1 E+05$ & $1 E+03$ & $1 E+05$ & U-234 \\
\hline U-235 & $6 E+02$ & $1 E+05$ & $6 E+02$ & $1 E+05$ & U-235 \\
\hline $\mathrm{U}-236$ & $2 E+04$ & $1 E+05$ & $2 E+04$ & $1 E+05$ & $U-236$ \\
\hline U-238 & $5 E+03$ & $1 E+05$ & $5 E+03$ & $1 E+05$ & $\mathrm{U}-238$ \\
\hline Np-237 & $4 E+02$ & $4 E+03$ & $4 E+02$ & $4 E+03$ & Np-237 \\
\hline $\mathrm{Pu}-238$ & $7 E+04$ & $1 E+05$ & $4 E+05$ & $1 E+05$ & $\mathrm{Pu}-238$ \\
\hline $\mathrm{Pu}-239$ & $6 E+03$ & $5 E+04$ & $6 E+03$ & $5 E+04$ & Pu-239 \\
\hline $\mathrm{Pu}-240$ & $6 E+03$ & $5 E+04$ & $7 E+03$ & $5 E+04$ & Pu-240 \\
\hline $\mathrm{Pu}-241$ & $2 E+05$ & $1 E+06$ & $3 E+05$ & $1 E+06$ & Pu-241 \\
\hline Pu-242 & $6 E+03$ & $5 E+04$ & $6 E+03$ & $5 E+04$ & Pu-242 \\
\hline Pu-244 & $4 E+02$ & $5 E+04$ & $4 E+02$ & $5 \mathrm{E}+04$ & Pu-244 \\
\hline Am-241 & $7 E+03$ & $5 E+04$ & $9 E+03$ & $5 E+04$ & Am-241 \\
\hline Am-243 & $9 E+02$ & $4 E+04$ & $9 E+02$ & $4 E+04$ & Am-243 \\
\hline $\mathrm{Cm}-243$ & $1 E+06$ & $8 E+05$ & $5 E+06$ & $8 E+05$ & $\mathrm{Cm}-243$ \\
\hline $\mathrm{Cm}-244$ & $2 E+06$ & $3 E+06$ & $2 E+06$ & $3 E+06$ & $\mathrm{Cm}-244$ \\
\hline Cm-245 & $1 E+03$ & $4 E+04$ & $1 E+03$ & $4 E+04$ & $\mathrm{Cm}-245$ \\
\hline $\mathrm{Cm}-246$ & $6 E+03$ & $5 E+04$ & $6 E+03$ & $5 E+04$ & $\mathrm{Cm}-246$ \\
\hline $\mathrm{Cm}-247$ & $3 E+02$ & $5 E+04$ & $3 E+02$ & $5 E+04$ & $\mathrm{Cm}-247$ \\
\hline Cm-248 & $2 E+03$ & $1 E+04$ & $2 E+03$ & $1 E+04$ & $\mathrm{Cm}-248$ \\
\hline Cf-249 & $8 E+02$ & $4 E+04$ & $1 E+03$ & $4 E+04$ & Cf-249 \\
\hline Cf-250 & $2 E+06$ & $9 E+06$ & $2 E+06$ & $9 E+06$ & Cf-250 \\
\hline Cf-251 & $2 E+03$ & $4 E+04$ & $2 E+03$ & $4 E+04$ & Cf-251 \\
\hline
\end{tabular}

a "NL" means No Limit - estimated permissible concentration is greater than the specific activity of the pure elemental radionuclide. 
Table 6-7. Permissible Concentrations for the Generic Disposal Designs at Paducah (permissible concentration related to the most limiting pathway for each facility design is highlighted in bold italic) (Part 1 of 2)

\begin{tabular}{|c|c|c|c|c|c|c|c|}
\hline \multirow[t]{2}{*}{ Nuclide } & \multicolumn{3}{|c|}{ Trench } & \multicolumn{3}{|c|}{ Tumulus } & \multirow[t]{2}{*}{ Nuclide } \\
\hline & $\begin{array}{c}C_{\text {w-Water }}{ }^{a, b} \\
\left(\mu \mathrm{Ci} / \mathrm{m}^{3}\right)\end{array}$ & $\begin{array}{l}C_{W-A t m}{ }^{c} \\
\left(\mu \mathrm{Ci} / \mathrm{m}^{3}\right)\end{array}$ & $\begin{array}{l}C_{W / n t r}^{d} \\
\left(\mu \mathrm{Ci} / \mathrm{m}^{3}\right)\end{array}$ & $\begin{array}{c}C_{\text {w.Water }}{ }^{2, b} \\
\left(\mu \mathrm{Ci} / \mathrm{m}^{3}\right)\end{array}$ & $\begin{array}{l}C_{W-A t m}^{c} \\
\left(\mu \mathrm{Ci} / \mathrm{m}^{3}\right)\end{array}$ & $\begin{array}{l}C_{\text {wr/ntr }}{ }^{d} \\
\left(\mu \mathrm{Ci} / \mathrm{m}^{3}\right)\end{array}$ & \\
\hline $\mathrm{H}-3$ & $5 E+05$ & $7 E+09$ & $7 E+07$ & $1 E+12$ & $7 E+09$ & $7 E+07$ & $\mathrm{H}-3$ \\
\hline$c-14$ & $3 E+03$ & $5 E+03$ & $1 E+04$ & $7 \mathrm{E}+03$ & $5 E+03$ & $1 E+04$ & C-14 \\
\hline AI-26 & $4 E+03$ & & $5 E+01$ & $8 \mathrm{E}+03$ & & $5 E+01$ & Al-26 \\
\hline Si-32 & NL & & $9 E+03$ & $\mathrm{NL}$ & & $1 E+04$ & Si-32 \\
\hline $\mathrm{Cl}-36$ & $3 E+01$ & & $2 E+02$ & $6 E+01$ & & $2 E+02$ & $\mathrm{Cl}-36$ \\
\hline$K-40$ & $3 E+01$ & & $7 E+02$ & $7 E+01$ & & $7 E+02$ & $K-40$ \\
\hline Co-60 & $\mathrm{NL}$ & & $3 E+10$ & - & & $3 E+10$ & Co-60 \\
\hline Ni-59 & - & & $3 E+06$ & - & & $3 E+06$ & $\mathrm{Ni}-59$ \\
\hline $\mathrm{Ni}-63$ & - & & $8 E+06$ & - & & $1 E+07$ & $\mathrm{Ni}-63$ \\
\hline Se-79 & - & & $2 E+05$ & - & & $2 E+05$ & Se-79 \\
\hline Sr-90 & $\mathrm{NL}$ & & $5 E+04$ & $\mathrm{NL}$ & & $5 E+04$ & Sr-90 \\
\hline $2 r-93$ & - & & $5 E+06$ & - & & $5 E+06$ & $2 r-93$ \\
\hline $\mathrm{Nb}-93 \mathrm{~m}$ & - & & $4 E+09$ & - & & $4 E+09$ & $\mathrm{Nb}-93 \mathrm{~m}$ \\
\hline $\mathrm{Nb}-94$ & - & & $9 E+01$ & - & & $1 E+02$ & $\mathrm{Nb}-94$ \\
\hline Tc-99 & $4 E+02$ & & $2 E+04$ & $9 E+02$ & & $2 E+04$ & Tc-99 \\
\hline Pd-107 & $4 E+05$ & & $6 \mathrm{E}+06$ & - & & $6 E+06$ & $P d-107$ \\
\hline Ag-108m & $\mathrm{NL}$ & & $5 E+02$ & - & & $1 E+03$ & $\mathrm{Ag}-108 \mathrm{~m}$ \\
\hline Cd-113m & $\mathrm{NL}$ & & $1 E+06$ & - & & $1 E+06$ & Cd-113m \\
\hline Sn-121m & - & & $2 E+07$ & - & & $5 E+07$ & Sn-121m \\
\hline Sn-126 & - & & $8 E+01$ & - & & $8 E+01$ & Sn-126 \\
\hline $1-129$ & $2 E+00$ & & $2 E+03$ & $5 E+00$ & & $2 E+03$ & I-129 \\
\hline Cs-135 & - & & $2 E+05$ & - & & $2 E+05$ & Cs-135 \\
\hline Cs-137 & - & & $3 E+05$ & - & & $8 E+05$ & Cs-137 \\
\hline $\mathrm{Ba}-133$ & $\mathrm{NL}$ & & $3 E+08$ & $\mathrm{NL}$ & & $3 E+08$ & Ba-133 \\
\hline Sm-151 & - & & $2 E+08$ & - & & $2 E+08$ & Sm-151 \\
\hline Eu-152 & - & & $2 E+07$ & - & & $2 E+07$ & Eu-152 \\
\hline Eu-154 & - & & $4 E+08$ & - & & $4 E+08$ & Eu-154 \\
\hline $\mathrm{Pb}-210$ & - & & $7 E+04$ & - & & $7 E+04$ & $\mathrm{~Pb}-210$ \\
\hline Ra-226 & - & & $8 E+01$ & - & & $9 E+01$ & Ra-226 \\
\hline Ra-228 & - & & $4 E+09$ & - & & $4 E+09$ & Ra-228 \\
\hline Th-229 & - & & $5 E+02$ & - & & $5 E+02$ & Th-229 \\
\hline Th-230 & - & & $8 E+01$ & - & & $8 E+01$ & Th-230 \\
\hline Th-232 & - & & $6 E+01$ & - & & $6 E+01$ & Th-232 \\
\hline $\mathrm{Pa}-231$ & - & & $2 E+02$ & - & & $2 E+02$ & Pa-231 \\
\hline
\end{tabular}


Table 6-7. Permissible Concentrations for the Generic Disposal Designs at Paducah (permissible concentration related to the most limiting pathway for each facility design is highlighted in bold italic) (Part 2 of 2)

\begin{tabular}{|c|c|c|c|c|c|c|c|}
\hline \multirow[t]{2}{*}{ Nuclide } & \multicolumn{3}{|c|}{ Trench } & \multicolumn{3}{|c|}{ Tumulus } & \multirow[t]{2}{*}{ Nuclide } \\
\hline & $\begin{array}{c}C_{\text {w.water }}{ }^{a, b} \\
\left(\mu \mathrm{Ci} / \mathrm{m}^{3}\right) \\
\end{array}$ & $\begin{array}{l}C_{W-A t m}^{c} \\
\left(\mu \mathrm{Ci} / \mathrm{m}^{3}\right)\end{array}$ & $\begin{array}{l}C_{W / n t r}^{d} \\
\left(\mu \mathrm{Ci} / m^{3}\right)\end{array}$ & $\begin{array}{c}C_{\text {w.water }}{ }^{a, b} \\
\left.(\mu \mathrm{Cum})^{3}\right)\end{array}$ & $\begin{array}{l}C_{W-A t m}{ }^{c} \\
\left(\mu \mathrm{Ci} / \mathrm{m}^{3}\right)\end{array}$ & $\begin{array}{l}C_{W / n t r}{ }^{d} \\
\left.(\mu \mathrm{Cilm})^{3}\right)\end{array}$ & \\
\hline U-232 & NL & & $2 E+03$ & $\mathrm{NL}$ & & $1 E+04$ & U-232 \\
\hline U-233 & $4 E+01$ & & $7 E+02$ & $5 E+01$ & & $7 E+02$ & U-233 \\
\hline U-234 & $1 E+02$ & & $1 E+03$ & $1 E+02$ & & $1 E+03$ & U-234 \\
\hline U-235 & $3 E+01$ & & $6 E+02$ & $3 E+01$ & & $6 E+02$ & U-235 \\
\hline U-236 & $2 E+02$ & & $2 E+04$ & $4 E+02$ & & $2 E+04$ & U-236 \\
\hline U-238 & $2 E+02$ & & $5 E+03$ & $4 E+02$ & & $5 E+03$ & U-238 \\
\hline $\mathrm{Np}-237$ & $1 E+01$ & & $4 E+02$ & $3 E+01$ & & $4 E+02$ & Np-237 \\
\hline $\mathrm{Pu}-238$ & $4 E+05$ & & $7 E+04$ & $4 E+05$ & & $1 E+05$ & Pu-238 \\
\hline Pu-239 & - & & $6 E+03$ & - & & $6 E+03$ & Pu-239 \\
\hline Pu-240 & - & & $6 E+03$ & - & & $7 E+03$ & Pu-240 \\
\hline $\mathrm{Pu}-241$ & $2 E+06$ & & $2 E+05$ & $4 \mathrm{E}+06$ & & $3 E+05$ & Pu-241 \\
\hline Pu-242 & - & & $6 E+03$ & - & & $6 E+03$ & Pu-242 \\
\hline Pu-244 & $=$ & & $4 E+02$ & - & & $4 E+02$ & Pu-244 \\
\hline$A m-241$ & $6 E+04$ & & $7 E+03$ & $1 E+05$ & & $9 E+03$ & Am-241 \\
\hline Am-243 & - & & $9 E+02$ & - & & $9 E+02$ & Am-243 \\
\hline $\mathrm{Cm}-243$ & - & & $8 E+05$ & - & & $8 E+05$ & $\mathrm{Cm}-243$ \\
\hline $\mathrm{Cm}-244$ & - & & $2 E+06$ & - & & $2 E+06$ & $\mathrm{Cm}-244$ \\
\hline $\mathrm{Cm}-245$ & - & & $1 E+03$ & - & & $1 E+03$ & $\mathrm{Cm}-245$ \\
\hline $\mathrm{Cm}-246$ & - & & $6 E+03$ & - & & $6 E+03$ & $\mathrm{Cm}-246$ \\
\hline $\mathrm{Cm}-247$ & - & & $3 E+02$ & - & & $3 E+02$ & $\mathrm{Cm}-247$ \\
\hline $\mathrm{Cm}-248$ & - & & $2 E+03$ & - & & $2 E+03$ & $\mathrm{Cm}-248$ \\
\hline Cf-249 & - & & $8 E+02$ & - & & $1 E+03$ & Cf-249 \\
\hline Cf-250 & - & & $2 E+06$ & - & & $2 E+06$ & Cf-250 \\
\hline Cf-251 & - & & $2 E+03$ & - & & $2 E+03$ & Cf-251 \\
\hline
\end{tabular}

a "NL" means No Limit - estimated permissible concentration factor is greater than the specific activity of the pure elemental radionuclide.

b "-" Indicates that the radionuclide concentration is based on an arrival time beyond $10,000 \mathrm{y}$; see Table $6-4$ for specific values.

c Results presented for radionclides expected to be volatile under disposal facility conditions.

d Concentration is based on the most restrictive intrusion scenario assumed for the site; see Table $6-6$. 
For the generic tumulus design, 10 radionuclides were limited by the water pathway, one radionuclide was limited by the atmospheric pathway, and 47 radionuclides were limited by intrusion scenarios. Among the 47 radionuclides limited by intrusion scenarios for the tumulus at Paducah, 30 were controlled by homesteader intrusion, while 17 were controlled by post-drilling.

For the trench design, the concentrations for seven radionuclides that arrived at the performance boundary before $10,000 \mathrm{y}$ in the water pathway analysis have no limit (i.e., Si-32, Co-60, Sr-90, Ag-108m, Cd-113m, Ba-133, and U-232). For the tumulus design, 4 radionuclides have no limit for the water pathway (Si-32, Sr-90, Ba-133, and U-232). As discussed in Section 6.5.1, the calculated concentrations for those radionuclides reported as NL (No Limit) were above the specific activity of the pure elemental radionuclide, implying that the performance measure of $4 \mathrm{mrem}(0.04 \mathrm{mSv})$ per year would not be reached under the given release and transport assumptions.

As also discussed in Section 6.5.1, values for some radionuclides are not reported in Table 6-7 for the water pathway analysis. Arrival times for these radionuclides were beyond the 10,000-y performance period. For these radionuclides, the estimated waste concentrations are presented in Table 6-4 for information purposes but are not listed in Table 6-7. Consistent with the approach used in LLW performance assessments, these values were not considered in determining the most restrictive disposal limit from among the evaluated pathways because arrival times for these radionuclides were beyond $10,000 \mathrm{y}$.

For both the trench and tumulus designs, the radionuclides limited by the water pathway generally tended to be highly mobile (e.g., $\mathrm{H}-3$ and Tc-99). The radiums, thoriums, and some of the transuranics are not shown as being limited by the water pathway because their peak arrival times were beyond $10,000 \mathrm{y}$.

At Paducah, there is no significant difference in the permissible waste concentrations computed for the trench as compared to the tumulus. That is, there is less than one order of magnitude difference in the waste limits between the two disposal facility designs. The notable exceptions include $\mathrm{H}-3$ and Pd-107, both of which are limited by the water pathway for the trench and by intrusion for the tumulus.

\subsubsection{Discussion}

The results of the PE are based on the framework of assumptions summarized in Chapter 1 of this volume and discussed in detail in Volume 2 of this report and on the site-specific conceptual model for contaminant transport discussed in this chapter. Using alternative assumptions about the conceptual model has the potential to affect the results. Changes in the conceptual model could include alternative assumptions about the disposal facility, the source term, and radionuclide movement in the three pathways. Depending on the degree of possible variation and the relative importance of the parameters used in the calculation of estimated permissible radionuclide concentrations, variability in parameter values can also affect the results. 
For parameters, results could vary depending on the amount of change in values of both the generic and the site-specific parameters used in the PE analysis.

The effect on results from using alternative generic assumptions and parameter values is discussed in Chapter 6 of Volume 2. In addition, a discussion is provided in that chapter of the effects of using alternative values for site-specific parameters. Based on this discussion, four parameters were identified (three site-specific and one generic, all used in the water pathway analysis) that could potentially influence the results to the degree that the calculated waste concentrations become limited by a pathway other than the one determined for the PE (Table 6-7). The impacts on the results of using alternative values for these four parameters for the water pathway in the PE for PGDP are discussed in this section. The basis for and possible variation in the values used in the PE for these parameters are discussed in Section 6.6.2.2.

\subsubsection{Parameter Sensitivity Analysis}

The PE provided results for two disposal facility designs: a RCRA-compliant, belowground trench and a RCRA-compliant, above-ground tumulus. Similar assumptions about the integrity of engineered barriers were made in the PE for both facility designs. Because the factors used to estimate transport of radionuclides in the water pathway for both designs were similar, the discussion in this section focuses on examining the results for the indicator radionuclides reported for the tumulus design (indicator radionuclides are defined in Chapter 7 of Volume 2).

As discussed in Chapter 6 of Volume 2, four parameters used in the PE were identified as having a potential range of values that might affect results: annual natural recharge through the disposal facility $(i)$; groundwater Darcy velocity $\left(q_{g w}\right)$; plan-view area of the facility $(A)$; and distribution coefficients $\left(K_{d} s\right)$. These parameter values for Paducah are summarized in Table 6-8.

Table 6-8. Parameter Values Used in the PE for Paducah with Potential Variability That Could Affect the Results

\begin{tabular}{|l|l|}
\hline \multicolumn{1}{|c|}{ Parameter } & \multicolumn{1}{c|}{ Value } \\
\hline Natural recharge through local soils, $i$ & $\begin{array}{l}0.12 \mathrm{~m} / \mathrm{y} \text { (based on site information; see } \\
\text { Section 6.3.1.1) }\end{array}$ \\
\hline $\begin{array}{l}\text { Distribution coefficients for geologic } \\
\text { media, } K_{d}\end{array}$ & see Table 6-2 in this chapter for values \\
\hline Groundwater Darcy velocity, $q_{g w}$ & $\begin{array}{l}25 \mathrm{~m} / \mathrm{y} \text { (based on site-specific measurement; } \\
\text { see Section } 6.4 .1 \text { for discussion) }\end{array}$ \\
\hline Plan-view Area, $A$ & $2500 \mathrm{~m}^{2}$ (standard PE value) \\
\hline
\end{tabular}

The traditional procedure for performing a sensitivity analysis is to vary the parameters used in the calculations and observe the effect on the results. To be meaningful, this method 
requires some knowledge of the statistical distribution of each of the parameters considered, including their likely maximum and minimum values. For the $\mathrm{PE}$ calculations, the potential variability of the parameters used to calculate the permissible waste concentrations for the two different facility designs was not estimated. For most of the radionuclides considered in the PE, there were only two exposure pathways: the water pathway and intruder exposure scenarios (the atmospheric pathway is considered only for $\mathrm{H}-3$ and $\mathrm{C}-14$ ). The intruder-pathway results provide a baseline that can be used for comparison with the water-pathway results because the intruder scenarios used in the PE were relatively independent of the physical characteristics of the individual sites. For $\mathrm{H}-3$ and $\mathrm{C}-14$, the atmospheric pathway results provide a baseline that can also be used for comparison with the water pathway because the atmospheric pathway results are not highly sensitive to any individual input parameter (see Chapter 6 of Volume 2).

The intruder and atmospheric baselines provided an alternative method of performing sensitivity analyses for the PE. The input parameters for the water pathway were varied to determine if the limiting exposure pathway could be altered (e.g., the results could be changed from intruder-scenario-controlled [or atmospheric-pathway-controlled] to water-pathwaycontrolled). After new values for the water pathway parameters were determined, these values were examined for reasonableness based on physical constraints at the site.

To analyze the sensitivity of the results to changes in the parameter values for recharge, groundwater Darcy velocity, and area of the facility, the parameter values used in the PE for Paducah were varied. Only one parameter value was varied at a time for each indicator radionuclide, leaving the others equal to their $\mathrm{PE}$ values. In most instances, the parameter value was varied until the waste concentrations for the water and intruder (or atmospheric) pathways became equal, regardless of the likelihood (or physical impossibility) of the value to occur.

The parameter values that caused the permissible concentrations for the water and intruder pathways to become equal are listed in Table 6-9a for the 8 indicator radionuclides. For the indicator radionuclides $\mathrm{H}-3, \mathrm{Sr}-90$, and $\mathrm{Cs}-137$, no variation in values for these parameters resulted in equal concentrations. For $\mathrm{C}$-14, the limiting pathway is the atmospheric pathway, so the water versus intruder comparison is not applicable. For Tc-99 and U-238, the value for recharge had to decrease by about one order of magnitude, or the groundwater velocity had to increase by about one order of magnitude for the limiting pathway to change from water to intruder. For U-238, this change in recharge caused the arrival time to be beyond $10,000 \mathrm{y}$. For $\mathrm{Pu}-239$, all values that caused the pathways to become equal also arrived at the performance boundary beyond 10,000 y. For Am-241, the value for recharge had to increase by more than one order of magnitude, the groundwater velocity had to decrease by about one order of magnitude, or the facility area had to increase about three orders of magnitude for the water and intruder pathway concentrations to be equal. 
Table 6-9. Parameter Values That Caused the Permissible Concentrations for the Water and Intruder Pathways to Be Equal for Indicator Radionuclides at Paducah (tumulus design) (bold italic type indicates limiting pathway in the PE)

(a) Water/Intruder Pathways

\begin{tabular}{|c|c|c|c|c|c|c|}
\hline \multirow[t]{4}{*}{$\begin{array}{l}\text { Indicator } \\
\text { Nuclide }\end{array}$} & \multirow[t]{4}{*}{$\begin{array}{c}\text { PE } \\
C_{\text {Whater }} \\
\left(\mu \mathrm{Ci} / \mathrm{m}^{3}\right)\end{array}$} & \multirow[t]{4}{*}{$\begin{array}{c}\text { PE } \\
c_{W / \ln t} \\
\left(\mu \mathrm{Ci} / \mathrm{m}^{3}\right)\end{array}$} & \multirow[t]{4}{*}{$\begin{array}{c}\text { PE } \\
C_{\text {W-Intr }} \\
C_{W-W a t e r}\end{array}$} & $\begin{array}{c}\text { Natural } \\
\text { Recharge, } \\
\text { i } \\
(\mathrm{m} / \mathrm{y})\end{array}$ & $\begin{array}{l}\text { Groundwater } \\
\text { Darcy } \\
\text { Velocity, } q_{g w} \\
(\mathrm{~m} / \mathrm{y})\end{array}$ & $\begin{array}{c}\text { Area, } \\
\text { A } \\
\left(\mathrm{m}^{2}\right)\end{array}$ \\
\hline & & & & \multicolumn{3}{|c|}{ PE Values } \\
\hline & & & & 0.12 & 25 & 2500 \\
\hline & & & & \multicolumn{3}{|c|}{$\begin{array}{c}\text { Value That Caused Equal } \\
\text { Concentrations }\end{array}$} \\
\hline $\mathrm{H}-3$ & $1 E+12$ & $7 E+07$ & $7 \mathrm{E}-05$ & b & $\bar{b}$ & $b$ \\
\hline$C-14$ & $7 E+03$ & $1 E+04$ & 1.4 & 0.06 & 55 & 550 \\
\hline Sr-90 & NL & $5 E+04$ & - & b & $b$ & $b$ \\
\hline Tc-99 & $9 E+02$ & $2 E+04$ & 22 & 0.006 & 450 & $<100$ \\
\hline Cs-137 & $\mathrm{NL}^{\mathrm{c}}$ & $8 E+05$ & - & $b$ & b & $\mathrm{b}$ \\
\hline$U-238$ & $4 E+02$ & $5 E+03$ & 13 & $0.01^{c}$ & 300 & $<100$ \\
\hline Pu-239 & $1 \mathrm{E}+03^{\circ}$ & $6 E+03$ & 6 & $0.08^{c}$ & $150^{c}$ & $<100^{c}$ \\
\hline $\begin{array}{l}\mathrm{Am}-241 \\
(\mathrm{~Np}-237)^{d}\end{array}$ & $1 E+05^{\circ}$ & $9 E+03$ & 0.09 & $2.5^{\circ}$ & $1^{\circ}$ & $1,000,000^{\circ}$ \\
\hline
\end{tabular}

a "NL" means No Limit - estimated permissible concentration is greater than the specific activity of the pure elemental radionuclide.

b No variation in values caused equal concentrations.

c Arrival time at the performance boundary is greater than $10,000 \mathrm{y}$.

d The dominant decay product for Am-241

e Based on the dominant decay product, Np-237

"_." Value could not be calculated.

(b) Water/Atmospheric Pathways

\begin{tabular}{|c|c|c|c|c|c|c|}
\hline \multirow[t]{4}{*}{$\begin{array}{l}\text { Indicator } \\
\text { Nuclide }\end{array}$} & \multirow[t]{4}{*}{$\begin{array}{c}\text { PE } \\
C_{w-W a t e r} \\
\left(\mu \mathrm{Ci} / \mathrm{m}^{3}\right)\end{array}$} & \multirow[t]{4}{*}{$\begin{array}{c}\text { PE } \\
C_{W-A t m} \\
\left(\mu \mathrm{Ci} / \mathrm{m}^{3}\right)\end{array}$} & \multirow[t]{4}{*}{$\begin{array}{c}\text { PE } \\
\frac{C_{W-A t m}}{C_{W-W a t e r}}\end{array}$} & $\begin{array}{c}\text { Natural } \\
\text { Recharge, } \\
i \\
(\mathrm{~m} / \mathrm{y})\end{array}$ & $\begin{array}{l}\text { Groundwater } \\
\text { (Aquifer) } \\
\text { Velocity, } q_{g w} \\
(\mathrm{~m} / \mathrm{y})\end{array}$ & $\begin{array}{c}\text { Area, } \\
\text { A } \\
\left(\mathrm{m}^{2}\right)\end{array}$ \\
\hline & & & & \multicolumn{3}{|c|}{ PEValues. } \\
\hline & & & & 0.12 & 25 & 2500 \\
\hline & & & & \multicolumn{3}{|c|}{$\begin{array}{c}\text { Value That Caused Equal } \\
\text { Concentrations }\end{array}$} \\
\hline $\mathrm{H}-3$ & $1 \mathrm{E}+12$ & $7 E+09$ & 0.007 & 1.8 & a & $a$ \\
\hline$C-14$ & $7 E+03$ & $5 E+03$ & 0.7 & 0.2 & 15 & 8,000 \\
\hline
\end{tabular}

a No variation in values caused equal concentrations. 
The parameter values that caused the permissible concentrations for the water and atmospheric pathways to become equal are listed in Table 6-9b for $\mathrm{H}-3$ and $\mathrm{C}-14$. For $\mathrm{H}-3$, the limiting pathway is the intrusion scenario, so this comparison is not applicable. For C-14, the recharge had to increase by a factor of 2 , the groundwater velocity had to decrease by about a factor of 2 , or the plan area had to increase by a factor of 3 to change the limiting pathway from atmospheric to water.

The $K_{d}$ values that caused the permissible concentrations for the water and intruder pathways to be the same are listed in Table 6-10 for 5 of the indicator radionuclides. The indicator radionuclides $\mathrm{H}-3, \mathrm{C}-14$, and Tc-99 were not considered in this analysis because general consensus is that the $K_{d}$ values for these radionuclides are small. A $K_{d}$ value of about $42 \mathrm{~mL} / \mathrm{g}$ for the geologic media resulted in an arrival time at the performance boundary equal to $10,000 \mathrm{y}$.

Table 6-10. Variation of $K_{d}$ Values for the Geologic Media at Paducah (tumulus design) (a $K_{d}$ value of $42 \mathrm{~mL} / \mathrm{g}$ caused radionuclide arrival at the performance boundary equal to $10,000 \mathrm{y})$

\begin{tabular}{|c|c|c|c|c|c|}
\hline $\begin{array}{l}\text { Indicator } \\
\text { Nuclide }\end{array}$ & $\begin{array}{c}\text { PE } \\
K_{d} \\
(\mathrm{~mL} / \mathrm{g})\end{array}$ & $\begin{array}{c}\text { PE } \\
C_{W-\text { Water }}\end{array}$ & $\begin{array}{l}\text { PE } \\
C_{W-\text {-ntr }}\end{array}$ & $\begin{array}{c}\text { PE } \\
\frac{C_{W-I n t r}}{C_{W-W a t e r}}\end{array}$ & $\begin{array}{l}K_{d} \text { Value That } \\
\text { Caused Equal } \\
\text { Concentrations }\end{array}$ \\
\hline Sr-90 & 15 & NL & $5 E+04$ & - & c \\
\hline Cs-137 & 280 & $\mathrm{NL}^{b}$ & $8 E+05$ & - & 0 \\
\hline U-238 & 35 & $4 E+02$ & $5 E+03$ & 13 & $c, d$ \\
\hline Pu-239 & 550 & $1 E+03^{b}$ & $6 E+03$ & 6 & $800^{b, g}$ \\
\hline $\begin{array}{l}A m-241 \\
(\mathrm{~Np}-237)^{\circ}\end{array}$ & $\begin{array}{c}1900 \\
(5)\end{array}$ & $1 E+05^{f}$ & $9 E+03$ & 0.09 & 14 \\
\hline
\end{tabular}

a "NL" means No Limit - the estimated permissible waste concentration is greater than the specific activity of the pure elemental radionuclide.

b Arrival time at the performance boundary is greater than $10,000 \mathrm{y}$.

c No variation in value caused equal concentrations.

d Value greater than $42 \mathrm{~mL}$ g caused arrival at the performance boundary after $10,000 \mathrm{y}$, which changed the limiting pathway.

e The dominant decay product for Am-241

f Concentration determined by Np-237 (see Appendix E in Volume 2)

g Value less than $42 \mathrm{~mL} g$ caused arrival at the performance boundary before10,000 y, which changed the limiting pathway.

-" Value could not be calculated.

For Cs-137, a decrease in $K_{d}$ of about 2 orders of magnitude to $0 \mathrm{~mL} / \mathrm{g}$ caused the pathway concentrations to become equal. For $U-238$, any $K_{d}$ value over $42 \mathrm{~mL} / \mathrm{g}$ caused the arrival time at the performance boundary to be greater than $10,000 \mathrm{y}$, thereby changing the limiting pathway from water to intruder. For Pu-239, a $K_{d}$ value of $800 \mathrm{~mL} / \mathrm{g}$ caused the water pathway concentration to equal the intruder pathway concentration although the arrival time still 
exceeded $10,000 \mathrm{y}$; the $K_{d}$ value had to be decreased to less than $42 \mathrm{~mL} / \mathrm{g}$ for the limiting pathway to change from intruder to water. The PE permissible waste concentration for Am-241 was limited by the decay product $(\mathrm{Np}-237)$ contribution to the dose. If the $K_{d}$ value for Am-241 was reduced to $14 \mathrm{~mL} / \mathrm{g}$, then the water pathway concentration was limited by the parent radionuclide (Am-241) and the water pathway controlled. Due to the long half-life of Np-237, reduction of its $K_{d}$ had no effect on the resulting waste concentration.

\subsubsection{Physical Constraints on Sensitivity Analysis Values}

The PE results for Paducah are based on parameter values provided by the Paducah technical staff for site-specific parameters used in calculations. Descriptions and technical justifications of these values are provided in Sections 6.3 and 6.4. The range and statistical distribution may not be known for each input parameter value; however, site-specific knowledge can be used to determine whether the values determined in the sensitivity analysis are reasonable and physically possible at Paducah.

\section{Natural Recharge}

The sensitivity analysis results indicate it was possible to change the limiting pathway for $\mathrm{C}-14$ from atmosphere to water by increasing the recharge. The values for recharge estimated in the sensitivity analysis range from 0.006 to $2.5 \mathrm{~m} / \mathrm{y}(0.02$ to $8.2 \mathrm{ft} / \mathrm{y}$ ) (Table 6-9) compared to the $P E$ value of $0.12 \mathrm{~m} / \mathrm{y}(0.39 \mathrm{ft} / \mathrm{y})$. The natural recharge at Paducah has no documented range. Doubling the recharge to $0.2 \mathrm{~m} / \mathrm{y}(0.66 \mathrm{ft} / \mathrm{y})$ as for $\mathrm{C}-14$ is probably reasonable for this site (Table 6-9b). The remaining indicator radionuclides (Tc-99, U-328, and Pu-239) had very small values which are not physically reasonable, and Am-241 had an unreasonably large value.

\section{Groundwater Darcy Velocity}

The sensitivity analysis results indicate it is possible to change the limiting pathway for $\mathrm{C}-14$ from the atmospheric to water pathway by decreasing the groundwater velocity. The values for the groundwater Darcy velocity estimated by the sensitivity analysis vary from 1 to $450 \mathrm{~m} / \mathrm{y}$ (3 to $1480 \mathrm{ft} / \mathrm{y}$ ) (Table 6-9) compared to the PE value of $25 \mathrm{~m} / \mathrm{y}$ ( $82 \mathrm{ft} / \mathrm{y})$. At Paducah, the groundwater Darcy velocity range is estimated to be about $3.5 \mathrm{~m} / \mathrm{y}$ to $175 \mathrm{~m} / \mathrm{y}(11 \mathrm{ft} / \mathrm{y}$ to $574 \mathrm{ft} / \mathrm{y})$. The C-14 sensitivity analysis value falls within this range and is probably reasonable. The sensitivity analysis values for Tc-99, U-238, Pu-239, and Am-241 did not fall within the estimated range and are probably not physically reasonable.

\section{Facility Area}

The sensitivity analysis results indicate it was possible to change the limiting pathway for $\mathrm{C}-14$ from atmosphere to water by increasing the facility size. The value for the facility area estimated in the sensitivity analysis ranged from $550 \mathrm{~m}^{2}$ to $1,000,000 \mathrm{~m}^{2}$ (Table 6-9). The sites considered at PGDP for a MWDF could accommodate a facility with a size up to about $140 \mathrm{~m}$ by $140 \mathrm{~m}\left(20,000 \mathrm{~m}^{2}\right)$. Only the sensitivity analysis value for C-14 is less than $20,000 \mathrm{~m}^{2}$. 


\section{Distribution Coefficients}

The results shown in Table 6-10 indicate that it is possible to change the limiting exposure pathway from water to intruder by changing the $K_{d}$ of U-238. Changing the $K_{d}$ for U-238 to 42 $\mathrm{mL} / \mathrm{g}$ (the $K_{d}$ required to cause arrival at the performance boundary at $10,000 \mathrm{y}$ ) is reasonable because this value is within the reported range of $1.78 \mathrm{~mL} / \mathrm{g}$ to $45 \mathrm{~mL} / \mathrm{g}$ for U-238 at Paducah. A $K_{d}$ of $42 \mathrm{~mL} / \mathrm{g}$ also changes the limiting pathway for $\mathrm{Pu}-239$, but this value does not fall within the reported range of $100 \mathrm{~mL} / \mathrm{g}$ to $550 \mathrm{~mL} / \mathrm{g}$ reported for $\mathrm{Pu}-239$ at Paducah, and therefore is not reasonable. The large changes required to change the limiting pathways for Cs-137 and Am-241 are probably not reasonable.

\subsection{OBSERVATIONS}

Based on the results of the PE and the parameter-sensitivity analysis, the following observations can be made about MLLW disposal at PGDP:

- The Paducah site has characteristics that are typical of a humid climate. Among DOE sites, the annual rainfall and the natural recharge at Paducah are high $(1.2 \mathrm{~m} / \mathrm{y}$ and $0.12 \mathrm{~m} / \mathrm{y}$ [3.9 $\mathrm{ft} / \mathrm{y}$ and $0.39 \mathrm{ft} / \mathrm{y}]$, respectively). The thickness of the vadose zone at the selected site at Paducah is $1.5 \mathrm{~m}(4.9 \mathrm{ft})$, underlain by a saturated semi-confining layer of $14.0 \mathrm{~m}(45.9 \mathrm{ft})$ thickness. Thus, the total thickness of the zone of vertical transport is $15.5 \mathrm{~m}(50.8 \mathrm{ft})$. Below this zone is the Regional Gravel Aquifer. Travel times as short as $100 \mathrm{y}$ and up to $910,000 \mathrm{y}$ have been computed for some radionuclides for the water pathway at Paducah.

- For Paducah, the results indicate that, of the 58 radionuclides evaluated in the PE, 45 radionuclides for the trench design and 47 radionuclides for the tumulus design would be limited by the intrusion scenarios. These results reflect the dominant role of the selected human intrusion scenarios that is demonstrated for almost all the sites considered in the PE (see Sections 7.5 and 7.6 in Volume 2). This dominance indicates a need to be aware of the inability to predict the social behavior of populations far into the future.

The results also indicate that for the water pathway, 34 radionuclides for the trench design and 38 radionuclides for the tumulus design would arrive at the performance boundary after the 10,000-y period of consideration in the $\mathrm{PE}$ analysis of the water pathway. Of the radionuclides that would arrive before 10,000 y, 7 for the trench design and 4 for the tumulus design had no limit on waste concentration.

Because Paducah has many radionuclides that either are limited by the intrusion scenarios, arrive at the performance boundary after $10,000 \mathrm{y}$, or have no limit on waste concentration, this site may have flexibility in accepting a variety of radionuclides for disposal. 
- Using either a tumulus design is feasible at Paducah. A trench is not considered feasible because of the presence of groundwater at a shallow depth. At Paducah, there is no significant difference in the permissible waste concentrations computed with the PE methodology for the trench as compared to the tumulus. That is, there is less than one order of magnitude difference in the waste limits between the two disposal facility designs. The notable exceptions include H-3 and Pd-107, both of which are limited by the water pathway for the trench and by intrusion for the tumulus.

- Paducah has physical constraints that could limit disposal activities. There is limited space available at Paducah for an MLLW disposal facility.

- The sensitivity analysis for PGDP indicates that of the indicator radionuclides, the limiting pathway for C-14 was sensitive to selection of values for natural recharge, groundwater Darcy velocity, and facility area (Table 6-9).

In flow and transport problems, the $K_{d}$ values are often the most uncertain site-specific input parameters. Of the indicator radionuclides, the limiting pathway for U-238 was sensitive to selection of $K_{d}$ values (Table 6-10).

- The PE was a scoping analysis performed using assumptions that are conservative relative to most LLW performance assessments. There are no site-specific studies to compare with the PE results. A more detailed performance assessment would be required for permitting or other disposal planning. 


\subsection{REFERENCES}

Baer, T.A., L. L. Price, J. N. Emery, N. E. Olague, 1994. Second Performance Assessment Iteration of the Greater Confinement Disposal Facility at the Nevada Test Site.

SAND93-0089. Albuquerque, NM: Sandia National Laboratories.

Clausen, J. L., J. W. Douthitt, K. R. Davis, and B. E. Phillips, 1992. "Report of the Paducah Gaseous Diffusion Plant Groundwater Investigation Phase III," KY/E-150, Uranium Enrichment Organization, Paducah, Kentucky.

Clausen, J.L., 1994. Personal communication as facsimile to J. C. Wang (ORNL) dated October $20,1994$.

Cooper, C.D., and F.C. Alley, 1986. Air Pollution Control: A Design Approach. Prospect Heights, $\mathbb{L}$ : Waveland Press, Inc.

CRC, 1981. CRC Handbook of Chemistry and Physics. Eds. Robert C. Weast and Melvin J. Astle. Boca Raton, FL: CRC Press, Inc.

Davis, K.R., 1995a. Personal communication as electronic mail to J.C. Wang (ORNL) dated May $2,1995$.

Davis, K.R., 1995b. Memorandum to LLW Repository Files, dated April 6, 1995.

Davis, K.R., 1995c. Facsimile communication from Ken Davis (PGDP) to Jim Wang (ORNL), April 28, 1995.

DOE 1989. "Environmental Survey Preliminary Report, Paducah Gaseous Diffusion Plant, Paducah, Kentucky," DOE/EH/OEV-20P, U.S. Department of Energy, Washington, D.C.

EPA, 1992. User's Guide for the Industrial Source Complex (ISC2) Dispersion Models, Volume I: User Instructions. EPA Publication No. EPA-450/4-92-008a. Research Triangle, NC: U.S. Environmental Protection Agency.

FFCAct, 1992. Federal Facility Compliance Act of 1992. P.L. 102-386, October 1992.

GeoTrans, Inc., 1990. Numerical Modeling of the Groundwater Flow at the Paducah Gaseous Diffusion Plant, Phase III-Calibrated Three-Dimensional Groundwater Flow Model, Final Report. Sterling, VA: GeoTrans, Inc.

Gruebel, Marilyn M., Robert D. Waters, Maryann B. Hospelhorn, and Margaret S. Y. Chu, eds., 1994. Framework for DOE Mixed Low-Level Waste Disposal: Site Fact Sheets. SAND942728. Albuquerque, NM: Sandia National Laboratories. 
Kincaid, C.T., J.W. Shade, G.A. Whyatt, M.G. Piepho, K. Rhoads, J.A. Voogd, J.H. Westsik, Jr., M.D. Freshley, K.A. Blanchard, and B.G. Lauzon, eds., 1993. Performance Assessment of Grouted Double-Shell Tank Waste Disposal at Hanford. WHC-SD-WM-EE-004, Rev. 0. U.S. Department of Energy, Pacific Northwest Laboratory and Westinghouse Hanford Company.

Kornegay, F. C., D. C. West, and T. G. Jett, 1991. "Paducah Gaseous Diffusion Plant Environmental Report for 1990," ES/ESH-18/V3, Martin Marietta Energy Systems, Oak Ridge, Tennessee.

Kornegay, F. C., D. C. West, V. W. Jones, and C. M. Horak, 1994. "Paducah Gaseous Diffusion Plant Environmental Report for 1993," ES/ESH-53/V3, Martin Marietta Energy Systems, Oak Ridge, Tennessee.

Lee, D. W., J. C. Wang, and D. C. Kocher, 1995. "Operating Limit Study for the Proposed Solid Waste Landfill at Paducah Gaseous Diffusion Plant," ORNL/TM-13008, Oak Ridge National Laboratory, Oak Ridge, Tennessee.

Maheras, Steven J., Arthur S. Rood, Swen O. Magnuson, Mary E. Sussman, and Rajiv N. Bhatt, 1994. Radioactive Waste Management Complex Low-Level Waste Radiological Performance Assessment. EGG-WM-8773. Idaho Falls, ID: U.S. Department of Energy Office of Environmental Restoration and Waste Management, DOE Idaho Operations Office.

MMES (Martin Marietta Energy Systems), EG\&G Idaho, Inc., and Westinghouse Savannah River Company, 1994. Radiological Performance Assessment for the E-Area Vaults Disposal Facility (U). WSRC-RP-94-218, Rev. 0. Aiken, SC: Westinghouse Savannah River Company.

ORNL (Oak Ridge National Laboratory), 1994. Performance Assessment for Continuing and Future Operations at Solid Waste Storage Area 6. ORNL-6783. Oak Ridge, TN: U.S. Department of Energy, Oak Ridge National Laboratory.

Rogers, J. G., D. L. Ashburn, and M. R. Aaron, 1988. "Environmental Surveillance of the U.S. Department of Energy Paducah Reservation and Surrounding Environs during 1987," ES/ESH-4/V3, Martin Marietta Energy Systems, Oak Ridge, Tennessee.

Rogers, J. G., and T. G. Jett 1989. "Paducah Gaseous Diffusion Plant Site Environmental Report for 1988," ES/ESH-8/V3, Martin Marietta Energy Systems, Oak Ridge, Tennessee.

Ruffner, J. A., 1985. "Climates of the States, National Oceanic and Atmospheric Administration Narrative Summaries, Tables, and Maps for Each State with Overviews of State Climatologist Programs," 3rd ed., Gale Research Co., Detroit, Michigan. 
Thibault, D.H., M.I. Sheppard, and P.A. Smith, 1990. A Critical Compilation and Review of Default Soil SolidLiquid Partition Coefficients, Kd, for Use in Environmental Assessments. AECL-10125. Pinawa, Manitoba, Canada: Whiteshell Nuclear Research Establishment, Atomic Energy of Canada Limited.

Shaia, G., 1995. Personal communication as electronic mail to Greg Zimmerman (ORNL) dated March 27, 1995.

USGS 1982. "Joppa, IL - KY Quadrangle - 7.5 Minute Series Topographic Map," DMA 3258 III NE - Series V863, U. S. Geological Survey, Reston, VA.

Wang, J. C., D. W. Lee, R. H. Ketelle, R. R. Lee, and D. C. Kocher, 1994. "Determination of Operating Limits for Radionuclides for a Proposed Landfill at Paducah Gaseous Diffusion Plant," p. 95 in Tenth Proceedings of Nuclear Thermal Hydraulics, 1994 ANS Winter Meeting, November 13-17, Washington, DC.

\section{Acknowledgments}

The ORNL Core Team acknowledges the contributions of Greg Shaia, Mark Shanks, and Ken Davis of the Paducah staff. 


\section{Nevada: NEVADA TEST SITE (NTS) \\ Core Team Contacts: Margaret S.Y. Chu and Marilyn M. Gruebel}

The Federal Facility Compliance Act (FFCAct, 1992) requires the Department of Energy (DOE) to establish plans in conjunction with its regulators and with members of the public for the treatment of DOE's mixed low-level waste (MLLW). Although the FFCAct did not specifically address disposal of treated MLLW, both DOE and the States recognized that disposal issues were an integral part of treatment discussions. Since 1992, DOE has worked with the States to define and develop an evaluation process for disposal options. Preliminary activities of this joint DOEState process have narrowed the sites for further evaluation from 49 to 15 .

The Disposal Workgroup (DWG), which was established by DOE to develop a process for evaluating disposal options, designed a performance evaluation (PE) to quantify and compare the limitations of the remaining $15 \mathrm{DOE}$ sites for MLLW disposal. The principal goal of the PE was to estimate, for grouted residuals resulting from the treatment of MLLW, permissible concentrations of radionuclides in waste that could be disposed at each site. These "permissible waste concentrations" were based solely on long-term physical performance of the disposal facility and did not take into account any operational waste acceptance criteria that a site might have developed. The PE did not address any ethical, social, or policy considerations relevant to siting such facilities.

The PE used analyses that are consistent with the approach used in many low-level waste (LLW) performance assessments. The objective was to use a set of modeling assumptions of sufficient detail to capture major site-specific characteristics and yet be general enough for consistent application at all sites. Additionally, the analyses were designed to ensure that the sites were analyzed consistently, and that all major assumptions were clearly stated.

The remainder of this chapter provides the PE results for the Nevada Test Site (NTS), one of the 15 sites being evaluated. The chapter contains the following information:

Section 7.1: brief, general description of the site, based on previous work done by the DWG (Gruebel et al., 1994) and on information provided by the site

Section 7.2: plans for MLLW disposal, if any, and the location evaluated in the PE

Section 7.3: current understanding of radionuclide movement at the selected location based on available information, and the conceptual model used for each pathway that was evaluated at the site

Section 7.4: site-specific and generic values used in the PE calculations and their sources

Section 7.5: estimates of maximum waste concentrations determined in the PE calculations for the pathways evaluated at NTS, along with calculated values used in determining these results

Section 7.6: summary of results based on disposal-facility design

Section 7.7: observations based on the results of the PE

Section 7.8: references 
The general assumptions and methodology used in the PE are summarized in Chapter 1 of this volume and explained in more detail in Volume 2 of this report. Overall results for all the sites are discussed in Chapter 7 of Volume 2.

\subsection{GENERAL DESCRIPTION OF THE SITE}

The Nevada Test Site is located in southern Nevada, approximately $105 \mathrm{~km}(65 \mathrm{mi})$ northwest of Las Vegas, Nevada (Figure 7-1). The site is a DOE facility occupying $3500 \mathrm{~km}^{2}$ $\left(1350 \mathrm{mi}^{2}\right)$ of federally owned land in Nye County (Figure 7-2). The site is bordered to the west, north, and east by the U.S. Air Force Nellis Base Range, another government-owned, restrictedaccess area. To the south, the NTS is bordered by land under the control of the U.S. Bureau of Land Management (ERDA, 1977).

No permanent population is within $10 \mathrm{~km}(6.2 \mathrm{mi})$ of the center of the site. Mercury, located in the southeast corner of the site, is the main base camp at the NTS and serves as the administrative and logistical center. Nearby towns within $50 \mathrm{~km}(31 \mathrm{mi})$ include Beatty (population 1600), Indian Springs (population 1200), and Armagosa Valley (population 800), for an estimated population of 3600 . Pahrump is approximately $64 \mathrm{~km}(40 \mathrm{mi})$ south-southwest of Mercury, with a population of approximately 15,000 .

The Nevada Test Site was the primary location for testing the nation's nuclear weapons and devices between 1951 and 1992, when a testing moratorium was established. Programmatic functions include the management and disposal of wastes generated by NTS activities and by other DOE-approved, defense-related facilities across the United States. Capabilities include the storage and disposal of LLW and storage of transuranic waste. Hazardous waste management includes the treatment of waste explosives in the Explosive Ordnance Disposal Unit and the storage of hazardous waste on the Hazardous Waste Storage Unit prior to treatment and/or disposal at an off-site RCRA-permitted facility.

The Nevada Test Site is located within an arid climate region of the northernmost portion of the Mojave Desert. The average annual precipitation at the NTS is $25 \mathrm{~cm}$ (10 in.) in the surrounding mountains and varies from 8 to $15 \mathrm{~cm}$ (3 to $6 \mathrm{in}$.) in individual valleys (Kearl, 1982). The prevailing winds are northerly from 10 to $14 \mathrm{kph}$ (6 to $9 \mathrm{mph}$ ) during the winter months, and southerly from 17 to $35 \mathrm{kph}$ (10 to $22 \mathrm{mph}$ ) during the warm summer months (Gruebel et al., 1994). Average temperatures over the valley floors are characterized by a large daily range. Average temperatures for the warmest and coldest hours in Frenchman Flat in January are $12^{\circ} \mathrm{C}$ and $-3^{\circ} \mathrm{C}\left(53^{\circ} \mathrm{F}\right.$ and $\left.25^{\circ} \mathrm{F}\right)$, respectively. Corresponding temperatures in July are $36^{\circ} \mathrm{C}$ and $17^{\circ} \mathrm{C}$ $\left(97^{\circ} \mathrm{F}\right.$ and $\left.62^{\circ} \mathrm{F}\right)$, respectively (ERDA, 1977). 


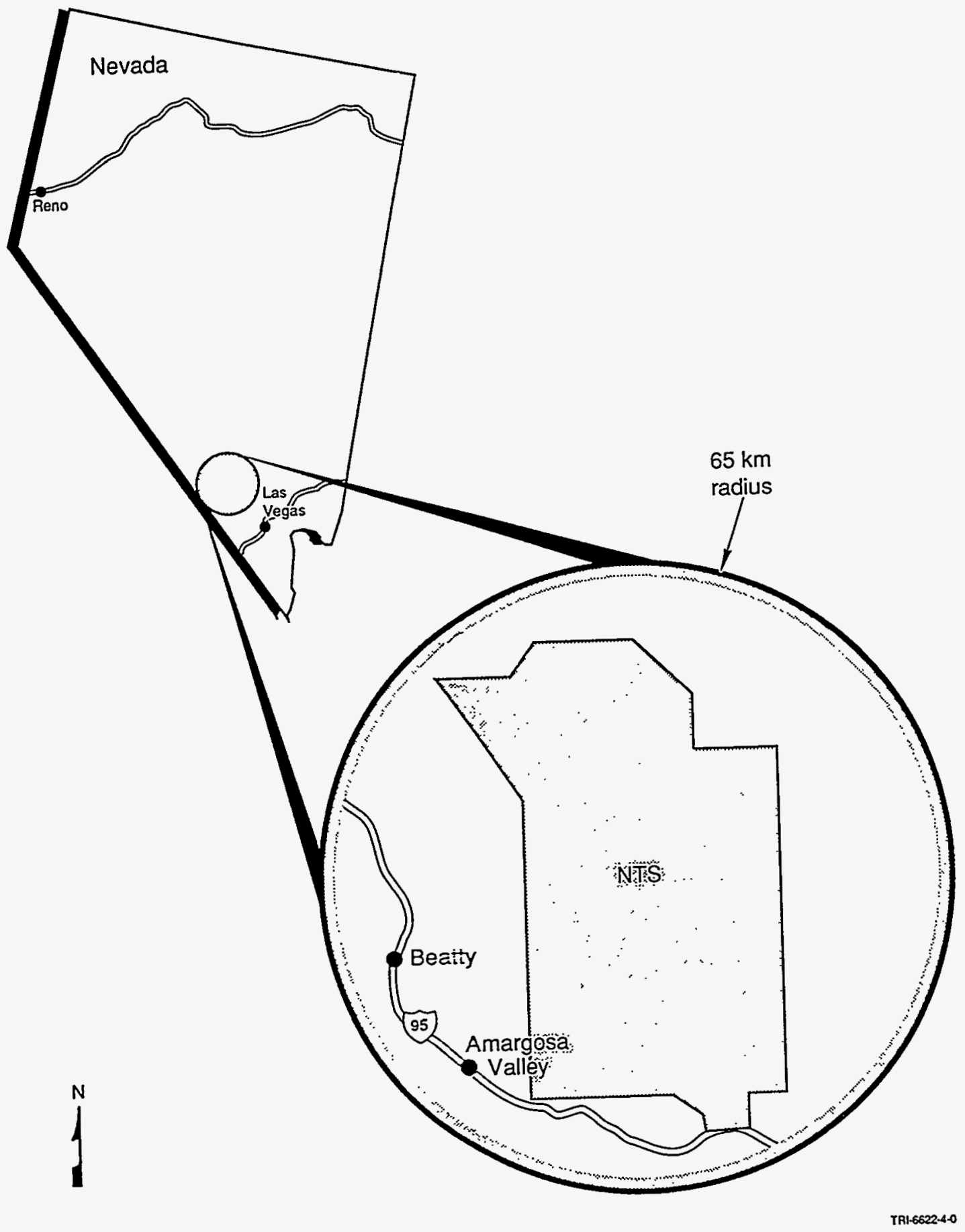

Figure 7-1. Location map for Nevada Test Site. 


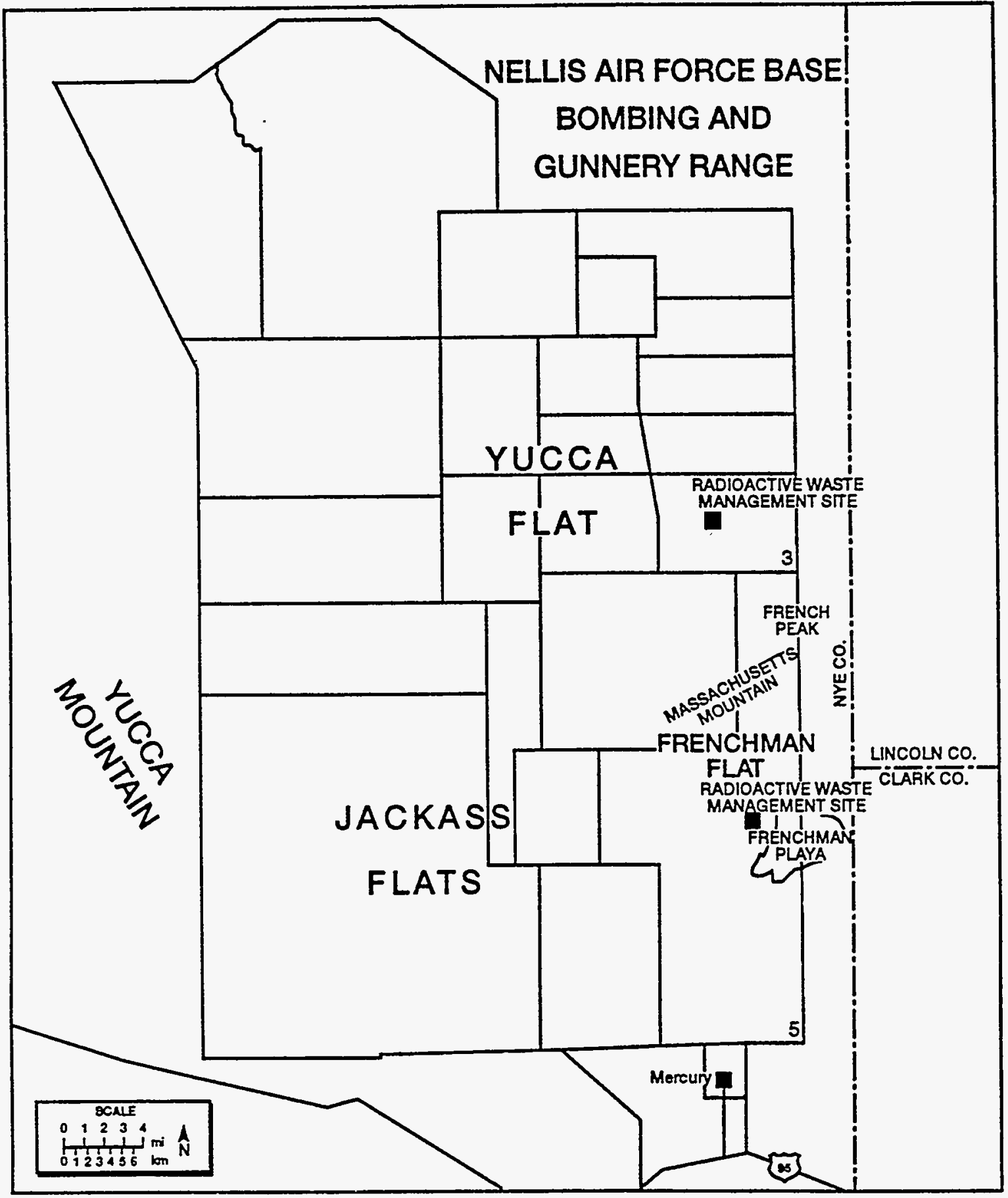

Figure 7-2. Site map for Nevada Test Site. 
The terrain of the NTS is typical of much of the Basin and Range physiographic province in Nevada, Arizona, and Utah. The province consists of intervening valleys and ranges, all nearly parallel and trending roughly north-south. A typical Basin and Range valley is a gently sloping, alluvium-filled basin with a playa located in the bottom. The terrain at the NTS is extremely irregular, with elevations ranging from a high of $2350 \mathrm{~m}(7700 \mathrm{ft})$ on Rainier Mesa in the

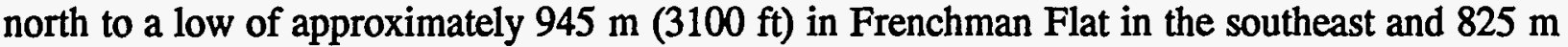
$(2700 \mathrm{ft})$ in the extreme southwest corner on the edge of the Amargosa Desert. There is a general but frequently interrupted downward slope from north to south.

No aquifers in the NTS area have been designated by the U.S. Environmental Protection Agency (EPA) as sole source aquifers as defined in 40 CFR Part 149.2.

\subsection{STATUS AND SITING OF MLLW DISPOSAL FACILITY}

Two principal sites for defense waste management that accept LLW for disposal are located at the NTS: Area 3 Radioactive Waste Management Site (RWMS) and Area 5 RWMS. The Area 3 RWMS, established in 1974, is located in Yucca Flat, a closed basin within the northeast quadrant of the NTS. The Area 3 RWMS covers an area of approximately 20 hectares $(50 \mathrm{ac})$, with two disposal cells located within the facility boundaries. Each waste management cell is comprised of two subsidence craters that have resulted from underground nuclear tests, with the area between the two craters excavated to make one large, oval-shaped landfill cell. The U3axbl cell was operational prior to regulatory controls for MLLW and may contain MLLW. In order to meet regulatory concerns, U3axbl will have a RCRA-approved closure. The U3ahat cell accepts only LLW. The Area 3 RWMS currently does not accept MLLW, and there are no future plans for acceptance. An additional three craters within the Area 3 RWMS have not been used.

The Area 5 RWMS (Figure 7-3), established in 1978, is located in northern Frenchman Flat, a closed basin along the eastern boundary of the NTS. The developed portion of the Area 5 RWMS occupies 37 hectares (92 ac) in the southeast corner of the 296 hectares (732 ac) designated area. The developed portion of the RWMS currently is used to dispose defense LLW in 17 landfill cells (pits and trenches) (REECo, 1991). Greater Confinement Disposal (GCD) facilities and a transuranic and MLLW storage pad are also located at the Area 5 RWMS.

At the time of the PE, NTS personnel were formulating plans for on-site disposal of MLLW at the Area 5 RWMS. One MLLW disposal facility, Pit 3, is located in the Area 5 RWMS. Interim status was issued for Pit 3 in 1987 by the State of Nevada, and it was in operation until May 4, 1990, when operations were suspended due to compliance issues. In July 1992, the DOE submitted a RCRA Part B permit application for a proposed Mixed Waste Disposal Unit (MWDU) at the Area 5 RWMS. The application describes the proposed MWDU as consisting of 10 landfill cells with a total area of $0.2 \mathrm{~km}^{2}\left(0.08 \mathrm{mi}^{2}\right)$. Each cell is designed to contain approximately $12,040 \mathrm{~m}^{3}\left(425,250 \mathrm{ft}^{3}\right)$ of MLLW. This disposal capacity was based on the maximum number of $1.2 \times 2.1 \times 1.2 \mathrm{~m}(4 \times 7 \times 4 \mathrm{ft})$ waste packages that will fit into each cell with the appropriate amount of fill material (NTS, 1992). 


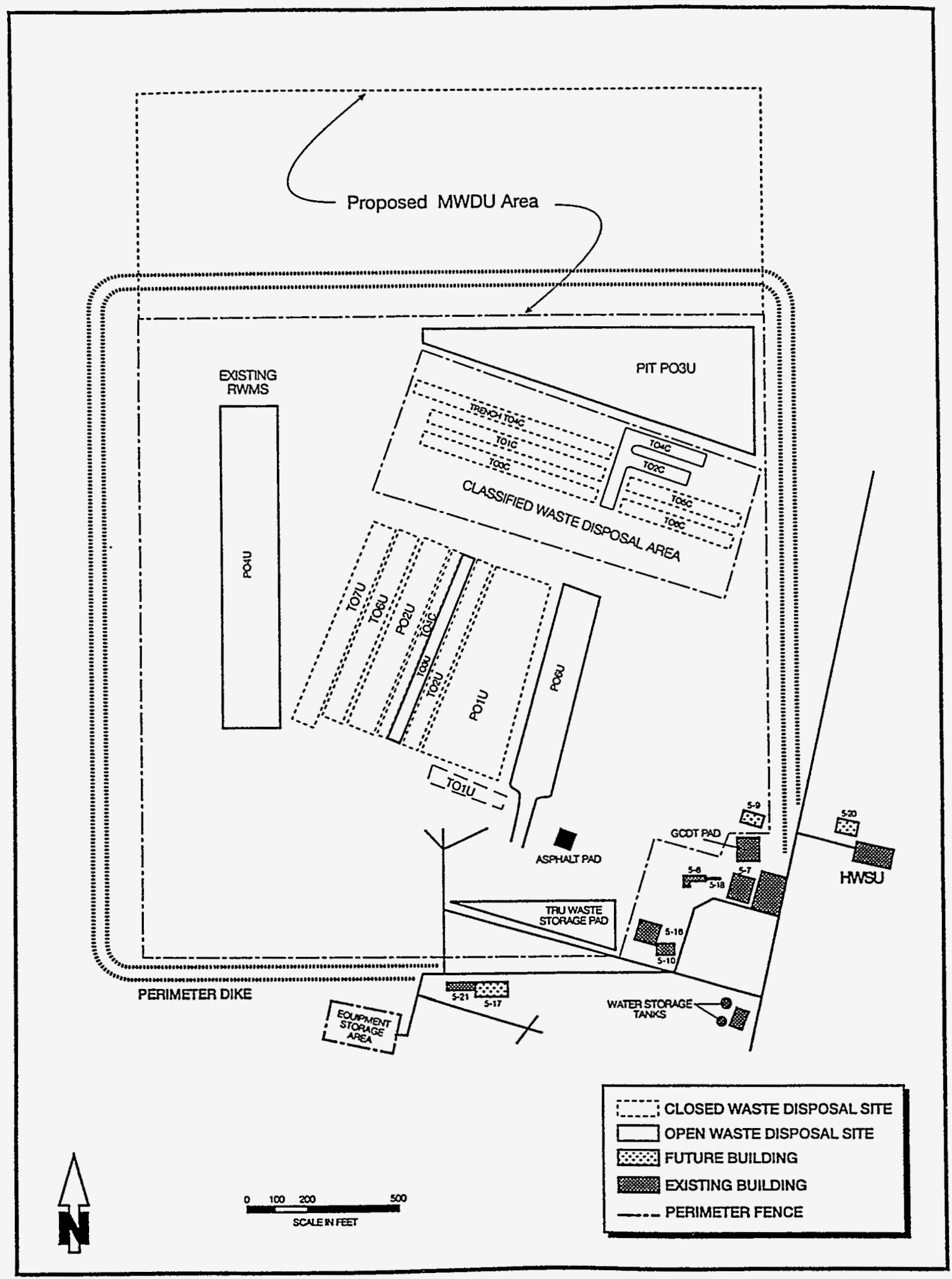

Figure 7-3. Site layout of the Area 5 RWMS. 
Two generic disposal facilities were considered in the PE: a RCRA-compliant, belowground trench and a RCRA-compliant, above-ground tumulus (described in more detail in Chapter 5 of Volume 2). The generic facilities were selected to provide consistency in analysis of the performance of the 15 sites. Both generic facilities were assumed to be square with a plan area of $2500 \mathrm{~m}^{2}\left(26,910 \mathrm{ft}^{2}\right)$.

\subsection{BASIS FOR CONCEPTUAL MODEL USED IN THE PE}

Knowledge of site conditions at NTS was based on radiological performance assessments at the Area 5 RWMS and on hydrologic characterization studies of the site. A radiological performance assessment of the LLW facilities at the Area 5 RWMS was conducted in 1991 and revised in 1992 (Magnuson et al., 1992) to demonstrate compliance of LLW disposal facilities with the appropriate radiological criteria of DOE Order 5820.2A. A third revision of the performance assessment was underway at the time of the PE and was expected to be completed in 1995.

In the performance assessment of the LLW facilities, waste was assumed to be disposed in a square-shaped area approximately $305 \mathrm{~m}^{2}\left(3390 \mathrm{ft}^{2}\right)$, with a depth of $7.5 \mathrm{~m}(24.5 \mathrm{ft})$; the closed facility was covered with $2.4 \mathrm{~m}$ (7.9 ft) of soil, $1.2 \mathrm{~m}(3.9 \mathrm{ft})$ of which is above grade. The calculations involved modeling the transport of radionuclides from buried waste to surface soil and subsurface media and eventually to members of the general public via groundwater, atmospheric, and food chain pathways. Calculations in the performance assessment also focused on modeling the impacts of inadvertent human intrusion into the waste.

A preliminary performance assessment was conducted (Price et al., 1993) to demonstrate compliance with EPA's 40 CFR 191 for TRU waste in the GCD boreholes located at the Area 5 RWMS. The GCD facilities are deep boreholes (120 $\mathrm{ft}[37 \mathrm{~m}])$ used for disposal of DOE's special-case waste, including TRU waste. Various scenarios were examined, including groundwater pathways and surface release mechanisms.

The descriptions below summarize the recent hydrological characterization studies (REECo, 1994) and the assumptions incorporated into the RWMS performance assessments. This information established the basis for understanding site conditions at NTS and determining the data used in the PE analysis.

\subsubsection{Water Pathway}

Knowledge of groundwater flow and radionuclide movement in the water pathway at NTS provided the basis in the $\mathrm{PE}$ for understanding site conditions. This understanding encompassed the site technical staff's current knowledge of site-specific geology, hydrology, water table and aquifer characteristics, and transport pathways.

\subsubsection{Current Understanding of Relevant Hydrogeology}

The Area 5 RWMS, the proposed site for an MLLW disposal facility, is located in northern Frenchman Flat, a closed basin along the eastern boundary of the NTS. The Frenchman 
Flat watershed extends into Nellis Air Force Range on the east and into other NTS operation areas on the north, west, and south. Alluvial fans emanating from the surrounding mountains slope gently toward Frenchman Lake, a playa lake that occupies the central portion of the basin. The Area $5 \mathrm{RWMS}$ is located at the juncture of three of these coalescing alluvial fans. Some of the natural topography and drainage features within the watershed have been altered by construction and operation of the facilities in Area 5.

Frenchman Flat is an alluvium-filled basin. Although the alluvium may be quite permeable, the rapid rates of precipitation associated with summer convective thunderstorms tend to enhance runoff rates and may produce flash floods. Surface runoff drains toward the central playa, where small amounts of surface water are stored temporarily. Any significant mass wasting or erosion is usually associated with stream channels.

The features of the groundwater system around the radioactive waste management sites from northern Yucca Flat to southern Frenchman Flat are shown in generalized cross-sectional view in Figure 7-4. The groundwater system can be generally viewed as a deformed layer cake, the bottom part of which is saturated with water. In this area, it is divided into the unsaturated zone and the underlying saturated zone. The top of the saturated zone is the water table and represents the depth necessary to drill a well to produce water.

Three primary rock units compose this groundwater system regardless of whether they are above or below the water table. Above the water table, they are referred to by their rock names; below the water table, they also can be called aquifers. From the surface to depth, these units are (1) the unconsolidated valley fill layer, commonly termed the alluvium; (2) the volcanic ash and lava flow layer, commonly termed the volcanics; and (3) the carbonate rock layer. Below the water table, these same rocks are called (1) the alluvial aquifer; (2) the volcanic aquifer; and (3) the carbonate aquifer. These aquifers may contain confining units. In particular, the volcanic rocks contain a confining unit that greatly reduces the downward flow of water.

Near the waste disposal sites, the alluvial and volcanic aquifers are restricted to valleys, whereas the carbonate aquifer is considered to be regional. Groundwater moves over considerable distances within the regional carbonate aquifer. The locations of the radioactive waste management sites with respect to the NTS boundary, Ash Meadows, and other regional geographic features are shown in Figure 7-5. Flow of groundwater in the carbonate aquifer under the NTS is generally considered to be from north to south through Yucca Flat and Frenchman Flat, where it turns and flows southwest toward Ash Meadows and Death Valley (Borg et al., 1976).

Waste at the Area 5 RWMS is disposed in pits and trenches excavated into alluvium. No chimneys or craters are located near the disposal pits and trenches. An extensive site characterization program demonstrated the uniformity of the hydrologic properties of the alluvium at this site. No evidence of perching layers or preferential pathways for water flow was found (REECo, 1993). 

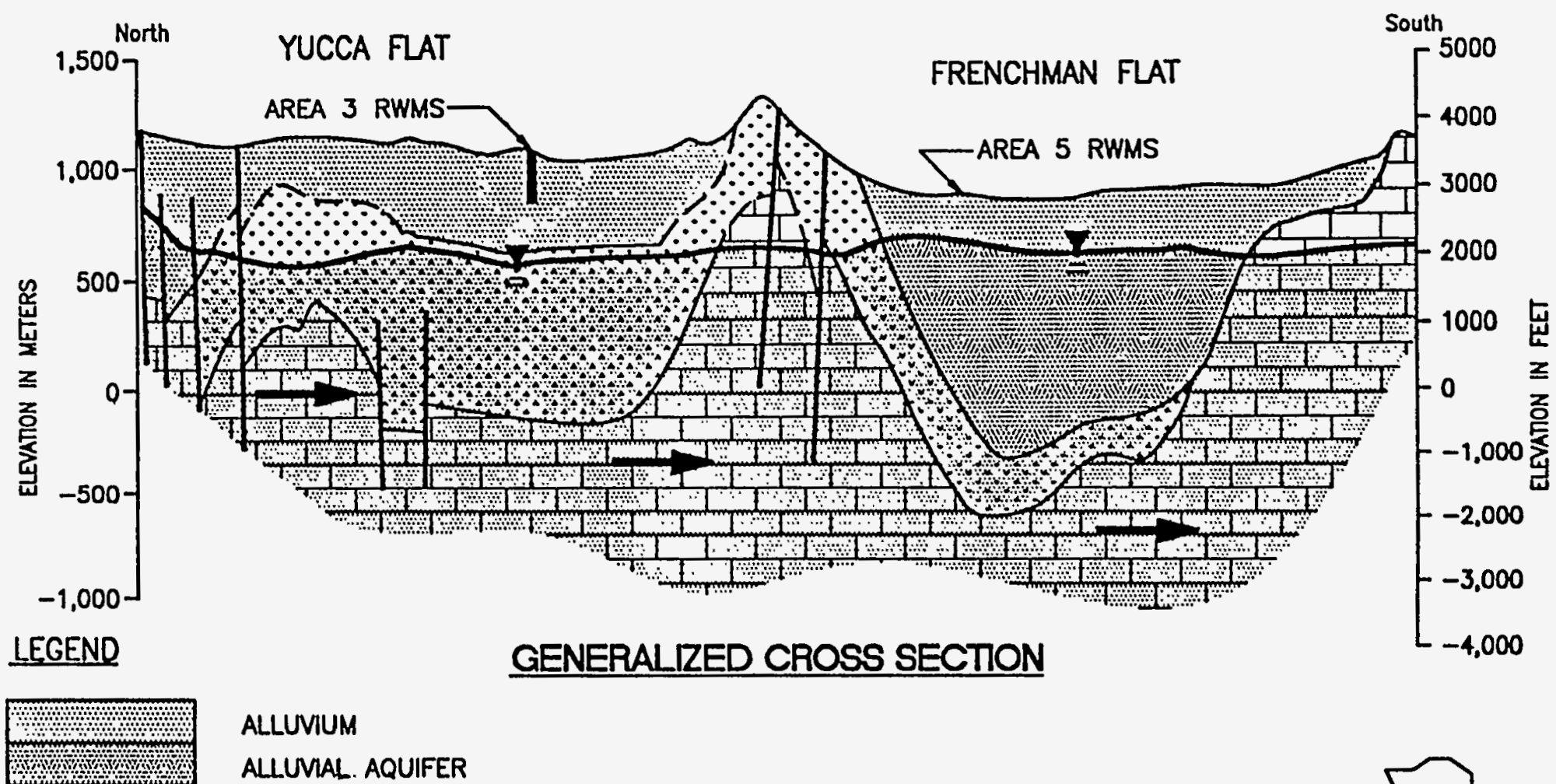

$\because \because \because \because \because \quad$ VOLCANICS

WU VOLCANIC AQUIFER and CONFINING UNIT

CATBONATES

CARBONATE AQUIFER
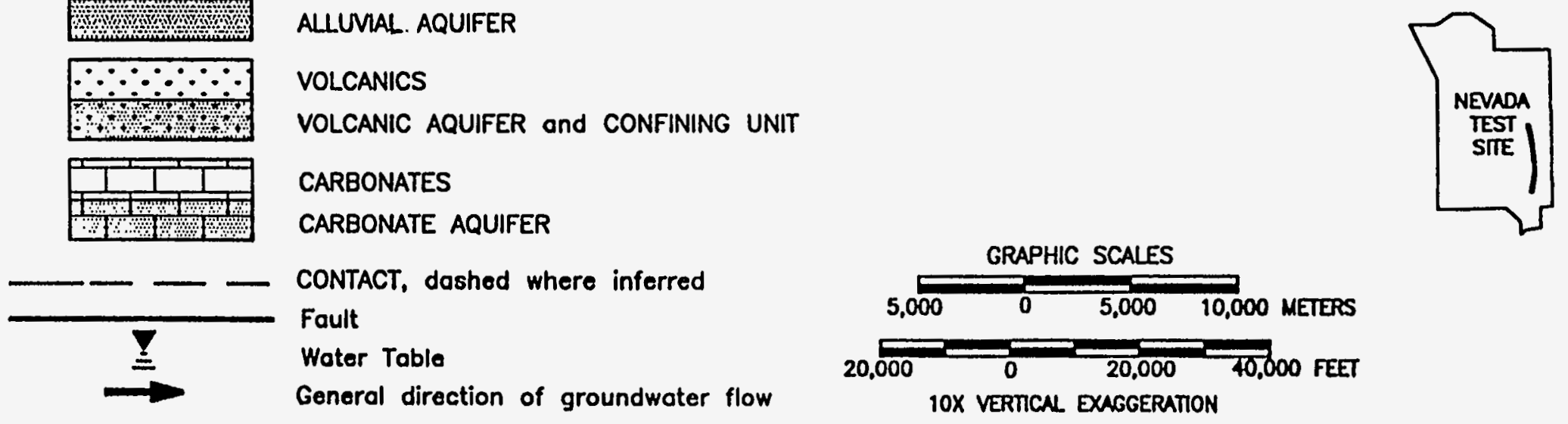

Figure 7-4. Generalized groundwater flow beneath Frenchman Flat and Yucca Flat. 


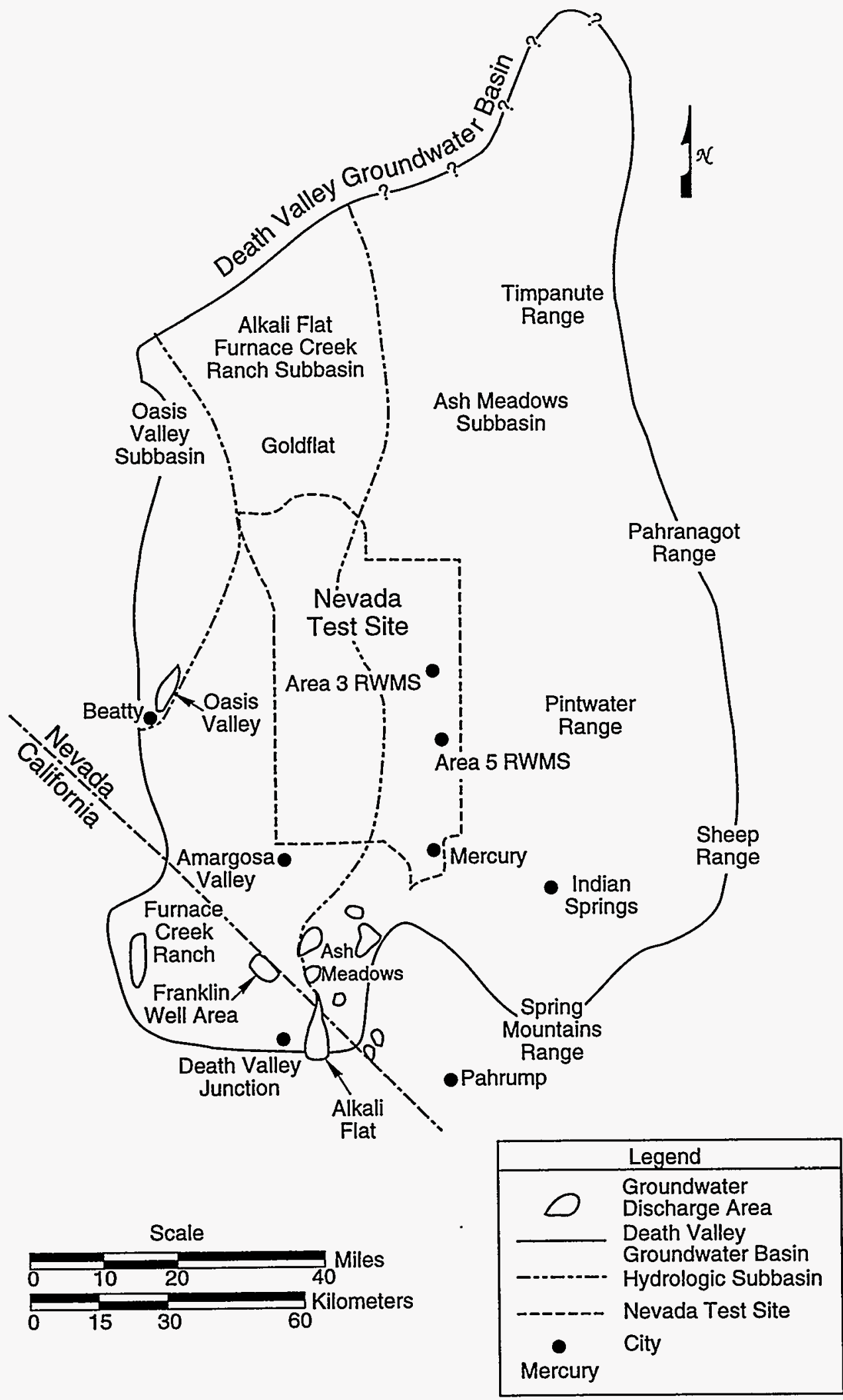

TRl-6622-44-0

Figure 7-5. Groundwater subbasins of the Death Valley groundwater basin. 
The mean annual precipitation at Area 5 is $12 \mathrm{~cm}$ (5 in.) (NOAA, 1994). The potential evapotranspiration is 14 times greater than the precipitation. The strong evaporative conditions typical of arid regions control the long-term movement of water in approximately the upper $40 \mathrm{~m}$ $(130 \mathrm{ft})$ in Area 5 (Detty et al., 1993). Environmental tracer studies conducted by the Desert Research Institute and Sandia National Laboratories have confirmed that surface water has not moved to the alluvial aquifer for thousands of years. The small amount of water that is now found in the alluvium is attributed to increased infiltration during an earlier, wetter climate (Conrad, 1993). Under the current climatic conditions, all precipitation falling on the ground surface returns to the atmosphere through evaporation and the transpiration of plants (Detty et al., 1993).

The average rate of downward water movement through the alluvium below the 40-m evaporative zone can be estimated. The largest mean volumetric water content that was observed in three pilot wells from about $40 \mathrm{~m}(130 \mathrm{ft})$ below the land surface to the water table (a distance of about $200 \mathrm{~m}$ [650 ft]) was $11.1 \%$ (REECo, 1993). The mean unsaturated hydraulic conductivity, calculated at that volumetric water content, was about $1 \times 10^{-9} \mathrm{~cm} / \mathrm{s}$ $\left(4 \times 10^{-10} \mathrm{in} . / \mathrm{s}\right)$. Based on an average water-filled porosity of about $10 \%$, the mean pore velocity is estimated at about $3 \mathrm{~mm} / \mathrm{y}(0.01 \mathrm{in} . / \mathrm{y})$. These calculations indicate that it would take approximately $65,000 \mathrm{y}$ for water to travel from just below the $40-\mathrm{m}$ (130-ft) evaporative zone to the water table under current hydrologic conditions (REECo, 1994).

The unsaturated hydraulic conductivity values used to estimate the linear velocity are obtained from fitting a model to the measured water retention behavior of the alluvium samples. These models are not accurate at very low water contents such as those found in the alluvium at the NTS. The characterization of transport properties at low water contents is an area of soil physics that has received little attention. Thus, the calculations above are "screening" estimates used to evaluate the relative importance of recharge (M. Sully, [REECo], personal communication, 1995).

Additional impediments to contaminant migration to off-site wells and springs are found below the unsaturated geologic section underlying Areas 3 and 5 . These impediments include rocks that resist the flow of water; slow water movement through the aquifers; and long distances (Borg et al., 1976). At both radioactive waste management sites, the groundwater pathway is (1) downward through the alluvial aquifer and the underlying volcanic confining unit and aquifer, (2) into the regional carbonate aquifer, (3) and then south and southwest laterally in the carbonate aquifer to off-site wells or springs. Because the alluvial and volcanic rocks are restricted to the Yucca Flat and Frenchman Flat basins, credible hypotheses of migration involve this "down and out" scenario. The volcanic confining unit is very resistive to flow and is the dominant barrier to contaminant migration. Estimates of flow rate range from $50 \mathrm{~mm}(0.2 \mathrm{ft})$ per year to less than $0.01 \mathrm{~mm}(0.00003 \mathrm{ft})$ per year, with resulting travel times to the carbonate aquifer of 6,000 to 2 million $y$. The volcanic and regional carbonate aquifers are more transmissive to water flow but, because of the distances to Ash Meadows (at least $55 \mathrm{~km}$ [35 mi]), the travel times listed above would increase by hundreds to thousands of years (Winograd and Thordarson, 1975). 
These estimates of travel time assume that no significant changes in the groundwater flow system will occur. In particular, the assumption is made that no major water withdrawals will be initiated near the NTS. Major uses of the regional carbonate aquifer from the flow path for Areas 3 and 5 and for Ash Meadows are unlikely because of the probable adverse impact on the Ash Meadows area. This point has been summarized in a report on the regional carbonate aquifer (Dettinger, 1989): "Sustained withdrawal of water from the carbonate-rock aquifers would entail (1) depleting some of the large store of water in transit through the aquifers and (2) capturing some water that would otherwise discharge from the Ash Meadows, Muddy River Springs, and Death Valley areas." Current water use at the NTS from the regional carbonate aquifer is minor and is unlikely to affect the travel times listed above. This conclusion is supported by two separate studies (Avon and Durbin, 1994; Brown and Lehman, 1993). Both studies conclude that there is little or no evidence of impact on Devil's Hole, a natural spring near Ash Meadows, from pumping at Army \# 1 Water Well on the southern boundary of NTS.

Three pilot wells surrounding the Area 5 RWMS, drilled in the alluvial aquifer to the southeast and northeast of the site and in the tuff aquifer to the northwest of the site, have defined an almost horizontal water table below the Area 5 RWMS. The depth to the top of the alluvial aquifer is approximately $235 \mathrm{~m}(750 \mathrm{ft})$ below land surface (REECo, 1994).

\subsubsection{Conceptual Model Used in the PE}

For most of the sites, the PE used a generic conceptual model to describe the water pathway (summarized in Section 1.1.2 of this volume and described in detail in Chapter 5 of Volume 2). However, based on the information summarized in Section 7.3.1.1-that (1) recharge from infiltration is probably not occurring in the vadose zone in the Area 5 RWMS and (2) the unretarded travel time in the unsaturated zone is much greater than 10,000 y even if downward migration could occur - the water pathway was not considered a credible mechanism for transport of radionuclides at NTS and was not evaluated in the PE.

\subsubsection{Atmospheric Pathway}

The conceptual model used in the PE for evaluating the atmospheric pathway was derived from performance assessments for LLW disposal facilities at Hanford (Kincaid et al., 1993), INEL (Maheras et al., 1994), NTS (Baer et al., 1994), ORR (ORNL, 1994), and SRS (MMES et al., 1994). The model was generalized for the $P E$ but used site-specific values for many of the parameters.

\subsubsection{Current Understanding of Relevant Meteorology}

For atmospheric releases calculated in the LLW performance assessment for the Area 5 RWMS, the soil concentrations generated though the intruder-agriculture scenario were conservatively used to bound the dose through atmospheric transport to a member of the public located $100 \mathrm{~m}(328 \mathrm{ft})$ from the Area 5 RWMS. In this calculation, the atmospheric dispersion factor $(\chi / Q)$ at $100 \mathrm{~m}(328 \mathrm{ft})$ was estimated to be $0.0085 \mathrm{sec} / \mathrm{m}^{3}\left(2 \times 10^{-4} \mathrm{sec} / \mathrm{ft}^{3}\right)$. As a result, the dose from atmospheric transport was estimated to be less than $1 \%$ from the intrusion scenario. The results indicated that doses to members of the general public through atmospheric transport were insignificant compared to those doses projected for an intruder. 
In the preliminary performance assessment for the GCD boreholes, the following surface release mechanisms were considered:

- Vapor phase diffusion of radon to the ground surface;

- Vapor phase diffusion of radon upward to plant roots;

- Diffusion of radionuclides in the liquid phase upward to the ground surface; and

- Diffusion of radionuclides in the liquid phase upward to plant roots.

This study concluded that upward migration of radionuclides from diffusion was possible for current climatic conditions, but the amount released through this pathway was found to be very small (Baer et al., 1994).

Meteorological data used in the PE were based on STAR data files summarized by the windrose in Figure 7-6. These data were obtained from hourly average meteorological readings

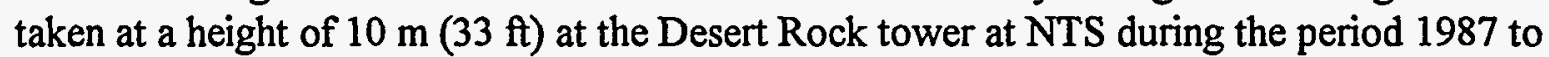
1991.

\subsubsection{Conceptual Model Used in the PE}

The PE used a generic conceptual model to describe the atmospheric pathway (summarized in Section 1.2 of this volume and described in detail in Chapter 5 of Volume 2). Only H-3 (tritium) and C-14 were expected to be volatile for the disposal facility conditions and thus were the only radionuclides considered for atmospheric transport in the PE. In the model, radionuclides were transported from the disposal facility to the soil surface by vapor (tritium) and gaseous (carbon dioxide carrying the $\mathrm{C}$-14 isotope) diffusion. When the radionuclides reached the soil surface, they were entrained in the air in vapor form as volatiles. Once airborne, these radionuclides were transported via atmospheric dispersion to a receptor located at the performance boundary.

Two components of the atmospheric pathway were evaluated separately: (1) the zone from the top of the disposal facility to the soil surface as indicated by the upward radionuclide diffusion profile; and (2) the zone in which a radionuclide was emitted to the atmosphere, mixed with the ambient air, and dispersed downwind from the waste disposal facility boundary to the 100-m (328-ft) performance boundary.

The arrival time of radionuclides at the performance boundary was assumed to be $100 \mathrm{y}$ based on the following generic assumptions of the PE:

- The waste form was grouted MLLW treatment residuals. Based on this assumption, tritium as vapor was bound in the pore water of the hydrophilic grout, and carbon dioxide as a gas carrying the $\mathrm{C}-14$ isotope was limited by the high $\mathrm{pH}$ of the grout, so that the waste form provided retention of these volatile radionuclides in the disposal facility.

- The disposal facility was capped by a RCRA-compliant cover system. Based on this assumption, the cover system was maintained to provide low permeability for $100 \mathrm{y}$. 


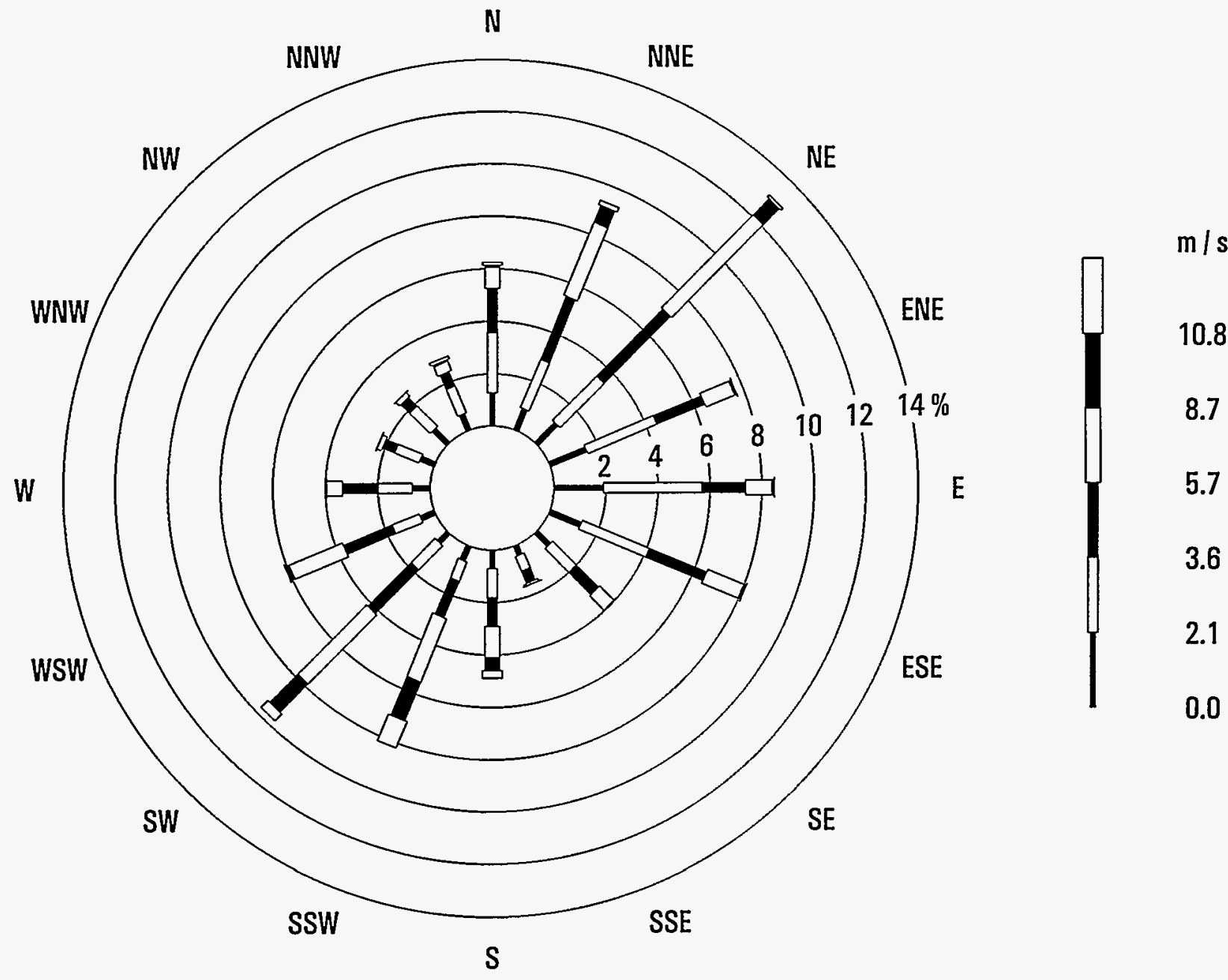

Figure 7-6. Windrose for NTS for the period 1987 to 1991 . The frequency of winds from each direction is plotted as a series of connected bars that extend from the center of the circular diagram toward the direction from which the winds originate. Wind speed categories are denoted by bar widths and shadings. The frequency of winds in each wind speed category is indicated by the length of the corresponding bar. 


\subsubsection{Inadvertent Intruder Pathways}

Standard intrusion scenarios were used in the PE, with information derived from performance assessments of LLW disposal facilities at SRS (MMES et al., 1994) and ORR (ORNL, 1994) indicating that only two chronic-exposure scenarios needed to be considered for most sites and facility designs. Any variations in these scenarios were based on discussions with site technical staff about such factors as the types of activities that reasonably could result in exposure to buried waste at the site and the effectiveness of active or passive institutional controls and engineered barriers in precluding access to the waste.

\subsubsection{Current Understanding of Potential Modes of Inadvertent Intrusion}

Three intruder scenarios were evaluated in the LLW performance assessment for the Area 5 RWMS: (1) intruder agriculture (with and without a basement); (2) intruder construction (with and without a basement); and (3) intruder drilling. One scenario was a chronic scenario and the other two were acute scenarios. All intrusions were assumed to occur $100 \mathrm{y}$ after site closure. In the intruder agriculture scenario, an intruder was assumed to construct a basement and drill a well into the waste. The waste from the excavation was spread around the site and food was grown in it, and contaminated water from the well was used for consumption, watering of stock, and irrigation. The results indicated that, while the intruder scenarios were the main dose contributors, the doses were still well below the regulatory limits.

\subsubsection{Conceptual Model Used in the PE}

The PE used two standard intrusion scenarios that could be modified for site-specific conditions to describe potential modes of inadvertent intrusion (summarized in Section 1.3 of this volume and described in detail in Chapter 5 of Volume 2). The first scenario, the agriculture (homesteader) scenario, included establishment by an intruder of a permanent homestead directly above a disposal facility with the foundation of the home extending into the waste; some of the waste exhumed from the disposal facility was mixed with native soil in the intruder's vegetable garden. The second scenario, the post-drilling scenario, considered the construction of a well for a domestic water supply by an intruder. The well was drilled through the disposal facility, and the cuttings were mixed with soil in the intruder's vegetable garden. The intruder gardened in some of the exhumed waste but did not reside permanently above the disposal facility. In both scenarios, exposure occurred where an intruder dug or drilled into the disposal facility.

For the generic intruder scenarios, the time of intrusion for the homesteader scenario was assumed to be $300 \mathrm{y}$ for the trench design and $500 \mathrm{y}$ for the tumulus design. The time of intrusion for the post-drilling scenario was assumed to be $100 \mathrm{y}$.

\subsection{DATA USED IN THE PE}

The data presented in this section apply to the PE conceptual models described in Section 7.3. The calculations for determining permissible waste concentrations for the radionuclides considered in the PE are discussed in more detail in Chapter 5 of Volume 2 and summarized in 
Chapter 1 of this volume. The results of the calculations for NTS are presented in Section 7.5 and discussed in Section 7.6 of this volume.

\subsubsection{Water Transport}

As discussed in Section 7.3.1, the water pathway was not considered a credible mechanism for transport of radionuclides at NTS. Therefore, this pathway was not analyzed in the PE.

\subsubsection{Atmospheric Transport}

Site-specific data required to perform the atmospheric pathway analysis came from site personnel as data either from site characterizations and reports or from general literature. These values are shown in Table 7-1. Necessary atmospheric dispersion data included wind speed and direction and stability class, which are summarized in Section 7.3.2.1.

Table 7-1. Parameters and Values Used in the PE for the Atmospheric Pathway at NTS (generic $\mathrm{PE}$ values are in bold; these values and the standard $\mathrm{PE}$ method for applying them are summarized in Chapter 1 of this volume and discussed in more detail in Chapter 5 of Volume 2)

\begin{tabular}{|c|c|c|c|}
\hline Parameter & Value & $\begin{array}{l}\text { Data } \\
\text { Type* }\end{array}$ & Comments \\
\hline $\begin{array}{l}\text { Disposal facility cover } \\
\text { thickness, } x\end{array}$ & $1.0 \mathrm{~m}$ & D & Standard PE value \\
\hline $\begin{array}{l}\text { Depth of the soil } \\
\text { surface, } d\end{array}$ & $0.01 \mathrm{~m}$ & $\mathbf{D}$ & $\begin{array}{l}\text { Standard PE value based on } \\
\text { Maheras et al. (1994) } \\
\end{array}$ \\
\hline Porosity, $n$ & 0.36 & A & Magnuson et al., 1992 \\
\hline Percent saturation, $s$ & 0.19 & A & Magnuson et al., 1992 \\
\hline $\begin{array}{l}\text { Ratio of water density } \\
\text { in air to liquid, } r\end{array}$ & $9.2 E-06$ & D & $\begin{array}{l}\text { Standard PE value based on MMES } \\
\text { et al. (1994) }\end{array}$ \\
\hline $\begin{array}{l}\text { Ratio of } \mathrm{CO}^{2} \\
\text { concentration in air to } \\
\text { dissolved in water, } r\end{array}$ & 4.3E-04 & D & $\begin{array}{l}\text { Standard PE value based on Foust } \\
\text { et al. (as cited in Cooper and Alley, } \\
\text { 1986) }\end{array}$ \\
\hline $\begin{array}{l}\text { Tritium diffusion } \\
\text { coefficient in air, D }\end{array}$ & $2.39 E-05 \mathrm{~m}^{2} / \mathrm{s}$ & D & $\begin{array}{l}\text { Standard PE value based on CRC } \\
\text { (1981) }\end{array}$ \\
\hline $\begin{array}{l}\text { Carbon diffusion } \\
\text { coefficient in air, } D\end{array}$ & $1.4 \mathrm{E}-05 \mathrm{~m}^{2} / \mathrm{s}$ & D & $\begin{array}{l}\text { Standard PE value based on CRC } \\
\text { (1981) }\end{array}$ \\
\hline $\begin{array}{l}\text { Atmospheric dispersion } \\
\text { term, } A_{D}\end{array}$ & $\begin{array}{c}0.26 \\
\left(\mu \mathrm{Ci} / \mathrm{m}^{3} /\left(\mu \mathrm{Ci} / \mathrm{m}^{2}-\mathrm{s}\right)\right.\end{array}$ & $B$ & $\begin{array}{l}\text { Value is estimated using the Industrial } \\
\text { Source Complex-Version } 2 \text { Long Term Air } \\
\text { Dispersion Model (ISCLT2) (EPA, 1992) } \\
\text { based on site-specific STAR data }\end{array}$ \\
\hline
\end{tabular}

- $A=$ site measurement; $B=$ result of site numerical analysis; $C=$ =literature selected by the site; $D=$ generic $P E$ value 


\subsubsection{Inadvertent Intruder Exposure}

As explained in Section 7.3.3, the PE used two standard intrusion scenarios to describe potential modes of inadvertent intrusion at all the sites. Because these intrusion scenarios were considered applicable to all sites, no values specific to NTS are used in the calculation of exposures to inadvertent intruders.

\subsection{RESULTS OF THE PE ANALYSIS}

The performance evaluation provided estimates of permissible waste concentrations in disposed MLLW. The two calculations that formed the foundation of the PE for NTS-for the atmospheric and inadvertent intruder pathways - are summarized in Sections 1.2, and 1.3, respectively, of this volume and discussed in detail in Chapter 5 of Volume 2.

For the two pathways the maximum permissible waste concentration at the performance boundary was determined for each radionuclide by using the performance measures: $10 \mathrm{mrem}$ $(0.1 \mathrm{mSv})$ per year from all pathways for atmospheric releases, and 100 mrem ( $1 \mathrm{mSv})$ per year from all exposure pathways for chronic exposure of inadvertent intruders; and the appropriate pathway or scenario dose conversion factors (annual effective dose equivalent per unit concentration) based on EPA dose conversion factors. The basis for the performance measures used in the PE is discussed in more detail in Chapter 5 of Volume 2. For the atmospheric pathway, the concentration reduction provided by the environment (i.e., the CRF) was estimated using results of site analyses and data. For the intruder analyses, concentration reduction was estimated for appropriate exposure pathways for two intrusion scenarios that, in general, were the same for all the sites. The results of the calculations for the pathways that were analyzed at NTS are provided in this section and discussed in Section 7.6.

\subsubsection{Water Transport}

As discussed in Section 7.3.1, the water pathway was not considered a credible mechanism for transport of radionuclides at NTS. Therefore, this pathway was not analyzed in the PE. Implicit in the exclusion of the water pathway in the PE was the assumption that waste concentrations were not limited by the water pathway at NTS.

\subsubsection{Atmospheric Transport}

Two CRFs were used to account for the attenuation encompassing diffusion to the ground surface, mixing in air, and dispersion in the atmosphere to the performance boundary. The CRF for diffusion in soil, $C R F_{D i f f}$, was defined as the ratio of the radionuclide concentration in the waste to its resulting concentration in the upper one centimeter of soil. The CRF for dispersion in air, $C R F_{D i s p}$, was defined as the ratio of the radionuclide concentration in the upper one centimeter of soil to its resulting concentration in air at the performance boundary. The effect of radioactive decay was also included in the PE. 
Application of the PE methodology for atmospheric transport of the two volatile radionuclides considered in the PE (H-3 and C-14) produced the results shown in Table 7-2 for both the generic trench and tumulus designs; there was no assumed difference in these two disposal technologies with respect to permissible waste limits based on the atmospheric pathway at NTS. The table shows permissible waste concentrations based on transport in the atmospheric pathway $\left(C_{W-A t m}\right)$ as well as the values used in calculating the permissible waste concentrations. For both $\mathrm{H}-3$ and $\mathrm{C}-14$, the greatest concentration reduction was assumed to occur as the radionuclides diffused from the top of the disposal facility to the soil surface.

Table 7-2. Results of Calculations for the Atmospheric Pathway

\begin{tabular}{|c|c|c|c|c|c|c|c|}
\hline \multirow[t]{2}{*}{ Nuclide } & \multirow[b]{2}{*}{$\begin{array}{c}S D C F_{A l m} \\
(r e m / y) /(\mu \mathrm{Cin})\end{array}$} & \multicolumn{6}{|c|}{ Generic Trench and Tumulus } \\
\hline & & $\begin{array}{c}C R F_{\text {Dit }} \\
\text { (almanzlonless) }\end{array}$ & $\begin{array}{c}C R F_{\text {Diep }} \\
\text { (dilmensionless) }\end{array}$ & $\begin{array}{c}C_{\text {dilmenslonless) }} \\
\text { (ditm }\end{array}$ & $\begin{array}{l}\text { Arrival } \\
\text { Time (y) }\end{array}$ & $\begin{array}{c}\text { roecay } \\
\text { (dimensionloss) }\end{array}$ & $\begin{array}{r}C_{W-A m m} \\
\left(\mu \mathrm{Ci} / \mathrm{m}^{3}\right)\end{array}$ \\
\hline $\mathrm{H}-3$ & $8.33 E+02$ & $8 \mathrm{E}+05$ & $1 E+03$ & $8 E+08$ & 100 & 300 & $3 E+09$ \\
\hline c-14 & 2.20E+05 & $2 E+04$ & $2 E+03$ & $4 E+07$ & 100 & 1 & $2 E+03$ \\
\hline
\end{tabular}

The time of arrival at the performance boundary for both radionuclides is shown in Table 7-2 as $100 \mathrm{y}$. However, the actual migration of H-3 and C-14 from the disposal facility to the surface and downwind to the performance boundary was calculated to be on the order of hours, not years. As discussed in Section 7.3.2.2, the waste form and RCRA cover are assumed to retain these volatile radionuclides in the disposal facility for at least $100 \mathrm{y}$.

\subsubsection{Inadvertent Intruder Exposure}

The calculation of permissible waste concentrations for inadvertent intruder exposures did not utilize CRFs. Instead, the total dose resulting from an intrusion scenario (the sum of the doses from all exposure pathways involved in that intrusion) was modified by scenario dose conversion factors (SDCFs) that were applied to specific exposure pathways. The important exposure pathways for each radionuclide are listed in Appendix D of Volume 2. These values were radionuclide-specific and facility-design-specific and were the same for all sites. Values for the radioactive decay term were based on time of intrusion into the disposal facility (for the homesteader scenario, $300 \mathrm{y}$ for the trench design and $500 \mathrm{y}$ for the tumulus design; for the postdrilling scenario, $100 \mathrm{y}$ for both disposal designs). However, results based on intruder scenarios should be evaluated carefully because future social behavior, and intrusion scenarios, are difficult to predict.

The permissible waste concentrations for the two generic facility designs for each of the 58 radionuclides based on the standard PE intrusion scenarios are listed in Table 7-3. The most restrictive radionuclide concentration limits for each generic facility are indicated with bold type. 
Table 7-3. Permissible Waste Concentrations for the Standard Intrusion Scenarios (most limiting radionuclide concentration for each facility design is highlighted in bold italic) (Part 1 of 2)

\begin{tabular}{|c|c|c|c|c|c|}
\hline \multirow[t]{2}{*}{ Nuclide } & \multicolumn{2}{|c|}{ Trench } & \multicolumn{2}{|c|}{ Tumulus } & \multirow[t]{2}{*}{ Nuclide } \\
\hline & $\begin{array}{c}C_{W-1 n t r} \\
\text { Homesteader } \\
\left(\mu \mathrm{Ci} / \mathrm{m}^{3}\right) \\
\end{array}$ & $\begin{array}{c}C_{W-\ln t} \\
\text { Post-Drilling } \\
\left(\mu \mathrm{Ci} / \mathrm{m}^{3}\right) \\
\end{array}$ & $\begin{array}{c}C_{W-/ n \pi}{ }^{a} \\
\text { Homesteader } \\
\left(\mu \mathrm{Ci} / \mathrm{m}^{3}\right) \\
\end{array}$ & $\begin{array}{c}C_{\text {w/Intr }} \\
\text { Post-Drilling } \\
\left(\mu \mathrm{Ci} / \mathrm{m}^{3}\right) \\
\end{array}$ & \\
\hline $\mathrm{H}-3$ & $1 E+12$ & $7 E+07$ & $\mathrm{NL}$ & $7 E+07$ & $\mathrm{H}-3$ \\
\hline $\mathrm{C}-14$ & $1 E+04$ & $7 E+04$ & $1 E+04$ & $7 E+04$ & $c-14$ \\
\hline Al-26 & $5 E+01$ & $5 E+04$ & $5 E+01$ & $5 \mathrm{E}+04$ & Al-26 \\
\hline Si-32 & $9 E+03$ & $1 E+04$ & $4 E+04$ & $1 E+04$ & Si-32 \\
\hline $\mathrm{Cl}-36$ & $2 E+02$ & $9 \mathrm{E}+02$ & $2 E+02$ & $9 E+02$ & Cl-36 \\
\hline$K-40$ & $7 E+02$ & $2 E+04$ & $7 E+02$ & $2 E+04$ & $K-40$ \\
\hline Co-60 & $\mathrm{NL}$ & $3 E+10$ & $\mathrm{NL}$ & $3 E+10$ & Co-60 \\
\hline Ni-59 & $3 E+06$ & $1 E+07$ & $3 E+06$ & $1 E+07$ & $\mathrm{Ni}-59$ \\
\hline $\mathrm{Ni}-63$ & $8 E+06$ & 1E+07 & $3 E+07$ & $1 E+07$ & $\mathrm{Ni}-63$ \\
\hline Se-79 & $2 E+05$ & $8 E+05$ & $2 E+05$ & $8 E+05$ & Se-79 \\
\hline Sr-90 & $1 \mathrm{E}+06$ & $5 E+04$ & $1 E+08$ & $5 E+04$ & Sr-90 \\
\hline Zr-93 & $5 E+06$ & $3 E+07$ & $5 E+06$ & $3 E+07$ & $Z r-93$ \\
\hline $\mathrm{Nb}-93 \mathrm{~m}$ & $5 E+12$ & $4 E+09$ & $\mathrm{NL}$ & $4 E+09$ & $\mathrm{Nb}-93 \mathrm{~m}$ \\
\hline $\mathrm{Nb}-94$ & $9 E+01$ & $9 E+04$ & $1 E+02$ & $9 E+04$ & $\mathrm{Nb}-94$ \\
\hline Tc-99 & $2 E+04$ & $8 \mathrm{E}+04$ & $2 E+04$ & $8 E+04$ & Tc-99 \\
\hline $\mathrm{Pd}-107$ & $6 E+06$ & $3 E+07$ & $6 E+06$ & $3 E+07$ & $P d-107$ \\
\hline $\mathrm{Ag}-108 \mathrm{~m}$ & $5 E+02$ & $1 E+05$ & $1 E+03$ & $1 E+05$ & $\mathrm{Ag}-108 \mathrm{~m}$ \\
\hline $\mathrm{Cd}-113 \mathrm{~m}$ & $4 E+09$ & $1 E+06$ & $7 E+13$ & $1 E+06$ & $\mathrm{Cd}-113 \mathrm{~m}$ \\
\hline$S n-121 m$ & $2 E+07$ & $5 E+07$ & $2 E+08$ & $5 E+07$ & Sn-121m \\
\hline Sn-126 & $8 E+01$ & $7 E+04$ & $8 E+01$ & $7 E+04$ & Sn-126 \\
\hline $1-129$ & $2 E+03$ & $1 E+04$ & $2 E+03$ & $1 E+04$ & I-129 \\
\hline Cs-135 & $2 E+05$ & $8 E+05$ & $2 E+05$ & $8 E+05$ & Cs-135 \\
\hline Cs-137 & $3 E+05$ & $8 E+05$ & $3 E+07$ & $8 E+05$ & Cs-137 \\
\hline $\mathrm{Ba}-133$ & $2 E+11$ & $3 E+08$ & $\mathrm{NL}$ & $3 E+08$ & $\mathrm{Ba}-133$ \\
\hline Sm-151 & $2 E+08$ & $2 E+08$ & $8 E+08$ & $2 E+08$ & Sm-151 \\
\hline Eu-152 & $6 \mathrm{E}+08$ & $2 E+07$ & $2 E+13$ & $2 E+07$ & Eu-152 \\
\hline Eu-154 & $4 E+12$ & $4 E+08$ & $\mathrm{NL}$ & $4 E+08$ & Eu-154 \\
\hline $\mathrm{Pb}-210$ & $7 E+06$ & $7 E+04$ & $4 E+09$ & $7 E+04$ & $\mathrm{~Pb}-210$ \\
\hline Ra-226 & $8 E+01$ & $3 E+03$ & $9 E+01$ & $3 E+03$ & Ra-226 \\
\hline Ra-228 & NL & $4 E+09$ & $\mathrm{NL}$ & $4 E+09$ & Ra-228 \\
\hline Th-229 & $5 E+02$ & $3 E+04$ & $5 E+02$ & $3 E+04$ & Th-229 \\
\hline Th-230 & $8 E+01$ & $7 E+04$ & $8 E+01$ & $7 E+04$ & Th-230 \\
\hline Th-232 & $6 E+01$ & $2 E+04$ & $6 E+01$ & $2 E+04$ & Th-232 \\
\hline $\mathrm{Pa}-231$ & $2 E+02$ & $5 E+03$ & $2 E+02$ & $5 E+03$ & $\mathrm{~Pa}-231$ \\
\hline
\end{tabular}


Table 7-3. Permissible Waste Concentrations for the Standard Intrusion Scenarios (most limiting radionuclide concentration for each facility design is highlighted in bold italic) (Part 2 of 2)

\begin{tabular}{|c|c|c|c|c|c|}
\hline \multirow[t]{2}{*}{ Nuclide } & \multicolumn{2}{|c|}{ Trench } & \multicolumn{2}{|c|}{ Tumulus } & \multirow[t]{2}{*}{ Nuclide } \\
\hline & $\begin{array}{c}C_{w / n r^{\prime}} \\
\text { Homesteader } \\
\left(\mu \mathrm{Ci} / \mathrm{m}^{3}\right) \\
\end{array}$ & $\begin{array}{c}C_{\text {w-lntr }} \\
\text { Post-Drilling } \\
\left(\mu \mathrm{Ci} / \mathrm{m}^{3}\right)\end{array}$ & $\begin{array}{c}C_{w-/ n t r} \\
\text { Homesteader } \\
\left(\mu \mathrm{Ci} / \mathrm{m}^{3}\right) \\
\end{array}$ & $\begin{array}{c}C_{w-1 n t} \\
\text { Post-Drilling } \\
\left(\mu \mathrm{Ci} / \mathrm{m}^{3}\right) \\
\end{array}$ & \\
\hline $\mathrm{U}-232$ & $2 E+03$ & $5 E+04$ & $1 E+04$ & $5 E+04$ & U-232 \\
\hline U-233 & $7 E+02$ & $1 E+05$ & $7 E+02$ & $1 E+05$ & U-233 \\
\hline$U-234$ & $1 E+03$ & $1 E+05$ & $1 E+03$ & $1 E+05$ & U-234 \\
\hline U-235 & $6 E+02$ & $1 E+05$ & $6 E+02$ & $1 E+05$ & U-235 \\
\hline U-236 & $2 E+04$ & $1 E+05$ & $2 E+04$ & $1 E+05$ & $\mathrm{U}-236$ \\
\hline$U-238$ & $5 E+03$ & $1 E+05$ & $5 E+03$ & $1 E+05$ & $U-238$ \\
\hline Np-237 & $4 E+02$ & $4 E+03$ & $4 E+02$ & $4 E+03$ & $\mathrm{~Np}-237$ \\
\hline Pu-238 & $7 E+04$ & $1 E+05$ & $4 E+05$ & $1 E+05$ & Pu-238 \\
\hline Pu-239 & $6 E+03$ & $5 E+04$ & $6 E+03$ & $5 E+04$ & $\mathrm{Pu}-239$ \\
\hline Pu-240 & $6 E+03$ & $5 E+04$ & $7 E+03$ & $5 E+04$ & Pu-240 \\
\hline Pu-241 & $2 E+05$ & $1 E+06$ & $3 E+05$ & $1 E+06$ & $\mathrm{Pu}-241$ \\
\hline Pu-242 & $6 E+03$ & $5 E+04$ & $6 E+03$ & $5 E+04$ & Pu-242 \\
\hline Pu-244 & $4 E+02$ & $5 E+04$ & $4 E+02$ & $5 E+04$ & $\mathrm{Pu}-244$ \\
\hline$A m-241$ & $7 E+03$ & $5 E+04$ & $9 E+03$ & $5 E+04$ & Am-241 \\
\hline Am-243 & $9 E+02$ & $4 E+04$ & $9 E+02$ & $4 E+04$ & Am-243 \\
\hline $\mathrm{Cm}-243$ & $1 E+06$ & $8 E+05$ & $5 E+06$ & $8 E+05$ & $\mathrm{~cm}-243$ \\
\hline $\mathrm{Cm}-244$ & $2 E+06$ & $3 E+06$ & $2 E+06$ & $3 E+06$ & $\mathrm{Cm}-244$ \\
\hline Cm-245 & $1 E+03$ & $4 E+04$ & $1 E+03$ & $4 E+04$ & $\mathrm{Cm}-245$ \\
\hline $\mathrm{Cm}-246$ & $6 E+03$ & $5 E+04$ & $6 E+03$ & $5 E+04$ & $\mathrm{Cm}-246$ \\
\hline $\mathrm{Cm}-247$ & $3 E+02$ & $5 E+04$ & $3 E+02$ & $5 E+04$ & $\mathrm{Cm}-247$ \\
\hline $\mathrm{Cm}-248$ & $2 E+03$ & $1 E+04$ & $2 E+03$ & $1 E+04$ & $\mathrm{Cm}-248$ \\
\hline Cf-249 & $8 E+02$ & $4 E+04$ & $1 E+03$ & $4 E+04$ & Cf-249 \\
\hline Cf-250 & $2 E+06$ & $9 E+06$ & $2 E+06$ & $9 E+06$ & Cf-250 \\
\hline Cf-251 & $2 E+03$ & $4 E+04$ & $2 E+03$ & $4 E+04$ & Cf-251 \\
\hline
\end{tabular}

a "NL" means No Limit - estimated permissible concentration is greater than the specific activity of the pure elemental radionuclide. 
For six radionuclides in the table (U-233, U-234, U-235, U-238, Pu-244, and Cm-247), the time of homesteader intrusion was changed to $10,000 \mathrm{y}$, the end of the performance period. For these six radionuclides, ingrowth of decay products yields scenario doses that increase over time. The doses at $10,000 \mathrm{y}$, therefore, represent the maximum that could be encountered during the performance period. Also, for Th-230 and $\mathrm{Cm}-245$, ingrowth of decay products likewise produces a scenario dose that increases over time and peaks within the 10,000-y performance period. The times of homesteader intrusion for these two radionuclides (Th-230 and Cm-245) were taken as the time of maximum dose, 9000 and $1000 \mathrm{y}$, respectively.

For the trench design, the post-drilling scenario generally yielded more restrictive waste limits than the homesteader scenario for those radionuclides with half-lives shorter than about 30 y. For the tumulus design, the post-drilling scenario generally yielded more restrictive limits than the homesteader scenario for those radionuclides with half-lives shorter than about $130 \mathrm{y}$.

\subsection{SUMMARY AND DISCUSSION OF RESULTS}

The limiting concentrations in disposed MLLW for the atmospheric and intruder analyses for the generic trench and tumulus designs are shown in Table 7-4. As discussed in Section 7.3.1, the water pathway was not evaluated for NTS because of the very long water travel time and negligible amount of infiltration in the vadose zone.

\subsubsection{Results Based on Disposal Design}

For both the generic trench and tumulus designs at NTS, all radionuclides were limited by the intrusion scenarios except C-14, which was limited by the atmospheric pathway. The majority of the radionuclide concentrations were limited by the homesteader scenario; the short-lived radionuclides with half-lives less than about $30 \mathrm{y}$ were limited by the post-drilling scenario. Concentrations for some of the uranium isotopes (U-234, U-235, and U-238) and Np-237 were based on exposure at $10,000 \mathrm{y}$ because, due to ingrowth of decay products, the scenario dose conversion factors were still increasing at $10,000 \mathrm{y}$.

\subsubsection{Discussion}

Based on the results of the PE analysis, MLLW disposal at NTS is almost exclusively limited by the intrusion scenarios. Only $\mathrm{C}-14$ shows more restrictive waste limits from the atmospheric pathway. The extremely dry conditions at the NTS, where infiltration is negligible and the distance to the groundwater is great, inhibit the migration of radionuclides via the water pathway.

The trench design produced waste concentrations that were slightly more restrictive (approximately a factor of 2) than the tumulus design. Therefore, the tumulus design provides no significant advantage over the trench design at the NTS. 
Table 7-4. Permissible Concentrations for the Generic Disposal Designs at the NTS (permissible concentration related to the most limiting pathway for each facility design is highlighted in bold italic) (Part 1 of 2)

\begin{tabular}{|c|c|c|c|c|c|c|c|}
\hline \multirow[t]{2}{*}{ Nuclide } & \multicolumn{3}{|c|}{ Trench } & \multicolumn{3}{|c|}{ Tumulus } & \multirow[t]{2}{*}{ Nuclide } \\
\hline & $\begin{array}{c}C_{\text {whwater }} \\
\left(\mu \mathrm{Ci} / \mathrm{m}^{3}\right) \\
\end{array}$ & $\begin{array}{l}C_{W \cdot A t m} \\
\left(\mu \mathrm{Ci} / \mathrm{m}^{3}\right)\end{array}$ & $\begin{array}{l}C_{w / n t^{\circ}}{ }^{b} \\
\left(\mu \mathrm{Ci} / \mathrm{m}^{3}\right) \\
\end{array}$ & $\begin{array}{c}C_{\text {W.Water }} \\
\left(\mu \mathrm{Ci} / \mathrm{m}^{3}\right) \\
\end{array}$ & $\begin{array}{l}C_{W \cdot A t m} \\
\left(\mu \mathrm{Ci} / m^{3}\right)\end{array}$ & $\begin{array}{l}C_{\text {wentr }}{ }^{b} \\
\left(\mu \mathrm{Ci} / \mathrm{m}^{3}\right) \\
\end{array}$ & \\
\hline $\mathrm{H}-3$ & - & $3 E+09$ & $7 E+07$ & - & $3 E+09$ & $7 E+07$ & $\mathrm{H}-3$ \\
\hline$C-14$ & - & $2 E+03$ & $1 E+04$ & - & $2 E+03$ & $1 E+04$ & C-14 \\
\hline Al-26 & - & & $5 E+01$ & $=$ & & $5 E+01$ & $\mathrm{Al}-26$ \\
\hline Si-32 & - & & $9 E+03$ & - & & $1 E+04$ & Si-32 \\
\hline $\mathrm{Cl}-36$ & - & & $2 E+02$ & - & & $2 E+02$ & $\mathrm{Cl}-36$ \\
\hline$K-40$ & - & & $7 E+02$ & - & & $7 E+02$ & $K-40$ \\
\hline Co-60 & - & & $3 E+10$ & - & & $3 E+10$ & Co-60 \\
\hline $\mathrm{Ni}-59$ & - & & $3 E+06$ & - & & $3 E+06$ & Ni-59 \\
\hline $\mathrm{Ni}-63$ & - & & $8 E+06$ & - & & $1 E+07$ & $\mathrm{Ni}-63$ \\
\hline Se-79 & - & & $2 E+05$ & - & & $2 E+05$ & Se-79 \\
\hline Sr-90 & - & & $5 E+04$ & - & & $5 E+04$ & Sr-90 \\
\hline $2 r-93$ & - & & $5 E+06$ & - & & $5 E+06$ & $z r-93$ \\
\hline $\mathrm{Nb}-93 \mathrm{~m}$ & - & & $4 E+09$ & $=$ & & $4 E+09$ & $\mathrm{Nb}-93 \mathrm{~m}$ \\
\hline $\mathrm{Nb}-94$ & - & & $9 E+01$ & - & & $1 E+02$ & Nb-94 \\
\hline Tc-99 & - & & $2 E+04$ & $=$ & & $2 E+04$ & Tc-99 \\
\hline$P d-107$ & - & & $6 E+06$ & - & & $6 E+06$ & $\mathrm{Pd}-107$ \\
\hline$A g-108 m$ & - & & $5 E+02$ & - & & $1 E+03$ & $\mathrm{Ag}-108 \mathrm{~m}$ \\
\hline $\mathrm{Cd}-113 \mathrm{~m}$ & - & & $1 E+06$ & - & & $1 E+06$ & $\mathrm{Cd}-113 \mathrm{~m}$ \\
\hline Sn-121m & - & & $2 E+07$ & - & & $5 E+07$ & Sn-121m \\
\hline Sn-126 & - & & $8 E+01$ & - & & $8 E+01$ & $5 n-126$ \\
\hline $1-129$ & - & & $2 E+03$ & - & & $2 E+03$ & $1-129$ \\
\hline Cs-135 & - & $\cdot$ & $2 E+05$ & - & & $2 E+05$ & Cs-135 \\
\hline Cs-137 & - & & $3 E+05$ & $=$ & & $8 E+05$ & Cs-137 \\
\hline$B a-133$ & - & & $3 E+08$ & - & & $3 E+08$ & $\mathrm{Ba}-133$ \\
\hline$S m-151$ & - & & $2 E+08$ & $=$ & & $2 E+08$ & $S m-151$ \\
\hline Eu-152 & - & & $2 E+07$ & - & & $2 E+07$ & $E u-152$ \\
\hline Eu-154 & - & & $4 E+08$ & $=$ & & $4 E+08$ & Eu-154 \\
\hline $\mathrm{Pb}-210$ & - & & $7 E+04$ & - & & $7 E+04$ & $\mathrm{~Pb}-210$ \\
\hline Ra-226 & - & & $8 E+01$ & $=$ & & $9 E+01$ & Ra-226 \\
\hline Ra-228 & - & & $4 E+09$ & - & & $4 E+09$ & Ra-228 \\
\hline Th-229 & - & & $5 E+02$ & $=$ & & $5 E+02$ & Th-229 \\
\hline Th-230 & - & & $8 E+01$ & - & & $8 E+01$ & Th-230 \\
\hline Th-232 & - & & $6 E+01$ & $=$ & & $6 E+01$ & Th-232 \\
\hline $\mathrm{Pa}-231$ & - & & $2 E+02$ & $=$ & & $2 E+02$ & Pa-231 \\
\hline
\end{tabular}


Table 7-4. Permissible Concentrations for the Generic Disposal Designs at the NTS (permissible concentration related to the most limiting pathway for each facility design is highlighted in bold italic) (Part 2 of 2)

\begin{tabular}{|c|c|c|c|c|c|c|c|}
\hline \multirow[t]{2}{*}{ Nuclide } & \multicolumn{3}{|c|}{ Trench } & \multicolumn{3}{|c|}{ Tumulus } & \multirow[t]{2}{*}{ Nuclide } \\
\hline & $\begin{array}{r}C_{\text {w.water }} \\
\left(\mu \mathrm{Cu} / \mathrm{m}^{3}\right) \\
\end{array}$ & $\begin{array}{l}C_{W-A t m} \\
\left(\mu \mathrm{Cl} / \mathrm{m}^{3}\right) \\
\end{array}$ & $\begin{array}{l}C_{w / n t^{b}} \\
\left(\mu \mathrm{CU/m^{3 } )}\right. \\
\end{array}$ & $\begin{array}{l}C_{\text {whewater }} \\
\left(\mu \mathrm{Ci} / \mathrm{m}^{3}\right)\end{array}$ & $\begin{array}{l}C_{w \cdot A t m} \\
\left(\mu \mathrm{Ci} / m^{3}\right) \\
\end{array}$ & $\begin{array}{l}C_{\text {W-Antr }}{ }^{b} \\
\left(\mu \mathrm{Ci} / \mathrm{m}^{3}\right)\end{array}$ & \\
\hline U-232 & - & & $2 E+03$ & - & & $1 E+04$ & $\mathrm{U}-232$ \\
\hline$U-233$ & - & & $7 E+02$ & - & & $7 E+02$ & U-233 \\
\hline$U-234$ & - & & $1 E+03$ & - & & $1 E+03$ & U-234 \\
\hline $\mathrm{U}-235$ & - & & $6 E+02$ & - & & $6 E+02$ & U-235 \\
\hline$U-236$ & - & & $2 E+04$ & - & & $2 E+04$ & $\mathrm{U}-236$ \\
\hline$U-238$ & - & & $5 E+03$ & - & & $5 E+03$ & $\mathrm{U}-238$ \\
\hline $\mathrm{Np}-237$ & - & & $4 E+02$ & - & & $4 E+02$ & Np-237 \\
\hline Pu-238 & - & & $7 E+04$ & - & & $1 E+05$ & Pu-238 \\
\hline Pu-239 & - & & $6 E+03$ & - & & $6 E+03$ & Pu-239 \\
\hline Pu-240 & - & & $6 E+03$ & - & & $7 E+03$ & $\mathrm{Pu}-240$ \\
\hline Pu-241 & - & & $2 E+05$ & - & & $3 E+05$ & $\mathrm{Pu}-241$ \\
\hline Pu-242 & - & & $6 E+03$ & - & & $6 E+03$ & Pu-242 \\
\hline Pu-244 & - & & $4 E+02$ & $=$ & & $4 E+02$ & Pu-244 \\
\hline Am-241 & - & & $7 E+03$ & - & & $9 E+03$ & Am-241 \\
\hline Am-243 & - & & $9 E+02$ & - & & $9 E+02$ & Am-243 \\
\hline $\mathrm{Cm}-243$ & - & & $8 E+05$ & - & & $8 E+05$ & $\mathrm{Cm}-243$ \\
\hline $\mathrm{Cm}-244$ & - & & $2 E+06$ & - & & $2 E+06$ & $\mathrm{Cm}-244$ \\
\hline $\mathrm{Cm}-245$ & - & & $1 E+03$ & - & & $1 E+03$ & $\mathrm{Cm}-245$ \\
\hline $\mathrm{Cm}-246$ & - & & $6 E+03$ & - & & $6 E+03$ & $\mathrm{Cm}-246$ \\
\hline $\mathrm{Cm}-247$ & - & & $3 E+02$ & - & & $3 E+02$ & $\mathrm{Cm}-247$ \\
\hline $\mathrm{Cm}-248$ & - & & $2 E+03$ & - & & $2 E+03$ & $\mathrm{Cm}-248$ \\
\hline Cf-249 & - & & $8 E+02$ & - & & $1 E+03$ & Cf-249 \\
\hline Cf-250 & - & & $2 E+06$ & - & & $2 E+06$ & Cf-250 \\
\hline Cf-251 & - & & $2 E+03$ & - & & $2 E+03$ & Cf-251 \\
\hline
\end{tabular}

a Results presented for radionuclides expected to be volatile under disposal facility conditions.

b Concentration is based on the most restrictive intrusion scenario for the site; see Table 7-3.

"." Indicates that the radionuclide concentration is based on an arrival time beyond $10,000 \mathrm{y}$. 


\subsection{OBSERVATIONS}

Based on the results of the PE, the following observations can be made about MLLW disposal at NTS:

- The NTS has characteristics that are typical of an arid climate. The area has a very thick vadose zone, and recharge from infiltration is considered negligible.

- Downward transport via the water pathway does not appear to be a mechanism for movement of radionuclides at NTS. This concept is based on hydrologic studies performed by NTS and other technical personnel who concluded that recharge because of infiltration was negligible. In addition, the site assessment for disposal of LLW at Area 5 estimated that, even if downward migration could occur, unretarded travel time through most of the unsaturated zone was about $65,000 \mathrm{y}$, much greater than the $10,000-\mathrm{y}$ performance period considered in the $\mathrm{PE}$.

- For both the trench and tumulus designs at NTS, the results indicate that of the $\mathbf{5 8}$ radionuclides evaluated in the $\mathrm{PE}, 57$ radionuclides were limited by intrusion scenarios. These results reflect both the extremely dry conditions at the NTS and the dominant role of the selected human intrusion scenarios that is demonstrated for almost all the sites considered in the PE (see Sections 7.5 and 7.6 in Volume 2). This dominance indicates a need to be aware of the inability to predict the social behavior of populations far into the future.

For the water pathway, all of the 58 radionuclides were assumed to arrive at the performance boundary after the 10,000 -y period of consideration in the $\mathrm{PE}$ analysis of the water pathway.

Because NTS has many radionuclides that either are limited by the intrusion scenarios or arrive at the performance boundary after $10,000 \mathrm{y}$, this site may have flexibility in accepting a variety of radionuclides for disposal.

- Using either a trench or tumulus design is feasible at NTS. However, all on-site disposal - of radioactive waste to date has been below ground in trenches, pits, or boreholes.

- The NTS does not appear to have physical constraints that could limit disposal activities. The site has a large areal extent and a very thick unsaturated zone.

- The PE was a scoping analysis performed using assumptions that are conservative relative to most LLW performance assessments. A performance assessment for LLW disposal at NTS was being drafted at the time the PE was performed. While the draft LLW performance assessment was not available to make detailed comparisons of the analyses, the PE team worked closely with the performance assessment team at the site to ensure that the latest information was incorporated into the $\mathrm{PE}$ analysis. 


\subsection{REFERENCES}

Avon, Lizanne, and Timothy J. Durbin, 1994. Hydrologic Evaluation of Recent Water-Level Decline at Devils Hole. Hydrologic Consultants, Inc.

Baer, T.A., L. L. Price, J. N. Emery, N. E. Olague, 1994. Second Performance Assessment Iteration of the Greater Confinement Disposal Facility at the Nevada Test Site. SAND930089. Albuquerque, NM: Sandia National Laboratories.

Borg, I.Y., R. Stone, H.B. Levy, and L.D. Ramspott, 1976. Information Pertinent to the Migration of Radionuclides in Ground Water at the Nevada Test Site-Part 1: Review and Analysis of Existing Information. UCRL-52078 Pt. 1. Livermore, CA: Lawrence Livermore National Laboratory.

Brown, Tim P., and Linda L. Lehman, 1993. Updated Analysis of Water Levels in Devil's Hole, Nevada. Burnsville, MN: L. Lehman \& Associates.

Conrad, Stephen H., 1993. "Using Environmental Tracers to Estimate Recharge through an Arid Basin," presented at 1993 International High-Level Radioactive Waste Management Conference, Las Vegas, NV, April 26-30, 1993.

Cooper, C.D., and F.C. Alley, 1986. Air Pollution Control: A Design Approach. Prospect Heights, IL: Waveland Press, Inc.

CRC, 1981. CRC Handbook of Chemistry and Physics. Eds. Robert C. Weast and Melvin J. Astle. Boca Raton, FL: CRC Press, Inc.

Dettinger, Michael D., 1989. Distribution of Carbonate-Rock Aquifers in Southern Nevada and the Potential for their Development: Summary of Findings, 1985-88. Summary Report No. 1. Carson City, NV: Program for the Study and Testing of Carbonate-Rock Aquifers in Eastern and Southern Nevada, U.S. Geological Survey.

Detty, T.E., D.P. Hammermeister, D.O. Blout, M.J. Sully, R.L. Dodge, J. Chapman, and S.W. Tyler. 1993. "Water Fluxes in a Deep Arid-Region Vadose Zone," Abstract in Proceedings of the 1993 Fall Meeting, American Geophysical Union. Supplement to Eos, October 26, 1993.

EPA, 1992. User's Guide for the Industrial Source Complex (ISC2) Dispersion Models, Volume I: User Instructions. EPA Publication No. EPA-450/4-92-008a. Research Triangle, NC: U.S. Environmental Protection Agency.

ERDA, 1977. Final Environmental Impact Statement-Nevada Test Site, Nye County, Nevada. ERDA 155. U.S. Energy Research \& Development Administration.

FFCAct, 1992. Federal Facility Compliance Act of 1992. P.L. 102-386, October 1992. 
Gruebel, Marilyn M., Robert D. Waters, Maryann B. Hospelhorn, and Margaret S.Y. Chu, eds., 1994. Framework for DOE Mixed Low-Level Waste Disposal: Site Fact Sheets. SAND942728. Albuquerque, NM: Sandia National Laboratories.

Kearl, Peter M., 1982. Water Transport in Desert Alluvial Soil. Publication 45024 (DOE/NV/10162-2). Water Resources Center, Desert Research Institute, University of Nevada System.

Kincaid, C.T., J.W. Shade, G.A. Whyatt, M.G. Piepho, K. Rhoads, J.A. Voogd, J.H. Westsik, Jr., M.D. Freshley, K.A. Blanchard, and B.G. Lauzon, eds., 1993. Performance Assessment of Grouted Double-Shell Tank Waste Disposal at Hanford. WHC-SD-WM-EE-004, Rev. 0. U.S. Department of Energy, Pacific Northwest Laboratory and Westinghouse Hanford Company.

Magnuson, Swen O., Steven J. Majeras, Hoa D. Nguyen, Arthur S. Rood, Janice L. Sipos, Marilyn J. Case, Michael A. McKenzie-Carter, and Mary E. Donahue, 1992. Radiological Performance Assessment for the Area 5 Radioactive Waste Management Site at the Nevada Test Site. 11-1-2, Rev. 1. Idaho Falls, ID: U.S. Department of Energy, DOE Idaho Field Office.

Maheras, Steven J., Arthur S. Rood, Swen O. Magnuson, Mary E. Sussman, and Rajiv N. Bhatt, 1994. Radioactive Waste Management Complex Low-Level Waste Radiological Performance Assessment. EGG-WM-8773. Idaho Falls, ID: U.S. Department of Energy Office of Environmental Restoration and Waste Management, DOE Idaho Operations Office.

MMES (Martin Marietta Energy Systems, Inc.), EG\&G Idaho, Inc., and Westinghouse Savannah River Company, 1994. Radiological Performance Assessment for the E-Area Vaults Disposal Facility. WSRC-RP-94-218, Rev. 0. Aiken, SC: Westinghouse Savannah River Company.

NOAA, 1994. Nevada Test Site Monthly Precipitation. Weather Service Nuclear Support Office.

NTS, 1992. RCRA Part B Application for Nevada Test Site, July, 1992. Nevada Test Site.

ORNL, 1994. Performance Assessment for Continuing and Future Operations at Solid Waste Storage Area 6. ORNL-6783. Oak Ridge, TN: U.S. Department of Energy, Oak Ridge National Laboratory.

Price, Laura. L., Stephen H. Conrad, D.A. Zimmerman, Natalie E. Olague, Katherine C. Gaither, Warren B. Cox, James T. McCord, and Charlene P. Harlan, 1993. Preliminary Performance Assessment of the Greater Confinement Disposal Facility at the Nevada Test Site. SAND910047. 3 vol. Albuquerque, NM: Sandia National Laboratories. 
REECo, 1991. Site Book for Waste Management. Las Vegas, NV: Reynolds Electrical and Engineering Co., Inc., Waste Management Department.

REECo, 1993. Hydrological Data for Science Trench Boreholes at the Area 5 Radioactive Waste Management Site, Nevada Test Site, Nye County, Nevada. Las Vegas, NV: Special Projects Section, Environmental Restoration \& Technology Development Section, Environmental Management Division, Reynolds Electrical and Engineering Co., Inc.

REECo, 1994. Site Characterization and Monitoring Data from Area 5 Pilot Wells, Nevada Test Site, Nye County, Nevada. DOE/NV/11432-74. Las Vegas, NV: Special Projects Section, Environmental Restoration \& Technology Development Section, Environmental Management Division, Reynolds Electrical and Engineering Co., Inc.

Winograd, Isaac J., and William Thordarson, 1975. Hydrogeologic and Hydrochemical Framework, South-Central Great Basin, Nevada-California, with Special Reference to the Nevada Test Site. Geological Survey Professional Paper 712-C. Washington, DC: United States Geological Survey on behalf of the U.S. Atomic Energy Commission.

\section{Acknowledgments}

The SNL Core Team acknowledges the contributions of Greg Shott, Curtis Muller, and Brian Dozier of Reynolds Electrical and Engineering Co., Inc. (REECo); and Jim Henderson, Scott Harrington, Stuart Rawlinson, Dennis Gustafson, and Julianne Miller of Raytheon Services Nevada (RSN). 


\section{New Mexico: LOS ALAMOS NATIONAL LABORATORY (LANL) Core Team Contact: Alva M. Parsons}

The Federal Facility Compliance Act (FFCAct, 1992) requires the Department of Energy (DOE) to establish plans in conjunction with its regulators and with members of the public for the treatment of DOE's mixed low-level waste (MLLW). Although the FFCAct did not specifically address disposal of treated MLLW, both DOE and the States recognized that disposal issues were an integral part of treatment discussions. Since 1992, DOE has worked with the States to define and develop an evaluation process for disposal options. Preliminary activities of this joint DOEState process have narrowed the sites for further evaluation from 49 to 15 .

The Disposal Workgroup (DWG), which was established by DOE to develop a process for evaluating disposal options, designed a performance evaluation (PE) to quantify and compare the limitations of the remaining $15 \mathrm{DOE}$ sites for MLLW disposal. The principal goal of the PE was to estimate, for grouted residuals resulting from the treatment of MLLW, permissible concentrations of radionuclides in waste for disposal at each site. These "permissible waste concentrations" were based solely on long-term physical performance of the disposal facility and did not take into account any operational waste acceptance criteria that a site might have developed. The PE did not address any ethical, social, or policy considerations relevant to siting such facilities.

The PE used analyses that are consistent with the approach used in many low-level waste (LLW) performance assessments. The objective was to use a set of modeling assumptions of sufficient detail to capture major site-specific characteristics and yet be general enough for consistent application at all sites. Additionally, the analyses were designed to ensure that the sites were analyzed consistently and that all major assumptions were clearly stated.

The remainder of this chapter provides the PE results for Los Alamos National Laboratory (LANL), one of the 15 sites being evaluated. The chapter contains the following information:

Section 8.1: brief, general description of the site, based on previous work done by the DWG (Gruebel et al., 1994)

Section 8.2: plans for MLLW disposal, and the location evaluated in the PE

Section 8.3: current understainding of radionuclide movement at the selected location based on available information, and the conceptual model used for the evaluation of each of three pathways (water, atmospheric, and inadvertent intruder)

Section 8.4: site-specific and generic values used in the PE calculations and their sources

Section 8.5: estimates of maximum waste concentrations determined in the PE calculations for each of the three pathways, along with calculated values used in determining these results

Section 8.6: summary of results based on disposal-facility design; discussion with respect to such issues as uncertainty and sensitivity 
Section 8.7: observations based on the results of the PE and the parameter sensitivity analysis

Section 8.8: references

The general assumptions and methodology used in the PE are summarized in Chapter 1 of this volume and explained in more detail in Volume 2 of this report. Overall results for all the sites are discussed in Chapter 7 of Volume 2.

\subsection{GENERAL DESCRIPTION OF THE SITE}

Los Alamos National Laboratory (LANL) is located in Los Alamos County in northcentral New Mexico, approximately $97 \mathrm{~km}$ (60 mi) north-northeast of Albuquerque and $40 \mathrm{~km}$ $(25 \mathrm{mi})$ northwest of Santa Fe (Figure 8-1). LANL occupies an area of $112 \mathrm{~km}^{2}\left(43 \mathrm{mi}^{2}\right)$ located directly south of the city of Los Alamos (Figure 8-2). Most laboratory and community developments are confined to mesa tops. The surrounding area is largely undeveloped.

The population in this region is concentrated in two residential and related commercial areas in Los Alamos County. The Los Alamos townsite has an estimated population of 11,400. The White Rock area has about 6,800 residents. Population estimates for 1991 indicate about 18,500 persons living within a 10-km (6.2 mi) radius of Los Alamos; estimated population within a $50-\mathrm{km}(31 \mathrm{mi})$ radius is 102,500 .

LANL is a multidisciplinary research and development institution of the DOE, managed by the University of California since 1943. LANL's mission is the application of science and technology to solve national problems including weapons development, energy supply, and conservation programs, while basic scientific research complements and strengthens its fundamental technical capabilities.

The Los Alamos area has a semi-arid, temperate mountain climate. Summers are generally sunny with moderate, warm days and cool nights. Maximum summer daily temperatures are usually below $32^{\circ} \mathrm{C}\left(90^{\circ} \mathrm{F}\right)$ while night-time temperatures typically drop below $16^{\circ} \mathrm{C}\left(60^{\circ} \mathrm{F}\right)$. Winter temperatures typically range from about -1 to $10^{\circ} \mathrm{C}\left(30\right.$ to $\left.50^{\circ} \mathrm{F}\right)$ during the day and from -9 to $-4^{\circ} \mathrm{C}\left(15\right.$ to $\left.25^{\circ} \mathrm{F}\right)$ during the night. Average annual precipitation in the LANL area is about $53 \mathrm{~cm}$ (21 in.) (Bowen, 1990), but the precipitation rate varies with elevation. Generally, about $40 \%$ of the annual precipitation occurs during brief afternoon and evening thunderstorms in July and August. Winter precipitation falls primarily as snow, with accumulations of about $150 \mathrm{~cm}$ (59 in.) annually. Evapotranspiration rates in the area vary between approximately 70 to $100 \%$. Average annual evaporation from shallow lakes in the area could be as much as $137 \mathrm{~cm}$ (54 in.).

Surface winds are light at Los Alamos, averaging $11 \mathrm{kph}(7 \mathrm{mph})$. Wind speeds are strongest from March through May and weakest in December and January. The strongest winds are generally southwesterly to northwesterly and occur in the afternoon and evening. Night winds are usually west-northwesterly at the western edge of the Pajarito Plateau due to persistent cold air drainage down the plateau. Daytime winds are generally southeasterly to southwesterly, caused by up-slope and up-valley winds, but can also be westerly during the windy season, March through May. 


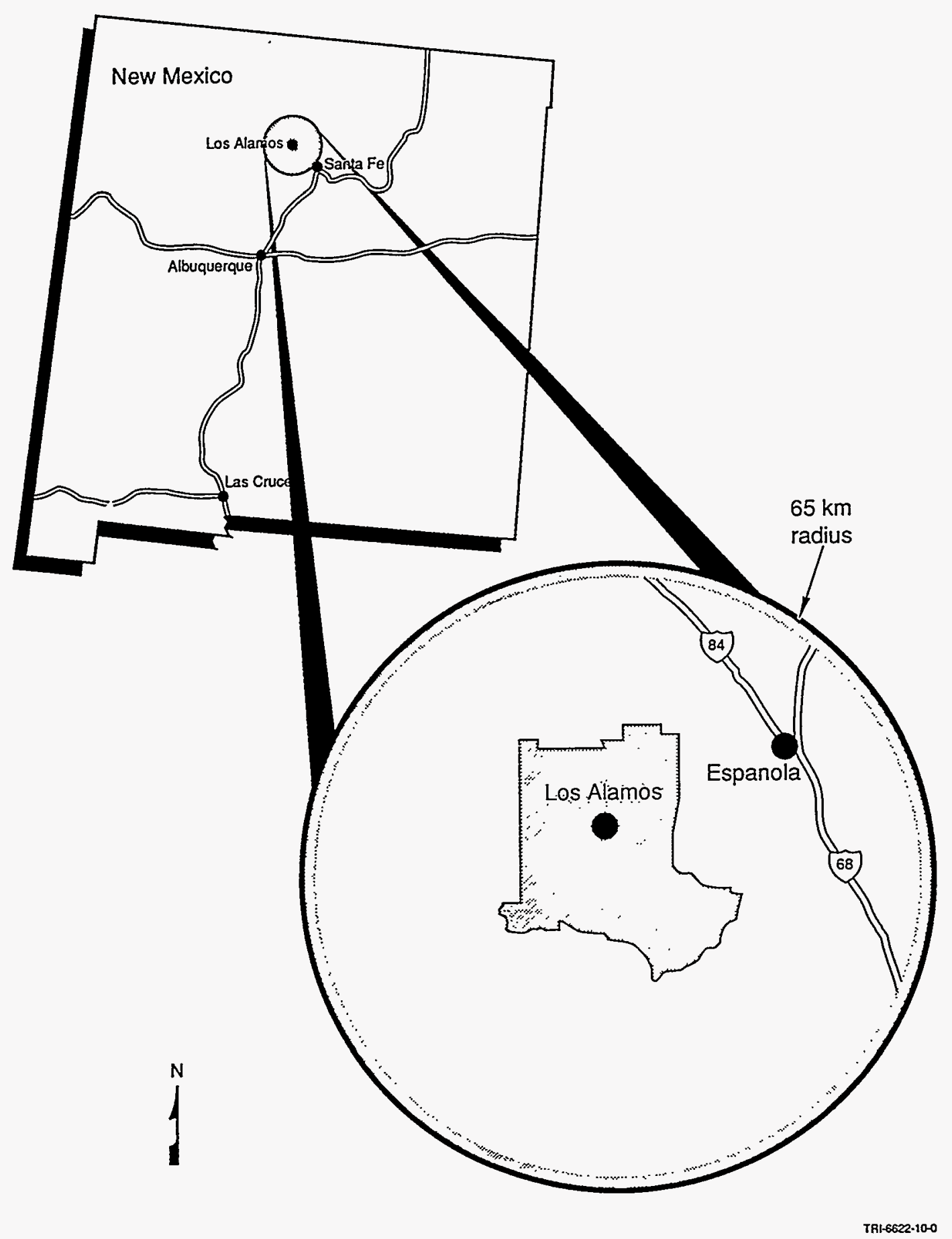

Figure 8-1. Location map for Los Alamos National Laboratory. 


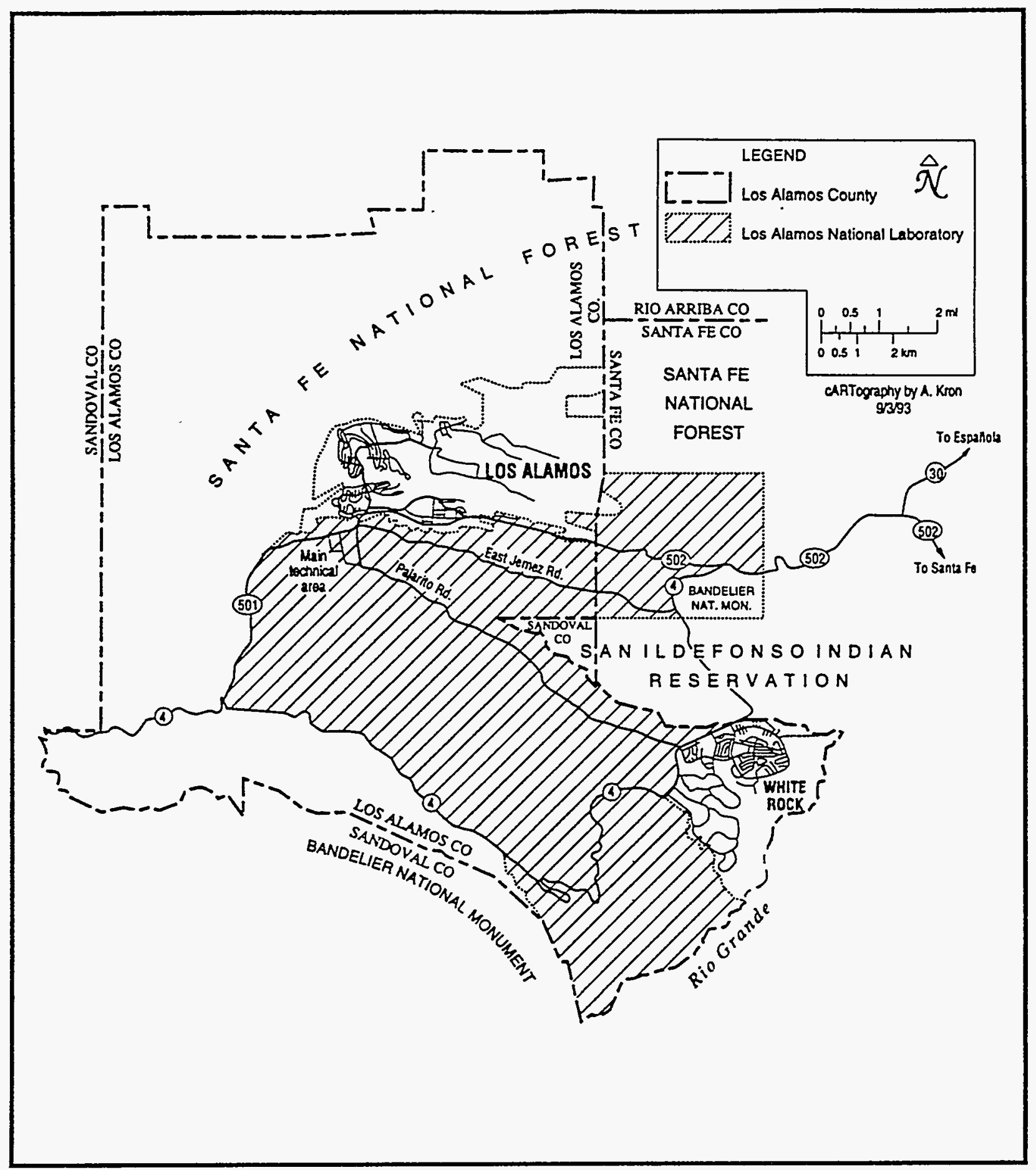

Figure 8-2. Site map for Los Alamos National Laboratory. 
LANL is situated on the Pajarito Plateau, which lies between the Jemez Mountains and the White Rock Canyon of the Rio Grande River. The plateau has a gentle regional southeastdipping slope. The Pajarito Plateau is capped by the Bandelier Tuff, a thick sequence of ash-flow and air-fall pyroclastics that encircle much of the Jemez Mountains. Below the tuff lies a series of interbedded volcanic and sedimentary rocks (Figure 8-3). Subsequent incision of the plateau into the relatively soft tuff created numerous deep canyons that separate narrow, finger-like mesas which radiate out from the Valles caldera (in the vicinity of Sierra de los Valles in Figure 8-3) and become progressively narrower and dissected to the southeast.

The most important tectonic feature in the LANL area is the Pajarito Fault system, composed of large-scale steeply-dipping normal faults, located immediately west of LANL (Figure 8-3). There has been Holocene movement and seismicity associated with this fault system. To the east beneath LANL, many additional faults have been recognized in the subsurface, but only two of these have broken the surface of the Bandelier Tuff (Turin and Rosenberg, 1994).

Surface water in the LANL area occurs primarily as intermittent streams in canyons that cut into Pajarito Plateau and flow westward toward the Rio Grande. Springs on the flanks of the Sierra los Valles west of LANL supply base flow into upper reaches of some of the canyons, but the amount is insufficient to maintain surface flow across the plateau before it is depleted by evaporation, transpiration, and infiltration (Purtymun, 1995). Run-off from heavy thunderstorms and heavy snowmelt reaches the Rio Grande several times a year in some drainages (Purtymun, 1995).

Groundwater in the LANL area occurs as: (1) water in shallow alluvium in some of the larger canyons, (2) perched groundwater (a groundwater body above an impermeable layer that separates it from the underlying main body of water by an unsaturated zone), and (3) the main aquifer (Purtymun, 1995). The main aquifer is the only aquifer capable of large-scale municipal water supply (Purtymun, 1984), and it behaves like a confined aquifer throughout the Pajarito Plateau (LANL, 1992a). This aquifer supplies the primary source of drinking water for the towns of Los Alamos and White Rock, but it has not been classified by the U.S. Environmental Protection Agency (EPA) as a sole source aquifer as defined in 40 CFR Part 149.2. The surface of the main aquifer is located from 180 to $360 \mathrm{~m}$ (600 to $1200 \mathrm{ft}$ ) below the mesa-tops (LANL, 1992a).

\subsection{STATUS AND SITING OF MLLW DISPOSAL FACILITY}

At the time of the PE, personnel at LANL were planning for on-site disposal of MLLW. All operational MLLW is currently being stored at Technical Area-54 (TA-54) Area G, located on Mesita del Buey in the central portion of LANL (see lower right portion of Figure 8-4), and no disposal of MLLW is currently ongoing. Beginning in 1957, disposal of both LLW and MLLW occurred in TA-54 trenches. Since 1986, operational MLLW has been segregated for storage at TA-54 Area G, while disposal of LLW continues to occur. 

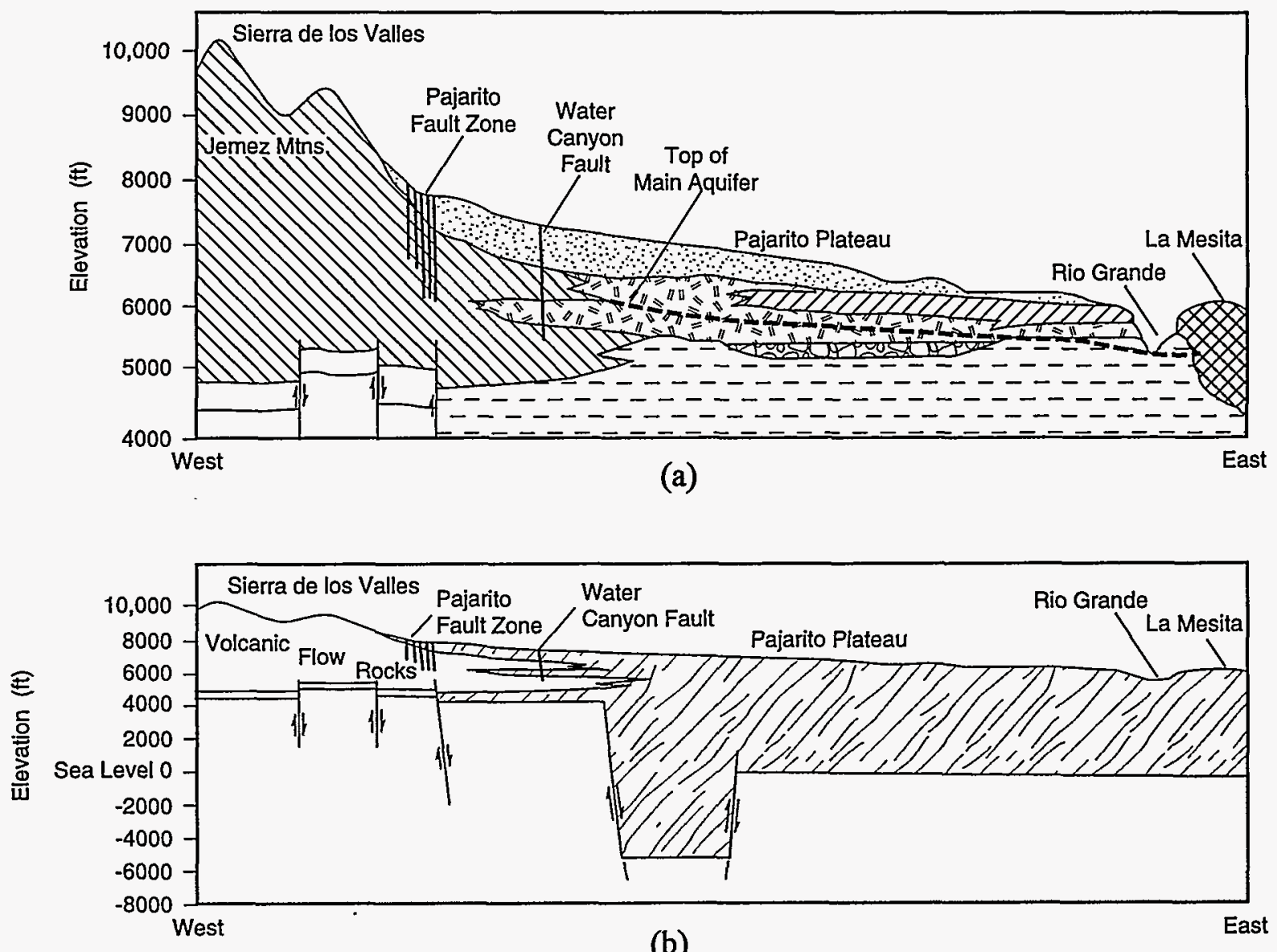

$\begin{array}{ll}\square \text { Tschicoma Formation } & \square \text { Precambrian Crystalline Rock }\end{array}$

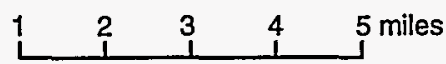

TRI-6622-37-0

Figure 8-3. Geologic sections showing (a) the stratigraphy and (b) the structure from the Sierra de los Valles across the Pajarito Plateau to the Rio Grande (modified from Purtymun, 1995). 


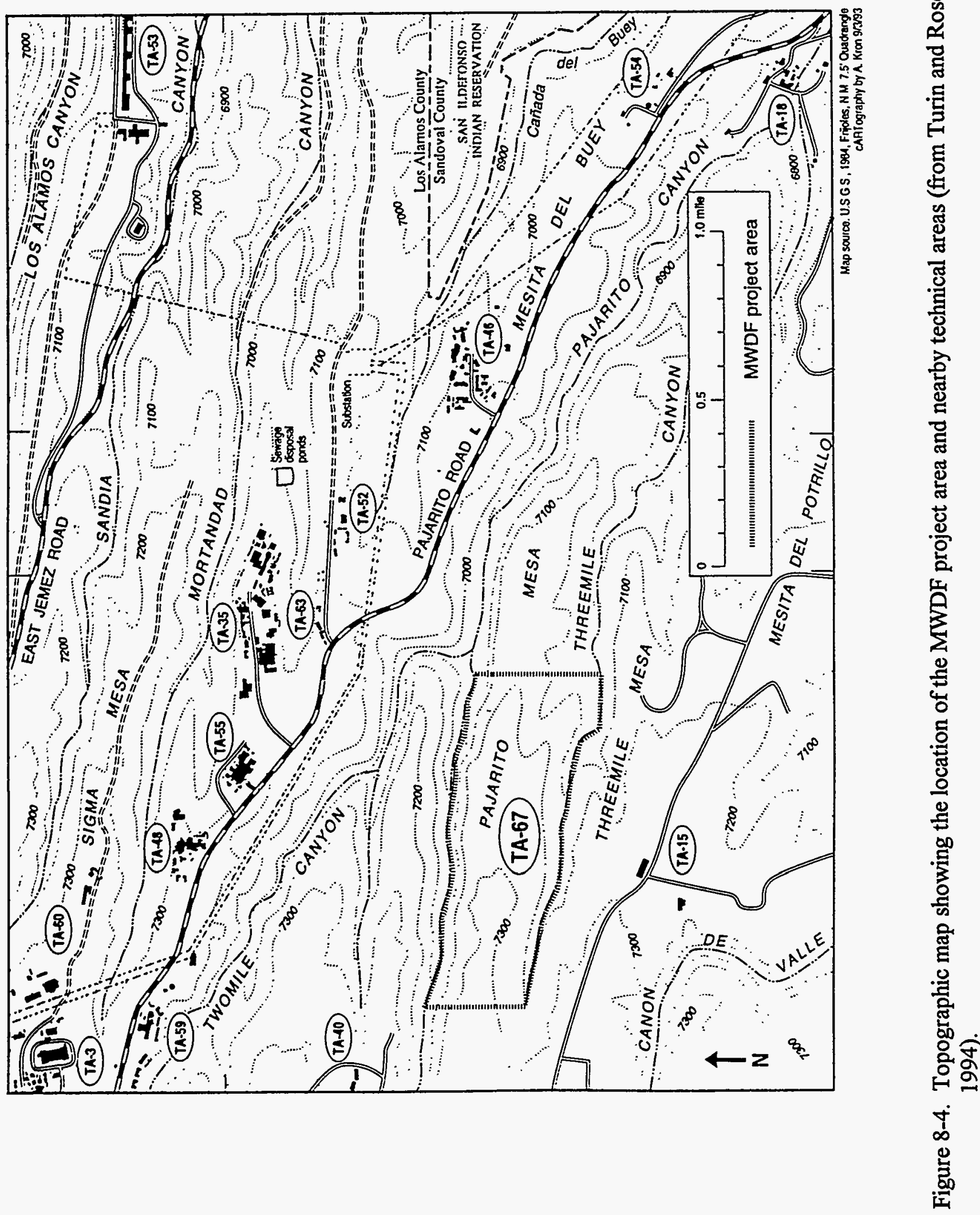


LANL has proposed constructing a RCRA Mixed Waste Disposal Facility (MWDF) at TA-67 on Pajarito Mesa for disposal of Environmental Restoration MLLW. TA-67 is located directly west of the existing facilities at TA-54 Area G (Figure 8-4), bound on the north by Pajarito Canyon (approximately 60 to $75 \mathrm{~m}$ [200 to $250 \mathrm{ft}$ ] deep) and on the south by Three Mile Canyon (about $30 \mathrm{~m}[100 \mathrm{ft}]$ deep). Pajarito Mesa has a relatively flat surface approximately $7 \mathrm{~km}(4.3 \mathrm{mi})$ long with steep walls dropping into the canyons. At TA-67, the mesa is approximately $500 \mathrm{~m}(1640 \mathrm{ft})$ wide between the two canyons. The proposed MWDF is a lined and capped disposal pit approximately $76 \times 520 \times 9 \mathrm{~m}(250 \times 1700 \times 30 \mathrm{ft})$ (LeedshillHerkenhoff, 1995).

The TA-67 location on Pajarito Plateau is used for the LANL PE analysis of the generic trench and tumulus disposal facilities. This location meets the original three screening requirements of (1) not being located within a 100-y floodplain or (2) not within $61 \mathrm{~m}$ (200 ft) of an active fault, and (3) having sufficient area to accommodate a 100-m (328-ft) buffer zone. A performance assessment to meet the objectives of DOE Order 5820.2A has begun for the proposed MWDF, but results will not be available until fall 1995 . No site-specific facility analysis was performed for the LANL PE because the proposed MWDF is in the design phase and there are no site-specific results for comparison.

Two generic disposal facilities were considered in the PE: a RCRA-compliant, belowground trench and a RCRA-compliant, above-ground tumulus (described in more detail in Chapter 5 of Volume 2). The generic facilities were selected to provide consistency in analysis of the performance of the 15 sites. Both generic facilities were assumed to be square with a plan area of $2500 \mathrm{~m}^{2}\left(26,910 \mathrm{ft}^{2}\right)$.

\subsection{BASIS FOR CONCEPTUAL MODEL USED IN THE PE}

The current understanding and the chosen conceptual model for the LANL PE at the TA-67 site is based upon available site literature and interactions with the site technical staff. Pajarito Mesa is currently being investigated to determine if it is a suitable location for the proposed MWDF facility. Recently the stratigraphy, mineralogy, and chemistry of the tuffs (Broxton et al., 1994); the fracture and fault traces (Vaniman and Chipera, 1994); and the mesaedge slope stability (Reneau, 1994) have been examined on Pajarito Mesa. In addition, TA-54 Area $\mathrm{G}$ has been extensively studied in support of a different LLW performance assessment for continued LLW disposal operations. The first draft of these performance assessment results is expected by summer 1995 . Other hydrogeologic site characterization work has been conducted on nearby mesas and canyons by the LANL Environmental Restoration Program and the U.S. Geological Survey.

\subsubsection{Water Pathway}

Knowledge of groundwater flow and radionuclide movement in the water pathway at LANL provided the basis for the conceptual model considered in the PE. The conceptual model encompasses the site technical staff's current understanding of site-specific geology, hydrology, water table and aquifer characteristics, and transport pathways. 


\subsubsection{Current Understanding of Relevant Hydrogeology}

There are no deep boreholes or water supply wells located in TA-67 near the proposed MWDF. Turin and Rosenberg (1994) present east-west and north-south geologic cross-sections based upon data from three boreholes and one water supply well located from about $1.6 \mathrm{~km}$

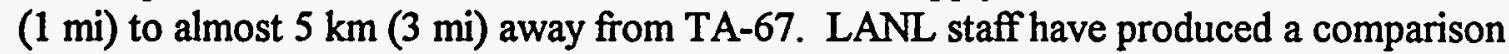
between the lithologic sections of three water supply wells located about $2.4 \mathrm{~km}(1.5 \mathrm{mi})$ to the east of TA-67 (RFI Work Plan for OU 1148, 1992). Broxton et al. (1994) describe five stratigraphic sections measured in the upper Bandelier Tuff exposed on the north walls of Three Mile and Pajarito Canyons and use these data to interpret two shallow north-south trending crosssections across Pajarito Mesa. Broxton, Reneau, and Vaniman (Sep 1994) infer a stratigraphic section at TA-67 along State Plane Line $1624300 \mathrm{E}$ based upon all available data (Figure 8-5).

\section{Stratigraphy}

The geologic units located beneath Pajarito Mesa at TA-67 are summarized below in order from youngest to oldest, based upon descriptions from Turin and Rosenberg (1994), LANL (1992a,b), and Broxton et al. (1994).

Bandelier Tuff. The Bandelier Tuff has been subdivided into two different members that represent two eruptive phases. The Tshirege Member is composed of multiple flow units of crystal-rich ash-flow tuff about $90 \mathrm{~m}(295 \mathrm{ft})$ thick. The Tshirege Member displays significant variations in welding and alteration within a single stratigraphic section and at varying distances from the Valles caldera. Broxton et al. (1993) mapped subdivisions within the Tshirege Member based upon degree of welding and subsequent fracturing (Unit 4, Unit 3, Nonwelded Unit, Unit 2, and Unit 1). The Otowi Member is a nonwelded, vitric, ashflow tuff composed of multiple flow units that exhibits highly variable thickness due to infilling previous topography, ranging from 30 to $140 \mathrm{~m}$ (100 to $460 \mathrm{ft})$. At the base of the Otowi is an air-fall pumice, the Guaje Pumice. Guaje Pumice bed is nonwelded with few penetrating fractures ( 0 to $9 \mathrm{~m}[0$ to $30 \mathrm{ft}]$ thick).

Cerro Toledo Rhyolite and Interbedded Sediments are an interbedded sequence of rhyolitic tuff and sediments that commonly occur between the Tshirege and Otowi members of the Bandelier Tuff ranging from 0 to $46 \mathrm{~m}(0$ to $150 \mathrm{ft})$ in thickness. The sediments are epiclastic sands and sandy gravels. It is not known if these units exist at TA-67. If present, this unit could cause perched water conditions.

The Puye Formation is a lithologically variable fanglomerate shed from Jemez Mountain volcanic center, from 170 to $220 \mathrm{~m}(545$ to $730 \mathrm{ft}$ ) thick. Most of the conglomerates contain cobbles of dacitic to andesitic composition in a volcanic sand matrix.

Cerros del Rio Basalts are basaltic to andesitic flows, breccias, and scoria which interfinger with the Puye Formation. It is not known if the basalts exist beneath TA-67. If Cerros del Rio Basalts are present, they would most likely occur in thin layers, interbedded with sedimentary units. The basalts can cause perched water conditions. 


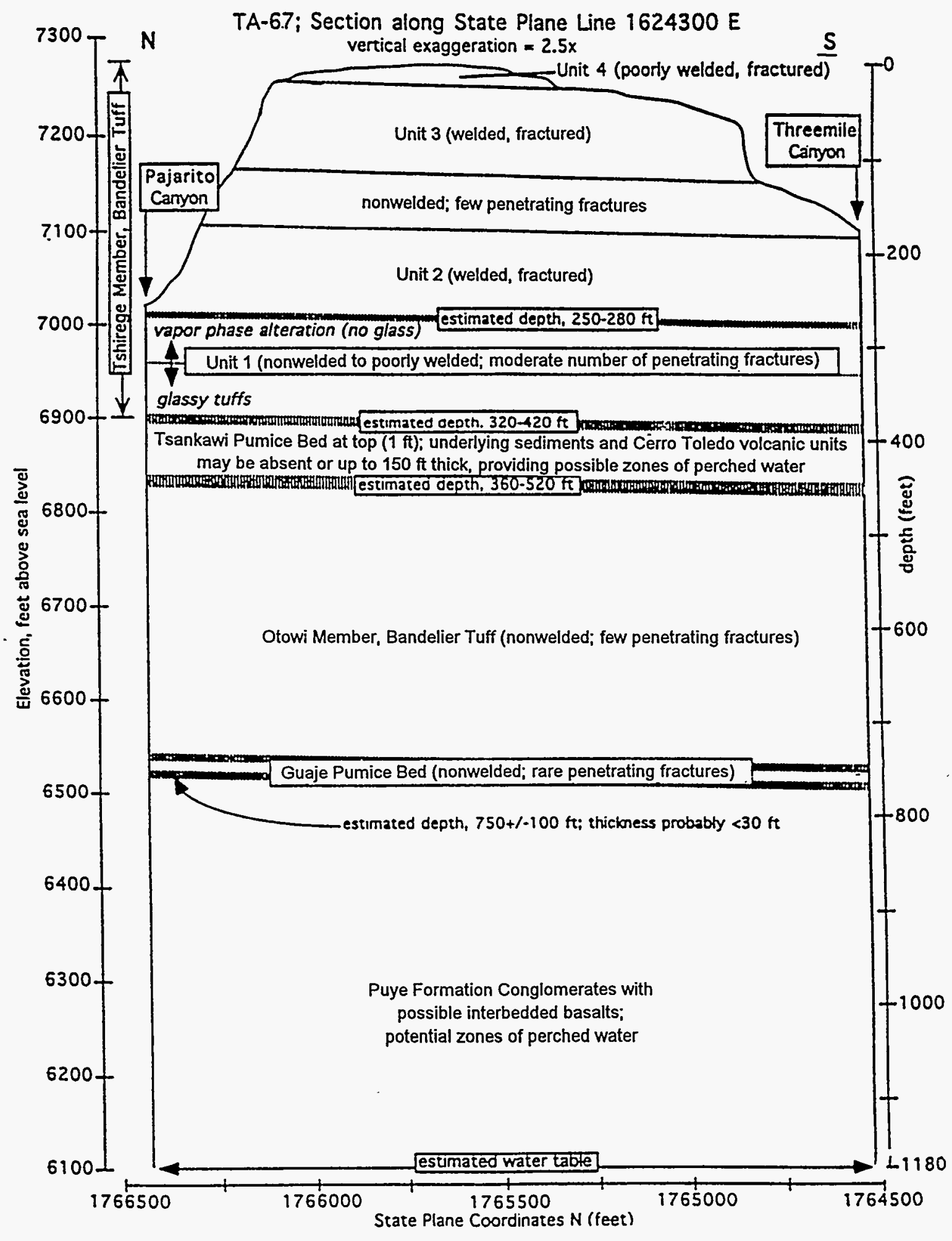

Figure 8-5. Inferred stratigraphic section at TA-67 (from Broxton, Reneau, and Vaniman, 1994). 
The Santa Fe Group is comprised of fluvial sandstone, siltstone, and conglomerate with eolian deposits, ash beds, lacustrine rocks and interbedded basalts. These are the most extensive rocks filling the Rio Grande rift, with a total thickness greater than $480 \mathrm{~m}$ (1570 ft). These deposits comprise the main aquifer for Los Alamos.

\section{Fractures and Welding in the Tuff}

In the Bandelier Tuff, cooling joints are spatially related to the welding zones within a cooling unit where the greater the welding, the greater the fracture density (Winograd and Thordarson, 1975). Also, secondary tectonic joints related to tectonic activity can create fractures and joints that extend through one type of bedding to another. Vaniman and Chipera (1994) mapped vertical fractures that penetrate from Unit 3 down into the Nonwelded Unit and found that fractures tend to be open within Unit 3 and filled with tuff detritus and clay in the nonwelded tuffs. The fracture apertures average about $1 \mathrm{~cm}(0.4 \mathrm{in}$.) with a density of 40 to 75 fractures per $1000 \mathrm{ft}(300 \mathrm{~m})$ of horizontal transect (Vaniman and Chipera, 1994). The underlying Otowi member is significantly less fractured (Baltz et al., 1963).

\section{Liquid-Phase Fracture Flow in Vadose Zone}

In general, the role that fractures play in liquid-phase contaminant transport through the Bandelier Tuff at TA-67 remains unclear (Turin and Rosenberg, 1994). Precipitation in this area occurs in the form of short, intense storm events or as seasonal snow melt (LANL, 1992a). Fracture flow in the near surface tuff probably does occur episodically. It is possible that there are some fractures, particularly those associated with tectonic activity, that extend through several different tuff units. However, relatively large quantities of water would be required to sustain continuous fracture flow. Under unsaturated flow conditions, fractures may actually act as barriers to flow while the tuff matrix can act as a "sponge", damping out fracture movement. As pulses of liquid enter the tuff fracture system, most likely the unsaturated tuff matrix begins to attenuate the fracture flow phenomenon by pulling moisture into the matrix (Wang and Narasimhan, 1985). This phenomenon has been observed in the field by Rush and Dexter (1985) who noted elevated moisture contents in the vicinity of some fractures in the Bandelier Tuff. Christenson and Thomas (1962) observed increased gross alpha activity and moisture content that coincided with visual identification of a vertical fracture that intersected a number of their horizontal borings. They found that, in general, peak alpha activity was associated with fractures in the tuff. Abeele et al. (1981) found that fractures are commonly filled with fine-grained weathering products within $10 \mathrm{~m}(33 \mathrm{ft})$ of the surface, but are open at greater depths and show no signs of weathering. Roots were observed to penetrate the filled fractures, because they were attracted by the higher moisture available in the fine-grained materials.

Field evidence also suggests that air flow may occur through the interconnected fracture system and through surge beds (highly fractured horizontal features present in the bedded tuff sequence). Vaniman and Chipera (1994) found some evaporites (gypsum and halite) filling fractures, providing evidence that some evaporative processes may be occurring in the subsurface. If air flow occurs horizontally through the mesa, it could further dry out the tuff matrix. Air movement through lower tuff layers could possibly inhibit liquid-fracture flow by evaporating liquid in the fractures or by creating greater suction gradients between the fracture and the matrix. There is no field data from Pajarito Mesa (TA-67) to determine whether air flow through the mesa is a significant process. 
Deep Recharge Through the Bandelier Tuff

There are no definitive field measurements that quantify natural recharge through the mesa tops. However, Turin and Rosenberg (1994) report that the average precipitation rate at the elevation of TA-67 is about $40.6 \mathrm{~cm} / \mathrm{y}(15.8 \mathrm{in} . / \mathrm{y})$ with a large estimated average evapotranspiration rate. Therefore, $40.6 \mathrm{~cm} / \mathrm{y}(15.8 \mathrm{in} . / \mathrm{y})$ is available for evapotranspiration, runoff, or infiltration into the subsurface. The amount of runoff is also unknown. However, the upper bound for the deep recharge is significantly less than $40.6 \mathrm{~cm} / \mathrm{y}(15.8 \mathrm{in} . / \mathrm{y})$. In addition, core data exist which can provide a basis for estimating deep recharge(see Section 8.4), and a numerical modeling study of the effectiveness of the cover design for the proposed MWDF at TA-67 was performed. These results also suggest a recharge significantly lower (on the order of a few centimeters per year) than the precipitation rate.

\section{Lateral Flow in Vadose Zone}

The tuff has alternate layers of nonwelded tuff to densely welded tuff. Contacts between extremely different tuff units can influence migration pathways. For example, the contact between the Tshirege nonwelded unit and Unit 2 is an abrupt change in welding characteristics where the nonwelded unit is expected to have higher porosities and permeabilities than Unit 2. This contact may inhibit downward flow or divert water laterally (Broxton et al., 1994). For example, boreholes drilled from the mesa top beneath TA-54 encountered zones with elevated moisture contents at several stratigraphic intervals within the tuffs and underlying basalts (Krier, 1995).

Seeps and springs can be found on the sides of some mesas in the LANL area; however, there is no evidence of large seeps or springs exiting from the sides of Pajarito Mesa (TA-67) (Personal communication, J. Turin [LANL] with A. Parsons [SNL], 12/20/94). Thus, there is no direct support for leachate migration from the mesa top out onto the surface of the canyon walls and subsequently into the perennial streams that exist in both Pajarito and Three Mile canyons.

\section{Perched Groundwater Water in Alluvium}

Intermittent stream flow in the canyons deposited alluvium that ranges from less than $1 \mathrm{~m}$ $(3 \mathrm{ft})$ to up to $23 \mathrm{~m}(76 \mathrm{ft})$ thick. Water movement through the alluvium is impeded by the underlying sediments, which results in a shallow groundwater body that moves down the gradient within the alluvium (Purtymun, 1995). Shallow alluvial groundwater exists in Pajarito Canyon downstream of TA-67 (Stoker et al., 1991); however, these water bodies are small and limited to the canyon-fill alluvium locations (i.e., these zones do not exist beneath the meas tops). Thus, there is no pathway for leachate to migrate from the mesa top, through the mesa, and into a shallow alluvial aquifer.

\section{Perched Groundwater in Volcanic Sediments and Basalts}

If a significant amount of alluvial perched groundwater infiltrates the underlying rock units, deeper groundwater bodies within the Cerros del Rio basalts or Puye Formation may be formed (Turin and Rosenberg, 1994). Such deeper perched aquifers are known to exist beneath some of the larger canyons (Purtymun, 1995). During the drilling of borehole SHB-3 (Gardner et al., 1993), perched groundwater was encountered west of TA-67 within the Bandelier Tuff, less than $240 \mathrm{~m}(790 \mathrm{ft})$ below the top of the mesa. However, with no deep boreholes at TA-67, there are no data to provide evidence for or against the existence of perched groundwater beneath Pajarito Mesa within the Bandelier Tuff or the Puye Conglomerate (Turin and Rosenberg, 1994). 


\section{Regional Aquifer}

The main aquifer water table is located at an approximate depth of $360 \mathrm{~m}(1180 \mathrm{ft})$ below the mesa surface (Broxton, Reneau, and Vaniman; Sep 1994). The predominant portion of the main aquifer resides in the Santa Fe Formation (Purtymun, 1995); however, the water table beneath TA-67 probably resides within the upper Puye Formation (Broxton et al., 1994). The Puye Formation is more permeable than the underlying Santa Fe Formation (LANL, 1992a).

\subsubsection{Conceptual Model Used in the PE}

The PE used a generic conceptual model to describe the water pathway (summarized in Section 1.1.2 of this volume and described in detail in Chapter 5 of Volume 2). In the unsaturated zone, leachate was generated by constant flow of water through the disposal facility at a rate that was controlled by the assumed performance of the disposal facility. When all engineered barriers had failed, the rate was assumed to be equal to the natural recharge through local soils. The volumetric flow of water through the facility that generated leachate was based on the assumed performance and size of the disposal facility. No dilution was assumed to occur in the unsaturated zone, so at steady state, the concentration that reached groundwater equaled the leachate concentration. No lateral spreading was assumed, so the leachate flux through the unsaturated zone was confined to the soil column directly below the plan area of the facility.

As contaminated water entered the saturated zone, the contaminant mixed with clean groundwater, forming a plume with a shape controlled by aquifer and contaminant properties. The generic conceptual model assumed that instantaneous and complete mixing within the aquifer occurred directly below the facility. Mixing in the vertical direction occurred by hydrodynamic dispersion, and the contaminant mixing depth was an estimated value.

The generic conceptual model was adapted to conditions at LANL based on site-specific knowledge of the geology and water flow paths. As illustrated by Figure 8-6, the conceptual model for the LANL PE consists of a single pathway where leachate exits the bottom of the disposal facility, moves vertically from the waste site to the water table, and travels horizontally through the lower aquifer to the $100-\mathrm{m}(328-\mathrm{ft})$ performance boundary. The following assumptions were made in addition to the standard assumptions listed in Chapter 1 of this volume to determine the LANL PE flow and transport system geometry and behavior:

- The complex stratigraphy shown in Figure 8-5 was simplified into two units (the Bandelier Tuff and the Puye Formation) based upon similar hydrologic characteristics. Figure 8-7 describes the actual geologic units and the ranges of thickness used to develop the assumed hydrologic stratigraphy. Average unit thicknesses were used to approximate the assumed hydrogeologic profile.

- Liquid-phase fracture flow was assumed to occur in the upper fractured tuff unit (Unit 3), hence creating a "fast-path." Due to the negligible travel time through Unit 3, this unit was not included in the assumed hydrologic stratigraphy. No fracture flow was assumed to occur below the first nonwelded, low fracture density zone (Nonwelded Unit) (see Figure 8-7). 


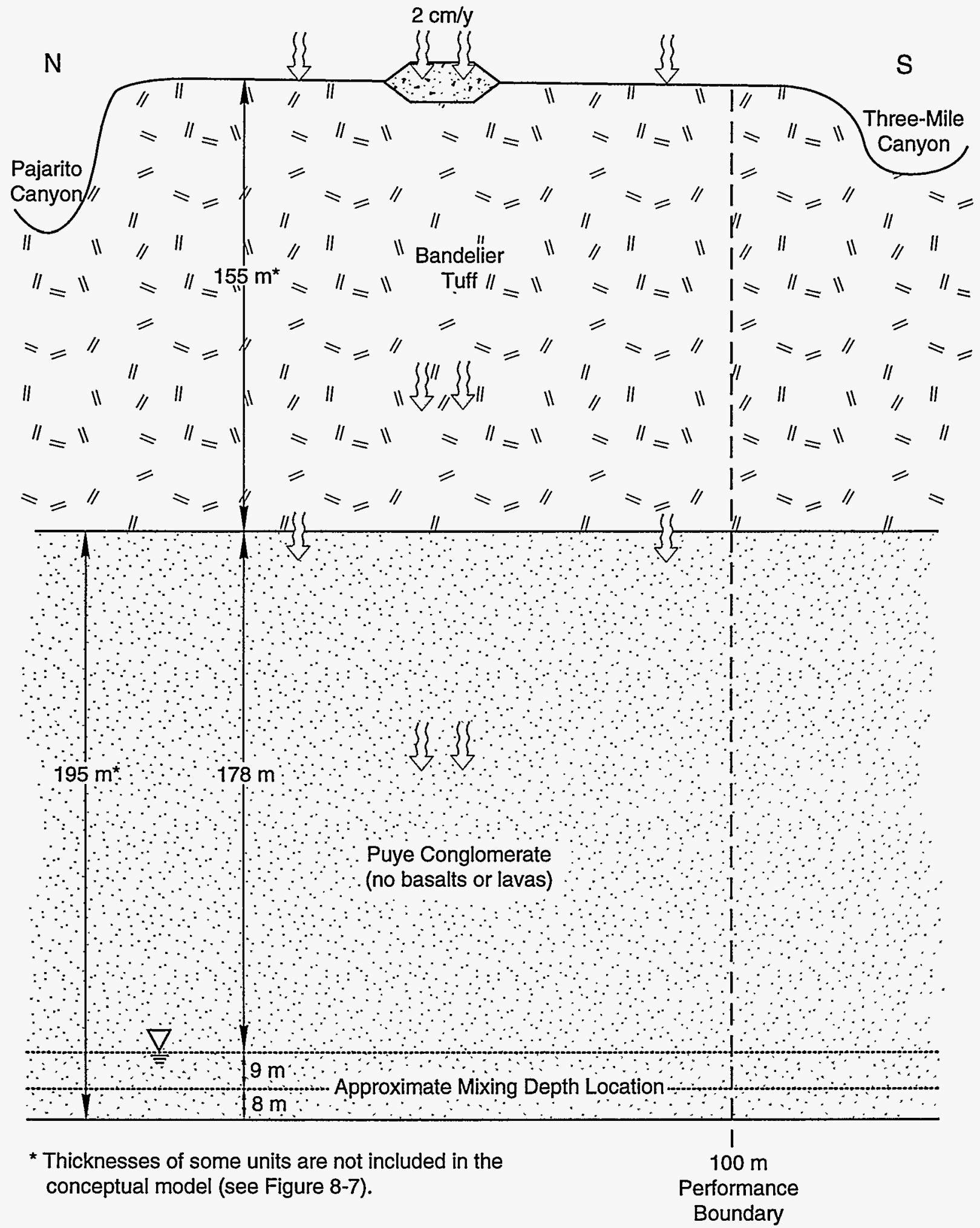

TAI-6622-38-0

Figure 8-6. Conceptual model for water transport at LANL. 


\begin{tabular}{|c|c|c|c|}
\hline Unit & $\frac{\text { Thickness }}{\frac{\text { Range }}{\text { (m) }}}$ & $\frac{\frac{\text { Assumed }}{\text { Thickness }}}{\frac{1}{1(\mathrm{~m})}}$ & Discussion \\
\hline Bandelier Tuff Unit 3 & $24-30$ & 0 & $\begin{array}{l}\text { Assume this unit has "fast travel paths" } \\
\text { through fractures, implying negligible } \\
\text { travel time through Unit } 3 \text {. Therefore it } \\
\text { is not included in the simplified } \\
\text { hydrologic stratigraphy. }\end{array}$ \\
\hline $\begin{array}{l}\text { Bandelier Tuff } \\
\text { NonWelded }\end{array}$ & $8-12$ & 10 & $\begin{array}{l}\text { Assume no significant fracture flow } \\
\text { occurs. }\end{array}$ \\
\hline Bandelier Tuff Unit 2 & $23-32$ & 28 & $\begin{array}{l}\text { Assume no significant fracture flow } \\
\text { occurs. }\end{array}$ \\
\hline Bandelier Tuff Unit 1 & $12-51$ & 32 & $\begin{array}{l}\text { Assume no significant fracture flow } \\
\text { occurs. }\end{array}$ \\
\hline $\begin{array}{l}\text { Cerro Toledo Rhyolite } \\
\text { and Sediments }\end{array}$ & $0-46$ & 0 & $\begin{array}{l}\text { Existence of this unit below TA-67 is not } \\
\text { known. The volcanic units create } \\
\text { possible perched zones, and no perched } \\
\text { conditions are assumed to occur. } \\
\text { Therefore they are neglected in the } \\
\text { simplified hydrologic stratigraphy. }\end{array}$ \\
\hline Bandelier Tuff Otowi & $30-140$ & 85 & $\begin{array}{l}\text { Assume no significant fracture flow } \\
\text { occurs. }\end{array}$ \\
\hline $\begin{array}{l}\text { Total Assumed Thickness } \\
\text { of Bandelier Tuff }\end{array}$ & & 155 & \\
\hline Guaje Pumice & 0.9 & 0 & $\begin{array}{l}\text { Existence of this unit below TA- } 67 \text { is not } \\
\text { known. The pumice creates possible } \\
\text { perched zones, and no perched } \\
\text { conditions are assumed to occur. } \\
\text { Therefore it is neglected in the simplified } \\
\text { hydrologic stratigraphy }\end{array}$ \\
\hline Puye Formation & $170-220$ & 195 & $\begin{array}{l}\text { Assume no interbedded basalts or lavas } \\
\text { are present. }\end{array}$ \\
\hline \multicolumn{2}{|l|}{$\begin{array}{l}\text { Total Assumed Thickness } \\
\text { of Puye Formation }\end{array}$} & 195 & \\
\hline
\end{tabular}

Notes: 1 - Average thickness used for all units, with exception of those with unknown occurrence at TA-67.

Figure 8-7. Geologic stratigraphy and assumptions for forming simplified LANL/PE hydrologic stratigraphy. 
- To account for the fractured units where fracture flow was assumed to provide "fastpaths," the adjusted vadose zone thickness is $333 \mathrm{~m}(1093 \mathrm{ft})$ below the mesa top. The actual vadose zone thickness is about $360 \mathrm{~m}(1180 \mathrm{ft})$ below the mesa top, based upon the estimated depth to the water table (Broxton, Reneau, and Vaniman, 1994). The adjusted vadose zone thickness was obtained by subtracting the Bandelier Tuff Unit 3 thickness $(27 \mathrm{~m}[89 \mathrm{ft}])$ from the actual thickness.

- A natural deep recharge of $2 \mathrm{~cm} / \mathrm{y}$ was assumed. This was based on (1) precipitation/ runoff/evapotranspiration data, (2) unsaturated hydraulic conductivity of the Bandelier Tuff estimated from core data, and (3) HELP model results of the DBS\&A TA-67 performance assessment modeling team (see Section 8.3.1.1).

- Steady-state one-dimensional flow under unit gradient conditions occurs in the vadose zone. According to unsaturated flow characteristics of the layered tuff, lateral flow could occur (see Section 8.3.1.1). However, it was assumed for the LANL PE that any lateral flow paths are not significant.

- No perched zones were assumed to be present between the mesa top and the main aquifer.

- Groundwater flow was assumed to occur in the uppermost portion of the aquifer below TA-67, the Puye Formation.

\subsubsection{Atmospheric Pathway}

The conceptual model used in the PE for evaluating the atmospheric pathway was derived from performance assessments for LLW disposal facilities at Hanford (Kincaid et al., 1993), INEL (Maheras et al., 1994), NTS (Baer et al., 1994), ORR (ORNL, 1994), and SRS (MMES et al., 1994). The model was generalized for the PE but used site-specific values for many of the parameters.

\subsubsection{Current Understanding of Relevant Meteorology}

Site-specific atmospheric transport data are not available for TA-67, although several studies have been conducted at TA-54 Area G in support of site characterization for the TA-54 performance assessment work and for the LANL Radioactive Air Emission Management Program. Beginning in 1994 a series of six portable meteorological towers were sited at TA-54 Area $\mathrm{G}$ to gather data for better understanding the atmospheric flow field and dispersion in the local complex terrain of mesas and canyons. According to Vold et al. (1996), these data suggest that mesa top air flow is very similar at different points, while the mesa top and canyon bottom air flows are quite different from each other. As shown by the windrose in Figure 8-8, the dominant mesa top flow is from the south to southwest with a large variation in direction. Windrose data were obtained from hourly average meteorological readings taken at a height of $10 \mathrm{~m}(33 \mathrm{ft})$ at the G-Area meteoroiogical tower at LANL during the period of 1987 to 1989. 


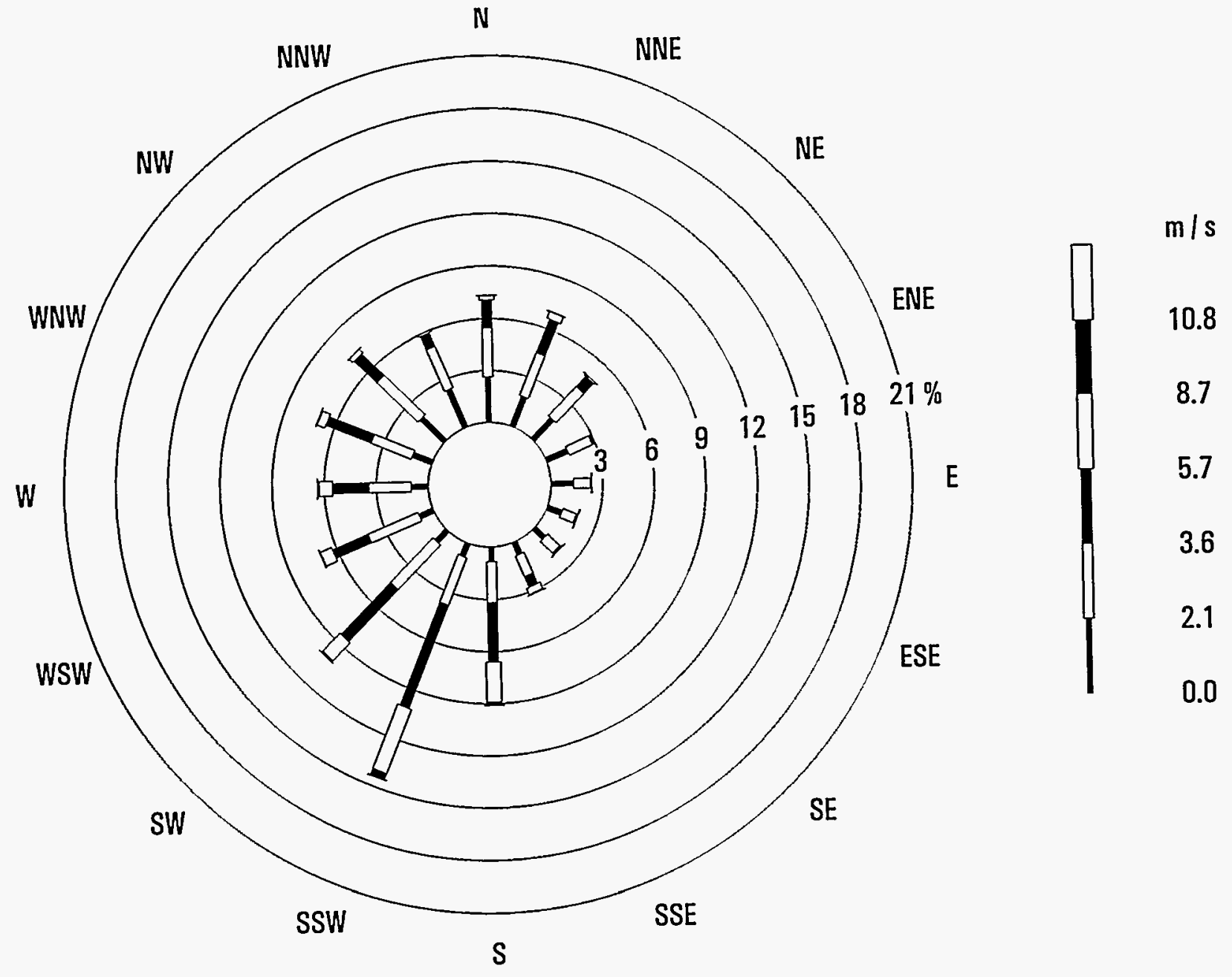

Figure 8-8. Windrose for Los Alamos National Laboratory for the period 1987 to 1989. The frequency of winds from each direction is plotted as a series of connected bars that extend from the center of the circular diagram toward the direction from which the winds originate. Wind speed categories are denoted by bar widths and shadings. The frequency of winds in each wind speed category is indicated by the length of the corresponding bar. 
The local canyon bottom flows are strictly bi-modal, flowing up the canyon during the day and down the canyon at night (not shown on windrose). An implication for atmospheric transport is that contributions from several mesa top wind sectors may combine into a canyon flow where the most likely point of maximum off-site concentrations would be up canyon, to the north of the TA-54 disposal site (Vold et al., 1996). A simple analysis of this effect will be included in the TA-54 performance assessment.

The impact of fugitive emissions of tritiated water and contaminated wind blown dust from the disposal site at TA-54 Area G was evaluated (Kowalewsky et al., 1995). Annual emission rates for tritium, Ur-238, Cs-137, Pu-239, Pu-240, and Sr-90 were calculated. The CAP-88 atmospheric transport model was used to predict areas potentially affected by long-term dust deposition and atmospheric concentrations. These results were used to develop effective dose equivalents (EDEs) for receptor locations downwind of Area G. All EDEs were several orders of magnitude below the national standard of $10 \mathrm{mrem} / \mathrm{y}$, and fugitive air emissions from Area $\mathrm{G}$ were found not to pose a health threat to persons living or working downwind of the facility (Kowalewsky et al., 1995).

\subsubsection{Conceptual Model Used in the PE}

The PE used a generic conceptual model to describe the atmospheric pathway (summarized in Section 1.2 of this volume and described in detail in Chapter 5 of Volume 2). Only H-3 (tritium) and C-14 were expected to be volatile for the disposal facility conditions and thus were the only radionuclides considered for atmospheric transport in the PE. In the model, radionuclides were transported from the disposal facility to the soil surface by vapor (tritium) and gaseous (carbon dioxide carrying the $\mathrm{C}-14$ isotope) diffusion. When the radionuclides reached the soil surface, they were entrained in the air in vapor form as volatiles. Once airborne, these radionuclides were transported via atmospheric dispersion to a receptor located at the performance boundary.

Two components of the atmospheric pathway were evaluated separately: (1) the zone from the top of the disposal facility to the soil surface as indicated by the upward radionuclide diffusion profile; and (2) the zone in which a radionuclide was emitted to the atmosphere, mixed with the ambient air, and dispersed downwind from the waste disposal facility boundary to the 100-m (328-ft) performance boundary.

The arrival time of radionuclides at the performance boundary was assumed to be $100 \mathrm{y}$ based on the following generic assumptions of the PE:

- The waste form was grouted MLLW treatment residuals. Based on this assumption, tritium as vapor was bound in the pore water of the hydrophilic grout, and carbon dioxide as a gas carrying the $\mathrm{C}-14$ isotope was limited by the high $\mathrm{pH}$ of the grout, so that the waste form provided retention of these volatile radionuclides in the disposal facility.

- The disposal facility was capped by a RCRA-compliant cover system. Based on this assumption, the cover system was maintained to provide low permeability for $100 \mathrm{y}$. 


\subsubsection{Inadvertent Intruder Pathways}

Standard intrusion scenarios were used in the PE, with information derived from performance assessments of LLW disposal facilities at SRS (MMES et al., 1994) and ORR (ORNL, 1994) indicating that only two chronic-exposure scenarios needed to be considered for most sites and facility designs. Any variations in these scenarios were based on discussions with site technical staff about such factors as the types of activities that reasonably could result in exposure to buried waste at the site and the effectiveness of active or passive institutional controls and engineered barriers in precluding access to the waste.

\subsubsection{Current Understanding of Potential Modes of Inadvertent Intrusion}

Intruder scenarios for the LANL area being addressed in the ongoing performance assessment work are consistent with the two standard PE intrusion scenarios. Groundwater is the primary source of drinking water in the LANL area. Irrigation is common in this area and crops could be grown at the TA-67 site. Basements are not commonly installed here. Erosion from the sides of the mesa, eventually exposing the waste are an additional concern here. Based upon mesa-edge instability data from Pajarito Mesa, the proposed MWDF location can be situated to assure integrity of the disposal pits for the next 10,000 y (Reneau, 1994). No erosion is assumed to occur into the sides of the disposal pits during the period of analysis for the LANL PE. The TA-54 performance assessment will address the construction and agriculture scenarios.

\subsubsection{Intruder Scenarios Used in the PE}

The PE used two standard intrusion scenarios that could be modified for site-specific conditions to describe potential modes of inadvertent intrusion (summarized in Section 1.3 of this volume and described in detail in Chapter 5 of Volume 2). The first scenario, the agriculture (homesteader) scenario, included establishment by an intruder of a permanent homestead directly above a disposal facility with the foundation of the home extending into the waste; some of the waste exhumed from the disposal facility was mixed with native soil in the intruder's vegetable garden. The second scenario, the post-drilling scenario, considered the construction of a well for a domestic water supply by an intruder. The well was drilled through the disposal facility, and the cuttings were mixed with soil in the intruder's vegetable garden. The intruder gardened in some of the exhumed waste but did not reside permanently above the disposal facility. In both scenarios, exposure occurred where an intruder dug or drilled into the disposal facility. These standard intrusion scenarios will likely bound any potential scenarios that could access the waste at the proposed MWDF in TA-67.

For the generic intruder scenarios, the time of intrusion for the homesteader scenario was assumed to be $300 \mathrm{y}$ for the trench design and $500 \mathrm{y}$ for the tumulus design. The time of intrusion for the post-drilling scenario was assumed to be $100 \mathrm{y}$.

\subsection{DATA USED IN THE PE}

The data presented in this section apply to the PE conceptual models described in Section 8.3. The calculations for determining permissible waste concentrations for the radionuclides 
considered in the PE are discussed in more detail in Chapter 5 of Volume 2 and summarized in Chapter 1 of this volume. The results of the calculations for LANL are presented in Section 8.5 and discussed in Section 8.6 of this volume.

\subsubsection{Water Transport}

Site-specific values required to perform the water pathway analysis were selected by site technical staff either from site characterizations and reports, from site-specific modeling results, or from general literature. For the unsaturated zone, the site-specific data that were required for the PE were distance between the disposal facility and groundwater; ambient moisture content; dry bulk density of the geologic medium; and distribution coefficients $\left(K_{d} s\right)$ of the radionuclides in the geologic medium; and natural recharge. For the saturated zone, the site-specific data that were required were porosity; dry bulk density of the geologic medium; and distribution coefficients $\left(K_{d} \mathrm{~s}\right)$ of the radionuclides in the geologic medium; groundwater Darcy flow rates; and mixing depth in the aquifer.

These values for LANL are listed in Table 8-1 along with generic values that were used in the PE. Also indicated in the table is a designation of the type of data that the value represents and the source of the value. The values were determined from one or more of four data sources: (A) measurement performed by the site, state, or federal agency; (B) result of a numerical analysis performed by the site, state, or federal agency; $(C)$ general literature value selected by the site; and (D) generic value of the PE.

Of the parameters in the PE that depended on site-specific values, only three potentially encompassed enough variability in values to significantly affect the results: natural recharge, $i$; distribution coefficients $\left(K_{d} s\right)$ for the geologic media; and groundwater Darcy velocity $\left(q_{g_{w}}\right)$. The sources of these values are discussed in this section. The sensitivity of the results to changes in the values of these parameters is discussed in Section 8.6.2 of this volume and Chapter 6 of Volume 2.

The natural recharge at LANL is not known. A value of $2 \mathrm{~cm} / \mathrm{y}(0.78 \mathrm{in} / \mathrm{y})$ was chosen based on: (1) precipitation data (average rate of $40.6 \mathrm{~cm} / \mathrm{y}$ [15.8 in./y] at TA-67, see Section 8.3.1), (2) unsaturated hydraulic conductivity of the Bandelier Tuff estimated from core data, and (3) numerical modeling results. The $2 \mathrm{~cm} / \mathrm{y}(0.78 \mathrm{in} . / \mathrm{y})$ value falls within the range of the core data.

Based on Bandelier Tuff core data, the deep recharge may vary from 0.0001 to $22 \mathrm{~cm} / \mathrm{y}$ ( 0.00004 to $8.6 \mathrm{in} . \mathrm{y})$. Core data can provide a physical basis for estimating the deep recharge assuming the tuff can be treated as a homogeneous porous media, because under steady-state, unit-gradient conditions, the flux rate through the vadose zone is equivalent to the hydraulic conductivity. The measured relationship between moisture content and pressure head was used to estimate the unsaturated hydraulic conductivity versus moisture content relationship of Bandelier Tuff from TA-54 Area G core data (Rogers and Gallaher, 1994) and from TA-67 core data (D.B. Stephens and Assoc., 1995). According to TA-54 data, at an initial volumetric moisture content of $5 \%$, the unsaturated hydraulic conductivity $(K)$ averages about $10^{-4} \mathrm{~cm} / \mathrm{y}(0.00004 \mathrm{in} . / \mathrm{y})$. 
Table 8-1. Parameters and Values Used in the PE for the Water Pathway at LANL (generic PE values are in bold; these values and the standard PE method for applying them are summarized in Chapter 1 of this volume and discussed in more detail in Chapter 5 of Volume 2) (Part 1 of 2)

\begin{tabular}{|c|c|c|c|}
\hline Parameter & Value & $\begin{array}{l}\text { Data } \\
\text { Type }\end{array}$ & Comments \\
\hline \multicolumn{4}{|l|}{ SOURCE TERM } \\
\hline $\begin{array}{l}\text { Volumetric water content } \\
\text { of the waste, } \theta_{0}\end{array}$ & 0.3 & $\mathbf{D}$ & Standard PE value \\
\hline $\begin{array}{l}\text { Bulk density of grouted } \\
\text { waste, } \rho_{0}\end{array}$ & $1.76 \mathrm{~cm}^{3}$ & D & Standard PE value \\
\hline $\begin{array}{l}\text { Distribution coefficients } \\
\text { for grouted waste, } K_{d}^{G}\end{array}$ & various & D & $\begin{array}{l}\text { Standard PE value, see Table } 8-2 \text { in } \\
\text { this chapter }\end{array}$ \\
\hline $\begin{array}{l}\text { Disposal facility plan } \\
\text { area, } A\end{array}$ & $2500 \mathrm{~m}^{2}$ & D & $\begin{array}{l}\text { Standard PE value; } A=a_{1} * a_{2}, \text { where } \\
a_{1}=a_{2}=50 \mathrm{~m}\end{array}$ \\
\hline $\begin{array}{l}\text { Waste mixing fraction for } \\
\text { trench, } f_{m}\end{array}$ & 0.67 & $\mathbf{D}$ & Standard PE value \\
\hline $\begin{array}{l}\text { Waste mixing fraction for } \\
\text { tumulus, } f_{m}\end{array}$ & 0.33 & D & Standard PE value \\
\hline $\begin{array}{l}\text { Annual rate of water flowing } \\
\text { through intact trench facility, } \\
g_{f}\end{array}$ & $0.02 \mathrm{~m} / \mathrm{y}$ & $D$ & $\begin{array}{l}\text { Standard PE value is } 3 \mathrm{~cm} / \mathrm{y} \text {. Natural } \\
\text { recharge is lower for this site. }\end{array}$ \\
\hline $\begin{array}{l}\text { Annual rate of water } \\
\text { flowing through intact } \\
\text { tumulus facility, } q_{f}\end{array}$ & $0.00003 \mathrm{~m} / \mathrm{y}$ & D & Standard PE value \\
\hline $\begin{array}{l}\text { Time to failure of } \\
\text { leachate collection and } \\
\text { liner systems }\end{array}$ & $30 y$ & D & Standard PE value \\
\hline $\begin{array}{l}\text { Time to failure of trench } \\
\text { facility }\end{array}$ & $100 y$ & D & Standard PE value \\
\hline $\begin{array}{l}\text { Time to failure of } \\
\text { tumulus facility }\end{array}$ & $300 y$ & D & Standard PE value \\
\hline $\begin{array}{l}\text { Natural recharge through } \\
\text { local soils, } i\end{array}$ & $0.02 \mathrm{~m} / \mathrm{y}$ & B & $\begin{array}{l}\text { Natural recharge not known. Value based } \\
\text { on 1) precipitation, runoff, } \\
\text { evapotranspiration data, 2) unsaturated } \\
\text { hydraulic conductivity of the Bandelier Tuff } \\
\text { estimated from core data, and 3) HELP } \\
\text { model results of the DBS\&A TA-67 } \\
\text { performance assessment modeling team } \\
\text { (see Section 8.3.1.1). }\end{array}$ \\
\hline
\end{tabular}

- $A=$ site measurement; $B=$ result of site numerical analysis; $C=$ literature value selected by the site; $D=$ generic $P E$ value 
Table 8-1. Parameters and Values Used in the PE for the Water Pathway at LANL (generic PE values are in bold; these values and the standard PE method for applying them are summarized in Chapter 1 of this volume and discussed in more detail in Chapter 5 of Volume 2) (Part 2 of 2)

\begin{tabular}{|c|c|c|c|}
\hline Parameter & Value & $\begin{array}{l}\text { Data } \\
\text { Type* }\end{array}$ & Comments \\
\hline \multicolumn{4}{|c|}{ UNSATURATED ZONE (BANDELIER TUFF) } \\
\hline Moisture content, $\theta_{w}$ & 0.05 & A & $\begin{array}{l}\text { Based on neutron logging results in Bandelier } \\
\text { Tuff from TA-54 (LANL, 1992) and TA-16 } \\
\text { (Nyhan, 1989). }\end{array}$ \\
\hline Bulk density, $\rho_{b}$ & $1.22 \mathrm{~g} / \mathrm{cm}^{3}$ & A & $\begin{array}{l}\text { Rogers and Gallaher (1994, Table 22), mean } \\
\text { from } 141 \text { core samples. }\end{array}$ \\
\hline $\begin{array}{l}\text { Distribution coefficients for } \\
\text { geologic media, } K_{d}\end{array}$ & Various & C & See Table 8-2 in this chapter \\
\hline $\begin{array}{l}\text { Thickness from land surface to top } \\
\text { of Puye Formation }\end{array}$ & $155 \mathrm{~m}$ & A & $\begin{array}{l}\text { Average thicknesses estimated from } \\
\text { stratigraphic column presented by Broxton, } \\
\text { Reneau, and Vaniman (1994), with Bandelier } \\
\text { Tuff Unit } 3 \text { removed due to "fast travel paths" } \\
\text { through fractures. (see Figure 8-7) }\end{array}$ \\
\hline \multicolumn{4}{|c|}{ UNSATURATED AND SATURATED ZONES (PUYE FORMATION) } \\
\hline Moisture content, $\theta_{w}$ & 0.05 & A & $\begin{array}{l}\text { No data available, assumed to remain } \\
\text { constant from overlying Bandelier Tuff. }\end{array}$ \\
\hline Porosity, $n$ & 0.30 & A & $\begin{array}{l}\text { Freeze and Cherry ( } 1979, \text { Table } 2.4, p .37) \text {. } \\
\text { Within range of porosities reported for a sand } \\
\text { and a conglomerate. }\end{array}$ \\
\hline Bulk density, $\rho_{b}$ & $1.86 \mathrm{~g} / \mathrm{cm}^{3}$ & $\bar{A}$ & $\begin{array}{l}\text { CRC Handbook of Tables for Applied } \\
\text { Engineering Science (1987, Table 6-42, } \\
\text { p.636). Literature value for a mixed-grained } \\
\text { sand, dense. }\end{array}$ \\
\hline $\begin{array}{l}\text { Distribution coefficients for } \\
\text { geologic media, } K_{d}\end{array}$ & Various & $\bar{C}$ & See Table 8-2 in this chapter \\
\hline $\begin{array}{l}\text { Thickness from bottom of } \\
\text { Bandelier Tuff to water table }\end{array}$ & $178 m$ & $\bar{A}$ & $\begin{array}{l}\text { Took depth-to-water-table estimate reported } \\
\text { by Broxton, Reneau, and Vaniman (1994), } \\
\text { and subtracted } 155 \mathrm{~m} \text { (the assumed } \\
\text { Bandelier Tuff thickness). }\end{array}$ \\
\hline Total thickness & $195 \mathrm{~m}$ & A & $\begin{array}{l}\text { Average unit thickness estimated from range } \\
\text { reported by Turin and Rosenberg }(1994, p .4) \text {. }\end{array}$ \\
\hline Mixing depth, $d_{m}$ & $9 \mathrm{~m}$ & B & $\begin{array}{l}\text { Depth of mixing predicted by PAGAN code } \\
\text { (Chu et al., 1991) at a 100-m boundary at } \\
\text { steady state. }\end{array}$ \\
\hline Groundwater seepage velocity, $v$ & $\begin{array}{l}250 \mathrm{ft} / \mathrm{y} \\
(76 \mathrm{~m} / \mathrm{y})\end{array}$ & $\bar{A}$ & $\begin{array}{l}\text { Based on pump test results in Puye } \\
\text { Formation (Purtymun, 1984, p.18). }\end{array}$ \\
\hline Groundwater Darcy velocity, $q_{\mathrm{gw}}$ & $\begin{array}{c}75 \mathrm{ft} / \mathrm{y} \\
(23 \mathrm{~m} / \mathrm{y})\end{array}$ & A & $\begin{array}{l}\text { Determined from seepage velocity value, } \\
\text { assuming a porosity of } 0.30 \text {. }\end{array}$ \\
\hline $\begin{array}{l}\text { Distance to performance } \\
\text { boundary from facility } \\
\text { boundary }\end{array}$ & $100 \mathrm{~m}$ & $\mathbf{D}$ & Standard PE value \\
\hline
\end{tabular}

* $A=$ site measurement; $B=$ result of site numerical analysis; $C=$ iiterature value selected by the site; $D=$ generic $P E$ value 
Table 8-2. Solid/Liquid Distribution Coefficients $\left(K_{d} s\right)$ Used in the PE at LANL

\begin{tabular}{|c|c|c|c|}
\hline \multirow[t]{2}{*}{ Element } & \multirow{2}{*}{$\begin{array}{c}\text { Waste } K_{d}^{G} \\
(\mathrm{~mL} / \mathrm{g})^{*}\end{array}$} & \multicolumn{2}{|c|}{$K_{d}$ for Geologic Media $(\mathrm{m} L \mathrm{~g})$} \\
\hline & & Bandelier Tuff & $\begin{array}{c}\text { Puye } \\
\text { Conglomerate }\end{array}$ \\
\hline $\mathrm{H}$ & 0 & $0^{b}$ & 0.1 \\
\hline C & 10 & $0^{b}$ & 5 \\
\hline$\overline{A l}$ & 100 & $130^{\circ}$ & 35 \\
\hline Si & 100 & $35^{d}$ & 35 \\
\hline $\mathrm{Cl}$ & 0 & $0^{b}$ & 15 \\
\hline $\mathrm{K}$ & 1 & $15^{d}$ & 15 \\
\hline $\mathrm{Co}_{0}$ & 100 & $0.45^{\mathrm{e}}$ & 60 \\
\hline $\mathrm{Ni}$ & 10 & $50^{b}$ & 400 \\
\hline $\mathrm{Se}$ & 1 & $2^{b}$ & 150 \\
\hline $\mathrm{Sr}$ & 100 & $116^{f}$ & 15 \\
\hline $\mathrm{Zr}$ & 10 & $500^{b}$ & 600 \\
\hline $\mathrm{Nb}$ & 10 & $100^{b}$ & 160 \\
\hline TC & 1 & $0.3^{f}$ & 0.1 \\
\hline $\mathrm{Pd}$ & 100 & $50^{b}$ & 55 \\
\hline $\mathrm{Ag}$ & 100 & $90^{d}$ & 90 \\
\hline $\mathrm{Cd}$ & 100 & $80^{d}$ & 80 \\
\hline Sn & 10 & $50^{b}$ & 130 \\
\hline 1 & 1 & $0^{b}$ & 1 \\
\hline Cs & 10 & $428^{f}$ & 280 \\
\hline $\mathrm{Ba}$ & 10 & $946^{\prime}$ & 15 \\
\hline$s m$ & 10 & $50^{\mathrm{b}}$ & 245 \\
\hline Eu & 10 & $50^{\mathrm{b}}$ & 245 \\
\hline $\mathrm{Pb}$ & 100 & $25^{b}$ & 270 \\
\hline$R a$ & 10 & $200^{b}$ & 500 \\
\hline Th & 100 & $500^{b}$ & 3200 \\
\hline $\mathrm{Pa}$ & 100 & $100^{b}$ & 550 \\
\hline$\underline{U}$ & 100 & $1.8^{f}$ & 35 \\
\hline $\mathrm{Np}$ & 100 & $0.007^{8}$ & 5 \\
\hline $\mathrm{Pu}$ & 100 & $110^{t}$ & 550 \\
\hline $\mathrm{Am}$ & 100 & $130^{\prime}$ & 1900 \\
\hline $\mathrm{Cm}$ & 100 & $50^{\circ}$ & 4000 \\
\hline $\mathrm{Cf}$ & 100 & $130^{\circ}$ & 4000 \\
\hline
\end{tabular}

a Standard PE values; see Chapter 5 in Volume 2

b Brookins, 1984

c Estimated based upon similarity with Am (III) and Cf (III), Am (III) and AI (III), and Am (III) and actinium (III).

d Sand value reported by Thibault et al., 1990

- Polzer et al., 1985

f Wolisberg. 1980

g Triay et al., 1994 
The average $K$ is about $0.03 \mathrm{~cm} / \mathrm{y}(0.012$ in./y) at $10 \%$ moisture. The $K$ values derived from samples collected at TA-67 exhibiting the highest saturated hydraulic conductivity (core \#B1-103-104 and B4-104-106.4 with $K_{\text {sat }}=1.5 \times 10^{-2} \mathrm{~cm} / \mathrm{s}$ [0.006 in./s] [D.B. Stephens and Assoc, 1995]) were 0.3 and $0.07 \mathrm{~cm} / \mathrm{y}(0.12$ and 0.03 in./y) for $5 \%$ moisture, and 22.4 and $6.3 \mathrm{~cm} / \mathrm{y}(8.7$ and $2.5 \mathrm{in} . / \mathrm{y})$ for $10 \%$ moisture content, respectively.

D.B. Stephens and Associates performed an analysis of cover design effectiveness for the proposed facility at TA-67 using the HELP model (Schroeder et al., 1994). They calculated about a $2 \mathrm{~cm} / \mathrm{y}(0.78 \mathrm{in}$./y) flux from the bottom of the facility at late time after no credit is taken for the facility (personal communication, A. Parsons [SNL] with R. MacKinnon [DBS\&A], $3 / 7 / 95)$.

Purtymun (1984) reports a seepage velocity of $76 \mathrm{~m} / \mathrm{y}$ ( $249 \mathrm{ft} / \mathrm{y}$ )(corresponding to a Darcy velocity of $23 \mathrm{~m} / \mathrm{y}$ [ $75 \mathrm{ft} / \mathrm{y}$ ], assuming a porosity of 0.30 ) based on pump tests in the Puye Formation. The value measured in the Puye Formation was used here because it is the geologic unit consistent with the LANL PE conceptual model, and it easily falls within the reported range for Darcy velocities measured in this area. The groundwater Darcy velocity for the main aquifer in the LANL area varies from 6 to $105 \mathrm{~m} / \mathrm{y}$ (20 to $340 \mathrm{ft} / \mathrm{y}$ ) (Purtymun and Stoker, 1988). These values were obtained by pump tests conducted in three different well fields and three test wells located throughout LANL; several were conducted in the Santa Fe Formation which underlies the Puye Conglomerate.

The mixing depth in the aquifer was estimated to be about $9 \mathrm{~m}(30 \mathrm{ft})$. This value was calculated with the PAGAN code (Chu et al., 1991), the aquifer porosity, Darcy velocity, longitudinal dispersivity, and transverse dispersivity. The assumed longitudinal dispersivity was

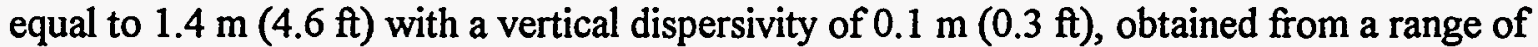
literature values reported for greywacke alluvium (gravels) and greywacke gravel with cobbles (EPRI, 1985, Table 2-1, p. 2-13-2-15).

Values for distribution coefficients $\left(K_{d} \mathrm{~S}\right)$ are listed in Table 8-2 for the 58 radionuclides (32 elements) considered in the PE. In addition to the $K_{d}$ values for the geologic media, grout $K_{d}$ values are listed for determining the desorption from the source term resulting from the grouted waste form. Two sets of geologic $K_{d} s$ were used for the LANL PE: one for the Bandelier Tuff unit, and one for the Puye Conglomerate unit (see Section 8.3.1.2). Site-specific $K_{d}$ values for Bandelier Tuff are not available. However, $K_{d}$ s for the tuff found at Yucca Mountain, Nevada, have been measured. Assuming the Yucca Mountain tuffs are similar to the Bandelier Tuff, the Yucca Mountain tuff $K_{d} s$ values have been used in the LANL PE. If tuff data were not available for a certain radionuclide, then a literature value for sand reported by Thibault et al. (1990) was used. Site-specific $K_{d}$ values for the Puye Conglomerate are not available either. For this unit, the literature values for sand reported by Thibault et al. (1990) were used. In addition to the $K_{d}$ s for the geologic media, grout $K_{d} \mathrm{~S}$ are listed for determining the retardation in the source term resulting from the grouted waste form. 


\subsubsection{Atmospheric Transport}

Site-specific data required to perform the atmospheric pathway analysis came from site personnel as data either from site characterizations and reports or from general literature. The site-specific data required for the soil diffusion calculation were the same as some of those required for the water transport analysis (Section 8.4.1). These values are shown in Table 8-3. Necessary atmospheric dispersion data included wind speed and direction and stability class, which are summarized in Section 8.3.2.1.

Table 8-3. Parameters and Values Used in the PE for the Atmospheric Pathway at LANL

\begin{tabular}{|c|c|c|c|}
\hline Parameter & Value & $\begin{array}{l}\text { Data } \\
\text { Type* }\end{array}$ & Comments \\
\hline $\begin{array}{l}\text { Disposal facility cover } \\
\text { thickness, } x\end{array}$ & $1.0 \mathrm{~m}$ & D & Standard PE value \\
\hline $\begin{array}{l}\text { Depth of the soil } \\
\text { surface, } d\end{array}$ & $0.01 \mathrm{~m}$ & D & $\begin{array}{l}\text { Standard PE value based on } \\
\text { Maheras et al., } 1994\end{array}$ \\
\hline Porosity, $n$ & 0.48 & A & $\begin{array}{l}\text { Mean of } 139 \text { core samples Rogers and } \\
\text { Gallaher, 1994, Table 23). }\end{array}$ \\
\hline Percent saturation, $S$ & 0.10 & A & $\begin{array}{l}\text { Based on volumetric moisture content } \\
\text { measured by neutron logging Bandelier } \\
\text { Tuff at TA-54 (LANL, 1992) and TA-16 } \\
\text { (Nyhan, 1989). }\end{array}$ \\
\hline $\begin{array}{l}\text { Ratio of water density } \\
\text { in air to liquid, } r\end{array}$ & $9.2 E-06$ & D & $\begin{array}{l}\text { Standard PE value based on MMES } \\
\text { et al., } 1994\end{array}$ \\
\hline $\begin{array}{l}\text { Ratio of } \mathrm{CO}_{2} \\
\text { concentration in air to } \\
\text { dissolved in water, } r\end{array}$ & 4.3E-04 & D & $\begin{array}{l}\text { Standard PE value based on Foust } \\
\text { et al. (as cited in Copper and Alley, } \\
1986 \text { ) }\end{array}$ \\
\hline $\begin{array}{l}\text { Tritium diffusion } \\
\text { coefficient in air, } D\end{array}$ & $2.39 E-05 \mathrm{~m}^{2} / \mathrm{s}$ & D & $\begin{array}{l}\text { Standard PE value based on CRC } \\
\text { (1981) }\end{array}$ \\
\hline $\begin{array}{l}\text { Carbon diffusion } \\
\text { coefficient in air, } D\end{array}$ & $1.4 E-05 \mathrm{~m}^{2} / \mathrm{s}$ & D & $\begin{array}{l}\text { Standard PE value based on CRC } \\
(1981)\end{array}$ \\
\hline $\begin{array}{l}\text { Atmospheric dispersion } \\
\text { term, } A_{D}\end{array}$ & $\begin{array}{c}0.36 \\
\left(\mu \mathrm{C} / \mathrm{m}^{3}\right) /\left(\mu \mathrm{C} / \mathrm{m}^{2}-\mathrm{s}\right)\end{array}$ & B & $\begin{array}{l}\text { Value is estimated using the Industrial } \\
\text { Source Complex-Version } 2 \text { Long Term Air } \\
\text { Dispersion Model (ISCLT2) (EPA, 1992) } \\
\text { based on site-specific STAR data. }\end{array}$ \\
\hline
\end{tabular}

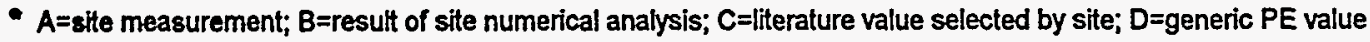

\subsubsection{Inadvertent Intruder Exposure}

As explained in Section 8.3.3, the PE used two standard intrusion scenarios to describe potential modes of inadvertent intrusion at all the sites. Because these intrusion scenarios were considered applicable to all sites, no values specific to LANL are used in the calculation of exposures to inadvertent intruders. 


\subsection{RESULTS OF THE PE}

The performance evaluation provided estimates of permissible waste concentrations in disposed MLLW. The three calculations that formed the foundation of the PE-for the water, atmospheric, and inadvertent intruder pathways-are summarized in Sections 1.1, 1.2, and 1.3, respectively, of this volume and discussed in detail in Chapter 5 of Volume 2.

For each pathway the maximum permissible waste concentration at the performance boundary was determined for each radionuclide by using the performance measures: $4 \mathrm{mrem}$ $(0.04 \mathrm{mSv})$ per year from the water pathway for releases to drinking water; $10 \mathrm{mrem}(0.1 \mathrm{mSv})$ per year from all pathways for atmospheric releases; and $100 \mathrm{mrem}(1 \mathrm{mSv})$ per year from all exposure pathways for chronic exposure of inadvertent intruders; and the appropriate pathway or scenario dose conversion factors (annual effective dose equivalent per unit concentration) based on EPA dose conversion factors. The basis for the performance measures used in the PE is discussed in more detail in Chapter 5 of Volume 2. For the water and atmospheric pathways, the concentration reduction provided by the environment (i.e., the CRF) was estimated using results of site analyses and data. For the intruder analyses, concentration reduction was estimated for appropriate exposure pathways for two intrusion scenarios that, in general, were the same for all the sites. The results of the calculations for the pathways that were analyzed at LANL are provided in this section and discussed in Section 8.6.

\subsubsection{Water Transport}

Two CRFs were calculated for the water pathway: the source $\mathrm{CRF}, C R F_{\text {source, }}$ and the environmental transport $\mathrm{CRF}$ for water, $C R F_{\text {Water. }}$ The source $\mathrm{CRF}$ represents the concentration attenuation between the disposed waste and leachate exiting the bottom of the disposal facility and was defined as the dimensionless ratio of the waste concentration to the resulting leachate concentration. Desorption with infiltrating water was the mechanism used to describe the leaching of radionuclides from the grout. Because a generic method was used to determine the $C R F_{\text {Source }}$ for the 58 radionuclides considered in the PE (summarized in Section 1.1 of this volume and discussed in more detail in Chapter 5 of Volume 2), the radionuclide-specific values for the source CRF for each type of generic facility were the same for all 15 sites.

The environmental transport CRF for water was defined as the ratio of the concentration of the leachate exiting the disposal facility to the resulting concentration in water at the performance boundary. The concentration attenuation represented by $C R F_{\text {Water }}$ consisted of dilution due to mixing with uncontaminated groundwater. Effects of radioactive decay and decay product ingrowth were also included in the PE.

In the PE, water travel time from the facility location to the performance boundary was calculated as a basis for comparison with the retarded travel time of the radionuclides. For LANL, water travel time from the land surface to the performance boundary (i.e., without consideration of a disposal facility) was estimated at about $830 \mathrm{y}$. 
The calculation of travel time through the vadose zone for a radionuclide, on the other hand, must account both for the lower flow rate because of the facility's RCRA cover and for the retardation defined by the distribution coefficient for the geologic media. In the PE, the calculation for travel time in the vadose zone first determined the distance a radionuclide traveled at the lower infiltration rate. Then, if the radionuclide had not fully traversed the vadose zone, the additional time required to complete travel in the vadose zone under the higher infiltration rate based on the natural recharge through local soils was calculated and added to the time determined at the lower infiltration rate.

At LANL, this procedure was used for calculations of travel time through the vadose zone for a tumulus facility because the assumed rate of water flowing through the concrete vaults was less than the natural recharge. However, for a trench at LANL, the natural recharge was less than the assumed rate of water flowing through a RCRA cover; calculations through the vadose zone for a trench facility were based entirely on the natural recharge.

In the PE, the detention time in the facility for a radionuclide was the time during which water flowing through the facility was assumed to be caught by the leachate collection system. Specifically, the calculation of travel time for a radionuclide accounted for the following:

- For the trench design, the leachate collection system was assumed to catch water flowing through the facility for the first $30 \mathrm{y}$. After $30 \mathrm{y}$, the liner and leachate collection system failed, and the rate of water flowing through the facility for the next $70 \mathrm{y}$ was assumed to be $0.02 \mathrm{~m} / \mathrm{y}(0.067 \mathrm{ft} / \mathrm{y})$, which was the lesser of the natural recharge for local soils and the rate based on a unit hydraulic gradient and the saturated hydraulic conductivity of the RCRA cover system $(0.03 \mathrm{~m} / \mathrm{y}[0.1 \mathrm{ft} / \mathrm{y}])$.

- For the tumulus design, the leachate collection system was assumed to catch water flowing through the facility for the first $30 \mathrm{y}$. After $30 \mathrm{y}$, the liner and leachate collection system was assumed to fail, and the rate of water flowing through the facility for the next $270 \mathrm{y}$ was assumed to be $0.00003 \mathrm{~m} / \mathrm{y}(0.0001 \mathrm{ft} / \mathrm{y})$ based on a unit hydraulic gradient and the saturated hydraulic conductivity of the concrete vaults. After a total of $300 \mathrm{y}$ of reduced flow because of engineered barriers ( $30 \mathrm{y}$ detention plus $270 \mathrm{y}$ limited by the concrete vaults), the rate was assumed to be the average recharge for local soils, $0.02 \mathrm{~m} / \mathrm{y}$ $(0.07 \mathrm{ft} / \mathrm{y})$.

Travel time through the aquifer was independent of facility design and was about one year, based on groundwater Darcy velocity and a 100-m distance to the performance boundary (see Section 1.1.2 of this volume for a summary of these assumptions and Chapter 5 of Volume 2 for additional details). The arrival time of a radionuclide at the performance boundary is the sum of the detention time in the facility, travel time through the vadose zone, and travel time through the aquifer.

Retardation of radionuclides by interaction with soils and rock in the vadose and saturated zones increased travel times for individual radionuclides. This effect was particularly important for short-lived radionuclides because of radioactive decay. For short-lived radionuclides, the 
effects of radioactive decay combined with long travel times increased the permissible concentrations in the disposal facility.

Application of the PE methodology for water transport of the 58 radionuclides considered in the PE produced the results shown in Table 8-4 for the generic trench and tumulus designs at LANL. The table shows permissible waste concentrations based on transport through the water pathway $\left(C_{W-W a t e r}\right)$ as well as the values used in calculating the permissible waste concentrations.

Some radionuclides listed in Table 8-4 have no limit (NL) on their permissible waste concentrations, the result of the combined effects of relatively short half-lives and sufficiently long travel time to the performance boundary. "No limit" is defined as a permissible waste concentration that is greater than the specific activity of the pure elemental radionuclide. For disposal of the maximum possible waste concentration of these relatively short-lived radionuclides, the water pathway produced a dose at the performance boundary of less than $4 \mathrm{mrem}(0.04 \mathrm{mSv})$ per year and, therefore, the permissible waste concentration was unlimited based on exposures from this pathway.

For some radionuclides, no value is listed in Table 8-4 for the radioactive decay term, $r_{\text {Decay. }}$ These radionuclides had radioactive decay terms that were very large (e.g., greater than $1 \times 10^{50}$ ). Any radionuclide with a radioactive decay term greater than $1 \times 10^{50}$ was ensured a calculated permissible waste concentration greater than the specific activity of the pure elemental radionuclide, which, as described previously, resulted in no limit (NL) on permissible waste concentrations for disposal.

Arrival times for some radionuclides listed in Table 8-4 were beyond the 10,000-y performance period. For those radionuclides, the estimated waste concentrations are presented in Table 8-4 for information purposes only. Consistent with the approach used in LLW performance assessments, these values were not considered in determining the most restrictive disposal limit from among the evaluated pathways.

For all radionuclides in Table 8-4, the natural recharge at the time of facility failure controlled the subsurface transport (i.e., the subsurface movement of the radionuclides in the trench and tumulus was controlled by recharge at $100 \mathrm{y}$ after closure for the trench [when the cover failed] and at $300 \mathrm{y}$ for the tumulus [when the concrete vaults failed]).

For the tumulus, the total undecayed CRFs (the product of the $C R F_{\text {Source }}$ and the $C R F_{\text {Water }}$ ) for the water pathway were about twice the total undecayed CRFs for the trench, given the same overall rate of flow (i.e., at the time of hydrologic failure of the facility). This result was due to the difference in the volume fraction of waste (the ratio of waste material to total material in the disposal unit) between the two technologies - twice as much waste leached from the trench for a given rate of flow because a given volume of trench was assumed to contain twice as much waste as the tumulus. 
Table 8-4. Results of Calculations for the Water Pathway at LANL (water travel time from land surface to performance boundary [excluding facility detention] $=830 \mathrm{y})($ Part 1 of 2$)$

\begin{tabular}{|c|c|c|c|c|c|c|c|c|c|c|c|c|}
\hline \multirow[t]{2}{*}{ Nuclide } & \multirow[b]{2}{*}{$\begin{array}{c}\text { PDCF } \\
\text { remly per } \mu \text { CuL }\end{array}$} & \multicolumn{5}{|c|}{ Trench } & \multicolumn{5}{|c|}{ Tumulus } & \multirow[t]{2}{*}{ Nuclide } \\
\hline & & $\begin{array}{l}\text { CRF source } \\
\text { (dimensionless) }\end{array}$ & $\begin{array}{l}\text { CRF Wmorer } \\
\text { (dimenzionioss) }\end{array}$ & $\begin{array}{l}\text { Arrival } \\
\text { Time (y) }\end{array}$ & \begin{tabular}{|c|}
$r_{\text {Decay }}$ \\
(dimensionless)
\end{tabular} & $\begin{array}{c}C_{W-W e r w r}^{b} \\
\left(\mu \mathrm{C} / \mathrm{m}^{3}\right)\end{array}$ & $\begin{array}{l}\text { CRF source } \\
\text { (dimentionless) }\end{array}$ & $\begin{array}{c}\text { CRF warer } \\
\text { (dimensionless) }\end{array}$ & $\begin{array}{c}\text { Arrival } \\
\text { Time }(y)\end{array}$ & $\underset{\text { (dimensionlocs) }}{\text { roveny }}$ & $\begin{array}{c}C_{\text {w.wamer }}^{b} \\
(\mu \mathrm{Ci/m})\end{array}$ & \\
\hline $\mathrm{H}-3$ & 4.67E-02 & 0.45 & 210 & $2.5 E+03$ & e & NL & 0.9 & 210 & $2.8 \mathrm{E}+03$ & e & NL & $\mathrm{H}-3$ \\
\hline C-14 & $1.52 \mathrm{E}+\infty 0$ & 27 & 210 & $8.4 E+04$ & $2.5 E+04$ & $4 E+08$ & 54 & 210 & $8.4 E+04$ & $2.6 E+04$ & $8 E+08$ & $\mathrm{C}-14$ \\
\hline Al-26 & $1.06 \mathrm{E}+01$ & 270 & 210 & $1.7 \mathrm{E}+06$ & $5.2 E+00$ & $1 E+05$ & 540 & 210 & $1.8 \mathrm{E}+06$ & $5.6 E+\infty 0$ & $2 E+05$ & Al-26 \\
\hline Si-32 & $7.99 \mathrm{E}+\infty 0$ & 270 & 210 & $8.9 E+05$ & e & $\overline{N L}$ & 540 & 210 & $9.1 E+05$ & e & $\mathrm{NL}$ & Si-32 \\
\hline $\mathrm{Cl}-36$ & $2.21 E+\infty 0$ & 0.45 & 210 & $2.5 \mathrm{E}+05$ & $1.8 \mathrm{E}+00$ & $3 E+02$ & 0.9 & 210 & $2.5 E+05$ & $1.8 E+\infty 0$ & $6 \mathrm{E}+02$ & $\mathrm{Cl} 36$ \\
\hline$K-40$ & $1.36 \mathrm{E}+01$ & 3.1 & 210 & $3.8 \mathrm{E}+05$ & $1.0 E+00$ & $2 E+02$ & 6.2 & 210 & $3.9 E+05$ & $1.0 \mathrm{E}+00$ & $4 E+02$ & $K-40$ \\
\hline Co-60 & $1.97 E+01$ & 270 & 210 & $1.0 \mathrm{E}+06$ & e & $\mathrm{NL}$ & 540 & 210 & $1.0 \mathrm{E}+06$ & $e$ & $\mathrm{NL}$ & Co-60 \\
\hline Ni-59 & $1.53 \mathrm{E}-01$ & 27 & 210 & $7.1 E+06$ & $1.0 E+28$ & NL & 54 & 210 & $7.1 \mathrm{E}+06$ & $1.3 E+28$ & NL & Ni-59 \\
\hline Ni-63 & 4.21E-01 & 27 & 210 & $7.1 \mathrm{E}+06$ & e & $\mathrm{NL}$ & 54 & 210 & $7.1 E+06$ & e & NL & $\mathrm{Ni}-63$ \\
\hline Se-79 & $6.35 E+00$ & 3.1 & 210 & $2.5 E+06$ & $3.9 E+11$ & NL & 6.2 & 210 & $2.5 E+06$ & $4.0 \mathrm{E}+11$ & NL & Se-79 \\
\hline Sr-90 & $1.12 E+02$ & 270 & 210 & $1.3 \mathrm{E}+06$ & e & NL & 540 & 210 & $1.3 E+06$ & e & NL & Sr-90 \\
\hline Zr-93 & $1.59 E+00$ & 27 & 210 & $1.4 E+07$ & $7.8 \mathrm{E}+02$ & $1 E+07$ & 54 & 210 & $1.5 E+07$ & $8.8 E+02$ & $2 E+07$ & Zr-93 \\
\hline $\mathrm{Nb}-93 \mathrm{~m}$ & $3.81 \mathrm{E}-01$ & 27 & 210 & $3.5 E+06$ & e & NL & 54 & 210 & $3.6 \mathrm{E}+06$ & $e$ & $\mathrm{NL}$ & $\mathrm{Nb}-93 \mathrm{~m}$ \\
\hline $\mathrm{Nb}-94$ & $5.21 E+00$ & 27 & 210 & $3.5 E+06$ & e & NL & 54 & 210 & $3.6 E+06$ & e & NL & $\mathrm{Nb}-94$ \\
\hline Tc-99 & $1.07 E+00$ & 3.1 & 210 & $5.2 E+03$ & $1.0 \mathrm{E}+00$ & $2 E+03$ & 6.2 & 210 & $5.6 \mathrm{E}+03$ & $1.0 E+00$ & $5 E+03$ & Tc-99 \\
\hline Pd-107 & $1.09 E-01$ & 270 & 210 & $1.4 \mathrm{E}+06$ & $1.2 \mathrm{E}+00$ & $2 E+06$ & 540 & 210 & $1.4 E+06$ & $1.2 E+00$ & $5 E+06$ & Pd-107 \\
\hline $\mathrm{Ag}-108 \mathrm{~m}$ & $5.56 \mathrm{E}+00$ & 270 & 210 & $2.3 \mathrm{E}+06$ & e & NL & 540 & 210 & $2.3 E+06$ & e & NL & $\mathrm{Ag}-108 \mathrm{~m}$ \\
\hline $\mathrm{Cd}-113 \mathrm{~m}$ & $1.17 \mathrm{E}+02$ & 270 & 210 & $2.0 \mathrm{E}+06$ & e & $\mathrm{NL}$ & 540 & 210 & $2.1 E+06$ & e & $\mathrm{NL}$ & $\mathrm{Cd}-113 \mathrm{~m}$ \\
\hline$S n-121 m$ & $1.28 \mathrm{E}+00$ & 27 & 210 & $2.6 \mathrm{E}+06$ & e & NL & 54 & 210 & $2.6 E+06$ & e & $\overline{\mathrm{NL}}$ & Sn-121m \\
\hline$S n-126$ & $1.53 \mathrm{E}+01$ & 27 & 210 & $2.6 \mathrm{E}+06$ & $6.7 E+07$ & $1 E+11$ & 54 & 210 & $2.6 \mathrm{E}+06$ & $8.1 E+07$ & $\overline{N L}$ & Sn-126 \\
\hline $1-129$ & $2.01 E+02$ & 3.1 & 210 & $1.7 E+04$ & $1.0 \mathrm{E}+\infty 0$ & $1 E+01$ & 6.2 & 210 & $1.8 \mathrm{E}+04$ & $1.0 \mathrm{E}+00$ & $3 E+01$ & $1-129$ \\
\hline Cs-135 & $5.16 \mathrm{E}+00$ & 27 & 210 & $8.5 E+06$ & $1.3 E+01$ & $6 E+04$ & 54 & 210 & $8.7 E+06$ & $1.4 \mathrm{E}+01$ & $1 E+05$ & Cs-135 \\
\hline \begin{tabular}{|l|} 
Cs-137 \\
\end{tabular} & $3.65 \mathrm{E}+01$ & 27 & 210 & $8.5 \mathrm{E}+06$ & e & NL & 54 & 210 & $8.7 E+06$ & $e$ & $\mathrm{NL}$ & Cs-137 \\
\hline Ba-133 & $2.48 \mathrm{E}+00$ & 27 & 210 & $8.7 E+06$ & e & NL & 54 & 210 & $9.2 \mathrm{E}+06$ & e & NL & $B a-133$ \\
\hline Sm-151 & $2.84 E-01$ & 27 & 210 & $4.5 \mathrm{E}+06$ & $\mathbf{e}$ & NL & 54 & 210 & $4.5 \mathrm{E}+06$ & e & $\mathrm{NL}$ & $S m-151$ \\
\hline Eu-152 & $4.73 E+00$ & 27 & 210 & $4.5 \mathrm{E}+06$ & e & $\overline{N L}$ & 54 & 210 & $4.5 E+06$ & e & NL & Eu-152 \\
\hline Eu-154 & $6.97 \mathrm{E}+00$ & 27 & 210 & $4.5 E+06$ & e & NL & 54 & 210 & $4.5 E+06$ & e & NL & Eu-154 \\
\hline $\mathrm{Pb}-210$ & $5.30 \mathrm{E}+03$ & 270 & 210 & $4.7 \mathrm{E}+06$ & e & NL & 540 & 210 & $4.7 E+06$ & e & NL & $\mathrm{Pb}-210$ \\
\hline Ra-226 & $6.27 E+03$ & 27 & 210 & $1.0 \mathrm{E}+07$ & e & $\mathrm{NL}$ & 54 & 210 & $1.0 \mathrm{E}+07$ & e & $\mathrm{NL}$ & Ra-226 \\
\hline Ra-228 & $1.64 E+03$ & 27 & 210 & $1.0 \mathrm{E}+07$ & e & NL & 54 & 210 & $1.0 \mathrm{E}+07$ & e & NL & Ra-228 \\
\hline Th-229 & $2.94 E+03$ & 270 & 210 & $5.7 \mathrm{E}+07$ & e & NL & 540 & 210 & $5.8 E+07$ & e & $\mathrm{NL}$ & $T h-229$ \\
\hline Th-230 & $6.12 E+03$ & 270 & 210 & $5.7 E+07$ & $\overline{N A}$ & $4 E+01$ & 540 & 210 & $5.8 E+07$ & NA & $7 E+01$ & Th-230 \\
\hline Th-232 & $3.63 E+03$ & 270 & 210 & $5.7 \mathrm{E}+07$ & $1.0 \mathrm{E}+00$ & $6 E+01$ & 540 & 210 & $5.8 E+07$ & $1.0 E+\infty$ & $1 E+02$ & Th-232 \\
\hline Pa-231 & $1.85 \mathrm{E}+04$ & 270 & 210 & $1.0 E+07$ & $e$ & $\mathrm{NL}$ & 540 & 210 & $1.0 \mathrm{E}+07$ & e & $\overline{N L}$ & $\mathrm{~Pa}-231$ \\
\hline
\end{tabular}


$\stackrel{\infty}{\dot{\leftrightarrow}}$ Table 8-4. Results of Calculations for the Water Pathway at LANL (water travel time from land surface to performance boundary [excluding facility detention] $=830 \mathrm{y})($ Part 2 of 2)

\begin{tabular}{|c|c|c|c|c|c|c|c|c|c|c|c|c|c|c|}
\hline \multirow[t]{2}{*}{ Nuclide } & \multirow[b]{2}{*}{$\begin{array}{c}\text { PDCF } \\
\text { rem/y per } \mu \mathrm{Cin}\end{array}$} & \multicolumn{6}{|c|}{ Trench } & \multicolumn{6}{|c|}{ Tumulus } & \multirow[t]{2}{*}{ Nuclide } \\
\hline & & $\begin{array}{l}\text { CRF source } \\
\text { (dimensionless) }\end{array}$ & $\begin{array}{c}\text { CRF Water }_{\text {(dimensionless) }} \\
\end{array}$ & $\begin{array}{c}\text { Arrival } \\
\text { Time (y) } \\
\end{array}$ & $\underset{\text { (dimensionloss) }}{\text { rocay }^{a}}$ & $\begin{array}{r}C_{W \cdot \text { Wate }} \\
\left(\mu \mathrm{Ci} / \mathrm{m}^{3}\right. \\
\end{array}$ & & $\begin{array}{c}C R F_{\text {Source }} \\
\text { (dimensionloss) }\end{array}$ & $\begin{array}{c}C_{\text {(dimensionless) }} \\
\text { Water }\end{array}$ & $\begin{array}{l}\text { Arrival } \\
\text { Time (y) } \\
\end{array}$ & $\underset{\text { (dimensionloss) }}{\text { r Decay }^{a}}$ & $\begin{array}{r}C_{\text {Wewater }} \\
\left(\mu \mathrm{Ci} / \mathrm{m}^{3}\right) \\
\end{array}$ & & \\
\hline$U-232$ & $1.55 E+03$ & 270 & 210 & $6.0 E+05$ & e & $\mathrm{NL}$ & c & 540 & 210 & $6.0 E+05$ & $\mathbf{e}$ & NL & c & U-232 \\
\hline$U-233$ & $1.95 E+03^{d}$ & 270 & 210 & $6.0 \mathrm{E}+05$ & NA & $1 E+02$ & & 540 & 210 & $6.0 E+05$ & NA & $2 E+02$ & c & $U-233$ \\
\hline$U-234$ & $6.48 \mathrm{E}+02^{\mathrm{d}}$ & 270 & 210 & $6.0 \mathrm{E}+05$ & NA & $3 E+02$ & $\stackrel{\circ}{\circ}$ & 540 & 210 & $6.0 E+05$ & $\mathrm{NA}$ & $7 E+02$ & c & $U-234$ \\
\hline U-235 & $3.73 E+03$ & 270 & 210 & $6.0 \mathrm{E}+05$ & NA & $6 \mathrm{E}+01$ & 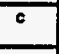 & 540 & 210 & $6.0 \mathrm{E}+05$ & $\mathrm{NA}$ & $1 \mathrm{E}+02$ & c & $U-235$ \\
\hline$U-236$ & $1.96 \mathrm{E}+02$ & 270 & 210 & $6.0 E+05$ & $1.0 E+00$ & $1 E+03$ & 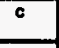 & 540 & 210 & $6.0 \mathrm{E}+05$ & $1.0 \mathrm{E}+\infty 0$ & $2 E+03$ & c & $\mathrm{U}-236$ \\
\hline U-238 & $2.07 E+02$ & 270 & 210 & $6.0 E+05$ & NA & $1 E+03$ & ${ }^{\circ}$ & 540 & 210 & $6.0 \mathrm{E}+05$ & NA & $2 E+03$ & c & U.238 \\
\hline$N p-237$ & $3.24 E+03$ & 270 & 210 & $8.4 E+04$ & $1.0 E+00$ & $7 E+01$ & c & 540 & 210 & $8.4 E+04$ & $1.0 \mathrm{E}+00$ & $1 E+02$ & c & Np-237 \\
\hline Pu-238 & $2.34 \mathrm{E}+03$ & 270 & 210 & $1.0 E+07$ & $\mathrm{e}$ & $9 E+05$ & 61 & 540 & 210 & $2.0 E+\infty$ & e & $2 \mathrm{E}+06$ & 91 & Pu-238 \\
\hline Pu-239 & $2.58 E+03$ & 270 & 210 & $1.0 E+07$ & e & $\mathrm{NL}$ & $\div$ & 540 & 210 & $1.0 E+07$ & e & $\mathrm{NL}$ & $c$ & Pu-239 \\
\hline Pu-240 & $2.58 E+03$ & 270 & 210 & $1.0 \mathrm{E}+07$ & e & $\mathrm{NL}$ & $\div$ & 540 & 210 & $1.0 \mathrm{E}+07$ & e & $\mathrm{NL}$ & $c$ & $\mathrm{Pu}-240$ \\
\hline Pu-241 & $4.82 E+08$ & 270 & 210 & $1.0 \mathrm{E}+07$ & $\mathbf{e}$ & $1 E+07$ & 61 & 540 & 210 & $1.0 \mathrm{E}+07$ & $\mathbf{e}$ & $2 E+07$ & 61 & Pu-241 \\
\hline Pu-242 & $2.45 E+03$ & 270 & 210 & $1.0 \mathrm{E}+07$ & $1.3 \mathrm{E}+08$ & $1 E+10$ & 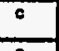 & 540 & 210 & $1.0 \mathrm{E}+07$ & $1.4 E+08$ & $3 E+10$ & $\bar{c}$ & Pu-242 \\
\hline Pu-244 & $4.11 E+03$ & 270 & 210 & $1.0 \mathrm{E}+07$ & NA & $5 E+01$ & c & 540 & 210 & $1.0 E+07$ & NA & $1 E+02$ & 5 & Pu-244 \\
\hline Am-241 & $2.66 \mathrm{E}+03$ & 270 & 210 & $3.3 E+07$ & $\mathrm{e}$ & $3 E+05$ & 01 & 540 & 210 & $3.3 \mathrm{E}+07$ & $e$ & $7 E+05$ & 01 & Am-241 \\
\hline Am-243 & $2.64 E+03$ & 270 & 210 & $3.3 E+07$ & e & $\mathrm{NL}$ & ${ }^{\circ}$ & 540 & 210 & $3.3 E+07$ & e & NL & $\div$ & Am-243 \\
\hline Cm-243 & $1.83 E+03$ & 270 & 210 & $6.7 \mathrm{E}+07$ & $e$ & $\mathrm{NL}$ & $\div$ & 540 & 210 & $6.7 \mathrm{E}+07$ & $e$ & $\mathrm{NL}$ & $\circ$ & $\mathrm{Cm}-243$ \\
\hline $\mathrm{Cm}-244$ & 1.47E+03 & 270 & 210 & $6.7 E+07$ & $\mathrm{e}$ & $\mathrm{NL}$ & e & 540 & 210 & $6.7 \mathrm{E}+07$ & e & $\mathrm{NL}$ & c & $\mathrm{Cm}-244$ \\
\hline $\mathrm{Cm}-245$ & $4.56 \mathrm{E}+03$ & 270 & 210 & $6.7 \mathrm{E}+07$ & NA & $5 E+01$ & $i^{\circ}$ & 540 & 210 & $6.7 E+07$ & $\mathrm{NA}$ & $1 E+02$ & 5 & $\mathrm{Cm}-245$ \\
\hline $\mathrm{Cm}-246$ & $2.70 E+03$ & 270 & 210 & $6.7 E+07$ & e & $\mathrm{NL}$ & $\circ$ & 540 & 210 & $6.7 E+07$ & $\mathbf{e}$ & $\mathrm{NL}$ & ${ }^{\circ}$ & $\mathrm{Cm}-246$ \\
\hline $\mathrm{Cm}-247$ & $4.34 E+03$ & 270 & 210 & $6.7 E+07$ & $\mathrm{NA}$ & $5 E+01$ & $\div$ & 540 & 210 & $6.7 \mathrm{E}+07$ & $\mathrm{NA}$ & $1 E+02$ & 5 & $\mathrm{Cm}-247$ \\
\hline $\mathrm{Cm}-248$ & $9.94 E+03$ & 270 & 210 & $6.7 E+07$ & e & $\mathrm{NL}$ & ${ }^{\circ}$ & 540 & 210 & $6.7 \mathrm{E}+07$ & e & $\mathrm{NL}$ & c & $\mathrm{Cm}-248$ \\
\hline Cf-249 & $3.46 \mathrm{E}+03$ & 270 & 210 & $6.7 E+07$ & e & $1 E+03$ & c & 540 & 210 & $6.7 \mathrm{E}+07$ & $e$ & $2 E+03$ & 27 & $C f-249$ \\
\hline$C f-250$ & $2.64 E+08$ & 270 & 210 & $6.7 E+07$ & e & $\mathrm{NL}$ & $c^{\circ}$ & 540 & 210 & $6.7 \mathrm{E}+07$ & $e$ & $\mathrm{NL}$ & 5 & Cf-250 \\
\hline Cf-251 & $3.54 E+03$ & 270 & 210 & $6.7 E+07$ & $\mathbf{e}$ & $\mathrm{NL}$ & 5 & 540 & 210 & $6.7 \mathrm{E}+07$ & $\mathbf{e}$ & $\mathrm{NL}$ & & $C f-251$ \\
\hline
\end{tabular}

a "NA" means Not Applicable - decay factor is implicit in the PDCF for this radionuclide.

b "NL" means No Limit - estimated permissible concentration is greater than the specific activity of the pure elemental radionuclide.

c Radionuclide concentration is based on arrival time at the performance boundary beyond $10,000 \mathrm{y}$.

d PDCF is a function of arrival time. See Chapter 1 of this volume for equation.

e $r_{\text {Docay }} \geq 1 E+50$

$f$ Contribution of decay product(s) is significant to determination of this value (see Table E-3 in Volume 2). Listed arrival time is that of the parent radionuclide. Arrival time of the significant decay product(s) is greater than $10,000 \mathrm{y}$. 
For the generic trench at LANL, the total undecayed CRFs for the water pathway ranged from about 95 to 57,000. Among the listed radionuclides, subsurface radionuclide travel times to the performance boundary time ranged from 2500 y to 67 million years, including the detention time in the facility before failure. The water travel time through the unsaturated zone accounted for about $98 \%$ of the total subsurface travel time.

For the generic tumulus at LANL, the total undecayed CRFs for the water pathway ranged from about 190 to 114,000. Among the listed radionuclides, subsurface radionuclide travel times to the performance boundary ranged from 2800 y to 67 million years, including the $300-y$ detention time in the facility before failure. Differences in these arrival times compared to the trench were attributable to (1) the assumed increased rate of flow at the time of failure of the facility ( $100 \mathrm{y}$ for the trench and $300 \mathrm{y}$ for the tumulus); and (2) the increased travel distance through the vadose zone for the tumulus (the bottom of the tumulus was at grade level, while the trench was a shallowly buried structure). For the tumulus, the longer subsurface travel times for $\mathrm{H}-3$ (as compared to releases from the trench) were associated with the low rate of flow and early time of release from the trench for this radionuclide.

\subsubsection{Atmospheric Transport}

Two CRFs were used to account for the attenuation encompassing diffusion to the ground surface, mixing in air, and dispersion in the atmosphere to the performance boundary. The CRF for diffusion in soil, $C R F_{D i f}$, was defined as the ratio of the radionuclide concentration in the waste to its resulting concentration in the upper one centimeter of soil. The CRF for dispersion in air, $C R F_{D i s p}$, was defined as the ratio of the radionuclide concentration in the upper one centimeter of soil to its resulting concentration in air at the performance boundary. The effect of radioactive decay was also included in the PE.

Application of the PE methodology for atmospheric transport of the two volatile radionuclides considered in the $\mathrm{PE}$ ( $\mathrm{H}-3$ and $\mathrm{C}-14)$ produced the results shown in Table 8-5 for both the generic trench and tumulus designs; there was no assumed difference in these two disposal technologies with respect to permissible waste limits based on the atmospheric pathway at LANL. The table shows permissible waste concentrations based on transport in the atmospheric pathway $\left(C_{\text {Wr-Atm }}\right)$ as well as the values used in calculating the permissible waste concentrations. For both $\mathrm{H}-3$ and $\mathrm{C}-14$, the greatest concentration reduction was assumed to occur as the radionuclides diffused from the top of the disposal facility to the soil surface.

Table 8-5. Results of Calculations for the Atmospheric Pathway

\begin{tabular}{|c|c|c|c|c|c|c|c|}
\hline \multirow[t]{2}{*}{ Nuclide } & \multirow[b]{2}{*}{$\begin{array}{c}S D C F_{A t m} \\
(\mathrm{rem} / \mathrm{y}) /(\mu \mathrm{Ci} / \mathrm{L})\end{array}$} & \multicolumn{6}{|c|}{ Generic Trench and Tumulus } \\
\hline & & $\begin{array}{c}C R F_{D I f} \\
\text { (dimensionless) }\end{array}$ & $\begin{array}{c}\text { CRF Disp } \\
\text { (dimensionless) }\end{array}$ & $\begin{array}{c}C_{\text {(dimensionioss) }} \\
\text { (iden }\end{array}$ & $\begin{array}{c}\text { Arrival } \\
\text { Time (y) }\end{array}$ & $\begin{array}{c}\text { rDocay } \\
\text { (dimensionless) }\end{array}$ & $\begin{array}{c}C_{W-A t m} \\
\left(\mu \mathrm{Ci} / \mathrm{m}^{3}\right)\end{array}$ \\
\hline $\mathrm{H}-3$ & $8.33 E+02$ & $5 E+05$ & $1 E+03$ & $5 E+08$ & 100 & 300 & $2 E+09$ \\
\hline C-14 & $2.20 E+05$ & $1 E+04$ & $2 E+03$ & $2 E+07$ & 100 & 1 & $1 E+03$ \\
\hline
\end{tabular}


The time of arrival at the performance boundary for both radionuclides is shown in Table 8-5 as $100 \mathrm{y}$. However, the actual migration of H-3 and C-14 from the disposal facility to the surface and downwind to the performance boundary was calculated to be on the order of hours, not years. As discussed in Section 8.3.2.2, the waste form and RCRA cover are assumed to retain these volatile radionuclides in the disposal facility for at least $100 \mathrm{y}$.

\subsubsection{Inadvertent Intruder Exposure}

The calculation of permissible waste concentrations for inadvertent intruder exposures did not utilize CRFs. Instead, the total dose resulting from an intrusion scenario (the sum of the doses from all exposure pathways involved in that intrusion) was modified by scenario dose conversion factors (SDCFs) that were applied to specific exposure pathways. The important exposure pathways for each radionuclide are listed in Appendix D of Volume 2. These values were radionuclide-specific and facility-design-specific and were the same for all sites. Values for the radioactive decay term were based on time of intrusion into the disposal facility (for the homesteader scenario, $300 \mathrm{y}$ for the trench design and $500 \mathrm{y}$ for the tumulus design; for the postdrilling scenario, $100 \mathrm{y}$ for both disposal designs). However, results based on intruder scenarios should be evaluated carefully because future social behavior, and intrusion scenarios, are difficult to predict.

The permissible waste concentrations for the two generic facility designs for each of the 58 radionuclides based on the standard PE intrusion scenarios are listed in Table 8-6. The most restrictive radionuclide concentration limits for each generic facility are indicated with bold type.

For six radionuclides in the table (U-233, U-234, U-235, U-238, Pu-244, and Cm-247), the time of homesteader intrusion was changed to $10,000 \mathrm{y}$, the end of the performance period. For these six radionuclides, ingrowth of decay products yields scenario doses that increase over time. The doses at 10,000 y, therefore, represent the maximum that could be encountered during the performance period. Also, for Th-230 and $\mathrm{Cm}-245$, ingrowth of decay products likewise produces a scenario dose that increases over time and peaks within the 10,000-y performance period. The times of homesteader intrusion for these two radionuclides (Th-230 and Cm-245) were taken as the time of maximum dose, 9000 and $1000 \mathrm{y}$, respectively.

For the trench design, the post-drilling scenario generally yielded more restrictive waste limits than the homesteader scenario for those radionuclides with half-lives shorter than about $30 \mathrm{y}$. For the tumulus design, the post-drilling scenario generally yielded more restrictive limits than the homesteader scenario for those radionuclides with half-lives shorter than about $130 \mathrm{y}$.

\subsection{SUMMARY AND DISCUSSION OF RESULTS}

The limiting waste concentrations in disposed MLLW for the water, atmospheric, and intruder analyses for the generic trench and tumulus designs are summarized in Table 8-7 and discussed in Section 8.6.1. An overall discussion of the results of the PE for LANL is contained in Section 8.6.2. 
Table 8-6. Permissible Waste Concentrations for the Standard Intrusion Scenarios (most limiting radionuclide concentration for each facility design is highlighted in bold italic) (Part 1 of 2)

\begin{tabular}{|c|c|c|c|c|c|}
\hline \multirow[t]{2}{*}{ Nuclide } & \multicolumn{2}{|c|}{ Trench } & \multicolumn{2}{|c|}{ Tumulus } & \multirow[t]{2}{*}{ Nuclide } \\
\hline & $\begin{array}{c}C_{w+m b r} \\
\text { Homesteader } \\
\left(\mu \mathrm{Cu} / m^{3}\right) \\
\end{array}$ & $\begin{array}{c}C_{\text {wants }} \\
\text { Post-Drilling } \\
\left(\mu \mathrm{Ci} / \mathrm{m}^{3}\right) \\
\end{array}$ & $\begin{array}{c}C_{\text {wdntr }} \\
\text { Homesteader } \\
\left(\mu \mathrm{Ci} / \mathrm{m}^{3}\right) \\
\end{array}$ & $\begin{array}{c}C_{\text {w-lntr }} \\
\text { Post-Drilling } \\
\left(\mu \mathrm{Ci} / \mathrm{m}^{3}\right)\end{array}$ & \\
\hline $\mathrm{H}-3$ & $1 E+12$ & $7 E+07$ & $\mathrm{NL}$ & $7 E+07$ & $\mathrm{H}-3$ \\
\hline$c-14$ & $1 E+04$ & $7 E+04$ & $1 E+04$ & $7 E+04$ & c-14 \\
\hline Al-26 & $5 E+01$ & $5 E+04$ & $5 E+01$ & $5 E+04$ & Al-26 \\
\hline Si-32 & $9 E+03$ & $1 E+04$ & $4 E+04$ & $1 E+04$ & Si-32 \\
\hline $\mathrm{Cl}-36$ & $2 E+02$ & $9 E+02$ & $2 E+02$ & $9 E+02$ & $\mathrm{Cl}-36$ \\
\hline$k-40$ & $7 E+02$ & $2 E+04$ & $7 E+02$ & $2 E+04$ & $K-40$ \\
\hline Co-60 & NL & $3 E+10$ & NL & $3 E+10$ & $\mathrm{Co}-60$ \\
\hline $\mathrm{Ni}-59$ & $3 E+06$ & $1 E+07$ & $3 E+06$ & $1 E+07$ & Ni-59 \\
\hline $\mathrm{Ni}-63$ & $8 E+06$ & $1 E+07$ & $3 E+07$ & $1 E+07$ & $\mathrm{Ni}-63$ \\
\hline Se-79 & $2 E+05$ & $8 E+05$ & $2 E+05$ & $8 E+05$ & Se-79 \\
\hline Sr-90 & $1 E+06$ & $5 E+04$ & $1 E+08$ & $5 E+04$ & ST-90 \\
\hline $\mathrm{Zr}-93$ & $5 E+06$ & $3 E+07$ & $5 E+06$ & $3 E+07$ & Zr-93 \\
\hline $\mathrm{Nb}-93 \mathrm{~m}$ & $5 E+12$ & $4 E+09$ & $\mathrm{NL}$ & $4 E+09$ & $\mathrm{Nb}-93 \mathrm{~m}$ \\
\hline $\mathrm{Nb}-94$ & $9 E+01$ & $9 E+04$ & $1 E+02$ & $9 E+04$ & $\mathrm{Nb}-94$ \\
\hline Tc-99 & $2 E+04$ & $8 E+04$ & $2 E+04$ & $8 E+04$ & Tc-99 \\
\hline$P d-107$ & $6 E+06$ & $3 E+07$ & $6 E+06$ & $3 E+07$ & Pd-107 \\
\hline $\mathrm{Ag}-108 \mathrm{~m}$ & $5 E+02$ & $1 E+05$ & $1 E+03$ & $1 E+05$ & $\mathrm{Ag}-108 \mathrm{~m}$ \\
\hline $\mathrm{Cd}-113 \mathrm{~m}$ & $4 E+09$ & $1 E+06$ & $7 E+13$ & $1 E+06$ & Cd-113m \\
\hline Sn-121m & $2 E+07$ & $5 E+07$ & $2 E+08$ & $5 E+07$ & $S n-121 m$ \\
\hline$S n-126$ & $8 E+01$ & $7 E+04$ & $8 E+01$ & $7 E+04$ & Sn-126 \\
\hline $1-129$ & $2 E+03$ & $1 E+04$ & $2 E+03$ & $1 E+04$ & 1-129 \\
\hline Cs-135 & $2 E+05$ & $8 E+05$ & $2 E+05$ & $8 E+05$ & Cs-135 \\
\hline Cs-137 & $3 E+05$ & $8 \mathrm{E}+05$ & $3 E+07$ & $8 E+05$ & Cs-137 \\
\hline $\mathrm{Ba}-133$ & $2 E+11$ & $3 E+08$ & NL & $3 E+08$ & Ba-133 \\
\hline Sm-151 & $2 E+08$ & $2 E+08$ & $8 E+08$ & $2 E+08$ & Sm-151 \\
\hline Eu-152 & $6 E+08$ & $2 E+07$ & $2 E+13$ & $2 E+07$ & Eu-152 \\
\hline Eu-154 & $4 E+12$ & $4 E+08$ & NL & $4 E+08$ & Eu-154 \\
\hline $\mathrm{Pb}-210$ & $7 E+06$ & $7 E+04$ & $4 E+09$ & $7 E+04$ & $\mathrm{~Pb}-210$ \\
\hline Ra-226 & $8 E+01$ & $3 E+03$ & $9 E+01$ & $3 E+03$ & Ra-226 \\
\hline Ra-228 & $\mathrm{NL}$ & $4 E+09$ & $\mathrm{NL}$ & $4 E+09$ & Ra-228 \\
\hline Th-229 & $5 E+02$ & $3 E+04$ & $5 E+02$ & $3 E+04$ & Th-229 \\
\hline Th-230 & $8 E+01$ & $7 E+04$ & $8 E+01$ & $7 E+04$ & Th-230 \\
\hline Th-232 & $6 E+01$ & $2 E+04$ & $6 E+01$ & $2 E+04$ & Th-232 \\
\hline $\mathrm{Pa}-231$ & $2 E+02$ & $5 E+03$ & $2 E+02$ & $5 \mathrm{E}+03$ & $\mathrm{~Pa}-231$ \\
\hline
\end{tabular}


Table 8-6. Permissible Waste Concentrations for the Standard Intrusion Scenarios (most limiting radionuclide concentration for each facility design is highlighted in bold italic) (Part 2 of 2)

\begin{tabular}{|c|c|c|c|c|c|}
\hline \multirow[t]{2}{*}{ Nuclide } & \multicolumn{2}{|c|}{ Trench } & \multicolumn{2}{|c|}{ Tumulus } & \multirow[t]{2}{*}{ Nuclide } \\
\hline & $\begin{array}{c}C_{w \text { wntr }}{ }^{\prime \prime} \\
\text { Homesteader } \\
\left(\mu \mathrm{Cu} \mathrm{m}^{3}\right)\end{array}$ & $\begin{array}{c}C_{W-1 n t r} \\
\text { Post-Drilling } \\
\left(\mu \mathrm{Ci} / m^{3}\right) \\
\end{array}$ & $\begin{array}{c}C_{W-1 n t r} \\
\text { Homesteader } \\
\left(\mu \mathrm{Cl} / \mathrm{m}^{3}\right) \\
\end{array}$ & $\begin{array}{c}C_{W-1 n t r} \\
\text { Post-Drilling } \\
\left(\mu \mathrm{Ci} / \mathrm{m}^{3}\right) \\
\end{array}$ & \\
\hline U-232 & $2 E+03$ & $5 \mathrm{E}+04$ & $1 E+04$ & $5 E+04$ & U-232 \\
\hline U-233 & $7 E+02$ & $1 E+05$ & $7 E+02$ & $1 E+05$ & $U-233$ \\
\hline U-234 & $1 E+03$ & $1 E+05$ & $1 E+03$ & $1 E+05$ & U-234 \\
\hline U-235 & $6 E+02$ & $1 E+05$ & $6 E+02$ & $1 E+05$ & U-235 \\
\hline U-236 & $2 E+04$ & $1 E+05$ & $2 E+04$ & $1 E+05$ & U-236 \\
\hline $\mathrm{U}-238$ & $5 E+03$ & $1 E+05$ & $5 E+03$ & $1 E+05$ & U-238 \\
\hline $\mathrm{Np}-237$ & $4 E+02$ & $4 E+03$ & $4 E+02$ & $4 E+03$ & $\mathrm{~Np}-237$ \\
\hline Pu-238 & $7 E+04$ & $1 E+05$ & $4 E+05$ & $1 E+05$ & Pu-238 \\
\hline $\mathrm{Pu}-239$ & $6 E+03$ & $5 E+04$ & $6 E+03$ & $5 \mathrm{E}+04$ & Pu-239 \\
\hline Pu-240 & $6 E+03$ & $5 E+04$ & $7 E+03$ & $5 E+04$ & Pu-240 \\
\hline Pu-241 & $2 E+05$ & $1 E+06$ & $3 E+05$ & $1 E+06$ & Pu-241 \\
\hline Pu-242 & $6 E+03$ & $5 E+04$ & $6 E+03$ & $5 E+04$ & Pu-242 \\
\hline Pu-244 & $4 E+02$ & $5 E+04$ & $4 E+02$ & $5 E+04$ & Pu-244 \\
\hline Am-241 & $7 E+03$ & $5 E+04$ & $9 E+03$ & $5 \mathrm{E}+04$ & Am-241 \\
\hline Am-243 & $9 E+02$ & $4 E+04$ & $9 E+02$ & $4 E+04$ & Am-243 \\
\hline $\mathrm{Cm}-243$ & $1 E+06$ & $8 E+05$ & $5 E+06$ & $8 E+05$ & $\mathrm{Cm}-243$ \\
\hline $\mathrm{Cm}-244$ & $2 E+06$ & $3 E+06$ & $2 E+06$ & $3 E+06$ & $\mathrm{Cm}-244$ \\
\hline $\mathrm{Cm}-245$ & $1 E+03$ & $4 E+04$ & $1 E+03$ & $4 E+04$ & $\mathrm{Cm}-245$ \\
\hline $\mathrm{Cm}-246$ & $6 E+03$ & $5 E+04$ & $6 E+03$ & $5 E+04$ & $\mathrm{Cm}-246$ \\
\hline $\mathrm{Cm}-247$ & $3 E+02$ & $5 E+04$ & $3 E+02$ & $5 E+04$ & $\mathrm{Cm}-247$ \\
\hline $\mathrm{Cm}-248$ & $2 E+03$ & $1 E+04$ & $2 E+03$ & $1 E+04$ & $\mathrm{Cm}-248$ \\
\hline Cf-249 & $8 E+02$ & $4 E+04$ & $1 E+03$ & $4 E+04$ & $C f-249$ \\
\hline Cf-250 & $2 E+06$ & $9 E+06$ & $2 E+06$ & $9 \mathrm{E}+06$ & Cf-250 \\
\hline Cf-251 & $2 E+03$ & $4 E+04$ & $2 E+03$ & $4 E+04$ & Cf-251 \\
\hline
\end{tabular}

a "NL" means No Limit - estimated permissible concentration is greater than the specific activity of the pure elemental radionuclide. 
Table 8-7. Permissible Concentrations for the Generic Disposal Designs at LANL (permissible concentration related to the most limiting pathway for each facility design is highlighted in bold italic) (Part 1 of 2)

\begin{tabular}{|c|c|c|c|c|c|c|c|}
\hline \multirow[t]{2}{*}{ Nuclide } & \multicolumn{3}{|c|}{ Trench } & \multicolumn{3}{|c|}{ Tumulus } & \multirow[t]{2}{*}{ Nuclide } \\
\hline & $\begin{array}{c}C_{\text {w-Water }}{ }^{a, b} \\
\left(\mu \mathrm{CU} / \mathrm{m}^{3}\right)\end{array}$ & $\begin{array}{l}C_{W \cdot A t m}^{c} \\
\left(\mu \mathrm{Ci} / m^{3}\right)\end{array}$ & $\begin{array}{l}C_{W-1 n r^{d}} \\
\left(\mu \mathrm{Ci} / \mathrm{m}^{3}\right)\end{array}$ & $\begin{array}{c}C_{\text {W-Water }}{ }^{a, b} \\
\left(\mu \mathrm{Ci} / \mathrm{m}^{3}\right) \\
\end{array}$ & $\begin{array}{l}C_{\text {W-Atm }}{ }^{c} \\
\left(\mu \mathrm{Ci} / \mathrm{m}^{3}\right)\end{array}$ & $\begin{array}{l}C_{W-1 n \pi^{d}} \\
\left(\mu \mathrm{Ci} / \mathrm{m}^{3}\right)\end{array}$ & \\
\hline $\mathrm{H}-3$ & $\mathrm{NL}$ & $2 E+09$ & $7 E+07$ & NL & $2 E+09$ & $7 E+07$ & $\mathrm{H}-3$ \\
\hline C-14 & - & $1 E+03$ & $1 E+04$ & - & $1 E+03$ & $1 E+04$ & $C-14$ \\
\hline Al-26 & - & & $5 E+01$ & - & & $5 E+01$ & Al-26 \\
\hline Si-32 & - & & $9 E+03$ & $=$ & & $1 E+04$ & Si-32 \\
\hline $\mathrm{Cl}-36$ & - & & $2 E+02$ & - & & $2 E+02$ & $\mathrm{Cl}-36$ \\
\hline$K-40$ & - & & $7 E+02$ & - & & $7 E+02$ & $K-40$ \\
\hline Co-60 & - & & $3 E+10$ & - & & $3 E+10$ & Co- 60 \\
\hline $\mathrm{Ni}-59$ & - & & $3 E+06$ & - & & $3 E+06$ & $\mathrm{Ni}-59$ \\
\hline $\mathrm{Ni}-63$ & - & & $8 E+06$ & - & & $1 E+07$ & $\mathrm{Ni}-63$ \\
\hline Se-79 & - & & $2 E+05$ & - & & $2 E+05$ & Se-79 \\
\hline Sr-90 & $=$ & & $5 E+04$ & - & & $5 E+04$ & Sr-90 \\
\hline Zr-93 & - & & $5 E+06$ & - & & $5 E+06$ & $\mathrm{Zr}-93$ \\
\hline $\mathrm{Nb}-93 \mathrm{~m}$ & - & & $4 E+09$ & - & & $4 E+09$ & $\mathrm{Nb}-93 \mathrm{~m}$ \\
\hline Nb-94 & - & & $9 E+01$ & - & & $1 E+02$ & $\mathrm{Nb}-94$ \\
\hline TC-99 & $2 E+03$ & & $2 E+04$ & $5 E+03$ & & $2 E+04$ & Tc-99 \\
\hline Pd-107 & - & & $6 E+06$ & - & & $6 E+06$ & $P d-107$ \\
\hline $\mathrm{Ag}-108 \mathrm{~m}$ & - & & $5 E+02$ & - & & $1 E+03$ & $\mathrm{Ag}-108 \mathrm{~m}$ \\
\hline $\mathrm{Cd}-113 \mathrm{~m}$ & - & & $1 E+06$ & - & & $1 E+06$ & $\mathrm{Cd}-113 \mathrm{~m}$ \\
\hline Sn-121m & - & & $2 E+07$ & - & & $5 E+07$ & $\mathrm{Sn}-121 \mathrm{~m}$ \\
\hline $5 n-126$ & - & & $8 E+01$ & - & & $8 E+01$ & Sn-126 \\
\hline I-129 & - & & $2 E+03$ & - & & $2 E+03$ & $1-129$ \\
\hline Cs-135 & - & & $2 E+05$ & - & & $2 E+05$ & Cs-135 \\
\hline Cs-137 & - & & $3 E+05$ & - & & $8 E+05$ & Cs-137 \\
\hline $\mathrm{Ba}-133$ & - & & $3 E+08$ & - & & $3 E+08$ & $\mathrm{Ba}-133$ \\
\hline Sm-151 & - & & $2 E+08$ & - & & $2 E+08$ & Sm-151 \\
\hline Eu-152 & - & & $2 E+07$ & - & & $2 E+07$ & Eu-152 \\
\hline Eu-154 & - & & $4 E+08$ & - & & $4 E+08$ & Eu-154 \\
\hline $\mathrm{Pb}-210$ & - & & $7 E+04$ & - & & $7 E+04$ & $\mathrm{~Pb}-210$ \\
\hline Ra-226 & - & & $8 E+01$ & - & & $9 E+01$ & Ra-226 \\
\hline Ra-228 & - & & $4 E+09$ & - & & $4 E+09$ & Ra-228 \\
\hline Th-229 & - & & $5 E+02$ & - & & $5 E+02$ & Th-229 \\
\hline Th-230 & - & & $8 E+01$ & - & & $8 E+01$ & Th-230 \\
\hline Th-232 & - & & $6 E+01$ & - & & $6 E+01$ & Th-232 \\
\hline $\mathrm{Pa}-231$ & - & & $2 E+02$ & - & & $2 E+02$ & $\mathrm{~Pa}-231$ \\
\hline
\end{tabular}


Table 8-7. Permissible Concentrations for the Generic Disposal Designs at LANL (permissible concentration related to the most limiting pathway for each facility design is highlighted in bold italic) (Part 2 of 2)

\begin{tabular}{|c|c|c|c|c|c|c|c|}
\hline \multirow[t]{2}{*}{ Nuclide } & \multicolumn{3}{|c|}{ Trench } & \multicolumn{3}{|c|}{ Tumulus } & \multirow[t]{2}{*}{ Nuclide } \\
\hline & $\begin{array}{c}C_{\text {w.Water }}{ }^{a, b} \\
\left(\mu \mathrm{Ci} / \mathrm{m}^{3}\right)\end{array}$ & $\begin{array}{l}C_{\text {W-Atm }}{ }^{c} \\
\left(\mu \mathrm{Ci} / \mathrm{m}^{3}\right) \\
\end{array}$ & $\begin{array}{l}C_{\text {W/mtr }}{ }^{d} \\
\left(\mu \mathrm{Ci} / \mathrm{m}^{3}\right)\end{array}$ & $\begin{array}{c}C_{\text {w-Water }}{ }^{\mathrm{a}, \mathrm{b}} \\
\left(\mu \mathrm{Ci} / \mathrm{m}^{3}\right) \\
\end{array}$ & $\begin{array}{l}C_{\text {W.Atm }}{ }^{c} \\
\left(\mu \mathrm{Ci} / \mathrm{m}^{3}\right) \\
\end{array}$ & $\begin{array}{l}C_{w-1 n t r}^{d} \\
\left(\mu \mathrm{Ci} / m^{3}\right) \\
\end{array}$ & \\
\hline $\mathrm{U}-232$ & - & & $2 E+03$ & - & & $1 E+04$ & U-232 \\
\hline U-233 & - & & $7 E+02$ & - & & $7 E+02$ & $\mathrm{U}-233$ \\
\hline U-234 & - & & $1 E+03$ & - & & $1 E+03$ & U-234 \\
\hline U-235 & - & & $6 E+02$ & - & & $6 E+02$ & U-235 \\
\hline U-236 & - & & $2 E+04$ & - & & $2 E+04$ & U-236 \\
\hline U-238 & - & & $5 E+03$ & - & & $5 E+03$ & U-238 \\
\hline $\mathrm{Np}-237$ & - & & $4 E+02$ & - & & $4 E+02$ & $\mathrm{~Np}-237$ \\
\hline $\mathrm{Pu}-238$ & - & & $7 E+04$ & - & & $1 E+05$ & Pu-238 \\
\hline Pu-239 & $=$ & & $6 E+03$ & $=$ & & $6 E+03$ & Pu-239 \\
\hline $\mathrm{Pu}-240$ & - & & $6 E+03$ & - & & $7 E+03$ & Pu-240 \\
\hline Pu-241 & - & & $2 E+05$ & - & & $3 E+05$ & Pu-241 \\
\hline Pu-242 & - & & $6 E+03$ & - & & $6 E+03$ & Pu-242 \\
\hline Pu-244 & - & & $4 E+02$ & - & & $4 E+02$ & Pu-244 \\
\hline Am-241 & - & & $7 E+03$ & - & & $9 E+03$ & Am-241 \\
\hline Am-243 & - & & $9 E+02$ & $=$ & & $9 E+02$ & Am-243 \\
\hline $\mathrm{Cm}-243$ & - & & $8 E+05$ & - & & $8 E+05$ & $\mathrm{Cm}-243$ \\
\hline $\mathrm{Cm}-244$ & - & & $2 E+06$ & - & & $2 E+06$ & $\mathrm{Cm}-244$ \\
\hline $\mathrm{Cm}-245$ & - & & $1 E+03$ & - & & $1 E+03$ & $\mathrm{Cm}-245$ \\
\hline $\mathrm{Cm}-246$ & - & & $6 E+03$ & - & & $6 E+03$ & $\mathrm{Cm}-246$ \\
\hline $\mathrm{Cm}-247$ & - & & $3 E+02$ & - & & $3 E+02$ & $\mathrm{Cm}-247$ \\
\hline $\mathrm{Cm}-248$ & - & & $2 E+03$ & - & & $2 E+03$ & $\mathrm{Cm}-248$ \\
\hline Cf-249 & - & & $8 E+02$ & - & & $1 E+03$ & Cf-249 \\
\hline Cf-250 & - & & $2 E+06$ & - & & $2 E+06$ & Cf-250 \\
\hline Cf-251 & - & & $2 E+03$ & - & & $2 E+03$ & Cf-251 \\
\hline
\end{tabular}

a "NL" means No Limit - estimated permissible concentration factor is greater than the specific activity of the pure elemental radionuclide.

b "-n indicates that the radionuclide concentration is based on an arrival time beyond 10,000 y; see Table $8-4$ for specific values.

c Results presented for radionclides expected to be volatile under disposal facility conditions.

d Concentration is based on the most restrictive intrusion scenario assumed for the site; see Table 8-6. 


\subsubsection{Results Based on Disposal Design}

For both the generic trench and tumulus designs at LANL, one radionuclide (Tc-99) was limited by the water pathway, one radionuclide (C-14) was limited by the atmospheric pathway, and 56 radionuclides were limited by intrusion scenarios, as shown in Table 8-7.

For both the trench and tumulus designs, the concentration for the water pathway analysis for one radionuclide ( $\mathrm{H}-3$ ) had no limit and arrived at the performance boundary before $10,000 \mathrm{y}$. As discussed in Section 8.5.1, the calculated concentrations for those radionuclides reported as NL (No Limit) were above the specific activity of the pure elemental radionuclide, implying that the performance measure of $4 \mathrm{mrem}(0.04 \mathrm{mSv})$ per year would not be reached under the given release and transport assumptions.

As also discussed in Section 8.5.1, values for some radionuclides are not reported in Table 8-7 for the water pathway analysis. Arrival times for these radionuclides were beyond the 10,000-y performance period. For these radionuclides, the estimated waste concentrations are presented in Table 8-4 for information purposes but are not listed in Table 8-7. Consistent with the approach used in LLW performance assessments, these values were not considered in determining the most restrictive disposal limit from among the evaluated pathways because arrival times for these radionuclides were beyond $10,000 \mathrm{y}$.

For both the trench and tumulus designs, only Tc-99 was limited by the water pathway. Technicium-99 is relatively mobile with a low soil $K_{d}(0.1 \mathrm{~mL} / \mathrm{g}$ to $0.3 \mathrm{~mL} / \mathrm{g})$ and long half-life $(200,000 \mathrm{y})$. For the water pathway, all other radionuclides had peak arrival times that were greater than the 10,000-y period of consideration for the $\mathrm{PE}$ analysis.

For both the trench and tumulus designs, only C-14 was limited by the atmospheric pathway. This result is based on conservative analysis because the conceptual model for the atmospheric pathway did not account for the effects of the grout material on the rate of $\mathrm{CO}_{2}$ emanation from the stabilized waste (see Section 6 of Volume 2).

\subsubsection{Discussion}

The results of the PE are based on the framework of assumptions summarized in Chapter 1 of this volume and discussed in detail in Volume 2 of this report and on the site-specific conceptual model for contaminant transport discussed in this chapter. Using alternative assumptions about the conceptual model has the potential to affect the results. Changes in the conceptual model could include alternative assumptions about the disposal facility, the source term, and radionuclide movement in the three pathways. Depending on the degree of possible variation and the relative importance of the parameters used in the calculation of estimated permissible radionuclide concentrations, variability in parameter values can also affect the results. For parameters, results could vary depending on the potential changes in values of both the generic and the site-specific parameters used in the PE analysis.

The effect on results from using alternative generic assumptions and parameter values is discussed in Chapter 6 of Volume 2. In addition, a discussion is provided in that chapter about 
the effects of using alternative values for site-specific parameters. Based on this discussion, four parameters were identified (three site-specific and one generic, all used in the water pathway analysis) that could potentially influence the results to the degree that the calculated waste concentrations become limited by a pathway other than the one determined for the PE (Table 8-7). The impacts on the results of using alternative values for these four parameters for the water pathway in the PE for LANL are discussed in this section. The basis for and possible variation in the values used in the PE for these parameters are discussed in Section 8.6.2.2.

\subsubsection{Parameter Sensitivity Analysis}

The PE provided results for two disposal facility designs: a RCRA-compliant, belowground trench and a RCRA-compliant, above-ground tumulus. Similar assumptions about the integrity of engineered barriers were made in the PE for both facility designs. Because the factors used to estimate transport of radionuclides in the water pathway for both designs were similar, the discussion in this section focuses on examining the results for the indicator radionuclides reported for the tumulus design (indicator radionuclides are defined in Chapter 7 of Volume 2).

As discussed in Chapter 6 of Volume 2, only four parameters used in the PE were identified as having a potential range of values that might affect results: recharge $(i)$; groundwater Darcy velocity $\left(q_{g w}\right)$; area of the facility $(A)$; and distribution coefficients $\left(K_{d} \mathrm{~S}\right)$. These parameter values for LANL are summarized in Table 8-8.

Table 8-8. Parameter Values Used in the PE for LANL with Potential Variability That Could Affect the Results

\begin{tabular}{|l|l|}
\hline \multicolumn{1}{|c|}{ Parameter } & \multicolumn{1}{|c|}{ Value } \\
\hline \hline Natural recharge through local soils, $i$ & $\begin{array}{l}\text { 0.02 } \mathrm{m} / \mathrm{y} \text { (based on site information; see Section } \\
8.3 .1 .1 \text { ) }\end{array}$ \\
\hline $\begin{array}{l}\text { Distribution coefficients for geologic } \\
\text { media, } K_{d}\end{array}$ & See Table 8-2 in this chapter for values \\
\hline Groundwater Darcy velocity, $q_{g w}$ & $\begin{array}{l}23 \mathrm{~m} / \mathrm{y} \text { (based on site-specific measurements; see } \\
\text { Section } 8.4 .1 \text { for discussion) }\end{array}$ \\
\hline Plan-view Area, $A$ & $2500 \mathrm{~m}^{2}$ (standard PE value) \\
\hline
\end{tabular}

The traditional procedure for performing a sensitivity analysis is to vary the parameters used in the calculations and observe the effect on the results. To be meaningful, this method requires some knowledge of the statistical distribution of each of the parameters considered, including their likely maximum and minimum values. For the PE calculations, the potential variability of the parameters used to calculate the permissible waste concentrations for the two different facility designs was not estimated. For most of the radionuclides considered in the PE, there were only two exposure pathways: the water pathway and intruder exposure scenarios (the atmospheric pathway was considered only for $\mathrm{H}-3$ and $\mathrm{C}-14$ ). The intruder-pathway results provide a baseline that can be used for comparison with the water-pathway results because the intruder scenarios used in the PE were relatively independent of the physical characteristics of the 
individual sites. For $\mathrm{H}-3$ and $\mathrm{C}-14$, the atmospheric-pathway results provide a baseline that can also be used for comparison with the water pathway because the atmospheric-pathway results are not highly sensitive to any individual input parameter (see Chapter 6 of Volume 2).

The intruder and atmospheric baselines provided an alternative method of performing sensitivity analyses for the PE. The input parameters for the water pathway were varied to determine if the controlling exposure pathway could be altered (e.g., the results could be changed from intruder-scenario controlled [or atmospheric-pathway controlled] to water-pathway controlled). After new values for the water pathway parameters were determined, these values were examined for reasonableness based on physical constraints at the site.

To analyze the sensitivity of the results to changes in the parameter values for recharge, groundwater Darcy velocity, and area of the facility, the parameter values used in the PE for LANL were varied. Only one parameter value was varied at a time for each indicator radionuclide, leaving the others equal to their $\mathrm{PE}$ values. In most instances, the parameter value was varied until the waste concentrations for the water and intruder (or atmospheric) pathways became equal, regardless of the likelihood (or physical impossibility) of the value to occur.

The parameter values that caused the permissible concentrations for the water and intruder pathways to become equal are listed in Table 8-9a for the 8 indicator radionuclides. For the indicator radionuclide $\mathrm{C}-14$, the controlling pathway is the atmospheric pathway, so it is more informative to compare the water and atmospheric pathways. For Tc-99, the value for recharge rate had to decrease by nearly an order of magnitude, the Darcy velocity had to increase by a factor of 3, or the value for disposal facility area had to decrease to less than $100 \mathrm{~m}^{2}\left(1080 \mathrm{ft}^{2}\right)$ to change the limiting pathway from water to intruder. For U-238, the value for recharge had to decrease by half, the groundwater velocity had to increase by a factor of 2 , or the area had to decrease by a factor of 5 in order for the water pathway concentration to equal the intruder pathway concentration. However, for all parameters, the arrival times for U-238 exceeded $10,000 \mathrm{y}$. For Am-241, the value for recharge had to increase by more than 2 orders of magnitude in order to change the limiting pathway. The Darcy velocity had to decrease by more than 2 orders of magnitude or the area had to increase by more than 4 orders of magnitude in order for the intruder concentration to equal the water pathway concentration, although the arrival time exceeded $10,000 \mathrm{y}$.

The parameter values that caused the permissible concentrations for the water and atmospheric pathways to become equal are listed in Table 8-9b for $\mathrm{H}-3$ and $\mathrm{C}-14$. For $\mathrm{H}-3$, the limiting pathway is the intrusion scenario, so this comparison is not applicable. For C-14, the recharge had to increase 45 times to change the controlling pathway from atmospheric to water. No variation in the values for Darcy velocity or area caused the atmospheric concentration to equal the water pathway concentration for $\mathrm{C}-14$.

At LANL the unsaturated zone travel time accounts for $98 \%$ of the water travel time from the disposal facility to the performance boundary. Therefore, $K_{d}$ values for the unsaturated zone were varied to perform the LANL sensitivity analysis. At this site there are two sets of PE $K_{d}$ values for the unsaturated zone (see Table 8-2). To simplify this sensitivity analysis, the same $K_{d}$ values were applied to the entire unsaturated zone. 
Table 8-9. Parameter Values That Caused the Permissible Concentrations for the Water and Intruder Pathways to Be Equal for Indicator Radionuclides at LANL (tumulus design) (bold italic type indicates limiting pathway in the PE)

(a) Water/Intruder Pathways

\begin{tabular}{|c|c|c|c|c|c|c|}
\hline \multirow[t]{4}{*}{$\begin{array}{l}\text { Indicator } \\
\text { Nuclide }\end{array}$} & \multirow[t]{4}{*}{$\begin{array}{c}\text { PE } \\
C_{w-W a t e r} \\
\left(\mu \mathrm{Ci} / \mathrm{m}^{3}\right)\end{array}$} & \multirow[t]{4}{*}{$\begin{array}{c}\text { PE } \\
C_{W-\operatorname{lnt}} \\
\left(\mu \mathrm{Ci} / \mathrm{m}^{3}\right)\end{array}$} & \multirow[t]{4}{*}{$\begin{array}{c}\text { PE } \\
\frac{C_{W-I n t r}}{C_{W-W a t e r}}\end{array}$} & $\begin{array}{c}\text { Natural } \\
\text { Recharge, } \\
i \\
(\mathrm{~m} / \mathrm{y})\end{array}$ & $\begin{array}{l}\text { Groundwater } \\
\text { Darcy } \\
\text { Velocity, } q_{g w} \\
\text { (m/y) }\end{array}$ & $\begin{array}{c}\text { Area, } \\
\text { A } \\
\left(\mathrm{m}^{2}\right)\end{array}$ \\
\hline & & & & \multicolumn{3}{|c|}{ PE Values } \\
\hline & & & & 0.02 & 23 & 2500 \\
\hline & & & & \multicolumn{3}{|c|}{$\begin{array}{c}\text { Value That Caused Equal } \\
\text { Concentrations }\end{array}$} \\
\hline $\mathrm{H}-3$ & $\mathrm{NL}$ & $7 E+07$ & - & c & c & c \\
\hline $\mathrm{C}-14$ & $8 E+08^{b}$ & $1 E+04$ & 1E-05 & $0.16^{b}$ & c & c \\
\hline Sr-90 & $\mathrm{NL}^{\mathrm{b}}$ & $5 E+04$ & - & c & c & c \\
\hline TC-99 & $5 E+03$ & $2 E+04$ & 4 & $0.007^{b}$ & 75 & $<100$ \\
\hline Cs-137 & $\mathrm{NL}^{\mathrm{b}}$ & $8 E+05$ & - & c & $c$ & c \\
\hline U-238 & $2 E+03^{b}$ & $5 E+03$ & 3 & $0.01^{b}$ & $50^{b}$ & $500^{b}$ \\
\hline Pu-239 & $\mathrm{NL}^{\mathrm{b}}$ & $6 E+03$ & - & $0.85^{b}$ & $c$ & c \\
\hline $\begin{array}{l}\text { Am-241 } \\
(\mathrm{Np}-237)^{\mathrm{d}}\end{array}$ & $7 E+05^{b, 0}$ & $9 E+03$ & 0.01 & $3^{\circ}$ & $0.1^{b, 0}$ & $5 E+07^{b, o}$ \\
\hline
\end{tabular}

a "NL" means No Limit - estimated permissible concentration is greater than the specific activity of the pure elemental radionuclide.

b Radionuclide arrival time at the performance boundary is greater than 10,000 y.

c No variation in values caused equal concentrations.

d The dominant decay product of Am-241.

e Based on the dominant decay product, Np-237.

"-" Value could not be calculated

(b) Water/Atmospheric Pathways

\begin{tabular}{|c|c|c|c|c|c|c|}
\hline \multirow[t]{4}{*}{$\begin{array}{l}\text { Indicator } \\
\text { Nuclide }\end{array}$} & \multirow[t]{4}{*}{$\begin{array}{c}\text { PE } \\
C_{W-W a t e r} \\
\left(\mu \mathrm{Ci} / \mathrm{m}^{3}\right)\end{array}$} & \multirow[t]{4}{*}{$\begin{array}{c}\text { PE } \\
C_{W-A t m} \\
\left(\mu \mathrm{Ci} / \mathrm{m}^{3}\right)\end{array}$} & \multirow[t]{4}{*}{$\begin{array}{c}\text { PE } \\
\frac{C_{\text {W-Atm }}}{C_{\text {W-Water }}}\end{array}$} & $\begin{array}{c}\text { Natural } \\
\text { Recharge, } \\
i \\
(\mathrm{~m} / \mathrm{y})\end{array}$ & $\begin{array}{l}\text { Groundwater } \\
\text { (Aquifer) } \\
\text { velocity, } q_{g w} \\
\text { (m/y) }\end{array}$ & $\begin{array}{c}\text { Area, } \\
\text { A } \\
\left(\mathrm{m}^{2}\right)\end{array}$ \\
\hline & & & & \multicolumn{3}{|c|}{ PE Values } \\
\hline & & & & 0.02 & 23 & 2500 \\
\hline & & & & \multicolumn{3}{|c|}{$\begin{array}{c}\text { Value That Caused Equal } \\
\text { Concentrations }\end{array}$} \\
\hline $\mathrm{H}-3$ & $\mathrm{NL}$ & $2 E+09$ & - & 100 & c & c \\
\hline$c-14$ & $8 E+08^{b}$ & $1 E+03$ & 1E-06 & 0.9 & c & c \\
\hline
\end{tabular}

a "NL" means No Limit - estimated permissible concentration is greater than the specific activity of the pure elemental radionuclide.

b Radionuclide arrival time at the performance boundary is greater than $10,000 \mathrm{y}$.

c No variation in values caused equal concentrations.

"-" Value could not be calculated. 
$\mathrm{A} K_{d}$ value of $0.3 \mathrm{~mL} / \mathrm{g}$ applied to the unsaturated zone would cause an arrival time at the performance boundary of $10,000 \mathrm{y}$. The $K_{d}$ values that caused the permissible concentrations for the water and intruder pathways to be the same are listed in Table 8-10 for 5 of the indicator radionuclides. The indicator radionuclides $\mathrm{H}-3, \mathrm{C}-14$, and Tc-99 are not considered in this analysis because general consensus is that the $K_{d}$ values for these radionuclides are small. For U-238, no variation in $K_{d}$ value caused the water pathway concentration to equal the intruder concentration; however, a $K_{d}$ less than $0.3 \mathrm{~mL} / \mathrm{g}$ caused the arrival time at the performance boundary to be less than $10,000 \mathrm{y}$, thereby changing the limiting pathway from intruder to water. The PE permissible waste concentration for Am-241 was limited by the decay product (Np-237) contribution to the dose. If the $K_{d}$ value for Am-241 was reduced to $0 \mathrm{~mL} / \mathrm{g}$, then the water pathway concentration was limited by the parent radionuclide (Am-241) and the water pathway controlled. Due to the long half-life of Np-237, reduction of its $K_{d}$ had no effect on the resulting waste concentration.

Table 8-10. Variation of $K_{d}$ Values for the Unsaturated Zone at LANL (tumulus design) (a $K_{d}$ value of $0.3 \mathrm{~mL} / \mathrm{g}$ caused radionuclide arrival at the performance boundary equal to $10,000 \mathrm{y})$

\begin{tabular}{|c|c|c|c|c|c|c|}
\hline $\begin{array}{l}\text { Indicator } \\
\text { Nuclide }\end{array}$ & $\begin{array}{c}P E \\
K_{d} \\
\text { Bandelier } \\
\text { Tuff } \\
(\mathrm{mL} / \mathrm{g})\end{array}$ & $\begin{array}{c}P E \\
K_{d} \\
\text { Puye } \\
\text { Formation } \\
(\mathrm{mL} / \mathrm{g}) \\
\end{array}$ & $\begin{array}{c}\text { PE } \\
C_{w-W a t e r}{ }^{a} \\
\left(\mu \mathrm{Ci} / \mathrm{m}^{3}\right)\end{array}$ & $\begin{array}{c}\text { PE } \\
C_{W / I n t r} \\
\left(\mu \mathrm{Ci} / \mathrm{m}^{3}\right)\end{array}$ & $\begin{array}{c}\text { PE } \\
\frac{C_{W \cdot I n t r}}{C_{W \cdot W a t e r}}\end{array}$ & $\begin{array}{l}K_{d} \text { Value that } \\
\text { Caused Equal } \\
\text { Concentrations }\end{array}$ \\
\hline Sr-90 & 116 & 15 & $\mathrm{NL}^{\mathrm{b}}$ & $5 E+04$ & - & c \\
\hline Cs-137 & 428 & 280 & $\mathrm{NL}^{\mathrm{b}}$ & $8 E+05$ & - & c \\
\hline U-238 & 1.8 & 35 & $2 E+03^{b}$ & $5 E+03$ & 3 & $c, d$ \\
\hline Pu-239 & 110 & 550 & $\mathrm{NL}^{\mathrm{b}}$ & $6 E+03$ & - & c \\
\hline $\begin{array}{l}A m-241 \\
(\mathrm{~Np}-237)^{\circ}\end{array}$ & $\begin{array}{c}130 \\
(0.007)\end{array}$ & $\begin{array}{c}1900 \\
(5)\end{array}$ & $7 E+05^{b, f}$ & $9 E+03$ & 0.01 & 0 \\
\hline
\end{tabular}

a "NL" means No Limit - the estimated permissible waste concentration is greater than the specific activity of the pure elemental radionuclide.

b Radionuclide arrival time at the performance boundary is greater than $10,000 \mathrm{y}$.

c No variation in value caused equal concentrations.

d Value less than $0.3 \mathrm{~mL} / \mathrm{g}$ caused arrival at performance boundary before $10,000 \mathrm{y}$, which changed the limiting pathway.

e The dominant decay product of Am-241

f Based on the dominant decay product, Np-237

"-" Value could not be calculated.

\subsubsection{Physical Constraints on Sensitivity Analysis Values}

The PE results for LANL are based on parameter values provided by the LANL technical staff for site-specific parameters used in calculations. Descriptions and technical justifications of these values are provided in Sections 8.3 and 8.4. Ranges and statistical distributions may not have been known for all of the input parameter values; however, site-specific knowledge can be used to determine whether the values determined in the sensitivity analysis are reasonable and physically possible at the proposed MWDF site at LANL. 


\section{Natural Recharge}

The values for natural recharge estimated in the sensitivity analysis range from 0.007 to $3 \mathrm{~m} / \mathrm{y}(0.023$ to $10 \mathrm{ft} / \mathrm{y}$ ) (Tables $8-9 \mathrm{a}$ and $\mathrm{b}$ ). The natural recharge at LANL is not known, and the $\mathrm{PE}$ value of $0.02 \mathrm{~m} / \mathrm{y}(0.07 \mathrm{ft} / \mathrm{y})$ is conservative based on (1) the measured precipitation rate, (2) unsaturated hydraulic conductivity inferred from core data, and (3) numerical modeling results (see Section 8.4.1), indicating that a lower recharge may be possible at the TA-67 MWDF site. However, all recharge values lower than the PE value $(0.02 \mathrm{~m} / \mathrm{y}[0.07 \mathrm{ft} / \mathrm{y}])$ produce results with corresponding radionuclide travel times greater than $10,000 \mathrm{y}$.

The increased recharge calculated for C-14 and Am-241 of 0.9 and $3 \mathrm{~m} / \mathrm{y}$ ( 3 and $10 \mathrm{ft} / \mathrm{y}$ ), respectively, are physically unreasonable at the TA-67 site because the average annual precipitation at TA-67 is about $0.41 \mathrm{~m} / \mathrm{y}(1.3 \mathrm{ft} / \mathrm{y})$ (Turin and Rosenberg, 1994). The value of $0.9 \mathrm{~m} / \mathrm{y}(3.0 \mathrm{ft} / \mathrm{y})$ is more than double the measured precipitation rate.

\section{Groundwater Darcy Velocity}

The values for the groundwater Darcy velocity estimated by the sensitivity analysis vary from 0.1 to $75 \mathrm{~m} / \mathrm{y}(0.3$ to $250 \mathrm{ft} / \mathrm{y})$ (Table $8-9 \mathrm{a})$ compared to the $P E$ value of $23 \mathrm{~m} / \mathrm{y}(75 \mathrm{ft} / \mathrm{y})$. However, the U-238 and Am-241 results (50 and $0.1 \mathrm{~m} / \mathrm{y}$ [160 and $0.3 \mathrm{ft} / \mathrm{y}$ ], respectively) correspond to an arrival time greater than $10,000 \mathrm{y}$. A Darcy velocity of $75 \mathrm{~m} / \mathrm{y}(250 \mathrm{ft} / \mathrm{y})$ for Tc-99 is physically possible at TA-67. This value easily falls within the range of aquifer property measurements collected at LANL (see Section 8.4.1).

\section{Facility Area}

The values for the facility area estimated in the sensitivity analysis range from less than $100 \mathrm{~m}^{2}$ to $50,000,000 \mathrm{~m}^{2}\left(1080 \mathrm{ft}^{2}\right.$ to $540,000,000 \mathrm{ft}^{2}$ ) (Table 8-9). The results for $\mathrm{U}-238$ and Am-241 correspond to arrival times greater than 10,000 y. For Tc-99, a facility size less than $100 \mathrm{~m}^{2}$ is not consistent with the proposed MWDF which has a plan-view area of $40,000 \mathrm{~m}^{2}$ $\left(432,000 \mathrm{ft}^{2}\right)$ (Leedshill-Herkenhoff, 1995).

\section{Distribution Coefficients}

The controlling pathway could be changed by a different $K_{d}$ value for the indicator radionuclides U-238 and Am-241. For U-238, it is reasonable to change the $K_{d}$ from the PE value of $1.8 \mathrm{~mL} / \mathrm{g}$ to less than $0.3 \mathrm{~mL} / \mathrm{g}$ (the value required for arrival at the performance boundary equal to $10,000 \mathrm{y}$ ) and change the limiting pathway from intruder to water. For Am-241, it was possible to change the controlling pathway from intruder to water when the $\dot{K}_{d}$ for Am-241 was changed to $0 \mathrm{~mL} / \mathrm{g}$ (Table 8-10), assuming one $K_{d}$ value for the entire unsaturated zone. A $K_{d}$ of $0 \mathrm{~mL} / \mathrm{g}$ is probably not reasonable for Am-241, which had PE $K_{d}$ values of 130 $\mathrm{mL} / \mathrm{g}$ in the Bandelier Tuff and $1800 \mathrm{~mL} / \mathrm{g}$ in the Puye Conglomerate. 


\subsection{OBSERVATIONS}

Based on the results of the PE and the parameter-sensitivity analysis, the following observations can be made about MLLW disposal at LANL:

- The LANL site has characteristics that are typical of an arid climate. A low natural recharge and thick unsaturated zone are found here. These site properties correspond with long radionuclide travel times through the unsaturated zone. In fact, $98 \%$ of the radionuclide travel time from the disposal facility to the performance boundary is accounted for by the unsaturated zone travel time.

- For both the trench and tumulus designs at LANL, the results indicate that of the 58 radionuclides evaluated in the $\mathrm{PE}, 56$ radionuclides would be limited by intrusion scenarios. These results reflect the dominant role of the selected human intrusion scenarios that is demonstrated for almost all the sites considered in the PE (see Sections 7.5 and 7.6 in Volume 2). This dominance indicates a need to be aware of the inability to predict the social behavior of populations far into the future.

The results also indicate that for the water pathway, 56 radionuclides for both the trench and tumulus designs would arrive at the performance boundary after the 10,000-y period of consideration in the $\mathrm{PE}$ analysis of the water pathway. Of the two radionuclides that arrive before $10,000 \mathrm{y}$, one for both the trench and tumulus designs had no limit on waste concentration.

Because LANL has many radionuclides that either are limited by the intrusion scenarios, arrive at the performance boundary after $10,000 \mathrm{y}$, or have no limit on waste concentration, this site may have flexibility in accepting a variety of radionuclides for disposal.

- Using either a trench or a tumulus design is feasible at LANL. The proposed MWDF at LANL is a trench design, and the very thick unsaturated zone allows a large buffer between the bottom of the proposed trench and the water table.

- LANL could have physical constraints that could limit disposal activities. The proposed MWDF site location within TA-67 at LANL is planned to have a plan-view area of approximately $40,000 \mathrm{~m}^{2}\left(432,000 \mathrm{ft}^{2}\right)$ The width of the mesa (about $500 \mathrm{~m}[1600 \mathrm{ft}]$ ) places physical constraints on how wide any facility could feasibly be at the TA-67 location. The plan-view orientation of the proposed MWDF facility was designed to take advantage of the mesa-top shape in that the length of the proposed facility is perpendicular to the mesa top width.

- The sensitivity analysis for LANL indicates that, in general, reasonable changes in values for the natural recharge, groundwater Darcy velocity, and facility size would not 
significantly change the results. The PE values for these parameters could not be changed in a reasonable way to change the limiting pathway from intruder to water for any of the indicator radionuclides with the exception of natural recharge and Darcy velocity for U-238, where the results were associated with an arrival time at the performance boundary greater than $10,000 \mathrm{y}$. The only reasonable parameter value change that caused the limiting pathway to change from water to intruder was the Darcy velocity for Tc-99.

In flow and transport problems, the $K_{d}$ values are often the most uncertain site-specific input parameters. For LANL, the $K_{d}$ value for U-238 could be changed in a reasonable way to change the controlling pathway from intruder to water.

- The PE was a scoping analysis performed using assumptions that are conservative relative to most LLW performance assessments. A performance assessment for LLW disposal at LANL was being drafted at the time the PE was performed. While the draft LLW performance assessment was not available to make detailed comparisons of the analyses, the PE team worked closely with the performance assessment team at the site to ensure that the latest information was incorporated into the $\mathrm{PE}$ analysis. 


\subsection{REFERENCES}

Abeele, W.V., M.L. Wheller, and B.W. Burton, 1981. Geohydrology of Bandelier Tuff. LA8962-MS. Los Alamos, NM: Los Alamos National Laboratory.

Baer, T.A., L. L. Price, J. N. Emery, N. E. Olague, 1994. Second Performance Assessment Iteration of the Greater Confinement Disposal Facility at the Nevada Test Site. SAND930089. Albuquerque, NM: Sandia National Laboratories.

Baltz, E.H., J.H. Abrahams, Jr., and W.D. Purtymun, 1963. Preliminary Report on the Geology and Hydrology of Martandad Canyon Near Los Alamos, New Mexico With Reference to Disposal of Liquid Low-Level Radioactive Waste. U.S. Geological Survey Open File Report. Albuquerque, NM: U.S. Geological Survey.

Bowen, B.M., 1990. Los Alamos Climatology. LA-11735-MS. Los Alamos, NM: Los Alamos National Laboratory.

Brookins, D.G., 1984. Geochemical Aspects of Radioactive Waste Disposal. New York: Springer-Verlag. $347 \mathrm{p}$.

Broxton, D.E., S.L. Reneau, and D.T. Vaniman, 1994. Surficial and Bedrock Stratigraphy at Proposed MWDF. Unpublished report. Los Alamos, NM: Los Alamos National Laboratory, Geology and Geochemistry Group.

Christenson, C.W. and R.G. Thomas, 1962. "Movement of Plutonium through Los Alamos Tuff," Ground Disposal of Radioactive Wastes. Second conference proceedings, No. 7628. Baltimore, MA: Johns Hopkins University.

Chu, M.S.Y., M.W. Kozak, J.E. Campbell, and B.M. Thompson, 1991. A Self-Teaching Curriculum for the NRC/SNL Low-Level Waste Performance Assessment Methodology. SAND90-0585.

Albuquerque, NM: Sandia National Laboratories.

Cooper, C.D., and F.C. Alley, 1986. Air Pollution Control: A Design Approach. Prospect Heights, IL: Waveland Press, Inc.

CRC, 1981. CRC Handbook of Chemistry and Physics. Eds. Robert C. Weast and Melvin J. Astle. Boca Raton, FL: CRC Press, Inc.

CRC, 1987. Handbook of Tables for Applied Engineering Science, 2nd edition. Eds. Bolz R.E., and G.L. Tuve. Boca Raton, FL: CRC Press, Inc.

EPRI (Electric Power Research Institute), 1985. A Review of Field-Scale Physical Solute Transport Processes in Saturated and Unsaturated Porous Media. EPRI EA-4190. Norris, TN: Tennessee Valley Authority. 
EPA, 1992. User's Guide for the Industrial Source Complex (ISC2) Dispersion Models, Volume I: User Instructions. EPA Publication No. EPA-450/4-92-008a. Research Triangle, NC: U.S. Environmental Protection Agency.

FFCAct, 1992. Federal Facility Compliance Act of 1992. P.L. 102-386, October 1992.

Freeze, R.A. and J.A. Cherry, 1979. Groundwater. Englewood Cliffs, NJ: Prentice-Hall, Inc. $604 \mathrm{p}$.

Gardner, J.N., T. Kolbe, and S. Change, 1993. Geology, Drilling and Some Hydrologic Aspects of Seismic Hazards Program Core Holes. LANL Report LA-12460-MS. Los Alamos, NM: Los Alamos National Laboratory.

Gruebel, M.M., R.D. Waters, M.B. Hospelhorn, and M.S.Y. Chu, eds., 1994. Framework for DOE Low-Level and Mixed Low-Level Waste Disposal: Site Fact Sheets. SAND94-2728. Albuquerque, NM: Sandia National Laboratories.

Kincaid, C.T., J.W. Shade, G.A. Whyatt, M.G. Piepho, K. Rhoads, J.A. Voogd, J.H. Westsik, Jr., M.D. Freshley, K.A. Blanchard, and B.G. Lauzon, eds., 1993. Performance Assessment of Grouted Double-Shell Tank Waste Disposal at Hanford. WHC-SD-WM-EE-004, Rev. 0. U.S. Department of Energy, Pacific Northwest Laboratory and Westinghouse Hanford Company.

Kowalewsky, K, B. Eklund, and E. Vold, 1995. Air Quality Impacts Analysis for Area G Final Report. RCN 640-015-04-01. Report prepared by Radian Corporation and Los Alamos National Laboratory for CST-14 Solid Radioactive Waste Management.

Krier, D., 1995. "MDA G Performance Assessment Data Review Task." Los Alamos National Laboratories Memorandum to E. Springer, February 2, 1995.

LANL, 1992a. Installation Work Plan for Environmental Restoration. Report LA-UR-92-3795. Los Alamos, NM: Los Alamos National Laboratory.

LANL, 1992b. RFI Work Plan for Operable Unit 1148. Report LA-UR-92-855. Los Alamos, NM: Los Alamos National Laboratory, Environmental Restoration Program.

Leedshill-Herkenhoff, 1995. Title I Design Summary, Volume II of V, Disposal Pit Development Report For RCRA Mixed Waste Disposal Facility. Albuquerque, NM: Leedshill-Herkenhoff, Inc.

Maheras, Steven J., Arthur S. Rood, Swen O. Magnuson, Mary E. Sussman, and Rajiv N. Bhatt, 1994. Radioactive Waste Management Complex Low-Level Waste Radiological Performance Assessment. EGG-WM-8773. Idaho Falls, ID: U.S. Department of Energy Office of Environmental Restoration and Waste Management, DOE Idaho Operations Office. 
MMES (Martin Marietta Energy Systems), EG\&G Idaho, Inc., and Westinghouse Savannah River Company, 1994. Radiological Performance Assessment for the E-Area Vaults Disposal Facility $(U)$. WSRC-RP-94-218, Rev. 0. Aiken, SC: Westinghouse Savannah River Co.

Nyhan, J.W., B. Drennon, and T.E. Hakonson, 1989. Field Evaluation of Two Shallow Land Burial Trench Cap Designs for Long-Term Stabilization And Closure of Waste Repositories at Los Alamos, New Mexico. LA-11281-MS. Los Alamos, NM: Los Alamos National Laboratory.

ORNL (Oak Ridge National Laboratory), 1994. Performance Assessment for Continuing and Future Operations at Solid Waste Storage Area 6. ORNL-6783. Oak Ridge, TN: U.S. Department of Energy, Oak Ridge National Laboratory.

Polzer, W.L., H.R. Fuentes, E.H. Essington, and F.R. Roensch, 1985. "Equilibrium Sorption of Cobalt, Cesium, and Strontium on Bandelier Tuff: Experiments and Analysis," Waste Management 1985. Pp. 175-181.

Purtymun, W.D., 1984. Hydrologic Characteristics of the Main Aquifer in the Los Alamos Area: Development of Ground Water Supplies. LA-9967-MS. Los Alamos, NM: Los Alamos National Laboratory.

Purtymun, W.D., 1995. Geologic and Hydrologic Records of Observation Wells, Test Holes, Supply Wells, Springs, and Surface Water Stations in the Los Alamos Area. LA-12883-MS. Los Alamos, NM: Los Alamos National Laboratory.

Purtymun, W.D. and A.K. Stoker, 1988. Water Supply at Los Alamos: Current Status of Wells and Future Water Supply. LANL Report LA-11332-MS. Los Alamos, NM: Los Alamos National Laboratory.

Reneau, 1994. Potential Mesa-Edge Instability at Pajarito Mesa, Los Alamos National Laboratory, New Mexico. Unpublished report. Los Alamos, NM: Los Alamos National Laboratory, Geology and Geochemistry Group.

Rogers, D.P., and B.M. Gallaher, 1994. "Unsaturated Hydraulic Characteristics of the Bandelier Tuff." Los Alamos National Laboratory Memorandum ESH-18/WQ\&H-94-525, October 31, 1994.

Rush, S.M., and J.J. Dexter, 1985. Vadose Zone Characterization of Technical Area 54, Waste Disposal Areas G and L, Los Alamos National Laboratory, New Mexico. Bendix Field Engineering Corporation, Grand Junction Operations.

Schroeder, P.R., T.S. Dozier, P.A. Zappi, B.M. McEnroe, J.W. Sjostrom, and RL. Peyton, 1994. The Hydrologic Evaluation of Landfill Performance (HELP) Model: Engineering Documentation for Version 3. EPA/600/9-94/168a. Cincinnati, OH: Risk Engineering Laboratory for the U.S. Environmental Protection Agency.

Stephens (D.B. Stephens \& Associates, Inc.), 1995. Laboratory Analysis of Soil Hydraulic Properties of LANL Mixed Waste Disposal Project Soil Samples. Albuquerque, NM: Daniel B. Stephens \& Associates, Inc., prepared for ERM Program Management Company, Los Alamos, NM. 
Stoker, AK., W.D. Purtymum, S.G. McLin, and M.N. Maes, 1991. Extent of Saturation in Mortandad Canyon. LA-UR-91-1660. Los Alamos, NM: Los Alamos National Laboratory.

Thibault, D.H., M.I. Sheppard, and P.A. Smith, 1990. A Critical Compilation and Review of Default Soil Solid/Liquid Partition Coefficients, $K_{d,}$ for Use in Environmental Assessments. AECL-10125. Pinawa, Manitoba, Canada: Whiteshell Nuclear Research Establishment, Atomic Energy of Canada Limited.

Triay, I.R., C.R. Cotter, S.M. Kraus, M.H. Huddlestob, S.J. Chipera, and D.L. Bish, 1994. Report on Radionuclide Sorption in Yucca Mountain Tuffs with J-13 Well Water: Neptunium, Uranium, and Plutonium Milestone \#3338. Draft report. Los Alamos, NM: Los Alamos National Laboratory. $12 \mathrm{p}$.

Turin, H.J., and N.D. Rosenberg, 1994. Summary of TA-67 Geology, Hydrogeology, and Seismicity for Radiological Performance Assessment-FY93 Report. LA-UR-94-4399. Los Alamos, NM: Los Alamos National Laboratory.

Vaniman, D. and S. Chipera, 1994. Mesa-Penetrating Fractures, Fracture Mineralogy, and Projected Foult Traces at Pajarito Mesa. Unpublished report. Los Alamos, NM: Los Alamos National Laboratory. $29 \mathrm{p}$.

Vold, E., M. Chanm and L. Sanders, 1996. The Los Alamos TA54 Complex Terrain Atmospheric Transport Study. Abstract submitted to the AMS 9th Joint Conference on Applications of Air Pollution Meteorology with the Air and Waste Management Association, Feb 28 - Mar 2, 1996, Atlanta, GA.

Wang, J.S.Y. and T.N. Narasimhan, 1985. "Hydrologic Mechanisms Governing Fluid Flow in a Partially Saturated, Fractured, Porous Medium," Water Resources Research. Vol. 21, No. 12. Pp. 1861-1874.

Winograd, I.J. and W. Thordarson, 1975. Hydrogeologic and Hydrochemical Framework, South Central Great Basin. Nevada-California, with Special Reference to the Nevada Test Site. U.S. Geological Survey Professional Paper 712-C. Washington, DC: U.S. Geological Survey.

Wolfsberg, K., 1980. "Sorptive Properties Of Tuff And Nuclide Transport Retardation" Evaluation of Tuff as a Medium for Nuclear Waste Repository: Interim Status Report on the Properties of Tuff. Eds. J.K. Johnstone and K. Wolfsberg. SAND80-1464. Albuquerque, NM: Sandia National Laboratories. Pp. 39-48.

\section{Acknowledgments}

The SNL Core Team acknowledges the contributions of Diana Hollis, Erik Vold, Jake Turin, Pat Longmire, Bruce Gallaher, Everett Springer, and David Rogers of the LANL staff, and contractors Bob MacKinnon, Rob Shuman, and Mike Goodrich. 


\section{New Mexico: SANDIA NATIONAL LABORATORIES (SNL/NM) Core Team Contacts: Michael T. Goodrich and Alva M. Parsons}

The Federal Facility Compliance Act (FFCAct, 1992) requires the Department of Energy (DOE) to establish plans in conjunction with its regulators and with members of the public for the treatment of DOE's mixed low-level waste (MLLW). Although the FFCAct did not specifically address disposal of treated MLLW, both DOE and the States recognized that disposal issues were an integral part of treatment discussions. Since 1992, DOE has worked with the States to define and develop an evaluation process for disposal options. Preliminary activities of this joint DOEState process have narrowed the sites for further evaluation from 49 to 15 .

The Disposal Workgroup (DWG), which was established by DOE to develop a process for evaluating disposal options, designed a performance evaluation (PE) to quantify and compare the limitations of the remaining 15 DOE sites for MLLW disposal. The principal goal of the PE was to estimate, for grouted residuals resulting from the treatment of MLLW, permissible concentrations of radionuclides in waste for disposal at each site. These "permissible waste concentrations" were based solely on long-term physical performance of the disposal facility and did not take into account any operational waste acceptance criteria that a site might have developed. The PE did not address any ethical, social, or policy considerations relevant to siting such facilities.

The PE used analyses that are consistent with the approach used in many low-level waste (LLW) performance assessments. The objective was to use a set of modeling assumptions of sufficient detail to capture major site-specific characteristics and yet be general enough for consistent application at all sites. Additionally, the analyses were designed to ensure that the sites were analyzed consistently and that all major assumptions were clearly stated.

The remainder of this chapter provides the PE results for Sandia National Laboratories/New Mexico (SNL/NM), one of the 15 sites being evaluated. The chapter contains the following information:

Section 9.1: brief, general description of the site, based on previous work done by the DWG (Gruebel et al., 1994)

Section 9.2: plans for MLLW disposal, if any, and the location evaluated in the PE

Section 9.3: current understanding of radionuclide movement at the selected location based on available information, and the conceptual model used for the evaluation of each of three pathways (water, atmospheric, and inadvertent intruder)

Section 9.4: site-specific and generic values used in the PE calculations and their sources

Section 9.5: estimates of maximum waste concentrations determined in the PE calculations for each of the three pathways, along with calculated values used in determining these results

Section 9.6: summary of results based on disposal-facility design; discussion with respect to such issues as uncertainty and sensitivity 
Section 9.7: $\begin{aligned} & \text { observations based on the results of the PE and the parameter sensitivity } \\ & \text { analysis }\end{aligned}$
Section 9.8: $\quad$ references

The general assumptions and methodology used in the PE are summarized in Chapter 1 of this volume and explained in more detail in Volume 2 of this report. Overall results for all the sites are discussed in Chapter 7 of Volume 2.

\subsection{GENERAL DESCRIPTION OF SNL/NM}

SNL/NM is located on Kirtland Air Force Base (KAFB), on the southern edge of the city of Albuquerque, New Mexico (Figure 9-1). The air force base is bordered on the north by the city, on the east by the Manzano Mountains, and on the west and south by the Isleta Indian reservation and NM State lands. The facility is adjacent to the south and east sides of the Albuquerque International Airport. Furthermore, KAFB is within several miles of the intersection of two major interstate highways, I-40 and I-25, which generally bisect the state into four quadrants and serve as major transportation routes through the region (Figure 9-1).

The city of Albuquerque, with a population of approximately 385,000 , is within $10 \mathrm{~km}$ $(6.2 \mathrm{mi})$ of the site. Within $50 \mathrm{~km}(31 \mathrm{mi})$ of the site, an additional population of about 193,000 is found in small towns, suburban communities, and Indian pueblos bringing the total population to about 578,000 (Culp et al., 1994).

In total, the KAFB reservation encompasses $190 \mathrm{~km}^{2}$ (47,000 ac), but DOE maintains land use agreements to operate only a fraction of this area. The SNL/NM site consists of five distinct technical areas and remote test areas that occupy $11.3 \mathrm{~km}^{2}(2,800 \mathrm{ac}$ ) (Figure 9-2). DOE also manages a security-restricted office building adjacent to the SNL/NM facilities, as well as an undeveloped area as a designated buffer zone at the southern end of the reservation (Culp et al., 1994).

The base is an Air Force Materiel Command base that supports the development, management, and retirement of nuclear weapons and associated systems. Defense-related research and development has been conducted at SNL/NM since the laboratory was founded in 1947. It has diversified since its inception to include a broad range of research initiatives.

The climate in the Albuquerque area is arid with low precipitation, high evapotranspiration, wide temperature extremes, and seasonal winds. The average annual temperature in Albuquerque is $13^{\circ} \mathrm{C}\left(56^{\circ} \mathrm{F}\right)$ with an average diurnal temperature range of $19.6^{\circ} \mathrm{C}$ $\left(28^{\circ} \mathrm{F}\right)$ (Culp et al., 1994). Normally, temperatures rarely fall below $-18^{\circ} \mathrm{C}\left(0^{\circ} \mathrm{F}\right)$. The valley and mesa areas are arid, with an average annual precipitation of about $23 \mathrm{~cm}$ (9 in.) (SNL, 1994). Half of the average annual precipitation occurs in the form of brief but heavy thunderstorms during the summer that are diverted to two natural surficial drainage channel (arroyo) systems on KAFB. Evapotranspiration in the area is estimated at $95 \%$ of the annual rainfall, or about $19.3 \mathrm{~cm}$ (7.6 in.). Average annual evaporation from shallow lakes in the area could be as much as $142 \mathrm{~cm}$ (56 in.). Wind directions vary seasonally but are typically from the south and east. Wind speed is generally greater in late winter and early spring, but sustained winds greater than $19.2 \mathrm{~km} / \mathrm{hr}$ (12 mph) occur only $20 \%$ of the year (Culp et al., 1994). 


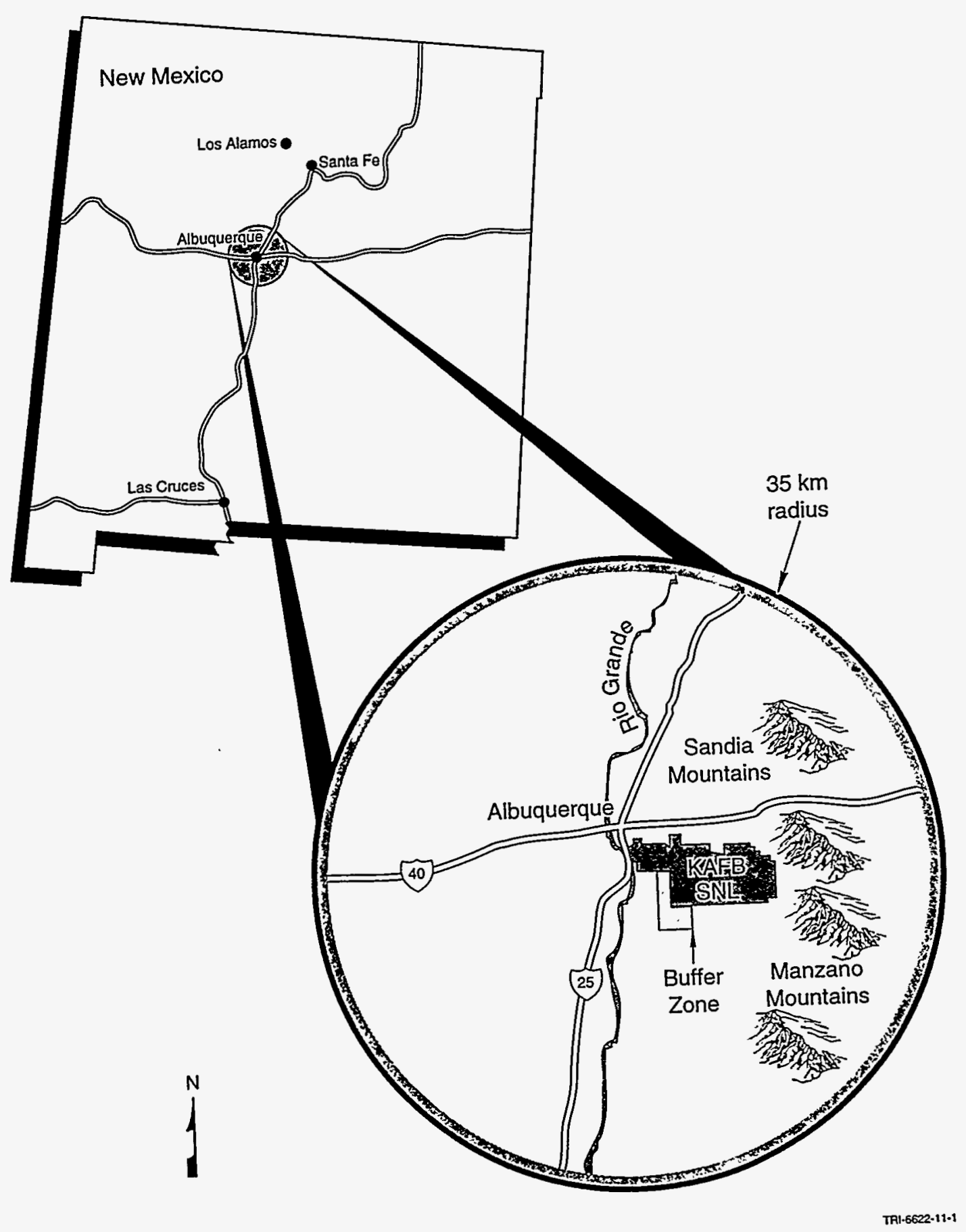

Figure 9-1. Location map for Sandia National Laboratories/New Mexico. 


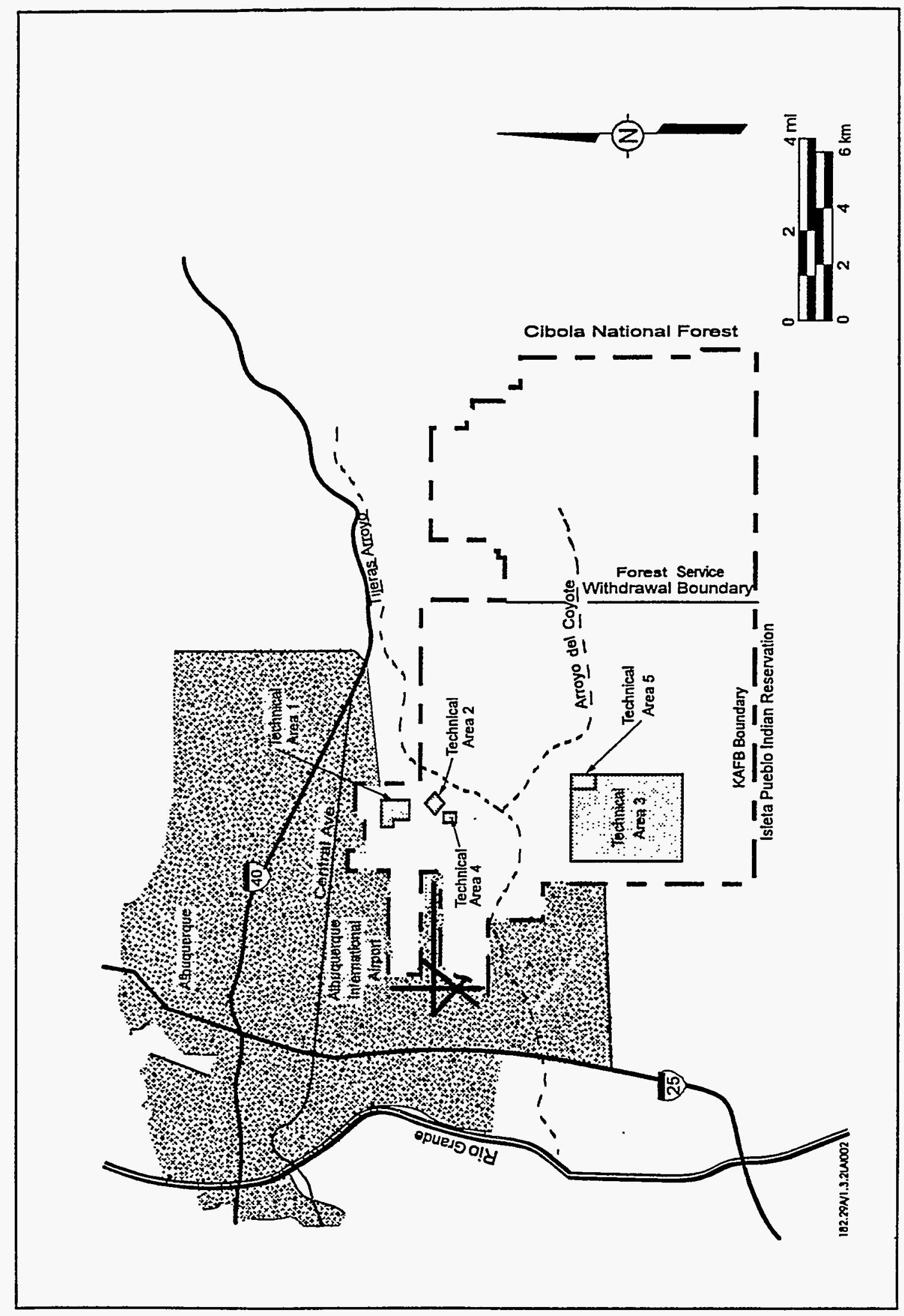

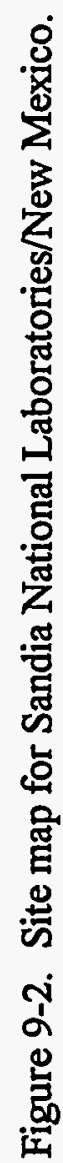


The air force base is situated in the eastern portion of the Albuquerque Basin, which is one of the largest of a series of north-trending basins along the Rio Grande (SNL, 1994). This basin is bounded by the Sandia and Manzano Mountains in the east, the Lucero uplift and Puerco plateau in the west, and the Nacimiento uplift in the north. Large-scale faulting, deepening of the basin, and tilting of the mountain areas occurred approximately 11.2 to 5.3 million years ago. Since then, basin deposits have been laid down in a complex sequence of sedimentary and volcanic rocks. With the exception of the Manzano Mountains on the eastern edge of the reservation, the KAFB topography is generally flat (SNL, 1994).

The majority of the Albuquerque Basin is composed of poorly consolidated sediments eroded from the surrounding mountain areas following the faulting and structural changes that occurred 11.2 to 5.3 million years ago (SNL, 1994). The upper part of the basin fill is comprised of a complex sequence of gravel, sand, silt, clay, and caliche deposits known as the Santa Fe Formation (middle to late Cenozoic). Underlying these rocks are sedimentary rocks of unknown total thickness, although gravity and aeromagnetic mapping indicate that these rocks extend about $4,600 \mathrm{~m}(15,000 \mathrm{ft})$ below ground level.

The major surface hydrologic feature in central New Mexico is the Rio Grande, which flows north to south through Albuquerque and lies approximately $8 \mathrm{~km}(5 \mathrm{mi})$ west of KAFB (SNL, 1994) (Figure 9-1). Surface water on KAFB is in the form of sheet flow draining into small arroyos and carried by natural and artificial flow paths into two primary arroyos that flow intermittently during heavy thunderstorms and spring snow melts. Most of this flow does not reach the Rio Grande as surface water due to evapotranspiration and percolation into the permeable alluvial deposits (SNL, 1994). Tijeras Arroyo and Arroyo del Coyote are identified by the U. S. Army Corps of Engineers as within the 100-y floodplain, but these channels remain undeveloped. No permanent surface water bodies are found on the reservation with the exception of a small pond on the Tijeras Arroyo Golf Course.

The vadose zone is an important part of the hydrologic system in the KAFB area and its thickness is generally quite large (from 15 to more than $150 \mathrm{~m}$ [50 to more than $500 \mathrm{ft}$ ) (SNL, 1994). Consequently, any contaminants released near the ground surface must travel a long distance before reaching the water table. The regional area recharge rate outside of the arroyos is estimated to be less than $5 \%$ of the total annual precipitation (SNL, 1994).

Three different hydrogeologic regions have been identified on KAFB. The regions are influenced by two very different geologic environments separated by an assemblage of fault systems (SNL, 1994). Region 1 encompasses essentially the entire western half of KAFB, with depths to groundwater in excess of $120 \mathrm{~m}(400 \mathrm{ft})$ and with unconfined and partially confined aquifers composed of basin-fill deposits. Region 3 comprises a large area on the east side of $\mathrm{KAFB}$ in the foothills and canyons of the Manzano Mountains and which is characterized by shallow unconfined groundwater with fractured rock hydrology. Region 2 represents the transition region between Regions 1 and 3, and is characterized by a system of steeply dipping normal faults and associated complex groundwater flow. 
The basin-fill deposits are the primary aquifer in the Albuquerque Basin. The basin-fill aquifer consists of interbedded gravel, sand, silt, and clay and is part of a complex stream-aquifer depositional system that has been extensively developed in parts of the basin for irrigation and for domestic and municipal water supplies. The aquifer properties have a considerable range of values due to the large variations in lithology of basin-fill deposits. Groundwater flow on a KAFB scale is generally to the west-northwest, with the flow direction strongly affected by a cone of depression caused by KAFB and Albuquerque municipal drinking water supply wells located on and north of KAFB (SNL, 1994). This groundwater system is used as the main water supply for the city of Albuquerque, as well as for other communities along the Rio Grande. Private wells to the west and south are also used by residents to withdraw potable water for domestic use. No aquifers in the SNL/NM area have been designated by the U.S. Environmental Protection Agency (EPA) as a sole source aquifers as defined in 40 CFR Part 149.2.

\subsection{STATUS AND SITING OF MLLW DISPOSAL FACILITY}

At the time of the PE, personnel at SNL/NM had no plans for on-site MLLW disposal. SNL/NM's Technical Area III (TA3) was chosen as the best location for a hypothetical MLLW disposal facility because it has areas already designated for waste management. Furthermore, it is in an area already under DOE control. Other technical areas considered were not suitable due to either high population or close proximity to the Albuquerque airport flight pattern.

The particular area of interest within TA3 is the southeast corner in the vicinity of the Radioactive and Mixed Waste Management Facility and the Chemical Waste Landfill (CWL) (Figure 9-3). The southeast corner of TA3 is actively under investigation by SNL/NM's Environmental Restoration (ER) Program, and hence, there is an abundance of hydrologic and geologic data available for this location. TA3 is located within the Region 1 hydrogeologic region where there is a deep basin-fill aquifer. Furthermore, it passes the PE site exclusion criteria of

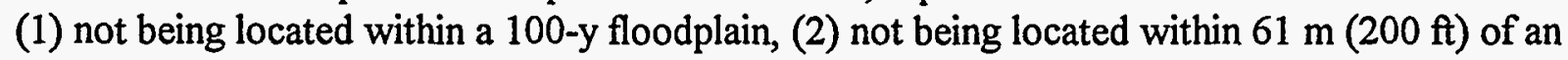
active fault, and (3) having sufficient area to accommodate a $100-\mathrm{m}(328-\mathrm{ft})$ buffer zone.

Two generic disposal facilities were considered in the PE: a RCRA-compliant, belowground trench and a RCRA-compliant, above-ground tumulus (described in more detail in Chapter 5 of Volume 2). The generic facilities were selected to provide consistency in analysis of the performance of the 15 sites. Both generic facilities were assumed to be square with a plan area of $2500 \mathrm{~m}^{2}\left(26,910 \mathrm{ft}^{2}\right)$. 


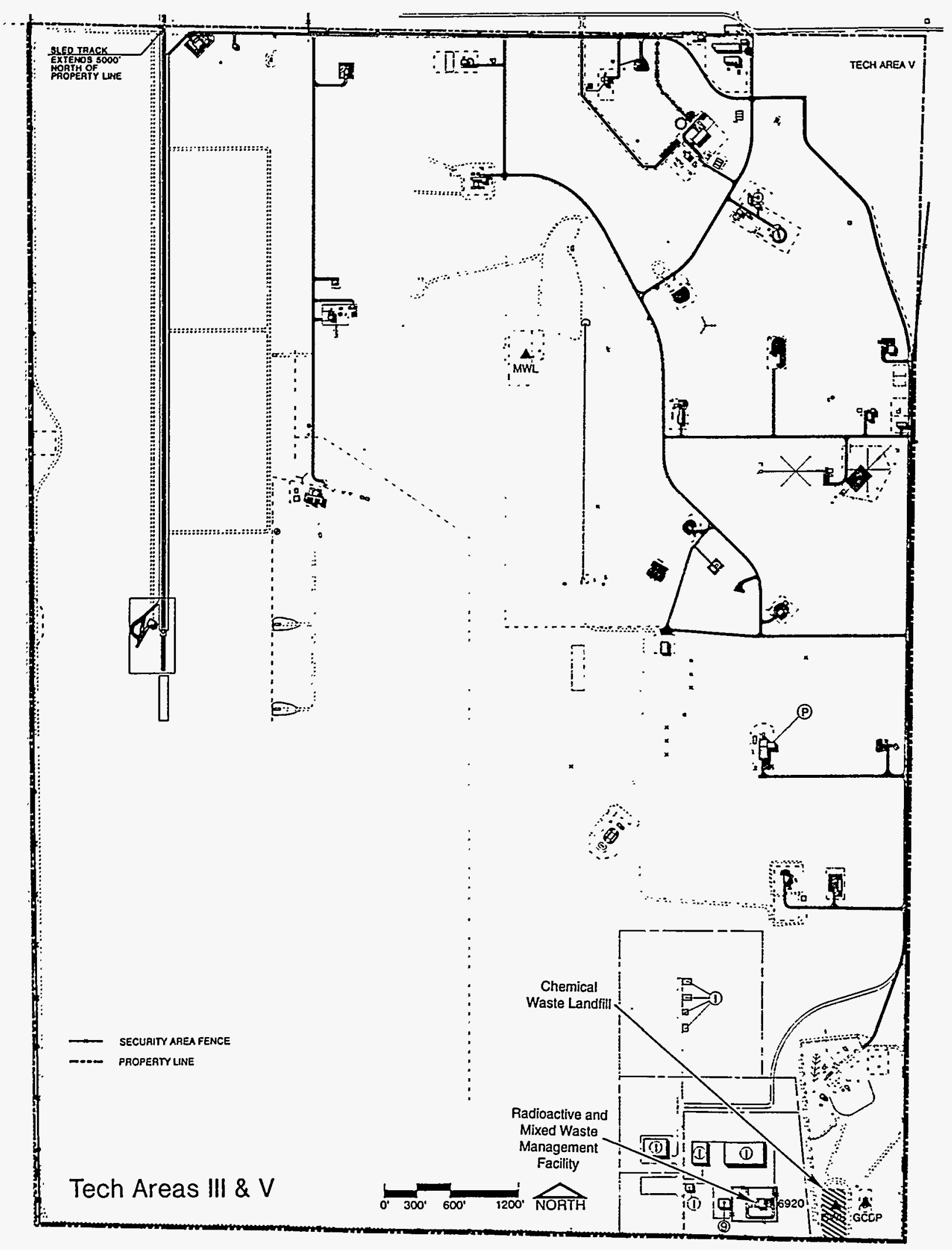

Figure 9-3. Location of the Radioactive and Mixed Waste Management Facility and the Chemical Waste Landfill. 


\subsection{BASIS FOR CONCEPTUAL MODEL USED IN THE PE}

The bulk of the data and parameters that describe the potential for contaminant migration at SNL/NM's hypothetical disposal site near TA3 are available in documents published by the ER Program. For example, the Sitewide Hydrologic Characterization Project has published an annual report for the past three years (SNL, 1995a; SNL, 1994; SNL, 1993) that depicts SNL/NM's current state of knowledge and understanding about the processes controlling fluid flow and contaminant migration on a KAFB-scale. These reports list specific data and parameters that describe the local hydrogeology. In addition, SNL/NM's Groundwater Protection Program and the Environmental Monitoring Program publish annual reports (SNL, 1995b; Culp et al., 1994) that supplement the data gathered by the ER Program. All the data used in the PE were gathered from these references.

\subsubsection{Water Pathway}

Knowledge of groundwater flow and radionuclide movement in the water pathway at SNL/NM provided the basis for the conceptual model considered in the PE. The conceptual model encompasses the site technical staff's current understanding of site-specific geology, hydrology, water-table and aquifer characteristics, and transport pathways.

\subsubsection{Current Understanding of Relevant Hydrogeology}

Numerous investigations by the SNL/NM ER Program have generated site-specific hydrogeologic data. Because the Chemical Waste Landfill (CWL) is in the vicinity of the hypothetical MLLW disposal facility, the current understanding of radionuclide movement at the hypothetical MLLW disposal facility is described below according to the site-specific knowledge at the CWL.

Data from monitoring wells drilled at the CWL site show a geologic profile consisting of a heterogeneous mixture of material ranging from clay to large gravel. Most layers are not true stratigraphic divisions but appear to be lenticular in shape and of limited lateral extent (probably less than $15 \mathrm{~m}$ [50 ft]). Thicknesses of the layers may vary from as little as a few centimeters up to several meters (SNL, 1994).

There is virtually no surface water present at the CWL. A small arroyo several hundred meters to the north occasionally (during extreme rainfall events) carries small amounts of water from east to west across TA3. Otherwise, a small percentage of the precipitation infiltrates and the rest is lost to evapotranspiration (SNL, 1994). Hence, the only water-based exposure pathway of concern for SNL/NM is via groundwater.

Monitoring wells drilled at the CWL indicate the average depth to the water table is about $150 \mathrm{~m}$ (SNL, 1995b). The direction of flow in the saturated zone at the CWL is to the northnorthwest under a relatively flat hydraulic gradient (SNL, 1995b). The aquifer (and the vadose zone above it) exists in the Santa Fe Formation. There is no change in lithology or stratigraphy associated with the water table location. Because of the unconfined nature of the aquifer, any contaminants that reach the water table will disperse vertically into the aquifer to some depth. This vertical thickness (i.e., mixing depth) is unknown at the CWL. 


\subsubsection{Conceptual Model Used in the PE}

The PE used a generic conceptual model to describe the water pathway (summarized in Section 1.1.2 of this volume and described in detail in Chapter 5 of Volume 2). In the unsaturated zone, leachate was generated by constant flow through the disposal facility at a rate that was controlled by the assumed performance of the disposal facility. When all engineered barriers had failed, the rate was assumed to be equal to the natural recharge through local soils. The volumetric flow of water through the facility that generated leachate was based on the assumed performance and size of the disposal facility. No dilution was assumed to occur in the unsaturated zone, so at steady state, the concentration that reached groundwater equaled the leachate concentration. No lateral spreading was assumed, so the leachate flux through the unsaturated zone was confined to the soil column directly below the plan area of the facility.

As contaminated water entered the saturated zone, the contaminant mixed with clean groundwater, forming a plume with a shape controlled by aquifer and contaminant properties. The generic conceptual model assumed that instantaneous and complete mixing within the aquifer occurred directly below the facility. Mixing in the vertical direction occurred by hydrodynamic dispersion, and the contaminant mixing depth was an estimated value.

The generic conceptual model was adapted to conditions at SNL/NM based on sitespecific knowledge of the geology and water flow paths. At SNL/NM's hypothetical site in TA3, the conceptual model for fluid flow and potential radionuclide transport (Figure 9-4) is consistent with the generic PE conceptual model. Fluid flows vertically downward through the vadose zone and horizontally through the saturated zone. Evapotranspiration is high, natural recharge is minimal, only porous media flow exists, and the water table is deep.

In the vadose zone, flow is assumed to be one-dimensional under a unit hydraulic gradient with leachate moving vertically through the unsaturated alluvial sediments of the Santa $\mathrm{Fe}$ Formation to the regional aquifer. There is no evidence that natural perched zones exist in TA3 (SNL, 1994), and lateral spreading of the leachate is minimal. While the assumption of no lateral spreading is not actually the case in an arid environment with a heterogeneous vadose zone, it is a conservative assumption that will permit calculation of a minimum amount of radioactive decay and a minimum travel time to the water table. Retardation of contaminant velocities due to adsorption of radionuclides to soil particles is assumed to occur. The distance from the land surface to the water table at TA3 is approximately $150 \mathrm{~m}(492 \mathrm{ft})$.

The saturated portion of the Santa Fe Formation is characterized by a large, unconfined regional aquifer that is the drinking water source for the city of Albuquerque. Some volume of contaminated fluid is assumed to leach out of the vadose zone and become diluted as it mixes with clean aquifer water in the Santa Fe Formation. Complete and instantaneous mixing is assumed to occur throughout the mixing depth. The mixing depth is assumed to be equal to an estimated plume thickness at the $100-\mathrm{m}(328-\mathrm{ft})$ performance boundary. Calculations with the PAGAN code (Chu et al., 1991), which uses site-specific aquifer data (SNL, 1994) and literature values for dispersivity (EPRI, 1985), estimate a mixing depth of about $15 \mathrm{~m}$ (49 ft). As in the vadose zone, travel time through the saturated zone is determined for the purpose of computing radioactive decay. Again, adsorption of some radionuclides is assumed to be occurring along this travel path, causing retardation of radionuclide movement. 


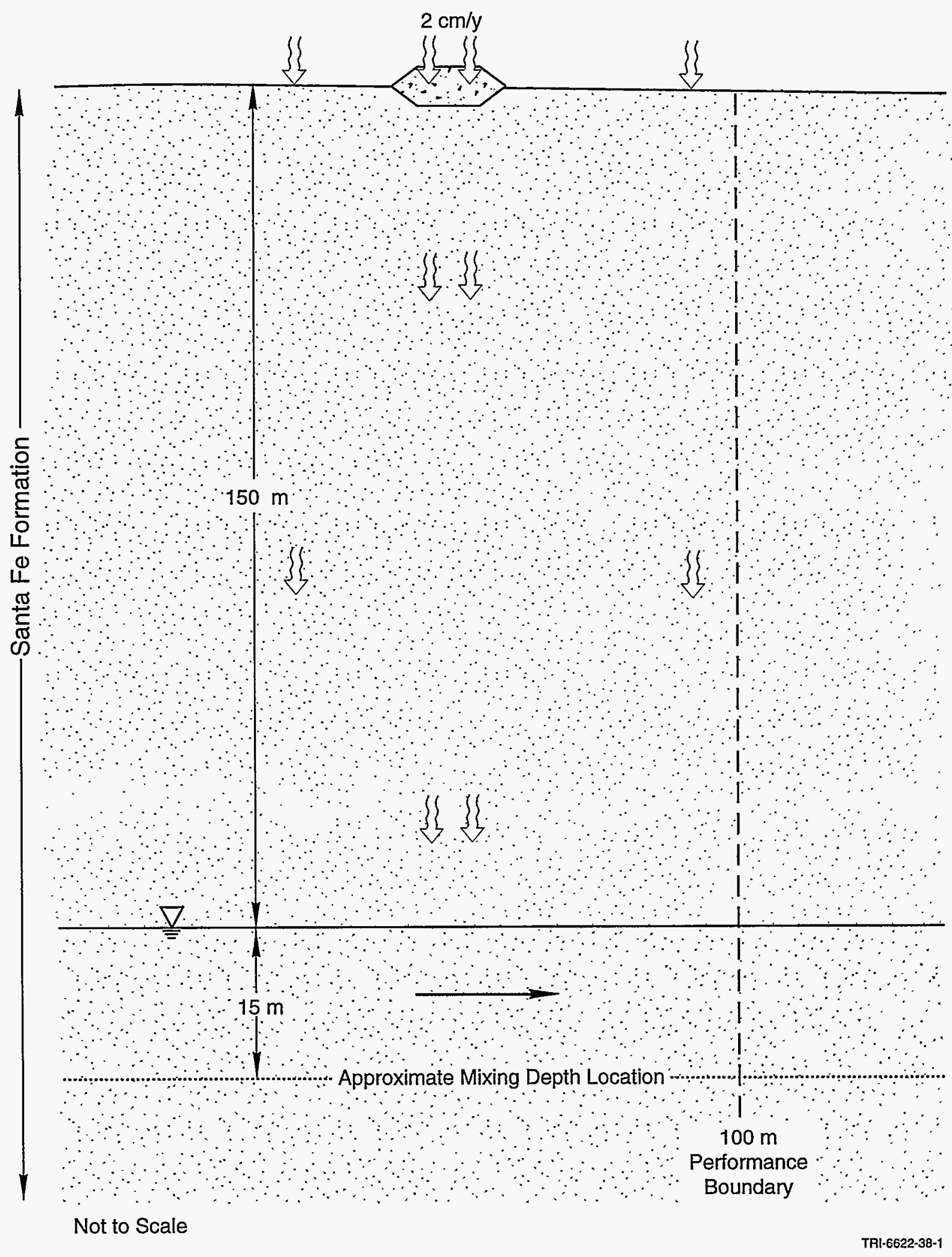

Figure 9-4. Conceptual model for water transport at SNL/NM. 


\subsubsection{Atmospheric Pathway}

The conceptual model used in the PE for evaluating the atmospheric pathway was derived from performance assessments for LLW disposal facilities at Hanford (Kincaid et al., 1993), INEL (Maheras et al., 1994), NTS (Baer et al., 1994), ORR (ORNL, 1994), and SRS (MMES et al., 1994). The model was generalized for the PE but used site-specific values for many of the parameters.

\subsubsection{Current Understanding of Relevant Meteorology}

The SNL/NM site provides yearly estimates of potential radiation doses from atmospheric exposures. The most recent report (Culp et al., 1994) presents estimates for calendar year 1993; the remainder of this section cites information from that report.

The SNL/NM site maintains air quality monitoring stations at seven locations across KAFB. The locations were selected on the basis of predominant wind direction, traffic patterns, potential for community exposure, potential for windblown dust, or combinations of these and other factors. However, those stations have only been operational since 1994. Meteorological data are based on STAR data files summarized by the windrose in Figure 9-5, which indicates that wind directions are variable but typically range from south-southwest to due east with rates that may be as high as $11 \mathrm{~m} / \mathrm{s}(22 \mathrm{mph})$. These data were obtained from hourly average meteorological readings taken at a height of $60 \mathrm{~m}(200 \mathrm{ft})$ at the Station A-36 meteorological tower at SNL/NM during 1994.

There are a few facilities at SNL/NM that routinely generate radioactive emissions. Calculations indicate that small quantities of $\mathrm{H}-3, \mathrm{~N}-13, \mathrm{O}-15, \mathrm{Ar}-41, \mathrm{Kr}-85$, and Xe-135 are released to the atmosphere at SNL/NM. However, the emissions are so small that they are undetectable with the monitoring equipment present at those facilities.

\subsubsection{Conceptual Model Used in the PE}

The PE used a generic conceptual model to describe the atmospheric pathway (summarized in Section 1.2 of this volume and described in detail in Chapter 5 of Volume 2). Only H-3 (tritium) and C-14 were expected to be volatile for the disposal facility conditions and thus were the only radionuclides considered for atmospheric transport in the PE. In the model, radionuclides were transported from the disposal facility to the soil surface by vapor (tritium) and gaseous (carbon dioxide carrying the $\mathrm{C}-14$ isotope) diffusion. When the radionuclides reached the soil surface, they were entrained in the air in vapor form as volatiles. Once airborne, these radionuclides were transported via atmospheric dispersion to a receptor located at the performance boundary.

Two components of the atmospheric pathway were evaluated separately: (1) the zone from the top of the disposal facility to the soil surface as indicated by the upward radionuclide diffusion profile; and (2) the zone in which a radionuclide was emitted to the atmosphere, mixed with the ambient air, and dispersed downwind from the waste disposal facility boundary to the $100-\mathrm{m}(328-\mathrm{ft})$ performance boundary. 


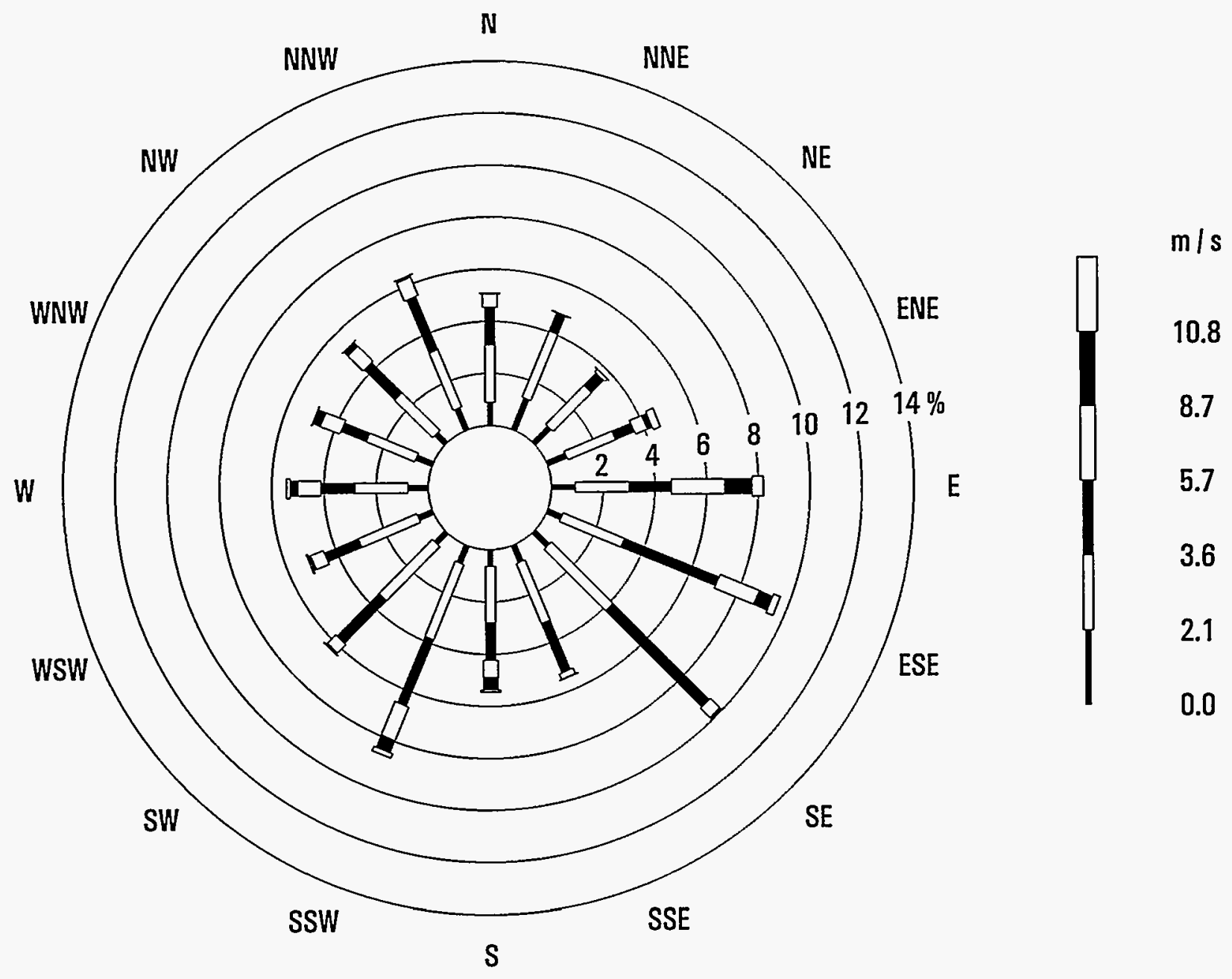

Figure 9-5. Windrose for SNL/NM for the period 1994. The frequency of winds from each direction is plotted as a series of connected bars that extend from the center of the circular diagram toward the direction from which the winds originate. Wind speed categories are denoted by bar widths and shadings. The frequency of winds in each wind speed category is indicated by the length of the corresponding bar. 
The arrival time of radionuclides at the performance boundary was assumed to be $100 \mathrm{y}$ based on the following generic assumptions of the PE:

- The waste form was grouted MLLW treatment residuals. Based on this assumption, tritium as vapor was bound in the pore water of the hydrophilic grout, and carbon dioxide as a gas carrying the $\mathrm{C}-14$ isotope was limited by the high $\mathrm{pH}$ of the grout, so that the waste form provided retention of these volatile radionuclides in the disposal facility.

- The disposal facility was capped by a RCRA-compliant cover system. Based on this assumption, the cover system was maintained to provide low permeability for $100 \mathrm{y}$.

\subsubsection{Inadvertent Intruder Pathways}

Standard intrusion scenarios were used in the PE, with information derived from performance assessments of LLW disposal facilities at SRS (MMES et al., 1994) and ORR (ORNL, 1994) indicating that only two chronic-exposure scenarios needed to be considered for most sites and facility designs. Any variations in these scenarios were based on discussions with site personnel about such factors as the types of activities that reasonably could result in exposure to buried waste at the site and the effectiveness of active or passive institutional controls and engineered barriers in precluding access to the waste.

\subsubsection{Current Understanding of Potential Modes of Inadvertent Intrusion}

There are no ongoing performance assessments for LLW disposal taking place for SNL/NM sites. Therefore, specific intruder scenarios were not developed. The city of Albuquerque is currently limited in size by the Sandia Pueblo on the north, National Forest land on the east, and KAFB on the south. If KAFB were to close in the future, southward growth of the city would be logical both in terms of more space and the availability of additional groundwater resources.

\subsubsection{Intruder Scenarios Used in the PE}

The PE used two standard intrusion scenarios that could be modified for site-specific conditions to describe potential modes of inadvertent intrusion (summarized in Section 1.3 of this volume and described in detail in Chapter 5 of Volume 2). The first scenario, the agriculture (homesteader) scenario, included establishment by an intruder of a permanent homestead directly above a disposal facility with the foundation of the home extending into the waste; some of the waste exhumed from the disposal facility was mixed with native soil in the intruder's vegetable garden. The second scenario, the post-drilling scenario, considered the construction of a well for a domestic water supply by an intruder. The well was drilled through the disposal facility, and the cuttings were mixed with soil in the intruder's vegetable garden. The intruder gardened in some of the exhumed waste but did not reside permanently above the disposal facility. In both scenarios, exposure occurred where an intruder dug or drilled into the disposal facility. These are plausible exposure scenarios for SNL/NM. 
For the generic intruder scenarios, the time of intrusion for the homesteader scenario was assumed to be $300 \mathrm{y}$ for the trench design and $500 \mathrm{y}$ for the tumulus design. The time of intrusion for the post-drilling scenario was assumed to be $100 \mathrm{y}$.

\subsection{DATA USED IN THE PE}

The data presented in this section apply to the PE conceptual models described in Section 9.3. The calculations for determining permissible waste concentrations for the radionuclides considered in the PE are discussed in more detail in Chapter 5 of Volume 2 and summarized in Chapter 1 of this volume. The results of the calculations for SNL/NM are presented in Section 9.5 and discussed in Section 9.6 of this volume.

\subsubsection{Water Transport}

Site-specific values required to perform the water pathway analysis were selected by site technical staff either from site characterizations and reports, from site-specific modeling results, or from general literature. For the unsaturated zone, the site-specific data that were required for the PE were distance between the disposal facility and groundwater; ambient moisture content; dry bulk density of the geologic medium; and distribution coefficients $\left(K_{d} \mathrm{~S}\right)$ of the radionuclides in the geologic medium; and natural recharge. For the saturated zone, the site-specific data that were required were porosity; dry bulk density of the geologic medium; and distribution coefficients $\left(K_{d} \mathrm{~s}\right.$ of the radionuclides in the geologic medium; groundwater Darcy flow rates; and mixing depth in the aquifer.

These values for SNL/NM are listed in Table 9-1 along with generic values that were used in the PE. Also indicated in the table is a designation of the type of data that the value represents and the source of the value. The values were determined from one or more of four data sources: (A) measurement performed by the site, state, or federal agency; (B) result of a numerical analysis performed by the site, state, or federal agency; (C) general literature value selected by the site; and (D) generic value of the PE.

Of the parameters in the PE that depended on site-specific values, only three potentially encompassed enough variability in values to significantly affect the results: natural recharge, $i$; distribution coefficients $\left(K_{d} \mathrm{~s}\right)$ for the geologic media; and groundwater Darcy velocity $\left(q_{g w}\right)$. The sources of these values are discussed in this section. The sensitivity of the results to changes in the values of these parameters is discussed in Section 9.6.2 of this volume and Chapter 6 of Volume 2.

The actual average recharge at this site is not known; therefore, the recharge was estimated with professional judgement based on the site-specific literature. Literature values reported for recharge on KAFB indicate that it varies from 0.05 to $5.0 \mathrm{~cm} / \mathrm{y}(0.02$ to $1.9 \mathrm{in} . / \mathrm{y})$ (SNL, 1994). Furthermore, average recharge is estimated to be approximately $10 \%$ of the annual precipitation of $23 \mathrm{~cm} / \mathrm{y}(9 \mathrm{in} . / \mathrm{y})$ or $2 \mathrm{~cm} / \mathrm{y}$ (SNL, 1994). Based on these data, an average recharge of $2 \mathrm{~cm} / \mathrm{y}(0.8 \mathrm{in} . / \mathrm{y})$ was used in the PE. 
Table 9-1. Parameters and Values Used in the PE for the Water Pathway at SNL/NM (generic PE values are in bold; these values and the standard PE method for applying them are summarized in Chapter 1 of this volume and discussed in more detail in Chapter 5 of Volume 2) (Part 1 of 2)

\begin{tabular}{|c|c|c|c|}
\hline Parameter & Value & $\begin{array}{l}\text { Data } \\
\text { Type }\end{array}$ & Comments \\
\hline \multicolumn{4}{|l|}{ SOURCE TERM } \\
\hline $\begin{array}{l}\text { Volumetric water content of } \\
\text { the grouted waste, } \theta_{0}\end{array}$ & 0.3 & D & Standard PE value \\
\hline $\begin{array}{l}\text { Bulk density of grouted } \\
\text { waste, } \rho_{0}\end{array}$ & $1.76 \mathrm{~g} / \mathrm{ml}$ & D & Standard PE value \\
\hline $\begin{array}{l}\text { Distribution coefficients for } \\
\text { grouted waste, } K_{d}^{G}\end{array}$ & various & D & $\begin{array}{l}\text { Standard PE value; } \\
\text { see Table } 9-2 \text { in this chapter }\end{array}$ \\
\hline Disposal facility plan area, $A$ & $2500 \mathrm{~m}^{2}$ & $\bar{D}$ & $\begin{array}{l}\text { Standard } P E \text { value; } A=a_{1} * a_{2} \text {, } \\
\text { where } a_{1}=a_{2}=50 \mathrm{~m}\end{array}$ \\
\hline $\begin{array}{l}\text { Waste mixing fraction for } \\
\text { trench, } f_{m}\end{array}$ & 0.67 & D & Standard PE value \\
\hline $\begin{array}{l}\text { Waste mixing fraction for } \\
\text { tumulus, } f_{m}\end{array}$ & 0.33 & D & Standard PE value \\
\hline $\begin{array}{l}\text { Annual rate of water flowing } \\
\text { through intact trench facility, } q_{f}\end{array}$ & $0.02 \mathrm{~m} / \mathrm{y}$ & B & $\begin{array}{l}\text { Standard PE value is } 0.03 \mathrm{~m} / \mathrm{y} \text {. } \\
\text { Natural recharge is lower for this } \\
\text { site. }\end{array}$ \\
\hline $\begin{array}{l}\text { Annual rate of water flowing } \\
\text { through intact tumulus } \\
\text { facility, } q_{f}\end{array}$ & $0.00003 \mathrm{~m} / \mathrm{y}$ & D & Standard PE value \\
\hline $\begin{array}{l}\text { Time to failure of leachate } \\
\text { collection and linear systems }\end{array}$ & $30 \mathrm{y}$ & D & Standard PE value \\
\hline \begin{tabular}{|l|}
$\begin{array}{l}\text { Time to failure of trench } \\
\text { facility }\end{array}$ \\
\end{tabular} & $100 y$ & $\mathbf{D}$ & Standard PE value \\
\hline $\begin{array}{l}\text { Time to failure of tumulus } \\
\text { facility }\end{array}$ & $300 y$ & D & Standard PE value \\
\hline $\begin{array}{l}\text { Natural recharge through local } \\
\text { soils, } i\end{array}$ & $0.02 \mathrm{~m} / \mathrm{y}$ & B & $\begin{array}{l}\text { SNL, 1994, p. } 5-115 \text {. Within the } \\
\text { reported range of } 0.05-5 \mathrm{~cm} / \mathrm{y} \text {, the } \\
\text { selected value is } 10 \% \text { of the average } \\
\text { precipitation rate. }\end{array}$ \\
\hline
\end{tabular}

* $A=$ site measurement; $B=$ result of site numerical analysis; $C=$ literature value selected by the site; $D=g e n e r i c ~ P E$ value 
Table 9-1. Parameters and Values Used in the PE for the Water Pathway at SNL/NM (generic PE values are in bold; these values and the standard PE method for applying them are summarized in Chapter 1 of this volume and discussed in more detail in Chapter 5 of Volume 2) (Part 2 of 2)

\begin{tabular}{|c|c|c|c|}
\hline Parameter & Value & $\begin{array}{l}\text { Data } \\
\text { Type }\end{array}$ & Comments \\
\hline \multicolumn{4}{|l|}{ VADOSE ZONE } \\
\hline Moisture content, $\theta_{w}$ & 0.07 & A & SNL, 1994, p. 4-25. \\
\hline Bulk density, $\rho_{b}$ & $1.8 \mathrm{~g} / \mathrm{cm}^{3}$ & A & $\begin{array}{l}\text { SNL, 1994, p. 4-25; personal } \\
\text { communication with Warren Strong } \\
\text { (INTERA), 3/95. }\end{array}$ \\
\hline $\begin{array}{l}\text { Distribution coefficients for } \\
\text { geologic media, } K_{d}\end{array}$ & Various & C & See Table 9-2 in this chapter. \\
\hline $\begin{array}{l}\text { Thickness between trench and } \\
\text { saturated zone, } l\end{array}$ & $141.2 \mathrm{~m}$ & D & Generic trench is 8.8 meters deep. \\
\hline $\begin{array}{l}\text { Thickness between tumulus and } \\
\text { saturated zone, } l\end{array}$ & $150 \mathrm{~m}$ & A & $\begin{array}{l}\text { SNL, 1995a, Appendix A. Average depth } \\
\text { to water at the Chemical Waste Landfill in } \\
\text { the southeast corner of TA-IIl. }\end{array}$ \\
\hline \multicolumn{4}{|l|}{ SATURATED ZONE } \\
\hline Porosity, $n$ & 0.30 & A & SNL, 1994, p. 4-25. \\
\hline Bulk density, $\rho_{b}$ & $1.8 \mathrm{~g} / \mathrm{cm}^{3}$ & A & SNL, 1994, p. 4-25. \\
\hline $\begin{array}{l}\text { Distribution coefficients for } \\
\text { geologic media, } K_{d}\end{array}$ & Various & C & See Table 9-2 in this chapter. \\
\hline Mixing depth, $d_{m}$ & $15 \mathrm{~m}$ & B & $\begin{array}{l}\text { Based on amount of vertical dispersion } \\
\text { estimated at the performance boundary at } \\
10,000 \text { y according to aquifer properties. }\end{array}$ \\
\hline Horizontal hydraulic gradient & 0.004 & A & $\begin{array}{l}\text { SNL, 1995a, Appendix A. Derived from } \\
\text { water levels in monitoring wells at the } \\
\text { Chemical Waste Landfill in the southeast } \\
\text { corner of TA-III. }\end{array}$ \\
\hline Saturated hydraulic conductivity & $126 \mathrm{~m} / \mathrm{y}$ & A & SNL, 1994, p. 4-25. \\
\hline Darcy velocity, $q_{g w}$ & $0.5 \mathrm{~m} / \mathrm{y}$ & A & $\begin{array}{l}\text { Product of hydraulic conductivity and } \\
\text { hydraulic gradient }\end{array}$ \\
\hline $\begin{array}{l}\text { Distance to performance } \\
\text { boundary from edge of } \\
\text { facility boundary }\end{array}$ & $100 \mathrm{~m}$ & $\mathbf{D}$ & Standard PE value. \\
\hline
\end{tabular}

- $A=s i t e$ measurement; $B=$ result of site numerical analysis; $C=$ literature value selected by the site; $D=g e n e r i c ~ P E$ value 
Table 9-2. Solid/Liquid Distribution Coefficients $\left(K_{d} \varsigma\right)$ Used in the PE at SNL/NM

\begin{tabular}{|c|c|c|}
\hline Element & $\begin{array}{c}\text { Waste } K_{d}^{G} \\
(\mathrm{~mL} / \mathrm{g})^{a}\end{array}$ & $\begin{array}{l}K_{d} \text { for Geologic Media } \\
(\mathrm{mL} / \mathrm{g})^{\mathrm{b}}\end{array}$ \\
\hline$\underline{H}$ & 0 & 0.1 \\
\hline c & 10 & 5 \\
\hline $\mathrm{Al}$ & 100 & $35^{\mathrm{c}}$ \\
\hline Si & 100 & 35 \\
\hline $\mathrm{Cl}$ & 0 & $15^{\mathrm{d}}$ \\
\hline$K$ & 1 & 15 \\
\hline Co & 100 & 60 \\
\hline $\mathrm{Ni}$ & 10 & 400 \\
\hline Se & 1 & 150 \\
\hline $\mathrm{Sr}$ & 100 & 15 \\
\hline $\mathrm{Zr}$ & 10 & 600 \\
\hline $\mathrm{Nb}$ & 10 & 160 \\
\hline TC & 1 & 0.1 \\
\hline$P d$ & 100 & 55 \\
\hline $\mathrm{Ag}$ & 100 & 90 \\
\hline $\mathrm{Cd}$ & 100 & 80 \\
\hline sn & 10 & 130 \\
\hline 1 & 1 & 1 \\
\hline Cs & 10 & 280 \\
\hline $\mathrm{Ba}$ & 10 & $15^{e}$ \\
\hline $\mathrm{sm}$ & 10 & 245 \\
\hline Eu & 10 & $245^{t}$ \\
\hline $\mathrm{Pb}$ & 100 & 270 \\
\hline $\mathbf{R a}$ & 10 & 500 \\
\hline$T h$ & 100 & 3200 \\
\hline $\mathrm{Pa}$ & 100 & 550 \\
\hline$\underline{U}$ & 100 & 35 \\
\hline $\mathrm{Np}$ & 100 & 5 \\
\hline $\mathrm{Pu}$ & 100 & 550 \\
\hline $\mathrm{Am}$ & 100 & 1900 \\
\hline $\mathrm{Cm}$ & 100 & 4000 \\
\hline Cf & 100 & $4000^{\circ}$ \\
\hline
\end{tabular}

Standard PE values; see Chapter 5 of Volume 2

Values for sand from Thibault et al., 1990

Based on similarity to $\mathrm{Si}$

Based on similarity to $\mathrm{Br}$

Based on similarity to $\mathrm{Sr}$

Based on similarity to $\mathrm{Sm}$

Based on similarity to $\mathrm{Cm}$ 
The mixing depth in the aquifer was estimated to be about $15 \mathrm{~m}(49 \mathrm{ft})$. This value was calculated with the PAGAN code (Chu et al., 1991) and longitudinal and transverse dispersivities of $2 \mathrm{~m}$ and $0.2 \mathrm{~m}$ ( $7 \mathrm{ft}$ and $0.7 \mathrm{ft}$ ), respectively (EPRI, 1985), and the aquifer porosity and Darcy velocity (see Table 9-1).

The Darcy velocity in the aquifer was calculated from the hydraulic conductivity and the hydraulic gradient. SNL (1994) reports saturated hydraulic conductivities for the KAFB area ranging from about $1 \mathrm{~m} / \mathrm{y}$ to $3 \times 10^{6} \mathrm{~m} / \mathrm{y}\left(3 \mathrm{ft} / \mathrm{y}\right.$ to $\left.1 \times 10^{7} \mathrm{ft} / \mathrm{y}\right)$ with an average of about $126 \mathrm{~m} / \mathrm{y}$ $(400 \mathrm{ft} / \mathrm{y})$. These data were derived from 113 core and sieve samples collected at various sites across KAFB. Water levels in monitoring wells at the CWL in TA3 (SNL, 1995b) indicate an average gradient of about 0.004 . The Darcy velocity was computed as the product of the conductivity and the gradient, or about $0.5 \mathrm{~m} / \mathrm{y}(1.6 \mathrm{ft} / \mathrm{y})$. Given the reported range in saturated hydraulic conductivity and assuming a gradient of 0.004 , the Darcy velocity ranges from $0.004 \mathrm{~m} / \mathrm{y}$ to $12,000 \mathrm{~m} / \mathrm{y}(0.013 \mathrm{ft} / \mathrm{y}$ to $39,000 \mathrm{ft} / \mathrm{y})$.

Values for distribution coefficients $\left(K_{d} \mathrm{~S}\right)$ are listed in Table 9-2 for the 58 radionuclides (32 elements) considered in the PE. In addition to the $K_{d}$ values for the geologic media, grout $K_{d}$ values are listed for determining the desorption from the source term resulting from the grouted waste form. Site-specific $K_{d}$ values have not been measured at SNL/NM. Therefore, literature values for sand (Thibault et al., 1990) were used in the SNL/NM PE. Values were not available in the general literature for several elements (aluminum, chlorine, barium, europium, and californium). Values for these elements were selected based on their similarity to other elements, as shown in the footnotes to Table 9-2.

\subsubsection{Atmospheric Transport}

Site-specific data required to perform the atmospheric pathway analysis came from site personnel as data either from site characterizations and reports or from general literature. The site-specific data required for the soil diffusion calculation were the same as some of those required for the water transport analysis (Section 9.4.1). These values are shown in Table 9-3. Necessary atmospheric dispersion data included wind speed and direction and stability class, which are summarized in Section 9.3.2.1.

\subsubsection{Inadvertent Intruder Exposure}

As explained in Section 9.3.3, the PE used two standard intrusion scenarios to describe potential modes of inadvertent intrusion at all the sites. Because these intrusion scenarios were considered applicable to all sites, no values specific to SNL/NM are used in the calculation of exposures to inadvertent intruders.

\subsection{RESULTS OF THE PE}

The performance evaluation provided estimates of permissible concentrations in disposed MLLW. The three calculations that formed the foundation of the PE-for the water, atmospheric, and inadvertent intruder pathways-are summarized in Sections 1.1, 1.2, and 1.3, respectively, of this volume and discussed in detail in Chapter 5 of Volume 2. 
Table 9-3. Parameters and Values Used in the PE for the Atmospheric Pathway at SNL/NM (generic PE values are in bold; these values and the standard PE method for applying them are summarized in Chapter 1 of this volume and discussed in more detail in Chapter 5 of Volume 2)

\begin{tabular}{|c|c|c|c|}
\hline Parameter & Value & $\begin{array}{l}\text { Data } \\
\text { Type }\end{array}$ & Comments \\
\hline $\begin{array}{l}\text { Disposal facility cover } \\
\text { thickness, } x\end{array}$ & $1.0 \mathrm{~m}$ & D & Standard PE value \\
\hline Depth of the soil surface, $d$ & $0.01 \mathrm{~m}$ & $\mathbf{D}$ & $\begin{array}{l}\text { Standard PE value based on } \\
\text { Maheras et al., } 1994\end{array}$ \\
\hline Porosity, $n$ & 0.30 & A & SNL, 1994, p.4-25. \\
\hline Percent saturation, $s$ & 0.23 & A & $\begin{array}{l}\text { SNL, 1994, p. } 4-25 \text { (volumetric water } \\
\text { content of } 0.07 \text { corresponds to this } \\
\text { saturation value). }\end{array}$ \\
\hline $\begin{array}{l}\text { Ratio of water density in air } \\
\text { to liquid, } r\end{array}$ & $9.2 E-06$ & $\mathbf{D}$ & $\begin{array}{l}\text { Standard PE value based on } \\
\text { MMES et al., } 1994\end{array}$ \\
\hline $\begin{array}{l}\text { Ratio of } \mathrm{CO}_{2} \text { concentration } \\
\text { in air to dissolved in water, } r\end{array}$ & 4.3E-04 & D & $\begin{array}{l}\text { Standard PE value based on } \\
\text { Foust et al. (as cited in Cooper } \\
\text { and Alley, 1986) }\end{array}$ \\
\hline $\begin{array}{l}\text { Tritium diffusion coefficient } \\
\text { in air, } D\end{array}$ & $\begin{array}{l}2.39 E-05 \\
\mathrm{~m}^{2} / \mathrm{s}\end{array}$ & D & $\begin{array}{l}\text { Standard PE value based on } \\
\text { CRC (1981) }\end{array}$ \\
\hline $\begin{array}{l}\text { Carbon diffusion coefficient } \\
\text { in air, } D\end{array}$ & $\begin{array}{c}1.4 E+05 \\
\mathrm{~m}^{2} / \mathrm{s}\end{array}$ & D & $\begin{array}{l}\text { Standard PE value based on } \\
\text { CRC (1981) }\end{array}$ \\
\hline Atmospheric dispersion term, $A_{D}$ & $\begin{array}{c}0.35 \\
\left(\mu \mathrm{Ci} / \mathrm{m}^{3}\right) /\left(\mu \mathrm{Ci} / \mathrm{m}^{2}\right. \\
s)\end{array}$ & B & $\begin{array}{l}\text { Value is estimated using the Industrial } \\
\text { Source Complex-Version } 2 \text { Long Term } \\
\text { Air Dispersion Model (ISCLT2) (EPA, } \\
\text { 1992) based on site-specific STAR } \\
\text { data. }\end{array}$ \\
\hline
\end{tabular}

- $A=$ site measurement; $B=$ result of site numerical analysis; $C=$ literature value selected by site; $D=$ generic $P E$ value

For each pathway the maximum permissible waste concentration at the performance boundary was determined for each radionuclide by using the performance measures: 4 mrem $(0.04 \mathrm{mSv})$ per year from the water pathway for releases to drinking water; 10 mrem $(0.1 \mathrm{mSv})$ per year from all pathways for atmospheric releases; and 100 mrem ( $1 \mathrm{mSv}$ ) per year from all exposure pathways for chronic exposure of inadvertent intruders; and the appropriate pathway or scenario dose conversion factors (annual effective dose equivalent per unit concentration) based on EPA dose conversion factors. The basis for the performance measures used in the PE is discussed in more detail in Chapter 5 of Volume 2. For the water and atmospheric pathways, the concentration reduction provided by the environment (i.e., the CRF) was estimated using results of site analyses and data. For the intruder analyses, concentration reduction was estimated for appropriate exposure pathways for two intrusion scenarios that, in general, were the same for all the sites. The results of the calculations for the pathways that were analyzed at SNL/NM are provided in this section and discussed in Section 9.6. 


\subsubsection{Water Transport}

Two CRFs were calculated for the water pathway: the source CRF, $C R F_{\text {Source, }}$ and the environmental transport $\mathrm{CRF}$ for water, $C R F_{\text {Water. }}$ The source $\mathrm{CRF}$ represents the concentration attenuation between the disposed waste and leachate exiting the bottom of the disposal facility and was defined as the dimensionless ratio of the waste concentration to the resulting leachate concentration. Desorption with infiltrating water was the mechanism used to describe the leaching of radionuclides from the grout. Because a generic method was used to determine the $C R F_{\text {Source }}$ for the 58 radionuclides considered in the PE (summarized in Section 1.1 of this volume and discussed in more detail in Chapter 5 of Volume 2), the radionuclide-specific values for the source CRF for each type of generic facility were the same for all 15 sites.

The environmental transport CRF for water was defined as the ratio of the concentration of the leachate exiting the disposal facility to the resulting concentration in water at the performance boundary. The concentration attenuation represented by $C R F_{\text {Water }}$ consisted of dilution due to mixing with uncontaminated groundwater. Effects of radioactive decay and decay product ingrowth were also included in the PE.

In the PE, water travel time from the facility location to the performance boundary was calculated as a basis for comparison with the retarded travel time of the radionuclides. For SNL/NM, water travel time from the land surface to the performance boundary (i.e., without consideration of a disposal facility) was estimated at about $585 \mathrm{y}$.

The calculation of travel time through the vadose zone for a radionuclide, on the other hand, must account both for the lower rate of flow because of the facility's RCRA cover and for the retardation defined by the distribution coefficient for the geologic media. In the PE, the calculation for travel time in the vadose zone first determined the distance a radionuclide traveled at the lower infiltration rate. Then, if the radionuclide had not fully traversed the vadose zone, the additional time required to complete travel in the vadose zone under the higher infiltration rate based on the natural recharge through local soils was calculated and added to the time determined at the lower infiltration rate.

At SNL/NM, this procedure was used for calculations of travel time through the vadose zone for a tumulus facility because the assumed rate of water flowing through the concrete vaults was less than the natural recharge. However, for a trench at SNL/NM, the natural recharge was less than the assumed rate of water flowing through a RCRA cover; calculations through the vadose zone for a trench facility were based entirely on the natural recharge.

In the PE, the detention time in the facility for a radionuclide was the time during which water flowing through the facility was assumed to be caught by the leachate collection system. Specifically, the calculation of travel time for a radionuclide accounted for the following:

- For the trench design, the leachate collection system was assumed to catch water flowing through the facility for the first $30 \mathrm{y}$. After $30 \mathrm{y}$, the liner and leachate collection system failed, and the rate of water flowing through the facility for the next $70 \mathrm{y}$ was assumed to be $0.02 \mathrm{~m} / \mathrm{y}(0.067 \mathrm{ft} / \mathrm{y})$, which was the lesser of the natural recharge for local soils and 
the rate based on a unit hydraulic gradient and the saturated hydraulic conductivity of the RCRA cover system $(0.03 \mathrm{~m} / \mathrm{y}[0.1 \mathrm{ft} / \mathrm{y}])$.

- For the tumulus design, the leachate collection system was assumed to catch water flowing through the facility for the first $30 \mathrm{y}$. After $30 \mathrm{y}$, the liner and leachate collection system was assumed to fail, and water flowing through the facility for the next $270 \mathrm{y}$ was assumed to be $0.00003 \mathrm{~m} / \mathrm{y}(0.0001 \mathrm{ft} / \mathrm{y})$ based on a unit hydraulic gradient and the saturated hydraulic conductivity of the concrete vaults. After a total of $300 \mathrm{y}$ of reduced flow because of engineered barriers ( $30 \mathrm{y}$ detention plus $270 \mathrm{y}$ limited by the concrete vaults), the rate was assumed to be the average recharge through local soils, $0.02 \mathrm{~m} / \mathrm{y}$ $(0.07 \mathrm{ft} / \mathrm{y})$.

Travel time through the aquifer was independent of facility design and was about $60 \mathrm{y}$, based on groundwater Darcy velocity and a 100-m (328-ft) distance to the performance boundary (see Section 1.1.2 of this volume for a summary of these assumptions and Chapter 5 of Volume 2 for additional details.

Retardation of radionuclides by interaction with soils and rock in the vadose and saturated zones increased travel times for individual radionuclides. This effect was particularly important for short-lived radionuclides because of radioactive decay. For short-lived radionuclides, the effects of radioactive decay combined with long travel times increased the permissible concentrations in the disposal facility.

Application of the PE methodology for water transport of the 58 radionuclides considered in the PE produced the results shown in Table 9-4 for the generic trench and tumulus designs at SNL/NM. The table shows permissible waste concentrations based on transport through the water pathway $\left(C_{W-\text { Water }}\right)$ as well as the values used in calculating the permissible waste concentrations.

Some radionuclides listed in Table 9-4 have no limit (NL) on their permissible waste concentrations, the result of the combined effects of relatively short half-lives and sufficiently long travel time to the performance boundary. "No limit" is defined as a permissible waste concentration that is greater than the specific activity of the pure elemental radionuclide. For disposal of the maximum possible waste concentration of these relatively short-lived radionuclides, the water pathway produced a dose at the performance boundary of less than $4 \mathrm{mrem}(0.04 \mathrm{mS})$ per year and, therefore, the permissible waste concentration was unlimited based on exposures from this pathway.

For some radionuclides, no value is listed in Table 9-4 for the radioactive decay term, $r_{\text {Decay. }}$. These radionuclides had radioactive decay terms that were very large (e.g., greater than $\left.1 \times 10^{50}\right)$. Any radionuclide with a radioactive decay term greater than $1 \times 10^{50}$ ensured a calculated permissible waste concentration greater than the specific activity of the pure elemental radionuclide, which, as described previously, resulted in no limit (NL) on permissible waste concentrations for disposal. 
Table 9-4. Results of Calculations for the Water Pathway at SNL/NM (water travel time from land surface to performance boundary [excluding facility detention] $=585 \mathrm{y})($ Part 1 of 2$)$

\begin{tabular}{|c|c|c|c|c|c|c|c|c|c|c|c|c|}
\hline \multirow[t]{2}{*}{ Nuclide } & \multirow[b]{2}{*}{$\begin{array}{c}\text { PDCF } \\
\text { rem/y per } \mu \mathrm{Cu} / \mathrm{L}\end{array}$} & \multicolumn{5}{|c|}{ Trench } & \multicolumn{5}{|c|}{ Tumulus } & \multirow[t]{2}{*}{ Nuclide } \\
\hline & & \begin{tabular}{|l|} 
CRF source \\
(dimensionless)
\end{tabular} & \begin{tabular}{c|} 
CRF Water \\
(dimensionloss)
\end{tabular} & $\begin{array}{l}\text { Arrival } \\
\text { Time (y) } \\
\end{array}$ & \begin{tabular}{|c|}
$\begin{array}{c}r_{\text {Decayy }}^{2} \\
\text { (dimensionless) }\end{array}$ \\
\end{tabular} & 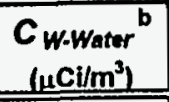 & \begin{tabular}{|l|} 
CRF Source \\
(dimensionloss) \\
\end{tabular} & \begin{tabular}{|c|} 
CRF Water \\
(dimensionless)
\end{tabular} & \begin{tabular}{|c|} 
Arrival \\
Time (y)
\end{tabular} & \begin{tabular}{|c|}
$\begin{array}{c}r_{\text {Decay }} \\
\text { (dimensionless) }\end{array}$ \\
\end{tabular} & $\begin{array}{c}C_{\text {w.W.Water }}{ }^{b} \\
\left(\mu \mathrm{Ci} / \mathrm{m}^{3}\right) \\
\end{array}$ & \\
\hline $\mathrm{H}-3$ & 4.67E-02 & 0.45 & 8.5 & $1.9 E+03$ & $1.5 E+46$ & $N L$ & 0.9 & 8.5 & $2.3 E+03$ & e & $\mathrm{NL}$ & $\mathrm{H}-3$ \\
\hline C-14 & $1.52 \mathrm{E}+00$ & 27 & 8.5 & $6.6 \mathrm{E}+04$ & $2.9 E+03$ & $2 E+06^{c}$ & 54 & 8.5 & $7.0 E+04$ & $4.9 E+03$ & $6 E+06$ & $C-14$ \\
\hline$A \mid-26$ & $1.06 E+01$ & 270 & 8.5 & $4.6 \mathrm{E}+05$ & $1.5 E+\infty$ & $1 E+03^{\circ}$ & 540 & 8.5 & $4.9 E+05$ & $1.6 E+00$ & $3 E+03$ & Al-26 \\
\hline Si-32 & $7.99 E+00$ & 270 & 8.5 & $4.6 E+05$ & e & $\mathrm{NL} \quad \mathrm{c}$ & 540 & 8.5 & $4.9 E+05$ & $e$ & $\mathrm{NL}$ & Si-32 \\
\hline Cl-36 & $2.21 \mathrm{E}+00$ & 0.45 & 8.5 & $2.0 E+05$ & $1.6 E+\infty 0$ & $1 E+01^{\circ}$ & 0.9 & 8.5 & $2.1 E+05$ & $1.6 E+00$ & $2 E+01 \quad c$ & $\mathrm{Cl}-36$ \\
\hline$K-40$ & $1.36 \mathrm{E}+01$ & 3.1 & 8.5 & $2.0 \mathrm{E}+05$ & $1.0 E+\infty$ & $8 E+00^{c}$ & 6.2 & 8.5 & $2.1 E+05$ & $1.0 E+\infty 0$ & $2 E+01 \quad c$ & $K-40$ \\
\hline$C 0-60$ & $1.97 \mathrm{E}+01$ & 270 & 8.5 & $7.8 E+05$ & e & $\mathrm{NL}$ & 540 & 8.5 & $8.3 E+05$ & e & $\mathrm{NL}$ & Co-60 \\
\hline Ni-59 & 1.53E-01 & 27 & 8.5 & $5.2 \mathrm{E}+06$ & $5.1 E+20$ & $\mathrm{NL}$ & 54 & 8.5 & $5.5 E+06$ & $9.2 E+21$ & NL & Ni-59 \\
\hline Ni-63 & 4.21E-01 & 27 & 8.5 & $5.2 E+06$ & e & $\mathrm{NL}$ & 54 & 8.5 & $5.5 E+06$ & e & $\mathrm{NL}$ & $\mathrm{Ni}-63$ \\
\hline Se-79 & $6.35 E+\infty$ & 3.1 & 8.5 & $2.0 E+06$ & $1.2 E+09$ & $2 E+10^{c}$ & 6.2 & 8.5 & $2.1 E+06$ & $4.3 E+09$ & $1 E+11^{\circ}$ & Se-79 \\
\hline Sr-90 & $1.12 E+02$ & 270 & 8.5 & $2.0 \mathrm{E}+05$ & e & $\mathrm{NL} \quad \mathrm{c}$ & 540 & 8.5 & $2.1 E+05$ & $e$ & $\mathrm{NL}$ & Sr-90 \\
\hline $\mathrm{Zr}-93$ & $1.59 \mathrm{E}+\infty$ & 27 & 8.5 & $7.8 E+06$ & $3.7 E+01$ & $2 E+04^{\circ}$ & 54 & 8.5 & $8.3 E+06$ & $4.7 E+01$ & $5 E+04$ & $z r-93$ \\
\hline $\mathrm{Nb}-93 \mathrm{~m}$ & 3.81E-01 & 27 & 8.5 & $2.1 E+06$ & e & $\mathrm{NL} \quad{ }^{\circ}$ & 54 & 8.5 & $2.2 E+06$ & e & $\mathrm{NL}$ & $\mathrm{Nb}-93 \mathrm{~m}$ \\
\hline $\mathrm{Nb}-94$ & $5.21 E+00$ & 27 & 8.5 & $2.1 E+06$ & $3.0 E+31$ & $\mathrm{NL}$ & 54 & 8.5 & $2.2 E+06$ & $2.5 \mathrm{E}+33$ & $\mathrm{NL}$ & $\mathrm{Nb}-94$ \\
\hline Tc-99 & $1.07 \mathrm{E}+00$ & 3.1 & 8.5 & $1.9 E+03$ & $1.0 E+00$ & $1 E+02$ & 6.2 & 8.5 & $2.3 E+03$ & $1.0 \mathrm{E}+00$ & $2 E+02$ & TC-99 \\
\hline$P d-107$ & $1.09 \mathrm{E}-01$ & 270 & 8.5 & $7.2 E+05$ & $1.1 E+00$ & $9 E+04^{\circ}$ & 540 & 8.5 & $7.6 \mathrm{E}+05$ & $1.1 E+00$ & $2 E+05 \quad c$ & $\mathrm{Pd}-107$ \\
\hline $\mathrm{Ag}-108 \mathrm{~m}$ & $5.56 \mathrm{E}+00$ & 270 & 8.5 & $1.2 E+06$ & e & $\mathrm{NL} \quad \mathrm{c}$ & 540 & 8.5 & $1.2 \mathrm{E}+\infty 6$ & e & $\mathrm{NL}$ & $\mathrm{Ag}-108 \mathrm{~m}$ \\
\hline Cd-113m & 1.17E+02 & 270 & 8.5 & $1.0 \mathrm{E}+06$ & e & NL & 540 & 8.5 & $1.1 \mathrm{E}+06$ & e & NL & Cd-113m \\
\hline $\mathrm{Sn}-121 \mathrm{~m}$ & $1.28 \mathrm{E}+00$ & 27 & 8.5 & $1.7 \mathrm{E}+06$ & e & $\mathrm{NL}$ & 54 & 8.5 & $1.8 \mathrm{E}+06$ & $\bar{e}$ & NL & $\mathrm{sn-121m}$ \\
\hline $\mathrm{Sn}-126$ & $1.53 E+01$ & 27 & 8.5 & $1.7 E+06$ & $1.3 E+05$ & $8 E+06^{\circ}$ & 54 & 8.5 & $1.8 \mathrm{E}+06$ & $2.7 E+05$ & $3 E+07 \quad c$ & $5 n-126$ \\
\hline $1-129$ & $2.01 E+02$ & 3.1 & 8.5 & $1.4 \mathrm{E}+04$ & $1.0 E+\infty 0$ & $5 E-01 \quad c$ & 6.2 & 8.5 & $1.5 \mathrm{E}+04$ & $1.0 E+00$ & $1 E+00^{\circ}$ & $1-129$ \\
\hline Cs-135 & $5.16 \mathrm{E}+00$ & 27 & 8.5 & 3.7E+06 & $3.0 \mathrm{E}+00$ & $5 \mathrm{E}+02^{\circ}$ & 54 & 8.5 & $3.9 \mathrm{E}+06$ & $3.2 E+\infty 0$ & $1 E+03$ & Cs-135 \\
\hline Cs-137 & $3.65 \mathrm{E}+01$ & 27 & 8.5 & $3.7 E+06$ & $e$ & $\mathrm{NL}$ & 54 & 8.5 & $3.9 E+06$ & $e$ & $\mathrm{NL}$ & Cs-137 \\
\hline$B a-133$ & $2.48 E+00$ & 27 & 8.5 & $2.0 \mathrm{E}+05$ & e & $\mathrm{NL}$ & 54 & 8.5 & $2.1 E+05$ & $\mathrm{e}$ & $N L$ & $8 a-133$ \\
\hline $5 m-151$ & $2.84 E-01$ & 27 & 8.5 & $3.2 E+06$ & e & $\mathrm{NL}$ & 54 & 8.5 & $3.4 \mathrm{E}+06$ & e & $\mathrm{NL}$ & $\mathrm{sm}-151$ \\
\hline Eu-152 & $4.73 \mathrm{E}+\infty 0$ & 27 & 8.5 & $3.2 E+06$ & e & $\mathrm{NL}$ & 54 & 8.5 & $3.4 E+06$ & e & $\mathrm{NL}$ & Eu-152 \\
\hline Eu-154 & $6.97 \mathrm{E}+00$ & 27 & 8.5 & $3.2 E+06$ & e & NL. & 54 & 8.5 & $3.4 \mathrm{E}+06$ & e & NL & Eu-154 \\
\hline $\mathrm{Pb}-210$ & $5.30 \mathrm{E}+03$ & 270 & 8.5 & $3.5 \mathrm{E}+06$ & e & $\mathrm{NL}$ & 540 & 8.5 & $3.7 E+06$ & e & NL & $\mathrm{Pb}-210$ \\
\hline$R a-226$ & $6.27 \mathrm{E}+03$ & 27 & 8.5 & $6.5 \mathrm{E}+06$ & e & $\mathrm{NL}$ & 54 & 8.5 & $6.9 \mathrm{E}+06$ & $e$ & NL & Ra-226 \\
\hline Ra-228 & $1.64 E+03$ & 27 & 8.5 & $6.5 E+06$ & e & NL & 54 & 8.5 & $6.9 \mathrm{E}+06$ & e & $\mathrm{NL}$ & Ra-228 \\
\hline Th-229 & $2.94 E+03$ & 270 & 8.5 & $4.2 E+07$ & e & $\mathrm{NL}$ & 540 & 8.5 & $4.4 E+07$ & e & $\mathrm{NL}$ & Th-229 \\
\hline Th-230 & $6.12 E+03$ & 270 & 8.5 & $4.2 \mathrm{E}+07$ & NA & $1 E+\infty 0^{\circ}$ & 540 & 8.5 & $4.4 E+07$ & NA & $3 E+\infty$ & Th-230 \\
\hline Th-232 & $3.63 E+03$ & 270 & 8.5 & $4.2 E+07$ & $1.0 \mathrm{E}+00$ & $2 E+00$ & 540 & 8.5 & $4.4 E+07$ & $1.0 \mathrm{E}+\infty 0$ & $5 E+00$ ? & Th-232 \\
\hline $\mathrm{Pa}-231$ & $1.85 E+04$ & 270 & 8.5 & $7.2 \mathrm{E}+06$ & e & $N L{ }^{\circ}$ & 540 & 8.5 & $7.6 \mathrm{E}+06$ & e & $\mathrm{NL}$ & Pa-231 \\
\hline
\end{tabular}


Table 9-4. Results of Calculations for the Water Pathway at SNL/NM (water travel time from land surface to performance boundary [excluding facility detention] $=585$ y) (Part 2 of 2$)$

\begin{tabular}{|c|c|c|c|c|c|c|c|c|c|c|c|c|}
\hline \multirow[t]{2}{*}{ Nuclide } & \multirow[b]{2}{*}{$\begin{array}{c}\text { PDCF } \\
\text { rem/y per } \mu \mathrm{Ch} \text {. }\end{array}$} & \multicolumn{5}{|c|}{ Trench } & \multicolumn{5}{|c|}{ Tumulus } & \multirow[t]{2}{*}{ Nuclide } \\
\hline & & $\begin{array}{l}\text { CRF source } \\
\text { (dimensionioss) }\end{array}$ & \begin{tabular}{|c|} 
CRF water $_{\text {wimensionloss) }}$ \\
(dim
\end{tabular} & $\begin{array}{l}\text { Arrival } \\
\text { Time (y) }\end{array}$ & \begin{tabular}{|c|}
$\begin{array}{c}r_{\text {Docay }} \\
\text { (dimensionlezs) }\end{array}$ \\
\end{tabular} & $\begin{array}{c}C_{w-W a t e r}^{b} \\
\left(\mu \mathrm{Cl} / \mathrm{m}^{3}\right) \\
\end{array}$ & $\begin{array}{l}\text { CRF } \\
\text { (dimensionloses) } \\
\end{array}$ & \begin{tabular}{|c|} 
CRF \\
(dimenzionioses) \\
\end{tabular} & $\begin{array}{l}\text { Arrival } \\
\text { Time (v) }\end{array}$ & $\begin{array}{c}\text { r Decay }^{a} \\
\text { (dimenzionlexs) }\end{array}$ & 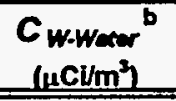 & \\
\hline$U-232$ & $1.55 E+03$ & 270 & 8.5 & $4.6 E+05$ & e & $\mathrm{NL}$ & 540 & 8.5 & $4.9 E+05$ & e & $\mathrm{NL}$ & $U-232$ \\
\hline U-233 & $1.95 E+03$ & 270 & 8.5 & $4.6 E+05$ & NA & $5 E+00^{\circ}$ & 540 & 8.5 & $4.9 E+05$ & NA & $9 E+00 c$ & U-233 \\
\hline$U-234$ & $6.48 E+02 d$ & 270 & 8.5 & $4.6 E+05$ & NA & $1 E+01^{\circ}$ & 540 & 8.5 & $4.9 E+05$ & NA & $3 E+01 \quad c$ & $U-234$ \\
\hline U-235 & $3.73 E+03$ & 270 & 8.5 & $4.6 \mathrm{E}+05$ & NA & $2 E+00^{\circ}$ & 540 & 8.5 & $4.9 E+05$ & NA & $5 E+00$ & $U-235$ \\
\hline U-236 & $1.96 \mathrm{E}+02$ & 270 & 8.5 & $4.6 E+05$ & $1.0 \mathrm{E}+00$ & $5 E+01<$ & 540 & 8.5 & $4.9 E+05$ & $1.0 E+\infty$ & $9 E+01 \quad \mathrm{C}$ & U-236 \\
\hline U-238 & $2.07 E+02$ & 270 & 8.5 & $4.6 \mathrm{E}+05$ & NA & $4 E+01^{\circ}$ & 540 & 8.5 & $4.9 E+05$ & NA & $9 E+01$ & $U-238$ \\
\hline Np-237 & $3.24 E+03$ & 270 & 8.5 & $6.6 E+04$ & $1.0 E+\infty$ & $3 E+00$ & 540 & 8.5 & $7.0 \mathrm{E}+04$ & $1.0 E+00$ & $6 E+00$ C & Np-237 \\
\hline Pu-238 & $2.34 E+03$ & 270 & 8.5 & $7.2 E+06$ & $e$ & $4 E+04 \cdot 1$ & 540 & 8.5 & $7.6 \mathrm{E}+06$ & e & $8 E+04 \quad c$ & $\mathrm{Pu}-238$ \\
\hline Pu-239 & $2.58 \mathrm{E}+03$ & 270 & 8.5 & $7.2 E+06$ & e & NL $\quad c$ & 540 & 8.5 & $7.6 \mathrm{E}+06$ & e & $\mathrm{NL}$ & $\mathrm{Pu}-239$ \\
\hline Pu-240 & $2.58 E+03$ & 270 & 8.5 & $7.2 \mathrm{E}+06$ & e & $\mathrm{NL}$ & 540 & 8.5 & $7.6 \mathrm{E}+06$ & e & $\mathrm{NL}$ & Pu-240 \\
\hline$P u-241$ & $4.82 E+08$ & 270 & 8.5 & $7.2 E+06$ & e & $4 E+05$ & 540 & 8.5 & $7.6 E+06$ & e & $9 E+05$ c & Pu-241 \\
\hline Pu-242 & $2.45 E+03$ & 270 & 8.5 & $7.2 E+06$ & $5.9 E+05$ & $2 E+06^{c}$ & 540 & 8.5 & $7.6 E+06$ & $1.3 E+06$ & $1 E+07$ C & $P u-242$ \\
\hline Pu-244 & $4.11 E+03$ & 270 & 8.5 & $7.2 \mathrm{E}+06$ & NA & $2 \mathrm{E}+00^{\circ}$ & 540 & 8.5 & $7.6 \mathrm{E}+06$ & NA & $4 E+00 \div$ & $P u-244$ \\
\hline$A m-241$ & $2.66 \mathrm{E}+03$ & 270 & 8.5 & $2.5 E+07$ & e & $1 E+04 c 7$ & 540 & 8.5 & $2.6 \mathrm{E}+07$ & e & $3 E+04 c$ & Am-241 \\
\hline Am-243 & $2.64 E+03$ & 270 & 8.5 & $2.5 E+07$ & e & $\mathrm{NL}$ & 540 & 8.5 & $2.6 \mathrm{E}+07$ & $\mathbf{e}$ & $\mathrm{NL}$ & $A m-243$ \\
\hline $\mathrm{Cm}-243$ & $1.83 E+03$ & 270 & 8.5 & $5.2 E+07$ & e & $N L$ & 540 & 8.5 & $5.5 \mathrm{E}+07$ & $\mathbf{e}$ & $\mathrm{NL}$ & $\mathrm{Cm}-243$ \\
\hline $\mathrm{Cm}-244$ & $1.47 E+03$ & 270 & 8.5 & $5.2 E+07$ & $e$ & $\mathrm{NL}$ & 540 & 8.5 & $5.5 E+07$ & $\mathbf{e}$ & $\mathrm{NL}$ & $\mathrm{Cm}-244$ \\
\hline $\mathrm{Cm}-245$ & $4.56 E+03$ & 270 & 8.5 & $5.2 E+07$ & NA & $2 E+00^{\circ}$ & 540 & 8.5 & $5.5 E+07$ & NA & $4 E+\infty 0^{\circ}$ & $\mathrm{Cm}-245$ \\
\hline $\mathrm{Cm}-246$ & $2.70 E+03$ & 270 & 8.5 & $5.2 \mathrm{E}+07$ & e & $\mathrm{NL}$ & 540 & 8.5 & $5.5 \mathrm{E}+07$ & e & $\mathrm{NL}$ & $\mathrm{Cm}-246$ \\
\hline $\mathrm{Cm-247}$ & $4.34 E+03$ & 270 & 8.5 & $5.2 \mathrm{E}+07$ & NA & $2 E+00^{\circ}$ & 540 & 8.5 & $5.5 E+07$ & NA & $4 E+00$ & $\mathrm{Cm}-247$ \\
\hline $\mathrm{Cm}-248$ & $9.94 \mathrm{E}+03$ & 270 & 8.5 & $5.2 E+07$ & $1.6 E+45$ & $\mathrm{NL}$ & 540 & 8.5 & $5.5 \mathrm{E}+07$ & $9.1 E+47$ & NL & $\mathrm{Cm}-248$ \\
\hline Cf-249 & $3.46 E+03$ & 270 & 8.5 & $5.2 E+07$ & $e$ & $5 E+01<1$ & 540 & 8.5 & $5.5 \mathrm{E}+07$ & $\mathrm{e}$ & $1 E+02$ & Cf-249 \\
\hline$C f-250$ & $2.64 E+08$ & 270 & 8.5 & $5.2 \mathrm{E}+07$ & e & $\mathrm{NL}$ & 540 & 8.5 & $5.5 E+07$ & e & $\mathrm{NL}$ & Cf-250 \\
\hline$C f-251$ & $3.54 E+03$ & 270 & 8.5 & $5.2 E+07$ & e & $\mathrm{NL}$ & 540 & 8.5 & $5.5 E+07$ & e & $\mathrm{NL}$ & Cf-251 \\
\hline
\end{tabular}

a "NA" means Not Applicable - decay factor is implicit in the PDCF for this radionuclide.

b "NL" means No Limit - estimated permissible concentration is greater than the specific activity of the pure elemental radionuclide.

c Radionuclide concentration is based on arival time at the performance boundary beyond 10,000 years.

d PDCF is a function of arrival time. See Chapter 1 of this volume for equation.

e $r_{\text {Decoy }} \geq 1 \mathrm{E}+50$

$f$ Contribution of decay product(s) is significant to determination of this value (see Table E-3 in Volume 2). Listed arrival time is that of the parent radionuclide. Arrival time of the significant decay product(s) is greater than $10,000 \mathrm{y}$. 
Arrival times for some radionuclides listed in Table 9-4 were beyond the 10,000-y performance period. For those radionuclides, the estimated waste concentrations are presented in Table 9-4 for information purposes only. Consistent with the approach used in LLW performance assessments, these values were not considered in determining the most restrictive disposal limit from among the evaluated pathways.

For all radionuclides in Table 9-4, the rate of water flow controlled the subsurface transport (i.e., the subsurface movement of the radionuclides was controlled by the flow rate at $100 \mathrm{y}$ after closure for the trench [when the cover failed] and at $300 \mathrm{y}$ for the tumulus [when the concrete vaults failed]).

For the tumulus, the total undecayed CRFs (i.e., the product of the $C R F_{\text {Source }}$ and the $C R F_{\text {Water }}$ ) for the groundwater pathway were about twice the total undecayed CRFs for the trench, given the same overall rate of flow (i.e., at the time of hydrologic failure of the facility). This result was due to the difference in the volume fraction of waste (the ratio of waste material to total material in the disposal unit) between the two technologies - twice as much waste leached from the trench for a given rate of flow because a given volume of trench contained twice as much waste as the tumulus.

For the generic trench at SNL/NM, the total undecayed CRFs for the water pathway ranged from about 4 to 2300 for the 58 radionuclides considered in this study. Total water travel time from the bottom of the trench to the performance boundary was $554 \mathrm{y}$, excluding facility retention time. Radionuclide subsurface travel times to the performance boundary ranged from 1900 to 52 million years, including the retention time in the facility before failure. The water travel time through the unsaturated zone accounted for about $89 \%$ of the total subsurface travel time.

For the generic tumulus at SNL/NM, the total undecayed CRFs for the water pathway ranged from about 8 to 4600 . Total water travel time from the bottom of the tumulus to the performance boundary was $585 \mathrm{y}$, excluding facility retention time. Radionuclide subsurface travel times to the performance boundary ranged from 2300 to 55 million years, including the $300-y$ retention time in the facility before failure. Differences in these arrival times compared to the trench were attributable to (1) the assumed time of hydrologic failure of the facility ( $30 \mathrm{y}$ for the trench and $300 \mathrm{y}$ for the tumulus); (2) the increased rate of flow at the time of failure of the facility compared to that when the leachate collection system failed; and (3) the increased travel distance through the vadose zone for the tumulus (the bottom of the tumulus was at grade level, while the trench was a shallowly buried structure). For the tumulus, the longer subsurface travel time for H-3 (as compared to releases from the trench) was associated with the low rate of flow and early time of release from the trench for this radionuclide.

\subsubsection{Atmospheric Transport}

Two CRFs were used to account for the attenuation encompassing diffusion to the ground surface, mixing in air, and dispersion in the atmosphere to the performance boundary. The CRF for diffusion in soil, $C R F_{D i f j}$, was defined as the ratio of the radionuclide concentration in the 
waste to its resulting concentration in the upper one centimeter of soil. The CRF for dispersion in air, $C R F_{D i s p}$, was defined as the ratio of the radionuclide concentration in the upper one centimeter of soil to its resulting concentration in air at the performance boundary. The effect of radioactive decay was also included in the PE.

Application of the PE methodology for atmospheric transport of the two volatile radionuclides considered in the PE (H-3 and C-14) produced the results shown in Table 9-5 for both the generic trench and tumulus designs; there was no assumed difference in these two disposal technologies with respect to permissible waste limits based on the atmospheric pathway at SNL/NM. The table shows permissible waste concentrations based on transport in the atmospheric pathway $\left(C_{W-A t m}\right)$ as well as the values used in calculating the permissible waste concentrations. For both $\mathrm{H}-3$ and $\mathrm{C}-14$, the greatest concentration reduction was assumed to occur as the radionuclides diffused from the top of the disposal facility to the soil surface.

Table 9-5. Results of Calculations for the Atmospheric Pathway

\begin{tabular}{|c|c|c|c|c|c|c|c|}
\hline \multirow[t]{2}{*}{ Nuclide } & \multirow[b]{2}{*}{$\begin{array}{c}\operatorname{SDCF}_{A t m} \\
(\mathrm{rem} / \mathrm{y}) /(\mu \mathrm{C} / \mathrm{L})\end{array}$} & \multicolumn{6}{|c|}{ Generic Trench and Tumulus } \\
\hline & & $\underset{\text { (dalmensilonless) }}{C R F_{\text {Dim }}}$ & 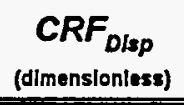 & 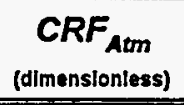 & $\begin{array}{c}\text { Arrival } \\
\text { Time (y) }\end{array}$ & $\begin{array}{c}r_{\text {Docay }} \\
\text { (dimensionless) }\end{array}$ & $\begin{array}{r}C_{w-A t m} \\
\left(\mu \mathrm{Ci} / \mathrm{m}^{3}\right)\end{array}$ \\
\hline $\mathrm{H}-3$ & $8.33 E+02$ & $8 E+05$ & $1 E+03$ & $8 E+08$ & 100 & 300 & $3 E+09$ \\
\hline$c-14$ & $2.20 E+05$ & $2 E+04$ & $3 E+03$ & $3 E+07$ & 100 & 1 & $2 \mathrm{E}+03$ \\
\hline
\end{tabular}

The time of arrival at the performance boundary for both radionuclides is shown in Table 9-5 as $100 \mathrm{y}$. However, the actual migration of $\mathrm{H}-3$ and $\mathrm{C}-14$ from the disposal facility to the surface and downwind to the performance boundary was calculated to be on the order of hours, not years. As discussed in Section 9.3.2.2, the waste form and RCRA cover are assumed to retain these volatile radionuclides in the disposal facility for at least $100 \mathrm{y}$.

\subsubsection{Inadvertent Intruder Exposure}

The calculation of permissible waste concentrations for inadvertent intruder exposures did not utilize CRFs. Instead, the total dose resulting from an intrusion scenario (the sum of the doses from all exposure pathways involved in that intrusion) was modified by scenario dose conversion factors (SDCFs) that were applied to specific exposure pathways. The important exposure pathways for each radionuclide are listed in Appendix D of Volume 2. These values were radionuclide-specific and facility-design-specific and were the same for all sites. Values for the radioactive decay term were based on time of intrusion into the disposal facility (for the homesteader scenario, $300 \mathrm{y}$ for the trench design and $500 \mathrm{y}$ for the tumulus design; for the postdrilling scenario, $100 \mathrm{y}$ for both disposal designs). However, results based on intruder scenarios should be evaluated carefully because future social behavior, and intrusion scenarios, are difficult to predict. 
The permissible waste concentrations for the two generic facility designs for each of the 58 radionuclides based on the standard PE intrusion scenarios are listed in Table 9-6. The most restrictive radionuclide concentration limits for each generic facility are indicated with bold type.

For six radionuclides in the table (U-233, U-234, U-235, U-238, Pu-244, and Cm-247), the time of homesteader intrusion was changed to $10,000 \mathrm{y}$, the end of the performance period. For these six radionuclides, ingrowth of decay products yields scenario doses that increase over time. The doses at 10,000 y, therefore, represent the maximum that could be encountered during the performance period. Also, for Th-230 and $\mathrm{Cm}-245$, ingrowth of decay products likewise produces a scenario dose that increases over time and peaks within the 10,000-y performance period. The times of homesteader intrusion for these two radionuclides (Th-230 and Cm-245) were taken as the time of maximum dose, 9000 and $1000 \mathrm{y}$, respectively.

For the trench design, the post-drilling scenario generally yielded more restrictive waste limits than the homesteader scenario for those radionuclides with half-lives shorter than about $30 \mathrm{y}$. For the tumulus design, the post-drilling scenario generally yielded more restrictive limits than the homesteader scenario for those radionuclides with half-lives shorter than about $130 \mathrm{y}$.

\subsection{SUMMARY AND DISCUSSION OF RESULTS}

The limiting waste concentrations in disposed MLLW for the water, atmospheric, and intruder analyses for the generic trench and tumulus designs are summarized in Table 9-7 and discussed in Section 9.6.1. An overall discussion of the results of the PE for SNL/NM is contained in Section 9.6.2.

\subsubsection{Results Based on Disposal Design}

For both the generic trench and tumulus designs at SNL/NM, one radionuclide (Tc-99) was limited by the water pathway, one radionuclide (C-14) was limited by the atmospheric pathway, and 56 radionuclides were limited by intrusion scenarios (Table 9-7).

For both the trench and tumulus designs, the concentration for one radionuclide (H-3) that arrived at the performance boundary before 10,000 y reported in Table 9-7 for the water pathway analysis had no limit. As discussed in Section 9.5.1, the calculated concentrations for those radionuclides reported as NL (No Limit) were above the specific activity of the pure elemental radionuclide, implying that the performance measure of $4 \mathrm{mrem}(0.04 \mathrm{mSv})$ per year would not be reached under the given release and transport assumptions.

As also discussed in Section 9.5.1, values for some radionuclides are not reported in Table 9-7 for the water pathway analysis. Arrival times for these radionuclides were beyond the 10,000-y performance period. For these radionuclides, the estimated waste concentrations are presented in Table 9-4 for information purposes but are not listed in Table 9-7. Consistent with the approach used in LLW performance assessments, these values were not considered in determining the most restrictive disposal limit from among the evaluated pathways because arrival times for these radionuclides were beyond $10,000 \mathrm{y}$. 
Table 9-6. Permissible Waste Concentrations for the Standard Intrusion Scenarios (most limiting radionuclide concentration for each facility design is highlighted in bold italic) (Part 1 of 2)

\begin{tabular}{|c|c|c|c|c|c|}
\hline \multirow[t]{2}{*}{ Nuclide } & \multicolumn{2}{|c|}{ Trench } & \multicolumn{2}{|c|}{ Tumulus } & \multirow[t]{2}{*}{ Nuclide } \\
\hline & $\begin{array}{c}C_{\text {W-dmor }} \\
\text { Homesteader } \\
\left(\mu \mathrm{Ci} / \mathrm{m}^{3}\right) \\
\end{array}$ & $\begin{array}{c}C_{W / n t r} \\
\text { Post-Drilling } \\
\left(\mu \mathrm{Ci} / \mathrm{m}^{3}\right) \\
\end{array}$ & $\begin{array}{c}C_{w-\ln r^{a}} \\
\text { Homesteader } \\
\left(\mu \mathrm{Ci} / \mathrm{m}^{3}\right) \\
\end{array}$ & $\begin{array}{c}C_{W-1 n t r} \\
\text { Post-Drilling } \\
\left(\mu \mathrm{Ci} / \mathrm{m}^{3}\right) \\
\end{array}$ & \\
\hline $\mathrm{H}-3$ & $1 E+12$ & $7 E+07$ & NL & $7 E+07$ & $\mathrm{H}-3$ \\
\hline C-14 & $1 E+04$ & $7 E+04$ & $1 E+04$ & $7 \mathrm{E}+04$ & C-14 \\
\hline Al-26 & $5 E+01$ & $5 E+04$ & $5 E+01$ & $5 E+04$ & Al-26 \\
\hline Si-32 & $9 E+03$ & $1 E+04$ & $4 E+04$ & $1 E+04$ & Si-32 \\
\hline $\mathrm{Cl}-36$ & $2 E+02$ & $9 E+02$ & $2 E+02$ & $9 \mathrm{E}+02$ & $\mathrm{Cl}-36$ \\
\hline$K-40$ & $7 E+02$ & $2 E+04$ & $7 E+02$ & $2 E+04$ & $K-40$ \\
\hline Co-60 & $\mathrm{NL}$ & $3 E+10$ & $\mathrm{NL}$ & $3 E+10$ & $\mathrm{Co}-60$ \\
\hline Ni-59 & $3 E+06$ & $1 E+07$ & $3 E+06$ & $1 E+07$ & Ni-59 \\
\hline $\mathrm{Ni}-63$ & $8 E+06$ & $1 E+07$ & $3 E+07$ & $1 E+07$ & $\mathrm{Ni}-63$ \\
\hline Se-79 & $2 E+05$ & $8 E+05$ & $2 E+05$ & $8 E+05$ & Se-79 \\
\hline Sr-90 & $1 E+06$ & $5 E+04$ & $1 E+08$ & $5 E+04$ & Sr-90 \\
\hline Zr-93 & $5 E+06$ & $3 E+07$ & $5 E+06$ & $3 E+07$ & Zr-93 \\
\hline $\mathrm{Nb}-93 \mathrm{~m}$ & $5 E+12$ & $4 E+09$ & $\mathrm{NL}$ & $4 E+09$ & $\mathrm{Nb}-93 \mathrm{~m}$ \\
\hline $\mathrm{Nb}-94$ & $9 E+01$ & $9 E+04$ & $1 E+02$ & $9 E+04$ & $\mathrm{Nb}-94$ \\
\hline Tc-99 & $2 E+04$ & $8 E+04$ & $2 E+04$ & $8 \mathrm{E}+04$ & TC-99 \\
\hline $\mathrm{Pd}-107$ & $6 E+06$ & $3 E+07$ & $6 E+06$ & $3 E+07$ & $\mathrm{Pd}-107$ \\
\hline $\mathrm{Ag}-108 \mathrm{~m}$ & $5 E+02$ & $1 E+05$ & $1 E+03$ & $1 E+05$ & $\mathrm{Ag}-108 \mathrm{~m}$ \\
\hline Cd-113m & $4 E+09$ & $1 E+06$ & $7 E+13$ & $1 E+06$ & $\mathrm{Cd}-113 \mathrm{~m}$ \\
\hline Sn-121m & $2 E+07$ & $5 \mathrm{E}+07$ & $2 E+08$ & $5 E+07$ & Sn-121m \\
\hline $5 n-126$ & $8 E+01$ & $7 E+04$ & $8 E+01$ & $7 E+04$ & $5 n-126$ \\
\hline $1-129$ & $2 E+03$ & $1 E+04$ & $2 E+03$ & $1 E+04$ & 1-129 \\
\hline Cs-135 & $2 E+05$ & $8 E+05$ & $2 E+05$ & $8 E+05$ & Cs-135 \\
\hline Cs-137 & $3 E+05$ & $8 E+05$ & $3 E+07$ & $8 E+05$ & Cs-137 \\
\hline $\mathrm{Ba}-133$ & $2 E+11$ & $3 E+08$ & $\mathrm{NL}$ & $3 E+08$ & $\mathrm{Ba}-133$ \\
\hline $\mathrm{Sm}-151$ & $2 E+08$ & $2 E+08$ & $8 E+08$ & $2 E+08$ & Sm-151 \\
\hline Eu-152 & $6 E+08$ & $2 E+07$ & $2 E+13$ & $2 E+07$ & Eu-152 \\
\hline Eu-154 & $4 E+12$ & $4 E+08$ & $\mathrm{NL}$ & $4 E+08$ & Eu-154 \\
\hline $\mathrm{Pb}-210$ & $7 E+06$ & $7 E+04$ & $4 E+09$ & $7 E+04$ & $\mathrm{~Pb}-210$ \\
\hline $\mathrm{Ra}-226$ & $8 E+01$ & $3 E+03$ & $9 E+01$ & $3 E+03$ & Ra-226 \\
\hline $\mathrm{Ra}-228$ & NL & $4 E+09$ & $\mathrm{NL}$ & $4 E+09$ & Ra-228 \\
\hline Th-229 & $5 E+02$ & $3 E+04$ & $5 E+02$ & $3 E+04$ & Th-229 \\
\hline Th-230 & $8 E+01$ & $7 E+04$ & $8 E+01$ & $7 E+04$ & Th-230 \\
\hline Th-232 & $6 E+01$ & $2 E+04$ & $6 E+01$ & $2 E+04$ & Th-232 \\
\hline $\mathrm{Pa}-231$ & $2 E+02$ & $5 E+03$ & $2 E+02$ & $5 E+03$ & $\mathrm{~Pa}-231$ \\
\hline
\end{tabular}


Table 9-6. Permissible Waste Concentrations for the Standard Intrusion Scenarios (most limiting radionuclide concentration for each facility design is highlighted in bold italic) (Part 2 of 2)

\begin{tabular}{|c|c|c|c|c|c|}
\hline \multirow[t]{2}{*}{ Nuclide } & \multicolumn{2}{|c|}{ Trench } & \multicolumn{2}{|c|}{ Tumulus } & \multirow[t]{2}{*}{ Nuclide } \\
\hline & $\begin{array}{c}C_{\text {w-mtr }}{ }^{a} \\
\text { Homesteader } \\
\left(\mu \mathrm{Ci} / \mathrm{m}^{3}\right) \\
\end{array}$ & $\begin{array}{c}C_{\text {w-Intr }} \\
\text { Post-Drilling } \\
\left(\mu \mathrm{Ci} / \mathrm{m}^{3}\right) \\
\end{array}$ & $\begin{array}{c}C_{w-1 n t r} \\
\text { Homesteader } \\
\left(\mu \mathrm{Ci} / \mathrm{m}^{3}\right) \\
\end{array}$ & 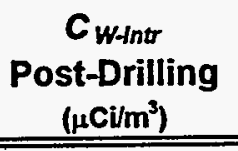 & \\
\hline $\mathrm{U}-232$ & $2 E+03$ & $5 E+04$ & $1 E+04$ & $5 E+04$ & $\mathrm{U}-232$ \\
\hline U-233 & $7 E+02$ & $1 E+05$ & $7 E+02$ & $1 E+05$ & $U-233$ \\
\hline U-234 & $1 E+03$ & $1 E+05$ & $1 E+03$ & $1 E+05$ & U-234 \\
\hline U-235 & $6 E+02$ & $1 \mathrm{E}+05$ & $6 E+02$ & $1 E+05$ & U-235 \\
\hline U-236 & $2 E+04$ & $1 E+05$ & $2 E+04$ & $1 E+05$ & U-236 \\
\hline$U-238$ & $5 E+03$ & $1 E+05$ & $5 E+03$ & $1 E+05$ & U-238 \\
\hline Np-237 & $4 E+02$ & $4 E+03$ & $4 E+02$ & $4 E+03$ & Np-237 \\
\hline Pu-238 & $7 E+04$ & $1 E+05$ & $4 E+05$ & $1 E+05$ & Pu-238 \\
\hline Pu-239 & $6 E+03$ & $5 E+04$ & $6 E+03$ & $5 E+04$ & Pu-239 \\
\hline $\mathrm{Pu}-240$ & $6 E+03$ & $5 E+04$ & $7 E+03$ & $5 E+04$ & Pu-240 \\
\hline Pu-241 & $2 E+05$ & $1 E+06$ & $3 E+05$ & $1 \mathrm{E}+06$ & Pu-241 \\
\hline Pu-242 & $6 E+03$ & $5 E+04$ & $6 E+03$ & $5 \mathrm{E}+04$ & Pu-242 \\
\hline Pu-244 & $4 E+02$ & $5 \mathrm{E}+04$ & $4 E+02$ & $5 E+04$ & Pu-244 \\
\hline Am-241 & $7 E+03$ & $5 E+04$ & $9 E+03$ & $5 E+04$ & Am-241 \\
\hline Am-243 & $9 E+02$ & $4 E+04$ & $9 E+02$ & $4 E+04$ & Am-243 \\
\hline $\mathrm{Cm}-243$ & $1 E+06$ & $8 E+05$ & $5 E+06$ & $8 E+05$ & $\mathrm{Cm}-243$ \\
\hline $\mathrm{Cm}-244$ & $2 E+06$ & $3 E+06$ & $2 E+06$ & $3 E+06$ & $\mathrm{Cm}-244$ \\
\hline $\mathrm{Cm}-245$ & $1 E+03$ & $4 E+04$ & $1 E+03$ & $4 E+04$ & $\mathrm{Cm}-245$ \\
\hline $\mathrm{Cm}-246$ & $6 E+03$ & $5 E+04$ & $6 E+03$ & $5 E+04$ & $\mathrm{Cm}-246$ \\
\hline $\mathrm{Cm}-247$ & $3 E+02$ & $5 E+04$ & $3 E+02$ & $5 E+04$ & $\mathrm{Cm}-247$ \\
\hline $\mathrm{Cm}-248$ & $2 E+03$ & $1 E+04$ & $2 E+03$ & $1 E+04$ & $\mathrm{Cm}-248$ \\
\hline Cf-249 & $8 E+02$ & $4 E+04$ & $1 E+03$ & $4 E+04$ & Cf-249 \\
\hline Cf-250 & $2 E+06$ & $9 \mathrm{E}+06$ & $2 E+06$ & $9 E+06$ & Cf-250 \\
\hline Cf-251 & $2 E+03$ & $4 E+04$ & $2 E+03$ & $4 E+04$ & Cf-251 \\
\hline
\end{tabular}

a "NL" means No Limit - estimated permissible concentration is greater than the specific activity of the pure elemental radionuclide. 
Table 9-7. Permissible Concentrations for the Generic Disposal Designs at SNL/NM (permissible concentration related to the most limiting pathway for each facility design is highlighted in bold italic) (Part 1 of 2)

\begin{tabular}{|c|c|c|c|c|c|c|c|}
\hline \multirow[t]{2}{*}{ Nuclide } & \multicolumn{3}{|c|}{ Trench } & \multicolumn{3}{|c|}{ Tumulus } & \multirow[t]{2}{*}{ Nuclide } \\
\hline & $\begin{array}{c}C_{\text {w-Water }}{ }^{2, b} \\
\left(\mu \mathrm{Ci} / \mathrm{m}^{3}\right)\end{array}$ & $\begin{array}{l}C_{W-A t m}{ }^{c} \\
\left(\mu \mathrm{Cu} / \mathrm{m}^{3}\right)\end{array}$ & $\begin{array}{l}C_{w-1 n t r}{ }^{d} \\
\left(\mu \mathrm{Ci} / \mathrm{m}^{3}\right)\end{array}$ & $\begin{array}{c}C_{\text {w-Water }}{ }^{2, b} \\
\left(\mu \mathrm{CU} \mathrm{m}^{3}\right)\end{array}$ & $\begin{array}{l}C_{W-A t m}{ }^{c} \\
\left(\mu \mathrm{Ci} / m^{3}\right) \\
\end{array}$ & $\begin{array}{l}C_{w-\operatorname{lntr}{ }^{d}} \\
\left(\mu \mathrm{Ci} / \mathrm{m}^{3}\right) \\
\end{array}$ & \\
\hline $\mathrm{H}-3$ & NL & $3 E+09$ & $7 E+07$ & NL & $3 E+09$ & $7 E+07$ & $\mathrm{H}-3$ \\
\hline$c-14$ & - & $2 E+03$ & $1 \mathrm{E}+04$ & - & $2 E+03$ & $1 \mathrm{E}+04$ & C-14 \\
\hline AI-26 & - & & $5 E+01$ & - & & $5 E+01$ & Al-26 \\
\hline Si-32 & - & & $9 E+03$ & - & & $1 E+04$ & Si-32 \\
\hline $\mathrm{Cl}-36$ & - & & $2 E+02$ & - & & $2 E+02$ & $\mathrm{Cl}-36$ \\
\hline$K-40$ & - & & $7 E+02$ & - & & $7 E+02$ & $\mathrm{~K}-40$ \\
\hline Co-60 & - & & $3 E+10$ & - & & $3 E+10$ & Co-60 \\
\hline $\mathrm{Ni}-59$ & - & & $3 E+06$ & - & & $3 E+06$ & $\mathrm{Ni}-59$ \\
\hline $\mathrm{Ni}-63$ & - & & $8 E+06$ & - & & $1 E+07$ & $\mathrm{Ni}-63$ \\
\hline Se-79 & - & & $2 E+05$ & - & & $2 E+05$ & Se-79 \\
\hline Sr-90 & - & & $5 E+04$ & - & & $5 E+04$ & Sr-90 \\
\hline Zr-93 & - & & $5 E+06$ & - & & $5 E+06$ & Zr-93 \\
\hline $\mathrm{Nb}-93 \mathrm{~m}$ & - & & $4 E+09$ & - & & $4 E+09$ & $\mathrm{Nb}-93 \mathrm{~m}$ \\
\hline $\mathrm{Nb}-94$ & - & & $9 E+01$ & - & & $1 E+02$ & $\mathrm{Nb}-94$ \\
\hline Tc-99 & $1 E+02$ & & $2 E+04$ & $2 E+02$ & & $2 E+04$ & Tc-99 \\
\hline$P d-107$ & - & & $6 E+06$ & - & & $6 E+06$ & $\mathrm{Pd}-107$ \\
\hline $\mathrm{Ag}-108 \mathrm{~m}$ & - & & $5 E+02$ & - & & $1 E+03$ & $\mathrm{Ag}-108 \mathrm{~m}$ \\
\hline $\mathrm{Cd}-113 \mathrm{~m}$ & - & & $1 E+06$ & - & & $1 E+06$ & $\mathrm{Cd}-113 \mathrm{~m}$ \\
\hline $\mathrm{Sn}-121 \mathrm{~m}$ & - & & $2 E+07$ & - & & $5 E+07$ & $\mathrm{Sn}-121 \mathrm{~m}$ \\
\hline$S n-126$ & - & & $8 E+01$ & - & & $8 E+01$ & Sn-126 \\
\hline $1-129$ & - & & $2 E+03$ & - & & $2 E+03$ & $\mid-129$ \\
\hline Cs-135 & $=$ & & $2 E+05$ & - & & $2 E+05$ & Cs-135 \\
\hline Cs-137 & - & & $3 E+05$ & - & & $8 E+05$ & Cs-137 \\
\hline $\mathrm{Ba}-133$ & - & & $3 E+08$ & - & & $3 E+08$ & Ba-133 \\
\hline$S m-151$ & - & & $2 E+08$ & - & & $2 E+08$ & Sm-151 \\
\hline Eu-152 & - & & $2 E+07$ & - & & $2 E+07$ & Eu-152 \\
\hline Eu-154 & - & & $4 E+08$ & - & & $4 E+08$ & Eu-154 \\
\hline $\mathrm{Pb}-210$ & - & & $7 E+04$ & - & & $7 E+04$ & $\mathrm{~Pb}-210$ \\
\hline Ra-226 & - & & $8 E+01$ & - & & $9 E+01$ & Ra-226 \\
\hline Ra-228 & - & & $4 E+09$ & - & & $4 E+09$ & Ra-228 \\
\hline Th-229 & - & & $5 E+02$ & - & & $5 E+02$ & Th-229 \\
\hline Th-230 & - & & $8 E+01$ & - & & $8 E+01$ & Th-230 \\
\hline Th-232 & - & & $6 E+01$ & - & & $6 E+01$ & Th-232 \\
\hline $\mathrm{Pa}-231$ & - & & $2 E+02$ & $=$ & & $2 E+02$ & $\mathrm{~Pa}-231$ \\
\hline
\end{tabular}


Table 9-7. Permissible Concentrations for the Generic Disposal Designs at SNL/NM (permissible concentration related to the most limiting pathway for each facility design is highlighted in bold italic) (Part 2 of 2)

\begin{tabular}{|c|c|c|c|c|c|c|c|}
\hline \multirow[t]{2}{*}{ Nuclide } & \multicolumn{3}{|c|}{ Trench } & \multicolumn{3}{|c|}{ Tumulus } & \multirow[t]{2}{*}{ Nuclide } \\
\hline & $\begin{array}{c}C_{\text {w.water }}{ }^{2, b} \\
\left(\mu \mathrm{Ci} / \mathrm{m}^{3}\right)\end{array}$ & $\begin{array}{l}C_{W \cdot A m m}{ }^{c} \\
\left(\mu \mathrm{Ci} / \mathrm{m}^{3}\right)\end{array}$ & $\begin{array}{l}C_{W-1 n t r}{ }^{d} \\
\left(\mu \mathrm{Ci} / \mathrm{m}^{3}\right)\end{array}$ & $\begin{array}{c}C_{\text {weswater }}{ }^{2, b} \\
\left.\left(\mu \mathrm{Ci}^{3}\right)^{3}\right)\end{array}$ & $\begin{array}{l}C_{W-A m m}{ }^{c} \\
\left(\mu \mathrm{Ci} / m^{3}\right)\end{array}$ & $\begin{array}{l}C_{W / n \pi r}^{d} \\
\left(\mu \mathrm{Ci} / \mathrm{m}^{3}\right)\end{array}$ & \\
\hline $\mathrm{U}-232$ & - & & $2 E+03$ & - & & $1 E+04$ & U-232 \\
\hline U-233 & - & & $7 E+02$ & - & & $7 E+02$ & $U-233$ \\
\hline $\mathrm{U}-234$ & - & & $1 E+03$ & $=$ & & $1 E+03$ & U-234 \\
\hline U-235 & - & & $6 E+02$ & $=$ & & $6 E+02$ & U-235 \\
\hline U-236 & - & & $2 E+04$ & - & & $2 E+04$ & $\mathrm{U}-236$ \\
\hline U-238 & - & & $5 E+03$ & - & & $5 E+03$ & $U-238$ \\
\hline Np-237 & - & & $4 E+02$ & $=$ & & $4 E+02$ & Np-237 \\
\hline $\mathrm{Pu}-238$ & - & & $7 E+04$ & - & & $1 E+05$ & Pu-238 \\
\hline Pu-239 & - & & $6 E+03$ & $=$ & & $6 E+03$ & Pu-239 \\
\hline $\mathrm{Pu}-240$ & - & & $6 E+03$ & - & & $7 E+03$ & Pu-240 \\
\hline Pu-241 & - & & $2 E+05$ & - & & $3 E+05$ & Pu-241 \\
\hline $\mathrm{Pu}-242$ & - & & $6 E+03$ & - & & $6 E+03$ & Pu-242 \\
\hline Pu-244 & - & & $4 E+02$ & - & & $4 E+02$ & Pu-244 \\
\hline Am-241 & - & & $7 E+03$ & - & & $9 E+03$ & Am-241 \\
\hline Am-243 & - & & $9 E+02$ & - & & $9 E+02$ & Am-243 \\
\hline $\mathrm{Cm}-243$ & - & & $8 E+05$ & - & & $8 E+05$ & $\mathrm{Cm}-243$ \\
\hline $\mathrm{Cm}-244$ & - & & $2 E+06$ & - & & $2 E+06$ & $\mathrm{Cm}-244$ \\
\hline Cm-245 & - & & $1 E+03$ & - & & $1 E+03$ & $\mathrm{Cm}-245$ \\
\hline $\mathrm{Cm}-246$ & - & & $6 E+03$ & - & & $6 E+03$ & $\mathrm{Cm}-246$ \\
\hline Cm-247 & - & & $3 E+02$ & - & & $3 E+02$ & $\mathrm{Cm}-247$ \\
\hline $\mathrm{Cm}-248$ & - & & $2 E+03$ & - & & $2 E+03$ & $\mathrm{Cm}-248$ \\
\hline Cf-249 & - & & $8 E+02$ & - & & $1 E+03$ & Cf-249 \\
\hline Cf-250 & - & & $2 E+06$ & - & & $2 E+06$ & Cf-250 \\
\hline Cf-251 & - & & $2 E+03$ & - & & $2 E+03$ & Cf-251 \\
\hline
\end{tabular}

a "NL" means No Limit - estimated permissible concentration factor is greater than the specific activity of the pure elemental radionuclide.

b "-" indicates that the radionuclide concentration is based on an arrival time beyond 10,000 years; see Table $9-4$ for specific values.

c Results presented for radionclides expected to be volatile under disposal facility conditions.

d Concentration is based on the most restrictive intrusion scenario assumed for the site; see Table 9-6. 
For both the trench and tumulus designs, only Tc-99 was limited by the water pathway. With a soil $K_{d}$ value of $0.1 \mathrm{~mL} / \mathrm{g}, \mathrm{Tc}-99$ is relatively mobile and long-lived (the half-life is $213,000 \mathrm{y})$.

For both the trench and tumulus designs, only C-14 was limited by the atmospheric pathway. This result is based on a conservative analysis because the conceptual model for the atmospheric pathway did not account for the effects of the grout material on the rate of $\mathrm{CO}_{2}$ emanation from the stabilized waste (see Chapter 6 of Volume 2).

\subsubsection{Discussion}

The results of the PE are based on the framework of assumptions summarized in Chapter 1 of this volume and discussed in detail in Volume 2 of this report and on the site-specific conceptual model for contaminant transport discussed in this chapter. Using alternative assumptions about the conceptual model has the potential to affect the results. Changes in the conceptual model could include alternative assumptions about the disposal facility, the source term, and radionuclide movement in the three pathways. Depending on the degree of possible variation and the relative importance of the parameters used in the calculation of estimated permissible radionuclide concentrations, variability in parameter values can also affect the results. For parameters, results could vary depending on potential changes in values of both the generic and the site-specific parameters used in the PE analysis.

The effect on results from using alternative generic assumptions and parameter values is discussed in Chapter 6 of Volume 2. In addition, a discussion is provided in that chapter about the effects of using alternative values for site-specific parameters. Based on this discussion, four parameters were identified (three site-specific and one generic, all used in the water pathway analysis) that could potentially influence the results to the degree that the calculated waste concentrations become limited by a pathway other than the one determined for the PE (Table 9-7). The effects on the results of using alternative values for these four parameters for the water pathway in the PE for SNL/NM are discussed in this section. The basis for and possible variation in the values used in the PE for these parameters are discussed in Section 9.6.2.2.

\subsubsection{Parameter Sensitivity Analysis}

The PE provided results for two disposal facility designs: a RCRA-compliant, belowground trench and a RCRA-compliant, above-ground tumulus. Similar assumptions about the integrity of engineered barriers were made in the PE for both facility designs. Because the factors used to estimate transport of radionuclides in the water pathway for both designs were similar, the discussion in this section focuses on examining the results for the indicator radionuclides reported for the tumulus design (indicator radionuclides are defined in Chapter 6 of Volume 2).

As discussed in Chapter 6 of Volume 2, four parameters used in the PE were identified as having a potential range of values that might affect results: natural recharge through the disposal facility $(i)$; groundwater Darcy velocity $\left(q_{g w}\right)$; plan-view area of the facility $(A)$; and distribution coefficients $\left(K_{d} s\right)$. These parameter values for SNL/NM are summarized in Table 9-8. 
Table 9-8. Parameter Values Used in the PE for SNL/NM with Potential Variability That Could Affect the Results

\begin{tabular}{|l|l|}
\hline \multicolumn{1}{|c|}{ Parameter } & \multicolumn{1}{|c|}{ Value } \\
\hline Natural recharge through local soils, $i$ & $\begin{array}{l}0.02 \mathrm{~m} / \mathrm{y} \text { (based on site information; see Section } \\
9.3 .1 .1)\end{array}$ \\
\hline $\begin{array}{l}\text { Distribution coefficients for geologic } \\
\text { media, } K_{d}\end{array}$ & see Table $9-1$ in this chapter for values \\
\hline Groundwater Darcy velocity, $q_{g w}$ & $\begin{array}{l}0.5 \mathrm{~m} / \mathrm{y} \text { (based on site-specific measurement; } \\
\text { see Section } 9.4 .1 \text { for discussion) }\end{array}$ \\
\hline Plan-view Area, $A$ & $2500 \mathrm{~m}^{2}$ (standard PE value) \\
\hline
\end{tabular}

The traditional procedure for performing a sensitivity analysis is to vary the parameters used in the calculations and observe the effect on the results. To be meaningful, this method requires some knowledge of the statistical distribution of each of the parameters considered, including their likely maximum and minimum values. For the PE calculations, the potential variability of the parameters used to calculate the permissible waste concentrations for the two different facility designs was not estimated. For most of the radionuclides considered in the PE, there were only two exposure pathways: the water pathway and intruder exposure scenarios (the atmospheric pathway is considered only for $\mathrm{H}-3$ and $\mathrm{C}-14$ ). The intruder pathway results provide a baseline that can be used for comparison with the water pathway results because the intruder scenarios used in the PE were relatively independent of the physical characteristics of the individual sites. For $\mathrm{H}-3$ and $\mathrm{C}-14$, the atmospheric pathway results present a baseline that can also be used for comparison with the water pathway because the atmospheric pathway input parameters do not significantly impact the results (see Section 6 of Volume 2).

The intruder and atmospheric baselines provided an alternative method of performing sensitivity analyses for the $\mathrm{PE}$. The input parameters for the water pathway were varied to determine if the controlling exposure pathway could be altered (e.g., the results could be changed from intruder-scenario-controlled [or atmospheric-pathway-controlled] to water-pathwaycontrolled). After new values for the water pathway parameters were determined, these values were examined for reasonableness based on physical constraints at the site.

To analyze the sensitivity of the results to changes in the parameter values for recharge, groundwater Darcy velocity, and area of the facility, the parameter values used in the PE for $\mathrm{SNL} / \mathrm{NM}$ were varied. Only one parameter value was varied at a time for each indicator radionuclide, leaving the others equal to their $\mathrm{PE}$ values. In most instances, the parameter value was varied until the waste concentrations for the water and intruder (or atmospheric) pathways became equal, regardless of the likelihood (or physical impossibility) of the value to occur. 
The parameter values that caused the permissible concentrations for the water and intruder pathways to become equal are listed in Table 9-9a for the 8 indicator radionuclides. For the indicator radionuclide C-14, the controlling pathway is the atmospheric pathway, so the water versus intruder comparison is not applicable. For Tc-99, the value for recharge had to decrease by about two orders of magnitude; the Darcy velocity had to increase by two orders of magnitude to change the limiting pathway from drinking water to intruder. For U-238, the value for the recharge had to decrease by about two orders of magnitude, or the groundwater velocity had to increase by a factor of 60 for the water pathway concentration to equal the intruder pathway concentration. However, for both parameters, the arrival times for U-238 exceeded 10,000 y. For Am-241, the value for recharge had to increase by nearly a factor of five to change the limiting pathway. Similarly, the Darcy velocity had to decrease by a factor of five or the area had to increase by a factor of 36 in order for the intruder concentration to equal the water pathway concentration. Again, for all parameters the arrival time exceeded 10,000 y.

The parameter values that caused the permissible concentrations for the water and atmospheric pathways to become equal are listed in Table 9-9b for $\mathrm{H}-3$ and $\mathrm{C}-14$. For $\mathrm{H}-3$, the limiting pathway is the intrusion scenario, so this comparison is not applicable. For C-14, the recharge had to increase by a factor of six to change the controlling pathway from atmospheric to water, although the result was associated with an arrival time greater than $10,000 \mathrm{y}$. No variation in the values for Darcy velocity or area caused the atmospheric concentration to equal the water pathway concentration for C-14.

The $K_{d}$ values that caused the permissible concentrations for the water and intruder pathways to be the same are listed in Table 9-10 for 5 of the indicator radionuclides. The indicator radionuclides $\mathrm{H}-3, \mathrm{C}-14$, and Tc-99 were not considered in this analysis because general consensus is that the $K_{d}$ values for these radionuclides are small. A $K_{d}$ value of $0.8 \mathrm{~mL} / \mathrm{g}$ resulted in an arrival time at the performance boundary equal to $10,000 \mathrm{y}$. For U-238, no variation in $K_{d}$ value caused the water pathway concentration to equal the intruder concentration, although a value less than $0.8 \mathrm{~mL} / \mathrm{g}$ caused an arrival at the performance boundary before $10,000 \mathrm{y}$, which changed the limiting pathway from intruder to water. The PE permissible waste concentration for Am-241 was limited by the decay product (Np-237) contribution to the dose. If the $K_{d}$ value for Am-241 was reduced to $0.26 \mathrm{~mL} / \mathrm{g}$, then the water pathway concentration was limited by the parent radionuclide (Am-241) and the water pathway controlled. Due to the long half-life of Np-237, reduction of its $K_{d}$ had no effect on the resulting waste concentration.

\subsubsection{Physical Constraints on Sensitivity Analysis Values}

The PE results for SNL/NM are based on parameter values provided by the SNL/NM technical staff for site-specific parameters used in calculations. Descriptions and technical justifications of these values are provided in Sections 9.3 and 9.4. The range and statistical distribution may not be known for each input parameter value; however, site-specific knowledge can be used to determine whether the values determined in the sensitivity analysis are reasonable and physically possible at SNL/NM. 
Table 9-9. Parameter Values That Caused the Permissible Concentrations for the Water and Intruder Pathways to Be Equal for Indicator Radionuclides at SNL/NM (tumulus design) (bold italic type indicates limiting pathway in the PE)

(a) Water/Intruder Pathways

\begin{tabular}{|c|c|c|c|c|c|c|}
\hline \multirow[t]{4}{*}{$\begin{array}{l}\text { Indicator } \\
\text { Nuclide }\end{array}$} & \multirow[t]{4}{*}{$\begin{array}{c}\text { PE } \\
C_{W-W a t e r} \\
\left(\mu \mathrm{Ci} / m^{3}\right)\end{array}$} & \multirow[t]{4}{*}{$\begin{array}{c}\text { PE } \\
C_{W / \text { ntr }} \\
\left(\mu \mathrm{Ci} / \mathrm{m}^{3}\right)\end{array}$} & \multirow[t]{4}{*}{$\begin{array}{c}\text { PE } \\
\frac{C_{W-\ln t r}}{C_{W \cdot W a t e r}}\end{array}$} & $\begin{array}{c}\text { Natural } \\
\text { Recharge, } \\
i \\
(\mathrm{~m} / \mathrm{y})\end{array}$ & $\begin{array}{l}\text { Groundwater } \\
\text { (Aquifer) } \\
\text { Velocity, } q_{g w} \\
\text { (m/y) }\end{array}$ & $\begin{array}{c}\text { Area, } \\
\text { A } \\
\left(m^{2}\right)\end{array}$ \\
\hline & & & & \multicolumn{3}{|c|}{ PE Values } \\
\hline & & & & 0.02 & 0.5 & 2500 \\
\hline & & & & \multicolumn{3}{|c|}{$\begin{array}{c}\text { Value That Caused Equal } \\
\text { Concentrations }\end{array}$} \\
\hline $\mathrm{H}-3$ & $\mathrm{NL}$ & $7 E+07$ & - & c & c & c \\
\hline$C-14$ & $6 E+06^{b}$ & $1 E+04$ & $2 \mathrm{E}-03$ & $0.06^{b}$ & c & $c$ \\
\hline Sr-90 & $\mathrm{NL}^{\mathrm{b}}$ & $5 E+04$ & - & c & c & c \\
\hline Tc-99 & $2 E+02$ & $2 E+04$ & 100 & $0.0003^{b}$ & 45 & $<100^{c}$ \\
\hline Cs-137 & $N^{b}$ & $8 E+05$ & - & c & c & c \\
\hline U-238 & $9 E+01^{b}$ & $5 E+03$ & 60 & $0.0003^{b}$ & $30^{b}$ & $<100^{c}$ \\
\hline Pu-239 & $\mathrm{NL}^{\mathrm{b}}$ & $6 E+03$ & - & $1.4^{b}$ & c & $c$ \\
\hline $\begin{array}{l}A m-241 \\
(\mathrm{~Np}-237)^{d}\end{array}$ & $3 E+04^{b, 0}$ & $9 E+03$ & $3 E-01$ & $0.09^{b, 0}$ & $0.1^{b, 0}$ & $9 E+04^{b, 0}$ \\
\hline
\end{tabular}

a "NL" means No Limit - estimated permissible concentration is greater than the specific activity of the pure elemental radionuclide.

b Radionuclide arrival time at the performance boundary is greater than $10,000 \mathrm{y}$.

c No variation in values caused equal concentrations.

d The dominant decay product for Am-241

e Based on the dominant decay product, Np-237

"-" Value could not be calculated.

(b) Water/Atmospheric Pathways

\begin{tabular}{|c|c|c|c|c|c|c|}
\hline \multirow[t]{4}{*}{$\begin{array}{l}\text { Indicator } \\
\text { Nuclide }\end{array}$} & \multirow[t]{4}{*}{$\begin{array}{c}\text { PE } \\
C_{\text {w-Water }}{ }^{2} \\
\left(\mu \mathrm{Ci} / \mathrm{m}^{3}\right)\end{array}$} & \multirow[t]{4}{*}{$\begin{array}{c}\text { PE } \\
C_{W-A t m} \\
\left(\mu \mathrm{Ci} / \mathrm{m}^{3}\right)\end{array}$} & \multirow[t]{4}{*}{$\begin{array}{c}\text { PE } \\
C_{\text {W-Atm }} \\
C_{\text {W-Water }}\end{array}$} & $\begin{array}{c}\text { Natural } \\
\text { Recharge, } \\
i \\
(\mathrm{~m} / \mathrm{y})\end{array}$ & $\begin{array}{l}\text { Groundwater } \\
\text { (Aquifer) } \\
\text { Velocity, } q_{\text {gw }} \\
\text { (m/y) }\end{array}$ & $\begin{array}{c}\text { Area, } \\
\text { A } \\
\left(\mathrm{m}^{2}\right)\end{array}$ \\
\hline & & & & \multicolumn{3}{|c|}{ PE Values } \\
\hline & & & & 0.02 & 0.5 & 2500 \\
\hline & & & & \multicolumn{3}{|c|}{$\begin{array}{l}\text { Value That Caused Equal } \\
\text { Concentrations }\end{array}$} \\
\hline $\mathrm{H}-3$ & $\mathrm{NL}^{\mathrm{b}}$ & $3 E+09$ & - & c & c & c \\
\hline C-14 & $6 E+06^{b}$ & $2 E+03$ & $3 E-04$ & $0.12^{b}$ & c & c \\
\hline
\end{tabular}

a "NL" means No Limit - estimated permissible concentration is greater than the specific activity of the pure elemental radionuclide.

b Radionuclide arrival time at the performance boundary is greater than $10,000 \mathrm{y}$.

c No variation in values caused equal concentrations.

"-" Value could not be calculated. 
Table 9-10. Variation of $K_{d}$ Values for the Geologic Media at SNL/NM (tumulus design) (a $K_{d}$ value of $0.8 \mathrm{~mL} / \mathrm{g}$ caused radionuclide arrival at the performance boundary equal to $10,000 \mathrm{y})$

\begin{tabular}{|c|c|c|c|c|c|}
\hline $\begin{array}{l}\text { Indicator } \\
\text { Nuclide }\end{array}$ & $\begin{array}{c}\text { PE } \\
K_{d} \\
(\mathrm{~mL} / \mathrm{g})\end{array}$ & $\begin{array}{c}\text { PE } \\
\text { Cwrwater }^{a}\end{array}$ & $\begin{array}{c}\text { PE } \\
C_{W-\ln t r}\end{array}$ & $\begin{array}{c}\text { PE } \\
\frac{C_{W-\ln t}}{C_{W-W a t e r}}\end{array}$ & $\begin{array}{l}K_{d} \text { Value that } \\
\text { Caused Equal } \\
\text { Concentrations }\end{array}$ \\
\hline Sr-90 & 15 & $\mathrm{NL}^{\mathrm{b}}$ & $5 E+04$ & - & c \\
\hline Cs-137 & 280 & $\mathrm{NL}^{\mathrm{b}}$ & $8 E+05$ & - & $c$ \\
\hline U-238 & 35 & $9 E+01^{b}$ & $5 E+03$ & 60 & $c, d$ \\
\hline Pu-239 & 550 & $\mathrm{NL}^{\mathrm{b}}$ & $6 E+03$ & - & - \\
\hline $\begin{array}{l}\mathrm{Am}-241 \\
(\mathrm{~Np}-237)^{\circ}\end{array}$ & $\begin{array}{l}1900 \\
(5)\end{array}$ & $3 E+04^{b, f}$ & $9 E+03$ & 0.3 & 0.26 \\
\hline \multicolumn{6}{|c|}{$\begin{array}{l}\text { "NL" means No Limit - the estimated permissible waste concentration is greater than the specific activity of the pure } \\
\text { elemental radionuclide. } \\
\text { Radivnuclide arrival time at the performance boundary is greater than } 10,000 \mathrm{y} \text {. } \\
\text { No variation in value caused equal concentrations. } \\
\text { Value less than } 0.8 \mathrm{~mL} / \mathrm{g} \text { caused arrival at performance boundary before } 10,000 \mathrm{y} \text {, which changed the limiting pathway. } \\
\text { The dominant decay product for Am-241 } \\
\text { Based on the dominant decay product, Np-237 } \\
\text { Value could not be calculated. }\end{array}$} \\
\hline
\end{tabular}

\section{Natural Recharge}

The values for natural recharge estimated in the sensitivity analysis range from 0.003 to $1.4 \mathrm{~m} / \mathrm{y}(0.01$ to $4.6 \mathrm{ft} / \mathrm{y}$ ) (Table $9-9 \mathrm{a}$ and $\mathrm{b}$ ). The natural recharge at SNL/NM is not well known, and the reported range for natural recharge is $0.0005 \mathrm{~m} / \mathrm{y}$ to $0.05 \mathrm{~m} / \mathrm{y}(0.0016$ to $0.16 \mathrm{ft} / \mathrm{y}$ ). However, all of the sensitivity analysis recharge values produced results with corresponding radionuclide travel times greater than $10,000 \mathrm{y}$.

\section{Groundwater Darcy Velocity}

The values for the groundwater Darcy velocity estimated by the sensitivity analysis vary from 0.1 to $45 \mathrm{~m} / \mathrm{y}(0.3$ to $148 \mathrm{ft} / \mathrm{y})$ (Table $9-9 \mathrm{a})$ compared to the $\mathrm{PE}$ value of $0.5 \mathrm{~m} / \mathrm{y}(0.16 \mathrm{ft} / \mathrm{y})$. However, the U-238 and Am-241 results (30 and $0.1 \mathrm{~m} / \mathrm{y}$ [98 and $0.3 \mathrm{ft} / \mathrm{y}$ ], respectively) correspond to an arrival time greater than $10,000 \mathrm{y}$. A Darcy velocity of $45 \mathrm{~m} / \mathrm{y}(148 \mathrm{ft} / \mathrm{y})$ for Tc-99 is physically possible as this value falls within the range of aquifer property measurements made at SNL/NM (see Section 9.4.1).

\section{Facility Area}

The value for the facility area estimated in the sensitivity analysis was $90,000 \mathrm{~m}^{2}$ $\left(970,000 \mathrm{ft}^{2}\right.$ ) for Am-241 (Table 9-9a). The results for Tc-99 and U-238 show that it was not possible to change the dominant pathway even when the total area was less than $100 \mathrm{~m}^{2}$ $\left(1080 \mathrm{ft}^{2}\right)$. For Am-241, a value of $90,000 \mathrm{~m}^{2}\left(970,000 \mathrm{ft}^{2}\right)$ still resulted in a travel time that was greater than $10,000 \mathrm{y}$.

\section{Distribution Coefficients}

The results shown in Table 9-10 indicate that it was not possible to change the dominant exposure pathway by changing the $K_{d}$ value. For Am-241, it was possible to change the controlling pathway from intruder to water when the $K_{d}$ for Am-241 was changed to near $0 \mathrm{~mL} / \mathrm{g}$; however, a $K_{d}$ of near $0 \mathrm{~mL} / \mathrm{g}$ is probably not reasonable for Am-241, which had a PE $K_{d}$ value of 
$1900 \mathrm{~mL} / \mathrm{g}$. Decreasing the $K_{d}$ value for U-238 about 2 orders of magnitude from the PE value of $35 \mathrm{~mL} / \mathrm{g}$ to $0.8 \mathrm{~mL} / \mathrm{g}$ is probably not reasonable.

\subsection{OBSERVATIONS}

Based on the results of the PE and the parameter-sensitivity analysis, the following observations can be made about MLLW disposal at SNL/NM:

- The SNL/NM site has characteristics that are typical of an arid climate. A low natural recharge and thick unsaturated zone are found here. These site properties correspond with long radionuclide travel times through the unsaturated zone. In fact, $89 \%$ of the radionuclide travel time from the disposal facility to the performance boundary is accounted for by the unsaturated zone travel time.

- For both the trench and tumulus designs at SNL/NM, the results indicate that of the 58 radionuclides evaluated in the $\mathrm{PE}, 56$ would be limited by the intrusion scenarios. These results reflect the dominant role of the selected human intrusion scenarios that is demonstrated for almost all the sites considered in the PE (see Sections 7.5 and 7.6 in Volume 2). This dominance indicates a need to be aware of the inability to predict the social behavior of populations far into the future.

The results also indicate that for the water pathway, 56 radionuclides for both the trench and tumulus designs would arrive at the performance boundary after the 10,000-y period of consideration in the PE analysis of the water pathway. Of the two radionuclides that would arrive before $10,000 \mathrm{y}$, one had no limit on waste concentration.

Because SNL/NM has many radionuclides that either are limited by the intrusion scenarios, arrive at the performance boundary after $10,000 \mathrm{y}$, or have no limit on waste concentration, this site may have flexibility in accepting a variety of radionuclides for disposal.

- Using either a trench or a tumulus design is feasible at SNL/NM. In either case, the thick unsaturated zone allows a large buffer between the bottom of the facility and the water table.

- The SNL/NM site does not appear to have physical constraints that could limit disposal activities. The site has an adequate areal extent and a thick unsaturated zone.

- The sensitivity analysis indicates that, in general, reasonable changes in values for the natural recharge, groundwater Darcy velocity, and facility size did not change the PE results. The only reasonable parameter value change that caused the controlling pathway to change from water to intruder was the Darcy velocity for Tc-99.

In flow and transport problems, the $K_{d}$ values are often the most uncertain site-specific input parameters. However, for SNL/NM none of the $K_{d}$ values for the indicator radionuclides could be changed in a reasonable way to change the controlling pathway. 
- The PE was a scoping analysis performed using assumptions that are conservative relative to most LLW performance assessments. There are no site-specific studies to compare with the PE results. A more detailed performance assessment would be required for permitting or other disposal planning.

\subsection{REFERENCES}

Baer, T.A., L. L. Price, J. N. Emery, N. E. Olague, 1994. Second Performance Assessment Iteration of the Greater Confinement Disposal Facility at the Nevada Test Site. SAND930089. Albuquerque, NM: Sandia National Laboratories.

Chu, M. S. Y., M. W. Kozak, J. E. Campbell, and B. M. Thompson, 1991. A Self-Teaching Curriculum for the NRC/SNL Low-Level Waste Performance Assessment Methodology, NUREG/CR-5539, SAND90-0585, Sandia National Laboratories, Albuquerque, New Mexico.

Cooper, C.D., and F.C. Alley, 1986. Air Pollution Control: A Design Approach. Prospect Heights, $\Pi$ : Waveland Press, Inc.

CRC, 1981. CRC Handbook of Chemistry and Physics. Eds. Robert C. Weast and Melvin J. Astle. Boca Raton, FL: CRC Press, Inc.

Culp, T. A., C. F. Cheng, W. Cox, N. Durand, M. Irwin, A. Jones, F. Lauffer, M. Lincoln, Y. McClellan, K. Molley, and T. Wolff, 1994. 1993 Site Environmental Report, Sandia National Laboratories, Albuquerque, New Mexico, SAND94-1293. Albuquerque, NM: Sandia National Laboratories.

EPRI (Electric Power Research Institute), 1985. A Review of Field-Scale Physical Solute Transport Processes in Saturated and Unsaturated Porous Media. EPRI EA-4190. Norris, TN: Tennessee Valley Authority.

EPA, 1992. User's Guide for the Industrial Source Complex (ISC2) Dispersion Models, Volume I: User Instructions. EPA Publication No. EPA-450/4-92-008a. Research Triangle, NC:

U.S. Environmental Protection Agency.

FFCAct, 1992. Federal Facility Compliance Act of 1992. P.L. 102-386, October 1992.

Gruebel, Marilyn M., Robert D. Waters, Maryann B. Hospelhorn, and Margaret S.Y. Chu, eds., 1994. Framework for DOE Mixed Low-Level Waste Disposal: Site Fact Sheets. SAND942728. Albuquerque, NM: Sandia National Laboratories.

Kincaid, C.T., J.W. Shade, G.A. Whyatt, M.G. Piepho, K. Rhoads, J.A. Voogd, J.H. Westsik, Jr., M.D. Freshley, K.A. Blanchard, and B.G. Lauzon, eds., 1993. Performance Assessment of Grouted Double-Shell Tank Waste Disposal at Hanford. WHC-SD-WM-EE-004, Rev. 0. U.S. Department of Energy, Pacific Northwest Laboratory and Westinghouse Hanford Company. 
Maheras, Steven J., Arthur S. Rood, Swen O. Magnuson, Mary E. Sussman, and Rajiv N. Bhatt, 1994. Radioactive Waste Management Complex Low-Level Waste Radiological Performance Assessment. EGG-WM-8773. Idaho Falls, ID: U.S. Department of Energy Office of Environmental Restoration and Waste Management, DOE Idaho Operations Office.

MMES (Martin Marietta Energy Systems), EG\&G Idaho, Inc., and Westinghouse Savannah River Company, 1994. Radiological Performance Assessment for the E-Area Vaults Disposal Facility (U). WSRC-RP-94-218, Rev. 0. Aiken, SC: Westinghouse Savannah River Company.

ORNL (Oak Ridge National Laboratory), 1994. Performance Assessment for Continuing and Future Operations at Solid Waste Storage Area 6. ORNL-6783. Oak Ridge, TN: U.S. Department of Energy, Oak Ridge National Laboratory.

Sandia National Laboratories (SNL), 1995a. Sitewide Hydrogeologic Characterization Program, Calendar Year 1994 Annual Report. Albuquerque, NM: Sandia National Laboratories, Environmental Restoration Program.

Sandia National Laboratories (SNL), 1995b. Groundwater Protection Program, Calendar Year 1994 Annual Groundwater Monitoring Report. Albuquerque, NM: Sandia National Laboratories, Groundwater Protection Program.

Sandia National Laboratories (SNL), 1994. Sitewide Hydrogeologic Characterization Program, Calendar Year 1993 Annual Report. Albuquerque, NM: Sandia National Laboratories, Environmental Restoration Program.

Sandia National Laboratories (SNL), 1993. Sitewide Hydrogeologic Characterization Program, Calendar Year 1992 Annual Report. Albuquerque, NM: Sandia National Laboratories, Environmental Restoration Program.

Thibault, D.H., M.I. Sheppard, and P.A. Smith, 1990. A Critical Compilation and Review of Default Soil Solid/Liquid Partition Coefficients, Kd, for Use in Environmental Assessments. AECL-10125. Pinawa, Manitoba, Canada: Whiteshell Nuclear Research Establishment, Atomic Energy of Canada Limited.

\section{Acknowledgments}

The SNL Core Team acknowledges the contributions of Maureen Lincoln, Jim McCord, and Todd Culp of the SNLNM staff. 


\section{New York: WEST VALLEY DEMONSTRATION PROJECT (WVDP) Core Team Contact: Alva M. Parsons}

The Federal Facility Compliance Act (FFCAct, 1992) requires the Department of Energy (DOE) to establish plans in conjunction with its regulators and with members of the public for the treatment of DOE's mixed low-level waste (MLLW). Although the FFCAct did not specifically address disposal of treated MLLW, both DOE and the States recognized that disposal issues were an integral part of treatment discussions. Since 1992, DOE has worked with the States to define and develop an evaluation process for disposal options. Preliminary activities of this joint DOEState process have narrowed the sites for further evaluation from 49 to 15 . The West Valley Demonstration Project (WVDP) is one of these 15 sites, but DOE's roles and responsibilities for the WVDP are specifically delineated in the WVDP Act of 1980. Because the WVDP Act does not authorize disposal of off-site waste, the PE for this New York State-owned site at West Valley evaluates only the on-site radionuclides of concern.

The Disposal Workgroup (DWG), which was established by DOE to develop a process for evaluating disposal options, designed a performance evaluation (PE) to quantify and compare the limitations of the remaining $15 \mathrm{DOE}$ sites for MLLW disposal. The principal goal of the PE was to estimate, for grouted residuals resulting from the treatment of MLLW, permissible concentrations of radionuclides in waste for disposal at each site. These "permissible waste concentrations" were based solely on long-term physical performance of the disposal facility and did not take into account any operational waste acceptance criteria that a site might have developed. The PE did not address any ethical, social, or policy considerations relevant to siting such facilities.

The PE used analyses that are consistent with the approach used in many low-level waste (LLW) performance assessments. The objective was to use a set of modeling assumptions of sufficient detail to capture major site-specific characteristics and yet be general enough for consistent application at all sites. Additionally, the analyses were designed to ensure that the sites were analyzed consistently and that all major assumptions were clearly stated.

The remainder of this chapter provides the PE results for the WVDP. The chapter contains the following information:

Section 10.1: brief, general description of the site, based on previous work done by the DWG (Gruebel et al., 1994)

Section 10.2: plans for MLLW disposal, and the location evaluated in the PE

Section 10.3: current understanding of radionuclide movement at the selected location based on available information, and the conceptual model used for the evaluation of each of three pathways (water, atmospheric, and inadvertent intruder)

Section 10.4: site-specific and generic values used in the PE calculations and their sources 
Section 10.5: estimates of maximum waste concentrations determined in the PE calculations for each of the three pathways, along with calculated values used in determining these results

Section 10.6: summary of results based on disposal-facility design; discussion with respect to such issues as uncertainty and sensitivity

Section 10.7: observations based on the results of the $\mathrm{PE}$ and the parameter sensitivity analysis

Section 10.8: references

The general assumptions and methodology used in the PE are summarized in Chapter 1 of this volume and explained in more detail in Volume 2 of this report. Overall results for all the sites are discussed in Chapter 7 of Volume 2.

\subsection{GENERAL DESCRIPTION OF THE SITE}

The West Valley Demonstration Project site is located in the town of Ashford, Cattaraugus County, about $56 \mathrm{~km}$ (35 mi) southeast of Buffalo, New York (Figure 10-1). Regional land uses are predominantly rural, with the land immediately adjacent to the site being used primarily for agriculture or arboriculture. Land use to the northwest of the site is mostly residential. Estimated population within a $10 \mathrm{~km}(6.2 \mathrm{mi})$ radius of the WVDP is 500; estimated population within a $50 \mathrm{~km}(31 \mathrm{mi})$ radius is 182,000 .

The WVDP occupies about $0.9 \mathrm{~km}^{2}\left(0.4 \mathrm{mi}^{2}\right)$ within the $13.5 \mathrm{~km}^{2}\left(5.3 \mathrm{mi}^{2}\right)$ Western New York Nuclear Service Center (WNYNSC) (Figure 10-2), which is owned by the New York State Energy Research and Development Authority. The DOE is operating the WVDP in conjunction with the New York State Energy Research and Development Authority. The DOE does not own the land or the waste associated with the WVDP and is not authorized to make decisions regarding on-site disposal of non-project waste. West Valley Nuclear Services, Inc., a subsidiary of the Westinghouse Corporation, manages the WVDP through a wholly-owned subsidiary.

From 1966 to 1972, the WNYNSC was the site of the only commercial nuclear fuel reprocessing facility operating in the United States. The plant reprocessed spent nuclear fuel assemblies from various nuclear power plants and government production reactors. Reprocessing operations generated approximately 2.3 million liters $(600,000$ gal $)$ of highly radioactive liquid waste that was stored in underground steel tanks. Nuclear fuel reprocessing operations were suspended in 1972, with the liquid waste left in the storage tanks. In 1980, the U.S. Congress authorized the DOE to carry out a nuclear waste management project at the WNYNSC. The WVDP was established to demonstrate that liquid waste from reprocessing spent nuclear fuel can be managed safely. Current activities at the WVDP are directed towards solidifying the high-level waste by vitrification and developing an environmental impact statement for future site closure activities. 


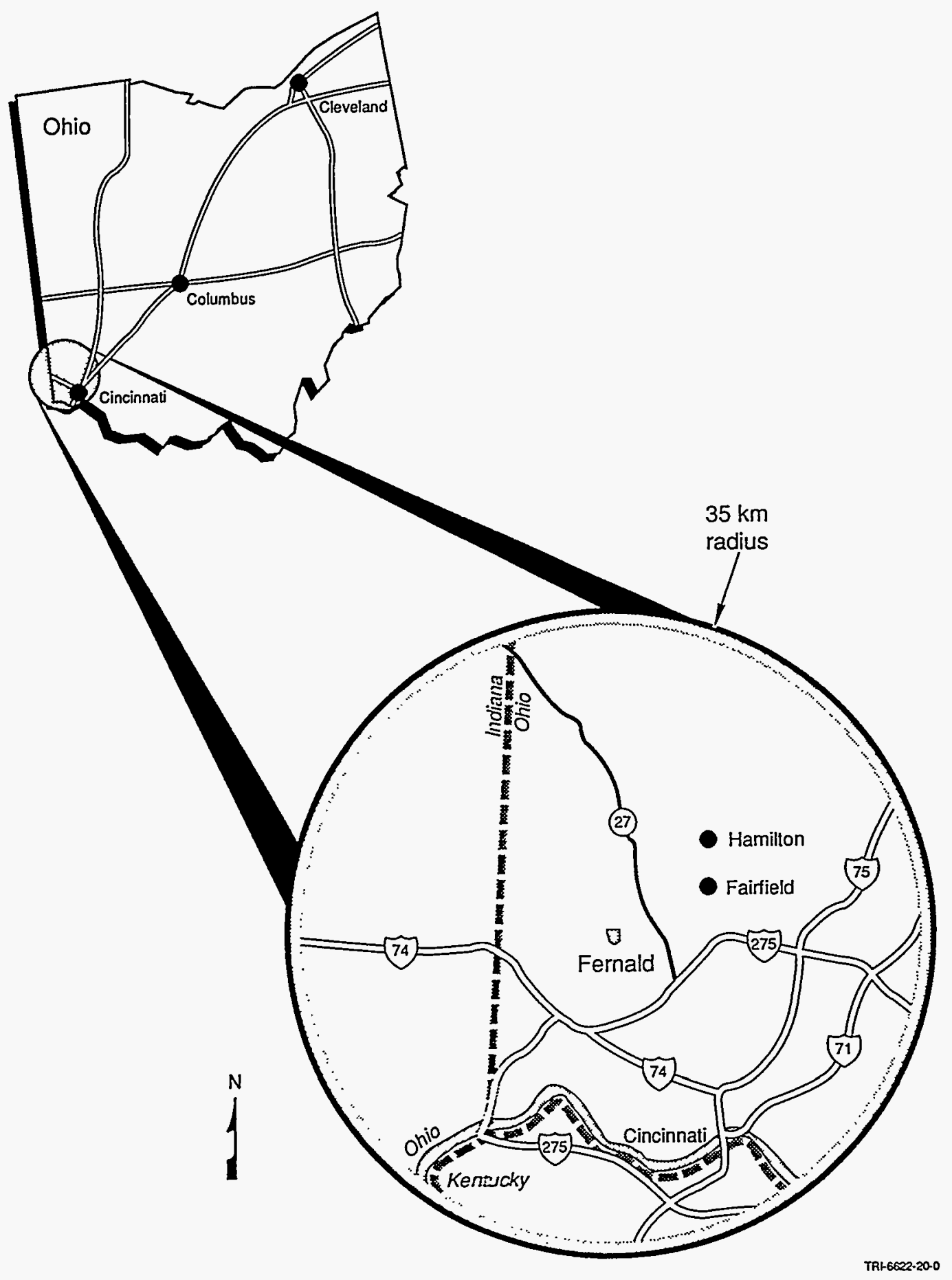

Figure 10-1. Location map for West Valley Demonstration Project. 


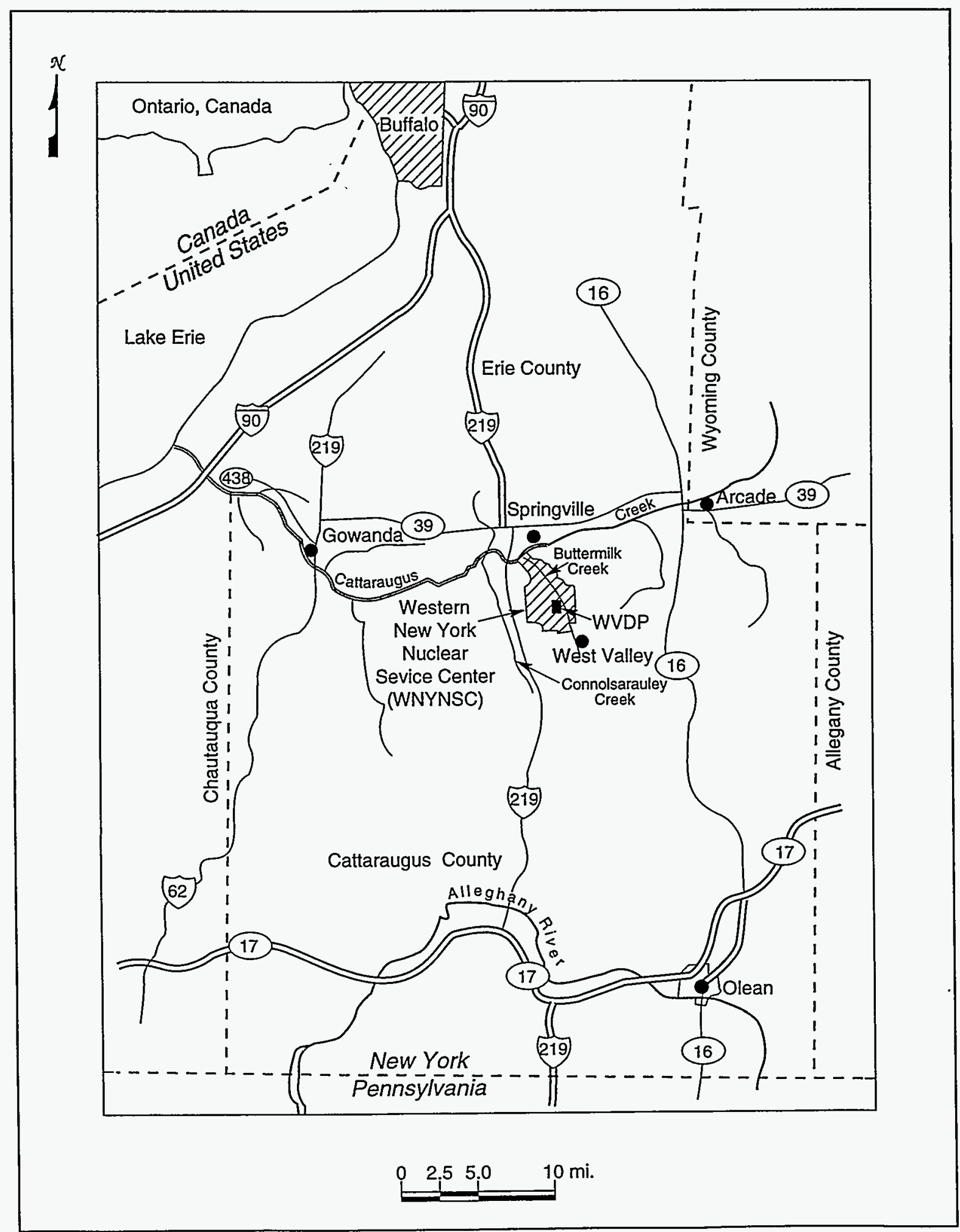

TR1-6622-33-1

Figure 10-2. Site map for West Valley Demonstration Project. 
The climate in western New York is moderate, with an average annual temperature of $7.2^{\circ} \mathrm{C}\left(45^{\circ} \mathrm{F}\right)$. Extremes of $37^{\circ} \mathrm{C}\left(98.6^{\circ} \mathrm{F}\right)$ and $-42^{\circ} \mathrm{C}\left(-43.6^{\circ} \mathrm{F}\right)$ have been recorded. Rainfall is relatively high, averaging about $104 \mathrm{~cm}$ (41 in.) per year. Precipitation is evenly distributed throughout the year and is markedly influenced by Lake Erie to the west and, to a lesser extent, by Lake Ontario to the north. Potential evapotranspiration in the area is estimated to be $91 \mathrm{~cm} / \mathrm{y}$ (36 in./y), or about $88 \%$ of the annual precipitation. Regional winds are predominantly from the west and south at about $4 \mathrm{~m} / \mathrm{s}(9 \mathrm{mph})$.

The WVDP is located within the Cattaraugus highlands, a transitional zone between the Appalachian Plateau Province and the Great Lakes Plain. The topography at the WVDP site is generally gently rolling. Total relief in the area is approximately $400 \mathrm{~m}$ (1300 ft), with summits reaching $732 \mathrm{~m}(2400 \mathrm{ft})$ above sea level (WVNSC, Inc., 1992).

Geologic conditions at the site are the result of geologically recent events, especially repeated glaciation about 1.6 million to $10,000 \mathrm{y}$ ago. The WVDP site rests on a thick sequence of glacial deposits that ranges up to $150 \mathrm{~m}(500 \mathrm{ft}$ ) in thickness (WVNSC, Inc., 1992). These glacial deposits are underlain by a bedrock valley eroded into the upper Devonian shales and siltstones of the Canadaway and Conneaut Groups, which dip southward at about $5 \mathrm{~m} / \mathrm{km}$ (26 ft/mi) (Rickard, 1975). No major geologic structures such as faults or folds are found within the WVDP area. Major soils types present at the WVDP include well-drained gravelly loam and poorly drained silty loam.

The WVDP site lies within the Cattaraugus Creek water shed (WVNSC, Inc., 1993a). Surface water drainage in the area consists of several creeks that generally flow to the north and northwest into Cattaraugus Creek which then flows west, northwest into Lake Erie (Figure 10-2). The WVDP installation receives all of its water supply from surface water reservoirs located within the WNYNSC but outside of the WVDP premises. Active erosion due to downcutting and headward advancement of the local streams occurs in the surface water drainages.

The uppermost water table beneath the site is encountered at shallow depths. Currently, groundwater beneath the site is not used for process or drinking water. However, prior to redevelopment of the WNYNSC, the farms located on the site are reported to have obtained water from wells in the site area.

The Cattaraugus Creek Basin Aquifer System, which encompasses the WVDP, has been designated by the U.S. EPA as a sole source aquifer (52 CFR Part 36100, 1987). The Cattaraugus Creek Basin Aquifer System covers approximately $325 \mathrm{mi}^{2}\left(845 \mathrm{~km}^{2}\right)$ within a portion of the Erie-Niagara drainage basin. The aquifer consists of laterally discontinuous permeable sand and gravel deposits, clayey glacial till, and fractured shale and bedrock. The regulations in effect at the time compelled the U.S. EPA to declare the boundaries of the overlying surface water drainage basin in which the WVDP site is located as the boundaries of the sole source aquifer. There are areas within the Cattaraugus Creek watershed that depend solely on the groundwater; however, the lateral discontinuity of water bearing units and the fact that the WVDP obtains all of its potable and process water from surface waters negate the notion that the 
WVDP is located above a sole source aquifer. The New York State Department of Environmental Conservation objected to the sole source aquifer designation, and the U.S. EPA subsequently changed its regulations to prevent misclassifications such as this in future proceedings.

The WVDP site can be divided into two hydrogeologic regions. These regions are the north plateau, on which the plant and its associated facilities reside, and the south plateau, which contains the NRC-licensed and state-licensed disposal areas (WVNSC, Inc., 1992).

\subsection{STATUS AND SITING OF MLLW DISPOSAL FACILITY}

The WVDP currently does not dispose of any waste on-site. An environmental impact statement (EIS) is being prepared to address disposal options for LLW in storage and projected to be generated. There is an inactive NRC-licensed LLW disposal facility located in the southern portion of the WVDP area. There is also an inactive state-licensed LLW disposal facility located east of the NRC-licensed facility on WNYNSC land just outside the WVDP boundary.

Disposal of MLLW is not considered as part of the environmental impact statement analysis. The assumption is that most existing or generated MLLW will be treated so that the residual waste is either MLLW or LLW. The assumed projected residual MLLW will be very small volumes, which are planned for off-site disposal. Therefore, currently there are no active plans for siting an MLLW disposal facility at the WVDP site.

For the purposes of the WVDP PE, hypothetical MLLW facilities were placed on the south plateau in the vicinity of the NRC-licensed disposal facility on state-owned land within the WVDP boundary (Figure 10-3). This area was selected because it meets screening criteria used earlier in the MLLW disposal siting process (see Chapter 2 in Volume 2): (1) it is not located within a 100-y floodplain; (2) it is not located within $61 \mathrm{~m} \mathrm{(200} \mathrm{ft)} \mathrm{of} \mathrm{an} \mathrm{active} \mathrm{fault;} \mathrm{and} \mathrm{(3)} \mathrm{it} \mathrm{has}$ sufficient area to accommodate a 100-m (328-ft) buffer zone. Many site-specific hydrogeologic measurements have been made near the NRC-licensed disposal facility. Hydrogeologic conditions are similar throughout the entire south plateau, negating the need for a more specific location for the hypothetical MLLW disposal facility. Additionally, the hypothetical MLLW facility is assumed to be located within $100 \mathrm{~m}(328 \mathrm{ft})$ of an ephemeral stream drainage (i.e., Frank's Creek).

The WVDP Act does not authorize disposal of wastes from off-site. Therefore, the DOE and States agreed that the PE for West Valley would be conducted for on-site PE provides results wastes only. The WVDP for only 18 radionuclides of concern for the WVDP site.

Two generic disposal facilities were considered in the PE: a RCRA-compliant, belowground trench and a RCRA-compliant, above-ground tumulus (described in more detail in Chapter 5 of Volume 2). The generic facilities were selected to provide consistency in analysis of the performance of the 15 sites. Both generic facilities were assumed to be square with a plan area of $2500 \mathrm{~m}^{2}\left(26,910 \mathrm{ft}^{2}\right)$. 


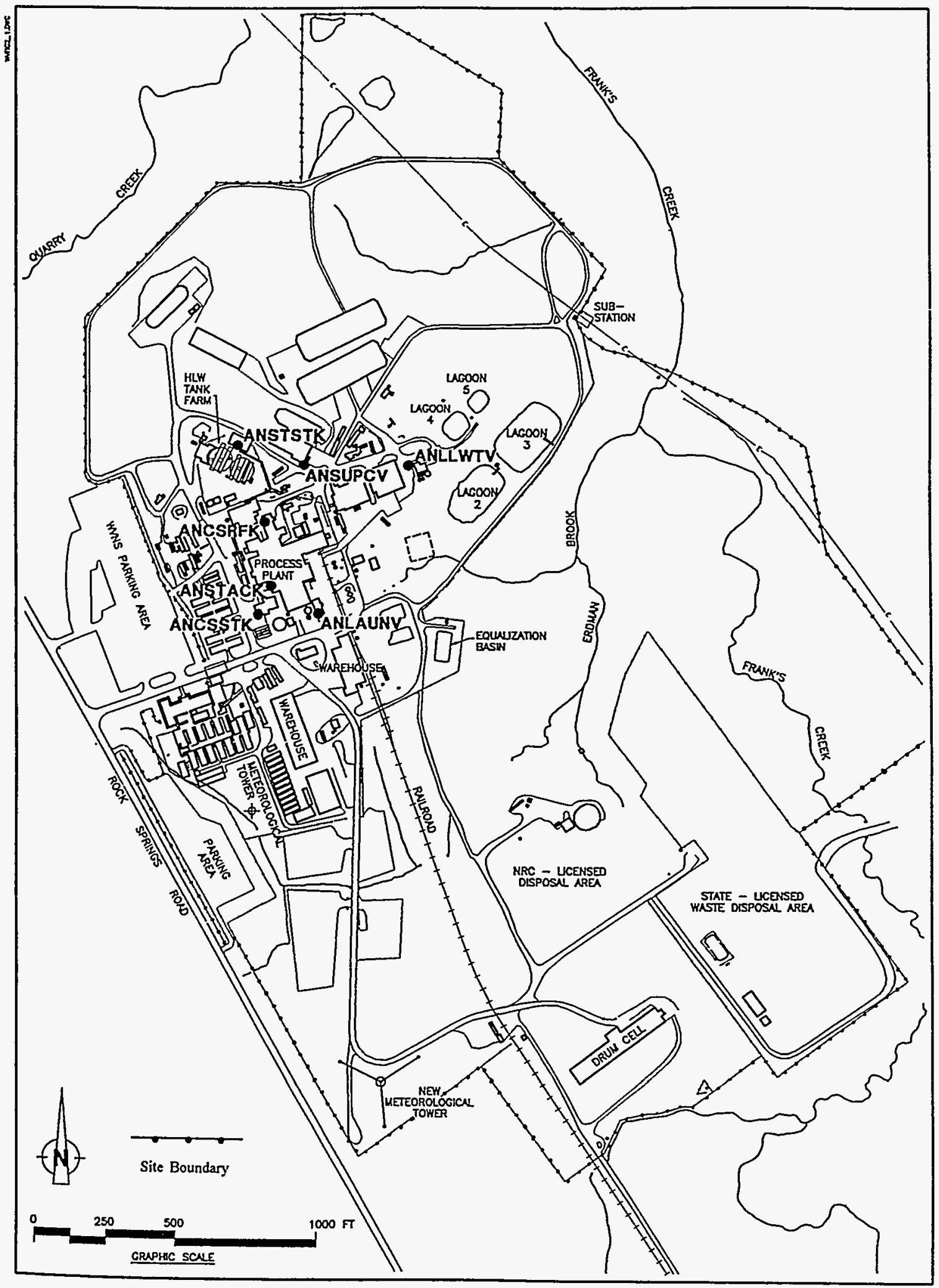

Figure 10-3. Vicinity of hypothetical MWDF location (modified from WVNSC, Inc., and Dames and Moore, 1994). 


\subsection{BASIS FOR CONCEPTUAL MODEL USED IN THE PE}

The south plateau is the location of the hypothetical MLLW site for the WVDP PE. The current understanding of radionuclide migration at the site, and the subsequent proposed conceptual model is based upon information about the south plateau conditions.

As previously stated, the WVDP Act does not authorize disposal of wastes from off-site. Therefore the WVDP PE provides results for 18 radionuclides of concern for the WVDP site (H-3, Sr-90, Cs-137, Co-60, K-40; U-232 -233, -234, -235, -236, -238; Pu-238, -239, -240; Am-241, I-129, C-14, and Tc-99) as presented in Table C-1.2 of the WVDP site environmental report (WVNSC, Inc. and Dames and Moore, 1994).

\subsubsection{Water Pathway}

Knowledge of groundwater flow and radionuclide movement in the water pathway at the WVDP provided the basis for the conceptual model considered in the PE. The conceptual model encompasses the site technical staff's current understanding of site-specific geology, hydrology, water table and aquifer characteristics, and transport pathways.

Numerous site characterization studies have been performed at the WVDP, beginning in 1963 by the U.S. Geological Survey and the N.Y. State Geological Survey. The Environmental Assessment for Disposal of Project $L L W$ provides an annotated chronological list of studies dealing with the site's geology, seismology, and hydrogeology (U.S. DOE, 1986). This study assessed the impacts of proposed disposal of LLW from the WVDP for a reference design which entails on-site disposal in below-grade trenches for low activity (Class A) waste, and in an abovegrade tumulus for higher activity (Class $\mathrm{B} / \mathrm{C}$ ) waste. A portion of this environmental impact analysis involved developing a groundwater flow model for the area and then simulating radionuclide leaching, release, and transport. In addition, the environmental information documents provide a detailed summary of the current understanding of the hydrogeologic environment at the WVDP site (WVNSC, Inc., 1993b).

\subsubsection{Current Understanding of Relevant Hydrogeology}

The WVDP site is underlain by igneous and metamorphic rocks older than 570 million years that are covered by approximately $2300 \mathrm{~m}(7546 \mathrm{ft})$ of nearly flat-lying sedimentary rocks deposited 570 to 245 million years ago. These rocks are covered by up to $150 \mathrm{~m}(500 \mathrm{ft})$ of unconsolidated glacial deposits. The two lowermost glacial deposits are clayey silt tills, the Kent and Olean Tills. Above these till deposits is a unit of recessional deposits composed of silt and clay.

Beneath the south plateau in the vicinity of the hypothetical MLLW disposal facility there are five main hydrogeologic units. The following descriptions are summarized from West Valley Nuclear Services, Co, Inc. (WVNSC, Inc., 1993b), beginning at the land surface. 
Weathered Lavery Till. This weathered till has been oxidized to a brown color, contains numerous root tubes, and is highly desiccated, resulting in intersecting horizontal and vertical fractures. Vertical fractures have been observed to extend to up to $8 \mathrm{~m}(26 \mathrm{ft})$ below the land surface, into the underlying unweathered till deposits.

Unweathered Lavery Till. This till is predominantly a silty clay glacial till that contains minor amounts of discontinuous, random pods or masses of stratified sand, gravel, silt, and claysilt laminations (Albanese et al., 1984). Minor fracturing found in this zone does not dominate groundwater flow characteristics. The NRC-licensed and state-licensed waste disposal areas have been emplaced in this unit.

Kent Recessional (has also been called Lacustrine Deposits). This unit consists of laminated silts and clay lacustrine deposits as well as some coarser grained deposits. Little coarse material is found within these units beneath the south plateau. If coarse zones are present, they exist as pods or lenses within the lacustrine deposits.

Kent Till. This till is much less permeable than the overlying Kent Recessional deposits (WVNSC, Inc., May 1992).

Bedrock. The bedrock beneath the site consists of a U-shaped buried valley comprised of Devonian shales and siltstones of the Conneaut and Canadaway Groups (Rickard, 1975). Bedding regionally dips approximately 0.5 degrees southward. This unit contains vertical joints which trend N68E and N45W.

Although precipitation is evenly distributed throughout the year, its contribution to groundwater is not. Intense infiltration occurs during the spring as a result of snowmelt superimposed on normal precipitation.

Surface water in the vicinity of the hypothetical MLLW site consists of small streams generally flowing to the north (Figure 10-3). Most of these streams are fed by runoff, but do receive some small contribution from groundwater discharge (U.S. DOE, 1986). Steep stream gradients provide for rapid discharge of runoff (U.S. DOE, 1986). Frank's Creek is the closest to the hypothetical MLLW disposal site location (100 m [328 ft] to the west); it is shallow, cutting into only the upper weathered Lavery Till unit. Butter Milk Creek is the closest significant stream, located about $730 \mathrm{~m}$ (2394 ft) from the hypothetical MLLW disposal site location. It cuts through the Kent Recessional deposits (Figure 10-4). Stream flows resulting from major rainfall events are primarily responsible for downcutting and gully advancement that occur in this watershed (WVNSC, Inc., 1993a). 


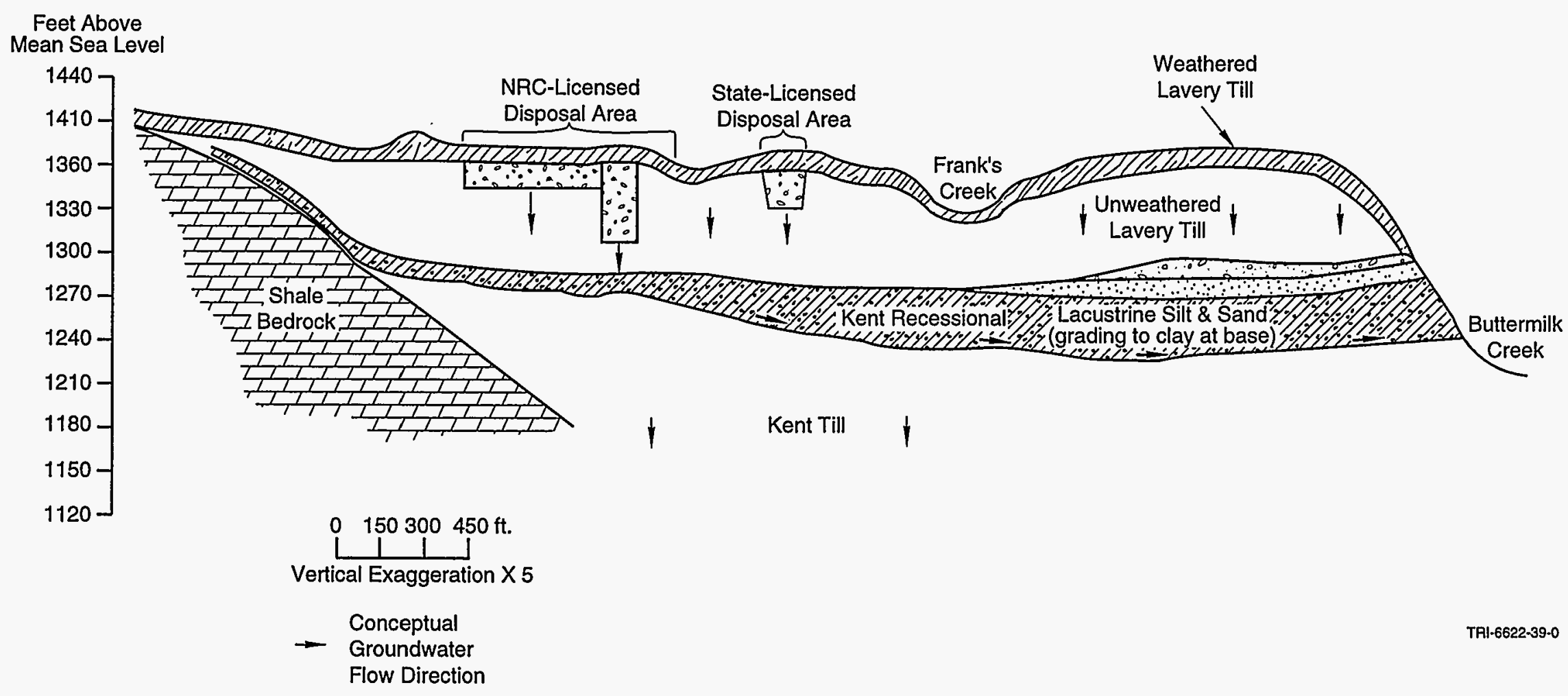

Figure 10-4. Current understanding of groundwater movement at the WVDP site (modified from WVNSC, 1992). 
On the south plateau, the water table occurs in the upper 0 to $6 \mathrm{~m}(0$ to $20 \mathrm{ft})$ of weathered Lavery Till. According to WVNSC, Inc. (May 1992), for the most part, groundwater flow in the unweathered Lavery Till is vertical to the Kent Recessional unit. The upper, weathered portion of the Lavery Till, however, exhibits a horizontal flow that enables groundwater to move laterally before moving downward or discharging to nearby land-surface depressions or stream channels. On a field scale, the hydraulic conductivity of the fractured, weathered till is ten times greater than that of the unfractured, unweathered till. The Kent Recessional deposits below the Lavery Till act as a semiconfined aquifer that is recharged primarily from the bedrock to the west. Flow through the lacustrine deposits is primarily to the northeast. The lake deposits are underlain by the relatively impermeable Kent Till (WVNSC, Inc., 1992) (see Figure 10-4).

\subsubsection{Conceptual Model Used in the PE}

The PE used a generic conceptual model to describe the water pathway (summarized in Section 1.1.2 of this volume and described in detail in Chapter 5 of Volume 2). In the unsaturated zone, leachate was generated by constant flow of water through the disposal facility at a rate that was controlled by the assumed performance of the disposal facility. When all engineered barriers had failed, the flow rate was assumed to be equal to the natural recharge through local soils. The volumetric flow of water through the facility that generated leachate was based on the assumed performance and size of the disposal facility. No dilution was assumed to occur in the unsaturated zone, so at steady state, the concentration that reached groundwater equaled the leachate concentration. No lateral spreading was assumed, so the leachate flux through the unsaturated zone was confined to the soil column directly below the plan area of the facility.

As contaminated water entered the saturated zone, the contaminant mixed with clean groundwater, forming a plume with a shape controlled by aquifer and contaminant properties. The generic conceptual model assumed that instantaneous and complete mixing within the aquifer occurred directly below the facility. Mixing in the vertical direction occurred by hydrodynamic dispersion, and the contaminant mixing depth was an estimated value.

The generic conceptual model was adapted to each PE site based on site-specific knowledge of the geology and water flow paths. The conceptual model for radionuclide migration through the water pathway at the WVDP site is presented here. Two water pathways were considered in the WVDP PE: (1) a shallow groundwater-to-ephemeral-stream-to-perennialstream pathway, and (2) a deep groundwater-to-well pathway (Figure 10-5). These pathways are consistent with the conceptual model used in the hydrogeologic modeling performed for the environmental assessment work (U.S. DOE, 1986) and the WVDP EIS analysis currently in progress with the exception of the deep well. Neither of these studies accounted for lateral flow through the Kent Recessional unit, which has very low productivity and generally could not support a domestic water supply. A hypothetical well was included in the WVDP PE primarily to remain consistent with the approach taken at the other $14 \mathrm{DOE}$ sites analyzed in the PE process. 


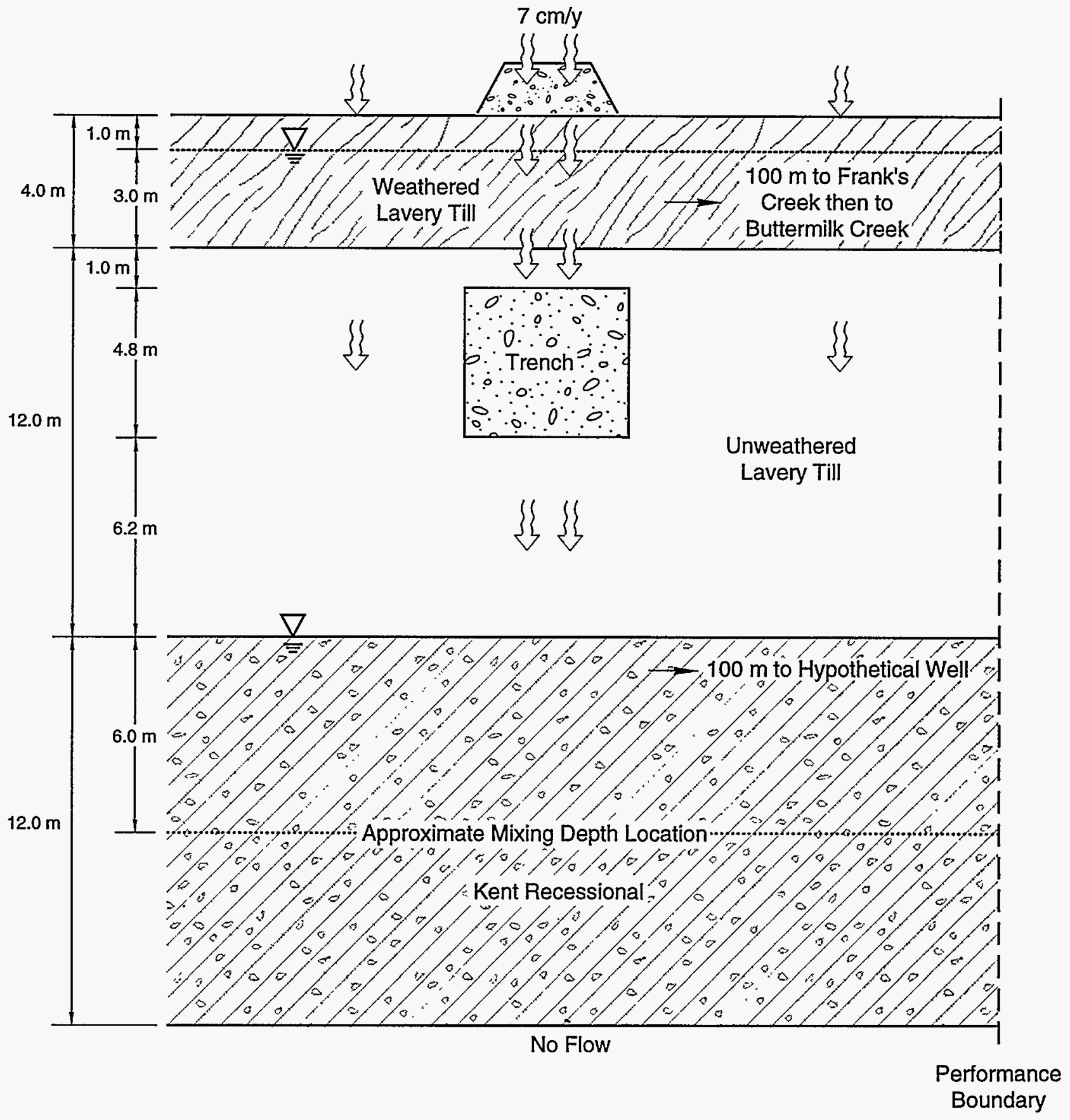

TRI-6622-40-0

Figure 10-5. Conceptual model for flow and transport at the WVDP site. 
At WVDP, the general conceptual model is consistent with the generic PE conceptual model with the exception of the following: (1) a lateral flow path through the unweathered till was analyzed, and (2) no vadose zone was accounted for, although vertical flow occurs down through the unweathered till similar to the unsaturated flow described in the PE model. Sitespecific assumptions for the WVDP site include the following:

- The hydrogeologic stratigraphy is composed of three homogeneous and isotropic units: (1) the upper Weathered Lavery Till, which is a highly fractured permeable unit; (2) the Unweathered Lavery Till, which is assumed to be unfractured with low permeability; and (3) the lower Kent Recessional, which has higher permeability than the unweathered till.

- The trench geometry is modified to reflect site disposal practices (see Figure 10-5). The hypothetical trench is located within the Unweathered Lavery Till. The depth of the trench is physically limited by the depth that a backhoe can dig. The top of the trench is located $1 \mathrm{~m}(3 \mathrm{ft})$ below the top of the Unweathered Lavery Till.

- The flux from the bottom of the tumulus disposal facility to the water table is assumed to occur instantaneously (i.e., no vadose zone travel time). The flux through the trench occurs through the trench cap located at the land surface. Due to the trench location within the Unweathered Lavery Till unit, leachate moves directly from the bottom of the trench into the saturated Unweathered Lavery Till.

- Preferential flow occurs vertically through the Weathered Lavery Till. When the flux rate through the facility is less than the saturated hydraulic conductivity of the Unweathered Lavery Till, then leachate also preferentially flows vertically through the Unweathered Lavery Till. However, when the flux rate through the facility exceeds the saturated hydraulic conductivity of the Unweathered Lavery Till, then

- For the tumulus, vertical flow through the Unweathered Lavery Till occurs at a maximum rate equal to the saturated hydraulic conductivity of the Unweathered Lavery Till, while excess leachate flows horizontally through the Weathered Lavery Till.

- For the trench, a "bath-tubbing effect" occurs. This effect results in leachate moving vertically through the Unweathered Lavery Till at a maximum rate equal to the saturated hydraulic conductivity of the Unweathered Lavery Till, while excess leachate overflows out of the trench and flows horizontally through the Weathered Lavery Till unit.

- When lateral flow occurs, leachate dilution due to mixing throughout the entire saturated portion of the Weathered Lavery Till is accounted for. Contaminant retardation is included for the purpose of determining travel time. 
- One-dimensional flow through the Unweathered Lavery Till occurs vertically downward under steady-state conditions (WVDP, Inc., 1993b). No lateral spreading occurs. Contaminant retardation is included for the purpose of determining travel time. No dilution occurs in this unit.

- One-dimensional horizontal flow occurs through the Kent Recessional deposits to a hypothetical well located at the 100-m (328-ft) performance boundary under steady-state conditions. Contaminant retardation is included for the purpose of determining travel time. No flow occurs into the underlying Kent Till.

- Leachate that enters the Kent Recessional undergoes instantaneous and complete vertical mixing throughout the entire aquifer mixing depth thickness, which provides leachate dilution. The mixing depth is assumed to be $6 \mathrm{~m}(20 \mathrm{ft})$, based on stratigraphic constraints of the Kent Recessional unit.

- If lateral flow occurs through the Weathered Lavery Till, then leachate discharges into Frank's Creek located approximately $100 \mathrm{~m}(328 \mathrm{ft})$ away from the edge of the hypothetical MWDF facility. Leachate is assumed to be instantaneously transported to Butter Milk Creek where instantaneous and complete mixing occurs, causing leachate dilution. The exposure point in Butter Milk Creek is assumed to be located just downstream from where the leachate enters the creek.

\subsubsection{Atmospheric Pathway}

The conceptual model used in the PE for evaluating the atmospheric pathway was derived from performance assessments for LLW disposal facilities at Hanford (Kincaid et al., 1993), INEL (Maheras et al., 1994), NTS (Baer et al., 1994), ORR (ORNL, 1994), and SRS (MMES et al., 1994). The model was generalized for the $P E$ but used site-specific values for many of the parameters.

\subsubsection{Current Understanding of Relevant Meteorology}

WVDP provides yearly estimates of potential radiation from atmospheric exposures. Air samplers are located at points remote from the site, at the perimeter of the site, and on the site itself. Locations were chosen to provide historical continuity or because the location would probably represent the highest potential airborne conentration of activity (WVNSC, Inc., and Dames and Moore, 1994). Wind speeds at the site are generally from the northwest to northnorthwest and from the south to south-southeast at speeds from $2 \mathrm{~m} / \mathrm{s}(7 \mathrm{ft} / \mathrm{s})$ up to 6 to $9 \mathrm{~m} / \mathrm{s}$ $(20$ to $30 \mathrm{ft} / \mathrm{s})$.

The main ventilation stack sampling system monitors the most significant on-site airborne effluent point. At the point of stack discharge, average radioactivity levels were already below DOE air concentration guidelines (WVNSC, Inc., and Dames and Moore, 1994). Data from the six perimeter and four remote sampling sites show that near-site radionuclide concentrations in 
the air are indistinguishable from background concentrations, and they all reflect normal seasonal variations (WVNSC, Inc., and Dames and Moore, 1994).

Meteorological data are based on STAR data files summarized by the windrose in Figure 10-6. These data were obtained from hourly average meteorological readings taken at a height of $10 \mathrm{~m} \mathrm{(33} \mathrm{ft)}$ at the meteorological tower at WVDP during the period 1987 to 1991.

\subsubsection{Conceptual Model Used in the PE}

The PE used a generic conceptual model to describe the atmospheric pathway (summarized in Section 1.2 of this volume and described in detail in Chapter 5 of Volume 2). Only H-3 (tritium) and C-14 were expected to be volatile for the disposal facility conditions and thus were the only radionuclides considered for atmospheric transport in the PE. In the model, radionuclides were transported from the disposal facility to the soil surface by vapor (tritium) and gaseous (carbon dioxide carrying the $\mathrm{C}-14$ isotope) diffusion. When the radionuclides reached the soil surface, they were entrained in the air in vapor form as volatiles. Once airborne, these radionuclides were transported via atmospheric dispersion to a receptor located at the performance boundary.

Two components of the atmospheric pathway were evaluated separately: (1) the zone from the top of the disposal facility to the soil surface as indicated by the upward radionuclide diffusion profile; and (2) the zone in which a radionuclide was emitted to the atmosphere, mixed with the ambient air, and dispersed downwind from the waste disposal facility boundary to the 100-m (328-ft) performance boundary.

The arrival time of radionuclides at the performance boundary was assumed to be $100 \mathrm{y}$ based on the following generic assumptions of the PE:

- The waste form was grouted MLLW treatment residuals. Based on this assumption, tritium as vapor was bound in the pore water of the hydrophilic grout, and carbon dioxide as a gas carrying the $\mathrm{C}-14$ isotope was limited by the high $\mathrm{pH}$ of the grout, so that the waste form provided retention of these volatile radionuclides in the disposal facility.

- The disposal facility was capped by a RCRA-compliant cover system. Based on this assumption, the cover system was maintained to provide low permeability for $100 \mathrm{y}$.

\subsubsection{Inadvertent Intruder Pathways}

Standard intrusion scenarios were used in the PE, with information derived from performance assessments of LLW disposal facilities at SRS (MMES et al., 1994) and ORR (ORNL, 1994) indicating that only two chronic-exposure scenarios needed to be considered for most sites and facility designs. Any variations in these scenarios were based on discussions with site technical staff about such factors as the types of activities that reasonably could result in exposure to buried waste at the site and the effectiveness of active or passive institutional controls and engineered barriers in precluding access to the waste. 


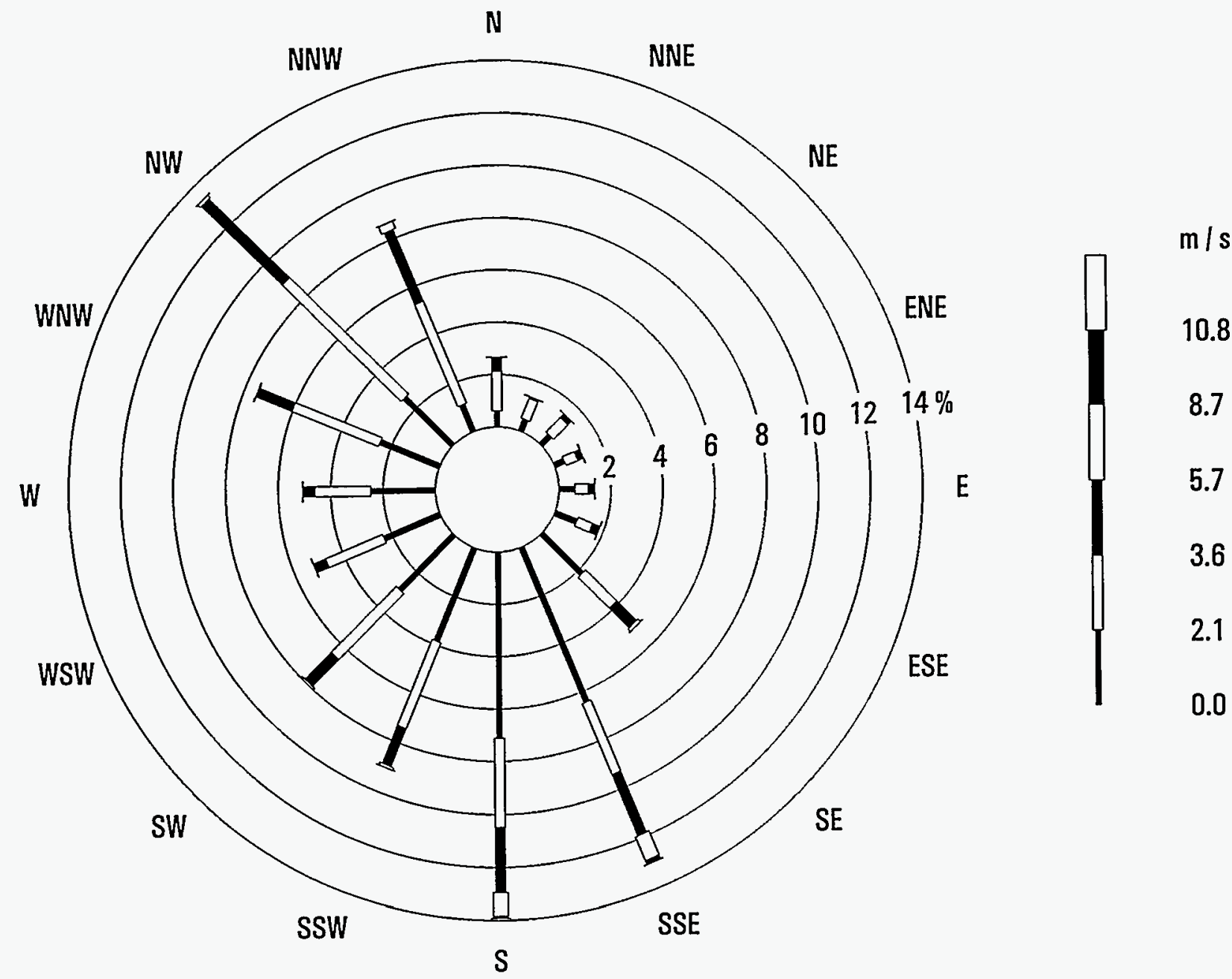

Figure 10-6. Windrose for WVDP for the period 1987 to 1991 . The frequency of winds from each direction is plotted as a series of connected bars that extend from the center of the circular diagram toward the direction from which the winds originate. Wind speed categories are denoted by bar widths and shadings. The frequency of winds in each wind speed category is indicated by the length of the corresponding bar. 


\subsubsection{Current Understanding of Potential Modes of Inadvertent Intrusion}

The on-going EIS work includes several different alternatives that describe different intruder scenarios. There is a concern that active surface erosion could eventually expose buried waste. WVDP staff agreed that two alternatives evaluated in the draft EIS are the most similar to the WVDP PE: (1) on-premises LLW disposal with an associated long-term erosion control design in place (i.e., no erosion occurs), and (2) in-place disposal of the existing waste with no closure activities of long-term effectiveness (i.e., erosion does occur). Erosion is not considered in the standard PE intrusion analysis, and it was agreed that erosion would not be considered for the WVDP PE analysis.

\subsubsection{Intruder Scenarios Used in the PE}

The PE used two standard intrusion scenarios that could be modified for site-specific conditions to describe potential modes of inadvertent intrusion (summarized in Section 1.3 of this volume and described in detail in Chapter 5 of Volume 2). Because the intrusion analysis for WVDP did not account for erosion, this analysis explicitly assumed that a control design for longterm erosion was in place (i.e., no erosion occurred) on site, just as for some of the draft EIS alternatives.

The first scenario, the agriculture (homesteader) scenario, included establishment by an intruder of a permanent homestead directly above a disposal facility with the foundation of the home extending into the waste; some of the waste exhumed from the disposal facility was mixed with native soil in the intruder's vegetable garden. The second scenario, the post-drilling scenario, considered the construction of a well for a domestic water supply by an intruder. The well was drilled through the disposal facility, and the cuttings were mixed with soil in the intruder's vegetable garden. The intruder gardened in some of the exhumed waste but did not reside permanently above the disposal facility. In both scenarios, exposure occurred where an intruder dug or drilled into the disposal facility.

For the generic intruder scenarios, the time of intrusion for the homesteader scenario was assumed to be $300 \mathrm{y}$ for the trench design and $500 \mathrm{y}$ for the tumulus design. The time of intrusion for the post-drilling scenario was assumed to be $100 \mathrm{y}$.

\subsection{DATA USED IN THE PE}

The data presented in this section apply to the PE conceptual models described in Section 10.3. The calculations for determining permissible waste concentrations for the radionuclides considered in the $P E$ are discussed in more detail in Chapter 5 of Volume 2 and summarized in Chapter 1 of this volume. The results of the calculations for WVDP are presented in Section 10.5 and discussed in Section 10.6 of this volume. 


\subsubsection{Water Transport}

Site-specific values required to perform the water pathway analysis were selected by site technical staff either from site characterizations and reports, from site-specific modeling results, or from general literature. For each of the hydrogeologic units in the saturated zone (the weathered Lavery Till, the unweathered Lavery Till, and the Kent Recessional), the required data were porosity, dry bulk density of the geologic medium, distribution coefficients $\left(K_{d} s\right)$ of the radionuclides in the geologic medium, Darcy flow rates, and mixing depth in the aquifer where horizontal movement occurs.

These values for WVDP are listed in Table 10-1 along with generic values that were used in the PE. Also indicated in the table is a designation of the type of data that the value represents and the source of the value. The values were determined from one or more of four data sources: (A) measurement performed by the site, state, or federal agency; (B) result of a numerical analysis performed by the site, state, or federal agency; (C) general literature value selected by the site; and (D) generic value of the PE.

Of the parameters in the PE that depended on site-specific values, only three potentially encompassed enough variability in values to significantly affect the results: natural recharge, $i$; distribution coefficients $\left(K_{d} s\right)$ for the geologic media; and groundwater Darcy velocity $\left(q_{g w}\right)$. The sources of these values are discussed in this section. The sensitivity of the results to changes in the values of these parameters is discussed in Section 10.6.2 of this volume and Chapter 6 of Volume 2.

The uniformly distributed average annual recharge to the Lavery till on the south plateau is $7 \mathrm{~cm} / \mathrm{y}(2.7 \mathrm{in} . / \mathrm{y})$. Deep drainage to the underlying Unweathered till averages $1 \mathrm{~cm} / \mathrm{y}(0.4 \mathrm{in} . / \mathrm{y})$, while the remainder (up to $6 \mathrm{~cm} / \mathrm{y}$ [2.3 in./y]) flows horizontally through the upper Weathered till to nearby streams (WVNSC, Inc., 1993c). These estimates are based upon water budget modeling studies and are consistent with field measurements of hydraulic conductivity, measured water levels, and other hydrologic modeling studies. In the PE, the deep recharge is assumed to be limited by the least conductive unit, the Kent Recessional, which has a reported range for saturated hydraulic conductivity of $1.47 \times 10^{-8} \mathrm{~cm} / \mathrm{s}$ to $1.26 \times 10^{-7} \mathrm{~cm} / \mathrm{s}(0.005$ to $0.04 \mathrm{~m} / \mathrm{y}[0.016$ to $0.13 \mathrm{ft} / \mathrm{y}])$.

Values for distribution coefficients $\left(K_{d} \mathrm{~s}\right)$ are listed in Table 10-2 for the 18 radionuclides considered in the WVDP PE. In addition to the $K_{d}$ values for the geologic media, grout $K_{d}$ values are listed for determining the desorption from the source term resulting from the grouted waste form. The $K_{d}$ values for the geologic media have been measured for a limited number of radionuclides for some of the West Valley soils (WVNSC, 1994); the tritium, cesium, and strontium $K_{d} \mathrm{~s}$ are based upon site specific measurements. Literature values of distribution coeffients for sand reported by Thibault et al. (1990) were used for the remaining 15 radionuclides evaluated for WVDP. 
Table 10-1. Parameters and Values Used in the PE for the Water Pathway at WVDP (generic PE values are in bold; these values and the standard PE method for applying them are summarized in Chapter 1 of this volume and discussed in more detail in Chapter 5 of Volume 2) (Part 1 of 3)

\begin{tabular}{|c|c|c|c|}
\hline Parameter & Value & $\begin{array}{c}\text { Data } \\
\text { Type * }\end{array}$ & Comments \\
\hline \multicolumn{4}{|l|}{ SOURCE TERM } \\
\hline $\begin{array}{l}\text { Volumetric water content } \\
\text { of the grouted waste, } \theta_{0}\end{array}$ & 0.3 & D & Standard PE value \\
\hline $\begin{array}{l}\text { Bulk density of grouted } \\
\text { waste, } \rho_{0}\end{array}$ & $\begin{array}{l}1.76 \\
\mathrm{~g} / \mathrm{cm}^{3}\end{array}$ & D & Standard PE value \\
\hline $\begin{array}{l}\text { Distribution coefficients } \\
\text { for grouted waste, } K_{d}^{G}\end{array}$ & various & D & $\begin{array}{l}\text { Standard PE value; see Table } 10-2 \text { in } \\
\text { this chapter }\end{array}$ \\
\hline $\begin{array}{l}\text { Disposal facility plan } \\
\text { area, } A\end{array}$ & $2500 \mathrm{~m}^{2}$ & $\bar{D}$ & $\begin{array}{l}\text { Standard } P E \text { value; } A=a_{1} * a_{2} \text {, where } \\
a_{1}=a_{2}=50 \mathrm{~m}\end{array}$ \\
\hline $\begin{array}{l}\text { Waste mixing fraction } \\
\text { for trench, } f_{m}\end{array}$ & 0.67 & D & Standard PE value \\
\hline $\begin{array}{l}\text { Waste mixing fraction } \\
\text { for tumulus, } f_{m}\end{array}$ & 0.33 & D & Standard PE value \\
\hline $\begin{array}{l}\text { Annual rate of water } \\
\text { flowing through intact } \\
\text { trench facility, } q_{f}\end{array}$ & $0.03 \mathrm{~m} / \mathrm{y}$ & D & Standard PE value \\
\hline $\begin{array}{l}\text { Annual rate of water } \\
\text { flowing through intact } \\
\text { tumulus facility, } q_{f}\end{array}$ & $\begin{array}{c}0.00003 \\
\mathrm{~m} / \mathrm{y}\end{array}$ & D & Standard PE value \\
\hline $\begin{array}{l}\text { Time to failure of } \\
\text { leachate collection and } \\
\text { liner systems }\end{array}$ & $30 y$ & D & Standard PE value \\
\hline $\begin{array}{l}\text { Time to failure of trench } \\
\text { facility }\end{array}$ & $100 y$ & D & Standard PE value \\
\hline $\begin{array}{l}\text { Time to failure of } \\
\text { tumulus facility }\end{array}$ & $300 y$ & D & Standard PE value \\
\hline $\begin{array}{l}\text { Natural recharge through } \\
\text { local soils, } i\end{array}$ & $\begin{array}{l}0.07 \\
\mathrm{~m} / \mathrm{y}\end{array}$ & A & $\begin{array}{l}\text { WVDP-EIS-009, Part 5, Rev 0, Sec } 3.2, \text { p. } 24 . \\
\text { (assumes } 0.06 \mathrm{~m} / \mathrm{y} \text { flows laterally through } \\
\text { weathered till, } 0.01 \mathrm{~m} / \mathrm{y} \text { percolates into } \\
\text { unweathered till). }\end{array}$ \\
\hline
\end{tabular}

- $A=$ site measurement; $B=$ result of site numerical analysis; $C=$ literature value selected by the site; $D=$ generic $P E$ value 
Table 10-1. Parameters and Values Used in the PE for the Water Pathway at WVDP (generic PE values are in bold; these values and the standard $\mathrm{PE}$ method for applying them are summarized in Chapter 1 of this volume and discussed in more detail in Chapter 5 of Volume 2) (Part 2 of 3)

\begin{tabular}{|c|c|c|c|}
\hline Parameter & Value & $\begin{array}{l}\text { Data } \\
\text { Type * }\end{array}$ & Comments \\
\hline \multicolumn{4}{|c|}{ UNSATURATED AND SATURATED ZONE (Weathered Lavery TII) } \\
\hline Moisture content, $\theta_{w}$ & 0.3 & A & $\begin{array}{l}\text { WVDP-EIS-009, Part 5, Rev 0, App. G, } \\
\text { Tensiometer data from US-1 \& US-2, Appendix } \\
\text { G. Varies seasonally. }\end{array}$ \\
\hline Porosity, $n$ & 0.36 & A & WVDP-EIS-009, Part 5, Rev 0, App. A, p. A-9. \\
\hline Bulk density, $\rho_{b}$ & $1.6 \mathrm{~g} / \mathrm{cm}^{3}$ & A & WVDP-EIS-009, Part 5, Rev 0, App. A, p. A-9. \\
\hline $\begin{array}{l}\text { Distribution coefficients for } \\
\text { geologic media, } K_{d}\end{array}$ & various & C & See Table $10-2$ in this chapter \\
\hline Thickness of weathered till & $4 \mathrm{~m}$ & A & $\begin{array}{l}\text { WVDP-EIS-009, Part 4, Rev 0, App. C. Well } \\
\text { logs } 1001 \text { and } 1005 .\end{array}$ \\
\hline $\begin{array}{l}\text { Thickness between trench } \\
\text { and saturated zone, } l\end{array}$ & - & & Hypothetical trench is placed below this unit. \\
\hline $\begin{array}{l}\text { Thickness between tumulus } \\
\text { and saturated zone, } l\end{array}$ & $1 \mathrm{~m}$ & A & $\begin{array}{l}\text { WVDP-EIS-009, Part 4, Rev 0, App. C, p. C-58. } \\
\text { Water elevations in monitoring well } 1005 \text { from } \\
3 / 90 \text { through } 5 / 92 \text {. }\end{array}$ \\
\hline $\begin{array}{l}\text { Horizontal saturated } \\
\text { hydraulic conductivity, } K_{\text {sat }}\end{array}$ & $8 \times 10^{-7} \mathrm{~cm} / \mathrm{s}$ & A & $\begin{array}{l}\text { WVDP-EIS-009, Part 4, Rev 0, Sec. 3.3.1.1, p. } \\
\text { 27. (Geometric mean of } 3 \text { samples, Table 3-6, } \\
\text { p. 178). }\end{array}$ \\
\hline Horizontal hydraulic gradient & 0.02 & A & $\begin{array}{l}\text { WVDP-EIS-009, Part 4, Rev 0, Sec. 3.3.2, p. } \\
28 \text {. }\end{array}$ \\
\hline $\begin{array}{l}\text { Distance to Frank's Creek } \\
\text { from hypothetical MWDF }\end{array}$ & $100 \mathrm{~m}$ & & WVDP PE assumption \\
\hline \multicolumn{4}{|c|}{ SATURATED ZONE (Unweathered Lavery Till) } \\
\hline Porosity, $n$ & 0.36 & A & WVDP-EIS-009, Part 5, Rev 0, App. A, p. A-9. \\
\hline Bulk density, $\rho_{b}$ & $1.7 \mathrm{~g} / \mathrm{cm}^{3}$ & A & WVDP-EIS-009, Part 5, Rev 0, App. A, p. A-9. \\
\hline $\begin{array}{l}\text { Distribution coefficients for } \\
\text { geologic media, } K_{d}\end{array}$ & various & $\mathrm{C}$ & See Table $10-2$ in this chapter \\
\hline Thickness & $12 m$ & A & $\begin{array}{l}\text { WVDP-EIS-009, Part 4, Rev 0, App. C. Logs } \\
\text { for monitoring wells } 1001 \& 1005\end{array}$ \\
\hline $\begin{array}{l}\text { Depth from bottom of } \\
\text { weathered till and top of } \\
\text { trench }\end{array}$ & $1 \mathrm{~m}$ & A & $\begin{array}{l}\text { Site practice (Personal communication, R. } \\
\text { Blickwedehl [Dames and Moore], 3/31/95). }\end{array}$ \\
\hline
\end{tabular}

* $A=$ site measurement; $B=$ result of site numerical analysis; $C=$ literature value selected by the site; $D=g$ eneric $P E$ value 
Table 10-1. Parameters and Values Used in the PE for the Water Pathway at WVDP (generic PE values are in bold; these values and the standard PE method for applying them are summarized in Chapter 1 of this volume and discussed in more detail in Chapter 5 of Volume 2) (Part 3 of 3)

\begin{tabular}{|c|c|c|c|}
\hline Parameter & Value & $\begin{array}{l}\text { Data } \\
\text { Type } \\
\star\end{array}$ & Comments \\
\hline \multicolumn{4}{|c|}{ SATURATED ZONE (Unweathered Lavery Till) (continued) } \\
\hline $\begin{array}{l}\text { Thickness between bottom of } \\
\text { trench and top of Kent } \\
\text { Recessional }\end{array}$ & $6.2 \mathrm{~m}$ & A & $\begin{array}{l}\text { Backhoe typically can dig up to } 32 \mathrm{ft}(9.8 \mathrm{~m} \text { ) } \\
\text { below the ground surface (Personal } \\
\text { communication, R. Blickwedehl [Dames and } \\
\text { Moore], 3/31/95). }\end{array}$ \\
\hline Vertical hydraulic gradient & 0.8 & A & $\begin{array}{l}\text { WVDP-EIS-009, Part } 4, \text { Rev } 0, \text { App. C. } \\
\text { Comparison between water levels in monitoring } \\
\text { wells } 1001 \& 1005,5 / 91 \text {. }\end{array}$ \\
\hline $\begin{array}{l}\text { Vertical hydraulic conductivity, } \\
K_{\text {sat }}\end{array}$ & $4 \times 10^{-8} \mathrm{~cm} / \mathrm{s}$ & A & $\begin{array}{l}\text { WVDP-El5-009, Part 4, Rev 0, Sec. 4.3.1.1, p. } \\
45 \text { (Geometric mean of } 19 \text { samples, Table 4-8, } \\
\text { p. 190). }\end{array}$ \\
\hline \multicolumn{4}{|c|}{ SATURATED ZONE (Kent Recessional) } \\
\hline Porosity, $n$ & 0.4 & C & $\begin{array}{l}\text { Mean estimate for silt, Freeze and Cherry ( } 1979 \text {, } \\
\text { p. 37). }\end{array}$ \\
\hline Bulk density, $\rho_{b}$ & $2 \mathrm{~g} / \mathrm{cm}^{3}$ & C & $\begin{array}{l}\text { Glacial till, CRC Handbook of Tables for Applied } \\
\text { Engineering Science, Table 6-42, p. } 636 \text {. }\end{array}$ \\
\hline $\begin{array}{l}\text { Distribution coefficients for } \\
\text { geologic media, } K_{d}\end{array}$ & various & C & See Table $10-2$ in this chapter \\
\hline Mixing depth, $d_{m}$ & $6 \mathrm{~m}$ & A & $\begin{array}{l}\text { This is a very stratified, heterogeneous material. } \\
\text { Well logs from } 1001 \text { and } 1005 \text { show a thickness } \\
\text { of approximately } 12 \mathrm{~m} \text {. EIS assumes a } 1 \mathrm{~m} \\
\text { thickness to be conservative. WVDP PE } \\
\text { assumes the conductive portion occurs within } \\
\text { one-half of the total Kent Recessional thickness. }\end{array}$ \\
\hline Horizontal hydraulic gradient & 0.023 & A & Bergeron, et al., 1987, p. 25. \\
\hline $\begin{array}{l}\text { Horizontal hydraulic } \\
\text { conductivity, } \mathrm{K}_{\text {eat }}\end{array}$ & $\begin{array}{c}4.2 \times 10^{-5} \\
\mathrm{~cm} / \mathrm{s} \\
(13.2 \mathrm{~m} / \mathrm{y})\end{array}$ & $\bar{A}$ & $\begin{array}{l}\text { WVDP-EIS-009, Part 4, Rev } 0, \text { Sec. 5.2.3, p. } \\
59 \text {. Effective hydraulic conductivity for flow } \\
\text { through parallel layers assuming } 1 \mathrm{~m} \text { thick } \\
\text { layers which have alternating high and low } \\
\text { hydraulic conductivities. }\end{array}$ \\
\hline Darcy velocity, $q_{g w}$ & $0.31 \mathrm{~m} / \mathrm{y}$ & A & $\begin{array}{l}\text { Product of hydraulic gradient and hydraulic } \\
\text { conductivity }\end{array}$ \\
\hline Flow in Butter Milk Creek, $Q_{B M}$ & $1.3 \mathrm{~m}^{3} / \mathrm{s}$ & A & U.S. DOE, 1982, p. 2-10. \\
\hline $\begin{array}{l}\text { Distance to performance } \\
\text { boundary from facility } \\
\text { boundary }\end{array}$ & $100 \mathrm{~m}$ & $\mathbf{D}$ & Standard $P E$ value \\
\hline
\end{tabular}

- $A=$ site measurement; $B=$ result of site numerical analysis; $C=$ literature value selected by the site; $D=g e n e r i c ~ P E$ value 
Table 10-2. Solid/Liquid Distribution Coefficients $\left(K_{d} s\right)$ Used in the PE at WVDP

\begin{tabular}{|l|c|c|}
\hline Element & $\begin{array}{c}\text { Waste } K_{d}^{G} \\
(\mathbf{m L} / \mathrm{g})^{\mathrm{a}}\end{array}$ & $\begin{array}{c}K_{d} \text { for Geologic Media } \\
(\mathrm{mL} / \mathrm{g})^{\mathrm{b}}\end{array}$ \\
\hline $\mathrm{H}$ & 0 & $0^{\mathrm{c}}$ \\
\hline $\mathrm{C}$ & 10 & 1 \\
\hline $\mathrm{K}$ & 1 & 15 \\
\hline $\mathrm{Co}$ & 100 & 60 \\
\hline $\mathrm{Sr}$ & 100 & $5^{\mathrm{d}}$ \\
\hline $\mathrm{TC}$ & 1 & $0 / 4^{\mathrm{e}}$ \\
\hline $\mathrm{I}$ & 1 & 1 \\
\hline $\mathrm{Cs}$ & 10 & $40^{\mathrm{d}}$ \\
\hline $\mathrm{U}$ & 100 & $35 / 9^{\mathrm{e}}$ \\
\hline $\mathrm{Pu}$ & 100 & $550 / 1760^{\mathrm{e}}$ \\
\hline Am & 100 & 1900 \\
\hline
\end{tabular}

The Darcy velocity for the Kent Recessional is not well known. The Darcy velocity used in the WVDP PE $(0.31 \mathrm{~m} / \mathrm{y})$ is based on the product of the effective saturated hydraulic conductivity and the horizontal hydraulic gradient. WVNSC, Inc. (1993b) reports the range of hydraulic conductivity for the Kent Recessional based upon falling head permeameter tests to be $5.5 \times 10^{-7} \mathrm{~cm} / \mathrm{s}$ to $1.5 \times 10^{-6} \mathrm{~cm} / \mathrm{s}$. Analysis of particle size data has yielded hydraulic conductivities of $8.4 \times 10^{-6} \mathrm{~cm} / \mathrm{s}$ for the lacustrine deposits and $8.4 \times 10^{-5} \mathrm{~cm} / \mathrm{s}$ for the coarser deposits within the Kent Recessional (WVNSC, Inc., 1993b). The effective hydraulic conductivity used in the WVDP PE $\left(4.2 \times 10^{-5} \mathrm{~cm} / \mathrm{s}\right)$ was estimated by assuming the unit is composed of alternating $1 \mathrm{~m}$ thick layers with hydraulic conductivities of either $5.5 \times 10^{-7} \mathrm{~cm} / \mathrm{s}$ or $8.4 \times 10^{-5}$ $\mathrm{cm} / \mathrm{s}$, and assuming flow through parallel layers. The hydraulic gradient $(0.023 \mathrm{~m} / \mathrm{m})$ was determined based upon water levels measured in wells in the south plateau completed near the base of the Kent Recessional (Bergeron et al., 1987). Assuming a constant gradient and a range in conductivity of $5.5 \times 10^{-7}$ to $8.4 \times 10^{-5} \mathrm{~cm} / \mathrm{s}(0.17$ to $26 \mathrm{~m} / \mathrm{y})$, then the resulting range for Darcy velocity is 0.004 to $0.6 \mathrm{~m} / \mathrm{y}(0.01$ to $2 \mathrm{ft} / \mathrm{y})$.

The mixing depth assumed for the Kent Recessional unit was $6 \mathrm{~m}$ (20 ft), one-half of the total unit thickness. The mixing depth in this unit was based upon an assumption that the horizontal flow occurs predominantly through the coarser portions of this unit and that the coarser layers occupy half of the total thickness due to the alternating and highly heterogeneous nature of the Kent Recessional deposits. The EIS assumed a thickness of $1 \mathrm{~m}(3.28 \mathrm{ft})$ for the Kent Recessional to be conservative (personal communication, A.Parsons [SNL] with R. Blickwedehl [Dames and Moore], 3/31/95). 


\subsubsection{Atmospheric Transport}

Site-specific data required to perform the atmospheric pathway analysis came from site personnel as data either from site characterizations and reports or from general literature. The site-specific data required for the soil diffusion calculation were the same as some of those required for the water transport analysis (Section 10.4.1). These values are shown in Table 10-3. Necessary atmospheric dispersion data included wind speed and direction and stability class, which are summarized in Section 10.3.2.1.

Table 10-3. Parameters and Values Used in the PE for the Atmospheric Pathway at WVDP (generic $\mathrm{PE}$ values are in bold; these values and the standard $\mathrm{PE}$ method for applying them are summarized in Chapter 1 of this volume and discussed in more detail in Chapter 5 of Volume 2)

\begin{tabular}{|c|c|c|c|}
\hline Parameter & Value & $\begin{array}{l}\text { Data } \\
\text { Type* }\end{array}$ & Comments \\
\hline $\begin{array}{l}\text { Disposal facility cover } \\
\text { thickness, } x\end{array}$ & $1.0 \mathrm{~m}$ & D & Standard PE value \\
\hline $\begin{array}{l}\text { Depth of the soil } \\
\text { surface, } d\end{array}$ & $0.01 \mathrm{~m}$ & $\mathbf{D}$ & $\begin{array}{l}\text { Standard PE value based on Maheras et } \\
\text { al. (1994) }\end{array}$ \\
\hline Porosity, $n$ & 0.36 & A & WVDP-EIS-009, Part 5, Rev 0, App. A, p. A-9. \\
\hline Percent saturation, $s$ & 1 & A & $\begin{array}{l}\text { Assumed there was no vadose zone (see } \\
\text { section 10.3.1.2) }\end{array}$ \\
\hline $\begin{array}{l}\text { Ratio of water density } \\
\text { in air to liquid, } r\end{array}$ & 9.2E-06 & $\mathbf{D}$ & $\begin{array}{l}\text { Standard PE value based on MMES et al. } \\
\text { (1994) }\end{array}$ \\
\hline $\begin{array}{l}\text { Ratio of } \mathrm{CO}_{2} \\
\text { concentration in air to } \\
\text { dissolved in water, } r\end{array}$ & 4.3E-04 & $\mathbf{D}$ & $\begin{array}{l}\text { Standard PE value based on Foust et al. } \\
\text { (as cited in Cooper and Alley, 1986) }\end{array}$ \\
\hline $\begin{array}{l}\text { Tritium diffusion } \\
\text { coefficient in air, } D\end{array}$ & $2.39 \mathrm{E}-05 \mathrm{~m}^{2} / \mathrm{s}$ & D & Standard PE value based on CRC (1981) \\
\hline $\begin{array}{l}\text { Carbon diffusion } \\
\text { coefficient in air, } D\end{array}$ & $1.4 \mathrm{E}-05 \mathrm{~m}^{2} / \mathrm{s}$ & D & Standard PE value based on CRC (1981) \\
\hline $\begin{array}{l}\text { Atmospheric dispersion } \\
\text { term, } A_{D}\end{array}$ & $\begin{array}{c}0.6 \\
\left(\mu \mathrm{Ci} / \mathrm{m}^{3}\right) /\left(\mu \mathrm{Ci} / \mathrm{m}^{2}-\mathrm{s}\right)\end{array}$ & $B$ & $\begin{array}{l}\text { Value is estimated using the Industrial Source } \\
\text { Complex-Version } 2 \text { Long Term Air Dispersion } \\
\text { Model (ISCLT2) (EPA, 1992) based on site- } \\
\text { specific STAR data }\end{array}$ \\
\hline
\end{tabular}

* $A=$ site measurement; $B=$ result of site numerical analysis; $C=$ literature value selected by the site; $D=$ generic $P E$ value

\subsubsection{Inadvertent Intruder Exposure}

As explained in Section 10.3.3, the PE used two standard intrusion scenarios to describe potential modes of inadvertent intrusion at all the sites. Because these intrusion scenarios were considered applicable to all sites, no values specific to WVDP are used in the calculation of exposures to inadvertent intruders. 


\subsection{RESULTS OF THE PE}

The performance evaluation provided estimates of permissible concentrations in disposed MLLW. The three calculations that formed the foundation of the PE-for the water, atmospheric, and inadvertent intruder pathways - are summarized in Sections 1.1, 1.2, and 1.3, respectively, of this volume and discussed in detail in Chapter 5 of Volume 2.

For each pathway the maximum permissible waste concentration at the performance boundary was determined for each radionuclide by using the performance measures: $4 \mathrm{mrem}$ $(0.04 \mathrm{mSv})$ per year from the water pathway for releases to drinking water; $10 \mathrm{mrem}(0.1 \mathrm{mSv})$ per year from all pathways for atmospheric releases; and $100 \mathrm{mrem}(1 \mathrm{mSv})$ per year from all exposure pathways for chronic exposure of inadvertent intruders) and the appropriate pathway or scenario dose conversion factors (annual effective dose equivalent per unit concentration; based on EPA dose conversion factors. The basis for the performance measures used in the PE is discussed in more detail in Chapter 5 of Volume 2. For the water and atmospheric pathways, the concentration reduction provided by the environment (i.e., the CRF) was estimated using results of site analyses and data. For the intruder analyses, concentration reduction was estimated for appropriate exposure pathways for two intrusion scenarios that, in general, were the same for all the sites. The results of the calculations for the pathways that were analyzed at WVDP are provided in this section and discussed in Section 10.6.

\subsubsection{Water Transport}

Two CRFs were calculated for the water pathway: the source CRF, $C R F_{\text {Source, }}$ and the environmental transport $\mathrm{CRF}$ for water, $C R F_{\text {Water }}$. The source $\mathrm{CRF}$ represents the concentration attenuation between the disposed waste and leachate exiting the bottom of the disposal facility and was defined as the dimensionless ratio of the waste concentration to the resulting leachate concentration. Desorption with infiltrating water was the mechanism used to describe the leaching of radionuclides from the grout. Because a generic method was used to determine the $C R F_{\text {Source }}$ for the 18 radionuclides considered in the PE (summarized in Section 1.1 of this volume and discussed in more detail in Chapter 5 of Volume 2), the radionuclide-specific values for the source CRF for each type of generic facility were the same for all 15 sites.

The environmental transport CRF for water was defined as the ratio of the concentration of the leachate exiting the disposal facility to the resulting concentration in water at the performance boundary. The concentration attenuation represented by $C R F_{\text {Water }}$ consisted of dilution due to mixing with uncontaminated groundwater and surface water. Effects of radioactive decay and decay product ingrowth were also included in the PE.

In the PE, water travel time from the facility location to the performance boundary was calculated as a basis for comparison with the retarded travel time of the radionuclides. For WVDP, water travel time from the land surface to the performance boundary (i.e., without consideration of a disposal facility) was estimated at about $670 \mathrm{y}$. 
Retardation of radionuclides by interaction with soils and rock in the vadose and saturated zones increased travel times for individual radionuclides. This effect was particularly important for short-lived radionuclides because of radioactive decay. For short-lived radionuclides, the effects of radioactive decay combined with long travel times increased the permissible concentrations in the disposal facility.

Application of the PE methodology for water transport of the 18 radionuclides considered in the WVDP PE was performed for both the shallow groundwater-to-surface-water pathway and the deep groundwater-to-well pathway. The permissible waste concentrations for the deep groundwater-to-well pathway were several orders of magnitude more restrictive than the shallow groundwater-to-surface-water pathway. Therefore, only the deep ground-water-to-well pathway permissible waste concentrations are reported here. The results for the generic trench and tumulus designs at WVDP for the deep groundwater-to-well pathway are shown in Table 10-4. The table shows permissible waste concentrations $\left(C_{\text {W-Water }}\right)$ as well as the values used in calculating the permissible waste concentrations.

Some radionuclides listed in Table 10-4 have no limit (NL) on their permissible waste concentrations, the result of the combined effects of relatively short half-lives and sufficiently long travel time to the performance boundary. "No limit" is defined as a permissible waste concentration that is greater than the specific activity of the pure elemental radionuclide. For disposal of the maximum possible waste concentration of these relatively short-lived radionuclides, the water pathway produced a dose at the performance boundary of less than $4 \mathrm{mrem}(0.04 \mathrm{mSv})$ per year and, therefore, the permissible waste concentration was unlimited based on exposures from this pathway.

For some radionuclides, no value is listed in Table 10-4 for the radioactive decay term, $r_{\text {Decay. }}$. These radionuclides had radioactive decay terms that were very large (e.g., greater than $\left.1 \times 10^{50}\right)$. Any radionuclide with a radioactive decay term greater than $1 \times 10^{50}$ was ensured a calculated permissible waste concentration greater than the specific activity of the pure elemental radionuclide, which, as described previously, resulted in no limit (NL) on permissible waste concentrations for disposal.

Arrival times for some radionuclides listed in Table 10-4 were beyond the 10,000-y performance period. For those radionuclides, the estimated waste concentrations are presented in Table 10-4 for information purposes only. Consistent with the approach used in LLW performance assessments, these values were not considered in determining the most restrictive disposal limit from among the evaluated pathways. 
5 Table 10-4. Results of Calculations for the Water Pathway at West Valley (water travel time from land surface to performance ฟू boundary [excluding facility detention] $=670 \mathrm{y}$

\begin{tabular}{|c|c|c|c|c|c|c|c|c|c|c|c|c|c|}
\hline \multirow[t]{2}{*}{ Nuclide } & \multirow[b]{2}{*}{$\begin{array}{c}\text { PDCF } \\
\text { rem/y per } \mu \mathrm{cin}\end{array}$} & \multicolumn{5}{|c|}{ Trench } & \multicolumn{6}{|c|}{ Tumulus } & \multirow[t]{2}{*}{ Nuclide } \\
\hline & & $\begin{array}{l}C R F_{\text {Source }} \\
\text { (dimensionless) }\end{array}$ & $\begin{array}{l}C R F_{\text {Water }} \\
\text { (dimonsionless) }\end{array}$ & $\begin{array}{l}\text { Arrival } \\
\text { Time (y) }\end{array}$ & $\begin{array}{c}r_{\text {Decayy }}{ }^{2} \\
\text { (dimensionloss) }\end{array}$ & $\begin{array}{c}C_{\text {Wwater }}{ }^{b} \\
\left(\mu \mathrm{Ci} / \mathrm{m}^{3}\right)\end{array}$ & $\begin{array}{l}\text { CRF } \\
\text { (dimensionless) }\end{array}$ & $\begin{array}{c}\text { CRF Water } \\
\text { (dimensionless) }\end{array}$ & $\begin{array}{l}\text { Arrival } \\
\text { Time (y) }\end{array}$ & $\begin{array}{c}r_{\text {Deccayy }} \\
\text { (dilmensionless) }\end{array}$ & $\begin{array}{l}C_{\text {W-Water }} \\
\left(\mu \mathrm{Ci} / \mathrm{m}^{3}\right)\end{array}$ & & \\
\hline $\mathrm{H}-3$ & 4.67E-02 & 0.45 & 4.7 & $3.8 E+02$ & $2.1 E+09$ & $4 E+11$ & 0.9 & 4.7 & $9.7 E+02$ & $4.4 E+23$ & NL & & $\mathrm{H}-3$ \\
\hline C-14 & $1.52 E+00$ & 27 & 4.7 & $2.1 \mathrm{E}+03$ & $1.3 \mathrm{E}+00$ & $4 E+02$ & 54 & 4.7 & $4.1 E+03$ & $1.6 \mathrm{E}+00$ & $1 E+03$ & & C-14 \\
\hline$K-40$ & $1.36 E+01$ & 3.1 & 4.7 & $2.6 E+04$ & $1.0 E+00$ & $4 E+00^{c}$ & 6.2 & 4.7 & $4.8 \mathrm{E}+04$ & 1.0E+00 & $9 E+00$ & c & $K-40$ \\
\hline $\mathrm{C}_{0}-60$ & 1.97E+01 & 270 & 4.7 & $1.0 \mathrm{E}+05$ & e & $\mathrm{NL} \quad{ }^{\circ}$ & 540 & 4.7 & $1.9 E+05$ & e & $\mathrm{NL}$ & c & Co-60 \\
\hline Sr-90 & $1.12 \mathrm{E}+02$ & 270 & 4.7 & $8.9 E+03$ & e & NL & 540 & 4.7 & 1.7E+04 & e & NL & c & Sr-90 \\
\hline TC-99 & 1.07E+00 & 3.1 & 4.7 & $4.6 \mathrm{E}+03$ & $1.0 E+00$ & $6 E+01$ & 6.2 & 4.7 & $9.1 E+03$ & 1.0E +00 & $1 E+02$ & & Tc-99 \\
\hline $1-129$ & $2.01 E+02$ & 3.1 & 4.7 & $2.1 E+03$ & $1.0 E+00$ & 3E-01 & 6.2 & 4.7 & 4.1E+03 & $1.0 \mathrm{E}+00$ & 6E-01 & & $\mid-129$ \\
\hline Cs-137 & $3.65 E+01$ & 27 & 4.7 & $6.8 E+04$ & e & $\mathrm{NL} \quad c$ & 54 & 4.7 & $1.3 E+05$ & e & NL & c & Cs-137 \\
\hline U-232 & $1.55 E+03$ & 270 & 4.7 & $3.2 E+04$ & e & $\mathrm{NL} \quad c$ & 540 & 4.7 & $5.9 E+04$ & e & NL & c & U-232 \\
\hline U-233 & $1.95 E+03^{d}$ & 270 & 4.7 & $3.2 E+04$ & NA & $2 E+01^{c}$ & 540 & 4.7 & $5.9 \mathrm{E}+04$ & NA & $5 E+00$ & c & U-233 \\
\hline U-234 & $6.48 \mathrm{E}+02^{d}$ & 270 & 4.7 & $3.2 E+04$ & NA & $2 E+01^{c}$ & 540 & 4.7 & $5.9 E+04$ & NA & $2 E+01$ & c & U-234 \\
\hline U-235 & $3.73 E+03 d$ & 270 & 4.7 & $3.2 E+04$ & NA & $3 E+01^{c}$ & 540 & 4.7 & $5.9 E+04$ & NA & $3 E+00$ & c & U-235 \\
\hline U-236 & $1.96 E+02$ & 270 & 4.7 & $3.2 E+04$ & $1.0 E+00$ & $3 E+01^{c}$ & 540 & 4.7 & $5.9 E+04$ & 1.0E+00 & $5 E+01$ & c & U-236 \\
\hline U-238 & $2.07 E+02$ & 270 & 4.7 & $3.2 E+04$ & NA & $2 E+01^{c}$ & 540 & 4.7 & $5.9 E+04$ & NA & $5 E+01$ & $c$ & U-238 \\
\hline Pu-238 & $2.34 \mathrm{E}+03$ & 270 & 4.7 & $2.2 E+06$ & e & $7 E+04^{\circ f}$ & 540 & 4.7 & $4.2 \mathrm{E}+06$ & e & $4 E+04$ & c 4 & $\mathrm{Pu}-238$ \\
\hline Pu-239 & $2.58 E+03$ & 270 & 4.7 & $2.2 E+06$ & $4.1 E+27$ & NL & 540 & 4.7 & $4.2 E+06$ & e & NL & c & Pu-239 \\
\hline$P u-240$ & $2.58 \mathrm{E}+03$ & 270 & 4.7 & $2.2 E+06$ & $\mathrm{e}$ & $\mathrm{NL}$ & 540 & 4.7 & $4.2 E+06$ & $\mathrm{e}$ & $\mathrm{NL}$ & $c$ & $\mathrm{Pu}-240$ \\
\hline Am-241 & $2.66 \mathrm{E}+03$ & 270 & 4.7 & $3.2 E+06$ & e & $8 E+03$ & 540 & 4.7 & $6.0 E+06$ & e & $2 E+04$ & 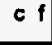 & Am-241 \\
\hline
\end{tabular}

a "NA" means Not Applicable - decay factor is implicit in the PDCF for this radionuclide.

b "NL" means No Limit - estimated permissible concentration is greater than the specific activity of the pure elemental radionuclide.

c Radionuclide concentration is based on arrival time at the performance boundary beyond $10,000 \mathrm{y}$.

d PDCF is a function of arrival time. See Chapter 1 of this volume for equation.

e racory $\geq 1 E+50$

f Contribution of decay product(s) is significant to determination of this value (see Table E-3 in Volume 2). Listed arrival time is that of the parent radionuclide. If this footnote does not appear in combination with footnote $c$, the arrival time of the significant decay product(s) is less than 10,000y. 
For the generic trench at WVDP, the total undecayed CRFs (the product of the $C R F_{\text {Source }}$ and the $C R F_{\text {Water }}$ ) for the water pathway ranged from about 2 to 1270 . Total water travel time was $350 \mathrm{y}$ from the bottom of the hypothetical trench to the performance boundary, while among the listed radionuclides, subsurface travel times to the performance boundary ranged from $380 \mathrm{y}$ to 3.2 million $y$, including the detention time in the facility before failure. The water travel time through the saturated zone accounted for all of the total subsurface travel time because vadose zone travel time was neglected in travel time calculations (see Section 10.3.1.2).

For the generic tumulus at WVDP, the total undecayed CRFs for the water pathway ranged from about 4 to 2500. Among the listed radionuclides, subsurface travel times to the performance boundary ranged from 970 y to 6 million $y$, including the 300-y retention time in the facility before failure. Differences in these arrival times compared to the trench were attributable to (1) the time of assumed hydrologic failure of the facility $(100 \mathrm{y}$ for the trench and $300 \mathrm{y}$ for the tumulus); (2) the increased flow rate at the time of failure of the facility compared to that when the leachate collection system failed; and (3) the increased travel distance through the vadose zone for the tumulus (the bottom of the tumulus was at grade level, while the trench bottom was located $10 \mathrm{~m}(33 \mathrm{ft})$ below grade).

\subsubsection{Atmospheric Transport}

Two CRFs were used to account for the attenuation encompassing diffusion to the ground surface, mixing in air, and dispersion in the atmosphere to the performance boundary. The CRF for diffusion in soil, $C R F_{D i f f}$, was defined as the ratio of the radionuclide concentration in the waste to its resulting concentration in the upper one centimeter of soil. The CRF for mixing and dispersion in air, $C R F_{\text {Disp, }}$ was defined as the ratio of the radionuclide concentration in the upper one centimeter of soil to its resulting concentration in air at the performance boundary. The effect of radioactive decay was also included in the PE.

Application of the PE methodology for atmospheric transport of the two volatile radionuclides considered in the $\mathrm{PE}$ ( $\mathrm{H}-3$ and $\mathrm{C}-14$ ) produced the results shown in Table 10-5 for both the generic trench and tumulus designs; there was no assumed difference in these two disposal technologies with respect to permissible waste limits based on the atmospheric pathway at WVDP. The table shows permissible waste concentrations based on transport in the atmospheric pathway $\left(C_{W-A t m}\right)$ as well as the values used in calculating the permissible waste concentrations. For both $\mathrm{H}-3$ and $\mathrm{C}-14$, the greatest concentration reduction occurred as the radionuclides diffuse from the top of the disposal facility to the soil surface.

The time of arrival at the performance boundary for both radionuclides is shown in Table $10-5$ as $100 \mathrm{y}$. However, the actual migration of $\mathrm{H}-3$ and $\mathrm{C}-14$ from the disposal facility to the surface and downwind to the performance boundary was calculated to be on the order of hours, not years. As discussed in Section 10.3.2.2, the waste form and RCRA cover are assumed to retain these volatile radionuclides in the disposal facility for at least $100 \mathrm{y}$. 
Table 10-5. Results of Calculations for the Atmospheric Pathway

\begin{tabular}{|c|c|c|c|c|c|c|c|}
\hline \multirow[t]{2}{*}{ Nuclide } & \multirow[b]{2}{*}{$\begin{array}{c}S D C F_{A t m} \\
(\mathrm{rem} / \mathrm{y}) /(\mu \mathrm{Ci} / \mathrm{L})\end{array}$} & \multicolumn{6}{|c|}{ Generic Trench and Tumulus } \\
\hline & & $\begin{array}{c}C_{\text {(dimensloniens) }} \\
\end{array}$ & 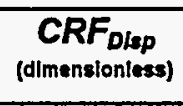 & $\begin{array}{c}\mathrm{CRF}_{\text {(dimensiontess) }} \\
\text { (dime }\end{array}$ & $\begin{array}{l}\text { Arrival } \\
\text { Time (y) }\end{array}$ & \begin{tabular}{|c|} 
roecay \\
(dimensionless) \\
\end{tabular} & $\begin{array}{c}C_{W-A t m} \\
\left(\mu \mathrm{Ci} / \mathrm{m}^{3}\right)\end{array}$ \\
\hline $\mathrm{H}-3$ & $8.33 E+02$ & $4 E+06$ & $6 E+02$ & $2 E+09$ & 100 & 300 & $9 \mathrm{E}+09$ \\
\hline C-14 & $2.20 E+05$ & $8 E+04$ & $1 E+03$ & $8 \mathrm{E}+07$ & 100 & 1 & $4 E+03$ \\
\hline
\end{tabular}

\subsubsection{Inadvertent Intruder Exposure}

The calculation of permissible waste concentrations for inadvertent intruder exposures did not utilize CRFs. Instead, the total dose resulting from an intrusion scenario (the sum of the doses from all exposure pathways involved in that intrusion) was modified by scenario dose conversion factors (SDCFs) that were applied to specific exposure pathways. The important exposure pathways for each radionuclide are listed in Appendix $\mathrm{D}$ of Volume 2. These values were radionuclide-specific and facility-design-specific and were the same for all sites. Values for the radioactive decay term were based on time of intrusion into the disposal facility (for the homesteader scenario, $300 \mathrm{y}$ for the trench design and $500 \mathrm{y}$ for the tumulus design; for the postdrilling scenario, $100 \mathrm{y}$ for both disposal designs). However, results based on intruder scenarios should be evaluated carefully because future social behavior, and intrusion scenarios, are difficult to predict.

The permissible waste concentrations for the two generic facility designs for each of the 18 radionuclides based on the standard PE intrusion scenarios are listed in Table 10-6. The most restrictive radionuclide concentration limits for each generic facility are indicated with bold type.

For four radionuclides in the table (U-233, U-234, U-235, and U-238), the time of homesteader intrusion was changed to $10,000 \mathrm{y}$, the end of the performance period. For these radionuclides, ingrowth of decay products yields scenario doses that increase over time. The doses at $10,000 \mathrm{y}$, therefore, represent the maximum that could be encountered during the performance period.

For the trench design, the post-drilling scenario generally yielded more restrictive waste limits than the homesteader scenario for those radionuclides with half-lives shorter than about $30 \mathrm{y}$. For the tumulus design, the post-drilling scenario generally yielded more restrictive limits than the homesteader scenario for those radionuclides with half-lives shorter than about $130 \mathrm{y}$. 
Table 10-6. Permissible Waste Concentrations for the Standard Intrusion Scenarios (most limiting radionuclide concentration for each facility design is highlighted in bold italic)

\begin{tabular}{|c|c|c|c|c|c|}
\hline \multirow[t]{2}{*}{ Nuclide } & \multicolumn{2}{|c|}{ Trench } & \multicolumn{2}{|c|}{ Tumulus } & \multirow[t]{2}{*}{ Nuclide } \\
\hline & $\begin{array}{c}C_{w-I n t r} \\
\text { Homesteader } \\
\left(\mu \mathrm{Ci} / \mathrm{m}^{3}\right)\end{array}$ & $\begin{array}{c}C_{\text {W/Intr }} \\
\text { Post-Drilling } \\
\left(\mu \mathrm{Ci} / \mathrm{m}^{3}\right)\end{array}$ & $\begin{array}{c}C_{W / n r^{2}} \\
\text { Homesteader } \\
\left(\mu \mathrm{Ci} / m^{3}\right)\end{array}$ & $\begin{array}{c}C_{w-I n t r} \\
\text { Post-Drilling } \\
\left(\mu \mathrm{Ci} / \mathrm{m}^{3}\right)\end{array}$ & \\
\hline $\mathrm{H}-3$ & $1 E+12$ & $7 E+07$ & $\mathrm{NL}$ & $7 E+07$ & $\mathrm{H}-3$ \\
\hline$C-14$ & $1 E+04$ & $7 E+04$ & $1 E+04$ & $7 E+04$ & C-14 \\
\hline Co-60 & $N L$ & $3 E+10$ & NL & $3 E+10$ & Co-60 \\
\hline Sr-90 & $1 E+06$ & $5 E+04$ & $1 E+08$ & $5 E+04$ & Sr-90 \\
\hline Tc-99 & $2 E+04$ & $8 E+04$ & $2 E+04$ & $8 E+04$ & TC-99 \\
\hline $1-129$ & $2 E+03$ & $1 E+04$ & $2 E+03$ & $1 E+04$ & I-129 \\
\hline Cs-137 & $3 E+05$ & $8 E+05$ & $3 E+07$ & $8 E+05$ & Cs-137 \\
\hline U-232 & $2 E+03$ & $5 E+04$ & $1 E+04$ & $5 E+04$ & $\mathrm{U}-232$ \\
\hline U-233 & $7 E+02$ & $1 E+05$ & $7 E+02$ & $1 E+05$ & $\mathrm{U}-233$ \\
\hline U-234 & $1 E+03$ & $1 E+05$ & $1 E+03$ & $1 E+05$ & U-234 \\
\hline U-235 & $6 E+02$ & $1 E+05$ & $6 E+02$ & $1 E+05$ & U-235 \\
\hline U-236 & $2 E+04$ & $1 E+05$ & $2 E+04$ & $1 E+05$ & U-236 \\
\hline U-238 & $5 E+03$ & $1 E+05$ & $5 E+03$ & $1 E+05$ & U-238 \\
\hline Pu-238 & $7 E+04$ & $1 E+05$ & $4 E+05$ & $1 E+05$ & $\mathrm{Pu}-238$ \\
\hline Pu-239 & $6 E+03$ & $5 E+04$ & $6 E+03$ & $5 E+04$ & Pu-239 \\
\hline $\mathrm{Pu}-240$ & $6 E+03$ & $5 E+04$ & $7 E+03$ & $5 E+04$ & Pu-240 \\
\hline Am-241 & $7 E+03$ & $5 \mathrm{E}+04$ & $9 E+03$ & $5 E+04$ & Am-241 \\
\hline
\end{tabular}

a "NL" means No Limit - estimated permissible concentration is greater than the specific activity of the pure elemental radionuclide.

\subsection{SUMMARY AND DISCUSSION OF RESULTS}

The limiting waste concentrations in disposed MLLW for the water, atmospheric, and intruder analyses for the generic trench and tumulus designs are summarized in Table 10-7 and discussed in Section 10.6.1. An overall discussion of the results of the PE for WVDP is contained in Section 10.6.2.

\subsubsection{Results Based on Disposal Design}

For both the generic trench and tumulus designs at WVDP, 3 of the 18 radionuclides (C-14, Tc-99, and I-129) were limited by the water pathway, no radionuclides were limited by the atmospheric pathway, and 15 radionuclides were limited by intrusion scenarios, as shown in Table 10-7. 
Table 10-7. Permissible Concentration for the Generic Disposal Designs at West Valley (permissible concentration related to the most limiting pathway for each facility design is highlighted in bold italic)

\begin{tabular}{|c|c|c|c|c|c|c|c|}
\hline \multirow[t]{2}{*}{ Nuclide } & \multicolumn{3}{|c|}{ Trench } & \multicolumn{3}{|c|}{ Tumulus } & \multirow[t]{2}{*}{ Nuclide } \\
\hline & $\begin{array}{c}C_{\text {w.Water }}{ }^{2, b} \\
\left(\mu \mathrm{Ci} / \mathrm{m}^{3}\right)\end{array}$ & $\begin{array}{l}C_{W-A t m}{ }^{c} \\
\left(\mu \mathrm{Ci} / \mathrm{m}^{3}\right)\end{array}$ & $\begin{array}{l}C_{W-1 n t r}{ }^{d} \\
\left(\mu \mathrm{Ci} / m^{3}\right)\end{array}$ & $\begin{array}{c}C_{\text {w-Water }}{ }^{2, b} \\
\left(\mu \mathrm{Ci} / \mathrm{m}^{3}\right)\end{array}$ & $\begin{array}{l}C_{\text {W-Amm }}{ }^{\mathrm{C}} \\
\left(\mu \mathrm{Ci} / \mathrm{m}^{3}\right)\end{array}$ & $\begin{array}{l}C_{W-1 n r^{d}} \\
\left(\mu \mathrm{Ci} / \mathrm{m}^{3}\right)\end{array}$ & \\
\hline $\mathrm{H}-3$ & $4 E+11$ & $9 E+09$ & $7 E+07$ & $\mathrm{NL}$ & $9 E+09$ & $7 E+07$ & $\mathrm{H}-3$ \\
\hline$C-14$ & $4 E+02$ & $4 E+03$ & $1 E+04$ & $1 E+03$ & $4 \mathrm{E}+03$ & $1 E+04$ & C-14 \\
\hline$K-40$ & - & & $7 E+02$ & - & & $7 E+02$ & $K-40$ \\
\hline Co-60 & - & & $3 E+10$ & - & & $3 E+10$ & Co-60 \\
\hline Sr-90 & NL & & $5 E+04$ & - & & $5 E+04$ & Sr-90 \\
\hline TC-99 & $6 E+01$ & & $2 E+04$ & $1 E+02$ & & $2 E+04$ & TC-99 \\
\hline I-129 & $3 E-01$ & & $2 E+03$ & $6 E-01$ & & $2 E+03$ & $1-129$ \\
\hline Cs-137 & - & & $3 E+05$ & - & & $8 E+05$ & Cs-137 \\
\hline U-232 & - & & $2 E+03$ & - & & $1 E+04$ & $U-232$ \\
\hline U-233 & - & & $7 E+02$ & - & & $7 E+02$ & $U-233$ \\
\hline U-234 & - & & $1 E+03$ & - & & $1 E+03$ & $\mathrm{U}-234$ \\
\hline U-235 & - & & $6 E+02$ & - & & $6 E+02$ & $\mathrm{U}-235$ \\
\hline U-236 & - & & $2 E+04$ & - & & $2 E+04$ & $\mathrm{U}-236$ \\
\hline U-238 & - & & $5 E+03$ & - & & $5 E+03$ & $\mathrm{U}-238$ \\
\hline $\mathrm{Pu}-238$ & - & & $7 E+04$ & - & & $1 E+05$ & Pu-238 \\
\hline Pu-239 & - & & $6 E+03$ & - & & $6 E+03$ & Pu-239 \\
\hline Pu-240 & - & & $6 E+03$ & - & & $7 E+03$ & Pu-240 \\
\hline Am-241 & $8 E+03$ & & $7 E+03$ & - & & $9 E+03$ & Am-241 \\
\hline
\end{tabular}

a "NL" means No Limit - estimated permissible concentration factor is greater than the specific activity of the pure elemental radionuclide.

b " $="$ indicates that the radionuclide concentration is based on an arrival time beyond 10,000 y; see Table 10-4 for specific values.

c Results presented for radionclides expected to be volatile under disposal facility conditions.

d Concentration is based on the most restrictive intrusion scenario assumed for the site; see Table $10-6$.

One radionuclide for the trench design (Sr-90) and one for the tumulus design $(\mathrm{H}-3)$ arrived at the performance boundary before 10,000 y and had no limit on permissible waste concentrations. As discussed in Section 10.5.1, the calculated concentrations for those radionuclides reported as NL (No Limit) were above the specific activity of the pure elemental radionuclide, implying that the performance measure of 4 mrem $(0.04 \mathrm{mSv})$ per year would not be reached under the given release and transport assumptions.

As also discussed in Section 10.5.1, values for some radionuclides are not reported in Table 10-7 for the water pathway analysis. Arrival times for these radionuclides were beyond the 10,000-y performance period. Consistent with the approach used in LLW performance assessments, these values were not considered in determining the most restrictive disposal limit from among the evaluated pathways because arrival times for these radionuclides were beyond $10,000 \mathrm{y}$. 
For both the trench and tumulus designs, C-14, Tc-99, and I-129 were limited by the water pathway. These are relatively mobile, long-lived radionuclides with $K_{d}$ values for the geologic media ranging from 0 to $1 \mathrm{~mL} / \mathrm{g}$, and half-lives ranging from $5.7 \times 10^{3}$ to $1.6 \times 10^{7} \mathrm{y}$.

\subsubsection{Discussion}

The results of the PE are based on the framework of assumptions summarized in Chapter 1 of this volume and discussed in detail in Volume 2 of this report and on the site-specific conceptual model for contaminant transport discussed in this chapter. Using alternative assumptions about the conceptual model has the potential to affect the results. Changes in the conceptual model could include alternative assumptions about the disposal facility, the source term, and radionuclide movement in the three pathways. Depending on the degree of possible variation and the relative importance of the parameters used in the calculation of estimated permissible radionuclide concentrations, variability in parameter values can also affect the results. For parameters, results could vary depending on potential changes in values of both the generic and the site-specific parameters used in the PE.

The effect on results from using alternative generic assumptions and parameter values is discussed in Chapter 6 of Volume 2. In addition, a discussion is provided in that chapter about the effects of using alternative values for site-specific parameters. Based on this discussion, four parameters were identified (three site-specific and one generic, all used in the water pathway analysis) that could potentially influence the results to the degree that the calculated waste concentrations become limited by a pathway other than the one determined for the PE (Table 10-7). The impacts on the results of using alternative values for these four parameters for the water pathway in the PE for WVDP are discussed in this section. The basis for and possible variation in the values used in the PE for these parameters are discussed in Section 10.6.2.2.

\subsubsection{Parameter Sensitivity Analysis}

The PE provided results for two disposal facility designs: a RCRA-compliant, belowground trench and a RCRA-compliant, above-ground tumulus. Similar assumptions about the integrity of engineered barriers were made in the PE for both facility designs. Because the factors used to estimate transport of radionuclides in the water pathway for both designs were similar, the discussion in this section focuses on examining the results for the indicator radionuclides reported for the tumulus design (indicator radionuclides are defined in Chapter 7 of Volume 2).

As discussed in Chapter 6 of Volume 2, only four parameters used in the PE were identified as having a potential range of values that might affect results: natural recharge $(i)$; groundwater Darcy velocity $\left(q_{g w}\right)$; area of the facility $(A)$; and distribution coefficients $\left(K_{d} \mathrm{~S}\right)$. These parameter values for WVDP are summarized in Table 10-8. 
Table 10-8. Parameter Values Used in the PE for WVDP with Potential Variability That Could Affect the Results

\begin{tabular}{|l|l|}
\hline \multicolumn{1}{|c|}{ Parameter } & \multicolumn{1}{|c|}{ Value } \\
\hline $\begin{array}{l}\text { Natural recharge through local } \\
\text { soils, } i\end{array}$ & $\begin{array}{l}0.07 \mathrm{~m} / \mathrm{y}(0.01 \mathrm{~m} / \mathrm{y} \text { moves down and } 0.06 \mathrm{~m} / \mathrm{r} \\
\text { moves laterally, based on site information; see } \\
\text { Section 10.3.1.1) }\end{array}$ \\
\hline $\begin{array}{l}\text { Distribution coefficients for } \\
\text { geologic media, } K_{d}\end{array}$ & see Table 10-2 in this chapter for values \\
\hline Groundwater Darcy velocity, $q_{g w}$ & $\begin{array}{l}0.31 \mathrm{~m} / \mathrm{y} \text { (based on site-specific measurements; } \\
\text { see Section 10.4.1 for discussion) }\end{array}$ \\
\hline Plan-view Area, $A$ & $2500 \mathrm{~m}^{2}$ (standard PE value) \\
\hline
\end{tabular}

The traditional procedure for performing a sensitivity analysis is to vary the parameters used in the calculations and observe the effect on the results. To be meaningful, this method requires some knowledge of the statistical distribution of each of the parameters considered, including their likely maximum and minimum values. For the PE calculations, the potential variability of the parameters used to calculate the permissible waste concentrations for the two different facility designs was not estimated. For most of the radionuclides considered in the PE, there were only two exposure pathways: the water pathway and intruder exposure scenarios (the atmospheric pathway was considered only for $\mathrm{H}-3$ and $\mathrm{C}-14$ ). The intruder-pathway results provide a baseline that can be used for comparison with the water-pathway results because the intruder scenarios used in the PE were relatively independent of the physical characteristics of the individual sites. This baseline provided an alternative method of performing sensitivity analyses for the PE. The input parameters for the water pathway were varied to determine if the controlling exposure pathway could be altered (e.g., the results could be changed from intruderscenario controlled to water-pathway controlled). After new values for the water pathway parameters were determined, these values were examined for reasonableness based on physical constraints at the site.

The sensitivity analysis was limited to a comparison of the water and intruder exposure pathways. A comparison between the water and atmospheric pathways was not conducted because the atmospheric pathway was not limiting.

To analyze the sensitivity of the results to changes in the parameter values for recharge, groundwater Darcy velocity, and area of the facility, the parameter values used in the PE for WVDP were varied. Only one parameter value was varied at a time for a radionuclide, leaving the others equal to their PE values. In most instances, the parameter value was varied until the waste concentrations for the water and intruder pathways became equal, regardless of the likelihood (or physical impossibility) of the value to occur. 
The parameter values that caused the permissible concentrations for the water and intruder pathways to become equal are listed in Table 10-9 for the 8 indicator radionuclides. For the indicator radionuclide C-14, the recharge had to decrease by an order of magnitude or the Darcy velocity had to increase 16 times to change the controlling pathway from water to intruder. For Tc-99, the value for recharge had to decrease by about two orders of magnitude, or the Darcy velocity had to increase by almost a factor of 200 to change the limiting pathway from water to intruder. For U-238, the value for the recharge had to decrease by more than two orders of magnitude, or the groundwater velocity had to increase by a factor of 130 in order for the water pathway concentration to equal the intruder pathway concentration. However, for both parameters, the arrival times for U-238 exceeded $10,000 \mathrm{y}$. For Am-241, the value for recharge had to double, the Darcy velocity had to decrease by one-half, or the plan-view area had to increase four times in order to change the limiting pathway from intruder to water, although the arrival time exceeded $10,000 \mathrm{y}$ for each of the parameters.

Table 10-9. Parameter Values That Caused the Permissible Concentrations for the Water and Intruder Pathways to Be Equal for Indicator Radionuclides at WVDP (tumulus design) (bold italic type indicates limiting pathway in the PE)

\begin{tabular}{|c|c|c|c|c|c|c|}
\hline \multirow[t]{4}{*}{$\begin{array}{l}\text { Indicator } \\
\text { Nuclide }\end{array}$} & \multirow[t]{4}{*}{$\begin{array}{c}\text { PE } \\
C_{\text {w-water }} \\
\left(\mu \mathrm{Ci} / \mathrm{m}^{3}\right)\end{array}$} & \multirow[t]{4}{*}{$\begin{array}{c}\mathrm{PE} \\
C_{W-1 \mathrm{ntr}} \\
\left(\mu \mathrm{Ci} / \mathrm{m}^{3}\right)\end{array}$} & \multirow[t]{4}{*}{$\begin{array}{c}P E \\
\frac{C_{W-\text { Int }}}{C_{\text {W-Water }}}\end{array}$} & $\begin{array}{c}\text { Natural } \\
\text { Recharge, } \\
i \\
(\mathrm{~m} / \mathrm{y})\end{array}$ & $\begin{array}{l}\text { Groundwater } \\
\text { Darcy } \\
\text { Velocity, } q_{\mathrm{gw}} \\
(\mathrm{m} / \mathrm{y}) \\
\end{array}$ & $\begin{array}{c}\text { Area, } \\
A \\
\left(\mathrm{~m}^{2}\right)\end{array}$ \\
\hline & & & & \multicolumn{3}{|c|}{ PE Values } \\
\hline & & & & 0.01 & 0.31 & 2500 \\
\hline & & & & \multicolumn{3}{|c|}{$\begin{array}{l}\text { Value That Caused Equal } \\
\text { Concentrations }\end{array}$} \\
\hline $\mathrm{H}-3$ & NL & $7 E+07$ & - & c & c & c \\
\hline$C-14$ & $1 E+03$ & $1 E+04$ & 10 & $0.002^{b}$ & 5 & $<100$ \\
\hline Sr-90 & $\mathrm{NL}^{\mathrm{b}}$ & $5 E+04$ & - & $\mathrm{c}$ & c & c \\
\hline TC-99 & $1 E+02$ & $2 E+04$ & 200 & $2 \mathrm{E}-04^{\mathrm{b}}$ & 55 & $<100$ \\
\hline Cs-137 & $\mathrm{NL}^{\mathrm{b}}$ & $8 E+05$ & - & c & c & c \\
\hline U-238 & $5 E+01^{b}$ & $5 E+03$ & 100 & $8 E-05^{b}$ & $40^{b}$ & $<100$ \\
\hline Pu-239 & $\mathrm{NL}^{\mathrm{b}}$ & $6 E+03$ & - & $\bar{c}$ & c & c \\
\hline $\begin{array}{l}\mathrm{Am-241} \\
(\mathrm{Np}-237)^{\mathrm{d}}\end{array}$ & $2 E+04^{b, e}$ & $9 E+03$ & 0.5 & $0.02^{\mathrm{b}, \mathrm{o}}$ & $0.15^{\mathrm{b}, \mathrm{o}}$ & $10,000^{b, 0}$ \\
\hline
\end{tabular}

a "NL" means No Limit - estimated permissible concentration is greater than the specific activity of the pure elemental radionuclide.

b Arrival time at the performance boundary is greater than $10,000 \mathrm{y}$.

c No variation In values caused equal concentrations.

d The dominant decay product for Am-241

e Based on the dominant decay product, Np-237

"." Value could not be calculated. 
A $K_{d}$ value of $2 \mathrm{~mL} / \mathrm{g}$ for the geologic media would cause an arrival time at the performance boundary of $10,000 \mathrm{y}$. The $K_{d}$ values that caused the permissible concentrations for the water and intruder pathways to be the same are listed in Table 10-10 for 5 of the indicator radionuclides. The indicator radionuclides $\mathrm{H}-3, \mathrm{C}-14$, and $\mathrm{Tc}-99$ are not considered in this analysis because general consensus is that the $K_{d}$ values for these radionuclides are small. For $\mathrm{U}-238$, a $K_{d}$ value less than $2 \mathrm{~mL} / \mathrm{g}$ for all units caused the arrival at the performance boundary to be less than $10,000 \mathrm{y}$, thereby changing the limiting pathway from intruder to water. For Pu-239, a $K_{d}$ value of $80 \mathrm{~mL} / \mathrm{g}$ for all units caused the water pathway concentration to exceed the intruder concentration; however the arrival time still exceded $10,000 \mathrm{y}$; the $K_{d}$ had to be decreased to less than $2 \mathrm{~mL} / \mathrm{g}$ for the water pathway concentration to be less than the intruder concentration and have an arrival time less than $10,000 \mathrm{y} . \mathrm{A} K_{d}$ value of $1 \mathrm{~mL} / \mathrm{g}$ for Am-241 caused the permissible waste concentration for the water pathway to be equal to the intruder pathway.

Table 10-10. Variation of $K_{d}$ Values for the Geologic Media at WVDP (tumulus design) (a $K_{d}$ value of $2 \mathrm{~mL} / \mathrm{g}$ caused radionuclide arrival at the performance boundary equal to $10,000 \mathrm{y})$

\begin{tabular}{|c|c|c|c|c|c|}
\hline $\begin{array}{l}\text { Indicator } \\
\text { Nuclide }\end{array}$ & $\begin{array}{c}\mathrm{PE} \\
K_{d} \\
(\mathrm{~mL} / \mathrm{g}) \\
\end{array}$ & $\begin{array}{c}\text { PE } \\
C_{W \cdot W a t e r}^{a} \\
\left(\mu \mathrm{Ci} / \mathrm{m}^{3}\right)\end{array}$ & $\begin{array}{c}\text { PE } \\
C_{W-1 n t r} \\
\left(\mu \mathrm{Ci} / \mathrm{m}^{3}\right)\end{array}$ & $\begin{array}{c}\text { PE } \\
C_{W-\text { Intr }} \\
C_{W-W \text { ater }}\end{array}$ & $\begin{array}{l}K_{d} \text { Value That } \\
\text { Caused Equal } \\
\text { Concentrations }\end{array}$ \\
\hline Sr-90 & 5 & $\mathrm{NL}^{\mathrm{b}}$ & $5 E+04$ & - & c \\
\hline Cs-137 & 40 & $\mathrm{NL}^{b}$ & $8 E+05$ & - & $c$ \\
\hline U-238 & $35 / 9^{d}$ & $5 E+01^{b}$ & $5 E+03$ & 100 & $c, e$ \\
\hline Pu-239 & $550 / 1960^{d}$ & $\mathrm{NL}^{b}$ & $6 E+03$ & - & $80^{b, a}$ \\
\hline $\begin{array}{l}A m-241 \\
(N p-237)^{f}\end{array}$ & $\begin{array}{l}1900 \\
(5)\end{array}$ & $2 E+04^{b, s}$ & $9 E+03$ & 0.5 & 1 \\
\hline
\end{tabular}

a "NL" means No Limit - the estimated permissible waste concentration is greater than the specific activity of the pure elemental radionuclide.

b Arrival time at the performance boundary is greater than $10,000 \mathrm{y}$.

c No variation in value caused equal concentrations.

d First value for Weathered Lavery Till and Kent Recessional; second value for Unweathered Lavery Till

e Value less than $2 \mathrm{~mL} g$ caused arrival at the performance boundary before $10,000 \mathrm{y}$, which changed the limiting pathway.

$f$ The dominant decay product of Am-241

g Based on the dominant decay product, Np-237

"-" Value could not be calculated.

\subsubsection{Physical Constraints on Sensitivity Analysis Values}

The PE results for WVDP are based on parameter values provided by the WVDP technical staff for site-specific parameters used in calculations. Descriptions and technical justifications of these values are provided in Sections 10.3 and 10.4. Ranges and statistical distributions may not have been known for all of the input parameter values; however, sitespecific knowledge can be used to examine whether the values determined in the sensitivity analysis are reasonable and physically possible at the hypothetical MWDF site at WVDP. 


\section{Natural Recharge}

The values for natural recharge estimated in the sensitivity analysis range from 0.02 to $8 \times 10^{-5} \mathrm{~m} / \mathrm{y}(0.07$ to $0.00026 \mathrm{ft} / \mathrm{y}$ ) (Table 10-9). The PE total recharge for WVDP is $0.07 \mathrm{~m} / \mathrm{y}$ $(0.23 \mathrm{ft} / \mathrm{y})$ (WVNSC, Inc., 1993c) based upon water budget modeling studies, where $0.01 \mathrm{~m} / \mathrm{y}$ $(0.033 \mathrm{ft} / \mathrm{y})$ moves down and $0.06 \mathrm{~m} / \mathrm{y}(0.2 \mathrm{ft} / \mathrm{y})$ moves laterally (see Section 10.4.1). The deep recharge value of $0.01 \mathrm{~m} / \mathrm{y}(0.033 \mathrm{ft} / \mathrm{y})$ used in the sensitivity analysis is an upper limit based upon the vertical saturated hydraulic conductivitity of the Unweathered Lavery Till unit, the least conductive of the hydrogeologic units at the WVDP site. Only the deep recharge value for Am$241(0.02 \mathrm{~m} / \mathrm{y}[0.07 \mathrm{ft} / \mathrm{y}])$ calculated in the sensitivity analysis falls within the reported range for saturated hydraulic conductivity for the Unweathered Lavery Till $(0.04$ to $0.005 \mathrm{~m} / \mathrm{y}$ [0.13 to $0.016 \mathrm{ft} / \mathrm{y}]$ ), the other calculated values are smaller than the lowest reported saturated hydraulic conductivity. However, all calculated recharge produces results with corresponding radionuclide travel times greater than $10,000 \mathrm{y}$.

\section{Groundwater Darcy Velocity}

The values for the groundwater Darcy velocity estimated by the sensitivity analysis vary from 0.15 to $60 \mathrm{~m} / \mathrm{y}(0.5$ to $200 \mathrm{ft} / \mathrm{y})$ (Table 10-9) compared to the PE value of $0.31 \mathrm{~m} / \mathrm{y}$ $(1.02 \mathrm{ft} / \mathrm{y})$. However, the U-238 and Am-241 results (40 and $0.15 \mathrm{~m} / \mathrm{y}$ [130 and $0.49 \mathrm{ft} / \mathrm{y}]$, respectively) correspond to an arrival time greater than $10,000 \mathrm{y}$. Darcy velocities of $5 \mathrm{~m} / \mathrm{y}$ $(16.4 \mathrm{ft} / \mathrm{y})$ for C-14 or $60 \mathrm{~m} / \mathrm{y}(197 \mathrm{ft} / \mathrm{y})$ for Tc-99 are not reasonable for the Kent Recessional unit at WVDP. These values are at least an order of magnitude greater than the highest reported Darcy velocities measured at WVDP (see Section 10.4.1).

\section{Facility Area}

The values for the facility area estimated in the sensitivity analysis either are less than $100 \mathrm{~m}^{2}\left(1080 \mathrm{ft}^{2}\right)$ or are $10,000 \mathrm{~m}^{2}\left(108,000 \mathrm{ft}^{2}\right)($ Table 10-9). The result for Am-241 corresponds to an arrival time greater than 10,000 y. For C-14, Tc-99, and U-238, a trench or tumulus facility size less than $100 \mathrm{~m}^{2}\left(1080 \mathrm{ft}^{2}\right)$ is not reasonable.

\section{Distribution Coefficients}

A $K_{d}$ value of $2 \mathrm{~mL} / \mathrm{g}$ corresponds to an arrival time of $10,000 \mathrm{y}$. According to Table $10-4,8$ out of 18 and 2 out of 18 radionuclides arrive at the performance boundary between $10,000 \mathrm{y}$ and $100,000 \mathrm{y}$ for the trench and tumulus design, respectively. For the tumulus, 7 radionuclides arrive just beyond 100,000 y. For U-238, it is probably reasonable to lower the $K_{d}$ about an order of magnitude to $2 \mathrm{~mL} / \mathrm{g}$, and change the limiting pathway from intruder to water. The $K_{d}$ for Pu-239 was calculated in the sensistivity analysis to be $80 \mathrm{~mL} / \mathrm{g}$ to make the water and intruder concentrations become equal, but $2 \mathrm{~mL} / \mathrm{g}$ is required to have an arrival at $10,000 \mathrm{y}$. The $\mathrm{PE} K_{d}$ for $\mathrm{Pu}-238$ is $550 \mathrm{~mL} / \mathrm{g}$, and a value as low as $2 \mathrm{~mL} / \mathrm{g}$ is probably not reasonable. The $K_{d}$ for Am-241 and its daughter product $\mathrm{Np}-237$ was calculated in the sensitivity analysis to be 1 $\mathrm{mL} / \mathrm{g}$ (Table 10-10). The PE value for Am-241 is $1900 \mathrm{~mL} / \mathrm{g}$ and the $K_{d}$ value of 1 is three orders of magnitude smaller than the PE $K_{d}$ value, which is probably not reasonable for Am-241. Due to the very long half-life of Np-237, no value for $K_{d}$ changes the permissible waste concentration. 


\subsection{OBSERVATIONS}

Based on the results of the PE and the parameter-sensitivity analysis, the following observations can be made about MLLW disposal at WVDP:

- The WVDP site is typical of a humid climate. The natural recharge is high and the site has essentially no unsaturated zone. Travel through the saturated zone accounts for the subsurface travel time.

- For both the trench and tumulus designs at WVDP, the results indicate that of the 18 radionuclides evaluated in the $P E, 15$ would be limited by intrusion scenarios. These results reflect the dominant role of the selected human intrusion scenarios that is demonstrated for almost all the sites considered in the PE (see Sections 7.5 and 7.6 in Volume 2). This dominance indicates a need to be aware of the inability to predict the social behavior of populations far into the future.

The results also indicate that for the water pathway, 13 radionuclides for the trench design and 14 radionuclides for the tumulus design would arrive at the performance boundary after the $10,000-y$ period of consideration in the PE analysis of the water pathway. Of the radionuclides that would arrive before $10,000 \mathrm{y}$, one for the trench design (Sr-90) and one for the tumulus design (H-3) had no limit on waste concentration.

Because WVDP has many radionuclides that either are limited by the intrusion scenarios, arrive at the performance boundary after $10,000 \mathrm{y}$, or have no limit on waste concentration, this site may have flexibility in accepting a variety of radionuclides for disposal.

- The most feasible disposal design at WVDP is the tumulus design. The shallow water table precludes trench disposal in the unsaturated zone; however, very low permeability of the Unweathered Lavery Till unit beneath the south plateau provides a zone for possible trench disposal below the water table that has been used for disposal in the past.

- The WVDP site may have physical constraints that could limit disposal activities. Limited space may be available for siting a disposal facility.

- The sensitivity analysis results indicate that reasonable changes in values for the natural recharge, groundwater Darcy velocity, and facility size did not significantly change the results.

In flow and transport problems, the $K_{d}$ values are often the most uncertain site-specific input parameters. For WVDP, the $K_{d}$ value for U-238 could be changed in a reasonable way to change the controlling pathway from intruder to water. 
- The PE was a scoping analysis performed using assumptions that are conservative relative to most LLW performance assessments. A more detailed performance assessment would be required for permitting or other serious disposal planning.

\subsection{REFERENCES}

Albanese, J.R. et al., 1984. Geological and Hydrogeologic Research at the Western New York Nuclear Service Center, West Valley, New York. Final Report, August 1982-December 1983. U.S Nuclear Regulatory Commission Report NUREG/CR-3782.

Baer, T.A., L.L. Price, J.N. Emery, N.E. Olague, 1994. Second Performance Assessment Iteration of the Greater Confinement Disposal Facility at the Nevada Test Site. SAND930089. Albuquerque, NM: Sandia National Laboratories.

Bergeron, M.P., W.M. Kappel, and R.M. Yager, 1987. Geohydrologic Conditions at the Nuclear Fuels Reprocessing Plant and Waste-Management Facilities at the Western New York Nuclear Service Center, Cattaraugus County, New York. USGS Report 85-4145. Ithaca, NY: U.S. Geological Survey.

Cooper, C.D., and F.C. Alley, 1986. Air Pollution Control: A Design Approach. Prospect Heights, IL: Waveland Press, Inc.

CRC, 1981. CRC Handbook of Chemistry and Physics. Eds. Robert C. Weast and Melvin J. Astle. Boca Raton, FL: CRC Press, Inc.

CRC, 1987. Handbook of Tables for Applied Engineering Science, 2nd edition. Eds. Bolz R.E., and G.L. Tuve. Boca Raton, FL: CRC Press, Inc.

Dames and Moore, 1995. Testing and Characterization of Glacial Deposits: Geochemical and Radionuclide Adsorption Data, West Valley Demonstration Project, West Valley, New York.

EPA, 1992. User's Guide for the Industrial Source Complex (ISC2) Dispersion Models, Volume I: User Instructions. EPA Publication No. EPA-450/4-92-008a. Research Triangle, NC: U.S. Environmental Protection Agency.

FFCAct, 1992. Federal Facility Compliance Act of 1992. P.L. 102-386, October 1992.

Freeze, R.A. and J.A. Cherry, 1979. Groundwater. Englewood Cliffs, NJ: Prentice-Hall, Inc.

Gruebel, M.M., R.D. Waters, M.B. Hospelhorn, and M.S.Y. Chu, eds., 1994. Framework for DOE Low-Level and Mixed Low-Level Waste Disposal: Site Fact Sheets. SAND94-2728. Albuquerque, NM: Sandia National Laboratories. 
Kincaid, C.T., J.W. Shade, G.A. Whyatt, M.G. Piepho, K. Rhoads, J.A. Voogd, J.H. Westsik, Jr., M.D. Freshley, K.A. Blanchard, and B.G. Lauzon, eds., 1993. Performance Assessment of Grouted Double-Shell Tank Waste Disposal at Hanford. WHC-SD-WM-EE-004, Rev. 0. U.S. Department of Energy, Pacific Northwest Laboratory and Westinghouse Hanford Company.

Maheras, Steven J., Arthur S. Rood, Swen O. Magnuson, Mary E. Sussman, and Rajiv N. Bhatt, 1994. Radioactive Waste Management Complex Low-Level Waste Radiological Performance Assessment. EGG-WM-8773. Idaho Falls, D: U.S. Department of Energy Office of Environmental Restoration and Waste Management, DOE Idaho Operations Office.

MMES (Martin Marietta Energy Systems), EG\&G Idaho, Inc., and Westinghouse Savannah River Company, 1994. Radiological Performance Assessment for the E-Area Vaults Disposal Facility (U). WSRC-RP-94-218, Rev. 0. Aiken, SC: Westinghouse Savannah River Company.

ORNL (Oak Ridge National Laboratory), 1994. Performance Assessment for Continuing and Future Operations at Solid Waste Storage Area 6. ORNL-6783. Oak Ridge, TN: U.S. Department of Energy, Oak Ridge National Laboratory.

Rickard, L.V., 1975. Correlation of the Siluraian and Devonian Rocks in New York State. New York State Museum and Science Service Map and Chart Series No. 24.

Thibault, D. H., M. I. Shepard, and P. A. Smith, 1990. A Critical Compilation and Review of Default Soil Solid/Liquid Partition Coefficients, Kd, for Use in Environmental Assessments. AECL-10125. Pinawa, Manitoba, Canada: Whiteshell Nuclear Research Establishment, Atomic Energy of Canada Limited.

U.S. DOE, 1982. Western New York Nuclear Service Center Study. TID-28905-2. Washington, DC: U.S. DOE.

U.S. DOE, 1986. Environmental Assessment for Disposal of Project Low-Level Waste West Valley Demonatration Project Part I: Environmental Assessment. DOE/EA-0295. U.S. DOE West Valley Project Office Report.

WVNSC, Inc., 1994. Environmental Information Document, Volume IV, Soils Characterization. WVDP-EIS-008. September 1994.

WVNSC, Inc., 1993a. Environmental Information Document, Volume III, Part 2, Surface Waster Hydrology. WVDP-EIS-009. January 1993.

WVNSC, Inc., 1993b. Environmental Information Document, Volume III, Part 4, Groundwater Hydrology and Geochemistry. WVDP-EIS-009. February 1993. 
WVNSC, Inc., 1993c. Environmental Information Document, Volume III, Part 5, Vadose Zone Hydrology. WVDP-EIS-009. February 1993.

WVNSC, Inc., 1993d. West Valley Demonstration Project, Process Building Closure Engineering Evaluation. , WVDP-EIS-018, Rev 0, Draft A. May 1993.

WVNSC, Inc., 1992. West Valley Demonstration Project Site Environmental Report for Calendar Year 1991. , Report prepared for U.S DOE Idaho Field Office and West Valley Project Office. May 1992.

WVNSC, Inc., and Dames and Moore, 1994. West Valley Demonstration Project Site Environmental Report Calendar Year 1993. Prepared for the Department of Energy Idaho Operations Office and West Valley Project Office, West Valley, NY.

\section{Acknowledgments}

The SNL Core Team acknowledges the contributions of Elizabeth Matthews, Bob Blickwedehl; and Lyle Roberts of the WVDP staff. 


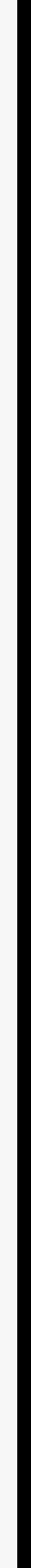




\section{Ohio: FERNALD ENVIRONMENTAL MANAGEMENT PROJECT (FEMP) \\ Core Team Contact: Gregory P. Zimmerman}

The Federal Facility Compliance Act (FFCAct, 1992) requires the Department of Energy (DOE) to establish plans in conjunction with its regulators and with members of the public for the treatment of DOE's mixed low-level waste (MLLW). Although the FFCAct did not specifically address disposal of treated MLLW, both DOE and the States recognized that disposal issues were an integral part of treatment discussions. Since 1992, DOE has worked with the States to define and develop an evaluation process for disposal options. Preliminary activities of this joint DOEState process have narrowed the sites for further evaluation from 49 to 15.

The Disposal Workgroup (DWG), which was established by DOE to develop a process for evaluating disposal options, designed a performance evaluation (PE) to quantify and compare the limitations of the remaining $15 \mathrm{DOE}$ sites for MLLW disposal. The principal goal of the PE was to estimate, for grouted residuals resulting from the treatment of MLLW, permissible concentrations of radionuclides in waste for disposal at each site. These "permissible waste concentrations" were based solely on long-term physical performance of the disposal facility and did not take into account any operational waste acceptance criteria that a site might have developed. The PE did not address any ethical, social, or policy considerations relevant to siting such facilities.

The PE used analyses that are consistent with the approach used in many low-level waste (LLW) performance assessments. The objective was to use a set of modeling assumptions of sufficient detail to capture major site-specific characteristics and yet be general enough for consistent application at all sites. Additionally, the analyses were designed to ensure that the sites were analyzed consistently and that all major assumptions were clearly stated.

The remainder of this chapter provides the PE results for Fernald Environmental Management Project (FEMP), one of the 15 sites being evaluated. The chapter contains the following information:

Section 11.1: brief, general description of the site, based on previous work done by the DWG (Gruebel et al., 1994)

Section 11.2: plans for MLLW disposal, if any, and the location evaluated in the PE

Section 11.3: current understanding of radionuclide movement at the selected location based on available information, and the conceptual model used for the evaluation of each of three pathways (water, atmospheric, and inadvertent intruder)

Section 11.4: site-specific and generic values used in the PE calculations and their sources

Section 11.5: estimates of maximum waste concentrations determined in the PE calculations for each of the three pathways, along with calculated values used in determining these results 
Section 11.6: summary of results based on disposal-facility design; discussion with respect to such issues as uncertainty and sensitivity

Section 11.7: observations based on the results of the PE and the parameter sensitivity analysis

Section 11.8: references

The general assumptions and methodology used in the PE are summarized in Chapter 1 of this volume and explained in more detail in Volume 2 of this report. Overall results for all the sites are discussed in Chapter 7 of Volume 2.

\subsection{GENERAL DESCRIPTION OF THE SITE}

The Fernald Environmental Management Project (FEMP) is located in southwestern Ohio, about $27 \mathrm{~km}$ (17 mi) northwest of downtown Cincinnati, Ohio (Figure 11-1). The facility is located just north of Fernald, a small farming community. The land contiguous to FEMP is primarily open land, such as agricultural and undeveloped lands, industrial lands, and some residential lands.

The largest population center near FEMP is the city of Cincinnati (population 364,000), located in Hamilton County. The estimated population within a $50-\mathrm{km}$ radius of the site is 1.5 million, located in the states of Ohio, Indiana, and Kentucky. The population within $10 \mathrm{~km}$ (6.2 mi) of the site is estimated to be 8,600 , mostly in Ross and Colerain Townships.

The FEMP site encompasses $4.2 \mathrm{~km}^{2}\left(1.6 \mathrm{mi}^{2}\right)$ (Figure 11-2). The primary mission of FEMP since 1954 was the production of purified uranium metal and uranium compounds for use at other DOE defense facilities. In 1989, DOE suspended production at the site and FEMP was placed on the National Priority List of federal facilities in need of remediation. In 1991, DOE formally ended production at FEMP and changed the mission to environmental restoration of the site.

The temperatures in the Cincinnati area cover a wide range. The average temperature is $-2^{\circ} \mathrm{C}\left(29^{\circ} \mathrm{F}\right)$ in January and $24^{\circ} \mathrm{C}\left(75^{\circ} \mathrm{F}\right)$ in July. Annual average precipitation is approximately $105 \mathrm{~cm}$ (41 in.). The prevailing wind near the FEMP site is from the southwest and the annual average wind speed is $8 \mathrm{~km} / \mathrm{hr}(5 \mathrm{mph})$.

The topography in the FEMP region is dominated by glacial features such as gouged troughs, glacial till, and terrace remnants. Most of the soils on the site are silty loams that are poorly drained and characterized by low permeability and seasonal saturation.

The FEMP site is located in the Great Miami River drainage basin, and a small portion is located in the 100-y floodplain. The Great Miami River, about $1 \mathrm{~km}(0.6 \mathrm{mi})$ east of FEMP, runs in a southwesterly direction and flows into the Ohio River about $39 \mathrm{~km}(24 \mathrm{mi})$ downstream of FEMP. Paddys Run, an intermittent stream that is periodically dry from July to October, begins north of FEMP and flows southward along the western edge of the site, and eventually flows into the Great Miami River. Natural drainage from FEMP to the Great Miami River is primarily by way of Paddys Run. The Great Miami River is not a source of public drinking water between FEMP and the Ohio River. 


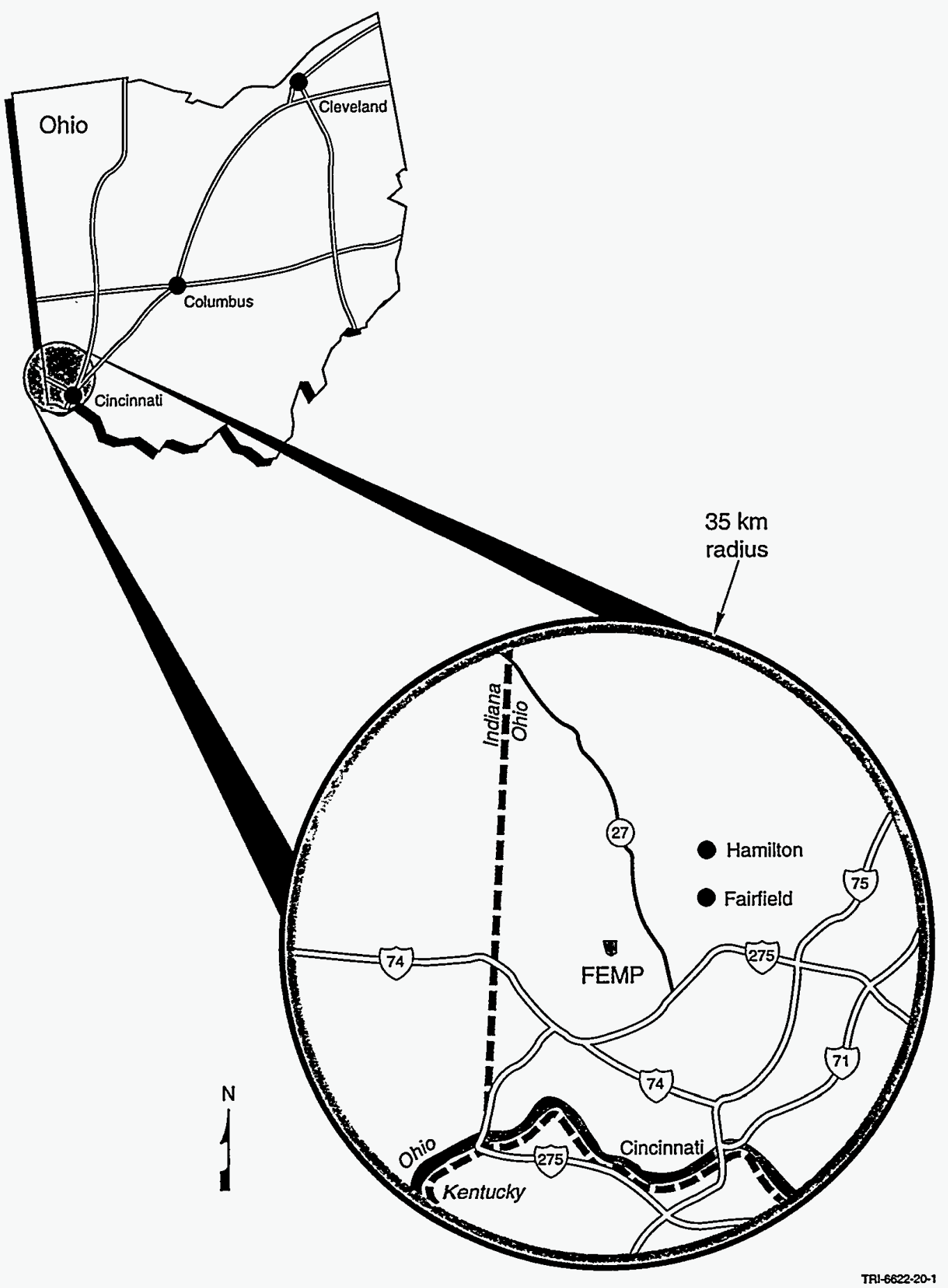

Figure 11-1. Location map for the Fernald Environmental Management Project. 


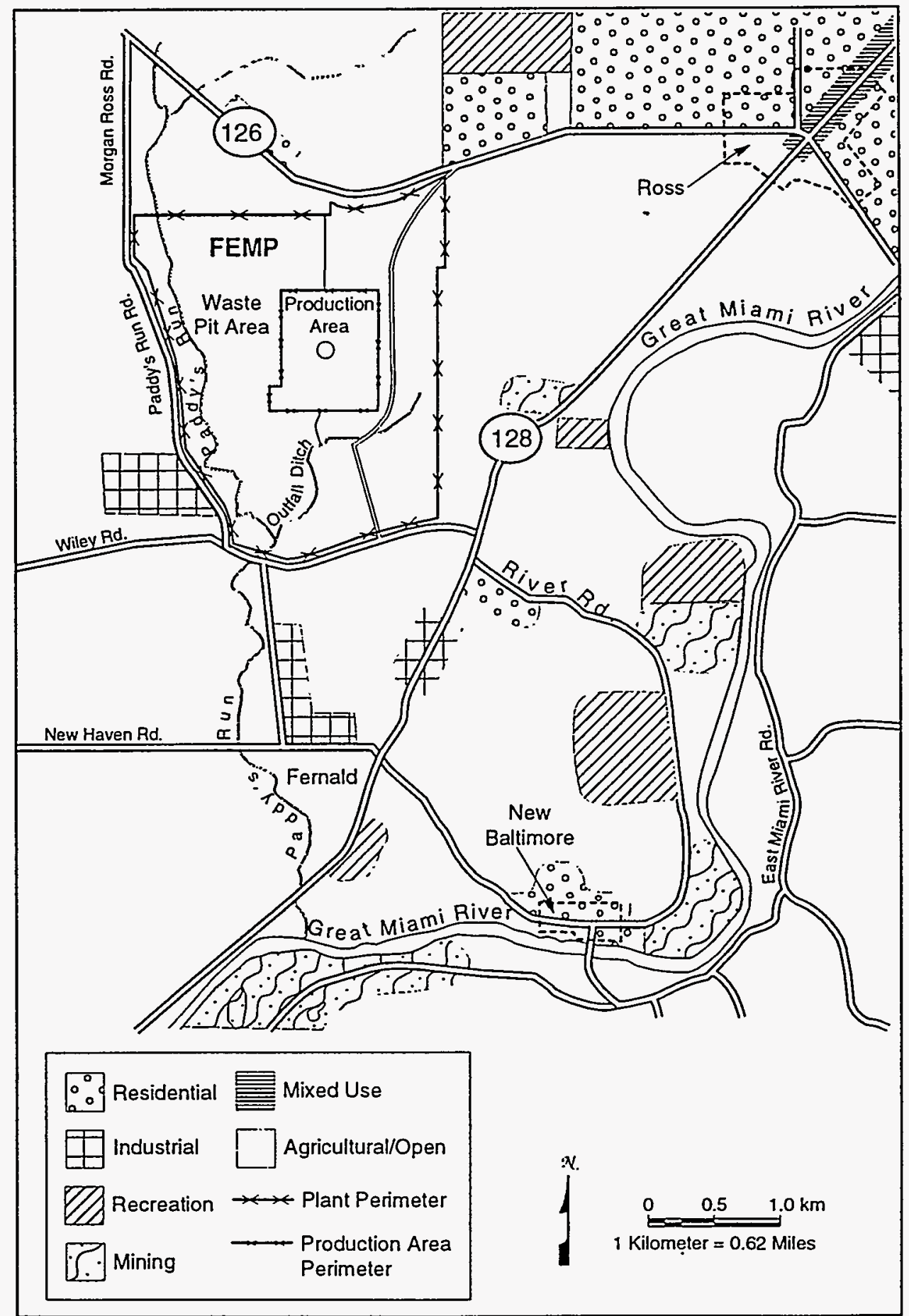

TRI.6622.30-0

Figure 11-2. Site map for the Fernald Environmental Management Project. 
Groundwater beneath the FEMP site occurs in the glacial overburden, as perched water tables, in the extensive sands and gravels that comprise the Great Miami Aquifer (UGMA), and in bedrock below the glacial deposits. The Great Miami Aquifer is an EPA-designated sole source aquifer. Groundwater generally moves eastward and southward from recharge areas in the glacial overburden toward the Great Miami River. The Great Miami Aquifer supplies drinking water to about 650,000 people and several major industries. Bottled water is being provided to residents near the FEMP with private wells because of contaminated groundwater; the aquifer currently is not being used for drinking water.

\subsection{STATUS AND SITING OF MLLW DISPOSAL FACILITY}

At the time of the PE, personnel at FEMP had no plans for on-site MLLW disposal. No facilities exist for the disposal of LLW or MLLW at FEMP. The FEMP stores LLW and MLLW in either warehouses or pad areas. Most of the waste stored at the FEMP is the result of uranium processing operations conducted over a 36-y period. Some mixed waste streams will be generated as a result of CERCLA environmental restoration activities, and a CERCLA disposal cell is being considered for FEMP.

This PE exercise required the identification of a suitable location for a future MLLW disposal facility at FEMP. As mentioned above, there are plans for a disposal facility for CERCLA remediation wastes to be located in the northeastern corner of the FEMP property (Figure 11-2). This PE analysis considers a generic trench and a generic tumulus at FEMP; the same area as for the CERCLA facility was chosen as the location for evaluation of the generic trench and generic tumulus.

Two generic disposal facilities were considered in the PE: a RCRA-compliant, belowground trench and a RCRA-compliant, above-ground tumulus (described in more detail in Chapter 5 of Volume 2). The generic facilities were selected to provide consistency in analysis of the performance of the 15 sites. Both generic facilities were assumed to be square with a plan area of $2500 \mathrm{~m}^{2}\left(26,910 \mathrm{ft}^{2}\right)$.

\subsection{BASIS FOR CONCEPTUAL MODEL USED IN THE PE}

The current understanding of radionuclide transport from a disposal facility at FEMP is based on various documents supporting the siting of a CERCLA disposal facility at FEMP and on studies relating to FEMP's groundwater operable units (U.S. DOE, 1995). The descriptions below summarize how this information was incorporated into the PE's conceptual model for FEMP.

\subsubsection{Water Pathway}

Knowledge of groundwater flow and radionuclide movement in the water pathway at FEMP provided the basis for the conceptual model considered in the PE. The conceptual model encompasses the site technical staffs current understanding of site-specific geology, hydrology, water table and aquifer characteristics, and transport pathways. 


\subsubsection{Current Understanding of Relevant Hydrogeology}

The bedrock underlying the FEMP region from 18 to $60 \mathrm{~m}(52$ to $197 \mathrm{ft})$ below ground surface is composed of alternating layers of limestone and shale deposited about 450 million years ago. Overlying the bedrock are sand and gravel that make up the Great Miami Aquifer. At the surface throughout most of the FEMP is a layer of clay-rich till.

\subsubsection{Conceptual Model Used in the PE}

The PE used a generic conceptual model to describe the water pathway (summarized in Section 1.1.2 of this volume and described in detail in Chapter 5 of Volume 2). In the unsaturated zone, leachate was generated by constant flow of water through the disposal facility at a rate that was controlled by the assumed performance of the disposal facility. When all engineered barriers had failed, the rate was assumed to be equal to the natural recharge through local soils. The volumetric flow of water through the facility that generated leachate was based on the assumed performance and size of the disposal facility. No dilution was assumed to occur in the unsaturated zone, so at steady state, the concentration that reached groundwater equaled the leachate concentration. No lateral spreading was assumed, so the leachate flux through the unsaturated zone was confined to the soil column directly below the plan area of the facility.

As contaminated water entered the saturated zone, the contaminant mixed with clean groundwater, forming a plume with a shape controlled by aquifer and contaminant properties. The generic conceptual model assumed that instantaneous and complete mixing within the aquifer occurred directly below the facility. Mixing in the vertical direction occurred by hydrodynamic dispersion, and the contaminant mixing depth was an estimated value.

The generic conceptual model was adapted to conditions at FEMP based on site-specific knowledge of the geology and water flow paths. The following description represents the conceptual model of the water pathway that was used in the PE for FEMP.

The conceptual model for the water pathway at FEMP is slightly different for the trench and tumulus disposal units (Figure 11-3). The actual vadose zone beneath the proposed location

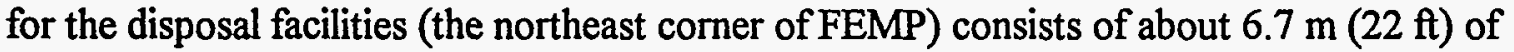
unsaturated glacial till overlying the Great Miami Aquifer (GMA), but also includes the upper $6.4 \mathrm{~m}(21 \mathrm{ft}$ ) of the GMA which is unsaturated (the UGMA), making a total vadose zone thickness of $13.1 \mathrm{~m}(43 \mathrm{ft})$. For simplicity, the unsaturated zone was modeled as a single unit. Therefore, for each of the disposal facilities, the most hydrogeologically significant unit was chosen.

The generic trench, excavated to a depth of $8.8 \mathrm{~m}(28.9 \mathrm{ft})$, was assumed to be cut through the till and into the top of the UGMA, so that the remaining $4.3 \mathrm{~m}(14.1 \mathrm{ft})$ of the UGMA made up the entire vadose zone beneath the trench. Because there is only one unsaturated unit below the trench, the modeled vadose zone was given the properties of the UGMA. In contrast, the tumulus, resting on the ground surface, benefited from the complete till and UGMA sequence. Because the attenuating effects of the UGMA are insignificant compared to those of the finer till, the properties and thickness of the till were chosen to represent the vadose zone beneath the tumulus. 


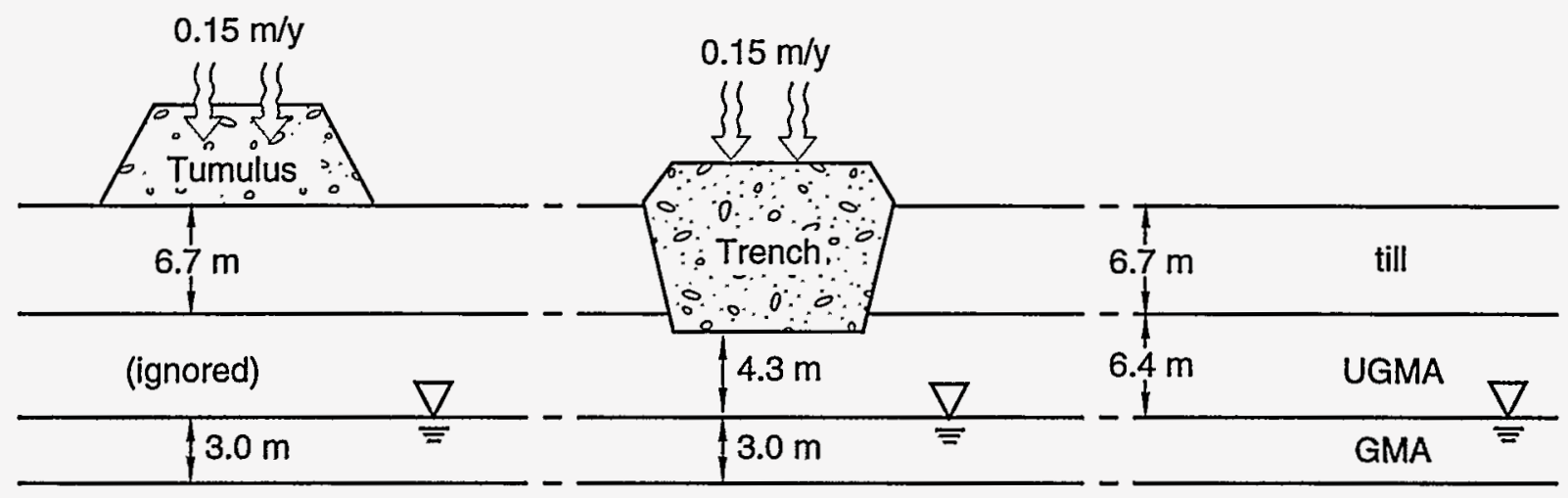

till - Glacial till

UGMA - Unsaturated part of GMA

GMA - Great Miami Aquifer

Not to Scale

TRI-6622-41-0

Figure 11-3. Conceptual model for water transport at FEMP.

\subsubsection{Atmospheric Pathway}

The conceptual model used in the PE for evaluating the atmospheric pathway was derived from performance assessments for LLW disposal facilities at Hanford (Kincaid et al., 1993), INEL (Maheras et al., 1994), NTS (Baer et al., 1994), ORR (ORNL, 1994), and SRS (MMES et al., 1994). The model was generalized for the PE but used site-specific values for many of the parameters.

\subsubsection{Current Understanding of Relevant Meteorology}

Meteorological data are based on STAR data files summarized by the windrose in Figure 11-4. These data were obtained from hourly average meteorological readings taken at a

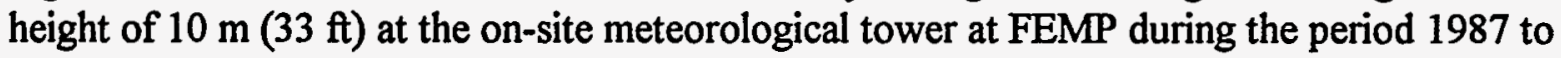
1992. 


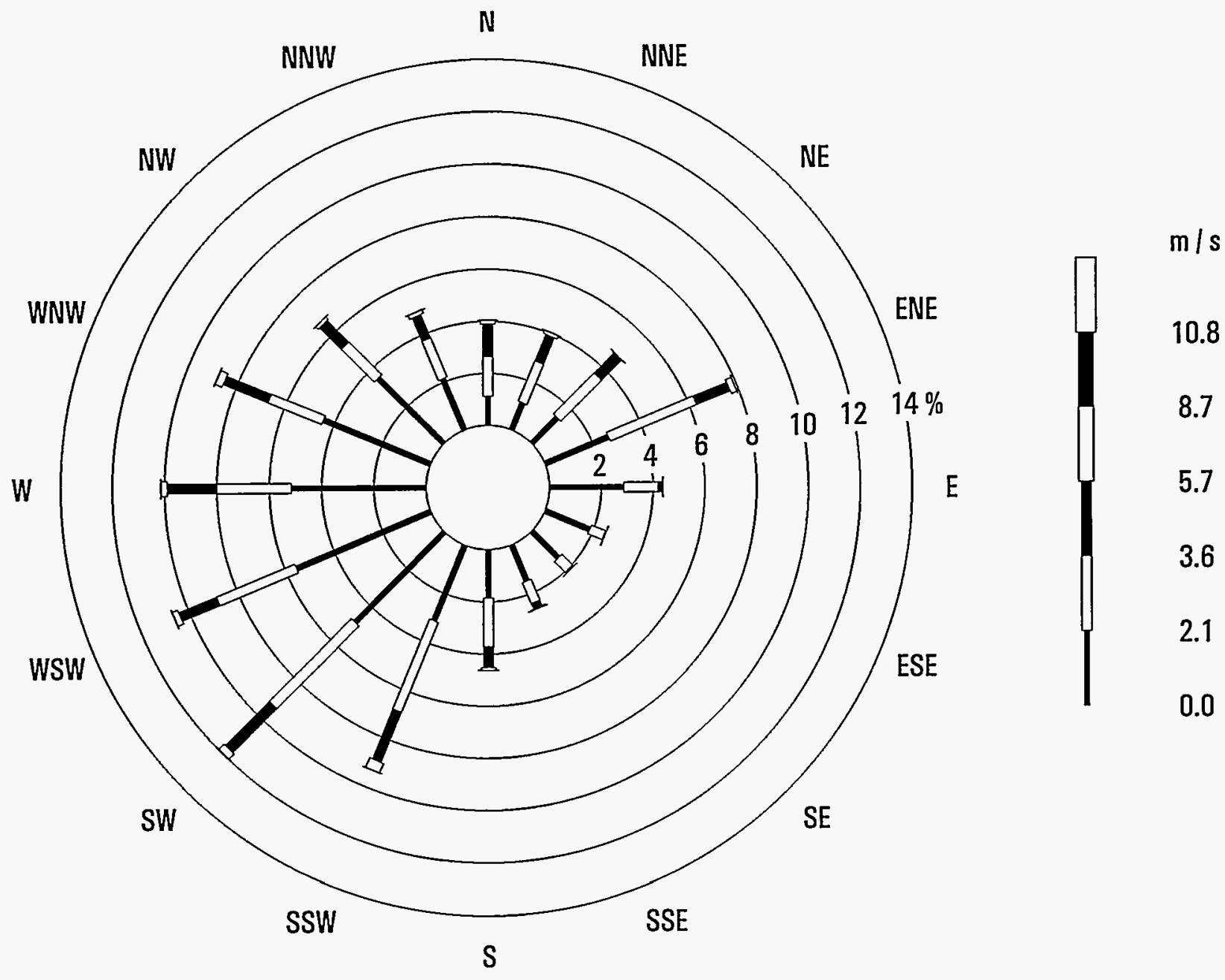

Figure 11-4. Windrose for FEMP for the period 1987 to 1992 . The frequency of winds from each direction is plotted as a series of connected bars that extend from the center of the circular diagram toward the direction from which the winds originate. Wind speed categories are denoted by bar widths and shadings. The frequency of winds in each wind speed category is indicated by the length of the corresponding bar. 


\subsubsection{Conceptual Model Used in the PE}

The PE used a generic conceptual model to describe the atmospheric pathway (summarized in Section 1.2 of this volume and described in detail in Chapter 5 of Volume 2). Only H-3 (tritium) and C-14 were expected to be volatile for the disposal facility conditions and thus were the only radionuclides considered for atmospheric transport in the PE. In the model, radionuclides were transported from the disposal facility to the soil surface by vapor (tritium) and gaseous (carbon dioxide carrying the $\mathrm{C}-14$ isotope) diffusion. When the radionuclides reached the soil surface, they were entrained in the air in vapor form as volatiles. Once airborne, these radionuclides were transported via atmospheric dispersion to a receptor located at the performance boundary.

Two components of the atmospheric pathway were evaluated separately: (1) the zone from the top of the disposal facility to the soil surface as indicated by the upward radionuclide diffusion profile; and (2) the zone in which a radionuclide was emitted to the atmosphere, mixed with the ambient air, and dispersed downwind from the waste disposal facility boundary to the $100-\mathrm{m}(328-\mathrm{ft})$ performance boundary.

The arrival time of radionuclides at the performance boundary was assumed to be $100 \mathrm{y}$ based on the following generic assumptions of the PE:

- The waste form was grouted MLLW treatment residuals. Based on this assumption, tritium as vapor was bound in the pore water of the hydrophilic grout, and carbon dioxide as a gas carrying the $\mathrm{C}-14$ isotope was limited by the high $\mathrm{pH}$ of the grout, so that the waste form provided retention of these volatile radionuclides in the disposal facility.

- The disposal facility was capped by a RCRA-compliant cover system. Based on this assumption, the cover system was maintained to provide low permeability for $100 \mathrm{y}$.

\subsubsection{Inadvertent Intruder Pathways}

Standard intrusion scenarios were used in the PE, with information derived from performance assessments of LLW disposal facilities at SRS (MMES et al., 1994) and ORR (ORNL, 1994) indicating that only two chronic-exposure scenarios needed to be considered for most sites and facility designs. Any variations in these scenarios were based on discussions with site technical staff about such factors as the types of activities that reasonably could result in exposure to buried waste at the site and the effectiveness of active or passive institutional controls and engineered barriers in precluding access to the waste.

The PE used two standard intrusion scenarios that could be modified for site-specific conditions to describe potential modes of inadvertent intrusion (summarized in Section 1.3 of this volume and described in detail in Chapter 5 of Volume 2). The first scenario, the agriculture (homesteader) scenario, included establishment by an intruder of a permanent homestead directly above a disposal facility with the foundation of the home extending into the waste; some of the waste exhumed from the disposal facility was mixed with native soil in the intruder's vegetable garden. The second scenario, the post-drilling scenario, considered the construction of a well for a domestic water supply by an intruder. The well was drilled through the disposal facility, and the cuttings were mixed with soil in the intruder's vegetable garden. The intruder gardened in some 
of the exhumed waste but did not reside permanently above the disposal facility. In both scenarios, exposure occurred where an intruder dug or drilled into the disposal facility.

For the generic intruder scenarios, the time of intrusion for the homesteader scenario was assumed to be $300 \mathrm{y}$ for the trench design and $500 \mathrm{y}$ for the tumulus design. The time of intrusion for the post-drilling scenario was assumed to be $100 \mathrm{y}$.

The two intrusion scenarios were discussed with FEMP personnel, who concurred with the applicability and credibility of these scenarios at FEMP.

\subsection{DATA USED IN THE PE}

The data presented in this section apply to the PE conceptual models described in Section 11.3. The calculations for determining permissible waste concentrations for the radionuclides considered in the PE are discussed in more detail in Chapter 5 of Volume 2 and summarized in Chapter 1 of this volume. The results of the calculations for FEMP are presented in Section 11.5 and discussed in Section 11.6 of this volume.

\subsubsection{Water Transport}

Site-specific values required to perform the water pathway analysis were selected by site technical staff from site characterizations and reports, from site-specific modeling results, or from general literature. For the unsaturated zone, the site-specific data that were required for the PE were distance between the disposal facility and groundwater; ambient moisture content; dry bulk density of the geologic medium; distribution coefficients $\left(K_{d} S\right)$ of the radionuclides in the geologic medium; and natural recharge. For the saturated zone, the site-specific data that were required were porosity; dry bulk density of the geologic medium; distribution coefficients $\left(K_{d} \mathrm{~s}\right)$ of the radionuclides in the geologic medium; groundwater Darcy flow rates; and mixing depth in the aquifer.

These values for FEMP are listed in Table 11-1 along with generic values that were used in the PE. Also indicated in the table is a designation of the type of data that the value represents and the source of the value. The values were determined from one or more of four data sources: (A) measurement performed by the site, state, or federal agency; (B) result of a numerical analysis performed by the site, state, or federal agency; (C) general literature value selected by the site; and (D) generic value of the PE.

Of the parameters in the PE that depended on site-specific values, only three potentially encompassed enough variability in values to significantly affect the results: natural recharge, $i$; distribution coefficients $\left(K_{d} s\right)$ for the geologic media; and groundwater Darcy velocity $\left(q_{g w}\right)$. The sources of these values are discussed in this section. The sensitivity of the results to changes in the values of these parameters is discussed in Section 11.6.2 of this volume and Chapter 6 of Volume 2. 
Table 11-1. Parameters and Values used in the PE for the Water Pathway at FEMP (generic PE values are in bold; these values and the standard PE method for applying them are summarized in Chapter 1 of this volume and discussed in more detail in Chapter 5 of Volume 2) (Part 1 of 2)

\begin{tabular}{|c|c|c|c|}
\hline Parameter & Value & $\begin{array}{l}\text { Data } \\
\text { Type* }\end{array}$ & Comments \\
\hline \multicolumn{4}{|l|}{ SOURCE TERM } \\
\hline $\begin{array}{l}\text { Volumetric water content of } \\
\text { the grouted waste, } \theta_{0}\end{array}$ & 0.3 & D & Standard PE value \\
\hline $\begin{array}{l}\text { Bulk density of grouted } \\
\text { waste, } \rho_{0}\end{array}$ & $1.76 \mathrm{~g} / \mathrm{cm}^{3}$ & D & Standard PE value \\
\hline $\begin{array}{l}\text { Distribution coefficients for } \\
\text { grouted waste, } K_{d}^{G}\end{array}$ & various & D & $\begin{array}{l}\text { Standard PE value; see } \\
\text { Table 11-2 in this chapter }\end{array}$ \\
\hline Disposal facility plan area, $A$ & $2,500 \mathrm{~m}^{2}$ & D & Standard PE value \\
\hline $\begin{array}{l}\text { Waste mixing fraction for } \\
\text { trench, } f_{m}\end{array}$ & 0.67 & D & Standard PE value \\
\hline $\begin{array}{l}\text { Waste mixing fraction for } \\
\text { tumulus, } f_{m}\end{array}$ & 0.33 & D & Standard PE value \\
\hline $\begin{array}{l}\text { Annual rate of water flowing } \\
\text { through intact trench facility, } \\
q_{f}\end{array}$ & $0.03 \mathrm{~m} / \mathrm{y}$ & D & Standard PE value \\
\hline $\begin{array}{l}\text { Annual rate of water flowing } \\
\text { through intact tumulus } \\
\text { facility, } q_{t}\end{array}$ & $\begin{array}{l}0.00003 \\
\mathrm{~m} / \mathrm{y}\end{array}$ & D & Standard PE value \\
\hline $\begin{array}{l}\text { Time to failure of leachate } \\
\text { collection system }\end{array}$ & $30 \mathrm{y}$ & D & Standard PE value \\
\hline $\begin{array}{l}\text { Time to failure of trench } \\
\text { facility }\end{array}$ & $100 y$ & D & Standard PE value \\
\hline $\begin{array}{l}\text { Time to failure of tumulus } \\
\text { facility }\end{array}$ & $300 y$ & D & Standard PE value \\
\hline $\begin{array}{l}\text { Natural recharge through local } \\
\text { soils, I }\end{array}$ & $0.15 \mathrm{~m} / \mathrm{y}$ & A & US DOE $(1995$, Table F.2-1) \\
\hline
\end{tabular}

- $A=$ =site measurement (U.S. DOE, 1995); $B=$ result of site numerical analysis; $C=$ literature value selected by the site; $D=$ generic PE value 
Table 11-1. Parameters and values used in the PE for the Water Pathway at FEMP (generic PE values are in bold; these values and the standard PE method for applying them are summarized in Chapter 1 of this volume and discussed in more detail in Chapter 5 of Volume 2) (Part 2 of 2)

\begin{tabular}{|c|c|c|c|}
\hline Parameter & Value & $\begin{array}{l}\text { Data } \\
\text { Type* }\end{array}$ & Comments \\
\hline \multicolumn{4}{|l|}{ UNSATURATED ZONE } \\
\hline $\begin{array}{l}\text { Moisture content for the trench } \\
\text { facility, } \theta_{W}\end{array}$ & 0.04 & A & $\begin{array}{l}\text { Unsaturated part of the Great Miami } \\
\text { Aquifer (UGMA) (US DOE, 1995, Table } \\
\text { F.5-2). Porosity } n=0.3 \text {, saturation } S= \\
0.13 \text {, so moisture content } \theta_{w}=n S=0.04 \text {. }\end{array}$ \\
\hline $\begin{array}{l}\text { Moisture content for the } \\
\text { tumulus facility, } Q_{W}\end{array}$ & 0.25 & A & $\begin{array}{l}\text { Glacial till (UGMA not considered) (Smith, } \\
\text { 1995). Porosity } n=0.26 \text {, saturation } S= \\
0.95 \text {, so water content } Q_{w}=n S=0.25 \text {. }\end{array}$ \\
\hline $\begin{array}{l}\text { Bulk density for the trench } \\
\text { facility, } \rho_{b}\end{array}$ & $1.6 \mathrm{~g} / \mathrm{cm}^{3}$ & A & US DOE (1995, Table F.5-2). \\
\hline $\begin{array}{l}\text { Bulk density for the tumulus } \\
\text { facility, } \rho_{b}\end{array}$ & $1.85 \mathrm{~g} / \mathrm{cm}^{3}$ & A & Smith (1995) \\
\hline $\begin{array}{l}\text { Distribution coefficients for } \\
\text { geologic media, } K_{d}\end{array}$ & various & & See Table $11-2$ in this chapter \\
\hline $\begin{array}{l}\text { Thickness between trench and } \\
\text { saturated zone, } l\end{array}$ & $4.3 \mathrm{~m}$ & A & $\begin{array}{l}\text { US DOE (1995, Figure F.5-10). Total } \\
\text { thickness of Layer } 1 \text { is } 6.7 \mathrm{~m}(22 \mathrm{ft}) \text { and } \\
\text { trench facility bottom is } 8.8 \mathrm{~m} \text { below } \\
\text { ground surface. This puts the bottom of } \\
\text { the trench } 2.1 \mathrm{~m} \text { into the Great Miami } \\
\text { Aquifer, which has an unsaturated zone } \\
6.4 \mathrm{~m}(20.2 \mathrm{ft} \text { ) thick, leaving } 4.3 \mathrm{~m} \text { of } \\
\text { unsaturated GMA. }\end{array}$ \\
\hline $\begin{array}{l}\text { Thickness between tumulus } \\
\text { and saturated zone, } l\end{array}$ & $6.7 \mathrm{~m}$ & A & $\begin{array}{l}\text { US DOE (1995, Figure F.5-10). Total } \\
\text { thickness of layer } 1 \text { is } 6.7 \mathrm{~m}(22 \mathrm{ft}) \text { and } \\
\text { tumulus facility bottom is at the ground } \\
\text { surface. Since unsaturated zone } \\
\text { parameters for the tumulus are based on } \\
\text { the properties of this layer, no credit is } \\
\text { given to the unsaturated part of the GMA, } \\
\text { which is much more conductive. }\end{array}$ \\
\hline \multicolumn{4}{|l|}{ SATURATED ZONE } \\
\hline Porosity, $n$ & 0.3 & A & US DOE (1995, Table F.5-2). \\
\hline Bulk density, $\rho_{b}$ & $1.6 \mathrm{~g} / \mathrm{cm}^{3}$ & A & US DOE (1995, Table F.5-2). \\
\hline $\begin{array}{l}\text { Distribution coefficients for } \\
\text { geologic media, } K_{d}\end{array}$ & various & & See Table 11-2 in this chapter \\
\hline Mixing depth, $d_{m}$ & $3 \mathrm{~m}$ & $\mathrm{C}$ & US DOE (1995, Figure F.5-10). \\
\hline Darcy velocity, $q_{\text {gw }}$ & $28 \mathrm{~m} / \mathrm{y}$ & $\mathrm{C}$ & US DOE (1995, Table F.5-2). \\
\hline $\begin{array}{l}\text { Distance to performance } \\
\text { boundary from facility } \\
\text { boundary }\end{array}$ & $100 \mathrm{~m}$ & $\mathbf{D}$ & Standard PE value \\
\hline
\end{tabular}

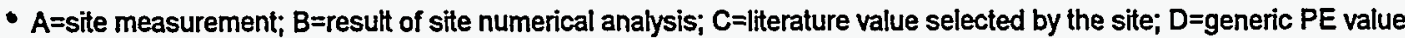


Table 11-2. Solid/Liquid Distribution Coefficients $\left(K_{d} \mathrm{~S}\right)$ Used in the PE at FEMP

\begin{tabular}{|c|c|c|c|}
\hline \multirow[t]{2}{*}{ Element } & \multirow{2}{*}{$\begin{array}{c}\text { Waste } K_{d}^{G} \\
(\mathrm{mLg})^{a} \\
\end{array}$} & \multicolumn{2}{|c|}{$K_{d}$ for Geologic Media $(\mathrm{mL} / \mathrm{g}){ }^{\mathrm{b}}$} \\
\hline & & $\begin{array}{l}\text { Unsaturated Zone } \\
\text { (tumulus) }\end{array}$ & Saturated Zone \\
\hline $\mathrm{H}$ & 0 & $0.1^{d}$ & 0.1 \\
\hline c & 10 & 5 & 5 \\
\hline $\mathrm{Al}$ & 100 & $99^{d}$ & 35 \\
\hline si & 100 & 35 & 35 \\
\hline $\mathrm{Cl}$ & 0 & $15^{\circ}$ & $15^{\circ}$ \\
\hline $\mathrm{K}$ & 1 & 15 & 15 \\
\hline$C_{0}$ & 100 & 60 & 60 \\
\hline $\mathrm{Ni}$ & 10 & 400 & 400 \\
\hline $\mathrm{Se}$ & 1 & 150 & 150 \\
\hline $\mathrm{Sr}$ & 100 & $20^{d}$ & 15 \\
\hline $\mathrm{Zr}$ & 10 & 600 & 600 \\
\hline $\mathrm{Nb}$ & 10 & 160 & 160 \\
\hline Tc & 1 & $0.02^{d}$ & $0.02^{d}$ \\
\hline $\mathrm{Pd}$ & 100 & 55 & 55 \\
\hline $\mathrm{Ag}$ & 100 & $90^{d}$ & 90 \\
\hline $\mathrm{Cd}$ & 100 & $160^{d}$ & 80 \\
\hline Sn & 10 & 130 & 130 \\
\hline 1 & 1 & 1 & 1 \\
\hline Cs & 10 & 280 & 280 \\
\hline $\mathrm{Ba}$ & 10 & $15^{\circ}$ & $15^{\circ}$ \\
\hline $\mathrm{Sm}$ & 10 & 245 & 245 \\
\hline Eu & 10 & $245^{\circ}$ & $245^{\circ}$ \\
\hline $\mathrm{Pb}$ & 100 & 270 & 270 \\
\hline $\mathrm{Ra}$ & 10 & $700^{d}$ & 500 \\
\hline Th & 100 & 3200 & 3200 \\
\hline $\mathrm{Pa}$ & 100 & 550 & 550 \\
\hline$U$ & 100 & $3.1^{\mathrm{d}}$ & 1. $18^{\mathrm{d}}$ \\
\hline $\mathrm{Np}$ & 100 & $2.4^{\mathrm{d}}$ & $2.4^{d}$ \\
\hline $\mathrm{Pu}$ & 100 & 550 & 550 \\
\hline $\mathrm{Am}$ & 100 & 1900 & 1900 \\
\hline $\mathrm{Cm}$ & 100 & 4000 & 4000 \\
\hline $\mathrm{Cf}$ & 100 & 4000 & 4000 \\
\hline
\end{tabular}

a Standard PE values; see Chapter 5 of Volume 2

b Values for sand from Thibault et al., 1990, unless otherwise noted

c Unsaturated zone $K_{d}$ values are for the tumulus only. $K_{d}$ values for the trench are equal to those of the saturated zone.

d US DOE, 1995, Tables F.2-4 and F.2-5

e Values for $\mathrm{Cl}, \mathrm{Ba}$, Eu, and $\mathrm{Cf}$ are based on similarities to $\mathrm{Br}, \mathrm{Sr}, \mathrm{Sm}$, and $\mathrm{Cm}$, respectively. 
The values presented in Table 11-1 include data used for calculations for the generic trench and tumulus design. For the generic tumulus facility, the unsaturated zone is assumed to have the characteristics (thickness, hydrogeologic properties, and $K_{d}$ values, as explained below) of the glacial overburden which overlies the Great Miami Aquifer. While the gravels of the aquifer do have an unsaturated zone, this zone was ignored since its effect would be much less significant than that of the overburden.

Values for recharge were estimated by analysts at FEMP for use in the HELP model. The proposed disposal cell site is over Infiltration Zones III and IV, which have values for recharge of 5.87 and $5.92 \mathrm{in} . / \mathrm{y}(14.91$ and $15.04 \mathrm{~cm} / \mathrm{y})$, respectively. Over all of the infiltration zones at the FEMP site, the recharge varies from 4.78 to 8.29 in./y (12.14 to $21.06 \mathrm{~cm} / \mathrm{y})$ (U.S. DOE, 1995). A range of values for groundwater velocities was not provided by FEMP staff.

For the generic trench, the depth of the facility would involve excavating the entire depth of the glacial overburden such that the bottom of the facility would be physically located in the top (unsaturated zone) of the Great Miami Aquifer. Therefore, the unsaturated zone thickness, hydrogeologic properties, and $K_{d}$ values (as explained below) for the trench differ from those used for the generic tumulus.

Values for the distribution coefficients ( $K_{d}$ values) are listed in Table 11-2 for the 58 radionuclides considered in this PE. In addition to the $K_{d}$ values for the geologic media, grout $K_{d}$ values are listed for determining the desorption from the source term resulting from the grouted waste form. The $K_{d}$ values for the subsurface flow pathway (both for the unsaturated and saturated zones) are taken from the standard PE values for sandy soils (Thibault et al., 1990), with the exception of the values for $\mathrm{Al}, \mathrm{Sr}, \mathrm{Tc}, \mathrm{Ag}, \mathrm{Cd}, \mathrm{Ra}, \mathrm{U}$, and $\mathrm{Np}$, for which site-specific values have been offered by the site technical staff at FEMP (U.S. DOE, 1995). Because the bottom of the trench is assumed to be deeper than the till, the UGMA $K_{d}$ values were used in the PE analysis for the vadose zone beneath the trench. However, the vadose zone for the tumulus was assumed to have the characteristics of the glacial till $K_{d}$ values.

\subsubsection{Atmospheric Transport}

Site-specific data required to perform the atmospheric pathway analysis came from site personnel as data either from site characterizations and reports or from general literature. The site-specific data required for the soil diffusion calculation were the same as some of those required for the water transport analysis (Section 11.4.1). The values used in the atmospheric dispersion analysis are shown in Table 11-3. Necessary atmospheric dispersion data included wind speed and direction and stability class, which are summarized in Section 11.3.2.1.

\subsubsection{Inadvertent Intruder Exposure}

As explained in Section 11.3.3, the PE used two standard intrusion scenarios to describe potential modes of inadvertent intrusion at all the sites. Because these intrusion scenarios were considered applicable to all sites, no values specific to FEMP are used in the calculation of exposures to inadvertent intruders. 
Table 11-3. Parameters and Values Used in the PE for the Atmospheric Pathway at FEMP (generic PE values are in bold; these values and the standard PE method for applying them are summarized in Chapter 1 of this volume and discussed in more detail in Chapter 5 of Volume 2)

\begin{tabular}{|c|c|c|c|}
\hline Parameter & Value & $\begin{array}{l}\text { Data } \\
\text { Type* }\end{array}$ & Comments \\
\hline $\begin{array}{l}\text { Disposal facility cover } \\
\text { thickness, } x\end{array}$ & $1.0 \mathrm{~m}$ & D & Standard PE value \\
\hline $\begin{array}{l}\text { Depth of the soil } \\
\text { surface, } d\end{array}$ & $0.01 \mathrm{~m}$ & D & $\begin{array}{l}\text { Standard PE value based on Maheras } \\
\text { et al. (1994) }\end{array}$ \\
\hline Porosity, $n$ & 0.4 & C & $\begin{array}{l}\text { CERCLA Feasibility Study Draft Report, } \\
\text { Table F.5-2, November 14, } 1994 .\end{array}$ \\
\hline Percent saturation, s & 0.6 & C & $\begin{array}{l}\text { CERCLA Feasibility Study Draft Report, } \\
\text { Table F.5-2, November 14, } 1994 .\end{array}$ \\
\hline $\begin{array}{l}\text { Ratio of water density } \\
\text { in air to liquid, } r\end{array}$ & 9.2E-06 & D & $\begin{array}{l}\text { Standard PE value based on MMES et } \\
\text { al. (1994) }\end{array}$ \\
\hline $\begin{array}{l}\text { Ratio of } \mathrm{CO}_{2} \\
\text { concentration in air to } \\
\text { dissolved in water, } r\end{array}$ & 4.3E-04 & D & $\begin{array}{l}\text { Standard PE value based on Foust et } \\
\text { al. (as cited in Cooper and Alley, } \\
\text { 1986) }\end{array}$ \\
\hline $\begin{array}{l}\text { Tritium diffusion } \\
\text { coefficient in air, } D\end{array}$ & $2.4 E-05 \mathrm{~m}^{2} / \mathrm{s}$ & D & $\begin{array}{l}\text { Standard PE value based on CRC } \\
\text { (1981) }\end{array}$ \\
\hline $\begin{array}{l}\text { Carbon diffusion } \\
\text { coefficient in air, } D\end{array}$ & $1.4 \mathrm{E}-05 \mathrm{~m}^{2} / \mathrm{s}$ & D & $\begin{array}{l}\text { Standard PE value based on CRC } \\
\text { (1981) }\end{array}$ \\
\hline $\begin{array}{l}\text { Atmospheric dispersion } \\
\text { term, } A_{D}\end{array}$ & $\begin{array}{c}0.5 \\
\left(\mu \mathrm{CV} \mathrm{m}^{3} /\left(\mu \mathrm{C} / \mathrm{m}^{2}-\mathrm{s}\right)\right.\end{array}$ & B & $\begin{array}{l}\text { Value is estimated using the Industrial } \\
\text { Source Complex-Version } 2 \text { Long Term Air } \\
\text { Dispersion Model (ISCLT2) (EPA, 1992) } \\
\text { based on site-specific STAR data. }\end{array}$ \\
\hline
\end{tabular}

* $A=$ site measurement; $B=$ result of site numerical analysis; $C=$ =literature value selected by the site; $D=g e n e r i c ~ P E$ value

\subsection{RESULTS OF THE PE}

The performance evaluation provided estimates of permissible waste concentrations in disposed MLLW. The three calculations that formed the foundation of the PE-for the water, atmospheric, and inadvertent intruder pathways - are summarized in Sections 1.1, 1.2, and 1.3, respectively, of this volume and discussed in detail in Chapter 5 of Volume 2.

For each pathway the maximum permissible waste concentration at the performance boundary was determined for each radionuclide by using the performance measures: $4 \mathrm{mrem}$ $(0.04 \mathrm{mSv})$ per year from the water pathway for releases to drinking water; $10 \mathrm{mrem}(0.1 \mathrm{mSv})$ per year from all pathways for atmospheric releases; and $100 \mathrm{mrem}(1 \mathrm{mSv})$ per year from all exposure pathways for chronic exposure of inadvertent intruders; and the appropriate pathway or scenario dose conversion factors (annual effective dose equivalent per unit concentration) based on EPA dose conversion factors. The basis for the performance measures used in the PE is discussed in more detail in Chapter 5 of Volume 2. For the water and atmospheric pathways, the concentration reduction provided by the environment (i.e., the CRF) was estimated using results 
of site analyses and data. For the intruder analyses, concentration reduction was estimated for appropriate exposure pathways for two intrusion scenarios that, in general, were the same for all the sites. The results of the calculations for the pathways that were analyzed at Fernald are provided in this section and discussed in Section 11.6.

\subsubsection{Water Transport}

Two CRFs were calculated for the water pathway: the source CRF, $C R F_{\text {Source, }}$ and the environmental transport $\mathrm{CRF}$ for water, $C R F_{\text {Water. }}$ The source $\mathrm{CRF}$ represents the concentration attenuation between the disposed waste and leachate exiting the bottom of the disposal facility and was defined as the dimensionless ratio of the waste concentration to the resulting leachate concentration. Desorption with infiltrating water was the mechanism used to describe the leaching of radionuclides from the grout. Because a generic method was used to determine the $C R F_{\text {Source }}$ for the 58 radionuclides considered in the PE (summarized in Section 1.1 of this volume and discussed in more detail in Chapter 5 of Volume 2), the radionuclide-specific values for the source CRF for each type of generic facility were the same for all 15 sites.

The environmental transport $\mathrm{CRF}$ for water was defined as the ratio of the concentration of the leachate exiting the disposal facility to the resulting concentration in water at the performance boundary. The concentration attenuation represented by $C R F_{\text {Water }}$ consisted of dilution due to mixing with uncontaminated groundwater. Effects of radioactive decay and decay product ingrowth were also included in the $\mathrm{PE}$.

In the PE, water travel time from the facility location to the performance boundary was calculated as a basis for comparison with the retarded travel time of the radionuclides. For Fernald, water travel time from the land surface to the performance boundary (i.e., without consideration of a disposal facility) was estimated at about $12 \mathrm{y}$.

The calculation of travel time through the vadose zone for a radionuclide, on the other hand, must account both for the lower flow because of the facility's RCRA cover and for the retardation defined by the distribution coefficient for the geologic media. In the PE, the calculation for travel time in the vadose zone first determined the distance a radionuclide traveled at the lower infiltration rate. Then, if the radionuclide had not fully traversed the vadose zone, the additional time required to complete travel in the vadose zone under the higher infiltration rate based on the natural recharge through local soils was calculated and added to the time determined at the lower infiltration rate.

In the $\mathrm{PE}$, the detention time in the facility for a radionuclide was the time during which water flowing through the facility was assumed to be caught by the leachate collection system. Specifically, the calculation of travel time for a radionuclide accounted for the following:

- For the trench design, the leachate collection system was assumed to catch water flowing through the facility for the first $30 \mathrm{y}$. After $30 \mathrm{y}$, the liner and leachate collection system failed, and water flowing through the facility for the next $70 \mathrm{y}$ was assumed to be $0.03 \mathrm{~m} / \mathrm{y}$ $(0.1 \mathrm{ft} / \mathrm{y})$ based on a unit hydraulic gradient and the saturated hydraulic conductivity of the 
RCRA cover system. After a total of $100 \mathrm{y}$ of reduced flow because of engineered barriers ( $30 \mathrm{y}$ of detention plus $70 \mathrm{y}$ limited by the RCRA cover system), the rate was assumed to be the average recharge for local soils, $0.15 \mathrm{~m} / \mathrm{y}(0.5 \mathrm{ft} / \mathrm{y})$.

- For the tumulus design, the leachate collection system was assumed to catch water flowing through the facility for the first $30 \mathrm{y}$. After $30 \mathrm{y}$, the liner and leachate collection system was assumed to fail, and water flowing through the facility for the next $270 \mathrm{y}$ was assumed to be $0.00003 \mathrm{~m} / \mathrm{y}(0.0001 \mathrm{ft} / \mathrm{y})$ based on a unit hydraulic gradient and the saturated hydraulic conductivity of the concrete vaults. After a total of $300 \mathrm{y}$ of reduced flow because of engineered barriers ( $30 \mathrm{y}$ detention plus $270 \mathrm{y}$ limited by the concrete vaults), the rate was assumed to be the average recharge through local soils, $0.15 \mathrm{~m} / \mathrm{y}$ $(0.5 \mathrm{ft} / \mathrm{y})$.

Travel time through the aquifer was independent of facility design and was about $1 \mathrm{y}$, based on groundwater Darcy velocity and a 100-m (328-ft) distance to the performance boundary (see Section 1.1.2 of this volume for a summary of these assumptions and Chapter 5 of Volume 2 for additional details). The arrival time of a radionuclide at the performance boundary is the sum of the detention time in the facility, travel time through the vadose zone, and travel time through the aquifer.

Retardation of radionuclides by interaction with soils and rock in the vadose and saturated zones increased travel times for individual radionuclides. This effect was particularly important for short-lived radionuclides because of radioactive decay. For short-lived radionuclides, the effects of radioactive decay combined with long travel times increased the permissible concentrations in the disposal facility.

Application of the PE methodology for water transport of the 58 radionuclides considered in the PE produced the results shown in Table 11-4 for the generic trench and tumulus designs at Fernald. The table shows permissible waste concentrations based on transport through the water pathway $\left(C_{\text {W-Water }}\right)$ as well as the values used in calculating the permissible waste concentrations.

Some radionuclides listed in Table 11-4 have no limit (NL) on their permissible waste concentrations, the result of the combined effects of relatively short half-lives and sufficiently.long travel time to the performance boundary. "No limit" is defined as a permissible waste concentration that is greater than the specific activity of the pure elemental radionuclide. For disposal of the maximum possible waste concentration of these relatively short-lived radionuclides, the water pathway produced a dose at the performance boundary of less than $4 \mathrm{mrem}(0.04 \mathrm{mSv})$ per year and, therefore, the permissible waste concentration was unlimited based on exposures from this pathway.

For some radionuclides, no value is listed in Table 11-4 for the radioactive decay term, $r_{\text {Decay. }}$. These radionuclides had radioactive decay terms that were very large (e.g., greater than $\left.1 \times 10^{50}\right)$. Any radionuclide with a radioactive decay term greater than $1 \times 10^{50}$ was ensured a calculated permissible waste concentration greater than the specific activity of the pure elemental radionuclide, which, as described previously, resulted in no limit (NL) on permissible waste concentrations for disposal. 
Table 11-4. Results of Calculations for the Water Pathway at FEMP (water travel time from land surface to performance boundary [excluding facility detention] = 12y) (Part 1 of 2)

\begin{tabular}{|c|c|c|c|c|c|c|c|c|c|c|c|c|}
\hline \multirow[t]{2}{*}{ Nuclide } & \multirow[b]{2}{*}{$\begin{array}{c}\text { PDCF } \\
\text { rem/y per } \mu \mathrm{Cl} / \mathrm{L}\end{array}$} & \multicolumn{5}{|c|}{ Trench } & \multicolumn{5}{|c|}{ Tumulus } & \multirow[t]{2}{*}{ Nuclide } \\
\hline & & \begin{tabular}{|l|} 
CRF source \\
(dimenstonless)
\end{tabular} & $\begin{array}{c}\text { CRF water } \\
\text { (dimenstoniess) }\end{array}$ & $\begin{array}{c}\text { Arrival } \\
\text { Time }(y) \\
\end{array}$ & $\begin{array}{c}\text { roecay }^{\prime \prime} \\
\text { (dimensioniess) }\end{array}$ & $\begin{array}{c}C_{\text {W-Water }}{ }^{b} \\
\left(\mu \mathrm{Ci} / \mathrm{m}^{3}\right)\end{array}$ & $\begin{array}{l}\text { CRF source } \\
\text { (dimentionless) }\end{array}$ & $\begin{array}{c}C_{\text {(dimentionlecs) }} \\
\text { (d) Water }\end{array}$ & $\begin{array}{c}\text { Arrival } \\
\text { Time (y) } \\
\end{array}$ & roscay $^{a}$ & $\begin{array}{c}C_{\text {w-Wmar }}{ }^{b} \\
\left(\mu \mathrm{Ci} / \mathrm{m}^{2}\right)\end{array}$ & \\
\hline $\mathrm{H}-3$ & 4.67E-02 & 0.45 & 57 & $6.0 \mathrm{E}+01$ & $3.0 \mathrm{E}+01$ & $6 E+04$ & 0.9 & 12 & $3.2 \mathrm{E}+02$ & $6.9 \mathrm{E}+07$ & $7 E+10$ & $\mathrm{H}-3$ \\
\hline C-14 & $1.52 E+00$ & 27 & 12 & $3.5 E+02$ & $1.0 \mathrm{E}+00$ & $9 E+02$ & 54 & 12 & $7.5 E+02$ & 1.1E+00 & $2 E+03$ & C-14 \\
\hline Al-26 & $1.06 E+01$ & 270 & 12 & $1.9 E+03$ & $1.0 \mathrm{E}+00$ & $1 E+03$ & 540 & 12 & $8.7 \mathrm{E}+03$ & $1.0 \mathrm{E}+00$ & $2 E+03$ & Al-26 \\
\hline Si-32 & $7.99 E+\infty 0$ & 270 & 12 & $1.9 E+03$ & $5.0 \mathrm{E}+05$ & $8 E+08$ & 540 & 12 & $3.4 \mathrm{E}+03$ & $1.8 E+10$ & $6 E+13$ & $5 i-32$ \\
\hline $\mathrm{Cl}-36$ & $2.21 E+\infty$ & 0.45 & 12 & $8.6 \mathrm{E}+02$ & $1.0 E+\infty 0$ & $1 E+01$ & 0.9 & 12 & $1.6 E+03$ & $1.0 E+00$ & $2 \mathrm{E}+01$ & $\mathrm{Cl}-36$ \\
\hline$K-40$ & $1.36 E+01$ & 3.1 & 12 & $8.6 E+02$ & $1.0 E+00$ & $1 E+01$ & 6.2 & 12 & $1.6 E+03$ & $1.0 E+00$ & $2 \mathrm{E}+01$ & $K-40$ \\
\hline$C 0-60$ & 1.97E+01 & 270 & 12 & $3.2 E+03$ & $e$ & $\mathrm{NL}$ & 540 & 12 & $5.6 \mathrm{E}+03$ & e & $\mathrm{NL}$ & $\mathrm{Co}-60$ \\
\hline Ni-59 & $1.53 \mathrm{E}-01$ & 27 & 12 & $2.1 \mathrm{E}+04$ & $1.2 \mathrm{E}+00$ & $1 E+04 c$ & 54 & 12 & $3.6 \mathrm{E}+04$ & $1.4 E+00$ & $2 E+04^{\circ}$ & Ni-59 \\
\hline $\mathrm{Ni}-63$ & 4.21E-01 & 27 & 12 & $2.1 E+04$ & $\mathrm{e}$ & $\mathrm{NL}$ & 54 & 12 & $3.6 \mathrm{E}+04$ & e & $\mathrm{NL}$ & $\mathrm{Ni}-63$ \\
\hline Se-79 & $6.35 \mathrm{E}+00$ & 3.1 & 12 & $7.8 \mathrm{E}+03$ & $1.1 E+00$ & $3 E+01$ & 6.2 & 12 & $1.4 E+04$ & $1.2 E+\infty$ & $6 E+01^{\circ}$ & Se-79 \\
\hline $5 r-90$ & $1.12 E+02$ & 270 & 12 & $8.6 E+02$ & $8.3 E+08$ & $9 E+10$ & 540 & 12 & $2.1 E+03$ & $1.6 E+21$ & $\mathrm{NL}$ & Sr-90 \\
\hline $2 r-93$ & $1.59 E+00$ & 27 & 12 & $3.1 \mathrm{E}+04$ & $1.0 \mathrm{E}+00$ & $8 E+02$ & 54 & 12 & $5.3 E+04$ & $1.0 E+00$ & $2 E+03^{\circ}$ & $\mathrm{Zr}-93$ \\
\hline $\mathrm{Nb}-93 \mathrm{~m}$ & $3.81 E-01$ & 27 & 12 & $8.3 E+03$ & $\mathbf{e}$ & $\mathrm{NL}$ & 54 & 12 & $1.4 E+04$ & e & $\mathrm{NL}$ & $\mathrm{Nb}-93 \mathrm{~m}$ \\
\hline $\mathrm{Nb}-94$ & $5.21 E+00$ & 27 & 12 & $8.3 E+03$ & $1.3 E+00$ & $3 E+02$ & 54 & 12 & $1.4 E+04$ & $1.7 E+00$ & $8 E+02^{c}$ & $\mathrm{Nb}-94$ \\
\hline Tc-99 & $1.07 E+00$ & 3.1 & 12 & $1.0 \mathrm{E}+02$ & $1.0 E+00$ & $1 E+02$ & 6.2 & 12 & $3.1 E+02$ & $1.0 \mathrm{E}+00$ & $3 E+02$ & Tc-99 \\
\hline$P d-107$ & 1.09E-01 & 270 & 12 & $2.9 E+03$ & $1.0 \mathrm{E}+00$ & $1 E+05$ & 540 & 12 & $5.2 \mathrm{E}+03$ & $1.0 E+00$ & $2 E+05$ & $\mathrm{Pd}-107$ \\
\hline $\mathrm{Ag}-108 \mathrm{~m}$ & $5.56 \mathrm{E}+00$ & 270 & 12 & $4.7 E+03$ & $9.1 \mathrm{E}+10$ & $2 E+14$ & 540 & 12 & $8.3 E+03$ & $1.4 \mathrm{E}+19$ & $\mathrm{NL}$ & $\mathrm{Ag}-108 \mathrm{~m}$ \\
\hline $\mathrm{Cd}-113 \mathrm{~m}$ & $1.17 \mathrm{E}+02$ & 270 & 12 & $4.2 \mathrm{E}+03$ & $\mathrm{e}$ & $\mathrm{NL}$ & 540 & 12 & $1.4 E+04$ & e & $\mathrm{NL}$ & $\mathrm{Cd}-113 \mathrm{~m}$ \\
\hline$S n-121 m$ & $1.28 \mathrm{E}+\infty 0$ & 27 & 12 & $6.8 \mathrm{E}+03$ & $1.6 \mathrm{E}+37$ & $\mathrm{NL}$ & 54 & 12 & $1.2 E+04$ & e & $\mathrm{NL}$ & $5 n-121 m$ \\
\hline Sn-126 & $1.53 E+01$ & 27 & 12 & $6.8 E+03$ & $1.0 \mathrm{E}+00$ & $9 E+01$ & 54 & 12 & $1.2 \mathrm{E}+04$ & $1.1 E+\infty$ & $2 E+02$ & $5 n-126$ \\
\hline $1-129$ & $2.01 E+02$ & 3.1 & 12 & $1.4 E+02$ & $1.0 \mathrm{E}+00$ & $7 E-01$ & 6.2 & 12 & $4.0 \mathrm{E}+02$ & $1.0 \mathrm{E}+\infty$ & $2 E+00$ & $1-129$ \\
\hline Cs-135 & $5.16 E+00$ & 27 & 12 & $1.5 \mathrm{E}+04$ & $1.0 E+00$ & $3 E+02{ }^{\circ}$ & 54 & 12 & $2.5 E+04$ & $1.0 E+00$ & $5 E+02$ & Cs-135 \\
\hline Cs-137 & $3.65 E+01$ & 27 & 12 & 1.5E+04 & e & $N L$ & 54 & 12 & $2.5 E+04$ & $e$ & $\mathrm{NL}$ & Cs-137 \\
\hline Ba-133 & $2.48 E+00$ & 27 & 12 & $8.6 E+02$ & $5.2 E+24$ & $\mathrm{NL}$ & 54 & 12 & $1.6 \mathrm{E}+03$ & $9.0 \mathrm{E}+46$ & NL & $B a-133$ \\
\hline $5 m-151$ & 2.84E-01 & 27 & 12 & $1.3 E+04$ & $3.8 \mathrm{E}+42$ & NL & 54 & 12 & $2.2 E+04$ & $e$ & NL & Sm-151 \\
\hline Eu-152 & $4.73 E+00$ & 27 & 12 & 1.3E+04 & e & NL & 54 & 12 & $2.2 E+04$ & e & NL & $E u-152$ \\
\hline Eu-154 & $6.97 E+00$ & 27 & 12 & 1.3E+04 & e & $\mathrm{NL}$ & 54 & 12 & $2.2 E+04$ & e & NL & Eu-154 \\
\hline$P b-210$ & $5.30 E+03$ & 270 & 12 & $1.4 E+04$ & $e$ & $\mathrm{NL}$ & 540 & 12 & $2.4 E+04$ & e & NL & $\mathrm{Pb}-210$ \\
\hline Ra-226 & $6.27 \mathrm{E}+03$ & 27 & 12 & $2.6 \mathrm{E}+04$ & $7.4 E+04$ & $2 E+04$ & 54 & 12 & $6.1 E+04$ & $3.0 \mathrm{E}+11$ & $1 E+11=$ & $\operatorname{Ra}-226$ \\
\hline Ra-228 & $1.64 E+03$ & 27 & 12 & $2.6 \mathrm{E}+04$ & e & $\mathrm{NL}$ & 54 & 12 & $6.1 E+04$ & $e$ & $N L^{\circ}$ & Ra-228 \\
\hline Th-229 & $2.94 \mathrm{E}+03$ & 270 & 12 & 1.7E+05 & $6.5 E+06$ & $3 \mathrm{E}+07 \quad c$ & 540 & 12 & $2.8 \mathrm{E}+05$ & $4.7 E+11$ & NL & Th-229 \\
\hline Th-230 & $6.12 E+03$ & 270 & 12 & $1.7 E+05$ & $\mathrm{NA}$ & $2 E+00$ & 540 & 12 & $2.8 \mathrm{E}+05$ & NA & $4 E+00=$ & Th-230 \\
\hline Th-232 & $3.63 E+03$ & 270 & 12 & $1.7 \mathrm{E}+05$ & $1.0 \mathrm{E}+00$ & $4 E+00$ & 540 & 12 & $2.8 \mathrm{E}+05$ & $1.0 \mathrm{E}+00$ & $7 E+\infty 0^{\circ}$ & Th-232 \\
\hline Pa-231 & $1.85 E+04$ & 270 & 12 & $2.8 \mathrm{E}+04$ & $1.8 E+00$ & $1 E+00$ & 540 & 12 & $4.9 E+04$ & $2.8 \mathrm{E}+\infty$ & $4 E+\infty 0$ & $\mathrm{Pa-231}$ \\
\hline
\end{tabular}


Table 11-4. Results of Calculations for the Water Pathway at FEMP (water travel time from land surface to performance boundary [excluding facility detention] $=12$ y) (Part 2 of 2$)$

\begin{tabular}{|c|c|c|c|c|c|c|c|c|c|c|c|c|}
\hline \multirow[t]{2}{*}{ Nuclide } & \multirow[b]{2}{*}{$\begin{array}{c}\text { PDCF } \\
\text { rem/y per } \mu \mathrm{Ch}\end{array}$} & \multicolumn{5}{|c|}{ Trench } & \multicolumn{5}{|c|}{ Tumulus } & \multirow[t]{2}{*}{ Nuclide } \\
\hline & & \begin{tabular}{l|} 
CRF source \\
(dimentionless)
\end{tabular} & $\begin{array}{c}\text { CRF Warer } \\
\text { (dimensionless) }\end{array}$ & $\begin{array}{c}\text { Arrival } \\
\text { Time }(y) \\
\end{array}$ & \begin{tabular}{|c|} 
PDecay $^{a}$ \\
(dimensionless)
\end{tabular} & $\begin{array}{c}C_{\text {w-Water }} \\
\left(\mu \mathrm{Ci} / \mathrm{m}^{3}\right) \\
\end{array}$ & $\begin{array}{l}\text { CRF source } \\
\text { (dimensionloss) }\end{array}$ & \begin{tabular}{|c|} 
CRF Water \\
(dimensionless)
\end{tabular} & $\begin{array}{c}\text { Arrival } \\
\text { Time }(y) \\
\end{array}$ & $\begin{array}{c}\text { roecay } \\
\text { (dimensionleas) }\end{array}$ & $\begin{array}{c}C_{\text {w.warer }}{ }^{b} \\
\left(\mu \mathrm{Ci} / \mathrm{m}^{3}\right) \\
\end{array}$ & \\
\hline $\mathrm{U}-232$ & $1.55 E+03$ & 270 & 12 & $1.8 \mathrm{E}+02$ & $5.9 E+\infty 0$ & $5 E+01$ & 540 & 12 & $5.8 E+02$ & $3.1 E+02$ & $5 E+03$ & U.-232 \\
\hline $\mathrm{U}-233$ & $3.65 \mathrm{E}+02$ & 270 & 12 & $1.8 E+02$ & NA & $5 E+01$ & 540 & 12 & $5.8 E+02$ & $\mathrm{NA}$ & $7 E+01$ & U-233 \\
\hline $\mathrm{U}-234$ & $2.12 \mathrm{E}+02$ & 270 & 12 & $1.8 E+02$ & NA & $6 E+01$ & 540 & 12 & $5.8 \mathrm{E}+02$ & NA & $1 E+02$ & U-234 \\
\hline $\mathrm{U}-235$ & $4.14 E+02$ & 270 & 12 & $1.8 E+02$ & NA & $5 E+01$ & 540 & 12 & $5.8 E+02$ & NA & $6 E+01$ & U-235 \\
\hline $\mathrm{U}-236$ & $1.96 \mathrm{E}+02$ & 270 & 12 & $1.8 E+02$ & $1.0 E+\infty$ & $7 E+01$ & 540 & 12 & $5.8 E+02$ & $1.0 \mathrm{E}+\infty$ & $1 E+02$ & U-236 \\
\hline U-238 & $2.07 \mathrm{E}+02$ & 270 & 12 & $1.8 \mathrm{E}+02$ & NA & $6 \mathrm{E}+01$ & 540 & 12 & $5.8 E+02$ & NA & $1 E+02$ & U-238 \\
\hline $\mathrm{Np}-237$ & $3.24 E+03$ & 270 & 12 & $2.1 E+02$ & $1.0 \mathrm{E}+00$ & $4 E+00$ & 540 & 12 & $5.2 E+02$ & $1.0 E+\infty$ & $8 E+00$ & $N p-237$ \\
\hline Pu-238 & $2.34 \mathrm{E}+03$ & 270 & 12 & $2.8 E+04$ & $e$ & $2 E+05$ & 540 & 12 & $4.9 E+04$ & $e$ & $3 \mathrm{E}+05$ & $\mathrm{Pu}-238$ \\
\hline $\mathrm{Pu}-239$ & $2.58 \mathrm{E}+03$ & 270 & 12 & $2.8 E+04$ & $2.3 E+00$ & $1 E+01$ & 540 & 12 & $4.9 E+04$ & $4.1 E+\infty 0$ & $4 E+01$ & Pu-239 \\
\hline $\mathrm{Pu}-240$ & $2.58 E+03$ & 270 & 12 & $2.8 E+04$ & $2.0 E+01$ & $1 E+02$ & 540 & 12 & $4.9 E+04$ & $1.8 E+02$ & $2 E+03 \quad c$ & Pu-240 \\
\hline Pu-241 & $4.82 \mathrm{E}+08$ & 270 & 12 & $2.8 \mathrm{E}+04$ & e & $6 \mathrm{E}+05$ & 540 & 12 & $4.9 E+0.4$ & $e$ & $1 E+06$ & Pu-241 \\
\hline Pu-242 & $2.45 E+03$ & 270 & 12 & $2.8 \mathrm{E}+04$ & $1.1 E+00$ & $6 E+00 \quad-$ & 540 & 12 & $4.9 E+04$ & $1.1 E+\infty$ & $1 E+01^{c}$ & $\mathrm{Pu}-242$ \\
\hline Pu-244 & $4.11 E+03$ & 270 & 12 & $2.8 E+04$ & NA & $3 E+\infty \quad c$ & 540 & 12 & $4.9 E+04$ & NA & $6 E+00^{\circ}$ & $\mathrm{Pu}-244$ \\
\hline Am-241 & $2.66 E+03$ & 270 & 12 & $9.8 E+04$ & $\mathbf{e}$ & $2 E+04$ & 540 & 12 & $1.7 E+05$ & e & $4 \mathrm{E}+04$ & Am-241 \\
\hline Am-243 & $2.64 E+03$ & 270 & 12 & $9.8 E+04$ & $1.0 E+04$ & $5 E+04 \quad$ & 540 & 12 & $1.7 E+05$ & $7.4 E+06$ & $7 E+07 \quad$ & Am-243 \\
\hline $\mathrm{Cm}-243$ & $1.83 E+03$ & 270 & 12 & $2.1 E+05$ & $e$ & $9 E+03: 7$ & 540 & 12 & $3.5 E+05$ & e & $3 E+04 \div 1$ & $\mathrm{Cm}-243$ \\
\hline $\mathrm{Cm}-244$ & $1.47 E+03$ & 270 & 12 & $2.1 E+05$ & e & $4 E+04 \div 1$ & 540 & 12 & $3.5 E+05$ & $e$ & $6 E+05$ & $\mathrm{Cm}-244$ \\
\hline $\mathrm{Cm}-245$ & $4.56 E+03$ & 270 & 12 & $2.1 E+05$ & NA & $3 E+00^{\circ}$ & 540 & 12 & $3.5 E+05$ & NA & $6 E+00$ C & $\mathrm{Cm}-245$ \\
\hline $\mathrm{Cm}-246$ & $2.70 E+03$ & 270 & 12 & $2.1 E+05$ & $1.1 E+13$ & NL & 540 & 12 & $3.5 E+05$ & $2.4 E+22$ & $\mathrm{NL}$ & $\mathrm{Cm}-246$ \\
\hline $\mathrm{Cm}-247$ & $4.34 E+03$ & 270 & 12 & $2.1 E+05$ & $\mathrm{NA}$ & $3 E+\infty \quad c$ & 540 & 12 & $3.5 E+05$ & NA & $6 E+00^{\circ}$ & $\mathrm{Cm}-247$ \\
\hline $\mathrm{Cm}-248$ & $9.94 E+03$ & 270 & 12 & $2.1 E+05$ & $1.5 E+00$ & $2 E+\infty \quad c$ & 540 & 12 & $3.5 E+05$ & $2.0 E+\infty 0$ & $5 E+00^{\circ}$ & $\mathrm{Cm}-248$ \\
\hline Cf-249 & $3.46 E+03$ & 270 & 12 & $2.1 E+05$ & e & $7 E+01$ & 540 & 12 & $3.5 E+05$ & $e$ & $1 E+02$ & $C 1-249$ \\
\hline Cf-250 & $2.64 E+08$ & 270 & 12 & $2.1 \mathrm{E}+05$ & $e$ & $\mathrm{NL}$ & 540 & 12 & $3.5 E+05$ & e & NL & $C f-250$ \\
\hline Cf-251 & $3.54 E+03$ & 270 & 12 & $2.1 E+05$ & e & NL & 540 & 12 & $3.5 \mathrm{E}+05$ & e & $\mathrm{NL}$ & $\mathrm{Cf}-251$ \\
\hline
\end{tabular}

a "NA" means Not Applicable - decay factor is implicit in the PDCF for this radionuclide.

b "NL" means No Limit - estimated permissible concentration is greater than the specific activity of the pure elemental radionuclide.

c Radionuclide concentration is based on arrival time at the performance boundary beyond $10,000 \mathrm{y}$.

d PDCF is a function of arrival time. See Chapter 1 of this volume for equation.

- $r_{\text {Dacay }} \geq 1 \mathrm{1E}+50$

f Contribution of decay product(s) is significant to determination of this value (see Table E-3 in Volume 2). Listed arrival time is that of the parent radionuclide. If this footnote does not appear in combination with footnote $c$, the arrival time of the significant decay product(s) is less than $10,000 \mathrm{y}$. 
Arrival times for some radionuclides listed in Table 11-4 were beyond the 10,000-y performance period. For those radionuclides, the estimated waste concentrations are presented in Tables 11-4 for information purposes only. Consistent with the approach used in LLW performance assessments, these values were not considered in determining the most restrictive disposal limit from among the evaluated pathways.

For all radionuclides in Table 11-4, the flow rate at the time of facility failure controlled the subsurface transport (i.e., the subsurface movement of the radionuclides in the trench and tumulus was controlled by flow at $100 \mathrm{y}$ after closure for the trench [when the cover failed] and at $300 \mathrm{y}$ for the tumulus [when the concrete vaults failed]) with one exception. For disposal of H-3 in the trench, the most restrictive waste concentration from the water pathway was produced when this radionuclide was released from the disposal unit at the end of the 30-y life of the leachate collection system. At this time the flow rate was low and was controlled by the still-functioning cover on the disposal facility (H-3 has a short half-life, as well as low $K_{d}$ values for both the grouted waste form and the unsaturated zone at Fernald). Otherwise, the subsurface movement of the other 57 radionuclides in the trench, as well as for all radionuclides in the tumulus, was controlled by flow at $300 \mathrm{y}$ for the tumulus and at $100 \mathrm{y}$ after closure for the trench.

For the tumulus, the total undecayed $\mathrm{CRFs}$ (the product of the $C R F_{\text {Source }}$ and the $C R F_{\text {Water }}$ ) for the groundwater pathway were about twice the total undecayed CRFs for the trench, given the same total rate of flow (i.e., at the time of hydrologic failure of the facility). This result was due to the difference in the volume fraction of waste (the ratio of waste material to total material in the disposal unit) between the two technologies - twice as much waste leached from the trench for a given rate of flow because a given volume of trench contained twice as much waste.

For the trench design at Fernald, the total undecayed CRFs for the groundwater pathway ranged from about 5 to 3,200 . Among the listed radionuclides, arrival times at the performance boundary ranged from $60 \mathrm{y}$ to $210,000 \mathrm{y}$, including the retention time in the facility before failure. The travel time through the unsaturated zone accounted for about $90 \%$ of the total subsurface travel time.

For the tumulus design, the total undecayed CRFs for the groundwater pathway ranged from about 11 to 6,400. Among the listed radiónuclides, arrival times at the performance boundary ranged from $320 \mathrm{y}$ to $350,000 \mathrm{y}$, including the retention time in the facility before failure. Differences in these arrival times compared to the trench were attributable to (1) the assumed time of hydrologic failure of the facility ( $100 \mathrm{y}$ for the trench and $300 \mathrm{y}$ for the tumulus); and (2) the increased travel distance through the vadose zone for the tumulus (the bottom of the tumulus was assumed to be at grade level, while the trench was assumed to be a shallow buried structure).

Another significant difference between the trench and tumulus at Fernald is the nature of the unsaturated zone as described in Section 11.3.1. For the PE analysis, the tumulus (which is at grade level) rests on $6.7 \mathrm{~m}(22 \mathrm{ft})$ of glacial till underlain by $8.4 \mathrm{~m}(28 \mathrm{ft})$ of the unsaturated zone within the Great Miami Aquifer. The trench (which is excavated) rests on only $4.3 \mathrm{~m}$ (14 ft) of the unsaturated zone within the Great Miami Aquifer. 


\subsubsection{Atmospheric Transport}

Two CRFs were used to account for the attenuation encompassing diffusion to the ground surface, mixing in air, and dispersion in the atmosphere to the performance boundary. The CRF for diffusion in soil, $C R F_{D i f}$, was defined as the ratio of the radionuclide concentration in the waste to its resulting concentration in the upper one centimeter of soil. The CRF for dispersion in air, $C R F_{D i s p}$, was defined as the ratio of the radionuclide concentration in the upper one centimeter of soil to its resulting concentration in air at the performance boundary. The effect of radioactive decay was also included in the PE.

Application of the PE methodology for atmospheric transport of the two volatile radionuclides considered in the $\mathrm{PE}(\mathrm{H}-3$ and $\mathrm{C}-14)$ produced the results shown in Table 11-5 for both the generic trench and tumulus designs; there was no assumed difference in these two disposal technologies with respect to permissible waste limits based on the atmospheric pathway at Fernald. The table shows permissible waste concentrations based on transport in the atmospheric pathway $\left(C_{W-A t m}\right)$, as well as the values used in calculating the permissible waste concentrations. For both $\mathrm{H}-3$ and $\mathrm{C}-14$, the greatest concentration reduction occurred as the radionuclides diffuse from the top of the disposal facility to the soil surface.

Table 11-5. Results of Calculations for the Atmospheric Pathway

\begin{tabular}{|c|c|c|c|c|c|c|c|}
\hline \multirow[t]{2}{*}{ Nuclide } & \multirow[b]{2}{*}{$\begin{array}{c}S D C F_{A t m} \\
(\mathrm{rem} / \mathrm{y}) /(\mu \mathrm{Ci} / \mathrm{L})\end{array}$} & \multicolumn{6}{|c|}{ Generic Trench and Tumulus } \\
\hline & & $\begin{array}{c}C R F_{D i t} \\
\text { (dimensionloss) }\end{array}$ & $\begin{array}{c}C R F_{D \mid s p} \\
\text { (dimensionloses) }\end{array}$ & $\begin{array}{c}C_{\text {(dimersionloss) }} \\
\text { (Atm }\end{array}$ & $\begin{array}{c}\text { Arrival } \\
\text { Time (y) }\end{array}$ & $\begin{array}{c}\text { TDecay } \\
\text { (dimersionloss) }\end{array}$ & $\begin{array}{r}C_{W-A t m} \\
\left(\mu \mathrm{Ci} / \mathrm{m}^{3}\right)\end{array}$ \\
\hline $\mathrm{H}-3$ & $8.33 E+02$ & $3 E+06$ & $8 E+02$ & $2 E+09$ & 100 & 300 & $7 E+09$ \\
\hline C-14 & $2.20 E+05$ & $6 E+04$ & $1 E+03$ & $6 \mathrm{E}+07$ & 100 & 1 & $3 E+03$ \\
\hline
\end{tabular}

The time of arrival at the performance boundary for both radionuclides is shown in Table $11-5$ as $100 \mathrm{y}$. However, the actual migration of $\mathrm{H}-3$ and $\mathrm{C}-14$ from the disposal facility to the surface and downwind to the performance boundary was calculated to be on the order of hours, not years. As discussed in Section 11.3.2, the waste form and RCRA cover are assumed to retain these volatile radionuclides in the disposal facility for at least $100 \mathrm{y}$.

\subsubsection{Inadvertent Intruder Exposure}

The calculation of permissible waste concentrations for inadvertent intruder exposures did not utilize CRFs. Instead, the total dose resulting from an intrusion scenario (the sum of the doses from all exposure pathways involved in that intrusion) was computed from scenario dose conversion factors (SDCFs) that were applied to specific exposure pathways. These SDCF values were radionuclide-specific and facility-design-specific and were the same for all sites. The exposure pathways evaluated for each radionuclide are listed in Appendix D of Volume 2. Values for the radioactive decay term were based on time of intrusion into the disposal facility (for the homesteader scenario: $300 \mathrm{y}$ for the trench design and $500 \mathrm{y}$ for the tumulus design; for the post-drilling scenario: 100 y for both disposal designs). However, results based on intruder 
scenarios should be evaluated carefully because future social behavior, and intruder scenarios, are difficult to predict.

The permissible waste concentrations for the two generic facility designs for each of the 58 radionuclides based on the standard PE intrusion scenarios are listed in Table 11-6. The most restrictive radionuclide concentrations for each generic facility are indicated with boldface type.

For six radionuclides in the table (U-233, U-234, U-235, U-238, Pu-244, and Cm-247), the time of homesteader intrusion was changed to $10,000 \mathrm{y}$, the end of the performance period. For these six radionuclides, ingrowth of decay products yields scenario doses that increase over time. The doses at $10,000 \mathrm{y}$, therefore, represent the maximum that could be encountered during the performance period. Also, for Th-230 and $\mathrm{Cm}-245$, ingrowth of decay products likewise produces a scenario dose that increases over time and peaks within the 10,000-y performance period. The times of homesteader intrusion for these two radionuclides (Th-230 and $\mathrm{Cm}-245$ ) were taken as the time of maximum dose, $9000 \mathrm{y}$ and $1000 \mathrm{y}$, respectively.

For the trench design, the permissible concentrations of 47 radionuclides were controlled by the homesteader scenario and 11 were controlled by the post-drilling scenario. For the trench design, the post-drilling scenario generally yielded more restrictive permissible concentrations than the homesteader scenario for those radionuclides with half-lives shorter than about $30 \mathrm{y}$. For the tumulus design, the permissible concentrations of 41 radionuclides were controlled by the homesteader scenario and 17 were controlled by the post-drilling scenario. For the tumulus design, the post-drilling scenario generally yielded more restrictive concentrations than the homesteader scenario for those radionuclides with half-lives shorter than about $130 \mathrm{y}$.

\subsection{SUMMARY AND DISCUSSION OF RESULTS}

The limiting waste concentrations in disposed MLLW for the water, atmospheric, and intruder analyses for the generic trench and tumulus designs are summarized in Table 11-7 and discussed in Section 11.6.1. An overall discussion of the results of the PE for Fernald is contained in Section 11.6.2.

\subsubsection{Results Based on Disposal Design}

For the generic trench design at Fernald, 15 radionuclides were limited by the water pathway, no radionuclides were limited by the atmospheric pathway, and 43 radionuclides were limited by intrusion scenarios, as shown in Table 11-7. Among the 43 radionuclides limited by intrusion for the trench design at Fernald, 33 were controlled by homesteader intrusion and 10 by post-drilling.

For the generic tumulus design, 13 radionuclides were limited by the water pathway, no radionuclides were limited by the atmospheric pathway, and 45 radionuclides were limited by intrusion scenarios. Among the 45 radionuclides limited by intrusion for the trench design at Fernald, 28 were controlled by homesteader intrusion and 17 by post-drilling. 
Table 11-6. Permissible Waste Concentrations for the Standard Intrusion Scenarios (most limiting radionuclide concentration for each facility design is highlighted in bold italic) (Part 1 of 2)

\begin{tabular}{|c|c|c|c|c|c|}
\hline \multirow[t]{2}{*}{ Nuclide } & \multicolumn{2}{|c|}{ Trench } & \multicolumn{2}{|c|}{ Tumulus } & \multirow[t]{2}{*}{ Nuclide } \\
\hline & $\begin{array}{c}C_{W-\operatorname{lntr}} \\
\text { Homesteader } \\
\left(\mu \mathrm{Ci} / \mathrm{m}^{3}\right) \\
\end{array}$ & $\begin{array}{c}C_{w-1 n t} \\
\text { Post-Drilling } \\
\left(\mu \mathrm{Ci} / \mathrm{m}^{3}\right) \\
\end{array}$ & $\begin{array}{c}\boldsymbol{C}_{W \text { dntr }} \\
\text { Homesteader } \\
\left(\mu \mathrm{Ci} / \mathrm{m}^{3}\right)\end{array}$ & $\begin{array}{c}C_{\text {went }} \\
\text { Post-Drilling } \\
\left(\mu \mathrm{Ci} / \mathrm{m}^{3}\right) \\
\end{array}$ & \\
\hline $\mathrm{H}-3$ & $1 E+12$ & $7 E+07$ & NL & $7 E+07$ & $\mathrm{H}-3$ \\
\hline C-14 & $1 E+04$ & $7 E+04$ & $1 E+04$ & $7 E+04$ & C-14 \\
\hline Al-26 & $5 E+01$ & $5 E+04$ & $5 E+01$ & $5 E+04$ & Al-26 \\
\hline Si-32 & $9 E+03$ & $1 E+04$ & $4 E+04$ & $1 E+04$ & Si-32 \\
\hline $\mathrm{Cl}-36$ & $2 E+02$ & $9 E+02$ & $2 E+02$ & $9 E+02$ & $\mathrm{Cl}-36$ \\
\hline$K-40$ & $7 E+02$ & $2 E+04$ & $7 E+02$ & $2 E+04$ & $K-40$ \\
\hline Co-60 & $\mathrm{NL}$ & $3 E+10$ & $\mathrm{NL}$ & $3 E+10$ & Co-60 \\
\hline $\mathrm{Ni}-59$ & $3 E+06$ & $1 E+07$ & $3 E+06$ & $1 E+07$ & Ni-59 \\
\hline $\mathrm{Ni}-63$ & $8 E+06$ & $1 E+07$ & $3 E+07$ & $1 E+07$ & Ni-63 \\
\hline Se-79 & $2 E+05$ & $8 E+05$ & $2 E+05$ & $8 E+05$ & Se-79 \\
\hline Sr-90 & $1 E+06$ & $5 E+04$ & $1 E+08$ & $5 E+04$ & Sr-90 \\
\hline $2 r-93$ & $5 E+06$ & $3 E+07$ & $5 E+06$ & $3 E+07$ & Zr-93 \\
\hline $\mathrm{Nb}-93 \mathrm{~m}$ & $5 E+12$ & $4 E+09$ & NL & $4 E+09$ & $\mathrm{Nb}-93 \mathrm{~m}$ \\
\hline $\mathrm{Nb}-94$ & $9 E+01$ & $9 E+04$ & $1 E+02$ & $9 \mathrm{E}+04$ & $\mathrm{Nb}-94$ \\
\hline TC-99 & $2 E+04$ & $8 E+04$ & $2 E+04$ & $8 E+04$ & Tc-99 \\
\hline Pd-107 & $6 E+06$ & $3 E+07$ & $6 E+06$ & $3 E+07$ & Pd-107 \\
\hline $\mathrm{Ag}-108 \mathrm{~m}$ & $5 E+02$ & $1 E+05$ & $1 E+03$ & $1 \mathrm{E}+05$ & $\mathrm{Ag}-108 \mathrm{~m}$ \\
\hline Cd-113m & $4 E+09$ & $1 E+06$ & $7 E+13$ & $1 E+06$ & Cd-113m \\
\hline $\mathrm{Sn-121m}$ & $2 E+07$ & $5 E+07$ & $2 \mathrm{E}+08$ & $5 E+07$ & Sn-121m \\
\hline Sn-126 & $8 E+01$ & $7 E+04$ & $8 E+01$ & $7 E+04$ & Sn-126 \\
\hline $\mid-129$ & $2 E+03$ & $1 E+04$ & $2 E+03$ & $1 E+04$ & | $1-129$ \\
\hline Cs-135 & $2 E+05$ & $8 E+05$ & $2 E+05$ & $8 E+05$ & Cs-135 \\
\hline Cs-137 & $3 E+05$ & $8 E+05$ & $3 E+07$ & $8 E+05$ & Cs-137 \\
\hline Ba-133 & $2 E+11$ & $3 E+08$ & $\mathrm{NL}$ & $3 E+08$ & $\mathrm{Ba}-133$ \\
\hline $\mathrm{Sm}-151$ & $2 E+08$ & $2 E+08$ & $8 E+08$ & $2 E+08$ & Sm-151 \\
\hline Eu-152 & $6 \mathrm{E}+08$ & $2 E+07$ & $2 E+13$ & $2 E+07$ & Eu-152 \\
\hline Eu-154 & $4 E+12$ & $4 E+08$ & $\mathrm{NL}$ & $4 E+08$ & Eu-154 \\
\hline $\mathrm{Pb}-210$ & $7 E+06$ & $7 E+04$ & $4 \mathrm{E}+09$ & $7 E+04$ & $\mathrm{~Pb}-210$ \\
\hline Ra-226 & $8 E+01$ & $3 E+03$ & $9 E+01$ & $3 E+03$ & Ra-226 \\
\hline $\mathrm{Ra}-228$ & $\mathrm{NL}$ & $4 E+09$ & NL & $4 E+09$ & Ra-228 \\
\hline Th-229 & $5 E+02$ & $3 E+04$ & $5 E+02$ & $3 E+04$ & Th-229 \\
\hline Th-230 & $8 E+01$ & $7 E+04$ & $8 E+01$ & $7 E+04$ & Th-230 \\
\hline Th-232 & $6 E+01$ & $2 E+04$ & $6 E+01$ & $2 E+04$ & Th-232 \\
\hline $\mathrm{Pa}-231$ & $2 E+02$ & $5 E+03$ & $2 E+02$ & $5 E+03$ & $\mathrm{~Pa}-231$ \\
\hline
\end{tabular}


Table 11-6. Permissible Waste Concentrations for the Standard Intrusion Scenarios (most limiting radionuclide concentration for each facility design is highlighted in bold italic) (Part 2 of 2)

\begin{tabular}{|c|c|c|c|c|c|}
\hline \multirow[t]{2}{*}{ Nuclide } & \multicolumn{2}{|c|}{ Trench } & \multicolumn{2}{|c|}{ Tumulus } & \multirow[t]{2}{*}{ Nuclide } \\
\hline & $\begin{array}{c}C_{w-m r^{a}} \\
\text { Homesteader } \\
\left(\mu \mathrm{Ci} / \mathrm{m}^{3}\right)\end{array}$ & $\begin{array}{c}C_{\text {w/ntr }} \\
\text { Post-Drilling } \\
\left(\mu \mathrm{Ci} / \mathrm{m}^{3}\right) \\
\end{array}$ & $\begin{array}{c}C_{w-1 n t r} \\
\text { Homesteader } \\
\left(\mu \mathrm{Ci} / \mathrm{m}^{3}\right) \\
\end{array}$ & $\begin{array}{c}C_{w-1 n t r} \\
\text { Post-Drilling } \\
\left.\left(\mu \mathrm{Ci}^{3}\right)^{3}\right) \\
\end{array}$ & \\
\hline U-232 & $2 E+03$ & $5 E+04$ & $1 E+04$ & $5 E+04$ & U-232 \\
\hline U-233 & $7 E+02$ & $1 E+05$ & $7 E+02$ & $1 \mathrm{E}+05$ & U-233 \\
\hline U-234 & $1 E+03$ & $1 E+05$ & $1 E+03$ & $1 E+05$ & U-234 \\
\hline U-235 & $6 E+02$ & $1 E+05$ & $6 E+02$ & $1 E+05$ & $\mathrm{U}-235$ \\
\hline U-236 & $2 E+04$ & $1 E+05$ & $2 E+04$ & $1 E+05$ & U-236 \\
\hline U-238 & $5 E+03$ & $1 E+05$ & $5 E+03$ & $1 E+05$ & $U-238$ \\
\hline $\mathrm{Np}-237$ & $4 E+02$ & $4 E+03$ & $4 E+02$ & $4 E+03$ & Np-237 \\
\hline Pu-238 & $7 E+04$ & $1 E+05$ & $4 E+05$ & $1 E+05$ & Pu-238 \\
\hline Pu-239 & $6 E+03$ & $5 E+04$ & $6 E+03$ & $5 E+04$ & Pu-239 \\
\hline Pu-240 & $6 E+03$ & $5 E+04$ & $7 E+03$ & $5 E+04$ & $\mathrm{Pu}-240$ \\
\hline $\mathrm{Pu}-241$ & $2 E+05$ & $1 E+06$ & $3 E+05$ & $1 E+06$ & Pu-241 \\
\hline $\mathrm{Pu}-242$ & $6 E+03$ & $5 E+04$ & $6 E+03$ & $5 E+04$ & Pu-242 \\
\hline $\mathrm{Pu}-244$ & $4 E+02$ & $5 \mathrm{E}+04$ & $4 E+02$ & $5 E+04$ & Pu-244 \\
\hline Am-241 & $7 E+03$ & $5 E+04$ & $9 E+03$ & $5 E+04$ & Am-241 \\
\hline Am-243 & $9 E+02$ & $4 E+04$ & $9 E+02$ & $4 E+04$ & Am-243 \\
\hline $\mathrm{Cm}-243$ & $1 E+06$ & $8 E+05$ & $5 E+06$ & $8 E+05$ & $\mathrm{Cm}-243$ \\
\hline $\mathrm{Cm}-244$ & $2 E+06$ & $3 E+06$ & $2 E+06$ & $3 E+06$ & $\mathrm{Cm}-244$ \\
\hline Cm-245 & $1 E+03$ & $4 E+04$ & $1 E+03$ & $4 E+04$ & $\mathrm{Cm}-245$ \\
\hline $\mathrm{Cm}-246$ & $6 E+03$ & $5 E+04$ & $6 E+03$ & $5 E+04$ & $\mathrm{Cm}-246$ \\
\hline $\mathrm{Cm}-247$ & $3 E+02$ & $5 E+04$ & $3 E+02$ & $5 E+04$ & $\mathrm{Cm}-247$ \\
\hline $\mathrm{Cm}-248$ & $2 E+03$ & $1 E+04$ & $2 E+03$ & $1 E+04$ & $\mathrm{Cm}-248$ \\
\hline Cf-249 & $8 E+02$ & $4 E+04$ & $1 E+03$ & $4 E+04$ & Cf-249 \\
\hline Cf-250 & $2 E+06$ & $9 E+06$ & $2 E+06$ & $9 E+06$ & Cf-250 \\
\hline Cf-251 & $2 E+03$ & $4 E+04$ & $2 E+03$ & $4 E+04$ & Cf-251 \\
\hline
\end{tabular}

a "NL" means No Limit - estimated permissible concentration is greater than the specific activity of the pure elemental radionuclide. 
Table 11-7. Permissible Concentrations for the Generic Disposal Designs at FEMP (permissible concentration related to the most limiting pathway for each facility design is highlighted in bold italic) (Part 1 of 2)

\begin{tabular}{|c|c|c|c|c|c|c|c|}
\hline \multirow[t]{2}{*}{ Nuclide } & \multicolumn{3}{|c|}{ Trench } & \multicolumn{3}{|c|}{ Tumulus } & \multirow[t]{2}{*}{ Nuclide } \\
\hline & $\begin{array}{c}C_{\text {W.Water }}{ }^{2, b} \\
\left(\mu \mathrm{Ci} / \mathrm{m}^{3}\right)\end{array}$ & $\begin{array}{c}C_{W-A t m}{ }^{c} \\
\left(\mu \mathrm{Ci} / \mathrm{m}^{3}\right)\end{array}$ & $\begin{array}{l}C_{W \cdot / n t r}{ }^{d} \\
\left(\mu \mathrm{Ci} / \mathrm{m}^{3}\right)\end{array}$ & $\begin{array}{c}C_{W \cdot W a t e r}{ }^{a, b} \\
\left(\mu \mathrm{Ci} / \mathrm{m}^{3}\right)\end{array}$ & $\begin{array}{c}C_{W-A t m}{ }^{c} \\
\left(\mu \mathrm{Ci} / \mathrm{m}^{3}\right)\end{array}$ & $\begin{array}{l}C_{W \cdot I n t r}{ }^{d} \\
\left.(\mu \mathrm{Cilm})^{3}\right)\end{array}$ & \\
\hline U-232 & $5 E+01$ & & $2 E+03$ & $5 E+03$ & & $1 E+04$ & $\mathrm{U}-232$ \\
\hline U-233 & $5 E+01$ & & $7 E+02$ & $7 E+01$ & & $7 E+02$ & U-233 \\
\hline U-234 & $6 E+01$ & & $1 E+03$ & $1 E+02$ & & $1 E+03$ & U-234 \\
\hline U-235 & $5 E+01$ & & $6 E+02$ & $6 E+01$ & & $6 E+02$ & U-235 \\
\hline U-236 & $7 E+01$ & & $2 E+04$ & $1 E+02$ & & $2 E+04$ & U-236 \\
\hline$U-238$ & $6 E+01$ & & $5 E+03$ & $1 E+02$ & & $5 E+03$ & U-238 \\
\hline $\mathrm{Np}-237$ & $4 E+00$ & & $4 E+02$ & $8 E+00$ & & $4 \mathrm{E}+02$ & Np-237 \\
\hline Pu-238 & $2 E+05$ & & $7 E+04$ & $3 E+05$ & & $1 E+05$ & $\mathrm{Pu}-238$ \\
\hline Pu-239 & - & & $6 E+03$ & - & & $6 E+03$ & Pu-239 \\
\hline Pu-240 & - & & $6 E+03$ & - & & $7 E+03$ & $\mathrm{Pu}-240$ \\
\hline Pu-241 & $6 \mathrm{E}+05$ & & $2 E+05$ & $1 E+06$ & & $3 E+05$ & $\mathrm{Pu}-241$ \\
\hline Pu-242 & - & & $6 E+03$ & - & & $6 E+03$ & $\mathrm{Pu}-242$ \\
\hline Pu-244 & - & & $4 E+02$ & - & & $4 E+02$ & $\mathrm{Pu}-244$ \\
\hline Am-241 & $2 E+04$ & & $7 E+03$ & $4 E+04$ & & $9 E+03$ & Am-241 \\
\hline Am-243 & - & & $9 E+02$ & - & & $9 E+02$ & Am-243 \\
\hline $\mathrm{Cm}-243$ & - & & $8 E+05$ & - & & $8 E+05$ & $\mathrm{Cm}-243$ \\
\hline $\mathrm{Cm}-244$ & $=$ & & $2 E+06$ & - & & $2 E+06$ & $\mathrm{Cm}-244$ \\
\hline Cm-245 & - & & $1 E+03$ & - & & $1 E+03$ & $\mathrm{Cm}-245$ \\
\hline $\mathrm{Cm}-246$ & - & & $6 E+03$ & - & & $6 E+03$ & $\mathrm{Cm}-246$ \\
\hline $\mathrm{Cm}-247$ & - & & $3 E+02$ & - & & $3 E+02$ & $\mathrm{Cm}-247$ \\
\hline $\mathrm{Cm}-248$ & - & & $2 E+03$ & - & & $2 E+03$ & $\mathrm{Cm}-248$ \\
\hline Cf-249 & - & & $8 E+02$ & - & & $1 E+03$ & Cf-249 \\
\hline Cf-250 & - & & $2 E+06$ & - & & $2 E+06$ & Cf-250 \\
\hline Cf-251 & - & & $2 E+03$ & - & & $2 E+03$ & Cf-251 \\
\hline
\end{tabular}

a "NL" means No Limit - estimated permissible concentration factor is greater than the specific activity of the pure elemental radionuclide.

b "-" indicates that the radionuclide concentration is based on an arrival time beyond $10,000 \mathrm{y}$; see Table 11-4 for specific values.

c Results presented for radionclides expected to be volatile under disposal facility conditions.

d Concentration is based on the most restrictive intrusion scenario assumed for the site; see Table 11-6. 
Table 11-7. Permissible Concentrations for the Generic Disposal Designs at FEMP (permissible concentration related to the most limiting pathway for each facility design is highlighted in bold italic) (Part 2 of 2)

\begin{tabular}{|c|c|c|c|c|c|c|c|}
\hline \multirow[t]{2}{*}{ Nuclide } & \multicolumn{3}{|c|}{ Trench } & \multicolumn{3}{|c|}{ Tumulus } & \multirow[t]{2}{*}{ Nuclide } \\
\hline & $\begin{array}{c}C_{\text {w-Water }}^{a, b} \\
\left(\mu \mathrm{Ci} / \mathrm{m}^{3}\right)\end{array}$ & $\begin{array}{c}C_{w-A t m}{ }^{c} \\
\left(\mu \mathrm{Ci} / \mathrm{m}^{3}\right)\end{array}$ & $\begin{array}{l}C_{W-/ n t r}{ }^{d} \\
\left(\mu \mathrm{Ci} / \mathrm{m}^{3}\right)\end{array}$ & $\begin{array}{c}C_{\text {w-Water }}{ }^{a, b} \\
\left(\mu \mathrm{Ci} / \mathrm{m}^{3}\right)\end{array}$ & $\begin{array}{l}C_{W-A t m}{ }^{c} \\
\left(\mu \mathrm{Ci} / m^{3}\right)\end{array}$ & $\begin{array}{l}C_{W-1 n t r}^{d} \\
\left(\mu \mathrm{Ci} / \mathrm{m}^{3}\right)\end{array}$ & \\
\hline $\mathrm{H}-3$ & $6 E+04$ & $7 E+09$ & $7 E+07$ & $7 E+10$ & $7 E+09$ & $7 E+07$ & $\mathrm{H}-3$ \\
\hline$C-14$ & $9 E+02$ & $3 E+03$ & $1 E+04$ & $2 E+03$ & $3 E+03$ & $1 E+04$ & C-14 \\
\hline Al-26 & $1 E+03$ & & $5 E+01$ & $2 E+03$ & & $5 E+01$ & Al-26 \\
\hline $\mathrm{Si}-32$ & $8 \mathrm{E}+08$ & & $9 E+03$ & $6 E+13$ & & $1 E+04$ & Si-32 \\
\hline $\mathrm{Cl}-36$ & $1 E+01$ & & $2 E+02$ & $2 E+01$ & & $2 E+02$ & $\mathrm{Cl}-36$ \\
\hline$K-40$ & $1 E+01$ & & $7 E+02$ & $2 E+01$ & & $7 E+02$ & $K-40$ \\
\hline Co-60 & NL & & $3 E+10$ & $\mathrm{NL}$ & & $3 E+10$ & $\mathrm{Co}-60$ \\
\hline Ni-59 & - & & $3 E+06$ & - & & $3 E+06$ & Ni-59 \\
\hline $\mathrm{Ni}-63$ & - & & $8 E+06$ & - & & $1 E+07$ & $\mathrm{Ni}-63$ \\
\hline Se-79 & $3 E+01$ & & $2 E+05$ & - & & $2 E+05$ & Se-79 \\
\hline Sr-90 & $9 \mathrm{E}+10$ & & $5 E+04$ & $\mathrm{NL}$ & & $5 E+04$ & Sr-90 \\
\hline$Z r-93$ & - & & $5 E+06$ & - & & $5 E+06$ & $\mathrm{Zr}-93$ \\
\hline Nb-93m & $\mathrm{NL}$ & & $4 E+09$ & - & & $4 E+09$ & $\mathrm{Nb}-93 \mathrm{~m}$ \\
\hline $\mathrm{Nb}-94$ & $3 E+02$ & & $9 E+01$ & - & & $1 E+02$ & Nb-94 \\
\hline Tc-99 & $1 E+02$ & & $2 E+04$ & $3 E+02$ & & $2 E+04$ & Tc-99 \\
\hline $\mathrm{Pd}-107$ & $1 E+05$ & & $6 \mathrm{E}+06$ & $2 E+05$ & & $6 E+06$ & Pd-107 \\
\hline $\mathrm{Ag}-108 \mathrm{~m}$ & $2 E+14$ & & $5 E+02$ & $\mathrm{NL}$ & & $1 E+03$ & $\mathrm{Ag}-108 \mathrm{~m}$ \\
\hline Cd-113m & $\mathrm{NL}$ & & $1 E+06$ & - & & $1 E+06$ & Cd-113m \\
\hline$S n-121 m$ & NL & & $2 E+07$ & - & & $5 E+07$ & Sn-121m \\
\hline Sn-126 & $9 E+01$ & & $8 E+01$ & - & & $8 E+01$ & Sn-126 \\
\hline $1-129$ & 7E-01 & & $2 E+03$ & $2 E+00$ & & $2 E+03$ & I-129 \\
\hline Cs-135 & - & & $2 E+05$ & - & & $2 E+05$ & Cs-135 \\
\hline Cs-137 & - & & $3 E+05$ & - & & $8 E+05$ & Cs-137 \\
\hline $\mathrm{Ba}-133$ & NL & & $3 E+08$ & $\mathrm{NL}$ & & $3 E+08$ & Ba-133 \\
\hline Sm-151 & - & & $2 E+08$ & - & & $2 E+08$ & Sm-151 \\
\hline Eu-152 & - & & $2 E+07$ & - & & $2 E+07$ & Eu-152 \\
\hline Eu-154 & - & & $4 E+08$ & - & & $4 E+08$ & Eu-154 \\
\hline $\mathrm{Pb}-210$ & $=$ & & $7 E+04$ & - & & $7 E+04$ & $\mathrm{~Pb}-210$ \\
\hline Ra-226 & - & & $8 E+01$ & - & & $9 E+01$ & Ra-226 \\
\hline Ra-228 & - & & $4 E+09$ & - & & $4 E+09$ & Ra-228 \\
\hline Th-229 & - & & $5 E+02$ & - & & $5 E+02$ & Th-229 \\
\hline Th-230 & - & & $8 E+01$ & - & & $8 E+01$ & Th-230 \\
\hline Th-232 & - & & $6 E+01$ & - & & $6 E+01$ & Th-232 \\
\hline $\mathrm{Pa}-231$ & - & & $2 E+02$ & - & & $2 E+02$ & $\mathrm{~Pa}-231$ \\
\hline
\end{tabular}


For the trench design, concentrations for five radionuclides (Co-60, Nb-93m, Cd-113m, $\mathrm{Sn}-121 \mathrm{~m}$, and $\mathrm{Ba}-133$ ) that arrived at the performance boundary before $10,000 \mathrm{y}$ reported in Table 11-7 for the water pathway analysis had no limit. For the tumulus design, concentrations for four radionuclides (Co-60, Sr-90, Ag-108m, and Ba-133) that arrived at the performance boundary before 10,000 y had no limit. As discussed in Section 11.5.1, the calculated concentrations for those radionuclides reported as NL (No Limit) were above the specific activity of the pure elemental radionuclide, implying that the performance measure of $4 \mathrm{mrem}(0.04 \mathrm{mSv})$ per year would not be reached under the given release and transport assumptions.

As also discussed in Section 11.5.1, values for some radionuclides are not reported in Table 11-7 for the water pathway analysis. Arrival times for these radionuclides were beyond the 10,000-y performance period. For these radionuclides, the estimated waste concentrations are presented in Tables 11-4 for information purposes but are not listed in Table 11-7. Consistent with the approach used in LLW performance assessments, these values were not considered in determining the most restrictive disposal limit from among the evaluated pathways because arrival times for these radionuclides were beyond $10,000 \mathrm{y}$.

For both the trench and tumulus designs at Fernald, about half of the 58 radionuclides had arrival times for the water pathway in excess of $10,000 \mathrm{y}$. With a few exceptions (most notably, $\mathrm{Ni}, \mathrm{Zr}$, and $\mathrm{Cs}$ ), those radionuclides with atomic numbers less than about 56 (i.e., barium) arrived at the performance boundary for the water pathway before $10,000 \mathrm{y}$. The radiums, thoriums, and most of the transuranics are not shown as being limited by the water pathway because their peak arrival times were beyond $10,000 \mathrm{y}$. For both the trench design and the tumulus design at Fernald, only two transuranic elements were limited by the water pathway: the uraniums and $\mathrm{Np}-237$, both of which have low $K_{d}$ values for the saturated and unsaturated zones based on experimental measurements at Fernald.

At Fernald, there is no significant difference in the permissible waste concentrations computed with the PE methodology for the trench as compared to the tumulus. That is, there is less than one order of magnitude difference in the waste limits between the two disposal facility designs. The notable exceptions are H-3, Se-79, and U-232, all of which are limited by the water pathway for the trench and by intrusion for the tumulus.

\subsubsection{Discussion}

The results of the PE are based on the framework of assumptions summarized in Chapter 1 of this volume and discussed in detail in Volume 2 of this report and on the site-specific conceptual model for contaminant transport discussed in this chapter. Using alternative assumptions about the conceptual model has the potential to affect the results. Changes in the conceptual model could include alternative assumptions about the disposal facility, the source term, and radionuclide movement in the three pathways. Depending on the degree of possible variation and the relative importance of the parameters used in the calculation of estimated permissible waste concentrations, variability in parameter values can also affect the results. For parameters, results could vary depending on potential changes in values of both the generic and the site-specific parameters used in the PE analysis. 
The effect on results from using alternative generic assumptions and parameter values is discussed in Chapter 6 of Volume 2. In addition, a discussion is provided in that chapter about the effects of using alternative values for site-specific parameters. Based on this discussion, four parameters were identified (three site-specific and one generic, all used in the water pathway analysis) that could potentially influence the results to the degree that the calculated waste concentrations become limited by a pathway other than the one determined for the PE (Table 11-7). The impacts on the results of using alternative values for these four parameters for the water pathway in the PE for FEMP are discussed in this section. The basis for and possible variation in the values used in the PE for these parameters are discussed in Section 11.6.2.2.

\subsubsection{Parameter Sensitivity Analysis}

The PE provided results for two disposal facility designs: a RCRA-compliant, belowground trench and a RCRA-compliant, above-ground tumulus. Similar assumptions about the integrity of engineered barriers were made in the PE for both facility designs. Because the factors used to estimate transport of radionuclides in the water pathway for both designs were similar, the discussion in this section focuses on examining the results for the indicator radionuclides reported for the tumulus design (indicator radionuclides are defined in Chapter 7 of Volume 2).

As discussed in Chapter 6 of Volume 2, only four parameters used in the PE were identified as having a potential range of values that might affect results: annual natural recharge through the disposal facility $(i)$; groundwater Darcy velocity $\left(q_{g^{w}}\right)$; area of the facility $(A)$; and distribution coefficients $\left(K_{d} \&\right)$. These parameter values for FEMP are summarized in Table 11-8.

Table 11-8. Parameter Values Used in the PE for FEMP with Potential Variability That Could Affect the Results

\begin{tabular}{|l|l|}
\hline \multicolumn{1}{|c|}{ Parameter } & \multicolumn{1}{c|}{ Value } \\
\hline \hline Natural recharge through local soils, $i$ & $0.15 \mathrm{~m} / \mathrm{y}$ \\
\hline $\begin{array}{l}\text { Distribution coefficients for geologic } \\
\text { media, } K_{d}\end{array}$ & $\begin{array}{l}\text { Sandy soil values from Thibault et al. (1990) } \\
\text { and some site specific values (U.S. DOE, } \\
1995) ; \text { see Table 11-2 in this chapter for values }\end{array}$ \\
\hline Groundwater Darcy velocity, $q_{\mathrm{gw}}$ & $28 \mathrm{~m} / \mathrm{y}$ \\
\hline Plan-view Area, $A$ & $2500 \mathrm{~m}^{2}$ (standard PE value) \\
\hline
\end{tabular}

The traditional procedure for performing a sensitivity analysis is to vary the parameters used in the calculations and observe the effect on the results. To be meaningful, this method requires some knowledge of the statistical distribution of each of the parameters considered, including their likely maximum and minimum values. For the PE calculations, the potential variability of the parameters used to calculate the permissible waste concentrations for the two different facility designs was not estimated. For most of the radionuclides considered in the PE, there were only two exposure pathways: the water pathway and intruder exposure scenarios (the atmospheric pathway was considered only for $\mathrm{H}-3$ and C-14). The intruder-pathway results provide a baseline that can be used for comparison with the water-pathway results because the 
intruder scenarios used in the PE were relatively independent of the physical characteristics of the individual sites. This baseline provided an alternative method of performing sensitivity analyses for the PE. The input parameters for the water pathway were varied to determine if the limiting exposure pathway could be altered (e.g., the results could be changed from intruder-scenario controlled to water-pathway controlled). After new values for the water pathway parameters were determined, these values were examined for reasonableness based on physical constraints at the site.

The sensitivity analysis was limited to a comparison of the water and intruder exposure pathways. A comparison between the water and atmospheric pathways was not conducted because the atmospheric pathway is not limiting.

To analyze the sensitivity of the results to changes in the parameter values for natural recharge, groundwater Darcy velocity, and area of the facility, the parameter values used in the $\mathrm{PE}$ for FEMP were varied. Only one parameter value was varied at a time for a radionuclide, leaving the others equal to their PE values. In most instances, the parameter value was varied until the waste concentrations for the water and intruder pathways became equal, regardless of the likelihood (or physical impossibility) of the value to occur.

The parameter values that caused the permissible concentrations for the water and intruder pathways to become equal are listed in Table 11-9 for the 8 indicator radionuclides. For the indicator radionuclide C-14, the recharge had to decrease by 6 times or the groundwater velocity had to increase by a factor of 8 to change the limiting pathway from water to intruder. For Tc-99 and U-238, values for recharge had to decrease by about two orders of magnitude or the groundwater velocity had to increase about two orders of magnitude to cause the waste concentrations for the water and intruder pathways to become equal; however, radionuclides would arrive at the performance boundary beyond 10,000 y for both Tc-99 and U-238 at this low recharge. For Pu-239, all values that caused the pathways to become equal also caused arrival at the performance boundary beyond 10,000 y. For Am-241, the value for recharge had to increase six times, the groundwater velocity had to decrease by a factor of 6 , or the facility plan area had to increase about two orders of magnitude to change the limiting pathway from intruder to water.

The PE analysis for FEMP utilized two sets of subsurface $K_{d}$ values, one for the unsaturated zone and one for the saturated zone. To simplify this sensitivity analysis, $K_{d}$ values for both the unsaturated and saturated zones were set equal and changed as a single value.

A $K_{d}$ value of about $110 \mathrm{~mL} / \mathrm{g}$ for the geologic media would cause an arrival time at the performance boundary of $10,000 \mathrm{y}$. The $K_{d}$ values that caused the permissible concentrations for the water and intruder pathways to be the same are listed in Table 11-10 for 5 of the indicator radionuclides. The indicator radionuclides $\mathrm{H}-3, \mathrm{C}-14$, and Tc-99 are not considered in this analysis because general consensus is that the $K_{d}$ values for these radionuclides are small. 
Table 11-9. Parameter Values That Caused the Permissible Concentrations for the Water and Intruder Pathways to Be Equal for Indicator Radionuclides at FEMP (tumulus design) (bold italic type indicates limiting pathway in the PE)

\begin{tabular}{|c|c|c|c|c|c|c|}
\hline \multirow[t]{4}{*}{$\begin{array}{l}\text { Indicator } \\
\text { Nuclide }\end{array}$} & \multirow[t]{4}{*}{$\begin{array}{c}\text { PE } \\
C_{\text {wh-Wator }}^{a} \\
\left(\mu \mathrm{Ci} / \mathrm{m}^{3}\right)\end{array}$} & \multirow[t]{4}{*}{$\begin{array}{c}\text { PE } \\
C_{W-1 n \pi} \\
\left(\mu \mathrm{Ci} / \mathrm{m}^{3}\right)\end{array}$} & \multirow[t]{4}{*}{$\begin{array}{c}P E \\
C_{\text {W-Intr }} \\
C_{\text {W-Water }}\end{array}$} & $\begin{array}{c}\text { Natural } \\
\text { Recharge, } \\
i \\
(\mathrm{~m} / \mathrm{y})\end{array}$ & $\begin{array}{l}\text { Groundwater } \\
\text { Darcy } \\
\text { Velocity, } q_{g w} \\
\text { (m/y) }\end{array}$ & $\begin{array}{c}\text { Area, } \\
\text { A } \\
\left(\mathrm{m}^{2}\right)\end{array}$ \\
\hline & & & & \multicolumn{3}{|c|}{ PE Values } \\
\hline & & & & 0.15 & 28 & 2500 \\
\hline & & & & \multicolumn{3}{|c|}{$\begin{array}{c}\text { Value That Caused Equal } \\
\text { Concentrations }\end{array}$} \\
\hline $\mathrm{H}-3$ & $7 E+10$ & $7 E+07$ & 0.001 & $b$ & $b$ & $b$ \\
\hline$C-14$ & $2 E+03$ & $1 E+04$ & 5 & 0.025 & 220 & $<100$ \\
\hline $\mathrm{Sr}-90$ & NL & $5 E+04$ & - & $b$ & $b$ & $b$ \\
\hline Tc-99 & $3 E+02$ & $2 E+04$ & 67 & $0.0024^{c}$ & 1750 & $<100$ \\
\hline Cs-137 & $\mathrm{NL}^{\mathrm{c}}$ & $8 E+05$ & - & $b$ & $b$ & $b$ \\
\hline U-238 & $1 E+02$ & $5 E+03$ & 50 & $0.0037^{c}$ & 1100 & $<100$ \\
\hline $\mathrm{Pu}-239$ & $4 E+01^{c}$ & $6 E+03$ & 150 & $0.039^{c}$ & $5,000^{C}$ & $<100^{\circ}$. \\
\hline $\begin{array}{l}\text { Am-241 } \\
(\mathrm{Np}-237)^{\mathrm{d}}\end{array}$ & $4 E+04^{\circ}$ & $9 E+03$ & 0.23 & $0.90^{\circ}$ & $4.5^{\circ}$ & $100,000^{\circ}$ \\
\hline
\end{tabular}

a "NL" means No Limit - estimated permissible concentration is greater than the specific activity of the pure elemental radionuclide.

b No variation in values caused equal concentrations.

c Arrival time at the performance boundary is greater than $10,000 \mathrm{y}$.

d The dominant decay product of Am-241

e Based on the dominant decay product, Np-237

"-"Value could not be calculated.

Table 11-10. Variation of $K_{d}$ Values at FEMP (tumulus design) (a $K_{d}$ value of $110 \mathrm{~mL} / \mathrm{g}$ caused radionuclide arrival at the performance boundary equal to $10,000 \mathrm{y}$ )

\begin{tabular}{|c|c|c|c|c|c|}
\hline $\begin{array}{l}\text { Indicator } \\
\text { Nuclide }\end{array}$ & $\begin{array}{l}\text { PE } K_{d} \\
(m \sqcup g)\end{array}$ & $\begin{array}{c}\text { PE } \\
C_{W-W a t e r} \\
\left(\mu \mathrm{Ci} / \mathrm{m}^{3}\right)\end{array}$ & $\begin{array}{c}\text { PE } \\
C_{W / n t r} \\
\left(\mu \mathrm{Ci} / \mathrm{m}^{3}\right)\end{array}$ & $\begin{array}{c}\text { PE } \\
\frac{C_{W \cdot \text { Intr }}}{C_{W \cdot \text { Water }}}\end{array}$ & $\begin{array}{l}K_{d} \text { Value that } \\
\text { Caused Equal } \\
\text { Concentrations }\end{array}$ \\
\hline ST-90 & $20 / 15$ & NL & $5 E+04$ & - & $c$ \\
\hline Cs-137 & 280 & $\mathrm{NL}^{\mathrm{b}}$ & $8 E+05$ & - & 1 \\
\hline $\mathrm{U}-238$ & $3.1 / 1.78$ & $1 E+02$ & $5 E+03$ & 50 & $c, d$ \\
\hline Pu-239 & 550 & $4 E+1^{b}$ & $6 E+03$ & 150 & $2500^{b, e}$ \\
\hline $\begin{array}{l}\mathrm{Am}-241 \\
(\mathrm{~Np}-237)^{f}\end{array}$ & $\begin{array}{l}1900 \\
(2.4)\end{array}$ & $4 E+04^{\circ}$ & $9 E+03$ & 0.23 & 45 \\
\hline
\end{tabular}

a "NL" means No Limit - the estimated permissible waste concentration is greater than the specific activity of the pure elemental radionuclide.

b Arrival time at the performance boundary is greater than $10,000 \mathrm{y}$.

c No variation in value caused equal concentrations.

d Value greater than $110 \mathrm{~mL} / \mathrm{g}$ caused arrival at the performance boundary after 10,000 y, which changed the limiting pathway.

e Value less than $110 \mathrm{~mL} / g$ caused arrival at the performance boundary before $10,000 \mathrm{y}$, which changed the limiting pathway.

f The dominant decay product of Am-241

g Based on the dominant decay product, Np-237

"-" Value could not be calculated. 
For Cs-137, the $K_{d}$ values had to decrease about two orders of magnitude to cause the limiting pathway to change from intruder to water. $\mathrm{A} K_{d}$ value greater than $110 \mathrm{~mL} / \mathrm{g}$ for U-238 caused the arrival time at the performance boundary to be greater than $10,000 \mathrm{y}$, and therefore changed the limiting pathway from water to intruder. $\mathrm{A} K_{d}$ value of $2500 \mathrm{~mL} / \mathrm{g}$ caused the permissible waste concentrations to become equal for Pu-239, but its arrival at the performance boundary was still beyond $10,000 \mathrm{y}$; the $K_{d}$ had to be decreased to $110 \mathrm{~mL} / \mathrm{g}$ for the limiting pathway to change from intruder to water. The $\mathrm{PE}$ result for Am-241 was limited by the decay product (Np-237) contribution to the dose. If the $K_{d}$ value for Am-241 was decreased about two orders of magnitude, then the water pathway concentration was limited by the parent radionuclide (Am-241), and the water pathway controlled. Due to the long half-life of Np-237, reduction of its $K_{d}$ had no effect on the resulting waste concentration, and therefore no variation in the Np-237 $K_{d}$ value caused a change.

\subsubsection{Physical Constraints on Sensitivity Analysis Values}

The PE results for FEMP are based on parameter values provided by the FEMP technical staff for site-specific parameters used in calculations. Descriptions and technical justifications of these values are provided in Sections 11.3 and 11.4. Ranges and statistical distributions were not known for most of the input parameter values; however, site-specific knowledge can be used to determine whether the values determined in the sensitivity analysis are reasonable and physically possible at FEMP.

\section{Natural Recharge}

The sensitivity analysis results indicate it was not possible to change the limiting pathway for any of the indicator radionuclides by changing the natural recharge. The values for recharge estimated in the sensitivity analysis range from 0.0037 to $0.9 \mathrm{~m} / \mathrm{y}(0.012$ to $3 \mathrm{ft} / \mathrm{y})$ (Table 11-9) compared to the $P E$ value of $0.15 \mathrm{~m} / \mathrm{y}(0.5 \mathrm{ft} / \mathrm{y})$. The natural recharge at FEMP is reported to vary from $0.12 \mathrm{~m} / \mathrm{y}$ to $0.21 \mathrm{~m} / \mathrm{y}(0.39$ to $0.69 \mathrm{ft} / \mathrm{y})$, based on HELP model results (Table F.2-1 from FEMP-05FS-4 DRAFT, 11/14/94). None of the sensitivity analysis values fall within the reported range for recharge at FEMP, and none are physically reasonable.

\section{Groundwater Darcy Velocity}

The sensitivity analysis results indicate it is possible to change the limiting pathway for C-14 from water to intruder by increasing the groundwater velocity. The values for the groundwater Darcy velocity estimated by the sensitivity analysis vary from 4.5 to $5,000 \mathrm{~m} / \mathrm{y}$ (15 to $16,000 \mathrm{ft} / \mathrm{y}$ ) (Table 11-9) compared to the PE value of $28 \mathrm{~m} / \mathrm{y}$ (92 ft/y). At FEMP, the groundwater Darcy velocity could vary from $10 \mathrm{~m} / \mathrm{y}$ to $500 \mathrm{~m} / \mathrm{y}$ (33 to $1600 \mathrm{ft} / \mathrm{y}$ ) if local pumping patterns were changed. The $\mathrm{C}-14$ sensitivity analysis value is reasonable because it falls within the estimated range for Darcy velocity at FEMP. All other indicator radionuclide sensitivity analysis values do not fall within the reported range and are not physically reasonable.

\section{Facility Area}

The sensitivity analysis results indicate it was not possible to change the limiting pathway by changing the facility size. The value for the facility area estimated in the sensitivity analysis was $100,000 \mathrm{~m}^{2}\left(1,080,000 \mathrm{ft}^{2}\right)$ for Am-241 (Table 11-9). This value is not reasonable because the area is tightly constrained in the vicinity of the proposed MWDF, and the maximum facility 
area which would fit is approximately $150 \mathrm{~m}$ by $150 \mathrm{~m}(500 \mathrm{ft}$ by $500 \mathrm{ft})\left(22,500 \mathrm{~m}^{2}\right.$ $\left.\left[240,000 \mathrm{ft}^{2}\right]\right)$.

\section{Distribution Coefficients}

The results shown in Table 11-10 indicate that it was possible to change the limiting exposure pathway for Pu-239 from intruder to water by decreasing the $K_{d}$. Changing the $K_{d}$ for $\mathrm{Pu}-239$ to $110 \mathrm{~mL} / \mathrm{g}$ (the $K_{d}$ required to cause arrival at the performance boundary at $10,000 \mathrm{y}$ ) is reasonable because this value is within an order of magnitude of the $P E K_{d}$ value of $550 \mathrm{~mL} / \mathrm{g}$. The large changes required to change the limiting pathways for Cs-137, U-238, and Am-241 are probably not reasonable.

\subsection{OBSERVATIONS}

Based on the results of the PE and the parameter-sensitivity analysis, the following observations can be made about MLLW disposal at FEMP:

- The Fernald site has characteristics that are typical of a humid climate. Among DOE sites, the annual rainfall and the recharge at Fernald are relatively high $(1 \mathrm{~m} / \mathrm{y}$ and $0.15 \mathrm{~m} / \mathrm{y}$ [3.3 ft/y and $0.49 \mathrm{ft} / \mathrm{y}$ ], respectively). The vadose zone at Fernald consists of $6.7 \mathrm{~m}(22 \mathrm{ft})$ of glacial till underlain by $8.4 \mathrm{~m}(27.6 \mathrm{ft})$ of the unsaturated portion of the Great Miami Aquifer. Travel times as short as $60 \mathrm{y}$ and up to $350,000 \mathrm{y}$ have been computed for some radionuclides in the water pathway at Fernald.

- For FEMP, the results indicate that of the 58 radionuclides evaluated in the PE, 43 radionuclides for the trench design and 45 radionuclides for the tumulus design would be limited by intrusion scenarios. These results reflect the dominant role of the selected human intrusion scenarios that is demonstrated for almost all the sites considered in the PE (see Sections 7.5 and 7.6 in Volume 2). This dominance indicates a need to be aware of the inability to predict the social behavior of populations far into the future.

The results also indicate that for the water pathway, 29 radionuclides for the trench design and 35 radionuclides for the tumulus design would arrive at the performance boundary after the 10,000-y period of consideration in the $\mathrm{PE}$ analysis of the water pathway. Of the radionuclides that would arrive before $10,000 \mathrm{y}, 5$ for the trench design and 4 for the tumulus design had no limit on waste concentration.

Because FEMP has many radionuclides that either are limited by the intrusion scenarios, arrive at the performance boundary after $10,000 \mathrm{y}$, or have no limit on waste concentration, this site may have flexibility in accepting a variety of radionuclides for disposal.

- The shallow depth to groundwater tends to make the tumulus design appear more favorable for disposal of MLLW, although current and planned disposal activities at Fernald have used trench-based disposal. The generic trench would be excavated into the aquifer beneath Fernald. 
- Fernald has physical constraints that could limit disposal activities. There is limited space available at Fernald for an MLLW disposal facility. The Fernald plant lies above the Great Miami Aquifer, an EPA-designated sole source aquifer.

- At Fernald, there is no significant difference in the permissible waste concentrations computed with the PE methodology for the trench as compared to the tumulus. That is, there is less than one order of magnitude difference in the waste limits between the two disposal facility designs. The notable exceptions are $\mathrm{H}-3$ and Se-79, which are limited by the water pathway for the trench and by intrusion for the tumulus, and U-232 which is limited by the water pathway for both designs.

- The sensitivity analysis for FEMP indicates that reasonable changes in values for the recharge, groundwater Darcy velocity, and facility for most radionuclides would not significantly change the results. The exception is the limiting pathway for $\mathrm{C}-14$, which is sensitive to the selection of the groundwater Darcy velocity.

In flow and transport problems, the $K_{d}$ values are often the most uncertain site-specific input parameters. The $K_{d}$ value for the indicator radionuclide Pu-239 for the geologic media at FEMP could have sufficient uncertainty to change the limiting pathway from intruder to water.

- The PE was a scoping analysis performed using assumptions that are conservative relative to most LLW performance assessments. A more detailed performance assessment would be required for permitting or other serious disposal planning.

\subsection{REFERENCES}

Baer, T.A., L. L. Price, J. N. Emery, N. E. Olague, 1994. Second Performance Assessment Iteration of the Greater Confinement Disposal Facility at the Nevada Test Site. SAND93-0089. Albuquerque, NM: Sandia National Laboratories.

Cooper, C.D., and F.C. Alley, 1986. Air Pollution Control: A Design Approach. Prospect Heights, IL: Waveland Press, Inc.

CRC, 1981. CRC Handbook of Chemistry and Physics. Eds. Robert C. Weast and Melvin J. Astle. Boca Raton, FL: CRC Press, Inc.

EPA, 1992. User's Guide for the Industrial Source Complex (ISC2) Dispersion Models, Volume I: User Instructions. EPA Publication No. EPA-450/4-92-008a. Research Triangle, NC: U.S. Environmental Protection Agency.

FFCAct, 1992. Federal Facility Compliance Act of 1992. P.L. 102-386, October 1992. 
Gruebel, M.M., R.D. Waters, M.B. Hospelhorn, and M.S.Y. Chu, eds., 1994. Framework for the DOE Low-Level and Mixed Low-Level Waste Disposal: Site Fact Sheets. SAND94-2728. Albuquerque, NM: Sandia National Laboratories.

Kincaid, C.T., J.W. Shade, G.A. Whyatt, M.G. Piepho, K. Rhoads, J.A. Voogd, J.H. Westsik, Jr., M.D. Freshley, K.A. Blanchard, and B.G. Lauzon, eds., 1993. Performance Assessment of Grouted Double-Shell Tank Waste Disposal at Hanford. WHC-SD-WM-EE-004, Rev. 0. . U.S. Department of Energy, Pacific Northwest Laboratory and Westinghouse Hanford Company.

Maheras, Steven J., Arthur S. Rood, Swen O. Magnuson, Mary E. Sussman, and Rajiv N. Bhatt, 1994. Radioactive Waste Management Complex Low-Level Waste Radiological Performance Assessment. EGG-WM-8773. Idaho Falls, ID: U.S. Department of Energy Office of Environmental Restoration and Waste Management, DOE Idaho Operations Office.

MMES (Martin Marietta Energy Systems), EG\&G Idaho, Inc., and Westinghouse Savannah River Company, 1994. Radiological Performance Assessment for the E-Area Vaults Disposal Facility (U). WSRC-RP-94-218, Rev. 0. Aiken, SC: Westinghouse Savannah River Company.

ORNL (Oak Ridge National Laboratory), 1994. Performance Assessment for Continuing and Future Operations at Solid Waste Storage Area 6. ORNL-6783. Oak Ridge, TN: U.S. Department of Energy, Oak Ridge National Laboratory.

Smith, B.J., 1995. Personal communication in telephone conversation with John Tauxe (ORNL) on May 1, 1995.

Thibault, D.H., M.I. Sheppard, and P.A. Smith, 1990. A Critical Compilation and Review of Default Soil Solid/Liquid Partition Coefficients, Kd, for Use in Environmental Assessments. AECL-10125. Pinawa, Manitoba, Canada: Whiteshell Nuclear Research Establishment, Atomic Energy of Canada Limited.

U.S. DOE, 1995. Feasibility Study Report for Operable Unit 5. Fernald, OH: U.S. DOE, Fernald Office.

\section{Acknowledgments}

The ORNL Core Team acknowledges the contributions of Nancy Weatherup, Greg Jones, Brett Smith, and J.D. Chiou of FERMCO. 


\section{Ohio: PORTSMOUTH GASEOUS DIFFUSION PLANT (PORTS) Core Team Contact: Gregory P. Zimmerman}

The Federal Facility Compliance Act (FFCAct, 1992) requires the Department of Energy (DOE) to establish plans in conjunction with its regulators and with members of the public for the treatment of DOE's mixed low-level waste (MLLW). Although the FFCAct did not specifically address disposal of treated MLLW, both DOE and the States recognized that disposal issues were an integral part of treatment discussions. Since 1992, DOE has worked with the States to define and develop an evaluation process for disposal options. Preliminary activities of this joint DOEState process have narrowed the sites for further evaluation from 49 to 15.

The Disposal Workgroup (DWG), which was established by DOE to develop a process for evaluating disposal options, designed a performance evaluation (PE) to quantify and compare the limitations of the remaining 15 DOE sites for MLLW disposal. The principal goal of the PE was to estimate, for grouted residuals resulting from the treatment of MLLW, permissible concentrations of radionuclides in waste for disposal at each site. These "permissible waste concentrations" were based solely on long-term physical performance of the disposal facility and did not take into account any operational waste acceptance criteria that a site might have developed. The PE did not address any ethical, social, or policy considerations relevant to siting such facilities.

The PE used analyses that are consistent with the approach used in many low-level waste (LLW) performance assessments. The objective was to use a set of modeling assumptions of sufficient detail to capture major site-specific characteristics and yet be general enough for consistent application at all sites. Additionally, the analyses were designed to ensure that the sites were analyzed consistently and that all major assumptions were clearly stated.

The remainder of this chapter provides the PE results for Portsmouth Gaseous Diffusion Plant, one of the 15 sites being evaluated. The chapter contains the following information:

Section 12.1: brief, general description of the site based on previous work done by the DWG (Gruebel et al., 1994)

Section 12.2: plans for MLLW disposal, if any, and the location evaluated in the PE

Section 12.3: current understanding of radionuclide movement at the selected location based on available information, and the conceptual model used for the evaluation of each of three pathways (water, atmospheric, and inadvertent intruder)

Section 12.4: site-specific and generic values used in the PE calculations and their sources

Section 12.5: estimates of maximum waste concentrations determined in the PE calculations for each of the three pathways, along with calculated values used in determining these results 
Section 12.6: summary of results based on disposal-facility design; discussion with respect to such issues as uncertainty and sensitivity

Section 12.7 observations based on the results of the PE and the parameter sensitivity analysis

Section 12.8: references

The general assumptions and methodology used in the PE are summarized in Chapter 1 of this volume and explained in more detail in Volume 2 of this report. Overall results for all the sites are discussed in Chapter 7 of Volume 2.

\subsection{GENERAL DESCRIPTION OF THE SITE}

The Portsmouth Gaseous Diffusion Plant (PORTS) is located in sparsely populated, rural Pike County, Ohio near the southern end of the Scioto River basin. The plant is about $1.6 \mathrm{~km}$ $(1 \mathrm{mi})$ east of the Scioto River valley and $32 \mathrm{~km}(20 \mathrm{mi})$ north of Portsmouth, Ohio where the Scioto River joins the Ohio River (Figures 12-1 and 12-2). PORTS occupies a $16-\mathrm{km}^{2}\left(6.3-\mathrm{mi}^{2}\right)$ upland area in the valley of the preglacial Portsmouth River which is bounded on the east and west by ridges of low-lying hills that have been deeply dissected by present and past drainage features (Law Engineering, 1978). The plant nominal elevation is $204 \mathrm{~m}$ (670 ft) above the mean sea level, $40 \mathrm{~m}(130 \mathrm{ft})$ above the normal stage of the Scioto River, and 27-40 m (90-130 ft) above the mile-wide Scioto River floodplain (USGS, 1979).

The nearest population center is the village of Piketon (population 1,700), $5 \mathrm{~km}$ ( $3 \mathrm{mi}$ ) north of PORTS (Figure 12-2). Waverly (population 4,500) is the largest community in Pike County and is located $13 \mathrm{~km}(8 \mathrm{mi})$ to the north. The nearest cities are Portsmouth (population $23,000), 32 \mathrm{~km}(20 \mathrm{mi})$ to the south, and Chillicothe (population 22,000), $32 \mathrm{~km}(20 \mathrm{mi})$ to the north. Within $10 \mathrm{~km}(6 \mathrm{mi})$ of the site, the population is estimated to be 2,500 . The total population within a $50-\mathrm{km}(31-\mathrm{mi})$ radius is approximately 231,000 .

PORTS was completed in 1954 (ERDA, 1977) to operate in conjunction with the Oak Ridge Gaseous Diffusion Plant in Tennessee and the Paducah Gaseous Diffusion Plant in Kentucky. The Oak Ridge plant is no longer in operation. The Energy Act of 1992 established the U.S. Enrichment Corporation (USEC) and gave it the responsibility of operating the Paducah and Portsmouth plants. The mission of the USEC at PORTS is the separation of uranium isotopes using a gaseous diffusion process, producing enriched uranium for nuclear fuel. The DOE mission at PORTS is to conduct investigations for identification and remediation of environmental contamination stemming from prior operations. The PORTS site is owned by DOE. Most of the facilities located within the perimeter road are leased to the USEC. 


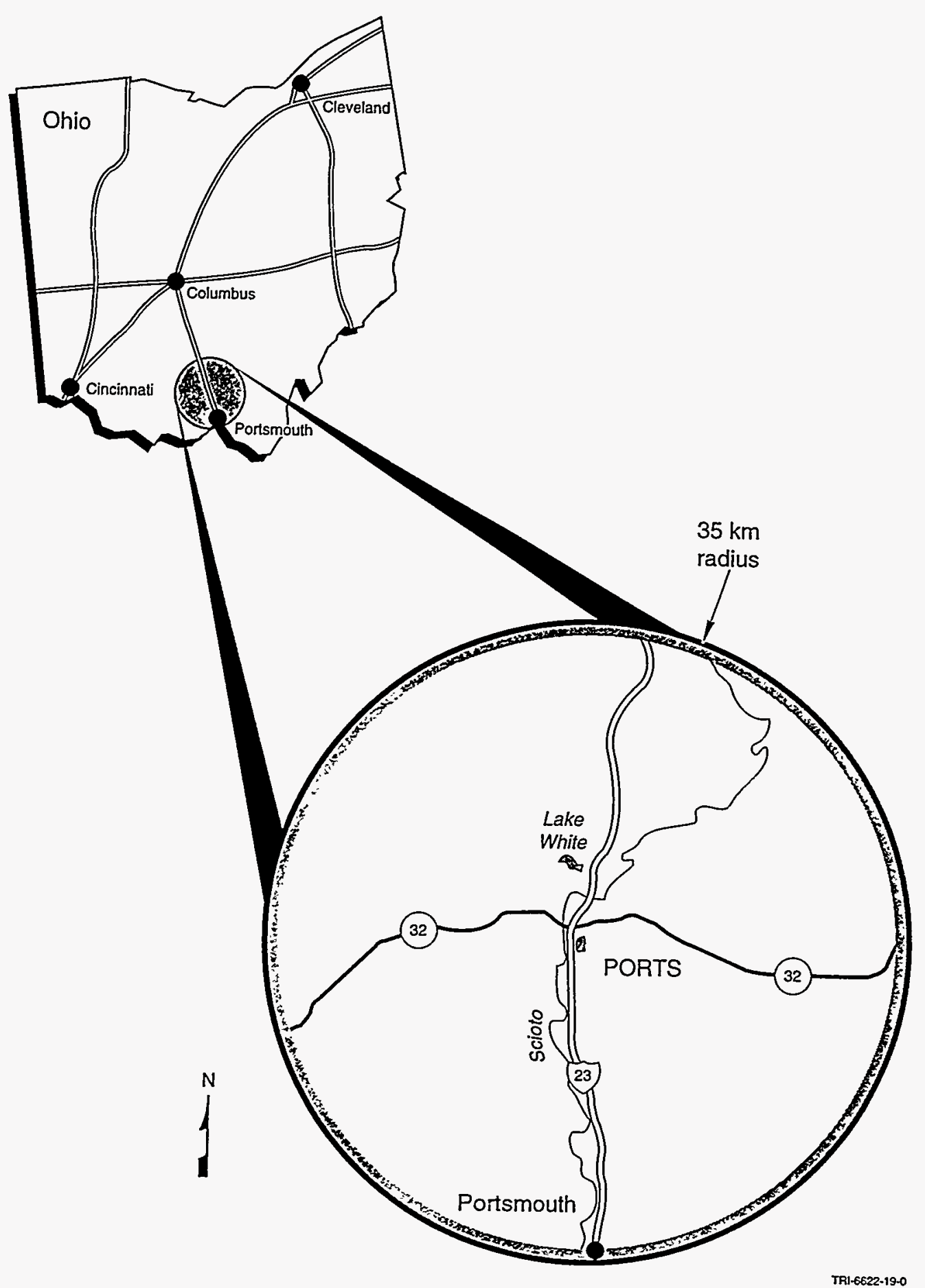

Figure 12-1. Location map for the Portsmouth Gaseous Diffusion Plant. 


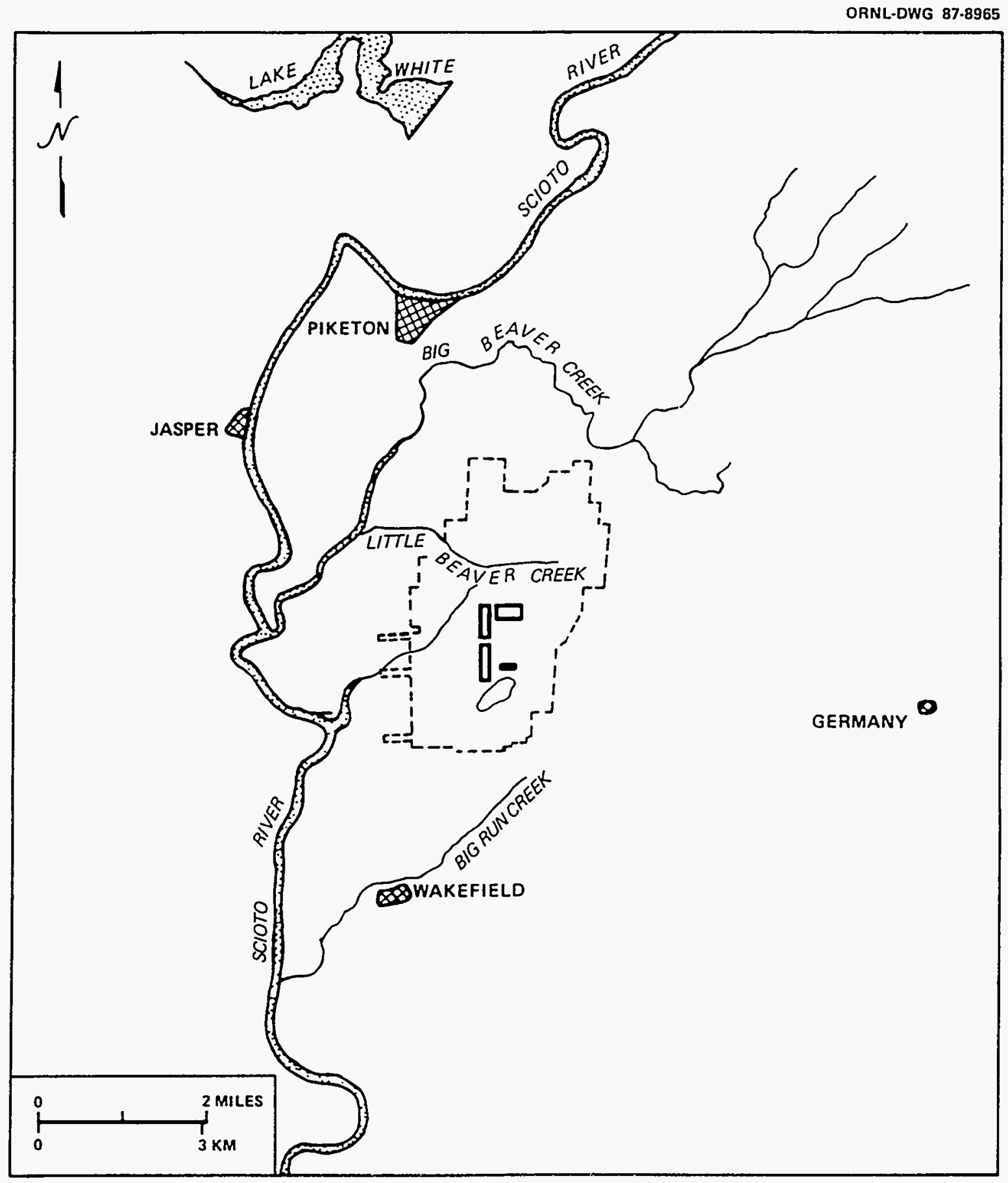

Figure 12-2. Site map for the Portsmouth Gaseous Diffusion Plant. 
Located west of the Appalachian Mountains, the region has a climate essentially continental in nature, characterized by moderate extremes temperature and humidity. According to records at Waverly from 1951 to 1980 (Ruffner, 1985), July is the hottest month with an average monthly temperature of $23^{\circ} \mathrm{C}\left(74^{\circ} \mathrm{F}\right)$, and January is the coldest month with an average temperature of $-1.1^{\circ} \mathrm{C}\left(30^{\circ} \mathrm{F}\right)$. Most of moisture in the area is supplied by air moving northward from the Gulf of Mexico. Precipitation is most abundant from March through August, and least in October and February. The average annual precipitation in the area is $103 \mathrm{~cm}(40.4 \mathrm{in}$.) (Ruffner, 1985). Snowfall is common from November through March with an annual average of $57 \mathrm{~cm}$ (22 in.). The predominant winds at PORTS blow from the south or southwest. The average wind speed is about $8 \mathrm{~km} / \mathrm{hr}(5 \mathrm{mph})$.

Both groundwater and surface water at PORTS are drained from the plant site by a network of tributaries of the Scioto River. Little Beaver Creek, the largest stream on the plant property, flows in a northwesterly direction just north of the main plant area (Figure 12-2) (Kornegay et al., 1991). It drains the northern and northeastern portions of the main plant site before discharging into Big Beaver Creek. About $3 \mathrm{~km} \mathrm{(2} \mathrm{mi)} \mathrm{from} \mathrm{the} \mathrm{confluence} \mathrm{of} \mathrm{Little} \mathrm{and}$ Big Beaver creeks, Big Beaver Creek empties into the Scioto River. Upstream from the plant, Little Beaver Creek has intermittent flow throughout the year.

In the southeast portion of the site, the southerly flowing stream (Big Run Creek, Figure 12-2) is situated in a relatively broad, gently sloping valley where significant deposits of recent alluvium have been laid down by the stream (Rogers et al., 1989). This intermittent stream receives overflow from the south holding pond $(\mathrm{X}-230 \mathrm{~K})$, which collects discharge of storm sewers on the south end of the plant site. Big Run Creek empties into the Scioto River about 8 $\mathrm{km}(5 \mathrm{mi})$ downstream from the mouth of Big Beaver Creek.

Two unnamed intermittent streams drain the western portion of the plant site. The stream in the southwest portion of the site flows to the south and west in a narrow, steep-walled valley with relatively little recent alluvium. It drains the southwest corner of the facility via the southwest holding pond. The stream near the west-central portion of the plant site flows to the northwest. It receives runoff from the central and western portions of the site via the west drainage ditch. Both of the unnamed streams flow directly to the Scioto River and carry only stormwater runoff (Rogers et al., 1989).

Water in the vicinity of PORTS is available from Lake White, the Scioto River, and groundwater (ERDA, 1977). The majority of the water used is taken from groundwater, although none of the groundwater sources at PORTS are classified as sole-source aquifers. Water used at PORTS also comes from groundwater (Saylor et al., 1990) and is supplied by wells completed in the Scioto River alluvium. These wells are located just east of the Scioto River and northwest of Piketon (Martin Marietta, 1991). 


\subsection{STATUS AND SITING OF MLLW DISPOSAL FACILITY}

At the time of the PE, personnel at the PORTS had no plans for MLLW disposal. This PE project required the identification of a suitable location for a future MLLW disposal facility at PORTS. Three primary areas were identified by the site technical staff as possible sites for such facilities: the north, east, and south sites, as shown in Figure 12-3. The south site was chosen for the PE calculation because it would provide the greatest amount of protection to the underlying aquifer. This site would, therefore, provide the largest permissible radionuclide concentrations in waste from among the three sites.

Two generic disposal facilities were considered in the PE: a RCRA-compliant, belowground trench and a RCRA-compliant, above-ground tumulus (described in more detail in Chapter 5 of Volume 2). The generic facilities were selected to provide consistency in analysis of the performance of the 15 sites. Both generic facilities were assumed to be square with a plan area of $2500 \mathrm{~m}^{2}\left(26,910 \mathrm{ft}^{2}\right)$.

\subsection{BASIS FOR CONCEPTUAL MODEL USED IN THE PE}

The current understanding of radionuclide transport from a disposal facility at PORTS is based on various environmental studies (ERDA, 1977; Law Engineering, 1978; and Saylor et al., 1990). Subsurface and groundwater data were taken from previous groundwater investigations (Geraghty \& Miller, 1989; Geraghty \& Miller, 1994; and Law Engineering, 1982). The descriptions below summarize how this information was incorporated into the PE's conceptual model for PORTS.

\subsubsection{Water Pathway}

Knowledge of groundwater flow and radionuclide movement in the water pathway at Portsmouth provided the basis for the conceptual model considered in the PE. The conceptual model encompasses the site technical staff's current understanding of site-specific geology, hydrology, water table and aquifer characteristics, and transport pathways.

\subsubsection{Current Understanding of Relevant Hydrogeology}

As shown in Figure 12-4, PORTS is located in the mile-wide preglacial Portsmouth River valley. Geologic units controlling groundwater flow beneath the PORTS site are, in descending order, the Minford and Gallia unconsolidated units (top layer in the Portsmouth River valley), Sunbury Shale, Berea Sandstone, and Bedford Shale. These units are underlain by the Ohio Shale and Greenfield Dolomite. The Cuyahoga shale, the youngest bedrock unit near the site, forms the hills east and west of the main plant site (Figure 12-4). 


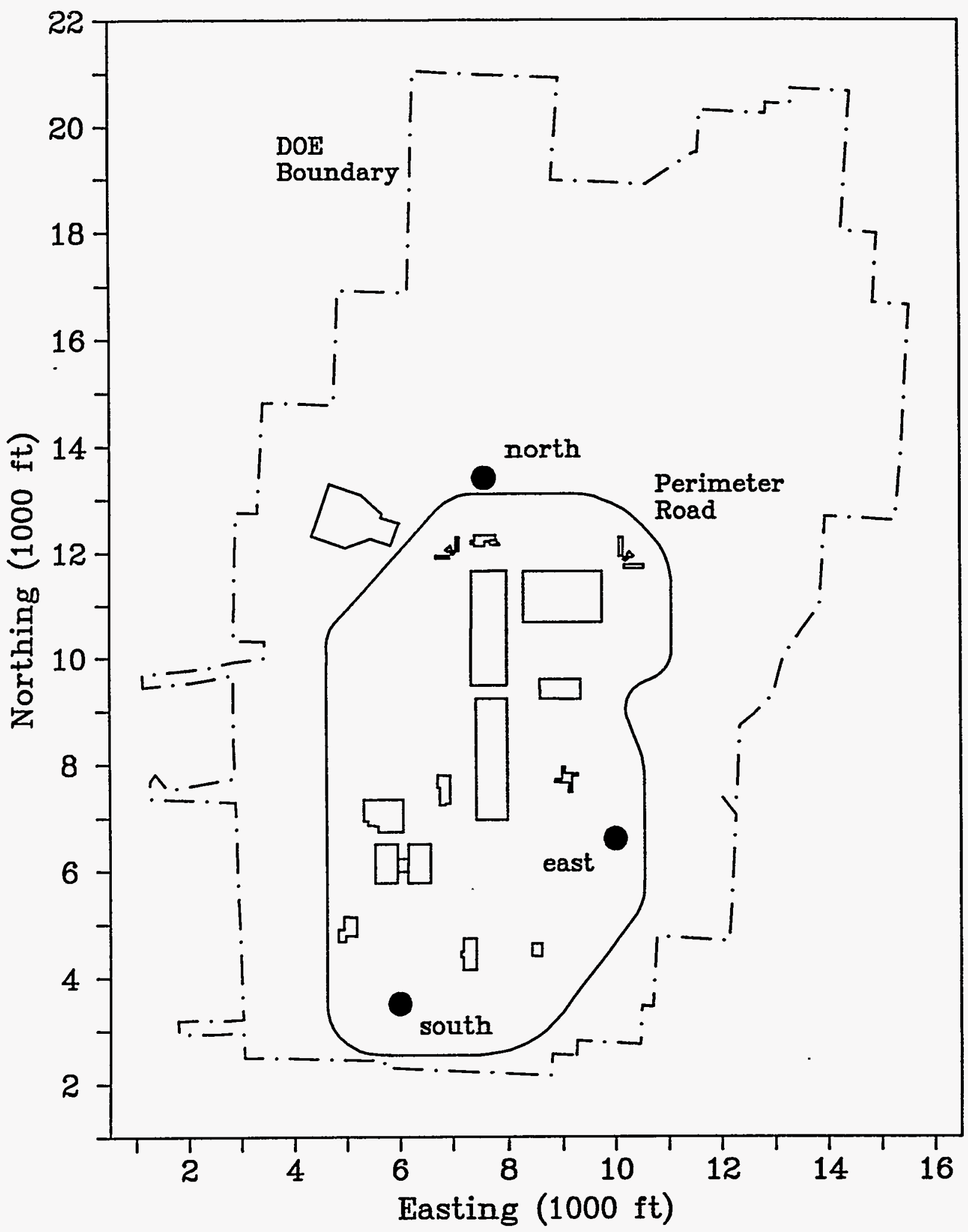

Figure 12-3. Possible MLLW disposal sites (north, east, and south) identified by the site technical staff. 
言

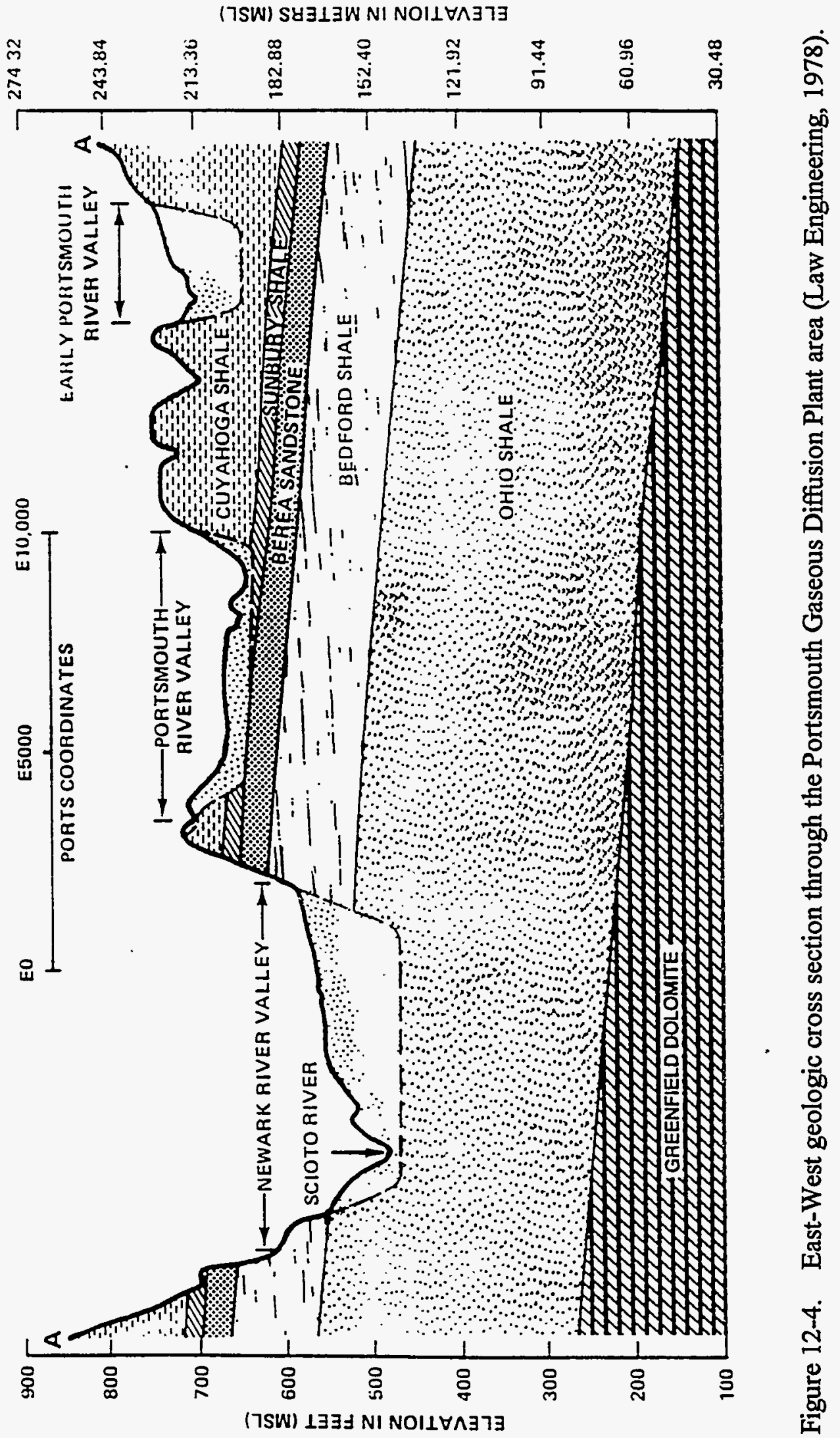


The Minford member averages $23.9 \mathrm{ft}$ in thickness at the PORTS site grading from predominantly silt at the base to clay and silty clay near the surface. Also present in some places is up to $20 \mathrm{ft}$ of artificial fill which is predominantly Minford silt and clay. Underlying the Minford is the Gallia which is composed of silty to clayey sand and gravel. The Gallia has an average thickness of $1 \mathrm{~m}(3.4 \mathrm{ft})$, but is not laterally continuous beneath PORTS. The Gallia sand and Minford silt form the uppermost, unconfined aquifer with a thickness of about $3.4 \mathrm{~m}(11 \mathrm{ft})$ (Geraghty \& Miller, 1989; Kornegay et al., 1994). Beneath the plant, the bottom of this aquifer has an elevation ranging from 192 to $195 \mathrm{~m}(630$ to $640 \mathrm{ft})$.

The Sunbury Shale underlies the Cuyahoga on the surrounding hilltops and the Gallia in the center of the abandoned Portsmouth River valley (Figure 12-4). The Sunbury ranges in thickness from 0 to $6.1 \mathrm{~m}(0$ to $20 \mathrm{ft})$ with an average of about $3 \mathrm{~m}(10 \mathrm{ft})$ over much of the site. The Berea Sandstone, which is about $9 \mathrm{~m}(30 \mathrm{ft})$ thick and exhibits little spatial variation in conductivity, is a confined aquifer separated from the Gallia and Minford aquifer by the Sunbury Shale. Where the Sunbury is absent or thin, the Gallia and Berea aquifers act essentially as one unit. About $30 \mathrm{~m}(100 \mathrm{ft})$ of Bedford Shale with a much lower hydraulic conductivity underlies the Berea.

\subsubsection{Conceptual Model Used in the PE}

The PE used a generic conceptual model to describe the water pathway (summarized in Section 1.1.2 of this volume and described in detail in Chapter 5 of Volume 2). In the unsaturated zone, leachate was generated by constant flow of water through the disposal facility at a rate that was controlled by the assumed performance of the disposal facility. When all engineered barriers had failed, the rate was assumed to be equal to the natural recharge through local soils. The volumetric flow of water through the facility that generated leachate was based on the assumed performance and size of the disposal facility. No dilution was assumed to occur in the unsaturated zone, so at steady state, the concentration that reached groundwater equaled the leachate concentration. No lateral spreading was assumed, so the leachate flux through the unsaturated zone was confined to the soil column directly below the plan area of the facility.

As contaminated water entered the saturated zone, the contaminant mixed with clean groundwater, forming a plume with a shape controlled by aquifer and contaminant properties. The generic conceptual model assumed that instantaneous and complete mixing within the aquifer occurred directly below the facility. Mixing in the vertical direction occurred by hydrodynamic dispersion, and the contaminant mixing depth was an estimated value.

The generic conceptual model was adapted to conditions at PORTS based on site-specific knowledge of the geology and water flow paths. The conceptual model for the water pathway at the south side at PORTS is illustrated in Figure 12-5. The conceptual model assumes that the unsaturated zone is a unit of local surficial soils with a thickness of $5 \mathrm{~m}(16.4 \mathrm{ft})$, and the saturated zone is a $2.5-\mathrm{m}(8.2-\mathrm{ft})$ thick unit with material properties approximating those of the Minford and Gallia unconsolidated units. This transmissive saturated zone is underlain by the 
Sunbury Shale, which acts as a lower impermeable layer. The generic trench would be excavated into the shale and is assumed to leak leachate directly into the saturated zone. Therefore, the unsaturated zone is given a zero thickness for the trench simulation. The groundwater near the south site is transported downgradient to the southwest (Geraghty \& Miller, 1994).

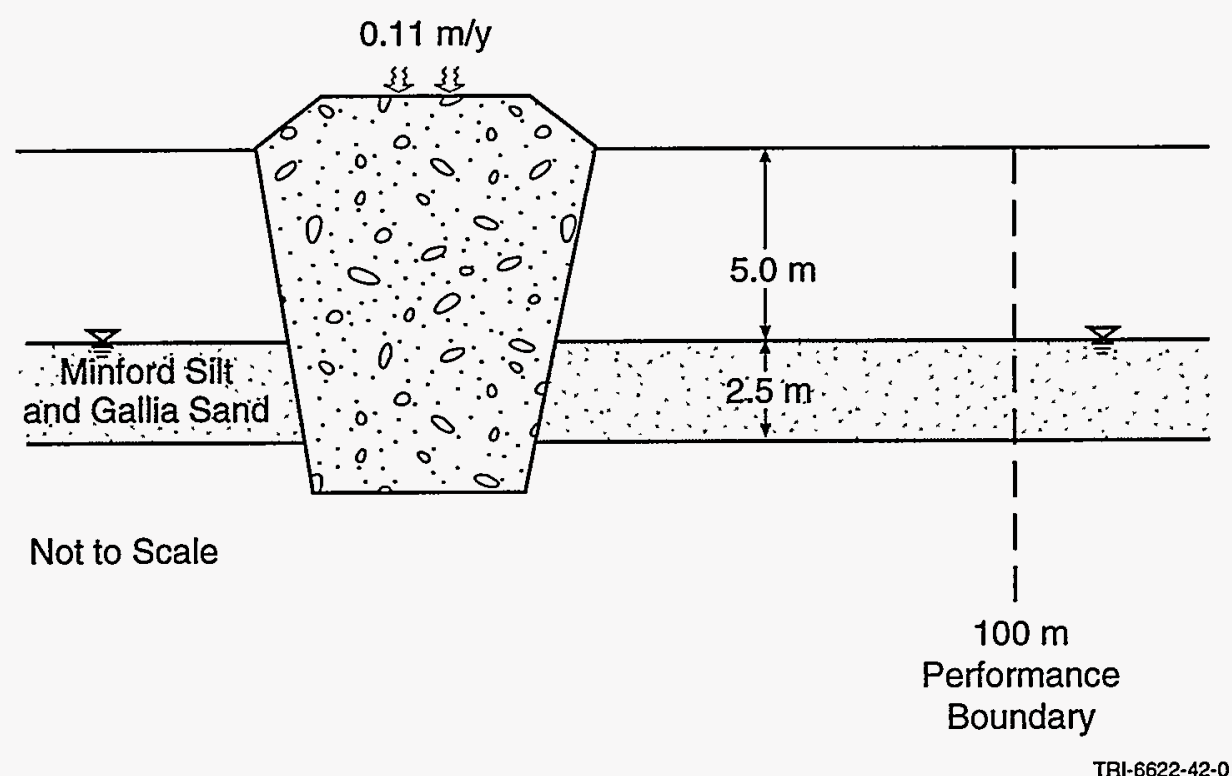

Figure 12-5. Conceptual model for groundwater transport at the Portsmouth Gaseous Diffusion Plant.

\subsubsection{Atmospheric Pathway}

The conceptual model used in the PE for evaluating the atmospheric pathway was derived from performance assessments for LLW disposal facilities at Hanford (Kincaid et al., 1993), INEL (Maheras et al., 1994), NTS (Baer et al., 1994), ORR (ORNL, 1994), and SRS (MMES et al., 1994). The model was generalized for the PE but used site-specific values for many of the parameters. Meteorological data are based on STAR data files summarized by the windrose in Figure 12-6. These data were obtained from hourly average meteorological readings taken at a height of $40 \mathrm{~m}(131 \mathrm{ft})$ at the on-site meteorological tower at Portsmouth during 1993. 


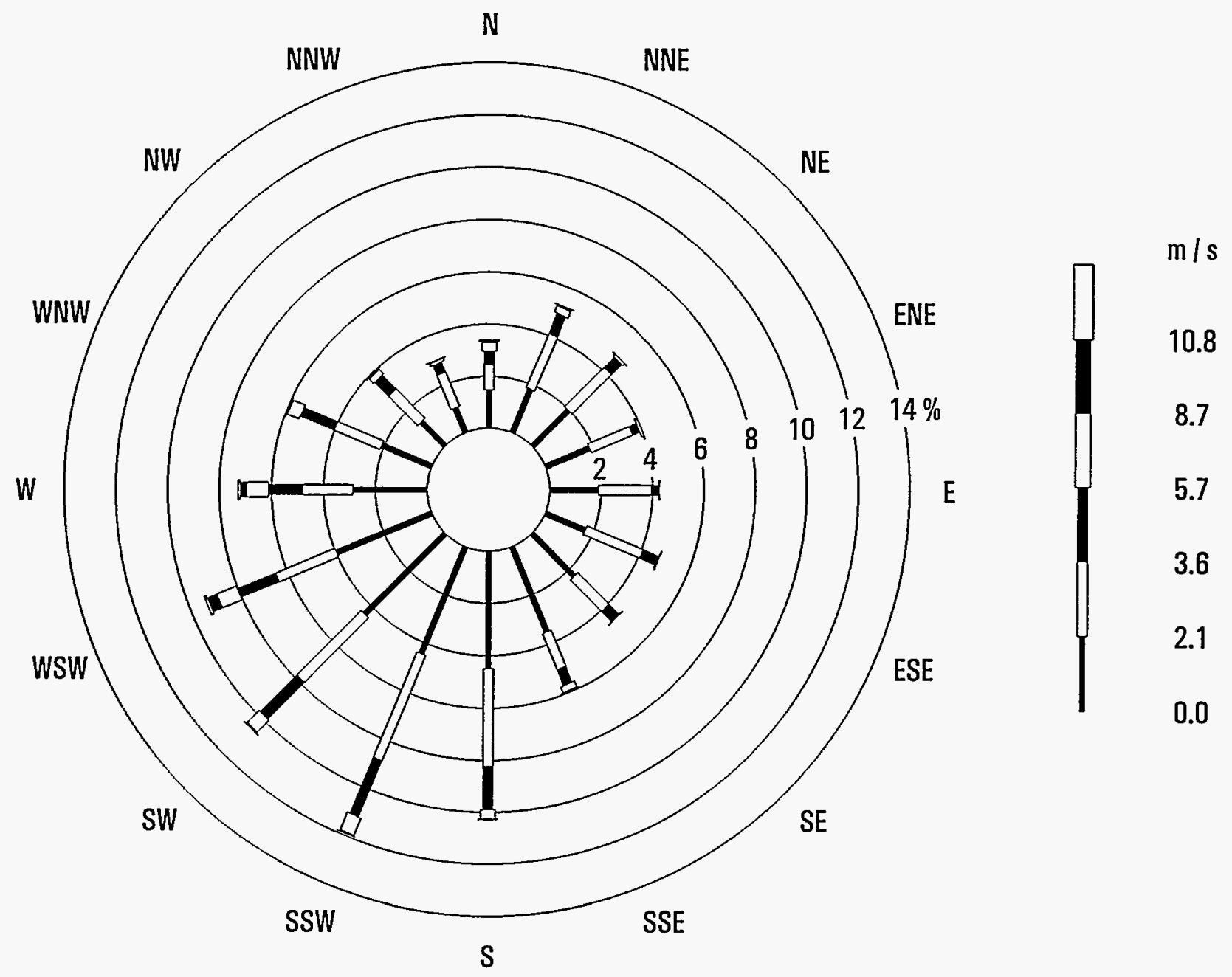

Figure 12-6. Windrose for Portsmouth for 1993. The frequency of winds from each direction is plotted as a series of connected bars that extend from the center of the circular diagram toward the direction from which the winds originate. Wind speed categories are denoted by bar widths and shadings. The frequency of winds in each wind speed category is indicated by the length of the corresponding bar. 
The PE used a generic conceptual model to describe the atmospheric pathway (summarized in Section 1.2 of this volume and described in detail in Chapter 5 of Volume 2). Only H-3 (tritium) and C-14 were expected to be volatile for the disposal facility conditions and thus were the only radionuclides considered for atmospheric transport in the PE. In the model, radionuclides were transported from the disposal facility to the soil surface by vapor (tritium) and gaseous (carbon dioxide carrying the $\mathrm{C}-14$ isotope) diffusion. When the radionuclides reached the soil surface, they were entrained in the air in vapor form as volatiles. Once airborne, these radionuclides were transported via atmospheric dispersion to a receptor located at the performance boundary.

Two components of the atmospheric pathway were evaluated separately: (1) the zone from the top of the disposal facility to the soil surface as indicated by the upward radionuclide diffusion profile; and (2) the zone in which a radionuclide was emitted to the atmosphere, mixed with the ambient air, and dispersed downwind from the waste disposal facility boundary to the $100-\mathrm{m}(328-\mathrm{ft})$ performance boundary.

The arrival time of radionuclides at the performance boundary was assumed to be $100 \mathrm{y}$ based on the following generic assumptions of the PE:

- The waste form was grouted MLLW treatment residuals. Based on this assumption, tritium as vapor was bound in the pore water of the hydrophilic grout, and carbon dioxide as a gas carrying the $\mathrm{C}-14$ isotope was limited by the high $\mathrm{pH}$ of the grout, so that the waste form provided retention of these volatile radionuclides in the disposal facility.

- The disposal facility was capped by a RCRA-compliant cover system. Based on this assumption, the cover system was maintained to provide low permeability for $100 \mathrm{y}$.

\subsubsection{Inadvertent Intruder Pathways}

Standard intrusion scenarios were used in the PE, with information derived from performance assessments of LLW disposal facilities at SRS (MMES et al., 1994) and ORR (ORNL, 1994) indicating that only two chronic-exposure scenarios needed to be considered for most sites and facility designs. Any variations in these scenarios were based on discussions with site technical staff about such factors as the types of activities that reasonably could result in exposure to buried waste at the site and the effectiveness of active or passive institutional controls and engineered barriers in precluding access to the waste.

The PE used two standard intrusion scenarios that could be modified for site-specific conditions to describe potential modes of inadvertent intrusion (summarized in Section 1.3 of this volume and described in detail in Chapter 5 of Volume 2). The first scenario, the agriculture (homesteader) scenario, included establishment by an intruder of a permanent homestead directly above a disposal facility with the foundation of the home extending into the waste; some of the waste exhumed from the disposal facility was mixed with native soil in the intruder's vegetable garden. The second scenario, the post-drilling scenario, considered the construction of a well for a domestic water supply by an intruder. The well was drilled through the disposal facility, and the cuttings were mixed with soil in the intruder's vegetable garden. The intruder gardened in some 
of the exhumed waste but did not reside permanently above the disposal facility. In both scenarios, exposure occurred where an intruder dug or drilled into the disposal facility.

For the generic intruder scenarios, the time of intrusion for the homesteader scenario was assumed to be $300 \mathrm{y}$ for the trench design and $500 \mathrm{y}$ for the tumulus design. The time of intrusion for the post-drilling scenario was assumed to be $100 \mathrm{y}$.

The two intrusion scenarios were discussed with PORTS personnel, who concurred with the applicability and credibility of these scenarios at PORTS.

\subsection{DATA USED IN THE PE}

The data presented in this section apply to the PE conceptual models described in Section 12.3. The calculations for determining permissible waste concentrations for the radionuclides considered in the $\mathrm{PE}$ are discussed in more detail in Chapter 5 of Volume 2 and summarized in Chapter 1 of this volume. The results of the calculations for Portsmouth are presented in Section 12.5 and discussed in Section 12.6 of this volume.

\subsubsection{Water Transport}

Site-specific values required to perform the water pathway analysis were selected by site technical staff either from site characterizations and reports, from site-specific modeling results, or from general literature. For the unsaturated zone, the site-specific data that were required for the $\mathrm{PE}$ were distance between the disposal facility and groundwater; ambient moisture content; dry bulk density of the geologic medium; distribution coefficients $\left(K_{d} s\right)$ of the radionuclides in the geologic medium; and natural recharge. For the saturated zone, the site-specific data that were required were porosity of the geologic medium; dry bulk density of the geologic medium; distribution coefficients $\left(K_{d} s\right)$ of the radionuclides in the geologic medium; groundwater Darcy flow rates; and mixing depth in the aquifer.

These values for Portsmouth are listed in Table 12-1 along with generic values that were used in the PE. Also indicated in the table is a designation of the type of data that the value represents and the source of the value. The values were determined from one or more of four data sources: (A) measurement performed by the site, state, or federal agency; (B) result of a numerical analysis performed by the site, state, or federal agency; (C) general literature value selected by the site; and (D) generic value of the PE.

Of the parameters in the PE that depended on site-specific values, only three potentially encompassed enough variability in values to significantly affect the results: natural recharge, $i$; distribution coefficients $\left(K_{d} s\right)$ for the geologic media; and groundwater Darcy velocity $\left(q_{g w}\right)$. The sources of these values are discussed in this section. The sensitivity of the results to changes in the values of these parameters is discussed in Section 12.6.2 of this volume and Chapter 6 of Volume 2.

The base case values for natural recharge and groundwater velocity at PORTS were provided by site staff (Campbell, 1995). No estimate for the range of values was given. 
Table 12-1. Parameters and Values Used in the PE for the Water Pathway at Portsmouth (generic PE values are in bold; these values and the standard PE method for applying them are summarized in Chapter 1 of this volume and discussed in more detail in Chapter 5 of Volume 2) (Part 1 of 2)

\begin{tabular}{|c|c|c|c|}
\hline Parameter & Value & $\begin{array}{c}\text { Data } \\
\text { Type* }\end{array}$ & Comments \\
\hline \multicolumn{4}{|l|}{ SOURCE TERM } \\
\hline $\begin{array}{l}\text { Volumetric water content } \\
\text { of the grouted waste, } \theta_{G}\end{array}$ & 0.3 & D & Standard PE value \\
\hline $\begin{array}{l}\text { Bulk density of grouted } \\
\text { waste, } \rho_{\theta}\end{array}$ & $1.76 \mathrm{~g} / \mathrm{cm}^{3}$ & D & Standard PE value \\
\hline $\begin{array}{l}\text { Distribution coefficients } \\
\text { for grouted waste, } K_{d}^{G}\end{array}$ & various & D & $\begin{array}{l}\text { Standard PE value; see Table 12-2 in } \\
\text { this chapter }\end{array}$ \\
\hline $\begin{array}{l}\text { Disposal facility plan area, } \\
\text { A }\end{array}$ & $2500 \mathrm{~m}^{2}$ & D & $\begin{array}{l}\text { Standard } P E \text { value; } A=a_{1} * a_{2} \text {, where } \\
a_{1}=a_{2}=50 \mathrm{~m}\end{array}$ \\
\hline $\begin{array}{l}\text { Waste mixing fraction for } \\
\text { trench, } f_{m}\end{array}$ & 0.67 & D & Standard $P E$ value \\
\hline $\begin{array}{l}\text { Waste mixing fraction for } \\
\text { tumulus, } f_{m}\end{array}$ & 0.33 & D & Standard PE value \\
\hline $\begin{array}{l}\text { Annual rate of water } \\
\text { flowing through intact } \\
\text { trench facility, } q_{f}\end{array}$ & $0.03 \mathrm{~m} / \mathrm{y}$ & D & Standard PE value \\
\hline $\begin{array}{l}\text { Annual rate of water } \\
\text { flowing through intact } \\
\text { tumulus facility, } q_{f}\end{array}$ & $\begin{array}{c}0.00003 \\
\mathrm{~m} / \mathrm{y}\end{array}$ & D & Standard PE value \\
\hline $\begin{array}{l}\text { Time to failure of leachate } \\
\text { collection system }\end{array}$ & $30 y$ & D & Standard $P E$ value \\
\hline $\begin{array}{l}\text { Time to failure of trench } \\
\text { facility }\end{array}$ & $100 \mathrm{y}$ & D & Standard $P E$ value \\
\hline $\begin{array}{l}\text { Time to failure of tumulus } \\
\text { facility }\end{array}$ & $300 \mathrm{y}$ & D & Standard $P E$ value \\
\hline $\begin{array}{l}\text { Natural recharge through local } \\
\text { soils, } i\end{array}$ & $0.11 \mathrm{~m} / \mathrm{y}$ & A & Campbell, 1995 \\
\hline
\end{tabular}

* $A=$ site measurement; $B=$ result of site numerical analysis; $C=$ literature value selected by the site; $D=$ generic $P E$ value 
Table 12-1. Parameters and Values Used in the PE for the Water Pathway at Portsmouth (generic PE values are in bold; these values and the standard PE method for applying them are summarized in Chapter 1 of this volume and discussed in more detail in Chapter 5 of Volume 2) (Part 2 of 2)

\begin{tabular}{|c|c|c|c|}
\hline Parameter & Value & $\begin{array}{l}\text { Data } \\
\text { Type }^{\star}\end{array}$ & Comments \\
\hline \multicolumn{4}{|l|}{ UNSATURATED ZONE } \\
\hline Moisture content, $\theta_{w}$ & 0.22 & A & Law Engineering (1982) \\
\hline Bulk density, $\rho_{b}$ & $1.7 \mathrm{~g} / \mathrm{cm}^{3}$ & $A$ & Campbell (1995) \\
\hline $\begin{array}{l}\text { Distribution coefficients for } \\
\text { geologic media, } K_{d}\end{array}$ & various & C & See Table $12-2$ in this chapter \\
\hline $\begin{array}{l}\text { Thickness between trench and } \\
\text { saturated zone, } l\end{array}$ & $0 \mathrm{~m}$ & A & $\begin{array}{l}\text { Cumulative unsaturated sediment thickness } \\
\text { is } 5 \mathrm{~m} \text { (Geraghty \& Miller, 1989); bottom of } \\
\text { generic trench facility is } 8.8 \mathrm{~m} \text { below ground } \\
\text { surface }\end{array}$ \\
\hline $\begin{array}{l}\text { Thickness between tumulus } \\
\text { and saturated zone, } l\end{array}$ & $5 \mathrm{~m}$ & $A$ & $\begin{array}{l}\text { Cumulative unsaturated sediment thickness } \\
\text { is } 5 \mathrm{~m} \text { (Geraghty \& Miller, 1989); tumulus } \\
\text { facility bottom is at ground surface }\end{array}$ \\
\hline \multicolumn{4}{|l|}{ SATURATED ZONE } \\
\hline Porosity, $n$ & 0.35 & A & Campbell (1995) \\
\hline Bulk density, $\rho_{b}$ & $1.5 \mathrm{~g} / \mathrm{cm}^{3}$ & $A$ & Campbell (1995) \\
\hline $\begin{array}{l}\text { Distribution coefficients for } \\
\text { geologic media, } K_{d}\end{array}$ & various & C & See Table $12-2$ in this chapter \\
\hline Mixing depth, $d_{m}$ & $2.5 \mathrm{~m}$ & C & (Geraghty \& Miller, 1989); \\
\hline Darcy velocity, $q_{G W}$ & $7.7 \mathrm{~m} / \mathrm{y}$ & c & Campbell (1995) \\
\hline $\begin{array}{l}\text { Distance to performance } \\
\text { boundary from facility } \\
\text { boundary }\end{array}$ & $100 \mathrm{~m}$ & $\mathbf{D}$ & Standard PE value \\
\hline
\end{tabular}

- $A=$ site measurement; $B=$ result of site numerical analysis; $C=$ literature value selected by the site; $D=g$ eneric $P E$ value 
Table 12-2. Solid/Liquid Distribution Coefficients $\left(K_{d} s\right)$ Used in the PE at PORTS

\begin{tabular}{|c|c|c|}
\hline Element & $\begin{array}{c}\text { Waste } K_{d}^{G} \\
(\mathrm{~mL} / \mathrm{g})^{a}\end{array}$ & $\begin{array}{c}K_{d} \text { for Geologic Media } \\
(\mathrm{mUg})^{\mathrm{b}}\end{array}$ \\
\hline $\mathrm{H}$ & 0 & 0.1 \\
\hline C & 10 & 5 \\
\hline $\mathrm{Al}$ & 100 & 35 \\
\hline$S i$ & 100 & 35 \\
\hline $\mathrm{Cl}$ & 0 & 15 \\
\hline$k$ & 1 & 15 \\
\hline$C_{0}$ & 100 & 60 \\
\hline $\mathrm{Ni}$ & 10 & 400 \\
\hline $\mathrm{Se}$ & 1 & 150 \\
\hline$S r$ & 100 & 15 \\
\hline $\mathrm{Zr}$ & 10 & 600 \\
\hline $\mathrm{Nb}$ & 10 & 160 \\
\hline TC & 1 & 0.1 \\
\hline$P d$ & 100 & 55 \\
\hline $\mathrm{Ag}$ & 100 & 90 \\
\hline $\mathrm{Cd}$ & 100 & 80 \\
\hline $\mathrm{sn}$ & 10 & 130 \\
\hline 1 & 1 & 1 \\
\hline Cs & 10 & 280 \\
\hline $\mathrm{Ba}$ & 10 & 15 \\
\hline $\mathrm{Sm}$ & 10 & 245 \\
\hline $\mathrm{Eu}$ & 10 & 245 \\
\hline $\mathrm{Pb}$ & 100 & 270 \\
\hline $\mathrm{Ra}$ & 10 & 500 \\
\hline Th & 100 & 3200 \\
\hline $\mathrm{Pa}$ & 100 & 550 \\
\hline$U$ & 100 & 35 \\
\hline $\mathrm{Np}$ & 100 & 5 \\
\hline $\mathrm{Pu}$ & 100 & 550 \\
\hline $\mathrm{Am}$ & 100 & 1900 \\
\hline $\mathrm{Cm}$ & 100 & 4000 \\
\hline $\mathrm{Cf}$ & 100 & 4000 \\
\hline
\end{tabular}

a Standard PE values; see Chapter 5 of Volume 2

b Values based on Thibault et al., 1990 
Values for distribution coefficients $\left(K_{d} s\right)$ are listed in Table 12-2 for the 58 radionuclides (32 elements) considered in the PE. In addition to the $K_{d}$ values for the geologic media, grout $K_{d}$ values are listed for determining the desorption from the source term resulting from the grouted waste form. The $K_{d}$ values for the subsurface flow pathway (both for the unsaturated and saturated zones) are taken from the standard PE values for sandy soils (Thibault et al., 1990).

\subsubsection{Atmospheric Transport}

Site-specific data required to perform the atmospheric pathway analysis came from site personnel as data either from site characterizations and reports or from general literature. The site-specific data required for the soil diffusion calculation were the same as some of those required for the water transport analysis (Section 12.4.1). These values are shown in Table 12-3. Necessary atmospheric dispersion data included wind speed and direction and stability class, which are summarized in Section 12.3.2.

Table 12-3. Parameters and Values Used in the PE for the Atmospheric Pathway at Portsmouth (generic PE values are in bold; these values and the standard PE method for applying them are summarized in Chapter 1 of this volume and discussed in more detail in Chapter 5 of Volume 2)

\begin{tabular}{|c|c|c|c|}
\hline Parameter & Value & $\begin{array}{l}\text { Data } \\
\text { Type* }\end{array}$ & Comments \\
\hline $\begin{array}{l}\text { Disposal facility cover } \\
\text { thickness, } x\end{array}$ & $1.0 \mathrm{~m}$ & D & Standard PE value \\
\hline $\begin{array}{l}\text { Depth of the soil } \\
\text { surface, } d\end{array}$ & $0.01 \mathrm{~m}$ & $\mathbf{D}$ & $\begin{array}{l}\text { Standard PE value based on Maheras } \\
\text { et al. (1994) }\end{array}$ \\
\hline Porosity, $n$ & 0.4 & $\mathrm{C}$ & $\begin{array}{l}\text { Facsimile communication from Jim Campbell } \\
\text { (PORTS) to Jim Wang (ORNL), April 30, } \\
\text { 1995; personal communication between Jim } \\
\text { Campbell and Jim Wang, May 2, } 1995 .\end{array}$ \\
\hline Percent saturation, $s$ & 0.55 & $\mathrm{C}$ & Law Engineering (1982) \\
\hline $\begin{array}{l}\text { Ratio of water density } \\
\text { in air to liquid, } r\end{array}$ & 9.2E-06 & D & $\begin{array}{l}\text { Standard PE value based on MMES et } \\
\text { al. (1994) }\end{array}$ \\
\hline $\begin{array}{l}\text { Ratio of } \mathrm{CO}_{2} \\
\text { concentration in air to } \\
\text { dissolved in water, } r\end{array}$ & 4.3E-04 & $\bar{D}$ & $\begin{array}{l}\text { Standard PE value based on Foust et } \\
\text { al. (as cited in Cooper and Alley, 1986) }\end{array}$ \\
\hline $\begin{array}{l}\text { Tritium diffusion } \\
\text { coefficient in air, } D\end{array}$ & $\begin{array}{c}2.39 E-05 \\
\mathrm{~m}^{2} / \mathrm{s}\end{array}$ & $\mathbf{D}$ & $\begin{array}{l}\text { Standard PE value based on CRC } \\
\text { (1981) }\end{array}$ \\
\hline $\begin{array}{l}\text { Carbon diffusion } \\
\text { Coefficient in air, } D\end{array}$ & $1.4 \mathrm{E}-05 \mathrm{~m}^{2} / \mathrm{s}$ & D & $\begin{array}{l}\text { Standard PE value based on CRC } \\
\text { (1981) }\end{array}$ \\
\hline $\begin{array}{l}\text { Atmospheric dispersion } \\
\text { term, } A_{D}\end{array}$ & $\begin{array}{c}2.37 E+05 \\
\left(\mu \mathrm{Ci} / \mathrm{m}^{3}\right) /\left(\mu \mathrm{Ci} / \mathrm{m}^{2}-s\right)\end{array}$ & $B$ & $\begin{array}{l}\text { Value is estimated using the Industrial } \\
\text { Source Complex-Version } 2 \text { Long Term Air } \\
\text { Dispersion Model (ISCLT2) (EPA, 1992) } \\
\text { based on site-specific STAR data }\end{array}$ \\
\hline
\end{tabular}

- $A=$ site measurement; $B=$ result of site numerical analysis; $C=1$ iterature value selected by the site; $D=g e n e r i c ~ P E$ value 


\subsubsection{Inadvertent Intruder Exposure}

As explained in Section 12.3.3, the PE used two standard intrusion scenarios to describe potential modes of inadvertent intrusion at all the sites. Because these intrusion scenarios were considered applicable to all sites, no values specific to Portsmouth are used in the calculation of exposures to inadvertent intruders.

\subsection{RESULTS OF THE PE}

The performance evaluation provided estimates of permissible concentrations in disposed MLLW. The three calculations that formed the foundation of the PE - for the water, atmospheric, and inadvertent intruder pathways are summarized in Sections 1.1, 1.2, and 1.3, respectively, of this volume and discussed in detail in Chapter 5 of Volume 2.

For each pathway the maximum permissible waste concentration at the performance boundary was determined for each radionuclide by using the performance measures: 4 mrem $(0.04 \mathrm{mSv})$ per year from the water pathway for releases to drinking water; 10 mrem $(0.1 \mathrm{mSv})$ per year from all pathways for atmospheric releases; and 100 mrem $(1 \mathrm{mSv})$ per year from all exposure pathways for chronic exposure of inadvertent intruders; and the appropriate pathway or scenario dose conversion factors (annual effective dose equivalent per unit concentration) based on EPA dose conversion factors. The basis for the performance measures used in the PE is discussed in more detail in Chapter 5 of Volume 2. For the water and atmospheric pathways, the concentration reduction provided by the environment (i.e., the CRF) was estimated using results of site analyses and data. For the intruder analyses, concentration reduction was estimated for appropriate exposure pathways for two intrusion scenarios that, in general, were the same for all the sites. The results of the calculations for the pathways that were analyzed at Portsmouth are provided in this section and discussed in Section 12.6.

\subsubsection{Water Transport}

Two CRFs were calculated for the water pathway: the source CRF, $C R F_{\text {Source, }}$ and the environmental transport $\mathrm{CRF}$ for water, $C R F_{\text {Water. }}$. The source $\mathrm{CRF}$ represents the concentration attenuation between the disposed waste and leachate exiting the bottom of the disposal facility and was defined as the dimensionless ratio of the waste concentration to the resulting leachate concentration. Desorption with infiltrating water was the mechanism used to describe the leaching of radionuclides from the grout. Because a generic method was used to determine the $C R F_{\text {Source }}$ for the 58 radionuclides considered in the PE (summarized in Section 1.1 of this volume and discussed in more detail in Chapter 5 of Volume 2), the radionuclide-specific values for the source CRF for each type of generic facility were the same for all 15 sites.

The environmental transport $\mathrm{CRF}$ for water was defined as the ratio of the concentration of the leachate exiting the disposal facility to the resulting concentration in water at the performance boundary. The concentration attenuation represented by $C R F_{\text {Water }}$ consisted of dilution due to mixing with uncontaminated groundwater. Effects of radioactive decay and decay product ingrowth were also included in the PE. 
In the PE, water travel time from the facility location to the performance boundary was calculated as a basis for comparison with the retarded travel time of the radionuclides. For Portsmouth, water travel time from the land surface to the performance boundary (i.e., without consideration of a disposal facility) was estimated at about $15 \mathrm{y}$.

The calculation of travel time through the vadose zone for a radionuclide, on the other hand, must account both for the lower infiltration rate because of the facility's RCRA cover and for the retardation defined by the distribution coefficient for the geologic media. In the PE, the calculation for travel time in the vadose zone first determined the distance a radionuclide traveled at the lower infiltration rate. Then, if the radionuclide had not fully traversed the vadose zone, the additional time required to complete travel in the vadose zone under the higher, infiltration rate based on the natural recharge through local soils was calculated and added to the time determined at the lower infiltration rate.

In the $\mathrm{PE}$, the detention time in the facility for a radionuclide was the time during which water flowing through the facility was assumed to be caught by the leachate collection system. Specifically, the calculation of travel time for a radionuclide accounted for the following:

- For the trench design, the leachate collection system was assumed to catch water flowing through the facility for the first $30 \mathrm{y}$. After $30 \mathrm{y}$, the liner and leachate collection system failed, and water flowing through the facility for the next $70 \mathrm{y}$ was assumed to be $0.03 \mathrm{~m} / \mathrm{y}$ $(0.1 \mathrm{ft} / \mathrm{y})$ based on a unit hydraulic gradient and the saturated hydraulic conductivity of the RCRA cover system. After a total of $100 \mathrm{y}$ of reduced flow because of engineered barriers ( $30 \mathrm{y}$ of detention plus $70 \mathrm{y}$ limited by the RCRA cover system), the flow rate was assumed to be the average recharge through local soils, $0.11 \mathrm{~m} / \mathrm{y}(0.36 \mathrm{ft} / \mathrm{y})$.

- For the tumulus design, the leachate collection system was assumed to catch water flowing through the facility for the first $30 \mathrm{y}$. After $30 \mathrm{y}$, the liner and leachate collection system was assumed to fail, and water flowing through the facility for the next $270 \mathrm{y}$ was assumed to be $0.00003 \mathrm{~m} / \mathrm{y}(0.0001 \mathrm{ft} / \mathrm{y})$ based on a unit hydraulic gradient and the saturated hydraulic conductivity of the concrete vaults. After a total of $300 \mathrm{y}$ of reduced flow because of engineered barriers ( $30 \mathrm{y}$ detention plus $270 \mathrm{y}$ limited by the concrete vaults), the flow rate was assumed to be the average recharge through local soils, $0.11 \mathrm{~m} / \mathrm{y}$ $(0.36 \mathrm{ft} / \mathrm{y})$.

Travel time through the aquifer was independent of facility design and was about $4.5 \mathrm{y}$, based on groundwater Darcy velocity and a 100-m (328-ft) distance to the performance boundary (see Section 1.1.2 of this volume for a summary of these assumptions and Chapter 5 of Volume 2 for additional details). The arrival time of a radionuclide at the performance boundary is the sum of the detention time in the facility, travel time through the vadose zone, and travel time through the aquifer.

Retardation of radionuclides by interaction with soils and rock in the vadose and saturated zones increased travel times for individual radionuclides. This effect was particularly important for short-lived radionuclides because of radioactive decay. For short-lived radionuclides, the 
effects of radioactive decay combined with long travel times increased the permissible concentrations in the disposal facility.

Application of the PE methodology for water transport of the 58 radionuclides considered in the PE produced the results shown in Table 12-4 for the generic trench and tumulus designs at Portsmouth. The table shows permissible waste concentrations based on transport through the water pathway $\left(C_{\text {W-Water }}\right)$ as well as the values used in calculating the permissible waste concentrations.

Some radionuclides listed in Table 12-4 have no limit (NL) on their permissible waste concentrations, the result of the combined effects of relatively short half-lives and sufficiently long travel time to the performance boundary. "No limit" is defined as a permissible waste concentration that is greater than the specific activity of the pure elemental radionuclide. For disposal of the maximum possible waste concentration of these relatively short-lived radionuclides, the water pathway produced a dose at the performance boundary of less than $4 \mathrm{mrem}(0.04 \mathrm{mSv})$ per year and, therefore, the permissible waste concentration was unlimited based on exposures from this pathway.

For some radionuclides, no value is listed in Table 12-4 for the radioactive decay term, $r_{\text {Decay. }}$ These radionuclides had radioactive decay terms that were very large (e.g., greater than $\left.1 \times 10^{50}\right)$. Any radionuclide with a radioactive decay term greater than $1 \times 10^{50}$ was ensured a calculated permissible waste concentration greater than the specific activity of the pure elemental radionuclide, which, as described previously, resulted in no limit (NL) on permissible waste concentrations for disposal.

Arrival times for some radionuclides listed in Table 12-4 were beyond the 10,000-y performance period. For those radionuclides, the estimated waste concentrations are presented in Tables 12-4 for information purposes only. Consistent with the approach used in LLW performance assessments, these values were not considered in determining the most restrictive disposal limit from among the evaluated pathways.

For all radionuclides in Table 12-4, the flow rate at the time of tumulus failure controlled the subsurface transport (i.e., the subsurface movement of the radionuclides for the tumulus was controlled by flow at $300 \mathrm{y}$ [when the concrete vaults failed]). However, for the trench, another phenomenon was observed. Because of the proximity of the bottom of the trench to the aquifer and the lack of any definable vadose zone, the permissible waste concentrations of several radionuclides were controlled by the release from the trench at $30 \mathrm{y}$ (i.e., the time of failure of the leachate collection system). At this time the rate was low and was controlled by the still-functioning cover on the trench. The radionuclides controlled by this mechanism for the trench include $\mathrm{H}-3$, Co-60, Sr-90, Nb-93m, Cd-113m, Cs-137, Ba-133, Eu-152, Eu-154, Pb-210, $\mathrm{Ra}-228, \mathrm{Pu}-241, \mathrm{Cm}-243, \mathrm{Cm}-244$, and $\mathrm{Cf}-250$. All of these radionuclides have relatively short half-lives and yield higher doses under early release from the trench than for times of later release when significant radioactive decay has occurred. Otherwise, the subsurface movement of the other 43 radionuclides in the trench and all radionuclides in the tumulus was controlled by flow at $300 \mathrm{y}$ for the tumulus and at $100 \mathrm{y}$ after closure for the trench. 
Table 12-4. Results of Calculations for the Water Pathway at Portsmouth (water travel time from land surface to performance boundary [excluding facility detention] $=15 \mathrm{y}$ ) (Part 1 of 2)

\begin{tabular}{|c|c|c|c|c|c|c|c|c|c|c|c|c|}
\hline \multirow[t]{2}{*}{ Nuclide } & \multirow[b]{2}{*}{$\begin{array}{c}\text { PDCF } \\
\text { rem/y per } \mu \mathrm{cu} /\end{array}$} & \multicolumn{5}{|c|}{ Trench } & \multicolumn{5}{|c|}{ Tumulus } & \multirow[t]{2}{*}{ Nuclide } \\
\hline & & $\begin{array}{l}\text { CRF } \\
\text { (dimensionless) }\end{array}$ & \begin{tabular}{|c|} 
CRF Water \\
(dimensionless)
\end{tabular} & \begin{tabular}{|c|} 
Arrival \\
Time (y) \\
\end{tabular} & $\underset{\text { (dimonsionioss) }}{r_{\text {Decay }}{ }^{a}}$ & $\begin{array}{c}C_{\text {w-water }}^{b} \\
\left(\mu \mathrm{Ci} / \mathrm{m}^{3}\right)\end{array}$ & \begin{tabular}{l|} 
CRF \\
(dimensioniess)
\end{tabular} & $\begin{array}{c}\text { CRF }_{\text {water }} \\
\text { (dimensionless) }\end{array}$ & \begin{tabular}{|c|} 
Arrival \\
Time $(y)$ \\
\end{tabular} & romcay $_{\text {(dimensionloss) }}$ & $\begin{array}{c}C_{w \cdot W a t e r}{ }^{b} \\
\left(\mu \mathrm{Ci} / \mathrm{m}^{3}\right)\end{array}$ & \\
\hline $\mathrm{H}-3$ & 4.67E-02 & 0.45 & 13.8 & $3.6 \mathrm{E}+01$ & $7.8 E+\infty$ & $4 E+03$ & 0.9 & 4.5 & $3.2 E+02$ & $8.2 E+07$ & $3 E+10$ & $\mathrm{H}-3$ \\
\hline$C-14$ & $1.52 E+\infty$ & 27 & 4.5 & $2.0 E+02$ & $1.0 E+\infty 0$ & $3 E+02$ & 54 & 4.5 & $8.0 E+02$ & $1.1 E+00$ & $7 E+02$ & $c-14$ \\
\hline Al-26 & $1.06 \mathrm{E}+01$ & 270 & 4.5 & $7.9 E+02$ & $1.0 \mathrm{E}+\infty 0$ & $4 E+02$ & 540 & 4.5 & $3.7 \mathrm{E}+03$ & $1.0 \mathrm{E}+\infty 0$ & $9 E+02$ & Al-26 \\
\hline Si-32 & $7.99 \mathrm{E}+00$ & 270 & 4.5 & $7.9 E+02$ & $2.3 E+02$ & $1 E+05$ & 540 & 4.5 & $3.7 \mathrm{E}+03$ & $1.4 \mathrm{E}+11$ & $2 E+14$ & Si-32 \\
\hline $\mathrm{Cl}-36$ & $2.21 E+\infty 0$ & 0.45 & 4.5 & $4.0 E+02$ & $1.0 \mathrm{E}+00$ & $4 E+00$ & 0.9 & 4.5 & $1.8 \mathrm{E}+03$ & $1.0 E+00$ & $7 E+00$ & $\mathrm{Cl}-36$ \\
\hline$K-40$ & $1.36 E+01$ & 3.1 & 4.5 & $4.0 E+02$ & $1.0 \mathrm{E}+00$ & $4 E+00$ & 6.2 & 4.5 & $1.8 \mathrm{E}+03$ & $1.0 E+00$ & $8 E+00$ & $K-40$ \\
\hline Co-60 & $1.97 E+01$ & 270 & 13.8 & $1.2 E+03$ & e & $\mathrm{NL}$ & 540 & 4.5 & $6.1 E+03$ & e & $N L$ & Co-60 \\
\hline Ni-59 & $1.53 E-01$ & 27 & 4.5 & $7.9 E+03$ & $1.1 E+00$ & $3 E+03$ & 54 & 4.5 & $3.9 \mathrm{E}+04$ & $1.4 E+00$ & $9 E+03$ & Ni-59 \\
\hline Ni-63 & $4.21 E-01$ & 27 & 4.5 & $7.9 E+03$ & $5.6 \mathrm{E}+23$ & $\mathrm{NL}$ & 54 & 4.5 & $3.9 \mathrm{E}+04$ & e & $\mathrm{NL}$ & Ni-63 \\
\hline Se-79 & $6.35 E+00$ & 3.1 & 4.5 & $3.0 E+03$ & $1.0 \mathrm{E}+00$ & $9 E+00$ & 6.2 & 4.5 & $1.5 E+04$ & $1.2 E+\infty 0$ & $2 E+01$ & Se-79 \\
\hline Sr-90 & $1.12 E+02$ & 270 & 13.8 & $3.3 E+02$ & $2.4 E+03$ & $3 E+05$ & 540 & 4.5 & $1.8 E+03$ & $1.8 E+18$ & $\mathrm{NL}$ & $5 r-90$ \\
\hline $8 r-93$ & $1.59 E+00$ & 27 & 4.5 & $1.2 \mathrm{E}+04$ & $1.0 E+00$ & $3 E+02$ & 54 & 4.5 & $5.8 E+04$ & $1.0 E+\infty$ & $6 E+02$ & $\mathrm{Zr}-93$ \\
\hline Nb-93m & $3.81 E-01$ & 27 & 13.8 & $3.2 E+03$ & e & $\mathrm{NL}$ & 54 & 4.5 & $1.6 E+04$ & e & NL & $\mathrm{Nb}-93 \mathrm{~m}$ \\
\hline $\mathrm{Nb}-94$ & $5.21 E+00$ & 27 & 4.5 & $3.2 E+03$ & $1.1 E+00$ & $1 E+02$ & 54 & 4.5 & $1.6 E+04$ & $1.7 E+\infty 0$ & $3 E+02$ & $\mathrm{Nb}-94$ \\
\hline Tc-99 & $1.07 E+00$ & 3.1 & 4.5 & $1.1 E+02$ & $1.0 \mathrm{E}+00$ & $5 E+01$ & 6.2 & 4.5 & $3.2 E+02$ & $1.0 \mathrm{E}+00$ & $1 E+02$ & TC-99 \\
\hline Pd-107 & $1.09 E-01$ & 270 & 4.5 & $1.2 \mathrm{E}+03$ & $1.0 \mathrm{E}+00$ & $4 E+04$ & 540 & 4.5 & $5.6 \mathrm{E}+03$ & $1.0 \mathrm{E}+\infty 0$ & $9 \mathrm{E}+04$ & Pd-107 \\
\hline $\mathrm{Ag}-108 \mathrm{~m}$ & $5.56 E+\infty 0$ & 270 & 4.5 & $1.9 E+03$ & $2.0 E+04$ & $2 E+07$ & 540 & 4.5 & $9.0 \mathrm{E}+03$ & $7.8 \mathrm{E}+20$ & $\mathrm{NL}$ & $\mathrm{Ag}-108 \mathrm{~m}$ \\
\hline Cd-113m & $1.17 E+02$ & 270 & 13.8 & $1.6 E+03$ & $1.0 \mathrm{E}+34$ & $\mathrm{NL}$ & 540 & 4.5 & $8.1 E+03$ & e & $\mathrm{NL}$ & $C d-113 m$ \\
\hline Sn-121m & $1.28 \mathrm{E}+00$ & 27 & 4.5 & $2.6 E+03$ & $2.7 E+14$ & NL & 54 & 4.5 & $1.3 \mathrm{E}+04$ & e & $\mathrm{NL}$ & $S n-121 m$ \\
\hline $5 n-126$ & $1.53 E+01$ & 27 & 4.5 & $2.6 E+03$ & $1.0 \mathrm{E}+00$ & $3 E+01$ & 54 & 4.5 & $1.3 E+04$ & $1.1 E+00$ & $7 E+01$ & $5 n-126$ \\
\hline $1-129$ & $2.01 E+02$ & 3.1 & 4.5 & $1.2 E+02$ & $1.0 \mathrm{E}+00$ & $3 E-01$ & 6.2 & 4.5 & $4.1 E+02$ & $1.0 E+00$ & $6 \mathrm{E}-01$ & $1-129$ \\
\hline Cs-135 & $5.16 E+\infty 0$ & 27 & 4.5 & $5.6 E+03$ & $1.0 E+00$ & $9 E+01$ & 54 & 4.5 & $2.7 E+04$ & $1.0 E+00$ & $2 E+02$ & Cs-135 \\
\hline Cs-137 & $3.65 E+01$ & 27 & 13.8 & $5.5 E+03$ & $e$ & $\mathrm{NL}$ & 54 & 4.5 & $2.7 E+04$ & $\mathrm{e}$ & $\mathrm{NL}$ & Cs-137 \\
\hline$B a-133$ & $2.48 E+\infty 0$ & 27 & 13.8 & $3.3 E+02$ & $2.3 E+09$ & $1 \mathrm{E}+12$ & 54 & 4.5 & $1.8 E+03$ & $e$ & $\mathrm{NL}$ & $B a-133$ \\
\hline $5 m-151$ & $2.84 E-01$ & 27 & 4.5 & $4.9 E+03$ & $2.1 E+16$ & $\mathrm{NL}$ & 54 & 4.5 & $2.4 E+04$ & e & $N L$ & sm-151 \\
\hline Eu-152 & $4.73 E+00$ & 27 & 13.8 & $4.8 E+03$ & e & $\mathrm{NL}$ & 54 & 4.5 & $2.4 \mathrm{E}+04$ & $e$ & NL & Eu-152 \\
\hline Eu-154 & $6.97 E+00$ & 27 & 13.8 & $4.8 \mathrm{E}+03$ & e & $\mathrm{NL}$ & 54 & 4.5 & $2.4 E+04$ & e & NL & Eu-154 \\
\hline Pb-210 & $5.30 \mathrm{E}+03$ & 270 & 13.8 & $5.3 E+03$ & e & $\mathrm{NL}$ & 540 & 4.5 & $2.6 E+04$ & e & $\mathrm{NL}$ & $\mathrm{Pb}-210$ \\
\hline Ra-226 & $6.27 E+03$ & 27 & 4.5 & $9.8 \mathrm{E}+03$ & $7.1 E+01$ & $5 E+\infty 0$ & 54 & 4.5 & $4.9 \mathrm{E}+04$ & $1.4 \mathrm{E}+09$ & $2 E+08$ & Ra-226 \\
\hline Ra-228 & $1.64 E+03$ & 27 & 13.8 & $9.8 \mathrm{E}+03$ & e & $\mathrm{NL}$ & 54 & 4.5 & $4.9 E+04$ & e & $\mathrm{NL}$ & Ra-228 \\
\hline Th-229 & $2.94 E+03$ & 270 & 4.5 & $6.2 E+04$ & $3.8 \mathrm{E}+02$ & $6 \mathrm{E}+02$ & 540 & 4.5 & $3.1 E+05$ & $6.0 E+12$ & $N L$ & Th-229 \\
\hline Th-230 & $6.12 E+03$ & 270 & 4.5 & $6.2 E+04$ & NA & $8 \mathrm{E}-01$ & 540 & 4.5 & $3.1 E+05$ & NA & $2 E+\infty$ & Th-230 \\
\hline Th-232 & $3.63 E+03$ & 270 & 4.5 & $6.2 E+04$ & $1.0 E+00$ & $1 E+\infty 0$ & 540 & 4.5 & $3.1 \mathrm{E}+05$ & $1.0 E+\infty 0$ & $3 E+\infty$ & Th-232 \\
\hline Pa-231 & $1.85 E+04$ & 270 & 4.5 & $1.1 \mathrm{E}+04$ & $1.3 E+00$ & 3E-01 & 540 & 4.5 & $5.4 E+04$ & $3.1 \mathrm{E}+\infty$ & $2 E+\infty 0$ & Pa-231 \\
\hline
\end{tabular}


$\sim$ Table 12-4. Results of Calculations for the Water Pathway at Portsmouth (water travel time from land surface to performance N boundary [excluding facility detention] $=15 \mathrm{y})($ Part 2 of 2$)$

\begin{tabular}{|c|c|c|c|c|c|c|c|c|c|c|c|c|}
\hline \multirow[t]{2}{*}{ Nuclide } & \multirow[b]{2}{*}{$\begin{array}{c}\text { PDCF } \\
\text { rem/y per } \mu \mathrm{Cl} / \mathrm{L}\end{array}$} & \multicolumn{5}{|c|}{ Trench } & \multicolumn{5}{|c|}{ Tumulus } & \multirow[t]{2}{*}{ Nuclide } \\
\hline & & $\begin{array}{l}\text { CRF }_{\text {Source }} \\
\text { (dimensionless) }\end{array}$ & $\begin{array}{c}\text { CRF Water } \\
\text { (dimensionless) }\end{array}$ & $\begin{array}{l}\text { Arrival } \\
\text { Time (y) }\end{array}$ & $\boldsymbol{r}_{\text {Dacay }}{ }_{\text {(dimensionloss) }}$ & $\begin{array}{c}C_{w-w a t e r}{ }^{b} \\
\left(\mu \mathrm{Ci} / \mathrm{m}^{3}\right)\end{array}$ & $\begin{array}{l}\text { CRF Source } \\
\text { (dimensionless) }\end{array}$ & $\begin{array}{l}C_{\text {(dimensionloss) }} \\
\text { (diter }\end{array}$ & \begin{tabular}{|l|} 
Arrival \\
Time $(y)$ \\
\end{tabular} & r Decay $_{\text {(dimensioniess) }}$ & $\begin{array}{c}C_{\text {w-water }}{ }^{b} \\
\left(\mu \mathrm{Ci} / \mathrm{m}^{3}\right)\end{array}$ & \\
\hline $\mathrm{U}-232$ & 1.55E+03 & 270 & 4.5 & $7.9 \mathrm{E}+02$ & $2.4 E+03$ & $7 E+03$ & 540 & 4.5 & $3.7 E+03$ & $8.2 E+15$ & NL & U-232 \\
\hline U-233 & $1.06 \mathrm{E}+03$ & 270 & 4.5 & $7.9 \mathrm{E}+02$ & NA & $1 E+01$ & 540 & 4.5 & $3.7 E+03$ & NA & $9 E+\infty 0$ & U-233 \\
\hline $\mathrm{U}-234$ & $3.16 \mathrm{E}+02$ & 270 & 4.5 & $7.9 \mathrm{E}+02$ & NA & $2 E+01$ & 540 & 4.5 & $3.7 E+03$ & NA & $3 E+01$ & U-234 \\
\hline U-235 & $1.58 \mathrm{E}+03$ & 270 & 4.5 & $7.9 E+02$ & NA & $1 E+01$ & 540 & 4.5 & $3.7 E+03$ & NA & $6 E+00$ & U-235 \\
\hline $\mathrm{U}-236$ & $1.96 \mathrm{E}+02$ & 270 & 4.5 & $7.9 \mathrm{E}+02$ & $1.0 E+00$ & $2 E+01$ & 540 & 4.5 & $3.7 E+03$ & $1.0 \mathrm{E}+00$ & $5 E+01$ & U-236 \\
\hline U-238 & $2.07 E+02$ & 270 & 4.5 & $7.9 E+02$ & NA & $2 E+01$ & 540 & 4.5 & $3.7 E+03$ & $\mathrm{NA}$ & $5 E+01$ & U-238 \\
\hline $\mathrm{Np}-237$ & $3.24 E+03$ & 270 & 4.5 & $2.0 \mathrm{E}+02$ & $1.0 E+00$ & $1 E+00$ & 540 & 4.5 & $8.0 E+02$ & $1.0 E+\infty 0$ & $3 E+00$ & $\mathrm{~Np}-237$ \\
\hline Pu-238 & $2.34 E+03$ & 270 & 4.5 & $1.1 \mathrm{E}+04$ & $1.4 \mathrm{E}+37$ & $6 E+04$ & 540 & 4.5 & $5.4 E+04$ & e & $9 E+04$ & Pu-238 \\
\hline Pu-239 & $2.58 E+03$ & 270 & 4.5 & $1.1 \mathrm{E}+04$ & $1.4 \mathrm{E}+00$ & $3 E+00$ & 540 & 4.5 & $5.4 E+04$ & $4.7 E+\infty 0$ & $2 E+01$ & Pu-239 \\
\hline$P u-240$ & $2.58 \mathrm{E}+03$ & 270 & 4.5 & $1.1 E+04$ & $3.1 E+\infty$ & $6 E+00$ & 540 & 4.5 & $5.4 E+04$ & $2.9 E+02$ & $1 E+03$ & Pu-240 \\
\hline Pu-241 & $4.82 \mathrm{E}+08$ & 270 & 13.8 & $1.1 \mathrm{E}+04$ & $\mathrm{e}$ & $2 E+05$ & 540 & 4.5 & $5.4 \mathrm{E}+04$ & $\mathrm{e}$ & $4 E+05$ & Pu-241 \\
\hline Pu-242 & $2.45 E+03$ & 270 & 4.5 & $1.1 E+04$ & $1.0 E+00$ & $2 E+\infty 0$ & 540 & 4.5 & $5.4 E+04$ & $1.1 E+00$ & $4 E+00$ & $\mathrm{Pu}-242$ \\
\hline Pu-244 & $4.11 \mathrm{E}+03$ & 270 & 4.5 & $1.1 E+04$ & NA & $1 E+\infty$ & 540 & 4.5 & $5.4 E+04$ & NA & $2 E+\infty$ & $P u-244$ \\
\hline Am-241 & $2.66 \mathrm{E}+03$ & 270 & 4.5 & $3.7 E+04$ & $6.4 \mathrm{E}+25$ & $7 E+03$ & 540 & 4.5 & $1.8 E+05$ & e & $1 E+04$ & Am-241 \\
\hline $4 m-243$ & $2.64 E+03$ & 270 & 4.5 & $3.7 E+04$ & $3.3 E+01$ & $6 E+01 \quad c$ & 540 & 4.5 & $1.8 E+05$ & $3.3 E+07$ & $1 E+08$ & $A m-243$ \\
\hline $\mathrm{Cm}-243$ & $1.83 E+03$ & 270 & 13.8 & $7.8 E+04$ & e & $2 E+03 \quad 1$ & 540 & 4.5 & $3.9 E+05$ & e & $1 E+04$ & Cm-243 \\
\hline $\mathrm{Cm}-244$ & 1.47E+03 & 270 & 13.8 & $7.8 \mathrm{E}+04$ & e & $2 E+03$ & 540 & 4.5 & $3.9 E+05$ & e & $4 E+05$ & $\mathrm{Cm}-244$ \\
\hline $\mathrm{Cm}-245$ & $4.56 E+03$ & 270 & 4.5 & $7.8 E+04$ & NA & $1 E+\infty$ & 540 & 4.5 & $3.9 \mathrm{E}+05$ & NA & $2 E+\infty$ & $\mathrm{Cm}-245$ \\
\hline $\mathrm{Cm}-246$ & $2.70 E+03$ & 270 & 4.5 & $7.8 E+04$ & $8.6 \mathrm{E}+0.4$ & $2 E+05$ & 540 & 4.5 & $3.9 E+05$ & $3.1 E+24$ & $\mathrm{NL}$ & $\mathrm{Cm}-246$ \\
\hline $\mathrm{Cm}-247$ & $4.34 \mathrm{E}+03$ & 270 & 4.5 & $7.8 \mathrm{E}+04$ & NA & $1 E+\infty$ & 540 & 4.5 & $3.9 E+05$ & NA & $2 E+\infty$ & $\mathrm{Cm}-247$ \\
\hline $\mathrm{Cm}-248$ & $9.94 E+03$ & 270 & 4.5 & $7.8 E+04$ & $1.2 \mathrm{E}+\infty$ & $6 \mathrm{E}-01$ & 540 & 4.5 & $3.9 E+05$ & $2.2 \mathrm{E}+00$ & $2 \mathrm{E}+\infty 0$ & $\mathrm{Cm}-248$ \\
\hline Cf-249 & $3.46 E+03$ & 270 & 4.5 & $7.8 \mathrm{E}+04$ & e & $3 E+01 \quad \circ$ & 540 & 4.5 & $3.9 E+05$ & e & $5 E+01$ & Cf-249 \\
\hline Cf-250 & $2.64 E+08$ & 270 & 13.8 & $7.8 E+04$ & - $\mathrm{e}$ & $5 E+07$ & 540 & 4.5 & $3.9 \mathrm{E}+05$ & e & $\mathrm{NL}$ & $C f-250$ \\
\hline Cf-251 & $3.54 \mathrm{E}+03$ & 270 & 4.5 & $7.8 E+04$ & $1.3 E+26$ & NL & 540 & 4.5 & $3.9 \mathrm{E}+05$ & $e$ & $\mathrm{NL}$ & $C f-251$ \\
\hline
\end{tabular}

a "NA" means Not Applicable - decay factor is implicit in the PDCF for this radionuclide.

b "NL" means No Limit - estimated permissible concentration is greater than the specific activity of the pure elemental radionuclide.

c Radionuclide concentration is based on arrival time at the performance boundary beyond $10,000 \mathrm{y}$.

d PDCF is a function of arrival time. See Chapter 1 of this volume for equation.

e rocay $\geq 1 E+50$

f Contribution of decay product(s) is significant to determination of this value (see Table E-3 in Volume 2). Listed arrival time is that of the parent radionuclide. If this footnote does not appear in combination with footnote $c$, the arrival time of the significant decay product(s) is less than $10,000 \mathrm{y}$. 
For the tumulus, the total undecayed CRFs (the product of the $C R F_{\text {Source }}$ and the $C R F_{\text {Water }}$ ) for the groundwater pathway were about twice the total undecayed CRFs for the trench, given the same total rate of flow (i.e., at the time of hydrologic failure of the facility) for most radionuclides. This result was due to the difference in the volume fraction of waste (the ratio of waste material to total material in the disposal unit) between the two technologies-twice as much waste leached from the trench for a given rate of flow because a given volume of trench contained twice as much waste.

For the trench design at Portsmouth, the total undecayed CRFs for the groundwater pathway ranged from about 2 to 3700 . Among the listed radionuclides, arrival times at the performance boundary ranged from 36 y to $78,000 \mathrm{y}$, including the retention time in the facility before failure. The travel time through the unsaturated zone is zero; the bottom of the trench lies in the water table, resulting in no vadose zone.

For the tumulus design, the total undecayed CRFs for the groundwater pathway ranged from about 4 to 2400 . Among the listed radionuclides, arrival times at the performance boundary ranged from $320 \mathrm{y}$ to $390,000 \mathrm{y}$, including the retention time in the facility before failure. Differences in these arrival times compared to the trench were attributable to (1) the assumed time of hydrologic failure of the facility (100y for the trench and $300 \mathrm{y}$ for the tumulus); and (2) the increased travel distance through the vadose zone for the tumulus (the bottom of the tumulus was assumed to be at grade level, while the trench was assumed to be a shallow buried structure resting in the water table). For the tumulus, the travel time through the unsaturated zone accounted for about $70 \%$ of the total subsurface travel time.

\subsubsection{Atmospheric Transport}

Two CRFs were used to account for the attenuation encompassing diffusion to the ground surface, mixing in air, and dispersion in the atmosphere to the performance boundary. The CRF for diffusion in soil, $C R F_{D i f f}$, was defined as the ratio of the radionuclide concentration in the waste to its resulting concentration in the upper one centimeter of soil. The CRF for dispersion in air, $C R F_{D i s p}$, was defined as the ratio of the radionuclide concentration in the upper one centimeter of soil to its resulting concentration in air at the performance boundary. The effect of radioactive decay was also included in the PE.

Application of the PE methodology for atmospheric transport of the two volatile radionuclides considered in the PE (H-3 and C-14) produced the results shown in Table 12-5 for both the generic trench and tumulus designs; there was no assumed difference in these two disposal technologies with respect to permissible waste limits based on the atmospheric pathway at Portsmouth. The table shows permissible waste concentrations based on transport in the atmospheric pathway $\left(C_{W \cdot A t m}\right)$, as well as the values used in calculating the permissible waste concentrations. For both $\mathrm{H}-3$ and $\mathrm{C}-14$, the greatest concentration reduction occurred as the radionuclides diffuse from the top of the disposal facility to the soil surface. 
Table 12-5. Results of Calculations for the Atmospheric Pathway

\begin{tabular}{|c|c|c|c|c|c|c|c|}
\hline \multirow[t]{2}{*}{ Nuclide } & \multirow[b]{2}{*}{$\begin{array}{c}S D C F_{A t m} \\
(\mathrm{rem} / \mathrm{y}) /(\mu \mathrm{Ci})\end{array}$} & \multicolumn{6}{|c|}{ Generic Trench and Tumulus } \\
\hline & & $\begin{array}{c}C R F_{\text {Dif }} \\
\text { (dimenotonlese) }\end{array}$ & 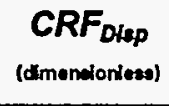 & $\begin{array}{c}C R F_{\text {Atm }} \\
\text { (dimenoloniew) }\end{array}$ & $\begin{array}{l}\text { Arrival } \\
\text { Time (y) }\end{array}$ & $\begin{array}{c}\text { roecay } \\
\text { (Idimeneloniese) }\end{array}$ & $\begin{array}{r}C_{W-A t m} \\
\left(\mu \mathrm{Ci} / \mathrm{m}^{3}\right)\end{array}$ \\
\hline $\mathrm{H}-3$ & $8.33 E+02$ & $2 E+06$ & $1 E+03$ & $2 E+09$ & 100 & 300 & $7 E+09$ \\
\hline C-14 & $2.20 E+05$ & $4 E+04$ & $2 E+03$ & $8 E+07$ & 100 & 1 & $4 E+03$ \\
\hline
\end{tabular}

The time of arrival at the performance boundary for both radionuclides is shown in Table 12-5 as $100 \mathrm{y}$. However, the actual migration of $\mathrm{H}-3$ and $\mathrm{C}-14$ from the disposal facility to the surface and downwind to the performance boundary was calculated to be on the order of hours, not years. As discussed in Section 12.3.2, the waste form and RCRA cover are assumed to retain these volatile radionuclides in the disposal facility for at least $100 \mathrm{y}$.

\subsubsection{Inadvertent Intruder Exposure}

The calculation of permissible waste concentrations for inadvertent intruder exposures did not utilize CRFs. Instead, the total dose resulting from an intrusion scenario (the sum of the doses from all exposure pathways involved in that intrusion) was computed from scenario dose conversion factors (SDCFs) that were applied to specific exposure pathways. These SDCF values were radionuclide-specific and facility-design-specific and were the same for all sites. The exposure pathways evaluated for each radionuclide are listed in Appendix D of Volume 2. Values for the radioactive decay term were based on time of intrusion into the disposal facility (for the homesteader scenario, $300 \mathrm{y}$ for the trench design and $500 \mathrm{y}$ for the tumulus design; for the post-drilling scenario, $100 \mathrm{y}$ for both disposal designs). However, results based on intruder scenarios should be evaluated carefully because future social behavior, and intrusion scenarios, are difficult to predict.

The permissible waste concentrations for the two generic facility designs for each of the 58 radionuclides based on the standard PE intrusion scenarios are listed in Table 12-6. The most restrictive radionuclide concentration limits for each generic facility are indicated with boldface type.

For six radionuclides in the table (U-233, U-234, U-235, U-238, Pu-244, and Cm-247), the time of homesteader intrusion was changed to $10,000 \mathrm{y}$, the end of the performance period. For these six radionuclides, ingrowth of decay products yields scenario doses that increase over time. The doses at $10,000 \mathrm{y}$, therefore, represent the maximum that could be encountered during the performance period. Also, for Th-230 and Cm-245, ingrowth of decay products likewise produces a scenario dose that increases over time and peaks within the 10,000-y performance period. The times of homesteader intrusion for these two radionuclides (Th-230 and Cm-245) were taken as the time of maximum dose, $9000 \mathrm{y}$ and $1000 \mathrm{y}$, respectively. 
Table 12-6. Permissible Waste Concentrations for the Standard Intrusion Scenarios (most limiting radionuclide concentration for each facility design is highlighted in bold italic) (Part 1 of 2)

\begin{tabular}{|c|c|c|c|c|c|}
\hline \multirow[t]{2}{*}{ Nuclide } & \multicolumn{2}{|c|}{ Trench } & \multicolumn{2}{|c|}{ Tumulus } & \multirow[t]{2}{*}{ Nuclide } \\
\hline & $\begin{array}{c}C_{w-1 n t r}{ }^{a} \\
\text { Homesteader } \\
\left(\mu \mathrm{Cil} / \mathrm{m}^{3}\right)\end{array}$ & $\begin{array}{c}C_{W-1 n t r} \\
\text { Post-Drilling } \\
\left(\mu \mathrm{Ci} / \mathrm{m}^{3}\right)\end{array}$ & $\begin{array}{c}C_{w / n t r} \\
\text { Homesteader } \\
\left(\mu \mathrm{Ci} / \mathrm{m}^{3}\right)\end{array}$ & $\begin{array}{c}C_{w-1 n t r} \\
\text { Post-Drilling } \\
\left(\mu \mathrm{Ci} / \mathrm{m}^{3}\right)\end{array}$ & \\
\hline $\mathrm{H}-3$ & $1 E+12$ & $7 E+07$ & $\mathrm{NL}$ & $7 E+07$ & $\mathrm{H}-3$ \\
\hline C-14 & $1 E+04$ & $7 E+04$ & $1 E+04$ & $7 E+04$ & $c-14$ \\
\hline Al-26 & $5 E+01$ & $5 E+04$ & $5 E+01$ & $5 E+04$ & Al-26 \\
\hline Si-32 & $9 E+03$ & $1 E+04$ & $4 E+04$ & $1 E+04$ & Si-32 \\
\hline $\mathrm{Cl}-36$ & $2 E+02$ & $9 E+02$ & $2 E+02$ & $9 E+02$ & $\mathrm{Cl}-36$ \\
\hline$K-40$ & $7 E+02$ & $2 E+04$ & $7 E+02$ & $2 E+04$ & $K-40$ \\
\hline Co-60 & NL & $3 E+10$ & NL & $3 E+10$ & Co-60 \\
\hline $\mathrm{Ni}-59$ & $3 E+06$ & $1 E+07$ & $3 E+06$ & $1 E+07$ & $\mathrm{Ni}-59$ \\
\hline $\mathrm{Ni}-63$ & $8 E+06$ & $1 E+07$ & $3 E+07$ & $1 E+07$ & $\mathrm{Ni}-63$ \\
\hline Se-79 & $2 E+05$ & $8 E+05$ & $2 E+05$ & $8 E+05$ & Se-79 \\
\hline Sr-90 & $1 E+06$ & $5 E+04$ & $1 E+08$ & $5 E+04$ & Sr-90 \\
\hline$Z r-93$ & $5 E+06$ & $3 E+07$ & $5 E+06$ & $3 E+07$ & Zr-93 \\
\hline $\mathrm{Nb}-93 \mathrm{~m}$ & $5 E+12$ & $4 E+09$ & NL. & $4 E+09$ & $\mathrm{Nb}-93 \mathrm{~m}$ \\
\hline $\mathrm{Nb}-94$ & $9 E+01$ & $9 E+04$ & $1 E+02$ & $9 E+04$ & $\mathrm{Nb}-94$ \\
\hline Tc-99 & $2 E+04$ & $8 \mathrm{E}+04$ & $2 E+04$ & $8 \mathrm{E}+04$ & Tc-99 \\
\hline$P d-107$ & $6 E+06$ & $3 E+07$ & $6 E+06$ & $3 E+07$ & Pd-107 \\
\hline $\mathrm{Ag}-108 \mathrm{~m}$ & $6 E+02$ & $1 E+05$ & $1 E+03$ & $1 E+05$ & $\mathrm{Ag}-108 \mathrm{~m}$ \\
\hline $\mathrm{Cd}-113 \mathrm{~m}$ & $4 E+09$ & $1 E+06$ & $7 E+13$ & $1 E+06$ & Cd-113m \\
\hline$S n-121 m$ & $2 E+07$ & $5 E+07$ & $2 E+08$ & $5 E+07$ & $S n-121 m$ \\
\hline$S n-126$ & $8 E+01$ & $7 E+04$ & $8 E+01$ & $7 E+04$ & $S n-126$ \\
\hline $1-129$ & $2 E+03$ & $1 E+04$ & $2 E+03$ & $1 E+04$ & I-129 \\
\hline Cs-135 & $2 E+05$ & $8 \mathrm{E}+05$ & $2 E+05$ & $8 E+05$ & Cs-135 \\
\hline Cs-137 & $3 E+05$ & $8 E+05$ & $3 E+07$ & $8 E+05$ & Cs-137 \\
\hline $\mathrm{Ba}-133$ & $2 \mathrm{E}+11$ & $3 E+08$ & NL & $3 E+08$ & $\mathrm{Ba}-133$ \\
\hline$S m-151$ & $2 E+08$ & $2 E+08$ & $8 E+08$ & $2 E+08$ & $\mathrm{Sm}-151$ \\
\hline Eu-152 & $6 E+08$ & $2 E+07$ & $2 E+13$ & $2 E+07$ & Eu-152 \\
\hline Eu-154 & $4 E+12$ & $4 E+08$ & NL & $4 E+08$ & Eu-154 \\
\hline Pb-210 & $7 E+06$ & $7 E+04$ & $4 E+09$ & $7 E+04$ & $\mathrm{~Pb}-210$ \\
\hline Ra-226 & $8 E+01$ & $3 E+03$ & $9 E+01$ & $3 E+03$ & Ra-226 \\
\hline Ra-228 & $\mathrm{NL}$ & $4 E+09$ & $\mathrm{NL}$ & $4 E+09$ & Ra-228 \\
\hline Th-229 & $5 E+02$ & $3 E+04$ & $5 E+02$ & $3 E+04$ & Th-229 \\
\hline Th-230 & $8 E+01$ & $7 E+04$ & $8 E+01$ & $7 E+04$ & Th-230 \\
\hline Th-232 & $6 E+01$ & $2 E+04$ & $6 E+01$ & $2 E+04$ & Th-232 \\
\hline $\mathrm{Pa}-231$ & $2 E+02$ & $5 E+03$ & $2 E+02$ & $5 E+03$ & $\mathrm{~Pa}-231$ \\
\hline
\end{tabular}


Table 12-6. Permissible Waste Concentrations for the Standard Intrusion Scenarios (most limiting radionuclide concentration for each facility design is highlighted in bold italic) (Part 2 of 2)

\begin{tabular}{|c|c|c|c|c|c|}
\hline \multirow[t]{2}{*}{ Nuclide } & \multicolumn{2}{|c|}{ Trench } & \multicolumn{2}{|c|}{ Tumulus } & \multirow[t]{2}{*}{ Nuclide } \\
\hline & $\begin{array}{c}C_{\text {wdrtr }}{ }^{2} \\
\text { Homesteader } \\
\left(\mu \mathrm{Ci} / \mathrm{m}^{3}\right) \\
\end{array}$ & $\begin{array}{c}C_{\text {w-Intr }} \\
\text { Post-Drilling } \\
\left(\mu \mathrm{Ci} / \mathrm{m}^{3}\right) \\
\end{array}$ & $\begin{array}{c}C_{w-1 n t r} \\
\text { Homesteader } \\
\left(\mu \mathrm{Ci} / \mathrm{m}^{3}\right) \\
\end{array}$ & $\begin{array}{c}C_{\text {W-Intr }} \\
\text { Post-Drilling } \\
\left(\mu \mathrm{Ci} / \mathrm{m}^{3}\right) \\
\end{array}$ & \\
\hline $\mathrm{U}-232$ & $2 E+03$ & $5 E+04$ & $1 E+04$ & $5 E+04$ & $\mathrm{U}-232$ \\
\hline U-233 & $7 E+02$ & $1 E+05$ & $7 E+02$ & $1 E+05$ & U-233 \\
\hline U-234 & $1 E+03$ & $1 E+05$ & $1 E+03$ & $1 E+05$ & U-234 \\
\hline U-235 & $6 E+02$ & $1 E+05$ & $6 E+02$ & $1 E+05$ & U-235 \\
\hline U-236 & $2 E+04$ & $1 E+05$ & $2 E+04$ & $1 E+05$ & U-236 \\
\hline U-238 & $5 E+03$ & $1 E+05$ & $5 E+03$ & $1 E+05$ & U-238 \\
\hline $\mathrm{Np}-237$ & $4 E+02$ & $4 E+03$ & $4 E+02$ & $4 E+03$ & Np-237 \\
\hline Pu-238 & $7 E+04$ & $1 E+05$ & $4 E+05$ & $1 E+05$ & Pu-238 \\
\hline Pu-239 & $6 E+03$ & $5 E+04$ & $6 E+03$ & $5 \mathrm{E}+04$ & Pu-239 \\
\hline Pu-240 & $6 E+03$ & $5 E+04$ & $7 E+03$ & $5 E+04$ & Pu-240 \\
\hline Pu-241 & $2 E+05$ & $1 E+06$ & $3 E+05$ & $1 \mathrm{E}+06$ & Pu-241 \\
\hline Pu-242 & $6 E+03$ & $5 E+04$ & $6 E+03$ & $5 E+04$ & Pu-242 \\
\hline Pu-244 & $4 E+02$ & $5 E+04$ & $4 E+02$ & $5 E+04$ & Pu-244 \\
\hline Am-241 & $7 E+03$ & $5 E+04$ & $9 E+03$ & $5 E+04$ & Am-241 \\
\hline Am-243 & $9 E+02$ & $4 E+04$ & $9 E+02$ & $4 E+04$ & Am-243 \\
\hline $\mathrm{Cm}-243$ & $1 E+06$ & $8 E+05$ & $5 E+06$ & $8 E+05$ & $\mathrm{Cm}-243$ \\
\hline $\mathrm{Cm}-244$ & $2 E+06$ & $3 E+06$ & $2 E+06$ & $3 E+06$ & $\mathrm{Cm}-244$ \\
\hline $\mathrm{Cm}-245$ & $1 E+03$ & $4 E+04$ & $1 E+03$ & $4 \mathrm{E}+04$ & $\mathrm{Cm}-245$ \\
\hline $\mathrm{Cm}-246$ & $6 E+03$ & $5 \mathrm{E}+04$ & $6 E+03$ & $5 E+04$ & $\mathrm{Cm}-246$ \\
\hline $\mathrm{Cm}-247$ & $3 E+02$ & $5 E+04$ & $3 E+02$ & $5 E+04$ & $\mathrm{Cm}-247$ \\
\hline $\mathrm{Cm}-248$ & $2 E+03$ & $1 E+04$ & $2 E+03$ & $1 E+04$ & $\mathrm{Cm}-248$ \\
\hline Cf-249 & $8 E+02$ & $4 E+04$ & $1 E+03$ & $4 E+04$ & Cf-249 \\
\hline Cf-250 & $2 E+06$ & $9 \mathrm{E}+06$ & $2 E+06$ & $9 \mathrm{E}+06$ & Cf-250 \\
\hline Cf-251 & $2 E+03$ & $4 \mathrm{E}+04$ & $2 E+03$ & $4 \mathrm{E}+04$ & Cf-251 \\
\hline
\end{tabular}

a "NL" means No Limit - estimated permissible concentration is greater than the specific activity of the pure elemental radionuclide. 
For the trench design, the waste limits of 47 radionuclides were controlled by the homesteader scenario and 11 were controlled by the post-drilling scenario. For the trench design, the post-drilling scenario generally yielded more restrictive waste limits than the homesteader scenario for those radionuclides with half-lives shorter than about $30 \mathrm{y}$. For the tumulus design, the waste limits of 41 radionuclides were controlled by the homesteader scenario and 17 were controlled by the post-drilling scenario. For the tumulus design, the post-drilling scenario generally yielded more restrictive limits than the homesteader scenario for those radionuclides with half-lives shorter than about $130 \mathrm{y}$.

\subsection{SUMMARY AND DISCUSSION OF RESULTS}

The limiting waste concentrations in disposed MLLW for the water, atmospheric, and intruder analyses for the generic trench and tumulus designs are summarized in Table 12-7 and discussed in Section 12.6.1. An overall discussion of the results of the PE for Portsmouth is contained in Section 12.6.2.

\subsubsection{Results Based on Disposal Design}

For the generic trench design at Portsmouth, 19 radionuclides were limited by the water pathway, no radionuclides were limited by the atmospheric pathway, 37 radionuclides were limited by intrusion scenarios, and two radionuclides (Pu-241 and Am-241) were limited by both the water pathway and intrusion scenarios, as shown in Table 12-7. For the generic tumulus design, 13 radionuclides were limited by the water pathway, no radionuclides were limited by the atmospheric pathway, and 45 radionuclides were limited by intrusion scenarios.

For the trench design, concentrations for 10 radionuclides that arrived at the performance boundary before $10,000 \mathrm{y}$ were reported for the water pathway analysis as having no limit. For the tumulus design, 6 waste concentrations had no limit. As discussed in Section 12.5.1, the calculated concentrations for those radionuclides reported as NL (No Limit) were above the specific activity of the pure elemental radionuclide, implying that the performance measure of $4 \mathrm{mrem}(0.04 \mathrm{mSv})$ per year would not be reached under the given release and transport assumptions.

As also discussed in Section 12.5.1, values for some radionuclides are not reported in Table 12-7 for the water pathway analysis. Arrival times for these radionuclides were beyond the 10,000-y performance period. For these radionuclides, the estimated waste concentrations are presented in Table 12-4 for information purposes but are not listed in Table 12-7. Consistent with the approach used in LLW performance assessments, these values were not considered in determining the most restrictive disposal limit from among the evaluated pathways because arrival times for these radionuclides were beyond $10,000 \mathrm{y}$. 
Table 12-7. Permissible Concentrations for the Generic Disposal Designs at Portsmouth (permissible concentration related to the most limiting pathway for each facility design is highlighted in bold italic) (Part 1 of 2)

\begin{tabular}{|c|c|c|c|c|c|c|c|}
\hline \multirow[t]{2}{*}{ Nuclide } & \multicolumn{3}{|c|}{ Trench } & \multicolumn{3}{|c|}{ Tumulus } & \multirow[t]{2}{*}{ Nuclide } \\
\hline & $\begin{array}{c}C_{\text {w-water }}{ }^{\mathrm{a}, \mathrm{b}} \\
\left(\mu \mathrm{Ci} / \mathrm{m}^{3}\right) \\
\end{array}$ & $\begin{array}{l}C_{W-A t m}{ }^{c} \\
\left(\mu \mathrm{Ci} / m^{3}\right)\end{array}$ & $\begin{array}{l}C_{w-1 n t r}{ }^{d} \\
\left(\mu \mathrm{Ci} / \mathrm{m}^{3}\right)\end{array}$ & $\begin{array}{c}C_{W-W a t o r}, b \\
\left(\mu \mathrm{Ci} / \mathrm{m}^{3}\right)\end{array}$ & $\begin{array}{l}C_{W-A t m} \\
\left(\mu \mathrm{Ci} / m^{3}\right)\end{array}$ & $\begin{array}{l}C_{W-\ln r^{d}} \\
\left(\mu \mathrm{Ci} / \mathrm{m}^{3}\right)\end{array}$ & \\
\hline $\mathrm{H}-3$ & $4 E+03$ & $7 E+09$ & $7 E+07$ & $3 E+10$ & $7 E+09$ & $7 E+07$ & $\mathrm{H}-3$ \\
\hline$C-14$ & $3 E+02$ & $4 E+03$ & $1 E+04$ & $7 E+02$ & $4 E+03$ & $1 E+04$ & $C-14$ \\
\hline Al-26 & $4 E+02$ & & $5 E+01$ & $9 E+02$ & & $5 E+01$ & Al-26 \\
\hline Si-32 & $1 E+05$ & & $9 E+03$ & $2 E+14$ & & $1 E+04$ & Si-32 \\
\hline $\mathrm{Cl}-36$ & $4 E+00$ & & $2 E+02$ & $7 E+00$ & & $2 E+02$ & $\mathrm{Cl}-36$ \\
\hline$K-40$ & $4 E+00$ & & $7 E+02$ & $8 E+00$ & & $7 E+02$ & $\mathrm{~K}-40$ \\
\hline $\mathrm{Co}-60$ & $\mathrm{NL}$ & & $3 E+10$ & $\mathrm{NL}$ & & $3 E+10$ & Co-60 \\
\hline Ni-59 & $3 E+03$ & & $3 E+06$ & - & & $3 E+06$ & $\mathrm{Ni}-59$ \\
\hline $\mathrm{Ni}-63$ & NL & & $8 E+06$ & - & & $1 E+07$ & $\mathrm{Ni}-63$ \\
\hline Se-79 & $9 E+00$ & & $2 E+05$ & - & & $2 E+05$ & Se-79 \\
\hline Sr-90 & $3 E+05$ & & $5 E+04$ & $\mathrm{NL}$ & & $5 E+04$ & ST-90 \\
\hline Zr-93 & - & & $5 E+06$ & - & & $5 E+06$ & $Z r-93$ \\
\hline $\mathrm{Nb}-93 \mathrm{~m}$ & $\mathrm{NL}$ & & $4 E+09$ & - & & $4 E+09$ & $\mathrm{Nb}-93 \mathrm{~m}$ \\
\hline $\mathrm{Nb}-94$ & $1 E+02$ & & $9 E+01$ & - & & $1 E+02$ & Nb-94 \\
\hline TC-99 & $5 E+01$ & & $2 E+04$ & $1 E+02$ & & $2 E+04$ & Tc-99 \\
\hline $\mathrm{Pd}-107$ & $4 E+04$ & & $6 E+06$ & $9 E+04$ & & $6 \mathrm{E}+06$ & $\mathrm{Pd}-107$ \\
\hline $\mathrm{Ag}-108 \mathrm{~m}$ & $2 E+07$ & & $5 E+02$ & $\mathrm{NL}$ & & $1 E+03$ & $\mathrm{Ag}-108 \mathrm{~m}$ \\
\hline $\mathrm{Cd}-113 \mathrm{~m}$ & NL & & $1 E+06$ & $\mathrm{NL}$ & & $1 E+06$ & Cd-113m \\
\hline Sn-121m & $\mathrm{NL}$ & & $2 E+07$ & - & & $5 E+07$ & $S n-121 m$ \\
\hline$S n-126$ & $3 E+01$ & & $8 E+01$ & - & & $8 E+01$ & Sn-126 \\
\hline $1-129$ & 3E-01 & & $2 E+03$ & 6E-01 & & $2 E+03$ & $1-129$ \\
\hline Cs-135 & $9 E+01$ & & $2 E+05$ & - & & $2 E+05$ & Cs-135 \\
\hline Cs-137 & NL & & $3 E+05$ & - & & $8 E+05$ & Cs-137 \\
\hline $\mathrm{Ba}-133$ & $1 E+12$ & & $3 E+08$ & NL & & $3 E+08$ & $\mathrm{Ba}-133$ \\
\hline$S m-151$ & NL & & $2 E+08$ & - & & $2 E+08$ & $S m-151$ \\
\hline Eu-152 & $\mathrm{NL}$ & & $2 E+07$ & - & & $2 E+07$ & Eu-152 \\
\hline Eu-154 & $\mathrm{NL}$ & & $4 E+08$ & - & & $4 E+08$ & Eu-154 \\
\hline $\mathrm{Pb}-210$ & NL & & $7 E+04$ & - & & $7 E+04$ & $\mathrm{~Pb}-210$ \\
\hline Ra-226 & $5 E+00$ & & $8 E+01$ & - & & $9 E+01$ & Ra-226 \\
\hline Ra-228 & $\mathrm{NL}$ & & $4 E+09$ & - & & $4 E+09$ & Ra-228 \\
\hline Th-229 & - & & $5 E+02$ & - & & $5 E+02$ & Th-229 \\
\hline Th-230 & - & & $8 E+01$ & - & & $8 E+01$ & Th-230 \\
\hline Th-232 & - & & $6 E+01$ & - & & $6 E+01$ & Th-232 \\
\hline $\mathrm{Pa}-231$ & - & & $2 E+02$ & - & & $2 E+02$ & $\mathrm{~Pa}-231$ \\
\hline
\end{tabular}


Table 12-7. Permissible Concentrations for the Generic Disposal Designs at Portsmouth (permissible concentration related to the most limiting pathway for each facility design is highlighted in bold italic) (Part 2 of 2)

\begin{tabular}{|c|c|c|c|c|c|c|c|}
\hline \multirow[t]{2}{*}{ Nuclide } & \multicolumn{3}{|c|}{ Trench } & \multicolumn{3}{|c|}{ Tumulus } & \multirow[t]{2}{*}{ Nuclide } \\
\hline & $\begin{array}{c}C_{w \cdot W a t e r}{ }^{a, b} \\
\left(\mu \mathrm{Ci} / \mathrm{m}^{3}\right)\end{array}$ & $\begin{array}{l}C_{W \cdot A m m}{ }^{c} \\
\left.(\mu \mathrm{Cilm})^{3}\right)\end{array}$ & $\begin{array}{l}C_{W / n t r}^{d} \\
\left(\mu \mathrm{Ci} / m^{3}\right)\end{array}$ & $\begin{array}{c}C_{\text {W-Wator }}{ }^{2, b} \\
\left(\mu \mathrm{Ci} / \mathrm{m}^{3}\right) \\
\end{array}$ & $\begin{array}{l}C_{W-A t m}{ }^{c} \\
\left(\mu \mathrm{Ci} / \mathrm{m}^{3}\right)\end{array}$ & $\begin{array}{l}C_{w-1 n t^{d}} \\
\left(\mu \mathrm{Ci} / \mathrm{m}^{3}\right) \\
\end{array}$ & \\
\hline U-232 & $7 E+03$ & & $2 E+03$ & $\mathrm{NL}$ & & $1 E+04$ & U-232 \\
\hline U-233 & $1 E+01$ & & $7 E+02$ & $9 E+00$ & & $7 E+02$ & U-233 \\
\hline U-234 & $2 E+01$ & & $1 E+03$ & $3 E+01$ & & $1 E+03$ & U-234 \\
\hline U-235 & $1 E+01$ & & $6 E+02$ & $6 E+00$ & & $6 \mathrm{E}+02$ & U-235 \\
\hline U-236 & $2 E+01$ & & $2 E+04$ & $5 E+01$ & & $2 E+04$ & U-236 \\
\hline $\mathrm{U}-238$ & $2 E+01$ & & $5 E+03$ & $5 E+01$ & & $5 E+03$ & $U-238$ \\
\hline $\mathrm{Np}-237$ & $1 E+00$ & & $4 E+02$ & $3 E+00$ & & $4 E+02$ & Np-237 \\
\hline $\mathrm{Pu}-238$ & $6 E+04$ & & $7 E+04$ & $9 E+04$ & & $1 \mathrm{E}+05$ & $\mathrm{Pu}-238$ \\
\hline Pu-239 & - & & $6 E+03$ & - & & $6 E+03$ & Pu-239 \\
\hline Pu-240 & - & & $6 E+03$ & - & & $7 E+03$ & Pu-240 \\
\hline $\mathrm{Pu}-241$ & $2 E+05$ & & $2 E+05$ & $4 E+05$ & & $3 E+05$ & Pu-241 \\
\hline Pu-242 & - & & $6 E+03$ & - & & $6 E+03$ & Pu-242 \\
\hline Pu-244 & - & & $4 E+02$ & - & & $4 E+02$ & Pu-244 \\
\hline Am-241 & $7 E+03$ & & $7 E+03$ & $1 E+04$ & & $9 E+03$ & Am-241 \\
\hline Am-243 & - & & $9 E+02$ & - & & $9 E+02$ & Am-243 \\
\hline $\mathrm{Cm}-243$ & - & & $8 E+05$ & - & & $8 E+05$ & $\mathrm{Cm}-243$ \\
\hline $\mathrm{Cm}-244$ & - & & $2 E+06$ & - & & $2 E+06$ & $\mathrm{Cm}-244$ \\
\hline Cm-245 & - & & $1 E+03$ & - & & $1 E+03$ & $\mathrm{Cm}-245$ \\
\hline $\mathrm{Cm}-246$ & - & & $6 E+03$ & - & & $6 E+03$ & $\mathrm{Cm}-246$ \\
\hline $\mathrm{Cm}-247$ & - & & $3 E+02$ & - & & $3 E+02$ & $\mathrm{Cm}-247$ \\
\hline Cm-248 & - & & $2 E+03$ & - & & $2 E+03$ & $\mathrm{Cm}-248$ \\
\hline Cf-249 & - & & $8 E+02$ & - & & $1 E+03$ & Cf-249 \\
\hline Cf-250 & - & & $2 E+06$ & - & & $2 E+06$ & Cf-250 \\
\hline Cf-251 & - & & $2 E+03$ & - & & $2 E+03$ & Cf-251 \\
\hline
\end{tabular}

a "NL" means No Limit - estimated permissible concentration factor is greater than the specific activity of the pure eiemental radionuclide.

b "-" indicates that the radionuclide concentration is based on an arrival time beyond 10,000 y; see Table $12-4$

for specific values.

c Results presented for radionclides expected to be volatile under disposal facility conditions.

d Concentration is based on the most restrictive intrusion scenario assumed for the site; see Table 12-6. 
With the exception of five radionuclides (H-3, Ni-59, Se-79, Cs-135, and Ra-226) at Portsmouth, there is no significant difference in the permissible waste concentrations computed with the PE methodology for the trench as compared to the tumulus. That is, there is less than one order of magnitude difference in the waste limits between the two disposal facility designs. An interesting finding of the PE calculation shown in Table 12-7 is that the permissible waste concentrations for U-233 and U-235 are higher for the trench than for the tumulus. This finding is the result of the pathway dose conversion factor which increases over time due to decay product ingrowth for these two parent radionuclides.

\subsubsection{Discussion}

The results of the PE are based on the framework of assumptions summarized in Chapter 1 of this volume and discussed in detail in Volume 2 of this report and on the site-specific conceptual model for contaminant transport discussed in this chapter. Using alternative assumptions about the conceptual model has the potential to affect the results. Changes in the conceptual model could include alternative assumptions about the disposal facility, the source term, and radionuclide movement in the three pathways. Depending on the degree of possible variation and the relative importance of the parameters used in the calculation of estimated permissible waste concentrations, variability in parameter values can also affect the results. For parameters, results could vary depending on potential changes in values of both the generic and the site-specific parameters used in the PE analysis.

The effect on results from using alternative generic assumptions and parameter values is discussed in Chapter 6 of Volume 2. In addition, a discussion is provided in that chapter about the effects of using alternative values for site-specific parameters. Based on this discussion, four parameters were identified (three site-specific and one generic, all used in the water pathway analysis) that could potentially influence the results to the degree that the calculated waste concentrations become limited by a pathway other than the one determined for the PE (Table 12-7). The impacts on the results of using alternative values for these four parameters for the water pathway in the PE for PORTS are discussed in this section. The basis for and possible variation in the values used in the PE for these parameters are discussed in Section 12.6.2.2.

\subsubsection{Parameter Sensitivity Analysis}

The PE provided results for two disposal facility designs: a RCRA-compliant, belowground trench and a RCRA-compliant, above-ground tumulus. Similar assumptions about the integrity of engineered barriers were made in the PE for both facility designs. Because the factors used to estimate transport of radionuclides in the water pathway for both designs were similar, the discussion in this section focuses on examining the results for the indicator radionuclides reported for the tumulus design (indicator radionuclides are defined in Chapter 7 of Volume 2).

As discussed in Chapter 6 of Volume 2, only four parameters used in the PE were identified as having a potential range of values that might affect results: annual natural recharge (i); groundwater Darcy velocity $\left(q_{\left.g_{w}\right)}\right)$; area of the facility $(A)$; and distribution coefficients $\left(K_{d} \mathrm{~s}\right)$. These parameter values for PORTS are summarized in Table 12-8. 
Table 12-8. Parameter Values Used in the PE for PORTS with Potential Variability That Could Affect the Results

\begin{tabular}{|l|l|}
\hline \multicolumn{1}{|c|}{ Parameter } & \multicolumn{1}{c|}{ Value } \\
\hline Natural recharge through local soils, $i$ & $0.11 \mathrm{~m} / \mathrm{y}$ \\
\hline $\begin{array}{l}\text { Distribution coefficients for geologic } \\
\text { media, } K_{d}\end{array}$ & $\begin{array}{l}\text { Sandy soil values from Thibault et al. (1990); } \\
\text { see Table 12-2 in this chapter for values }\end{array}$ \\
\hline Groundwater Darcy velocity, $q_{g w}$ & $7.7 \mathrm{~m} / \mathrm{y}$ \\
\hline Plan-view Area, $A$ & $2500 \mathrm{~m}^{2}$ (standard PE value) \\
\hline
\end{tabular}

The traditional procedure for performing a sensitivity analysis is to vary the parameters used in the calculations and observe the effect on the results. To be meaningful, this method requires some knowledge of the statistical distribution of each of the parameters considered, including their likely maximum and minimum values. For the $\mathrm{PE}$ calculations, the potential variability of the parameters used to calculate the permissible waste concentrations for the two different facility designs was not estimated. For most of the radionuclides considered in the PE, there were only two exposure pathways: the water pathway and intruder exposure scenarios (the atmospheric pathway was considered only for $\mathrm{H}-3$ and $\mathrm{C}-14$ ). The intruder-pathway results provide a baseline that can be used for comparison with the water-pathway results because the intruder scenarios used in the PE were relatively independent of the physical characteristics of the individual sites. This baseline provided an alternative method of performing sensitivity analyses for the PE. The input parameters for the water pathway were varied to determine if the limiting exposure pathway could be altered (e.g., the results could be changed from intruder-scenario controlled to water-pathway controlled). After new values for the water pathway parameters were determined, these values were examined for reasonableness based on physical constraints at the site.

The sensitivity analysis was limited to a comparison of the water and intruder exposure pathways. A comparison between the water and atmospheric pathways was not conducted because the atmospheric pathway is not limiting.

To analyze the sensitivity of the results to changes in the parameter values for natural recharge, groundwater Darcy velocity, and area of the facility, the parameter values used in the $\mathrm{PE}$ for PORTS were varied. Only one parameter value was varied at a time for a radionuclide, leaving the others equal to their $\mathrm{PE}$ values. In most instances, the parameter value was varied until the waste concentrations for the water and intruder pathways became equal, regardless of the likelihood (or physical impossibility) of the value to occur.

The parameter values that caused the permissible concentrations for the water and intruder pathways to become equal are listed in Table 12-9 for the 8 indicator radionuclides. For the indicator radionuclides $\mathrm{H}-3, \mathrm{Sr}-90$, and $\mathrm{Cs}-137$, no variation in values caused equal concentrations. For $\mathrm{C}-14$, the recharge had to decrease by 14 times or the groundwater velocity had to increase by 25 times to change the limiting pathway from water to intruder. For Tc-99 and 
U-238, values for recharge had to decrease more than two orders of magnitude or the groundwater velocity had to increase more than two orders of magnitude to change the limiting pathway from water to intruder; however, radionuclides would arrive at the performance boundary beyond 10,000 y for U-238 at this low recharge. For $\mathrm{Pu}-239$, all values that caused the pathways to become equal also arrived at the performance boundary beyond $10,000 \mathrm{y}$. For Am-241, the value for recharge had to double, the groundwater velocity had to decrease by onehalf, or the facility plan area had to increase more than 3 times to change the limiting pathway from intruder to water.

Table 12-9. Parameter Values That Caused the Permissible Concentrations for the Water and Intruder Pathways to Be Equal for Indicator Radionuclides at PORTS (tumulus design) (bold italic type indicates limiting pathway in the PE)

\begin{tabular}{|c|c|c|c|c|c|c|}
\hline \multirow[t]{4}{*}{$\begin{array}{l}\text { Indicator } \\
\text { Nuclide }\end{array}$} & \multirow[t]{4}{*}{$\begin{array}{c}\text { PE } \\
C_{W \cdot W a t w r}{ }^{a} \\
\left(\mu \mathrm{Ci} / \mathrm{m}^{3}\right)\end{array}$} & \multirow[t]{4}{*}{$\begin{array}{c}\text { PE } \\
C_{W / n t r} \\
\left(\mu \mathrm{Ci} / \mathrm{m}^{3}\right)\end{array}$} & \multirow[t]{4}{*}{$\begin{array}{c}\text { PE } \\
\frac{C_{W-\text { Intr }}}{C_{W-W a t e r}}\end{array}$} & $\begin{array}{c}\text { Natural } \\
\text { Recharge, } \\
i \\
(\mathrm{~m} / \mathrm{y})\end{array}$ & $\begin{array}{l}\text { Groundwater } \\
\text { Darcy } \\
\text { Velocity, } q_{g w} \\
(m / y)\end{array}$ & $\begin{array}{c}\text { Area, } \\
\text { A } \\
\left(\mathrm{m}^{2}\right)\end{array}$ \\
\hline & & & & \multicolumn{3}{|c|}{ PE Values } \\
\hline & & & & 0.11 & 7.7 & 2500 \\
\hline & & & & \multicolumn{3}{|c|}{$\begin{array}{c}\text { Value That Caused Equal } \\
\text { Concentrations }\end{array}$} \\
\hline $\mathrm{H}-3$ & $3 E+10$ & $7 E+07$ & 0.002 & $b$ & $\mathrm{~b}$ & b \\
\hline C-14 & $7 E+02$ & $1 E+04$ & 14.3 & 0.008 & 195 & $<100$ \\
\hline Sr-90 & NL & $5 E+04$ & - & $b$ & $b$ & b \\
\hline Tc-99 & $1 E+02$ & $2 E+04$ & 200 & 0.0006 & 1500 & $<100$ \\
\hline Cs-137 & $\mathrm{NL}^{\mathrm{c}}$ & $8 E+05$ & - & $\mathrm{b}$ & b & $\mathrm{b}$ \\
\hline$U-238$ & $5 E+01$ & $5 E+03$ & 100 & $0.0008^{c}$ & 1000 & $<100$ \\
\hline Pu-239 & $2 \mathrm{E}+01^{\mathrm{c}}$ & $6 E+03$ & 300 & $0.02^{c}$ & $4,800^{c}$ & $<100^{c}$ \\
\hline $\begin{array}{l}\mathrm{Am}-241 \\
(\mathrm{~Np}-237)^{d}\end{array}$ & $1 E+04^{\circ}$ & $9 E+03$ & 0.9 & $0.21^{\circ}$ & $4^{\circ}$ & $9,000^{\circ}$ \\
\hline
\end{tabular}

a "NL" means No Limit - estimated permissible concentration is greater than the specific activity of the pure elemental radionuclide.

b No variation in values caused equal concentrations.

c Arrival time at the performance boundary is greater than $10,000 \mathrm{y}$.

d The dominant decay product of Am-241

e Based on the dominant decay product, Np-237

-" Value could not be calculated.

$\mathrm{A} K_{d}$ value of about $100 \mathrm{~mL} / \mathrm{g}$ for the geologic media would cause an arrival time at the performance boundary of $10,000 \mathrm{y}$. The $K_{d}$ values that caused the permissible concentrations for the water and intruaier pathways to be the same are listed in Table 12-10 for 5 of the indicator radionuclides. The indicator radionuclides $\mathrm{H}-3, \mathrm{C}-14$, and Tc-99 are not considered in this analysis because general consensus is that the $K_{d}$ values for these radionuclides are small. 
Table 12-10. Variation of $K_{d}$ Values for the Geologic Media at PORTS (tumulus design) (a $K_{d}$ value of $100 \mathrm{~mL} / \mathrm{g}$ caused radionuclide arrival at the performance boundary equal to $10,000 \mathrm{y}$ )

\begin{tabular}{|c|c|c|c|c|c|}
\hline $\begin{array}{l}\text { Indicator } \\
\text { Nuclide }\end{array}$ & $\begin{array}{c}\text { PE } \\
K_{d} \\
(\mathrm{~mL} / \mathrm{g})\end{array}$ & $\begin{array}{c}\text { PE } \\
C_{w-W a t e r} \\
\left(\mu \mathrm{Ci} / \mathrm{m}^{3}\right)\end{array}$ & $\begin{array}{c}\text { PE } \\
C_{w-\operatorname{ntr}} \\
\left(\mu \mathrm{Ci} / \mathrm{m}^{3}\right)\end{array}$ & $\begin{array}{c}\text { PE } \\
\frac{c_{W-\text { Intr }}}{C_{W \cdot \text { Water }}}\end{array}$ & $\begin{array}{l}K_{d} \text { Value that } \\
\text { Caused Equal } \\
\text { Concentrations }\end{array}$ \\
\hline Sr-90 & 15 & NL & $5 E+04$ & - & c \\
\hline Cs-137 & 280 & $\mathrm{NL}^{b}$ & $8 E+05$ & - & 1 \\
\hline U-238 & 35 & $5 E+01$ & $5 E+03$ & 100 & $c, d$ \\
\hline Pu-239 & 550 & $2 E+1^{b}$ & $6 E+03$ & 300 & $2700^{b, 8}$ \\
\hline $\begin{array}{l}\mathrm{Am}-241 \\
(\mathrm{~Np}-237)^{\circ}\end{array}$ & $\begin{array}{c}1900 \\
(5)\end{array}$ & $1 E+04^{f}$ & $9 E+03$ & 0.9 & 47 \\
\hline
\end{tabular}

a "NL" means No Limit - the estimated permissible waste concentration is greater than the specific activity of the pure elemental radionuclide

b Arrival time at the performance boundary is greater than $10,000 \mathrm{y}$

c No variation in value caused equal concentrations

d Value greater than $100 \mathrm{~mL} / \mathrm{g}$ caused arrival at the performance boundary after $10,000 \mathrm{y}$, which changed the limiting pathway.

e The dominant decay product of Am-241

f Based on the dominant decay product, Np-237

g Value less than $100 \mathrm{~mL} / \mathrm{g}$ caused arrival at the performance boundary before $10,000 \mathrm{y}$; which changed the limiting pathway.

"." Value could not be calculated.

For $\mathrm{Sr}-90$, no variation in $K_{d}$ value could cause the water concentration to become less than or equal to the intruder concentration. For Cs-137, the $K_{d}$ value had to decrease about two orders of magnitude to cause the limiting pathway to change from intruder to water. For U-238, a $K_{d}$ value of greater than $100 \mathrm{~mL} / \mathrm{g}$ increased the arrival time at the performance boundary to greater than $10,000 \mathrm{y}$, which caused the limiting pathway to change from water to intruder. $\mathrm{A} K_{d}$ value of $2700 \mathrm{~mL} / \mathrm{g}$ caused the permissible waste concentrations to become equal for Pu-239, but its arrival at the performance boundary was beyond $10,000 \mathrm{y}$; the $K_{d}$ had to be decreased to 100 $\mathrm{mL} / \mathrm{g}$ for the limiting pathway to change from intruder to water. The PE result for Am-241 is limited by the decay product (Np-237) contribution to the dose. If the $K_{d}$ value for Am-241 was decreased by a factor of 40 , then the water pathway concentration was limited by the parent radionuclide (Am-241), and the water pathway limited. Due to the long half-life of Np-237, reduction of its $K_{d}$ had no effect on the resulting waste concentration, and therefore no variation in the $\mathrm{Np}-237 K_{d}$ value caused a change.

\subsubsection{Physical Constraints on Sensitivity Analysis Values}

The PE results for PORTS are based on parameter values provided by the PORTS technical staff for site-specific parameters used in calculations. Descriptions and technical justifications of these values are provided in Sections 12.3 and 12.4. Ranges and statistical distributions were not known for most of the input parameter values; however, site-specific 
knowledge can be used to determine whether the values determined in the sensitivity analysis are reasonable and physically possible at PORTS.

\section{Natural Recharge}

The sensitivity analysis results indicate it was possible to change the limiting pathway for Am-241 from intruder to water by increasing the natural recharge. The values for recharge estimated in the sensitivity analysis range from 0.0008 to $0.21 \mathrm{~m} / \mathrm{y}(0.0026$ to $0.69 \mathrm{ft} / \mathrm{y})$ (Table 12-9) compared to the PE value of $0.11 \mathrm{~m} / \mathrm{y}(0.36 \mathrm{ft} / \mathrm{y})$. The natural recharge at PORTS has no documented range. Doubling the recharge to $0.21 \mathrm{~m} / \mathrm{y}(0.69 \mathrm{ft} / \mathrm{y})$ as was done for Am-241 is probably reasonable for this site. The remaining indicator radionuclides (C-14, Tc-99, U-328, and Pu-239) all had very small values which are not physically reasonable.

\section{Groundwater Darcy Velocity}

The sensitivity analysis results indicate it is possible to change the limiting pathway for Am-241 by decreasing the groundwater velocity. The values for the groundwater Darcy velocity estimated by the sensitivity analysis vary from 4 to $4800 \mathrm{~m} / \mathrm{y}$ (Table 12-9) compared to the PE value of $7.7 \mathrm{~m} / \mathrm{y}$. At PORTS, the groundwater Darcy velocity range is not documented. The Am-241 sensitivity analysis value is probably reasonable because there was only a factor of 2 increase from the PE value. The sensitivity analysis values for C-14, Tc-99, U-238, and Pu-239 were significantly larger than their $\mathrm{PE}$ values and are not physically reasonable.

\section{Facility Area}

The sensitivity analysis results indicate it was possible to change the limiting pathway for Am-241 from intruder to water by increasing the facility size. The value for the facility area estimated in the sensitivity analysis for Am-241 was $9000 \mathrm{~m}^{2}$ (97,200 $\mathrm{ft}^{2}$ ) (Table 12-9). This value is possible because each of the three sites considered at PORTS for a MWDF could accommodate a facility with a size up to $500 \mathrm{~m}$ by $500 \mathrm{~m}$ (1640 ft by $1640 \mathrm{ft})\left(250,000 \mathrm{~m}^{2}\right.$ $\left.\left[2,700,000 \mathrm{ft}^{2}\right]\right)$.

\section{Distribution Coefficients}

The results shown in Table 12-10 indicate that it is possible to change the limiting exposure pathway by changing the $K_{d} \mathrm{~S}$ of U-238 and Pu-239. Changing the $K_{d} \mathrm{~S}$ for U-238 and $\mathrm{Pu}-239$ to $100 \mathrm{~mL} / \mathrm{g}$ (the $K_{d}$ required to cause arrival at the performance boundary at $10,000 \mathrm{y}$ ) is reasonable because this value is within an order of magnitude of their PE $K_{d}$ values. The large changes required to change the limiting pathways for Cs-137 and Am-241 are probably not reasonable.

\subsection{OBSERVATIONS}

Based on the results of the PE and the parameter-sensitivity analysis, the following observations can be made about MLLW disposal at PORTS:

- The Portsmouth site has characteristics that are typical of a humid climate. The annual rainfall and the recharge at Portsmouth are relatively high $(1 \mathrm{~m} / \mathrm{y}$ and $0.11 \mathrm{~m} / \mathrm{y}[3.3 \mathrm{ft} / \mathrm{y}$ and $0.36 \mathrm{ft} / \mathrm{y}$, respectively). The thickness of the vadose zone at the selected site at 
Portsmouth is $5 \mathrm{~m}(16.4 \mathrm{ft})$. Travel times as short as $36 \mathrm{y}$ and up to $390,000 \mathrm{y}$ have been computed for some radionuclides for the water pathway at Portsmouth.

- For PORTS, the results indicate that of the 58 radionuclides evaluated in the PE, 39 radionuclides for the trench design and 45 radionuclides would be limited by the intrusion scenarios. These results reflect the dominant role of the selected human intrusion scenarios that is demonstrated for almost all the sites considered in the PE (see Sections 7.5 and 7.6 in Volume 2). This dominance indicates a need to be aware of the inability to predict the social behavior of populations far into the future.

The results also indicate that for the water pathway, 19 radionuclides for the trench design and 34 radionuclides for the tumulus design would arrive at the performance boundary after the 10,000-y period of consideration in the $\mathrm{PE}$ analysis of the water pathway. Of the radionuclides that would arrive before $10,000 \mathrm{y}, 11$ for the trench design and 6 for the tumulus design had no limit on waste concentration.

Because PORTS has many radionuclides that either are limited by the intrusion scenarios, arrive at the performance boundary after $10,000 \mathrm{y}$, or have no limit on waste concentration, this site may have flexibility in accepting a variety of radionuclides for disposal.

- The most feasible disposal-facility design at Portsmouth is the tumulus design. While using either a trench or tumulus design is possible at Portsmouth, the depth to groundwater (5 $\mathrm{m}[16.4 \mathrm{ft}]$ ) would prohibit deep trench designs.

- Portsmouth has some physical constraints that could limit disposal activities. There is limited space available at Portsmouth for a MLLW disposal facility.

- The sensitivity analysis for PORTS indicates that reasonable changes in values for recharge, groundwater Darcy velocity, and facility size for most radionuclides would not significantly change the results. The exception was Am-241; the limiting pathway was sensitive to selection of values for all three of these parameters.

In flow and transport problems, the $K_{d}$ values are often the most uncertain site-specific input parameters. The $K_{d}$ values for the geologic media at PORTS for U-238 and Pu-239 could have sufficient uncertainty to affect the results (i.e., change the limiting pathway).

- The PE was a scoping analysis performed using assumptions that are conservative relative to most LLW performance assessments. There are no site-specific studies to compare with the PE results. A more detailed performance assessment would be required for permitting or other disposal planning. 


\subsection{REFERENCES}

Baer, T.A., L. L. Price, J. N. Emery, N. E. Olague, 1994. Second Performance Assessment Iteration of the Greater Confinement Disposal Facility at the Nevada Test Site.

SAND93-0089. Albuquerque, NM: Sandia National Laboratories.

Campbell, J., 1995. Personal communications with J.C. Wang (ORNL) by facsimile on April 30, 1995, and by telephone on May 2, 1995.

Cooper, C.D., and F.C. Alley, 1986. Air Pollution Control: A Design Approach. Prospect Heights, $\mathbf{L}$ : Waveland Press, Inc.

CRC, 1981. CRC Handbook of Chemistry and Physics. Eds. Robert C. Weast and Melvin J. Astle. Boca Raton, FL: CRC Press, Inc.

EPA, 1992. User's Guide for the Industrial Source Complex (ISC2) Dispersion Models, Volume I: User Instructions. EPA Publication No. EPA-450/4-92-008a. Research Triangle, NC:

U.S. Environmental Protection Agency.

ERDA, 1977. Final Environmental Impact Statement, Portsmouth Gaseous Diffusion Plant Site, Piketon, Ohio. ERDA-1555. Energy Research \& Development Administration.

FFCAct, 1992. Federal Facility Compliance Act of 1992. P.L. 102-386, October 1992.

Geraghty \& Miller, 1989. Site-Wide Ground-Water Flow Model of the Portsmouth Gaseous Diffusion Plant, Piketon, Ohio. Dublin Ohio: Geraghty \& Miller, Inc.

Geraghty \& Miller, 1994. Quadrant I, RFI Draft Final Report for the Portsmouth Gaseous Diffusion Plant, Piketon, Ohio. Dublin, OH: Geraghty \& Miller, Inc.

Gruebel, Marilyn M., Robert D. Waters, Maryann B. Hospelhorn, and Margaret S. Y. Chu, eds., 1994. Framework for DOE Mixed Low-Level Waste Disposal: Site Fact Sheets. SAND942728. Albuquerque, NM: Sandia National Laboratories.

Kincaid, C.T., J.W. Shade, G.A. Whyatt, M.G. Piepho, K. Rhoads, J.A. Voogd, J.H. Westsik, Jr., M.D. Freshley, K.A. Blanchard, and B.G. Lauzon, eds., 1993. Performance Assessment of Grouted Double-Shell Tank Waste Disposal at Hanford. WHC-SD-WM-EE-004, Rev. 0. U.S. Department of Energy, Pacific Northwest Laboratory and Westinghouse Hanford Company.

Kornegay, F. C., D. C. West, and R. R. Grant, 1991. Portsmouth Gaseous Plant Environmental Report for 1990. ES/ESH-18/V4. Oak Ridge, TN: Martin Marietta Energy System, Inc.

Kornegay, F. C., D. C. West, S. C. Newman, and C. M. Horak, 1994. Portsmouth Gaseous Diffusion Plant Environmental Report for 1993. ES/ESH-50. Oak Ridge, TN: Martin Marietta Energy Systems. 
Law Engineering, 1978. Final Report, Gas Centrifuge Enrichment Plant, Portsmouth, Ohio, Geotechnical Investigation. Marietta, GA: Law Engineering Testing Company.

Law Engineering, 1982. Final Report, Soil and Groundwater Investigations for the GCEP Landfill Pathways Analysis. Project No. 811049. Denver, CO: Law Engineering Testing Co.

Martin Marietta 1991. Portsmouth Uranium Enrichment Plant Technical Site Information. POEF-2059. Oak Ridge, TN: Martin Marietta Energy Systems, Inc.

Maheras, Steven J., Arthur S. Rood, Swen O. Magnuson, Mary E. Sussman, and Rajiv N. Bhatt, 1994. Radioactive Waste Management Complex Low-Level Waste Radiological Performance Assessment. EGG-WM-8773. Idaho Falls, ID: U.S. Department of Energy Office of Environmental Restoration and Waste Management, DOE Idaho Operations Office.

MMES (Martin Marietta Energy Systems), EG\&G Idaho, Inc., and Westinghouse Savannah River Company, 1994. Radiological Performance Assessment for the E-Area Vaults Disposal Facility $(U)$. WSRC-RP-94-218, Rev. 0. Aiken, SC: Westinghouse Savannah River Co.

ORNL (Oak Ridge National Laboratory), 1994. Performance Assessment for Continuing and Future Operations at Solid Waste Storage Area 6. ORNL-6783. Oak Ridge, TN: U.S. Department of Energy, Oak Ridge National Laboratory.

Rogers, J. G., et al. 1989. Portsmouth Gaseous Diffusion Plant Site Environmental Report for 1988. Oak Ridge, TN: Martin Marietta Energy Systems, Inc.

Ruffner, J. A., 1985. Climates of the States, National Oceanic and Atmospheric Administration Narrative Summaries, Tables, and Maps for Each State with Overviews of State Climatologist Programs, 3rd ed. Detroit, MI: Gale Research Co.

Saylor, R. E., et al. 1990. Data Package for the Atomic Vapor Laser Isotope Separation (AVLIS) Plant Environmental Impact Statement. ORNL/TM-11482. Oak Ridge, TN: Oak Ridge National Laboratory.

Thibault, D.H., M.I. Sheppard, and P.A. Smith, 1990. A Critical Compilation and Review of Default Soil Solid/Liquid Partition Coefficients, Kd, for Use in Environmental Assessments. AECL-10125. Pinawa, Manitoba, Canada: Whiteshell Nuclear Research Establishment, Atomic Energy of Canada Limited.

USGS 1979 (photo inspected), 1974 (photo revised). "Piketon, Ohio Quadrangle - Pike County 7.5 Minute Series Topographic Map." AMS 4362 II SE-Series V852. Reston, VA: U.S. Geological Survey, 1961.

\section{Acknowledgments}

The ORNL Core Team acknowledges the contributions of Jim Campbell of the Portsmouth staff. 


\section{South Carolina: SAVANNAH RIVER SITE (SRS) Core Team Contact: Gregory P. Zimmerman}

The Federal Facility Compliance Act (FFCAct, 1992) requires the Department of Energy (DOE) to establish plans in conjunction with its regulators and with members of the public for the treatment of DOE's mixed low-level waste (MLLW). Although the FFCAct did not specifically address disposal of treated MLLW, both DOE and the States recognized that disposal issues were an integral part of treatment discussions. Since 1992, DOE has worked with the States to define and develop an evaluation process for disposal options. Preliminary activities of this joint DOEState process have narrowed the sites for further evaluation from 49 to 15.

The Disposal Workgroup (DWG), which was established by DOE to develop a process for evaluating disposal options, designed a performance evaluation (PE) to quantify and compare the limitations of the remaining 15 DOE sites for MLLW disposal. The principal goal of the PE was to estimate, for grouted residuals resulting from the treatment of MLLW, permissible concentrations of radionuclides in waste for disposal at each site. These "permissible waste concentrations" were based solely on long-term physical performance of the disposal facility and did not take into account any operational waste acceptance criteria that a site might have developed. The PE did not address any ethical, social, or policy considerations relevant to siting such facilities.

The PE used analyses that are consistent with the approach used in many low-level waste (LLW) performance assessments. The objective was to use a set of modeling assumptions of sufficient detail to capture major site-specific characteristics and yet be general enough for consistent application at all sites. Additionally, the analyses were designed to ensure that the sites were analyzed consistently and that all major assumptions were clearly stated.

The remainder of this chapter provides the PE results for the Savannah River Site (SRS), one of the 15 sites being evaluated. The chapter contains the following information:

Section 13.1: brief, general description of the site, based on previous work done by the DWG (Gruebel et al., 1994)

Section 13.2: plans for MLLW disposal, if any, and the location evaluated in the PE

Section 13.3: current understanding of radionuclide movement at the selected location based on available information, and the conceptual model used for the evaluation of each of three pathways (water, atmospheric, and inadvertent intruder)

Section 13.4: site-specific and generic values used in the PE calculations and their sources

Section 13.5: estimates of maximum waste concentrations determined in the PE calculations for each of the three pathways, along with calculated values used in determining these results

Section 13.6: summary of results based on disposal-facility design; discussion with respect to such issues as uncertainty and sensitivity 
Section 13.7: observations based on the results of the PE and the parameter sensitivity analysis

Section 13.8: references

The general assumptions and methodology used in the PE are summarized in Chapter 1 of this volume and explained in more detail in Volume 2 of this report. Overall results for all the sites are discussed in Chapter 7 of Volume 2.

\subsection{GENERAL DESCRIPTION OF THE SITE}

The Savannah River Site (SRS) is located in south-central South Carolina (Figure 13-1), approximately $160 \mathrm{~km}(100 \mathrm{mi})$ from the Atlantic Coast. The major physical feature at SRS is the Savannah River, about $28 \mathrm{~km}(17 \mathrm{mi})$ of which serve as the southwestern boundary of the site and the South Carolina-Georgia border. The SRS includes portions of Aiken, Barnwell, and Allendale Counties in South Carolina.

The SRS occupies an almost circular area of approximately $780 \mathrm{~km}^{2}\left(300 \mathrm{mi}^{2}\right.$ or 192,000 acres) and is comprised of 18 production, service, and research and development areas scattered across the site (Figure 13-2). The production facilities occupy less than 10 percent of the SRS area; the remainder of the site is undeveloped forest or wetlands.

Because SRS is a controlled area, access by the general public is limited. The two largest population centers located in the vicinity of SRS are Augusta (45,000 residents), $40 \mathrm{~km}(25 \mathrm{mi})$ to the northwest, and Aiken (19,900 residents), $35 \mathrm{~km}$ (22 mi) to the north. Smaller towns of lesser populations within a $40-\mathrm{km}(25-\mathrm{mi})$ radius of the site include Jackson, Barnwell, and New Ellenton, South Carolina. It is estimated that fewer than 1000 people live within a $10-\mathrm{km}$ radius of SRS; the population within a $50-\mathrm{km}$ (31-mi) radius is estimated to be 420,000 .

Construction of SRS was begun by the U.S. Government in 1950. The current mission of SRS is to serve the national security interest by safely processing nuclear materials, while protecting employee and public health and the environment. There are five reactors at SRS for production of special nuclear materials; however, none of these reactors is currently in operation. SRS is owned and operated by the DOE; certain daily activities are carried out by managing and operating contractors, including the Westinghouse Savannah River Company.

In 1972, SRS was designated as the first of five DOE National Environmental Research Parks to be used to study complex ecological relationships and the effects of human activities on natural systems. The abundance of deer, turkey, and other wildlife offer a unique opportunity to study the interactions between a nuclear industrial site and the environment. Six endangered animal species visit or reside at the site. 


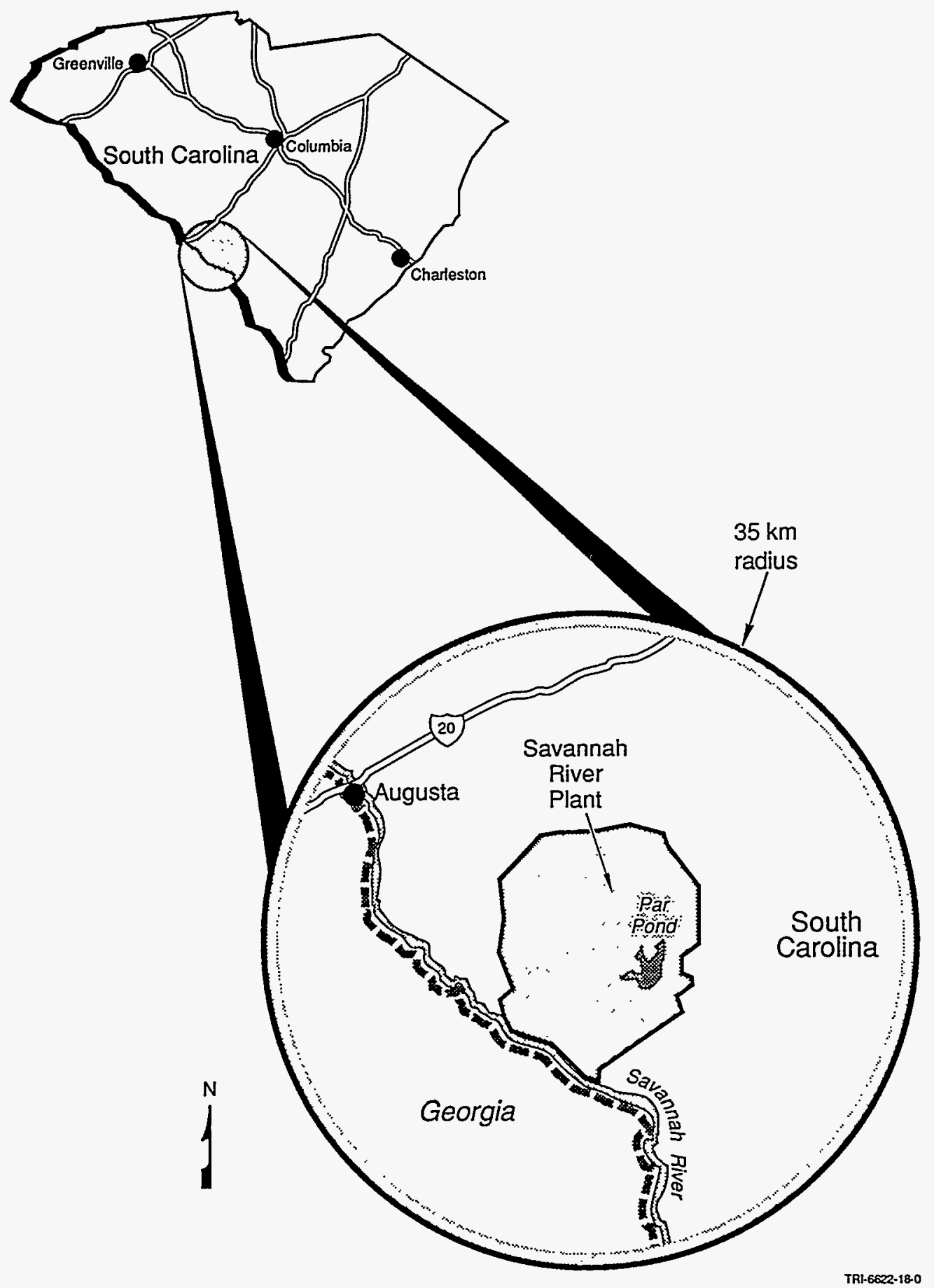

Figure 13-1. Location map for the Savannah River Site. 


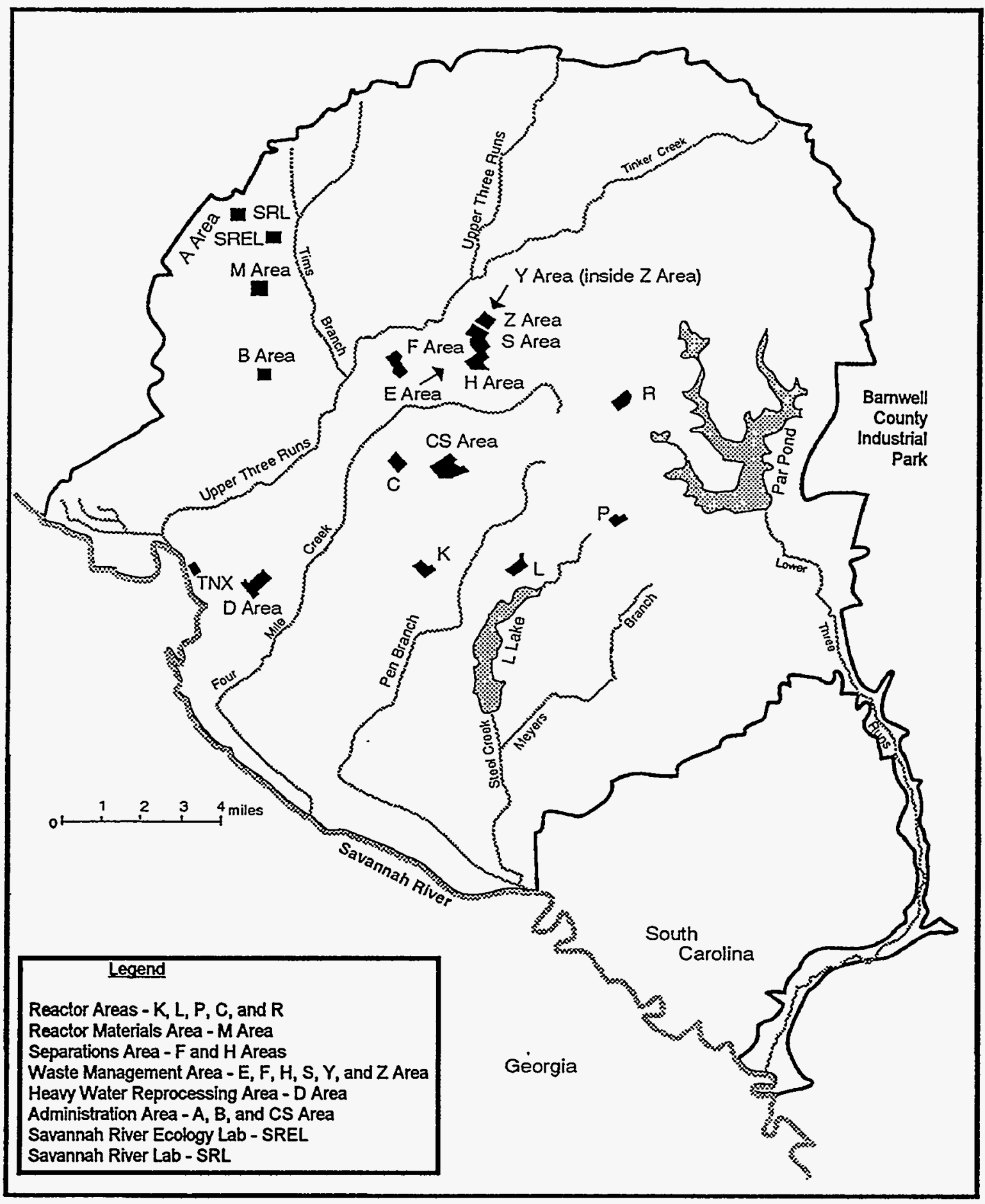

Figure 13-2. Site map for the Savannah River Site. 
The regional climate of SRS is classified as humid, subtropical characterized by short, mild winters and long, relatively warm and humid summers. Extremely cold temperatures associated with outbreaks of Arctic air into the United States are moderated by the Appalachian Mountains to the northwest of the area. Average temperatures at SRS are warmest in July $\left[27^{\circ} \mathrm{C}\left(81^{\circ} \mathrm{F}\right)\right]$ and coolest in January $\left[8^{\circ} \mathrm{C}\left(46^{\circ} \mathrm{F}\right)\right]$. Temperatures below freezing occur approximately 58 days per year. The average annual rainfall at SRS, based on data from 1952 through 1992, is about $123 \mathrm{~cm}$ (48 in.). Precipitation is fairly well distributed throughout the year.

Elevations at SRS range from $24 \mathrm{~m}(78 \mathrm{ft})$ above mean sea level at the Savannah River to about $122 \mathrm{~m}(400 \mathrm{ft})$ in the upper northwestern portion of SRS. The Pleistocene Coastal terraces and the Aiken Plateau form two distinct physiographic subregions at SRS. The Pleistocene Coastal terraces are below $82 \mathrm{~m}(270 \mathrm{ft})$ in elevation with the lowest terrace constituting the present floodplain of the Savannah River. The relatively flat Aiken Plateau occurs above $82 \mathrm{~m}$ $(270 \mathrm{ft})$.

The surface of the Upper Atlantic Coastal Plain Province, on which SRS is located, slopes gently seaward. This province is underlain by a seaward dipping wedge of unconsolidated and semi-consolidated sediments that extends and progressively thickens from the fall line southeastward to the edge of the continental shelf. The stratigraphic section underlying SRS consists of nearly $300 \mathrm{~m}(1000 \mathrm{ft})$ of mostly unconsolidated sands, clayey sands, sandy clays, and clays. The principal surface and near-surface soils are clayey sands averaging about one-third clay. These soils have demonstrated a good retention capacity for most radionuclides.

Current radioactive waste management activities occur in E-Area at SRS (see Figure 13-2). Area surface water bodies in the vicinity of E-Area consist of Four Mile Creek and Upper Three Runs Creek, and their tributaries. All drainage is to the Savannah River, approximately $13.7 \mathrm{~km}(8.5 \mathrm{mi})$ to the southwest. Near SRS, the flow of the Savannah River has been stabilized by the construction of upstream reservoirs. From SRS, river water usually reaches the coast in five or six days, but may take as few as three days.

The Savannah River is designated Class B (i.e., suitable for domestic use after treatment, for propagation of fish, and for industrial and agricultural uses). The Savannah River is used as a drinking water supply for about 65,000 persons downriver in Port Wentworth, Georgia, and near Beaufort, South Carolina. The nearest water intake is downriver, about $193 \mathrm{~km}(120 \mathrm{mi})$ from SRS.

Groundwater velocity in the water table aquifer has been estimated to be $8.1 \mathrm{~m} / \mathrm{y}$ $(26.6 \mathrm{ft} / \mathrm{y})$ and travel time to the nearest surface body of water was estimated at $20.5 \mathrm{y}$. Most municipal and industrial water supplies in Aiken County are developed from the aquifers in the unconsolidated sediments. Some municipal users in Barnwell and Allendale counties are also supplied with water from these aquifers. No aquifers in the SRS area have been designated by the U.S. Environmental Protection Agency (EPA) as sole source aquifers as defined in 40 CFR 149.2. 


\subsection{STATUS AND SITING OF MLLW DISPOSAL FACILITY}

At the time of the PE, personnel at SRS were planning for on-site disposal of MLLW. The E-Area at SRS (see Figure 13-2) has an area of approximately $0.7 \mathrm{~km}^{2}$ (200 acres) and is located immediately north of the current LLW waste burial grounds. The elevation in the vicinity of the disposal vaults in E-Area ranges from 76 to $88 \mathrm{~m}$ (250 to $290 \mathrm{ft})$ above mean sea level.

The E-Area is the location of a new LLW disposal facility at SRS: the E-Area Vault Disposal Facility. While this facility will incorporate radioactive solid waste generated at SRS for near-surface disposal, it is only one part of an integrated radioactive waste management system that is being put into place at SRS. The objective of the E-Area Vaults is to provide a new disposal and storage site for low-level, solid, non-hazardous radioactive waste to support continuing SRS operations. The SRS site currently has no disposal facility available for MLLW.

In order to properly dispose of hazardous waste and MLLW generated at SRS, a project to design and construct hazardous waste/MLLW disposal vaults was authorized in 1989. A RCRA Part B permit application as well as a location standards demonstration has been submitted to the State of South Carolina. This project has been temporarily suspended in order to assess current and projected needs. However, the location of a potential disposal site has been identified in E-Area at a rectangular, wooded area of $0.15 \mathrm{~km}^{2}$ (36 acres) north of the E-Area Vaults Disposal Facility. This Mixed Waste Disposal Facility (MWDF) is identified on maps (see Figure 13-3) in the performance assessment for the E-Area Vaults (MMES et al., 1994) but has not yet been constructed. The proposed MWDF will provide a RCRA-permitted facility for disposal of treated hazardous and mixed wastes that cannot be sent to existing or planned facilities at SRS. The MWDF location was chosen for the PE.

Two generic disposal facilities were considered in the PE: a RCRA-compliant, belowground trench and a RCRA-compliant, above-ground tumulus (described in more detail in Chapter 5 of Volume 2). The generic facilities were selected to provide consistency in analysis of the performance of the 15 sites. Both generic facilities were assumed to be square with a plan area of $2500 \mathrm{~m}^{2}\left(26,910 \mathrm{ft}^{2}\right)$.

\subsection{BASIS FOR CONCEPTUAL MODEL USED IN THE PE}

The current understanding of radionuclide transport from a disposal facility at SRS is based on referenced sources of information contained in the performance assessment (MMES et al., 1994) for SRS's E-Area Vaults, which are currently in operation for disposal of LLW. The descriptions below summarize how this information was incorporated into the PE's conceptual model for SRS.

\subsubsection{Water Pathway}

Knowledge of groundwater flow and radionuclide movement in the water pathway at SRS provided the basis for the conceptual model considered in the PE. The conceptual model encompasses the site technical staff's current understanding of site-specific geology, hydrology, water table and aquifer characteristics, and transport pathways. 

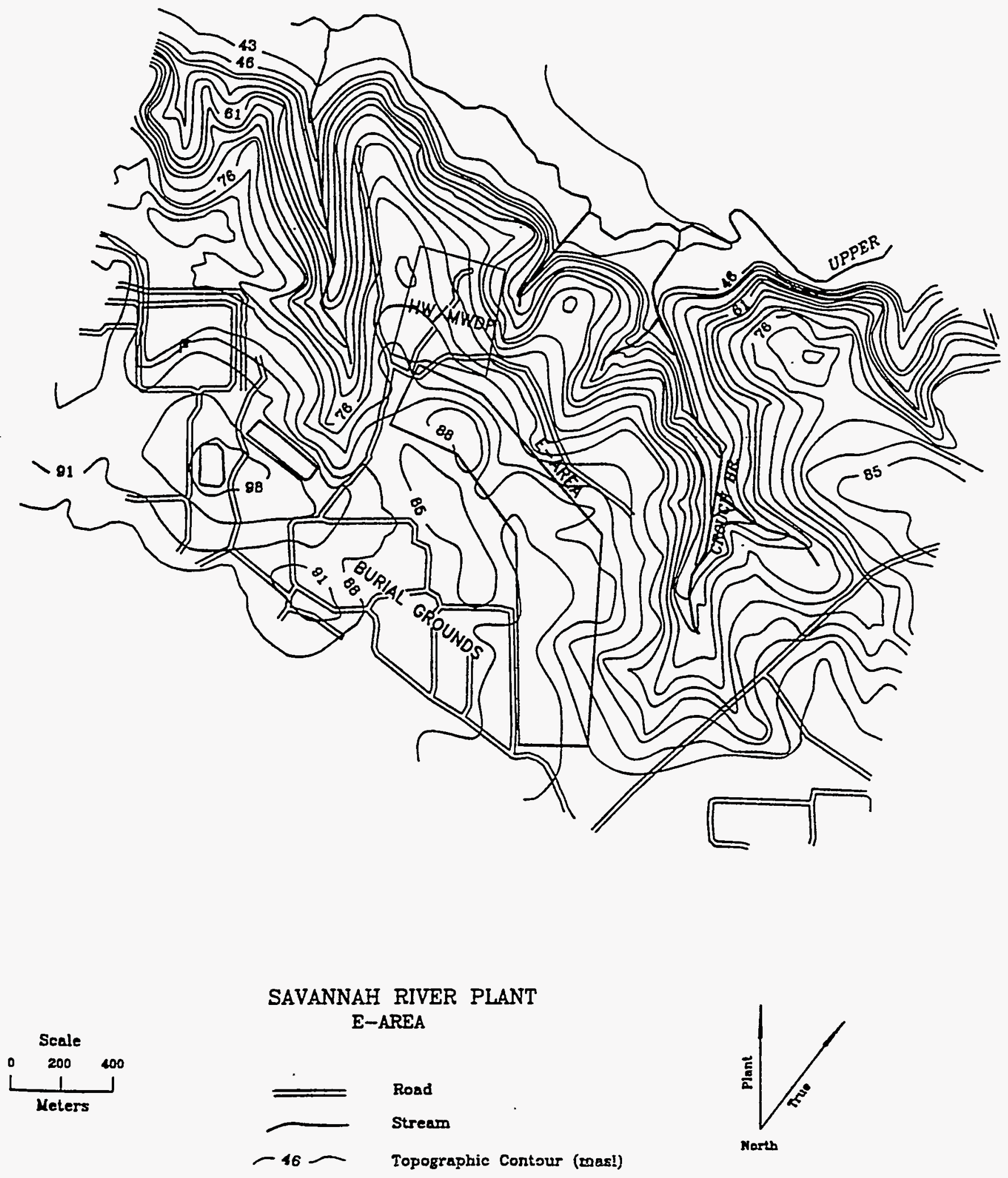

Figure 13-3. Location of the proposed Mixed Waste Disposal Facility (MWDF) within the E-Area at the Savannah River Site. 


\subsubsection{Current Understanding of Relevant Hydrogeology}

The SRS is underlain by a sequence of sediments that ranges in thickness from 180 to $370 \mathrm{~m}$ (590 to $1214 \mathrm{ft}$ ) and in age from Cretaceous to Recent (WSRC, 1992). These sediments can be subdivided into Aquifer System I and Aquifer System II, separated by confining System I-II (Figure 13-4). These strata are deeply dissected by creeks surrounding the MWDF site, and most groundwater eventually seeps into and is diluted by the nearby creeks. The depth of the unsaturated zone beneath the E-Area vaults is $17 \mathrm{~m}(55 \mathrm{ft})$.

The uppermost aquifer (water-table aquifer), Aquifer Unit IIB Zone 2, was determined to provide the fastest transport of radionuclides to the nearby surface discharge areas along Crouch Branch, Upper Three Runs Creek, and the unnamed branch. Contaminated surface waters will be less of a threat to future consumers of water near SRS than contaminated groundwater because the contamination of surface water would be an ephemeral phenomenon, initiated and diluted by surface water runoff. Groundwater poses a more significant threat; hence all the PE analyses are directed toward the groundwater in the water table aquifer, Aquifer Unit IIB-2. Hydrogeologic properties of the Aquifer Unit IIB-2 are assumed to be the same as those presented in the performance assessment because the E-Area Vaults are immediately adjacent to the MWDF site.

\subsubsection{Conceptual Model Used in the PE}

The PE used a generic conceptual model to describe the water pathway (summarized in Section 1.1.2 of this volume and described in detail in Chapter 5 of Volume 2). In the unsaturated zone, leachate was generated by constant flow of water through the disposal facility at a rate that was controlled by the assumed performance of the disposal facility. When all engineered barriers had failed, the rate was assumed to be equal to the natural recharge through local soils. The volumetric flow of water through the facility that generated leachate was based on the assumed performance and size of the disposal facility. No dilution was assumed to occur in the unsaturated zone, so at steady state, the concentration that reached groundwater equaled the leachate concentration. No lateral spreading was assumed, so the leachate flux through the unsaturated zone was confined to the soil column directly below the plan area of the facility.

As contaminated water entered the saturated zone, the contaminant mixed with clean groundwater, forming a plume with a shape controlled by aquifer and contaminant properties. The generic conceptual model assumed that instantaneous and complete mixing within the aquifer occurred directly below the facility. Mixing in the vertical direction occurred by hydrodynamic dispersion, and the contaminant mixing depth was an estimated value.

The generic conceptual model was adapted to conditions at SRS based on site-specific knowledge of the geology and water flow paths. The conceptual model for the water pathway at SRS is illustrated in Figure 13-5. For the proposed location, the subsurface stratigraphy was assumed to be identical to that underlying the E-Area Vaults (as documented in the performance assessment [MMES et al., 1994]), and that the water table maps presented in that performance assessment are an adequate representation of the water table under the proposed MLLW disposal facilities. 


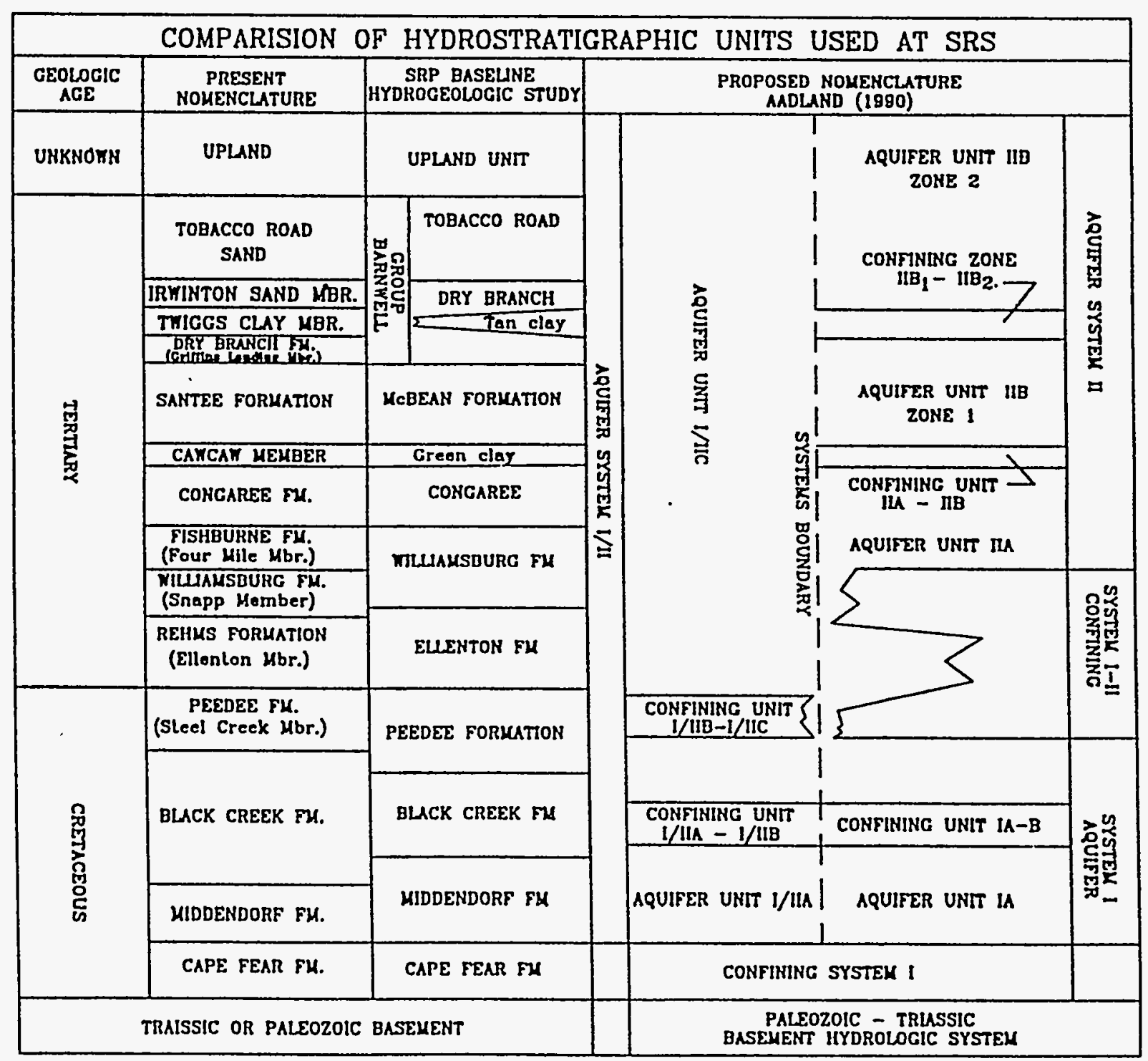

SRS111

Figure 13-4. Hydrologic and stratigraphic units underlying the SRS (MMES et al., 1994). 


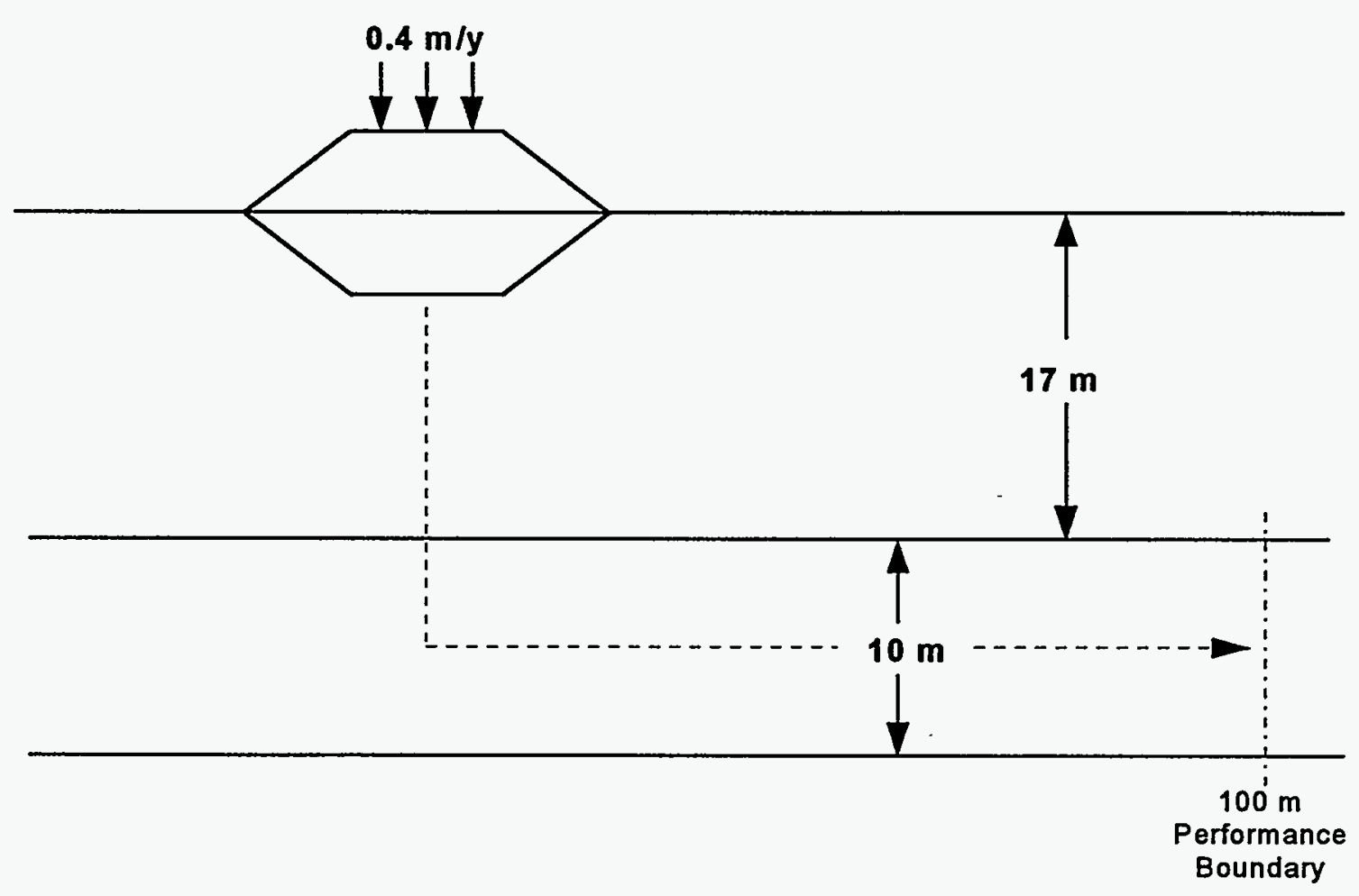

Figure 13-5. Conceptual model for water transport at SRS.

\subsubsection{Atmospheric Pathway}

The conceptual model used in the PE for evaluating the atmospheric pathway was derived from performance assessments for LLW disposal facilities at Hanford (Kincaid et al., 1993), INEL (Maheras et al., 1994), NTS (Baer et al., 1994), ORR (ORNL, 1994), and SRS (MMES et al., 1994). The model was generalized for the PE but used site-specific values for many of the parameters.

Meteorological data are based on STAR data files summarized by the windrose in Figure 13-6. These data were obtained from hourly average meteorological readings taken at a height of $61 \mathrm{~m}(200 \mathrm{ft})$ at the meteorological tower in the H-Area at SRS during the period 1987 to 1991.

The PE used a generic conceptual model to describe the atmospheric pathway (summarized in Section 1.2 of this volume and described in detail in Chapter 5 of Volume 2). Only $\mathrm{H}-3$ (tritium) and $\mathrm{C}-14$ were expected to be volatile for the disposal facility conditions and thus were the only radionuclides considered for atmospheric transport in the PE. In the model, radionuclides were transported from the disposal facility to the soil surface by vapor (tritium) and gaseous (carbon dicxide carrying the $\mathrm{C}-14$ isotope) diffusion. When the radionuclides reached the soil surface, they were entrained in the air in vapor form as volatiles. Once airborne, these radionuclides were transported via atmospheric dispersion to a receptor located at the performance boundary. 


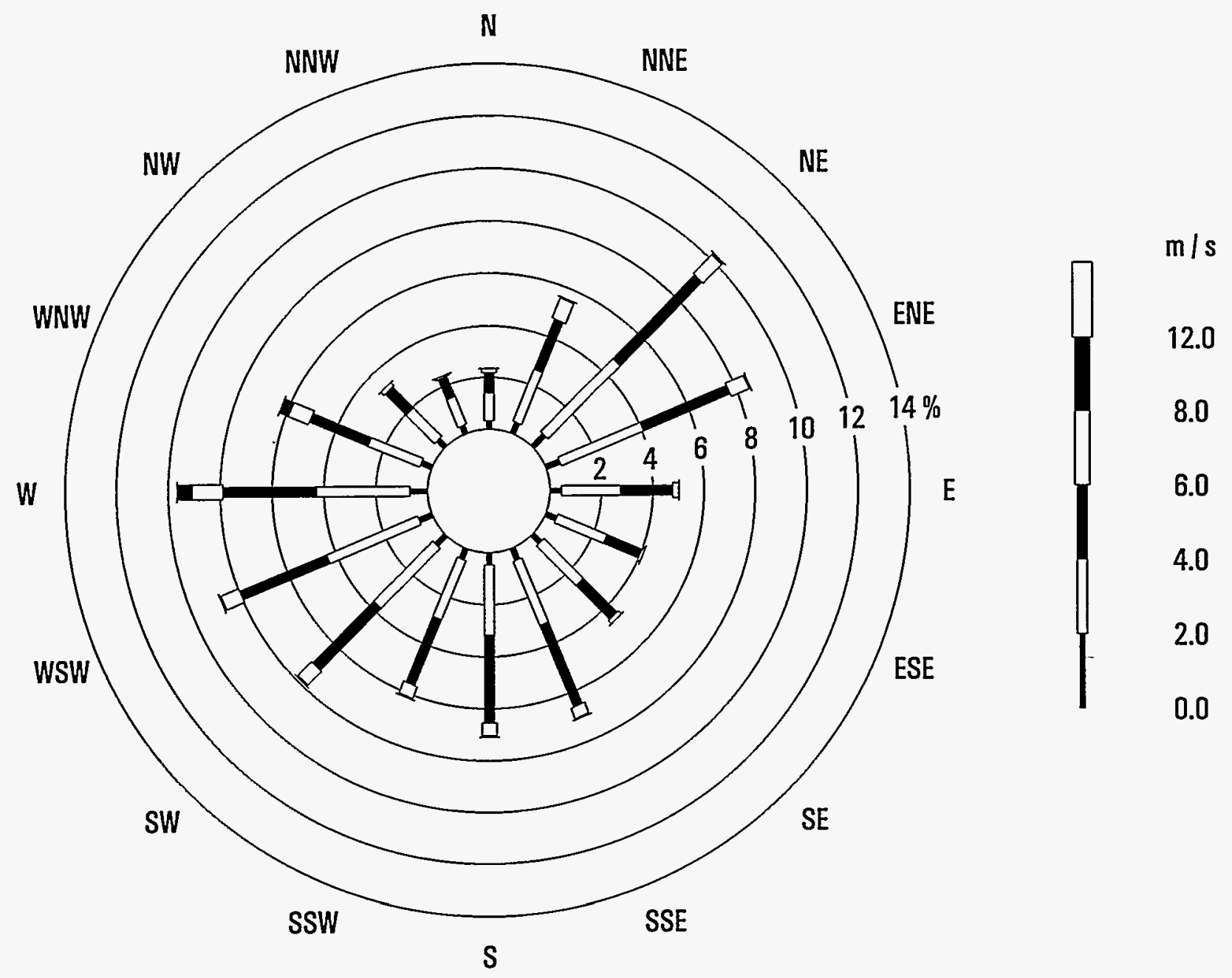

Figure 13-6. Windrose for SRS for the period 1987 to 1991 . The frequency of winds from each direction is plotted as a series of connected bars that extend from the center of the circular diagram toward the direction from which the winds originate. Wind speed categories are denoted by bar widths and shadings. The frequency of winds in each wind speed category is indicated by the length of the corresponding bar. 
Two components of the atmospheric pathway were evaluated separately: (1) the zone from the top of the disposal facility to the soil surface as indicated by the upward radionuclide diffusion profile; and (2) the zone in which a radionuclide was emitted to the atmosphere, mixed with the ambient air, and dispersed downwind from the waste disposal facility boundary to the $100-\mathrm{m}(328-\mathrm{ft})$ performance boundary.

The arrival time of radionuclides at the performance boundary was assumed to be $100 \mathrm{y}$ based on the following generic assumptions of the PE:

- The waste form was grouted MLLW treatment residuals. Based on this assumption, tritium as vapor was bound in the pore water of the hydrophilic grout, and carbon dioxide as a gas carrying the $\mathrm{C}-14$ isotope was limited by the high $\mathrm{pH}$ of the grout, so that the waste form provided retention of these volatile radionuclides in the disposal facility.

- The disposal facility was capped by a RCRA-compliant cover system. Based on this assumption, the cover system was maintained to provide low permeability for $100 \mathrm{y}$.

\subsubsection{Inadvertent Intruder Pathways}

Standard intrusion scenarios were used in the PE, with information derived from performance assessments of LLW disposal facilities at SRS (MMES et al., 1994) and ORR (ORNL, 1994) indicating that only two chronic-exposure scenarios needed to be considered for most sites and facility designs. Any variations in these scenarios were based on discussions with site technical staff about such factors as the types of activities that reasonably could result in exposure to buried waste at the site and the effectiveness of active or passive institutional controls and engineered barriers in precluding access to the waste.

\subsubsection{Current Understanding of Potential Modes of Inadvertent Intrusion}

Standard practices for the drilling of wells in the SRS area are somewhat different from those used in other parts of the United States. Standard drilling practices in the vicinity of the SRS site involve seeking those locations with predominantly sandy soils that are relatively easy to drill through. Because the drilling equipment commonly used in the area is not designed to drill through rock, the drill rig is usually relocated to a more favorable location if rock is encountered. The grouted waste form and engineered barriers of the generic tumulus and trench designs used in the PE would present similar obstacles to drilling until the time at which sufficient degradation of the disposal facility and the grouted waste form has occurred such that the waste is indistinguishable from the soil from the perspective of drilling.

\subsubsection{Intruder Scenarios Used in the PE}

The PE used two standard intrusion scenarios that could be modified for site-specific conditions to describe potential modes of inadvertent intrusion (summarized in Section 1.3 of this volume and described in detail in Chapter 5 of Volume 2). The first scenario, the agriculture (homesteader) scenario, included establishment by an intruder of a permanent homestead directly above a disposal facility with the foundation of the home extending into the waste; some of the 
waste exhumed from the disposal facility was mixed with native soil in the intruder's vegetable garden. The second scenario, the post-drilling scenario, considered the construction of a well for a domestic water supply by an intruder. The well was drilled through the disposal facility, and the cuttings were mixed with soil in the intruder's vegetable garden. The intruder gardened in some of the exhumed waste but did not reside permanently above the disposal facility. In both scenarios, exposure occurred where an intruder dug or drilled into the disposal facility.

Three scenarios of chronic exposure were considered in the SRS E-Area Vaults (EAV) performance assessment (MMES et al., 1994) in evaluating inadvertent intrusion: agriculture, resident, and post-drilling scenarios. Three scenarios of acute exposure were also evaluated. However, the evaluation of these acute scenarios showed that all three acute scenarios can be neglected of purposes of demonstrating compliance of the EAV with the performance objective for protection of intruders because the chronic agriculture, resident, and post-drilling scenarios will always be more restrictive (ibid., p.3-51).

The direct intrusion into disposal units was assumed to be precluded for the period of time after loss of active institutional control when the engineered barriers maintain their structural and physical integrity. That is, intact engineered barriers used in constructing disposal units were assumed to preclude direct access to waste in the disposal facility by the types of equipment that normally would be used in typical construction practices in the region. For the agriculture and resident scenarios, intrusion would occur at the time that the engineered barriers could be penetrated by the types of excavation equipment that normally would be used in digging a foundation for a home in the area.

For the post-drilling scenario, the intrusion is assumed to occur at the same time as the agriculture and resident scenarios. The basis for this assumption is that the types of drill bits normally used in constructing wells in the soft sand and clay soils at the SRS could not easily penetrate an intact engineered barrier. Therefore, in attempting to drill directly through a disposal facility, it seems reasonable to assume that an intruder would encounter considerable resistance and, instead of taking extraordinary measures to obtain a drill bit designed to penetrate through hard rock, would move the drilling operation to a different location away from the disposal facility (ibid., p. 3-47). As discussed in the EAV performance assessment, when the post-drilling scenario is assumed to occur at the same time as the agriculture scenario, the limiting radionuclide concentrations would be more restrictive for the agriculture scenario.

Based on the site-specific nature of the drilling practices in the SRS area mentioned above and discussed more thoroughly in the EAV performance assessment, the post drilling scenario was assumed to be credible at $300 \mathrm{y}$ after facility closure for the generic trench and at $500 \mathrm{y}$ for the generic tumulus. As discussed above, when the time of intrusion for the post-drilling scenario is the same as for the agriculture scenario, the agriculture scenario will provide more restrictive concentration limits. Because both intrusion scenarios are assumed to occur at the same time for each disposal facility at SRS, the post-drilling scenario is excluded from the SRS analysis. The effect of this site-specific assumption is presented in Section 13.6.1. 


\subsection{DATA USED IN THE PE}

The data presented in this section apply to the PE conceptual models described in Section 13.3. The calculations for determining permissible waste concentrations for the radionuclides considered in the PE are discussed in more detail in Chapter 5 of Volume 2 and summarized in Chapter 1 of this volume. The results of the calculations for SRS are presented in Section 13.5 and discussed in Section 13.6 of this volume.

\subsubsection{Water Transport}

Site-specific values required to perform the water pathway analysis were selected by site technical staff either from site characterizations and reports, from site-specific modeling results, or from general literature. For the unsaturated zone, the site-specific data that were required for the PE were distance between the disposal facility and groundwater; ambient moisture content; dry bulk density of the geologic medium; distribution coefficients $\left(K_{d} \mathrm{~s}\right)$ of the radionuclides in the geologic medium; and natural recharge. For the saturated zone, the site-specific data that were required were porosity; dry bulk density of the geologic medium; distribution coefficients $\left(K_{d} \mathrm{~S}\right)$ of the radionuclides in the geologic medium; groundwater Darcy flow rates; and mixing depth in the aquifer.

These values for SRS are listed in Table 13-1 along with generic values that were used in the PE. Also indicated in the table is a designation of the type of data that the value represents and the source of the value. The values were determined from one or more of four data sources: (A) measurement performed by the site, state, or federal agency; (B) result of a numerical analysis performed by the site, state, or federal agency; (C) general literature value selected by the site; and (D) generic value of the PE.

Of the parameters in the PE that depended on site-specific values, only three potentially encompassed enough variability in values to significantly affect the results: natural recharge through the disposal facility, $i$; distribution coefficients $\left(K_{d} \mathrm{~s}\right)$ for the geologic media; and groundwater Darcy velocity $\left(q_{g w}\right)$. The sources of these values are discussed in this section. The sensitivity of the results to changes in the values of these parameters is discussed in Section 13.6.2 of this volume and Chapter 6 of Volume 2.

Because the E-Area performance assessment does not directly address hydrogeologic conditions for the MWDF, depth to groundwater and groundwater gradient are inferred from surface elevation and water table maps in the performance assessment (MMES et al., 1994). Hydrogeologic properties of the Aquifer Unit IIB-2 are assumed to be the same as those presented in the performance assessment, since the E-Area Vaults are immediately adjacent to the MWDF site.

The values for natural recharge and groundwater velocity at SRS were provided in the E-Area vaults performance assessment (MMES et al., 1994). No estimate for a range of values were given. 
Table 13-1. Parameters and Values Used in the PE for the Water Pathway at SRS (generic PE values are in bold; these values and the standard PE method for applying them are summarized in Chapter 1 of this volume and discussed in more detail in Chapter 5 of Volume 2) (Part 1 of 2)

\begin{tabular}{|c|c|c|c|}
\hline Parameter & Value & $\begin{array}{l}\text { Data } \\
\text { Type * }\end{array}$ & Comments \\
\hline \multicolumn{4}{|l|}{ SOURCE TERM } \\
\hline $\begin{array}{l}\text { Volumetric water content } \\
\text { of the grouted waste, } \theta_{0}\end{array}$ & 0.3 & D & Standard PE value \\
\hline $\begin{array}{l}\text { Bulk density of grouted } \\
\text { waste, } \rho_{0}\end{array}$ & $1.76 \mathrm{~g} / \mathrm{ml}$ & D & Standard PE value \\
\hline $\begin{array}{l}\text { Distribution coefficients } \\
\text { for grouted waste, } K_{d}^{G}\end{array}$ & various & D & $\begin{array}{l}\text { Standard PE value; see Table 13-2 } \\
\text { in this chapter }\end{array}$ \\
\hline $\begin{array}{l}\text { Disposal facility plan } \\
\text { area, } A\end{array}$ & $2500 \mathrm{~m}^{2}$ & D & $\begin{array}{l}\text { Standard PE value; } A=a_{1} * a_{2} \text {, where } \\
a_{1}=a_{2}=50 \mathrm{~m}\end{array}$ \\
\hline $\begin{array}{l}\text { Waste mixing fraction for } \\
\text { trench, } f_{m}\end{array}$ & 0.67 & $\mathbf{D}$ & Standard PE value \\
\hline $\begin{array}{l}\text { Waste mixing fraction for } \\
\text { tumulus, } f_{m}\end{array}$ & 0.33 & D & Standard PE value \\
\hline $\begin{array}{l}\text { Annual rate of water } \\
\text { flowing through intact } \\
\text { trench facility, } q_{f}\end{array}$ & $0.03 \mathrm{~m} / \mathrm{y}$ & D & Standard PE value \\
\hline $\begin{array}{l}\text { Annual rate of water } \\
\text { flowing through intact } \\
\text { tumulus facility, } q_{f}\end{array}$ & $\begin{array}{c}0.00003 \\
\mathrm{~m} / \mathrm{y}\end{array}$ & D & Standard PE value \\
\hline $\begin{array}{l}\text { Time to failure of } \\
\text { leachate collection and } \\
\text { liner systems }\end{array}$ & $30 y$ & D & Standard PE value \\
\hline $\begin{array}{l}\text { Time to failure of trench } \\
\text { facility }\end{array}$ & $100 y$ & D & Standard PE value \\
\hline $\begin{array}{l}\text { Time to failure of tumulus } \\
\text { facility }\end{array}$ & $300 y$ & D & Standard PE value \\
\hline $\begin{array}{l}\text { Natural recharge through local } \\
\text { soils, } i\end{array}$ & $\begin{array}{l}0.4 \\
\mathrm{~m} / \mathrm{y}\end{array}$ & A & MMES et al., 1994 \\
\hline
\end{tabular}

- $A=$ site measurement; $B=$ result of site numerical analysis; $C=$ literature value selected by the site; $D=g e n e r i c ~ P E$ value 
Table 13-1. Parameters and Values Used in the PE for the Water Pathway at SRS (generic PE values are in bold; these values and the standard $\mathrm{PE}$ method for applying them are summarized in Chapter 1 of this volume and discussed in more detail in Chapter 5 of Volume 2) (Part 2 of 2)

\begin{tabular}{|c|c|c|c|}
\hline Parameter & Value & $\begin{array}{l}\text { Data } \\
\text { Type* }\end{array}$ & Comments \\
\hline \multicolumn{4}{|l|}{ UNSATURATED ZONE } \\
\hline Moisture content, $\theta_{w}$ & 0.2 & A & MMES et al., 1994 \\
\hline Bulk density, $\rho_{b}$ & $2.65 \mathrm{~g} / \mathrm{mL}$ & A & MMES et al., 1994 \\
\hline $\begin{array}{l}\text { Distribution coefficients of } \\
\text { geologic media, } K_{d}\end{array}$ & Various & AVC & See Table $13-2$ in this chapter \\
\hline $\begin{array}{l}\text { Thickness between trench } \\
\text { and saturated zone, } l\end{array}$ & $\begin{array}{c}8.2 \mathrm{~m} \\
(26.9 \mathrm{ft})\end{array}$ & A & $\begin{array}{l}\text { Cumulative unsaturated sediment thickness is } \\
17 \mathrm{~m} \text { (MMES et al., 1994) and trench facility } \\
\text { bottom is } 8.8 \mathrm{~m} \text { below ground surface }\end{array}$ \\
\hline $\begin{array}{l}\text { Thickness between tumulus } \\
\text { and saturated zone, } l\end{array}$ & $\begin{array}{c}17 \mathrm{~m} \\
(55.8 \mathrm{ft})\end{array}$ & A & $\begin{array}{l}\text { Cumulative unsaturated sediment thickness is } \\
17 \mathrm{~m} \text { (MMES et al., 1994) and tumulus facility } \\
\text { bottom is at ground surface }\end{array}$ \\
\hline \multicolumn{4}{|l|}{ SATURATED ZONE } \\
\hline Effective porosity, $n$ & 0.3 & A & MMES et al., 1994 \\
\hline Bulk density, $\rho_{b}$ & $2.65 \mathrm{~g} / \mathrm{mL}$ & $\mathrm{A}$ & MMES et al., 1994 \\
\hline $\begin{array}{l}\text { Distribution coefficients of } \\
\text { geologic media, } K_{d}\end{array}$ & Various & AC & See Table $13-2$ in this chapter \\
\hline Mixing depth, $d_{m}$ & $10 \mathrm{~m}$ & C & MMES et al., 1994 \\
\hline Darcy velocity, $q_{g w}$ & $\begin{array}{c}8.1 \mathrm{~m} / \mathrm{y} \\
(26.6 \mathrm{ft} / \mathrm{y})\end{array}$ & $\mathrm{C}$ & $\begin{array}{l}\text { Inferred from MMES (1994); see discussion in } \\
\text { text }\end{array}$ \\
\hline $\begin{array}{l}\text { Distance to performance } \\
\text { boundary from facility } \\
\text { boundary }\end{array}$ & $100 \mathrm{~m}$ & $\mathbf{D}$ & Standard PE value \\
\hline
\end{tabular}

- $A=$ site measurement; $B=$ result of site numerical analysis; $C=$ literature value selected by the site; $D=g$ generic $P E$ value 
Table 13-2. Solid/Liquid Distribution Coefficients $\left(K_{d} s\right)$ Used in the PE at SRS

\begin{tabular}{|c|c|c|}
\hline Element & $\begin{array}{c}\text { Waste } K_{d}^{G} \\
(\mathrm{~mL} / \mathrm{g})^{\mathrm{a}}\end{array}$ & $\begin{array}{c}K_{d} \text { for Geologic Media } \\
(\mathrm{mLg})^{b}\end{array}$ \\
\hline $\mathrm{H}$ & 0 & 0 \\
\hline C & 10 & 2 \\
\hline $\mathrm{Al}$ & 100 & 0 \\
\hline Si & 100 & 0 \\
\hline $\mathrm{Cl}$ & 0 & 0 \\
\hline$K$ & 1 & 0 \\
\hline Co & 100 & 10 \\
\hline $\mathrm{Ni}$ & 10 & 300 \\
\hline Se & 1 & 5 \\
\hline $\mathrm{sr}$ & 100 & 10 \\
\hline $\mathrm{Zr}$ & 10 & 0 \\
\hline $\mathrm{Nb}$ & 10 & 0 \\
\hline Tc & 1 & 0.4 \\
\hline$P d$ & 100 & 0 \\
\hline $\mathrm{Ag}$ & 100 & 10 \\
\hline $\mathrm{Cd}$ & 100 & 8 \\
\hline$S n$ & 10 & 130 \\
\hline 1 & 1 & 0.6 \\
\hline Cs & 10 & 100 \\
\hline $\mathrm{Ba}$ & 10 & 5 \\
\hline $\mathrm{sm}$ & 10 & 100 \\
\hline $\mathrm{Eu}$ & 10 & 100 \\
\hline $\mathrm{Pb}$ & 100 & 100 \\
\hline $\mathrm{Ra}$ & 10 & 500 \\
\hline Th & 100 & 3000 \\
\hline $\mathrm{Pa}$ & 100 & 10 \\
\hline$u$ & 100 & 50 \\
\hline $\mathrm{Np}$ & 100 & 10 \\
\hline $\mathrm{Pu}$ & 100 & 100 \\
\hline $\mathrm{Am}$ & 100 & 150 \\
\hline $\mathrm{Cm}$ & 100 & 150 \\
\hline $\mathrm{Cf}$ & 100 & 150 \\
\hline
\end{tabular}

a Standard PE values; see Chapter 5 of Volume 2

b MMES (1994, Table C.1-2). 
Values for distribution coefficients $\left(K_{d} \mathrm{~s}\right)$ are listed in Table 13-2 for the 58 radionuclides (32 elements) considered in the PE. In addition to the $K_{d}$ values for the geologic media, grout $K_{d}$ values are listed for determining the desorption from the source term resulting from the grouted waste form. The $K_{d}$ values for the subsurface flow pathway (both for the unsaturated and saturated zones) are taken from Table C.1-2 in the performance assessment for the E-Area Vaults (MMES et al., 1994); these values are specific to the analysis of the Low Activity Waste (LAW) vaults in the performance assessment. For a specified radionuclide, there is no difference in the $K_{d}$ values at SRS for the unsaturated and saturated zones.

\subsubsection{Atmospheric Transport}

Site-specific data required to perform the atmospheric pathway analysis came from site personnel as data either from site characterizations and reports or from general literature. The site-specific data required for the soil diffusion calculation were the same as some of those required for the water transport analysis (Section 13.4.1). These values are shown in Table 13-3. Necessary atmospheric dispersion data included wind speed and direction and stability class, which are summarized in Section 13.3.2.

Table 13-3. Parameters and Values Used in the PE for the Atmospheric Pathway at SRS (generic $P E$ values are in bold; these values and the standard PE method for applying them are summarized in Chapter 1 of this volume and discussed in more detail in Chapter 5 of Volume 2)

\begin{tabular}{|c|c|c|c|}
\hline Parameter & Value & $\begin{array}{c}\text { Data } \\
\text { Type * }\end{array}$ & Comments \\
\hline $\begin{array}{l}\text { Disposal facility cover } \\
\text { thickness, } x\end{array}$ & $1.0 \mathrm{~m}$ & $\mathbf{D}$ & Standard PE value \\
\hline $\begin{array}{l}\text { Depth of the soil surface, } \\
d\end{array}$ & $0.01 \mathrm{~m}$ & D & $\begin{array}{l}\text { Standard PE value based on } \\
\text { Maheras et al. (1994) }\end{array}$ \\
\hline Porosity, $n$ & 0.4 & C & MMES (1994, Appendix A, p. A-32) \\
\hline Percent saturation, $s$ & 1.0 & C & MMES (1994, Appendix A, p. A-32) \\
\hline $\begin{array}{l}\text { Ratio of water density in } \\
\text { air to liquid, } r\end{array}$ & 9.2E-06 & $\mathbf{D}$ & $\begin{array}{l}\text { Standard PE value based on } \\
\text { MMES et al. (1994) }\end{array}$ \\
\hline $\begin{array}{l}\text { Ratio of } \mathrm{CO}_{2} \\
\text { concentration in air to } \\
\text { dissolved in water, } r\end{array}$ & 4.3E-04 & D & $\begin{array}{l}\text { Standard PE value based on } \\
\text { Foust et al. (as cited in Cooper } \\
\text { and Alley, 1986) }\end{array}$ \\
\hline $\begin{array}{l}\text { Tritium diffusion } \\
\text { coefficient in air, } D\end{array}$ & $2.39 \mathrm{E}-05 \mathrm{~m}^{2} / \mathrm{s}$ & D & $\begin{array}{l}\text { Standard PE value based on CRC } \\
\text { (1981) }\end{array}$ \\
\hline $\begin{array}{l}\text { Carbon diffusion } \\
\text { coefficient in air, } D\end{array}$ & $1.4 \mathrm{E}+05 \mathrm{~m}^{2} / \mathrm{s}$ & $\mathbf{D}$ & $\begin{array}{l}\text { Standard PE value based on CRC } \\
\text { (1981) }\end{array}$ \\
\hline $\begin{array}{l}\text { Atmospheric dispersion term, } \\
A_{D}\end{array}$ & $\begin{array}{c}0.17 \\
\left(\mu \mathrm{Ci} / \mathrm{m}^{3}\right) /\left(\mu \mathrm{Ci} / \mathrm{m}^{2}-\mathrm{s}\right)\end{array}$ & B & $\begin{array}{l}\text { Value is estimated using the Industrial } \\
\text { Source Complex-Version } 2 \text { Long Term } \\
\text { Air Dispersion Model (ISCLT2) (EPA, } \\
\text { 1992) based on site-specific STAR data }\end{array}$ \\
\hline
\end{tabular}

* $A=$ site measurement; $B=$ result of site numerical analysis; $C=$ literature value selected by the site; $D=g e n e r i c ~ P E$ value 


\subsubsection{Inadvertent Intruder Exposure}

As explained in Section 13.3.3, the PE used two standard intrusion scenarios to describe potential modes of inadvertent intrusion at all the sites. Because these intrusion scenarios were considered applicable to all sites, no values specific to SRS are used in the calculation of exposures to inadvertent intruders except for times of intrusion. Based on the estimated failure times of the grouted waste form and the engineered barriers, the homesteader scenario was assumed to be credible at $300 \mathrm{y}$ after closure of the facility for the generic trench and at $500 \mathrm{y}$ for the generic tumulus.

\subsection{RESULTS OF THE PE}

The performance evaluation provided estimates of permissible waste concentrations in disposed MLLW. The three calculations that formed the foundation of the PE-for the water, atmospheric, and inadvertent intruder pathways—are summarized in Sections 1.1, 1.2, and 1.3, respectively, of this volume and discussed in detail in Chapter 5 of Volume 2.

For each pathway the maximum permissible waste concentration at the performance boundary was determined for each radionuclide by using the performance measures: $4 \mathrm{mrem}$ $(0.04 \mathrm{mSv})$ per year from the water pathway for releases to drinking water; 10 mrem $(0.1 \mathrm{mSv})$ per year from all pathways for atmospheric releases; and $100 \mathrm{mrem}(1 \mathrm{mSv})$ per year from all exposure pathways for chronic exposure of inadvertent intruders; and the appropriate pathway or scenario dose conversion factors (annual effective dose equivalent per unit concentration) based on EPA dose conversion factors. The basis for the performance measures used in the PE is discussed in more detail in Chapter 5 of Volume 2. For the water and atmospheric pathways, the concentration reduction provided by the environment (i.e., the CRF) was estimated using results of site analyses and data. For the intruder analyses, concentration reduction was estimated for appropriate exposure pathways for two intrusion scenarios that, in general, were the same for all the sites. The results of the calculations for the pathways that were analyzed at Savannah River are provided in this section and discussed in Section 13.6.

\subsubsection{Water Transport}

Two CRFs were calculated for the water pathway: the source CRF, $C R F_{\text {Source, }}$ and the environmental transport CRF for water, $C R F_{\text {Water. }}$ The source CRF represents the concentration attenuation between the disposed waste and leachate exiting the bottom of the disposal facility and was defined as the dimensionless ratio of the waste concentration to the resulting leachate concentration. Desorption with infiltrating water was the mechanism used to describe the leaching of radionuclides from the grout. Because a generic method was used to determine the $C R F_{\text {Source }}$ for the 58 radionuclides considered in the PE (summarized in Section 1.1 of this volume and discussed in more detail in Chapter 5 of Volume 2), the radionuclide-specific values for the source CRF for each type of generic facility were the same for all 15 sites.

The environmental transport CRF for water was defined as the ratio of the concentration of the leachate exiting the disposal facility to the resulting concentration in water at the performance boundary. The concentration attenuation represented by $C R F_{\text {Water }}$ consisted of 
dilution due to mixing with uncontaminated groundwater. Effects of radioactive decay and decay product ingrowth were also included in the PE.

In the PE, water travel time from the facility location to the performance boundary was calculated as a basis for comparison with the retarded travel time of the radionuclides. For Savannah River, water travel time from the land surface to the performance boundary (i.e., without consideration of a disposal facility) was estimated at about $12 \mathrm{y}$.

The calculation of travel time through the vadose zone for a radionuclide, on the other hand, must account both for the lower infiltration rate because of the facility's RCRA cover and for the retardation defined by the distribution coefficient for the geologic media. In the PE, the calculation for travel time in the vadose zone first determined the distance a radionuclide traveled at the lower infiltration rate. Then, if the radionuclide had not fully traversed the vadose zone, the additional time required to complete travel in the vadose zone under the higher, infiltration rate based on the natural recharge through local soils was calculated and added to the time determined at the lower infiltration rate.

In the $\mathrm{PE}$, the detention time in the facility for a radionuclide was the time during which water flowing through the facility was assumed to be caught by the leachate collection system. Specifically, the calculation of travel time for a radionuclide accounted for the following:

- For the trench design, the leachate collection system was assumed to catch water flowing through the facility for the first $30 \mathrm{y}$. After $30 \mathrm{y}$, the liner and leachate collection system failed, and water flowing through the facility for the next $70 \mathrm{y}$ was assumed to be $0.03 \mathrm{~m} / \mathrm{y}$ $(0.1 \mathrm{ft} / \mathrm{y})$ based on a unit hydraulic gradient and the saturated hydraulic conductivity of the RCRA cover system. After a total of $100 \mathrm{y}$ of reduced flow because of engineered barriers (30 y of detention plus $70 \mathrm{y}$ limited by the RCRA cover system), the flow rate was assumed to be the average recharge through local soils, $0.4 \mathrm{~m} / \mathrm{y}(1.3 \mathrm{ft} / \mathrm{y})$.

- For the tumulus design, the leachate collection system was assumed to catch water flowing through the facility for the first $30 \mathrm{y}$. After $30 \mathrm{y}$, the liner and leachate collection system was assumed to fail, and water flowing through the facility for the next $270 \mathrm{y}$ was assumed to be $0.00003 \mathrm{~m} / \mathrm{y}(0.0001 \mathrm{ft} / \mathrm{y})$ based on a unit hydraulic gradient and the saturated hydraulic conductivity of the concrete vaults. After a total of $300 \mathrm{y}$ of reduced flow because of engineered barriers ( $30 \mathrm{y}$ detention plus $270 \mathrm{y}$ limited by the concrete vaults), the flow rate was assumed to be the average recharge through local soils, $0.4 \mathrm{~m} / \mathrm{y}$ $(1.3 \mathrm{ft} / \mathrm{y})$.

Travel time through the aquifer was independent of facility design and was about $4 \mathrm{y}$, based on groundwater Darcy velocity, porosity, and a 100-m (328-ft) distance to the performance boundary (see Section 1.1.2 of this volume for a summary of these assumptions and Chapter 5 of Volume 2 for additional details). The arrival time of a radionuclide at the performance boundary is the sum of the detention time in the facility, travel time through the vadose zone, and travel time through the aquifer. 
Retardation of radionuclides by interaction with soils and rock in the vadose and saturated zones increased travel times for individual radionuclides. This effect was particularly important for short-lived radionuclides because of radioactive decay. For short-lived radionuclides, the effects of radioactive decay combined with long travel times increased the permissible concentrations in the disposal facility.

Application of the PE methodology for water transport of the 58 radionuclides considered in the PE produced the results shown in Table 13-4 for the generic trench and tumulus designs at Savannah River. The table shows permissible waste concentrations based on transport through the water pathway $\left(C_{W-W a t e r}\right)$ as well as the values used in calculating the permissible waste concentrations.

Some radionuclides listed in Table 13-4 have no limit (NL) on their permissible waste concentrations, the result of the combined effects of relatively short half-lives and sufficiently long travel time to the performance boundary. "No limit" is defined as a permissible waste concentration that is greater than the specific activity of the pure elemental radionuclide. For disposal of the maximum possible waste concentration of these relatively short-lived radionuclides, the water pathway produced a dose at the performance boundary of less than 4 mrem $(0.04 \mathrm{mSv})$ per year and, therefore, the permissible waste concentration was unlimited based on exposures from this pathway.

For some radionuclides, no value is listed in Table 13-4 for the radioactive decay term, $r_{\text {Decay. }}$. These radionuclides had radioactive decay terms that were very large (e.g., greater than $\left.1 \times 10^{50}\right)$. Any radionuclide with a radioactive decay term greater than $1 \times 10^{50}$ was ensured a calculated permissible waste concentration greater than the specific activity of the pure elemental radionuclide, which, as described previously, resulted in no limit (NL) on permissible waste concentrations for disposal.

Arrival times for some radionuclides listed in Table 13-4 were beyond the 10,000-y performance period. For those radionuclides, the estimated waste concentrations are presented in Table 13-4 for information purposes only. Consistent with the approach used in LLW performance assessments, these values were not considered in determining the most restrictive disposal limit from among the evaluated pathways.

For all radionuclides in Table 13-4, the flow rate at the time of facility failure controlled the subsurface transport (i.e., the subsurface movement of the radionuclides in the trench and tumulus was controlled by flow at $100 \mathrm{y}$ after closure for the trench [when the cover failed] and at $300 \mathrm{y}$ for the tumulus [when the concrete vaults failed]).

For the tumulus, the total undecayed CRFs (the product of the $C R F_{\text {Source }}$ and the $C R F_{\text {Water }}$ ) for the groundwater pathway were about twice the total undecayed CRFs for the trench, given the same total rate of flow (i.e., at the time of hydrologic failure of the facility). This result was due to the difference in the volume fraction of waste (the ratio of waste material to total material in the disposal unit) between the two technologies - twice as much waste leached from the trench for a given rate of flow because a given volume of trench contained twice as much waste. 


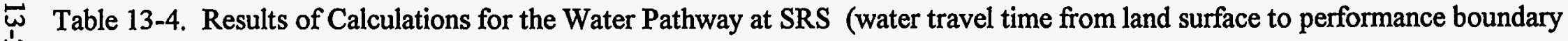
[excluding facility detention] $=12$ y) Part 1 of 2)

\begin{tabular}{|c|c|c|c|c|c|c|c|c|c|c|c|c|}
\hline \multirow[t]{2}{*}{ Nuclide } & \multirow[b]{2}{*}{$\begin{array}{c}\text { PDCF } \\
\text { rem/y per } \mu \text { Cin }\end{array}$} & \multicolumn{5}{|c|}{ Trench } & \multicolumn{5}{|c|}{ Tumulus } & \multirow[t]{2}{*}{ Nuclide } \\
\hline & & \begin{tabular}{|c|} 
CRF Souree \\
(dimensionless)
\end{tabular} & \begin{tabular}{|c|}
$C_{\text {(dimensionloss) }}$ \\
\end{tabular} & $\begin{array}{c}\text { Arrival } \\
\text { Time }(y)\end{array}$ & \begin{tabular}{|c|}
$r_{\text {Decayy }}$ \\
(dimonsionless)
\end{tabular} & $\begin{array}{c}C_{\text {w-Water }}^{b} \\
\left(\mu \mathrm{Ci} / \mathrm{m}^{3}\right)\end{array}$ & \begin{tabular}{|l|} 
CRF \\
(dimensionless) \\
\end{tabular} & $\begin{array}{c}\text { CRF Water } \\
\text { (dimensionless) }\end{array}$ & $\begin{array}{l}\text { Arrival } \\
\text { Time }(y)\end{array}$ & \begin{tabular}{c|} 
rovany $^{a}$ \\
(dimensionloss)
\end{tabular} & $\begin{array}{c}C_{\text {w-Water }}{ }^{b} \\
\left(\mu \mathrm{Cl} / \mathrm{m}^{3}\right)\end{array}$ & \\
\hline $\mathrm{H}-3$ & 4.67E-02 & 0.45 & 5.1 & $1.0 \mathrm{E}+02$ & $3.4 E+02$ & $7 E+04$ & 0.9 & 5.1 & $3.1 E+02$ & $4.2 \mathrm{E}+07$ & $2 E+10$ & $\mathrm{H}-3$ \\
\hline $\mathrm{C}-14$ & $1.52 E+\infty$ & 27 & 5.1 & $2.8 \mathrm{E}+02$ & $1.0 \mathrm{E}+00$ & $4 E+02$ & 54 & 5.1 & $6.0 \mathrm{E}+02$ & $1.1 \mathrm{E}+00$ & $8 \mathrm{E}+02$ & C-14 \\
\hline Al-26 & $1.06 \mathrm{E}+01$ & 270 & 5.1 & $1.0 \mathrm{E}+02$ & $1.0 \mathrm{E}+00$ & $5 E+02$ & 540 & 5.1 & $3.1 E+02$ & $1.0 \mathrm{E}+00$ & $1 \mathrm{E}+03$ & Al-26 \\
\hline Si-32 & $7.99 E+00$ & 270 & 5.1 & $1.0 \mathrm{E}+02$ & $2.1 E+\infty 0$ & $1 \mathrm{E}+03$ & 540 & 5.1 & $3.1 E+02$ & $8.7 \mathrm{E}+00$ & $1 E+04$ & Si-32 \\
\hline C1-36 & $2.21 E+00$ & 0.45 & 5.1 & $1.0 \mathrm{E}+02$ & $1.0 \mathrm{E}+00$ & $4 E+\infty$ & 0.9 & 5.1 & $3.1 E+02$ & $1.0 \mathrm{E}+00$ & $8 E+00$ & $\mathrm{Cl}-36$ \\
\hline$K-40$ & $1.36 E+01$ & 3.1 & 5.1 & $1.0 \mathrm{E}+02$ & $1.0 \mathrm{E}+00$ & $5 E+\infty$ & 6.2 & 5.1 & $3.1 E+02$ & $1.0 \mathrm{E}+\infty$ & $9 \mathrm{E}+00$ & $K-40$ \\
\hline Co-60 & $1.97 \mathrm{E}+01$ & 270 & 5.1 & $9.7 \mathrm{E}+02$ & e & NL & 540 & 5.1 & $1.8 \mathrm{E}+03$ & $e$ & NL & $\mathrm{Co}-60$ \\
\hline Ni-59 & 1.53E-01 & 27 & 5.1 & $2.6 E+04$ & $1.3 E+00$ & $4 E+03^{\circ}$ & 54 & 5.1 & $4.4 E+04$ & $1.5 \mathrm{E}+00$ & $1 \mathrm{E}+04$ & Ni-59 \\
\hline $\mathrm{Ni}-63$ & 4.21E-01 & 27 & 5.1 & $2.6 \mathrm{E}+04$ & e & $\mathrm{NL} \quad{ }^{\mathrm{C}}$ & 54 & 5.1 & $4.4 E+04$ & $e$ & NL & Ni-63 \\
\hline Se-79 & $6.35 \mathrm{E}+\infty 0$ & 3.1 & 5.1 & $5.4 \mathrm{E}+02$ & $1.0 \mathrm{E}+00$ & $1 E+01$ & 6.2 & 5.1 & $1.0 \mathrm{E}+03$ & $1.0 \mathrm{E}+00$ & $2 E+01$ & Se-79 \\
\hline Sr-90 & $1.12 \mathrm{E}+02$ & 270 & 5.1 & $9.7 E+02$ & $1.2 E+10$ & $6 \mathrm{E}+11$ & 540 & 5.1 & $1.8 \mathrm{E}+03$ & $1.8 \mathrm{E}+18$ & $\mathrm{NL}$ & Sr-90 \\
\hline Zr-93 & $1.59 \mathrm{E}+00$ & 27 & 5.1 & $1.0 E+02$ & $1.0 \mathrm{E}+00$ & $3 E+02$ & 54 & 5.1 & $3.1 E+02$ & $1.0 \mathrm{E}+00$ & $7 \mathrm{E}+02$ & Zr-93 \\
\hline $\mathrm{Nb}-93 \mathrm{~m}$ & $3.81 E-01$ & 27 & 5.1 & $1.0 \mathrm{E}+02$ & $8.7 E+01$ & $1 E+05$ & 54 & 5.1 & $3.1 \mathrm{E}+02$ & $6.9 E+05$ & $2 E+09$ & $\mathrm{Nb}-93 \mathrm{~m}$ \\
\hline $\mathrm{Nb}-94$ & $5.21 E+00$ & 27 & 5.1 & $1.0 \mathrm{E}+02$ & $1.0 \mathrm{E}+\infty 0$ & $1 E+02$ & 54 & 5.1 & $3.1 E+02$ & $1.0 \mathrm{E}+00$ & $2 \mathrm{E}+02$ & $\mathrm{Nb}-94$ \\
\hline TC-99 & $1.07 E+00$ & 3.1 & 5.1 & $1.3 E+02$ & $1.0 \mathrm{E}+\infty 0$ & $6 \mathrm{E}+01$ & 6.2 & 5.1 & $3.6 \mathrm{E}+02$ & $1.0 E+00$ & $1 \mathrm{E}+02$ & Tc-99 \\
\hline$P d-107$ & 1.09E-01 & 270 & 5.1 & $1.0 E+02$ & $1.0 \mathrm{E}+\infty$ & $5 \mathrm{E}+04$ & 540 & 5.1 & $3.1 E+02$ & $1.0 E+00$ & $1 \mathrm{E}+05$ & $\mathrm{Pd}-107$ \\
\hline Ag-108m & $5.56 \mathrm{E}+\infty 0$ & 270 & 5.1 & $9.7 E+02$ & $1.8 \mathrm{E}+02$ & $2 \mathrm{E}+05$ & 540 & 5.1 & $1.8 \mathrm{E}+03$ & $1.2 E+04$ & $2 E+07$ & $\mathrm{Ag}-108 \mathrm{~m}$ \\
\hline $\mathrm{Cd}-113 \mathrm{~m}$ & $1.17 \mathrm{E}+02$ & 270 & 5.1 & $8.0 E+02$ & $1.1 \mathrm{E}+17$ & $\mathrm{NL}$ & 540 & 5.1 & $1.5 \mathrm{E}+03$ & $3.1 \mathrm{E}+31$ & NL & $\mathrm{Cd}-113 \mathrm{~m}$ \\
\hline$S n-121 m$ & $1.28 \mathrm{E}+00$ & 27 & 5.1 & $1.1 E+04$ & e & $\mathrm{NL}$ & 54 & 5.1 & $1.9 E+04$ & $\mathbf{e}$ & $\mathrm{NL}$ & $S n-121 m$ \\
\hline$S n-126$ & $1.53 \mathrm{E}+01$ & 27 & 5.1 & $1.1 \mathrm{E}+04$ & $1.1 \mathrm{E}+\infty$ & $4 E+01^{\circ}$ & 54 & 5.1 & $1.9 E+04$ & $1.1 E+00$ & $8 \mathrm{E}+01$ & $5 n-126$ \\
\hline $1-129$ & $2.01 E+02$ & 3.1 & 5.1 & $1.5 E+02$ & $1.0 \mathrm{E}+00$ & 3E-01 & 6.2 & 5.1 & $4.0 \mathrm{E}+02$ & $1.0 \mathrm{E}+\infty$ & $6 E-01$ & $1-129$ \\
\hline Cs-135 & $5.16 E+00$ & 27 & 5.1 & $8.8 E+03$ & $1.0 E+\infty$ & $1 E+02$ & 54 & 5.1 & $1.5 E+04$ & $1.0 E+00$ & $2 E+02$ & Cs-135 \\
\hline Cs-137 & $3.65 E+01$ & 27 & 5.1 & $8.8 \mathrm{E}+03$ & $\mathbf{e}$ & $\mathrm{NL}$ & 54 & 5.1 & $1.5 E+04$ & 0 & $\mathrm{NL}$ & Cs-137 \\
\hline Ba-133 & $2.48 E+00$ & 27 & 5.1 & $5.4 E+02$ & $2.6 \mathrm{E}+15$ & $\mathrm{NL}$ & 54 & 5.1 & $1.0 E+03$ & $6.1 E+29$ & $\mathrm{NL}$ & $B a-133$ \\
\hline Sm-151 & $2.84 \mathrm{E}-01$ & 27 & 5.1 & $8.8 E+03$ & $2.9 E+29$ & $\mathrm{NL}$ & 54 & 5.1 & $1.5 E+04$ & $4.5 E+49$ & NL & $5 m-151$ \\
\hline$E u-152$ & $4.73 E+00$ & 27 & 5.1 & $8.8 E+03$ & $e$ & $\mathrm{NL}$ & 54 & 5.1 & $1.5 \mathrm{E}+04$ & $e$ & $\mathrm{NL}$ & $E u-152$ \\
\hline Eu-154 & $6.97 E+00$ & 27 & 5.1 & $8.8 \mathrm{E}+03$ & e & $\mathrm{NL}$ & 54 & 5.1 & $1.5 \mathrm{E}+04$ & $e$ & NL & $E u-154$ \\
\hline $\mathrm{Pb}-210$ & $5.30 E+03$ & 270 & 5.1 & $8.8 E+03$ & $e$ & $\mathrm{NL}$ & 540 & 5.1 & $1.5 \mathrm{E}+04$ & $e$ & NL & Pb-210 \\
\hline Ra-226 & $6.27 E+03$ & 27 & 5.1 & $4.4 E+04$ & $1.6 E+08$ & $1 E+07$ & 54 & 5.1 & $7.3 E+04$ & $5.4 \mathrm{E}+13$ & $\mathrm{NL}$ & Ra-226 \\
\hline Ra-228 & $1.64 \mathrm{E}+03$ & 27 & 5.1 & $4.4 \mathrm{E}+04$ & $e$ & $\mathrm{NL} \quad \mathrm{C}$ & 54 & 5.1 & $7.3 \mathrm{E}+04$ & e & $\mathrm{NL}$ & Ra-228 \\
\hline Th-229 & $2.94 E+03$ & 270 & 5.1 & $2.6 \mathrm{E}+05$ & $5.9 E+10$ & $1 E+11^{\circ}$ & 540 & 5.1 & $4.4 E+05$ & $9.8 E+17$ & NL & Th-229 \\
\hline Th-230 & $6.12 E+03$ & 270 & 5.1 & $2.6 E+05$ & NA & $9 E-01 \quad c$ & 540 & 5.1 & $4.4 \mathrm{E}+05$ & NA & $2 E+\infty$ & Th-230 \\
\hline Th-232 & $3.63 E+03$ & 270 & 5.1 & $2.6 E+05$ & $1.0 \mathrm{E}+00$ & $1 E+\infty 0^{\circ}$ & 540 & 5.1 & $4.4 \mathrm{E}+05$ & $1.0 \mathrm{E}+\infty$ & $3 E+\infty$ & Th-232 \\
\hline Pa-231 & $1.85 E+04$ & 270 & 5.1 & $9.7 E+02$ & $1.0 E+00$ & 3E-01 & 540 & 5.1 & $1.8 \mathrm{E}+03$ & $1.0 \mathrm{E}+\infty$ & 6E-01 & $\mathrm{Pa-231}$ \\
\hline
\end{tabular}


Table 13-4. Results of Calculations for the Water Pathway at SRS (water travel time from land surface to performance boundary [excluding facility detention] $=12$ y) Part 2 of 2 )

\begin{tabular}{|c|c|c|c|c|c|c|c|c|c|c|c|c|}
\hline \multirow[t]{2}{*}{ Nuclide } & \multirow[b]{2}{*}{$\begin{array}{c}\text { PDCF } \\
\text { remly per } \mu \text { Cin }\end{array}$} & \multicolumn{5}{|c|}{ Trench } & \multicolumn{5}{|c|}{ Tumulus } & \multirow[t]{2}{*}{ Nuclide } \\
\hline & & $\begin{array}{l}\text { CRF source } \\
\text { (dimenzionless) }\end{array}$ & $\underset{\text { (dimensioniess) }}{\mathbf{C R}}$ & $\begin{array}{c}\text { Arrival } \\
\text { Time (y) } \\
\end{array}$ & \begin{tabular}{|c|}
$r_{\text {Decay }}$ \\
(dimensionless)
\end{tabular} & $\begin{array}{c}C_{w-W a t e r} \\
\left(\mu \mathrm{C} / \mathrm{m}^{2}\right)\end{array}$ & \begin{tabular}{|l|} 
CRF souree \\
(dimensionless)
\end{tabular} & $\begin{array}{l}\text { CRF } \text { Werer } \\
\text { (dimensionless) }\end{array}$ & \begin{tabular}{c|} 
Arrival \\
Time (y)
\end{tabular} & 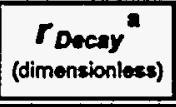 & $\begin{array}{c}C_{\text {w-Wawer }} \\
\left(\mu \mathrm{Ci} / \mathrm{m}^{3}\right)\end{array}$ & \\
\hline U-232 & $1.55 E+03$ & 270 & 5.1 & $4.5 E+03$ & $1.4 E+19$ & NL & 540 & 5.1 & $7.6 \mathrm{E}+03$ & $3.9 E+32$ & $\mathrm{NL}$ & U-232 \\
\hline U-233 & $1.69 E+03$ & 270 & 5.1 & $4.5 E+03$ & NA & $4 E+00$ & 540 & 5.1 & $7.6 \mathrm{E}+03$ & NA & $6 E+\infty 0$ & U-233 \\
\hline U-234 & $5.28 \mathrm{E}+02$ & 270 & 5.1 & $4.5 E+03$ & NA & $2 E+01$ & 540 & 5.1 & $7.6 \mathrm{E}+03$ & NA & $2 E+01$ & U-234 \\
\hline U-235 & $2.94 \mathrm{E}+03$ & 270 & 5.1 & $4.5 E+03$ & NA & $3 E+00$ & 540 & 5.1 & $7.6 E+03$ & NA & $4 E+\infty 0$ & U-235 \\
\hline $\mathrm{U}-236$ & $1.96 E+02$ & 270 & 5.1 & $4.5 E+03$ & $1.0 \mathrm{E}+00$ & $3 E+01$ & 540 & 5.1 & $7.6 E+03$ & $1.0 \mathrm{E}+\infty 0$ & $6 E+01$ & U-236 \\
\hline $\mathrm{U}-238$ & 2.07E+02 & 270 & 5.1 & $4.5 E+03$ & NA & $3 E+01$ & 540 & 5.1 & $7.6 \mathrm{E}+03$ & NA & $5 E+01$ & U-238 \\
\hline$N p-237$ & $3.24 E+03$ & 270 & 5.1 & $9.7 E+02$ & $1.0 \mathrm{E}+00$ & $2 E+00$ & 540 & 5.1 & $1.8 \mathrm{E}+03$ & $1.0 \mathrm{E}+\infty$ & $3 E+00$ & Np-237 \\
\hline Pu-238 & $2.34 E+03$ & 270 & 5.1 & $8.8 E+03$ & $1.7 E+30$ & $4 E+04$ & 540 & 5.1 & $1.5 \mathrm{E}+04$ & $e$ & $6 \mathrm{E}+04$ & $\mathrm{Pu}-238$ \\
\hline Pu-239 & $2.58 E+03$ & 270 & 5.1 & $8.8 E+03$ & $1.3 E+00$ & $3 E+00$ & 540 & 5.1 & $1.5 E+04$ & $1.5 E+\infty 0$ & $6 \mathrm{E}+00$ & Pu-239 \\
\hline Pu-240 & $2.58 \mathrm{E}+03$ & 270 & 5.1 & $8.8 E+03$ & $2.5 E+00$ & $5 E+00$ & 540 & 5.1 & $1.5 \mathrm{E}+04$ & $4.8 E+\infty 0$ & $2 E+01$ & Pu-240 \\
\hline Pu-241 & $4.82 E+08$ & 270 & 5.1 & $8.8 E+03$ & e & $2 E+05$ & 540 & 5.1 & $1.5 E+04$ & e & $5 E+05$ & Pu-241 \\
\hline Pu-242 & $2.45 E+03$ & 270 & 5.1 & $8.8 E+03$ & $1.0 E+00$ & $2 E+00$ & 540 & 5.1 & $1.5 E+04$ & $1.0 \mathrm{E}+\infty$ & $5 E+\infty$ & Pu-242 \\
\hline Pu-244 & $4.11 E+03$ & 270 & 5.1 & $8.8 E+03$ & $\overline{N A}$ & $1 E+00$ & 540 & 5.1 & $1.5 E+04$ & NA & $3 E+\infty 0$ & Pu-244 \\
\hline Am-241 & $2.66 \mathrm{E}+03$ & 270 & 5.1 & $1.3 E+04$ & $1.4 E+09$ & $8 E+03$ & 540 & 5.1 & $2.2 \mathrm{E}+04$ & $2.4 E+15$ & $2 E+04$ & Am-241 \\
\hline Am-243 & $2.64 E+03$ & 270 & 5.1 & $1.3 E+04$ & $3.4 E+00$ & $7 E+00$ & 540 & 5.1 & $2.2 E+04$ & $8.0 E+00$ & $3 E+01$ & Am-243 \\
\hline $\mathrm{Cm}-243$ & $1.83 E+03$ & 270 & 5.1 & $1.3 E+04$ & e & $2 E+03$ & 540 & 5.1 & $2.2 E+04$ & $e$ & $5 E+03$ & $\mathrm{Cm}-243$ \\
\hline $\mathrm{Cm}-244$ & $1.47 E+03$ & 270 & 5.1 & $1.3 E+04$ & e & $2 E+03$ & 540 & 5.1 & $2.2 E+04$ & e & $7 E+03 \quad \circ \quad 7$ & $\mathrm{Cm}-244$ \\
\hline $\mathrm{Cm}-245$ & $4.56 E+03$ & 270 & 5.1 & $1.3 E+04$ & NA & $1 E+00^{\circ}$ & 540 & 5.1 & $2.2 \mathrm{E}+04$ & NA & $2 E+\infty 0$ & $\mathrm{Cm}-245$ \\
\hline $\mathrm{Cm}-246$ & $2.70 E+03$ & 270 & 5.1 & 1.3E+04 & $6.8 \mathrm{E}+00$ & $1 E+01$ c & 540 & 5.1 & $2.2 E+04$ & $2.5 E+01$ & $1 E+02$ & $\mathrm{Cm}-246$ \\
\hline $\mathrm{Cm}-247$ & $4.34 E+03$ & 270 & 5.1 & $1.3 E+04$ & NA & $1 E+00$ ' & 540 & 5.1 & $2.2 E+04$ & NA & $2 E+\infty 0$ & $\mathrm{Cm}-247$ \\
\hline $\mathrm{Cm}-248$ & $9.94 E+03$ & 270 & 5.1 & $1.3 E+04$ & $1.0 \mathrm{E}+00$ & $5 E-01$ C & 540 & 5.1 & $2.2 E+0.4$ & $1.0 \mathrm{E}+00$ & $1 E+\infty$ & $\mathrm{Cm}-248$ \\
\hline Cf-249 & $3.46 E+03$ & 270 & 5.1 & $1.3 E+04$ & $1.9 E+11$ & $3 E+01<1$ & 540 & 5.1 & $2.2 E+04$ & $9.2 E+18$ & $6 E+01$ & $C f-249$ \\
\hline Cf-250 & $2.64 E+08$ & 270 & 5.1 & 1.3E+04 & e & $5 E+03 \quad 1$ & 540 & 5.1 & $2.2 E+0.4$ & e & $4 E+04$ & $C F-250$ \\
\hline Cf-251 & $3.54 E+03$ & 270 & 5.1 & $1.3 \mathrm{E}+04$ & $2.5 E+04$ & $4 E+04{ }^{\circ}$ & 540 & 5.1 & $2.2 E+04$ & $2.5 E+07$ & $8 E+07$ & $C f-251$ \\
\hline
\end{tabular}

a "NA" means Not Applicable - decay factor is implicit in the PDCF for this radionuclide.

b "NL" means No Limit - estimated permissible concentration is greater than the specific activity of the pure elemental radionuclide.

c Radionuclide concentration is based on arrival time at the performance boundary beyond $10,000 \mathrm{y}$.

d PDCF is a function of arrival time. See Chapter 1 of this volume for equation.

e rocar $\geq 1 E+50$

f Contribution of decay product(s) is significant to determination of this value (see Table E-3 in Volume 2). Listed arrival time is that of the parent radionuclide. If this footnote does not appear in combination with footnote $c$, the arrival time of the significant decay product(s) is less that $10,000 \mathrm{y}$. 
For the trench design at Savannah River, the total undecayed CRFs for the groundwater pathway ranged from about 2 to 1,400. Among the listed radionuclides, arrival times at the performance boundary ranged from $100 \mathrm{y}$ to $260,000 \mathrm{y}$, including the retention time in the facility before failure. The travel time through the unsaturated zone accounted for about $70 \%$ of the total subsurface travel time.

For the tumulus design, the total undecayed CRFs for the groundwater pathway ranged from about 5 to 2,800. Among the listed radionuclides, arrival times at the performance boundary ranged from $310 \mathrm{y}$ to $440,000 \mathrm{y}$, including the retention time in the facility before failure.

Differences in these arrival times compared to the trench were attributable to (1) the assumed time of hydrologic failure of the facility (100 y for the trench and $300 \mathrm{y}$ for the tumulus); and (2) the increased travel distance through the vadose zone for the tumulus (the bottom of the tumulus was assumed to be at grade level, while the trench was assumed to be a shallow buried structure).

Savannah River has plans for an MLLW disposal facility, the Mixed Waste Disposal Facility. Appendix A.2 presents the results of applying the PE method to that facility. Appendix A.2 also contains a comparison of the PE method for the water pathway and its results to the LLW performance assessment conducted for the SRS E-Area Vaults (MMES et al., 1994).

\subsubsection{Atmospheric Transport}

Two CRFs were used to account for the attenuation encompassing diffusion to the ground surface, mixing in air, and dispersion in the atmosphere to the performance boundary. The CRF for diffusion in soil, $C R F_{D i f f}$, was defined as the ratio of the radionuclide concentration in the waste to its resulting concentration in the upper one centimeter of soil. The CRF for dispersion in air, $C R F_{\text {Disp, }}$ was defined as the ratio of the radionuclide concentration in the upper one centimeter of soil to its resulting concentration in air at the performance boundary. The effect of radioactive decay was also included in the PE.

Application of the PE methodology for atmospheric transport of the two volatile radionuclides considered in the $\mathrm{PE}$ ( $\mathrm{H}-3$ and $\mathrm{C}-14$ ) produced the results shown in Table 13-5 for both the generic trench and tumulus designs; there was no assumed difference in these two disposal technologies with respect to permissible waste limits based on the atmospheric pathway at Savannah River. The table shows permissible waste concentrations based on transport in the atmospheric pathway $\left(C_{W-A t m}\right)$, as well as the values used in calculating the permissible waste concentrations. For both $\mathrm{H}-3$ and $\mathrm{C}-14$, the greatest concentration reduction occurred as the radionuclides diffuse from the top of the disposal facility to the soil surface.

Table 13-5. Results of Calculations for the Atmospheric Pathway

\begin{tabular}{|c|c|c|c|c|c|c|c|}
\hline \multirow[t]{2}{*}{ Nuclide } & \multirow[b]{2}{*}{$\underset{(\text { rom } / y) /(\mu \mathrm{Ci} / L)}{S D C F_{\text {Atm }}}$} & \multicolumn{6}{|c|}{ Generic Trench and Tumulus } \\
\hline & & $\begin{array}{c}C_{\text {(dimensionloss) }} \\
\end{array}$ & $\begin{array}{c}C R F_{\text {Disp }} \\
\text { (dimentionleas) } \\
\end{array}$ & $\begin{array}{c}\mathrm{CRF}_{\text {Atm }} \\
\text { (dimenesionideses) }\end{array}$ & $\begin{array}{c}\text { Arrival } \\
\text { Time (y) } \\
\end{array}$ & $\begin{array}{c}\text { rocacy } \\
\text { (dimentionleas) } \\
\end{array}$ & $\begin{array}{c}C_{W-A t m} \\
\left|\mu \mathrm{Ci} / \mathrm{m}^{3}\right|\end{array}$ \\
\hline $\mathrm{H}-3$ & $8.33 E+02$ & $4 E+06$ & $2 E+03$ & $8 E+09$ & 100 & 300 & $3 E+10$ \\
\hline C-14 & $2.20 E+05$ & $1 E+05$ & $4 E+03$ & $4 E+08$ & 100 & 1 & $2 E+04$ \\
\hline
\end{tabular}


The time of arrival at the performance boundary for both radionuclides is shown in Table 13-5 as $100 \mathrm{y}$. However, the actual migration of H-3 and C-14 from the disposal facility to the surface and downwind to the performance boundary was calculated to be on the order of hours, not years. As discussed in Section 13.3.2, the waste form and RCRA cover are assumed to retain these volatile radionuclides in the disposal facility for at least $100 \mathrm{y}$.

Savannah River has plans for an MLLW disposal facility, the Mixed Waste Disposal Facility. Appendix A.2 presents the results of applying the PE method to that facility. Appendix A.2 also contains a comparison of the PE method for the atmospheric pathway and its results to the LLW performance assessment conducted for the SRS E-Area Vaults (MMES et al., 1994).

\subsubsection{Inadvertent Intruder Exposure}

The calculation of permissible waste concentrations for inadvertent intruder exposures did not utilize CRFs. Instead, the total dose resulting from an intrusion scenario (the sum of the doses from all exposure pathways involved in that intrusion) was computed from scenario dose conversion factors (SDCFs) that were applied to specific exposure pathways. These SDCF values were radionuclide-specific and facility-design-specific and were the same for all sites. The exposure pathways evaluated for each radionuclide are listed in Appendix D of Volume 2. Results based on intruder scenarios should be evaluated carefully because future social behavior, and intrusion scenarios, are difficult to predict.

The standard PE intrusion analysis includes consideration of two intrusion scenarios: homesteader (or agricultural) intrusion and post-drilling intrusion. As described in Section 13.3.3.2, the post-drilling scenario at Savannah River never yields doses that would exceed the doses from the homesteader scenario. The permissible waste concentrations for the two generic facility designs for each of the 58 radionuclides based on the standard PE homesteader intrusion scenario are listed in Table 13-6.

Values for the radioactive decay term in Table 13-6 were based on the applicable time of homesteader intrusion into the disposal facility ( $300 \mathrm{y}$ for trench design and $500 \mathrm{y}$ for the tumulus design). For six radionuclides in the table (U-233, U-234, U-235, U-238, Pu-244, and Cm-247), the time of homesteader intrusion was changed to $10,000 \mathrm{y}$, the end of the performance period. For these six radionuclides, ingrowth of decay products yields scenario doses that increase over time. The doses at $10,000 \mathrm{y}$, therefore, represent the maximum that could be encountered during the performance period. Also, for Th-230 and $\mathrm{Cm}-245$, ingrowth of decay products likewise produces a scenario dose that increases over time and peaks within the 10,000-y performance period. The times of homesteader intrusion for these two radionuclides (Th-230 and Cm-245) were taken as the time of maximum dose, $9000 \mathrm{y}$ and $1000 \mathrm{y}$, respectively.

Savannah River has plans for an MLLW disposal facility, the Mixed Waste Disposal Facility. Appendix A.2 presents the results of applying the PE method to that facility. Appendix A.2 also contains a comparison of the PE method for the intrusion scenarios and its results to the LLW performance assessment conducted for the SRS E-Area Vaults (MMES et al., 1994). 
Table 13-6. Permissible Waste Concentrations for the Standard Intrusion Scenarios (most limiting radionuclide concentration for each facility design is highlighted in bold italic) (Part 1 of 2)

\begin{tabular}{|c|c|c|c|}
\hline \multirow[t]{2}{*}{ Nuclide } & Trench & Tumulus & \multirow[t]{2}{*}{ Nuclide } \\
\hline & $\begin{array}{c}C_{w-1 n t r} \\
\text { Homesteader } \\
\left(\mu \mathrm{Ci} / \mathrm{m}^{3}\right)\end{array}$ & $\begin{array}{c}C_{w-1 n t} \\
\text { Homesteader } \\
\left(\mu \mathrm{Cu} / \mathrm{m}^{3}\right)\end{array}$ & \\
\hline $\mathrm{H}-3$ & $1 E+12$ & $N L$ & $\mathrm{H}-3$ \\
\hline$c-14$ & $1 E+04$ & $1 E+04$ & C-14 \\
\hline Al-26 & $5 E+01$ & $6 E+01$ & Al-26 \\
\hline Si-32 & $9 E+03$ & $4 E+04$ & Si-32 \\
\hline $\mathrm{Cl}-36$ & $2 E+02$ & $2 E+02$ & $\mathrm{Cl}-36$ \\
\hline$K-40$ & $7 E+02$ & $7 E+02$ & $K-40$ \\
\hline Co-60 & $N L$ & $N L$ & Co-60 \\
\hline Ni-59 & $3 E+06$ & $3 E+06$ & Ni-59 \\
\hline $\mathrm{Ni}-63$ & $8 E+06$ & $3 E+07$ & Ni-63 \\
\hline Se-79 & $2 E+05$ & $2 E+05$ & Se-79 \\
\hline Sr-90 & $1 E+06$ & $1 E+08$ & Sr-90 \\
\hline $\mathrm{Zr}-93$ & $5 E+06$ & $5 E+06$ & Zr-93 \\
\hline $\mathrm{Nb}-93 \mathrm{~m}$ & $5 E+12$ & $N L$ & $\mathrm{Nb}-93 \mathrm{~m}$ \\
\hline $\mathrm{Nb}-94$ & $9 E+01$ & $1 E+02$ & $\mathrm{Nb}-94$ \\
\hline TC-99 & $2 E+04$ & $2 E+04$ & Tc-99 \\
\hline $\mathrm{Pd}-107$ & $6 E+06$ & $6 E+06$ & $\mathrm{Pd}-107$ \\
\hline $\mathrm{Ag}-108 \mathrm{~m}$ & $5 E+02$ & $1 E+03$ & $\mathrm{Ag}-108 \mathrm{~m}$ \\
\hline $\mathrm{Cd}-113 \mathrm{~m}$ & $4 E+09$ & $7 E+13$ & $\mathrm{Cd}-113 \mathrm{~m}$ \\
\hline Sn-121m & $2 E+07$ & $2 E+08$ & $\mathrm{Sn}-121 \mathrm{~m}$ \\
\hline Sn-126 & $8 E+01$ & $8 E+01$ & Sn-126 \\
\hline $1-129$ & $2 E+03$ & $2 E+03$ & $1-129$ \\
\hline Cs-135 & $2 E+05$ & $2 E+05$ & Cs-135 \\
\hline Cs-137 & $3 E+05$ & $3 E+07$ & Cs-137 \\
\hline $\mathrm{Ba}-133$ & $2 E+11$ & $N L$ & $\mathrm{Ba}-133$ \\
\hline Sm-151 & $2 E+08$ & $8 E+08$ & Sm-151 \\
\hline Eu-152 & $6 E+08$ & $2 E+13$ & Eu-152 \\
\hline Eu-154 & $4 E+12$ & $N L$ & Eu-154 \\
\hline $\mathrm{Pb}-210$ & $7 E+06$ & $4 E+09$ & $\mathrm{~Pb}-210$ \\
\hline Ra-226 & $8 E+01$ & $9 E+01$ & Ra-226 \\
\hline Ra-228 & $N L$ & $N L$ & $\mathrm{Ra}-228$ \\
\hline Th-229 & $5 E+02$ & $5 E+02$ & Th-229 \\
\hline Th-230 & $8 E+01$ & $8 E+01$ & Th-230 \\
\hline Th-232 & $6 E+01$ & $6 E+01$ & Th-232 \\
\hline $\mathrm{Pa}-231$ & $2 E+02$ & $2 E+02$ & $\mathrm{~Pa}-231$ \\
\hline
\end{tabular}


Table 13-6. Permissible Waste Concentrations for the Standard Intrusion Scenarios (most limiting radionuclide concentration for each facility design is highlighted in bold italic) (Part 2 of 2)

\begin{tabular}{|c|c|c|c|}
\hline \multirow[t]{2}{*}{ Nuclide } & Trench & Tumulus & \multirow[t]{2}{*}{ Nuclide } \\
\hline & $\begin{array}{c}C_{w-n t^{2}} \\
\text { Homesteader } \\
\left(\mu \mathrm{Ci} / \mathrm{m}^{3}\right)\end{array}$ & $\begin{array}{c}C_{w-m t^{2}} \\
\text { Homesteader } \\
\left(\mu \mathrm{Ci} / \mathrm{m}^{3}\right)\end{array}$ & \\
\hline U-232 & $2 E+03$ & $1 E+04^{\circ}$ & $\mathrm{U}-232$ \\
\hline U-233 & $7 E+02$ & $7 E+02$ & U-233 \\
\hline U-234 & $1 E+03$ & $1 E+03$ & U-234 \\
\hline U-235 & $6 E+02$ & $6 E+02$ & U-235 \\
\hline U-236 & $2 E+04$ & $2 E+04$ & $\mathrm{U}-236$ \\
\hline U-238 & $5 E+03$ & $5 E+03$ & U-238 \\
\hline Np-237 & $4 E+02$ & $4 E+02$ & Np-237 \\
\hline Pu-238 & $7 E+04$ & $4 E+05$ & Pu-238 \\
\hline Pu-239 & $6 E+03$ & $6 E+03$ & Pu-239 \\
\hline Pu-240 & $6 E+03$ & $7 E+03$ & Pu-240 \\
\hline Pu-241 & $2 E+05$ & $3 E+05$ & Pu-241 \\
\hline Pu-242 & $6 E+03$ & $6 E+03$ & Pu-242 \\
\hline Pu-244 & $4 E+02$ & $4 E+02$ & $\mathrm{Pu}-244$ \\
\hline Am-241 & $7 E+03$ & $9 E+03$ & Am-241 \\
\hline Am-243 & $9 E+02$ & $9 E+02$ & Am-243 \\
\hline $\mathrm{Cm}-243$ & $1 E+06$ & $5 E+06$ & $\mathrm{Cm}-243$ \\
\hline $\mathrm{Cm}-244$ & $2 E+06$ & $2 E+06$ & $\mathrm{Cm}-244$ \\
\hline $\mathrm{Cm}-245$ & $1 E+03$ & $1 E+03$ & $\mathrm{Cm}-245$ \\
\hline $\mathrm{Cm}-246$ & $6 E+03$ & $6 E+03$ & $\mathrm{Cm}-246$ \\
\hline $\mathrm{Cm}-247$ & $3 E+02$ & $3 E+02$ & $\mathrm{Cm}-247$ \\
\hline $\mathrm{Cm}-248$ & $2 E+03$ & $2 E+03$ & $\mathrm{Cm}-248$ \\
\hline Cf-249 & $8 E+02$ & $1 E+03$ & Cf-249 \\
\hline Cf-250 & $2 E+06$ & $2 E+06$ & Cf-250 \\
\hline$C f-251$ & $2 E+03$ & $2 E+03$ & Cf-251 \\
\hline
\end{tabular}

a "NL" means No Limit - estimated permissible concentration is greater than the specific activity of the pure elemental radionuclide. 


\subsection{SUMMARY AND DISCUSSION OF RESULTS}

The limiting waste concentrations in disposed MLLW for the water, atmospheric, and intruder analyses for the generic trench and tumulus designs are summarized in Table 13-7 and discussed in Section 13.6.1. An overall discussion of the results of the PE for Savannah River is contained in Section 13.6.2.

\subsubsection{Results Based on Disposal Design}

For the generic trench design at Savannah River, 26 radionuclides were limited by the water pathway, no radionuclides were limited by the atmospheric pathway, and 30 radionuclides were limited by the intrusion scenario, as shown in Table 13-7. In addition, Co-60 had no limit from any pathway; this is a relatively immobile radionuclide with a half-life of about $5 \mathrm{y}$. The radionuclide $\mathrm{Pu}-241$ had equal permissible waste concentrations for the water and intruder pathways.

For the generic tumulus design, 19 radionuclides were limited by the water pathway, no radionuclides were limited by the atmospheric pathway, and 37 radionuclides were limited by intrusion scenarios. Two radionuclides (Co-60 and $\mathrm{Ba}-133)$ had no limit from any of the pathways.

For the trench design, concentrations for 9 radionuclides that arrived at the performance boundary before $10,000 \mathrm{y}$ were reported for the water pathway analysis as having no limit; for the tumulus design, 5 waste concentrations had no limit. As discussed in Section 13.5.1, the calculated concentrations for those radionuclides reported as NL (No Limit) were above the specific activity of the pure elemental radionuclide, implying that the performance measure of $4 \mathrm{mrem}(0.04 \mathrm{mSv})$ per year would not be reached under the given release and transport assumptions.

As also discussed in Section 13.5.1, values for some radionuclides are not reported in Table 13-7 for the water pathway analysis. Arrival times for these radionuclides were beyond the $10,000-y$ performance period. For these radionuclides, the estimated waste concentrations are presented in Table 13-4 for information purposes but are not listed in Table 13-7. Consistent with the approach used in LLW performance assessments, these values were not considered in determining the most restrictive disposal limit from among the evaluated pathways because arrival times for these radionuclides were beyond $10,000 \mathrm{y}$.

For both the trench and tumulus designs, the radionuclides limited by the water pathway generally tended to be highly mobile (e.g., $\mathrm{H}-3$ and Tc-99). The americium and californium radionuclides are not shown as being limited by the water pathway because their peak arrival times were beyond $10,000 \mathrm{y}$. 
Table 13-7. Permissible Concentrations for the Generic Disposal Designs at SRS (permissible concentration related to the most limiting pathway for each facility design is highlighted in bold italic) (Part 1 of 2)

\begin{tabular}{|c|c|c|c|c|c|c|c|}
\hline \multirow[t]{2}{*}{ Nuclide } & \multicolumn{3}{|c|}{ Trench } & \multicolumn{3}{|c|}{ Tumulus } & \multirow[t]{2}{*}{ Nuclide } \\
\hline & $\begin{array}{c}C_{\text {w-water }}{ }^{a, b} \\
\left(\mu \mathrm{Cu} / \mathrm{m}^{3}\right)\end{array}$ & $\begin{array}{l}C_{\text {W.Atm }}{ }^{c} \\
\left(\mu \mathrm{Ci} / \mathrm{m}^{3}\right)\end{array}$ & $\begin{array}{l}C_{W-1 n t r}{ }^{d} \\
\left(\mu \mathrm{Ci} / m^{3}\right)\end{array}$ & $\begin{array}{c}C_{\text {w-Water }}{ }^{2, b} \\
\left(\mu \mathrm{Ci} / \mathrm{m}^{3}\right)\end{array}$ & $\begin{array}{l}C_{W-A t m}{ }^{c} \\
\left(\mu \mathrm{Ci} / m^{3}\right)\end{array}$ & $\begin{array}{l}C_{w-n t r}{ }^{d} \\
\left.(\mu \mathrm{Cilm})^{3}\right)\end{array}$ & \\
\hline $\mathrm{H}-3$ & $7 E+04$ & $3 E+10$ & $1 E+12$ & $2 E+10$ & $3 E+10$ & NL & $\mathrm{H}-3$ \\
\hline$C-14$ & $4 E+02$ & $2 E+04$ & $1 E+04$ & $8 E+02$ & $2 E+04$ & $1 E+04$ & $C-14$ \\
\hline Al-26 & $5 E+02$ & & $5 E+01$ & $1 E+03$ & & $5 E+01$ & Al-26 \\
\hline Si-32 & $1 E+03$ & & $9 \mathrm{E}+03$ & $1 E+04$ & & $4 E+04$ & Si-32 \\
\hline $\mathrm{Cl}-36$ & $4 E+00$ & & $2 E+02$ & $8 E+00$ & & $2 E+02$ & $\mathrm{Cl}-36$ \\
\hline$K-40$ & $6 E+00$ & & $7 E+02$ & $9 E+00$ & & $7 E+02$ & $K-40$ \\
\hline Co-60 & $N L$ & & $N L$ & $N L$ & & $N L$ & $\mathrm{Co}-60$ \\
\hline $\mathrm{Ni}-59$ & - & & $3 E+06$ & - & & $3 E+06$ & $\mathrm{Ni}-59$ \\
\hline $\mathrm{Ni}-63$ & - & & $8 E+06$ & - & & $3 E+07$ & $\mathrm{Ni}-63$ \\
\hline Se-79 & $1 E+01$ & & $2 E+05$ & $2 E+01$ & & $2 E+05$ & Se-79 \\
\hline Sr-90 & $6 E+11$ & & $1 E+06$ & NL & & $1 E+08$ & Sr-90 \\
\hline Zr-93 & $3 E+02$ & & $5 E+06$ & $7 E+02$ & & $5 E+06$ & $Z r-93$ \\
\hline $\mathrm{Nb}-93 \mathrm{~m}$ & $1 E+05$ & & $5 E+12$ & $2 E+09$ & & $\mathrm{NL}$ & $\mathrm{Nb}-93 \mathrm{~m}$ \\
\hline $\mathrm{Nb}-94$ & $1 E+02$ & & $9 E+01$ & $2 E+02$ & & $1 E+02$ & $\mathrm{Nb}-94$ \\
\hline Tc-99 & $6 E+01$ & & $2 E+04$ & $1 E+02$ & & $2 E+04$ & Tc-99 \\
\hline $\mathrm{Pd}-107$ & $5 E+04$ & & $6 \mathrm{E}+06$ & $1 E+05$ & & $6 \mathrm{E}+06$ & $P d-107$ \\
\hline $\mathrm{Ag}-108 \mathrm{~m}$ & $2 E+05$ & & $5 E+02$ & $2 E+07$ & & $1 E+03$ & $\mathrm{Ag}-108 \mathrm{~m}$ \\
\hline Cd-113m & NL & & $4 E+09$ & $\mathrm{NL}$ & & $7 E+13$ & $\mathrm{Cd}-113 \mathrm{~m}$ \\
\hline$S n-121 m$ & - & & $2 E+07$ & - & & $2 E+08$ & $\mathrm{Sn}-121 \mathrm{~m}$ \\
\hline Sn-126 & - & & $8 E+01$ & - & & $8 E+01$ & $\mathrm{Sn}-126$ \\
\hline $1-129$ & $3 E-01$ & & $2 E+03$ & $6 E-01$ & & $2 E+03$ & $1-129$ \\
\hline Cs-135 & $1 E+02$ & & $2 E+05$ & - & & $2 E+05$ & Cs-135 \\
\hline Cs-137 & NL & & $3 E+05$ & - & & $3 E+07$ & Cs-137 \\
\hline $\mathrm{Ba}-133$ & NL & & $2 E+11$ & $N L$ & & $N L$ & $\mathrm{Ba}-133$ \\
\hline $\mathrm{Sm}-151$ & NL & & $2 E+08$ & - & & $8 E+08$ & $\mathrm{Sm}-151$ \\
\hline Eu-152 & NL & & $6 E+08$ & - & & $2 E+13$ & Eu-152 \\
\hline Eu-154 & $\mathrm{NL}$ & & $4 E+12$ & - & & $N L$ & Eu-154 \\
\hline $\mathrm{Pb}-210$ & NL & & $7 E+06$ & - & & $4 E+09$ & $\mathrm{~Pb}-210$ \\
\hline Ra-226 & - & & $8 E+01$ & - & & $9 E+01$ & $\mathrm{Ra}-226$ \\
\hline Ra-228 & - & & $N L$ & - & & $N L$ & Ra-228 \\
\hline Th-229 & - & & $5 E+02$ & - & & $5 E+02$ & Th-229 \\
\hline Th-230 & - & & $8 E+01$ & - & & $8 E+01$ & Th-230 \\
\hline Th-232 & - & & $6 E+01$ & - & & $6 E+01$ & Th-232 \\
\hline $\mathrm{Pa}-231$ & $3 E-01$ & & $2 E+02$ & $6 E-01$ & & $2 E+02$ & $\mathrm{~Pa}-231$ \\
\hline
\end{tabular}


Table 13-7. Permissible Concentrations for the Generic Disposal Designs at SRS (permissible concentration related to the most limiting pathway for each facility design is highlighted in bold italic) (Part 2 of 2)

\begin{tabular}{|c|c|c|c|c|c|c|c|}
\hline \multirow[t]{2}{*}{ Nuclide } & \multicolumn{3}{|c|}{ Trench } & \multicolumn{3}{|c|}{ Tumulus } & \multirow[t]{2}{*}{ Nuclide } \\
\hline & $\begin{array}{c}C_{\text {w.water }}{ }^{2, b} \\
\left(\mu \mathrm{Ci} / \mathrm{m}^{3}\right)\end{array}$ & $\begin{array}{l}C_{W \cdot A t m}{ }^{c} \\
\left(\mu \mathrm{CI} / m^{3}\right)\end{array}$ & $\begin{array}{l}C_{W / n \pi^{d}} \\
\left(\mu \mathrm{Ci} / m^{3}\right)\end{array}$ & $\begin{array}{c}C_{\text {w-Water }}{ }^{2, b} \\
\left(\mu \mathrm{Ci} / \mathrm{m}^{3}\right)\end{array}$ & $\begin{array}{l}C_{W-A t m}{ }^{c} \\
\left(\mu \mathrm{Ci} / m^{3}\right)\end{array}$ & $\begin{array}{l}C_{w-1 n t r}{ }^{d} \\
\left(\mu \mathrm{Ci} / m^{3}\right)\end{array}$ & \\
\hline U-232 & NL & & $2 E+03$ & NL & & $1 E+04$ & $\mathrm{U}-232$ \\
\hline U-233 & $4 E+00$ & & $7 E+02$ & $6 E+00$ & & $7 E+02$ & U-233 \\
\hline U-234 & $2 E+01$ & & $1 E+03$ & $2 E+01$ & & $1 E+03$ & U-234 \\
\hline U-235 & $3 E+00$ & & $6 E+02$ & $4 E+00$ & & $6 E+02$ & U-235 \\
\hline U-236 & $3 E+01$ & & $2 E+04$ & $6 E+01$ & & $2 E+04$ & U-236 \\
\hline U-238 & $3 E+01$ & & $5 E+03$ & $5 E+01$ & & $5 \mathrm{E}+03$ & U-238 \\
\hline $\mathrm{Np}-237$ & $2 E+00$ & & $4 E+02$ & $3 E+00$ & & $4 E+02$ & $\mathrm{~Np}-237$ \\
\hline Pu-238 & $4 E+04$ & & $7 E+04$ & $6 E+04$ & & $4 E+05$ & Pu-238 \\
\hline Pu-239 & $3 E+00$ & & $6 \mathrm{E}+03$ & - & & $6 E+03$ & Pu-239 \\
\hline Pu-240 & $5 E+00$ & & $6 E+03$ & - & & $7 E+03$ & Pu-240 \\
\hline $\mathrm{Pu}-241$ & $2 E+05$ & & $2 E+05$ & $5 E+05$ & & $3 E+05$ & Pu-241 \\
\hline $\mathrm{Pu}-242$ & $2 E+00$ & & $6 E+03$ & - & & $6 E+03$ & Pu-242 \\
\hline Pu-244 & $1 E+00$ & & $4 E+02$ & - & & $4 E+02$ & Pu-244 \\
\hline Am-241 & $8 E+03$ & & $7 E+03$ & $2 E+04$ & & $9 E+03$ & Am-241 \\
\hline Am-243 & - & & $9 E+02$ & - & & $9 E+02$ & Am-243 \\
\hline $\mathrm{Cm}-243$ & $2 E+03$ & & $1 E+06$ & - & & $5 E+06$ & $\mathrm{Cm}-243$ \\
\hline $\mathrm{Cm}-244$ & $2 E+03$ & & $2 E+06$ & - & & $2 E+06$ & $\mathrm{Cm}-244$ \\
\hline $\mathrm{Cm}-245$ & - & & $1 E+03$ & - & & $1 E+03$ & $\mathrm{Cm}-245$ \\
\hline $\mathrm{Cm}-246$ & - & & $6 E+03$ & - & & $6 E+03$ & $\mathrm{Cm}-246$ \\
\hline $\mathrm{Cm}-247$ & - & & $3 E+02$ & - & & $3 E+02$ & $\mathrm{Cm}-247$ \\
\hline $\mathrm{Cm}-248$ & - & & $2 E+03$ & - & & $2 E+03$ & $\mathrm{Cm}-248$ \\
\hline Cf-249 & - & & $8 E+02$ & - & & $1 E+03$ & Cf-249 \\
\hline Cf-250 & - & & $2 E+06$ & - & & $2 E+06$ & Cf-250 \\
\hline Cf-251 & - & & $2 E+03$ & - & & $2 E+03$ & Cf-251 \\
\hline
\end{tabular}

a "NL" means No Limit - estimated permissible concentration factor is greater than the specific activity of the pure elemental radionuclide.

b "-" indicates that the radionuclide concentration is based on an arrival time beyond 10,000 y; see Table $13-4$ for specific values.

c Results presented for radionclides expected to be volatile under disposal facility conditions.

d Concentration is based on the most restrictive intrusion scenario assumed for the site; see Table 13-6. 
As mentioned previously, intrusion in the post-drilling scenario was assumed to occur ar the same time as the agricultural and resident scenarios. Because of this assumption, the limiting radionuclide concentrations would be more restrictive for the agricultural scenario; thus, only the results of evaluating this scenario are presented in Table 13-6. However, to assess the effect of this site-specific assumption, the differences in concentration limits for the radionuclides relative to the generic intrusion scenario are discussed below.

The effect of increasing the intrusion time for the post-drilling scenario from the standard $100 \mathrm{y}$ for both the trench and tumulus designs to $300 \mathrm{y}$ for the trench design and $500 \mathrm{y}$ for the tumulus design was to increase the permissible concentrations for 17 radionuclides $(\mathrm{H}-3, \mathrm{Si}-32$, Co-60, Ni-63, Sr-90, Nb-93m, Cd-113, Sn-121m, Cs-137, Ba-133, Sm-151, Eu-152, Eu-154, $\mathrm{Pb}-210, \mathrm{Ra}-228, \mathrm{Pu}-238$, and $\mathrm{Cm}-243)$. All other radionuclides considered in the PE were unaffected by the assumed time of intrusion of the post-drilling scenario. The 17 affected radionuclides have half-lives of $100 \mathrm{y}$ or less (12 have half-lives less than $50 \mathrm{y}$ ).

For the trench design, the limiting concentrations for 8 of the 17 radionuclides were unaffected by the assumed site-specific time of intrusion (i.e., the limiting concentrations highlighted in Table 13-7 for these radionuclides, in which the site-specific assumption of $300 \mathrm{y}$ was used, remained the more limiting when compared to concentrations determined for the postdrilling scenario at 100-y intrusion). For the other 9 radionuclides (Co-60, Sr-90, Cd-113, $\mathrm{Ba}-133, \mathrm{Eu}-152, \mathrm{Eu}-154, \mathrm{~Pb}-210, \mathrm{Ra}-228$, and $\mathrm{Cm}-243)$, the limiting concentrations would be changed by as little as a factor of $1.2(\mathrm{Cm}-243$, half-life $=29.1 \mathrm{y})$ and by as much as from "not limited" to some finite limit (Co-60, half-life $=5.3 \mathrm{y}$; Ra-228, half-life $=5.8 \mathrm{y}$ ). These last two radionuclides have half-lives just beyond the 5-y threshold used for determining the radionuclides to be evaluated in the PE.

For the tumulus design, the limiting concentrations for all but 2 (Si-32 and Nb-93m) of the 17 radionuclides were affected by the assumed site-specific time of intrusion. Of these 15 radionuclides, the limiting concentrations would be changed by as little as a factor of 3 (Ni-63, half-life $=100 \mathrm{y})$ and by as much as from "not limited" to some finite limit (Co-60, half-life $=$ 5.3y; Ba-133, half-life $=10.5 \mathrm{y}$; Eu-154, half-life $=8.6 \mathrm{y}$; and Ra-228, half-life $=5.8 \mathrm{y}$ ). The radionuclides whose concentrations would change from "not limited" to some finite limit have half-lives of less than about $10 \mathrm{y}$.

This discussion indicates the sensitivity of the limiting concentrations for the shorter-lived radionuclides to the assumed time of intrusion; the 41 radionuclides considered in the $\mathrm{PE}$ with half-lives greater than $100 \mathrm{y}$ were not affected by this assumption. Because the 17 shorter-lived radionuclides will decay relatively quickly after disposal, using the site-specific assumption of $300 \mathrm{y}$ for post-drilling intrusion at SRS did not significantly affect the results of the PE.

At Savannah River, the tumulus provides a significantly higher (i.e., greater than one order of magnitude) permissible waste concentration than the trench for 17 radionuclides: $\mathrm{H}-3, \mathrm{Sr}-90$, Nb-93m, Cd-113m, Sn-121m, Cs-135, Cs-137, Ba-133, Eu-152, Eu-154, Pb-210, Pu-239, 
Pu-240, Pu-242, Pu-244, Cm-243, and Cm-244 In general, these radionuclides have half-lives less than about $50 \mathrm{y}$; for those with longer half-lives (such as the plutoniums), the waste limit is controlled by the groundwater pathway for the trench and by the intrusion scenario for the tumulus.

\subsubsection{Discussion}

The results of the PE are based on the framework of assumptions summarized in Chapter 1 of this volume and discussed in detail in Volume 2 of this report and on the site-specific conceptual model for contaminant transport discussed in this chapter. Using alternative assumptions about the conceptual model has the potential to affect the results. Changes in the conceptual model could include alternative assumptions about the disposal facility, the source term, and radionuclide movement in the three pathways. Depending on the degree of possible variation and the relative importance of the parameters used in the calculation of estimated permissible waste concentrations, variability in parameter values can also affect the results. For parameters, results could vary depending on potential changes in values of both the generic and the site-specific parameters used in the PE analysis.

The effect on results from using alternative generic assumptions and parameter values is discussed in Chapter 6 of Volume 2. In addition, a discussion is provided in that chapter about the effects of using alternative values for site-specific parameters. Based on this discussion, four parameters were identified (three site-specific and one generic, all used in the water pathway analysis) that could potentially influence the results to the degree that the calculated waste concentrations become limited by a pathway other than the one determined for the PE (Table 13-7). The impacts on the results of using alternative values for these four parameters for the water pathway in the PE for SRS are discussed in this section. The basis for and possible variation in the values used in the PE for these parameters are discussed in Section 13.6.2.2.

\subsubsection{Parameter Sensitivity Analysis}

The PE provided results for two disposal facility designs: a RCRA-compliant, belowground trench and a RCRA-compliant, above-ground tumulus. Similar assumptions about the integrity of engineered barriers were made in the PE for both facility designs. Because the factors used to estimate transport of radionuclides in the water pathway for both designs were similar, the discussion in this section focuses on examining the results for the indicator radionuclides reported for the tumulus design (indicator radionuclides are defined in Chapter 7 of Volume 2).

As discussed in Chapter 6 of Volume 2, only four parameters used in the PE were identified as having a potential range of values that might affect results: annual natural recharge (i); groundwater Darcy velocity $\left(q_{g w}\right)$; area of the facility $(A)$; and distribution coefficients $\left(K_{d} \mathrm{~s}\right)$. These parameter values for SRS are summarized in Table 13-8. 
Table 13-8. Parameter Values Used in the PE for SRS with Potential Variability That Could Affect the Results

\begin{tabular}{|l|l|}
\hline \multicolumn{1}{|c|}{ Parameter } & \multicolumn{1}{c|}{ Value } \\
\hline Natural recharge through local soils, $i$ & $0.4 \mathrm{~m} / \mathrm{y}$ (MMES et al., 1994) \\
\hline $\begin{array}{l}\text { Distribution coefficients for geologic } \\
\text { media, } K_{d}\end{array}$ & $\begin{array}{l}\text { Values from performance assessment of } \\
\text { Area E vaults (MMES et al., 1994); see } \\
\text { Table 13-2 in this chapter for values }\end{array}$ \\
\hline Groundwater Darcy velocity, $q_{g w}$ & $\begin{array}{l}8.1 \mathrm{~m} / \mathrm{y} \text { (inferred by PE analysts based on } \\
\text { data in MMES [1994]) }\end{array}$ \\
\hline Plan-view Area, $A$ & $2500 \mathrm{~m}^{2}$ (standard PE value) \\
\hline
\end{tabular}

The traditional procedure for performing a sensitivity analysis is to vary the parameters used in the calculations and observe the effect on the results. To be meaningful, this method requires some knowledge of the statistical distribution of each of the parameters considered, including their likely maximum and minimum values. For the PE calculations, the potential variability of the parameters used to calculate the permissible waste concentrations for the two different facility designs was not estimated. For most of the radionuclides considered in the PE, there were only two exposure pathways: the water pathway and intruder exposure scenarios (the atmospheric pathway was considered only for $\mathrm{H}-3$ and $\mathrm{C}-14$ ). The intruder-pathway results provide a baseline that can be used for comparison with the water-pathway results because the intruder scenarios used in the PE were relatively independent of the physical characteristics of the individual sites. This baseline provided an alternative method of performing sensitivity analyses for the PE. The input parameters for the water pathway were varied to determine if the limiting exposure pathway could be altered (e.g., the results could be changed from intruder-scenario controlled to water-pathway controlled). After new values for the water pathway parameters were determined, these values were examined for reasonableness based on physical constraints at the site.

The sensitivity analysis was limited to a comparison of the water and intruder exposure pathways. A comparison between the water and atmospheric pathways was not conducted because the atmospheric pathway is not limiting.

To analyze the sensitivity of the results to changes in the parameter values for natural recharge, groundwater Darcy velocity, and area of the facility, the parameter values used in the $\mathrm{PE}$ for SRS were varied. Only one parameter value was varied at a time for a radionuclide, leaving the others equal to their PE values. In most instances, the parameter value was varied until the waste concentrations for the water and intruder pathways became equal, regardless of the likelihood (or physical possibility) of the value to occur.

The parameter values that caused the permissible concentrations for the water and intruder pathways to become equal are listed in Table 13-9 for the 8 indicator radionuclides. For the indicator radionuclide $\mathrm{H}-3$, the value for recharge had to decrease by more than 18 times; and for C-14, the recharge had to decrease by 15 times or the groundwater velocity had to increase by 22 times to change the limiting pathway from water to intruder. For Sr-90, the recharge had to 
increase by almost 40 times to change the limiting pathway from intruder to water. For Tc-99 and U-238, values for recharge had to decrease by about two orders of magnitude or the groundwater velocity had to increase 2 to 3 orders of magnitude to cause the waste concentrations for the water and intruder concentrations to become equal; however, radionuclides would arrive at the performance boundary after 10,000 y at this low recharge. For $\mathrm{Pu}-239$, all values that caused the pathways to become equal also arrived at the performance boundary beyond 10,000 y. For Am-241, the value for recharge had to double, the groundwater velocity had to decrease by onehalf, or the facility plan area had to increase almost 5 times to change the limiting pathway from intruder to water.

Table 13-9. Parameter Values That Caused the Permissible Concentrations for the Water and Intruder Pathways to Be Equal for Indicator Radionuclides at SRS (tumulus design) (bold type indicates limiting pathway in the PE)

\begin{tabular}{|c|c|c|c|c|c|c|}
\hline \multirow[t]{4}{*}{$\begin{array}{l}\text { Indicator } \\
\text { Nuclide }\end{array}$} & \multirow[t]{4}{*}{$\begin{array}{c}\text { PE } \\
\text { CW-Water }^{a} \\
\left(\mu \mathrm{Ci} / \mathrm{m}^{3}\right)\end{array}$} & \multirow[t]{4}{*}{$\begin{array}{c}\text { PE } \\
C_{W-\operatorname{lnt}} \\
\left(\mu \mathrm{Ci} / \mathrm{m}^{3}\right)\end{array}$} & \multirow[t]{4}{*}{$\begin{array}{c}\text { PE } \\
C_{W-\text { Intr }} \\
C_{W-W a t e r}\end{array}$} & $\begin{array}{c}\text { Natural } \\
\text { Recharge, } \\
i \\
(\mathrm{~m} / \mathrm{y})\end{array}$ & $\begin{array}{c}\text { Groundwater } \\
\text { Darcy } \\
\text { Velocity, } \\
q_{g w} \\
(\mathrm{~m} / \mathrm{y})\end{array}$ & $\begin{array}{c}\text { Area, } \\
\text { A } \\
\left(\mathrm{m}^{2}\right)\end{array}$ \\
\hline & & & & \multicolumn{3}{|c|}{ PE Values } \\
\hline & & & & 0.4 & 8.1 & 2500 \\
\hline & & & & \multicolumn{3}{|c|}{$\begin{array}{c}\text { Value That Caused Equal } \\
\text { Concentrations }\end{array}$} \\
\hline$H-3^{b}$ & $2 E+10$ & $\mathrm{NL}$ & - & 0.022 & c & $<100$ \\
\hline$C-14$ & $8 E+02$ & $1 E+04$ & 12.5 & 0.027 & 180 & $<100$ \\
\hline Sr-90 & NL & $1 E+08$ & - & 15 & c & c \\
\hline TC-99 & $1 E+02$ & $2 E+04$ & 200 & $0.002^{d}$ & 1350 & $<100$ \\
\hline Cs-137 & $\mathrm{NL}^{d}$ & $3 E+07$ & - & c & $c$ & $c$ \\
\hline U-238 & $5 E+01$ & $5 E+03$ & 100 & $0.003^{d}$ & 900 & $<100$ \\
\hline Pu-239 & $6 E+00^{d}$ & $6 E+03$ & 1000 & $0.027^{d}$ & $11,000^{d}$ & $<100^{d}$ \\
\hline $\begin{array}{l}\text { Am-241 } \\
(\mathrm{Np}-237)^{\circ}\end{array}$ & $2 E+04^{f}$ & $9 E+03$ & 0.45 & $0.9^{f}$ & $3.6^{t}$ & $12,000^{f}$ \\
\hline
\end{tabular}

a "NL" means No Limit - estimated permissible concentration is greater than the specific activity of the pure elemental radionuclide.

b Values for $\mathrm{H}-3$ were varied until $C_{\text {wwater }}$ equaled "NL."

c No variation in values caused equal concentrations.

d Arrival time at the performance boundary is greater than $10,000 \mathrm{y}$.

e The dominant decay product for Am-241

f Based on the dominant decay product, Np-237

"- Value could not be calculated. 
A $K_{d}$ value of about $66 \mathrm{~mL} / \mathrm{g}$ for the geologic media would cause an arrival time at the performance boundary of $10,000 \mathrm{y}$. The $K_{d}$ values that caused the permissible concentrations for the water and intruder pathways to be the same are listed in Table 13-10 for 5 of the indicator radionuclides. The indicator radionuclides $\mathrm{H}-3, \mathrm{C}-14$, and Tc-99 are not considered in this analysis because general consensus is that the $K_{d}$ values for these radionuclides are small.

Table 13-10. Variation of $K_{d}$ Values for the Geologic Media at SRS (tumulus design) (a $K_{d}$ value of $66 \mathrm{~mL} / \mathrm{g}$ caused radionuclide arrival at the performance boundary equal to $10,000 \mathrm{y}$ )

\begin{tabular}{|c|c|c|c|c|c|}
\hline $\begin{array}{l}\text { Indicator } \\
\text { Nuclide }\end{array}$ & $\begin{array}{c}P E \\
K_{d} \\
(m \sqcup g)\end{array}$ & $\begin{array}{c}\text { PE } \\
C_{w-w a t e r}{ }^{\star} \\
\left(\mu \mathrm{Ci} / \mathrm{m}^{3}\right)\end{array}$ & $\begin{array}{c}\text { PE } \\
C_{W-/ n t r} \\
\left(\mu \mathrm{Ci} / \mathrm{m}^{3}\right)\end{array}$ & $\begin{array}{c}\text { PE } \\
\frac{C_{W-\text { Intr }}}{C_{W-\text { Water }}}\end{array}$ & $\begin{array}{l}K_{d} \text { Value that } \\
\text { Caused Equal } \\
\text { Concentrations }\end{array}$ \\
\hline Sr-90 & 10 & NL & $1 E+08$ & - & 1 \\
\hline Cs-137 & 100 & $N L^{b}$ & $3 E+07$ & - & 2 \\
\hline U-238 & 50 & $5 E+01$ & $5 E+03$ & 100 & $c, d$ \\
\hline Pu-239 & 100 & $6 E+0^{b}$ & $6 E+03$ & 1000 & $1800^{b, e}$ \\
\hline $\begin{array}{l}A m-241 \\
(\mathrm{~Np}-237)^{\circ}\end{array}$ & $\begin{array}{l}150 \\
(10)\end{array}$ & $2 E+04^{f}$ & $9 E+03$ & 0.45 & 31 \\
\hline
\end{tabular}

a "NL" means No Limit - the estimated permissible waste concentration is greater than the specific activity of the pure elemental radionuclide.

b Permissible waste concentration is based on arrival time at the performance boundary beyond $10,000 \mathrm{y}$.

c No variation in value caused equal concentrations.

d Value greater than $66 \mathrm{~mL} / \mathrm{g}$ caused arrival at the performance boundary after 10,000 y, which changed the limiting pathway.

e Value less than $66 \mathrm{mLg}$ caused arrival at the performance boundary before $10,000 \mathrm{y}$, which changed the limiting pathway.

f Based on the dominant decay product, Np-237

g The dominant decay product of Am-241

"-" Value could not be calculated.

For Sr-90 and Cs-137, the $K_{d}$ values had to decrease at least an order of magnitude to cause the limiting pathway to change from intruder to water. For U-238, a $K_{d}$ value of greater than $66 \mathrm{~mL} / \mathrm{g}$ increased the arrival time to $10,000 \mathrm{y}$, which caused the limiting pathway to change from water to intruder. A $K_{d}$ value of $1800 \mathrm{~mL} / \mathrm{g}$ caused the permissible waste concentrations to become equal for Pu-239, but its arrival at the performance boundary was still beyond $10,000 \mathrm{y}$; the $K_{d}$ had to be decreased to $66 \mathrm{~mL} / \mathrm{g}$ for the limiting pathway to change from intruder to water. The PE result for Am-241 was limited by the decay product (Np-237) contribution to the dose. If the $K_{d}$ value for Am-241 is decreased about five times, then the water pathway concentration is limited by the parent radionuclide (Am-241), and the water pathway would control. Due to the long half-life of Np-237, reduction of its $K_{d}$ has no effect on the resulting waste concentration, and therefore no variation in the $\mathrm{Np}-237 K_{d}$ value caused a change in results. 
The PE results for SRS are based on parameter values provided by the SRS technical staff for site-specific parameters used in calculations. Descriptions and technical justifications of these values are provided in Sections 13.3 and 13.4. Ranges and statistical distributions were not known for most of the input parameter values; however, site-specific knowledge can be used to determine whether the values determined in the sensitivity analysis are reasonable and physically possible at SRS.

\section{Natural Recharge}

The sensitivity analysis results indicate it was possible to change the limiting pathway for Am-241 from intruder to water by increasing the natural recharge. The values for recharge estimated in the sensitivity analysis range from 0.002 to $0.9 \mathrm{~m} / \mathrm{y}(0.007$ to $3 \mathrm{ft} / \mathrm{y})$ (Table 13-9) compared to the PE value of $0.4 \mathrm{~m} / \mathrm{y}(1.3 \mathrm{ft} / \mathrm{y})$. The natural recharge at SRS has no documented range. Doubling the recharge to $0.9 \mathrm{~m} / \mathrm{y}(3 \mathrm{ft} / \mathrm{y})$ as was done for Am-241 may be reasonable for this site. The remaining indicator radionuclides (H-3, C-14, Tc-99, U-328, and Pu-239) all had very small values or very large values $(\mathrm{Sr}-90)$ which are not physically reasonable.

\section{Groundwater Darcy Velocity}

The sensitivity analysis results indicate it is possible to change the limiting pathway for Am-241 by decreasing the groundwater velocity. The values for the groundwater Darcy velocity estimated by the sensitivity analysis vary from 3.6 to $11,000 \mathrm{~m} / \mathrm{y}(11.8$ to $36,000 \mathrm{ft} / \mathrm{y})$ (Table 13-9) compared to the PE value of $8.1 \mathrm{~m} / \mathrm{y}(26.6 \mathrm{ft} / \mathrm{y})$. At SRS, the groundwater Darcy velocity range is not documented. The Am-241 sensitivity analysis value may be reasonable because there was only a factor of 2 increase from the $P E$ value. The sensitivity analysis values for C-14, Tc-99, U-238, and Pu-239 were significantly larger than their PE values and are probably not physically reasonable.

\section{Facility Area}

The sensitivity analysis results indicate it was possible to change the limiting pathway for Am-241 from intruder to water by increasing the facility size. The value for the facility area estimated in the sensitivity analysis was $12,000 \mathrm{~m}^{2}\left(129,600 \mathrm{ft}^{2}\right)($ Table $13-9)$. This value is possible because the plateau where the MWDF is located could accommodate a facility with a size up to $400 \mathrm{~m}$ by $400 \mathrm{~m}(1312$ by $1312 \mathrm{ft})\left(160,000 \mathrm{~m}^{2}\left[1,728,000 \mathrm{ft}^{2}\right]\right)$.

\section{Distribution Coefficients}

The results shown in Table 13-10 indicate that it is possible to change the limiting exposure pathway by changing the $K_{d}$ values of Sr-90, U-238, Pu-239, and Am-241. Changing the $K_{d}$ values for U-238 and Pu-239 to $66 \mathrm{~mL} / \mathrm{g}$ (the $K_{d}$ required to cause arrival at the performance boundary at $10,000 \mathrm{y}$ ) is reasonable because this value is close to their assumed PE $K_{d}$ values. The changes required for Sr-90 and Am-241 are within an order of magnitude of their $\mathrm{PE}$ values. The large change required to change the limiting pathway for $\mathrm{Cs}-137$ is probably not reasonable. 


\subsubsection{Comparison of Conceptual Models and Results between the PE and the SRS (E-Area Vaults)}

Performance Assessment

The conceptual model selected to represent a site can be considerably more important to the results than the parameter values selected for that particular model. The conceptual model for flow and transport used in the water pathway analysis for the performance assessment for the E-Area Vaults at the Savannah River Site (MMES et al., 1994) attempted to be representative of expected site behavior. The conceptual model used in this PE analysis is believed to be conservative compared to that used in the Savannah River performance assessment because relatively few attenuation mechanisms have been used in the PE. The comparison of results and conceptual models between the Savannah River PE and the Savannah River performance assessment provides an opportunity to determine the differences in conservatism used in these two analyses. The comparison of results and conceptual models is described in detail in Appendix A.2 and is summarized here.

The major differences between the conceptual models used in the Savannah River performance assessment and in the PE are highlighted below.

- The PE methodology ignored the solubility of radionuclides in the leachate from the disposal facility. In the Savannah River performance assessment, solubility limitations were implemented, but only for uranium and plutonium.

- The PE methodology uses $0.04 \mathrm{mSv} / \mathrm{y}$ (4 mrem/y) as the limiting dose for the groundwater pathway. In the Savannah River performance assessment, maximum concentration limits (MCLs) for protection of groundwater were used as surrogates for dose.

- In the Savannah River performance assessment, the groundwater analyses were conducted with the PORFLOW-3D computer code. Three separate models were developed: (1) the closure cap, modeled with two-dimensional unsaturated flow, (2) the combined disposal facility and vadose zone, modeled with two-dimensional unsaturated flow and transport, and (3) the saturated zone in which steady-state flow fields were established assuming constant recharge. The PE uses a one-dimensional flow analogy that is simpler than the three models described above.

- In the Savannah River performance assessment, hydrodynamic dispersion is considered in the subsurface transport analyses. Hydrodynamic dispersion is not a part of the $\mathrm{PE}$ methodology.

This discussion pertains only to comparison of the analyses contained in the performance assessment for the E-Area Vaults and the Savannah River PE. No quantitative statements can be made about the degree of conservatism of either analysis with respect to the actual behavior of any specific radionuclide at Savannah River over a 10,000-y time period.

In the published performance assessment for the LAW vaults (MMES et al., 1994), 18 radionuclides were subjected to detailed subsurface transport analyses. The comparative 
exercise between the PE methodology and the performance assessment shows that for many of the radionuclides, the PE results compare well to the findings published in the performance assessment. Using the PE methodology, the arrival time at the compliance boundary was predicted within a factor of two of the value in the performance assessment for 15 of the 18 radionuclides. For 14 of the 18 radionuclides, the concentration reduction factor (CRF) from the $\mathrm{PE}$ was within a factor of about 50 of that from the performance assessment. The permissible waste concentration obtained from the PE methodology was within a factor of about ten of that in the performance assessment for 9 of the 18 radionuclides.

\subsection{OBSERVATIONS}

Based on the results of the PE and the parameter-sensitivity analysis, the following observations can be made about MLLW disposal at SRS:

- The Savannah River Site has characteristics that are typical of a humid climate. The annual rainfall and natural recharge at SRS are relatively high $(1.2 \mathrm{~m} / \mathrm{y}$ and $0.4 \mathrm{~m} / \mathrm{y}$ [3.9 ft/y and $1.3 \mathrm{ft} / \mathrm{y}])$, respectively. The thickness of the vadose zone is $17 \mathrm{~m}(56 \mathrm{ft})$. Travel times of 100 to $440,000 \mathrm{y}$ have been estimated for some radionuclides for the water pathway at SRS.

- For SRS, the results indicate that of the 58 radionuclides evaluated in the PE, 30 radionuclides for the trench design and 35 radionuclides for the tumulus design would be limited by intrusion scenarios. These results reflect the dominant role of the selected human intrusion scenarios that is demonstrated for almost all the sites considered in the PE (see Sections 7.5 and 7.6 in Volume 2). This dominance indicates a need to be aware of the inability to predict the social behavior of populations far into the future.

The results also indicate that for the water pathway, 17 radionuclides for the trench design and 29 radionuclides for the tumulus design would arrive at the performance boundary after the 10,000-y period of consideration in the $\mathrm{PE}$ analysis of the water pathway. Of the radionuclides that would arrive before $10,000 \mathrm{y}, 9$ for the trench design and 5 for the tumulus design had no limit on waste concentration.

Two radionuclides for the trench design (Co-60 and $\mathrm{Ra}-228)$ and four radionuclides for the tumulus design (Co-60, Ba-133, Eu-154, and Ra-228) had no limit on permissible waste concentration from any pathway. These radionuclides were unlimited because either (1) they were unlimited in both the water and intruder pathways or (2) they arrived at the performance boundary in the water pathway beyond $10,000 \mathrm{y}$ and they were unlimited in the intruder pathway.

Because SRS has many radionuclides that either are limited by the intrusion scenarios, arrive at the performance boundary after $10,000 \mathrm{y}$, or have no limit on waste 
concentration, this site may have flexibility in accepting a variety of radionuclides for disposal.

- Using either a trench or tumulus design may be feasible at Savannah River. However, current LLW disposal practices at SRS involve vault technology. At SRS, the PE methodology indicated that the tumulus provided a significantly higher (i.e., greater than one order of magnitude) permissible waste concentration that the trench for 17 radionuclides. In general, these radionuclides have half-lives less than about $50 \mathrm{y}$; for those with longer half-lives (such as the plutoniums), the permissible waste concentration was controlled by the water pathway for the trench and by the intrusion scenario for the tumulus.

- The SRS site generally does not have physical constraints that could limit disposal activities. Areas of adequate size and sufficient depth to groundwater are available to accommodate future LLW disposal. A mixed waste disposal facility is planned.

- The sensitivity analysis for SRS indicates that reasonable changes in values for natural recharge, groundwater Darcy velocity, and facility size for most radionuclides would not significantly change the results. The exception is the limiting pathway for Am-241, which is sensitive to the selection of values for all three of these parameters.

In flow and transport problems, the $K_{d}$ values are often the most uncertain site-specific input parameters. The $K_{d}$ values for the indicator radionuclides Sr-90, U-238, Pu-239, and Am-241 for the geologic media at FEMP could have sufficient uncertainty to change the limiting pathway from intruder to water.

- The conceptual models for water flow and intrusion used in the PE for SRS were based on the LLW performance assessment for the E-Area vaults. The differences in the results of the two analyses have been identified and quantified (see Appendix A.2).

\subsection{REFERENCES}

Baer, T.A., L. L. Price, J. N. Emery, N. E. Olague, 1994. Second Performance Assessment Iteration of the Greater Confinement Disposal Facility at the Nevada Test Site.

SAND93-0089. Albuquerque, NM: Sandia National Laboratories.

Cooper, C.D., and F.C. Alley, 1986. Air Pollution Control: A Design Approach. Prospect Heights, IL: Waveland Press, Inc.

CRC, 1981. CRC Handbook of Chemistry and Physics. Eds. Robert C. Weast and Melvin J. Astle. Boca Raton, FL: CRC Press, Inc. 
EPA, 1992. User's Guide for the Industrial Source Complex (ISC2) Dispersion Models, Volume I: User Instructions. EPA Publication No. EPA-450/4-92-008a. Research Triangle, NC: U.S. Environmental Protection Agency.

FFCAct, 1992. Federal Facility Compliance Act of 1992. P.L. 102-386, October 1992.

Gruebel, M.M., R.D. Waters, M.B. Hospelhorn, and M.S.Y. Chu, eds., 1994. Framework for DOE Low-Level and Mixed Low-Level Waste Disposal: Site Fact Sheets. SAND94-2728. Albuquerque, NM: Sandia National Laboratories.

Kincaid, C.T., J.W. Shade, G.A. Whyatt, M.G. Piepho, K. Rhoads, J.A. Voogd, J.H. Westsik, Jr., M.D. Freshley, K.A. Blanchard, and B.G. Lauzon, eds., 1993. Performance Assessment of Grouted Double-Shell Tank Waste Disposal at Hanford. WHC-SD-WM-EE-004, Rev. 0. U.S. Department of Energy, Pacific Northwest Laboratory and Westinghouse Hanford Company.

Maheras, Steven J., Arthur S. Rood, Swen O. Magnuson, Mary E. Sussman, and Rajiv N. Bhatt, 1994. Radioactive Waste Management Complex Low-Level Waste Radiological

Performance Assessment. EGG-WM-8773. Idaho Falls, ID: U.S. Department of Energy Office of Environmental Restoration and Waste Management, DOE Idaho Operations Office.

MMES (Martin Marietta Energy Systems), EG\&G Idaho, Inc., and Westinghouse Savannah River Company, 1994. Radiological Performance Assessment for the E-Area Vaults Disposal Facility (U). WSRC-RP-94-218, Rev. 0. Aiken, SC: Westinghouse Savannah River Company.

ORNL (Oak Ridge National Laboratory), 1994. Performance Assessment for Continuing and Future Operations at Solid Waste Storage Area 6. ORNL-6783. Oak Ridge, TN: U.S. Department of Energy, Oak Ridge National Laboratory.

WSRC (Westinghouse Savannah River Company), 1992. Radiological Performance Assessment for the Z-Area Saltstone Disposal Facility. WSRC-RP-92-1360, Rev. 0. Aiken, SC: Prepared by Martin Marietta Energy Systems, Inc.; EG\&G Idaho, Inc.; Westinghouse Hanford Company; and Westinghouse Savannah River Company.

\section{Acknowledgments}

The ORNL Core Team acknowledges the contributions of Elmer Wilhite and Jim Cook of Westinghouse Savannah River Company. 


\section{Tennessee: OAK RIDGE RESERVATION (ORR) Core Team Contact: Robert D. Waters}

The Federal Facility Compliance Act (FFCAct, 1992) requires the Department of Energy (DOE) to establish plans in conjunction with its regulators and with members of the public for the treatment of DOE's mixed low-level waste (MLLW). Although the FFCAct did not specifically address disposal of treated MLLW, both DOE and the States recognized that disposal issues were an integral part of treatment discussions. Since 1992, DOE has worked with the States to define and develop an evaluation process for disposal options. Preliminary activities of this joint DOEState process have narrowed the sites for further evaluation from 49 to 15.

The Disposal Workgroup (DWG), which was established by DOE to develop a process for evaluating disposal options, designed a performance evaluation (PE) to quantify and compare the limitations of the remaining $15 \mathrm{DOE}$ sites for MLLW disposal. The principal goal of the PE was to estimate, for grouted residuals resulting from the treatment of MLLW, permissible concentrations of radionuclides in waste for disposal at each site. These "permissible waste concentrations" were based solely on long-term physical performance of the disposal facility and did not take into account any operational waste acceptance criteria that a site might have developed. The PE did not address any ethical, social, or policy considerations relevant to siting such facilities.

The PE used analyses that are consistent with the approach used in many low-level waste (LLW) performance assessments. The objective was to use a set of modeling assumptions of sufficient detail to capture major site-specific characteristics and yet be general enough for consistent application at all sites. Additionally, the analyses were designed to ensure that the sites were analyzed consistently and that all major assumptions were clearly stated.

The remainder of this chapter provides the PE results for Oak Ridge Reservation (ORR), one of the 15 sites being evaluated. The chapter contains the following information:

Section 14.1: brief, general description of the site, based on previous work done by the DWG (Gruebel et al., 1994)

Section 14.2: plans for MLLW disposal, if any, and the location evaluated in the PE

Section 14.3: current understanding of radionuclide movement at the selected location based on available information, and the conceptual model used for the evaluation of each of three pathways (water, atmospheric, and inadvertent intruder)

Section 14.4: site-specific and generic values used in the PE calculations and their sources

Section 14.5: estimates of maximum waste concentrations determined in the PE calculations for each of the three pathways, along with calculated values used in determining these results

Section 14.6: summary of results based on disposal-facility design; discussion with respect to such issues as uncertainty and sensitivity 
Section 14.7: observations based on the results of the PE and the parameter sensitivity analysis

Section 14.8: references

The general assumptions and methodology used in the PE are summarized in Chapter 1 of this volume and explained in more detail in Volume 2 of this report. Overall results for all the sites are discussed in Chapter 7 of Volume 2.

\subsection{GENERAL DESCRIPTION OF THE SITE}

Oak Ridge Reservation (ORR) is in eastern Tennessee about $10 \mathrm{~km}$ (6 mi) west of the city of Knoxville (Figure 14-1). Oak Ridge Reservation lies in a valley between the Cumberland and southern Appalachian Mountain ranges. The Cumberland Mountains are about $16 \mathrm{~km}(10 \mathrm{mi})$ to the northwest; the Great Smoky Mountains are approximately $113 \mathrm{~km}(70 \mathrm{mi})$ to the southeast. Topography limits land use in the region, but substantial agricultural lands yield hay, tobacco, and corn. The region ranges from rural to urban with a tendency toward increasing urbanization.

The population in this region is concentrated along the Interstate 40 and Interstate 75 corridors and in the cities of Knoxville (population 165,100), about $10 \mathrm{~km}(6 \mathrm{mi})$ east of the site, and Oak Ridge (population 27,000). Although located within the corporate city limits of Oak Ridge, ORR is predominantly to the west and south of the population center. The estimated population within a $10-\mathrm{km}(6.2-\mathrm{mi})$ radius of $O R R$ is 30,000 ; estimated population within a $50-\mathrm{km}(31-\mathrm{mi})$ radius is 308,000 .

The ORR facilities are located on a $150-\mathrm{km}^{2}(37,000-\mathrm{ac})$ tract of federally controlled lands (Figure 14-2). Oak Ridge Reservation is controlled by DOE-Oak Ridge Operations and managed under contract by Martin Marietta Energy Systems, Inc. Oak Ridge Reservation contains three major operating facilities: Oak Ridge National Laboratory (ORNL), Oak Ridge Y-12 Plant, and the Oak Ridge K-25 Site.

Oak Ridge National Laboratory was originally constructed as a research and development facility to support plutonium production technology. It is engaged in basic research supporting the fission nuclear fuel cycle, with considerable efforts also directed toward nuclear fusion technology. The Oak Ridge Y-12 was constructed to produce highly enriched uranium by electromagnetic separation. With the development of gaseous diffusion, its primary mission changed to the manufacture of nuclear weapons components. The K-25 Site, formerly known as the Oak Ridge Gaseous Diffusion Plant, was built to produce highly enriched uranium for use in the manufacture of nuclear weapons. The plant was permanently closed in 1987. The Environmental Restoration Program was designated the site landlord in 1989, and the facility's emphasis shifted from uranium production to applied technology activities, support of DOE's environmental restoration and waste management activities, and hosting the Toxic Substances Control Act incinerator, a facility designed for the destruction of mixed radioactive waste. 


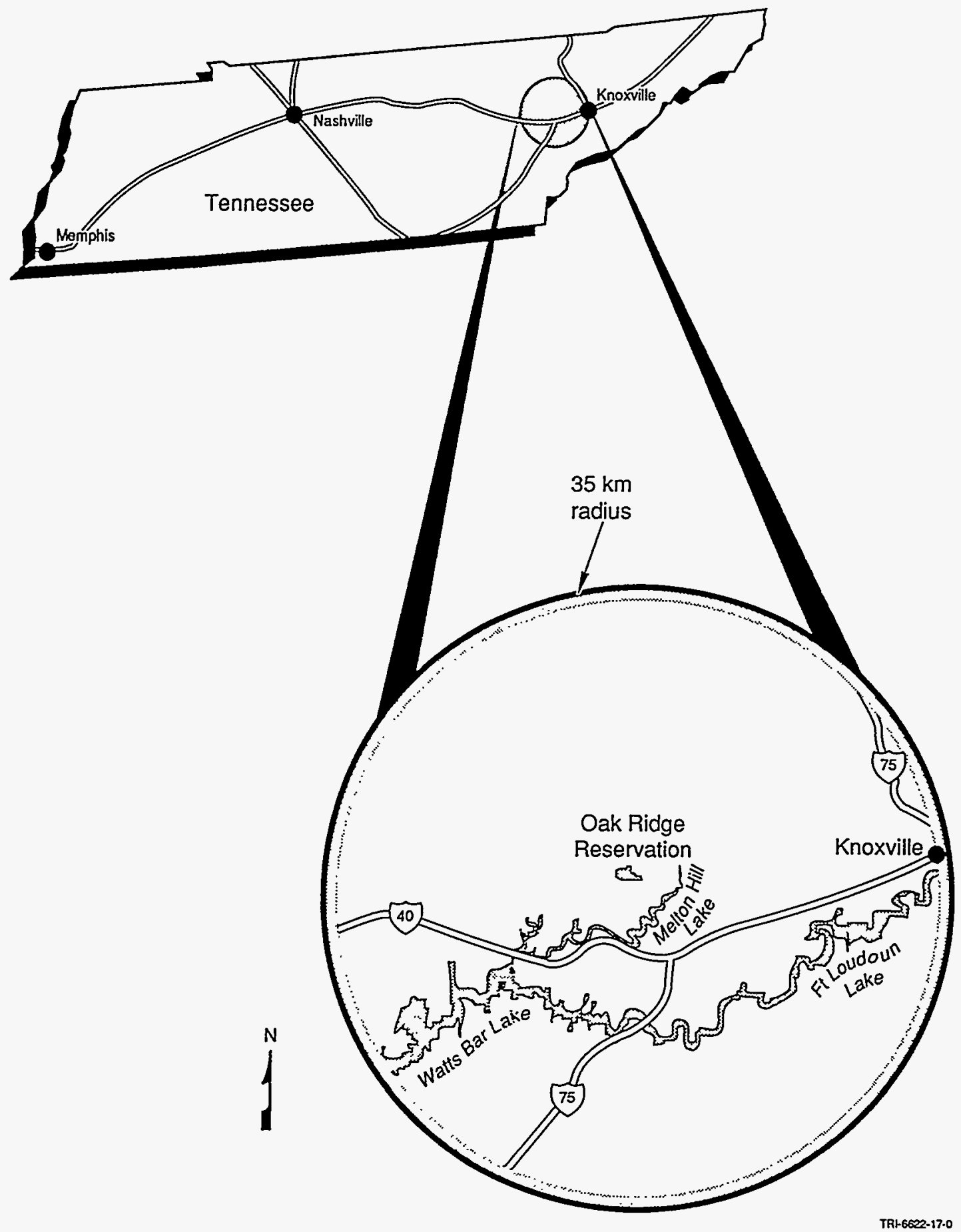

Figure 14-1. Location map for Oak Ridge Reservation. 


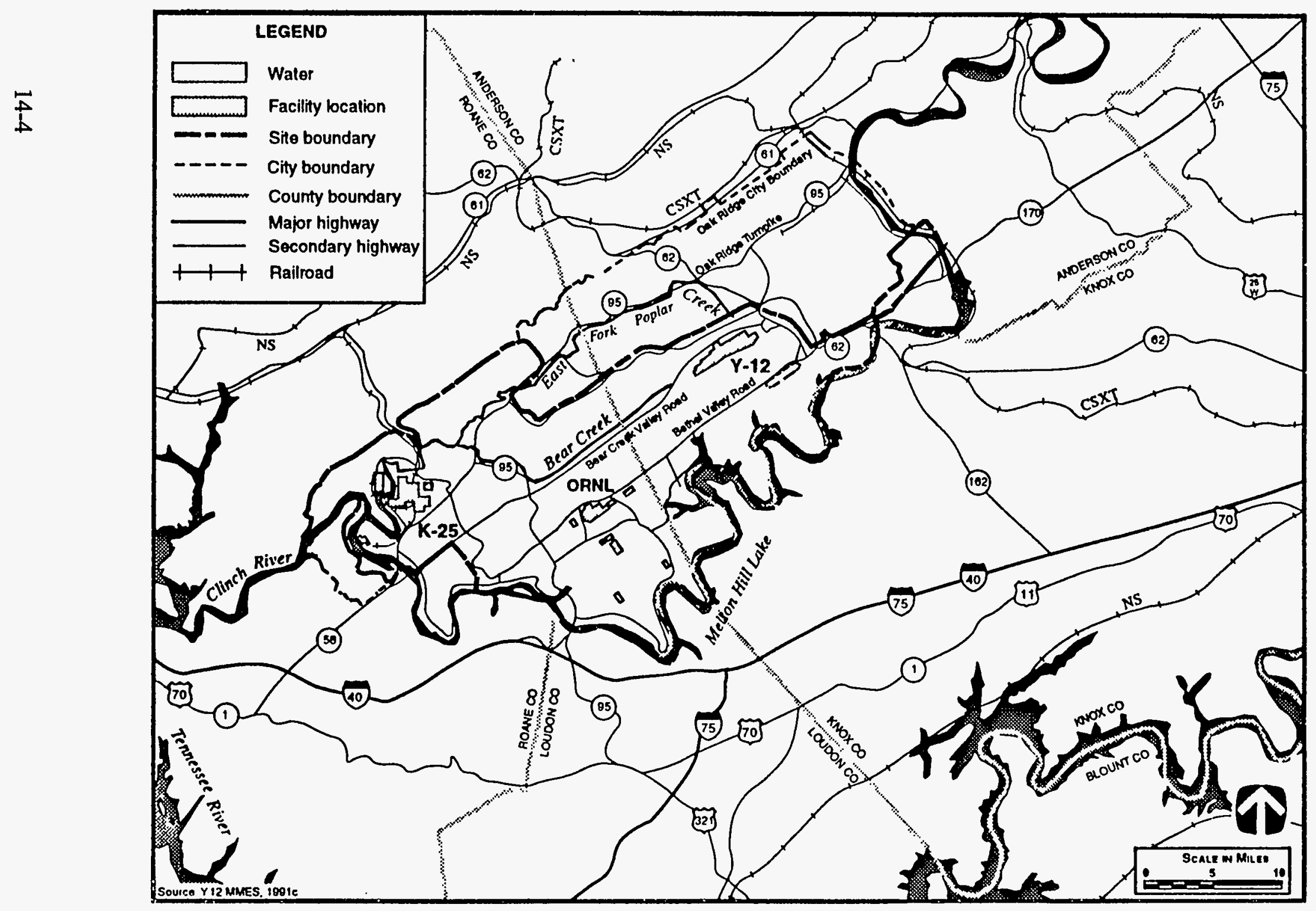

Figure 14-2. Site map for Oak Ridge Reservation (ORNL, 1994a). 
The Solid Waste Storage Area (SWSA) 6, located in Melton Valley in the western portion of the ORR, is currently being operated as a disposal site of LLW using above-grade tumulus technology (ORNL, 1994a). The facility began accepting waste in 1969 and became the sole waste-disposal facility for ORR in 1973. A performance assessment based on the objectives of DOE Order $5820.2 \mathrm{~A}$ has been prepared for the continued operations.

The ORR climate is typical of the humid southern Appalachian region. The local climate is influenced by topography. Temperatures range from an average daily minimum of $-2.4^{\circ} \mathrm{C}$ $\left(27.7^{\circ} \mathrm{F}\right)$ in January to an average daily maximum of $30.7^{\circ} \mathrm{C}\left(87.2^{\circ} \mathrm{F}\right)$ in July. Annual precipitation measured in the vicinity averages $138 \mathrm{~cm}(54.4 \mathrm{in}$.), ranging from $94.9 \mathrm{~cm}$ to 186.9 $\mathrm{cm}$ (37.4 in. to $76.3 \mathrm{in.}$.). Average annual evaporation from reservoirs in the area is about $84 \mathrm{~cm}$ (33 in.). The prevailing winds are variable and dominated by low wind speed and stable conditions. Average wind speed is between 0.9 and $3.3 \mathrm{~m} / \mathrm{s}(1.1$ and $4.6 \mathrm{mph})$ and occurs about half of the year.

Located in the Appalachian Highlands, ORR lies within the Valley and Ridge physiographic province bordering the Cumberland Plateau. Site topography is characterized by a series of alternating, elongated, and parallel valley troughs and ridges trending northeast to southwest in accord with the strike of the underlying rock strata. Surface elevations range from about $225 \mathrm{~m}(740 \mathrm{ft})$ at Clinch River to about $413 \mathrm{~m}$ (1356 ft) at the crest of Melton Hill (Figure 14-2).

The rocks underlying the ORR were deposited approximately 300 million years ago. They include sandstones, shales, limestones, and dolomites of the Rome Formation, Conasauga Group, Knox Group, and Chickamauga Group (Figure 14-3). These deposits generally are covered by unconsolidated residual material 5 to $30 \mathrm{~m}$ (16 to $98 \mathrm{ft}$ ) thick. The valleys have been eroded in areas underlain by the less resistant limestone and shale strata, while the ridges are underlain by more resistant sandstone, shale, and cherty dolomite formations. The formation of karst solution pits and sinkholes has occurred in the carbonate bedrock.

Geologic structures present on the ORR include regional scale thrust faults, local faults having various orientations, local folds, and numerous sets of local joints and fractures. Bedrock fracturing is ubiquitous in the area, with variation in the degree of fracturing based on bedrock type and proximity to local or regional scale folds and faults (ORNL, 1994a). The Copper Creek and White Oak Mountain thrust faults are two regionally important faults found on the ORR (Figure 14-3). There is no evidence of displacement along either fault system for hundreds of millions of years.

Surface water drainage in the area generally follows the northeast-southwest trending valleys. The Clinch River is the major surface water body located on the ORR (Figure 14-2). The major portion of the industrial and drinking water supplies in the Oak Ridge area is taken from surface water sources. 


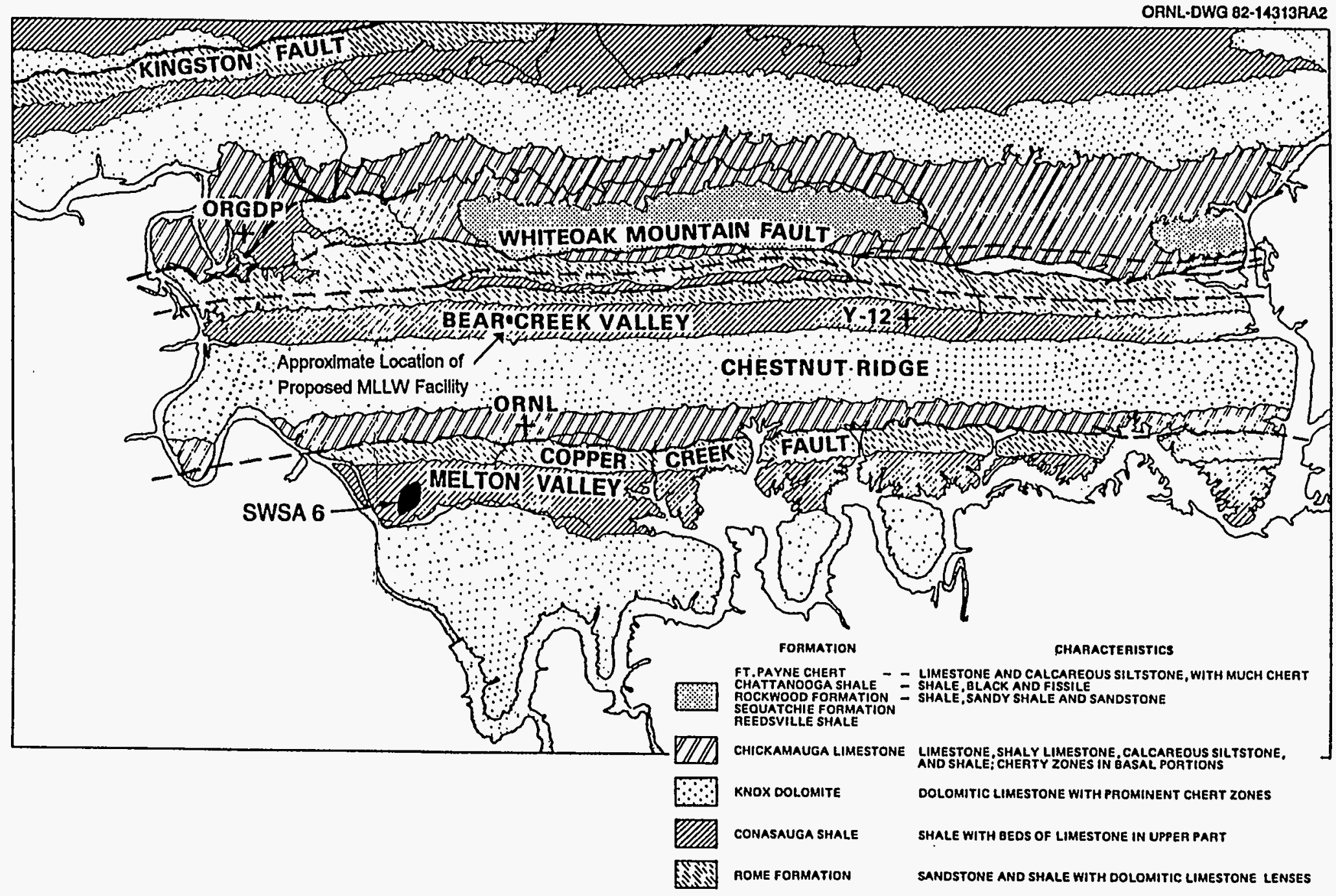
- fault taAce

Figure 14-3. Generalized geologic map of the Oak Ridge area (ORNL, 1994a). 
The Knox Dolomite is the principal aquifer in the Oak Ridge area. The Conasauga Group and the Chickamauga Group are potential low-yield groundwater sources. Springs are primary natural sources of base flow for creeks on the ORR. In general, the water table is shallow, and its location varies substantially both spatially and temporally. Groundwater is not used as a source of potable water on the ORR. However, single-family wells are common in adjacent rural areas not served by a public water supply system. No aquifer in the ORR area has been designated by the U.S. Environmental Protection Agency as a sole source aquifer as defined in 40 CFR 149.2.

\subsection{STATUS AND SITING OF MLLW DISPOSAL FACILITY}

At the time of the PE, personnel at Oak Ridge Reservation were planning for on-site MLLW disposal, but no disposal of MLLW is currently ongoing at ORR. The site is in the conceptual stages of developing an on-site mixed waste-disposal facility (MWDF) at Bear Creek Valley (ORNL, 1994b) as noted in Figure 14-2. The conceptual MWDF is a tumulus design with a plan area of approximately $81,600 \mathrm{~m}^{2}(20 \mathrm{ac})$. The size of the conceptual MWDF is generally based on available land, is not based on any estimate of waste volumes, and will likely be revised as additional waste volume information is developed. A feasibility study for the proposed MWDF is ongoing.

The Bear Creek Valley location is used for the ORR PE analysis of the generic disposal facilities (Figure 14-4). The location of the generic disposal facility at Bear Creek Valley is assumed to provide a minimum of $100 \mathrm{~m}(328 \mathrm{ft})$ of buffer zone between the edge of the facility and any surface water. The small size of the generic facility ensures that this buffer zone can be provided at the Bear Creek Valley location. No site-specific facility analysis was performed for the ORR PE because the proposed MWDF is in the early design phase.

Two generic disposal facilities were considered in the PE: a RCRA-compliant, belowground trench and a RCRA-compliant, above-ground tumulus. The generic facilities were selected to provide consistency in analysis of the performance of the 15 sites. Both generic facilities were assumed to be square with a plan area of $2500 \mathrm{~m}^{2}\left(26,910 \mathrm{ft}^{2}\right)$.

\subsection{BASIS FOR CONCEPTUAL MODEL USED IN THE PE}

The PE analysis was conducted for the proposed MWDF located in Bear Creek Valley. Current understanding of radionuclide movement from a disposal facility at Bear Creek Valley is based principally on references contained in the performance assessment for SWSA 6 (ORNL, 1994a) in Melton Valley, located two valleys to the south (Figure 14-3). Two routes to potential human exposure were considered in the SWSA 6 performance assessment: (1) a water transport pathway to surface and groundwater receptor locations and (2) inadvertent intrusion.

\subsubsection{Water Pathway}

Knowledge of groundwater flow and radionuclide movement in the water pathway at ORR provided the basis for the conceptual model considered in the PE. The conceptual model encompasses the site technical staff's current understanding of site-specific geology, hydrology, water-table and aquifer characteristics, and transport pathways. 


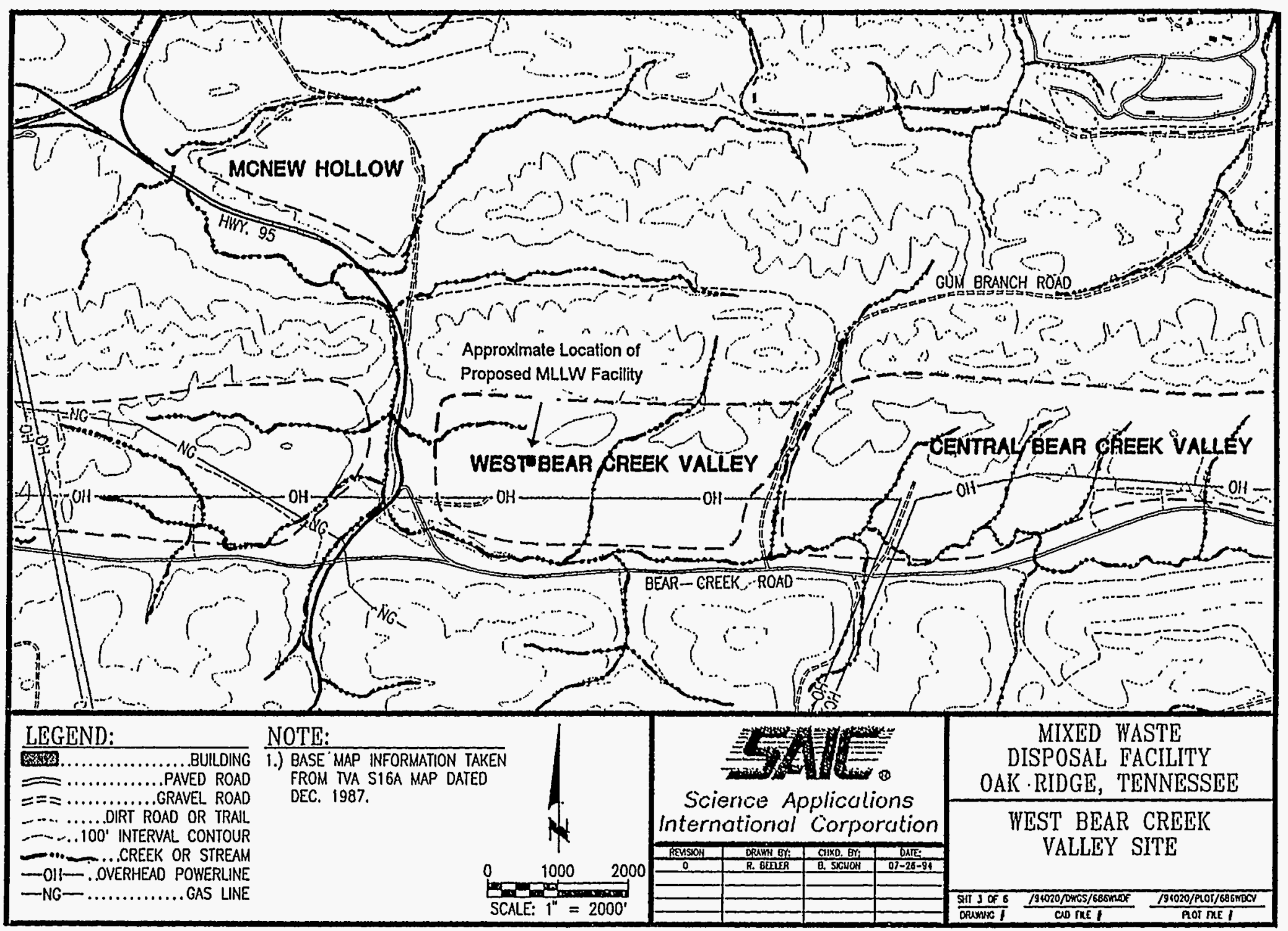

Figure 14-4. Location and orientation of the generic MLLW disposal facilities at ORR (ORNL, 1994b). 


\subsubsection{Current Understanding of Relevant Hydrogeology}

The geohydrologic characteristics of Melton Valley and Bear Creek Valley can be inferred to be similar because both are located in the same geologic units and in similar structural environments due to the repeated geologic formations in the Valley and Ridge physiographic province (Figure 14-3). The geologic and hydrologic site characteristics in Melton Valley have been intensely studied and analyzed in support of the LLW performance assessment of SWSA 6. Some site-specific hydrogeologic studies have been performed in Bear Creek Valley. In fact, tracer studies conducted in Bear Creek Valley have been used to estimate radionuclide movement in Melton Valley (ORNL, 1994a).

The location of the proposed MWDF in Bear Creek Valley is underlain by limestone and shale or siltstone in beds of the Maryville Formation, part of the Conasauga Group (communication between R. Waters [SNL] and M. Yambert [ORNL], 10/26/94). The Conasauga Group generally dips at an attitude of 10 to $15^{\circ}$ to the southeast at this site. Overlying the bedrock is a sequence of weathered bedrock (saprolite) overlain by a thin $(<0.5 \mathrm{~m})$ soil column of residuum and/or colluvium (ORNL, 1994a).

The surface water drainage pattern in the vicinity of the MWDF is shown in Figure 14-4. Bear Creek is the nearest perennial stream to the proposed facility, located about $450 \mathrm{~m}$ (1475 ft) away from the MWDF. Small ephemeral streams channel surface runoff into Bear Creek. Bear Creek is the closest potential drinking water supply near the MWDF. The ephemeral streams contain water only during and shortly after storm events and cannot be considered a reasonable domestic water supply for a potential nearby resident (ORNL, 1994a).

The regional ground-water flow system at the MWDF is a shallow, unconfined aquifer located in the saprolite and underlying bedrock. In general, the water table is a subdued replica of the land surface topography, constrained by ground surface elevations at streams. Groundwater normally discharges to streams. The vadose zone is thin or nonexistent, located primarily within the soil and saprolite units.

The primary porosity of the bedrock is extremely low, and groundwater flows in fractures and weathered zones. The most prominent fracture orientations are parallel to the geologic strike and include both bedding planes and strike-parallel fractures and joints. Less prominent and penetrative fractures occur perpendicular and oblique to local strike. The combined influences of bedrock dip and fracture control of groundwater flow cause anisotropy of the aquifer hydraulic conductivity. Maximum hydraulic conductivity in this regime normally occurs parallel to local geologic strike, and the saturated hydraulic conductivity in the Conasauga Group generally decreases with increasing depth below land surface (ORNL, 1994a).

The hydrologic framework for ORR has been described in terms of the following four zones (ORNL, 1994a, p. 3-14) (Figure 14-5): 

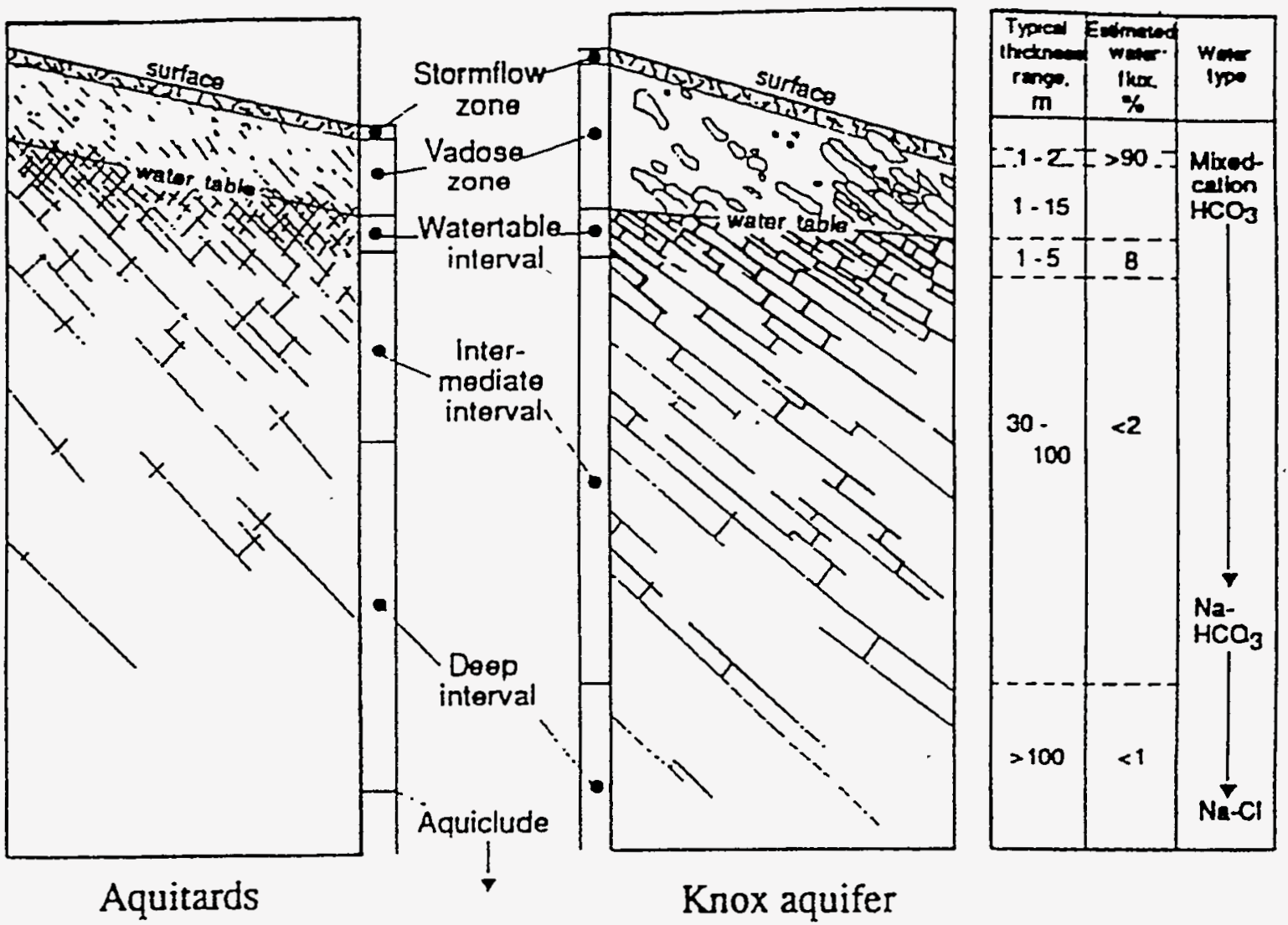

Nol to scale

Figure 14-5. Schematic profile showing subsurface flow zones and intervals, general thickness ranges, estimated relative annual water flux, and change in water type with depth (ORNL, 1994a).

- A stormflow zone composed of the upper 1 to $2 \mathrm{~m}$ ( 3 to $7 \mathrm{ft}$ ) of the soil profile, in which precipitation-driven lateral flow generates about $90 \%$ of the stream flow. This zone is a major pathway for transporting contaminants from the subsurface to surface waters.

- A vadose zone which is predominantly unsaturated, consisting of weathered saprolite of 1 to $15 \mathrm{~m}$ ( 3 to $49 \mathrm{ft}$ ) thickness with a fluctuating water table as the lower boundary. This zone has exponentially decreasing hydraulic conductivity with depth.

- A groundwater zone which contributes the remaining $10 \%$ of streamflow that occurs through a permeable saprolite layer called the water-table interval. This flow zone has a thickness of 1 to $5 \mathrm{~m}$ ( 3 to $16 \mathrm{ft}$ ). Deeper intervals of the aquifer have thicknesses of up to $100 \mathrm{~m}(328 \mathrm{ft})$ and contribute very little to the stream flow due to low hydraulic conductivity and disconnected fractures.

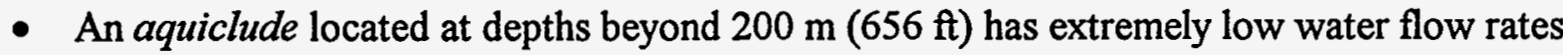
that are estimated to change on geologic time scales. 
These four hydrologically active features control essentially all radionuclide transport from disposal units (ORNL, 1994a). At the Bear Creek location, preferential flow in the stormflow zone is from the facility towards an ephemeral stream to the east.

Chemical adsorption and matrix diffusion have been identified as important geochemical processes that retard chemical transport in facility soils (ORNL, 1994a, p. 3-14). The SWSA 6 performance assessment assumes that chemical adsorption which occurs during transport in the stormflow and vadose zones also provides concentration attenuation in addition to retardation.

Three waterborne pathways to potential drinking water sources are considered in the ORR SWSA 6 performance assessment:

1. Leachate to vadose zone to shallow stormflow zone to ephemeral stream to surface water.

2. Leachate to vadose zone to groundwater to ephemeral stream to surface water.

3. Leachate to vadose zone to groundwater to well.

Although the groundwater does recharge ephemeral streams, the SWSA 6 performance assessment results for the groundwater-to-surface-water pathway are generally two or more orders of magnitude lower with different peak times compared with results from the shallowstormflow-zone-to-surface-water pathway. Therefore, the groundwater-to-surface-water pathway is not considered in the ORR PE analysis.

\subsubsection{Conceptual Model Used in the PE}

The PE used a generic conceptual model to describe the water pathway (summarized in Section 1.1.2 of this volume and described in detail in Chapter 5 of Volume 2). In the unsaturated zone, leachate was generated by constant flow of water through the disposal facility at a rate that was controlled by the assumed performance of the disposal facility. When all engineered barriers had failed, the rate was assumed to be equal to the natural recharge through local soils. The volumetric flow of water through the facility that generated leachate was based on the assumed performance and size of the disposal facility. No dilution was assumed to occur in the unsaturated zone, so at steady state, the concentration that reached groundwater equaled the leachate concentration. No lateral spreading was assumed, so the leachate flux through the unsaturated zone was confined to the soil column directly below the plan area of the facility.

As contaminated water entered the saturated zone, the contaminant mixed with clean groundwater, forming a plume with a shape controlled by aquifer and contaminant properties. The generic conceptual model assumed that instantaneous and complete mixing within the aquifer occurred directly below the facility. Mixing in the vertical direction occurred by hydrodynamic dispersion, and the contaminant mixing depth was an estimated value.

The generic conceptual model was adapted to conditions at ORR based on site-specific knowledge of the geology and water flow paths. The following description represents the conceptual model of the water pathway that was used in the PE for ORR. The conceptual model for the water pathway at ORR is illustrated in Figure 14-6. 


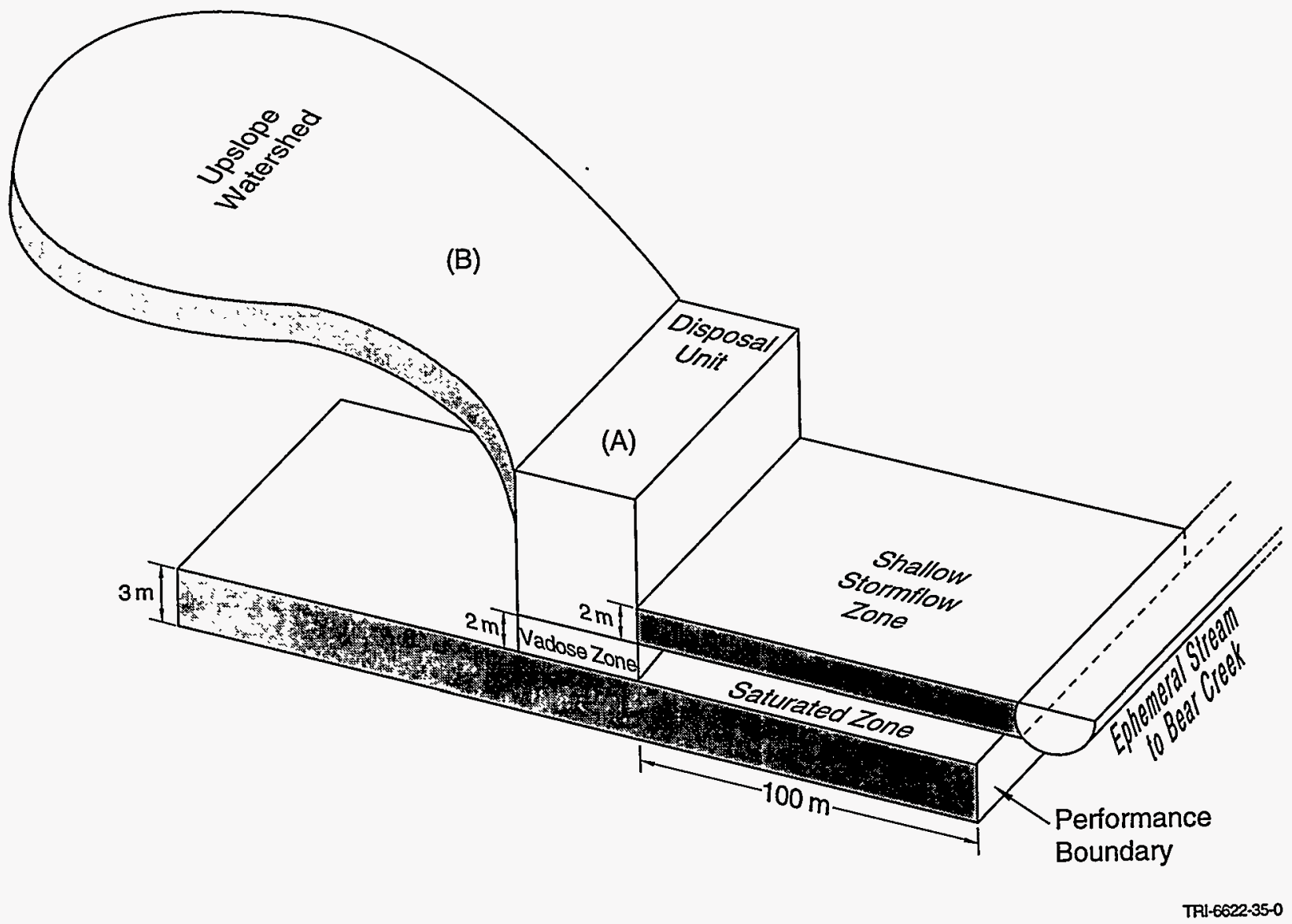

Figure 14-6. Conceptual model for groundwater and shallow stormflow zone transport at ORR. 
Infiltration

- Infiltration through the bottom of the facility is assumed to be a step function which is controlled by engineered barriers during early time and natural flow conditions (i.e., the total infiltration into the facility) after the engineered barriers fail (see Section 1.0 of this volume).

- After engineered barriers fail, infiltration through the facility was assumed to be the sum of areal vertical recharge and upslope watershed stormflow contributions which enter the facility through the shallow stormflow zone (Figure 14-6). The contribution of flow from the up-slope area of the watershed is normalized to the facility plan area with a $B / A$ ratio where $B$ is the area of the up-slope watershed that flows through the facility of plan area, $A$. Thus, the equation for infiltration through the disposal facility is (ORNL, 1994a, p. 3-27):

Infiltration $=$ Natural Recharge to Groundwater + Shallow Stormflow + B/A (Shallow Stormflow $)$

\section{Vadose Zone}

- Leachate from the disposal facility preferentially flows vertically to the water table. When the flux rate through the facility is less than the saturated hydraulic conductivity of the vadose zone at a unit hydraulic gradient, then all leachate flows to the aquifer. When the flux rate through the facility exceeds the saturated hydraulic conductivity of the vadose zone, then vertical flow occurs at a rate equal to the hydraulic conductivity while excess leachate flows through the stormflow zone (Figure 14-6).

- Because the vadose zone is highly fractured and thin at the proposed location, no credit is taken for contaminant travel time.

\section{Groundwater Pathway}

- Leachate which reaches the aquifer is instantaneously mixed over the entire water-table interval of the aquifer beneath the facility plan area (see Figure 14-5) to determine the dilution factor. The water-table interval is the upper part of the aquifer assumed to be the most fractured and weathered and therefore, the most conductive. ORNL (1994a) estimates that the water-table interval ranges from 1 to $5 \mathrm{~m} \mathrm{(3} \mathrm{to} 16 \mathrm{ft})$ in thickness. The ORR PE assumes an aquifer mixing depth thickness of $3 \mathrm{~m}(10 \mathrm{ft})$.

- Leachate in the groundwater is transported horizontally to the $100-\mathrm{m}$ (328-ft) performance boundary.

\section{Stormflow Zone Pathway}

- When lateral flow occurs, the leachate travels through the shallow stormflow zone to an ephemeral stream which flows into Bear Creek. In this case, calculations for both the stormflow pathway and the groundwater pathway are performed.

- Dilution due to leachate mixing in Bear Creek provides a concentration reduction in the stormflow-zone-to-surface-water pathway. The mixing is assumed to be instantaneous and complete.

- Leachate travel time through the stormflow zone is accounted for by Darcy flow. Travel time through the ephemeral stream to Bear Creek is assumed to be instantaneous. 


\subsubsection{Atmospheric Pathway}

The conceptual model used in the PE for evaluating the atmospheric pathway was derived from performance assessments for LLW disposal facilities at Hanford (Kincaid et al., 1993), INEL (Maheras et al., 1994), NTS (Baer et al., 1994), ORR (ORNL, 1994a), and SRS (MMES et al., 1994). The model was generalized for the PE but used site-specific values for many of the parameters.

\subsubsection{Current Understanding of Relevant Meteorology}

No analysis of atmospheric transport was performed in the current SWSA 6 performance assessment. As a result of peer review comments, a supplemental study was performed for tritium and C-14 which showed minimal impacts from volatile radionuclide emissions (Lombardi and Socolof, 1994). The supplemental study approach was similar to the generic PE analysis for the atmospheric pathway.

Meteorological data are based on STAR data files summarized by the windrose in Figure 14-7. These data were obtained from hourly average meteorological readings taken at a

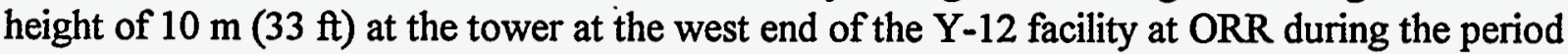
1989 to 1993.

\subsubsection{Conceptual Model Used in the PE}

The PE used a generic conceptual model to describe the atmospheric pathway (summarized in Section 1.2 of this volume and described in detail in Chapter 5 of Volume 2). Only $\mathrm{H}-3$ (tritium) and C-14 were expected to be volatile for the disposal facility conditions and thus were the only radionuclides considered for atmospheric transport in the PE. In the model, radionuclides were transported from the disposal facility to the soil surface by vapor (tritium) and gaseous (carbon dioxide carrying the $\mathrm{C}-14$ isotope) diffusion. When the radionuclides reached the soil surface, they were entrained in the air in vapor form as volatiles. Once airborne, these radionuclides were transported via atmospheric dispersion to a receptor located at the performance boundary.

Two components of the atmospheric pathway were evaluated separately: (1) the zone from the top of the disposal facility to the soil surface as indicated by the upward radionuclide diffusion profile; and (2) the zone in which a radionuclide was emitted to the atmosphere and mixed with the ambient air, and dispersed downwind from the waste disposal facility boundary to the $100-\mathrm{m}(328-\mathrm{ft})$ performance boundary.

The arrival time of radionuclides at the performance boundary was assumed to be $100 \mathrm{y}$ based on the following generic assumptions of the PE:

- The waste form was grouted MLLW treatment residuals. Based on this assumption, tritium as vapor was bound in the pore water of the hydrophilic grout, and carbon dioxide as a gas carrying the $\mathrm{C}-14$ isotope was limited by the high $\mathrm{pH}$ of the grout, so that the waste form provided retention of these volatile radionuclides in the disposal facility.

- The disposal facility was capped by a RCRA-compliant cover system. Based on this assumption, the cover system was maintained to provide low permeability for $100 \mathrm{y}$. 


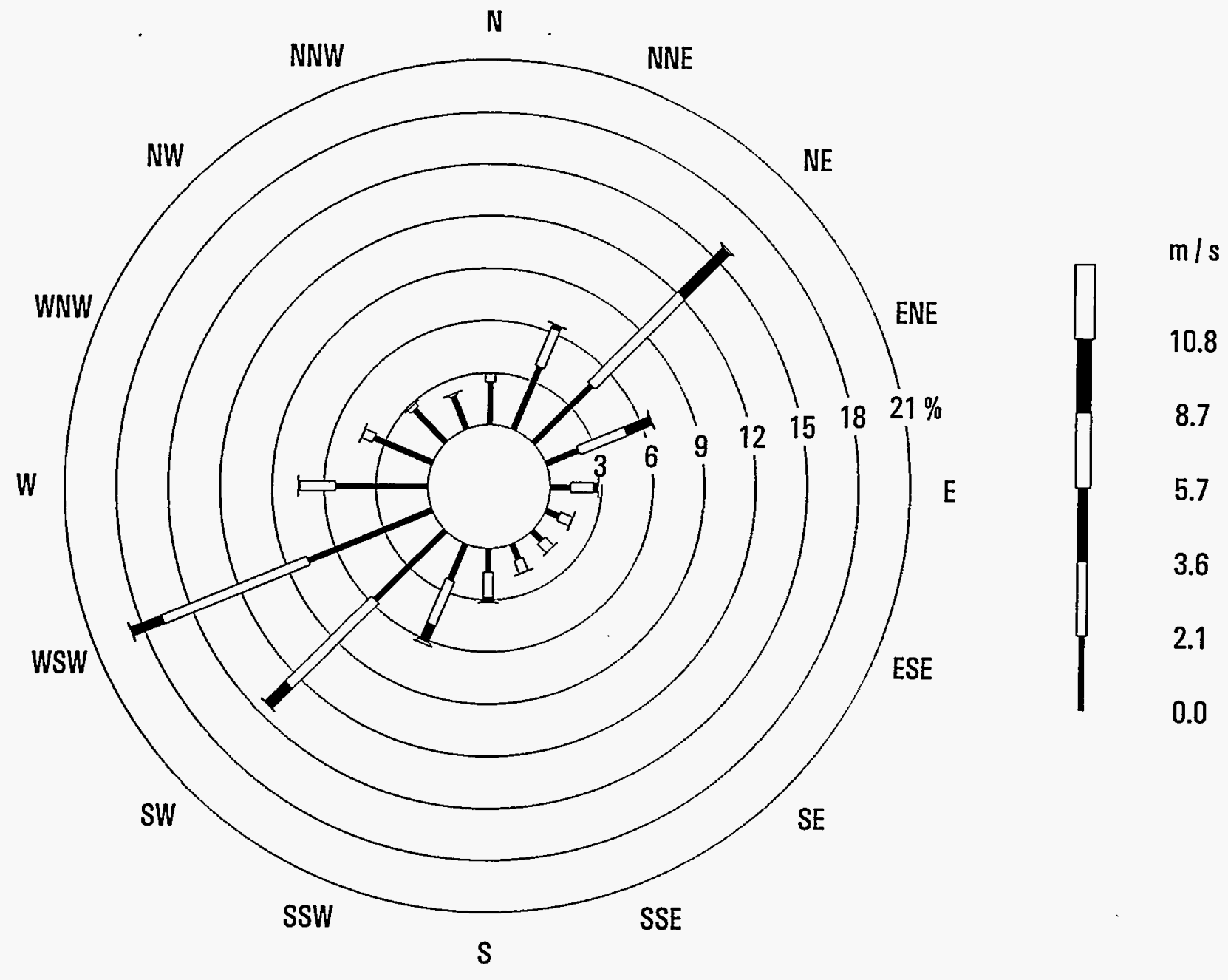

Figure 14-7. Windrose for the Oak Ridge Reservation for the period 1989 to 1993 . The frequency of winds from each direction is plotted as a series of connected bars that extend from the center of the circular diagram toward the direction from which the winds originate. Wind speed categories are denoted by bar widths and shadings. The frequency of winds in each wind speed category is indicated by the length of the corresponding bar. 


\subsubsection{Inadvertent Intruder Pathways}

Standard intrusion scenarios were used in the PE, with information derived from performance assessments of LLW disposal facilities at SRS (MMES et al., 1994) and ORR (ORNL, 1994a) indicating that only two chronic-exposure scenarios needed to be considered for most sites and facility designs. Any variations in these scenarios were based on discussions with site personnel about such factors as the types of activities that reasonably could result in exposure to buried waste at the site and the effectiveness of active or passive institutional controls and engineered barriers in precluding access to the waste.

\subsubsection{Current Understanding of Potential Modes of Inadvertent Intrusion}

Four scenarios were considered in the SWSA 6 performance assessment in evaluating inadvertent intrusion: agriculture, resident, discovery, and post-drilling scenarios. In all scenarios, the intruder was assumed to establish a permanent homestead on the disposal site any time beyond $100 \mathrm{y}$ after disposal, and to establish on-site sources of foodstuffs. The intruder was assumed to have no prior knowledge of waste-disposal activities at the facility. Exposures to radionuclides from the disposal facilities were evaluated and tabulated in the SWSA 6 performance assessment. A detailed explanation of the methodology used to evaluate exposures is given in Appendix G of the SWSA 6 performance assessment (ORNL, 1994a).

\subsubsection{Intruder Scenarios Used in the PE}

The PE used two standard intrusion scenarios that could be modified for site-specific conditions to describe potential modes of inadvertent intrusion (summarized in Section 1.3 of this volume and described in detail in Chapter 5 of Volume 2). The first scenario, the agriculture (homesteader) scenario, included establishment by an intruder of a permanent homestead directly above a disposal facility with the foundation of the home extending into the waste; some of the waste exhumed from the disposal facility was mixed with native soil in the intruder's vegetable garden. The second scenario, the post-drilling scenario, considered the construction of a well for a domestic water supply by an intruder. The well was drilled through the disposal facility, and the cuttings were mixed with soil in the intruder's vegetable garden. The intruder gardened in some of the exhumed waste but did not reside permanently above the disposal facility. In both scenarios, exposure occurred where an intruder dug or drilled into the disposal facility.

For the generic intruder scenarios, the time of intrusion for the homesteader scenario was assumed to be $300 \mathrm{y}$ for the trench design and $500 \mathrm{y}$ for the tumulus design. The time of intrusion for the post-drilling scenario was assumed to be $100 \mathrm{y}$.

\subsection{DATA USED IN THE PE}

The data presented in this section apply to the PE conceptual models described in Section 14.3. The calculations for determining permissible waste concentrations for the radionuclides considered in the PE are discussed in more detail in Chapter 5 of Volume 2 and summarized in Chapter 1 of this volume. The results of the calculations for ORR are presented in Section 14.5 and discussed in Section 14.6 of this volume. 


\subsubsection{Water Transport}

Site-specific values required to perform the water pathway analysis were selected by site technical staff from site-specific characterizations and reports, from site-specific modeling results, or from general literature. For the shallow stormflow zone, the site-specific data that were required for the $\mathrm{PE}$ were the ambient moisture content; dry bulk density of the geologic medium; distribution coefficients $\left(K_{d} s\right)$ of the radionuclides in the geologic medium; natural recharge; and the flow in Bear Creek. For the saturated zone, the site-specific data that were required were porosity; dry bulk density of the geologic medium; and distribution coefficients $\left(K_{d} s\right)$ of the radionuclides in the geologic medium; groundwater Darcy flow rates; and mixing depth in the aquifer.

These values for ORR are listed in Table 14-1 along with generic values that were used in the PE. Also indicated in the table is a designation of the type of data the value represents and the source of the value. The values were determined from one or more of four data sources: (A) measurement performed by the site, state, or federal agency; (B) result of a numerical analysis performed by the site, state, or federal agency; (C) general literature value selected by the site; and (D) generic value of the PE.

Of the parameters in the PE that depended on site-specific values, only three potentially encompassed enough variability in values to significantly affect the results: natural recharge, $i$; distribution coefficients $\left(K_{d s}\right)$ for the geologic media; and groundwater Darcy velocity $\left(q_{g w}\right)$. The sources of the values used in the ORR PE for these parameters are discussed below; the sensitivity of the results to changes in the values of these parameters is discussed in Section 14.6.2 of this volume and Chapter 6 of Volume 2.

The value used for the natural recharge to groundwater, $i$, is based on annual averages of monthly Unified Transport Model (UTM) hydrologic simulations contained in the SWSA 6 performance assessment (ORNL, 1994a), which are calibrated to field observations. The natural recharge is limited by the measured hydraulic conductivity of the fractured saprolite underlying the disposal site.

The value used for the groundwater Darcy velocity, $q_{g w}$, is based on U.S. Geological Survey Method of Characteristics simulations contained in the SWSA 6 performance assessment (ORNL, 1994a), which are calibrated to field observations. The groundwater Darcy velocity is calibrated to measured hydraulic conductivities of the fractured saprolite underlying the disposal site.

Values for distribution coefficients $\left(K_{d} s\right)$ are listed in Table 14-2 for the 58 radionuclides (32 elements) considered in the PE. In addition to the $K_{d}$ values for the geologic media, grout $K_{d}$ values are listed for determining the desorption from the source term resulting from the grouted waste form. The values used for soil distribution coefficients, $K_{d}$, are from the SWSA 6 performance assessment (ORNL, 1994a) where available and supplemented by literature values (Thibault et al., 1990). All values were reviewed and approved by site staff familiar with sorption processes at Oak Ridge. 
Table 14-1. Parameters and Values Used in the PE for the Water Pathway at ORR (generic PE values are in bold; these values and the standard PE method for applying them are summarized in Chapter 1 of this volume and discussed in more detail in Chapter 5 of Volume 2) (Part 1 of 2)

\begin{tabular}{|c|c|c|c|}
\hline Parameter & Value & $\begin{array}{l}\text { Data } \\
\text { Type }\end{array}$ & Comments \\
\hline \multicolumn{4}{|l|}{ SOURCE TERM } \\
\hline $\begin{array}{l}\text { Volumetric water content } \\
\text { of the waste, } \theta_{G}\end{array}$ & 0.3 & D & Standard PE value \\
\hline $\begin{array}{l}\text { Bulk density of grouted } \\
\text { waste, } \rho_{0}\end{array}$ & $1.76 \mathrm{~g} / \mathrm{ml}$ & D & Standard PE value \\
\hline $\begin{array}{l}\text { Distribution coefficient } \\
\text { for grouted waste, } K_{d}^{G}\end{array}$ & various & $\mathbf{D}$ & $\begin{array}{l}\text { Standard PE value. See Table } 14-2 \text { in } \\
\text { this volume. }\end{array}$ \\
\hline $\begin{array}{l}\text { Disposal facility plan } \\
\text { area, } \mathbf{A}\end{array}$ & $2500 \mathrm{~m}^{2}$ & D & $\begin{array}{l}\text { Standard PE value; } A=a_{1} * a_{2}, \text { where } \\
a_{1}=a_{2}=50 \mathrm{~m}\end{array}$ \\
\hline $\begin{array}{l}\text { Waste mixing fraction for } \\
\text { trench, } f_{m}\end{array}$ & 0.67 & D & Standard PE value \\
\hline $\begin{array}{l}\text { Waste mixing fraction for } \\
\text { tumulus, } f_{m}\end{array}$ & 0.33 & D & Standard PE value \\
\hline Shallow stormflow & $0.45 \mathrm{~m} / \mathrm{y}$ & B & ORNL (1994a) \\
\hline B/A: generic facility & 3.4 & B & MMES et al. (1994) \\
\hline $\begin{array}{l}\text { Annual rate of water } \\
\text { flowing through intact } \\
\text { trench facility, } q_{f}\end{array}$ & $0.03 \mathrm{~m} / \mathrm{y}$ & D & Standard PE value \\
\hline $\begin{array}{l}\text { Annual rate of water } \\
\text { flowing through intact } \\
\text { tumulus facility, } q_{f}\end{array}$ & $\begin{array}{l}0.00003 \\
\mathrm{~m} / \mathrm{y}\end{array}$ & D & Standard PE value \\
\hline $\begin{array}{l}\text { Time to failure of leachate } \\
\text { collection and linear } \\
\text { systems }\end{array}$ & $30 y$ & D & Standard PE value \\
\hline $\begin{array}{l}\text { Time to failure of trench } \\
\text { facility }\end{array}$ & $100 y$ & D & Standard PE value \\
\hline $\begin{array}{l}\text { Time to failure of tumulus } \\
\text { facility }\end{array}$ & $300 y$ & D & Standard PE value \\
\hline $\begin{array}{l}\text { Natural recharge through } \\
\text { shallow soils, } i_{S}\end{array}$ & $2.2 \mathrm{~m} / \mathrm{y}$ & B & $\begin{array}{l}\text { ORNL (1994a). See equation 14-1 in text of } \\
\text { this chapter. }\end{array}$ \\
\hline $\begin{array}{l}\text { Natural recharge to } \\
\text { groundwater, } i\end{array}$ & $0.18 \mathrm{~m} / \mathrm{y}$ & B & ORNL (1994a, p. 4-6, 8) \\
\hline
\end{tabular}

- $A=$ site measurement; $B=$ result of site numerical analysis; $C=$ =literature value selecled by the site; $D=g$ eneric $P E$ value 
Table 14-1. Parameters and Values Used in the PE for the Water Pathway at ORR (generic PE values are in bold; these values and the standard $\mathrm{PE}$ method for applying them are summarized in Chapter 1 of this volume and discussed in more detail in Chapter 5 of Volume 2) (Part 2 of 2)

\begin{tabular}{|c|c|c|c|}
\hline Parameter & Value & $\begin{array}{l}\text { Data } \\
\text { Type }\end{array}$ & Comments \\
\hline \multicolumn{4}{|c|}{ SHALLOW STORMFLOW ZONE } \\
\hline Field capacity, $\theta_{r e}$ & 0.305 & A & $\begin{array}{l}\text { Field capacity is defined as the volumetric } \\
\text { moisture content at }-100 \mathrm{Kpa} \\
\text { (ORNL, 1994a, p. D-4) }\end{array}$ \\
\hline Bulk density, $\rho_{b}$ & $1.35 \mathrm{~g} / \mathrm{cm}^{3}$ & $A$ & ORNL (1994a, p. E-3) \\
\hline $\begin{array}{l}\text { Distribution coefficients of } \\
\text { geologic media, } K_{d}\end{array}$ & Various & AC & See Table $14-2$ in this chapter \\
\hline Porosity, $n$ & 0.39 & A & ORNL (1994a, p. D-4) \\
\hline Darcy velocity, $q_{s s}$ & $9.49 \mathrm{~m} / \mathrm{y}$ & A & ORNL (1994a) \\
\hline Flow in Bear Creek, $Q_{B C}$ & $\begin{array}{c}5.7 E+06 \\
\mathrm{~m}^{3} / \mathrm{y} \\
\end{array}$ & A & $\begin{array}{l}\text { Value is the } 5 \text {-y average flow at Oak Ridge } \\
\text { Bear Creek gauging station (Flohr et al., 1990) }\end{array}$ \\
\hline \multicolumn{4}{|l|}{ UNSATURATED ZONE } \\
\hline Field capacity, $\theta_{t}$ & 0.305 & A & $\begin{array}{l}\text { Field capacity is defined as the volumetric } \\
\text { moisture content at }-100 \mathrm{Kpa} \text { (ORNL, 1994a, } \\
\text { p. D-4) }\end{array}$ \\
\hline Moisture content, $\theta_{w}$ & 0.39 & A & ORNL (1994a, p. D-4) \\
\hline Bulk density, $\rho_{b}$ & $1.35 \mathrm{~g} / \mathrm{cm}^{3}$ & A & ORNL (1994a) \\
\hline $\begin{array}{l}\text { Distribution coefficients of } \\
\text { geologic media, } K_{d}\end{array}$ & Various & ACC & See Table 14-2 in this chapter \\
\hline $\begin{array}{l}\text { Saturated hydraulic } \\
\text { conductivity, } K_{\text {sat }}\end{array}$ & $0.18 \mathrm{~m} / \mathrm{y}$ & A & ORNL (1994a, p. F-1) \\
\hline $\begin{array}{l}\text { Thickness between trench and } \\
\text { saturated zone, } l\end{array}$ & $2 \mathrm{~m}$ & A & ORNL (1994a, p. 3-15) \\
\hline $\begin{array}{l}\text { Thickness between tumulus } \\
\text { and saturated zone, },\end{array}$ & $2 m$ & $A$ & ORNL (1994a, p.3-15) \\
\hline \multicolumn{4}{|l|}{ SATURATED ZONE } \\
\hline Porosity, $n$ & 0.035 & A & $\begin{array}{l}\text { ORNL (1994a) and corrected based on } \\
\text { communication between R. Waters (SNL) and } \\
\text { M. Yambert (ORNL), 9/29/94. }\end{array}$ \\
\hline Bulk density, $\rho_{b}$ & $1.35 \mathrm{~g} / \mathrm{cm}^{3}$ & A & ORNL (1994a, p. E-3). \\
\hline $\begin{array}{l}\text { Distribution coefficients of } \\
\text { geologic media, } K_{d}\end{array}$ & Various & AVC & See Table $14-2$ in this chapter \\
\hline Mixing depth, $d_{m}$ & $3.0 \mathrm{~m}$ & A & ORNL (1994a, p. E-3) \\
\hline Darcy velocity, $q_{q w}$ & $2.92 \mathrm{~m} / \mathrm{y}$ & A & ORNL (1994a) \\
\hline $\begin{array}{l}\text { Distance to performance } \\
\text { boundary from facility } \\
\text { boundary }\end{array}$ & $100 \mathrm{~m}$ & D & Standard PE value \\
\hline
\end{tabular}

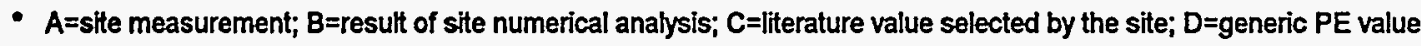


Table 14-2. Solid/Liquid Distribution Coefficients $\left(K_{d} S\right)$ Used in the PE at ORR

\begin{tabular}{|c|c|c|}
\hline Element & Waste $K_{d}^{G}(\mathrm{~mL} / \mathrm{g})$ & $\begin{array}{c}K_{d} \text { for Geologic Media } \\
(\mathrm{mL} / \mathrm{g})^{b}\end{array}$ \\
\hline$H$ & 0 & 0 \\
\hline C & 10 & 0 \\
\hline $\mathrm{Al}$ & 100 & 3000 \\
\hline Si & 100 & 35 \\
\hline $\mathrm{Cl}$ & 0 & 0 \\
\hline$K$ & 1 & $15^{c}$ \\
\hline Co & 100 & 3000 \\
\hline $\mathrm{Ni}$ & 10 & 2000 \\
\hline $\mathrm{Se}$ & 1 & $150^{\circ}$ \\
\hline $\mathrm{Sr}$ & 100 & 30 \\
\hline $\mathrm{Zr}$ & 10 & $600^{\circ}$ \\
\hline $\mathrm{Nb}$ & 10 & $160^{\circ}$ \\
\hline TC & 1 & 0 \\
\hline $\mathrm{Pd}$ & 100 & $55^{c}$ \\
\hline $\mathrm{Ag}$ & 100 & $90^{\circ}$ \\
\hline $\mathrm{Cd}$ & 100 & 200 \\
\hline$S n$ & 10 & $130^{c}$ \\
\hline 1 & 1 & $1^{c}$ \\
\hline Cs & 10 & 3000 \\
\hline $\mathrm{Ba}$ & 10 & $3000^{d}$ \\
\hline$S m$ & 10 & $245^{\circ}$ \\
\hline Eu & 10 & 3000 \\
\hline $\mathrm{Pb}$ & 100 & $270^{\circ}$ \\
\hline $\mathrm{Ra}$ & 10 & 3000 \\
\hline Th & 100 & 40 \\
\hline $\mathrm{Pa}$ & 100 & $550^{\circ}$ \\
\hline$U$ & 100 & 40 \\
\hline $\mathrm{Np}$ & 100 & 40 \\
\hline $\mathrm{Pu}$ & 100 & 40 \\
\hline Am & 100 & 40 \\
\hline $\mathrm{Cm}$ & 100 & 40 \\
\hline Cf & 100 & 40 \\
\hline
\end{tabular}

a Standard PE values; see Chapter 5 of Volume 2.

b Based on ORNL, 1994a

c Based on Thibault et al. (1990) with concurrence by R. Luxmoore (ORNL), 9/29/94

d Based on similarity with cesium [communication between R. Waters (SNL) and R. Luxmoore (OR:11.), 9/29/94] 


\subsubsection{Atmospheric Transport}

Site-specific data required to perform the atmospheric pathway analysis came from site personnel as data either from site characterizations and reports or from general literature. The site-specific data required for the soil diffusion calculation were the same as some of those required for the water transport analysis (Section 14.4.1). These values are shown in Table 14-3. Necessary atmospheric dispersion data included wind speed and direction and stability class, which are summarized in Section 14.3.2.1.

Table 14-3. Parameters and Values Used in the PE for the Atmospheric Pathway at ORR (generic PE values are in bold; these values and the standard PE method for applying them are summarized in Chapter 1 of this volume and discussed in more detail in Chapter 5 of Volume 2)

\begin{tabular}{|c|c|c|c|}
\hline Parameter & Value & $\begin{array}{l}\text { Data } \\
\text { Type* }\end{array}$ & Comments \\
\hline $\begin{array}{l}\text { Disposal facility cover } \\
\text { thickness, } x\end{array}$ & $1.0 \mathrm{~m}$ & $\mathbf{D}$ & Standard PE value \\
\hline $\begin{array}{l}\text { Depth of the soil } \\
\text { surface, } d\end{array}$ & $0.01 \mathrm{~m}$ & D & $\begin{array}{l}\text { Standard PE value based on } \\
\text { Maheras et al. (1994) }\end{array}$ \\
\hline Porosity, $n$ & 0.39 & A & ORNL (1994a, p. D-4) \\
\hline Percent saturation, $s$ & 1.0 & A & ORNL (1994a) \\
\hline $\begin{array}{l}\text { Ratio of water density } \\
\text { in air to liquid, } r\end{array}$ & 9.2E-06 & D & $\begin{array}{l}\text { Standard PE value based on MMES } \\
\text { et al. (1994) }\end{array}$ \\
\hline $\begin{array}{l}\text { Ratio of } \mathrm{CO}_{2} \\
\text { concentration in air to } \\
\text { dissolved in water, } r\end{array}$ & 4.3E-04 & D & $\begin{array}{l}\text { Standard PE value based on Foust } \\
\text { et al. (as cited in Cooper and Alley, } \\
\text { 1986) }\end{array}$ \\
\hline $\begin{array}{l}\text { Tritium diffusion } \\
\text { coefficient in air, } D\end{array}$ & $2.39 \mathrm{E}-05 \mathrm{~m}^{2} / \mathrm{s}$ & D & $\begin{array}{l}\text { Standard PE value based on CRC } \\
\text { (1981) }\end{array}$ \\
\hline $\begin{array}{l}\text { Carbon diffusion } \\
\text { coefficient in air, } D\end{array}$ & $1.4 \mathrm{E}-05 \mathrm{~m}^{2} / \mathrm{s}$ & $\bar{D}$ & $\begin{array}{l}\text { Standard PE value based on CRC } \\
\text { (1981) }\end{array}$ \\
\hline $\begin{array}{l}\text { Atmospheric dispersion } \\
\text { term, } A_{D}\end{array}$ & $\begin{array}{c}0.75 \\
\left(\mu \mathrm{Ci} / \mathrm{m}^{3}\right) /\left(\mu \mathrm{Ci} / \mathrm{m}^{2}-\mathrm{s}\right)\end{array}$ & $B$ & $\begin{array}{l}\text { Value is estimated using the Industrial } \\
\text { Source Complex-Version } 2 \text { Long Term Air } \\
\text { Dispersion Model (ISCLT2) (EPA, 1992) } \\
\text { based on site-specific STAR data. }\end{array}$ \\
\hline
\end{tabular}

- $A=$ site measurement; $B=$ result of site numerical analysis; $C=$ literature value selected by the site; $D=g e n e r i c ~ P E$ value

\subsubsection{Inadvertent Intruder Exposure}

As explained in Section 14.3.3, the PE used two standard intrusion scenarios to describe potential modes of inadvertent intrusion at all the sites. Because these intrusion scenarios were considered applicable to all sites, no values specific to ORR are used in the calculation of exposures to inadvertent intruders. 


\subsection{RESULTS OF THE PE}

The performance evaluation provided estimates of permissible waste concentrations in disposed MLLW. The three calculations that formed the foundation of the PE-for the water, atmospheric, and inadvertent intruder pathways-are summarized in Sections 1.1, 1.2, and 1.3, respectively, of this volume and discussed in detail in Chapter 5 of Volume 2.

For each pathway the maximum permissible waste concentration at the performance boundary was determined for each radionuclide by using the performance measures: $4 \mathrm{mrem}$ $(0.04 \mathrm{mSv})$ per year from the water pathway for releases to drinking water; $10 \mathrm{mrem}(0.1 \mathrm{mSv})$ per year from all pathways for atmospheric releases; and $100 \mathrm{mrem}(1 \mathrm{mSv})$ per year from all exposure pathways for chronic exposure of inadvertent intruders; and the appropriate pathway or scenario dose conversion factors (annual effective dose equivalent per unit concentration) based on EPA dose conversion factors. The basis for the performance measures used in the PE is discussed in more detail in Chapter 5 of Volume 2. For the water and atmospheric pathways, the concentration reduction provided by the environment (i.e., the $\mathrm{CRF}$ ) was estimated using results of site analyses and data. For the intruder analyses, concentration reduction was estimated for appropriate exposure pathways for two intrusion scenarios that, in general, were the same for all the sites. The results of the calculations for the pathways that were analyzed at ORR are provided in this section and discussed in Section 14.6. A comparison of the PE results and the performance assessment results for the SWSA 6 is contained in Appendix A.3.

\subsubsection{Water Transport}

Two CRFs were calculated for the water pathway: the source $\mathrm{CRF}, C R F_{\text {Source, }}$, and the environmental transport $\mathrm{CRF}$ for water, $C R F_{\text {Water. }}$ The source $\mathrm{CRF}$ represents the concentration attenuation between the disposed waste and leachate exiting the bottom of the disposal facility and was defined as the dimensionless ratio of the waste concentration to the resulting leachate concentration. Desorption with infiltrating water was the mechanism used to describe the leaching of radionuclides from the grout. Because a generic method was used to determine the $C R F_{\text {Source }}$ for the 58 radionuclides considered in the $\mathrm{PE}$ (summarized in Section 1.1 of this volume and discussed in more detail in Chapter 5 of Volume 2), the radionuclide-specific values for the source CRF for each type of generic facility were the same for all 15 sites.

The environmental transport $\mathrm{CRF}$ for water was defined as the ratio of the concentration of the leachate exiting the disposal facility to the resulting concentration in water at the performance boundary. The concentration attenuation represented by $C R F_{\text {Water }}$ consisted of dilution due to mixing with uncontaminated groundwater or surface water. Effects of radioactive decay and decay product ingrowth were also included in the PE.

All of the leachate from the facility preferentially flows to the groundwater at an early time while the flux rate from the facility is controlled by the engineered barriers. After the barriers fail, the flow rate through the facility increases to $2.2 \mathrm{~m} / \mathrm{y}(7.2 \mathrm{ft} / \mathrm{y})$, and the leachate flow from the facility partitions between the groundwater and the surface water pathways. The ORR PE analyses show that approximately $10 \%$ of the flow out of the facility goes to the groundwater while the remaining $90 \%$ moves through the shallow stormflow zone to surface water. While 
$90 \%$ of the leachate flow reached the surface water, the large dilution in Bear Creek results in the groundwater pathway providing the most limiting concentrations. Therefore, only the groundwater pathway is discussed in this section.

Application of the PE methodology for water transport of the 58 radionuclides considered in the PE produced the results shown in Table 14-4 for the generic trench and tumulus designs at ORR. The table shows permissible waste concentrations based on transport through the groundwater pathway $\left(C_{\text {W-Water }}\right)$ as well as the values used in calculating the permissible waste concentrations for this pathway.

Some radionuclides listed in Table 14-4 have no limit (NL) on their permissible waste concentrations, the result of the combined effects of relatively short half-lives and sufficiently long travel time to the performance boundary. "No limit" is defined as a permissible waste concentration that is greater than the specific activity of the pure elemental radionuclide. For disposal of the maximum possible waste concentration of these relatively short-lived radionuclides, the water pathway produces a dose at the performance boundary of less than $4 \mathrm{mrem}(0.04 \mathrm{mSv})$ per year and, therefore, the permissible waste concentration was unlimited based on exposures from this pathway.

For some radionuclides, no value is listed in Table 14-4 for the radioactive decay term, $r_{\text {Decay. }}$ These radionuclides had radioactive decay terms that were very large (e.g., greater than $1 \times 10^{50}$ ). Any radionuclide with a radioactive decay term greater than $1 \times 10^{50}$ ensured a calculated permissible waste concentration greater than the specific activity of the pure elemental radionuclide, which, as described previously, resulted in no limit (NL) on permissible waste concentrations for disposal.

Due to the large rate of water flowing through the disposal facilities after failure, only radionuclides with very short half-lives are controlled by the early plateau. For most radionuclides, the rate at the time of facility failure controls the subsurface transport. Exceptions are the short-lived radionuclides $\mathrm{H}-3$, Co-60, Nb-93m, Cd-113m, Ba-133, Eu-152, Eu-154, $\mathrm{Pb}-210$ (only for trench), $\mathrm{Ra}-228, \mathrm{Pu}-241, \mathrm{Cm}-244$, and $\mathrm{Cf}-250$ which are limited by the lower flow of water through the facility prior to facility failure.

Arrival times for some radionuclides listed in Table 14-4 were beyond the 10,000-y performance period. For those radionuclides, the estimated waste concentrations are presented in Table 14-4 for information purposes only. Consistent with the approach used in LLW performance assessments, these values were not considered in determining the most restrictive disposal limit from among the evaluated pathways.

For the tumulus, the total undecayed CRFs (the product of the $C R F_{\text {Source }}$ and the $C R F_{\text {Water }}$ ) for the groundwater pathway were about twice the total undecayed CRFs for the trench, given the same total rate of flow (i.e., at the time of hydrologic failure of the facility) for most radionuclides. This result was due to the difference in the volume fraction of waste (the ratio of waste material to total material in the disposal unit) between the two technologies-twice as 
F Table 14-4. Results of Calculations for the Water Pathway at ORR (water travel time from land surface to performance boundary [ [excluding facility detention] $=1.2 \mathrm{y})($ Part 1 of 2$)$

\begin{tabular}{|c|c|c|c|c|c|c|c|c|c|c|c|c|}
\hline \multirow[t]{2}{*}{ Nuclide } & \multirow[b]{2}{*}{$\begin{array}{c}\text { PDCF } \\
\text { remly per } \mu \mathrm{CI} /\end{array}$} & \multicolumn{5}{|c|}{ Trench } & \multicolumn{5}{|c|}{ Tumulus } & \multirow[t]{2}{*}{ Nuclide } \\
\hline & & \begin{tabular}{|l|} 
CRF \\
(dimensionless) \\
\end{tabular} & \begin{tabular}{|c|} 
CRF Water \\
(dimensionloss)
\end{tabular} & $\begin{array}{c}\text { Arrival } \\
\text { Time }(y)\end{array}$ & \begin{tabular}{|c|}
${ }^{2}$ Decay \\
(dimenstonless)
\end{tabular} & $\begin{array}{c}C_{W-W a t e r}^{b} \\
\left(\mu \mathrm{Ci} / \mathrm{m}^{3}\right)\end{array}$ & \begin{tabular}{|l|} 
CRF Source \\
(dimensionless)
\end{tabular} & \begin{tabular}{|c|} 
CRF Water \\
(dimensionless)
\end{tabular} & $\begin{array}{c}\text { Arrival } \\
\text { Time }(y)\end{array}$ & $\begin{array}{c}\text { Decay } \\
\text { (dimensionloss) }\end{array}$ & $\begin{array}{c}C_{W-W a t e r}^{b} \\
\left(\mu \mathrm{Ci} / \mathrm{m}^{3}\right)\end{array}$ & \\
\hline $\mathrm{H}-3$ & 4.67E-02 & 0.45 & 6.8 & $3.1 E+01$ & $5.8 E+00$ & $2 E+03$ & 0.9 & 5800 & $3.1 E+01$ & $5.8 \mathrm{E}+00$ & $3 E+06$ & $\mathrm{H}-3$ \\
\hline C-14 & $1.52 \mathrm{E}+00$ & 27 & 2.0 & $1.0 \mathrm{E}+02$ & $1.0 \mathrm{E}+00$ & $1 E+02$ & 54 & 2.0 & $3.0 E+02$ & $1.0 \mathrm{E}+00$ & $3 E+02$ & C-14 \\
\hline Al-26 & $1.06 \mathrm{E}+01$ & 270 & 2.0 & $1.4 E+05$ & $1.1 E+00$ & $2 E+02$ & 540 & 2.0 & $1.4 E+05$ & $1.1 E+00$ & $5 E+02$ & $\mathrm{Al}-26$ \\
\hline Si-32 & $7.99 \mathrm{E}+00$ & 270 & 2.0 & $1.7 \mathrm{E}+03$ & $1.5 \mathrm{E}+05$ & $4 E+07$ & 540 & 2.0 & $1.9 E+03$ & $6.0 \mathrm{E}+05$ & $3 E+08$ & SI-32 \\
\hline $\mathrm{Cl}-36$ & $2.21 E+00$ & 0.45 & 2.0 & $1.0 \mathrm{E}+02$ & $1.0 \mathrm{E}+\infty 0$ & $2 E+\infty 0$ & 0.9 & 2.0 & $3.0 \mathrm{E}+02$ & $1.0 E+00$ & $3 E+00$ & $\mathrm{Cl}-36$ \\
\hline$K-40$ & $1.36 E+01$ & 3.1 & 2.0 & $7.9 E+02$ & $1.0 \mathrm{E}+\infty 0$ & $2 E+\infty 0$ & 6.2 & 2.0 & $9.9 \mathrm{E}+02$ & $1.0 E+00$ & $4 E+00$ & $K-40$ \\
\hline Co-60 & $1.97 E+01$ & 270 & 6.8 & $1.4 E+05$ & e & $\mathrm{NL} \quad \mathrm{c}$ & 540 & 5800 & $1.4 \mathrm{E}+05$ & e & NL & Co-60 \\
\hline Ni-59 & $1.53 E-01$ & 27 & 2.0 & $9.3 E+04$ & $2.3 E+\infty 0$ & $3 E+03^{\circ}$ & 54 & 2.0 & $9.3 E+04$ & $2.3 E+00$ & $7 E+03$ & Ni-59 \\
\hline Ni-63 & 4.21E-01 & 27 & 2.0 & $9.3 E+04$ & $e$ & $\mathrm{NL} \quad$ & 54 & 2.0 & $9.3 E+04$ & e & NL & $\mathrm{Ni}-63$ \\
\hline Se-79 & $6.35 E+\infty 0$ & 3.1 & 2.0 & $7.0 \mathrm{E}+03$ & $1.1 \mathrm{E}+\infty$ & $4 E+\infty$ & 6.2 & 2.0 & $7.2 \mathrm{E}+03$ & $1.1 E+00$ & $8 E+\infty$ & Se-79 \\
\hline Sr-90 & $1.12 E+02$ & 270 & 2.0 & $1.5 \mathrm{E}+03$ & $2.5 E+15$ & $\mathrm{NL}$ & 540 & 2.0 & $1.7 E+03$ & $2.9 E+17$ & NL & Sr-90 \\
\hline $2 r-93$ & $1.59 \mathrm{E}+\infty 0$ & 27 & 2.0 & $2.8 E+04$ & $1.0 \mathrm{E}+\infty$ & $1 E+02^{\circ}$ & 54 & 2.0 & $2.8 \mathrm{E}+0.4$ & $1.0 E+\infty 0$ & $3 E+02$ & $\mathrm{Zr}-93$ \\
\hline $\mathrm{Nb}-93 \mathrm{~m}$ & 3.81E-01 & 27 & 6.8 & $7.4 E+03$ & e & $\mathrm{NL}$ & 54 & 5800 & $7.4 E+03$ & e & $\mathrm{NL}$ & $\mathrm{Nb}-93 \mathrm{~m}$ \\
\hline $\mathrm{Nb}-94$ & $5.21 \mathrm{E}+00$ & 27 & 2.0 & $7.5 E+03$ & $1.3 \mathrm{E}+\infty$ & $5 E+01$ & 54 & 2.0 & $7.7 E+03$ & $1.3 E+00$ & $1 E+02$ & $\mathrm{Nb}-94$ \\
\hline Tc-99 & $1.07 E+\infty 0$ & 3.1 & 2.0 & $1.0 \mathrm{E}+02$ & $1.0 \mathrm{E}+\infty 0$ & $2 E+01$ & 6.2 & 2.0 & $3.0 \mathrm{E}+02$ & $1.0 \mathrm{E}+00$ & $5 E+01$ & Tc-99 \\
\hline$P d-107$ & 1.09E-01 & 270 & 2.0 & $2.6 \mathrm{E}+03$ & $1.0 \mathrm{E}+00$ & $2 E+04$ & 540 & 2.0 & $2.8 E+03$ & $1.0 \mathrm{E}+00$ & $4 E+04$ & Pd-107 \\
\hline$A g-108 m$ & $5.56 \mathrm{E}+\infty 0$ & 270 & 2.0 & $4.3 E+03$ & $7.4 E+09$ & $3 E+12$ & 540 & 2.0 & $4.5 \mathrm{E}+03$ & $2.2 E+10$ & $2 E+13$ & $\mathrm{Ag}-108 \mathrm{~m}$ \\
\hline $\mathrm{Cd}-113 \mathrm{~m}$ & $1.17 E+02$ & 270 & 6.8 & $9.3 E+03$ & e & NL & 540 & 5800 & $9.3 E+03$ & $e$ & $\mathrm{NL}$ & $\mathrm{cd}-113 \mathrm{~m}$ \\
\hline $5 n-121 m$ & $1.28 E+\infty$ & 27 & 2.0 & $6.1 E+03$ & $2.8 E+33$ & $\mathrm{NL}$ & 54 & 2.0 & $6.3 \mathrm{E}+03$ & $3.5 \mathrm{E}+34$ & NL & $\mathrm{Sn-121m}$ \\
\hline $5 n-126$ & $1.53 E+01$ & 27 & 2.0 & $6.1 E+03$ & $1.0 \mathrm{E}+\infty 0$ & $1 E+01$ & 54 & 2.0 & $6.3 E+03$ & $1.0 E+\infty 0$ & $3 E+01$ & Sn-126 \\
\hline $1-129$ & $2.01 E+02$ & 3.1 & 2.0 & $1.5 E+02$ & $1.0 \mathrm{E}+\infty$ & 1E-01 & 6.2 & 2.0 & $3.5 \mathrm{E}+02$ & $1.0 \mathrm{E}+00$ & $2 E-01$ & $1-129$ \\
\hline Cs-135 & $5.16 E+\infty 0$ & 27 & 2.0 & $1.4 E+05$ & $1.0 \mathrm{E}+\infty 0$ & $4 E+01^{c}$ & 54 & 2.0 & $1.4 E+05$ & $1.0 \mathrm{E}+00$ & $9 \mathrm{E}+01$ & Cs-135 \\
\hline Cs-137 & $3.65 \mathrm{E}+01$ & 27 & 2.0 & $1.4 E+05$ & e & $\mathrm{NL} \quad \mathrm{c}$ & 54 & 2.0 & $1.4 E+05$ & e & NL & Cs-137 \\
\hline Ba-133 & $2.48 E+00$ & 27 & 6.8 & $1.4 E+05$ & e & $\mathrm{NL}$ & 54 & 5800 & $1.4 \mathrm{E}+05$ & e & $\mathrm{NL}$ & Ba-133 \\
\hline$S m-151$ & $2.84 E-01$ & 27 & 2.0 & $1.1 E+04$ & $1.7 E+38$ & $\mathrm{NL}$ & 54 & 2.0 & $1.2 E+04$ & $7.8 E+38$ & $\mathrm{NL}$ & $S m-151$ \\
\hline Eu-152 & $4.73 E+00$ & 27 & 6.8 & $1.4 E+05$ & $e$ & $\mathrm{NL}$ & 54 & 5800 & $1.4 E+05$ & e & NL & Eu-152 \\
\hline Eu-154 & $6.97 E+\infty$ & 27 & 6.8 & $1.4 E+05$ & e & $\mathrm{NL}$ & 54 & 5800 & $1.4 E+05$ & $e$ & NL & Eu-154 \\
\hline $\mathrm{Pb}-210$ & $5.30 E+03$ & 270 & 6.8 & $1.3 E+04$ & e & NL & 540 & 2.0 & 1.3E+04 & e & NL & $P b-210$ \\
\hline $\mathrm{Ra}-226$ & $6.27 E+03$ & 27 & 2.0 & $1.4 E+05$ & $1.3 E+26$ & NL & 54 & 2.0 & $1.4 E+05$ & $1.4 E+26$ & NL & Ra-226 \\
\hline Ra-228 & $1.64 E+03$ & 27 & 6.8 & $1.4 \mathrm{E}+05$ & $e$ & $N L$ & 54 & 5800 & $1.4 E+05$ & $e$ & $N L$ & Ra-228 \\
\hline Th-229 & $2.94 E+03$ & 270 & 2.0 & $2.0 E+03$ & $1.2 E+00$ & $9 E-01$ & 540 & 2.0 & $2.2 E+03$ & $1.2 \mathrm{E}+00$ & $2 \mathrm{E}+\infty$ & Th-229 \\
\hline Th-230 & $4.16 E+03$ & 270 & 2.0 & $2.0 E+03$ & NA & $5 E-01$ & 540 & 2.0 & $2.2 E+03$ & NA & $1 E+00$ & Th-230 \\
\hline Th-232 & $3.63 E+03$ & 270 & 2.0 & $2.0 \mathrm{E}+03$ & $1.0 \mathrm{E}+00$ & $6 E-01$ & 540 & 2.0 & $2.2 E+03$ & $1.0 \mathrm{E}+\infty 0$ & $1 E+\infty$ & Th-232 \\
\hline $\mathrm{Pa}-231$ & $1.85 E+04$ & 270 & 2.0 & $2.6 E+04$ & $1.7 E+00$ & $2 E-01$ & 540 & 2.0 & $2.6 E+04$ & $1.7 E+00$ & $4 E-01$ & $\mathrm{~Pa}-231$ \\
\hline
\end{tabular}


Table 14-4. Results of Calculations for the Water Pathway at ORR (water travel time from land surface to performance boundary [excluding facility detention] $=1.2 \mathrm{y})($ Part 2 of 2$)$

\begin{tabular}{|c|c|c|c|c|c|c|c|c|c|c|c|c|}
\hline \multirow[t]{2}{*}{ Nuclide } & \multirow[b]{2}{*}{$\begin{array}{c}\text { PDCF } \\
\text { remly per } \mu \mathrm{CI} \Omega\end{array}$} & \multicolumn{5}{|c|}{ Trench } & \multicolumn{5}{|c|}{ Tumulus } & \multirow[t]{2}{*}{ Nuclide } \\
\hline & & $\begin{array}{l}\text { CRF }_{\text {Source }} \\
\text { (dimensionlezs) }\end{array}$ & $\begin{array}{c}\mathrm{CRF}_{\text {Water }} \\
\text { (dimensionless) }\end{array}$ & $\begin{array}{l}\text { Arrival } \\
\text { Time }(y)\end{array}$ & $\begin{array}{c}\text { rDecay }^{\prime \prime} \\
\text { (dimonsionloss) }\end{array}$ & $\begin{array}{c}C_{\text {w-Water }}{ }^{b} \\
\left(\mu \mathrm{Ci} / \mathrm{m}^{3}\right)\end{array}$ & \begin{tabular}{|l|} 
CRF $_{\text {Source }}$ \\
(dimensionless) \\
\end{tabular} & $\begin{array}{c}\text { CRF Water } \\
\text { (dimensioniess) }\end{array}$ & $\begin{array}{c}\text { Arrival } \\
\text { Time }(y)\end{array}$ & $\begin{array}{c}\text { roucay }^{a} \\
\text { (dimonsionloss) }\end{array}$ & $\begin{array}{c}C_{\text {w-Wowr }}{ }^{\mathrm{b}} \\
\left(\mu \mathrm{Cim \textrm {m } ^ { 3 }}\right)\end{array}$ & \\
\hline $\mathrm{U}-232$ & $1.55 E+03$ & 270 & 2.0 & $2.0 \mathrm{E}+03$ & $2.4 E+08$ & $3 E+08$ & 540 & 2.0 & $2.2 E+03$ & $1.8 E+09$ & $5 E+09$ & $\mathrm{U}-232$ \\
\hline$U-233$ & $7.37 \mathrm{E}+02$ व & 270 & 2.0 & $2.0 E+03$ & NA & $3 E+00$ & 540 & 2.0 & $2.2 E+03$ & $\mathrm{NA}$ & $6 \mathrm{E}+00$ & $\mathrm{U}-233$ \\
\hline$U-234$ & $2.51 E+02$ & 270 & 2.0 & $2.0 E+03$ & NA & $8 E+00$ & 540 & 2.0 & $2.2 E+03$ & NA & $2 E+01$ & U-234 \\
\hline U-235 & $1.01 E+03$ वे & 270 & 2.0 & $2.0 E+03$ & NA & $2 E+00$ & 540 & 2.0 & $2.2 E+03$ & NA & $4 E+\infty 0$ & U-235 \\
\hline U-236 & $1.96 \mathrm{E}+02$ & 270 & 2.0 & $2.0 \mathrm{E}+03$ & $1.0 \mathrm{E}+00$ & $1 E+01$ & 540 & 2.0 & $2.2 E+03$ & $1.0 E+00$ & $2 E+01$ & U-236 \\
\hline $\mathrm{U}-238$ & $2.07 E+02$ & 270 & 2.0 & $2.0 E+03$ & $\mathrm{NA}$ & $1 \mathrm{E}+01$ & 540 & 2.0 & $2.2 \mathrm{E}+03$ & NA & $2 E+01$ & U-238 \\
\hline$N p-237$ & $3.24 E+03$ & 270 & 2.0 & $2.0 \mathrm{E}+03$ & $1.0 \mathrm{E}+00$ & $6 \mathrm{E}-01$ & 540 & 2.0 & $2.2 E+03$ & $1.0 \mathrm{E}+00$ & $1 E+00$ & Np-237 \\
\hline Pu-238 & $2.34 E+03$ & 270 & 2.0 & $2.0 E+03$ & $5.0 E+06$ & $2 E+04$ & 540 & 2.0 & $2.2 E+03$ & $2.4 E+07$ & $5 E+04$ & Pu-238 \\
\hline $\mathrm{Pu}-239$ & $2.58 \mathrm{E}+03$ & 270 & 2.0 & $2.0 E+03$ & $1.1 E+00$ & $9 \mathrm{E}-01$ & 540 & 2.0 & $2.2 \mathrm{E}+03$ & 1.1E+00 & $2 E+\infty 0$ & Pu-239 \\
\hline Pu-240 & $2.58 \mathrm{E}+03$ & 270 & 2.0 & $2.0 \mathrm{E}+03$ & $1.2 \mathrm{E}+00$ & $1 E+\infty 0$ & 540 & 2.0 & $2.2 E+03$ & $1.3 E+00$ & $2 E+\infty 0$ & $\mathrm{Pu}-240$ \\
\hline Pu-241 & $4.82 E+08$ & 270 & 6.8 & $1.9 E+03$ & $2.1 E+39$ & $5 E+02$ & 540 & 5800 & $1.9 E+03$ & $2.1 E+39$ & $1 E+03$ & $\mathrm{Pu-241}$ \\
\hline Pu-242 & $2.45 \mathrm{E}+03$ & 270 & 2.0 & $2.0 E+03$ & $1.0 E+00$ & $9 \mathrm{E}-01$ & 540 & 2.0 & $2.2 E+03$ & $1.0 \mathrm{E}+00$ & $2 E+00$ & Pu-242 \\
\hline Pu-244 & $4.11 E+03$ & 270 & 2.0 & $2.0 \mathrm{E}+03$ & NA & $5 E-01$ & 540 & 2.0 & $2.2 E+03$ & NA & $1 E+\infty 0$ & Pu-244 \\
\hline Am-241 & $2.66 \mathrm{E}+03$ & 270 & 2.0 & $2.0 E+03$ & $2.3 E+01$ & $2 E+01$ & 540 & 2.0 & $2.2 \mathrm{E}+03$ & $3.1 \mathrm{E}+01$ & $5 E+01$ & Am-241 \\
\hline$A m-243$ & $2.64 E+03$ & 270 & 2.0 & $2.0 E+03$ & $1.2 \mathrm{E}+00$ & $9 \mathrm{E}-01$ & 540 & 2.0 & $2.2 \mathrm{E}+03$ & $1.2 \mathrm{E}+\infty$ & $2 E+00$ & Am-243 \\
\hline $\mathrm{Cm}-243$ & $1.83 E+03$ & 270 & 2.0 & $2.0 E+03$ & $1.5 \mathrm{E}+20$ & $7 E+02$ & 540 & 2.0 & $2.2 E+03$ & $1.8 \mathrm{E}+22$ & $1 E+03$ & $\mathrm{Cm}-243$ \\
\hline $\mathrm{Cm}-244$ & $1.47 \mathrm{E}+03$ & 270 & 6.8 & $1.9 E+03$ & $1.9 \mathrm{E}+31$ & $4 E+02$ & 540 & 5800 & $1.9 E+03$ & $1.9 E+31$ & $7 E+02$ & $\mathrm{Cm}-244$ \\
\hline $\mathrm{Cm}-245$ & $4.56 E+03$ & 270 & 2.0 & $2.0 \mathrm{E}+03$ & NA & $5 E-01$ & 540 & 2.0 & $2.2 E+03$ & NA & 9E-01 & $\mathrm{Cm}-245$ \\
\hline $\mathrm{Cm}-246$ & $2.70 E+03$ & 270 & 2.0 & $2.0 \mathrm{E}+03$ & $1.3 E+\infty$ & $1 E+\infty$ & 540 & 2.0 & $2.2 E+03$ & $1.4 E+\infty$ & $2 E+\infty$ & $\mathrm{Cm}-246$ \\
\hline $\mathrm{Cm}-247$ & $4.34 E+03$ & 270 & 2.0 & $2.0 E+03$ & $\mathrm{NA}$ & $5 E-01$ & 540 & 2.0 & $2.2 E+03$ & NA & $1 E+\infty 0$ & $\mathrm{Cm}-247$ \\
\hline $\mathrm{Cm}-248$ & $9.94 E+03$ & 270 & 2.0 & $2.0 \mathrm{E}+03$ & $1.0 \mathrm{E}+\infty 0$ & $2 \mathrm{E}-01$ & 540 & 2.0 & $2.2 E+03$ & $1.0 E+\infty$ & $4 E-01$ & $\mathrm{Cm}-248$ \\
\hline Cf-249 & $3.46 \mathrm{E}+03$ & 270 & 2.0 & $2.0 E+03$ & 4.7E+01 & $1 E+01$ & 540 & 2.0 & $2.2 \mathrm{E}+03$ & $7.0 \mathrm{E}+01$ & $2 E+01$ & Cf-249 \\
\hline Cf-250 & $2.64 \mathrm{E}+08$ & 270 & 6.8 & $1.9 E+03$ & $1.6 E+43$ & $4 E+02$ & 540 & 5800 & $1.9 E+03$ & $1.6 E+43$ & $8 E+02$ & Cf-250 \\
\hline Cf-251 & $3.54 E+03$ & 270 & 2.0 & $2.0 \mathrm{E}+03$ & $4.5 E+00$ & $3 E+\infty$ & 540 & 2.0 & $2.2 E+03$ & $5.2 E+\infty 0$ & $6 \mathrm{E}+\infty$ & Cf-251 \\
\hline
\end{tabular}

a "NA" means Not Applicable - decay factor is implicit in the PDCF for this radionuclide.

b "NL" means No Limit - estimated permissible concentration is greater than the specific activity of the pure elemental radionuclide.

c Radionuclide concentration is based on arrival time at the performance boundary beyond 10,000 y.

d PDCF is a function of arrival time. See Chapter 1 of this volume for equation.

e $r_{\text {Docay }} \geq 1 \mathrm{1E}+50$

$f$ Contribution of decay product(s) is significant to determination of this value (see Table E-3 in Volume 2). Listed arrival time is that of the parent radionuclide. If this footnote does not appear in combination with footnote $c$, the arrival time of the significant decay product(s) is less than $10,000 \mathrm{y}$. 
For the trench design at ORR, the total undecayed CRFs for the groundwater pathway ranged from about 1 to 1,800 . Water travel time was $1.2 \mathrm{y}$, with travel time through the saturated zone accounting for all subsurface travel time. Among the listed radionuclides, arrival times at the performance boundary ranged from $31 \mathrm{y}$ to $140,000 \mathrm{y}$, including the retention time in the facility before failure.

For the generic tumulus at ORR, the total undecayed CRFs for the groundwater pathway ranged from about 2 to about 3 million. Water travel time was $1.2 \mathrm{y}$, with travel time through the saturated zone accounting for all subsurface travel time. Among the listed radionuclides, arrival times at the performance boundary ranged from $31 \mathrm{y}$ to $140,000 \mathrm{y}$, including the retention time in the facility before failure.

\subsubsection{Atmospheric Transport}

Two CRFs were used to account for the attenuation encompassing diffusion to the ground surface, mixing in air, and dispersion in the atmosphere to the performance boundary. The CRF

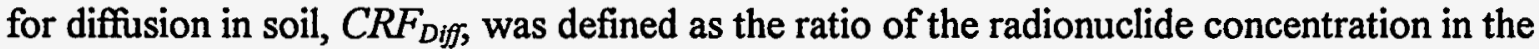
waste to its resulting concentration in the upper one centimeter of soil. The CRF for dispersion in air, $C R F_{D i s p}$, was defined as the ratio of the radionuclide concentration in the upper one centimeter of soil to its resulting concentration in air at the performance boundary. The effect of radioactive decay was also included in the PE.

Application of the PE methodology for atmospheric transport of the two volatile radionuclides considered in the $\mathrm{PE}(\mathrm{H}-3$ and $\mathrm{C}-14)$ produced the results shown in Table 14-5 for both the generic trench and tumulus designs; there was no assumed difference in these two disposal technologies with respect to permissible waste limits based on the atmospheric pathway at ORR. The table shows permissible waste concentrations based on transport in the atmospheric pathway $\left(C_{W-A t m}\right)$ as well as the values used in calculating the permissible waste concentrations. For both $\mathrm{H}-3$ and $\mathrm{C}-14$, the greatest concentration reduction occurred as the radionuclides diffuse from the top of the disposal facility to the soil surface.

Table 14-5. Results of Calculations for the Atmospheric Pathway

\begin{tabular}{|c|c|c|c|c|c|c|c|}
\hline \multirow[t]{2}{*}{ Nuclide } & \multirow[b]{2}{*}{$\begin{array}{c}S D C F_{A t m} \\
(r e m(y) /(\mu \mathrm{Ci} L)\end{array}$} & \multicolumn{6}{|c|}{ Generic Trench and Tumulus } \\
\hline & & $\underset{\text { (dlmensionless) }}{C R F_{D I f}}$ & $\begin{array}{c}c R F_{\text {Disp }} \\
\text { (dimensioniess) }\end{array}$ & $\begin{array}{c}C R F_{\text {Atm }} \\
\text { (dilmensionless) }\end{array}$ & $\begin{array}{c}\text { Arrival } \\
\text { Time (y) }\end{array}$ & $\begin{array}{c}r_{\text {Docay }} \\
\text { (dilmensionless) }\end{array}$ & $\begin{array}{c}C_{W-A t m} \\
\left(\mu \mathrm{Ci} / \mathrm{m}^{3}\right)\end{array}$ \\
\hline $\mathrm{H}-3$ & $8.33 E+02$ & $4 E+06$ & $5 E+02$ & $2 E+09$ & 100 & 280 & $7 E+09$ \\
\hline C-14 & $2.20 E+05$ & $9 E+04$ & $1 E+03$ & $9 E+07$ & 100 & 1 & $4 E+03$ \\
\hline
\end{tabular}

The time of arrival at the performance boundary for both radionuclides is shown in Table 14-5 as $100 \mathrm{y}$. However, the actual migration of $\mathrm{H}-3$ and $\mathrm{C}-14$ from the disposal facility to the surface and downwind to the performance boundary was calculated to be on the order of hours, not years. As discussed in Section 14.3.2.2, the waste form and RCRA cover are assumed to retain these volatile radionuclides in the disposal facility for at least $100 \mathrm{y}$. 


\subsubsection{Inadvertent Intruder Exposure}

The calculation of permissible waste concentrations for inadvertent intruder exposures did not utilize CRFs. Instead, the total dose resulting from an intrusion scenario (the sum of the doses from all exposure pathways involved in that intrusion) was modified by scenario dose conversion factors (SDCFs) that were applied to specific exposure pathways. The important exposure pathways for each radionuclide are listed in Appendix D of Volume 2. These values were radionuclide-specific and facility-design-specific and were the same for all sites. Values for the radioactive decay term were based on time of intrusion into the disposal facility (for the homesteader scenario, $300 \mathrm{y}$ for the trench design and $500 \mathrm{y}$ for the tumulus design; for the postdrilling scenario, $100 \mathrm{y}$ for both disposal designs). However, results based on intruder scenarios should be evaluated carefully because future social behavior, and intrusion scenarios, are difficult to predict.

The permissible waste concentrations for the two generic facility designs for each of the 58 radionuclides based on the standard PE intrusion scenarios are listed in Table 14-6. The most restrictive radionuclide concentration limits for each generic facility are indicated with bold type.

For six radionuclides in the table (U-233, U-234, U-235, U-238, Pu-244, and Cm-247), the time of homesteader intrusion was changed to $10,000 \mathrm{y}$, the end of the performance period. For these six radionuclides, ingrowth of decay products yields scenario doses that increase over time. The doses at $10,000 \mathrm{y}$, therefore, represent the maximum that could be encountered during the performance period. Also, for Th-230 and Cm-245, ingrowth of decay products likewise produces a scenario dose that increases over time and peaks within the 10,000-y performance period. The times of homesteader intrusion for these two radionuclides (Th-230 and Cm-245) were taken as the time of maximum dose, 9000 and $1000 \mathrm{y}$, respectively.

For the trench design, the post-drilling scenario generally yielded more restrictive waste limits than the homesteader scenario for those radionuclides with half-lives shorter than about $30 \mathrm{y}$. For the tumulus design, the post-drilling scenario generally yielded more restrictive limits than the homesteader scenario for those radionuclides with half-lives shorter than about $130 \mathrm{y}$.

\subsection{SUMMARY AND DISCUSSION OF RESULTS}

The limiting waste concentrations in disposed MLLW for the water, atmospheric, and intruder analyses for the generic trench and tumulus designs are summarized in Section 14.6.1. An overall discussion of the results of the PE for ORR is contained in Section 14.6.2, and the conceptual models and results of the PE and the SWSA6 performance assessment are compared in Section 14.6.2.3. 
Table 14-6. Permissible Waste Concentrations for the Standard Intrusion Scenarios (most limiting radionuclide concentration for each facility design is highlighted in bold italic) (Part 1 of 2)

\begin{tabular}{|c|c|c|c|c|c|}
\hline \multirow[t]{2}{*}{ Nuclide } & \multicolumn{2}{|c|}{ Trench } & \multicolumn{2}{|c|}{ Tumulus } & \multirow[t]{2}{*}{ Nuclide } \\
\hline & $\begin{array}{c}C_{w-1 n t r^{a}} \\
\text { Homesteader } \\
\left(\mu \mathrm{Ci} / \mathrm{m}^{3}\right)\end{array}$ & $\begin{array}{c}C_{w-n t r} \\
\text { Post-Drilling } \\
\left(\mu \mathrm{Ci} / \mathrm{m}^{3}\right)\end{array}$ & $\begin{array}{c}C_{W-1 n t r}{ }^{a} \\
\text { Homesteader } \\
\left(\mu \mathrm{Ci} \mathrm{m}^{3}\right)\end{array}$ & $\begin{array}{c}C_{\text {wAntr }} \\
\text { Post-Drilling } \\
\left(\mu \mathrm{Ci} / \mathrm{m}^{3}\right)\end{array}$ & \\
\hline $\mathrm{H}-3$ & $1 E+12$ & $7 E+07$ & $\mathrm{NL}$ & $7 E+07$ & $\mathrm{H}-3$ \\
\hline$c-14$ & $1 E+04$ & $7 E+04$ & $1 E+04$ & $7 E+04$ & $C-14$ \\
\hline Al-26 & $5 E+01$ & $5 \mathrm{E}+04$ & $5 E+01$ & $5 E+04$ & $\mathrm{Al}-26$ \\
\hline Si-32 & $9 E+03$ & $1 E+04$ & $4 E+04$ & $1 E+04$ & Si-32 \\
\hline $\mathrm{Cl}-36$ & $2 E+02$ & $9 E+02$ & $2 E+02$ & $9 E+02$ & $\mathrm{Cl}-36$ \\
\hline$K-40$ & $7 E+02$ & $2 E+04$ & $7 E+02$ & $2 E+04$ & $K-40$ \\
\hline Co-60 & $\mathrm{NL}$ & $3 E+10$ & $\mathrm{NL}$ & $3 E+10$ & Co-60 \\
\hline Ni-59 & $3 E+06$ & $1 E+07$ & $3 E+06$ & $1 E+07$ & $\mathrm{Ni}-59$ \\
\hline $\mathrm{Ni}-63$ & $8 E+06$ & $1 E+07$ & $3 E+07$ & $1 E+07$ & $\mathrm{Ni}-63$ \\
\hline Se-79 & $2 E+05$ & $8 E+05$ & $2 E+05$ & $8 E+05$ & Se-79 \\
\hline Sr-90 & $1 E+06$ & $5 E+04$ & $1 E+08$ & $5 E+04$ & Sr-90 \\
\hline Zr-93 & $5 E+06$ & $3 E+07$ & $5 E+06$ & $3 E+07$ & Zr-93 \\
\hline $\mathrm{Nb}-93 \mathrm{~m}$ & $5 E+12$ & $4 E+09$ & $\mathrm{NL}$ & $4 E+09$ & $\mathrm{Nb}-93 \mathrm{~m}$ \\
\hline $\mathrm{Nb}-94$ & $9 E+01$ & $9 E+04$ & $1 E+02$ & $9 E+04$ & $\mathrm{Nb}-94$ \\
\hline Tc-99 & $2 E+04$ & $8 E+04$ & $2 E+04$ & $8 E+04$ & TC-99 \\
\hline Pd-107 & $6 E+06$ & $3 E+07$ & $6 E+06$ & $3 E+07$ & $\mathrm{Pd}-107$ \\
\hline $\mathrm{Ag}-108 \mathrm{~m}$ & $5 E+02$ & $1 E+05$ & $1 E+03$ & $1 E+05$ & $\mathrm{Ag}-108 \mathrm{~m}$ \\
\hline $\mathrm{Cd}-113 \mathrm{~m}$ & $4 \mathrm{E}+09$ & $1 E+06$ & $7 E+13$ & $1 E+06$ & Cd-113m \\
\hline Sn-121m & $2 E+07$ & $5 E+07$ & $2 E+08$ & $5 E+07$ & $\mathrm{Sn}-121 \mathrm{~m}$ \\
\hline Sn-126 & $8 E+01$ & $7 E+04$ & $8 E+01$ & $7 E+04$ & Sn-126 \\
\hline $\mid-129$ & $2 E+03$ & $1 E+04$ & $2 E+03$ & $1 E+04$ & I-129 \\
\hline Cs-135 & $2 E+05$ & $8 E+05$ & $2 E+05$ & $8 E+05$ & Cs-135 \\
\hline Cs-137 & $3 E+05$ & $8 E+05$ & $3 E+07$ & $8 E+05$ & Cs-137 \\
\hline Ba-133 & $2 E+11$ & $3 E+08$ & $\mathrm{NL}$ & $3 E+08$ & $\mathrm{Ba}-133$ \\
\hline$S m-151$ & $2 E+08$ & $2 E+08$ & $8 E+08$ & $2 E+08$ & $S m-151$ \\
\hline Eu-152 & $6 E+08$ & $2 E+07$ & $2 E+13$ & $2 E+07$ & Eu-152 \\
\hline Eu-154 & $4 E+12$ & $4 E+08$ & $\mathrm{NL}$ & $4 E+08$ & Eu-154 \\
\hline $\mathrm{Pb}-210$ & $7 E+06$ & $7 E+04$ & $4 E+09$ & $7 E+04$ & $\mathrm{~Pb}-210$ \\
\hline Ra-226 & $8 E+01$ & $3 E+03$ & $9 E+01$ & $3 E+03$ & Ra-226 \\
\hline Ra-228 & NL & $4 E+09$ & $\mathrm{NL}$ & $4 E+09$ & Ra-228 \\
\hline Th-229 & $5 E+02$ & $3 E+04$ & $5 E+02$ & $3 E+04$ & Th-229 \\
\hline Th-230 & $8 E+01$ & $7 E+04$ & $8 E+01$ & $7 E+04$ & Th-230 \\
\hline Th-232 & $6 E+01$ & $2 E+04$ & $6 E+01$ & $2 E+04$ & Th-232 \\
\hline Pa-231 & $2 E+02$ & $5 E+03$ & $2 E+02$ & $5 E+03$ & $\mathrm{~Pa}-231$ \\
\hline
\end{tabular}


Table 14-6. Permissible Waste Concentrations for the Standard Intrusion Scenarios (most limiting radionuclide concentration for each facility design is highlighted in bold italic) (Part 2 of 2)

\begin{tabular}{|c|c|c|c|c|c|}
\hline \multirow[t]{2}{*}{ Nuclide } & \multicolumn{2}{|c|}{ Trench } & \multicolumn{2}{|c|}{ Tumulus } & \multirow[t]{2}{*}{ Nuclide } \\
\hline & $\begin{array}{c}C_{W-1 n t r}^{a} \\
\text { Homesteader } \\
\left(\mu \mathrm{C} / \mathrm{m}^{3}\right)\end{array}$ & $\begin{array}{c}C_{W-1 n t r} \\
\text { Post-Drilling } \\
\left(\mu \mathrm{Cl} / \mathrm{m}^{3}\right)\end{array}$ & $\begin{array}{c}C_{\text {W-Intr }} \\
\text { Homesteader } \\
\left(\mu \mathrm{Ci} / \mathrm{m}^{3}\right)\end{array}$ & $\begin{array}{c}C_{W-\ln t} \\
\text { Post-Drilling } \\
\left(\mu \mathrm{Ci} / \mathrm{m}^{3}\right)\end{array}$ & \\
\hline $\mathrm{U}-232$ & $2 E+03$ & $5 E+04$ & $1 E+04$ & $5 E+04$ & U-232 \\
\hline U-233 & $7 E+02$ & $1 E+05$ & $7 E+02$ & $1 E+05$ & U-233 \\
\hline$U-234$ & $1 E+03$ & $1 E+05$ & $1 E+03$ & $1 E+05$ & U-234 \\
\hline U-235 & $6 E+02$ & $1 E+05$ & $6 E+02$ & $1 E+05$ & U-235 \\
\hline U-236 & $2 E+04$ & $1 E+05$ & $2 E+04$ & $1 E+05$ & U-236 \\
\hline U-238 & $5 E+03$ & $1 E+05$ & $5 E+03$ & $1 E+05$ & U-238 \\
\hline $\mathrm{Np}-237$ & $4 E+02$ & $4 E+03$ & $4 E+02$ & $4 E+03$ & $\mathrm{~Np}-237$ \\
\hline Pu-238 & $7 E+04$ & $1 E+05$ & $4 E+05$ & $1 E+05$ & Pu-238 \\
\hline Pu-239 & $6 E+03$ & $5 E+04$ & $6 E+03$ & $5 E+04$ & Pu-239 \\
\hline $\mathrm{Pu}-240$ & $6 E+03$ & $5 E+04$ & $7 E+03$ & $5 E+04$ & Pu-240 \\
\hline Pu-241 & $2 E+05$ & $1 E+06$ & $3 E+05$ & $1 E+06$ & Pu-241 \\
\hline $\mathrm{Pu}-242$ & $6 E+03$ & $5 E+04$ & $6 E+03$ & $5 \mathrm{E}+04$ & $\mathrm{Pu}-242$ \\
\hline Pu-244 & $4 E+02$ & $5 E+04$ & $4 E+02$ & $5 E+04$ & Pu-244 \\
\hline Am-241 & $7 E+03$ & $5 E+04$ & $9 E+03$ & $5 E+04$ & Am-241 \\
\hline Am-243 & $9 E+02$ & $4 \mathrm{E}+04$ & $9 E+02$ & $4 E+04$ & Am-243 \\
\hline $\mathrm{Cm}-243$ & $1 E+06$ & $8 E+05$ & $5 E+06$ & $8 E+05$ & $\mathrm{Cm}-243$ \\
\hline Cm-244 & $2 E+06$ & $3 E+06$ & $2 E+06$ & $3 E+06$ & $\mathrm{Cm}-244$ \\
\hline $\mathrm{Cm}-245$ & $1 E+03$ & $4 E+04$ & $1 E+03$ & $4 E+04$ & $\mathrm{Cm}-245$ \\
\hline $\mathrm{Cm}-246$ & $6 E+03$ & $5 E+04$ & $6 E+03$ & $5 E+04$ & $\mathrm{Cm}-246$ \\
\hline $\mathrm{Cm}-247$ & $3 E+02$ & $5 E+04$ & $3 E+02$ & $5 E+04$ & $\mathrm{Cm}-247$ \\
\hline Cm-248 & $2 E+03$ & $1 E+04$ & $2 E+03$ & $1 E+04$ & $\mathrm{Cm}-248$ \\
\hline Cf-249 & $8 E+02$ & $4 E+04$ & $1 E+03$ & $4 E+04$ & Cf-249 \\
\hline Cf-250 & $2 E+06$ & $9 E+06$ & $2 E+06$ & $9 E+06$ & Cf-250 \\
\hline Cf-251 & $2 E+03$ & $4 E+04$ & $2 E+03$ & $4 E+04$ & Cf-251 \\
\hline
\end{tabular}

a "NL" means No Limit - estimated permissible concentration is greater than the specific activity of the pure elemental radionuclide. 


\subsubsection{Results Based on Disposal Design}

For the generic trench design at ORR, 36 radionuclides were limited by the water pathway, no radionuclides were limited by the atmospheric pathway, and 22 radionuclides were limited by intrusion scenarios, as shown in Table 14-7. For the generic tumulus, 35 radionuclides were limited by the water pathway, no radionuclides were limited by the atmospheric pathway, 22 radionuclides were limited by intrusion scenarios, and one radionuclide was limited by both the water pathway and the intrusion scenarios. The radionuclides limited by the water pathway generally tended to be either highly mobile (e.g., H-3, Tc-99) or thorium, uranium, and the transuranics.

For both the trench and tumulus designs, concentrations for four radionuclides ( $\mathrm{Sr}-90$, $\mathrm{Nb}-93 \mathrm{~m}, \mathrm{Cd}-113 \mathrm{~m}$, and $\mathrm{Sn}-121 \mathrm{~m}$ ) that arrived at the performance boundary before $10,000 \mathrm{y}$ reported in Table 14-7 for the water pathway analysis had no limit. As discussed in Section 14.5.1, the calculated concentrations for those radionuclides reported as NL (No Limit) were above the specific activity of the pure elemental radionuclide, indicating that the performance measure of $4 \mathrm{mrem}(0.04 \mathrm{mSv})$ per year would not be reached under the given release and transport assumptions.

As also discussed in Section 14.5.1, values for some radionuclides are not reported in Table 14-7 for the water pathway analysis. Arrival times for these radionuclides were beyond the 10,000-y performance period. For these radionuclides, the estimated waste concentrations are presented in Table 14-4 for information purposes but are not listed in Table 14-7. Consistent with the approach used in LLW performance assessments, these values were not considered in determining the most restrictive disposal limit from among the evaluated pathways because arrival times for these radionuclides were beyond $10,000 \mathrm{y}$.

\subsubsection{Discussion}

The results of the PE are based on the framework of assumptions summarized in Chapter 1 of this volume and discussed in detail in Volume 2 of this report and on the site-specific conceptual model for contaminant transport discussed in this chapter. Using alternative assumptions about the conceptual model has the potential to affect the results. Changes in the conceptual model could include alternative assumptions about the disposal facility, the source term, and radionuclide movement in the three pathways. Depending on the degree of possible variation and the relative importance of the parameters used in the calculation of estimated permissible waste concentrations, variability in parameter values can also affect the results. For parameters, results could vary depending on potential changes in values of both the generic and the site-specific parameters used in the PE analysis. 
Table 14-7. Permissible Concentrations for the Generic Disposal Designs at ORR (permissible concentration related to the most limiting pathway for each facility design is highlighted in bold italic) (Part 1 of 2)

\begin{tabular}{|c|c|c|c|c|c|c|c|}
\hline \multirow[t]{2}{*}{ Nuclide } & \multicolumn{3}{|c|}{ Trench } & \multicolumn{3}{|c|}{ Tumulus } & \multirow[t]{2}{*}{ Nuclide } \\
\hline & $\begin{array}{c}C_{w \cdot w a t e r}{ }^{a, b} \\
\left(\mu \mathrm{Ci} / \mathrm{m}^{3}\right)\end{array}$ & $\begin{array}{l}C_{W-A t m}{ }^{c} \\
\left(\mu \mathrm{Ci} / m^{3}\right)\end{array}$ & $\begin{array}{l}C_{w \cdot / n t r}{ }^{d} \\
\left(\mu \mathrm{Ci} / m^{3}\right)\end{array}$ & $\begin{array}{c}C_{\text {w-Water }}{ }^{2, b} \\
\left(\mu \mathrm{Ci} / \mathrm{m}^{3}\right)\end{array}$ & $\begin{array}{l}C_{w \cdot A t m} \\
\left(\mu \mathrm{Ci} / \mathrm{m}^{3}\right)\end{array}$ & $\begin{array}{l}C_{\text {WAntr }}{ }^{d} \\
\left(\mu \mathrm{Ci} / \mathrm{m}^{3}\right)\end{array}$ & \\
\hline $\mathrm{H}-3$ & $2 E+03$ & $7 E+09$ & $7 E+07$ & $3 E+06$ & $7 E+09$ & $7 \mathrm{E}+07$ & $\mathrm{H}-3$ \\
\hline$c-14$ & $1 E+02$ & $4 E+03$ & $1 E+04$ & $3 E+02$ & $4 E+03$ & $1 E+04$ & C-14 \\
\hline Al-26 & - & & $5 E+01$ & - & & $5 E+01$ & Al-26 \\
\hline Si-32 & $4 E+07$ & & $9 E+03$ & $3 E+08$ & & $1 E+04$ & Si-32 \\
\hline $\mathrm{Cl}-36$ & $2 E+00$ & & $2 E+02$ & $3 E+00$ & & $2 E+02$ & $\mathrm{Cl}-36$ \\
\hline$K-40$ & $2 E+00$ & & $7 E+02$ & $4 E+00$ & & $7 E+02$ & $K-40$ \\
\hline Co-60 & - & & $3 E+10$ & - & & $3 E+10$ & Co-60 \\
\hline $\mathrm{Ni}-59$ & - & & $3 E+06$ & - & & $3 E+06$ & Ni-59 \\
\hline Ni-63 & - & & $8 E+06$ & - & & $1 E+07$ & $\mathrm{Ni}-63$ \\
\hline Se-79 & $4 E+00$ & & $2 E+05$ & $8 E+00$ & & $2 E+05$ & Se-79 \\
\hline Sr-90 & $\mathrm{NL}$ & & $5 E+04$ & NL & & $5 E+04$ & Sr-90 \\
\hline Zr-93 & - & & $5 E+06$ & - & & $5 E+06$ & Zr-93 \\
\hline $\mathrm{Nb}-93 \mathrm{~m}$ & $\mathrm{NL}$ & & $4 E+09$ & $\mathrm{NL}$ & & $4 E+09$ & $\mathrm{Nb}-93 \mathrm{~m}$ \\
\hline $\mathrm{Nb}-94$ & $5 E+01$ & & $9 \mathrm{E}+01$ & $1 E+02$ & & $1 E+02$ & $\mathrm{Nb}-94$ \\
\hline TC-99 & $2 E+01$ & & $2 E+04$ & $5 E+01$ & & $2 E+04$ & Tc-99 \\
\hline$P d-107$ & $2 E+04$ & & $6 E+06$ & $4 E+04$ & & $6 E+06$ & Pd-107 \\
\hline $\mathrm{Ag}-108 \mathrm{~m}$ & $3 E+12$ & & $5 E+02$ & $2 E+13$ & & $1 E+03$ & $\mathrm{Ag}-108 \mathrm{~m}$ \\
\hline $\mathrm{Cd}-113 \mathrm{~m}$ & $\mathrm{NL}$ & & $1 E+06$ & $\mathrm{NL}$ & & $1 E+06$ & $\mathrm{Cd}-113 \mathrm{~m}$ \\
\hline $5 n-121 m$ & $\mathrm{NL}$ & & $2 E+07$ & NL & & $5 E+07$ & Sn-121m \\
\hline $5 n-126$ & $1 E+01$ & & $8 E+01$ & $3 E+01$ & & $8 E+01$ & Sn-126 \\
\hline $1-129$ & $1 E-01$ & & $2 E+03$ & $2 E-01$ & & $2 \mathrm{E}+03$ & $1-129$ \\
\hline Cs-135 & - & & $2 E+05$ & - & & $2 E+05$ & Cs-135 \\
\hline Cs-137 & - & & $3 E+05$ & - & & $8 E+05$ & Cs-137 \\
\hline $\mathrm{Ba}-133$ & - & & $3 E+08$ & - & & $3 E+08$ & $\mathrm{Ba}-133$ \\
\hline Sm-151 & - & & $2 E+08$ & - & & $2 E+08$ & Sm-151 \\
\hline Eu-152 & - & & $2 E+07$ & - & & $2 E+07$ & Eu-152 \\
\hline Eu-154 & - & & $4 E+08$ & - & & $4 E+08$ & Eu-154 \\
\hline $\mathrm{Pb}-210$ & - & & $7 E+04$ & - & & $7 E+04$ & $\mathrm{~Pb}-210$ \\
\hline Ra-226 & - & & $8 E+01$ & - & & $9 E+01$ & Ra-226 \\
\hline Ra-228 & - & & $4 E+09$ & - & & $4 E+09$ & Ra-228 \\
\hline Th-229 & $9 E-01$ & & $5 E+02$ & $2 E+00$ & & $5 E+02$ & Th-229 \\
\hline Th-230 & $5 E-01$ & & $8 E+01$ & $1 E+00$ & & $8 E+01$ & Th-230 \\
\hline Th-232 & 6E-01 & & $6 E+01$ & $1 E+00$ & & $6 E+01$ & Th-232 \\
\hline $\mathrm{Pa}-231$ & - & & $2 E+02$ & - & & $2 E+02$ & $\mathrm{~Pa}-231$ \\
\hline
\end{tabular}


Table 14-7. Permissible Concentrations for the Generic Disposal Designs at ORR (permissible concentration related to the most limiting pathway for each facility design is highlighted in bold italic) (Part 2 of 2)

\begin{tabular}{|c|c|c|c|c|c|c|c|}
\hline \multirow[t]{2}{*}{ Nuclide } & \multicolumn{3}{|c|}{ Trench } & \multicolumn{3}{|c|}{ Tumulus } & \multirow[t]{2}{*}{ Nuclide } \\
\hline & $\begin{array}{c}C_{\text {whwater }}{ }^{a, b} \\
\left(\mu \mathrm{Ci} / \mathrm{m}^{3}\right)\end{array}$ & $\begin{array}{l}C_{W-A t m}{ }^{c} \\
\left(\mu \mathrm{Ci} / \mathrm{m}^{3}\right)\end{array}$ & $\begin{array}{l}C_{W \cdot \ln r^{d}} \\
\left(\mu \mathrm{Ci} / \mathrm{m}^{3}\right) \\
\end{array}$ & $\begin{array}{c}C_{\text {w.water }}{ }^{a, b} \\
\left(\mu \mathrm{Ci} / \mathrm{m}^{3}\right)\end{array}$ & $\begin{array}{l}C_{w-A t m}{ }^{c} \\
\left(\mu \mathrm{Ci} / \mathrm{m}^{3}\right)\end{array}$ & $\begin{array}{l}C_{w / n t r}{ }^{d} \\
\left(\mu \mathrm{Ci} / \mathrm{m}^{3}\right)\end{array}$ & \\
\hline U-232 & $3 E+08$ & & $2 E+03$ & $5 E+09$ & & $1 E+04$ & U-232 \\
\hline U-233 & $3 E+00$ & & $7 E+02$ & $6 E+00$ & & $7 E+02$ & U-233 \\
\hline U-234 & $8 E+00$ & & $1 E+03$ & $2 E+01$ & & $1 E+03$ & U-234 \\
\hline $\mathrm{U}-235$ & $2 E+00$ & & $6 E+02$ & $4 E+00$ & & $6 \mathrm{E}+02$ & U-235 \\
\hline U-236 & $1 E+01$ & & $2 E+04$ & $2 E+01$ & & $2 E+04$ & U-236 \\
\hline U-238 & $1 E+01$ & & $5 E+03$ & $2 E+01$ & & $5 E+03$ & U-238 \\
\hline $\mathrm{Np}-237$ & $6 E-01$ & & $4 E+02$ & $1 E+00$ & & $4 E+02$ & Np-237 \\
\hline Pu-238 & $2 E+04$ & & $7 E+04$ & $5 E+04$ & & $1 E+05$ & Pu-238 \\
\hline Pu-239 & $9 E-01$ & & $6 \mathrm{E}+03$ & $2 E+00$ & & $6 E+03$ & Pu-239 \\
\hline Pu-240 & $1 E+00$ & & $6 E+03$ & $2 E+00$ & & $7 E+03$ & Pu-240 \\
\hline Pu-241 & $5 E+02$ & & $2 E+05$ & $1 E+03$ & & $3 E+05$ & Pu-241 \\
\hline Pu-242 & $9 E-01$ & & $6 E+03$ & $2 E+00$ & & $6 \mathrm{E}+03$ & Pu-242 \\
\hline Pu-244 & 5E-01 & & $4 E+02$ & $1 E+00$ & & $4 E+02$ & Pu-244 \\
\hline Am-241 & $2 E+01$ & & $7 E+03$ & $5 E+01$ & & $9 \mathrm{E}+03$ & Am-241 \\
\hline Am-243 & $9 E-01$ & & $9 E+02$ & $2 E+00$ & & $9 \mathrm{E}+02$ & Am-243 \\
\hline $\mathrm{Cm}-243$ & $7 E+02$ & & $8 E+05$ & $1 E+03$ & & $8 E+05$ & $\mathrm{Cm}-243$ \\
\hline $\mathrm{Cm}-244$ & $4 E+02$ & & $2 E+06$ & $7 E+02$ & & $2 E+06$ & $\mathrm{Cm}-244$ \\
\hline $\mathrm{Cm}-245$ & 5E-01 & & $1 E+03$ & $9 E-01$ & & $1 E+03$ & $\mathrm{Cm}-245$ \\
\hline $\mathrm{Cm}-246$ & $1 E+00$ & & $6 \mathrm{E}+03$ & $2 E+00$ & & $6 E+03$ & $\mathrm{Cm}-246$ \\
\hline $\mathrm{Cm}-247$ & 5E-01 & & $3 E+02$ & $1 E+00$ & & $3 E+02$ & $\mathrm{Cm}-247$ \\
\hline $\mathrm{Cm}-248$ & 2E-01 & & $2 E+03$ & 4E-01 & & $2 E+03$ & $\mathrm{Cm}-248$ \\
\hline Cf-249 & $1 E+01$ & & $8 E+02$ & $2 E+01$ & & $1 E+03$ & Cf-249 \\
\hline Cf-250 & $4 E+02$ & & $2 E+06$ & $8 E+02$ & & $2 E+06$ & Cf-250 \\
\hline Cf-251 & $3 E+00$ & & $2 E+03$ & $6 E+00$ & & $2 E+03$ & Cf-251 \\
\hline
\end{tabular}

a "NL" means No Limit - estimated permissible concentration factor is greater than the specific activity of the pure elemental radionuclide.

b "-" Indicates that the radionuclide concentration is based on an arrival time beyond $10,000 \mathrm{y}$; see Table $14-4$ for specific values.

c Results presented for radionclides expected to be volatile under disposal facility conditions.

d Concentration is based on the most restrictive intrusion scenario assumed for the site; see Table 14-6. 
The effects on results from using alternative generic assumptions and parameter values is discussed in Chapter 6 of Volume 2. In addition, a discussion is provided in that chapter about the effects of using alternative values for site-specific parameters. Based on this discussion, four parameters were identified (three site-specific and one generic, all used in the water pathway analysis) that could potentially influence the results to the degree that the calculated waste concentrations become limited by a pathway other than the one determined for the PE (Table 14-7). The impacts on the results of using alternative values for these four parameters for the water pathway in the PE for ORR are discussed in this section. The basis for and possible variation in the values used in the PE for these parameters are discussed in Section 14.6.2.2.

\subsubsection{Parameter Sensitivity Analysis}

The PE provided results for two disposal facility designs: a RCRA-compliant, belowground trench and a RCRA-compliant, above-ground tumulus. Similar assumptions about the integrity of engineered barriers were made in the PE for both facility designs. Because the factors used to estimate transport of radionuclides in the water pathway for both designs were similar, the discussion in this section focuses on examining the results for the indicator radionuclides reported for the tumulus design (indicator radionuclides are defined in Chapter 7 of Volume 2).

As discussed in Chapter 6 of Volume 2, only four parameters used in the PE were identified as having a potential range of values that might affect results: natural recharge through the disposal facility $(i)$; groundwater Darcy velocity $\left(q_{g w}\right)$; area of the facility $(A)$; and distribution coefficients $\left(K_{d} \mathrm{~S}\right)$. These parameter values for ORR are summarized in Table 14-8.

Table 14-8. Parameter Values Used in the PE for ORR with Potential Variability That Could Affect the Results

\begin{tabular}{|l|l|}
\hline \multicolumn{1}{|c|}{ Parameter } & \multicolumn{1}{c|}{ Value } \\
\hline Natural recharge to groundwater, $i$ & $0.18 \mathrm{~m} / \mathrm{y}$ (ORNL, 1994a, $\mathrm{p} . \mathrm{F}-1)$ \\
\hline $\begin{array}{l}\text { Distribution coefficients for geologic } \\
\text { media, } K_{d}\end{array}$ & $\begin{array}{l}\text { See Table 14-2 in this chapter } \\
\text { for values }\end{array}$ \\
\hline Groundwater Darcy velocity, $q_{\mathrm{ow}}$ & $2.92 \mathrm{~m} / \mathrm{y}$ (ORNL, 1994a) \\
\hline Plan-view Area, $A$ & $2500 \mathrm{~m}$ (standard PE value) \\
\hline
\end{tabular}

The traditional procedure for performing a sensitivity analysis is to vary the parameters used in the calculations and observe the effect on the results. To be meaningful, this method requires some knowledge of the statistical distribution of each of the parameters considered, including their likely maximum and minimum values. For the PE calculations, the potential variability of the parameters used to calculate the permissible waste concentrations for the two different facility designs was not estimated. For most of the radionuclides considered in the PE, there were only two limiting exposure pathways: the water pathway and intruder exposure scenarios (the atmospheric pathway was considered only for $\mathrm{H}-3$ and $\mathrm{C}-14$ ). The intruderpathway results provide a baseline that can be used for comparison with the water-pathway results because the intruder scenarios used in the PE were relatively independent of the physical characteristics of the individual sites. This baseline provided an alternative method of performing 
sensitivity analyses for the PE. The input parameters for the water pathway were varied to determine if the controlling exposure pathway could be altered (e.g., the results could be changed from intruder-scenario controlled to water-pathway controlled). After new values for the water pathway parameters were determined, these values were examined for reasonableness based on physical constraints at the site.

The sensitivity analysis was limited to a comparison of the water and intruder exposure pathways. A comparison between the water and atmospheric pathways was not conducted because the atmospheric pathway was not limiting.

To analyze the sensitivity of the results to changes in the parameter values for natural recharge, groundwater Darcy velocity, and area of the facility, the parameter values used in the $\mathrm{PE}$ for ORR were varied. Only one parameter value was varied at a time for a radionuclide, leaving the others equal to their PE values. In most instances, the parameter value was varied until the waste concentrations for the water and intruder pathways became equal, regardless of the likelihood (or physical impossibility) of the value to occur. The parameter values that caused the permissible concentrations for the water and intruder pathways to become equal are listed in Table 14-9 for the 8 indicator radionuclides.

Table 14-9. Parameter Values That Caused the Permissible Concentrations for the Water and Intruder Pathways to Be Equal for Indicator Radionuclides at ORR (tumulus design) (bold italic type indicates limiting pathway in the PE)

\begin{tabular}{|c|c|c|c|c|c|c|}
\hline \multirow[t]{4}{*}{$\begin{array}{l}\text { Indicator } \\
\text { Nuclide }\end{array}$} & \multirow[t]{4}{*}{$\begin{array}{c}\text { PE } \\
C_{w-w a t e r}^{a} \\
\left(\mu \mathrm{Ci} / \mathrm{m}^{3}\right)\end{array}$} & \multirow[t]{4}{*}{$\begin{array}{c}\text { PE } \\
C_{W-1 n t r} \\
\left(\mu \mathrm{Ci} / \mathrm{m}^{3}\right)\end{array}$} & \multirow[t]{4}{*}{$\begin{array}{c}\text { PE } \\
\frac{C_{W-\text { Intr }}}{C_{W-\text { Water }}}\end{array}$} & $\begin{array}{c}\text { Natural } \\
\text { Recharge, } \\
i \\
(\mathrm{~m} / \mathrm{y})\end{array}$ & $\begin{array}{l}\text { Groundwater } \\
\text { (Darcy) } \\
\text { Velocity, } q_{g w} \\
\text { (m/y) }\end{array}$ & $\begin{array}{c}\text { Area, } \\
\underset{\left(\mathrm{m}^{2}\right)}{A}\end{array}$ \\
\hline & & & & \multicolumn{3}{|c|}{ PE Values } \\
\hline & & & & 0.18 & 2.9 & 2500 \\
\hline & & & & \multicolumn{3}{|c|}{$\begin{array}{c}\text { Value That Caused Equal } \\
\text { Concentrations }\end{array}$} \\
\hline $\mathrm{H}-3$ & $3 E+06$ & $7 E+07$ & 23 & c & 0.024 & $<100$ \\
\hline $\mathrm{C}-14$ & $3 E+02$ & $1 E+04$ & 33 & 0.0019 & 280 & $<100$ \\
\hline$S r-90$ & $\mathrm{NL}$ & $5 E+04$ & - & $c$ & c & c \\
\hline Tc-99 & $5 E+01$ & $2 E+04$ & 400 & 0.00025 & 2100 & $<100$ \\
\hline Cs-137 & $\mathrm{NL}^{\mathrm{b}}$ & $8 E+05$ & - & c & c & c \\
\hline$U-238$ & $2 E+01$ & $5 E+03$ & 250 & 0.00038 & 1400 & $<100$ \\
\hline $\mathrm{Pu}-239$ & $2 E+00$ & $6 E+03$ & 3000 & 0.000025 & 22,000 & $<100$ \\
\hline $\begin{array}{l}\mathrm{Am}-241 \\
\mathrm{~Np}-237^{d}\end{array}$ & $5 E+01$ & $9 E+03$ & 180 & $0.093^{\circ}$ & $5^{\circ}$ & $<100$ \\
\hline
\end{tabular}

a "NL" means No Limit - estimated permissible concentration is greater than the specific activity of the pure elemental radionuclide.

b Arrival time at the performance boundary is greater than $10,000 \mathrm{y}$.

c No variation in valuE: caused equal concentrations.

d The dominant decay product for Am-241

e Based on the dominant decay product, Np-237

"." Value could not be calculated. 
For the parameters listed in Table 14-9, significant variations in values are needed to change the limiting pathways based on the $\mathrm{PE}$ results for all of the indicator radionuclides. For instance, $\mathrm{C}-14$ values for recharge would have to decrease by two orders of magnitude, and values for Tc-99, U-238, and Am-241 would need to decrease by about three orders of magnitude to change the limiting pathway from water to intruder exposure scenarios. No change in the recharge value for $\mathrm{H}-3, \mathrm{Sr}-90$, and $\mathrm{Cs}-137$ would change the limiting pathway. For C-14, Tc-99, and $\mathrm{U}-238$, values for groundwater velocity would need to increase by two to three orders of magnitude to change the limiting pathway. Values for $\mathrm{H}-3$ would have to decrease by two orders of magnitude for the same result. For Pu-239, a change of five orders of magnitude in groundwater velocity would change the limiting pathway. For Am-241, the recharge would have to decrease about 2 times or the groundwater velocity would have to increase almost 2 times to change the limiting pathway from water to intruder. The values for disposal facility plan area would need to decrease to less than $100 \mathrm{~m}^{2}$ to change the limiting pathway for all radionuclides.

At ORR, the saturated zone travel time accounts for essentially all of the water travel time from the disposal facility to the performance boundary. Therefore, $K_{d}$ values for the saturated zone were varied.

A $K_{d}$ value of $220 \mathrm{~mL} / \mathrm{g}$ applied to the saturated zone would cause an arrival time at the performance boundary of $10,000 \mathrm{y}$. The $K_{d}$ values that caused the permissible concentrations for the water and intruder pathways to be the same are listed in Table 14-10 for 5 of the indicator radionuclides. The indicator radionuclides $\mathrm{H}-3, \mathrm{C}-14$, and Tc-99 were not considered in this analysis because general consensus is that the $K_{d}$ values for these radionuclides are small.

Table 14-10. Variation of $K_{d}$ Values for the Saturated Zone at ORR (tumulus design) (bold type indicates limiting pathway in the PE) (a $K_{d}$ value of $220 \mathrm{~mL} / \mathrm{g}$ caused radionuclide arrival at the performance boundary equal to $10,000 \mathrm{y}$ )

\begin{tabular}{|c|c|c|c|c|c|}
\hline $\begin{array}{l}\text { Indicator } \\
\text { Nuclide }\end{array}$ & $\begin{array}{c}P E \\
K_{d} \\
(m L g) \\
\end{array}$ & $c_{\text {W-Water }}^{\mathrm{PE}}$ & $\begin{array}{c}\text { PE } \\
C_{W-\text { Intr }}\end{array}$ & $\begin{array}{c}\text { PE } \\
C_{W \text {-Intr }} \\
C_{W \text {-Water }} \\
\end{array}$ & $\begin{array}{l}K_{d} \text { Value That } \\
\text { Caused Equal } \\
\text { Concentrations }\end{array}$ \\
\hline Sr-90 & 30 & NL & $5 E+04$ & - & 0 \\
\hline Cs-137 & 3000 & $\mathrm{NL}^{\mathrm{b}}$ & $8 E+05$ & - & 4 \\
\hline U-238 & 40 & $2 E+01$ & $5 E+03$ & 250 & $c, d$ \\
\hline Pu-239 & 40 & $2 E+00$ & $6 E+03$ & 3000 & $6200^{b, d}$ \\
\hline $\begin{array}{l}\mathrm{Am}-241 \\
(\mathrm{~Np}-237)^{\circ}\end{array}$ & $\begin{array}{c}40 \\
(40)\end{array}$ & $5 E+01$ & $9 \mathrm{E}+03$ & 180 & $20,000^{b, d}$ \\
\hline
\end{tabular}

a "NL" means No Limit - the estimated permissible waste concentration is greater than the specific activity of the pure elemental radionuclide.

b Radionuclide arrival time at the performance boundary is greater than $10,000 \mathrm{y}$.

c No variation in values caused equal concentrations.

d Value greater than $220 \mathrm{~mL} / \mathrm{g}$ caused arrival at the performance boundary after $10,000 \mathrm{y}$, which changed the limiting pathway. .

- The dominant decay product of Am-241

"-" Value could not be calculated. 
For Sr-90 and Cs-137, using very small $K_{d}$ values near zero caused the permissible waste concentrations for the water pathway to equal those of the intruder pathway. For U-238, Pu-239, and Am-241, increasing the $K_{d}$ values by a factor of five to greater than $220 \mathrm{~mL} / \mathrm{g}$ caused the travel time in the water pathway to become greater than 10,000 y so that the limiting pathway changed from water to intruder for these radionuclides. The $K_{d}$ values must be increased much more to cause the permissible waste concentrations to equal intruder values.

\subsubsection{Physical Constraints on Sensitivity Analysis Values}

The PE results for ORR are based on parameter values provided by the ORR technical staff for site-specific parameters used in calculations. Descriptions and references for these values are provided in Sections 14.3 and 14.4. Ranges and statistical distributions are generally not known for all of the input parameter values; however, site-specific knowledge can be used to determine whether the values determined in the sensitivity analysis are reasonable and physically possible at ORR. The values used in the PE were based on input or calculated values from the performance assessment for LLW disposal ORR (ORNL, 1994a).

\section{Natural Recharge}

The value used for the natural recharge to groundwater $\left(0.18 \mathrm{~m} / \mathrm{y}[0.59 \mathrm{ft} / \mathrm{y}]\right.$ or $5.7 \times 10^{-7}$ $\mathrm{cm} / \mathrm{s}$ ) was based on the saturated hydraulic conductivity of the saprolite at SWSA 6 (ORNL, $1994 a$, p. 2-14). The conductivity tends to decrease with depth from about $10^{-4} \mathrm{~cm} / \mathrm{s}$ in the upper half meter below the ground surface to about $10^{-8} \mathrm{~cm} / \mathrm{s}$ at $4 \mathrm{~m}(13 \mathrm{ft})$ below the ground surface. Because the groundwater zone is assumed in this analysis to be between 2 and $5 \mathrm{~m}$ ( 7 and $16 \mathrm{ft}$ ) below the ground surface, the range of hydraulic conductivities for this zone is fairly small. The hydraulic conductivities in the shallower horizons are associated with the shallow stormflow zone, in which approximately $90 \%$ of the leachate is calculated to flow. The much higher hydraulic conductivities support this result. The sensitivity analysis described above suggests that the assumed hydraulic conductivity would have to be reduced by one to three orders of magnitude to change the limiting pathway for several indicator radionuclides. Because the assumed hydraulic conductivity is already on the order of a compacted clay, values for this parameter that are one to three orders of magnitude less than the value used in the PE are unlikely.

\section{Groundwater Darcy Velocity}

The value for the groundwater Darcy velocity $(2.9 \mathrm{~m} / \mathrm{y}$ [9.5 ft/y]) was based on calculated results in the SWSA 6 performance assessment (ORNL, 1994a), using a groundwater model which was calibrated to water-table elevations at the site. While this Darcy velocity is low, the pore velocities are much higher because the effective porosity is on the order of 0.035 , due primarily to the presence of fractures. These high pore velocities cause a water travel time to the $100-\mathrm{m}(328-\mathrm{ft})$ performance boundary of about $1.5 \mathrm{y}$. The sensitivity analysis described above indicates that the Darcy velocity would have to be increased by two to three orders of magnitude to change the limiting pathway for C-14, Tc-99, U-238, and Pu-239. An increase of this magnitude would cause unrealistically high pore velocities. Therefore, it is unlikely that the limiting pathway would be changed by using different values for the groundwater Darcy velocity for these radionuclides. For Am-241, it is probably reasonable to double the groundwater velocity and thus change the limiting pathway from water to intruder. 


\section{Facility Area}

The generic trench and tumulus designs used in the PE were a standard size ( $50 \mathrm{~m}$ by $50 \mathrm{~m}\left[2500 \mathrm{~m}^{2}\right]$ [ $164 \mathrm{ft}$ by $164 \mathrm{ft}$ or $\left.26,910 \mathrm{ft}^{2}\right]$ ) and shape (square) for all sites. The ORR staff are in the early stages of developing a disposal facility for MLLW, and their preliminary estimates of the size of the facility is on the order of $80,000 \mathrm{~m}^{2}$ (about $20 \mathrm{ac}$ ). As shown by the sensitivity analysis, for all indicator radionuclides a tumulus facility would need to be very small (less than $\left.100 \mathrm{~m}^{2}\left[1080 \mathrm{ft}^{2}\right]\right)$ to change the limiting pathway from water to intrusion. For a larger facility, the permissible waste concentrations calculated for the water pathway would be smaller than estimates provided in this analysis.

\section{Distribution Coefficients}

The PE for ORR used values for distribution coefficients $\left(K_{d} s\right)$ for the geologic media that were identical to values used in the SWSA 6 performance assessment (ORNL, 1994a). These values were generally based on site-specific analyses which generally agreed well with literature values for similar soils. The sensitivity analysis indicated that changes in $K_{d}$ values have the ability to affect the results by changing travel times of the radionuclides in the geologic media. According to Table 14-4, 39 radionuclides with concentration limits arrived before 10,000 y; three radionuclides with concentrations limits (Ni-59, Zr-93, and $\mathrm{Pa}-231)$ arrived at the performance boundary between 10,000 and 100,000 y. For two of these radionuclides ( $\mathrm{Zr}-93$ and $\mathrm{Pa}-231$, which arrived at 28,000 and $26,000 \mathrm{y}$, respectively), changes in their $K_{d}$ values of about a factor of two would cause them to arrive before 10,000 y. For Ni-63 $\left(K_{d}=2000 \mathrm{~mL} / \mathrm{g}\right)$, a reduction in $K_{d}$ of an order of magnitude would cause it to arrive before $10,000 \mathrm{y}$. Because waste concentrations in the water pathway were not considered in the $\mathrm{PE}$ results if the radionuclide arrived after $10,000 \mathrm{y}$, a decrease in arrival time to less than $10,000 \mathrm{y}$ could cause a change in limiting pathway if the waste concentration for a radionuclide in the water pathway is more restrictive than that in the intrusion pathway. The water pathway would limit the permissible waste concentration for all three of these radionuclides if their arrival times were less than $10,000 \mathrm{y}$.

The PE results for ORR are based on estimated parameter values developed by the site technical staff for site-specific parameters used in calculations for the water pathway and represent the current knowledge of the site technical staff. In addition, the site-specific conceptual model for water flow paths agrees with the conceptual model used in the SWSA 6 performance assessment. Differences in assumptions related to radionuclide transport mechanisms between the PE and SWSA 6 performance assessment are summarized in Section 14.6.2.3 and described in more detail in Appendix A.3.

\subsubsection{Comparison of Conceptual Models and Results between the PE and the SWSA 6 Performance Assessment}

The conceptual model selected to represent a site can be considerably more important to the results than the parameter values selected for that particular model. The generic conceptual model for flow and transport used in the water-pathway analysis for the SWSA 6 performance assessment is believed to be conservative with respect to actual site behavior because few mechanisms are used to represent the environmental concentration attenuation that is known or believed to occur. The PE conceptual model is believed to be even more conservative than that 
used in the SWSA 6 performance assessment with respect to site behavior because even fewer attenuation mechanisms have been used. The comparison of the results and conceptual models between the ORR PE and SWSA 6 performance assessment provides an opportunity to determine the differences in conservatism used in these two analyses. This comparison of results and conceptual models is described in detail in Appendix A.3 and is summarized here. The SWSA 6 performance assessment results are based on the Integrated Waste Management Facility (IWMF), an above-ground tumulus facility at SWSA 6.

The three major differences in conceptual models are related to radionuclide transport mechanisms and are identified in Table 14-11. The source term in the SWSA 6 performance assessment is finite based on the disposed inventory at that site, while the ORR PE source term is assumed continuous. This continuous source assumption results in no vadose zone attenuation in the ORR PE. The SWSA 6 performance assessment uses an empirical model based on the duration of the release and the assumed soil $K_{d}$ to provide some concentration attenuation in the vadose-zone. Lastly, the SWSA 6 performance assessment assumes concentration attenuation in the groundwater due to dilution of leachate in clean groundwater, dispersion, and additional groundwater dilution from regional recharge. The PE assumes only dilution of leachate in clean groundwater.

Table 14-11. Comparison of Assumptions Used in the SWSA 6 Performance Assessment and ORR PE Groundwater Transport Analyses

\begin{tabular}{|c|c|c|}
\hline Assumption & SWSA 6 Performance Assessment & ORR PE \\
\hline Source Term & Finite with time-dependent rates & Continuous with constant rate \\
\hline Vadose Zone & $\begin{array}{l}C R F_{v}{ }^{1} \text { is a function of an empirical } \\
\text { vadose zone sorption model }\end{array}$ & $\begin{array}{l}C R F_{V}=1 \text {, implicitly, due to } \\
\text { equilibrium resulting from } \\
\text { continuous source assumption }\end{array}$ \\
\hline Saturated Zone & $\begin{array}{l}\text { CRF }{ }_{\text {Sat }}{ }^{2} \text { is a function of dilution when } \\
\text { leachate is mixed with groundwater, } \\
\text { dispersion, and additional groundwater } \\
\text { dilution from regional recharge }\end{array}$ & $\begin{array}{l}C R F_{\text {Sat }}=C R F_{\text {Water }}{ }^{3} \text { is a function } \\
\text { of dilution when leachate is } \\
\text { mixed with groundwater }\end{array}$ \\
\hline
\end{tabular}

${ }^{1} \mathrm{CRF}_{\mathrm{V}}$ - concentration reduction factor in the vadose zone = concentration in leachate $/$ concentration entering ground water

${ }^{2} \mathrm{CRF}_{\mathrm{Sex}}$ - concentration reduction factor in the saturated zone = concentration entering ground water $/$ concentration at $100 \mathrm{~m}$

${ }^{3} \mathrm{CRF}_{\text {werer }}$ - concentration reduction factor in the water pathway $=C R F_{V} \times C R F_{s \text { st }}$

The effects of the differences in these assumptions are shown in Table 14-12. In this table, the values for the concentration reduction factors for each concentration attenuation mechanism are shown for the performance assessment and PE results. The SWSA 6 performance assessment uses four mechanisms to provide concentration attenuation, while the ORR PE uses one mechanism. The last two columns compare the total environmental transport CRF values for the performance assessment and PE. The performance assessment $C R F_{\text {Water }}$ values are 20 to 60 times larger than the PE values; indicating that the conceptual model used in the ORR PE provides results which are 20 to 60 times more conservative than those of the SWSA 6 performance assessment. This effect is due solely to the differences in assumptions of transport mechanisms used in the two analyses. 
Table 14-12. Comparison of the Individual Impacts of the SWSA 6 Performance Assessment and ORR PE Transport Assumptions for the Radionuclides in the SWSA 6 IWMF

\begin{tabular}{|c|c|c|c|c|c|c|c|c|}
\hline Nuclide & $\begin{array}{c}\text { Assumed } \\
\text { Vadosel } \\
\text { Saturated } \\
K_{d} \\
(\mathrm{~mL} / \mathrm{g})\end{array}$ & $\begin{array}{c}\begin{array}{c}\text { Duration } \\
\text { of Release }\end{array} \\
(y)^{b}\end{array}$ & $\begin{array}{c}\text { Performance } \\
\text { Assessment } \\
\text { CRFF } \\
\text { (dilmenslontess) }\end{array}$ & $\begin{array}{c}\text { Performance } \\
\text { Assessment } \\
C^{2} F_{\text {Diturtion }} \\
\text { (dilmensionless) }\end{array}$ & $\begin{array}{l}\text { Performance } \\
\text { Assessment } \\
C F_{\text {Recherge }} \\
\text { (dilmenslontess) }\end{array}$ & $\begin{array}{l}\text { Performance } \\
\text { Assessment } \\
\text { CRF }_{\text {Disporse }} \\
\text { (dilmenslonless) }\end{array}$ & $\begin{array}{c}\text { Performance } \\
\text { Assessment } \\
\text { CRF Water } \\
\text { (dilmensioniess) }\end{array}$ & $\begin{array}{c}\text { PE } \\
\text { CRF Water } \\
\text { (dlmenslonless) }\end{array}$ \\
\hline $\mathrm{H}-3$ & 0.10 .2 & 10 & 3.6 & 2.2 & 3.1 & $1.6^{\circ}$ & 39 & 2.2 \\
\hline$c-14$ & $0 / 0.2$ & 10 & 4.8 & 2.2 & 3.1 & 2.2 & 72 & 2.2 \\
\hline Al-26 & 3000 & - & - & 2.2 & 3.1 & - & - & 2.2 \\
\hline $\mathrm{Cl}-36$ & $0 / 0.2$ & - & - & 2.2 & 3.1 & 1.3 & - & 2.2 \\
\hline Ni-63 & 2000 & - & - & 2.2 & 3.1 & - & $=$ & 2.2 \\
\hline Sr-90 & 30 & 120 & 25 & 2.2 & 3.1 & - & - & 2.2 \\
\hline Tc-99 & $0 / 0.2$ & 20 & 3.5 & 2.2 & 3.1 & 1.6 & 38 & 2.2 \\
\hline Cs-137 & 3000 & 90 & 1600 & 2.2 & 3.1 & - & - & 2.2 \\
\hline Eu-152 & 3000 & - & - & 2.2 & 3.1 & - & - & 2.2 \\
\hline Th-232 & 40 & 210 & 3.6 & 2.2 & 3.1 & - & - & 2.2 \\
\hline U-233 & 40 & 230 & 6.0 & 2.2 & 3.1 & 3.2 & 131 & 2.2 \\
\hline $\mathrm{U}-238$ & 40 & 360 & 0.4 & 2.2 & 3.1 & - & - & 2.2 \\
\hline $\mathrm{Pu}-239$ & 40 & 230 & 4.6 & 2.2 & 3.1 & 3.2 & 100 & 2.2 \\
\hline$A m-241$ & 40 & 250 & 3.3 & 2.2 & 3.1 & - & - & 2.2 \\
\hline Am-243 & 40 & 250 & 4.5 & 2.2 & 3.1 & 3.1 & 95 & 2.2 \\
\hline
\end{tabular}

a Values taken from Table 3.7 and E.2 (ORNL, 1994a).

b Values estimated from leach rate figures in Appendix F for the IWMF (ORNL, 1994a); duration of release to 10\% of peak release.

c Values copled from Table ORR-4 of Appendix A.3 of this report.

d Values copled from Table ORR-6 of Appendix A.3 of this report.

e Product of the four component performance assessment CRF values in this table.

$f$ Values copied from Table ORR-2 of Appendix A.3 of this report.

Of the four concentration reduction mechanisms used in the SWSA 6 performance assessment, no single mechanism dominated, with the exception of $C R F_{V}$ for the high- $K_{d}$ radionuclide Cs-137. Instead, it was the combined effect of the four concentration reduction mechanisms that provided the differences in the results of the ORR PE and the SWSA 6 performance assessment. For example, for U-233 the result of each of the concentration reduction mechanisms used in the SWSA 6 performance assessment was less than an order of magnitude, yet the combined effect of the four mechanisms resulted in a concentration reduction that was about sixty times greater than that provided by the ORR PE $\left(C R F_{\text {Water }}=131\right.$ vs. 2.2).

This result leads to an important conclusion with respect to the performance evaluation project: ignoring individual concentration reduction mechanisms because their individual effect on the overall results is minor leads to greater conservatism with respect to the combined effect of the individual mechanisms. The conservatism increases with the increased number of mechanisms. This result is particularly evident when comparing the ORR PE with the SWSA 6 performance assessment, which used many concentration reduction mechanisms, each having a relatively small effect on the overall results. 
This discussion pertains only to comparison of the analyses contained in the SWSA 6 performance assessment and the ORR PE. No quantitative statements can be made about the degree of conservatism of either analysis with respect to actual site behavior over a 10,000-y time period.

\subsection{OBSERVATIONS}

Based on the results of the PE and the parameter-sensitivity analysis, the following observations can be made about MLLW disposal at ORR:

- The ORR site has characteristics that are typical of a humid climate. The natural recharge is high, and the site essentially has no unsaturated zone. Travel time through the saturated zone accounts for the subsurface travel time.

- The ORR site also has some unique characteristics:

- The low porosity of the geologic media is due mainly to fractures that tend to cause subsurface flow to be parallel to strike.

- The hydraulic conductivity decreases exponentially with depth. This characteristic causes approximately $90 \%$ of the leachate that flows through the shallow subsurface zone to go to surface water via ephemeral streams.

- The large dilution provided by the surface waters causes less restrictive radionuclide concentrations than those produced from the remaining $10 \%$ of the leachate entering the groundwater system.

- The high clay content and fractured nature of geologic media may tend to provide high retardation for some radionuclides. Efforts supporting performance assessments at ORR are attempting to establish the degree of irreversibility of the sorption that occurs in this media.

- For ORR, the results indicate that of the 58 radionuclides evaluated in the PE, 22 for the trench design and 23 for the tumulus design would be limited by the intrusion scenarios. These results reflect a less dominant role for the selected intrusion scenarios than is demonstrated for almost all of the other sites considered in the PE (see Sections 7.5 and 7.6 in Volume 2).

The results also indicate that for the water pathway, 15 radionuclides for both the trench and tumulus designs would arrive at the performance boundary after the 10,000-y period of consideration in the PE analysis of the water pathway. Of the radionuclides that would arrive before $10,000 \mathrm{y}, 4$ for both designs had no limit on waste concentration.

Because ORR has many radionuclides that are limited by the water pathway and few that either arrive at the performance boundary after $10,000 \mathrm{y}$ or have no limit on waste concentration, this site may have limited flexibility in accepting a variety of radionuclides for disposal. 
- The most feasible disposal-facility design at ORR is the tumulus design. The thinness of the unsaturated zone precludes below-ground disposal, and the conceptual MWDF currently being developed is a tumulus design.

- The depth to groundwater at ORR could place physical constraints on disposal activities. An above-ground tumulus approach is being used for current LLW disposal activities and is also being considered for mixed waste disposal.

- The sensitivity analysis for ORR indicates that reasonable changes in values for natural recharge, groundwater Darcy velocity, and facility size for most radionuclides would not significantly change the results. The groundwater Darcy velocity could likely be changed in a reasonable way to change the limiting pathway from water to intruder.

In flow and transport problems, the $K_{d}$ values are often the most uncertain site-specific input parameters. However, for ORR none of the $K_{d}$ values had sufficient uncertainty to affect the results (i.e., change the limiting pathway).

- The conceptual model for water flow used in the ORR PE was based on the performance assessment at SWSA 6, with the conceptual model for radionuclide transport being more conservative than the one used in the SWSA 6 performance assessment. Based on a comparison of the two analyses, the ORR PE is more conservative than the SWSA 6 performance assessment by 20 to 60 times. This result is due primarily to additional concentration reduction mechanisms used in the SWSA 6 performance assessment that are not used in the ORR PE. The differences in the results of the two analyses have been identified and quantified.

\subsection{REFERENCES}

Baer, T.A., L. L. Price, J. N. Emery, N. E. Olague, 1994. Second Performance Assessment Iteration of the Greater Confinement Disposal Facility at the Nevada Test Site. SAND930089. Albuquerque, NM: Sandia National Laboratories.

Cooper, C.D., and F.C. Alley, 1986. Air Pollution Control: A Design Approach. Prospect Heights, IL: Waveland Press, Inc.

CRC, 1981. CRC Handbook of Chemistry and Physics. Eds. Robert C. Weast and Melvin J. Astle. Boca Raton, FL: CRC Press, Inc.

EPA, 1992. User's Guide for the Industrial Source Complex (ISC2) Dispersion Models, Volume I: User Instructions. EPA Publication No. EPA-450/4-92-008a. Research Triangle, NC: U.S. Environmental Protection Agency.

FFCAct, 1992. Federal Facility Compliance Act of 1992. P.L. 102-386, October 1992. 
Flohr, D.F., P.H. Counts, F.D. Edwards, and J.W. Garrett, 1990. Water Resources Data: Tennessee-Water Year 1990. Water-Data Report TN-90-1. U.S. Geological Survey.

Gruebel, M.M., R.D. Waters, M.B. Hospelhorn, and M.S.Y. Chu, eds., 1994. Framework for DOE Low-Level and Mixed Low-Level Waste Disposal: Site Fact Sheets. SAND94-2728. Albuquerque, NM: Sandia National Laboratories.

Kincaid, C.T., J.W. Shade, G.A. Whyatt, M.G. Piepho, K. Rhoads, J.A. Voogd, J.H. Westsik, Jr., M.D. Freshley, K.A. Blanchard, and B.G. Lauzon, eds., 1993. Performance Assessment of Grouted Double-Shell Tank Waste Disposal at Hanford. WHC-SD-WM-EE-004, Rev. 0. U.S. Department of Energy, Pacific Northwest Laboratory and Westinghouse Hanford Company.

Lombardi, D.A. and M. L. Socolof, 1994. Atmospheric Pathway Analysis for Potential Emissions of Volatile Radionuclides from Solid Waste Storage Area 6 (SWSA 6). Response to Peer Review Comments of Performance Assessment for Continuing and Future Operations at Solid Waste Storage Area 6, ORNL-6783.

Maheras, Steven J., Arthur S. Rood, Swen O. Magnuson, Mary E. Sussman, and Rajiv N. Bhatt, 1994. Radioactive Waste Management Complex Low-Level Waste Radiological Performance Assessment. EGG-WM-8773. Idaho Falls, ID: U.S. Department of Energy Office of Environmental Restoration and Waste Management, DOE Idaho Operations Office.

MMES (Martin Marietta Energy Systems, Inc.), EG\&G Idaho, Inc., and Westinghouse Savannah River Company, 1994. Radiological Performance Assessment for the E-Area Vaults Disposal Facility. WSRC-RP-94-218, Rev. 0. Aiken, SC: Westinghouse Savannah River Company.

ORNL, 1994a. Performance Assessment for Continuing and Future Operations at Solid Waste Storage Area 6. ORNL-6783. Oak Ridge, TN: U.S. Department of Energy, Oak Ridge National Laboratory.

ORNL, 1994b. Mixed Waste Disposal Facility Waste Management Report. 94-097P/081194, $90 \%$ Draft (August 12). Oak Ridge, TN: Oak Ridge National Laboratory.

Thibault, D.H., M.I. Sheppard, and P.A. Smith, 1990. A Critical Compilation and Review of Default Soil Solid/Liquid Partition Coefficients, $K_{d,}$ for Use in Environmental Assessments. AECL-10125. Pinawa, Manitoba, Canada: Whiteshell Nuclear Research Establishment, Atomic Energy of Canada Limited.

\section{Acknowledgments}

The SNL Core Team acknowledges the contributions of Don Lee, Bob Luxmoore, Alan Icenhour, Mark Yambert, Herchel Godbey, and Lynn Tharp of Oak Ridge National Laboratory. 


\section{Texas: PANTEX PLANT Core Team Contact: Bruce M. Thomson}

The Federal Facility Compliance Act (FFCAct, 1992) requires the Department of Energy (DOE) to establish plans in conjunction with its regulators and with members of the public for the treatment of DOE's mixed low-level waste (MLLW). Although the FFCAct did not specifically address disposal of treated MLLW, both DOE and the States recognized that disposal issues were an integral part of treatment discussions. Since 1992, DOE has worked with the States to define and develop an evaluation process for disposal options. Preliminary activities of this joint DOEState process have narrowed the sites for further evaluation from 49 to 15 .

The Disposal Workgroup (DWG), which was established by DOE to develop a process for evaluating disposal options, designed a performance evaluation (PE) to quantify and compare the limitations of the remaining 15 DOE sites for MLLW disposal. The principal goal of the PE was to estimate, for grouted residuals resulting from the treatment of MLLW, permissible concentrations of radionuclides in waste for disposal at each site. These "permissible waste concentrations" were based solely on long-term physical performance of the disposal facility and did not take into account any operational waste acceptance criteria that a site might have developed. The PE did not address any ethical, social, or policy considerations relevant to siting such facilities.

The PE used analyses that are consistent with the approach used in many low-level waste (LLW) performance assessments. The objective was to use a set of modeling assumptions of sufficient detail to capture major site-specific characteristics and yet be general enough for consistent application at all sites. Additionally, the analyses were designed to ensure that the sites were analyzed consistently and that all major assumptions were clearly stated.

The remainder of this chapter provides the PE results for Pantex, one of the 15 sites being evaluated. The chapter contains the following information:

Section 15.1: brief, general description of the site, based on previous work done by the DWG (Gruebel et al., 1994)

Section 15.2: plans for MLLW disposal, and the location evaluated in the PE

Section 15.3: current understanding of radionuclide movement at the selected location based on available information, and the conceptual model used for the evaluation of each of three pathways (water, atmospheric, and inadvertent intruder)

Section 15.4: site-specific and generic values used in the PE calculations and their sources Section 15.5: estimates of maximum waste concentrations determined in the PE calculations for each of the three pathways, along with calculated values used in determining these results 
Section 15.6: summary of results based on disposal-facility design; discussion with respect to such issues as uncertainty and sensitivity

Section 15.7: observations based on the results of the PE and the parameter sensitivity analysis

Section 15.8: references

The general assumptions and methodology used in the PE are summarized in Chapter 1 of this volume and explained in more detail in Volume 2 of this report. Overall results for all the sites are discussed in Chapter 7 of Volume 2.

\subsection{GENERAL DESCRIPTION OF THE SITE}

The Pantex Plant is located in the Texas Panhandle in Carson County, Texas. It is about $27 \mathrm{~km}$ (17 mi) northeast of Amarillo (Figure 15-1). The Pantex Plant facility consists of 4079 ha $(10,080 \mathrm{ac})$, which consists of $3643 \mathrm{ha}$ (9002 ac) in the main Plant area and $436 \mathrm{ha}(1078 \mathrm{ac})$ located approximately $4 \mathrm{~km}(2.4 \mathrm{mi})$ northeast of the Plant area. In addition, the DOE leases $2370 \mathrm{ha}(5856 \mathrm{ac})$ of land immediately south of the Plant from Texas Technological University (Texas Tech) to serve as a security buffer zone. The region is semiarid and includes extensive farming and ranching activities. In recent years several industries have located their facilities in the vicinity of Pantex.

In 1991 the total population residing within $80 \mathrm{~km}$ (50 mi) of the Plant was 274,000 (M\&H, 1994a). The major population center is Amarillo to the southwest which contains about 156,000 residents. The other principal nearby community is Pampa, $40 \mathrm{mi}(64 \mathrm{~km})$ northeast with 21,000 residents.

Pantex is a government-owned, contractor-operated facility. Mason\&Hanger-Silas Mason Co., Inc. (M\&H) has been the operating contractor since 1956. In 1991 the environmental health and safety and waste management programs were subcontracted to Battelle Pantex.

The property was first used in 1942 by the U.S. Army Ordnance Corps for loading conventional ammunition shells and bombs during World War II. Major operations were terminated in 1945, and the plant was deactivated. The property was subsequently sold to Texas Tech with the land being subject to recall. The property was reclaimed by the federal government as a location for a nuclear weapons assembly facility. In 1951 the Atomic Energy Commission began rehabilitating portions of the original Plant and constructing new facilities for this new mission. During the 1960s and 1970s, similar nuclear-weapons-related assembly operations from facilities located in Clarksville, TN, Medina, TX, and Burlington, IA, were consolidated at Pantex. 


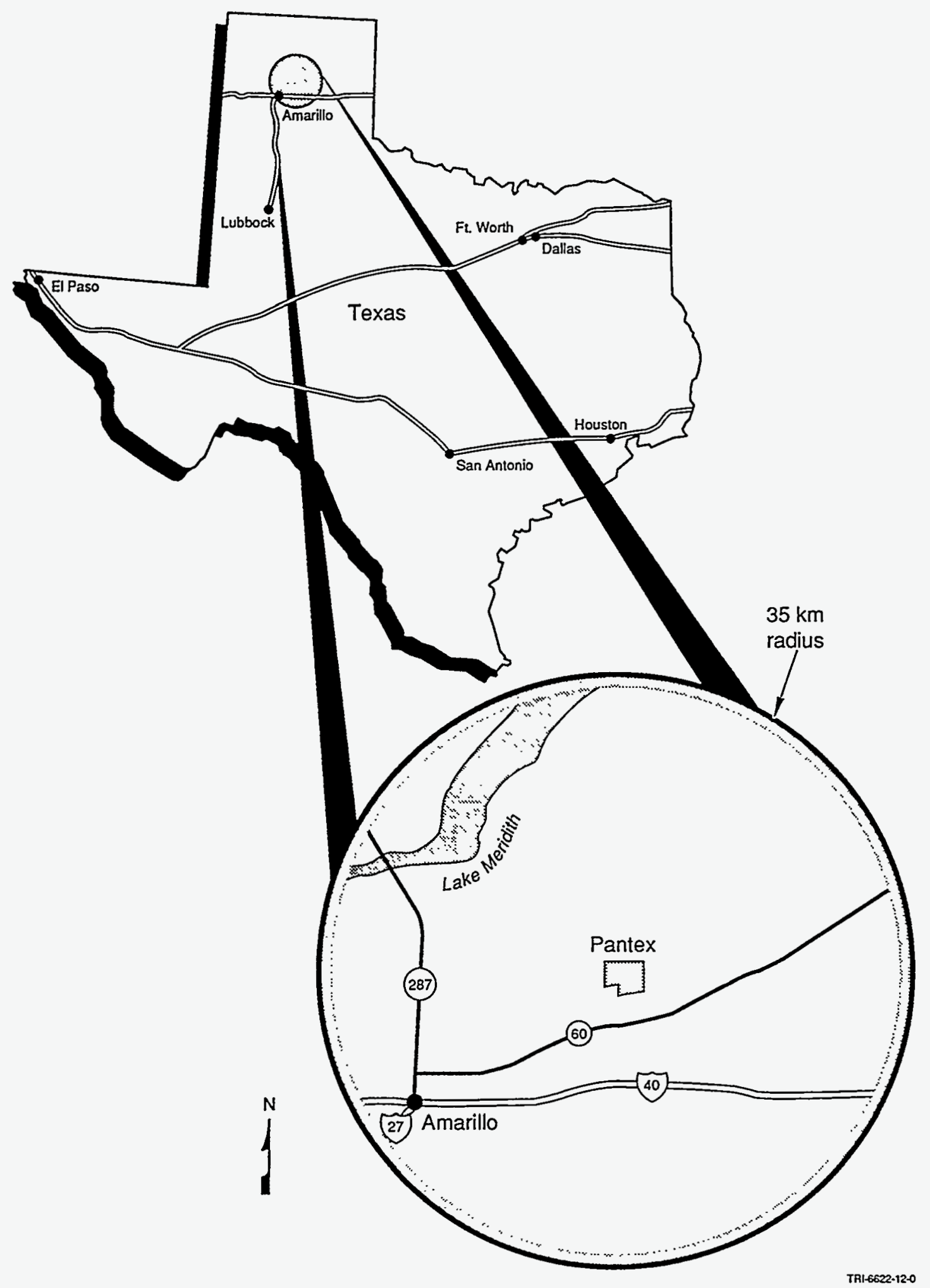

Figure 15-1. Location map for Pantex Plant. 
The principal operations presently performed at Pantex include the assembly and disassembly of nuclear weapons in the U.S. stockpile using components from other DOE facilities and high explosives (HE) fabricated at the Plant; operation of an experimental $\mathrm{HE}$ synthesis and characterization group; surveillance testing of nuclear weapon components; obsolete nuclear weapons disassembly; open controlled burning of the HE components and HE-contaminated material; and the storage, maintenance, modification, repair, and nonexplosive testing of nuclear weapons components. These activities involve short-term handling (but not processing) of encapsulated uranium, plutonium, and tritium, as well as a variety of nonradioactive toxic chemicals (M\&H, 1994a).

Pantex is divided into several functional areas which are referred to as zones (Figure 15-2). A description of major activities within each zone is presented in the "1993 Environmental Report" (M\&H, 1994a).

Pantex lies on the Southern High Plains of the Great Plains Province in northern Texas, an area that is also known as the Llano Estacado (staked plains). The topography is relatively flat, consisting of grassy plains and contains literally thousands of playa lakes. These lakes are small (generally less than $1 \mathrm{~km}$ in diameter), ephemeral bodies of water which receive surface runoff from surrounding areas and have no surface water discharge. Several playa lakes are present on the Plant property.

The climate at Pantex is semiarid with mild winters and hot, dry summers. It is characterized by low relative humidity, has large variations in daily temperatures, and experiences moderate amounts of rainfall which occur during infrequent but often intense storms. The Texas Panhandle is a windy area with prevailing winds from the south-southwest. Rainfall averages approximately $50 \mathrm{~cm} / \mathrm{y}(20 \mathrm{in} / \mathrm{y})$, while the average potential lake surface evaporation rate is about $185 \mathrm{~cm} / \mathrm{y}$ (73 in./y). Pantex experiences thunderstorms (which can produce tornadoes) about 49 days per year. The Panhandle is classified as a moderate to high hazard zone for tornadoes.

Three major subsurface faults and one minor surficial fault have been identified in the area of the Plant. In addition, the Meers fault in Oklahoma is important because it has experienced at least three episodes of movement between 4000 and $5000 \mathrm{y}$ ago. The occasional occurrence of small to moderate earthquakes in the Panhandle region demonstrates that the Amarillo Uplift is tectonically active at a low level. By contrast, the Palo Duro Basin seems to have hosted only two small shocks since 1925. The "Draft Environmental Information Document" (Battelle Columbus, 1995) summarizes earthquake phenomena within $50 \mathrm{mi}$ of the Pantex Plant Site. 


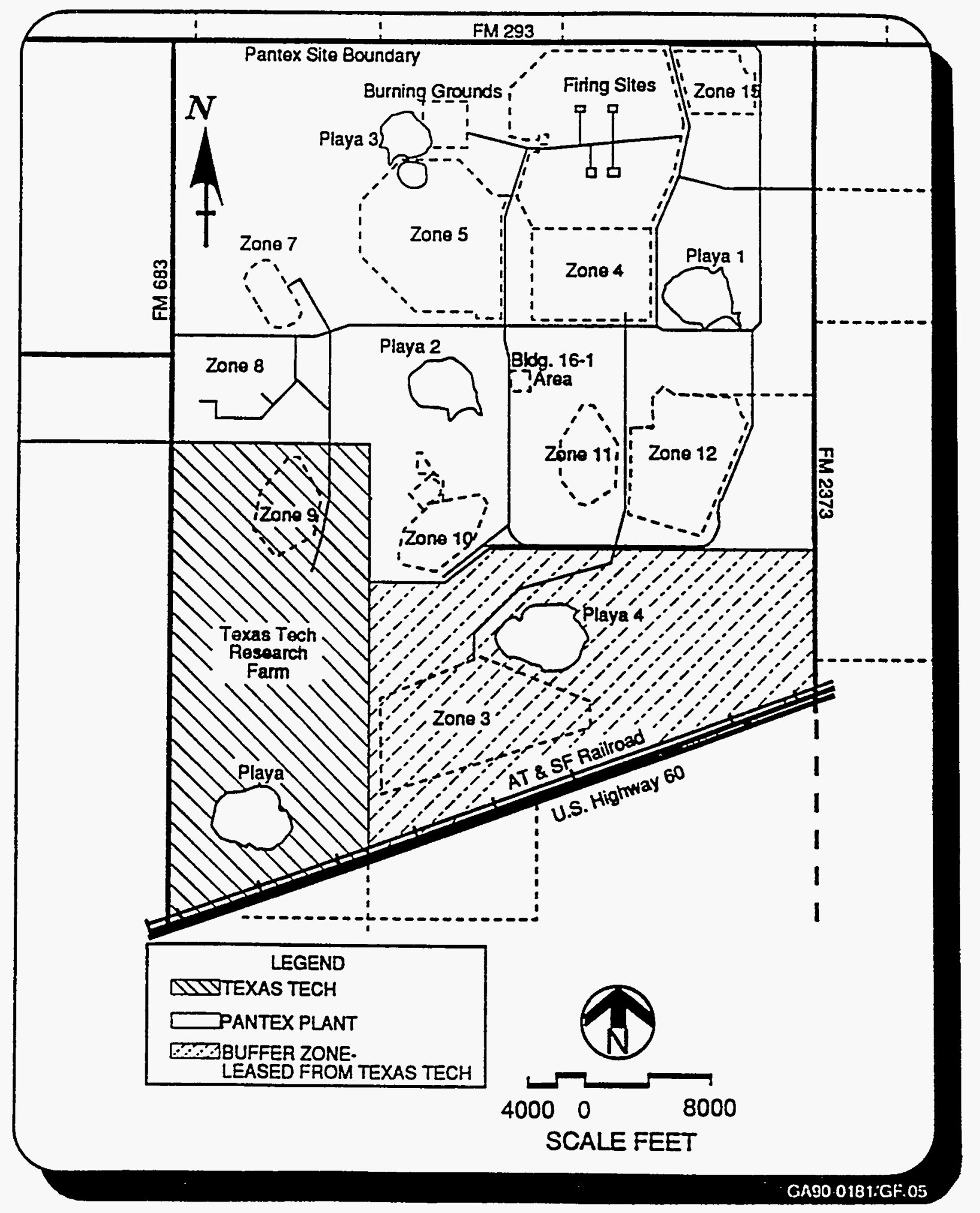

Figure 15-2. Site map for Pantex Plant. 
The Palo Duro Basin is a shallow basin (3000 to $4000 \mathrm{~m}$ [9800 to $13,000 \mathrm{ft}$ ] deep) occupying an area of $25,000 \mathrm{~km}^{2}\left(9750 \mathrm{mi}^{2}\right)$. The Precambrian basement rocks in the area are overlain by Upper Paleozoic, Mesozoic, and Cenozoic sedimentary rocks. The Upper Paleozoic strata in the area consists of Pennsylvanian rocks and Permian evaporites, which form collapse basins in the overlying deposits where dissolution has occurred. The Permian evaporites are unconformably overlain by the Triassic Dockum Group Formations. These formations are used in some areas of the Southern High Plains province as a groundwater resource for irrigation and domestic water supply. Overlying the Dockum Group is the Tertiary Ogallala Formation, which consists of sand, silt, clay, and gravel. This regional aquifer is used extensively for irrigation and municipal water supply. Overlying the Ogallala Formation is the Blackwater Draw Formation, which consists of eolian sands with thin layers of caliche.

Even though no aquifers in this area are EPA-designated sole source aquifers, the Ogallala is the only aquifer in this area.

\subsection{STATUS AND SITING OF MLLW DISPOSAL FACILITY}

At the time of the PE, personnel at Pantex had no plans for on-site MLLW disposal. A Draft Site Treatment Plan for mixed waste generated at Pantex has recently been prepared by DOE (US DOE, 1995). The Site Treatment Plan addresses the treatment of mixed waste generated at Pantex, along with proposed schedules for development of treatment options. The preferred options consist of existing on-site treatment, development of mobile treatment units (MTUs), and off-site commercial treatment.

The existing treatment consists of a burning ground for explosives, as well as separating, surveying, and decontamination facilities. The MTU technologies under consideration include macroencapsulation, waste stabilization and precipitation, hydrothermal oxidation, thermal desorption and evaporative oxidation, and amalgamation. The MTUs will be operated in the Hazardous Waste Treatment and Processing Facility, which is planned to be operational by the year 2001.

The location of a possible MWDF has not been determined by Pantex technical staff; however, it is generally agreed that it would most likely be in an interplaya region, possibly in Zone 4 or 5 near the northwestern corner of the site. The justification for this selection is that groundwater recharge is lowest in the interplaya region and that this location would have the least impact on other plant activities. In addition, there is probably no underlying perched water formation which would reduce the likelihood of groundwater resources becoming contaminated during the 10,000-y performance period for a disposal facility.

Two generic disposal facilities were considered in the PE: a RCRA-compliant, belowground trench and a RCRA-compliant, above-ground tumulus (described in more detail in Chapter 5 of Volume 2). The generic facilities were selected to provide consistency in analysis of the performance of the 15 sites. Both generic facilities were assumed to be square with a plan area of $2500 \mathrm{~m}^{2}\left(26,910 \mathrm{ft}^{2}\right)$. 


\subsection{BASIS FOR CONCEPTUAL MODEL USED IN THE PE}

Because there are no current plans for constructing an MLLW disposal facility at the Pantex Plant, a formal performance assessment for such a facility has not been conducted. Therefore, the information needed to evaluate each of the three exposure routes considered in the $\mathrm{PE}$ process was developed from other sources. Major sources of data used in the PE analysis are described below. The procedure for calculating exposure mechanisms at an MWDF are described in Volume 2 of this report. The following section summarizes the conditions at Pantex that are relevant to the PE process.

\subsubsection{Water Pathway}

Knowledge of groundwater flow and radionuclide movement in the water pathway at Pantex provided the basis for the conceptual model considered in the PE. The conceptual model encompasses the site technical staff's current understanding of site-specific geology, hydrology, water table and aquifer characteristics, and transport pathways.

\subsubsection{Current Understanding of Relevant Hydrogeology}

The present understanding of Pantex site hydrogeology is summarized in documents prepared for the Pantex groundwater monitoring program. These include the "1993 Environmental Report for Pantex Plant" (Mason \& Hanger, 1994); "Fate and Transport Integration Study for Pantex Plant and Vicinity" (Battelle Pantex, 1994a); "Corrective Action Management Unit Overall Plan" (Battelle Pantex, 1994b); “Geology, Seismology and Engineering Geology" (Battelle Pantex, 1995a); "Environmental Information Document, Draft-Revision 2" (Battelle Columbus, 1995); "Interim Guidance Document for Pantex Plant Plays" (Triebel et al., 1994); and "Hydrogeology and Hydrochemistry of the Ogallala Aquifer, Southern High Plains, Texas Panhandle and Eastern New Mexico" (Nativ, 1988).

A comprehensive discussion of the geology in the vicinity of Pantex has recently been published in draft form as Chapter 3 of the "Environmental Information Document" (Battelle Columbus, 1995). This chapter addresses the geology of the region to assist in developing an understanding of the groundwater environment as well as any significant geologic phenomena.

The primary surface deposits at Pantex are Pullman soils on the plains surface and Randall soils in the playas. These soils represent the uppermost section of the Blackwater Draw Formation. This formation consists of a sequence of buried soil horizons with an upper unit of mostly silty clay loam and caliche that is approximately $3 \mathrm{~m}(10 \mathrm{ft})$ thick and a $10-$ to $24-\mathrm{m}$ (40- to 75-ft) thick lower unit of silty sand with caliche (Battelle Columbus, 1995). The Blackwater Draw Formation overlies the Ogallala Formation.

The Ogallala Formation consists of fluvial sands and gravels that occupy the paleovalleys and aeolian sands and silts that overlay paleouplands between the paleovalleys, as well as fluvial sections. The formation includes sand, silt, clay, gravel, and some caliche. The base of the 
Ogallala is an irregular surface that represents the pre-Ogallala topography. As a result, depths to the base of this formation vary. At the Pantex Plant, the depth to the base of the Ogallala varies from $90 \mathrm{~m}(300 \mathrm{ft})$ at the southwest corner of the Plant to $220 \mathrm{~m}(720 \mathrm{ft})$ at the northeast corner.

Underlying the Ogallala Formation are the sedimentary rocks of the Lower Dockum Group. These rocks consist of a confining layer of clays and shales, clayey siltstone, and sandstone. The Lower Dockum Group is less than $30 \mathrm{~m}(100 \mathrm{ft})$ thick beneath Pantex and is underlain by Permian rocks. Permian sediments consist of interbedded sandstones, mudstones, anhydrites, gypsum, limestones, dolomites, and bedded salts. Figure 15-3 is a generalized stratigraphic cross section of the Pantex Plant from north to south and shows the respective relationships of the three near-surface formations.

A perched water zone is present at several locations at the Pantex Plant and has been encountered in wells near Playas One, Two, and Three. Perched water has also been encountered to the north and west of the plant site. The largest perched zone appears to be thickest near Playa One; this thicknesss is attributed to focused recharge from this lake (Battelle Columbus, 1995). This playa contains a permanent pool of water throughout the year due to a continuous discharge from the plant's wastewater treatment facility. Additional recharge of the perched formations may occur through drainage ditches throughout the facility, several of which have been used for discharge of process water in the past. A perched water table map was prepared by the U.S. Army Corps of Engineers, Tulsa, OK District and is presented in Figure 15-4. The interplaya regions in Zones 4 and 5 have few monitoring wells which can be used to determine the areal extent of the perched zone.

Recent interpretations suggest that up to four discontinuous perching zones may be present, with separate zones of saturation occurring at Pantex (Battelle Pantex, 1994). The perched water formation(s) overlies a zone of fine-grained material that functions as an aquitard to limit vertical groundwater flow to the underlying Ogallala aquifer. This fine-grained zone underlies much of the plant property; however, it may not be continuous throughout the site. Near Playa One the perched aquifer is believed to be located in a paleochannel 76 to $91 \mathrm{~m}$ ( 250 to $300 \mathrm{ft}$ ) below the surface. Investigations of the vadose zone hydrogeology at Pantex have focused on the perched water formation(s) as it has been found to be contaminated by plant activities. Major investigations of Pantex hydrology in recent years have been conducted by the U.S. Army Corps of Engineers, the Texas Bureau of Economic Geology, Argonne National Laboratory, the University of Texas (Austin) Department of Geological Sciences, and the Texas Tech Water Resources Center (Battelle Pantex, 1994).

Detailed environmental investigations are currently under way to determine the magnitude and extent of surface and subsurface contamination at Pantex. A major component of these investigations is development of a site-wide fate and transport study. This study, described in the draft report "Fate and Transport Integration Study for Pantex Plant and Vicinity," (Battelle Pantex, 1994b), includes review of existing data, analysis of data validity, identification of potential chemical degradation processes and transport mechanisms, integration of validated data for further analyses, and determination of future data needs. 
NORTH

SOUTH

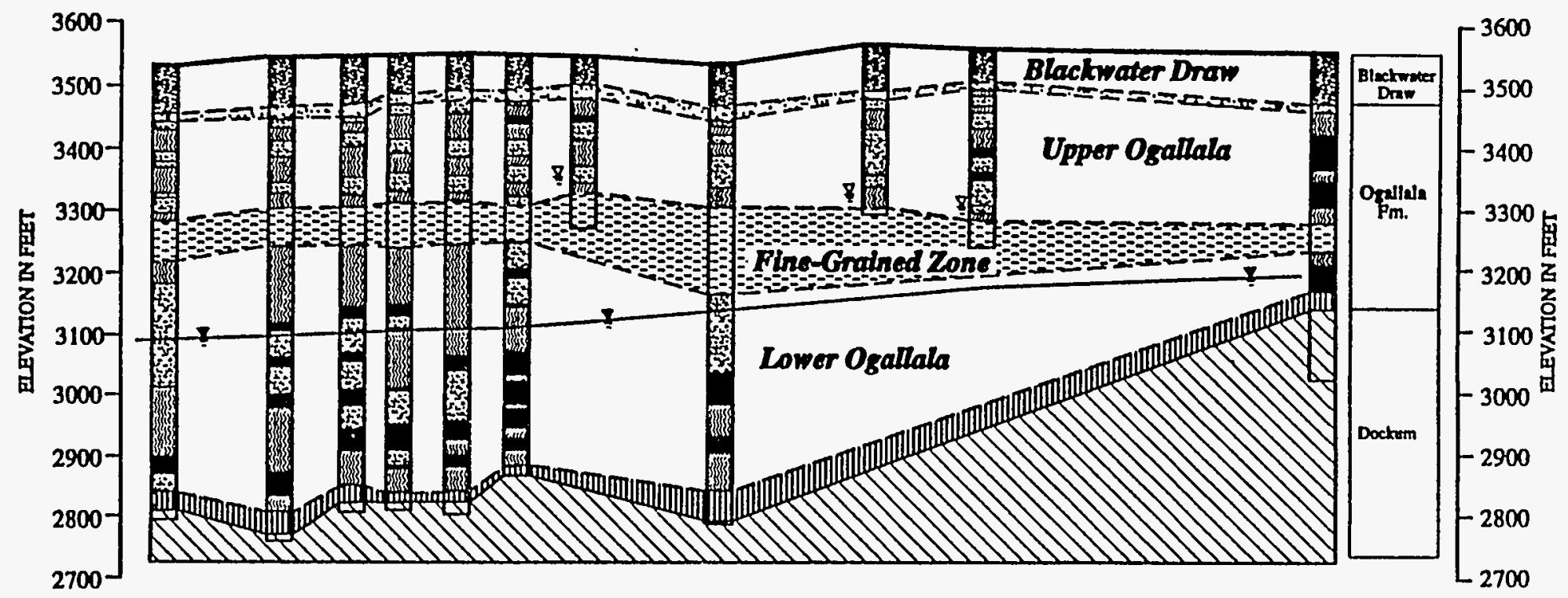

BLACKWATER DRAW FORMATION

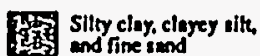

DOCKUM GROUP

$\triangle 1$ Shate, muditione.

QGALALA FORMATTON

Water levels in perched zone

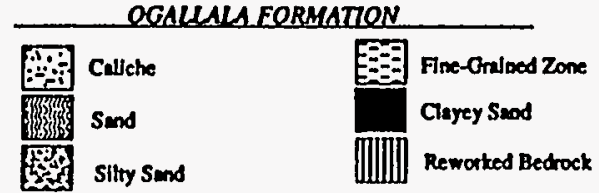

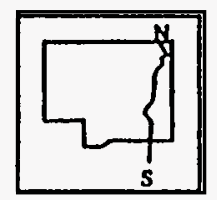

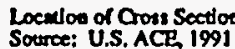

Water level In Malin Ozallala Aquilfer

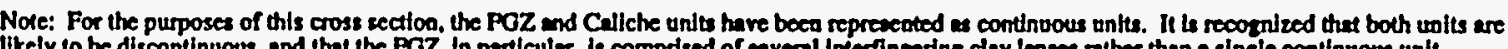

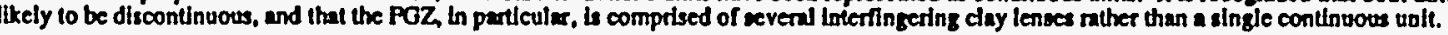




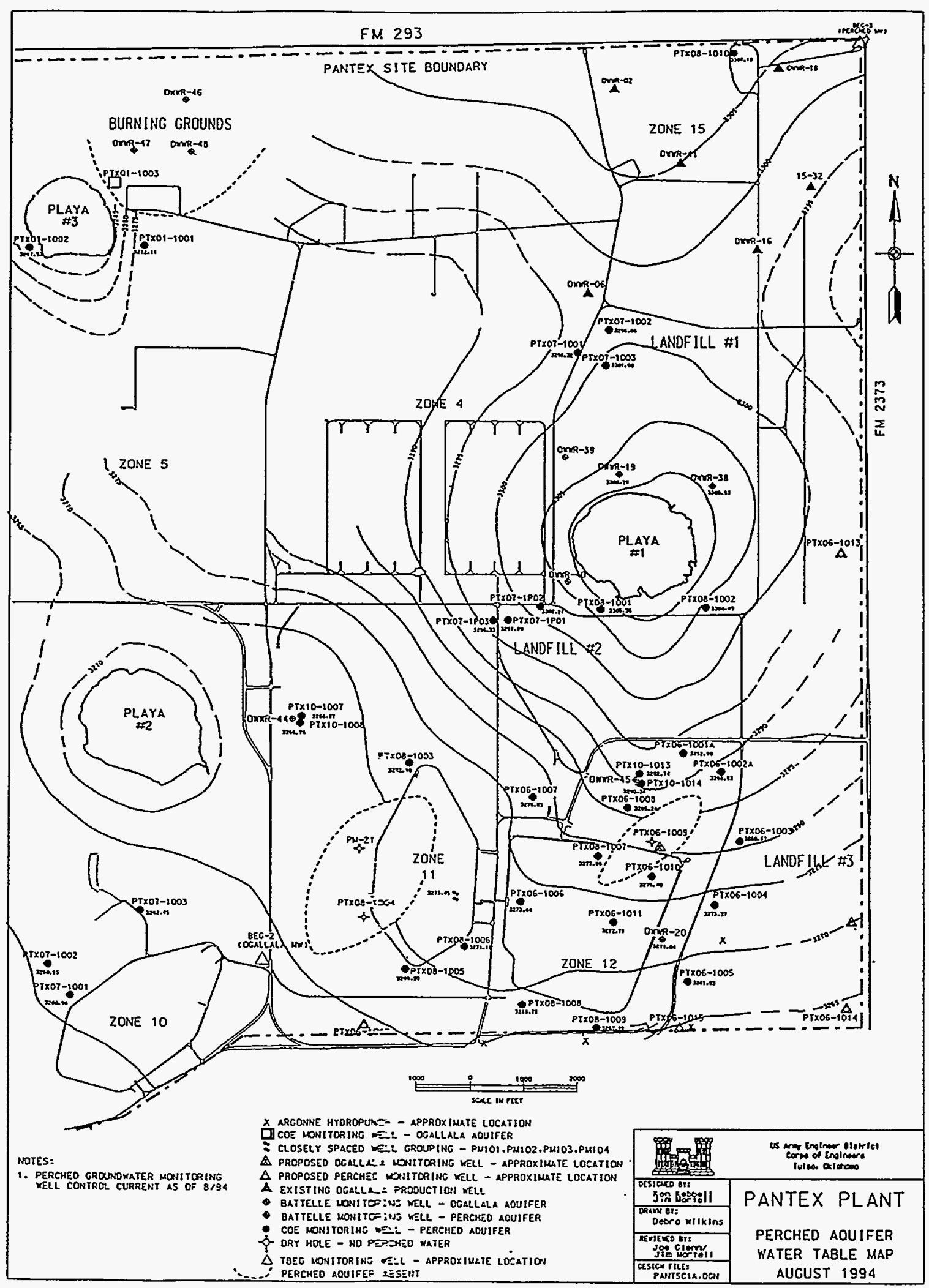

Figure 15-4. Contour map of perched water zone. 
Land use prior to establishment of the Pantex plant (pre-1942) consisted of farming and ranching activities. Numerous homesteads that relied upon private wells for water supply were established in the region. When the homesteads were abandoned, the water wells were also abandoned. A total of 16 abandoned homestead sites containing 8 water wells have been identified at Pantex. Each abandoned well represents a potential for preferential contaminant transport to the underlying Ogallala aquifer. Efforts to locate and properly plug abandoned water wells in compliance with Texas Natural Resource Conservation Commission regulations at Pantex are ongoing.

The City of Amarillo Municipal Well Field is within $2 \mathrm{mi}(3 \mathrm{~km})$ of Pantex and draws water from the Ogallala Aquifer. This aquifer spreads over parts of 8 states in the Great Plains region of the southwest. The City well field is located to the northeast and to the north of the Pantex Plant. The Ogallala Aquifer is the most important source of water in the region and is used for both potable water and agricultural uses. This aquifer provides water supply for the Pantex Plant.

To date no contamination of the Ogallala Aquifer underlying the Pantex Plant has been detected; however, few monitoring wells have been completed in this aquifer. Due to the low vertical hydraulic conductivity of the underlying fine-grained zone, it is believed that all contamination is limited to the perched water formation(s) and the unsaturated vadose zone soils above it.

\subsubsection{Conceptual Model Used in the PE}

The PE used a generic conceptual model to describe the water pathway (summarized in Section 1.1.2 of this volume and described in detail in Chapter 5 of Volume 2). In the unsaturated zone, leachate was generated by constant flow of water through the disposal facility at a rate that was controlled by the assumed performance of the disposal facility. When all engineered barriers had failed, the rate was assumed to be equal to the natural recharge through local soils. The volumetric flow of water through the facility that generated leachate was based on the assumed performance and size of the disposal facility. No dilution was assumed to occur in the unsaturated zone, so at steady state, the concentration that reached groundwater equaled the leachate concentration. No lateral spreading was assumed, therefore, the leachate flux through the unsaturated zone was confined to the soil column directly below the plan area of the facility.

As contaminated water entered the saturated zone, the contaminant mixed with clean groundwater, forming a plume with a shape controlled by aquifer and contaminant properties. The generic conceptual model assumed that instantaneous and complete mixing within the aquifer occurred directly below the facility. Mixing in the vertical direction occurred by hydrodynamic dispersion, and the contaminant mixing depth was an estimated value.

The generic conceptual model was adapted to conditions at Pantex based on site-specific knowledge of the geology and water flow paths. The following description represents the conceptual model of the water pathway that was used in the PE for Pantex. The conceptual model for the water pathway at Pantex is illustrated in Figure 15-5. 


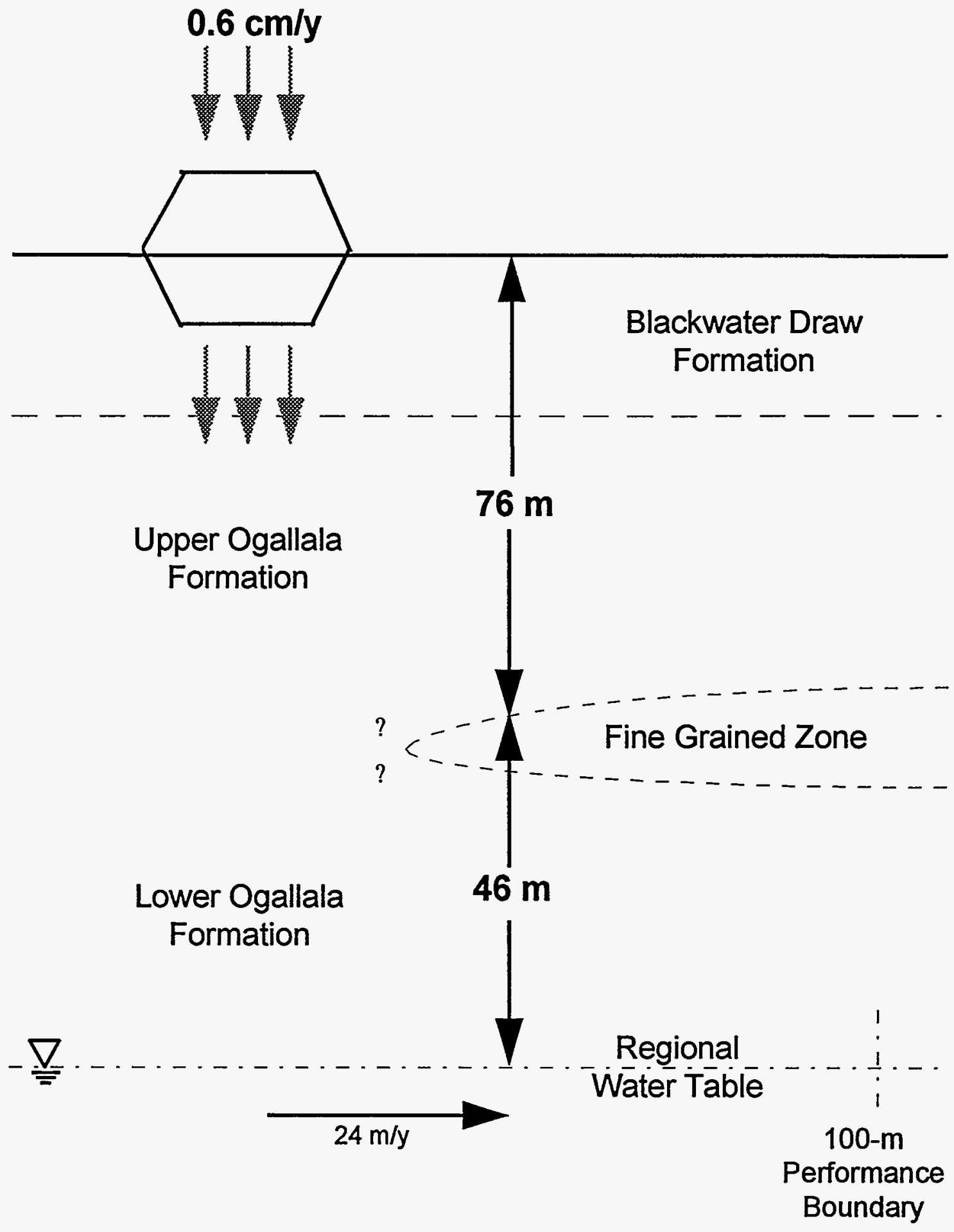

Figure 15-5. Conceptual model of the water pathway. 
Site contacts at Pantex and their hydrogeology contractor at Argonne National Laboratory participated in the development of the conceptual model for groundwater contaminant transport. The receptor body of water for the PE analysis at this site was assumed to be the Ogallala aquifer. This decision was based on the observation that the perched formation(s) is not continuous, that the perched water is not truly an aquifer in the sense that it can provide useable quantities of water, and that its presence may be the result of plant activities, principally the continuous discharge of treated wastewater to Playa One. Due to the relative uniformity of the site, the exact location of a disposal facility is not likely to affect the results of the PE analysis. Consideration of a hypothetical disposal site located in the interplaya region in Zone 4 or 5 means that radionuclide transport to the performance boundary can be calculated without considering possible dilution or retention resulting from a perched saturated zone.

The upper vadose zone includes soils from the Blackwater Draw Formation and the Upper Ogallala Formation. Although a specific proposed location for a potential mixed waste disposal facility was not identified in this study, it was assumed that it would be located in an interplaya region to minimize the potential for surface water contamination due to occasional high water levels in a playa lake. A further consideration is that there is less chance of encountering perched water beneath the interplaya region. The presence of a perched water formation would complicate selection of a site for a disposal facility by possibly constituting an alternative performance boundary closer to the surface.

The conceptual model for the water pathway contains three zones (Figure 15-5). This analysis did not consider the presence of a perched water zone, although the fine grained zone depicted in Figures 15-3 and 15-5 is believed to extend beneath much of the plant (Battelle Columbus, 1995). The "Environmental Information Document, Draft Revision 2" states that the age of groundwater in the perched aquifer is about $75 \mathrm{y}$ based on isotopic data (Battelle Columbus, 1995). However, Aggarwal (1995) has collected more recent data that suggest the age of perched water in the interplaya region near Zone 12 is approximately $20 \mathrm{y}$. The presence of preferential flow paths has been noted by Wood and Sanford (1995) as well as site investigators (Scanlon et al., 1995; Aggarwal, 1995). These paths are formed by root tubules, ped faces, and organic soil-filled structures (Scanlon et al., 1995). Paleo root tubules and other discontinuities are believed to occur throughout the soil column at the site. While these features may facilitate flow of water under saturated conditions, their affect on flow of water through the vadose zone is not known. Therefore, contaminant transport calculations at Pantex were performed assuming uniform flow through the unsaturated zone. This is consistent with the approach used at all other sites and is described in Volume 2, Chapter 5.

The uppermost regional aquifer at the Pantex Plant is in the Lower Ogallala Formation. Its porosity is reported at 0.25 , and the interstitial groundwater velocity is reported to be $24 \mathrm{~m} / \mathrm{y}$ $(79 \mathrm{ft} / \mathrm{y})$ (Battelle Columbus, 1995). Therefore, the travel time through the saturated zone to the $100-\mathrm{m}(328-\mathrm{ft})$ performance boundary of $4 \mathrm{y}$ is inconsequential in comparison to the vertical groundwater flow to the water table through the vadose zone. 


\subsubsection{Atmospheric Pathway}

The conceptual model used in the PE for evaluating the atmospheric pathway was derived from performance assessments for LLW disposal facilities at Hanford (Kincaid et al., 1993), INEL (Maheras et al., 1994), NTS (Baer et al., 1994), ORR (ORNL, 1994), and SRS (MMES et al., 1994). The model was generalized for the $P E$ but used site-specific values for many of the parameters.

\subsubsection{Current Understanding of Relevant Meteorology}

Surface winds at Pantex are predominantly from the south. Intense summer thunderstorms can generate very high winds at the site. The Pantex Plant experiences thunderstorms (which can produce tornadoes) about 49 days per year. The Panhandle is classified as a moderate to high hazard zone for tornadoes. A meteorological station is located at the facility to collect atmospheric data. An extensive air quality monitoring system has been established to collect data on atmospheric contaminant concentrations throughout the Plant, around the plant perimeter, and at several offsite locations.

Meteorological data are based on STAR data files summarized by the windrose in Figure 15-6. These data were obtained from hourly average meteorological readings taken at a height of $10 \mathrm{~m}(33 \mathrm{ft}$ ) at the on-site meteorological tower at Pantex during the period 1993 to 1994.

\subsubsection{Conceptual Model Used in the PE}

The PE used a generic conceptual model to describe the atmospheric pathway (summarized in Section 1.2 of this volume and described in detail in Chapter 5 of Volume 2). Only H-3 (tritium) and C-14 were expected to be volatile for the disposal facility conditions and thus were the only radionuclides considered for atmospheric transport in the PE. In the model, radionuclides were transported from the disposal facility to the soil surface by vapor (tritium) and gaseous (carbon dioxide carrying the $\mathrm{C}-14$ isotope) diffusion. When the radionuclides reached the soil surface, they were entrained in the air in vapor form as volatiles. Once airborne, these radionuclides were transported via atmospheric dispersion to a receptor located at the performance boundary.

Two components of the atmospheric pathway were evaluated separately: (1) the zone from the top of the disposal facility to the soil surface as indicated by the upward radionuclide diffusion profile; and (2) the zone in which a radionuclide was emitted to the atmosphere, mixed with the ambient air, and dispersed downwind from the waste disposal facility boundary to the $100-\mathrm{m}(328-\mathrm{ft})$ performance boundary. 


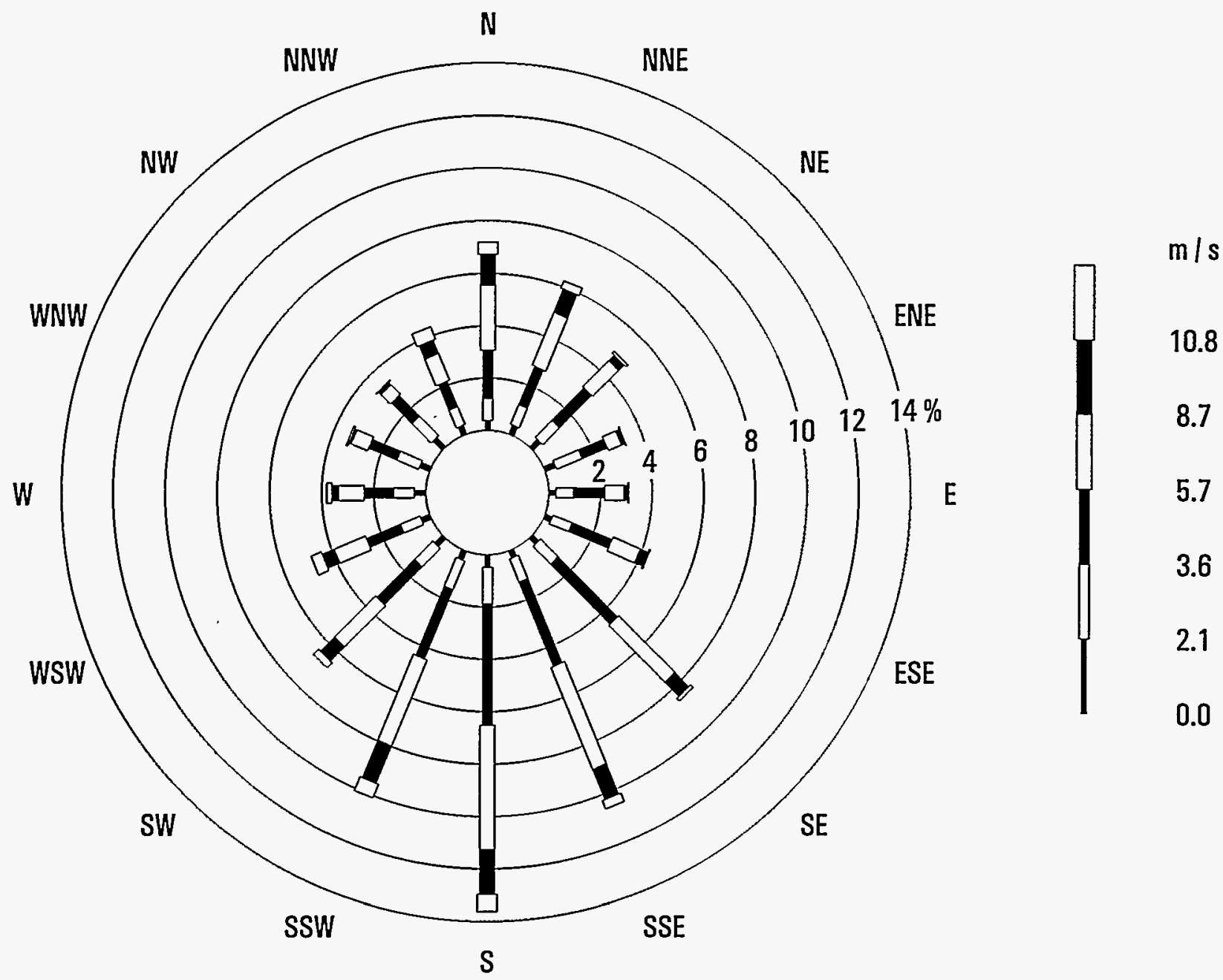

Figure 15-6. Windrose for Pantex Plant for the period 1993 to 1994. The frequency of winds from each direction is plotted as a series of connected bars that extend from the center of the circular diagram toward the direction from which the winds originate. Wind speed categories are denoted by bar widths and shadings. The frequency of winds in each wind speed category is indicated by length of the corresponding bar. 
The arrival time of radionuclides at the performance boundary was assumed to be $100 \mathrm{y}$ based on the following generic assumptions of the PE:

- The waste form was grouted MLLW treatment residuals. Based on this assumption, tritium as vapor was bound in the pore water of the hydrophilic grout, and carbon dioxide as a gas carrying the $\mathrm{C}-14$ isotope was limited by the high $\mathrm{pH}$ of the grout, so that the waste form provided retention of these volatile radionuclides in the disposal facility.

- The disposal facility was capped by a RCRA-compliant cover system. Based on this assumption, the cover system was maintained to provide low permeability for $100 \mathrm{y}$.

\subsubsection{Inadvertent Intruder Pathways}

Standard intrusion scenarios were used in the PE, with information derived from performance assessments of LLW disposal facilities at SRS (MMES et al., 1994) and ORR (ORNL, 1994) indicating that only two chronic-exposure scenarios needed to be considered for most sites and facility designs. Any variations in these scenarios were based on discussions with site technical staff about such factors as the types of activities that reasonably could result in exposure to buried waste at the site and the effectiveness of active or passive institutional controls and engineered barriers in precluding access to the waste.

\subsubsection{Current Understanding of Potential Modes of Inadvertent Intrusion}

The area adjacent to Pantex includes a mixture of agricultural and industrial activities. In 1991 the total population residing within $80 \mathrm{~km}$ (50 mi) of the Plant was 274,000 (M\&H, 1994a). The major population center is Amarillo to the southwest which contains about 156,000 residents. The other principal nearby community is Pampa, $40 \mathrm{mi}(64 \mathrm{~km})$ northeast with 21,000 residents. Due to the presence of numerous small ranches and farms in the vicinity of the plant, the intruder scenarios are justified for consideration at this facility.

\subsubsection{Intruder Scenarios Used in the PE}

The PE used two standard intrusion scenarios that could be modified for site-specific concitions to describe potential modes of inadvertent intrusion (summarized in Section 1.3 of this volume and described in detail in Chapter 5 of Volume 2). The first scenario, the agriculture (homesteader) scenario, included establishment by an intruder of a permanent homestead directly above a disposal facility with the foundation of the home extending into the waste; some of the waste exhumed from the disposal facility was mixed with native soil in the intruder's vegetable garden. The second scenario, the post-drilling scenario, considered the construction of a well for a domestic water supply by an intruder. The well was drilled through the disposal facility, and the cuttings were mixed with soil in the intruder's vegetable garden. The intruder gardened in some of the exhumed waste but did not reside permanently above the disposal facility. In both scenarios, exposure occurred where an intruder dug or drilled into the disposal facility. Possible intruder scenarios for the Pantex Plant are consistent with the two standard PE intrusion scenarios. 
For the generic intruder scenarios, the time of intrusion for the homesteader scenario was assumed to be $300 \mathrm{y}$ for the trench design and $500 \mathrm{y}$ for the tumulus design. The time of intrusion for the post-drilling scenario was assumed to be $100 \mathrm{y}$.

\subsection{DATA USED IN THE PE}

The data presented in this section apply to the PE conceptual models described in Section 15.3. The calculations for determining permissible waste concentrations for the radionuclides considered in the PE are discussed in more detail in Chapter 5 of Volume 2 and summarized in Chapter 1 of this volume. The results of the calculations for Pantex are presented in Section 15.5 and discussed in Section 15.6 of this volume.

\subsubsection{Water Transport}

Site-specific values required to perform the water pathway analysis were selected by site technical staff either from site characterizations and reports, from site-specific modeling results, or from general literature. For the unsaturated zone, the site-specific data that were required for the PE were distance between the disposal facility and groundwater; ambient moisture content; dry bulk density of the geologic medium; distribution coefficients $\left(K_{d} s\right)$ of the radionuclides in the geologic medium; and natural recharge. For the saturated zone, the site-specific data that were required were porosity; dry bulk density of the geologic medium; distribution coefficients $\left(K_{d} \mathrm{~S}\right)$ of the radionuclides in the geologic medium; groundwater Darcy flow rates; and mixing depth in the aquifer.

These values for Pantex are listed in Table 15-1 along with generic values that were used in the PE. Also indicated in the table is a designation of the type of data that the value represents and the source of the value. The values were determined from one or more of four data sources: (A) measurement performed by the site, state, or federal agency; (B) result of a numerical analysis performed by the site, state, or federal agency; (C) general literature value selected by the site; and $(D)$ generic value of the $\mathrm{PE}$.

Of the parameters in the PE that depended on site-specific values, only three potentially encompassed enough variability in values to significantly affect the results: natural recharge, $i$; distribution coefficients $\left(K_{d} s\right)$ for the geologic media; and groundwater Darcy velocity $\left(q_{g_{w}}\right)$. The sources of these values are discussed in this section. The sensitivity of the results to changes in the values of these parameters is discussed in Section 15.6.2 of this volume and Chapter 6 of Volume 2. 
Table 15-1. Parameters and Values Used in the PE for the Water Pathway at Pantex (generic PE values are in bold; these values and the standard $\mathrm{PE}$ method for applying them are summarized in Chapter 1 of this volume and discussed in more detail in Chapter 5 of Volume 2) (Part 1 of 2)

\begin{tabular}{|c|c|c|c|}
\hline Parameter & Value & $\begin{array}{c}\text { Data } \\
\text { Type }^{*}\end{array}$ & Comments \\
\hline \multicolumn{4}{|l|}{ SOURCE TERM } \\
\hline $\begin{array}{l}\text { Volumetric water content } \\
\text { of the grouted waste, } \theta_{G}\end{array}$ & 0.3 & D & Standard PE value \\
\hline $\begin{array}{l}\text { Bulk density of grouted } \\
\text { waste, } \rho_{G}\end{array}$ & $\begin{array}{l}1.76 \\
\mathrm{~g} / \mathrm{cm}^{3}\end{array}$ & D & Standard PE value \\
\hline $\begin{array}{l}\text { Distribution coefficients } \\
\text { for grouted waste, } K_{d}^{G}\end{array}$ & various & D & Standard PE value; see Table 15-2 \\
\hline $\begin{array}{l}\text { Disposal facility plan } \\
\text { area, } A\end{array}$ & $2500 \mathrm{~m}^{2}$ & $\bar{D}$ & Standard PE value \\
\hline $\begin{array}{l}\text { Waste mixing fraction } \\
\text { for trench, } f_{m}\end{array}$ & 0.67 & D & Standard PE value \\
\hline $\begin{array}{l}\text { Waste mixing fraction } \\
\text { for tumulus, } f_{m}\end{array}$ & 0.33 & D & Standard PE value \\
\hline $\begin{array}{l}\text { Annual rate of water flowing } \\
\text { through intact trench facility, } \\
q_{f}\end{array}$ & $0.006 \mathrm{~m} / \mathrm{y}$ & c & $\begin{array}{l}\text { Standard PE value is } 3 \mathrm{~cm} / \mathrm{y} \text {. Natural recharge } \\
\text { is lower for this site. }\end{array}$ \\
\hline $\begin{array}{l}\text { Annual rate of water } \\
\text { flowing through intact } \\
\text { tumulus facility, } q_{f}\end{array}$ & $\begin{array}{c}0.00003 \\
\mathrm{~m} / \mathrm{y}\end{array}$ & D & Standard PE value \\
\hline $\begin{array}{l}\text { Time to failure of } \\
\text { leachate collection and } \\
\text { liner systems }\end{array}$ & $30 y$ & D & Standard PE value \\
\hline $\begin{array}{l}\text { Time to failure of trench } \\
\text { facility }\end{array}$ & $100 y$ & D & Standard PE value \\
\hline $\begin{array}{l}\text { Time to failure of } \\
\text { tumulus facility }\end{array}$ & $300 y$ & D & Standard PE value \\
\hline $\begin{array}{l}\text { Natural recharge through } \\
\text { local soils, } i\end{array}$ & $0.006 \mathrm{~m} / \mathrm{y}$ & C & Wood and Sanford (1995) \\
\hline
\end{tabular}

- $A=$ site measurement; $B=$ result of site numerical analysis; $C=$ literature value selected by the site; $D=$ generic $P E$ value 
Table 15-1. Parameters and Values Used in the PE for the Water Pathway at Pantex (generic PE values are in bold; these values and the standard $P E$ method for applying them are summarized in Chapter 1 of this volume and discussed in more detail in Chapter 5 of Volume 2) (Part 2 of 2)

\begin{tabular}{|c|c|c|c|}
\hline Parameter & Value & $\begin{array}{c}\text { Data } \\
\text { Type* }^{*}\end{array}$ & Comments \\
\hline \multicolumn{4}{|l|}{ UNSATURATED ZONE } \\
\hline Moisture content, $\theta_{w}$ & 0.1 & $\mathrm{C}$ & Calculated value \\
\hline Bulk density, $\rho_{b}$ & $1.9 \mathrm{~g} / \mathrm{cm}^{3}$ & A & Calculated from data in Battelle Pantex (1994) \\
\hline $\begin{array}{l}\text { Distribution coefficients for } \\
\text { geologic media, } K_{d}\end{array}$ & various & $\mathrm{D}$ & See Table $\mathbf{1 5 - 2}$ in this chapter \\
\hline $\begin{array}{l}\text { Thickness between trench } \\
\text { and saturated zone, } l\end{array}$ & $113.2 \mathrm{~m}$ & A & $\begin{array}{l}\text { Battelle Columbus (1995), Figure 4.3.1-2, } \\
\text { without consideration of } 76 \mathrm{~m} \text { with suspected } \\
\text { preferential flow path }\end{array}$ \\
\hline $\begin{array}{l}\text { Thickness between tumulus } \\
\text { and saturated zone, } l\end{array}$ & $122 \mathrm{~m}$ & A & $\begin{array}{l}\text { Battelle Columbus (1995), Figure 4.3.1-2, } \\
\text { without consideration of } 76 \mathrm{~m} \text { with suspected } \\
\text { preferential flow path }\end{array}$ \\
\hline \multicolumn{4}{|c|}{ SATURATED ZONE (Lower Ogallala Formation) } \\
\hline Porosity, $n$ & 0.25 & A & Battelle Columbus (1995), page 4-24 \\
\hline Bulk density, $\rho_{b}$ & $1.9 \mathrm{~g} / \mathrm{cm}^{3}$ & A & Calculated from data in Battelle Pantex (1994) \\
\hline $\begin{array}{l}\text { Distribution coefficients for } \\
\text { geologic media, } K_{d}\end{array}$ & various & $D$ & See Table $15-2$ in this chapter \\
\hline Mixing depth, $d_{m}$ & $11 \mathrm{~m}$ & $\mathrm{~B}$ & Predicted by PAGAN code (Chu et al., 1991) \\
\hline Total thickness & $>70 \mathrm{~m}$ & A & Battelle Pantex (1994), Figure 3-2 \\
\hline $\begin{array}{l}\text { Interstitial groundwater } \\
\text { velocity }\end{array}$ & $24 \mathrm{~m} / \mathrm{y}$ & A & Battelle Columbus (1995), page 4-24 \\
\hline Darcy velocity, $q_{g w}$ & $6 \mathrm{~m} / \mathrm{y}$ & A & $\begin{array}{l}\text { Calculated from data in Battelle Columbus } \\
\text { (1995), page 4-24 }\end{array}$ \\
\hline $\begin{array}{l}\text { Distance to } \\
\text { performance boundary } \\
\text { from facility boundary }\end{array}$ & $100 \mathrm{~m}$ & D & Standard PE value \\
\hline
\end{tabular}

- $A=$ site measurement; $B=$ result of site numerical analysis; $C=$ literature value selected by the site; $D=$ generic $P E$ value 
Table 15-2. Solid/Liquid Distribution Coefficients $\left(K_{d} s\right)$ Used in the PE at Pantex

\begin{tabular}{|c|c|c|}
\hline Element & $\begin{array}{c}\text { Waste } K_{d}^{G} \\
(\mathrm{ml} / \mathrm{g})^{\bullet}\end{array}$ & $\begin{array}{c}K_{d} \text { for Geologic Media } \\
(\mathrm{ml} / \mathrm{g})^{\mathrm{b}}\end{array}$ \\
\hline $\mathrm{H}$ & 0 & 0.1 \\
\hline C & 10 & 5 \\
\hline $\mathrm{Al}$ & 100 & 35 \\
\hline Si & 100 & 35 \\
\hline $\mathrm{Cl}$ & 0 & 15 \\
\hline$K$ & 1 & 15 \\
\hline Co & 100 & 60 \\
\hline $\mathrm{Ni}$ & 10 & 400 \\
\hline $\mathrm{Se}$ & 1 & 150 \\
\hline $\mathrm{Sr}$ & 100 & 15 \\
\hline $\mathrm{Zr}$ & 10 & 600 \\
\hline $\mathrm{Nb}$ & 10 & 160 \\
\hline TC & 1 & 0.1 \\
\hline$P d$ & 100 & 55 \\
\hline $\mathrm{Ag}$ & 100 & 90 \\
\hline $\mathrm{Cd}$ & 100 & 80 \\
\hline$S n$ & 10 & 130 \\
\hline 1 & 1 & 1 \\
\hline Cs & 10 & 280 \\
\hline $\mathrm{Ba}$ & 10 & 15 \\
\hline $\mathrm{Sm}$ & 10 & 245 \\
\hline $\mathrm{Eu}$ & 10 & 245 \\
\hline $\mathrm{Pb}$ & 100 & 270 \\
\hline $\mathrm{Ra}$ & 10 & 500 \\
\hline Th & 100 & 3200 \\
\hline$\overline{\mathrm{Pa}}$ & 100 & 550 \\
\hline$U$ & 100 & 35 \\
\hline $\mathrm{Np}$ & 100 & 5 \\
\hline $\mathrm{Pu}$ & 100 & 550 \\
\hline $\mathrm{Am}$ & 100 & 1900 \\
\hline $\mathrm{Cm}$ & 100 & 4000 \\
\hline$\overline{C f}$ & 100 & 4000 \\
\hline
\end{tabular}

a Standard PE values; see Chapter 5 of Volume 2

b Based on Thibault et al., 1990 
At present there is little information on the infiltration rates in the interplaya region at Pantex. However, because of the importance of the Ogallala aquifer as a major water source in the Southern High Plains region, there have been a number of investigations of the regional aquifer recharge rates, dating as far back as the turn of the century. Wood and Sanford (1995) have recently published a comprehensive review of chemical and isotopic methods for determining regional groundwater recharge rates in the Southern High Plains region. They confirmed the findings of previous investigators that much of the groundwater recharge in the region occurs through playa lakes and is referred to as "focused recharge." The interplaya recharge rate is calculated to be about $6 \mathrm{~mm} / \mathrm{y}(0.2 \mathrm{in} . / \mathrm{y})$. This rate is found by assuming that the regional recharge rate is $11 \mathrm{~mm} / \mathrm{y}(0.4 \mathrm{in} . / \mathrm{y})$, that $50 \%$ of the recharge occurs as infiltration through the playas, and that the playas account for $4 \%$ of the total area in the Pantex region (Wood and Sanford, 1995). This information was used in the radionuclide transport calculations for the water pathway.

As discussed in Section 15.3.1.2, the entire $122 \mathrm{~m}$ ( $400 \mathrm{ft}$ ) thickness of the unsaturated soil was used in calculating the travel time through the vadose zone. An interplaya recharge rate of $6 \mathrm{~mm} / \mathrm{y}(0.2 \mathrm{in} . / \mathrm{y})$ was used. A volumetric moisture content of 0.1 was calculated using the Brooks and Corey equation which relates soil moisture content to soil particle size (Jury et al., 1991).

Values for distribution coefficients $\left(K_{d} \mathrm{~s}\right)$ are listed in Table 15-2 for the 58 radionuclides (32 elements) considered in the PE. In addition to the $K_{d}$ values for the geologic media, grout $K_{d}$ values were used for determining the desorption from the source term resulting from the grouted waste form. Due to the presence of only a few specific radionuclides at Pantex, no site-specific $K_{d}$ values have been developed. Therefore, $K_{d}$ values for sandy soils compiled by Thibault et al. (1990) were used in the PE analysis.

Most of the site-specific values for parameters used in the Pantex PE are based on hydrologic studies conducted for Pantex and summarized in reports prepared by Battelle Columbus (1995) and Battelle Pantex (1994). A recent paper by Wood and Sanford (1995) was used to develop data for calculating contaminant transport through the vadose zone. In addition, the $K_{d}$ values for sandy soils in Table 15-2 from the compilation by Thibault et al. (1990) were reviewed by Pantex technical staff and determined to be appropriate for use in the PE analysis.

\subsubsection{Atmospheric Transport}

Site-specific data required to perform the atmospheric pathway analysis came from site personnel as data either from site characterizations and reports or from general literature. The site-specific data required for the soil diffusion calculation were the same as some of those required for the water transport analysis (Section 15.4.1). These values are shown in Table 15-3. Necessary atmospheric dispersion data included wind speed and direction and stability class, which are summarized in Section 15.3.2.1. 
Table 15-3. Parameters and Values Used in the PE for the Atmospheric Pathway at the Pantex Plant (generic PE values are in bold; these values and the standard PE method for applying them are summarized in Chapter 1 of this volume and discussed in more detail in Chapter 5 of Volume 2)

\begin{tabular}{|c|c|c|c|}
\hline Parameter & Value & $\begin{array}{l}\text { Data } \\
\text { Type* }\end{array}$ & Comments \\
\hline $\begin{array}{l}\text { Disposal facility cover } \\
\text { thickness, } x\end{array}$ & $1.0 \mathrm{~m}$ & D & Standard PE value \\
\hline $\begin{array}{l}\text { Depth of the soil surface, } \\
\text { d }\end{array}$ & $0.01 \mathrm{~m}$ & D & $\begin{array}{l}\text { Standard PE value based on } \\
\text { Maheras et al. (1994) }\end{array}$ \\
\hline Porosity, $n$ & 0.3 & $\bar{A}$ & $\begin{array}{l}\text { Hillel (1980) for soils similar to those at } \\
\text { Pantex }\end{array}$ \\
\hline Percent saturation, $s$ & 0.1 & A & Wood \& Sanford (1995) \\
\hline $\begin{array}{l}\text { Ratio of water density in } \\
\text { air to liquid, } r\end{array}$ & 9.2E-06 & $\mathbf{D}$ & $\begin{array}{l}\text { Standard PE value based on MMES } \\
\text { (1994) }\end{array}$ \\
\hline $\begin{array}{l}\text { Ratio of } \mathrm{CO}_{2} \\
\text { concentration in air to } \\
\text { dissolved in water, } r\end{array}$ & 4.3E-04 & D & $\begin{array}{l}\text { Standard PE value based on Foust } \\
\text { et al. (as cited in Cooper and Alley, } \\
\text { 1986) }\end{array}$ \\
\hline $\begin{array}{l}\text { Tritium diffusion } \\
\text { coefficient in air, } D\end{array}$ & $2.39 E-05 \mathrm{~m}^{2} / \mathrm{s}$ & $\mathbf{D}$ & $\begin{array}{l}\text { Standard PE value based on CRC } \\
\text { (1981) }\end{array}$ \\
\hline $\begin{array}{l}\text { Carbon diffusion } \\
\text { coefficient in air, } D\end{array}$ & $1.4 \mathrm{E}+05 \mathrm{~m}^{2} / \mathrm{s}$ & $\mathbf{D}$ & $\begin{array}{l}\text { Standard PE value based on CRC } \\
\text { (1981) }\end{array}$ \\
\hline $\begin{array}{l}\text { Atmospheric dispersion term, } \\
A_{D}\end{array}$ & $\begin{array}{c}0.36 \\
\left(\mu \mathrm{Ci} / \mathrm{m}^{3}\right) /\left(\mu \mathrm{Ci} / \mathrm{m}^{2}-\mathrm{s}\right)\end{array}$ & $\bar{B}$ & $\begin{array}{l}\text { Value estimated using the Industrial Source } \\
\text { Complex - Version } 2 \text { Long Term Air } \\
\text { Dispersion Model (ISCLT2) (EPA, 1992) } \\
\text { based on site-specific STAR data }\end{array}$ \\
\hline
\end{tabular}

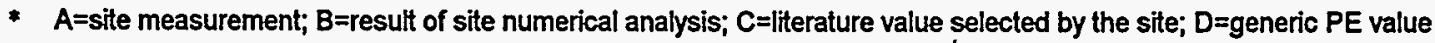

\subsubsection{Inadvertent Intruder Exposure}

As explained in Section 15.3.3, the PE used two standard intrusion scenarios to describe potential modes of inadvertent intrusion at all the sites. Because these intrusion scenarios were considered applicable to all sites, no values specific to Pantex are used in the calculation of exposures to inadvertent intruders.

\subsection{RESULTS OF THE PE}

The performance evaluation provided estimates of permissible waste concentrations in disposed MLLW. The three calculations that formed the foundation of the PE-for the water, atmospheric, and inadvertent intruder pathways-are summarized in Sections 1.1, 1.2, and 1.3, respectively, of this volume and discussed in detail in Chapter 5 of Volume 2. 
For each pathway the maximum permissible waste concentration at the performance boundary was determined for each radionuclide by using the performance measures: $4 \mathrm{mrem}$ $(0.04 \mathrm{mSv})$ per year from the water pathway for releases to drinking water; $10 \mathrm{mrem}(0.1 \mathrm{mSv})$ per year from all pathways for atmospheric releases; and $100 \mathrm{mrem}(1 \mathrm{mSv})$ per year from all exposure pathways for chronic exposure of inadvertent intruders; and the appropriate pathway or scenario dose conversion factors (annual effective dose equivalent per unit concentration) based on EPA dose conversion factors. The basis for the performance measures used in the PE is discussed in more detail in Chapter 5 of Volume 2. For the water and atmospheric pathways, the concentration reduction provided by the environment (i.e., the CRF) was estimated using results of site analyses and data. For the intruder analyses, concentration reduction was estimated for appropriate exposure pathways for two intrusion scenarios that, in general, were the same for all the sites. The results of the calculations for the pathways that were analyzed at Pantex are provided in this section and discussed in Section 15.6.

\subsubsection{Water Transport}

Two CRFs were calculated for the water pathway: the source $C R F, C R F_{\text {Source, }}$ and the environmental transport $\mathrm{CRF}$ for water, $C R F_{\text {Water. }}$. The source $\mathrm{CRF}$ represents the concentration attenuation between the disposed waste and leachate exiting the bottom of the disposal facility and was defined as the dimensionless ratio of the waste concentration to the resulting leachate concentration. Desorption with infiltrating water was the mechanism used to describe the leaching of radionuclides from the grout. Because a generic method was used to determine the $C R F_{\text {Source }}$ for the 58 radionuclides considered in the PE (summarized in Section 1.1 of this volume and discussed in more detail in Chapter 5 of Volume 2), the radionuclide-specific values for the source CRF for each type of generic facility were the same for all 15 sites.

The environmental transport $\mathrm{CRF}$ for water was defined as the ratio of the concentration of the leachate exiting the disposal facility to the resulting concentration in water at the performance boundary. The concentration attenuation represented by $C R F_{\text {Water }}$ consisted of dilution due to mixing with uncontaminated groundwater. Effects of radioactive decay and decay product ingrowth were also included in the PE.

In the PE, water travel time from the facility location to the performance boundary was calculated as a basis for comparison with the retarded travel time of the radionuclides. For Pantex, water travel time from the land surface to the performance boundary (i.e., without consideration of a disposal facility) was estimated at about $2,000 \mathrm{y}$.

The calculation of travel time through the vadose zone for a radionuclide, on the other hand, must account for the retardation defined by the distribution coefficient for the geologic media. In the PE, the detention time in the facility for a radionuclide was the time during which water flowing through the facility was assumed to be retained by the leachate collection system. Specifically, the calculation of travel time for a radionuclide accounted for the following: 
- For the trench design, the leachate collection system was assumed to catch water flowing through the facility for the first $30 \mathrm{y}$. After $30 \mathrm{y}$, the liner and leachate collection system failed, and the rate of water flowing through the facility for the next $70 \mathrm{y}$ was assumed to be $0.03 \mathrm{~m} / \mathrm{y}(0.1 \mathrm{ft} / \mathrm{y})$ based on a unit hydraulic gradient and the saturated hydraulic conductivity of the RCRA cover system. However, at Pantex the natural recharge was estimated to be $0.006 \mathrm{~m} / \mathrm{y}(0.02 \mathrm{ft} / \mathrm{y})$, which is less than the value assumed for the RCRA cover system in the generic PE. Therefore, a value of $0.006 \mathrm{~m} / \mathrm{y}(0.02 \mathrm{ft} / \mathrm{y})$ was used throughout the 10,000-y performance period for the facility.

- For the tumulus design, the leachate collection system was assumed to catch water flowing through the facility for the first $30 \mathrm{y}$. After $30 \mathrm{y}$, the liner and leachate collection system was assumed to fail, and the rate of water flowing through the facility for the next $270 \mathrm{y}$ was assumed to be $0.00003 \mathrm{~m} / \mathrm{y}(0.0001 \mathrm{ft} / \mathrm{y})$ based on a unit hydraulic gradient and the saturated hydraulic conductivity of the concrete vaults. After a total of $300 \mathrm{y}$ of reduced flow because of engineered barriers ( $30 \mathrm{y}$ detention plus $270 \mathrm{y}$ limited by the concrete vaults), the rate was assumed to be the average natural recharge for the local climate of $0.006 \mathrm{~m} / \mathrm{y}(0.02 \mathrm{ft} / \mathrm{y})$.

Travel time through the aquifer was independent of facility design and was about $4 \mathrm{y}$, based on groundwater Darcy velocity and a 100-m (328-ft) distance to the performance boundary (see Section 1.1.2 of this volume for a summary of these assumptions and Chapter 5 of Volume 2 for additional details). The arrival time of a radionuclide at the performance boundary is the sum of the detention time in the facility, travel time through the vadose zone, and travel time through the aquifer.

Retardation of radionuclides by interaction with soils and rock in the vadose and saturated zones increased travel times for individual radionuclides. This effect was particularly important for short-lived radionuclides because of radioactive decay. For short-lived radionuclides, the effects of radioactive decay combined with long travel times increased the permissible concentrations in the disposal facility.

Application of the PE methodology for water transport of the 58 radionuclides considered in the PE produced the results shown in Table 15-4 for the generic trench and tumulus designs at Pantex. The table shows permissible waste concentrations based on transport through the water pathway $\left(C_{\text {W-Water }}\right)$ as well as the values used in calculating the permissible waste concentrations.

Some of the radionuclides listed in Table 15-4 have no limit (NL) on their permissible waste concentrations, the result of the combined effects of relatively short half-lives and sufficiently long travel time to the performance boundary. "No limit" is defined as a permissible waste concentration that is greater than the specific activity of the pure elemental radionuclide. For disposal of the maximum possible waste concentration of these relatively short-lived radionuclides, the water pathway produced a dose at the performance boundary of less than $4 \mathrm{mrem}(0.04 \mathrm{mSv})$ per year, and therefore, the permissible waste concentration was unlimited based on exposures from this pathway. 
Table 15-4. Results of Calculations for the Water Pathway at Pantex (water travel time from land surface to performance boundary [excluding facility detention] $=2000 \mathrm{y})$ (Part 1 of 2)

\begin{tabular}{|c|c|c|c|c|c|c|c|c|c|c|c|c|}
\hline \multirow[t]{2}{*}{ Nuclide } & \multirow[b]{2}{*}{$\begin{array}{c}\text { PDCF } \\
\text { remly per } \mu \mathrm{Ch}\end{array}$} & \multicolumn{5}{|c|}{ Trench } & \multicolumn{5}{|c|}{ Tumulus } & \multirow[t]{2}{*}{ Nuclide } \\
\hline & & $\begin{array}{l}\text { CRF source } \\
\text { (dimensionlets) }\end{array}$ & $\begin{array}{l}\text { CRF Wanter }_{\text {(dimonsionloss) }} \\
\text { (d) }\end{array}$ & \begin{tabular}{|c|} 
Arrival \\
Time $(y)$ \\
\end{tabular} & $\begin{array}{c}r_{\text {Docayy }}{ }^{a} \\
\text { (dimonsionloss) }\end{array}$ & $\begin{array}{c}C_{w-W a t e r}^{b} \\
\left(\mu \mathrm{Cl} / \mathrm{m}^{3}\right)\end{array}$ & $\begin{array}{l}\text { CRF source } \\
\text { (dimonsionless) }\end{array}$ & $\begin{array}{l}\mathbf{C R F}_{\text {Waner }} \\
\text { (dimensionloss) }\end{array}$ & \begin{tabular}{|c|} 
Arrival \\
Time (y) \\
\end{tabular} & \begin{tabular}{|c|}
$r_{\text {Decay }}$ \\
(dimonsioniess) \\
\end{tabular} & $\begin{array}{c}C_{\text {wowner }}{ }^{b} \\
\left(\mu \mathrm{Ci} / \mathrm{m}^{3}\right)\end{array}$ & \\
\hline $\mathrm{H}-3$ & 4.67E-02 & 0.45 & 220 & $5.6 E+03$ & e & NL & 0.9 & 220 & $6.3 E+03$ & e & NL & $\mathrm{H}-3$ \\
\hline $\mathrm{C}-14$ & $1.52 E+00$ & 27 & 220 & $1.9 E+05$ & $5.9 E+09$ & NL & 54 & 220 & $2.0 E+05$ & $3.5 E+10$ & NL & C-14 \\
\hline Al-26 & $1.06 E+01$ & 270 & 220 & $1.3 E+06$ & $3.4 E+00$ & $7 E+04$ & 540 & 220 & $1.4 \mathrm{E}+06$ & $3.7 E+00$ & $2 E+05$ & Al-26 \\
\hline $5 i-32$ & $7.99 \mathrm{E}+00$ & 270 & 220 & $1.3 E+06$ & e & $\mathrm{NL}$ & 540 & 220 & $1.4 E+06$ & $\mathbf{e}$ & NL & Si-32 \\
\hline $\mathrm{Cl}-36$ & $2.21 E+\infty 0$ & 0.45 & 220 & $5.5 E+05$ & $3.6 E+00$ & $6 E+02$ & 0.9 & 220 & $6.0 \mathrm{E}+05$ & $4.0 E+00$ & $1 E+03$ & $\mathrm{Cl}-36$ \\
\hline$K-40$ & $1.36 \mathrm{E}+01$ & 3.1 & 220 & $5.5 \mathrm{E}+05$ & $1.0 \mathrm{E}+\infty$ & $2 E+02$ & 6.2 & 220 & $6.0 \mathrm{E}+05$ & $1.0 E+00$ & $4 E+02$ & $\mathrm{~K}-40$ \\
\hline Co-60 & 1.97E+01 & 270 & 220 & $2.2 E+06$ & e & NL & 540 & 220 & $2.4 E+06$ & e & $\mathrm{NL}$ & Co-60 \\
\hline \begin{tabular}{|l|} 
Ni-59 \\
\end{tabular} & $1.53 E-01$ & 27 & 220 & $1.5 E+07$ & e & $N L$ & 54 & 220 & $1.6 \mathrm{E}+07$ & $e$ & NL & Ni-59 \\
\hline $\mathrm{Ni}-63$ & $4.21 E-01$ & 27 & 220 & $1.5 E+07$ & e & NL & 54 & 220 & $1.6 E+07$ & $\mathrm{e}$ & $\mathrm{NL}$ & $\mathrm{Ni}-63$ \\
\hline Se-79 & $6.35 E+00$ & 3.1 & 220 & $5.5 E+06$ & $3.9 \mathrm{E}+25$ & $\mathrm{NL}$ & 6.2 & 220 & $6.0 \mathrm{E}+06$ & $3.8 E+27$ & $\mathrm{NL}$ & Se-79 \\
\hline Sr-90 & $1.12 E+02$ & 270 & 220 & $5.5 E+05$ & e & $\mathrm{NL}$ & 540 & 220 & $6.0 \mathrm{E}+05$ & e & $\overline{N L}$ & Sr-90 \\
\hline $2 r-93$ & $1.59 E+00$ & 27 & 220 & $2.2 E+07$ & 2.7E+0.4 & $4 E+08$ & 54 & 220 & $2.4 \mathrm{E}+07$ & $6.0 \mathrm{E}+04$ & $2 E+09$ & $\mathrm{Zr}-93$ \\
\hline $\mathrm{Nb}-93 \mathrm{~m}$ & $3.81 E-01$ & 27 & 220 & $5.9 E+06$ & e & NL & 54 & 220 & $6.4 \mathrm{E}+06$ & e & NL & Nb-93m \\
\hline $\mathrm{Nb}-94$ & $5.21 E+\infty 0$ & 27 & 220 & $5.9 E+06$ & e & $N L$ & 54 & 220 & $6.4 \mathrm{E}+06$ & e & $\mathrm{NL}$ & Nb-94 \\
\hline Tc-99 & $1.07 E+00$ & 3.1 & 220 & $5.6 E+03$ & $1.0 E+\infty$ & $3 E+03$ & 6.2 & 220 & $6.3 E+03$ & $1.0 \mathrm{E}+00$ & $5 E+03$ & TC-99 \\
\hline$P d-107$ & 1.09E-01 & 270 & 220 & $2.0 E+06$ & $1.2 E+\infty$ & $3 E+06$ & 540 & 220 & $2.2 E+06$ & $1.3 E+00$ & $5 E+06$ & Pd-107 \\
\hline $\mathrm{Ag}-108 \mathrm{~m}$ & $5.56 \mathrm{E}+\infty 0$ & 270 & 220 & $3.3 E+06$ & e & $\mathrm{NL}$ & 540 & 220 & $3.6 \mathrm{E}+06$ & e & NL & $\mathrm{Ag}-108 \mathrm{~m}$ \\
\hline Cd-113m & $1.17 E+02$ & 270 & 220 & $2.9 E+06$ & e & $\mathrm{NL}$ & 540 & 220 & $3.2 E+06$ & e & $\mathrm{NL}$ & $\mathrm{Cd}-113 \mathrm{~m}$ \\
\hline Sn-121m & $1.28 E+\infty$ & 27 & 220 & $4.8 \mathrm{E}+06$ & e & $\mathrm{NL}$ & 54 & 220 & $5.2 E+06$ & e & $\mathrm{NL}$ & $S n-121 m$ \\
\hline $5 n-126$ & $1.53 E+01$ & 27 & 220 & $4.8 E+06$ & $2.6 E+14$ & $\overline{N L}$ & 54 & 220 & $5.2 E+06$ & $3.4 E+15$ & NL & Sn-126 \\
\hline $1-129$ & $2.01 E+02$ & 3.1 & 220 & $3.9 E+04$ & $1.0 \mathrm{E}+00$ & $1 E+01$ & 6.2 & 220 & $4.2 E+04$ & $1.0 E+00$ & $3 E+01$ & $1-129$ \\
\hline Cs-135 & $5.16 E+\infty$ & 27 & 220 & $1.0 \mathrm{E}+07$ & $2.2 E+01$ & $1 E+05$ & 54 & 220 & $1.1 E+07$ & $2.8 E+01$ & $3 E+05$ & Cs-135 \\
\hline Cs-137 & $3.65 E+01$ & 27 & 220 & $1.0 \mathrm{E}+07$ & e & $\mathrm{NL}$ & 54 & 220 & $1.1 \mathrm{E}+07$ & e & NL & Cs-137 \\
\hline$B a-133$ & $2.48 E+\infty 0$ & 27 & 220 & $5.5 E+05$ & e & NL & 54 & 220 & $6.0 \mathrm{E}+05$ & e & $\mathrm{NL}$ & $\mathrm{Ba}-133$ \\
\hline Sm-151 & 2.84E-01 & 27 & 220 & $9.0 E+06$ & e & $\mathrm{NL}$ & 54 & 220 & $9.7 E+06$ & $\mathrm{e}$ & $\mathrm{NL}$ & $\mathrm{Sm}-151$ \\
\hline$E u-152$ & $4.73 E+\infty 0$ & 27 & 220 & $9.0 E+06$ & e & $\mathrm{NL}$ & 54 & 220 & $9.7 E+06$ & e & $\overline{N L}$ & Eu-152 \\
\hline Eu-154 & $6.97 \mathrm{E}+\infty 0$ & 27 & 220 & $9.0 E+06$ & e & NL & 54 & 220 & $9.7 E+06$ & e & $\mathrm{NL}$ & Eu-154 \\
\hline $\mathrm{Pb}-210$ & $5.30 E+03$ & 270 & 220 & $9.9 E+06$ & $\bar{e}$ & $\mathrm{NL}$ & 540 & 220 & $1.1 E+07$ & e & NL & $\mathrm{Pb}-210$ \\
\hline Ra-226 & $6.27 E+03$ & 27 & 220 & $1.8 E+07$ & $e$ & NL & 54 & 220 & $2.0 \mathrm{E}+07$ & $e$ & NL & Ra-226 \\
\hline Ra-228 & $1.64 E+03$ & 27 & 220 & $1.8 \mathrm{E}+07$ & e & $\mathrm{NL}$ & 54 & 220 & $2.0 \mathrm{E}+07$ & e & $\mathrm{NL}$ & $\mathrm{Ra}-228$ \\
\hline Th-229 & $2.94 E+03$ & 270 & 220 & $1.2 E+08$ & e & NL & 540 & 220 & $1.3 E+08$ & $e$ & $\mathrm{NL}$ & Th-229 \\
\hline Th-230 & $6.12 E+03$ & 270 & 220 & $1.2 E+08$ & NA & $4 E+01$ & 540 & 220 & $1.3 E+08$ & NA & $8 E+01$ & Th-230 \\
\hline Th-232 & $3.63 E+03$ & 270 & 220 & $1.2 E+08$ & $1.0 E+00$ & $6 E+01$ & 540 & 220 & $1.3 E+08$ & $1.0 \mathrm{E}+00$ & $1 E+02$ & Th-232 \\
\hline Pa-231 & $1.85 E+04$ & 270 & 220 & $2.0 E+07$ & e & $N L$ & 540 & 220 & $2.2 E+07$ & e & $\mathrm{NL}$ & Pa-231 \\
\hline
\end{tabular}


iั Table 15-4. Results of Calculations for the Water Pathway at Pantex (water travel time from land surface to performance boundary [excluding facility detention] $=2000 \mathrm{y}$ ) (Part 2 of 2 )

\begin{tabular}{|c|c|c|c|c|c|c|c|c|c|c|c|c|c|}
\hline \multirow[t]{2}{*}{ Nuclide } & \multirow[b]{2}{*}{$\begin{array}{c}\text { PDCF } \\
\text { remly per } \mu \mathrm{Cl} \text {. }\end{array}$} & \multicolumn{5}{|c|}{ Trench } & \multicolumn{6}{|c|}{ Tumulus } & \multirow[t]{2}{*}{ Nuclide } \\
\hline & & \begin{tabular}{|l|} 
CRF source \\
(dimensionless)
\end{tabular} & $\begin{array}{c}\text { CRF Water } \\
\text { (dimensionless) }\end{array}$ & \begin{tabular}{|c|} 
Arrival \\
Time (y)
\end{tabular} & $\begin{array}{c}r_{\text {Decay }}{ }^{a} \\
\text { (dimensionloss) }\end{array}$ & $\begin{array}{c}C_{\text {w.Wator }}{ }^{b} \\
\left(\mu \mathrm{Ci} / \mathrm{m}^{3}\right)\end{array}$ & \begin{tabular}{|l|} 
CRF \\
(dimonsionless)
\end{tabular} & 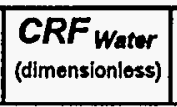 & $\begin{array}{l}\text { Arrival } \\
\text { Time }(y) \\
\end{array}$ & \begin{tabular}{|c|} 
r Decayy $^{2}$ \\
(dimonsionloss)
\end{tabular} & $\begin{array}{c}C_{\text {W-Wate }} \\
\left(\mu \mathrm{Ci} / \mathrm{m}^{3}\right.\end{array}$ & & \\
\hline U-232 & $1.55 E+03$ & 270 & 220 & $1.3 E+06$ & e & $\mathrm{NL}$ & 540 & 220 & $1.4 \mathrm{E}+06$ & e & NL & ${ }^{c}$ & $U-232$ \\
\hline U-233 & $1.95 \mathrm{E}+03$ & 270 & 220 & $1.3 E+06$ & NA & $1 E+02$ & 540 & 220 & $1.4 E+06$ & NA & $2 \mathrm{E}+02$ & ${ }^{\circ}$ & U-233 \\
\hline $\mathrm{U}-234$ & $6.48 \mathrm{E}+02$ & 270 & 220 & $1.3 E+06$ & NA & $4 \mathrm{E}+02$ & 540 & 220 & $1.4 \mathrm{E}+06$ & NA & $7 E+02$ & $\circ$ & U-234 \\
\hline$U-235$ & $3.73 E+03$ & 270 & 220 & $1.3 E+06$ & NA & $6 E+01$ & 540 & 220 & $1.4 \mathrm{E}+06$ & NA & $1 E+02$ & $\mathrm{c}$ & U-235 \\
\hline $\mathrm{U}-236$ & $1.96 \mathrm{E}+02$ & 270 & 220 & 1.3E+06 & $1.0 \mathrm{E}+00$ & $1 E+03$ & 540 & 220 & $1.4 \mathrm{E}+06$ & $1.0 E+00$ & $3 E+03$ & c & U-236 \\
\hline U-238 & $2.07 E+02$ & 270 & 220 & $1.3 E+06$ & NA & $1 E+03$ & 540 & 220 & $1.4 \mathrm{E}+06$ & NA & $2 E+03$ & $\mathrm{c}$ & U-238 \\
\hline Np-237 & $3.24 E+03$ & 270 & 220 & $1.9 E+05$ & $1.1 E+\infty$ & $8 E+01$ & 540 & 220 & $2.0 E+05$ & $1.1 \mathrm{E}+00$ & $2 \mathrm{E}+02$ & $\mathrm{c}$ & $\mathrm{Np}-237$ \\
\hline Pu-238 & $2.34 E+03$ & 270 & 220 & $2.0 E+07$ & e & $1 E+06$ & 540 & 220 & $2.2 E+07$ & e & $2 E+06$ & i & $\mathrm{Pu}-238$ \\
\hline Pu-239 & $2.58 E+03$ & 270 & 220 & $2.0 \mathrm{E}+07$ & e & $\mathrm{NL}$ & 540 & 220 & $2.2 \mathrm{E}+07$ & e & NL & c & $\mathrm{Pu}-239$ \\
\hline Pu-240 & $2.58 E+03$ & 270 & 220 & $2.0 E+07$ & e & NL & 540 & 220 & $2.2 E+07$ & e & $\overline{N L}$ & ${ }^{\circ}$ & Pu-240 \\
\hline Pu-241 & $4.82 E+08$ & 270 & 220 & $2.0 E+07$ & e & $1 E+07$ & 540 & 220 & $2.2 E+07$ & e & $2 E+07$ & $\circ$ & Pu-241 \\
\hline Pu-242 & $2.45 \mathrm{E}+03$ & 270 & 220 & $2.0 E+07$ & $1.8 E+16$ & $\mathrm{NL}$ & 540 & 220 & $2.2 E+07$ & $3.3 \mathrm{E}+17$ & NL & $\mathrm{c}$ & $\mathrm{Pu}-242$ \\
\hline Pu-244 & $4.11 E+03$ & 270 & 220 & $2.0 \mathrm{E}+07$ & NA & $6 \mathrm{E}+01$ & 540 & 220 & $2.2 E+07$ & $\mathrm{NA}$ & $1 E+02$ & ${ }^{\circ}$ & Pu-244 \\
\hline Am-241 & $2.66 \mathrm{E}+03$ & 270 & 220 & $7.0 \mathrm{E}+07$ & e & $4 E+05$ & 540 & 220 & $7.5 \mathrm{E}+07$ & $e$ & $8 E+05$ & c & Am-241 \\
\hline Am-243 & $2.64 E+03$ & 270 & 220 & $7.0 \mathrm{E}+07$ & e & $N L$ & 540 & 220 & $7.5 E+07$ & e & NL & c & Am-243 \\
\hline $\mathrm{Cm}-243$ & $1.83 E+03$ & 270 & 220 & $1.5 E+08$ & e & $\mathrm{NL}$ & 540 & 220 & $1.6 E+08$ & e & $\mathrm{NL}$ & - & $\mathrm{Cm}-243$ \\
\hline $\mathrm{Cm}-244$ & $1.47 E+03$ & 270 & 220 & $1.5 E+08$ & e & $\mathrm{NL}$ & 540 & 220 & $1.6 E+08$ & e & NL & c & $\mathrm{Cm}-244$ \\
\hline $\mathrm{Cm}-245$ & $4.56 \mathrm{E}+03$ & 270 & 220 & $1.5 E+08$ & NA & $5 E+01$ & 540 & 220 & $1.6 \mathrm{E}+08$ & NA & $1 E+02$ & c & Cm-245 \\
\hline $\mathrm{Cm}-246$ & $2.70 E+03$ & 270 & 220 & $1.5 \mathrm{E}+08$ & e & $\mathrm{NL}$ & 540 & 220 & $1.6 \mathrm{E}+08$ & $e$ & NL & $\circ$ & $\mathrm{Cm}-246$ \\
\hline $\mathrm{Cm}-247$ & $4.34 E+03$ & 270 & 220 & $1.5 E+08$ & NA & $5 E+01$ & 540 & 220 & $1.6 \mathrm{E}+08$ & NA & $1 E+02$ & 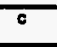 & $\mathrm{Cm}_{\mathrm{m}-247}$ \\
\hline $\mathrm{Cm}-248$ & $9.94 E+03$ & 270 & 220 & $1.5 \mathrm{E}+08$ & e & $\mathrm{NL}$ & 540 & 220 & $1.6 \mathrm{E}+08$ & e & $\mathrm{NL}$ & c & $\mathrm{Cm}-248$ \\
\hline Cf-249 & $3.46 E+03$ & 270 & 220 & $1.5 E+08$ & e & $1 E+03$ & 540 & 220 & $1.6 \mathrm{E}+08$ & e & $3 E+03$ & c & Cf-249 \\
\hline$C f-250$ & $2.64 E+08$ & 270 & 220 & $1.5 E+08$ & e & NL & 540 & 220 & $1.6 E+08$ & e & NL & c & Cf -250 \\
\hline$C 1-251$ & $3.54 E+03$ & 270 & 220 & $1.5 \mathrm{E}+08$ & $e$ & NL & 540 & 220 & $1.6 \mathrm{E}+08$ & e & $\mathrm{NL}$ & $\mathrm{c}$ & Cf-251 \\
\hline
\end{tabular}

a "NA" means Not Applicable - decay factor is implicit in the PDCF for this radionuclide.

b "NL" means No Limit - estimated permissible concentration is greater than the specific activity of the pure elemental radionuclide.

c Radionuclide concentration is based on arrival time at the performance boundary beyond $10,000 \mathrm{y}$.

d PDCF is a function of arrival time. See Chapter 1 of this volume for equation.

e rocay $\geq 1 E+50$

Contribution of decay product(s) is significant to determination of this value (see Table E-3 in Volume 2). Listed arrival time is that of the parent radionuclide. Arrival time of the significant decay product(s) is greater than $10,000 \mathrm{y}$. 
For some radionuclides, no value is listed in Table 15-4 for the radioactive decay term, $r_{\text {Decay. }}$. These radionuclides had radioactive decay terms that were very large (e.g., greater than $\left.1 \times 10^{50}\right)$. Any radionuclide with a radioactive decay term greater than $1 \times 10^{50}$ was ensured a calculated permissible waste concentrations greater than the specific activity of the pure elemental radionuclide, which, as described previously, resulted in no limit (NL) on permissible waste concentrations for disposal.

Arrival times for all of the radionuclides listed in Table 15-4 except H-3 and Tc-99 were beyond the 10,000-y performance period for both the RCRA trench design and the tumulus design. For all radionuclides except $\mathrm{H}-3$ and Tc-99, the estimated waste concentrations are presented in Table 15-4 for information purposes only. Consistent with the approach used in LLW performance assessments, these values were not considered in determining the most restrictive disposal limit from among the evaluated pathways.

For the trench design at Pantex, the total undecayed CRFs (the product of the $C R F_{\text {Source }}$ and the $C R F_{\text {Water }}$ ) for the water pathway ranged from about 100 to 59,000 . Among the listed radionuclides, arrival times at the performance boundary ranged from $5600 \mathrm{y}$ to 150 million years, including the retention time in the facility before failure. For the tumulus design, the $C R F_{\text {Total }}$ values ranged from about 200 to 120,000 , reflecting the reduced amount of waste available to occupy the tumulus facility. Among the listed radionuclides, arrival times at the performance boundary ranged from $6300 \mathrm{y}$ to 160 million years, including the retention time in the facility before failure. The long arrival times for radionuclides released from the trench result in very high maximum permissible waste concentrations $\left(C_{W-W a t e r}\right)$ for most of the radionuclides. Of the 58 isotopes considered, 35 have permissible concentrations that exceed the specific activities of the pure elemental radionuclides (reported as "NL") for both the trench and tumulus designs. Thus, differences in the arrival times between the trench and tumulus designs were negligible because of the very small natural infiltration rate in the region and the depth between the fine-grained zone and the lower Ogalalla aquifer.

\subsubsection{Atmospheric Transport}

Two CRFs were used to account for the attenuation encompassing diffusion to the ground surface, mixing in air, and dispersion in the atmosphere to the performance boundary. The CRF for diffusion in soil, $C R F_{D i f f}$, was defined as the ratio of the radionuclide concentration in the waste to its resulting concentration in the upper one centimeter of soil. The CRF for dispersion in air, $C R F_{D i s p}$, was defined as the ratio of the radionuclide concentration in the upper one centimeter of soil to its resulting concentration in air at the performance boundary. The effect of radioactive decay was also included in the PE.

Application of the PE methodology for atmospheric transport of the two volatile radionuclides considered in the $\mathrm{PE}(\mathrm{H}-3$ and $\mathrm{C}-14)$ produced the results shown in Table 15-5 for both the generic trench and tumulus designs; there was no assumed difference in these two disposal technologies with respect to permissible waste limits based on the atmospheric pathway at Pantex. The table shows permissible waste concentrations based on transport in the atmospheric pathway $\left(C_{W-A t m}\right)$ as well as the values used in calculating the permissible waste 
concentrations. For both $\mathrm{H}-3$ and $\mathrm{C}-14$, the greatest concentration reduction was assumed to occur as the radionuclides diffused from the top of the disposal facility to the soil surface.

Table 15-5. Results of Calculations for the Atmospheric Pathway

\begin{tabular}{|c|c|c|c|c|c|c|c|}
\hline \multirow[t]{2}{*}{ Nuclide } & \multirow[b]{2}{*}{$\begin{array}{c}S D C F_{A t m} \\
(\mathrm{rem} / \mathrm{y}) /(\mu \mathrm{Ci} / \mathrm{L})\end{array}$} & \multicolumn{6}{|c|}{ Generic Trench and Tumulus } \\
\hline & & $\begin{array}{c}C R F_{\text {Diff }} \\
\text { (dimensionless) }\end{array}$ & $\underset{\text { (dimensioniess) }}{C R F_{\text {Disp }}}$ & $\begin{array}{c}\text { CRFAtm } \\
\text { (dilmensionless) }\end{array}$ & $\begin{array}{l}\text { Arrival } \\
\text { Time (y) }\end{array}$ & $\begin{array}{c}\text { roecay } \\
\text { (dilmensionless) }\end{array}$ & $\begin{array}{c}C_{W-A t m} \\
\left(\mu \mathrm{Ci} / \mathrm{m}^{3}\right)\end{array}$ \\
\hline $\mathrm{H}-3$ & $8.33 E+02$ & $2 E+06$ & $2 E+03$ & $4 \mathrm{E}+09$ & 100 & 300 & $1 E+10$ \\
\hline lc-14 & $2.20 E+05$ & $4 E+04$ & $3 E+03$ & $1 E+08$ & 100 & 1 & $5 E+03$ \\
\hline
\end{tabular}

The time of arrival at the performance boundary for both radionuclides is shown in Table $15-5$ as $100 \mathrm{y}$. However, the actual migration of H-3 and C-14 from the disposal facility to the surface and downwind to the performance boundary was calculated to be on the order of hours, not years. As discussed in Section 15.3.2.2, the waste form and RCRA cover are assumed to retain these volatile radionuclides in the disposal facility for at least $100 \mathrm{y}$.

\subsubsection{Inadvertent Intruder Exposure}

The calculation of permissible waste concentrations for inadvertent intruder exposures did not utilize CRFs. Instead, the total dose resulting from an intrusion scenario (the sum of the doses from all exposure pathways involved in that intrusion) was modified by scenario dose conversion factors (SDCFs) that were applied to specific exposure pathways. The important exposure pathways for each radionuclide are listed in Appendix D of Volume 2. These values were radionuclide-specific and facility-design-specific and were the same for all sites. Values for the radioactive decay term were based on time of intrusion into the disposal facility (for the homesteader scenario, $300 \mathrm{y}$ for the trench design and $500 \mathrm{y}$ for the tumulus design; for the postdrilling scenario, $100 \mathrm{y}$ for both disposal designs). However, results based on intruder scenarios should be evaluated carefully because future social behavior, and intrusion scenarios, are difficult to predict.

The permissible waste concentrations for the two generic facility designs for each of the 58 radionuclides based on the standard PE intrusion scenarios are listed in Table 15-6. The most restrictive radionuclide concentration limits for each generic facility are indicated with bold type.

For six radionuclides in the table (U-233, U-234, U-235, U-238, Pu-244, and Cm-247), the time of homesteader intrusion was changed to $10,000 \mathrm{y}$, the end of the performance period. For these six radionuclides, ingrowth of decay products yields scenario doses that increase over time. The doses at $10,000 \mathrm{y}$, therefore, represent the maximum that could be encountered during the performance period. Also, for Th-230 and $\mathrm{Cm}-245$, ingrowth of decay products likewise produces a scenario dose that increases over time and peaks within the 10,000-y performance period. The times of homesteader intrusion for these two radionuclides (Th-230 and Cm-245) were taken as the time of maximum dose, 9000 and $1000 \mathrm{y}$, respectively. 
Table 15-6. Permissible Waste Concentrations for the Standard Intrusion Scenarios (most limiting radionuclide concentration for each facility design is highlighted in bold italic) (Part 1 of 2)

\begin{tabular}{|c|c|c|c|c|c|}
\hline \multirow[t]{2}{*}{ Nuclide } & \multicolumn{2}{|c|}{ Trench } & \multicolumn{2}{|c|}{ Tumulus } & \multirow[t]{2}{*}{ Nuclide } \\
\hline & $\begin{array}{c}C_{W-1 n t r} \\
\text { Homesteader } \\
\left(\mu \mathrm{Ci} / \mathrm{m}^{3}\right) \\
\end{array}$ & $\begin{array}{c}C_{\text {w-intr }} \\
\text { Post-Drilling } \\
\left(\mu \mathrm{Ci} / \mathrm{m}^{3}\right) \\
\end{array}$ & $\begin{array}{c}C_{\text {W-lntr }}{ }^{2} \\
\text { Homesteader } \\
\left(\mu \mathrm{Ci} / \mathrm{m}^{3}\right) \\
\end{array}$ & $\begin{array}{c}C_{\text {w-Int }} \\
\text { Post-Drilling } \\
\left(\mu \mathrm{Ci} / \mathrm{m}^{3}\right) \\
\end{array}$ & \\
\hline $\mathrm{H}-3$ & $1 E+12$ & $7 E+07$ & NL & $7 E+07$ & $\mathrm{H}-3$ \\
\hline$c-14$ & $1 E+04$ & $7 E+04$ & $1 E+04$ & $7 E+04$ & C-14 \\
\hline Al-26 & $5 E+01$ & $5 E+04$ & $5 E+01$ & $5 E+04$ & Al-26 \\
\hline Si-32 & $9 E+03$ & $1 E+04$ & $4 E+04$ & $1 E+04$ & Si-32 \\
\hline $\mathrm{Cl}-36$ & $2 E+02$ & $9 E+02$ & $2 E+02$ & $9 E+02$ & $\mathrm{Cl}-36$ \\
\hline$K-40$ & $7 E+02$ & $2 E+04$ & $7 E+02$ & $2 E+04$ & $K-40$ \\
\hline Co-60 & NL & $3 E+10$ & NL & $3 E+10$ & Co-60 \\
\hline $\mathrm{Ni}-59$ & $3 E+06$ & $1 E+07$ & $3 E+06$ & $1 E+07$ & $\mathrm{Ni}-59$ \\
\hline $\mathrm{Ni}-63$ & $8 E+06$ & $1 E+07$ & $3 E+07$ & $1 E+07$ & $\mathrm{Ni}-63$ \\
\hline Se-79 & $2 E+05$ & $8 E+05$ & $2 E+05$ & $8 E+05$ & Se-79 \\
\hline Sr-90 & $1 E+06$ & $5 E+04$ & $1 E+08$ & $5 E+04$ & Sr-90 \\
\hline $2 r-93$ & $5 E+06$ & $3 E+07$ & $5 E+06$ & $3 E+07$ & $\mathrm{Zr}-93$ \\
\hline $\mathrm{Nb}-93 \mathrm{~m}$ & $5 E+12$ & $4 E+09$ & NL & $4 E+09$ & $\mathrm{Nb}-93 \mathrm{~m}$ \\
\hline $\mathrm{Nb}-94$ & $9 E+01$ & $9 E+04$ & $1 E+02$ & $9 E+04$ & $\mathrm{Nb}-94$ \\
\hline Tc-99 & $2 E+04$ & $8 E+04^{\circ}$ & $2 E+04$ & $8 E+04$ & TC-99 \\
\hline Pd-107 & $6 E+06$ & $3 E+07$ & $6 E+06$ & $3 E+07$ & Pd-107 \\
\hline $\mathrm{Ag}-108 \mathrm{~m}$ & $5 E+02$ & $1 E+05$ & $1 E+03$ & $1 E+05$ & $\mathrm{Ag}-108 \mathrm{~m}$ \\
\hline $\mathrm{Cd}-113 \mathrm{~m}$ & $4 E+09$ & $1 E+06$ & $7 E+13$ & $1 E+06$ & $\mathrm{Cd}-113 \mathrm{~m}$ \\
\hline Sn-121m & $2 E+07$ & $5 E+07$ & $2 E+08$ & $5 E+07$ & Sn-121m \\
\hline$S n-126$ & $8 E+01$ & $7 E+04$ & $8 E+01$ & $7 E+04$ & $\mathrm{Sn}-126$ \\
\hline $1-129$ & $2 E+03$ & $1 E+04$ & $2 E+03$ & $1 E+04$ & $1-129$ \\
\hline Cs-135 & $2 E+05$ & $8 E+05$ & $2 E+05$ & $8 E+05$ & Cs-135 \\
\hline Cs-137 & $3 E+05$ & $8 E+05$ & $3 E+07$ & $8 E+05$ & Cs-137 \\
\hline $\mathrm{Ba}-133$ & $2 E+11$ & $3 E+08$ & NL & $3 E+08$ & $\mathrm{Ba}-133$ \\
\hline Sm-151 & $2 E+08$ & $2 E+08$ & $8 E+08$ & $2 E+08$ & $\mathrm{Sm}-151$ \\
\hline Eu-152 & $6 \mathrm{E}+08$ & $2 E+07$ & $2 E+13$ & $2 E+07$ & Eu-152 \\
\hline Eu-154 & $4 E+12$ & $4 E+08$ & $\mathrm{NL}$ & $4 E+08$ & Eu-154 \\
\hline $\mathrm{Pb}-210$ & $7 E+06$ & $7 E+04$ & $4 E+09$ & $7 E+04$ & $\mathrm{~Pb}-210$ \\
\hline Ra-226 & $8 E+01$ & $3 E+03$ & $9 E+01$ & $3 E+03$ & Ra-226 \\
\hline Ra-228 & $\mathrm{NL}$ & $4 E+09$ & $\mathrm{NL}$ & $4 E+09$ & Ra-228 \\
\hline Th-229 & $5 E+02$ & $3 E+04$ & $5 E+02$ & $3 E+04$ & Th-229 \\
\hline Th-230 & $8 E+01$ & $7 E+04$ & $8 E+01$ & $7 E+04$ & Th-230 \\
\hline Th-232 & $6 E+01$ & $2 E+04$ & $6 E+01$ & $2 E+04$ & Th-232 \\
\hline $\mathrm{Pa}-231$ & $2 E+02$ & $5 E+03$ & $2 E+02$ & $5 E+03$ & $\mathrm{~Pa}-231$ \\
\hline
\end{tabular}


Table 15-6. Permissible Waste Concentrations for the Standard Intrusion Scenarios (most limiting radionuclide concentration for each facility design is highlighted in bold italic) (Part 2 of 2)

\begin{tabular}{|c|c|c|c|c|c|}
\hline \multirow[t]{2}{*}{ Nuclide } & \multicolumn{2}{|c|}{ Trench } & \multicolumn{2}{|c|}{ Tumulus } & \multirow[t]{2}{*}{ Nuclide } \\
\hline & $\begin{array}{c}C_{w-1 n t r} \\
\text { Homesteader } \\
\left(\mu \mathrm{Ci} / \mathrm{m}^{3}\right)\end{array}$ & $\begin{array}{c}C_{W-\ln t} \\
\text { Post-Drilling } \\
\left(\mu \mathrm{Ci} / \mathrm{m}^{3}\right) \\
\end{array}$ & $\begin{array}{c}C_{\text {w/ntr }}{ }^{a} \\
\text { Homesteader } \\
\left(\mu \mathrm{Ci} / \mathrm{m}^{3}\right)\end{array}$ & $\begin{array}{c}C_{w-1 n t r} \\
\text { Post-Drilling } \\
\left(\mu \mathrm{Ci} / \mathrm{m}^{3}\right)\end{array}$ & \\
\hline U-232 & $2 E+03$ & $5 E+04$ & $1 E+04$ & $5 E+04$ & $U-232$ \\
\hline U-233 & $7 E+02$ & $1 E+05$ & $7 E+02$ & $1 E+05$ & U-233 \\
\hline U-234 & $1 E+03$ & $1 E+05$ & $1 E+03$ & $1 E+05$ & U-234 \\
\hline U-235 & $6 E+02$ & $1 E+05$ & $6 E+02$ & $1 E+05$ & U-235 \\
\hline U-236 & $2 E+04$ & $1 E+05$ & $2 E+04$ & $1 E+05$ & U-236 \\
\hline $\mathrm{U}-238$ & $5 E+03$ & $1 E+05$ & $5 E+03$ & $1 E+05$ & U-238 \\
\hline $\mathrm{Np}-237$ & $4 E+02$ & $4 E+03$ & $4 E+02$ & $4 E+03$ & Np-237 \\
\hline Pu-238 & $7 E+04$ & $1 E+05$ & $4 E+05$ & $1 E+05$ & Pu-238 \\
\hline $\mathrm{Pu}-239$ & $6 E+03$ & $5 E+04$ & $6 E+03$ & $5 E+04$ & Pu-239 \\
\hline Pu-240 & $6 E+03$ & $5 E+04$ & $7 E+03$ & $5 E+04$ & $\mathrm{Pu}-240$ \\
\hline Pu-241 & $2 E+05$ & $1 \mathrm{E}+06$ & $3 E+05$ & $1 E+06$ & Pu-241 \\
\hline $\mathrm{Pu}-242$ & $6 E+03$ & $5 E+04$ & $6 E+03$ & $5 E+04$ & Pu-242 \\
\hline Pu-244 & $4 E+02$ & $5 E+04$ & $4 E+02$ & $5 E+04$ & $\mathrm{Pu}-244$ \\
\hline Am-241 & $7 E+03$ & $5 E+04$ & $9 E+03$ & $5 E+04$ & Am-241 \\
\hline Am-243 & $9 E+02$ & $4 E+04$ & $9 E+02$ & $4 E+04$ & Am-243 \\
\hline $\mathrm{Cm}-243$ & $1 E+06$ & $8 E+05$ & $5 E+06$ & $8 E+05$ & $\mathrm{Cm}-243$ \\
\hline $\mathrm{Cm}-244$ & $2 E+06$ & $3 E+06$ & $2 E+06$ & $3 E+06$ & $\mathrm{Cm}-244$ \\
\hline $\mathrm{Cm}-245$ & $1 E+03$ & $4 E+04$ & $1 E+03$ & $4 E+04$ & $\mathrm{Cm}-245$ \\
\hline $\mathrm{Cm}-246$ & $6 E+03$ & $5 E+04$ & $6 E+03$ & $5 E+04$ & $\mathrm{Cm}-246$ \\
\hline $\mathrm{Cm}-247$ & $3 E+02$ & $5 E+04$ & $3 E+02$ & $5 E+04$ & $\mathrm{Cm}-247$ \\
\hline $\mathrm{Cm}-248$ & $2 E+03$ & $1 E+04$ & $2 E+03$ & $1 E+04$ & $\mathrm{Cm}-248$ \\
\hline Cf-249 & $8 E+02$ & $4 E+04$ & $1 E+03$ & $4 E+04$ & Cf-249 \\
\hline Cf-250 & $2 E+06$ & $9 E+06$ & $2 E+06$ & $9 \mathrm{E}+06$ & Cf-250 \\
\hline Cf-251 & $2 E+03$ & $4 E+04$ & $2 E+03$ & $4 E+04$ & Cf-251 \\
\hline
\end{tabular}

a "NL" means No Limit - estimated permissible concentration is greater than the specific activity of the pure elemental radionuclide. 
For the trench design, the post-drilling scenario generally yielded more restrictive waste limits than the homesteader scenario for those radionuclides with half-lives shorter than about $30 \mathrm{y}$. For the tumulus design, the post-drilling scenario generally yielded more restrictive limits than the homesteader scenario for those radionuclides with half-lives shorter than about $130 \mathrm{y}$.

\subsection{SUMMARY AND DISCUSSION OF RESULTS}

The limiting waste concentrations in disposed MLLW for the water, atmospheric, and intruder analyses for the generic trench and tumulus designs are summarized in Table 15-7 and discussed in Section 15.6.1. An overall discussion of the results of the PE for Pantex Plant is contained in Section 15.6.2.

\subsubsection{Results Based on Disposal Design}

Due to the long travel times to the performance boundary for the water exposure pathway, the results for both the generic trench and tumulus designs are nearly identical; the differences in the expected containment time for the two designs represent a small fraction of the contaminant travel times. For both the generic trench and tumulus designs at Pantex Plant, one radionuclide (Tc-99) was limited by the water pathway, one radionuclide (C-14) was limited by the atmospheric pathway, and 56 radionuclides were limited by intrusion scenarios, as shown in Table 15-7. For several of the heavier radionuclides, the maximum concentrations are calculated based on predicted exposure to the isotope itself as well as exposure to its principal decay products.

For the trench and tumulus designs, the concentration for one radionuclide $(\mathrm{H}-3)$ that arrived at the performance boundary before 10,000 y reported for Table 15-7 had no limit. As discussed in Section 15.5.1, the calculated concentrations for those radionuclides reported as NL (No Limit) were above the specific activity of the pure elemental radionuclide, indicating that the performance measure of $4 \mathrm{mrem}(0.04 \mathrm{mSv})$ per year would not be reached under the given release and transport assumptions.

As also discussed in Section 15.5.1, values for some radionuclides are not reported in Table 15-7 for the water pathway analysis. Arrival times for these radionuclides were beyond the 10,000-y performance period. For these radionuclides, the estimated waste concentrations are presented in Table 15-4 for information purposes but are not listed in Table 15-7. Consistent with the approach used in LLW performance assessments, these values were not considered in determining the most restrictive disposal limit from among the evaluated pathways because arrival times for these radionuclides were beyond $10,000 \mathrm{y}$. 
Table 15-7. Permissible Concentrations for the Generic Disposal Designs at Pantex (permissible concentration related to the most limiting pathway for each facility design is highlighted in bold italic) (Part 1 of 2)

\begin{tabular}{|c|c|c|c|c|c|c|c|}
\hline \multirow[t]{2}{*}{ Nuclide } & \multicolumn{3}{|c|}{ Trench } & \multicolumn{3}{|c|}{ Tumulus } & \multirow[t]{2}{*}{ Nuclide } \\
\hline & $\begin{array}{c}C_{\text {wh-Water }}{ }^{2, b} \\
\left(\mu \mathrm{Ci} / \mathrm{m}^{3}\right)\end{array}$ & $\begin{array}{l}C_{W \cdot A t m}{ }^{c} \\
\left(\mu \mathrm{Ci} / \mathrm{m}^{3}\right)\end{array}$ & $\begin{array}{l}C_{w / n t r}^{d} \\
\left(\mu \mathrm{Ci} / \mathrm{m}^{3}\right)\end{array}$ & $\begin{array}{c}C_{\text {w-water }}{ }^{a, b} \\
\left(\mu \mathrm{Ci} / \mathrm{m}^{3}\right)\end{array}$ & $\begin{array}{l}C_{W-A t m}{ }^{e} \\
\left(\mu \mathrm{Ci} / \mathrm{m}^{3}\right)\end{array}$ & $\begin{array}{l}C_{W-\ln r^{d}} \\
\left(\mu \mathrm{Ci} / \mathrm{m}^{3}\right)\end{array}$ & \\
\hline $\mathrm{H}-3$ & NL & $1 E+10$ & $7 E+07$ & NL & $1 E+10$ & $7 E+07$ & $\mathrm{H}-3$ \\
\hline C-14 & - & $5 E+03$ & $1 E+04$ & - & $5 E+03$ & $1 E+04$ & C-14 \\
\hline Al-26 & - & & $5 E+01$ & - & & $5 E+01$ & $\mathrm{Al}-26$ \\
\hline Si-32 & - & & $9 E+03$ & - & & $1 E+04$ & Si-32 \\
\hline $\mathrm{Cl}-36$ & - & & $2 E+02$ & - & & $2 E+02$ & $\mathrm{Cl}-36$ \\
\hline$K-40$ & - & & $7 E+02$ & - & & $7 E+02$ & $k-40$ \\
\hline Co-60 & - & & $3 E+10$ & - & & $3 E+10$ & Co-60 \\
\hline $\mathrm{Ni}-59$ & - & & $3 E+06$ & - & & $3 E+06$ & Ni-59 \\
\hline $\mathrm{Ni}-63$ & - & & $8 E+06$ & - & & $1 E+07$ & $\mathrm{Ni}-63$ \\
\hline Se-79 & - & & $2 E+05$ & - & & $2 E+05$ & Se-79 \\
\hline Sr-90 & - & & $5 E+04$ & - & & $5 E+04$ & Sr-90 \\
\hline Zr-93 & - & & $5 E+06$ & - & & $5 E+06$ & $2 r-93$ \\
\hline $\mathrm{Nb}-93 \mathrm{~m}$ & - & & $4 E+09$ & - & & $4 E+09$ & $\mathrm{Nb}-93 \mathrm{~m}$ \\
\hline $\mathrm{Nb}-94$ & - & & $9 E+01$ & - & & $1 E+02$ & $\mathrm{Nb}-94$ \\
\hline Tc-99 & $3 E+03$ & & $2 E+04$ & $5 E+03$ & & $2 E+04$ & TC-99 \\
\hline Pd-107 & - & & $6 E+06$ & - & & $6 E+06$ & Pd-107 \\
\hline $\mathrm{Ag}-108 \mathrm{~m}$ & - & & $5 E+02$ & - & & $1 E+03$ & $\mathrm{Ag}-108 \mathrm{~m}$ \\
\hline $\mathrm{Cd}-113 \mathrm{~m}$ & - & & $1 E+06$ & - & & $1 E+06$ & $\mathrm{Cd}-113 \mathrm{~m}$ \\
\hline $\mathrm{Sn}-121 \mathrm{~m}$ & - & & $2 E+07$ & - & & $5 E+07$ & $S n-121 m$ \\
\hline $5 n-126$ & - & & $8 E+01$ & - & & $8 E+01$ & $5 n-126$ \\
\hline $1-129$ & - & & $2 E+03$ & - & & $2 E+03$ & $1-129$ \\
\hline Cs-135 & - & & $2 E+05$ & - & & $2 E+05$ & Cs-135 \\
\hline Cs-137 & - & & $3 E+05$ & - & & $8 E+05$ & Cs-137 \\
\hline $\mathrm{Ba}-133$ & - & & $3 E+08$ & - & & $3 E+08$ & Ba-133 \\
\hline $\mathrm{Sm}-151$ & - & & $2 E+08$ & - & & $2 E+08$ & $\mathrm{Sm}-151$ \\
\hline Eu-152 & - & & $2 E+07$ & - & & $2 E+07$ & Eu-152 \\
\hline Eu-154 & - & & $4 E+08$ & - & & $4 E+08$ & Eu-154 \\
\hline $\mathrm{Pb}-210$ & - & & $7 E+04$ & - & & $7 E+04$ & $\mathrm{~Pb}-210$ \\
\hline Ra-226 & - & & $8 E+01$ & - & & $9 E+01$ & Ra-226 \\
\hline Ra-228 & - & & $4 E+09$ & - & & $4 E+09$ & Ra-228 \\
\hline Th-229 & - & & $5 E+02$ & - & & $5 E+02$ & Th-229 \\
\hline Th-230 & - & & $8 E+01$ & - & & $8 E+01$ & Th-230 \\
\hline Th-232 & - & & $6 E+01$ & - & & $6 E+01$ & Th-232 \\
\hline Pa-231 & - & & $2 E+02$ & - & & $2 E+02$ & $\mathrm{~Pa}-231$ \\
\hline
\end{tabular}


Table 15-7. Permissible Concentrations for the Generic Disposal Designs at Pantex (permissible concentration related to the most limiting pathway for each facility design is highlighted in bold italic) (Part 2 of 2)

\begin{tabular}{|c|c|c|c|c|c|c|c|}
\hline \multirow[t]{2}{*}{ Nuclide } & \multicolumn{3}{|c|}{ Trench } & \multicolumn{3}{|c|}{ Tumulus } & \multirow[t]{2}{*}{ Nuclide } \\
\hline & $\begin{array}{c}C_{\text {W.Wator }}{ }^{a, b} \\
\left(\mu \mathrm{Ci} / \mathrm{m}^{3}\right)\end{array}$ & $\begin{array}{l}C_{W-A t m}{ }^{c} \\
\left(\mu \mathrm{C} / \mathrm{m}^{3}\right)\end{array}$ & $\begin{array}{l}C_{w / n t r}{ }^{d} \\
\left(\mu \mathrm{Ci} / m^{3}\right)\end{array}$ & $\begin{array}{c}C_{\text {w.Water }}{ }^{a, b} \\
\left(\mu \mathrm{Ci} / \mathrm{m}^{3}\right)\end{array}$ & $\begin{array}{c}C_{W-A t m}{ }^{c} \\
\left(\mu \mathrm{Ci} / \mathrm{m}^{3}\right)\end{array}$ & $\begin{array}{l}C_{W-\operatorname{mtr} t^{d}} \\
\left(\mu \mathrm{Ci} / \mathrm{m}^{3}\right)\end{array}$ & \\
\hline U-232 & - & & $2 E+03$ & - & & $1 E+04$ & U-232 \\
\hline$U-233$ & - & & $7 E+02$ & - & & $7 E+02$ & U-233 \\
\hline U-234 & - & & $1 E+03$ & - & & $1 E+03$ & U-234 \\
\hline U-235 & - & & $6 E+02$ & - & & $6 E+02$ & U-235 \\
\hline U-236 & - & & $2 E+04$ & - & & $2 E+04$ & $\mathrm{U}-236$ \\
\hline$U-238$ & - & & $5 E+03$ & - & & $5 E+03$ & U-238 \\
\hline $\mathrm{Np}-237$ & - & & $4 E+02$ & - & & $4 E+02$ & Np-237 \\
\hline Pu-238 & - & & $7 E+04$ & - & & $1 E+05$ & $\mathrm{Pu}-238$ \\
\hline Pu-239 & - & & $6 E+03$ & - & & $6 E+03$ & $\mathrm{Pu}-239$ \\
\hline $\mathrm{Pu}-240$ & - & & $6 E+03$ & - & & $7 E+03$ & Pu-240 \\
\hline Pu-241 & $=$ & & $2 E+05$ & - & & $3 E+05$ & Pu-241 \\
\hline Pu-242 & - & & $6 E+03$ & - & & $6 E+03$ & Pu-242 \\
\hline Pu-244 & - & & $4 E+02$ & - & & $4 E+02$ & Pu-244 \\
\hline$A m-241$ & - & & $7 E+03$ & - & & $9 E+03$ & Am-241 \\
\hline$A m-243$ & - & & $9 E+02$ & - & & $9 E+02$ & Am-243 \\
\hline $\mathrm{Cm}-243$ & - & & $8 E+05$ & - & & $8 E+05$ & $\mathrm{Cm}-243$ \\
\hline $\mathrm{Cm}-244$ & - & & $2 E+06$ & - & & $2 E+06$ & $\mathrm{Cm}-244$ \\
\hline $\mathrm{Cm}-245$ & - & & $1 E+03$ & - & & $1 E+03$ & $\mathrm{Cm}-245$ \\
\hline $\mathrm{Cm}-246$ & - & & $6 E+03$ & - & & $6 E+03$ & $\mathrm{Cm}-246$ \\
\hline $\mathrm{Cm}-247$ & - & & $3 E+02$ & - & & $3 E+02$ & $\mathrm{Cm}-247$ \\
\hline $\mathrm{Cm}-248$ & - & & $2 E+03$ & - & & $2 E+03$ & $\mathrm{Cm}-248$ \\
\hline Cf-249 & - & & $8 E+02$ & - & & $1 E+03$ & Cf-249 \\
\hline C $\{-250$ & - & & $2 E+06$ & - & & $2 E+06$ & Cf-250 \\
\hline$C f-251$ & - & & $2 E+03$ & - & & $2 E+03$ & $C f-251$ \\
\hline
\end{tabular}

a "NL" means No Limit - estimated permissible concentration factor is greater than the specific activity of the pure elemental radionuclide.

b "-" Indicates that the radionuclide concentration is based on an arrival time beyond $10,000 \mathrm{y}$; see Table 15-4 for specilic values.

c Results presented for radionclides expected to be volatile under disposal facility conditions.

d Concentration is based on the most restrictive intrusion scenario assumed for the site; see Table 15-6. 


\subsubsection{Discussion}

The results of the PE are based on the framework of assumptions summarized in Chapter 1 of this volume and discussed in detail in Volume 2 of this report and on the site-specific conceptual model for contaminant transport discussed in this chapter. Using alternative assumptions about the conceptual model has the potential to affect the results. Changes in the conceptual model could include alternative assumptions about the disposal facility, the source term, and radionuclide movement in the three pathways. Depending on the degree of possible variation and the relative importance of the parameters used in the calculation of estimated permissible waste concentrations, variability in parameter values can also affect the results. For parameters, results could vary depending on potential changes in values of both the generic and the site-specific parameters used in the PE analysis.

The effect on results from using alternative generic assumptions and parameter values is discussed in Chapter 6 of Volume 2. In addition, a discussion is provided in that chapter about the effects of using alternative values for site-specific parameters. Based on this discussion, four parameters were identified (three site-specific and one generic, all used in the water pathway analysis) that could potentially influence the results to the degree that the calculated waste concentrations become limited by a pathway other than the one determined for the PE (Table 157). The impacts on the results of using alternative values for these four parameters for the water pathway in the PE for Pantex Plant are discussed in this section. The basis for and possible variation in the values used in the PE for these parameters are discussed in Section 15.6.2.2.

\subsubsection{Parameter Sensitivity Analysis}

The PE provided results for two disposal facility designs: a RCRA-compliant, belowground trench and a RCRA-compliant, above-ground tumulus. Similar assumptions about the integrity of engineered barriers were made in the PE for both facility designs. Because the factors used to estimate transport of radionuclides in the water pathway for both designs were similar, the discussion in this section focuses on examining the results for the indicator radionuclides reported for the tumulus design (indicator radionuclides are defined in Chapter 7 of Volume 2).

As discussed in Chapter 6 of Volume 2, only four parameters used in the PE were identified as having a potential range of values that might affect results: natural recharge ( $i)$; groundwater Darcy velocity $\left(q_{g w}\right)$; area of the facility $(A)$; and distribution coefficients $\left(K_{d} \mathrm{~s}\right)$. These parameter values for Pantex Plant are summarized in Table 15-8. 
Table 15-8. Parameter Values Used in the PE for Pantex Plant with Potential Variability That Could Affect the Results

\begin{tabular}{|l|l|}
\hline \multicolumn{1}{|c|}{ Parameter } & \multicolumn{1}{|c|}{ Value } \\
\hline Natural recharge through local soils, $i$ & $0.006 \mathrm{~m} / \mathrm{y}$ \\
\hline Distribution coefficients for geologic & $\begin{array}{l}\text { Sandy soil values from Thibault et al. (1990); } \\
\text { see Table 15-2 in this chapter for values }\end{array}$ \\
\hline media, $K_{d}$ & $\begin{array}{l}6 \mathrm{~m} / \mathrm{y} \text { (based on aquifer properties; see Section } \\
\text { Groundwater Darcy velocity, } q_{g w}\end{array}$ \\
\hline Plan-view Area, $A$ & $2500 \mathrm{~m}^{2}$ (standard PE value) \\
\hline
\end{tabular}

The traditional procedure for performing a sensitivity analysis is to vary the parameters used in the calculations and observe the effect on the results. To be meaningful, this method requires some knowledge of the statistical distribution of each of the parameters considered, including their likely maximum and minimum values. For the $\mathrm{PE}$ calculations, the potential variability of the parameters used to calculate the permissible waste concentrations for the two different facility designs was not estimated. For most of the radionuclides considered in the PE, there were only two exposure pathways: the water pathway and intruder exposure scenarios (the atmospheric pathway was considered only for $\mathrm{H}-3$ and $\mathrm{C}-14$ ). The intruder-pathway results provide a baseline that can be used for comparison with the water-pathway results because the intruder scenarios used in the PE were relatively independent of the physical characteristics of the individual sites. For $\mathrm{H}-3$ and $\mathrm{C}-14$, the atmospheric pathway results provide a baseline that can also be used for comparison with the water pathway because the atmospheric pathway results are not highly sensitive to any individual input parameter (see Chapter 6 of Volume 2).

The intruder and atmospheric baselines provided an alternative method of performing sensitivity analyses for the PE. The input parameters for the water pathway were varied to determine if the limiting exposure pathway could be altered (e.g., the results could be changed from intruder-scenario-controlled [or atmospheric-pathway-controlled] to water-pathwaycontrolled). After new values for the water pathway parameters were determined, these values were examined for reasonableness based on physical constraints at the site.

To analyze the sensitivity of the results to changes in the parameter values for natural recharge, groundwater Darcy velocity, and area of the facility, the parameter values used in the $\mathrm{PE}$ for Pantex were varied. Only one parameter value was varied at a time for each indicator radionuclide, leaving the others equal to their $\mathrm{PE}$ values. In most instances, the parameter value was varied until the waste concentrations for the water and intruder (or atmospheric) pathways became equal, regardless of the likelihood (or physical impossibility) of the value to occur. 
The parameter values that caused the permissible concentrations for the water and intruder pathways to become equal are listed in Table 15-9a for the 8 indicator radionuclides. For the indicator radionuclides $\mathrm{H}-3, \mathrm{Sr}-90$, and $\mathrm{Cs}-137$, no value variations of these parameters resulted in equal concentrations. For C-14, the limiting pathway is the atmospheric pathway, so the water versus intruder comparison is not applicable. For Tc-99, the value for recharge had to decrease by 3 times, the groundwater velocity had to increase by a factor of about 3 , or the facility size had to decrease by an order of magnitude to change the limiting pathway from water to intruder. For $\mathrm{U}-238$, all values that caused equal concentrations also arrived at the performance boundary beyond 10,000 y. For Pu-239, the value for recharge had to increase over one order of magnitude for the water pathway concentration to equal the intruder pathway concentration, although the arrival time remains beyond $10,000 \mathrm{y}$. No value variations in the groundwater velocity or facility area resulted in equal water pathway and intruder pathway concentrations for Pu-239. For Am-241, the value for recharge had to increase by over two orders of magnitude or the groundwater velocity had to decrease by about one order of magnitude, or the plan area of the disposal facility had to increase by over four orders of magnitude for the water and intruder pathway concentrations to be equal, although the variation in groundwater velocity and facility size resulted in an arrival time later than $10,000 \mathrm{y}$.

The parameter values that caused the permissible concentrations for the water and atmospheric pathways to become equal are listed in Table 15-9b for H-3 and C-14. For C-14, the recharge had to increase by over an order of magnitude in order for the limiting pathway to change from atmospheric to water. The groundwater velocity and plan area could not be changed to change the limiting pathway.

The $K_{d}$ values that caused the permissible concentrations for the water and intruder pathways to be the same are listed in Table 15-10 for 5 of the indicator radionuclides. The indicator radionuclides $\mathrm{H}-3, \mathrm{C}-14$, and Tc-99 were not considered in this analysis because general consensus is that the $K_{d}$ values for these radionuclides are small. A $K_{d}$ value of $0.2 \mathrm{~mL} / \mathrm{g}$ resulted in an arrival time at the performance boundary equal to $10,000 \mathrm{y}$.

For Sr-90, Cs-137, and Am-241, no $K_{d}$ value caused the water and intruder permissible waste concentrations to become equal. A $K_{d}$ value less than $0.2 \mathrm{~mL} / \mathrm{g}$ for U-238 caused the arrival time at the performance boundary to be less than $10,000 \mathrm{y}$, and therefore changed the limiting pathway from intruder to water. For $\mathrm{Pu}-239$, a $K_{d}$ value of $8 \mathrm{~mL} / \mathrm{g}$ caused the water pathway concentration to equal the intruder pathway concentration, although the arrival time still exceeded $10,000 \mathrm{y}$; the $K_{d}$ value had to be decreased to less than $0.2 \mathrm{~mL} / \mathrm{g}$ for the limiting pathway to change from intruder to water. 
Table 15-9. Parameter Values That Caused the Permissible Concentrations for the Water and Intruder Pathways to Be Equal for Indicator Radionuclides at Pantex (tumulus design) (bold italic type indicates limiting pathway in the PE)

(a) Water/Intruder Pathways

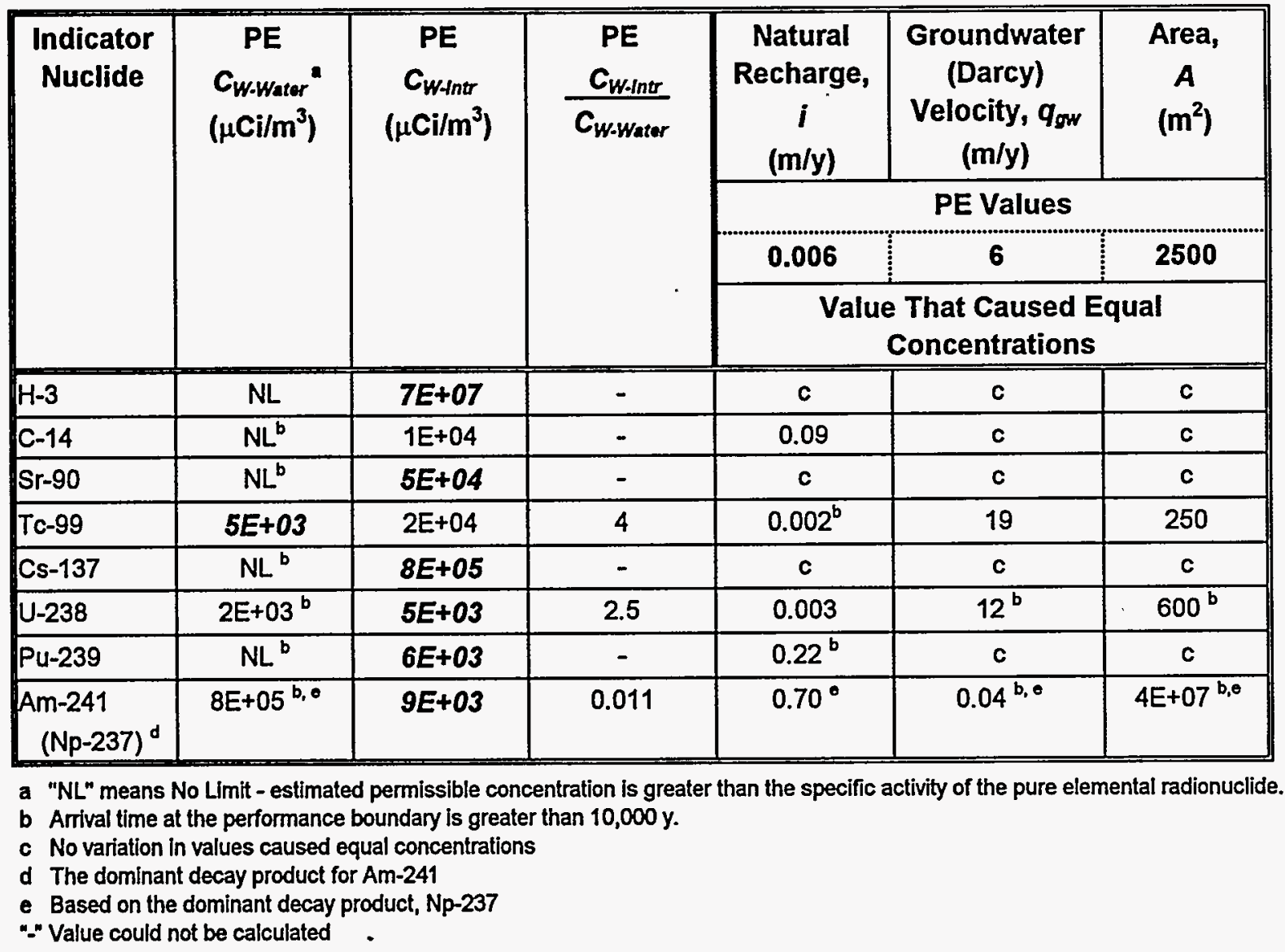

(b) Water/Atmospheric Pathways

\begin{tabular}{|c|c|c|c|c|c|c|}
\hline \multirow[t]{4}{*}{$\begin{array}{l}\text { Indicator } \\
\text { Nuclide }\end{array}$} & \multirow[t]{4}{*}{$\begin{array}{c}\text { PE } \\
C_{W-W a t e r} \\
\left(\mu \mathrm{Ci} / \mathrm{m}^{3}\right)\end{array}$} & \multirow[t]{4}{*}{$\begin{array}{c}\text { PE } \\
C_{W-A t m} \\
\left(\mu \mathrm{Ci} / \mathrm{m}^{3}\right)\end{array}$} & \multirow[t]{4}{*}{$\begin{array}{c}\text { PE } \\
\frac{C_{W-A t m}}{C_{W-W \text { ater }}}\end{array}$} & $\begin{array}{c}\text { Natural } \\
\text { Recharge, } \\
\text { i } \\
(\mathrm{m} / \mathrm{y})\end{array}$ & $\begin{array}{l}\text { Groundwater } \\
\text { (Darcy) } \\
\text { Velocity, } q_{\text {gw }} \\
(\mathrm{m} / \mathrm{y})\end{array}$ & $\begin{array}{c}\text { Area, } \\
\begin{array}{c}A \\
\left(\mathrm{~m}^{2}\right)\end{array}\end{array}$ \\
\hline & & & & \multicolumn{3}{|c|}{ PE Values } \\
\hline & & & & 0.006 & 6 & 2500 \\
\hline & & & & \multicolumn{3}{|c|}{$\begin{array}{c}\text { Value That Caused Equal } \\
\text { Concentrations }\end{array}$} \\
\hline $\mathrm{H}-3$ & $\mathrm{NL}$ & $1 \mathrm{E}+10$ & - & $a$ & $a$ & $\mathbf{a}$ \\
\hline$c-14$ & $\mathrm{NL}^{\mathrm{b}}$ & $5 E+03$ & - & 0.08 & $a$ & $a$ \\
\hline
\end{tabular}

a No variation in values caused equal concentrations.

b Arrival time at the performance boundary is greater than $10,000 \mathrm{y}$. 
Table 15-10. Variation of $K_{d}$ Values for the Geologic Media at Pantex (tumulus design) (a $K_{d}$ value of $0.2 \mathrm{~mL} / \mathrm{g}$ caused radionuclide arrival at the performance boundary equal to $10,000 \mathrm{y})$

\begin{tabular}{|c|c|c|c|c|c|}
\hline $\begin{array}{l}\text { Indicator } \\
\text { Nuclide }\end{array}$ & $\begin{array}{c}P E \\
K_{d} \\
(m \cup g)\end{array}$ & $\begin{array}{c}\text { PE } \\
C_{W \text {-Water }}\end{array}$ & $\begin{array}{l}\text { PE } \\
C_{W-\ln t}\end{array}$ & $\begin{array}{c}\text { PE } \\
C_{W \text {-ntre }} \\
C_{W \text {-Water }}\end{array}$ & $\begin{array}{l}K_{d} \text { Value That } \\
\text { Caused Equal } \\
\text { Concentrations }\end{array}$ \\
\hline ST-90 & 2 & NL & $5 E+04$ & - & c \\
\hline Cs-137 & 20 & $\mathrm{NL}^{\mathrm{b}}$ & $8 E+05$ & - & c \\
\hline$U-238$ & 1000 & $2 E+03^{b}$ & $5 E+03$ & 2.5 & $c, d$ \\
\hline Pu-239 & 2000 & $\mathrm{NL}^{\mathrm{b}}$ & $6 E+03$ & - & $8^{b, d}$ \\
\hline $\begin{aligned} A m-241 \\
(\mathrm{~Np}-237)^{\circ}\end{aligned}$ & $\begin{array}{c}1900 \\
(5)\end{array}$ & $6 E+05^{b, f}$ & $9 E+03$ & 0.011 & 2 \\
\hline
\end{tabular}

a "NL" means No Limit - the estimated permissible waste concentration is greater than the specific activity of the pure elemental radionuclide.

b Arrival time at the performance boundary is greater than $10,000 \mathrm{y}$.

c No variation in value caused equal concentrations.

d A value less than $0.2 \mathrm{~mL} / g$ would cause arrival at the performance boundary before $10,000 \mathrm{y}$, which changes the limiting pathway.

e The dominant decay product for Am-241

f Concentration determined by Np-237 (see Appendix E in Volume 2)

" Value could not be calculated.

\subsubsection{Physical Constraints on Sensitivity Analysis Values}

The PE results for Pantex are based on parameter values provided by the Pantex technical staff for site-specific parameters used in calculations. Descriptions and technical justifications of these values are provided in Sections 15.3 and 15.4. The range and statistical distributions may not be known for each input parameter values; however, site-specific knowledge can be used to determine whether the values determined in the sensitivity analysis are reasonable and physically possible at Pantex.

\section{Natural Recharge}

The sensitivity analysis results indicate it was possible to change the limiting pathway for C-14 and Am-241 by changing the natural recharge. The values for recharge estimated in the sensitivity analysis range from 0.09 to $0.70 \mathrm{~m} / \mathrm{y}(0.3$ to $2.3 \mathrm{ft} / \mathrm{y}$ ) (Table $15-9 \mathrm{a}$ and $\mathrm{b}$ ) compared to the $P E$ value of $0.006 \mathrm{~m} / \mathrm{y}(0.02 \mathrm{ft} / \mathrm{y})$. The natural recharge at Pantex is unknown, although average recharge including playa and inter-playa regions is estimated at $0.011 \mathrm{~m} / \mathrm{y}(0.036 \mathrm{ft} / \mathrm{y})$. The sensitivity analysis values for Am-241 (Table 15-9a) and C-14 (Table 15-9b) are well above this value. The remaining indicator radionuclides either could not change the limiting pathway with changes in recharge $(\mathrm{H}-3, \mathrm{Sr}-90$, and $\mathrm{Cs}-137)$ or arrived at the performance boundary beyond $10,000 \mathrm{y}$. 


\section{Groundwater Darcy Velocity}

The sensitivity analysis results indicate it is possible to change the limiting pathway for Tc-99, U-238, and Am-241 by changing the groundwater velocity. The values for the groundwater Darcy velocity estimated by the sensitivity analysis vary from 0.04 to $19 \mathrm{~m} / \mathrm{y}(0.13$ to $62 \mathrm{ft} / \mathrm{y}$ ) (Table 15-9a) compared to the PE value of $6 \mathrm{~m} / \mathrm{y}(20 \mathrm{ft} / \mathrm{y})$. However, the arrival time at the performance boundary is beyond $10,000 \mathrm{y}$ for all these radionuclides.

\section{Facility Area}

The sensitivity analysis results indicate it was possible to change the limiting pathway for Tc-99, U-238, and Am-241 by changing the facility size. The value for the facility area estimated in the sensitivity analysis ranged from $250 \mathrm{~m}^{2}\left(2700 \mathrm{ft}^{2}\right)$ to $4 \times 10^{7} \mathrm{~m}^{2}\left(4 \times 10^{8} \mathrm{ft}^{2}\right)$ (Table 15-9a). All of these values are possible because there are no particular physical constraints which limit the size of an MWDF at Pantex. However, U-238 and Am-241 arrived at the performance boundary beyond $10,000 \mathrm{y}$, and for Tc-99, a facility limited in plan view area to $250 \mathrm{~m}^{2}\left(2700 \mathrm{ft}^{2}\right.$ ) (about 14 $\mathrm{m}$ by $14 \mathrm{~m}$ [ $46 \mathrm{ft}$ by $46 \mathrm{ft}$ ] square) is probably not reasonable.

\section{Distribution Coefficients}

The results shown in Table 15-10 indicate that it was not possible to change the limiting exposure pathway by changing the $K_{d}$. The radionuclide $\mathrm{Pu}-239$ was the most sensitive of the indicator radionuclides; it was possible to change the limiting pathway from intruder to water when its $K_{d}$ was changed to $0.2 \mathrm{~mL} / \mathrm{g}$ (the $K_{d}$ required to cause arrival at the performance boundary at $10,000 \mathrm{y}$ ). This is probably not a reasonable value; $\mathrm{Pu}-239$ had a $\mathrm{PE}$ value of $550 \mathrm{~mL} / \mathrm{g}$ at Pantex.

\subsection{OBSERVATIONS}

Based on the results of the PE and the parameter-sensitivity analysis, the following observations can be made about MLLW disposal at Pantex:

- Pantex Plant has characteristics of an arid climate. The average recharge is low and the depth to the regional water table is relatively large. Thus, the slow contaminant migration rate through the vadose zone and the large depth to groundwater result in long travel times to the performance boundary via the water pathway.

- For Pantex Plant, the results indicate that of the 58 radionuclides evaluated in the PE, 56 radionuclides for both the trench and tumulus designs would be limited by the intrusion scenarios. These results reflect the dominant role of the selected human intrusion scenarios that is demonstrated for almost all the sites considered in the PE (see Sections 7.5 and 7.6 in Volume 2). This dominance indicates a need to be aware of the inability to predict the social behavior of populations far into the future.

The results also indicate that for the water pathway, 56 radionuclides for both the trench and tumulus designs would arrive at the performance boundary after the 10,000-y period of consideration in the PE analysis of the water pathway. The primary reason for these arrival times is the small recharge at Pantex Plant and the large distance in the unsaturated 
zone between the fine-grained zone and the regional water table aquifer. Of the radionuclides that would arrive before $10,000 \mathrm{y}$, one had no limit on waste concentration.

Because Pantex Plant has many radionuclides that either are limited by the intrusion scenarios, arrive at the performance boundary after $10,000 \mathrm{y}$, or have no limit on waste concentration, this site may have flexibility in accepting a variety of radionuclides for disposal.

- Either a trench or tumulus facility design may be feasible for disposal of MLLW at Pantex Plant. The site has a low natural water recharge and a large thickness of unsaturated zone between a trench disposal facility and the aquifer.

- Pantex Plant has few surface physical constraints that could limit disposal activities. The principal criteria that might limit the siting of an MWDF would be the location of existing facilities and of playa lakes on the site. An MWDF would likely not be located in or near a playa as it might be susceptible to flooding. Moreover, the playa lakes are believed to function as regions of high recharge so that radionuclides released in their vicinity would reach the performance boundary much more rapidly than predicted in the $\mathrm{PE}$ analysis.

- The sensitivity analysis for Pantex Plant indicates that reasonable changes in values for the natural recharge, groundwater Darcy velocity, and facility size for most radionuclides would not significantly change the results. For Tc-99, reducing the natural recharge by one-third could affect the results (i.e., change the limiting pathway).

In flow and transport problems, the $K_{d}$ values are often the most uncertain site-specific input parameters. However, according to the results of the sensitivity analysis, none of the $K_{d}$ values for the 5 indicator radionuclides have sufficient uncertainty to change the limiting pathway.

- The PE did not consider the possible presence of preferential flow paths in the unsaturated zone at Pantex that may facilitate contaminant transport through the vadose zone. A more thorough evaluation of this mechanism should be conducted if a performance assessment is performed.

Likewise, the PE did not consider the impact that a possible perched water zone might have on a potential waste disposal facility at Pantex. One scenario that should be evaluated if a performance assessment is performed would involve contaminant transport through the vadose zone to the perched water table and horizontal transport in the perched water zone beyond the plant boundaries, followed by vertical flow into the underlying Ogallala aquifer through an improperly constructed private well. This scenario may be important because the Ogallala aquifer underlies the Pantex Plant and is a major source of water supply for potable and agricultural uses in the region. The city of Amarillo has an important well field within two miles of Pantex which draws water from this formation. 
- The PE was a scoping analysis performed using assumptions that are conservative relative to most LLW performance assessments. There are no site-specific studies to compare with the PE results. A more detailed performance assessment would be required for permitting or other disposal planning.

\subsection{REFERENCES}

Aggarwal, P., (1995). Personal communication, Argonne National Laboratory, Chicago, IL.

Baer, T.A., L. L. Price, J. N. Emery, N. E. Olague, 1994. Second Performance Assessment Iteration of the Greater Confinement Disposal Facility at the Nevada Test Site. SAND930089. Albuquerque, NM: Sandia National Laboratories.

Battelle Columbus, (1995). Environmental Information Document, Draft-Revision 2. Columbus, $\mathrm{OH}$.

Battelle Pantex, (1994a). Fate and Transport Integration Study for Pantex Plant and Vicinity, Draft Report. Amarillo, TX: Environmental Restoration Department.

Battelle Pantex, (1994b). Corrective Action Management Unit Overall Plan, Draft Report. Amarillo, TX: Environmental Restoration Department.

Cooper, C.D., and F.C. Alley, 1986. Air Pollution Control: A Design Approach. Prospect Heights, IL: Waveland Press, Inc.

CRC, 1981. CRC Handbook of Chemistry and Physics. Eds. Robert C. Weast and Melvin J. Astle. Boca Raton, FL: CRC Press, Inc.

EPA (Environmental Protection Agency), 1992. Clean Air Act Assessment Package - 1988. CAP88-PC, Version 1.00. Washington, DC: U.S. Environmental Protection Agency.

FFCAct, 1992. Federal Facility Compliance Act of 1992. P.L. 102-386, October 1992.

Gruebel, M.M., R.D. Waters, M.B. Hospelhorn, and M.S.Y. Chu, eds., 1994. Framework for DOE Low-Level and Mixed Low-Level Waste Disposal: Site Fact Sheets. SAND94-2728. Albuquerque, NM: Sandia National Laboratories.

Kincaid, C.T., J.W. Shade, G.A. Whyatt, M.G. Piepho, K. Rhoads, J.A. Voogd, J.H. Westsik, Jr., M.D. Freshley, K.A. Blanchard, and B.G. Lauzon, eds., 1993. Performance Assessment of Grouted Double-Shell Tank Waste Disposal at Hanford. WHC-SD-WM-EE-004, Rev. 0. U.S. Department of Energy, Pacific Northwest Laboratory and Westinghouse Hanford Co.

M\&H, (1994). 1993 Environmental Report for Pantex Plant. DOE/AL/65030-9413. Amarillo, TX: prepared for US DOE Albuquerque Operations Office. 
Maheras, Steven J., Arthur S. Rood, Swen O. Magnuson, Mary E. Sussman, and Rajiv N. Bhatt, 1994. Radioactive Waste Management Complex Low-Level Waste Radiological Performance Assessment. EGG-WM-8773. Idaho Falls, ID: U.S. Department of Energy Office of Environmental Restoration and Waste Management, DOE Idaho Operations Office.

MMES (Martin Marietta Energy Systems), EG\&G Idaho, Inc., and Westinghouse Savannah River Company, 1994. Radiological Performance Assessment for the E-Area Vaults Disposal Facility (U). WSRC-RP-94-218, Rev. 0. Aiken, SC: Westinghouse Savannah River Company.

Nativ, R., (1988). Hydrogeology and Hydrochemistry of the Ogallala Aquifer, Southern High Plains, Texas Panhandle and Eastern New Mexico. Report of Investigations No. 177. Austin, TX: Bureau of Economic Geology, University of Texas at Austin.

ORNL (Oak Ridge National Laboratory), 1994. Performance Assessment for Continuing and Future Operations at Solid Waste Storage Area 6. ORNL-6783. Oak Ridge, TN: U.S. Department of Energy, Oak Ridge National Laboratory.

Scanlon, B., Goldsmith, R., Coker, D., Liao, J., He, L., (1995). "Unsaturated Zone Hydrology," presentation at Geologic Information Meeting, Pantex Plant, Feb. 7, 1995.

Thibault, D.H., M.I. Sheppard, and P.A. Smith, 1990. A Critical Compilation and Review of Default Soil Solid/Liquid Partition Coefficients, $K_{d}$, for Use in Environmental Assessments. AECL-10125. Pinawa, Manitoba, Canada: Whiteshell Nuclear Research Establishment, Atomic Energy of Canada Limited.

Triebel, D.F., Ferguson, D.J., Loucks, V., Gabert, G.W., Tilton, L.D., 1994. Interim Guidance Document for Pantex Plant Playas. Amarillo, TX: Prepared by DOE, AAO Playa Vicinity Land Management Team.

US DOE, (1995). Pantex Plant, Federal Facility Compliance Act, Proposed Site Treatment Plan/Compliance Plan, Draft Report. Amarillo, TX: US DOE Environmental Restoration Department.

Wood, W.W., Sanford, W.E., (1995). "Chemical and Isotopic Methods for Quantifying GroundWater Recharge in a Regional, Semiarid Environment." Ground Water, Vol. 33, pp. 458-468.

\section{Acknowledgments}

The SNL Core Team acknowledges the contributions of Dan Ferguson and Johnnie Guelker (U.S. DOE Pantex), Terry Gibson (Battelle Pantex), and Pradeep Aggarwal (Argonne National Laboratory). 


\section{Washington: HANFORD SITE Core Team Contact: Gregory P. Zimmerman}

The Federal Facility Compliance Act (FFCAct, 1992) requires the Department of Energy (DOE) to establish plans in conjunction with its regulators and with members of the public for the treatment of DOE's mixed low-level waste (MLLW). Although the FFCAct did not specifically address disposal of treated MLLW, both DOE and the States recognized that disposal issues were an integral part of treatment discussions. Since 1992, DOE has worked with the States to define and develop an evaluation process for disposal options. Preliminary activities of this joint DOEState process have narrowed the sites for further evaluation from 49 to 15.

The Disposal Workgroup (DWG), which was established by DOE to develop a process for evaluating disposal options, designed a performance evaluation (PE) to quantify and compare the limitations of the remaining $15 \mathrm{DOE}$ sites for MLLW disposal. The principal goal of the PE was to estimate, for grouted residuals resulting from the treatment of MLLW, permissible concentrations of radionuclides in waste for disposal at each site. These "permissible waste concentrations" were based solely on long-term physical performance of the disposal facility and did not take into account any operational waste acceptance criteria that a site might have developed. The PE did not address any ethical, social, or policy considerations relevant to siting such facilities.

The PE used analyses that are consistent with the approach used in many low-level waste (LLW) performance assessments. The objective was to use a set of modeling assumptions of sufficient detail to capture major site-specific characteristics and yet be general enough for consistent application at all sites. Additionally, the analyses were designed to ensure that the sites were analyzed consistently and that all major assumptions were clearly stated.

The remainder of this chapter provides the PE results for the Hanford Site, one of the 15 sites being evaluated. The chapter contains the following information:

Section 16.1: brief, general description of the site, based on previous work done by the DWG (Gruebel et al., 1994)

Section 16.2: plans for MLLW disposal, if any, and the location evaluated in the PE

Section 16.3: current understanding of radionuclide movement at the selected location based on available information, and the conceptual model used for the evaluation of each of three pathways (water, atmospheric, and inadvertent intruder)

Section 16.4: site-specific and generic values used in the PE calculations and their sources

Section 16.5: estimates of maximum waste concentrations determined in the PE calculations for each of the three pathways, along with calculated values used in determining these results

Section 16.6: summary of results based on disposal-facility design; discussion with respect to such issues as uncertainty and sensitivity 
Section 16.7: observations based on the results of the PE and the parameter sensitivity analysis

Section 16.8: references

The general assumptions and methodology used in the PE are summarized in Chapter 1 of this volume and explained in more detail in Volume 2 of this report. Overall results for all the sites are discussed in Chapter 7 of Volume 2.

\subsection{GENERAL DESCRIPTION OF THE SITE}

The Hanford Site is located in the southeast corner of Washington State (Figure 16-1) and is situated in a structural and topographic depression of the Columbia Plateau known as the Pasco Basin. The northern and eastern boundaries of the site generally follow the Columbia River. The western boundary of the site is generally bounded by the Rattlesnake Hills, and the southern boundary by the Yakima River. The Hanford Site covers approximately $1,450 \mathrm{~km}^{2}\left(560 \mathrm{mi}^{2}\right)$ of treeless, semiarid land (Figure 16-2). With the exception of a few natural basalt hills, the site is relatively flat.

Key facilities of interest at the Hanford Site are eight reactor facilities located along the Columbia River in the 100 Area and reactor fuel processing and waste management facilities (including the waste burial grounds) located in the 200 Areas, which lie on a plateau approximately $11 \mathrm{~km}(7 \mathrm{mi})$ from the Columbia River.

The nearest population center consists of three small cities (Richland, Kennewick, and Pasco) situated on the Columbia River to the southeast of the Hanford site. Richland (population $34,000)$ is approximately $35 \mathrm{~km}(22 \mathrm{mi})$ from the existing waste management activities in the 200 West Area, which is on the 200 Area Plateau. Estimated population within a 50-km (31-mi) radius from the approximate centroid of the 200 Area plateau is 230,000 .

In early 1943, the U.S. Army Corps of Engineers selected the Hanford Site as the location for reactor, chemical separation, and related facilities and activities for the production and purification of plutonium. The Hanford mission is to clean up the Hanford Site, eliminate potential risks to the public and site workers, and serve as the DOE model in environmental restoration. The Hanford Site is owned by the U.S. Government and managed by the DOE-RL.

The climate at the Hanford Site is characterized by relatively cool, mild winters and warm summers. Average maximum and minimum temperatures for January, the coldest month, are $3^{\circ} \mathrm{C}$ and $-6^{\circ} \mathrm{C}\left(37^{\circ} \mathrm{F}\right.$ and $\left.22^{\circ} \mathrm{F}\right)$, respectively. For July, the warmest month, average maximum and minimum temperatures are $33^{\circ} \mathrm{C}$ and $16^{\circ} \mathrm{C}\left(91^{\circ} \mathrm{F}\right.$ and $\left.61^{\circ} \mathrm{F}\right)$, respectively. Average annual rainfall is about $16 \mathrm{~cm}$ (6.3 in.), which supports the site vegetation of mainly sagebrush and cheatgrass. Average wind speeds are about 10 to $15 \mathrm{~km} / \mathrm{hr}$ ( 6 to $9 \mathrm{mph}$ ), but periods of infrequent high winds of up to $128 \mathrm{~km} / \mathrm{hr}(80 \mathrm{mph})$ are possible. Prevailing wind directions are from the northwest in all months with secondary maxima from the southwest. 


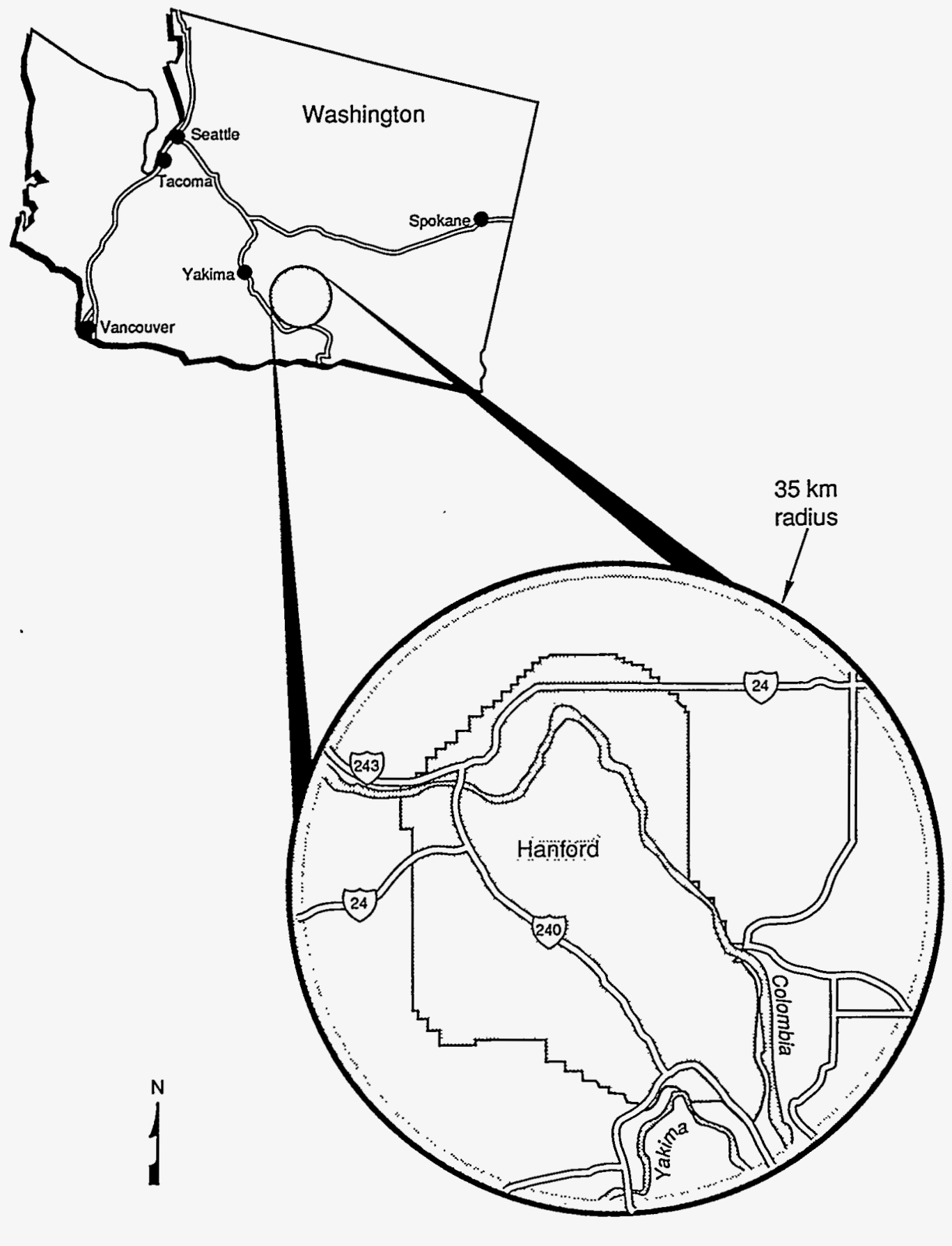

TA1-6622-1-0

Figure 16-1. Location map for the Hanford Site. 


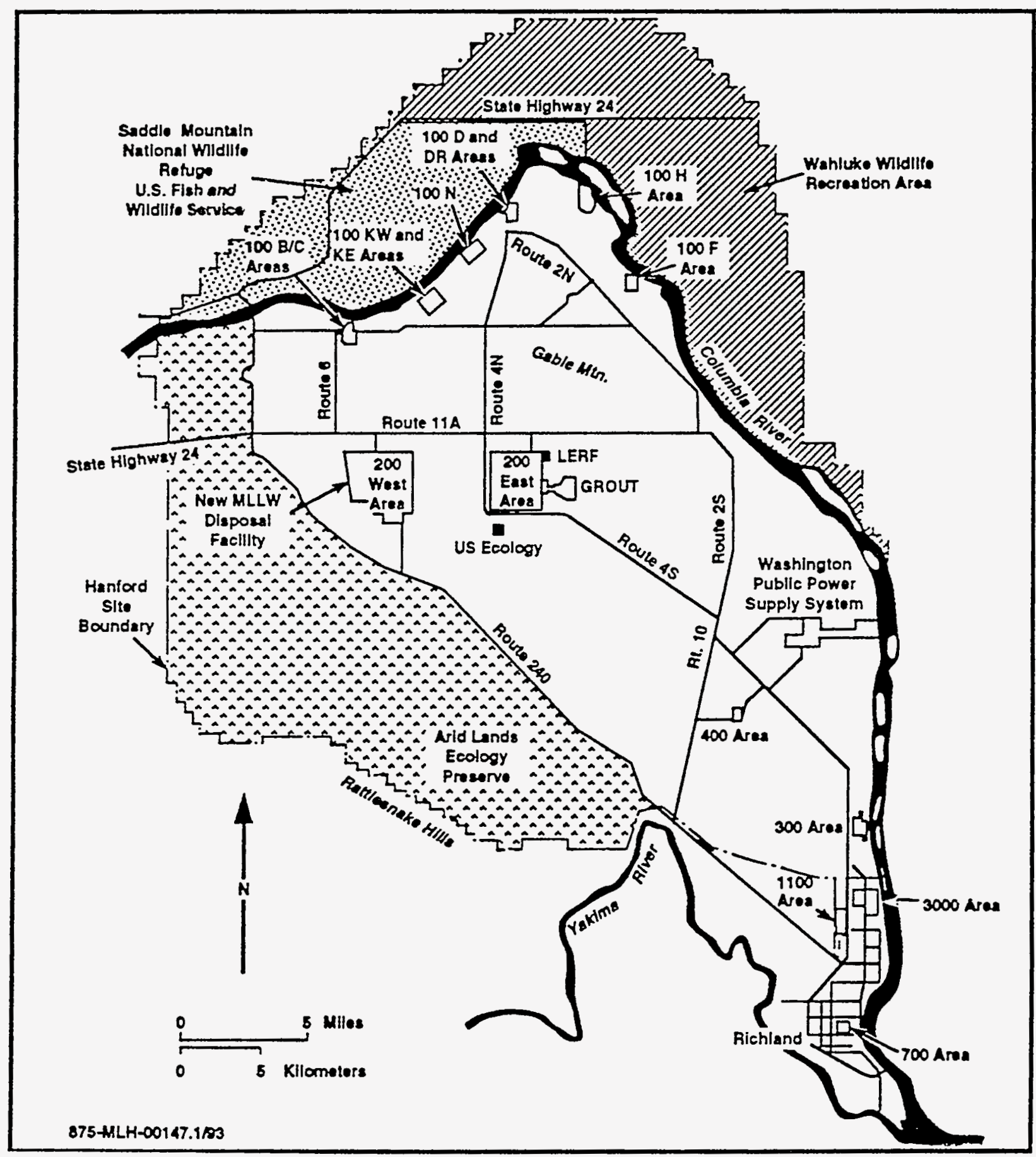

Figure 16-2. Site map for the Hanford Site. 
The dominant geologic features of the Hanford Site include the Columbia River, sand dunes located near the Columbia River, and the Basaltic Ridges, including the Rattlesnake Hills that rise to an elevation of greater than $1100 \mathrm{~m}$ (3600 ft). The principal soils and geologic formations below the Hanford burial grounds comprise an alluvial plain that consists of interbedded sediments of sands and gravels approximately 60 to $90 \mathrm{~m}$ ( 200 to $300 \mathrm{ft}$ ) deep deposited approximately 13,000 y ago. The elevation of this alluvial plain in the 200 Areas ranges from 190 to $245 \mathrm{~m}$ ( 620 to $800 \mathrm{ft}$ ) above mean sea level. This alluvial plain is supported by

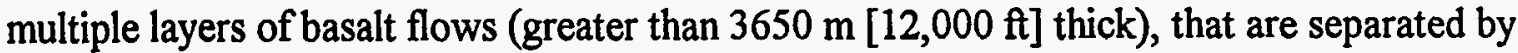
interbeds of silts, sands, and gravels (Hanford and Ringold Formations). These basalt flows are estimated to range in age from 17 to 6 million years old.

Surface waters within the Hanford Site includes the Columbia River, which flows through the northern part of the site and along the eastern boundary, small ponds and ditches from on-site process plants, and natural runoff. Water from the ponds, ditches, and natural runoff does not reach the Columbia River, due to evapotranspiration and percolation into the natural alluvium.

Groundwater under the site occurs under unconfined and confined conditions. The unconfined aquifer is contained within the interbedded sediments of sands and gravels above the multiple basalt flows, with the bottom of this aquifer being the top surface of the basalt. Sources of natural recharge to the unconfined aquifer are rainfall and runoff from the higher bordering elevations, water infiltrating from small ephemeral streams, and influent river water. Groundwater contamination plumes, in excess of drinking water standards, of tritium, uranium, nitrate, and carbon tetrachloride exist on the Hanford Site. The top of the water table (unconfined aquifer) in the 200 Areas ranges from 56 to $100 \mathrm{~m}$ (184 to $328 \mathrm{ft}$ ) beneath the ground surface. The flow direction of this aquifer generally is to the east and southeast toward the Columbia River.

The confined aquifer is located between the basalt layers within the interbeds of sands and gravels. The main water bearing portions of the interbed zones occur within a network of interconnecting vesicles of the flow tops or bottoms. The confined aquifer is not known to be contaminated as a result of past Hanford activities. The Low Level Burial Grounds are not located over an EPA-designated sole source aquifer.

\subsection{STATUS AND SITING OF MLLW DISPOSAL FACILITY}

At the time of the PE, personnel at the Hanford Site were planning for on-site disposal of MLLW. Shallow land disposal of solid waste has occurred at the Hanford Site since the late 1940 s, and the Hanford Site still has active LLW disposal facilities. Historically, disposal of other LLW has occurred at Hanford. On-site disposal of MLLW is not currently permitted; storage of nonremote-handled mixed waste in above-ground buildings is the current practice. Two types of mixed waste typically considered for disposal in the pre-1987 trenches are remote-handled mixed waste (with exposures of greater than $200 \mathrm{mrem} / \mathrm{hr}$ at the container surface) and special waste. This special waste includes unique waste that requires special handling or unusual waste, such as decommissioned reactor vessels. 
Mixed waste disposal is planned for the Hanford Site using two trenches at the southern end of the W-5 Burial Ground in the 200 West Area Burial Grounds. A RCRA-compliant disposal facility for solid MLLW is under construction, with operations planned to start in Fiscal Year 1995. These new Radioactive Mixed Waste Land Disposal Facility (RMWLDF) trenches are located in Burial 218-W-5, identified on the map of the 200 West Area Burial Ground (Figure 16-3). Although an analysis specific to the RMWLDF is not contained in the performance assessment for the 200 West Area Burial Grounds (Wood et al., 1994), the RMWLDF is included as part of the larger 200 West Area. The elevation of the burial grounds in the 200 West Area is about $225 \mathrm{~m}(740 \mathrm{ft})$ above mean sea level. The MLLW disposal facility (namely the RMWLDF) to be located in the 200 West Area was chosen for evaluation in the PE.

Two generic disposal facilities were considered in the PE: a RCRA-compliant, belowground trench and a RCRA-compliant, above-ground tumulus (described in more detail in Chapter 5 of Volume 2). The generic facilities were selected to provide consistency in analysis of the performance of the 15 sites. Both generic facilities were assumed to be square with a plan area of $2500 \mathrm{~m}^{2}\left(26,910 \mathrm{ft}^{2}\right)$.

\subsection{BASIS FOR CONCEPTUAL MODEL USED IN THE PE}

The current understanding of radionuclide transport from a disposal facility at Hanford is based on referenced sources of information contained in the performance assessment (Wood et al., 1994) for the 200 West Area Burial Grounds, which are currently in operation for disposal of LLW. The descriptions below summarize how this information was incorporated into the PE's conceptual model for Hanford.

\subsubsection{Water Pathway}

Knowledge of groundwater flow and radionuclide movement via the water pathway at Hanford provided the basis for the conceptual model considered in the PE. The conceptual model encompasses the site technical staff's current understanding of site-specific geology, hydrology, water table and aquifer characteristics, and transport pathways. The current understanding of radionuclide movement is based upon referenced sources of information contained in the performance assessment (Wood et al., 1994) for Hanford's 200 West Area burial grounds.

\subsubsection{Current Understanding of Revelant Hydrogeology}

The 200 West Area is underlain by a generally flat-lying sedimentary sequence about $200 \mathrm{~m}(650 \mathrm{ft})$ in thickness over basalt flows typical of the Columbia Plateau (Figure 16-4). The uppermost basalt flow is overlain by the Ringold Formation, which is subdivided into Basal, Lower, Middle, and Upper units, with the water table appearing in the Middle Ringold at a depth of about $70 \mathrm{~m}(230 \mathrm{ft})$. Overlying the Ringold are a cemented Plio-Pleistocene Unit, an Early "Palouse" Soil Unit, the flood deposits of the Hanford Formation, and surficial Holocene eolian deposits. Recharge to the unconfined aquifer occurs in the hills west of the 200 West Area, and groundwater flow is generally to the east, toward the Columbia River. Very little recharge (0 to $0.05 \mathrm{~m} / \mathrm{y}$ [0 to $0.16 \mathrm{ft} / \mathrm{y}$ ) is attributed to natural infiltration at the 200 West Area, since most precipitation is lost to evapotranspiration (Wood et al., 1994). 


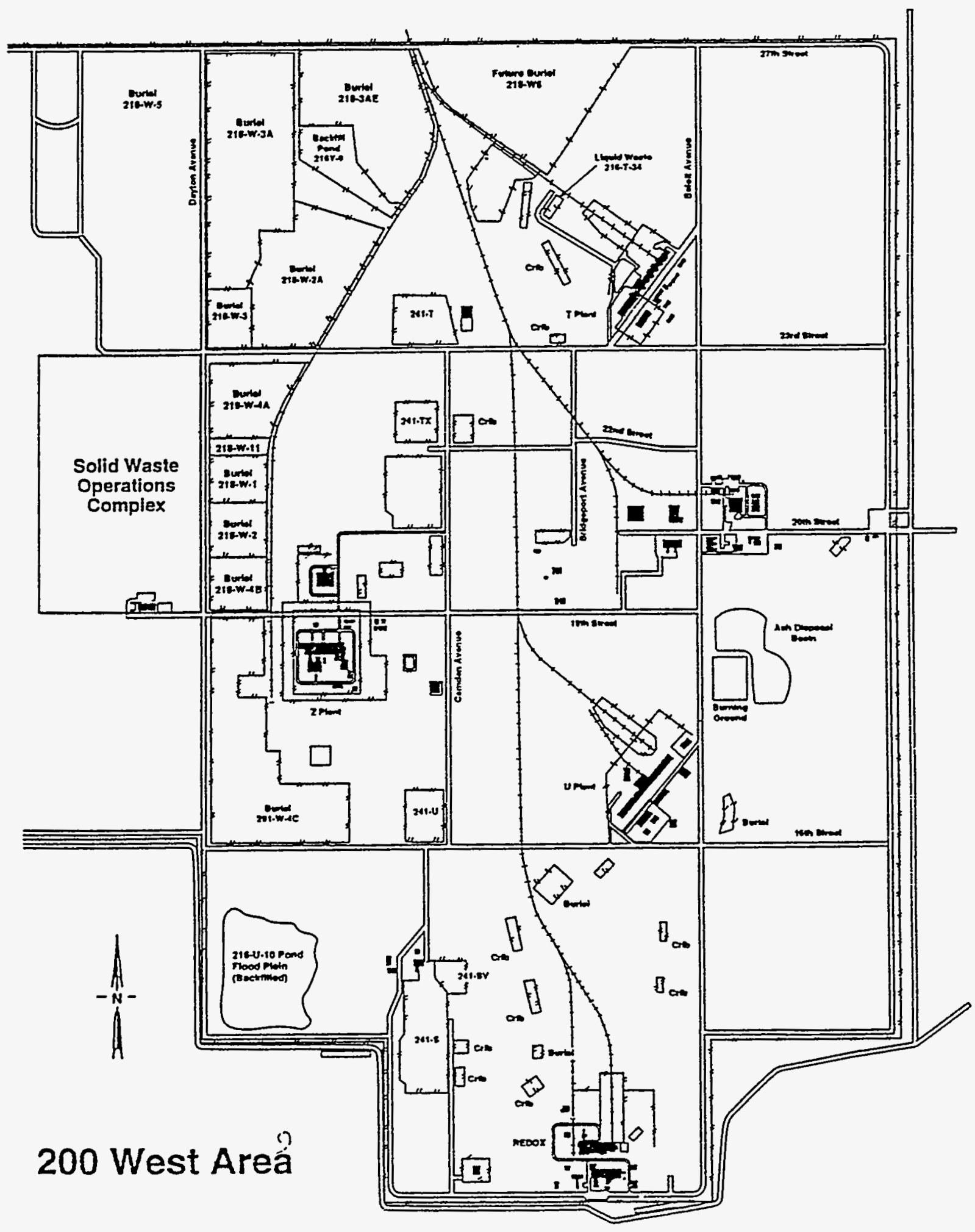

875-4LLH-00200.398

Figure 16-3. Location of the proposed Radioactive Mixed Waste Land Disposal Facility (RMWLDF) within the 200 West Area at the Hanford Site. The RMWLDF is at the southern end of Burial 218-W-5, located in the northwestern corner of the 200 West Area. 


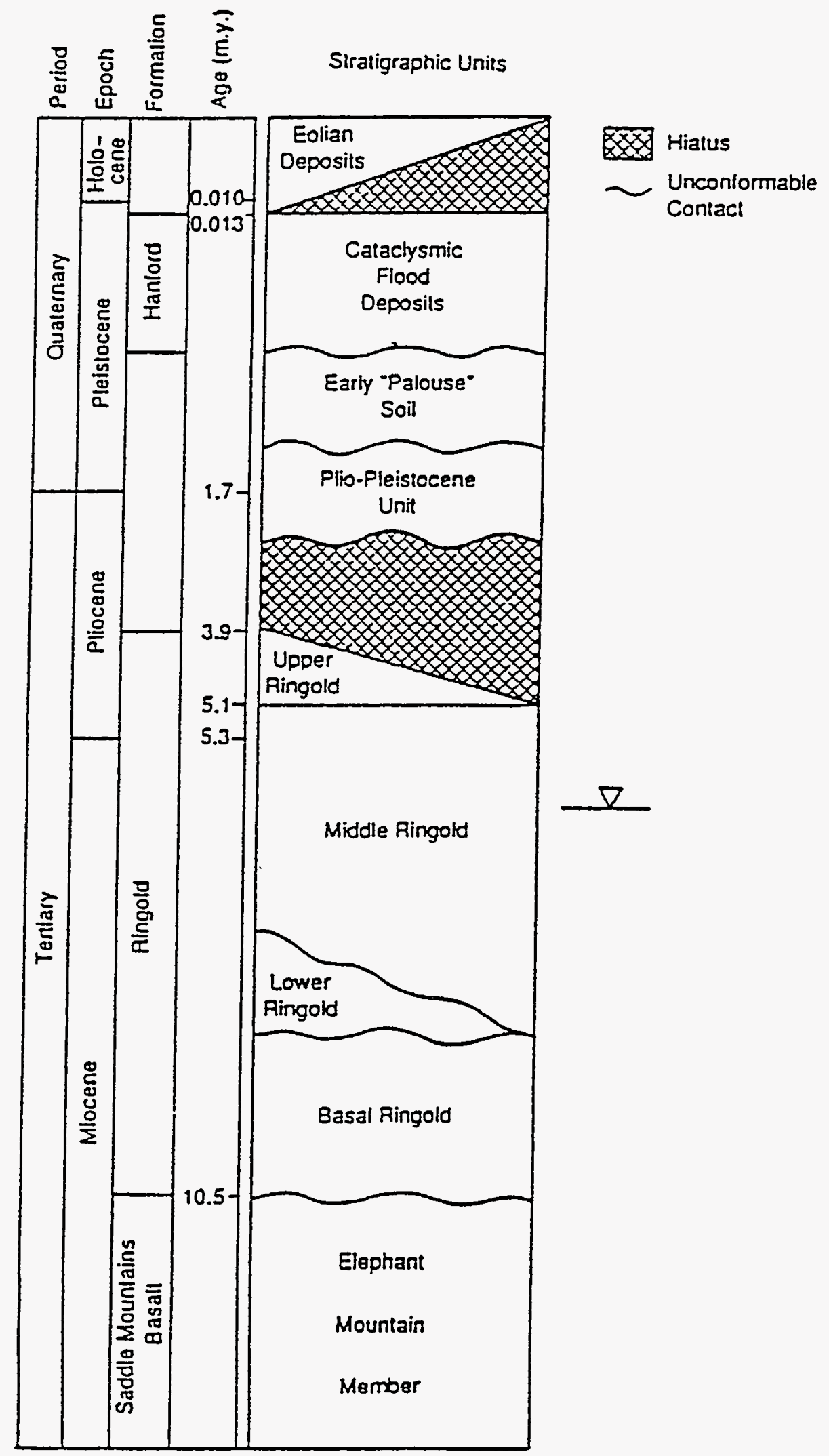

Figure 16-4. Stratigraphic chart for the 200 West Area (Wood et al., 1994). 


\subsubsection{Conceptual Model Used in the PE}

The PE used a generic conceptual model to describe the water pathway (summarized in Section 1.1.2 of this volume and described in detail in Chapter 5 of Volume 2). In the unsaturated zone, leachate was generated by constant flow of water through the disposal facility at a rate that was controlled by the assumed performance of the disposal facility. When all engineered barriers had failed, the rate was assumed to be equal to the natural recharge through local soils. The volumetric flow of water through the facility that generated leachate was based on the assumed performance and size of the disposal facility. No dilution was assumed to occur in the unsaturated zone, so at steady state, the concentration that reached groundwater equaled the leachate concentration. No lateral spreading was assumed, so the leachate flux through the unsaturated zone was confined to the soil column directly below the plan area of the facility.

As contaminated water entered the saturated zone, the contaminant mixed with clean groundwater, forming a plume with a shape controlled by aquifer and contaminant properties. The generic conceptual model assumed that instantaneous and complete mixing within the aquifer occurred directly below the facility. Mixing in the vertical direction occurred by hydrodynamic dispersion, and the contaminant mixing depth was an estimated value.

The generic conceptual model was adapted to conditions at the Hanford Site based on site-specific knowledge of the geology and water flow paths. The following description represents the conceptual model of the water pathway that was used in the PE for the Hanford Site.

The conceptual model for the water pathway at the Hanford Site is illustrated in Figure 16-5. Environmental transport in the 200 West Area performance assessment is based on a simple conceptual model. Leachate moves through the unsaturated zone in one dimension, subject to advection and longitudinal and transverse dispersion, with dispersivities of $a_{L}=1.0 \mathrm{~m}$ and $a_{T}=0.1 \mathrm{~m}$ (Khaleel, 1995). For a transient source, this results in a roughly tenfold reduction of concentration through the vadose zone. For a continuous source, both the PE and performance assessment calculations show no reduction from either dilution with uncontaminated vadose zone waters or longitudinal dispersion. Once the contaminant reaches the water table, it mixes with uncontaminated groundwater and is transported downstream to the compliance well. Transport in the saturated zone is much faster than in the vadose zone, and accounts for only about $1 \%$ of the total travel time. Since the vertical dispersivity is very small, the plume is concentrated in the upper few meters of the aquifer.

\subsubsection{Atmospheric Pathway}

The conceptual model used in the PE for evaluating the atmospheric pathway was derived from performance assessments for LLW disposal facilities at Hanford (Kincaid et al., 1993), INEL (Maheras et al., 1994), NTS (Baer et al., 1994), ORR (ORNL, 1994), and SRS (MMES et al., 1994). The model was generalized for the PE but used site-specific values for many of the parameters. 


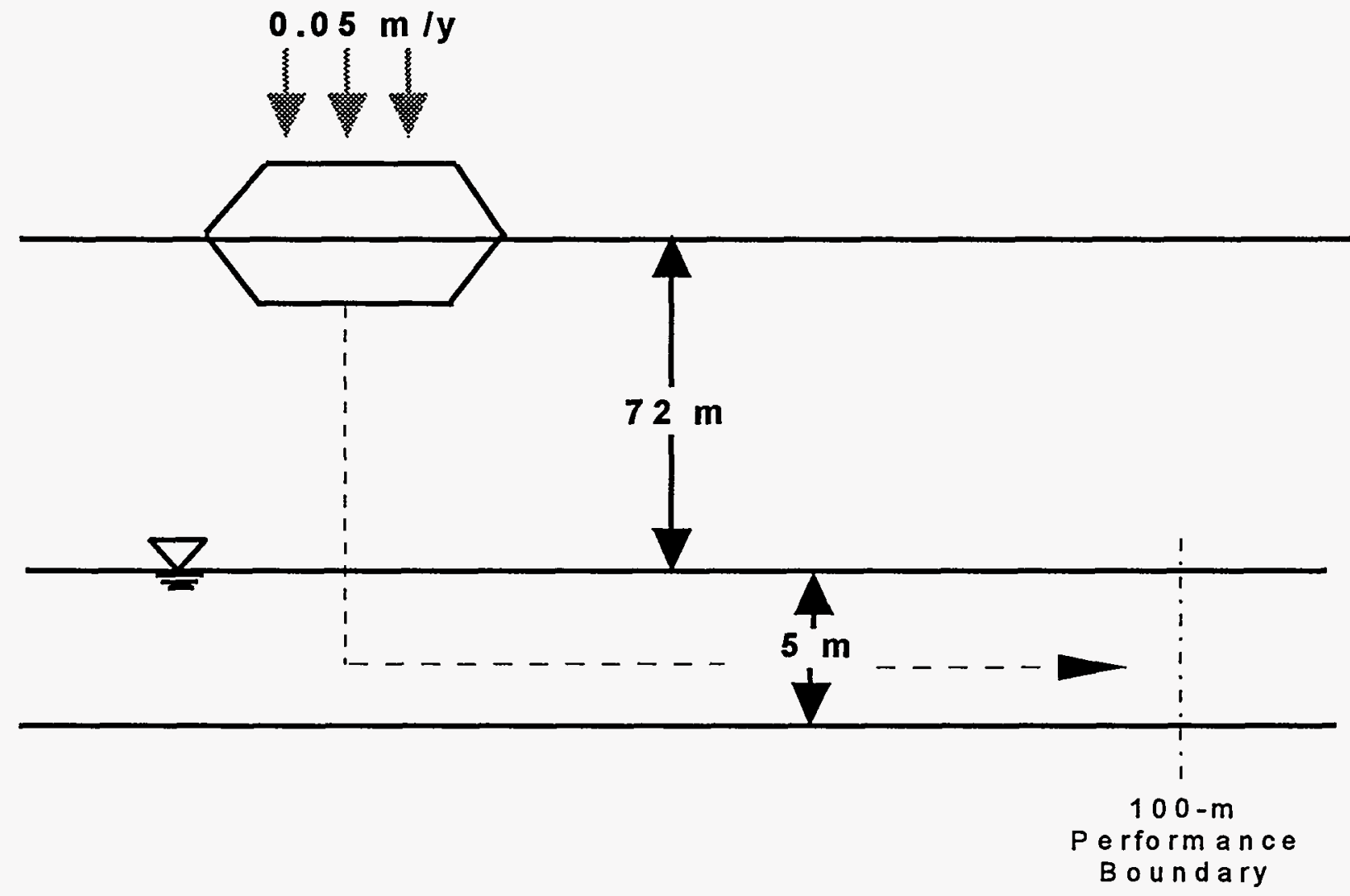

Figure 16-5. Conceptual model for water transport at the Hanford Site.

Meteorological data are based on STAR data files summarized by the windrose in Figure 16-6. These data were obtained from hourly average meteorological readings taken at a height of $10 \mathrm{~m}(33 \mathrm{ft})$ at the 200 West Area at Hanford during the period 1983 to 1991.

The PE used a generic conceptual model to describe the atmospheric pathway (summarized in Section 1.2 of this volume and described in detail in Chapter 5 of Volume 2). Only H-3 (tritium) and C-14 were expected to be volatile for the disposal facility conditions and thus were the only radionuclides considered for atmospheric transport in the PE. In the model, radionuclides were transported from the disposal facility to the soil surface by vapor (tritium) and gaseous (carbon dioxide carrying the $\mathrm{C}-14$ isotope) diffusion. When the radionuclides reached the soil surface, they were entrained in the air in vapor form as volatiles. Once airborne, these radionuclides were transported via atmospheric dispersion to a receptor located at the performance boundary.

Two components of the atmospheric pathway were evaluated separately: (1) the zone from the top of the disposal facility to the soil surface as indicated by the upward radionuclide diffusion profile; and (2) the zone in which a radionuclide was emitted to the atmosphere, mixed with the ambient air, and dispersed downwind from the waste disposal facility boundary to the 100-m (328-ft) performance boundary. 


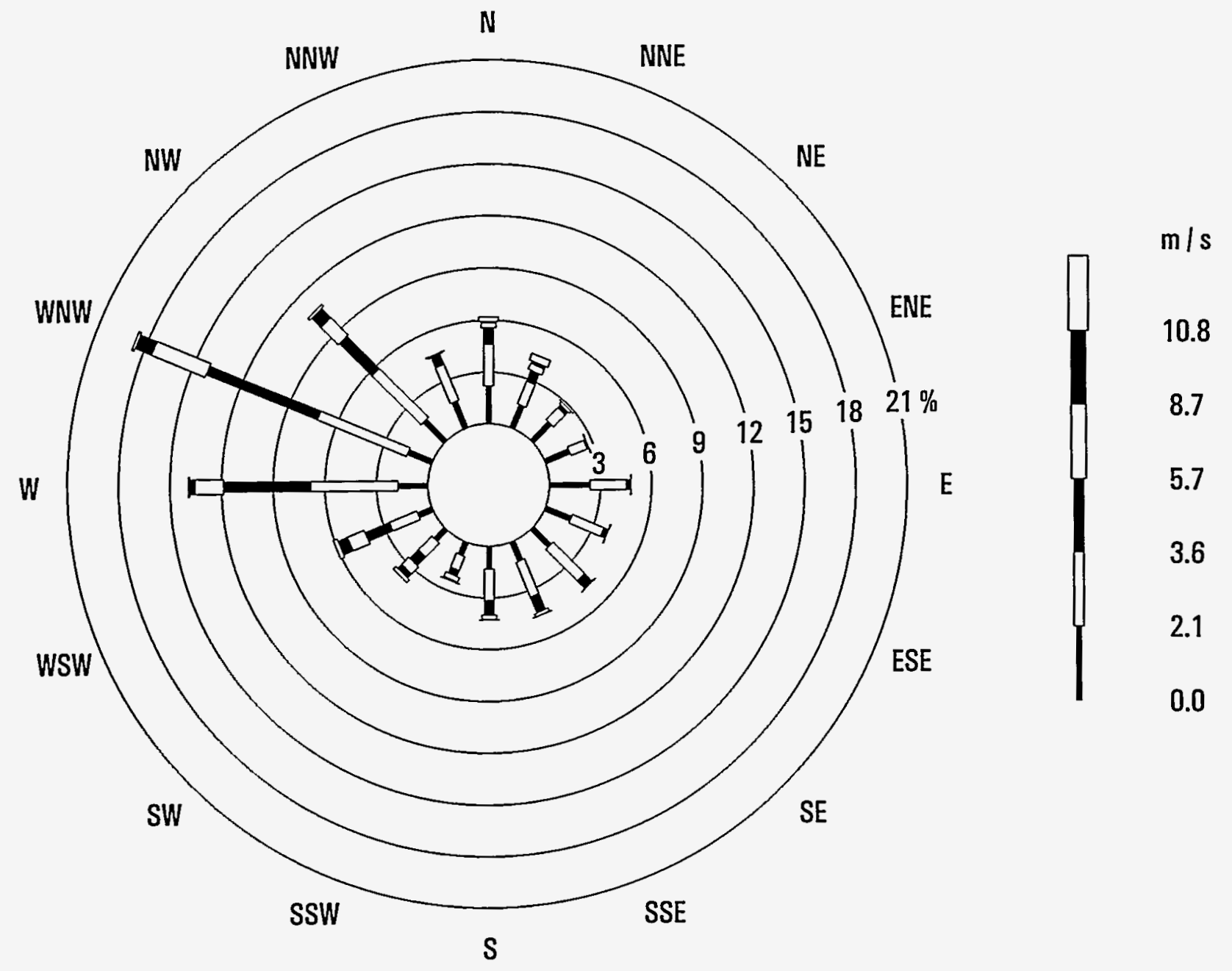

Figure 16-6. Windrose for Hanford for the period 1983 to 1991 . The frequency of winds from each direction is plotted as a series of connected bars that extend from the center of the circular diagram toward the direction from which the winds originate. Wind speed categories are denoted by bar widths and shadings. The frequency of winds in each wind speed category is indicated by the length of the corresponding bar. 
The arrival time of radionuclides at the performance boundary was assumed to be $100 \mathrm{y}$ based on the following generic assumptions of the PE:

- The waste form was grouted MLLW treatment residuals. Based on this assumption, tritium as vapor was bound in the pore water of the hydrophilic grout, and carbon dioxide as a gas carrying the $\mathrm{C}-14$ isotope was limited by the high $\mathrm{pH}$ of the grout, so that the waste form provided retention of these volatile radionuclides in the disposal facility.

- The disposal facility was capped by a RCRA-compliant cover system. Based on this assumption, the cover system was maintained to provide low permeability for $100 \mathrm{y}$.

\subsubsection{Inadvertent Intruder Pathways}

Standard intrusion scenarios were used in the PE, with information derived from performance assessments of LLW disposal facilities at SRS (MMES et al., 1994) and ORR (ORNL, 1994) indicating that only two chronic-exposure scenarios needed to be considered for most sites and facility designs. Any variations in these scenarios were based on discussions with site technical staff about such factors as the types of activities that reasonably could result in exposure to buried waste at the site and the effectiveness of active or passive institutional controls and engineered barriers in precluding access to the waste.

The PE used two standard intrusion scenarios that could be modified for site-specific conditions to describe potential modes of inadvertent intrusion (summarized in Section 1.3 of this volume and described in detail in Chapter 5 of Volume 2). The first scenario, the agriculture (homesteader) scenario, included establishment by an intruder of a permanent homestead directly above a disposal facility with the foundation of the home extending into the waste; some of the waste exhumed from the disposal facility was mixed with native soil in the intruder's vegetable garden. The second scenario, the post-drilling scenario, considered the construction of a well for a domestic water supply by an intruder. The well was drilled through the disposal facility, and the cuttings were mixed with soil in the intruder's vegetable garden. The intruder gardened in some of the exhumed waste but did not reside permanently above the disposal facility. In both scenarios, exposure occurred where an intruder dug or drilled into the disposal facility.

For the generic intruder scenarios, the time of intrusion for the homesteader scenario was assumed to be $300 \mathrm{y}$ for the trench design and $500 \mathrm{y}$ for the tumulus design. The time of intrusion for the post-drilling scenario was assumed to be $100 \mathrm{y}$.

The two intrusion scenarios were discussed with Hanford personnel, who concurred with the applicability and credibility of these scenarios at Hanford.

\subsection{DATA USED IN THE PE}

The data presented in this section apply to the PE conceptual models described in Section 16.3. The calculations for determining permissible waste concentrations for the radionuclides considered in the PE are discussed in more detail in Chapter 5 of Volume 2 and summarized in Chapter 1 of this volume. The results of the calculations for the Hanford Site are presented in Section 16.5 and discussed in Section 16.6 of this volume. 


\subsubsection{Water Transport}

Site-specific values required to perform the water pathway analysis were selected by site technical staff either from site characterizations and reports, from site-specific modeling results, or from general literature. For the unsaturated zone, the site-specific data that were required for the PE were distance between the disposal facility and groundwater; ambient moisture content; dry bulk density of the geologic medium; distribution coefficients $\left(K_{d} \mathrm{~s}\right)$ of the radionuclides in the geologic medium; and natural recharge. For the saturated zone, the site-specific data that were required were porosity; dry bulk density of the geologic medium; distribution coefficients $\left(K_{d} s\right)$ of the radionuclides in the geologic medium; groundwater Darcy flow rates; and mixing depth in the aquifer.

These values for the Hanford Site are listed in Table 16-1 along with generic values that were used in the PE. Also indicated in the table is a designation of the type of data that the value represents and the source of the value. The values were determined from one or more of four data sources: (A) measurement performed by the site, state, or federal agency; (B) result of a numerical analysis performed by the site, state, or federal agency; (C) general literature value selected by the site; and (D) generic value of the PE.

Of the parameters in the PE that depended on site-specific values, only three potentially encompassed enough variability in values to significantly affect the results: natural recharge, $i$; distribution coefficients $\left(K_{d} \mathrm{~s}\right)$ for the geologic media; and groundwater Darcy velocity $\left(q_{g w}\right)$. The sources of these values are discussed in this section. The sensitivity of the results to changes in the values of these parameters is discussed in Section 16.6.2 of this volume and Chapter 6 of Volume 2.

The unsaturated zone is represented with uniform properties based on guidance offered by site technical staff (Wood, 1995). Bulk density and volumetric water content have been adjusted within reasonable ranges to calibrated unsaturated zone travel times to those reported in the performance assessment.

The performance assessment for the 200 West Area Burial Grounds discusses estimates of natural recharge which vary from 0 to $0.1 \mathrm{~m} / \mathrm{y}$ ( 0 to $0.3 \mathrm{ft} / \mathrm{y}$ ) (Wood et al., 1994). The performance assessment uses a groundwater Darcy velocity of $22 \mathrm{~m} / \mathrm{y}(72 \mathrm{ft} / \mathrm{y})$ in its calculations, but this value has been estimated to be as high as $1600 \mathrm{~m} / \mathrm{y}(5200 \mathrm{ft} / \mathrm{y})($ Wood, 1994).

Values for distribution coefficients $\left(K_{d} s\right)$ are listed in Table 16-2 for the 58 radionuclides (32 elements) considered in the PE. In addition to the $K_{d}$ values for the geologic media, grout $K_{d}$ values are listed for determining the desorption from the source term resulting from the grouted waste form. The $K_{d}$ values for the subsurface flow pathway (both for the unsaturated and saturated zones) are taken from Table 3-5 in the performance assessment for the 200 West Area burial grounds (Wood et al., 1994); additional values for $\mathrm{Cl}, \mathrm{Al}, \mathrm{Si}, \mathrm{Ag}, \mathrm{Pb}$, and $\mathrm{Cf}$ were provided by site technical staff (Wood, 1995). 
Table 16-1. Parameters and Values Used in the PE for the Water Pathway at Hanford (generic $P E$ values are in bold; these values and the standard PE method for applying them are summarized in Chapter 1 of this volume and discussed in more detail in Chapter 5 of Volume 2) (Part 1 of 2)

\begin{tabular}{|c|c|c|c|}
\hline Parameter & Value & $\begin{array}{l}\text { Data } \\
\text { Type * }\end{array}$ & Comments \\
\hline \multicolumn{4}{|l|}{ SOURCE TERM } \\
\hline $\begin{array}{l}\text { Volumetric water content } \\
\text { of the grouted waste, } \theta_{0}\end{array}$ & 0.3 & D & Standard PE value \\
\hline $\begin{array}{l}\text { Bulk density of grouted } \\
\text { waste, } \rho_{G}\end{array}$ & $1.76 \mathrm{~g} / \mathrm{mI}$ & D & Standard PE value \\
\hline $\begin{array}{l}\text { Distribution coefficients } \\
\text { for grouted waste, } K_{d}^{G}\end{array}$ & various & D & $\begin{array}{l}\text { Standard PE value; see Table } 16-2 \text { in } \\
\text { this chapter }\end{array}$ \\
\hline $\begin{array}{l}\text { Disposal facility plan } \\
\text { area, } A\end{array}$ & $2500 \mathrm{~m}^{2}$ & $\bar{D}$ & $\begin{array}{l}\text { Standard } P E \text { value; } A=a_{1} * a_{2}, \text { where } \\
a_{1}=a_{2}=50 \mathrm{~m}\end{array}$ \\
\hline $\begin{array}{l}\text { Waste mixing fraction } \\
\text { for trench, } f_{m}\end{array}$ & 0.67 & D & Standard PE value \\
\hline $\begin{array}{l}\text { Waste mixing fraction } \\
\text { for tumulus, } f_{m}\end{array}$ & 0.33 & D & Standard PE value \\
\hline $\begin{array}{l}\text { Annual rate of water } \\
\text { flowing through intact } \\
\text { trench facility, } q_{f}\end{array}$ & $0.03 \mathrm{~m} / \mathrm{y}$ & D & Standard $P E$ value \\
\hline $\begin{array}{l}\text { Annual rate of water } \\
\text { flowing through intact } \\
\text { tumulus facility, } q_{f}\end{array}$ & $\begin{array}{c}0.00003 \\
\mathrm{~m} / \mathrm{y}\end{array}$ & D & Standard PE value \\
\hline $\begin{array}{l}\text { Time to failure of } \\
\text { leachate collection and } \\
\text { liner systems }\end{array}$ & $30 y$ & D & Standard PE value \\
\hline $\begin{array}{l}\text { Time to failure of trench } \\
\text { facility }\end{array}$ & $100 y$ & D & Standard PE value \\
\hline $\begin{array}{l}\text { Time to failure of } \\
\text { tumulus facility }\end{array}$ & $300 y$ & D & Standard PE value \\
\hline $\begin{array}{l}\text { Natural recharge through } \\
\text { local soils, } i\end{array}$ & $\begin{array}{l}0.05 \\
\mathrm{~m} / \mathrm{y}\end{array}$ & A & $\begin{array}{l}\text { for Case } 1 \text { (base case) simulations (Wood et } \\
\text { al., 1994) }\end{array}$ \\
\hline
\end{tabular}

* $A=$ site measurement; $B=$ result of site numerical analysis; $C=$ literature value selected by the site; $D=$ generic $P E$ value 
Table 16-1. Parameters and Values Used in the PE for the Water Pathway at Hanford (generic PE values are in bold; these values and the standard PE method for applying them are summarized in Chapter 1 of this volume and discussed in more detail in Chapter 5 of Volume 2) (Part 2 of 2)

\begin{tabular}{|c|c|c|c|}
\hline Parameter & Value & $\begin{array}{l}\text { Data } \\
\text { Type }^{\star}\end{array}$ & Comments \\
\hline \multicolumn{4}{|l|}{ UNSATURATED ZONE } \\
\hline Moisture content, $\theta_{w}$ & 0.09 & c & $\begin{array}{l}\text { Selected by staff as representative of the } \\
\text { unsaturated zone and used to calibrate travel } \\
\text { times to the performance assessment; confirmed } \\
\text { by Wood (1995). }\end{array}$ \\
\hline Bulk density, $\rho_{b}$ & $1.5 \mathrm{~g} / \mathrm{mL}$ & C & $\begin{array}{l}\text { Selected by staff as representative of the } \\
\text { unsaturated zone and used to calibrate travel } \\
\text { times to the performance assessment; confirmed } \\
\text { by Wood (1995). }\end{array}$ \\
\hline $\begin{array}{l}\text { Distribution coefficients of } \\
\text { geologic media, } K_{d}\end{array}$ & Various & AVC & See Table $16-2$ in this chapter \\
\hline $\begin{array}{l}\text { Thickness between trench } \\
\text { and saturated zone }\end{array}$ & $\begin{array}{c}63.2 \mathrm{~m} \\
(207.3 \mathrm{ft})\end{array}$ & A & $\begin{array}{l}\text { Cumulative unsaturated sediment thickness is } 72 \\
\mathrm{~m} \text { (Wood et al., 1994) and trench facility bottom } \\
\text { is } 8.8 \mathrm{~m} \text { below ground surface }\end{array}$ \\
\hline $\begin{array}{l}\text { Thickness between tumulus } \\
\text { and saturated zone, } l\end{array}$ & $\begin{array}{c}72 \mathrm{~m} \\
(236.2 \mathrm{ft})\end{array}$ & A & $\begin{array}{l}\text { Cumulative unsaturated sediment thickness is } 72 \\
\mathrm{~m} \text { (Wood et al., 1994) and tumulus facility } \\
\text { bottom is at ground surface }\end{array}$ \\
\hline \multicolumn{4}{|l|}{ SATURATED ZONE } \\
\hline Effective porosity, $n$ & 0.31 & A & Wood et al., 1994 \\
\hline Bulk density, $\rho_{b}$ & $1.6 \mathrm{~g} / \mathrm{mL}$ & A & Wood et al., 1994 \\
\hline $\begin{array}{l}\text { Distribution coefficients of } \\
\text { geologic media, } K_{d}\end{array}$ & Various & AC & See Table $16-2$ in this chapter \\
\hline Mixing depth, $d_{m}$ & $5 \mathrm{~m}$ & C & Khaleel, 1995 \\
\hline Darcy velocity, $q_{\text {gw }}$ & $\begin{array}{c}22 \mathrm{~m} / \mathrm{y} \\
(72.2 \mathrm{ft} / \mathrm{y})\end{array}$ & C & Khaleel, 1995 \\
\hline $\begin{array}{l}\text { Distance to } \\
\text { performance boundary } \\
\text { from facility boundary }\end{array}$ & $100 \mathrm{~m}$ & D & Standard PE value \\
\hline
\end{tabular}

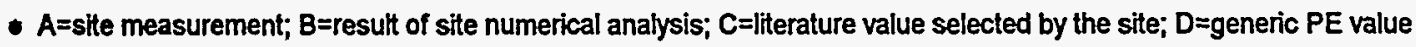


Table 16-2. Solid/Liquid Distribution Coefficients $\left(K_{d} s\right)$ Used in the PE at Hanford

\begin{tabular}{|c|c|c|}
\hline Element & $\begin{array}{c}\text { Waste } K_{d}^{G} \\
(\mathrm{~mL} / \mathrm{g})^{\mathrm{a}}\end{array}$ & $\begin{array}{c}K_{d} \text { for Geologic Media } \\
(\mathrm{mL} / \mathrm{g})^{b}\end{array}$ \\
\hline $\mathrm{H}$ & 0 & 0 \\
\hline C & 10 & 0 \\
\hline $\mathrm{Al}$ & 100 & $10^{c}$ \\
\hline$S i$ & 100 & $10^{\circ}$ \\
\hline $\mathrm{Cl}$ & 0 & $0^{\circ}$ \\
\hline $\mathrm{K}$ & 1 & 10 \\
\hline Co & 100 & 1 \\
\hline $\mathrm{Ni}$ & 10 & 100 \\
\hline $\mathrm{Se}$ & 1 & 0 \\
\hline$S r$ & 100 & 1 \\
\hline$z r$ & 10 & 100 \\
\hline $\mathrm{Nb}$ & 10 & 100 \\
\hline Tc & 1 & 0 \\
\hline $\mathrm{Pd}$ & 100 & 10 \\
\hline $\mathrm{Ag}$ & 100 & $10^{c}$ \\
\hline $\mathrm{Cd}$ & 100 & 100 \\
\hline $\mathrm{Sn}$ & 10 & 100 \\
\hline 1 & 1 & 0 \\
\hline Cs & 10 & 1 \\
\hline $\mathrm{Ba}$ & 10 & 1 \\
\hline $\mathrm{Sm}$ & 10 & 100 \\
\hline $\mathrm{Eu}$ & 10 & 10 \\
\hline $\mathrm{Pb}$ & 100 & $100^{\circ}$ \\
\hline Ra & 10 & 10 \\
\hline Th & 100 & 100 \\
\hline $\mathrm{Pa}$ & 100 & 1 \\
\hline$U$ & 100 & 0 \\
\hline $\mathrm{Np}$ & 100 & 10 \\
\hline $\mathrm{Pu}$ & 100 & 100 \\
\hline $\mathrm{Am}$ & 100 & 100 \\
\hline $\mathrm{Cm}$ & 100 & 100 \\
\hline$\overline{C f}$ & 100 & $100^{\circ}$ \\
\hline
\end{tabular}

a Standard PE values; see Chapter 5 of Volume 2

b Wood et al. (1994) except as noted

c Wood (1995) 


\subsubsection{Atmospheric Transport}

Site-specific data required to perform the atmospheric pathway analysis came from site personnel as data either from site characterizations and reports or from general literature. The site-specific data required for the soil diffusion calculation were the same as some of those required for the water transport analysis (Section 16.4.1). These values are shown in Table 16-3. Necessary atmospheric dispersion data included wind speed and direction and stability class, which are summarized in Section 16.3.2.

Table 16-3. Parameters and Values Used in the PE for the Atmospheric Pathway at Hanford (generic PE values are in bold; these values and the standard PE method for applying them are summarized in Chapter 1 of this volume and discussed in more detail in Chapter 5 of Volume 2)

\begin{tabular}{|c|c|c|c|}
\hline Parameter & Value & $\begin{array}{l}\text { Data } \\
\text { Type }^{*}\end{array}$ & Comments \\
\hline $\begin{array}{l}\text { Disposal facility cover } \\
\text { thickness, } x\end{array}$ & $\begin{array}{c}1.0 \mathrm{~m} \\
.\end{array}$ & D & Standard PE value \\
\hline $\begin{array}{l}\text { Depth of the soil } \\
\text { surface, } d\end{array}$ & $0.01 \mathrm{~m}$ & D & $\begin{array}{l}\text { Standard PE value based on Maheras } \\
\text { et al. (1994) }\end{array}$ \\
\hline Porosity, $n$ & 0.5 & C & Wood et al. (1994, pp. 4-56 and 4-57) \\
\hline Percent saturation, $s$ & 0.14 & C & Wood et al. (1994, pp. 4-56 and 4-57) \\
\hline $\begin{array}{l}\text { Ratio of water density } \\
\text { in air to liquid, } r\end{array}$ & 9.2E-06 & D & $\begin{array}{l}\text { Standard PE value based on MMES et } \\
\text { al. (1994) }\end{array}$ \\
\hline $\begin{array}{l}\text { Ratio of } \mathrm{CO}_{2} \\
\text { concentration in air to } \\
\text { dissolved in water, } r\end{array}$ & 4.3E-04 & D & $\begin{array}{l}\text { Standard PE value based on Foust et } \\
\text { al. (as cited in Cooper and Alley, 1986) }\end{array}$ \\
\hline $\begin{array}{l}\text { Tritium diffusion } \\
\text { coefficient in air, } D\end{array}$ & $2.39 \mathrm{E}-05 \mathrm{~m}^{2} / \mathrm{s}$ & D & $\begin{array}{l}\text { Standard PE value based on CRC } \\
\text { (1981) }\end{array}$ \\
\hline $\begin{array}{l}\text { Carbon diffusion } \\
\text { coefficient in air, } D\end{array}$ & $1.4 \mathrm{E}+05 \mathrm{~m}^{2} / \mathrm{s}$ & D & $\begin{array}{l}\text { Standard PE value based on CRC } \\
\text { (1981) }\end{array}$ \\
\hline $\begin{array}{l}\text { Atmospheric dispersion } \\
\text { term, } A_{D}\end{array}$ & $\begin{array}{c}0.34 \\
\left(\mu \mathrm{CV} / \mathrm{m}^{3}\right) /\left(\mu \mathrm{Ci} / \mathrm{m}^{2}-\mathrm{s}\right)\end{array}$ & B & $\begin{array}{l}\text { Value is estimated using the industrial Source } \\
\text { Complex-Version } 2 \text { Long Term Air Dispersion } \\
\text { Model (ISCLT2) (EPA, 1992) based on site- } \\
\text { specific STAR data }\end{array}$ \\
\hline
\end{tabular}

- $A=$ site measurement; $B=$ result of site numerical analysis; $C=$ literature value selected by the site; $D=g e n e r i c ~ P E$ value 


\subsubsection{Inadvertent Intruder Exposure}

As explained in Section 16.3.3, the PE used two standard intrusion scenarios to describe potential modes of inadvertent intrusion at all the sites. Because these intrusion scenarios were considered applicable to all sites, no values specific to the Hanford Site are used in the calculation of exposures to inadvertent intruders.

\subsection{RESULTS OF THE PE}

The performance evaluation provided estimates of permissible waste concentrations in disposed MLLW. The three calculations that formed the foundation of the PE-for the water, atmospheric, and inadvertent intruder pathways —are summarized in Sections 1.1, 1.2, and 1.3, respectively, of this volume and discussed in detail in Chapter 5 of Volume 2.

For each pathway the maximum permissible waste concentration at the performance boundary was determined for each radionuclide by using the performance measures: $4 \mathrm{mrem}$ $(0.04 \mathrm{mSv})$ per year from the water pathway for releases to drinking water; 10 mrem $(0.1 \mathrm{mSv})$ per year from all pathways for atmospheric releases; and $100 \mathrm{mrem}(1 \mathrm{mSv})$ per year from all exposure pathways for chronic exposure of inadvertent intruders; and the appropriate pathway or scenario dose conversion factors (annual effective dose equivalent per unit concentration) based on EPA dose conversion factors. The basis for the performance measures used in the PE is discussed in more detail in Chapter 5 of Volume 2. For the water and atmospheric pathways, the concentration reduction provided by the environment (i.e., the CRF) was estimated using results of site analyses and data. For the intruder analyses, concentration reduction was estimated for appropriate exposure pathways for two intrusion scenarios that, in general, were the same for all the sites. The results of the calculations for the pathways that were analyzed at Hanford are provided in this section and discussed in Section 16.6.

\subsubsection{Water Transport}

Two CRFs were calculated for the water pathway: the source CRF, $C R F_{\text {Source, }}$ and the environmental transport $\mathrm{CRF}$ for water, $C R F_{\text {Water. }}$. The source $\mathrm{CRF}$ represents the concentration attenuation between the disposed waste and leachate exiting the bottom of the disposal facility and was defined as the dimensionless ratio of the waste concentration to the resulting leachate concentration. Desorption with infiltrating water was the mechanism used to describe the leaching of radionuclides from the grout. Because a generic method was used to determine the $C R F_{\text {Source }}$ for the 58 radionuclides considered in the PE (summarized in Section 1.1 of this volume and discussed in more detail in Chapter 5 of Volume 2), the radionuclide-specific values for the source CRF for each type of generic facility were the same for all 15 sites.

The environmental transport CRF for water was defined as the ratio of the concentration of the leachate exiting the disposal facility to the resulting concentration in water at the performance boundary. The concentration attenuation represented by $C R F_{\text {Water }}$ consisted of dilution due to mixing with uncontaminated groundwater. Effects of radioactive decay and decay product ingrowth were also included in the PE. 
In the PE, water travel time from the facility location to the performance boundary was calculated as a basis for comparison with the retarded travel time of the radionuclides. For Hanford, water travel time from the land surface to the performance boundary (i.e., without consideration of a disposal facility) was estimated at about $130 \mathrm{y}$.

The calculation of travel time through the vadose zone for a radionuclide, on the other hand, must account both for the lower infiltration rate because of the facility's RCRA cover and for the retardation defined by the distribution coefficient for the geologic media. In the PE, the calculation for travel time in the vadose zone first determined the distance a radionuclide traveled at the lower infiltration rate. Then, if the radionuclide had not fully traversed the vadose zone, the additional time required to complete travel in the vadose zone under the higher, infiltration rate based on natural recharge through local soils was calculated and added to the time determined at the lower infiltration rate.

In the $\mathrm{PE}$, the detention time in the facility for a radionuclide was the time during which water flowing through the facility was assumed to be caught by the leachate collection system. Specifically, the calculation of travel time for a radionuclide accounted for the following:

- For the trench design, the leachate collection system was assumed to catch water flowing through the facility for the first $30 \mathrm{y}$. After $30 \mathrm{y}$, the liner and leachate collection system failed, and the rate of water flowing through the facility for the next $70 \mathrm{y}$ was assumed to be $0.03 \mathrm{~m} / \mathrm{y}(0.1 \mathrm{ft} / \mathrm{y})$ based on a unit hydraulic gradient and the saturated hydraulic conductivity of the RCRA cover system. After a total of $100 \mathrm{y}$ of reduced flow because of engineered barriers ( $30 \mathrm{y}$ of detention plus $70 \mathrm{y}$ limited by the RCRA cover system), the rate was assumed to be the average recharge through local soils, $0.05 \mathrm{~m} / \mathrm{y}(0.16 \mathrm{ft} / \mathrm{y})$.

- For the tumulus design, the leachate collection system was assumed to catch water flowing through the facility for the first $30 \mathrm{y}$. After $30 \mathrm{y}$, the liner and leachate collection system was assumed to fail, and the rate of water flowing through the facility for the next $270 \mathrm{y}$ was assumed to be $0.00003 \mathrm{~m} / \mathrm{y}(0.0001 \mathrm{ft} / \mathrm{y})$ based on a unit hydraulic gradient and the saturated hydraulic conductivity of the concrete vaults. After a total of $300 \mathrm{y}$ of reduced flow because of engineered barriers ( $30 \mathrm{y}$ detention plus $270 \mathrm{y}$ limited by the concrete vaults), the rate was assumed to be the average recharge through local soils, $0.05 \mathrm{~m} / \mathrm{y}(0.16 \mathrm{ft} / \mathrm{y})$.

Travel time through the aquifer was independent of facility design and was about $1.4 \mathrm{y}$, based on groundwater Darcy velocity and a $100-\mathrm{m}(328-\mathrm{ft})$ distance to the performance boundary (see Section 1.1.2 of this volume for a summary of these assumptions and Chapter 5 of Volume 2 for additional details). The arrival time of a radionuclide at the performance boundary is the sum of the detention time in the facility, travel time through the vadose zone, and travel time through the aquifer.

Retardation of radionuclides by interaction with soils and rock in the vadose and saturated zones increased travel times for individual radionuclides. This effect was particularly important for short-lived radionuclides because of radioactive decay. For short-lived radionuclides, the 
effects of radioactive decay combined with long travel times increased the permissible concentrations in the disposal facility.

Application of the PE methodology for water transport of the 58 radionuclides considered in the PE produced the results shown in Table 16-4 for the generic trench and generic tumulus designs at Hanford. The table shows permissible waste concentrations based on transport through the water pathway $\left(C_{W-W a t e r}\right)$ as well as the values used in calculating the permissible waste concentrations.

Some radionuclides listed in Table 16-4 have no limit (NL) on their permissible waste concentrations, the result of the combined effects of relatively short half-lives and sufficiently long travel time to the performance boundary. "No limit" is defined as a permissible waste concentration that is greater than the specific activity of the pure elemental radionuclide. For disposal of the maximum possible waste concentration of these relatively short-lived radionuclides, the water pathway produced a dose at the performance boundary of less than $4 \mathrm{mrem}(0.04 \mathrm{mSv})$ per year and, therefore, the permissible waste concentration was unlimited based on exposures from this pathway.

For some radionuclides, no value is listed in Table 16-4 for the radioactive decay term, $r_{\text {Decay. }}$ These radionuclides had radioactive decay terms that were very large (e.g., greater than $1 \times 10^{50}$ ). Any radionuclide with a radioactive decay term greater than $1 \times 10^{50}$ was ensured a calculated permissible waste concentration greater than the specific activity of the pure elemental radionuclide, which, as described previously, resulted in no limit (NL) on permissible waste concentrations for disposal.

Arrival times for some radionuclides listed in Table 16-4 were beyond the 10,000-y performance period. For those radionuclides, the estimated waste concentrations are presented in Table 16-4 for information purposes only. Consistent with the approach used in LLW performance assessments, these values were not considered in determining the most restrictive disposal limit from among the evaluated pathways.

For all radionuclides in Table 16-4, the flow rate at the time of facility failure controlled the subsurface transport (i.e., the subsurface movement of the radionuclides in the trench and tumulus was controlled by the flow rate at $100 \mathrm{y}$ after closure for the trench [when the cover failed] and at $300 \mathrm{y}$ for the tumulus [when the concrete vaults failed]). None of the radionuclides was controlled by flow rates at earlier times.

For the tumulus, the total undecayed CRFs (the product of the $C R F_{\text {Source }}$ and the $C R F_{\text {Water }}$ ) for the groundwater pathway were about twice the total undecayed CRFs for the trench, given the same total rate of flow (i.e., at the time of hydrologic failure of the facility). This result was due to the difference in the volume fraction of waste (the ratio of waste material to total material in the disposal unit) between the two technologies_twice as much waste leached from the trench for a given rate of flow because a given volume of trench contained twice as much waste. 
Table 16-4. Results of Calculations for the Water Pathway at Hanford (water travel time from land surface to performance boundary [excluding facility detention] $=130 \mathrm{y})($ Part 1 of 2$)$

\begin{tabular}{|c|c|c|c|c|c|c|c|c|c|c|c|c|c|}
\hline \multirow[t]{2}{*}{ Nuclide } & \multirow[b]{2}{*}{$\begin{array}{c}\text { PDCF } \\
\text { remly per } \mu \mathrm{cu} \text {. }\end{array}$} & \multicolumn{5}{|c|}{ Trench } & \multicolumn{6}{|c|}{ Tumulus } & \multirow[t]{2}{*}{ Nuclide } \\
\hline & & $\begin{array}{l}\text { CRF Source } \\
\text { (dimensionless) }\end{array}$ & $\begin{array}{c}\text { CRF Whar } \\
\text { (dimensionloss) }\end{array}$ & \begin{tabular}{|l|} 
Arrival \\
Time (y) \\
\end{tabular} & \begin{tabular}{|c|}
$r_{\text {Decay }}$ \\
(dimonsionless) \\
\end{tabular} & $\begin{array}{c}C_{\text {w-water }} \\
\left(\mu \mathrm{Ci} / \mathrm{m}^{3}\right)\end{array}$ & $\begin{array}{l}\text { CRF source } \\
\text { (dimensionless) }\end{array}$ & \begin{tabular}{|c|} 
CRF Water \\
(dimensionless)
\end{tabular} & \begin{tabular}{|c|} 
Arrival \\
Time (y) \\
\end{tabular} & $\begin{array}{c}\text { rDecay }^{a} \\
\text { (dimensiontoss) }\end{array}$ & $\begin{array}{c}C_{w-W m a r}^{b} \\
\left(\mu \mathrm{Ci} / \mathrm{m}^{3}\right)\end{array}$ & & \\
\hline $\mathrm{H}-3$ & 4.67E-02 & 0.45 & 45 & 1.7E+02 & 1.7E+04 & $3 E+07$ & 0.9 & 45 & $4.3 E+02$ & $3.3 E+10$ & $1 E+14$ & & $\mathrm{H}-3$ \\
\hline$c-14$ & $1.52 E+\infty 0$ & 27 & 45 & $1.7 \mathrm{E}+02$ & $1.0 \mathrm{E}+\infty$ & $3 E+03$ & 54 & 45 & $4.3 E+02$ & $1.1 E+00$ & $7 E+03$ & & C-14 \\
\hline Al-26 & $1.06 E+01$ & 270 & 45 & $1.9 \mathrm{E}+04$ & $1.0 \mathrm{E}+00$ & $5 E+03$ & 540 & 45 & $2.2 E+04$ & $1.0 \mathrm{E}+00$ & $9 E+03$ & 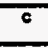 & Al-26 \\
\hline Si-32 & $7.99 E+00$ & 270 & 45 & $1.9 \mathrm{E}+04$ & e & $\mathrm{NL}$ & 540 & 45 & $2.2 E+04$ & e & $\overline{N L}$ & 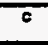 & Si-32 \\
\hline $\mathrm{Cl}-36$ & $2.21 E+\infty 0$ & 0.45 & 45 & $1.7 E+02$ & $1.0 \mathrm{E}+\infty 0$ & $4 E+01$ & 0.9 & 45 & $4.3 E+02$ & $1.0 E+00$ & $7 E+01$ & & $\mathrm{Cl}-36$ \\
\hline$K-40$ & $1.36 \mathrm{E}+01$ & 3.1 & 45 & $1.9 E+04$ & $1.0 \mathrm{E}+00$ & $4 E+01$ & 6.2 & 45 & $2.2 E+04$ & $1.0 E+00$ & $8 E+01$ & $c$ & $K-40$ \\
\hline Co-60 & $1.97 \mathrm{E}+01$ & 270 & 45 & $2.1 E+03$ & e & NL & 540 & 45 & $2.6 \mathrm{E}+03$ & e & NL & & $C 0-60$ \\
\hline Ni-59 & $1.53 \mathrm{E}-01$ & 27 & 45 & $1.9 E+05$ & $5.7 E+\infty 0$ & $2 E+05$ & 54 & 45 & $2.2 \mathrm{E}+05$ & $7.2 E+\infty$ & $5 E+05$ & 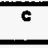 & Ni-59 \\
\hline Ni-63 & $4.21 \mathrm{E}-01$ & 27 & 45 & $1.9 E+05$ & $\mathrm{e}$ & $\mathrm{NL}$ & 54 & 45 & $2.2 E+05$ & e & NL & c & $\mathrm{Ni}-63$ \\
\hline Se-79 & $6.35 E+00$ & 3.1 & 45 & $1.7 E+02$ & $1.0 \mathrm{E}+00$ & $9 E+01$ & 6.2 & 45 & $4.3 E+02$ & $1.0 \mathrm{E}+\infty$ & $2 E+02$ & & Se-79 \\
\hline Sr-90 & $1.12 E+02$ & 270 & 45 & $2.1 E+03$ & $3.0 \mathrm{E}+21$ & $\mathrm{NL}$ & 540 & 45 & $2.6 \mathrm{E}+03$ & $7.5 E+26$ & $\mathrm{NL}$ & & Sr-90 \\
\hline $2 \mathrm{r}-93$ & $1.59 \mathrm{E}+00$ & 27 & 45 & $1.9 E+05$ & $1.1 E+\infty$ & $3 E+03$ & 54 & 45 & $2.2 E+05$ & $1.1 E+\infty 0$ & $7 E+03$ & ${ }^{\circ}$ & Zr-93 \\
\hline Nb-93m & $3.81 E-01$ & 27 & 45 & $1.9 E+05$ & $\mathrm{e}$ & $\mathrm{NL}$ & 54 & 45 & $2.2 E+05$ & e & NL & c & $\mathrm{Nb}-93 \mathrm{~m}$ \\
\hline $\mathrm{Nb}-94$ & $5.21 E+00$ & 27 & 45 & $1.9 E+05$ & $7.4 E+02$ & $7 E+05$ & 54 & 45 & $2.2 \mathrm{E}+05$ & $1.9 E+03$ & $3 E+06$ & $\mathrm{c}$ & Nb-94 \\
\hline Tc-99 & $1.07 E+00$ & 3.1 & 45 & $1.7 \mathrm{E}+02$ & $1.0 \mathrm{E}+00$ & $5 E+02$ & 6.2 & 45 & $4.3 E+02$ & $1.0 \mathrm{E}+\infty 0$ & $1 \mathrm{E}+03$ & & Tc-99 \\
\hline Pd-107 & $1.09 \mathrm{E}-01$ & 270 & 45 & $1.9 E+04$ & $1.0 \mathrm{E}+00$ & $4 E+05$ & 540 & 45 & $2.2 E+04$ & $1.0 \mathrm{E}+00$ & $9 E+05$ & $c$ & $P d-107$ \\
\hline $\mathrm{Ag}-108 \mathrm{~m}$ & $5.56 \mathrm{E}+00$ & 270 & 45 & $1.9 E+04$ & $3.0 \mathrm{E}+44$ & $\mathrm{NL}$ & 540 & 45 & $2.2 E+04$ & e & $\mathrm{NL}$ & C & $\mathrm{Ag}-108 \mathrm{~m}$ \\
\hline $\mathrm{Cd}-113 \mathrm{~m}$ & $1.17 E+02$ & 270 & 45 & $1.9 E+05$ & e & NL & 540 & 45 & $2.2 E+05$ & e & $\mathrm{NL}$ & ${ }^{\circ}$ & Cd-113m \\
\hline$S n-121 m$ & $1.28 E+\infty 0$ & 27 & 45 & $1.9 E+05$ & $e$ & $\mathrm{NL}$ & 54 & 45 & $2.2 \mathrm{E}+05$ & e & $\mathrm{NL}$ & $c$ & Sn-121m \\
\hline Sn-126 & $1.53 \mathrm{E}+01$ & 27 & 45 & $1.9 E+05$ & $3.7 E+00$ & $1 E+03$ & 54 & 45 & $2.2 \mathrm{E}+05$ & $4.5 E+\infty$ & $3 E+03$ & c & $5 n-126$ \\
\hline $1-129$ & $2.01 E+02$ & 3.1 & 45 & $1.7 E+02$ & $1.0 E+00$ & $3 E+\infty$ & 6.2 & 45 & $4.3 E+02$ & $1.0 E+\infty$ & $6 E+00$ & & $1-129$ \\
\hline Cs-135 & $5.16 \mathrm{E}+00$ & 27 & 45 & $2.1 E+03$ & $1.0 E+00$ & $9 E+02$ & 54 & 45 & $2.6 \mathrm{E}+03$ & $1.0 E+\infty$ & $2 E+03$ & & Cs-135 \\
\hline Cs-137 & $3.65 E+01$ & 27 & 45 & $2.1 E+03$ & $5.0 E+20$ & $\mathrm{NL}$ & 54 & 45 & $2.6 \mathrm{E}+03$ & $7.9 E+25$ & $\mathrm{NL}$ & & Cs-137 \\
\hline $8 a-133$ & $2.48 E+00$ & 27 & 45 & $2.1 \mathrm{E}+03$ & e & NL & 54 & 45 & $2.6 \mathrm{E}+03$ & e & $\mathrm{NL}$ & & $\mathrm{Ba}-133$ \\
\hline$S m-151$ & $2.84 E-01$ & 27 & 45 & $1.9 E+05$ & $e$ & $\mathrm{NL}$ & 54 & 45 & $2.2 E+05$ & e & $\mathrm{NL}$ & ${ }^{\circ}$ & $5 m-151$ \\
\hline Eu-152 & $4.73 E+00$ & 27 & 45 & $1.9 E+04$ & e & NL & 54 & 45 & $2.2 \mathrm{E}+04$ & e & $\mathrm{NL}$ & ${ }^{2}$ & Eu-152 \\
\hline Eu-154 & $6.97 E+00$ & 27 & 45 & $1.9 E+04$ & e & NL & 54 & 45 & $2.2 E+0.4$ & e & $\mathrm{NL}$ & c & Eu-154 \\
\hline $\mathrm{Pb}-210$ & $5.30 E+03$ & 270 & 45 & $1.9 E+05$ & e & NL & 540 & 45 & $2.2 E+05$ & e & NL & ${ }^{\circ}$ & $\mathrm{Pb}-210$ \\
\hline Ra-226 & $6.27 E+03$ & 27 & 45 & $1.9 \mathrm{E}+04$ & $4.1 E+03$ & $3 E+03 \quad c$ & 54 & 45 & $2.2 E+04$ & $1.4 \mathrm{E}+04$ & $2 E+04$ & ${ }^{\circ}$ & Ra-226 \\
\hline Ra-228 & $1.64 E+03$ & 27 & 45 & $1.9 \mathrm{E}+04$ & e & $\mathrm{NL}$ & 54 & 45 & $2.2 E+04$ & e & $\mathrm{NL}$ & ${ }^{\circ}$ & Ra-228 \\
\hline Th-229 & $2.94 E+03$ & 270 & 45 & $1,9 E+05$ & $7.2 E+07$ & $1 \mathrm{E}+09^{\circ}$ & 540 & 45 & $2.2 E+05$ & $9.0 \mathrm{E}+08$ & $3 E+10$ & 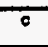 & Th-229 \\
\hline Th-230 & $6.12 E+03$ व & 270 & 45 & $1.9 E+05$ & NA & $8 E+\infty 0^{\circ}$ & 540 & 45 & $2.2 E+05$ & NA & $2 E+01$ & $\circ$ & Th-230 \\
\hline Th-232 & $3.63 E+03$ & 270 & 45 & $1.9 E+05$ & $1.0 E+00$ & $1 E+01$ & 540 & 45 & $2.2 E+05$ & $1.0 E+00$ & $3 E+01$ & c & Th-232 \\
\hline $\mathrm{Pa}-231$ & $1.85 E+04$ & 270 & 45 & $2.1 E+03$ & $1.0 \mathrm{E}+00$ & $3 E+\infty$ & 540 & 45 & $2.6 \mathrm{E}+03$ & $1.1 E+\infty$ & $5 E+\infty$ & & Pa-231 \\
\hline
\end{tabular}


Table 16-4. Results of Calculations for the Water Pathway at Hanford (water travel time from land surface to performance boundary [excluding facility detention] $=130 \mathrm{y})($ Part 2 of 2$)$

\begin{tabular}{|c|c|c|c|c|c|c|c|c|c|c|c|c|c|}
\hline \multirow[t]{2}{*}{ Nuclide } & \multirow[b]{2}{*}{$\begin{array}{c}\text { PDCF } \\
\text { rem/y per } \mu \mathrm{ci} / 2 \\
\end{array}$} & \multicolumn{5}{|c|}{ Trench } & \multicolumn{6}{|c|}{ Tumulus } & \multirow[t]{2}{*}{ Nuclide } \\
\hline & & $\begin{array}{l}\text { CRF source } \\
\text { (dimensionloss) }\end{array}$ & $\begin{array}{c}\mathrm{CRF}_{\text {Water }} \\
\text { (dimensionless) }\end{array}$ & $\begin{array}{c}\text { Arrival } \\
\text { Time }(y) \\
\end{array}$ & $\underset{\text { (dimensionloss) }}{r_{\text {Decayy }}}$ & $\begin{array}{c}C_{\text {W-Water }}{ }^{b} \\
\left(\mu \mathrm{Cl} / \mathrm{m}^{3}\right)\end{array}$ & $\begin{array}{l}\text { CRF source } \\
\text { (dimensionloss) }\end{array}$ & $\begin{array}{c}\text { CRF Water } \\
\text { (dimensionless) }\end{array}$ & $\begin{array}{c}\text { Arrival } \\
\text { Time }(y) \\
\end{array}$ & $\begin{array}{c}r_{\text {Decayy }}{ }^{a} \\
\text { (dimensionloss) }\end{array}$ & $\begin{array}{c}C_{\text {w.water }}^{b} \\
\left(\mu \mathrm{Cl} / \mathrm{m}^{3}\right)\end{array}$ & & \\
\hline U-232 & $1.55 E+03$ & 270 & 45 & $1.7 E+02$ & $5.6 \mathrm{E}+\infty 0$ & $2 E+02$ & 540 & 45 & 4.3E+02 & 7.1E+01 & $4 E+03$ & & U-232 \\
\hline U-233 & $3.28 \mathrm{E}+02$ & 270 & 45 & $1.7 \mathrm{E}+02$ & NA & $2 E+02$ & 540 & 45 & $4.3 E+02$ & NA & $3 E+02$ & & $U-233$ \\
\hline U-234 & $2.10 \mathrm{E}+02$ & 270 & 45 & $1.7 \mathrm{E}+02$ & NA & $2 \mathrm{E}+02$ & 540 & 45 & $4.3 \mathrm{E}+02$ & NA & $5 \mathrm{E}+02$ & & $U-234$ \\
\hline $\mathrm{U}-235$ & $3.56 \mathrm{E}+02$ व & 270 & 45 & $1.7 E+02$ & NA & $2 \mathrm{E}+02$ & 540 & 45 & $4.3 \mathrm{E}+02$ & NA & $3 E+02$ & & U-235 \\
\hline U-236 & $1.96 \mathrm{E}+02$ & 270 & 45 & $1.7 E+02$ & $1.0 E+00$ & $2 \mathrm{E}+02$ & 540 & 45 & $4.3 E+02$ & $1.0 E+00$ & $5 E+02$ & & U-236 \\
\hline U-238 & $2.07 E+02$ & 270 & 45 & $1.7 E+02$ & NA & $2 E+02$ & 540 & 45 & $4.3 E+02$ & NA & $5 E+02$ & & $U-238$ \\
\hline $\mathrm{Np}-237$ & $3.24 \mathrm{E}+03$ & 270 & 45 & $1.9 \mathrm{E}+04$ & $1.0 E+00$ & $1 E+01$ & 540 & 45 & $2.2 E+04$ & $1.0 \mathrm{E}+00$ & $3 E+01$ & c & Np-237 \\
\hline $\mathrm{Pu}-238$ & $2.34 E+03$ & 270 & 45 & $1.9 \mathrm{E}+05$ & e & $6 \mathrm{E}+05$ & 540 & 45 & $2.2 E+05$ & e & $1 E+06$ & & Pu-238 \\
\hline Pu-239 & $2.58 \mathrm{E}+03$ & 270 & 45 & $1.9 \mathrm{E}+05$ & $2.4 E+02$ & $4 \mathrm{E}+03^{\circ}$ & 540 & 45 & $2.2 E+05$ & $5.2 E+02$ & $2 E+04$ & c & Pu-239 \\
\hline Pu-240 & $2.58 E+03$ & 270 & 45 & $1.9 E+05$ & $5.5 E+08$ & $1 E+10^{c}$ & 540 & 45 & $2.2 E+05$ & $9.2 E+09$ & $3 E+11$ & c & Pu-240 \\
\hline $\mathrm{Pu}-241$ & $4.82 E+08$ & 270 & 45 & $1.9 \mathrm{E}+05$ & $\mathrm{e}$ & $2 E+06 \div 1$ & 540 & 45 & $2.2 E+05$ & e & $4 E+06$ & .1 & Pu-241 \\
\hline $\mathrm{Pu}-242$ & $2.45 E+03$ & 270 & 45 & $1.9 \mathrm{E}+05$ & $1.4 \mathrm{E}+00$ & $3 \mathrm{E}+01^{\circ}$ & 540 & 45 & $2.2 E+05$ & $1.5 \mathrm{E}+00$ & $6 \mathrm{E}+01$ & c & $\mathrm{Pu}-242$ \\
\hline Pu-244 & $4.11 E+03$ & 270 & 45 & $1.9 \mathrm{E}+05$ & NA & $1 E+01^{c}$ & 540 & 45 & $2.2 E+05$ & NA & $2 \mathrm{E}+01$ & $\bar{c}$ & $\mathrm{Pu}-244$ \\
\hline$A m-241$ & $2.66 \mathrm{E}+03$ & 270 & 45 & $1.9 \mathrm{E}+05$ & e & $7 E+04 \quad-7$ & 540 & 45 & $2.2 \mathrm{E}+05$ & e & $1 E+05$ & 01 & Am-241 \\
\hline Am-243 & $2.64 \mathrm{E}+03$ & 270 & 45 & $1.9 \mathrm{E}+05$ & $6.0 \mathrm{E}+07$ & $1 E+09=$ & 540 & 45 & $2.2 E+05$ & $7.4 \mathrm{E}+08$ & $3 E+10$ & c & Am-243 \\
\hline $\mathrm{Cm}-243$ & $1.83 \mathrm{E}+03$ & 270 & 45 & $1.9 \mathrm{E}+05$ & e & $4 E+06 \div 1$ & 540 & 45 & $2.2 E+05$ & e & $2 E+07$ & .7 & $\mathrm{Cm}-243$ \\
\hline $\mathrm{Cm}-244$ & $1.47 E+03$ & 270 & 45 & $1.9 E+05$ & e & $4 E+12$ & 540 & 45 & $2.2 \mathrm{E}+05$ & e & $\mathrm{NL}$ & 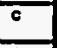 & $\mathrm{Cm}-244$ \\
\hline $\mathrm{Cm}-245$ & $4.56 E+03$ & 270 & 45 & $1.9 E+05$ & NA & $1 E+01$ & 540 & 45 & $2.2 E+05$ & NA & $2 \mathrm{E}+01$ & c & $\mathrm{Cm}-245$ \\
\hline $\mathrm{Cm}-246$ & $2.70 E+03$ & 270 & 45 & $1.9 E+05$ & 1.1E+12 & $\mathrm{NL}$ & 540 & 45 & $2.2 E+05$ & $5.4 \mathrm{E}+13$ & $\mathrm{NL}$ & c & $\mathrm{Cm}-246$ \\
\hline $\mathrm{Cm-247}$ & $4.34 E+03$ & 270 & 45 & $1.9 \mathrm{E}+05$ & NA & $1 \mathrm{E}+01$ & 540 & 45 & $2.2 E+05$ & NA & $2 E+01$ & 5 & $\mathrm{Cm}-247$ \\
\hline $\mathrm{Cm}-248$ & $9.94 E+03$ & 270 & 45 & $1.9 \mathrm{E}+05$ & $1.5 E+\infty$ & $7 E+00$ & 540 & 45 & $2.2 E+05$ & $1.5 \mathrm{E}+\infty$ & $1 E+01$ & c & $C m-248$ \\
\hline Cf-249 & $3.46 E+03$ & 270 & 45 & $1.9 E+05$ & $\mathbf{e}$ & $3 E+02$ & 540 & 45 & $2.2 E+05$ & e & $5 E+02$ & 61 & $C f-249$ \\
\hline Cf-250 & $2.64 E+08$ & 270 & 45 & $1.9 E+05$ & $\mathbf{e}$ & NL & 540 & 45 & $2.2 E+05$ & $e$ & $\mathrm{NL}$ & c & Cf-250 \\
\hline Cf-251 & $3.54 \mathrm{E}+03$ & 270 & 45 & $1.9 E+05$ & $\mathrm{e}$ & $\mathrm{NL}$ & 540 & 45 & $2.2 E+05$ & e & $\mathrm{NL}$ & c & Cf-251 \\
\hline
\end{tabular}

a "NA" means Not Applicable - decay factor is implicit in the PDCF for this radionuclide.

b "NL" means No Limit - estimated permissible concentration is greater than the specific activity of the pure elemental radionuclide.

c Radionuclide concentration is based on arrival time at the performance boundary beyond $10,000 \mathrm{y}$.

d PDCF is a function of arrival time. See Chapter 1 of this volume for equation.

e $r_{\text {Docay }} \geq 1 \mathrm{E}+50$

$f$ Contribution of decay product(s) is significant to determination of this value (see Table E-3 in Volume 2). Listed arrival time is that of the parent radionuclide. If this footnote does not appear in combination with footnote $c$, the arrival time of the significant decay product(s) is less than $10,000 \mathrm{y}$. 
For the trench design at Hanford, the total undecayed CRFs for the groundwater pathway ranged from about 20 to 12,000 . Among the listed radionuclides, arrival times at the performance boundary ranged from $170 \mathrm{y}$ to $190,000 \mathrm{y}$, including the retention time in the facility before failure. The travel time through the unsaturated zone accounted for about $99 \%$ of the total subsurface travel time.

For the tumulus design, the total undecayed CRFs for the groundwater pathway ranged from about 40 to 24,000 . Among the listed radionuclides, arrival times at the performance boundary ranged from $430 \mathrm{y}$ to $220,000 \mathrm{y}$, including the retention time in the facility before failure. Differences in these arrival times compared to the trench were attributable to (1) the assumed time of hydrologic failure of the facility (100 y for the trench and $300 \mathrm{y}$ for the tumulus); and (2) the increased travel distance through the vadose zone for the tumulus (the bottom of the tumulus was assumed to be at grade level, while the trench was assumed to be a shallow buried structure).

Hanford has plans for an MLLW disposal facility, the Radioactive Mixed Waste Land Disposal Facility. The results of applying the PE method to that facility are presented in Appendix A.4. The appendix also contains a comparison of the PE method for the water pathway and its results to the LLW performance assessment conducted for Hanford's 200-West Area Burial Grounds (Wood et al., 1994).

\subsubsection{Atmospheric Transport}

Two CRFs were used to account for the attenuation encompassing diffusion to the ground surface, mixing in air, and dispersion in the atmosphere to the performance boundary. The CRF for diffusion in soil, $C R F_{D i f}$, was defined as the ratio of the radionuclide concentration in the waste to its resulting concentration in the upper one centimeter of soil. The CRF for dispersion in

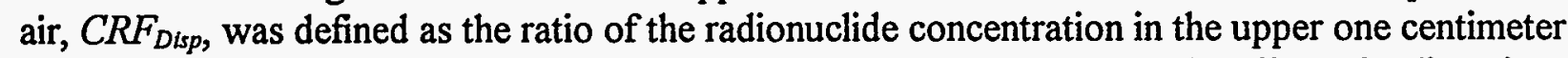
of soil to its resulting concentration in air at the performance boundary. The effect of radioactive decay was also included in the PE.

Application of the PE methodology for atmospheric transport of the two volatile radionuclides considered in the $\mathrm{PE}(\mathrm{H}-3$ and $\mathrm{C}-14)$ produced the results shown in Table 16-5 for both the generic trench and tumulus designs; there was no assumed difference in these two disposal technologies with respect to permissible waste limits based on the atmospheric pathway at Hanford. The table shows permissible waste concentrations based on transport in the atmospheric pathway $\left(C_{W-A t m}\right)$, as well as the values used in calculating the permissible waste concentrations. For both $\mathrm{H}-3$ and $\mathrm{C}-14$, the greatest concentration reduction occurred as the radionuclides diffuse from the top of the disposal facility to the soil surface. 
Table 16-5. Results of Calculations for the Atmospheric Pathway

\begin{tabular}{|c|c|c|c|c|c|c|c|}
\hline \multirow[t]{2}{*}{ Nuclide } & \multirow[b]{2}{*}{$\underset{(\mathrm{rem} / \mathrm{y}) /(\mu \mathrm{Ci} / L)}{S D C F_{\text {L }}}$} & \multicolumn{6}{|c|}{ Generic Trench and Tumulus } \\
\hline & & $\begin{array}{c}C R F_{\text {Diff }} \\
\text { (dilmenedontess) }\end{array}$ & $\underset{\text { (dimeneiontest) }}{C R F_{\text {Dixp }}}$ & $\underset{\text { (dimenestonteres) }}{C R F_{\text {Atm }}}$ & $\begin{array}{l}\text { Arrival } \\
\text { Time (y) }\end{array}$ & $\begin{array}{c}r_{\text {Docay }} \\
\text { (dimenationless) }\end{array}$ & $\begin{array}{c}C_{W \cdot A t m} \\
\left(\mu \mathrm{Ci} / \mathrm{m}^{3}\right)\end{array}$ \\
\hline $\mathrm{H}-3$ & $8.33 E+02$ & $8 E+05$ & $8 \mathrm{E}+02$ & $6 E+08$ & 100 & 300 & $2 E+09$ \\
\hline C-14 & $2.20 E+05$ & $2 E+04$ & $1 E+03$ & $3 E+07$ & 100 & 1 & $1 E+03$ \\
\hline
\end{tabular}

The time of arrival at the performance boundary for both radionuclides is shown in Table 16-5 as $100 \mathrm{y}$. However, the actual migration of $\mathrm{H}-3$ and $\mathrm{C}-14$ from the disposal facility to the surface and downwind to the performance boundary was calculated to be on the order of hours, not years. As discussed in Section 16.3.2, the waste form and RCRA cover are assumed to retain these volatile radionuclides in the disposal facility for at least $100 \mathrm{y}$.

Hanford has plans for an MLLW disposal facility, the Radioactive Mixed Waste Land Disposal Facility. Appendix A.4 presents the results of applying the PE method to that facility. Appendix A.4 also contains a comparison of the PE method for the atmospheric pathway and its results to the LLW performance assessment conducted for Hanford's 200-West Area Burial Grounds (Wood et al., 1994).

\subsubsection{Inadvertent Intruder Exposure}

The calculation of permissible waste concentrations for inadvertent intruder exposures did not utilize CRFs. Instead, the total dose resulting from an intrusion scenario (the sum of the doses from all exposure pathways involved in that intrusion) was computed from scenario dose conversion factors (SDCFs) that were applied to specific exposure pathways. These SDCF values were radionuclide-specific and facility-design-specific and were the same for all sites. The exposure pathways evaluated for each radionuclide are listed in Appendix D of Volume 2. Values for the radioactive decay term were based on time of intrusion into the disposal facility (for the homesteader scenario: $300 \mathrm{y}$ for the trench design and $500 \mathrm{y}$ for the tumulus design; for the post-drilling scenario: $100 \mathrm{y}$ for both disposal designs). However, results based on intruder scenarios should be evaluated carefully because future social behavior, and intrusion scenarios, are difficult to predict.

The permissible waste concentrations for the two generic facility designs for each of the 58 radionuclides based on the standard PE intrusion scenarios are listed in Table 16-6. The most restrictive radionuclide concentration limits for each generic facility are indicated with boldface type. 
Table 16-6. Permissible Waste Concentrations for the Standard Intrusion Scenarios (most limiting radionuclide concentration for each facility design is highlighted in bold italic) (Part 1 of 2)

\begin{tabular}{|c|c|c|c|c|c|}
\hline \multirow[t]{2}{*}{ Nuclide } & \multicolumn{2}{|c|}{ Trench } & \multicolumn{2}{|c|}{ Tumulus } & \multirow[t]{2}{*}{ Nuclide } \\
\hline & $\begin{array}{c}C_{\text {w/mtr }} \\
\text { Homesteader } \\
\left(\mu \mathrm{Ci} / \mathrm{m}^{3}\right) \\
\end{array}$ & $\begin{array}{c}C_{\text {w/nt }} \\
\text { Post-Drilling } \\
\left(\mu \mathrm{Ci} / \mathrm{m}^{3}\right) \\
\end{array}$ & $\begin{array}{c}C_{\text {w/nntr }} \\
\text { Homesteader } \\
\left(\mu \mathrm{Ci} / \mathrm{m}^{3}\right) \\
\end{array}$ & $\begin{array}{c}C_{w-I n t r} \\
\text { Post-Drilling } \\
\left(\mu \mathrm{Ci} / \mathrm{m}^{3}\right) \\
\end{array}$ & \\
\hline $\mathrm{H}-3$ & $1 E+12$ & $7 E+07$ & $\mathrm{NL}$ & $7 E+07$ & $\mathrm{H}-3$ \\
\hline$c-14$ & $1 E+04$ & $7 E+04$ & $1 E+04$ & $7 E+04$ & C-14 \\
\hline Al-26 & $5 E+01$ & $5 E+04$ & $5 E+01$ & $5 E+04$ & Al-26 \\
\hline Si-32 & $9 E+03$ & $1 E+04$ & $4 E+04$ & $1 E+04$ & Si-32 \\
\hline $\mathrm{Cl}-36$ & $2 E+02$ & $9 E+02$ & $2 E+02$ & $9 E+02$ & $\mathrm{Cl}-36$ \\
\hline$K-40$ & $7 E+02$ & $2 E+04$ & $7 E+02$ & $2 E+04$ & $K-40$ \\
\hline Co-60 & NL & $3 E+10$ & $\mathrm{NL}$ & $3 E+10$ & Co-60 \\
\hline $\mathrm{Ni}-59$ & $3 E+06$ & $1 E+07$ & $3 E+06$ & $1 E+07$ & $\mathrm{Ni}-59$ \\
\hline $\mathrm{Ni}-63$ & $8 E+06$ & $1 E+07$ & $3 E+07$ & $1 E+07$ & $\mathrm{Ni}-63$ \\
\hline Se-79 & $2 E+05$ & $8 E+05$ & $2 E+05$ & $8 E+05$ & Se-79 \\
\hline Sr-90 & $1 E+06$ & $5 E+04$ & $1 E+08$ & $5 E+04$ & Sr-90 \\
\hline Zr-93 & $5 E+06$ & $3 E+07$ & $5 E+06$ & $3 E+07$ & $\mathrm{Zr}-93$ \\
\hline $\mathrm{Nb}-93 \mathrm{~m}$ & $5 E+12$ & $4 E+09$ & $\mathrm{NL}$ & $4 E+09$ & $\mathrm{Nb}-93 \mathrm{~m}$ \\
\hline $\mathrm{Nb}-94$ & $9 E+01$ & $9 E+04$ & $1 E+02$ & $9 E+04$ & $\mathrm{Nb}-94$ \\
\hline Tc-99 & $2 E+04$ & $8 E+04$ & $2 E+04$ & $8 E+04$ & Tc-99 \\
\hline$P d-107$ & $6 E+06$ & $3 E+07$ & $6 E+06$ & $3 E+07$ & $P d-107$ \\
\hline $\mathrm{Ag}-108 \mathrm{~m}$ & $5 E+02$ & $1 E+05$ & $1 E+03$ & $1 E+05$ & $\mathrm{Ag}-108 \mathrm{~m}$ \\
\hline $\mathrm{Cd}-113 \mathrm{~m}$ & $4 E+09$ & $1 E+06$ & $7 E+13$ & $1 E+06$ & Cd-113m \\
\hline Sn-121m & $2 E+07$ & $5 E+07$ & $2 E+08$ & $5 E+07$ & $\mathrm{Sn}-121 \mathrm{~m}$ \\
\hline Sn-126 & $8 E+01$ & $7 E+04$ & $8 E+01$ & $7 E+04$ & Sn-126 \\
\hline $\mid-129$ & $2 E+03$ & $1 E+04$ & $2 E+03$ & $1 E+04$ & $\mid-129$ \\
\hline Cs-135 & $2 E+05$ & $8 E+05$ & $2 E+05$ & $8 E+05$ & Cs-135 \\
\hline Cs-137 & $3 E+05$ & $8 E+05$ & $3 E+07$ & $8 E+05$ & Cs-137 \\
\hline $\mathrm{Ba}-133$ & $2 E+11$ & $3 E+08$ & NL & $3 E+08$ & $\mathrm{Ba}-133$ \\
\hline Sm-151 & $2 E+08$ & $2 E+08$ & $8 E+08$ & $2 E+08$ & Sm-151 \\
\hline Eu-152 & $6 E+08$ & $2 E+07$ & $2 E+13$ & $2 E+07$ & Eu-152 \\
\hline Eu-154 & $4 E+12$ & $4 E+08$ & $\mathrm{NL}$ & $4 E+08$ & Eu-154 \\
\hline $\mathrm{Pb}-210$ & $7 E+06$ & $7 E+04$ & $4 E+09$ & $7 E+04$ & $\mathrm{~Pb}-210$ \\
\hline Ra-226 & $8 E+01$ & $3 E+03$ & $9 E+01$ & $3 E+03$ & Ra-226 \\
\hline Ra-228 & $\mathrm{NL}$ & $4 E+09$ & $\mathrm{NL}$ & $4 E+09$ & Ra-228 \\
\hline Th-229 & $5 E+02$ & $3 E+04$ & $5 E+02$ & $3 E+04$ & Th-229 \\
\hline Th-230 & $8 E+01$ & $7 E+04$ & $8 E+01$ & $7 E+04$ & Th-230 \\
\hline Th-232 & $6 E+01$ & $2 E+04$ & $6 E+01$ & $2 E+04$ & Th-232 \\
\hline $\mathrm{Pa}-231$ & $2 E+02$ & $5 E+03$ & $2 E+02$ & $5 E+03$ & $\mathrm{~Pa}-231$ \\
\hline
\end{tabular}


Table 16-6. Permissible Waste Concentrations for the Standard Intrusion Scenarios (most limiting radionuclide concentration for each facility design is highlighted in bold italic) (Part 2 of 2)

\begin{tabular}{|c|c|c|c|c|c|}
\hline \multirow[t]{2}{*}{ Nuclide } & \multicolumn{2}{|c|}{ Trench } & \multicolumn{2}{|c|}{ Tumulus } & \multirow[t]{2}{*}{ Nuclide } \\
\hline & $\begin{array}{c}\text { Cw-tntr }^{a} \\
\text { Homesteader } \\
\left(\mu \mathrm{Ci} / \mathrm{m}^{3}\right)\end{array}$ & $\begin{array}{c}C_{w-1 n t r} \\
\text { Post-Drilling } \\
\left(\mu \mathrm{Ci} / \mathrm{m}^{3}\right)\end{array}$ & $\begin{array}{c}C_{w / n r^{a}} \\
\text { Homesteader } \\
\left(\mu \mathrm{Ci} / \mathrm{m}^{3}\right)\end{array}$ & $\begin{array}{c}\text { Cwalntr } \\
\text { Post-Drilling } \\
\left(\mu \mathrm{Ci} / \mathrm{m}^{3}\right)\end{array}$ & \\
\hline U-232 & $2 E+03$ & $5 E+04$ & $1 E+04$ & $5 E+04$ & U-232 \\
\hline $\mathrm{U}-233$ & $7 E+02$ & $1 E+05$ & $7 E+02$ & $1 E+05$ & U-233 \\
\hline U-234 & $1 E+03$ & $1 E+05$ & $1 E+03$ & $1 E+05$ & U-234 \\
\hline U-235 & $6 E+02$ & $1 E+05$ & $6 E+02$ & $1 E+05$ & U-235 \\
\hline U-236 & $2 E+04$ & $1 E+05$ & $2 E+04$ & $1 E+05$ & U-236 \\
\hline U-238 & $5 E+03$ & $1 E+05$ & $5 E+03$ & $1 E+05$ & U-238 \\
\hline $\mathrm{Np}-237$ & $4 E+02$ & $4 E+03$ & $4 E+02$ & $4 E+03$ & Np-237 \\
\hline Pu-238 & $7 E+04$ & $1 E+05$ & $4 E+05$ & $1 E+05$ & Pu-238 \\
\hline Pu-239 & $6 E+03$ & $5 E+04$ & $6 E+03$ & $5 E+04$ & Pu-239 \\
\hline Pu-240 & $6 E+03$ & $5 E+04$ & $7 E+03$ & $5 E+04$ & Pu-240 \\
\hline Pu-241 & $2 E+05$ & $1 E+06$ & $3 E+05$ & $1 E+06$ & $\mathrm{Pu}-241$ \\
\hline Pu-242 & $6 E+03$ & $5 E+04$ & $6 E+03$ & $5 E+04$ & $\mathrm{Pu}-242$ \\
\hline Pu-244 & $4 E+02$ & $5 E+04$ & $4 E+02$ & $5 E+04$ & Pu-244 \\
\hline Am-241 & $7 E+03$ & $5 E+04$ & $9 E+03$ & $5 E+04$ & Am-241 \\
\hline Am-243 & $9 E+02$ & $4 E+04$ & $9 E+02$ & $4 E+04$ & Aim-243 \\
\hline Cm-243 & $1 E+06$ & $8 E+05$ & $5 E+06$ & $8 E+05$ & $\mathrm{Cm}-243$ \\
\hline Cm-244 & $2 E+06$ & $3 E+06$ & $2 E+06$ & $3 E+06$ & Cm-244 \\
\hline Cm-245 & $1 E+03$ & $4 E+04$ & $1 E+03$ & $4 E+04$ & $\mathrm{Cm}-245$ \\
\hline $\mathrm{Cm}-246$ & $6 E+03$ & $5 E+04$ & $6 E+03$ & $5 E+04$ & $\mathrm{Cm}-246$ \\
\hline $\mathrm{Cm}-247$ & $3 E+02$ & $5 E+04$ & $3 E+02$ & $5 E+04$ & Cm-247 \\
\hline $\mathrm{Cm}-248$ & $2 E+03$ & $1 E+04$ & $2 E+03$ & 1E+04 & $\mathrm{Cm}-248$ \\
\hline Cf-249 & $8 E+02$ & $4 E+04$ & $1 E+03$ & $4 E+04$ & Cf-249 \\
\hline Cf-250 & $2 E+06$ & $9 E+06$ & $2 E+06$ & $9 E+06$ & Cf-250 \\
\hline Cf-251 & $2 E+03$ & $4 E+04$ & $2 E+03$ & $4 E+04$ & Cf-251 \\
\hline
\end{tabular}

a "NL" means No Limit - estimated permissible concentration is greater than the specific activity of the pure elemental radionuclide. 
For six radionuclides in the table (U-233, U-234, U-235, U-238, Pu-244, and Cm-247), the time of homesteader intrusion was changed to $10,000 \mathrm{y}$, the end of the performance period. For these six radionuclides, ingrowth of decay products yields scenario doses that increase over time. The doses at $10,000 \mathrm{y}$, therefore, represent the maximum that could be encountered during the performance period. Also, for Th-230 and $\mathrm{Cm}-245$, ingrowth of decay products likewise produces a scenario dose that increases over time and peaks within the 10,000-y performance period. The times of homesteader intrusion for these two radionuclides (Th-230 and Cm-245) were taken as the time of maximum dose, $9000 \mathrm{y}$ and $1000 \mathrm{y}$, respectively.

For the trench design, the permissible waste concentrations of 46 radionuclides were limited by the homesteader scenario, 11 were limited by the post-drilling scenario, and one was limited by both the homesteader and post-drilling scenarios. For the trench design, the post-drilling scenario generally yielded more restrictive waste limits than the homesteader scenario for those radionuclides with half-lives shorter than about $30 \mathrm{y}$. For the tumulus design, the permissible waste concentrations of 41 radionuclides were limited by the homesteader scenario and 17 were limited by the post-drilling scenario. For the tumulus design, the post-drilling scenario generally yielded more restrictive limits than the homesteader scenario for those radionuclides with half-lives shorter than about $130 \mathrm{y}$.

Hanford has plans for an MLLW disposal facility, the Radioactive Mixed Waste Land Disposal Facility. The results of applying the PE method to that facility are presented in Appendix A.4. That appendix also contains a comparison of the PE method for the intrusion scenarios and its results to the LLW performance assessment conducted for Hanford's 200-West Area Burial Grounds (Wood et al., 1994).

\subsection{SUMMARY AND DISCUSSION OF RESULTS}

The limiting waste concentrations in disposed MLLW for the water, atmospheric, and intruder analyses for the generic trench and tumulus designs are summarized in Table 16-7 and discussed in Section 16.6.1. An overall discussion of the results of the PE for Hanford is contained in Section 16.6.2.

\subsubsection{Results Based on Disposal Design}

For the generic trench design at Hanford, 13 radionuclides were limited by the water pathway, one radionuclide (C-14) was limited by the atmospheric pathway, and 44 radionuclides were limited by intrusion scenarios, as shown in Table 16-7. Among the 44 radionuclides limited by intrusion scenarios for the trench design at Hanford, 34 were controlled by homesteader intrusion, while 10 were controlled by post-drilling.

For the generic tumulus design, 12 radionuclides were limited by the water pathway, one radionuclide (C-14) was limited by the atmospheric pathway, and 45 radionuclides were limited by intrusion scenarios. Among the 45 radionuclides limited by intrusion scenarios for the tumulus design at Hanford, 28 were controlled by homesteader intrusion, while 17 were controlled by post-drilling. 
Table 16-7. Permissible Concentrations for the Generic Disposal Designs at Hanford (permissible concentration related to the limiting pathway for each facility design is highlighted in bold italic) (Part 1 of 2 )

\begin{tabular}{|c|c|c|c|c|c|c|c|}
\hline \multirow[t]{2}{*}{ Nuclide } & \multicolumn{3}{|c|}{ Trench } & \multicolumn{3}{|c|}{ Tumulus } & \multirow[t]{2}{*}{ Nuclide } \\
\hline & $\begin{array}{c}C_{\text {w.Water }}{ }^{a, b} \\
\left(\mu \mathrm{Ci} / \mathrm{m}^{3}\right) \\
\end{array}$ & $\begin{array}{l}C_{W-A t m}{ }^{c} \\
\left(\mu \mathrm{Ci} / \mathrm{m}^{3}\right)\end{array}$ & $\begin{array}{l}C_{w-1 n t^{d}} \\
\left(\mu \mathrm{Ci} / \mathrm{m}^{3}\right)\end{array}$ & $\begin{array}{c}C_{W \cdot W_{\text {ator }}}{ }^{a, b} \\
\left(\mu \mathrm{Ci} / \mathrm{m}^{3}\right)\end{array}$ & $\begin{array}{l}C_{W-A t m}^{c} \\
\left(\mu \mathrm{Ci} / \mathrm{m}^{3}\right) \\
\end{array}$ & $\begin{array}{l}C_{w-1 m t r}^{d} \\
\left(\mu \mathrm{Ci} / \mathrm{m}^{3}\right)\end{array}$ & \\
\hline $\mathrm{H}-3$ & $3 E+07$ & $2 E+09$ & $7 E+07$ & $1 E+14$ & $2 E+09$ & $7 E+07$ & $\mathrm{H}-3$ \\
\hline$c-14$ & $3 E+03$ & $1 E+03$ & $1 E+04$ & $7 E+03$ & $1 E+03$ & $1 E+04$ & $c-14$ \\
\hline Al-26 & - & & $5 E+01$ & - & & $5 E+01$ & $\mathrm{Al}-26$ \\
\hline Si-32 & - & & $9 E+03$ & - & & $1 E+04$ & Si-32 \\
\hline $\mathrm{Cl}-36$ & $4 E+01$ & & $2 E+02$ & $7 E+01$ & & $2 \mathrm{E}+02$ & $\mathrm{Cl}-36$ \\
\hline$K-40$ & - & & $7 E+02$ & - & & $7 E+02$ & $K-40$ \\
\hline $\mathrm{Co}-60$ & NL & & $3 E+10$ & NL & & $3 E+10$ & $\mathrm{Co}-60$ \\
\hline Ni-59 & - & & $3 E+06$ & - & & $3 E+06$ & $\mathrm{Ni}-59$ \\
\hline $\mathrm{Ni}-63$ & - & & $8 E+06$ & - & & $1 E+07$ & $\mathrm{Ni}-63$ \\
\hline Se-79 & $9 E+01$ & & $2 E+05$ & $2 E+02$ & & $2 E+05$ & Se-79 \\
\hline St-90 & NL & & $5 E+04$ & NL & & $5 E+04$ & Sr-90 \\
\hline Zr-93 & - & & $5 E+06$ & - & & $5 E+06$ & $\mathrm{Zr}-93$ \\
\hline $\mathrm{Nb}-93 \mathrm{~m}$ & - & & $4 E+09$ & - & & $4 E+09$ & $\mathrm{Nb}-93 \mathrm{~m}$ \\
\hline $\mathrm{Nb}-94$ & - & & $9 E+01$ & - & & $1 E+02$ & $\mathrm{Nb}-94$ \\
\hline TC-99 & $5 E+02$ & & $2 E+04$ & $1 E+03$ & & $2 E+04$ & Tc-99 \\
\hline$P d-107$ & - & & $6 E+06$ & - & & $6 E+06$ & $\mathrm{Pd}-107$ \\
\hline $\mathrm{Ag}-108 \mathrm{~m}$ & - & & $5 E+02$ & - & & $1 E+03$ & $\mathrm{Ag}-108 \mathrm{~m}$ \\
\hline $\mathrm{Cd}-113 \mathrm{~m}$ & - & & $1 E+06$ & - & & $1 E+06$ & $\mathrm{Cd}-113 \mathrm{~m}$ \\
\hline Sn-121m & - & & $2 E+07$ & - & & $5 E+07$ & Sn-121m \\
\hline Sn-126 & - & & $8 E+01$ & - & & $8 E+01$ & Sn-126 \\
\hline I-129 & $3 E+00$ & & $2 E+03$ & $6 E+00$ & & $2 E+03$ & $1-129$ \\
\hline Cs-135 & $9 E+02$ & & $2 E+05$ & $2 E+03$ & & $2 E+05$ & Cs-135 \\
\hline Cs-137 & NL & & $3 E+05$ & $\mathrm{NL}$ & & $8 E+05$ & Cs-137 \\
\hline $\mathrm{Ba}-133$ & $\mathrm{NL}$ & & $3 E+08$ & $\mathrm{NL}$ & & $3 E+08$ & $\mathrm{Ba}-133$ \\
\hline$S m-151$ & - & & $2 E+08$ & - & & $2 E+08$ & $\mathrm{Sm}-151$ \\
\hline Eu-152 & - & & $2 E+07$ & - & & $2 E+07$ & Eu-152 \\
\hline Eu-154 & - & & $4 E+08$ & - & & $4 E+08$ & Eu-154 \\
\hline $\mathrm{Pb}-210$ & - & & $7 E+04$ & - & & $7 E+04$ & $\mathrm{~Pb}-210$ \\
\hline Ra-226 & - & & $8 E+01$ & - & & $9 E+01$ & $\mathrm{Ra}-226$ \\
\hline Ra-228 & - & & $4 E+09$ & - & & $4 E+09$ & Ra-228 \\
\hline Th-229 & - & & $5 E+02$ & - & & $5 E+02$ & Th-229 \\
\hline Th-230 & - & & $8 E+01$ & - & & $8 E+01$ & Th-230 \\
\hline Th-232 & - & & $6 E+01$ & - & & $6 E+01$ & Th-232 \\
\hline $\mathrm{Pa}-231$ & $3 E+00$ & & $2 E+02$ & $5 E+00$ & & $2 E+02$ & Pa-231 \\
\hline
\end{tabular}


Table 16-7. Permissible Concentrations for the Generic Disposal Designs at Hanford (permissible concentration related to the limiting pathway for each facility design is highlighted in bold italic) (Part 2 of 2)

\begin{tabular}{|c|c|c|c|c|c|c|c|}
\hline \multirow[t]{2}{*}{ Nuclide } & \multicolumn{3}{|c|}{ Trench } & \multicolumn{3}{|c|}{ Tumulus } & \multirow[t]{2}{*}{ Nuclide } \\
\hline & $\begin{array}{c}C_{\text {w.Water }}{ }^{a, b} \\
\left(\mu \mathrm{Ci} / \mathrm{m}^{3}\right)\end{array}$ & $\begin{array}{l}C_{W-A t m}{ }^{c} \\
\left(\mu \mathrm{Ci} / \mathrm{m}^{3}\right)\end{array}$ & $\begin{array}{l}C_{\text {Wdntr }}{ }^{d} \\
\left(\mu \mathrm{Ci} / \mathrm{m}^{3}\right)\end{array}$ & $\begin{array}{c}C_{\text {w.Water }}{ }^{2, b} \\
\left(\mu \mathrm{Ci} / \mathrm{m}^{3}\right)\end{array}$ & $\begin{array}{c}C_{W-A t m}{ }^{c} \\
\left(\mu \mathrm{Ci} / m^{3}\right)\end{array}$ & $\begin{array}{l}C_{w-I n t r}{ }^{d} \\
\left(\mu \mathrm{Cil} / \mathrm{m}^{3}\right)\end{array}$ & \\
\hline U-232 & $2 E+02$ & & $2 E+03$ & $4 E+03$ & & $1 E+04$ & U-232 \\
\hline U-233 & $2 E+02$ & & $7 E+02$ & $3 E+02$ & & $7 E+02$ & U-233 \\
\hline U-234 & $2 E+02$ & & $1 E+03$ & $5 E+02$ & & $1 E+03$ & U-234 \\
\hline U-235 & $2 E+02$ & & $6 E+02$ & $3 E+02$ & & $6 E+02$ & U-235 \\
\hline U-236 & $2 E+02$ & & $2 E+04$ & $5 E+02$ & & $2 E+04$ & U-236 \\
\hline U-238 & $2 E+02$ & & $5 E+03$ & $5 E+02$ & & $5 E+03$ & U-238 \\
\hline Np-237 & - & & $4 E+02$ & - & & $4 E+02$ & $\mathrm{~Np}-237$ \\
\hline Pu-238 & $6 E+05$ & & $7 E+04$ & $1 E+06$ & & $1 E+05$ & Pu-238 \\
\hline Pu-239 & - & & $6 E+03$ & - & & $6 E+03$ & Pu-239 \\
\hline Pu-240 & - & & $6 E+03$ & - & & $7 E+03$ & Pu-240 \\
\hline Pu-241 & - & & $2 E+05$ & - & & $3 E+05$ & Pu-241 \\
\hline Pu-242 & - & & $6 E+03$ & - & & $6 E+03$ & Pu-242 \\
\hline Pu-244 & - & & $4 E+02$ & - & & $4 E+02$ & Pu-244 \\
\hline Am-241 & - & & $7 E+03$ & - & & $9 E+03$ & Am-241 \\
\hline Am-243 & - & & $9 E+02$ & - & & $9 E+02$ & Am-243 \\
\hline $\mathrm{Cm}-243$ & - & & $8 E+05$ & - & & $8 E+05$ & $\mathrm{Cm}-243$ \\
\hline $\mathrm{Cm}-244$ & - & & $2 E+06$ & - & & $2 E+06$ & $\mathrm{Cm}-244$ \\
\hline $\mathrm{Cm}-245$ & - & & $1 E+03$ & - & & $1 E+03$ & $\mathrm{Cm}-245$ \\
\hline $\mathrm{Cm}-246$ & - & & $6 E+03$ & - & & $6 E+03$ & $\mathrm{Cm}-246$ \\
\hline $\mathrm{Cm}-247$ & - & & $3 E+02$ & - & & $3 E+02$ & $\mathrm{Cm}-247$ \\
\hline $\mathrm{Cm}-248$ & - & & $2 E+03$ & - & & $2 E+03$ & $\mathrm{Cm}-248$ \\
\hline Cf-249 & - & & $8 E+02$ & $=$ & & $1 E+03$ & Cf-249 \\
\hline$C f-250$ & - & & $2 E+06$ & - & & $2 E+06$ & Cf-250 \\
\hline$C f-251$ & - & & $2 E+03$ & - & & $2 E+03$ & Cf-251 \\
\hline
\end{tabular}

a "NL" means No Limit - estimated permissible concentration factor is greater than the specific activity of the pure elemental radionuclide.

b "--" indicates that the radionuclide concentration is based on an arrival time beyond 10,000 y; see Table $16-4$ for specific values.

c Results presented for radionclides expected to be volatile under disposal facility conditions.

d Concentration is based on the most restrictive intrusion scenario assumed for the site; see Table 16-6. 
For both the trench design and the tumulus design, concentrations for four radionuclides (Co-60, Sr-90, Cs-137, and Ba-133) that arrived at the performance boundary before 10,000 y reported in Table 16-7 for the water pathway analysis had no limit. As discussed in Section 16.5.1, the calculated concentrations for those radionuclides reported as NL (No Limit) were above the specific activity of the pure elemental radionuclide, implying that the performance measure of $4 \mathrm{mrem}(0.04 \mathrm{mSv})$ per year would not be reached under the given release and transport assumptions.

As also discussed in Section 16.5.1, values for some radionuclides are not reported in Table 16-7 for the water pathway analysis. Arrival times for these radionuclides were beyond the 10,000-y performance period. For these radionuclides, the estimated waste concentrations are presented in Table 16-4 for information purposes but are not listed in Table 16-7. Consistent with the approach used in LLW performance assessments, these values were not considered in determining the most restrictive disposal limit from among the evaluated pathways because arrival times for these radionuclides were beyond $10,000 \mathrm{y}$.

For both the trench and tumulus designs at Hanford, the radionuclides limited by the water pathway generally tended to be highly mobile (e.g., H-3 and Tc-99). The radiums, thoriums, and most of the transuranics are not shown as being limited by the water pathway because their peak arrival times were beyond $10,000 \mathrm{y}$. For the both the trench design and the tumulus design, uranium is limited by the water pathway.

At Hanford, there is no significant difference in the permissible waste concentrations computed with the PE methodology for the trench as compared to the tumulus. That is, there is less than one order of magnitude difference in the waste limits between the two disposal facility designs.

\subsubsection{Discussion}

The results of the $\mathrm{PE}$ are based on the framework of assumptions summarized in Chapter 1 of this volume and discussed in detail in Volume 2 of this report and on the site-specific conceptual model for contaminant transport discussed in this chapter. Using alternative assumptions about the conceptual model has the potential to affect the results. Changes in the conceptual model could include alternative assumptions about the disposal facility, the source term, and radionuclide movement in the three pathways. Depending on the degree of possible variation and the relative importance of the parameters used in the calculation of estimated permissible radionuclide concentrations, variability in parameter values can also affect the results. For parameters, results could vary depending on potential changes in values of both the generic and the site-specific parameters used in the PE analysis. The effect on results from using alternative generic assumptions and parameter values is discussed in Chapter 6 of Volume 2. In addition, a discussion is provided in that chapter of the effects of using alternative values for sitespecific parameters. Based on this discussion, four parameters were identified (three site-specific and one generic, all used in the water pathway analysis) that could potentially influence the results to the degree that the calculated waste concentrations become limited by a pathway other than the one determined for the PE (Table 16-7). The impacts on the results of using alternative values for these four parameters for the water pathway in the PE for Hanford are discussed in this section. 
The basis for and possible variation in the values used in the PE for these parameters are discussed in Section 16.6.2.2.

\subsubsection{Parameter Sensitivity Analysis}

The PE provided results for two disposal facility designs: a RCRA-compliant, belowground trench and a RCRA-compliant, above-ground tumulus. Similar assumptions about the integrity of engineered barriers were made in the $\mathrm{PE}$ for both facility designs. Because the factors used to estimate transport of radionuclides in the water pathway for both designs were similar, the discussion in this section focuses on examining the results for the indicator radionuclides reported for the tumulus design (indicator radionuclides are defined in Chapter 7 of Volume 2).

As discussed in Chapter 6 of Volume 2, four parameters used in the PE were identified as having a potential range of values that might affect results: annual natural recharge ( $i)$; groundwater Darcy velocity $\left(q_{g w}\right)$; plan-view area of the facility $(A)$; and distribution coefficients $\left(K_{\alpha} s\right)$. These parameter values for Hanford are summarized in Table 16-8.

Table 16-8. Parameter Values Used in the PE for Hanford with Potential Variability That Could Affect the Results

\begin{tabular}{|l|l|}
\hline \multicolumn{1}{|c|}{ Parameter } & \multicolumn{1}{c|}{ Value } \\
\hline Natural recharge through local soils, $i$ & $\begin{array}{l}0.05 \mathrm{~m} / \mathrm{y} \text { (based on site information; see } \\
\text { Section 16.3.1.1) }\end{array}$ \\
\hline $\begin{array}{l}\text { Distribution coefficients for geologic } \\
\text { media, } K_{d}\end{array}$ & see Table 16-2 in this chapter for values \\
\hline Groundwater Darcy velocity, $q_{g w}$ & $\begin{array}{l}22 \mathrm{~m} / \mathrm{y} \text { (based on site-specific measurement; } \\
\text { see Section 16.4.1 for discussion) }\end{array}$ \\
\hline Plan-view Area, $A$ & $2500 \mathrm{~m}^{2}$ (standard PE value) \\
\hline
\end{tabular}

The traditional procedure for performing a sensitivity analysis is to vary the parameters used in the calculations and observe the effect on the results. To be meaningful, this method requires some knowledge of the statistical distribution of each of the parameters considered, including their likely maximum and minimum values. For the PE calculations, the potential variability of the parameters used to calculate the permissible waste concentrations for the two different facility designs was not estimated. For most of the radionuclides considered in the PE, there were only two exposure pathways: the water pathway and intruder exposure scenarios (the atmospheric pathway is considered only for $\mathrm{H}-3$ and $\mathrm{C}-14$ ). The intruder-pathway results provide a baseline that can be used for comparison with the water-pathway results because the intruder scenarios used in the PE were relatively independent of the physical characteristics of the individual sites. For $\mathrm{H}-3$ and $\mathrm{C}-14$, the atmospheric-pathway results present a baseline that can also be used for comparison with the water pathway because the atmospheric-pathway results are not highly sensitive to any individual input parameter (see Chapter 6 of Volume 2). 
The intruder and atmospheric baselines provided an alternative method of performing sensitivity analyses for the $\mathrm{PE}$. The input parameters for the water pathway were varied to determine if the limiting exposure pathway could be altered (e.g., the results could be changed from intruder-scenario-controlled [or atmospheric-pathway-controlled] to water-pathwaycontrolled). After new values for the water pathway parameters were determined, these values were examined for reasonableness based on physical constraints at the site.

To analyze the sensitivity of the results to changes in the parameter values for natural recharge, groundwater Darcy velocity, and area of the facility, the parameter values used in the $\mathrm{PE}$ for Hanford were varied. Only one parameter value was varied at a time for a radionuclide, leaving the others equal to their PE values. In most instances, the parameter value was varied until the waste concentrations for the water and intruder (or atmospheric) pathways became equal, regardless of the likelihood (or physical impossibility) of the value to occur.

The parameter values that caused the permissible concentrations for the water and intruder pathways to become equal are listed in Table 16-9a for the 8 indicator radionuclides. For the indicator radionuclide $\mathrm{H}-3$, no value variations of these parameters resulted in equal concentrations. For C-14, the limiting pathway is the atmospheric pathway, so the water versus intruder comparison is not applicable. For Sr-90 and Cs-137, increases in recharge of about 2 orders of magnitude were required to change the limiting pathway from intruder to water. No value variations in the groundwater velocity or facility area resulted in equal concentrations for these two radionuclides. For Tc-99 and U-238, the value for recharge had to decrease by at least one order of magnitude, or the groundwater velocity had to increase by at least one order of magnitude to change the limiting pathway from water to intruder. For both Tc-99 and U-238, a facility area as small as $100 \mathrm{~m}^{2}$ did not result in a water pathway concentration as large as the intruder pathway concentration. For Pu-239, all variations caused arrival times beyond 10,000 y. For Am-241, the value for recharge had to increase by more than three orders of magnitude, the groundwater velocity had to decrease by more than a factor of 20 , or the facility area had to increase by about three orders of magnitude for the water and intruder pathway concentrations to be equal. However, the variations in groundwater velocity and area resulted in arrival times later than $10,000 \mathrm{y}$.

The parameter values that caused the permissible concentrations for the water and atmospheric pathways to become equal are listed in Table 16-9b for H-3 and C-14. For H-3, the limiting pathway is the intrusion scenario, so this comparison is not applicable. For the indicator radionuclide $\mathrm{C}-14$, the recharge had to increase by a factor of 8 , the groundwater velocity had to decrease by one order of magnitude, or the plan area had to increase by a factor of 40 to change the limiting pathway from atmospheric to water.

A $K_{d}$ value of about $4 \mathrm{~mL} / \mathrm{g}$ for the geologic media resulted in an arrival time at the performance boundary of $10,000 \mathrm{y}$. The $K_{d}$ values that caused the permissible concentrations for the water and intruder pathways to be the same are listed in Table 16-10 for 5 of the indicator radionuclides. The indicator radionuclides $\mathrm{H}-3, \mathrm{C}-14$, and $\mathrm{Tc}-99$ were not considered in this analysis because general consensus is that the $K_{d}$ values for these radionuclides are small. 
Table 16-9. Parameter Values That Caused the Permissible Concentrations for the Water and Intruder Pathways to Be Equal for Indicator Radionuclides at Hanford (tumulus design) (bold italic type indicates limiting pathway in the PE)

(a) Water/Intruder Pathways

\begin{tabular}{|c|c|c|c|c|c|c|}
\hline \multirow[t]{4}{*}{$\begin{array}{l}\text { Indicator } \\
\text { Nuclide }\end{array}$} & \multirow[t]{4}{*}{$\begin{array}{c}\text { PE } \\
C_{W-W a t e r} \\
\left(\mu \mathrm{Ci} / \mathrm{m}^{3}\right)\end{array}$} & \multirow[t]{4}{*}{$\begin{array}{c}\text { PE } \\
C_{W-\ln t} \\
\left(\mu \mathrm{Ci} / \mathrm{m}^{3}\right)\end{array}$} & \multirow[t]{4}{*}{$\begin{array}{c}\text { PE } \\
\frac{C_{W-\ln t}}{C_{W-\text { water }}}\end{array}$} & $\begin{array}{c}\text { Natural } \\
\text { Recharge, } \\
i \\
(\mathrm{~m} / \mathrm{y})\end{array}$ & $\begin{array}{l}\text { Groundwater } \\
\text { (Aquifer) } \\
\text { Velocity, } q_{g w} \\
\text { (m/y) }\end{array}$ & $\begin{array}{c}\text { Area, } \\
\text { A } \\
\left(\mathrm{m}^{2}\right)\end{array}$ \\
\hline & & & & \multicolumn{3}{|c|}{ PE Values } \\
\hline & & & & 0.05 & 22 & 2500 \\
\hline & & & & \multicolumn{3}{|c|}{$\begin{array}{c}\text { Value That Caused Equal } \\
\text { Concentrations }\end{array}$} \\
\hline $\mathrm{H}-3$ & $1 E+14$ & $7 E+07$ & $7 E-07$ & b & $\bar{b}$ & $\bar{b}$ \\
\hline C-14 & $7 E+03$ & $1 E+04$ & 1.4 & 0.025 & 45 & 1000 \\
\hline Sr-90 & NL & $5 E+04$ & - & 10 & b & b \\
\hline Tc-99 & $1 E+03$ & $2 E+04$ & 20 & 0.003 & 350 & $<100^{b}$ \\
\hline Cs-137 & $\mathrm{NL}$ & $8 E+05$ & - & 78 & $\mathrm{~b}$ & $\mathrm{~b}$ \\
\hline$U-238$ & $5 E+02$ & $5 E+03$ & 10 & 0.005 & 220 & $<100^{b}$ \\
\hline Pu-239 & $2 E+04^{c}$ & $6 E+03$ & 0.3 & $0.06^{c}$ & $6^{c}$ & $2.8 \mathrm{E}+04^{c}$ \\
\hline $\begin{array}{l}\text { Am-241 } \\
(\mathrm{Np}-237)^{\mathrm{d}}\end{array}$ & $1 E+05^{c, \theta}$ & $9 E+03$ & 0.09 & $120^{\circ}$ & $0.9^{c .0}$ & $1.5 \mathrm{E}+06^{c, e}$ \\
\hline
\end{tabular}

a "NL" means No Limit - estimated permissible concentration is greater than the specific activity of the pure elemental radionuclide.

b No variation in values caused equal concentrations.

c Arrival time at the performance boundary is greater than $10,000 \mathrm{y}$.

d The dominant decay product for Am-241

- Based on the dominant decay product, Np-237

"." Value could not be calculated.

(b) Water/Atmospheric Pathways

\begin{tabular}{|c|c|c|c|c|c|c|}
\hline \multirow[t]{4}{*}{$\begin{array}{l}\text { Indicator } \\
\text { Nuclide }\end{array}$} & \multirow[t]{4}{*}{$\begin{array}{c}\mathrm{PE} \\
C_{W \cdot \text { Water }} \\
\left(\mu \mathrm{Ci} / \mathrm{m}^{3}\right)\end{array}$} & \multirow[t]{4}{*}{$\begin{array}{c}\mathrm{PE} \\
C_{W \cdot A t m} \\
\left(\mu \mathrm{Ci} / \mathrm{m}^{3}\right)\end{array}$} & \multirow[t]{4}{*}{$\begin{array}{c}\text { PE } \\
\frac{C_{W-A t m}}{C_{W-W a t e r}}\end{array}$} & $\begin{array}{c}\text { Natural } \\
\text { Recharge, } \\
i \\
(\mathrm{~m} / \mathrm{y})\end{array}$ & $\begin{array}{l}\text { Groundwater } \\
\text { (Aquifer) } \\
\text { Velocity, } q_{\text {ow }} \\
\text { (m/y) }\end{array}$ & $\begin{array}{c}\text { Area, } \\
A \\
\left(\mathrm{~m}^{2}\right)\end{array}$ \\
\hline & & & & \multicolumn{3}{|c|}{ PEValues } \\
\hline & & & & 0.05 & 22 & 2500 \\
\hline & & & & \multicolumn{3}{|c|}{$\begin{array}{l}\text { Value That Caused Equal } \\
\text { Concentrations }\end{array}$} \\
\hline $\mathrm{H}-3$ & $1 E+14$ & $2 E+09$ & $2 E-05$ & 21 & $a$ & $a$ \\
\hline$C-14$ & $7 E+03$ & $1 E+03$ & 0.14 & 0.4 & 2 & $1.0 E+05$ \\
\hline
\end{tabular}

a No variation in values caused equal concentrations. 
Table 16-10. Variation of $K_{d}$ Values for the Geologic Media at Hanford (tumulus design) (a $K_{d}$ value of $4 \mathrm{~mL} / \mathrm{g}$ caused radionuclide arrival at the performance boundary equal to $10,000 \mathrm{y}$ )

\begin{tabular}{|c|c|c|c|c|c|}
\hline $\begin{array}{l}\text { Indicator } \\
\text { Nuclide }\end{array}$ & $\begin{array}{c}\text { PE } \\
K_{d} \\
(\mathrm{~mL} / \mathrm{g})\end{array}$ & $\begin{array}{c}\text { PE } \\
\text { Cw-water }^{2}\end{array}$ & $\begin{array}{l}\text { PE } \\
C_{W \cdot \ln t r}\end{array}$ & $\begin{array}{c}\text { PE } \\
C_{W \text {-ntr }} \\
C_{W-\text { water }}\end{array}$ & $\begin{array}{l}K_{d} \text { Value That } \\
\text { Caused Equal } \\
\text { Concentrations }\end{array}$ \\
\hline Sr-90 & 1 & NL & $5 E+04$ & - & b \\
\hline Cs-137 & 1 & NL & $8 E+05$ & - & b \\
\hline U-238 & 0 & $5 E+02$ & $5 E+03$ & 10 & $b, c$ \\
\hline $\mathrm{Pu}-239$ & 100 & $2 E+04^{d}$ & $6 E+03$ & 0.3 & $80^{d, 0}$ \\
\hline $\begin{array}{l}\text { Am-241 } \\
(\mathrm{Np}-237)^{f}\end{array}$ & $\begin{array}{l}100 \\
(10)\end{array}$ & $1 E+05^{d, g}$ & $9 E+03$ & 0.09 & 1 \\
\hline
\end{tabular}

a "NL" means No Limit - the estimated permissible waste concentration is greater than the specific activity of the pure elemental radionuclide.

b No variation in value caused equal concentrations.

c Value greater than $4 \mathrm{mU} / \mathrm{g}$ caused arrival at the performance boundary after $10,000 \mathrm{y}$, which caused the limiting pathway.

d Arrival time at the performance boundary is greater than $10,000 \mathrm{y}$.

e Value less than $4 \mathrm{~mL} / \mathrm{g}$ caused arrival at the performance boundary before $10,000 \mathrm{y}$, which caused the limiting pathway.

f The dominant decay product for Am-241

g Based on the dominant decay product, Np-237

-- Value could not be calculated.

For $\mathrm{Sr}-90$ and Cs-137, no variation in $K_{d}$ value caused the permissible waste concentrations to become equal. A $K_{d}$ value greater than $4 \mathrm{~mL} / \mathrm{g}$ for U-238 caused the arrival time at the performance boundary to exceed $10,000 \mathrm{y}$ and therefore changed the limiting pathway from water to intruder. For Pu-239, a $K_{d}$ value of $80 \mathrm{~mL} / \mathrm{g}$ caused the water pathway concentration to equal the intruder pathway concentration, although the arrival time still exceeded $10,000 \mathrm{y}$; the $K_{d}$ value had to be decreased to less than $4 \mathrm{~mL} / \mathrm{g}$ for the limiting pathway to change from intruder to water. The PE result for Am-241 was limited by the decay product (Np-237) contribution to the dose. However, if the $K_{d}$ value for Am-241 is reduced to 1, then the water pathway waste concentration will be limited by the parent radionuclide (Am-241) and the water pathway will control. Due to the long half-life of Np-237, reduction of its $K_{d}$ has no effect on the resulting waste concentration.

\subsubsection{Physical Constraints on Sensitivity Analysis Values}

The PE results for Hanford are based on parameter values provided by the Hanford technical staff for site-specific parameters used in calculations. Descriptions and technical justifications of these values are provided in Sections 16.3 and 16.4. The range and statistical distribution may not be known for each input parameter value; however, site-specific knowledge can be used to determine whether the values determined in the sensitivity analysis are reasonable and physically possible at Hanford. 


\section{Natural Recharge}

The sensitivity analysis results indicate it was possible to change the limiting pathway for Tc-99, U-238, and C-14 by changing the natural recharge. The values for recharge estimated in the sensitivity analysis range from 0.025 to $120 \mathrm{~m} / \mathrm{y}(0.082$ to $390 \mathrm{ft} / \mathrm{y})($ Table $16-9 \mathrm{a}$ and b) compared to the $P E$ value of $0.05 \mathrm{~m} / \mathrm{y}(0.16 \mathrm{ft} / \mathrm{y})$. The natural recharge at Hanford may vary from $0 \mathrm{~m} / \mathrm{y}$ to $0.1 \mathrm{~m} / \mathrm{y}(0$ to $0.3 \mathrm{ft} / \mathrm{y})$. Although values as low as $5.0 \times 10^{-6} \mathrm{~m} / \mathrm{y}(0.000016 \mathrm{ft} / \mathrm{y})$ are reported, the performance assessment evaluated the cases of $0.05 \mathrm{~m} / \mathrm{y}(0.16 \mathrm{ft} / \mathrm{y})$ and $0.005 \mathrm{~m} / \mathrm{y}(0.016 \mathrm{ft} / \mathrm{y})$. The greater of these was chosen for the PE for conservation. According to the largest reported range, the sensitivity analysis values for Tc-99, U-238, Pu-239 (Table 16-9a), and C-14 (Table 16-9b) all fall within the reported range, although Pu-239 arrived at the performance boundary beyond $10,000 \mathrm{y}$. The remaining indicator radionuclide values (Sr-90, Cs-137, and Am-241) all fell outside of the reported range for recharge at Hanford and are not physically reasonable.

\section{Groundwater Darcy Velocity}

The sensitivity analysis results indicate it is possible to change the limiting pathway for Tc-99 and U-238 by increasing the groundwater velocity. The values for the groundwater Darcy velocity estimated by the sensitivity analysis vary from 0.9 to $350 \mathrm{~m} / \mathrm{y}(3$ to $1150 \mathrm{ft} / \mathrm{y})$ (Table 16-9a and b) compared to the PE value of $22 \mathrm{~m} / \mathrm{y}(72 \mathrm{ft} / \mathrm{y})$. At Hanford, the groundwater Darcy velocity varies from about $22 \mathrm{~m} / \mathrm{y}$ to $1600 \mathrm{~m} / \mathrm{y}(72 \mathrm{ft} / \mathrm{y}$ to $5200 \mathrm{ft} / \mathrm{y})(\mathrm{Khaleel}, 1995)$. The Tc-99 and U-238 sensitivity analysis values are reasonable because they fall within the reported range for Darcy velocity at Hanford. All other indicator radionuclide sensitivity analysis values (Pu-239, Am-241 and C-14) do not fall within the reported range and are probably not physically reasonable.

\section{Facility Area}

The sensitivity analysis results indicate it was possible to change the limiting pathway from atmospheric to water for $\mathrm{C}-14$ by increasing the facility size. The values for the facility area estimated in the sensitivity analysis ranged from $1000 \mathrm{~m}^{2}$ to $1,500,000 \mathrm{~m}^{2}\left(10,800 \mathrm{ft}^{2}\right.$ to $16,200,000 \mathrm{ft}^{2}$ ) (Table 16-9a and $\mathrm{b}$ ). All of these values are possible as there are no particular physical constraints which limit the size of a MWDF at Hanford. However, in the sensitivity analysis, Pu-239 and Am-241 arrived at the performance boundary beyond 10,000 y.

\section{Distribution Coefficients}

The results shown in Table 16-10 indicate that limiting pathway for U-238 could be changed by changing the $K_{d}$ from 0 to $4 \mathrm{~mL} / \mathrm{g}$. U-238, Pu-239 and Am-241 were the most sensitive of the indicator radionuclides. A decrease in about 2 orders of magnitude for the $\mathrm{Pu}-239$ or Am-241 $K_{d}$ values are probably not reasonable at Hanford; they both had a PE values of $100 \mathrm{~mL} / \mathrm{g}$. The change for U-238 from the PE value of $0 \mathrm{~mL} / \mathrm{g}$ to $4 \mathrm{~mL} / \mathrm{g}$ (the $K_{d}$ required to cause arrival at the performance boundary at $10,000 \mathrm{y}$ ) is reasonable.

16.6.2.3 Comparison of Conceptual Models and Results between the PE and the Hanford Performance Assessment

The conceptual model selected to represent a site can be considerably more important to the results than the parameter values selected for that particular model. The conceptual model for 
flow and transport used in the water pathway analysis for the Hanford LLW performance assessment (Wood, et al., 1994) is believed to be conservative with respect to actual site behavior because relatively few mechanisms are used to represent the environmental concentration that is known or believed to occur. The conceptual model used in this PE analysis is believed to be much more conservative compared to that used in the Hanford LLW performance assessment because fewer attenuation mechanisms have been used. The comparison of results and conceptual models between the Hanford PE and Hanford's LLW performance assessment provides an opportunity to determine the differences in conservatism used in these two analyses. The comparison of results and conceptual models is described in detail in Appendix A.4 and is summarized here.

The major differences between the conceptual models used in Hanford's LLW performance assessment and in the PE, as well as their implications, are highlighted below.

- The PE method assumes that there is no dispersion or dilution in the unsaturated zone. In the 200-West Area performance assessment, both of these mechanisms were incorporated into the groundwater models (lateral dispersion and dilution from regionally infiltrating waters were the primary mechanisms) (Khaleel, 1995). The result shows roughly a tenfold reduction in concentration between the leachate and the waters just above the water table. This reduction is not included in the PE method.

- The PE method assumes a continuous release of leachate from the disposal facility. In the 200-West Area performance assessment, the peak release occurs as the finite inventory escapes from the degrading facility. This release creates a pulse input into the subsurface transport regime. Although a continuous input will eventually produce concentrations at the performance boundary that are the same for all $K_{d}$ values (and retardation, $R$ ), an instantaneous input in conjunction with dispersion effects will produce lesser concentrations. This reduction is not included in the PE method.

In the published performance assessment for the 200 West Area Burial Grounds (Wood et al., 1994), 52 radionuclides were subjected to detailed subsurface transport analyses. The comparative exercise between the PE methodology and the performance assessment shows that the PE results compare extremely well with the findings published in the performance assessment. Using the PE methodology, the arrival time at the performance boundary was predicted within a factor of two of the value in the performance assessment for all 52 radionuclides. For these same radionuclides, the concentration reduction factor (CRF) from the PE was also within a factor of two of the value from the performance assessment. Where the permissible waste concentration was numerically presented in the performance assessment (i.e., the waste concentration of many of the radionuclides showed "No Limit" from the groundwater pathway), the agreement between the PE and the performance assessment was within a factor of two.

This discussion pertains only to comparison of the analyses contained in the performance assessment for the 200-West Area Burial Grounds and the Hanford PE. No quantitative statements can be made about the degree of conservatism of either analysis with respect to the actual behavior of any specific radionuclide at Hanford over a 10,000-y time period. 


\subsection{OBSERVATIONS}

Based on the results of the PE and the parameter-sensitivity analysis, the following observations can be made about MLLW disposal at Hanford:

- The Hanford site has characteristics that are typical of an arid climate. The annual rainfall and natural recharge at Hanford are relatively low $(0.16 \mathrm{~m} / \mathrm{y}$ and $0.05 \mathrm{~m} / \mathrm{y}[0.52 \mathrm{ft} / \mathrm{y}$ and $0.16 \mathrm{ft} / \mathrm{y}$ ], respectively). The thickness of the vadose zone at Hanford is $72 \mathrm{~m}(236 \mathrm{ft})$. Travel times of up to $220,000 \mathrm{y}$ have been computed for some radionuclides at Hanford.

- For Hanford, of the 58 radionuclides evaluated in the PE, 44 radionuclides for the trench design and 45 radionuclides for the tumulus design would be limited by the intrusion scenarios. These results reflect the dominant role of the selected human intrusion scenarios that is demonstrated for almost all the sites considered in the PE (see Sections 7.5 and 7.6 in Volume 2). This dominance indicates a need to be aware of the inability to predict the social behavior of populations far into the future.

The results also indicate that for the water pathway, 39 radionuclides for both the trench and tumulus designs would arrive at the performance boundary after the 10,000-y period of consideration in the $\mathrm{PE}$ analysis of the water pathway. Of the radionuclides that arrived before $10,000 \mathrm{y}$, four had no limit on waste concentration for both the trench and tumulus designs.

Because Hanford has many radionuclides that either are limited by the intrusion scenarios, arrive at the performance boundary after $10,000 \mathrm{y}$, or have no limit on waste concentration, this site may have flexibility in accepting a variety of radionuclides for disposal.

- Using either a trench or tumulus design is feasible at Hanford. Current LLW disposal practices at Hanford involve trench designs. At Hanford, there is no significant difference in the permissible waste concentrations computed with the PE methodology for the trench as compared to the tumulus.

- Hanford does not have physical constraints that could limit disposal activities. There are currently available land areas at Hanford of adequate size and possessing sufficient depth to groundwater to accommodate future LLW disposal.

- The sensitivity analysis for Hanford indicates that reasonable changes in values for natural recharge, groundwater Darcy velocity, and facility size for many radionuclides would not significantly change the results. However, values for natural recharge for C-14, Tc-99, and U-238 could be changed sufficiently to significantly affect the results (i.e., change the limiting pathway). Changes in values for groundwater Darcy velocity could change the limiting pathway for Tc-99 and U-238, and changes in values for facility area could change the limiting pathway for C-14. 
In flow and transport problems, the $K_{d}$ values are often the most uncertain site-specific parameters. The $K_{d}$ value for U-238 could change sufficiently to change the limiting pathway.

- The conceptual model for water flow used in the Hanford PE is based on the 200-West Area performance assessment. The conceptual model for radionuclide transport is believed to be much more conservative than the one used in the performance assessment due primarily to additional concentration reduction mechanisms used in the performance assessment that are not used in the Hanford PE. The differences in the results of the two analyses have been identified and quantified (see Appendix A.4).

- The conceptual models for the intrusion scenarios as used in the Hanford PE are based on the LLW performance assessment for Hanford's 200-West Area. The conceptual model for homesteader intrusion in the PE analysis is believed to produce results within one order of magnitude of the performance assessment; however, there is no real trend as to overprediction versus underprediction of waste limits. The conceptual model for postdrilling intrusion in the $\mathrm{PE}$ analysis is believed to produce results two orders of magnitude more restrictive than the performance assessment. The differences in the results of the two analyses have been identified and quantified (see Appendix A.4).

\subsection{REFERENCES}

Baer, T.A., L. L. Price, J. N. Emery, N. E. Olague, 1994. Second Performance Assessment Iteration of the Greater Confinement Disposal Facility at the Nevada Test Site. SAND93-0089. Albuquerque, NM: Sandia National Laboratories.

Cooper, C.D., and F.C. Alley, 1986. Air Pollution Control: A Design Approach. Prospect Heights, IL: Waveland Press, Inc.

CRC, 1981. CRC Handbook of Chemistry and Physics. Eds. Robert C. Weast and Melvin J. Astle. Boca Raton, FL: CRC Press, Inc.

EPA, 1992. User's Guide for the Industrial Source Complex (ISC2) Dispersion Models, Volume I: User Instructions. EPA Publication No. EPA-450/4-92-008a. Research Triangle, NC: U.S. Environmental Protection Agency.

FFCAct, 1992. Federal Facility Compliance Act of 1992. P.L. 102-386, October 1992.

Gruebel, M.M., R.D. Waters, M.B. Hospelhorn, and M.S.Y. Chu, eds., 1994. Framework for DOE Low-Level and Mixed Low-Level Waste Disposal: Site Fact Sheets. SAND94-2728. Albuquerque, NM: Sandia National Laboratories.

Khaleel, R., 1995. Personal communication with J.D. Tauxe, Oak Ridge National Laboratory, Oak Ridge Tennessee, January 13, 1995. 
Kincaid, C.T., J.W. Shade, G.A. Whyatt, M.G. Piepho, K. Rhoads, J.A. Voogd, J.H. Westsik, Jr., M.D. Freshley, K.A. Blanchard, and B.G. Lauzon, eds., 1993. Performance Assessment of Grouted Double-Shell Tank Waste Disposal at Hanford. WHC-SD-WM-EE-004, Rev. 0. U.S. Department of Energy, Pacific Northwest Laboratory and Westinghouse Hanford Company.

Maheras, Steven J., Arthur S. Rood, Swen O. Magnuson, Mary E. Sussman, and Rajiv N. Bhatt, 1994. Radioactive Waste Management Complex Low-Level Waste Radiological Performance Assessment. EGG-WM-8773. Idaho Falls, ID: U.S. Department of Energy Office of Environmental Restoration and Waste Management, DOE Idaho Operations Office.

MMES (Martin Marietta Energy Systems), EG\&G Idaho, Inc., and Westinghouse Savannah River Company, 1994. Radiological Performance Assessment for the E-Area Vaults Disposal Facility (U). WSRC-RP-94-218, Rev. 0. Aiken, SC: Westinghouse Savannah River Company.

ORNL (Oak Ridge National Laboratory), 1994. Performance Assessment for Continuing and Future Operations at Solid Waste Storage Area 6. ORNL-6783. Oak Ridge, TN: U.S. Department of Energy, Oak Ridge National Laboratory.

Thibault, D.H., M.I. Sheppard, and P.A. Smith, 1990. A Critical Compilation and Review of Default Soil Solid/Liquid Partition Coefficients, Kd, for Use in Environmental Assessments. AECL-10125. Pinawa, Manitoba, Canada: Whiteshell Nuclear Research Establishment, Atomic Energy of Canada Limited.

Wood, M. W., 1994. Personal communication with ORNL Core Team during site visit to Hanford, 26 September, 1994.

Wood, M. W., 1995. Personal communication with John Tauxe (ORNL) on December 20, 1994, and January 10, 1995.

Wood, M. W., R. Khaleel, P. D. Rittman, A. H. Lu, S. H. Finfrock, R. J. Serne, K. J. Cantrell, T. H. DeLorenzo, 1994. Performance Assessment for the Disposal of Low-Level Waste in the 200 West Area Burial Grounds, WHC-EP-0645, prepared for the U. S. Department of Energy, Office of Environmental Restoration and Waste Management by Westinghouse Hanford Company, Richland, Wash.

\section{Acknowledgments}

The ORNL Core Team acknowledges the contributions of Don Plowman and Fred Mann of the Hanford staff and Marc Wood and Raz Khaleel of the Westinghouse Hanford Company. 


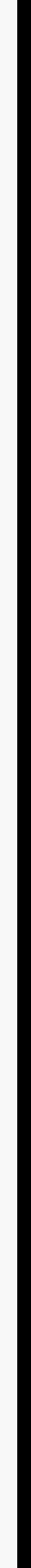




\section{APPENDIX A:}

COMPARISON OF PE RESULTS WITH RESULTS AT SITES WITH LLW PERFORMANCE ASSESSMENTS 


\section{Contents}

A.1 Idaho National Engineering Laboratory .....................................................A-INEL-1

A.2 Savannah River Site.............................................................................SRS-1

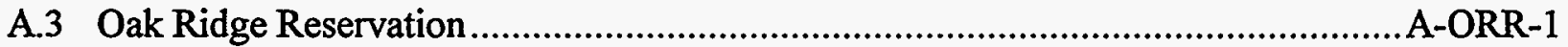

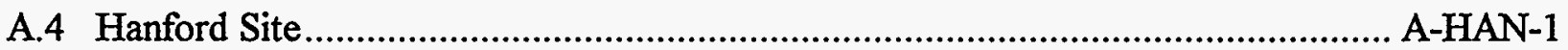


Appendix A.1: Idaho National Engineering Laboratory (INEL) 


\section{NOMENCLATURE}

$b \quad$ Effective mixing thickness (L)

C Concentration or activity of the constituent of interest $\left(M / L^{3}\right)$

$\mathrm{CRF} \quad$ Concentration reduction factor (dimensionless)

$C R F_{E T} \quad$ Concentration reduction factor for environmental transport (dimensionless)

$C R F_{\text {Dispersion }}$ Concentration reduction factor for environmental transport by dispersion in the aquifer (dimensionless)

$C_{\text {Wr-Frater }}$ Radionuclide-specific waste concentration for permissible releases to groundwater or surface water $\left(\mu \mathrm{Ci} / \mathrm{m}^{3}\right)$

$D_{x} \quad$ Dispersion coefficient in the $x$-direction $\left(\mathrm{L}^{2} / \mathrm{T}\right)$ where the dispersion coefficient $D_{x}$ is calculated from the longitudinal dispersivity $a_{L}$ as $D_{x}=a_{L} \times U$.

$D_{y} \quad$ Dispersion coefficient in the $y$-direction $\left(\mathrm{L}^{2} / \mathrm{T}\right)$ where the dispersion coefficient $D_{y}$ is calculated from the transverse dispersivity $a_{T}$ as $D_{y}=a_{T} \times U$.

INEL Idaho National Engineering Laboratory

$K_{d} \quad$ Solid/liquid distribution coefficient for the geologic media $(\mathrm{mL} / \mathrm{g})$

$\lambda \quad$ Radioactive decay coefficient $(1 / T)$

$L \quad$ Length of the source in the $x$ - (downgradient) direction $(L)$

LLW Low-level waste

$M \quad$ Initial mass or activity in the volume defined by $L \times W \times b(M)$

$n \quad$ Porosity of the aquifer

PA Performance assessment

$\mathrm{PE} \quad$ Performance evaluation

$R \quad$ Retardation factor (dimensionless)

RWMC Radioactive Waste Management Complex

SDCF Radionuclide-specific scenario dose conversion factor for all exposure pathways for atmospheric releases $\left([\mathrm{rem} / \mathrm{y}] /\left[\mu \mathrm{Ci} / \mathrm{m}^{3}\right]\right)$

$t \quad$ Time from instantaneous release (T)

$U \quad$ Groundwater or seepage velocity in the $x$-direction $(\mathrm{L} / \mathrm{T})$

$W \quad$ Width of the source in the $y$-direction $(\mathrm{L})$

$x \quad$ Distance from source in the downgradient direction (L)

$y \quad$ Distance from source perpendicular to the downgradient direction $(\mathrm{L})$ 


\section{APPENDIX A.1. IDAHO NATIONAL ENGINEERING LABORATORY (INEL)}

The performance assessment (Maheras et al., 1994) for Idaho National Engineering Laboratory's (INEL) Radioactive Waste Management Complex (RWMC) considers the release of radionuclides from near-surface disposal facilities. The findings of that performance assessment were used as the basis for the comparison of results obtained from the implementation of the performance evaluation (PE) method as documented in Volume 2, Chapter 5 in this report. This appendix discusses the findings of that comparison process.

\section{A.1.1 OVERVIEW OF THE EXISTING PERFORMANCE ASSESSMENT}

The RWMC performance assessment considered three time periods: (1) the operational period from 1984 through 2020, during which time radioactive waste would be placed into the disposal facility, (2) the period of institutional control from 2021 through 2120 , and (3) the postinstitutional period, from 2120 to the future. The RWMC performance assessment is "inventorybased" in that the performance assessment uses known or projected inventories of disposed waste to compute compliance point doses for comparison with performance objectives. The RWMC performance assessment inventory includes the amount accumulated from 1984 through 1993, plus the amount projected to accumulate until 2020 .

Two receptor types were assessed in the RWMC performance assessment: (1) a member of the public, assumed to reside at the INEL boundary during the operational and institutional control periods and to reside $100 \mathrm{~m}$ from the boundary of the RWMC during the post-institutional control period, and (2) an inadvertent intruder who would gain access to the site during the postinstitutional control period.

Two disposal technologies were evaluated in the RWMC performance assessment: pits and soil vaults. Trench disposal was discontinued at INEL in 1981. Pits are normally used for routine, solid, low-level beta-gamma contaminated waste with radiation levels below $500 \mathrm{mR} / \mathrm{h}$ at $0.9 \mathrm{~m}$. Current pits are excavated into rock to a depth of $9 \mathrm{~m}$, then backfilled with $0.6 \mathrm{~m}$ of soil over rock. After the waste is emplaced, the pits are backfilled with at least $0.9 \mathrm{~m}$ of soil.

High radiation (greater than $500 \mathrm{mR} / \mathrm{h}$ ) beta-gamma waste is normally deposited in soil vaults. Rows of these vaults are drilled along centerlines and are separated by $0.6 \mathrm{~m}$. Soil vault diameters vary from 0.4 to $2 \mathrm{~m}$, and the minimum depth is $2 \mathrm{~m}$. Earth fill ( $0.9 \mathrm{~m}$ minimum) provides shielding to personnel and the environment after the vault is filled and closed.

A 5-m thick soil cover was assumed to be placed over the pits and soil vaults at the time of closure. This cover was assumed to be maintained during the 100-y period of institutional control. At the end of that period, maintenance activities were assumed to cease and erosion of the cover was assumed to occur over time. At the time of maximum erosion, $2.4 \mathrm{~m}$ of cover would remain over the pits and $3.3 \mathrm{~m}$ over the soil vaults. 
The estimate of the current net recharge into cover soils, waste pits, and the remainder of the RWMC is given in the performance assessment as approximately 4 to $10 \mathrm{~cm} / \mathrm{y}$. An intermediate value of $7 \mathrm{~cm} / \mathrm{y}$ was used as the recharge in calculations for the performance assessment. An estimated recharge of $1 \mathrm{~cm} / \mathrm{y}$ was used for the engineered barrier/cover to be placed over the operational cover of the pits and soil vaults. This engineered barrier might include a thick soil barrier and a capillary barrier. The time for complete hydraulic failure of the engineered barrier was estimated to be $5 \mathrm{y}$ after the end of institutional control. At the time of failure, the recharge was assumed to return to $7 \mathrm{~cm} / \mathrm{y}$.

The ORIGEN2 computer code was used to decay and ingrow the inventory and forecast data. The decay and ingrowth calculated was based on time, as in the following example. The inventory for pits in 1984 was decayed and ingrown for one year and added to the inventory disposed in 1985. This sum was decayed and ingrown for one year and then added to the inventory disposed in 1986 . This process was continued until the year 2020, at which time the facility was assumed to be closed. The inventory in 2020 was decayed and ingrown for a 10,000-y compliance period.

In the RWMC performance assessment, the GWSCREEN and PORFLOW computer codes were used to determine the impacts of subsurface transport of radionuclides. For purposes of simplifying the transport calculations, the RWMC was assumed to be an area source of uniform thickness in which the waste was uniformly mixed with the backfill. The waste was assumed to be released from waste containers or waste forms and leach at an exponentially decreasing rate into the unsaturated zone beneath the RWMC as a result of low constant moisture infiltration. Physical processes, such as decay and sorption, were allowed to reduce or retard this downward movement of radionuclides. The representation of subsurface transport is undoubtedly greatly simplified over the true processes that occur, reflecting the lack of definitive understanding of water movement in the subsurface beneath the RWMC.

\section{A.1.2 COMPARISON OF THE PE METHODOLOGY WITH THE RWMC PERFORMANCE ASSESSMENT}

\section{A.1.2.1 Water Pathway}

This section discusses the straightforward application of the PE method (as documented in Volume 2, Section 5 of this report) to the LLW disposal facility at the RWMC, using values from Table INEL-1. Most of these values were extracted from the Engineering Design File RWMC-760 (Rood et al., 1994), which documents the calculations presented in the RWMC performance assessment. Fifteen of the radionuclides included in the PE were examined in the RWMC performance assessment, providing a basis for comparison between the $\mathrm{PE}$ and performance assessment methods. 
Table INEL-1. Parameters and Values Used in the PE Analysis for the RWMC at INEL

\begin{tabular}{|c|c|c|c|}
\hline Parameter & Value & $\begin{array}{l}\text { Data } \\
\text { Type }\end{array}$ & Comments \\
\hline \multicolumn{4}{|l|}{ SOURCE TERM } \\
\hline initial waste concentration & $1 \mathrm{mCi} / \mathrm{m}^{3}$ & D & $\begin{array}{l}\text { a unit concentration is part of the } \\
\text { standard PE method }\end{array}$ \\
\hline $\begin{array}{l}\text { waste volumetric water } \\
\text { content }\end{array}$ & 0.32 & A & Rood et al. 1994 \\
\hline waste bulk density & $1.5 \mathrm{~g} / \mathrm{mL}$ & A & Rood et al. 1994 \\
\hline facility length & $257 \mathrm{~m}$ & A & Rood et al. 1994 \\
\hline facility width & $122 m$ & A & Rood et al. 1994 \\
\hline waste area & $31,354 \mathrm{~m}^{2}$ & A & $257 \mathrm{~m} \times 122 \mathrm{~m}$ \\
\hline waste mixing fraction & 1 & A & none assumed \\
\hline $\begin{array}{l}\text { annual rate of water flowing } \\
\text { through intact facility }\end{array}$ & $0.07 \mathrm{~m} / \mathrm{y}$ & A & same as regional rate \\
\hline $\begin{array}{l}\text { time to failure of leachate } \\
\text { collection system }\end{array}$ & oy & A & $\begin{array}{l}\text { releases assumed to begin at closure } \\
\text { (year 2020) (Rood et al. 1994) }\end{array}$ \\
\hline time to failure of facility & $0 y$ & A & $\begin{array}{l}\text { releases assumed to begin at closure } \\
\text { (year 2020) (Rood et al. 1994) }\end{array}$ \\
\hline \multicolumn{4}{|l|}{ UNSATURATED ZONE } \\
\hline volumetric water content & 0.168 & A & Rood et al. 1994 \\
\hline bulk density & $1.5 \mathrm{~g} / \mathrm{mL}$ & A & Rood et al. 1994 \\
\hline $\begin{array}{l}\text { unsaturated zone thickness } \\
\text { below facility }\end{array}$ & $12.5 \mathrm{~m}$ & A & $\begin{array}{l}\text { Cumulative unsaturated sediment } \\
\text { thickness is } 12.5 \mathrm{~m} \text { at the RWMC } \\
\text { (Rood et al. 1994) }\end{array}$ \\
\hline $\begin{array}{l}\text { natural recharge through } \\
\text { local soils }\end{array}$ & $0.07 \mathrm{~m} / \mathrm{y}$ & A & Rood et al. 1994 \\
\hline \multicolumn{4}{|l|}{ SATURATED ZONE } \\
\hline aquifer porosity & 0.1 & A & Rood et al. 1994 \\
\hline bulk density & $1.9 \mathrm{~g} / \mathrm{mL}$ & A & Rood et al. 1994 \\
\hline mixing depth & $12 \mathrm{~m}$ & A & Rood et al. 1994 \\
\hline Darcy velocity & $56 \mathrm{~m} / \mathrm{y}$ & A & Rood et al. 1994 \\
\hline $\begin{array}{l}\text { distance to compliance point } \\
\text { from facility boundary }\end{array}$ & $100 \mathrm{~m}$ & A & $\begin{array}{l}\text { Rood et al. 1994; same as for } \\
\text { standard PE method }\end{array}$ \\
\hline $\begin{array}{l}\text { distance to compliance point } \\
\text { from facility center } \\
\text { (compliance distance) }\end{array}$ & $228.5 \mathrm{~m}$ & A & $\begin{array}{l}\text { Rood et al. 1994; same as for } \\
\text { standard PE method }\end{array}$ \\
\hline
\end{tabular}

$A=$ Site measurement; $B=$ Result of site numerical analysis; $C=$ Literature value selected by site; $D=G e n e r i c$ PE value 
Values for the solid/liquid distribution coefficients $\left(K_{d} \mathrm{~s}\right)$ used in the RWMC performance assessment are presented in Table INEL-2. The RWMC performance assessment differentiates between $K_{d}$ values for the unsaturated and saturated zones: it assigns values to the saturated zone equal to one-tenth the value for the unsaturated zone for elements with atomic number 82 and higher ( $R a$ and subsequent elements in Table INEL-2).

Table INEL-2. Solid/Liquid Distribution Coefficients $\left(K_{d}\right)$ Used in the RWMC Performance Assessment at INEL

\begin{tabular}{|c|c|c|c|}
\hline Element & $\begin{array}{l}K_{d} \text { for } \\
\text { Waste } \\
(\mathrm{mL} / \mathrm{g})\end{array}$ & $\begin{array}{c}K_{d} \text { for } \\
\text { Unsaturated Zone } \\
(\mathrm{mL} / \mathrm{g})\end{array}$ & $\begin{array}{c}K_{d} \text { for } \\
\text { Saturated Zone } \\
(\mathrm{mL})\end{array}$ \\
\hline H & 0 & 0 & 0 \\
\hline c & 0 & 0 & 0 \\
\hline $\mathbf{K}$ & 0.55 & 0.55 & 0.55 \\
\hline $\mathrm{Ni}$ & 100 & 100 & 100 \\
\hline $\mathrm{Sr}$ & 2 & 2 & 2 \\
\hline Tc & 0.15 & 0.15 & 0.15 \\
\hline 1 & 0.05 & 0.05 & 0.05 \\
\hline $\mathbf{R a}$ & 50 & 50 & 5 \\
\hline Th & 1000 & 1000 & 100 \\
\hline $\mathbf{U}$ & 1000 & 1000 & 100 \\
\hline $\mathrm{Np}$ & 50 & 50 & 5 \\
\hline $\mathrm{Pu}$ & 2000 & 2000 & 200 \\
\hline
\end{tabular}

The values from Tables INEL-1 and INEL-2 were incorporated into the PE equations (see Vol. 2, Sect. 5 in this report). Table INEL-3 shows the comparative results. The results of the comparison exercise show that for all radionuclides, the PE compares very well to the performance assessment calculations, with results within one order of magnitude. The PE method assumes that all inventories are emplaced at the time of closure of the facility, and that no releases to the environment occur before failure of the leachate collection system. For the RWMC, the time of closure was assumed to be the year 2020. However, emplacement of most radionuclides into the facility occurs throughout the operation of the facility, which began in 1984 .

In addition to the differences in emplacement of radionuclides into the facility, the performance assessment and the PE make different assumptions about the release of the source. The performance assessment uses a transient release, while the $\mathrm{PE}$ assumed a constant release rate and steady-state transport model. For INEL, this difference is most noticeable in the saturated zone, where the performance assessment allowed the contaminants to undergo time-variant releases and two-dimensional advection-dispersion. The PE assumes a constant release and no dispersion.

\section{A-INEL-6}


Table INEL-3. Comparison of the Results from the PE Method with the Findings of the RWMC Performance Assessment for the Groundwater Pathway at INEL

\begin{tabular}{|c|c|c|c|c|c|c|c|}
\hline \multirow[t]{2}{*}{ Nuclide } & \multicolumn{2}{|c|}{$\begin{array}{c}\text { Environmental } \\
\text { Transport } \\
\text { CRF } \\
\text { (no decay) } \\
\end{array}$} & \multicolumn{2}{|c|}{ Arrival Time } & \multicolumn{2}{|c|}{$\begin{array}{c}\text { Permissible Waste } \\
\text { Concentration } \\
C_{W-\text { Water }} \\
\left(\mu \mathrm{Ci} / \mathrm{m}^{2}\right) \\
\end{array}$} & \multirow[t]{2}{*}{ Nuclide } \\
\hline & PA & PE & PA & PE & PA & PE & \\
\hline $\mathrm{H}-3$ & 45.9 & 38.4 & $4.6 E+1$ & $3.0 E+1$ & $8.8 E+3$ & $5.8 E+3$ & $\mathrm{H}-3$ \\
\hline$C-14$ & 45.3 & 38.4 & $6.5 E+1$ & $3.0 E+1$ & 2.7E+2 & $3.2 E+1$ & C-14 \\
\hline $\mathrm{K}-40$ & 49.0 & 38.4 & $2.2 E+2$ & $1.8 E+2$ & $2.0 E+1$ & $1.3 E+1$ & $K-40$ \\
\hline Ni-59 & 45.2 & 38.4 & $3.2 E+4$ & $2.7 E+4$ & 3.7E+5 & $1.9 E+5$ & Ni-59 \\
\hline Sr-90 & 53.6 & 38.4 & $6.0 \mathrm{E}+2$ & $5.7 \mathrm{E}+2$ & $1.5 E+7$ & $3.8 E+6$ & Sr-90 \\
\hline Tc-99 & 46.5 & 38.4 & $2.2 E+2$ & $7.1 E+1$ & $1.9 E+2$ & $7.8 \mathrm{E}+1$ & Tc-99 \\
\hline $1-129$ & 45.5 & 38.4 & $7.9 E+1$ & $4.4 E+1$ & $5.8 E-1$ & $3.0 \mathrm{E}-1$ & $\mid-129$ \\
\hline Ra-226 & 44.0 & 38.4 & $1.4 E+4$ & $1.3 E+4$ & $6.4 E+3$ & $6.2 E+2$ & Ra-226 \\
\hline Th-230 & 42.7 & 38.4 & $2.7 E+5$ & $2.7 E+5$ & $7.9 \mathrm{E}+3$ & 3.7E+1 & Th-230 \\
\hline Th-232 & 44.5 & 38.4 & $2.7 E+5$ & $2.7 E+5$ & $7.4 \mathrm{E}+1$ & $6.3 E+1$ & Th-232 \\
\hline U-234 & 45.2 & 38.4 & $2.7 E+5$ & 2.7E+5 & $3.1 E+3$ & $3.6 E+2$ & U-234 \\
\hline U-235 & 45.1 & 38.4 & $2.7 E+5$ & 2.7E+5 & $1.5 E+3$ & $6.2 E+1$ & $\mathrm{U}-235$ \\
\hline U-238 & 45.0 & 38.4 & $2.7 E+5$ & $2.7 E+5$ & $1.6 \mathrm{E}+3$ & 1.1E+3 & $\mathrm{U}-238$ \\
\hline Np-237 & 45.0 & 38.4 & $1.4 E+4$ & $1.3 E+4$ & $4.2 E+0$ & $3.6 \mathrm{E}+0$ & $\mathrm{~Np}-237$ \\
\hline Pu-239 & 45.6 & 38.4 & $5.4 \mathrm{E}+5$ & $5.4 \mathrm{E}+5$ & $1.1 E+9$ & $8.9 E+8$ & Pu-239 \\
\hline
\end{tabular}

Studying the effect of dispersion in the aquifer helps to clarify this difference. The end result is that the peak radionuclide concentration at the point of compliance (i.e., at the well) is reduced from the concentration at its point of initial mixing below the facility by a factor of 0.83 ; that is, the well concentration is $83 \%$ of the initial aquifer concentration, due to horizontal dispersion. Alternatively, this may be thought of as a dispersion concentration reduction factor (CRF):

$$
C R F_{\text {Dispersion }}=(0.83)^{-1}=1.2
$$

Superimposing this simple calculation upon the standard PE method reduces the source of the aforementioned differences to the characterization of the source term alone, having matched the environmental transport calculations very well.

Derivation of the value for $C R F_{\text {Dispersion }}$ is as follows. The code used for groundwater calculations in the RWMC performance assessment is named GWSCREEN (Rood, 1994), and uses a transient solution of the two-dimensional advection-dispersion equation for an instantaneous release from a rectangular plane source. The form of this equation is (Rood, 1994): 


$$
C(x, y, t)=\frac{M e^{-2 t}}{n R b} \cdot \frac{1}{2 L}\left[\operatorname{erf}\left(\frac{x+\frac{L}{2}-\frac{U t}{R}}{\sqrt{\frac{4 D_{x} t}{R}}}\right)-e r f\left(\frac{x-\frac{L}{2}-\frac{U t}{R}}{\sqrt{\frac{4 D_{x} t}{R}}}\right)\right] \cdot \frac{1}{2 W}\left[\operatorname{erf}\left(\frac{y+\frac{W}{2}}{\sqrt{\frac{4 D_{y} t}{R}}}\right)-e r f\left(\frac{-y+\frac{W}{2}}{\sqrt{\frac{4 D_{y} t}{R}}}\right)\right]
$$

where

C concentration or activity of the constituent of interest $\left(M / L^{3}\right)$

$x \quad$ distance from source in the downgradient direction (L)

$y$ distance from source perpendicular to the downgradient direction (L)

$t \quad$ time from instantaneous release (T)

$M \quad$ initial mass or activity in the volume defined by $L \times W \times b(\mathrm{M})$

$\lambda$ radioactive decay coefficient $(1 / T)$

$n \quad$ porosity of the aquifer

$R \quad$ retardation factor

$b \quad$ effective mixing thickness (L)

$L \quad$ length of the source in the $x$ (downgradient) direction (L)

$U$ groundwater or seepage velocity in the $x$ direction $(\mathrm{L} / \mathrm{T})$

$D_{x} \quad$ dispersion coefficient in the $x$ direction $\left(\mathrm{L}^{2} / \mathrm{T}\right)$

Note: The dispersion coefficient $D_{x}$ is calculated from the longitudinal dispersivity $\alpha_{L}$ as $D_{x}=\alpha_{L} \times U$.

W width of the source in the $y$ direction (L)

$\mathrm{D}_{y} \quad$ dispersion coefficient in the $y$ direction $\left(\mathrm{L}^{2} / \mathrm{T}\right)$

Note: The dispersion coefficient $D_{y}$ is calculated from the transverse dispersivity $\alpha_{T}$ as $D_{y}=\alpha_{T} \times U$.

If a unit initial activity $M=1 \mathrm{Ci}$ and values for $n, b, L$, and $W$ are taken from Table INEL-1, the initial aqueous groundwater concentration below the source is:

$$
\frac{M}{n b L W}=\frac{1 \mathrm{Ci}}{0.1 \bullet 12 \mathrm{~m} \cdot 257 \mathrm{~m} \bullet 122 \mathrm{~m}}=2.66 \times 10^{-5} \mathrm{Ci} / \mathrm{m}^{3}
$$

Given the parameter values in Table INEL-1, and the additional information $\lambda=0 \mathrm{y}^{-1}$ (implying $R=1), \alpha_{L}=9 \mathrm{~m}$, and $\alpha_{T}=4 \mathrm{~m}$ (Rood et al. 1994), the maximum activity at the compliance point, as calculated by the equation for concentration above, is $2.20 \times 10^{-5} \mathrm{Ci} / \mathrm{m}^{3}$. The ratio of these concentrations gives the value of $C R F_{\text {Dispersion }}$ as 1.2.

This solution is for an instantaneous release and so is not applicable to the PE method, which assumes a continuous release. It is presented here only to demonstrate that the hydrogeological differences between the performance assessment and PE methods are understood and quantifiable. The effect of incorporating the dispersion CRF into the saturated zone CRF is to change it from 38 to 46 , which is a much better match to the performance assessment values presented in Table INEL-3. 


\section{A.1.2.2 Atmospheric Pathway}

In the RWMC performance assessment, the primary source of radionuclides for airborne transport was biointrusion by plant roots and harvester ants. Radioactivity was brought to the surface by these mechanisms, resuspended, and atmospherically dispersed downwind to a receptor. The receptor was located in the east-northeast sector because that sector yielded the largest annual average air concentration at the $100 \mathrm{~m}$ distance. That same sector also yielded the highest dose among all sixteen sectors considered.

The GENII computer code was used to calculate the dose to the off-site receptor from the following pathways: inhalation, exposure to contaminated ground surfaces, air immersion, and ingestion based upon the consumption of contaminated produce, leafy vegetables, milk and meat. Only the chronic release option of GENII was exercised in the performance assessment.

For the biointrusion scenarios, the maximum doses occurred at the end of the institutional control period. The maximum dose was $0.13 \mathrm{mrem} / \mathrm{y}$ and was for the soil vaults. The dominant contributors were Cs-137 and $\mathrm{Ni}-63$.

For gaseous release of $\mathrm{H}-3$ and $\mathrm{C}-14$, the RWMC performance assessment used release rates based on the hydrological model used to calculate groundwater impacts. Instead of $\mathrm{H}-3$ and C-14 moving downward with infiltrating water, these radionuclides were assumed to move upward as gases. They were then transported to receptors downwind of the RWMC. The H-3 and C-14 dose assessments were identical to those for the biointrusion scenario; the GENII code was used.

During the operational and institutional control period, the peak release rate for $\mathrm{C}-14$ was $0.24 \mathrm{Ci} / \mathrm{y}$, and the peak for $\mathrm{H}-3$ was $220 \mathrm{Ci} / \mathrm{y}$. The dose associated with these releases was $0.0016 \mathrm{mrem} / \mathrm{y}$. During the post-institutional control period (i.e., beyond $100 \mathrm{y}$ after facility closure), the peak release rate was $0.23 \mathrm{Ci} / \mathrm{y}$ for $\mathrm{C}-14$ and $5.3 \times 10^{-3} \mathrm{Ci} / \mathrm{y}$ for $\mathrm{H}-3$. The associated dose was $0.69 \mathrm{mrem} / \mathrm{y}$.

No data have been located that would facilitate the comparison of the PE methodology with the findings of the performance assessment. That is, no waste concentrations and associated doses are published in the performance assessment, and no data are available for comparison. Therefore, no comparison of the PE method with the performance assessment findings is possible.

\section{A.1.2.3 Inadvertent Intruder Scenarios}

In the RWMC performance assessment, two general categories of intrusion scenarios are evaluated. The first involves chronic exposures and includes an agricultural scenario and a radon scenario. In the agricultural scenario, the intruder obtains a portion of his food from farming at the site and uses water from a well drilled at the edge of the waste. In the radon scenario, the receptor excavates a basement and is exposed to radon and its short-lived progeny that diffused through the basement foundation. Neither the consumption of contaminated water nor the doses from radon (and its short-lived progeny) are included in the PE intruder scenarios. 
The second category of intrusion in the RWMC performance assessment involves acute exposure scenarios and includes a construction scenario and a well-drilling scenario. In the acute construction scenario, the intruder builds a house at the RWMC and is exposed to contaminated soil while excavating a basement. In the well-drilling scenario, the intruder is exposed to contaminated drill cuttings that are spread over the ground.

The exposure pathways evaluated in the RWMC performance assessment include ingestion of contaminated food and water, inhalation of contaminated airborne particulates, and external exposure to radionuclides in the air and on the ground (or soil) surface. The agricultural products consumed by members of the public are contaminated via a food chain transport of radionuclides deposited from air onto soil or plant surfaces or from irrigation water.

For the pits and the soil vaults, the RWMC performance assessment found that the peak dose from the acute drilling scenario occurred at the end of the institutional control period. The doses were $8.3 \mathrm{mrem}$ for the pits and $190 \mathrm{mrem}$ for the soil vaults. For the pits, inhalation accounted for the majority of the dose with U-232 as the dominant radionuclide. For the soil vaults, inhalation and external exposure accounted for approximately equal portions of the dose. The dominant radionuclide for the external exposure pathway was Cs-137; Ni-63 was the dominant radionuclide for inhalation. The acute dose of $190 \mathrm{mrem}$ was higher than the annual doses from any of the chronic intrusion scenarios. However, for intrusion scenarios, the performance objective for acute exposures is $500 \mathrm{mrem}$, compared to $100 \mathrm{mrem} / \mathrm{y}$ for chronic exposures.

An attempt was made to obtain representative dose and waste concentration values from the RWMC performance assessment for direct comparison to the PE methodology. Table INEL-4 compares the INEL performance assessment (Maheras et al., 1994) chronic intruder agricultural scenario for the pits at $100 \mathrm{y}$ post-institutional control to the $\mathrm{PE}$ methodology for the homesteader intruder scenario for the generic trench at $100 \mathrm{y}$. While this allows for the closest comparison, several differences in methodology, parameters, and data presentation make it difficult to establish a one-to-one comparison of results.

Available tabulated data from the performance assessment include annual effective dose equivalents calculated by the GENII code, as listed in INEL's Engineering Design File (EG\&G, 1993). These data - presented on p. 14-16 of the Engineering Design File - are based on an inhalation rate of $8,030 \mathrm{~m}^{3} / \mathrm{y}$ (approximately equal to that used in the $\mathrm{PE}$ ) and do not include external doses. To compare results to the PE, the annual effective doses were divided by the waste concentrations in the pits at $100 \mathrm{y}$ of post-institutional control (year 2120) to approximate a decayed scenario dose conversion factor (SDCF). These waste concentrations are found in Table C-1, Column 1 of the INEL performance assessment. Table INEL-4 presents these "scenario dose conversion factors" (including the decay factor for intrusion at $100 \mathrm{y}$ ) for the performance assessment and the $\mathrm{PE}$, as well as the ratio of the results ${ }^{1}$.

${ }^{1}$ The SDCF values presented in the table do not include decay products that are not in secular equilibrium at the time of intrusion. The waste limits for both the performance assessment and the PE method, on the other hand, were developed by accounting for the parent's radioactive decay, as well as ingrowth of any radiologically significant decay products at the time of intrusion. 
Table INEL-4. Comparison of the Results from the PE Method with the Performance Assessment Findings for the Agricultural (Homesteader) Intrusion Scenarios at INEL (Part 1 of 2)

\begin{tabular}{|c|c|c|c|c|c|c|c|}
\hline \multirow[t]{2}{*}{ Nuclide } & \multirow{2}{*}{\begin{tabular}{|c|} 
PA - Chronic \\
Intruder- \\
Agricultural \\
Scenario for \\
Pits \\
Calculated \\
"Decayed \\
SDCF" at \\
100 y \\
$(\mathrm{rem} / \mathrm{y}$ per \\
$\left.\mu \mathrm{Ci} / \mathrm{m}^{3}\right)$ \\
\end{tabular}} & \multicolumn{2}{|c|}{\begin{tabular}{|c|} 
PE Method - \\
Homesteader \\
(Agricultural) \\
Scenario for Generic \\
Trench \\
\end{tabular}} & \multirow[b]{2}{*}{$\begin{array}{c}\text { Ratio } \\
\text { PE : PA } \\
\text { "Decayed } \\
\text { SDCF" } \\
\text { Value } \\
\end{array}$} & \multicolumn{2}{|c|}{ Waste Limit } & \multirow[b]{2}{*}{$\begin{array}{l}\text { Ratio } \\
\text { PE : PA } \\
\text { Waste } \\
\text { Limit } \\
\text { Value } \\
\end{array}$} \\
\hline & & $\begin{array}{c}\text { Time of } \\
\text { Intrusion } \\
(y)\end{array}$ & $\begin{array}{c}\text { "Decayed } \\
\text { sDCF" } \\
(\mathrm{rem} / \mathrm{y} \text { per } \\
\left.\mu \mathrm{Ci} / \mathrm{m}^{3}\right) \\
\end{array}$ & & $\begin{array}{c}\text { Calculated } \\
\text { PA Waste } \\
\text { Limit } \\
\left(\mu \mathrm{Ci} \mathrm{m}^{3}\right) \\
\end{array}$ & $\begin{array}{c}\text { PE Waste } \\
\text { Limit - } \\
\left(w / f_{\mathrm{g}}=0.5\right) \\
\mu \mathrm{Ci} / \mathrm{m}^{3} \\
\end{array}$ & \\
\hline $\mathrm{H}-3$ & 2.13E-20 & 100 & 7.1E-09 & $3.3 E+11$ & $4.70 \mathrm{E}+18$ & $1.4 \mathrm{E}+07$ & $3.0 \mathrm{E}-12$ \\
\hline C-14 & $6.82 E-13$ & 100 & $7.4 E-06$ & $1.1 E+07$ & $1.47 E+11$ & $1.3 E+04$ & 9.2E-08 \\
\hline Al-26 & $\mathrm{NA}$ & 100 & $1.9 \mathrm{E}-03$ & $\mathrm{NA}$ & NA & $5.2 E+01$ & NA \\
\hline Si-32 & NA & 100 & 4.3E-05 & NA & NA & $2.3 E+03$ & NA \\
\hline $\mathrm{Cl}-36$ & NA & 100 & 5.9E-04 & $\mathrm{NA}$ & NA & $1.7 \mathrm{E}+02$ & NA \\
\hline $\mathrm{K}-40$ & $2.73 E-08$ & 100 & $1.4 \mathrm{E}-04$ & $5.2 E+03$ & $3.67 E+06$ & $7.0 \mathrm{E}+02$ & 1.9E-04 \\
\hline Co-60 & $5.78 \mathrm{E}-10$ & 100 & 3.5E-09 & $6.0 \mathrm{E}+00$ & $1.73 E+08$ & $2.9 E+07$ & 1.7E-01 \\
\hline Ni-59 & NA & 100 & $3.5 E-08$ & NA & NA & $2.8 \mathrm{E}+06$ & $\mathrm{NA}$ \\
\hline Ni-63 & $8.73 \mathrm{E}-11$ & 100 & 4.9E-08 & $5.6 \mathrm{E}+02$ & $1.15 E+09$ & $2.1 E+06$ & $1.8 \mathrm{E}-03$ \\
\hline Se-79 & $\mathrm{NA}$ & 100 & $6.2 \mathrm{E}-07$ & NA & $\mathrm{NA}$ & $1.6 \mathrm{E}+05$ & NA \\
\hline Sr-90+d & 1.06E-07 & 100 & 9.1E-06 & $8.6 E+01$ & $9.41 \mathrm{E}+05$ & $1.1 \mathrm{E}+04$ & 1.2E-02 \\
\hline$Z r-93$ & $1.44 \mathrm{E}-11$ & 100 & $2.0 \mathrm{E}-08$ & $1.4 \mathrm{E}+03$ & $6.96 E+09$ & $4.9 E+06$ & 7.0E-04 \\
\hline $\mathrm{Nb}-93 \mathrm{~m}$ & $1.02 E-11$ & 100 & $1.2 \mathrm{E}-10$ & $1.2 \mathrm{E}+01$ & $9.79 E+09$ & $8.2 E+08$ & 8.4E-02 \\
\hline $\mathrm{Nb}-94$ & $1.45 \mathrm{E}-10$ & 100 & 1.1E-03 & $7.3 E+06$ & $6.90 E+08$ & $9.4 E+01$ & 1.4E-07 \\
\hline Tc-99 & 1.10E-08 & 100 & 6.1E-06 & $5.5 \mathrm{E}+02$ & $9.06 E+06$ & $1.6 E+04$ & $1.8 \mathrm{E}-03$ \\
\hline Pd-107 & NA & 100 & 1.7E-08 & NA & NA & $5.8 E+06$ & $\mathrm{NA}$ \\
\hline $\mathrm{Ag}-108 \mathrm{~m}$ & NA & 100 & $6.2 E-04$ & NA & NA & $1.6 \mathrm{E}+02$ & NA \\
\hline Cd-113m & NA & 100 & 4.9E-07 & NA & NA & $2.0 \mathrm{E}+05$ & NA \\
\hline $5 n-121 m$ & NA & 100 & $7.2 E-08$ & NA & NA & $1.4 E+06$ & NA \\
\hline$S n-126+d$ & NA & 100 & 1.3E-03 & NA & NA & $7.7 E+01$ & NA \\
\hline $\mid-129$ & 3.40 E-08 & 100 & $4.0 \mathrm{E}-05$ & $1.2 E+03$ & $2.94 E+06$ & $2.5 E+03$ & $8.4 E-04$ \\
\hline Cs-135 & $\mathrm{NA}$ & 100 & 6.0 E-07 & NA & $\overline{N A}$ & $1.7 E+05$ & NA \\
\hline $\mathrm{Cs}-137+d$ & 4.10E-09 & 100 & $3.8 \mathrm{E}-05$ & $9.3 E+03$ & $2.44 E+07$ & $2.6 E+03$ & 1.1E-04 \\
\hline$B a-133$ & NA & 100 & $3.0 \mathrm{E}-07$ & NA & NA & $3.3 E+05$ & NA \\
\hline $5 m-151$ & NA & 100 & 2.7E-09 & $\mathrm{NA}$ & NA & $3.7 \mathrm{E}+07$ & NA \\
\hline Eu-152 & $7.90 \mathrm{E}-11$ & 100 & $4.5 E-06$ & $5.7 \mathrm{E}+04$ & $1.27 E+09$ & $2.2 E+04$ & $1.8 \mathrm{E}-05$ \\
\hline Eu-154 & $1.13 \mathrm{E}-10$ & 100 & $2.6 E-07$ & $2.3 E+03$ & $8.82 E+08$ & $3.8 E+05$ & 4.3E-04 \\
\hline $\mathrm{Pb}-210+\mathrm{d}$ & 1.53E-07 & 100 & $6.9 \mathrm{E}-06$ & $4.5 \mathrm{E}+01$ & $6.55 E+05$ & $1.4 \mathrm{E}+04$ & $2.2 \mathrm{E}-02$ \\
\hline$R a-226+d$ & 5.79E-09 & 100 & $1.3 \mathrm{E}-03$ & $2.3 E+05$ & $1.73 E+07$ & $7.5 \mathrm{E}+01$ & 4.3E-06 \\
\hline Ra-228 & 4.71E-09 & 100 & 1.1E-08 & $2.3 E+00$ & $2.12 E+07$ & $9.4 E+06$ & 4.4E-01 \\
\hline$T h-229+d$ & $7.92 \mathrm{E}-08$ & 100 & $2.1 E-04$ & $2.7 E+03$ & $1.26 E+06$ & $4.7 E+02$ & $3.7 E-04$ \\
\hline Th-230 & $1.25 \mathrm{E}-08$ & 100 & $6.2 E-05$ & $5.0 \mathrm{E}+03$ & $8.00 E+06$ & $1.6 \mathrm{E}+03$ & 2.0E-04 \\
\hline$T h-232+d$ & 5.86E-08 & 100 & $1.8 E-03$ & $3.1 \mathrm{E}+04$ & $1.71 E+06$ & $5.5 E+01$ & 3.2E-05 \\
\hline Pa-231 & $6.12 E-08$ & 100 & 4.1E-04 & $6.8 \mathrm{E}+03$ & $1.63 E+06$ & $2.4 E+02$ & $1.5 E-04$ \\
\hline
\end{tabular}


Table INEL-4. Comparison of the Results from the PE Method with the Performance Assessment Findings for the Agricultural (Homesteader) Intrusion Scenarios at INEL (Part 2 of 2)

\begin{tabular}{|c|c|c|c|c|c|c|c|}
\hline \multirow[t]{2}{*}{ Nuclide } & \multirow{2}{*}{\begin{tabular}{|c|} 
PA - Chronic \\
Intruder- \\
Agricultural \\
Scenario for \\
Pits \\
Calculated \\
"Decayed \\
SDCF" at \\
100 y \\
$(r e m / y$ per \\
$\left.\mu \mathrm{Ci} / \mathrm{m}^{3}\right)$ \\
\end{tabular}} & \multicolumn{2}{|c|}{$\begin{array}{c}\text { PE Method - } \\
\text { Homesteader } \\
\text { (Agricultural) } \\
\text { Scenario for Generic } \\
\text { Trench }\end{array}$} & \multirow[b]{2}{*}{$\begin{array}{l}\text { Ratio } \\
\text { PE : PA } \\
\text { "Decayed } \\
\text { SDCF" } \\
\text { Value } \\
\end{array}$} & \multicolumn{2}{|c|}{ Waste Limit } & \multirow[b]{2}{*}{$\begin{array}{l}\text { Ratio } \\
\text { PE : PA } \\
\text { Waste } \\
\text { Limit } \\
\text { Value }\end{array}$} \\
\hline & & $\begin{array}{c}\text { Time of } \\
\text { Intrusion } \\
(y)\end{array}$ & $\begin{array}{c}\text { "Decayed } \\
\text { SDCF" } \\
\text { (rem/y per } \\
\left.\mu \mathrm{Ci} / \mathrm{m}^{3}\right) \\
\end{array}$ & & $\begin{array}{c}\text { Calculated } \\
\text { PA Waste } \\
\text { Limit } \\
\left(\mu \mathrm{Ci} / \mathrm{m}^{3}\right)\end{array}$ & $\begin{array}{c}\text { PE Waste } \\
\text { Limit - } \\
\left(w / f_{a}=0.5\right) \\
\mu C i / m^{3} \\
\end{array}$ & \\
\hline $\mathrm{U}-232+\mathrm{d}$ & 3.90E-08 & 100 & 4.3E-04 & $1.1 \mathrm{E}+04$ & $2.56 \mathrm{E}+06$ & $2.3 \mathrm{E}+02$ & 9.1E-05 \\
\hline $\mathrm{U}-233$ & $8.00 \mathrm{E}-09$ & 100 & 8.0E-06 & $1.0 \mathrm{E}+03$ & $1.25 \mathrm{E}+07$ & $1.3 \mathrm{E}+04$ & 1.0E-03 \\
\hline $\mathrm{U}-234$ & $7.75 E-09$ & 100 & 5.9E-06 & $7.6 \mathrm{E}+02$ & $1.29 \mathrm{E}+07$ & $1.7 \mathrm{E}+04$ & 1.3E-03 \\
\hline $\mathrm{U}-235+\mathrm{d}$ & 7.50 E-09 & 100 & 8.9E-05 & $1.2 \mathrm{E}+04$ & $1.33 E+07$ & $1.1 \mathrm{E}+03$ & $8.4 E-05$ \\
\hline U-236 & 7.41E-09 & 100 & 5.5E-06 & $7.5 E+02$ & $1.35 E+07$ & $1.8 \mathrm{E}+04$ & 1.3E-03 \\
\hline$U-238+d$ & 7.17E-09 & 100 & 2.0E-05 & $2.8 \mathrm{E}+03$ & $1.39 \mathrm{E}+07$ & $5.0 \mathrm{E}+03$ & $3.6 \mathrm{E}-04$ \\
\hline $\mathrm{Np}-237+d$ & $2.10 \mathrm{E}-07$ & 100 & 2.6E-04 & $1.3 E+03$ & $4.76 E+05$ & $3.8 \mathrm{E}+02$ & 8.0E-04 \\
\hline Pu-238 & 1.65E-08 & 100 & 6.7E-06 & $4.0 E+02$ & $6.06 E+06$ & $1.5 \mathrm{E}+04$ & $2.5 \mathrm{E}-03$ \\
\hline Pu-239 & 1.81E-08 & 100 & 1.6E-05 & $8.9 E+02$ & $5.54 \mathrm{E}+06$ & $6.2 \mathrm{E}+03$ & 1.1E-03 \\
\hline $\mathrm{Pu}-240$ & $1.83 E-08$ & 100 & $1.6 \mathrm{E}-05$ & $8.7 E+02$ & $5.45 E+06$ & $6.3 E+03$ & 1.1E-03 \\
\hline Pu-241 & $3.44 E-10$ & 100 & $6.9 E-07$ & $2.0 \mathrm{E}+03$ & $2.90 E+08$ & $1.5 \mathrm{E}+05$ & 5.0E-04 \\
\hline Pu-242 & $1.64 E-08$ & 100 & 1.5E-05 & $9.4 E+02$ & $6.09 \mathrm{E}+06$ & $6.5 E+03$ & 1.1E-03 \\
\hline Pu-244 & 1.74E-08 & 100 & 2.4E-04 & $1.4 \mathrm{E}+04$ & $5.75 \mathrm{E}+06$ & $4.2 \mathrm{E}+02$ & 7.3E-05 \\
\hline Am-241 & $2.19 \mathrm{E}-08$ & 100 & $2.0 \mathrm{E}-05$ & $9.2 E+02$ & $4.56 \mathrm{E}+06$ & $5.0 \mathrm{E}+03$ & $1.1 \mathrm{E}-03$ \\
\hline Am-243+d & 2.28E-08 & 100 & 1.2E-04 & $5.1 E+03$ & $4.38 \mathrm{E}+06$ & $8.6 \mathrm{E}+02$ & $2.0 \mathrm{E}-04$ \\
\hline $\mathrm{Cm}-243$ & 1.24E-08 & 100 & $6.6 \mathrm{E}-06$ & $5.4 E+02$ & $8.06 \mathrm{E}+06$ & $1.5 \mathrm{E}+04$ & $1.9 \mathrm{E}-03$ \\
\hline $\mathrm{Cm}-244$ & 1.07E-08 & 100 & $2.4 \mathrm{E}-07$ & $2.3 E+01$ & $9.38 \mathrm{E}+06$ & $4.1 E+05$ & 4.4E-02 \\
\hline $\mathrm{Cm}-245$ & $1.94 \mathrm{E}-08$ & 100 & 5.7E-05 & $2.9 E+03$ & $5.16 E+06$ & $1.8 E+03$ & $3.4 \mathrm{E}-04$ \\
\hline $\mathrm{Cm}-246$ & $1.90 \mathrm{E}-08$ & 100 & $1.6 \mathrm{E}-05$ & $8.6 \mathrm{E}+02$ & $5.27 \mathrm{E}+06$ & $6.1 E+03$ & 1.2E-03 \\
\hline $\mathrm{Cm}-247$ & $\mathrm{NA}$ & 100 & 2.2E-04 & $\mathrm{NA}$ & NA & $4.5 E+02$ & $\overline{N A}$ \\
\hline $\mathrm{Cm}-248$ & 6.67E-08 & 100 & 6.1E-05 & $9.2 \mathrm{E}+02$ & $1.50 E+06$ & $1.6 \mathrm{E}+03$ & 1.1E-03 \\
\hline Cf-249 & NA & 100 & $1.9 \mathrm{E}-04$ & NA & $\overline{N A}$ & $5.4 E+02$ & $\overline{N A}$ \\
\hline Cf-250 & NA & 100 & $9.3 E-08$ & $\overline{\mathrm{NA}}$ & $\overline{N A}$ & $1.1 \mathrm{E}+06$ & NA \\
\hline Cf-251 & NA & 100 & 7.4E-05 & $\overline{\mathrm{NA}}$ & $\overline{N A}$ & $1.4 \mathrm{E}+03$ & NA \\
\hline
\end{tabular}

" $+d$ " denotes short-lived decay products that are assumed to be in secular equilibrium with the parent radionuclide.

NA indicates that the radionuclide was not subjected to detailed intrusion analyses in the INEL performance assessment. 
Using the SDCF derived from the performance assessment, a permissible waste concentration can also be calculated using the $100 \mathrm{mrem} / \mathrm{y}$ dose limit. The derived waste limit is calculated by dividing the dose limit by the decayed SDCF. Table INEL-4 also presents these waste limits derived from the performance assessment, those calculated for the PE, and the ratio of the two. The waste limits from the performance assessment are generally 2 to 3 orders of magnitude greater (i.e., waste limits are less restrictive) than the $P E$ values, with a range from zero to six orders of magnitude (excluding a couple of outliers).

One factor contributing to these differences is that the values tabulated in the performance assessment for this comparison do not include external exposures. However, this alone would not account for the differences. Other contributors include differing exposure scenarios, exposure pathways, and parameter values. For example, the RWMC performance assessment includes water pathway and meat/milk ingestion in the intruder scenarios, whereas the $\mathrm{PE}$ analysis does not. The RWMC performance assessment uses the GENII computer code; the code assumes that soil, plants, and animal products are contaminated from both air and water. The PE analysis does not address intruder contamination from these pathways. Furthermore, the performance assessment included the decay of the waste inventory during operation of the disposal facility. Such decay was not accounted for in the PE. In the RWMC performance assessment, the GENII code is also used to determine ingestion and inhalation doses for H-3 and C-14. For terrestrial exposure pathways, GENII incorporates special models for these two radionuclides, which differ from those used in the PE.

\section{A.1.3 DISCUSSION OF THE RESULTS OF THE COMPARATIVE EXERCISE}

One objective of this comparative exercise is to gain insight into the differences between the scoping methodology of the PE and the more detailed evaluations conducted for the sitespecific performance assessment. Observations regarding this objective are discussed below.

No unusual, unique, or site-specific radionuclide transport or dose exposure phenomena (i.e., none that are not already accounted for in the PE methodology) were discovered during the exercise. In particular, the groundwater pathway shows excellent agreement between the two methods.

For the atmospheric pathway at INEL, no data are available for direct comparison between the performance assessment and the PE methods. The RWMC performance assessment does, however, examine a biointrusion mechanism, in which harvester ants bring waste material to the surface. Subsequent resuspension and atmospheric dispersion of that waste is evaluated against a performance objective of $10 \mathrm{mrem} / \mathrm{y}$. The PE methodology does not include such biointrusion or resuspension mechanisms. Also, the RWMC performance assessment uses the GENII computer code to determine ingestion and inhalation doses for $\mathrm{H}-3$ and $\mathrm{C}-14$. For the terrestrial portion of the "all pathways" exposure, GENII incorporates special models for these two radionuclides. Differences are acknowledged to exist between the PE methodology and the GENII code; however, there is no reason to conclude that one is better or more accurate than the other. 
For the groundwater pathway at INEL, excellent agreement was observed between the PE and the performance assessment. The PE results not only matched the RWMC performance assessment $\mathrm{CRF}$ values, but also the subsurface arrival times. The waste limits of all radionuclides matched within one order of magnitude.

For the intrusion scenarios at INEL, reasonable agreement was observed between the PE and the performance assessment. The RWMC performance assessment includes water pathway and meat/milk ingestion in the intruder scenarios, whereas the PE analysis does not. The RWMC also uses the GENII computer code as described above. The code assumes that soil, plants, and animal products are contaminated from both air and water. The PE analysis does not address intruder exposures from these pathways. Nevertheless, the PE results for permissible waste concentrations were consistently two to three orders of magnitude more restrictive than those extracted from the performance assessment.

\section{A.1.4 REFERENCES}

Maheras, Steven J., Arthur S. Rood, Swen O. Magnuson, Mary E. Sussman, Rajiv N. Bhatt, 1994. Radioactive Waste Management Complex, Low-Level Waste Radiological Performance Assessment. EGG-WM-8773. Idaho Falls, ID: U.S. Department of Energy Office of Environmental Restoration and Waste Management, DOE Idaho Operations Office.

EG\&G Idaho, Inc. (EG\&G) 1993. Engineering Design File—Revised Doses to Inadvertent Intruders for the RWMC Radiological Performance Assessment. November 1993.

Gruebel, M.M., R.D. Waters, M.B. Hospelhorn, and M.S.Y. Chu, eds., 1994. Framework for DOE Low-Level and Mixed Low-Level Waste Disposal: Site Fact Sheets, SAND94-2728, Sandia National Laboratories, Albuquerque, NM.

Rood, A.S., 1994. GWSCREEN: A Semi-Analytical Model for Assessment of the Groundwater Pathway from Surface or Buried Contamination, Theory and User's Manual, Version 2.0, EGG-GEO-10797, Rev. 2, Idaho National Engineering Laboratory, EG\&G Idaho, Inc., Idaho Falls, ID.

Rood, A.S., et al. 1994. Engineering Design File RWMC-760, Idaho National Engineering Laboratory, EG\&G Idaho, Inc., Idaho Falls, ID. 


\section{Appendix A.2: Savannah River Site (SRS)}




\section{NOMENCLATURE}

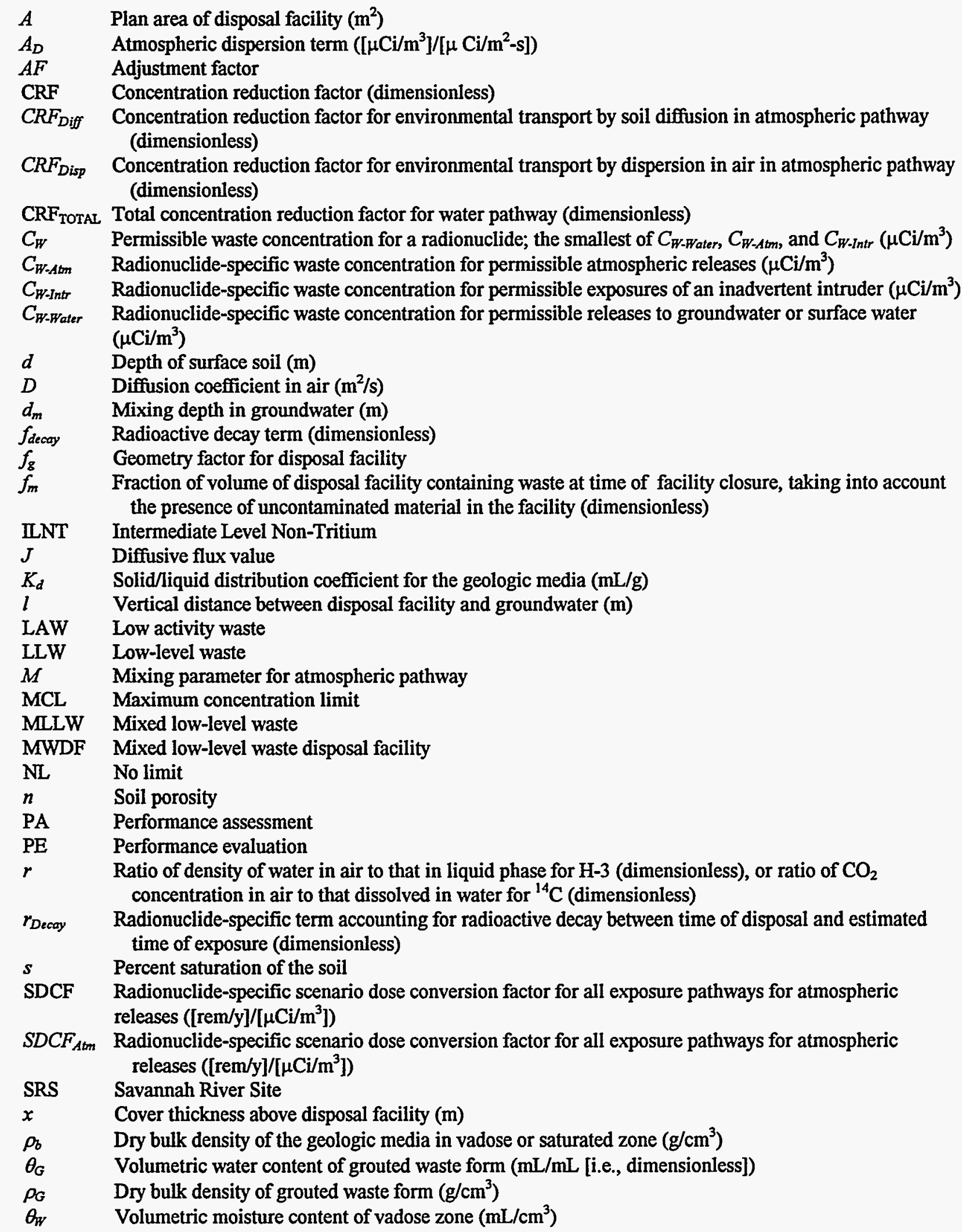




\section{APPENDIX A.2: SAVANNAH RIVER SITE (SRS)}

In order to evaluate the applicability of the standard performance evaluation (PE) method to the Mixed Waste Disposal Facility (MWDF) at the Savannah River Site (SRS), it is appropriate to apply the method to an existing site that has been well studied. The SRS E-Area performance assessment (WSRC, 1994) considers the release of radionuclides from the Low Activity Waste (LAW) vaults, which were determined to be similar in design to the proposed MWDF vaults. The findings of that performance assessment (PA) were used as the basis for comparison of results obtained from the implementation of the PE method as documented in Volume 2, Section 5 in this report. This appendix discusses the findings of that comparative process (Section SRS.2) and presents the PE results (Section SRS.3) regarding permissible waste concentrations for the MWDF at Savannah River.

\section{A.2.1 OVERVIEW OF THE EXISTING PERFORMANCE ASSESSMENT}

Much of the approach developed for the E-Area performance assessment served as the prototype for the $\mathrm{PE}$ methodology. In particular, the atmospheric pathway and intrusion scenarios for the PE method are based upon the E-Area performance assessment. The following discussion highlights the approach, conceptual model, and specifics incorporated into the E-Area performance assessment. The key features of the conceptual model for the performance assessment can be summarized as follows:

- Radionuclides are assumed to be immobile until contacted by water.

- Water entering the vaults is assumed to be a mixture of concrete pore fluid and groundwater in equilibrium with carbon dioxide.

- Waste is assumed to be a homogenous mass of material with the properties of soil; corroded steel boxes inside the vault create reducing conditions and hydrous $\mathrm{Fe}(\mathrm{III})$ oxides.

- Aqueous concentrations in the vaults are controlled by sorption ( $K_{d}$ effect) onto corrosion products and grout.

- Solubility limitations were implemented, but only for uranium and plutonium radionuclides.

- Migration of radionuclides is controlled by the water flow rate and by the $K_{d}$ in concrete and soil.

A total of 730 radionuclides are considered in the E-Area performance assessment; however, not all of these are subjected to detailed analyses for each and every release pathway. Because the specific radionuclides that may be encountered in the waste during disposal operations are not known, a conservative screening method is incorporated into the performance assessment to determine the allowable inventories of a large suite of candidate radionuclides. 
These limits are called "trigger values" in the performance assessment and are used to indicate the level of inventory at which the performance objectives may be exceeded. The use of the "trigger values" reduces the number of candidate radionuclides to smaller numbers for detailed evaluation.

The LAW vaults at SRS will provide for disposal and storage of solid, low-level, non-hazardous radioactive waste. The LAW vaults are designed to receive waste radiating less than $200 \mathrm{mR} / \mathrm{hr}$ at $5 \mathrm{~cm}$ from the exterior of the outer disposal container and containing less than $10 \mathrm{Ci}$ of tritium per package. The LAW vaults are concrete structures that consist of two or three modules, depending upon the location of the vault. Each module contains four cells. Each three-module vault is approximately $200 \mathrm{~m}$ long, $44 \mathrm{~m}$ wide, and $8.2 \mathrm{~m}$ high, while the two-module vaults are only $130 \mathrm{~m}$ long. All exterior walls of the $\mathrm{LAW}$ vaults are $0.6 \mathrm{~m}$ thick and are structurally mated to a $0.8-\mathrm{m}$ thick footer. Interior cell walls are $0.3 \mathrm{~m}$ thick. The floor slab is $0.3 \mathrm{~m}$ thick and is not mated to the footer or to the walls.

In the performance assessment, the presence of a cap (cover) over the LAW vaults is assumed to reduce recharge from $40 \mathrm{~cm} / \mathrm{y}$ to $4 \mathrm{~cm} / \mathrm{y}$. Recharge is always assumed to be steadystate. Erosion of the cap is considered in the performance assessment, but the cap was assumed to remain functional until the vault roof collapses. While cracks are assumed to develop in the roof at about $1400 \mathrm{y}$, roof collapse is not assumed to occur until about $3000 \mathrm{y}$. The lengthy time until failure at SRS is attributed to the purity and $\mathrm{pH}$ of rainfall in the area, combined with the low oxidation/reduction potential of the sandy soils.

Two receptor types were assessed in the E-Area performance assessment: (1) a member of the public, assumed to reside at the SRS boundary during the institutional control period and to reside $100 \mathrm{~m}$ from the boundary of the disposal facility during the post-institutional control period, and (2) an inadvertent intruder who would gain access to the site during the postinstitutional control period.

The performance assessment analyses are not specifically "inventory based," in that $1 \mathrm{Ci}$ per set of vaults is consistently used as the source term for each radionuclide. From this input value, the allowable waste inventories are computed as controlled by the most restrictive exposure pathway. From this information, the values in the performance assessment can be used to directly compute permissible waste concentrations. These concentrations are thus available for direct comparison with the results of the PE methodology.

In the performance assessment, the groundwater analyses were conducted with the PORFLOW-3D computer code. Three separate models were developed: (1) the closure cap, modeled with two-dimensional unsaturated flow, (2) the combined vault and vadose zone, modeled with two-dimensional unsaturated flow and transport, and (3) the saturated zone in which steady-state flow fields were established assuming constant recharge. The mass transport from the vadose zone model was used as source input to the saturated zone model. The groundwater analyses were conducted to compute the maximum concentration in groundwater at or beyond the $100-\mathrm{m}$ zone as a function of time. 
Peak groundwater concentrations are presented in the E-Area performance assessment for the time of arrival at the performance boundary, as well as concentrations at the performance boundary at the end of the 10,000-y compliance period. Longitudinal dispersion is considered in the performance assessment subsurface transport analyses, but is not a part of the PE methodology. As discussed above, solubility limits were imposed upon all uranium and plutonium radionuclides as they were leached from the disposal facility prior to subsurface transport. This limitation is not a feature of the PE methodology.

For the groundwater pathway, the E-Area performance assessment incorporates maximum concentration limits (MCLs) for protection of groundwater resources. The performance objective is interpreted as requiring that concentrations of contaminants in groundwater should not exceed values specified in EPA standards for public drinking water supplies (40 CFR Part 141). These standards include the method prescribed by the EPA for calculating MCLs for beta/gamma-emitting radionuclides based upon internal dosimetry data from ICRP Publication 2 (ICRP, 1959) and the specified MCLs for $\mathrm{H}-3$ and Sr-90. In addition, a compliance limit for uranium of $20 \mu \mathrm{g} / \mathrm{L}$ is incorporated into the performance assessment.

In the performance assessment, the limiting concentrations of radionuclides in groundwater pathway are then determined from the more restrictive of two performance objectives: (1) a maximum effective dose equivalent of $25 \mathrm{mrem} / \mathrm{y}$ from all exposure pathways involving the use of contaminated water, and (2) the MCLs or other specified concentration limits of radionuclides in drinking water. The PE method includes consideration of an effective dose equivalent of $4 \mathrm{mrem} / \mathrm{y}$ from only the direct ingestion of contaminated water; it does not consider MCLs.

Atmospheric releases of the volatile radionuclides $\mathrm{H}-3$ and $\mathrm{C}-14$ are also included in the E-Area performance assessment. The principle mechanism is upward vapor diffusion followed by atmospheric dispersion toward a receptor. The location of the receptor is at the SRS boundary during the period of institutional control and at $100 \mathrm{~m}$ from the disposal facility thereafter.

The detailed dose analysis for inadvertent intruders in the performance assessment included three chronic exposure scenarios. The performance assessment found that the chronic scenarios, as opposed to the acute scenarios, always control the permissible waste concentrations. The chronic scenarios for inadvertent intruders included:

- an agricultural scenario involving direct excavation into the disposal units,

- a resident scenario involving residence in a home on top of the intact engineered barriers of the disposal facility, and

- a post-drilling scenario involving removal of waste from the disposal units by drilling.

For each scenario the performance objective is $100 \mathrm{mrem} / \mathrm{y}$ and is assumed to apply for $10,000 \mathrm{y}$ after closure of the facility. However, an intruder dose analysis was also performed for times beyond 10,000 y if the maximum dose could occur at such times (e.g., for the ingrowth of radiologically significant decay products). The resident scenario is not considered in the PE methodology. 


\section{A.2.2 COMPARISON OF THE PE METHODOLOGY WITH THE E-AREA PERFORMANCE ASSESSMENT}

\section{A.2.2.1 Water Pathway}

This section discusses the straightforward application of the PE method to the LAW Vaults, using values from Table SRS-1. Where possible, these values have been extracted from the E-Area performance assessment. Twenty of the radionuclides included in the performance evaluation were examined in the E-Area performance assessment, providing a basis for comparison between the $\mathrm{PE}$ and performance assessment methods.

The performance assessment analysis uses PORFLOW to calculate the flow and transport from the waste form to the water table and from the water table to the performance boundary in two numerical discretized simulations. No intermediate results at the water table are reported, and none at the top of the vadose zone were calculated. Regional recharge is constant at 0.40 $\mathrm{m} / \mathrm{y}$, with $0.04 \mathrm{~m} / \mathrm{y}$ penetrating the vault cover and flowing through all parts of disposal facility.

The E-Area is irregularly shaped. The PE method applied to the LAW vaults used a modified shape of the facility, since the $\mathrm{PE}$ assumes a rectangular shape oriented with the groundwater gradient. The objective of this application of the PE is to mimic the results of the performance assessment, so the modification is justified. Figure 4.1-6 in the E-Area performance assessment shows the plumes resulting from the performance assessment analysis and the location of the well chosen as the compliance well. The LAW vaults are arranged in two arms of a "boomerang", with 11 in the southeast arm and 10 in the west arm. (The smaller tail to the west contains only ILNT vaults). It is apparent from the figure that the southeast arm contributes little to the plume which intersects the LAW compliance well. The PE approximates this effect by using only 10 vaults, laid out in the western arm. Each of the ten vaults is oriented with its long axis parallel to groundwater flow, which is generally to the north, and the row of ten is oriented east-west. This makes the overall facility $250 \mathrm{~m}$ long (parallel to groundwater flow) and $500 \mathrm{~m}$ wide. Each of the 10 vaults has a length of $196 \mathrm{~m}$ and a width of $44 \mathrm{~m}$ (Fig. $2.5-1$ in the E-Area performance assessment), so the total waste area is $86,240 \mathrm{~m}^{2}$.

Values for the solid/water distribution coefficients $\left(K_{d}\right)$ used in the SRS performance assessment for E-Area vaults are presented in Table SRS-2. The LAW vaults used $K_{d}$ values for the waste based on adsorption to goethite, $\mathrm{FeO}(\mathrm{OH})$, which is a byproduct of corrosion of the steel containers housing the disposed waste. These values were also used for the $\mathrm{PE}$ methodology as applied to the LAW vaults. Where the E-Area performance assessment used a wide variety of $K_{d} s$ for the various subsurface materials, the PE methodology was applied using identical soil $K_{d} s$ for both unsaturated and saturated zones, assuming uniform materials. 
Table SRS-1. Parameters and Values Used in the PE Analysis for the Low Activity Waste (LAW) Vaults at SRS E-Area

\begin{tabular}{|c|c|c|c|}
\hline Parameter & Value & $\begin{array}{l}\text { Data } \\
\text { Type }\end{array}$ & Comments \\
\hline \multicolumn{4}{|l|}{ SOURCE TERM } \\
\hline initial waste concentration & $1 \mu \mathrm{Ci} / \mathrm{m}^{3}$ & $D$ & $\begin{array}{l}\text { a unit concentration is part of the } \\
\text { standard PE method }\end{array}$ \\
\hline waste volumetric water content & 0.3 & c & staff \\
\hline waste bulk density & $2.65 \mathrm{~g} / \mathrm{mL}$ & C & staff \\
\hline facility length & $250 \mathrm{~m}$ & A & see discussion in text \\
\hline facility width & $500 \mathrm{~m}$ & $A$ & see discussion in text \\
\hline waste area & $86,240 \mathrm{~m}^{2}$ & A & $\begin{array}{l}196 \mathrm{~m} \times 44 \mathrm{~m} \text { for } 10 \text { vaults, } \\
\text { see discussion in text }\end{array}$ \\
\hline waste mixing fraction & 0.5 & $A$ & staff \\
\hline $\begin{array}{l}\text { annual rate of water flowing } \\
\text { through intact facility }\end{array}$ & $0.04 \mathrm{~m} / \mathrm{y}$ & A & WSRC, 1994 \\
\hline $\begin{array}{l}\text { time to failure of leachate } \\
\text { collection system }\end{array}$ & $30 y$ & D & standard PE method \\
\hline time to failure of facility & $3000 y$ & $\mathrm{~B}$ & WSRC, 1994 \\
\hline \multicolumn{4}{|l|}{ UNSATURATED ZONE } \\
\hline volumetric water content & 0.2 & A & WSRC, 1994 \\
\hline bulk density & $2.65 \mathrm{~g} / \mathrm{mL}$ & A & WSRC, 1994 \\
\hline $\begin{array}{l}\text { unsaturated zone thickness } \\
\text { below facility }\end{array}$ & $8 m$ & A & WSRC, 1994 \\
\hline $\begin{array}{l}\text { natural recharge through local } \\
\text { soils }\end{array}$ & $0.40 \mathrm{~m} / \mathrm{y}$ & A & WSRC, 1994 \\
\hline \multicolumn{4}{|l|}{ SATURATED ZONE } \\
\hline aquifer porosity & 0.3 & A & WSRC, 1994 \\
\hline bulk density & $2.65 \mathrm{~g} / \mathrm{mL}$ & A & WSRC, 1994 \\
\hline mixing depth & $10 \mathrm{~m}$ & C & staff \\
\hline groundwater (seepage) velocity & $24 \mathrm{~m} / \mathrm{y}$ & C & inferred by staff from WSRC, 1994 \\
\hline $\begin{array}{l}\text { distance to performance } \\
\text { boundary from facility boundary }\end{array}$ & $100 \mathrm{~m}$ & $\bar{D}$ & $\begin{array}{l}\text { WSRC, 1994; same as for standard } \\
\text { PE method }\end{array}$ \\
\hline $\begin{array}{l}\text { distance to performance } \\
\text { boundary from facility center }\end{array}$ & $225 \mathrm{~m}$ & D & standard PE method \\
\hline
\end{tabular}

" $A=$ Site measurement; $B=$ Result of site numerical analysis; $C=$ Literature value selected by site; $D=$ Generic $P E$ value 
Table SRS-2. Solid/Liquid Distribution Coefficients ( $K_{d}$ values) Used in the Performance Assessment for the E-Area Vaults at the Savannah River Site

\begin{tabular}{|l|c|c|}
\hline Element & $\begin{array}{c}K_{d} \text { for Waste } \\
\text { (goethite) } \\
(\mathrm{mL} / \mathrm{g})\end{array}$ & $\begin{array}{c}K_{d} \text { for Saturated and } \\
\text { Unsaturated Zones } \\
(\mathrm{mL} / \mathrm{g})\end{array}$ \\
\hline $\mathrm{H}$ & 0 & 0 \\
\hline $\mathrm{C}$ & 0 & 2 \\
\hline $\mathrm{Ni}$ & 1200 & 300 \\
\hline $\mathrm{Se}$ & 170 & 5 \\
\hline $\mathrm{Sr}$ & 3 & 10 \\
\hline $\mathrm{Tc}$ & 0 & 0.36 \\
\hline $\mathrm{Sn}$ & 50 & 130 \\
\hline $\mathrm{I}$ & 0 & 0.6 \\
\hline $\mathrm{Th}$ & 2200 & 3000 \\
\hline $\mathrm{Np}$ & 750 & 10 \\
\hline $\mathrm{Am}$ & 3700 & 150 \\
\hline $\mathrm{Cm}$ & 3700 & 150 \\
\hline $\mathrm{Cf}$ & 3700 & 150 \\
\hline
\end{tabular}

The values from Tables SRS-1 and SRS-2 were incorporated into the PE equations (see Volume 2, Section 5 of this report). Table SRS-3 shows the comparative results. The results of the comparative exercise show that for many of the radionuclides, the PE results compare well (i.e., waste limits within about one order of magnitude) to the findings published in the performance assessment. Exceptions to this general agreement include H-3, C-14, Cs-135, Th-232, Cm-245, Cm-246, Cm-247, Cm-248, and Cf-249. The reasons for the discrepancies have not yet been completely resolved but are believed to be associated with the hydrodynamic dispersion included in the performance assessment calculations. Such dispersion is not included as part of the PE methodology.

\section{A.2.2.2 Atmospheric Pathway}

The PE method is applied to the LAW vaults to compare the results of the PE atmospheric analysis with the findings of the performance assessment for the E-Area vaults. Only the two volatile radionuclides, $\mathrm{H}-3$ and $\mathrm{C}-14$, were subjected to atmospheric pathway analyses as part of the PE methodology. A performance objective of $10 \mathrm{mrem} / \mathrm{y}$ from all pathways was incorporated into the analyses. 
Table SRS-3. Comparison of the Results from the PE Method with the PA Findings for the Groundwater Pathway at SRS

\begin{tabular}{|c|c|c|c|c|c|c|c|}
\hline \multirow[t]{2}{*}{ Nuclide } & \multicolumn{2}{|c|}{$\begin{array}{c}\text { Total CRF } \\
\text { (corrected for 10,000 y } \\
\text { compliance time in PA) } \\
\text { (no decay) }\end{array}$} & \multicolumn{2}{|c|}{ Arrival Time } & \multicolumn{2}{|c|}{$\begin{array}{c}\text { Permissible Waste } \\
\text { Concentration } \\
C_{\text {w-Water }} \\
\left(\mu \mathrm{Ci} / \mathrm{m}^{3}\right) \\
\end{array}$} & \multirow[t]{2}{*}{ Nuclide } \\
\hline & PA & PE & PA & PE & PA & $\mathrm{PE}$ & \\
\hline $\mathrm{H}-3$ & $2.0 E+7$ & $4.9 E+0$ & $9.7 E+1$ & $7.4 E+1$ & $9.4 E+10$ & $2.8 \mathrm{E}+4$ & $\mathrm{H}-3$ \\
\hline C-14 & $3.4 \mathrm{E}+2$ & 1.0E+0 & $5.4 E+3$ & $3.2 E+3$ & $7.3 E+4$ & $4.0 \mathrm{E}+0$ & C-14 \\
\hline $\mathrm{Ni}-59$ & $2.6 E+4$ & $6.1 E+4$ & $1.0 E+4$ & $3.0 \mathrm{E}+4$ & $1.6 \mathrm{E}+4$ & $3.7 \mathrm{E}+5$ & $\mathrm{Ni}-59$ \\
\hline Se-79 & $1.8 \mathrm{E}+2$ & $1.6 \mathrm{E}+3$ & $3.6 \mathrm{E}+3$ & $3.3 E+3$ & $1.3 E+2$ & $1.0 \mathrm{E}+3$ & Se-79 \\
\hline Sr-90 & & & infinity & $3.7 E+3$ & no limit & $1.9 E+38$ & Sr-90 \\
\hline TC-99 & $5.1 \mathrm{E}+1$ & $1.0 \mathrm{E}+0$ & $3.4 E+3$ & $3.1 E+3$ & $4.2 E+1$ & $3.9 \mathrm{E}+0$ & TC-99 \\
\hline Sn-126 & $1.9 E+3$ & $4.6 \mathrm{E}+2$ & $1.0 \mathrm{E}+4$ & $1.4 E+4$ & $6.1 E+2$ & $1.3 \mathrm{E}+2$ & Sn-126 \\
\hline $1-129$ & 4.1E+1 & $1.0 E+0$ & $1.8 E+3$ & $3.1 \mathrm{E}+3$ & 2.1E-2 & 2.0E-2 & $1-129$ \\
\hline Cs-135 & $1.5 \mathrm{E}+3$ & $1.0 E+0$ & $8.4 E+3$ & 1.2E+4 & 1.2E+3 & 8.0E-1 & Cs-135 \\
\hline Th-232 & $8.2 E+16$ & $3.8 E+16$ & $1.0 \mathrm{E}+4$ & $2.7 E+5$ & $5.8 E+14$ & $2.2 \mathrm{E}+1$ & Th-232 \\
\hline Np-237 & $6.1 \mathrm{E}+2$ & $6.8 E+3$ & 1.0E+4 & 3.7E+3 & $5.5 E+0$ & $8.4 \mathrm{E}+0$ & $\mathrm{~Np}-237$ \\
\hline Am-241 & $7.9 \mathrm{E}+5$ & $3.4 E+4$ & 8.7E+3 & $1.6 E+4$ & $2.7 E+4$ & $4.2 E+4$ & Am-241 \\
\hline Am-243 & $9.1 E+4$ & $1.4 E+5$ & $1.0 \mathrm{E}+4$ & $1.6 E+4$ & $1.8 E+3$ & $2.4 E+2$ & Am-243 \\
\hline Cm-244 & & & infinity & 1.6E+4 & no limit & no limit & $\mathrm{Cm}-244$ \\
\hline $\mathrm{Cm}-245$ & $3.9 E+5$ & $4.6 \mathrm{E}+5$ & 1.0E+4 & $1.6 E+4$ & $6.8 \mathrm{E}+3$ & $3.0 E+1$ & $\mathrm{Cm}-245$ \\
\hline $\mathrm{Cm}-246$ & $4.0 E+5$ & 1.6E+5 & $1.0 \mathrm{E}+4$ & $1.6 E+4$ & $1.3 E+4$ & $5.3 E+2$ & $\mathrm{Cm}-246$ \\
\hline $\mathrm{Cm}-247$ & $3.3 E+5$ & $2.5 \mathrm{E}+6$ & $1.0 E+4$ & $1.6 \mathrm{E}+4$ & $2.8 \mathrm{E}+3$ & $3.1 \mathrm{E}+1$ & $\mathrm{Cm}-247$ \\
\hline Cm-248 & $3.2 E+5$ & $2.3 E+6$ & 1.0E+4 & $1.6 \mathrm{E}+4$ & $6.9 E+2$ & 1.4E+1 & $\mathrm{Cm}-248$ \\
\hline Cf-249 & $2.2 \mathrm{E}+6$ & $3.4 E+4$ & 8.1E+3 & $1.6 \mathrm{E}+4$ & 1.7E+5 & $7.2 \mathrm{E}+2$ & Cf-249 \\
\hline Cf-251 & $1.4 \mathrm{E}+5$ & $1.8 E+4$ & $1.0 E+4$ & $1.6 \mathrm{E}+4$ & $2.4 \mathrm{E}+6$ & 1.1E+7 & Cf-251 \\
\hline
\end{tabular}

Table SRS-4 shows the relevant input for the PE methodology for comparison to the findings of the performance assessment for the LAW vaults. The total waste area of the LAW Vaults is $86,240 \mathrm{~m}^{2}$ compared to the $10,000 \mathrm{~m}^{2}$ area of the proposed MWDF. The meteorological data unique to SRS were obtained from hourly average meteorological readings taken at a height of $61-\mathrm{m}$ at the meteorological tower in the H-Area at SRS for the period 1987 to 1991. Both the site-specific meteorological data and the waste area were used to determine the $M$ and $A_{D}$ values, and thus the CRFs, for atmospheric dispersion of the radionuclides once they reached the surface by diffusion. The other parameters and values used in this comparative analysis are the same as those used to determine CRFs for the proposed MWDF. 
Table SRS-4. Parameters and Values Used in the PE Method for the Atmospheric Pathway for the LAW Vaults at the SRS E-Area (standard PE method values are discussed in Volume 2, Chapter 5 of this report)

\begin{tabular}{|c|c|c|c|}
\hline Parameter & Value & $\begin{array}{l}\text { Data } \\
\text { Type* }\end{array}$ & Comments \\
\hline $\begin{array}{l}\text { Cover thickness above the } \\
\text { disposal facility, } x\end{array}$ & $1.0 \mathrm{~m}$ & B & Value is site-specific (WSRC 1994) \\
\hline Depth of the soil surface, $d$ & $0.01 \mathrm{~m}$ & D & $\begin{array}{l}\text { Standard PE method; value is generic } \\
\text { and not site-specific (WSRC 1994) }\end{array}$ \\
\hline Soil porosity, $n$ & 0.5 & A & Value is site-specific (WSRC 1994) \\
\hline Fraction saturation, $s$ & 1.0 & A & Value is site-specific (WSRC 1994) \\
\hline $\begin{array}{l}\text { Ratio of the density of water } \\
\text { in air to that in the liquid } \\
\text { phase for } \mathrm{H}-3, r\end{array}$ & $9.20 E-6$ & D & $\begin{array}{l}\text { Standard PE method; value is generic } \\
\text { and not site-specific }\end{array}$ \\
\hline $\begin{array}{l}\text { Ratio of the } \mathrm{CO}_{2} \\
\text { concentration in air to that } \\
\text { in dissolved water for } \mathrm{C}-14 \text {, } \\
r\end{array}$ & $4.25 E-4$ & D & $\begin{array}{l}\text { Standard PE method; value is generic } \\
\text { and not site-specific }\end{array}$ \\
\hline $\begin{array}{l}\text { Diffusion coefficient in air } \\
\text { for } H-3, D\end{array}$ & $\begin{array}{c}2.39 E-5 \\
\mathrm{~m}^{2} / \mathrm{s}\end{array}$ & D & $\begin{array}{l}\text { Standard PE method; value is generic } \\
\text { and not site-specific }\end{array}$ \\
\hline $\begin{array}{l}\text { Diffusion coefficient in air } \\
\text { for } C-14, D\end{array}$ & $\begin{array}{l}1.40 E-5 \\
\mathrm{~m}^{2} / \mathrm{s}\end{array}$ & D & $\begin{array}{l}\text { Standard PE method; value is generic } \\
\text { and not site-specific }\end{array}$ \\
\hline Mixing parameter, $\boldsymbol{M}$ & 8.77 & A & $\begin{array}{l}\text { Value is site-specific and calculated } \\
\text { using the ISCLT2 air dispersion model. } \\
\text { Important model input parameters } \\
\text { were the surface area of the LAW } \\
\text { Vaults equal to } 86,240 \mathrm{~m}^{2} \text { and site- } \\
\text { specific meteorological data (see } \\
\text { Volume } 3 \text {, Section 13.3.2) }\end{array}$ \\
\hline $\begin{array}{l}\text { Atmospheric dispersion } \\
\text { parameter, } A_{D}\end{array}$ & 2.57 & A & $\begin{array}{l}\text { Value is site-specific and calculated } \\
\text { using the ISCLT2 air dispersion model. } \\
\text { Important model input parameters } \\
\text { were the surface area of the LAW } \\
\text { Vaults equal to } 86,240 \mathrm{~m}^{2} \text { and site- } \\
\text { specific meteorological data (see } \\
\text { Volume } 3 \text {, Section 13.3.2) }\end{array}$ \\
\hline $\begin{array}{l}\text { Atmospheric Scenario Dose } \\
\text { Conversion Factor for } \mathrm{H}-3 \text {, } \\
\text { SDCF }\end{array}$ & $\begin{array}{c}8.33 \mathrm{E}+2 \\
\mathrm{mrem} / \mathrm{y} \mathrm{per} \\
\mu \mathrm{Ci} / \mathrm{m}^{3}\end{array}$ & D & $\begin{array}{l}\text { Standard PE method; value is generic } \\
\text { and not site-specific. Includes "all } \\
\text { pathways" considerations. }\end{array}$ \\
\hline $\begin{array}{l}\text { Atmospheric Scenario Dose } \\
\text { Conversion Factor for C-14, } \\
\text { SDCF }\end{array}$ & $\begin{array}{l}2.20 \mathrm{E}+5 \\
\mathrm{mrem} / \mathrm{y} \text { per } \\
\mu \mathrm{Ci} / \mathrm{m}^{3}\end{array}$ & D & $\begin{array}{l}\text { Standard PE method; value is generic } \\
\text { and not site-specific. Includes "all } \\
\text { pathways" considerations. }\end{array}$ \\
\hline
\end{tabular}

${ }^{2} A=$ Site measurement; $B=$ Result of site numerical analysis; $C=L$ iterature value selected by site; $D=G e n e r i c P E$ value 
Table SRS-5 shows the results of the comparative atmospheric analysis, including CRF values, the time of arrival, and the permissible waste limits that can be disposed of without exceeding the $\mathrm{PE}$ performance measure (i.e., a dose of $10 \mathrm{mrem} / \mathrm{y}$ from all pathways). These values were compared to those reported in SRS E-Area performance assessment for the LAW vaults. Only total $\mathrm{CRF}$ values were compared because the performance assessment did not break the CRF into the soil diffusion and atmospheric dispersion terms components as does the PE analyses. Total CRFs were calculated as the product of the soil diffusion and atmospheric diffusion CRFs. The results of the PE method are less conservative (i.e., higher permissible waste limits) than the performance assessment values for both $\mathrm{H}-3$ and $\mathrm{C}-14$.

Table SRS-5. Comparison of the Results from the PE Method with the Performance Assessment Findings for the Atmospheric Pathway for the LAW Vaults at SRS E-Area

\begin{tabular}{|c|c|c|c|c|c|c|}
\hline Nuclide & \multicolumn{2}{|c|}{ Total CRF } & \multicolumn{2}{|c|}{$\begin{array}{c}\text { Time of Arrival } \\
(\mathrm{y})\end{array}$} & \multicolumn{2}{|c|}{$\begin{array}{c}\text { Permissible Waste } \\
\text { Concentration, } \\
C_{\text {W-Atm }} \\
\left(\mu \mathrm{Ci} / \mathrm{m}^{3}\right)\end{array}$} \\
\hline & $\mathrm{PA}$ & $\mathrm{PE}$ & $\mathrm{PA}$ & $\mathrm{PE}$ & $\mathrm{PA}$ & $\mathrm{PE}$ \\
\hline $\mathrm{H}-3$ & $1 \mathrm{E}+10$ & $9 \mathrm{E}+8$ & 100 & 100 & $2 \mathrm{E}+7$ & $3 \mathrm{E}+9$ \\
\hline $\mathrm{C}-14$ & $3 \mathrm{E}+8$ & $3 \mathrm{E}+7$ & 100 & 100 & $8 \mathrm{E}+2$ & $2 \mathrm{E}+3$ \\
\hline
\end{tabular}

Total CRF values and permissible waste concentrations are different between the PE method and the PA analysis as shown in Table SRS-5. These differences are due to calculational variations in several parameters as shown in Table SRS-6 and as discussed in detail below.

For both $\mathrm{H}-3$ and C-14, the $A_{D}$ value from the performance assessment is $1.7 \times 10^{-1}$, which is about 15 times lower than the $A_{D}$ value calculated using the PE method. A lower $A_{D}$ indicates lower annual average atmospheric concentrations, and therefore, greater atmospheric dispersion. The LAW vaults analysis assumed that $\mathrm{H}-3$ releases would occur at the time of closure and therefore, the site boundary - located $5 \mathrm{~km}$ from the disposal facility - was used as the performance boundary. The PE method assumed the point of compliance would be $100-\mathrm{m}$ from the disposal facility boundary at the end of the institutional control period $(100 \mathrm{y})$. Therefore, the larger distance to the performance boundary assumed in the performance assessment allows for greater atmospheric dispersion, and subsequently, a lower $A_{D}$ value. 
Table SRS-6. Comparison between Atmospheric Dispersion Parameters Calculated Using the PE Method and the LAW Vaults at SRS E-Area

\begin{tabular}{|c|c|c|c|c|}
\hline Nuclide & Parameter & $\begin{array}{l}\text { Value used in } \\
\text { the PE Method }\end{array}$ & $\begin{array}{c}\text { Value from the } \\
\text { Performance } \\
\text { Assessment } \\
\text { (PA) }\end{array}$ & $\begin{array}{c}\text { Ratio of the PE } \\
\text { Value to the PA } \\
\text { Value }\end{array}$ \\
\hline \multirow[t]{4}{*}{$\mathrm{H}-3$} & $\begin{array}{l}\text { Inverse of the } \\
\text { atmospheric } \\
\text { dispersion } \\
\text { parameter, } 1 / A_{D}{ }^{a}\end{array}$ & $3.8 \mathrm{E}-1$ & 5.9E0 & $6.4 \mathrm{E}-2$ \\
\hline & $\begin{array}{l}\text { Inverse of the } \\
\text { atmospheric } \\
\text { scenario dose } \\
\text { conversion factor, } \\
1 / S D C F^{a}\end{array}$ & $1.2 E-03$ & 1.3E-04 & $9.2 \mathrm{E} 0$ \\
\hline & $\begin{array}{l}\text { Radioactive decay } \\
\text { term, } f_{\text {decay }}\end{array}$ & $2.8 E+02$ & 1.0E0 & $2.8 \mathrm{E}+02$ \\
\hline & \multicolumn{3}{|c|}{ Product of the ratios $=$ adjustment factor for $\mathrm{H}-3, A F_{\mathrm{H}-3}$} & $1.8 E+02$ \\
\hline \multirow[t]{5}{*}{ C-14 } & $\begin{array}{l}\text { Inverse of the } \\
\text { atmospheric } \\
\text { dispersion } \\
\text { parameter, } 1 / A_{D}{ }^{a}\end{array}$ & $3.8 \mathrm{E}-1$ & 5.9E0 & $6.4 \mathrm{E}-02$ \\
\hline & $\begin{array}{l}\text { Inverse of the } \\
\text { diffusive flux, } 1 / \mathrm{J}^{3}\end{array}$ & $5.6 E+01$ & $8.8 E+03$ & 6.4E-03 \\
\hline & $\begin{array}{l}\text { Inverse of Henry's } \\
\text { Constant, } 1 / r^{a}\end{array}$ & $2.4 E+03$ & $1.0 E 0$ & $2.4 E+03$ \\
\hline & $\begin{array}{l}\text { Inverse of the } \\
\text { atmospheric } \\
\text { scenario dose } \\
\text { conversion factor, } \\
1 / S D C F^{2}\end{array}$ & 4.5E-06 & 2.4E-06 & 1.9EO \\
\hline & \multicolumn{3}{|c|}{ Product of the ratios $=$ adjustment factor for $C-14, A F_{C-14}$} & 1.8E0 \\
\hline
\end{tabular}

- Inverses are reported because these parameters appear in the denominator of the overall calculation of permissible waste concentrations (see Volume 2, Section 5 of this report). 
For $\mathrm{C}-14$, the diffusive flux value, $J$, from the performance assessment is about $1.0 \times 10^{-4}$ $\mathrm{Ci} / \mathrm{m}^{2} / \mathrm{y}$, which is about 150 times less than the $J$ value calculated with the PE method. Note that $J$ is not an explicit parameter used in the PE method, but is implicitly calculated as part of soil diffusion and mixing CRFs. Both the E-Area performance assessment and the PE method assume linear, first-order diffusion of volatile radionuclides. However, the inventory of C-14 in the LAW vaults is relatively low and the entire amount would diffuse to the surface in much less than a year. Therefore, the performance assessment normalized $J$ over a one-year period to calculate the annual effective dose equivalent. Since $J$ was assumed to be zero for much of the year, the annual normalized value was much less than the PE method value.

Also for C-14, the performance assessment assumed that the entire pore space was filled with gas phase ${ }^{14} \mathrm{CO}_{2}$. This is equivalent to setting the Henry's Constant, $r$, equal to 1.0 and produces the result that the CRF estimate is about 2000 times less than the PE method.

The performance assessment used the AIRDOS-PC model (EPA, 1989) to compute annual effective dose equivalents from atmospheric emissions. For both $\mathrm{H}-3$ and $\mathrm{C}-14$, the SDCFs used in the model are different from those used in the PE method. AIRDOS-PC uses a SDCF for $\mathrm{H}-3$ of about $8 \times 10^{3} \mathrm{mrem} / \mathrm{y}$ per $\mu \mathrm{Ci} / \mathrm{m}^{3}$, which is 10 times greater than the $\mathrm{PE}$ value. The agreement between the model and PE SDCF is much closer for C-14, where the AIRDOS$P C$ value is about $4.2 \times 10^{5} \mathrm{mrem} / \mathrm{y}$ per $\mu \mathrm{Ci} / \mathrm{m}^{3}$ compared to the $\mathrm{PE}$ value of $2.2 \times 10^{5} \mathrm{mrem} / \mathrm{y}$ per $\mu \mathrm{Ci} / \mathrm{m}^{3}$ (about a factor of two difference).

The final difference between the performance assessment and the PE method is the treatment of radioactive decay. As discussed earlier, the performance assessment assumes that atmospheric releases begin at the time of closure and radioactive decay of the volatile radionuclides is ignored. The PE method assumes that atmospheric releases are controlled during the period of institutional control and that uncontrolled releases would begin at the end of this period (i.e., $100 \mathrm{y}$ ). For $\mathrm{H}-3$, the $\mathrm{PE}$ method assumes $100 \mathrm{y}$ of radioactive decay resulting in a permissible waste concentration that is about 300 times greater than that in the performance assessment. Because the half-life for $\mathrm{C}-14$ is relatively long, the different treatment of radioactive decay between the two methods does not result in a discernible variation in the $\mathrm{C}-14$ permissible waste concentration.

For each volatile radionuclide, individual factor differences between the $\mathrm{LAW}$ vaults analysis and the PE method can be multiplied to yield an overall difference between the two methods. This product is the adjustment factor, $A F$, necessary to reconcile the differences between the PE method and the performance assessment. For $\mathrm{H}-3, A F$ is equal to 180 , indicating that the performance assessment is about 180 times more restrictive overall than the PE method. For $\mathrm{C}-14, A F$ is equal to 1.8 , indicating that the performance assessment is about 1.8 times more restrictive overall than the PE method. 


\section{A.2.2.3 Inadvertent Intruder Scenarios}

The LAW vaults in the E-Area were used as the basis for comparison of the PE method to published performance assessment results. The LAW vault design is similar to that proposed for the Mixed Waste Disposal Facility (MWDF) at SRS. Because the PE methodology for intrusion scenarios (see Volume 2, Appendix D of this report for details) is patterned after that used in the performance assessment for the E-Area Vaults, agreement between the PE method and the performance assessment published values is expected to be good. This section discusses the actual agreement.

In the E-Area performance assessment, the concrete roof for the LAW vaults was assumed to collapse at $3000 \mathrm{y}$ after facility closure. This value is used in the performance assessment as the earliest time for which the agricultural and post-drilling scenarios would be credible. Unlike other sites, standard drilling practices in the vicinity of SRS involve seeking those locations with predominately sandy soils that are relatively easy to drill through. The drilling equipment commonly used in the area is ineffective when rock is encountered. In such an event, the drill rig is usually relocated to a more favorable location. The concrete roof of the LAW vaults would present similar opposition to drilling until the time at which the roof collapses. Both the agricultural and post-drilling scenarios are therefore assumed to be credible as early as $3000 \mathrm{y}$ after facility closure for the LAW vaults at SRS. While the E-Area performance assessment contains values for later times (e.g., $5000 \mathrm{y}$ ) for agricultural intrusion, for the purposes of this comparative exercise, intrusion is assumed to occur at $3000 \mathrm{y}$.

The geometry factor, $f_{g}$, is specified in the performance assessment as 0.8 for the agricultural intrusion scenario and 1.0 for the post-drilling scenario. These values were incorporated into the PE method for the purpose of comparison.

Tables SRS-7 and SRS-8 show the comparative results for the intrusion scenarios (agricultural and post-drilling, respectively) for the LAW vaults at SRS. The columns in these two tables labeled "PA Data" contain values extracted directly from the performance assessment for the E-Area Vaults. The scenario dose conversion factors were obtained from Table 4.1-10 in the performance assessment for the agricultural (homesteader) scenario and from Table 4.1-12 for the post-drilling scenario. The waste limits were also extracted directly from tables in the E-Area Vault performance assessment: Table 4.1-15 in the performance assessment (i.e., the values for intrusion at $3000 \mathrm{y}$ ) was used for the agricultural scenario, and Table 4.1-22 was used for the post-drilling scenario. The columns in Tables SRS-7 and SRS-8 labeled "PE Method" contain values computed with the PE method as described in Volume 2, Appendix D of this report.

For the agricultural intrusion scenario at SRS, Table SRS-7 shows the performance assessment and $\mathrm{PE}$ values for the scenario dose conversion factors to be in excellent agreement. The slight differences are primarily associated with the use of EPA dose conversion factors (EPA, 1988; EPA, 1993) in the PE method, while the performance assessment uses DOE values (DOE, 1988). 
Table SRS-7. Comparison of the Results from the PE Method with the Performance Assessment Findings for the Agricultural Intrusion Scenario at SRS (Part 1 of 2)

\begin{tabular}{|c|c|c|c|c|c|c|c|}
\hline \multirow[t]{2}{*}{ Nuclide } & \multicolumn{3}{|c|}{$\begin{array}{c}\text { Agricultural Scenario } \\
\text { "Undecayed" Dose Conversion } \\
\text { Factor } \\
\left.\text { (rem/y per } \mu \mathrm{Ci} / \mathrm{m}^{3}\right)\end{array}$} & \multirow[t]{2}{*}{$\begin{array}{l}\text { Time of } \\
\text { Intrusion } \\
\text { (y) }\end{array}$} & \multicolumn{3}{|c|}{$\begin{array}{c}\text { Waste Limit } \\
\left(\mu \mathrm{Ci} / \mathrm{m}^{3}\right)\end{array}$} \\
\hline & PA Data & PE Method & $\begin{array}{l}\text { Ratio } \\
\text { PE : PA } \\
\text { Value } \\
\end{array}$ & & PA Data & PE Method & $\begin{array}{l}\text { Ratio } \\
\text { PE : PA } \\
\text { Value }\end{array}$ \\
\hline $\mathrm{H}-3$ & $3.9 E-06$ & 4.0E-06 & 1.01 & 3000 & NA & $8.4 E+77$ & NA \\
\hline$C-14$ & $1.5 E-05$ & 1.5E-05 & 1.00 & 3000 & $1.2 E+04$ & $1.2 E+04$ & 1.00 \\
\hline Al-26 & 3.9E-03 & $3.8 \mathrm{E}-03$ & 0.98 & 3000 & $3.2 E+01$ & $3.3 E+01$ & 1.02 \\
\hline Si-32 & NA & 1.7E-04 & NA & 3000 & NA & $7.9 E+11$ & NA \\
\hline $\mathrm{Cl}-36$ & NA & $1.2 \mathrm{E}-03$ & NA & 3000 & NA & $1.1 E+02$ & NA \\
\hline$K-40$ & NA & 2.9E-04 & NA & 3000 & NA & $4.4 E+02$ & NA \\
\hline Co-60 & $3.5 \mathrm{E}-03$ & $3.6 \mathrm{E}-03$ & 1.02 & 3000 & NA & $7.5 E+172$ & NA \\
\hline Ni-59 & $6.8 \mathrm{E}-08$ & $7.1 \mathrm{E}-08$ & 1.04 & 3000 & $1.9 \mathrm{E}+06$ & $1.8 \mathrm{E}+06$ & 0.96 \\
\hline Ni-63 & $1.8 \mathrm{E}-07$ & $1.9 \mathrm{E}-07$ & 1.08 & 3000 & NA & $6.9 E+14$ & NA \\
\hline Se-79 & $1.2 \mathrm{E}-06$ & $1.2 \mathrm{E}-06$ & 1.04 & 3000 & $1.1 \mathrm{E}+05$ & $1.0 \mathrm{E}+05$ & 0.94 \\
\hline Sr-90 + d & $1.8 \mathrm{E}-04$ & $2.0 \mathrm{E}-04$ & 1.10 & 3000 & NA & $6.8 E+33$ & NA \\
\hline$Z r-93$ & 4.5E-08 & 4.1E-08 & 0.91 & 3000 & $2.8 E+06$ & $3.1 E+06$ & 1.09 \\
\hline $\mathrm{Nb}-93 \mathrm{~m}$ & $1.9 \mathrm{E}-08$ & $1.8 \mathrm{E}-08$ & 0.95 & 3000 & NA & $8.6 E+62$ & NA \\
\hline Nb-94 & NA & $2.1 \mathrm{E}-03$ & NA & 3000 & NA & $6.5 E+01$ & NA \\
\hline Tc-99 & 1.1E-05 & $1.2 \mathrm{E}-05$ & 1.10 & 3000 & $1.3 E+04$ & $1.0 E+04$ & 0.80 \\
\hline Pd-107 & $3.2 E-08$ & $3.4 \mathrm{E}-08$ & 1.07 & 3000 & $3.9 E+06$ & $3.7 E+06$ & 0.94 \\
\hline $\mathrm{Ag}-108 \mathrm{~m}$ & NA & 2.1E-03 & NA & 3000 & NA & $5.2 E+08$ & NA \\
\hline Cd-113m & $1.3 E-04$ & 1.3E-04 & 1.03 & 3000 & NA & 1.0E+67 & NA \\
\hline Sn-121m & 4.7E-07 & $5.1 \mathrm{E}-07$ & 1.08 & 3000 & NA & $6.5 \mathrm{E}+21$ & NA \\
\hline$S n-126+d$ & 2.6E-03 & 2.6E-03 & 1.00 & 3000 & $4.9 E+01$ & $4.9 E+01$ & 1.00 \\
\hline $1-129$ & 8.3E-05 & $8.1 \mathrm{E}-05$ & 0.97 & 3000 & $1.0 \mathrm{E}+07$ & $1.6 \mathrm{E}+03$ & 0.00 \\
\hline Cs-135 & 1.2E-06 & $1.2 \mathrm{E}-06$ & 1.01 & 3000 & $1.0 E+05$ & $1.0 E+05$ & 1.03 \\
\hline Cs-137+d & 7.7E-04 & $7.6 \mathrm{E}-04$ & 0.99 & 3000 & NA & $1.4 E+32$ & NA \\
\hline$B a-133$ & NA & 4.4E-04 & NA & 3000 & NA & 1.7E+88 & NA \\
\hline$S m-151$ & 1.4E-08 & $1.2 E-08$ & 0.82 & 3000 & NA & $1.2 E+17$ & NA \\
\hline Eu-152 & NA & $1.5 \mathrm{E}-03$ & $N A$ & 3000 & $\mathrm{NA}$ & $8.0 E+68$ & NA \\
\hline Eu-154 & 1.7E-03 & 1.7E-03 & 0.99 & 3000 & NA & $1.0 \mathrm{E}+107$ & NA \\
\hline $\mathrm{Pb}-210+\mathrm{d}$ & 3.0E-04 & $3.1 \mathrm{E}-04$ & 1.03 & 3000 & NA & 1.3E+43 & NA \\
\hline$R a-226+d$ & 2.7E-03 & $2.8 \mathrm{E}-03$ & 1.03 & 3000 & NA & $1.6 E+02$ & NA \\
\hline Ra-228 & NA & 3.6E-03 & NA & 3000 & NA & $2.1 E+158$ & $\mathrm{NA}$ \\
\hline Th-229+d & 4.3E-04 & 4.3E-04 & 1.00 & 3000 & NA & $3.9 \mathrm{E}+02$ & NA \\
\hline Th-230 & 1.1E-05 & 1.1E-05 & 0.99 & 3000 & NA & $6.3 E+01$ & NA \\
\hline Th-232+d & $3.6 \mathrm{E}-03$ & 3.6E-03 & 1.01 & 3000 & $3.5 \mathrm{E}+01$ & $3.4 \mathrm{E}+01$ & 0.98 \\
\hline$P a-231+d$ & 8.3E-04 & 8.3E-04 & 1.00 & 3000 & NA & $1.6 \mathrm{E}+02$ & NA \\
\hline
\end{tabular}


Table SRS-7. Comparison of the Results from the PE Method with the Performance Assessment Findings for the Agricultural Intrusion Scenario at SRS (Part 2 of 2)

\begin{tabular}{|c|c|c|c|c|c|c|c|}
\hline \multirow[t]{2}{*}{ Nuclide } & \multicolumn{3}{|c|}{$\begin{array}{c}\text { Agricultural Scenario } \\
\text { "Undecayed" Dose Conversion } \\
\text { Factor } \\
\left(\mathrm{rem} / \mathrm{y} \text { per } \mu \mathrm{Ci} / \mathrm{m}^{3}\right)\end{array}$} & \multirow[t]{2}{*}{$\begin{array}{c}\text { Time of } \\
\text { Intrusion } \\
\text { (y) }\end{array}$} & \multicolumn{3}{|c|}{$\begin{array}{l}\text { Waste Limit } \\
\left(\mu \mathrm{Ci} / \mathrm{m}^{3}\right)\end{array}$} \\
\hline & PA Data & PE Method & $\begin{array}{l}\text { Ratio - } \\
\text { PE : PA } \\
\text { Value }\end{array}$ & & PA Data & PE Method & $\begin{array}{l}\text { Ratio } \\
\text { PE : PA } \\
\text { Value }\end{array}$ \\
\hline$U-232+d$ & 2.3E-03 & $2.3 \mathrm{E}-03$ & 1.00 & 3000 & NA & $4.3 E+14$ & NA \\
\hline $\mathrm{U}-233$ & 1.1E-05 & $1.2 \mathrm{E}-05$ & 1.09 & 3000 & $1.1 E+04$ & $1.1 E+03$ & 0.10 \\
\hline$U-234$ & 1.1E-05 & 1.2E-05 & 1.06 & 10000 & $6.6 E+02$ & $6.4 E+02$ & 0.97 \\
\hline$U-235+d$ & $1.8 \mathrm{E}-04$ & $1.8 \mathrm{E}-04$ & 0.99 & 10000 & $3.7 E+02$ & $3.7 E+02$ & 1.00 \\
\hline U-236 & $1.0 \mathrm{E}-05$ & 1.1E-05 & 1.11 & 3000 & $1.3 E+04$ & 1.1E+04 & 0.87 \\
\hline$U-238+d$ & $3.9 \mathrm{E}-05$ & $4.0 \mathrm{E}-05$ & 1.02 & 10000 & $3.0 E+03$ & $3.0 E+03$ & 0.99 \\
\hline $\mathrm{Np}-237+\mathrm{d}$ & $5.0 \mathrm{E}-04$ & $5.3 \mathrm{E}-04$ & 1.05 & 10000 & $2.5 E+02$ & $2.4 E+02$ & 0.95 \\
\hline $\mathrm{Pu}-238$ & 3.4E-05 & $2.9 \mathrm{E}-05$ & 0.86 & 3000 & NA & $8.2 E+06$ & NA \\
\hline Pu-239 & $4.0 \mathrm{E}-05$ & $3.2 \mathrm{E}-05$ & 0.81 & 3000 & $3.4 E+03$ & $4.2 E+03$ & 1.24 \\
\hline Pu-240 & 4.0E-05 & $3.2 \mathrm{E}-05$ & 0.81 & 3000 & $4.3 E+03$ & $5.3 E+03$ & 1.23 \\
\hline Pu-241 & 7.7E-07 & $6.2 \mathrm{E}-07$ & 0.81 & 3000 & NA & $7.5 E+06$ & NA \\
\hline Pu-242 & $3.8 \mathrm{E}-05$ & $3.1 \mathrm{E}-05$ & 0.81 & 3000 & $3.3 E+03$ & $4.1 E+03$ & 1.24 \\
\hline Pu-244 & 3.7E-05 & 3.0E-05 & 0.82 & 3000 & $3.4 E+03$ & $2.6 \mathrm{E}+02$ & 0.08 \\
\hline$A m-241$ & 5.6E-05 & 4.7E-05 & 0.84 & 3000 & $2.8 E+05$ & $2.6 E+05$ & 0.91 \\
\hline$A m-243+d$ & $2.5 E-04$ & $2.3 \mathrm{E}-04$ & 0.94 & 3000 & $6.7 E+02$ & $7.0 E+02$ & 1.04 \\
\hline $\mathrm{Cm}-243$ & 1.6E-04 & $1.5 \mathrm{E}-04$ & 0.94 & 3000 & NA & $3.6 E+06$ & $\overline{N A}$ \\
\hline$C m-244$ & $2.0 \mathrm{E}-05$ & $1.8 \mathrm{E}-05$ & 0.91 & 3000 & NA & $1.9 E+06$ & NA \\
\hline $\mathrm{Cm}-245$ & 1.1E-04 & 1.1E-04 & 0.99 & 3000 & $1.5 E+03$ & $1.0 E+03$ & 0.67 \\
\hline Cm-246 & $4.0 \mathrm{E}-05$ & 3.3E-05 & 0.83 & 3000 & $4.8 E+03$ & $5.8 E+03$ & 1.21 \\
\hline$C m-247+d$ & $4.4 E-04$ & $4.4 E-04$ & 1.00 & 3000 & $2.8 E+02$ & $2.5 E+02$ & 0.90 \\
\hline $\mathrm{Cm}-248$ & 1.4E-04 & 1.2E-04 & 0.87 & 3000 & $9.0 E+02$ & $1.0 E+03$ & 1.14 \\
\hline Cf-249 & 4.6E-04 & $4.5 \mathrm{E}-04$ & 0.98 & 3000 & $1.0 \mathrm{E}+05$ & $7.3 E+04$ & 0.73 \\
\hline Cf-250 & 1.7E-05 & $1.9 \mathrm{E}-05$ & 1.13 & 3000 & NA & $2.1 E+06$ & NA \\
\hline Cf-251 & 1.6E-04 & $1.6 \mathrm{E}-04$ & 1.00 & 3000 & $7.9 E+03$ & $7.9 E+03$ & 1.00 \\
\hline
\end{tabular}

" $+d "$ denotes short-lived decay products that are assumed to be in secular equilibrium with the parent radionuclide.

NA indicates that the radionuclide was not subjected to detailed intrusion analyses in the SRS E-Area performance assessment. 
Table SRS-8. Comparison of the Results from the PE Method with the Performance Assessment Fndings for the Post-Drilling Intrusion Scenario at SRS (Part 1 of 2)

\begin{tabular}{|c|c|c|c|c|c|c|c|}
\hline \multirow[t]{2}{*}{ Nuclide } & \multicolumn{3}{|c|}{$\begin{array}{c}\text { Post-Drilling Scenario } \\
\text { "Undecayed" Dose Conversion } \\
\text { Factor } \\
\left(\mathrm{rem} / \mathrm{y} \text { per } \mu \mathrm{Ci} / \mathrm{m}^{3}\right) \\
\end{array}$} & \multirow[t]{2}{*}{$\begin{array}{l}\text { Time of } \\
\text { Intrusion } \\
\text { (y) }\end{array}$} & \multicolumn{3}{|c|}{$\begin{array}{c}\text { Waste Limit } \\
\left(\mu \mathrm{Ci} / \mathrm{m}^{3}\right)\end{array}$} \\
\hline & PA Data & PE Method & $\begin{array}{c}\text { Ratio } \\
\text { PE : PA } \\
\text { Value }\end{array}$ & & PA Data & PE Method & $\begin{array}{l}\text { Ratio } \\
\text { PE : PA } \\
\text { Value }\end{array}$ \\
\hline $\mathrm{H}-3$ & $3.9 E-07$ & 4.0E-07 & 1.01 & 3000 & NA & $6.7 E+78$ & NA \\
\hline C-14 & $1.5 \mathrm{E}-06$ & $1.5 \mathrm{E}-06$ & 1.00 & 3000 & $9.7 E+04$ & $9.6 \mathrm{E}+04$ & 0.99 \\
\hline Al-26 & $1.8 \mathrm{E}-06$ & 1.8E-06 & 1.01 & 3000 & $5.5 E+04$ & $5.5 E+04$ & 1.00 \\
\hline Si-32 & NA & 1.7E-05 & NA & 3000 & NA & $6.3 E+12$ & NA \\
\hline $\mathrm{Cl}-36$ & NA & $1.2 \mathrm{E}-04$ & NA & 3000 & NA & $8.6 E+02$ & NA \\
\hline$K-40$ & NA & $5.8 \mathrm{E}-06$ & NA & 3000 & NA & 1.7E+04 & NA \\
\hline Co-60 & $1.8 \mathrm{E}-06$ & $1.8 \mathrm{E}-06$ & 1.01 & 3000 & NA & $1.2 E+176$ & NA \\
\hline Ni-59 & $6.8 \mathrm{E}-09$ & 7.1E-09 & 1.04 & 3000 & $1.5 \mathrm{E}+07$ & $1.5 \mathrm{E}+07$ & 0.97 \\
\hline $\mathrm{Ni}-63$ & $1.8 \mathrm{E}-08$ & $1.9 \mathrm{E}-08$ & 1.08 & 3000 & NA & $5.5 E+15$ & NA \\
\hline Se-79 & $1.2 \mathrm{E}-07$ & $1.2 \mathrm{E}-07$ & 1.04 & 3000 & $9.0 \mathrm{E}+05$ & $8.3 E+05$ & 0.92 \\
\hline Sr-90 + d & $1.8 \mathrm{E}-05$ & $2.0 \mathrm{E}-05$ & 1.10 & 3000 & NA & $5.5 E+34$ & NA \\
\hline Zr-93 & 3.5E-09 & 3.1E-09 & 0.88 & 3000 & $2.9 E+07$ & $3.2 E+07$ & 1.12 \\
\hline Nb-93m & $1.8 \mathrm{E}-09$ & 1.7E-09 & 0.96 & 3000 & NA & $7.2 \mathrm{E}+63$ & NA \\
\hline $\mathrm{Nb}-94$ & NA & 1.1E-06 & NA & 3000 & NA & $1.0 E+05$ & NA \\
\hline TC-99 & 1.1E-06 & $1.2 \mathrm{E}-06$ & 1.10 & 3000 & $1.0 \mathrm{E}+05$ & $8.3 E+04$ & 0.83 \\
\hline Pd-107 & 3.2E-09 & 3.4E-09 & 1.06 & 3000 & $3.1 E+07$ & $3.0 E+07$ & 0.95 \\
\hline $\mathrm{Ag}-108 \mathrm{~m}$ & NA & 1.5E-06 & NA & 3000 & NA & $5.9 E+11$ & NA \\
\hline $\mathrm{Cd}-113 \mathrm{~m}$ & 1.3E-05 & 1.3E-05 & 1.03 & 3000 & NA & $8.3 E+67$ & NA \\
\hline $\mathrm{Sn-121m}$ & 5.3E-09 & 7.0E-09 & 1.32 & 3000 & NA & $3.8 E+23$ & NA \\
\hline$S n-126+d$ & 1.4E-06 & $1.4 \mathrm{E}-06$ & 1.01 & 3000 & $7.3 E+04$ & $7.2 E+04$ & 0.98 \\
\hline $\mid-129$ & 8.1E-06 & $7.8 \mathrm{E}-06$ & 0.96 & 3000 & $8.2 E+07$ & 1.3E+04 & 0.00 \\
\hline Cs-135 & $1.2 E-07$ & 1.2E-07 & 1.01 & 3000 & $8.3 E+05$ & 8.3E+05 & 1.00 \\
\hline Cs-137+d & 1.2E-06 & $1.2 \mathrm{E}-06$ & 1.03 & 3000 & NA & $7.0 \mathrm{E}+34$ & NA \\
\hline Ba-133 & NA & $2.6 \mathrm{E}-07$ & NA & 3000 & NA & $2.2 E+91$ & NA \\
\hline $5 m-151$ & $9.3 \mathrm{E}-10$ & 1.1E-09 & 1.15 & 3000 & NA & $1.0 E+18$ & NA \\
\hline Eu-152 & NA & 7.7E-07 & NA & 3000 & NA & 1.3E+72 & NA \\
\hline Eu-154 & 8.4E-07 & 8.5E-07 & 1.01 & 3000 & NA & $1.6 \mathrm{E}+110$ & NA \\
\hline $\mathrm{Pb}-210+\mathrm{d}$ & 3.0E-05 & 3.1E-05 & 1.03 & 3000 & NA & $1.0 E+44$ & NA \\
\hline $\operatorname{Ra}-226+d$ & 3.2E-05 & 3.4E-05 & 1.06 & 3000 & NA & 1.1E+04 & NA \\
\hline Ra-228 & NA & 4.6E-06 & NA & 3000 & NA & 1.3E+161 & NA \\
\hline Th-229+d & $2.9 \mathrm{E}-06$ & $3.0 \mathrm{E}-06$ & 1.04 & 3000 & NA & $4.4 E+04$ & NA \\
\hline Th-230 & 3.4E-07 & 3.5E-07 & 1.01 & 3000 & NA & 4.1E+03 & NA \\
\hline Th-232+d & $5.9 \mathrm{E}-06$ & $6.3 \mathrm{E}-06$ & 1.07 & 3000 & 1.7E+04 & $1.6 \mathrm{E}+04$ & 0.93 \\
\hline $\mathrm{Pa}-231+\mathrm{d}$ & $1.8 \mathrm{E}-05$ & $1.9 \mathrm{E}-05$ & 1.07 & 3000 & NA & $5.5 \mathrm{E}+03$ & NA \\
\hline
\end{tabular}


Table SRS-8. Comparison of the Results from the PE Method with the Performance Assessment Fndings for the Post-Drilling Intrusion Scenario at SRS (Part 2 of 2)

\begin{tabular}{|c|c|c|c|c|c|c|c|}
\hline \multirow[t]{2}{*}{ Nuclide } & \multicolumn{3}{|c|}{$\begin{array}{c}\text { Post-Drilling Scenario } \\
\text { "Undecayed" Dose Conversion } \\
\text { Factor } \\
\left(\mathrm{rem} / \mathrm{y} \text { per } \mu \mathrm{Ci} / \mathrm{m}^{3}\right)\end{array}$} & \multirow[t]{2}{*}{$\begin{array}{l}\text { Time of } \\
\text { Intrusion } \\
\text { (y) }\end{array}$} & \multicolumn{3}{|c|}{$\begin{array}{c}\text { Waste Limit } \\
\left(\mu \mathrm{Ci} / \mathrm{m}^{3}\right)\end{array}$} \\
\hline & PA Data & PE Method & $\begin{array}{l}\text { Ratio } \\
\text { PE : PA } \\
\text { Value }\end{array}$ & & PA Data & PE Method & $\begin{array}{l}\text { Ratio } \\
\text { PE : PA } \\
\text { Value }\end{array}$ \\
\hline $\mathrm{U}-232+\mathrm{d}$ & 5.6E-06 & 5.7E-06 & 1.02 & 3000 & NA & 1.4E+17 & NA \\
\hline$U-233$ & 7.5E-07 & $8.1 E-07$ & 1.08 & 3000 & 1.3E+05 & $6.5 E+04$ & 0.50 \\
\hline $\mathrm{U}-234$ & $7.3 E-07$ & $7.9 \mathrm{E}-07$ & 1.08 & 3000 & $9.1 E+04$ & $8.4 E+04$ & 0.93 \\
\hline$U-235+d$ & $7.9 \mathrm{E}-07$ & $8.4 \mathrm{E}-07$ & 1.06 & 3000 & $5.2 E+04$ & $5.0 E+04$ & 0.96 \\
\hline U-236 & $6.9 \mathrm{E}-07$ & $7.5 \mathrm{E}-07$ & 1.09 & 3000 & $1.4 \mathrm{E}+05$ & $1.3 E+05$ & 0.95 \\
\hline$U-238+d$ & $6.6 \mathrm{E}-07$ & 7.3E-07 & 1.11 & 3000 & $1.5 \mathrm{E}+05$ & $1.3 E+05$ & 0.90 \\
\hline $\mathrm{Np}-237+\mathrm{d}$ & $2.4 E-05$ & 2.7E-05 & 1.13 & 3000 & $4.2 E+03$ & $3.7 E+03$ & 0.88 \\
\hline Pu-238 & $2.1 \mathrm{E}-06$ & $1.8 \mathrm{E}-06$ & 0.86 & 3000 & NA & $2.4 E+08$ & NA \\
\hline Pu-239 & $2.5 \mathrm{E}-06$ & $2.0 \mathrm{E}-06$ & 0.80 & 3000 & $4.3 E+04$ & $5.4 E+04$ & 1.26 \\
\hline Pu-240 & $2.5 \mathrm{E}-06$ & $2.0 \mathrm{E}-06$ & 0.80 & 3000 & $5.5 \mathrm{E}+04$ & $6.8 E+04$ & 1.24 \\
\hline Pu-241 & $4.8 E-08$ & $3.9 \mathrm{E}-08$ & 0.81 & 3000 & NA & $4.5 E+14$ & NA \\
\hline Pu-242 & $2.4 \mathrm{E}-06$ & 1.9E-06 & 0.79 & 3000 & $4.2 E+04$ & $5.3 E+04$ & 1.26 \\
\hline Pu-244 & $2.3 \mathrm{E}-06$ & 1.9E-06 & 0.82 & 3000 & $4.3 E+04$ & $3.8 E+04$ & 0.88 \\
\hline Am-241 & $3.1 E-06$ & $2.5 \mathrm{E}-06$ & 0.80 & 3000 & $4.0 E+06$ & $3.9 E+06$ & 0.98 \\
\hline$A m-243+d$ & 3.2E-06 & $2.6 \mathrm{E}-06$ & 0.80 & 3000 & $4.2 E+04$ & $4.8 E+04$ & 1.14 \\
\hline $\mathrm{Cm}-243$ & $1.6 \mathrm{E}-06$ & $1.5 \mathrm{E}-06$ & 0.91 & 3000 & NA & $4.6 E+07$ & NA \\
\hline Cm-244 & 1.3E-06 & $1.1 \mathrm{E}-06$ & 0.85 & 3000 & NA & $2.5 E+07$ & NA \\
\hline$C m-245$ & $2.5 \mathrm{E}-06$ & $2.1 \mathrm{E}-06$ & 0.84 & 3000 & $5.1 E+04$ & $2.7 E+04$ & 0.53 \\
\hline Cm-246 & $2.5 E-06$ & $2.0 \mathrm{E}-06$ & 0.82 & 3000 & $6.2 E+04$ & $7.6 E+04$ & 1.22 \\
\hline $\mathrm{Cm}-247+\mathrm{d}$ & $2.5 \mathrm{E}-06$ & $2.1 \mathrm{E}-06$ & 0.84 & 3000 & $4.0 E+04$ & $3.6 E+04$ & 0.91 \\
\hline $\mathrm{Cm}-248$ & $8.9 E-06$ & $7.5 \mathrm{E}-06$ & 0.84 & 3000 & $1.1 E+04$ & 1.3E+04 & 1.22 \\
\hline Cf-249 & 2.7E-06 & $2.8 \mathrm{E}-06$ & 1.05 & 3000 & $1.4 E+07$ & $4.3 E+06$ & 0.31 \\
\hline Cf-250 & $1.0 \mathrm{E}-06$ & $1.2 \mathrm{E}-06$ & 1.17 & 3000 & NA & $2.7 E+07$ & NA \\
\hline Cf-251 & $2.6 E-06$ & $2.7 E-06$ & 1.05 & 3000 & $3.9 E+05$ & $3.7 E+05$ & 0.94 \\
\hline
\end{tabular}

$"+\alpha^{m}$ denotes short-lived decay products that are assumed to be in secular equilibrium with the parent radionuclide.

NA indicates that the radionuclide was not subjected to detailed intrusion analyses in the SRS E-Area performance assessment. 
Agreement between the performance assessment and PE values for permissible waste concentrations is also excellent for the agricultural intrusion scenario. The one notable exception is I-129, which shows a significantly higher waste limit (by about four orders of magnitude) in the performance assessment than was computed with the PE method. The approach taken in the performance assessment includes the removal of radionuclides by leaching prior to the time of intrusion; I-129 undergoes appreciable leaching from the LAW vaults. The performance assessment waste limit for I-129, therefore, reflects the fact that a large fraction of the disposed radionuclide is no longer present in the facility at the time of agricultural intrusion at $3000 \mathrm{y}$.

For the post-drilling intrusion scenario at SRS, Table SRS-8 also shows the performance assessment and PE values for the scenario dose conversion factors, as well as for the permissible waste concentrations, to be in excellent agreement. Again, the single notable exception is I-129, which shows a significantly higher waste limit (by about three orders of magnitude) in the performance assessment than was computed with the PE method. The reason for the difference, as explained above, is the performance assessment assumption of removal of I-129 by leaching prior to intrusion. The performance assessment waste limit for I-129 reflects the fact that a significant fraction of the disposed I-129 was no longer present in the facility at the time of postdrilling intrusion (i.e., at $3000 \mathrm{y}$ ).

Many of the radionuclides listed in Tables SRS-7 and SRS-8 were not subjected to detailed intrusion analyses in the performance assessment for the E-Area Vaults and, therefore, do not have published values for the permissible waste concentrations. "Trigger values" were developed in the performance assessment to screen radionuclides from detailed evaluation. The extremely large permissible waste limits in Tables SRS-7 and SRS-8 as computed with the PE methodology provide evidence that the performance assessment screening method adequately focused the performance assessment analyses upon only those radionuclides deserving of detailed evaluation of intrusion scenarios.

\section{A.2.2.4 Discussion of the Results of the Comparative Exercise}

One objective of this comparative exercise was to gain insight into the differences between the scoping methodology of the PE and the more detailed evaluations conducted for the sitespecific performance assessment. Observations regarding this objective are discussed below.

No unusual, unique, or site-specific radionuclide transport or dose exposure phenomena (i.e., none that are not already accounted for in the PE methodology) were discovered during the exercise. The use of the E-Area approach as a pattern for the atmospheric pathway and intrusion scenarios appears to have been properly implemented in the PE method. The inclusion of longitudinal dispersion in the performance assessment, while not part of the PE methodology, appears to account for differences in the results for the groundwater pathway. 


\section{A.2.3 PE CALCULATIONS FOR THE MIXED WASTE DISPOSAL FACILITY}

Based on the above exercise, the application of the PE approach closely mimics the findings of the performance assessment for the E-Area vaults. A PE analysis was therefore conducted for the proposed Mixed Waste Disposal Facility (MWDF) at the Savannah River Site. As in the SRS PE for a generic trench and generic tumulus facility (see Chapter 13 in this volume), three pathways were separately analyzed, and the individual results combined to discern the most restrictive permissible waste concentration among all three pathways. This section describes the results for each pathway and concludes with a presentation of the overall results for the MWDF at Savannah River. Details of the PE methodology are contained in Volume 2, Chapter 5 of this report; data used in that methodology are described below.

\section{A.2.3.1 Water Transport for the MWDF}

Site-specific values required to perform the water pathway analysis were selected by site technical staff either from site-specific characterizations and reports, from site-specific modeling results, or from the general literature. The values applicable to the MWDF in the E-Area at Savannah River are listed in Table SRS-9, along with the generic values used in the PE. Also indicated in the table is a designation of the type of data represented by the value and its source. The values are representative of one or more of four data types: (A) measurements performed by the site, state, or federal agency; (B) results of a numerical analysis performed by the site, state, or federal agency; (C) general literature values selected by the site; and (D) generic values used in the PE.

Values for the distribution coefficients ( $K_{d}$ values) are listed in Table SRS-10 for the 58 radionuclides considered in the $\mathrm{PE}$ analysis. In addition to the $K_{d}$ values for the geologic media, grout $K_{d}$ values are listed for determining the desorption from the grouted waste form. The $K_{d}$ values for the subsurface flow pathway (both for the unsaturated and saturated zones) are taken from Table C.1-2 in the performance assessment for the E-Area Vaults (WSRC, 1994); these values are specific to the analysis of the LAW vaults in the performance assessment. For a specified radionuclide, there is no difference in the $K_{d}$ values at SRS for the unsaturated and saturated zones.

Application of the PE methodology for water transport of the 58 radionuclides considered in the PE analysis produced the results shown in Table SRS-11. The table shows the permissible waste concentrations based upon transport through the water pathway $\left(C_{\text {W-Water }}\right)$, as well as the values used in calculating the permissible concentrations. 
Table SRS-9. Parameters and Values Used in the PE Analysis for the Mixed Waste Disposal Facility at the Savannah River Site

\begin{tabular}{|c|c|c|c|}
\hline Parameter & Value & $\begin{array}{l}\text { Data } \\
\text { Type }\end{array}$ & Comments \\
\hline \multicolumn{4}{|l|}{ SOURCE TERM } \\
\hline Initial waste concentration, $C_{W}$ & $1 \mu \mathrm{Ci} / \mathrm{m}^{3}$ & $D$ & $\begin{array}{l}\text { A unit concentration is part of the } \\
\text { standard } P E \text { value }\end{array}$ \\
\hline $\begin{array}{l}\text { Volumetric water content of the } \\
\text { waste, } \theta_{G}\end{array}$ & 0.3 & $D$ & Standard PE value \\
\hline Bulk density of the waste, $\rho_{G}$ & $1.76 \mathrm{~g} / \mathrm{mL}$ & D & Standard PE value \\
\hline $\begin{array}{l}\text { Plan area for MWDF facility, } A \\
(131 \mathrm{~m} \text { by } 180 \mathrm{~m})\end{array}$ & $9,290 \mathrm{~m}^{2}$ & C & Staff and WSRC 1994 \\
\hline $\begin{array}{l}\text { Waste mixing fraction for } \\
\text { MWDF, } f_{m}\end{array}$ & 0.50 & C & Staff \\
\hline $\begin{array}{l}\text { Annual rate of water flowing } \\
\text { through intact MWDF }\end{array}$ & $\begin{array}{c}0.00003 \\
\mathrm{~m} / \mathrm{y}\end{array}$ & C & Staff \\
\hline $\begin{array}{l}\text { Annual rate of water flowing } \\
\text { through failed facilities }\end{array}$ & $0.40 \mathrm{~m} / \mathrm{y}$ & A & WSRC 1994 \\
\hline $\begin{array}{l}\text { Time to failure of leachate } \\
\text { collection system }\end{array}$ & $30 y$ & $D$ & Standard PE value \\
\hline Time to failure of MWDF facility & $3000 y$ & C & $\begin{array}{l}\text { Assumed to be the same as for the } \\
\text { LAW Vaults, as reported in WSRC } \\
1994\end{array}$ \\
\hline \multicolumn{4}{|l|}{ UNSATURATED ZONE } \\
\hline Volumetric water content, $\theta_{w}$ & 0.2 & A & WSRC, 1994 \\
\hline Bulk density, $\rho_{b}$ & $2.65 \mathrm{~g} / \mathrm{mL}$ & A & WSRC, 1994 \\
\hline $\begin{array}{l}\text { Thickness between bottom of } \\
\text { MWDF and saturated zone, } l\end{array}$ & $17 \mathrm{~m}$ & A & $\begin{array}{l}\text { Cumulative unsaturated sediment } \\
\text { thickness is } 17 \mathrm{~m} \text { (WSRC 1994) and } \\
\text { MWDF bottom is at ground surface. }\end{array}$ \\
\hline \multicolumn{4}{|l|}{ SATURATED ZONE } \\
\hline Aquifer porosity, $n$ & 0.3 & A & WSRC 1994 \\
\hline Bulk density, $\rho_{b}$ & $2.65 \mathrm{~g} / \mathrm{mL}$ & A & WSRC 1994 \\
\hline Mixing depth, $d_{m}$ & $10 \mathrm{~m}$ & C & Staff \\
\hline Groundwater (seepage) velocity & $27 \mathrm{~m} / \mathrm{y}$ & C & $\begin{array}{l}\text { Inferred from WSRC } 1994 \text { (see } \\
\text { discussion in text) }\end{array}$ \\
\hline $\begin{array}{l}\text { Distance to performance } \\
\text { boundary from facility boundary }\end{array}$ & $100 \mathrm{~m}$ & $D$ & Standard PE value and WSRC, 1994 \\
\hline
\end{tabular}

${ }^{2} A=$ Site measurement; $B=$ Result of site numerical analysis; $C=$ Literature value selected by site; $D=G e n e r i c$ PE value 
Table SRS-10. Solid/Liquid Distribution Coefficients ( $K_{d}$ values) Used in the PE Analyses for the Mixed Waste Disposal Facility at the Savannah River Site

\begin{tabular}{|l|c|c|}
\hline Element & $\begin{array}{c}K_{d} \text { for } \\
\text { Waste } \\
(\mathbf{m L} / \mathrm{g})\end{array}$ & $\begin{array}{c}K_{\text {d }} \text { for } \\
\text { Saturated and } \\
\text { Unsaturated } \\
\text { Zones } \\
(\mathrm{mL} / \mathrm{g})\end{array}$ \\
\hline $\mathrm{H}$ & 0 & 0 \\
\hline $\mathrm{C}$ & 10 & 2 \\
\hline $\mathrm{Al}$ & 100 & 0 \\
\hline $\mathrm{Si}$ & 100 & 0 \\
\hline $\mathrm{Cl}$ & 0 & 0 \\
\hline $\mathrm{K}$ & 1 & 0 \\
\hline $\mathrm{Co}$ & 100 & 10 \\
\hline $\mathrm{Ni}$ & 10 & 300 \\
\hline $\mathrm{Se}$ & 1 & 5 \\
\hline $\mathrm{Sr}$ & 100 & 10 \\
\hline $\mathrm{Zr}$ & 10 & 0 \\
\hline $\mathrm{Nb}$ & 10 & 0 \\
\hline $\mathrm{Tc}$ & 1 & 0.4 \\
\hline $\mathrm{Pd}$ & 100 & 0 \\
\hline $\mathrm{Ag}$ & 100 & 10 \\
\hline $\mathrm{Cd}$ & 100 & 8 \\
\hline & & \\
\hline
\end{tabular}

\begin{tabular}{|l|c|c|}
\hline Element & $\begin{array}{c}K_{d} \text { for } \\
\text { Waste } \\
\text { (mLg) }\end{array}$ & $\begin{array}{c}K_{d} \text { for } \\
\text { Saturated and } \\
\text { Unsaturated } \\
\text { Zones } \\
(\mathrm{mL} / \mathrm{g})\end{array}$ \\
\hline $\mathrm{Sn}$ & 10 & 130 \\
\hline $\mathrm{I}$ & 1 & 0.6 \\
\hline $\mathrm{Cs}$ & 10 & 100 \\
\hline $\mathrm{Ba}$ & 10 & 5 \\
\hline $\mathrm{Sm}$ & 10 & 100 \\
\hline $\mathrm{Eu}$ & 10 & 100 \\
\hline $\mathrm{Pb}$ & 100 & 100 \\
\hline $\mathrm{Ra}$ & 10 & 500 \\
\hline $\mathrm{Th}$ & 100 & 3000 \\
\hline $\mathrm{Pa}$ & 100 & 10 \\
\hline $\mathrm{U}$ & 100 & 50 \\
\hline $\mathrm{Np}$ & 100 & 10 \\
\hline $\mathrm{Pu}$ & 100 & 100 \\
\hline $\mathrm{Am}$ & 100 & 150 \\
\hline $\mathrm{Cm}$ & 100 & 150 \\
\hline $\mathrm{Cf}$ & 100 & 150 \\
\hline
\end{tabular}

Waste $K_{d}$ values are uniquely applicable to the grouted waste form assumed in this PE. See Chapter 1 of this volume andor Chapter 5 of Volume 2 for additional details. 
Table SRS-11. Results of the PE Water Pathway Calculations for the Mixed Waste Disposal Facility at the Savannah River Site (Part 1 of 2)

\begin{tabular}{|c|c|c|c|c|c|}
\hline Nuclide & $\begin{array}{l}\text { CRF rotal } \\
\text { (no decay) }\end{array}$ & $\begin{array}{c}\text { Arrival Time } \\
\text { (y) } \\
\end{array}$ & $r_{\text {Decay }}$ & 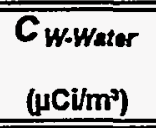 & Nuclide \\
\hline $\mathrm{H}-3$ & 1.5E+0 & $3.0 E+3$ & $5.2 E+73$ & no limit & $\mathrm{H}-3$ \\
\hline C-14 & $9.1 E+1$ & $3.3 \mathrm{E}+3$ & 1.5E+0 & $3.6 \mathrm{E}+2$ & C-14 \\
\hline Al-26 & $9.0 \mathrm{E}+2$ & $3.0 \mathrm{E}+3$ & $1.0 \mathrm{E}+0$ & $3.4 E+2$ & Al-26 \\
\hline Si-32 & $9.0 E+2$ & $3.0 \mathrm{E}+3$ & $1.2 E+9$ & $5.2 E+11$ & Si-32 \\
\hline $\mathrm{Cl}-36$ & $1.5 \mathrm{E}+0$ & $3.0 \mathrm{E}+3$ & $1.0 E+0$ & $2.8 E+0$ & $\mathrm{Cl}-36$ \\
\hline$K-40$ & $1.0 E+1$ & $3.0 \mathrm{E}+3$ & $1.0 \mathrm{E}+0$ & $3.1 E+0$ & $\mathrm{~K}-40$ \\
\hline Co-60 & $9.0 \mathrm{E}+2$ & $4.5 \mathrm{E}+3$ & 1.1E+255 & no limit & $\mathrm{Co}-60$ \\
\hline $\mathrm{Ni}-59$ & $9.1 E+1$ & $4.7 E+4$ & $1.5 E+0$ & $3.6 \mathrm{E}+3$ & Ni-59 \\
\hline Ni-63 & $9.1 E+1$ & 4.7E+4 & $2.1 E+140$ & no limit & $\mathrm{Ni}-63$ \\
\hline Se-79 & $1.0 \mathrm{E}+1$ & $3.7 E+3$ & 1.0E+0 & $6.9 \mathrm{E}+0$ & Se-79 \\
\hline Sr-90 & $9.0 \mathrm{E}+2$ & $4.5 \mathrm{E}+3$ & $1.6 \mathrm{E}+46$ & $5.0 \mathrm{E}+47$ & Sr-90 \\
\hline $\mathrm{Zr}-93$ & $9.1 E+1$ & $3.0 \mathrm{E}+3$ & $1.0 \mathrm{E}+0$ & $2.3 E+2$ & $\mathrm{Zr}-93$ \\
\hline $\mathrm{Nb}-93 \mathrm{~m}$ & $9.1 E+1$ & $3.0 E+3$ & $2.1 E+56$ & no limit & $\mathrm{Nb}-93 \mathrm{~m}$ \\
\hline $\mathrm{Nb}-94$ & $9.1 E+1$ & $3.0 E+3$ & $1.1 E+0$ & $7.8 E+1$ & $\mathrm{Nb}-94$ \\
\hline TC-99 & $1.0 E+1$ & $3.1 E+3$ & $1.0 \mathrm{E}+0$ & 4.0E+1 & TC-99 \\
\hline $\mathrm{Pd}-107$ & $9.0 \mathrm{E}+2$ & $3.0 \mathrm{E}+3$ & 1.0E+0 & $3.3 E+4$ & $\mathrm{Pd}-107$ \\
\hline $\mathrm{Ag}-108 \mathrm{~m}$ & $9.0 E+2$ & $4.5 \mathrm{E}+3$ & $2.2 E+10$ & $1.4 E+13$ & $\mathrm{Ag}-108 \mathrm{~m}$ \\
\hline $\mathrm{Cd}-113 \mathrm{~m}$ & $9.0 E+2$ & $4.2 E+3$ & $1.3 E+89$ & no limit & $\mathrm{Cd}-113 \mathrm{~m}$ \\
\hline Sn-121m & $9.1 E+1$ & $2.2 E+4$ & $7.9 E+119$ & no limit & Sn-121m \\
\hline Sn-126 & $9.1 E+1$ & $2.2 E+4$ & $1.2 E+0$ & $2.8 \mathrm{E}+1$ & Sn-126 \\
\hline $1-129$ & $1.0 E+1$ & $3.1 E+3$ & $1.0 E+0$ & $2.1 \mathrm{E}-1$ & $1-129$ \\
\hline Cs-135 & $9.1 E+1$ & $1.8 \mathrm{E}+4$ & $1.0 \mathrm{E}+0$ & 7.1E+1 & Cs-135 \\
\hline Cs-137 & $9.1 E+1$ & 1.8E+4 & $1.2 E+175$ & no limit & Cs-137 \\
\hline $\mathrm{Ba}-133$ & $9.1 \mathrm{E}+1$ & $3.7 E+3$ & $7.6 \mathrm{E}+106$ & no limit & Ba-133 \\
\hline Sm-151 & $9.1 E+1$ & $1.8 \mathrm{E}+4$ & $4.9 E+58$ & no limit & Sm-151 \\
\hline Eu-152 & $9.1 E+1$ & $1.8 E+4$ & infinity & no limit & Eu-152 \\
\hline Eu-154 & $9.1 E+1$ & 1.8E+4 & infinity & no limit & Eu-154 \\
\hline $\mathrm{Pb}-210$ & $9.0 E+2$ & 1.8E+4 & $7.2 E+236$ & no limit & $\mathrm{Pb}-210$ \\
\hline Ra-226 & $9.1 \mathrm{E}+1$ & $7.6 \mathrm{E}+4$ & 1.7E+14 & $1.0 E+13$ & Ra-226 \\
\hline Ra-228 & $9.1 \mathrm{E}+1$ & $7.6 E+4$ & infinity & no limit & Ra-228 \\
\hline Th-229 & $9.0 E+2$ & $4.4 E+5$ & $1.3 E+18$ & $1.6 E+18$ & Th-229 \\
\hline Th-230 & $9.0 E+2$ & $4.4 E+5$ & case 2 & $5.8 \mathrm{E}-1$ & Th-230 \\
\hline Th-232 & $9.0 E+2$ & $4.4 \mathrm{E}+5$ & $1.0 \mathrm{E}+0$ & 9.9E-1 & Th-232 \\
\hline Pa-231 & $9.0 \mathrm{E}+2$ & $4.5 E+3$ & $1.1 E+0$ & $2.1 E-1$ & Pa-231 \\
\hline
\end{tabular}


Table SRS-11. Results of the PE Water Pathway Calculations for the Mixed Waste Disposal Facility at the Savannah River Site (Part 2 of 2)

\begin{tabular}{|c|c|c|c|c|c|}
\hline Nuclide & $\begin{array}{l}\text { CRF total } \\
\text { (no decay) }\end{array}$ & $\begin{array}{c}\text { Arrival Time } \\
\text { (y) } \\
\end{array}$ & $\overline{r_{\text {Decay }}}$ & $\begin{array}{c}C_{\text {W-Water }} \\
\left(\mu \mathrm{Ci} / \mathrm{m}^{2}\right)\end{array}$ & Nuclide \\
\hline U-232 & $9.0 \mathrm{E}+2$ & 1.0E+4 & 1.6E+44 & 3.7E+44 & U-232 \\
\hline U-233 & $9.0 \mathrm{E}+2$ & $1.0 E+4$ & case 2 & $1.8 E+0$ & U-233 \\
\hline U-234 & $9.0 \mathrm{E}+2$ & 1.0E+4 & case 2 & $5.5 \mathrm{E}+0$ & U-234 \\
\hline U-235 & $9.0 \mathrm{E}+2$ & $1.0 \mathrm{E}+4$ & case 2 & $9.6 \mathrm{E}-1$ & U-235 \\
\hline U-236 & $9.0 \mathrm{E}+2$ & 1.0E+4 & 1.0E+0 & 1.8E+1 & U-236 \\
\hline U-238 & $9.0 \mathrm{E}+2$ & 1.0E+4 & $1.0 \mathrm{E}+0$ & 1.7E+1 & U-238 \\
\hline Np-237 & $9.0 \mathrm{E}+2$ & $4.3 E+3$ & $1.0 \mathrm{E}+0$ & 1.1E+0 & Np-237 \\
\hline Pu-238 & $9.0 \mathrm{E}+2$ & $1.8 \mathrm{E}+4$ & 1.7E+60 & 1.6E+4 & Pu-238 \\
\hline Pu-239 & $9.0 \mathrm{E}+2$ & $1.8 \mathrm{E}+4$ & 1.7E+0 & $2.3 E+0$ & Pu-239 \\
\hline $\mathrm{Pu}-240$ & $9.0 \mathrm{E}+2$ & $1.8 E+4$ & $6.4 \mathrm{E}+0$ & $8.9 E+0$ & Pu-240 \\
\hline Pu-241 & $9.0 \mathrm{E}+2$ & $1.8 E+4$ & infinity & $1.6 \mathrm{E}+5$ & $\mathrm{Pu}-241$ \\
\hline $\mathrm{Pu}-242$ & $9.0 \mathrm{E}+2$ & 1.8E+4 & $1.0 E+0$ & $1.5 E+0$ & Pu-242 \\
\hline $\mathrm{Pu}-244$ & $9.0 E+2$ & 1.8E+4 & $1.0 \mathrm{E}+0$ & 8.7E-1 & Pu-244 \\
\hline$A m-241$ & $9.0 \mathrm{E}+2$ & $2.5 \mathrm{E}+4$ & 1.8E+17 & $5.5 E+3$ & Am-241 \\
\hline Am-243 & $9.0 \mathrm{E}+2$ & $2.5 \mathrm{E}+4$ & $1.0 \mathrm{E}+1$ & $1.4 \mathrm{E}+1$ & Am-243 \\
\hline $\mathrm{Cm}-243$ & $9.0 \mathrm{E}+2$ & $2.5 E+4$ & $4.8 E+256$ & $1.9 \mathrm{E}+3$ & $\mathrm{Cm}-243$ \\
\hline $\mathrm{Cm}-244$ & $9.0 E+2$ & $2.5 \mathrm{E}+4$ & infinity & $3.2 E+3$ & $\mathrm{Cm}-244$ \\
\hline $\mathrm{Cm}-245$ & $9.0 E+2$ & $2.5 \mathrm{E}+4$ & $7.6 \mathrm{E}+0$ & $7.9 E-1$ & $\mathrm{Cm}-245$ \\
\hline $\mathrm{Cm}-246$ & $9.0 \mathrm{E}+2$ & $2.5 \mathrm{E}+4$ & 3.7E+1 & $4.9 \mathrm{E}+1$ & $\mathrm{Cm}-246$ \\
\hline $\mathrm{Cm}-247$ & $9.0 E+2$ & $2.5 E+4$ & $1.0 \mathrm{E}+0$ & 8.3E-1 & $\mathrm{Cm}-247$ \\
\hline $\mathrm{Cm}-248$ & $9.0 E+2$ & $2.5 E+4$ & 1.1E+0 & $3.8 \mathrm{E}-1$ & $\mathrm{Cm}-248$ \\
\hline Cf-249 & $9.0 E+2$ & $2.5 E+4$ & $1.9 E+21$ & $1.9 \mathrm{E}+1$ & Cf-249 \\
\hline Cf-250 & $9.0 \mathrm{E}+2$ & $2.5 E+4$ & infinity & $1.8 \mathrm{E}+4$ & Cf-250 \\
\hline Cf-251 & $9.0 \mathrm{E}+2$ & $2.5 \mathrm{E}+4$ & $2.0 E+8$ & $2.0 \mathrm{E}+8$ & Cf-251 \\
\hline
\end{tabular}




\section{A.2.3.2 Atmospheric Transport for the MWDF}

Site-specific data required to perform the atmospheric pathway analysis came from site personnel either as data from site characterizations and reports or from general literature. The site-specific data required for the soil diffusion calculation were identical to those required for the water transport analysis (see Section 13.4.1 in this volume). The values used in the atmospheric dispersion analysis are shown in Table SRS-12. Necessary atmospheric dispersion data include wind speed, wind direction, and stability class, which are discussed in Section 13.3.2.1 of this volume.

Application of the PE methodology for atmospheric transport of the two volatile radionuclides considered in the $\mathrm{PE}(\mathrm{H}-3$ and $\mathrm{C}-14)$ produced the results shown in Table SRS-13. The table shows permissible waste concentrations based on transport in the atmospheric pathway $\left(C_{W-A t m}\right)$, as well as the values used in calculating the permissible waste concentrations. For both H-3 and C-14, the greatest concentration reduction occurred as the radionuclides diffuse from the top of the disposal facility to the soil surface.

\section{A.2.3.3 Inadvertent Intruder Exposure for the MWDF}

As explained in Section 13.3.3 of this volume, the PE used two standard intrusion scenarios - agricultural (or homesteader) and post-drilling - to describe potential modes of inadvertent intrusion into the waste facility. Both intrusion scenarios are assumed to be credible and applicable for the MWDF at SRS. Based upon the estimated failure times of the MWDF's engineered barriers, the homesteader scenario was assumed to be credible at $3000 \mathrm{y}$ after closure of the facility.

The geometry factor, $f_{g}$, for the MWDF was assumed to be 0.5 , based upon information provided in the performance assessment for the E-Area vaults.

As described in Section SRS.2.3, the post-drilling scenario at Savannah River never occurs at times earlier than the homesteader scenario. Therefore, the post-drilling scenario never yields doses that would exceed the doses from the homesteader scenario. The permissible waste concentrations for the MWDF for each of the 58 radionuclides based on the standard PE homesteader intrusion scenario are listed in Table SRS- 14.

Values for the radioactive decay term in Table SRS-14 were based on the applicable time of homesteader intrusion into the disposal facility (3000 y). For six radionuclides in the table (U-233, U-234, U-235, U-238, Pu-244, and Cm-247), the time of homesteader intrusion was changed to $10,000 \mathrm{y}$, the end of the performance period. For these six radionuclides, ingrowth of decay products yields scenario doses that increase over time. The doses at $10,000 \mathrm{y}$, therefore, represent the maximum that could be encountered during the performance period. Also, for Th-230 and Cm-245, ingrowth of decay products likewise produces a scenario dose that increases over time and peaks within the 10,000-y performance period. The times of homesteader intrusion for these two radionuclides ( $\mathrm{Th}-230$ and $\mathrm{Cm}-245$ ) were taken as the time of maximum dose, $9000 \mathrm{y}$ and $1000 \mathrm{y}$, respectively. 
Table SRS-12. Parameters and Values Used in the Atmospheric Pathway PE Analysis for the Mixed Waste Disposal Facility at the Savannah River Site

\begin{tabular}{|c|c|c|c|}
\hline Parameter & Value & $\begin{array}{l}\text { Data } \\
\text { Type }\end{array}$ & Comments \\
\hline $\begin{array}{l}\text { Cover thickness above the } \\
\text { disposal facility, } x\end{array}$ & $1.0 \mathrm{~m}$ & $D$ & Standard PE value \\
\hline Depth of the soil surface, $d$ & $0.01 \mathrm{~m}$ & D & $\begin{array}{l}\text { Standard PE value based on } \\
\text { EG\&G } 1994\end{array}$ \\
\hline Void space in the soil, $n$ & 0.5 & C & Staff \\
\hline $\begin{array}{l}\text { Moisture content in the soil void } \\
\text { space, } s\end{array}$ & 1.0 & C & Staff \\
\hline $\begin{array}{l}\text { Ratio of the density of water in air } \\
\text { to that in the liquid phase for } \mathrm{H}-3 \text {, } \\
r\end{array}$ & $9.20 E-6$ & D & Standard PE value \\
\hline $\begin{array}{l}\text { Ratio of the } \mathrm{CO}_{2} \text { concentration in } \\
\text { air to that in dissolved water for } \\
\mathrm{C}-14, r\end{array}$ & $4.25 E-4$ & D & Standard PE value \\
\hline $\begin{array}{l}\text { Diffusion coefficient in air for } \mathrm{H}-3 \text {, } \\
\text { D }\end{array}$ & $\begin{array}{c}2.39 \mathrm{E}-5 \\
\mathrm{~m}^{2} / \mathrm{s}\end{array}$ & D & Standard PE value \\
\hline $\begin{array}{l}\text { Diffusion coefficient in air for } \\
C-14, D\end{array}$ & $\begin{array}{c}1.40 \mathrm{E}-5 \\
\mathrm{~m}^{2} / \mathrm{s}\end{array}$ & D & Standard PE value \\
\hline $\begin{array}{l}\text { Atmospheric dispersion } \\
\text { parameter, } A_{D} \text {, for site-specific } \\
\text { MWDF design }\end{array}$ & 0.75 & B & $\begin{array}{l}\text { Value is estimated using the } \\
\text { Industrial Source Complex-Version } \\
2 \text { Long Term Air Dispersion Model } \\
\text { (ISCLT2) (EPA 1992) based on } \\
\text { site-specific STAR data }\end{array}$ \\
\hline $\begin{array}{l}\text { Atmospheric Scenario Dose } \\
\text { Conversion Factor for } \mathrm{H}-3, \text { SDCF }\end{array}$ & $\begin{array}{c}8.33 \mathrm{E}+2 \\
\mathrm{mrem} / \mathrm{y} \text { per } \\
\mu \mathrm{Ci} / \mathrm{m}^{3}\end{array}$ & $D$ & $\begin{array}{l}\text { Standard PE value; includes "all } \\
\text { pathways" considerations. }\end{array}$ \\
\hline $\begin{array}{l}\text { Atmospheric Scenario Dose } \\
\text { Conversion Factor for } \mathrm{C}-14 \text {, } \\
\text { SDCF }\end{array}$ & $\begin{array}{c}2.20 \mathrm{E}+5 \\
\mathrm{mrem} / \mathrm{y} \text { per } \\
\mu \mathrm{Ci} / \mathrm{m}^{3}\end{array}$ & D & $\begin{array}{l}\text { Standard PE value; includes "all } \\
\text { pathways" considerations. }\end{array}$ \\
\hline
\end{tabular}

${ }^{2} A=$ Site measurement; $B=$ Result of site numerical analysis; $C=$ Literature value selected by site; $D=$ Generic PE value

Table SRS-13. Results of the Atmospheric Pathway Calculations for the Mixed Waste Disposal Facility

\begin{tabular}{|c|c|c|c|c|c|c|}
\hline Nuclide & $\begin{array}{c}S D C F_{A t m} \\
(r e m / y \text { per } \mu \mathrm{Cin})\end{array}$ & $\begin{array}{c}C R F_{\text {Dif }} \\
\text { (dimensionless) }\end{array}$ & $\begin{array}{c}C R F_{\text {Disp }} \\
\text { (dimensionless) }\end{array}$ & $\begin{array}{l}\text { Arrival } \\
\text { Time (y) }\end{array}$ & $\begin{array}{c}\text { roecay } \\
\text { (dimensionless) }\end{array}$ & $\begin{array}{c}C_{W-A t m} \\
\left(\mu \mathrm{Ci} / \mathrm{m}^{3}\right)\end{array}$ \\
\hline $\mathrm{H}-3$ & $8.33 E+02$ & $5 E+06$ & $6 E+02$ & 100 & 300 & $1 E+10$ \\
\hline$C-14$ & 2.37E+05 & $1 E+05$ & $1 E+03$ & 100 & 1 & $5 E+03$ \\
\hline
\end{tabular}


Table SRS-14. Permissible Waste Concentrations for the Homesteader (Agricultural) Intrusion Scenario for the Mixed Waste Disposal Facility at the Savannah River Site

\begin{tabular}{|c|c|}
\hline Nuclide & $\begin{array}{c}C_{\text {w-Intr }} \\
\text { Homesteader } \\
\left(\mu \mathrm{Ci} / \mathrm{m}^{3}\right) \\
\end{array}$ \\
\hline $\mathrm{H}-3$ & $\mathrm{NL}^{\mathrm{b}}$ \\
\hline C-14 & $2 E+04$ \\
\hline Al-26 & $5 E+01$ \\
\hline Si-32 & $1 E+12$ \\
\hline Cl-36 & $2 E+02$ \\
\hline$K-40$ & $7 E+02$ \\
\hline Co-60 & $N^{b}$ \\
\hline Ni-59 & $3 E+06$ \\
\hline Ni-63 & $\mathrm{NL}^{\mathrm{b}}$ \\
\hline Se-79 & $2 E+05$ \\
\hline Sr-90 & $N^{b}{ }^{b}$ \\
\hline$Z r-93$ & $5 E+06$ \\
\hline $\mathrm{Nb}-93 \mathrm{~m}$ & $N^{b}{ }^{b}$ \\
\hline $\mathrm{Nb}-94$ & $1 E+02$ \\
\hline TC-99 & $2 E+04$ \\
\hline $\mathrm{Pd}-107$ & $6 E+06$ \\
\hline Ag-108m & $8 E+08$ \\
\hline Cd-113m & $\mathrm{NL}^{\mathrm{b}}$ \\
\hline$S n-121 m$ & $N^{b}$ \\
\hline Sn-126 & $8 E+01$ \\
\hline $\mid-129$ & $2 E+03$ \\
\hline Cs-135 & $2 E+05$ \\
\hline Cs-137 & $\mathrm{NL}^{b}$ \\
\hline Ba-133 & $\mathrm{NL}^{\mathrm{b}}$ \\
\hline $\mathrm{Sm}-151$ & $\mathrm{NL}^{\mathrm{b}}$ \\
\hline Eu-152 & $\mathrm{NL}^{\mathrm{b}}$ \\
\hline Eu-154 & $\mathrm{NL}^{\mathrm{b}}$ \\
\hline $\mathrm{Pb}-210$ & $\mathrm{NL}^{\mathrm{b}}$ \\
\hline Ra-226 & $3 E+02$ \\
\hline Ra-228 & $\mathrm{NL}^{\mathrm{b}}$ \\
\hline
\end{tabular}

\begin{tabular}{|c|c|}
\hline Nuclide & $\begin{array}{c}C_{w-I n t r} \\
\text { Homesteader } \\
\left(\mu \mathrm{Ci} / \mathrm{m}^{3}\right)\end{array}$ \\
\hline Th-229 & $6 E+02$ \\
\hline Th-230 $\mathrm{c}$ & $8 E+01^{c}$ \\
\hline Th-232 & $6 E+01$ \\
\hline $\mathrm{Pa}-231$ & $3 E+02$ \\
\hline U-232 & $\mathrm{NL}^{\mathrm{b}}$ \\
\hline$U-233^{d}$ & $7 E+02^{d}$ \\
\hline $\mathrm{U}-234^{\mathrm{d}}$ & $1 E+03^{d}$ \\
\hline$U-235^{d}$ & $6 E+02^{d}$ \\
\hline U-236 & $2 E+04$ \\
\hline$U-238^{d}$ & $5 E+03^{d}$ \\
\hline $\mathrm{Np}-237$ & $4 E+02$ \\
\hline Pu-238 & $1 E+07$ \\
\hline Pu-239 & $7 E+03$ \\
\hline Pu-240 & $8 \mathrm{E}+03$ \\
\hline Pu-241 & $1 E+07$ \\
\hline Pu-242 & $7 E+03$ \\
\hline$P u-244^{d}$ & $4 E+02^{d}$ \\
\hline$A m-241$ & $4 E+05$ \\
\hline Am-243 & $1 E+03$ \\
\hline $\mathrm{Cm}-243$ & $6 E+06$ \\
\hline Cm-244 & $3 E+06$ \\
\hline Cm-245 & $2 E+03$ \\
\hline $\mathrm{Cm}-246$ & $9 \mathrm{E}+03$ \\
\hline $\mathrm{Cm}-247^{\mathrm{d}}$ & $3 E+02^{d}$ \\
\hline Cm-248 & $2 E+03$ \\
\hline Cf-249 & $1 E+05$ \\
\hline Cf-250 & $3 E+06$ \\
\hline Cf-251 & $1 E+04$ \\
\hline
\end{tabular}

a Except as otherwise noted, the time of homesteader intrusion is $3000 \mathrm{y}$ after closure of the disposal facility.

b "NL" = No Limit; the estimated permissible concentration exceeds the specific activity of the pure elemental radionuclide.

c Homesteader intrusion is assumed to occur at 9000 y after closure of the disposal facility, since the ingrowth of decay products for this radionuclide would produce the maximum dose at that time.

d Homesteader intrusion is assumed to occur at 10,000 y after closure of the disposal facility, since the ingrowth of decay products for this radionuclide would produce the maximum dose at that time. 


\section{A.2.3.4 PE Results for the MWDF at Savannah River}

The limiting waste concentrations in the disposed MLLW for the water, atmospheric, and intruder analyses for the MWDF are summarized in Table SRS-15.

For the MWDF design at Savannah River, 14 radionuclides were limited by the water pathway, one radionuclide (H-3) was limited by the atmospheric pathway, and 31 radionuclides were limited by intrusion scenarios, as shown in Table SRS-15. Fourteen radionuclides had no limit from any pathway. For these fourteen radionuclides-which have relatively short halflives-the MWDF design provides sufficient retention time to allow radioactive decay to reduce the activity of radionuclides to levels that are not of concern.

For the MWDF, five waste concentrations were reported for the water pathway analysis as having no limit. The calculated concentrations for those radionuclides reported as NL (No Limit) were above the specific activity of the pure elemental radionuclide, implying that the performance measure of $4 \mathrm{mrem}(0.04 \mathrm{mSv})$ per year would not be reached under the given release and transport assumptions.

Also, values for some radionuclides are not reported in Table SRS-15 for the water pathway analysis. Arrival times for these radionuclides were beyond the 10,000-y performance period. For these radionuclides, the estimated waste concentrations are presented in Table SRS-11 for information purposes but are not listed in Table SRS-15. Consistent with the approach used in LLW performance assessments, because arrival times for these radionuclides were beyond $10,000 \mathrm{y}$, these values were not considered in determining the most restrictive disposal limit from among the evaluated pathways.

For the MWDF, the radionuclides limited by the water pathway generally tended to be highly mobile (e.g., Tc-99 and I-129). The uraniums and transuranics are not shown as being limited by the water pathway because their peak arrival times were beyond $10,000 \mathrm{y}$. 
Table SRS-15. Permissible Waste Concentrations for the Mixed Waste Disposal Facility at the Savannah River Site (for each radionuclide, the most restrictive concentration among the three pathways is highlighted in boldface type) (Part 1 of 2)

\begin{tabular}{|c|c|c|c|c|}
\hline \multirow[b]{2}{*}{ Nuclide } & \multicolumn{3}{|c|}{ Mixed Waste Disposal Facility } & \multirow[b]{2}{*}{ Nuclide } \\
\hline & $\begin{array}{c}C_{\text {W.Watarer }} C^{2, b} \\
\left(\mu \mathrm{C} / \mathrm{m}^{3}\right)\end{array}$ & $\begin{array}{l}C_{\text {W-Atme }}{ }^{c} \\
\left(\mu \mathrm{Ci} \mathrm{m}^{3}\right)\end{array}$ & $\begin{array}{l}C_{\text {W-Intr }}{ }^{d} \\
\left(\mu \mathrm{Ci} / \mathrm{m}^{3}\right) \\
\end{array}$ & \\
\hline $\mathrm{H}-3$ & NL & $1 E+10$ & NL & $\mathrm{H}-3$ \\
\hline$c-14$ & $4 E+02$ & $5 E+03$ & $2 E+04$ & C-14 \\
\hline Al-26 & $3 E+02$ & & $5 E+01$ & Al-26 \\
\hline Si-32 & $5 E+11$ & & $1 E+12$ & Si-32 \\
\hline $\mathrm{Cl}-36$ & $3 E+00$ & & $2 E+02$ & Cl-36 \\
\hline$K-40$ & $3 E+00$ & & $7 E+02$ & $K-40$ \\
\hline $00-60$ & $N L$ & & $N L$ & Co-60 \\
\hline $\mathrm{Ni}-59$ & - & & $3 E+06$ & Ni-59 \\
\hline$N i-63$ & - & & $N L$ & Ni-63 \\
\hline Se-79 & $7 E+00$ & & $2 E+05$ & Se-79 \\
\hline$S r-90$ & $N L$ & & $N L$ & Sr-90 \\
\hline Zr-93 & $2 E+02$ & & $5 E+06$ & $2 r-93$ \\
\hline$N b-93 m$ & $N L$ & & $N L$ & $\mathrm{Nb}-93 \mathrm{~m}$ \\
\hline $\mathrm{Nb}-94$ & $8 E+01$ & & $1 E+02$ & $\mathrm{Nb}-94$ \\
\hline TC-99 & $4 E+01$ & & $2 E+04$ & Tc-99 \\
\hline Pd-107 & $3 E+04$ & & $6 E+06$ & Pd-107 \\
\hline$A g-108 m$ & $1 E+13$ & & $8 E+08$ & Ag-108m \\
\hline Cd-113m & $N L$ & & $N L$ & Cd-113m \\
\hline Sn-121m & - & & $N L$ & Sn-121m \\
\hline Sn-126 & $=$ & & $8 E+01$ & Sn-126 \\
\hline $1-129$ & 2E-01 & & $2 E+03$ & I-129 \\
\hline Cs-135 & $=$ & & $2 E+05$ & Cs-135 \\
\hline Cs-137 & - & & $N L$ & Cs-137 \\
\hline Ba-133 & $N L$ & & $N L$ & Ba-133 \\
\hline$S m-151$ & - & & $N L$ & $S m-151$ \\
\hline Eu-152 & - & & $N L$ & Eu-152 \\
\hline Eu-154 & - & & $N L$ & Eu-154 \\
\hline $\mathrm{Pb}-210$ & - & & $N L$ & $\mathrm{~Pb}-210$ \\
\hline Ra-226 & $=$ & & $3 E+02$ & Ra-226 \\
\hline aa-228 & $=$ & & $N L$ & Ra-228 \\
\hline Th-229 & $=$ & & $6 E+02$ & Th-229 \\
\hline Th-230 & $=$ & & $8 E+01$ & Th-230 \\
\hline$T h-232$ & - & & $6 E+01$ & Th-232 \\
\hline$\overline{P a-231}$ & $2 E-01$ & & $3 E+02$ & Pa-231 \\
\hline
\end{tabular}


Table SRS-15. Permissible Waste Concentrations for the Mixed Waste Disposal Facility at the Savannah River Site (for each radionuclide, the most restrictive concentration among the three pathways is highlighted in boldface type) (Part 2 of 2)

\begin{tabular}{|c|c|c|c|c|}
\hline \multirow[b]{2}{*}{ Nuclide } & \multicolumn{3}{|c|}{ Mixed Waste Disposal Facility } & \multirow[b]{2}{*}{ Nuclide } \\
\hline & $C_{\text {w-Wator }}{ }_{\left(\mu \mathrm{Ci} / \mathrm{m}^{3}\right)}$ & $C_{W \cdot A t m}^{c}$ & $\begin{array}{l}C_{W \text {-lntr }}{ }^{d} \\
\left(\mu \mathrm{Ci} / \mathrm{m}^{3}\right)\end{array}$ & \\
\hline U-238 & - & & $5 E+03$ & U-238 \\
\hline Np-237 & $1 E+00$ & & $4 E+02$ & Np-237 \\
\hline Pu-238 & - & & $1 E+07$ & $\mathrm{Pu}-238$ \\
\hline Pu-239 & - & & $7 E+03$ & Pu-239 \\
\hline Pu-240 & - & & $8 E+03$ & $\mathrm{Pu}-240$ \\
\hline $\mathrm{Pu}-241$ & - & & $1 E+07$ & Pu-241 \\
\hline Pu-242 & - & & $7 E+03$ & $\mathrm{Pu}-242$ \\
\hline Pu-244 & - & & $4 E+02$ & $\mathrm{Pu}-244$ \\
\hline Am-241 & - & & $4 E+05$ & Am-241 \\
\hline Am-243 & - & & $1 E+03$ & Am-243 \\
\hline Cm-243 & - & & $6 E+06$ & $\mathrm{Cm}-243$ \\
\hline Cm-244 & - & & $3 E+06$ & $\mathrm{Cm}-244$ \\
\hline $\mathrm{Cm}-245$ & - & & $2 E+03$ & $\mathrm{Cm}-245$ \\
\hline $\mathrm{Cm}-246$ & - & & $9 E+03$ & $\mathrm{Cm}-246$ \\
\hline Cm-247 & - & & $3 E+02$ & $\mathrm{Cm}-247$ \\
\hline $\mathrm{Cm}-248$ & - & & $2 E+03$ & $\mathrm{Cm}-248$ \\
\hline Cf-249 & $=$ & & $1 E+05$ & Cf-249 \\
\hline Cf-250 & - & & $3 E+06$ & Cf-250 \\
\hline Cf-251 & - & & $1 E+04$ & Cf-251 \\
\hline
\end{tabular}

- "NL" = No Limit; the estimated permissible waste concentration exceeds the specific activity of the pure elemental radionuclide.

b "- indicates that the waste concentration is based on a groundwater arrival time beyond $10,000 \mathrm{y}$; for specific values, see Table 13-4 in Chapter 13 of this volume.

- Results presented only for radionclides expected to be volatile under disposal facility conditions.

- Waste concentration is based on the most restrictive intrusion scenario (i.e., homesteader or post-drilling) for the site; see Table 13-6 in Chapter 13 of this volume for specific values. 


\section{A.2.4 REFERENCES}

DOE, 1988. Internal Dose Conversion Factors for Calculation of Dose to the Public. DOE/EH-0071. Washington, DC: U.S. Department of Energy.

EPA, 1988. Limiting Values of Radionuclide Intake and Air Concentration and Dose Conversion Factors for Inhalation, Submersion, and Ingestion. Federal Guidance Report No. 11, EPA-520/1-88-020. Washington, DC: Office of Radiation Programs.

EPA, 1993. External Exposure to Radionuclides in Air, Water, and Soil. Federal Guidance Report No. 12, EPA-402-R-93-081. Washington, DC: Office of Radiation Programs.

ICRP, 1959. Recommendations of the International Commission on Radiological Protection. International Commission on Radiological Protection, Publication No. 2. New York: Permagon Press.

WSRC, 1994. Radiological Performance Assessment for the E-Area Vaults Disposal Facility. WSRC-RP-94-218, Rev. 0. , Aiken, SC: Prepared for Westinghouse Savannah River Company, Aiken, South Carolina, by Martin Marietta Energy Systems, Inc., EG\&G Idaho, Inc., and Westinghouse Savannah River Company. 

Appendix A.3: Oak Ridge Reservation (ORR) 


\section{NOMENCLATURE}

\begin{tabular}{|c|c|}
\hline$A$ & Thickness of pad area \\
\hline$A_{D}$ & Atmospheric dispersion term \\
\hline$C_{W}$ & Permissible waste concentration for a radionuclide \\
\hline$C_{\text {HY-Atn }}$ & Radionuclide-specific waste concentration for permissible atmospheric releases \\
\hline CRF & Concentration reduction factor \\
\hline$C R F_{\text {Dilution }}$ & Concentration reduction factor for leachate dilution in groundwater \\
\hline$C R F_{\text {Disperse }}$ & Concentration reduction factor due to effects of dispersion \\
\hline$C R F_{\text {Recharge }}$ & Concentration reduction factor for dilution due to regional recharge \\
\hline$C R F_{\text {Sat }}$ & Concentration reduction factor for the saturated zone \\
\hline$C R F_{\text {Source }}$ & Concentration reduction factor for source \\
\hline$C R F_{V}$ & Concentration reduction factor for the vadose zone \\
\hline$C R F_{\text {Hater }}$ & Concentration reduction factor in the drinking water pathway \\
\hline DNC & Dissolved nuclide concentration \\
\hline$f_{g}$ & Geometry factor \\
\hline$i$ & natural recharge \\
\hline$i A$ & Annual flow volume through the vadose zone \\
\hline IWMF & Integrated Waste Management Facility \\
\hline$K_{d}$ & Distribution coefficient \\
\hline$l$ & Thickness of vadose \\
\hline MWDF & Mixed waste disposal facility \\
\hline$n$ & Porosity \\
\hline ORR & Oak Ridge Reservation \\
\hline PA & Performance assessment \\
\hline $\mathrm{PE}$ & Performance evaluation \\
\hline$q_{f}$ & Rate of water flowing through facility \\
\hline$Q_{G W}$ & Volumetric groundwater flow $\left(\mathrm{m}^{3} / \mathrm{y}\right)$ \\
\hline$Q_{f}$ & Volumetric flow of leachate from disposal facility $\left(\mathrm{m}^{3} / \mathrm{y}\right)$ \\
\hline SDCF & Scenario dose conversion factor \\
\hline SWSA & Solid Waste Storage Area \\
\hline USGS MOC & United States Geological Survey Method of Characteristics \\
\hline$V_{s}$ & Vadose zone soil volume \\
\hline$\theta_{f c}$ & Water content at field capacity \\
\hline$\rho_{b}$ & Bulk density \\
\hline
\end{tabular}




\section{Appendix A.3: Oak Ridge Reservation (ORR)}

A comparison of the results using the performance evaluation methodology for the Oak Ridge Reservation (ORR PE) with those of the performance assessment of the Integrated Waste Management Facility (IWMF) at the Solid Waste Storage Area 6 (SWSA 6 PA)(ORNL, 1994) is presented below. The SWSA 6 is the location of the existing low-level waste disposal facilities at ORR and the IWMF is an above-ground, tumulus facility within SWSA 6. The SWSA 6 is located in Melton Valley, which is hydrologically similar to Bear Creek Valley, the site of the proposed mixed waste disposal facility (MWDF) and the location of the ORR PE evaluation contained in Chapter 14 of this report.

The SWSA 6 PA analyzes the combined effects of eleven discrete disposal facilities, which generally result in calculated doses at the point of compliance from overlapping plumes from the different facilities. The IWMF is hydrologically isolated from the other ten disposal facilities of SWSA 6 (i.e., no overlapping plumes), so IWMF-specific results can be more readily extracted from the PA. In addition, leachate mass fluxes from the IWMF are reported in the SWSA 6 PA as intermediate results. Therefore, comparison of the environmental transport analyses of the SWSA 6 PA with the ORR PE can be made without detailed comparison of the disposal facility performance assumptions.

For this analysis, the performance evaluation methodology has been applied to the IWMF location at SWSA 6 so that a direct comparison of the ORR PE and IWMF PA results can be made. Therefore, some values and results used in the ORR PE water pathway analysis are slightly different than the values reported in Chapter 14 of this report.

A comparison of results from the ORR PE and SWSA 6 PA for the drinking water and atmospheric pathways and inadvertent intrusion are presented. Where differences in results are noted, the differences in assumptions are discussed and the magnitude of effects of the individual assumptions is ascertained.

\section{A.3.1 WATER PATHWAY ANALYSIS}

As described in Chapter 14 of this volume, the ORR PE incorporates the major flow pathways assumed in the SWSA 6 PA (ORNL, 1994). The SWSA 6 PA uses transport processes in addition to those used in the PE methodology. The major transport process assumptions used in the ORR PE and SWSA 6 PA are outlined in Table ORR-1.

In the text that follows, three topics are presented: (1) an overview of the groundwater pathway assumptions in the SWSA 6 PA and the ORR PE analyses, (2) a comparison of ORR PE and SWSA 6 PA results for the water pathway, and (3) a discussion of the effect of the additional transport assumptions used in the SWSA 6 PA on the ORR PE results. 
Table ORR-1. Comparison of Assumptions Used in the SWSA 6 PA and ORR PE Groundwater Transport Analyses

\begin{tabular}{|l|l|l||}
\hline \multicolumn{1}{|c|}{ Assumption } & \multicolumn{1}{|c|}{ SWSA 6 PA } & \multicolumn{1}{|c|}{ ORR PE } \\
\hline Source Term & Finite with time-dependent rates & Continuous with constant rate \\
\hline Vadose Zone & $\begin{array}{l}\text { Vadose zone transport is a function } \\
\text { of a vadose zone sorption model }\end{array}$ & $\begin{array}{l}C R F_{v}{ }^{4}=1 \text {, implicitly, due to } \\
\text { equilibrium resulting from continuous } \\
\text { source assumption }\end{array}$ \\
\hline Saturated Zone & $\begin{array}{l}\text { Saturated zone transport is a } \\
\text { function of dilution when leachate is } \\
\text { mixed with groundwater, dispersion, } \\
\text { and additional groundwater dilution } \\
\text { from regional recharge }\end{array}$ & $\begin{array}{l}C R F_{\text {Sat }}^{2}=C R F_{\text {Wator }}{ }^{3} \text { is a function of } \\
\text { dilution when leachate is mixed with } \\
\text { groundwater }\end{array}$ \\
\hline
\end{tabular}

$1 C R F_{v}$-concentration reduction factor in the vadose zone = concentration in leachate / concentration entering ground water $2 C R F_{\text {sat }}$ - concentration reduction factor in the saturated zone $=$ concentration entering gr. water $/$ concentration at $100 \mathrm{~m}$ $3 C R F_{\text {wator }}$ - concentration reduction factor in the drinking water pathway $=C R F_{v} \times C R F_{S a t}$

\section{A.3.1.1 Overview of Groundwater Pathway Assumptions in the SWSA 6 PA and the ORR PE}

Three pathways for leachate from the disposal facility to reach exposure points are considered in the SWSA 6 PA: (1) shallow subsurface transport to surface waters, (2) groundwater transport to surface waters, and (3) groundwater transport to the 100-m compliance point. The first two of these are not considered for the following reasons.

The radionuclide concentrations resulting from the shallow-subsurface-transport-tosurface-waters pathway include dilution by approximately $180,000 \mathrm{~m}^{3}$ in the SWSA 6 PA (ORNL, 1994, p. 4-23) based on predicted surface water runoff, which provides far more dilution than provided by mixing of leachate with clean water in the groundwater-to-compliance-point pathway. (Likewise in the PE, dilution is provided by mixing in Bear Creek, which has an annual flow of $5.7 \times 10^{6} \mathrm{~m}^{3}-$ a 30 times larger dilution effect than surface water runoff provided in the SWSA $6 \mathrm{PA}$ ). Therefore, the shallow-subsurface-transport-to-surface-waters pathway is less restrictive than the groundwater-transport-to-compliance-point pathway, and need not be discussed further.

The groundwater-transport-to-surface-waters pathway provides at least an order of magnitude less mass transport than provided by the shallow-subsurface-transport-to-surfacewaters pathway for all radionuclide results (ORNL, 1994, Tables 4.6 and 4.7). In addition, the peaks from these different pathways occur at different times. Therefore, the effect of the groundwater-transport-to-surface-waters pathway is always less than the shallow-subsurfacetransport-to-surface-waters pathway. This pathway was not considered in the ORR PE analysis. 


\section{Groundwater Pathway Modeling in the SWSA 6 PA}

The groundwater pathway analysis in the PA includes sorption effects in the thin vadose zone below the IWMF and dilution, dispersion, and sorption in the saturated zone. The sorption effects in the vadose zone are modeled with an annual time-step using the following equation presented in Appendix D of the SWSA 6 PA (ORNL, 1994, p. D-5):

$$
\text { Dissolved Nuclide Concentration = Total Chemical }(g) / \text { Volume Term }(m L)
$$

where the Dissolved Nuclide Concentration (DNC) is the dissolved concentration exiting the vadose zone to groundwater; and

$$
\text { Total Chemical }=\text { SorbedMass }+ \text { Dissolved Mass }+ \text { Added Leachate Mass }
$$

and

$$
\text { Volume Term }=\left[V_{s} \theta_{f c}+i A+\left(K_{d} \times V_{s} \times \rho_{b}\right)\right]
$$

where

$V_{s}=$ vadose zone soil volume;

$\theta_{j c}=$ water content at field capacity (defined as the moisture content at $-100 \mathrm{kPa}$ );

$i A=$ annual flow volume through the vadose zone;

$K_{d}=$ distribution coefficient; and

$\rho_{b}=$ bulk density.

The soil volume is equal to the product of the plan area of the disposal unit and the distance between the disposal unit and the water table.

Equations ORR-1 through ORR-3 produce results that are dependent on the assumed values of the distribution coefficient $\left(K_{d}\right)$ and the duration of release, with higher DNC values resulting from both lower $K_{d}$ values and longer durations of release.

Groundwater transport in the saturated zone in the SWSA 6 PA is modeled with the U.S. Geological Survey's Method of Characteristics (USGS MOC) code, which integrates the twodimensional advection-dispersion equation using a particle-tracking method along characteristic curves. This code is applied to a water velocity vector field calibrated to observed water table surfaces at SWSA 6. The radionuclide concentrations are averaged over a 3-m mixing depth in the groundwater. Dispersion and additional dilution from regional recharge further attenuate the radionuclide concentrations in the saturated zone during transport to the 100-m compliance point. 
The two water flow pathways included in the ORR PE are (1) shallow subsurface flow to surface water and (2) groundwater flow to the 100 -m performance boundary-identical to those used in the SWSA 6 PA. The transport processes considered in the ORR PE include (1) dilution of leachate when mixed with groundwater and (2) sorption in the vadose and saturated zones, resulting in retardation of radionuclide migration. This latter effect is used to estimate the arrival time of the radionuclides to account for radioactive decay and ingrowth of decay products.

\section{A.3.1.2 Comparison of ORR PE and SWSA 6 PA Water Pathway Results}

A comparison of the $C R F_{\text {Water }}$ values calculated for the IWMF at SWSA 6 based on intermediate PA results with the ORR PE results applied to the IWMF location is shown in Table ORR-2. Values in Table ORR-2 for the "Maximum Release Rate" have been estimated from the figures in the SWSA 6 PA (ORNL, 1994, Appendix F). Examples of these figures are shown in Figure ORR-1. The radionuclides listed in Table ORR-2 are those identified as the inventory of the IWMF.

The SWSA 6 PA includes the effects of radioactive decay in all intermediate results; these effects have been removed in Table ORR-2 to present "undecayed" $C R F_{\text {Water }}$ values. Cells in Table ORR-2 containing "." indicate that intermediate results were not available in the SWSA 6 PA. All but the last column in Table ORR-2 pertain to results from the SWSA 6 PA (ORNL, 1994).

As shown in the last two columns of Table ORR-2, the $C R F_{\text {Water }}$ values calculated from the PA results are 18 to 32 times larger than the ORR PE results for the low $K_{d}$ and shortduration release radionuclides $(\mathrm{H}-3, \mathrm{C}-14$, and $\mathrm{Tc}-99)$. The $C R F_{\text {Water }}$ values calculated from the PA results are 45 to 260 times larger than the ORR PE results for the intermediate-range $K_{d}$ and longer-duration release radionuclides (U-233, U-238, $\mathrm{Pu}-239$, and $\mathrm{Am}-243$ ). Intermediate results for the other radionuclides presented in Table ORR-2, particularly the high- $K_{d}$ radionuclides, are not available in the SWSA 6 PA, so that no direct comparisons of the overall $C R F_{\text {Water }}$ values can be made. Results for U-238 are based on an analytical extension of the groundwater code used for the other radionuclides. More details on the basis of the use of this different groundwater code are given in Section A.3.1.3.

The differences in results between the SWSA 6 PA and ORR PE analyses shown in Table ORR-2 are due to the differences in transport assumptions used in the two analyses. To ascertain the effects of the differences in these assumptions, the $C R F_{\text {Water }}$ is partitioned into a CRF for the vadose zone, $C R F_{V}$, and a CRF for the saturated zone, $C R F_{\text {Sat. }}$. The $C R F_{V}$ for the ORR PE is implicitly a value of one due to the equilibrium resulting in the vadose zone from the assumed continuous source term. Therefore for the ORR PE, the $C R F_{\text {Sat }}$ equals the $C R F_{\text {Water. }}$. 
Table ORR-2. Comparisons of $C R F_{\text {Water }}$ Based on Intermediate PA Results and PE Method for SWSA 6 IWMF

\begin{tabular}{|c|c|c|c|c|c|c|c|c|c|c|}
\hline Nuclide $^{a}$ & $\begin{array}{l}\text { Assumed } \\
\text { Vadosel } \\
\text { Saturated } \\
\text { Zone } K_{d} \\
(\mathrm{~mL} / \mathrm{g})^{b}\end{array}$ & $\begin{array}{c}\text { Maximum } \\
\text { Release } \\
\text { Rate } \\
(\mathrm{g} / \mathrm{y})^{\mathrm{c}}\end{array}$ & $\begin{array}{l}\text { Time of } \\
\text { Maximum } \\
\text { Release } \\
(y)^{c}\end{array}$ & $\begin{array}{c}\text { Duration } \\
\text { of Release } \\
(y)^{c}\end{array}$ & $\begin{array}{c}\text { Undecayed } \\
\text { Concentration } \\
\text { in Leachate } \\
(\mu \mathrm{Ci} / \mathrm{L})^{d}\end{array}$ & $\begin{array}{c}\text { Maximum } \\
\text { Concentration } \\
\text { in Groundwater } \\
(100 \mathrm{~m} \\
(\mu \mathrm{Ci} / \mathrm{L})^{\circ}\end{array}$ & $\begin{array}{l}\text { Arrival } \\
\text { Time } \\
\text { (y) }\end{array}$ & \begin{tabular}{|c|} 
Approximate \\
Undecayed \\
Concentration in \\
Groundwater \\
$(100 \mathrm{~m}$ \\
$(\mu \mathrm{Ci} / \mathrm{L})^{\mathrm{d}}$ \\
\end{tabular} & $\begin{array}{c}\text { PA } \\
\text { Calculated } \\
\text { CRF } F_{\text {wator }} \\
\text { (dimensionless) }\end{array}$ & \begin{tabular}{|c|} 
PE \\
Estimated \\
CRF \\
(dimensionless)
\end{tabular} \\
\hline $\mathrm{H}-3$ & $0 / 0.2$ & 0.0005 & 10 & 10 & $4.0 E+01$ & 1.9E-01 & 30 & $1.0 E+00$ & 40 & 2.2 \\
\hline C-14 & $0 / 0.2$ & 10 & 50 & 10 & $1.0 E+01$ & 1.4E-01 & 67 & 1.4E-01 & 71 & 2.2 \\
\hline Al-26 & 3000 & - & - & - & - & - & - & - & - & 2.2 \\
\hline $\mathrm{Cl}-36$ & $0 / 0.2$ & - & - & - & - & $6.8 E-02$ & 34 & 6.8E-02 & - & 2.2 \\
\hline Ni-63 & 2000 & - & - & - & - & - & - & - & - & 2.2 \\
\hline Sr-90 & 30 & 0.003 & 50 & 120 & 1.7E-01 & - & - & - & - & 2.2 \\
\hline Tc-99 & $0 / 0.2$ & 30 & 50 & 20 & 6.3E-02 & 1.6E-03 & 67 & 1.6E-03 & 39 & 2.2 \\
\hline Cs-137 & 3000 & 0.004 & 50 & 90 & 1.4E-01 & - & - & - & - & 2.2 \\
\hline Eu-152 & 3000 & - & - & - & - & - & - & - & - & 2.2 \\
\hline Th-232 & 40 & 20 & 50 & 210 & 2.7E-07 & - & - & - & - & 2.2 \\
\hline U-233 & 40 & 1 & 50 & 230 & $1.2 E-03$ & $8.9 E-06$ & 2400 & $9.0 \mathrm{E}-06$ & 130 & 2.2 \\
\hline$U-238$ & 40 & 300 & 50 & 360 & $1.2 E-05$ & 2.1E-08 & 5920 & 2.1E-08 & 570 & 2.2 \\
\hline Pu-239 & 40 & 0.06 & 50 & 230 & 4.6E-04 & 4.2E-06 & 2400 & 4.5E-06 & 100 & 2.2 \\
\hline$A m-241$ & 40 & 0.0001 & 50 & 250 & 4.6E-05 & - & - & - & - & 2.2 \\
\hline$A m-243$ & 40 & 0.001 & 50 & 250 & 2.5E-05 & 2.1E-07 & 2400 & 2.6E-07 & 100 & 2.2 \\
\hline
\end{tabular}

a Radionuclides assumed to be in the Integrated Waste Management Facility (IWMF) from Table 2.13 (ORNL, 1994).

b Values taken from Table 3.7 for the vadose zone and E.2 for the saturated zone. A single value is used for both zones (ORNL, 1994).

c Values estimated from leach rate figures in Appendix F for the IWMF (ORNL, 1994); duration of release to 10\% of peak release.

d Half-lives and specific activities from Table 3.7; time-dependent recharge from Table 4.2 based on monthly recharge estimates summarized from hourty precipitation estimates (ORNL, 1994).

e Values taken from Table 4.5 except for U-238 which is taken from Table E.17 (ORNL, 1994).

f Quotient of "Undecayed Concentration in Leachate" and "Undecayed Concentration in Groundwater Water @ $100 \mathrm{~m}$ " columns. 


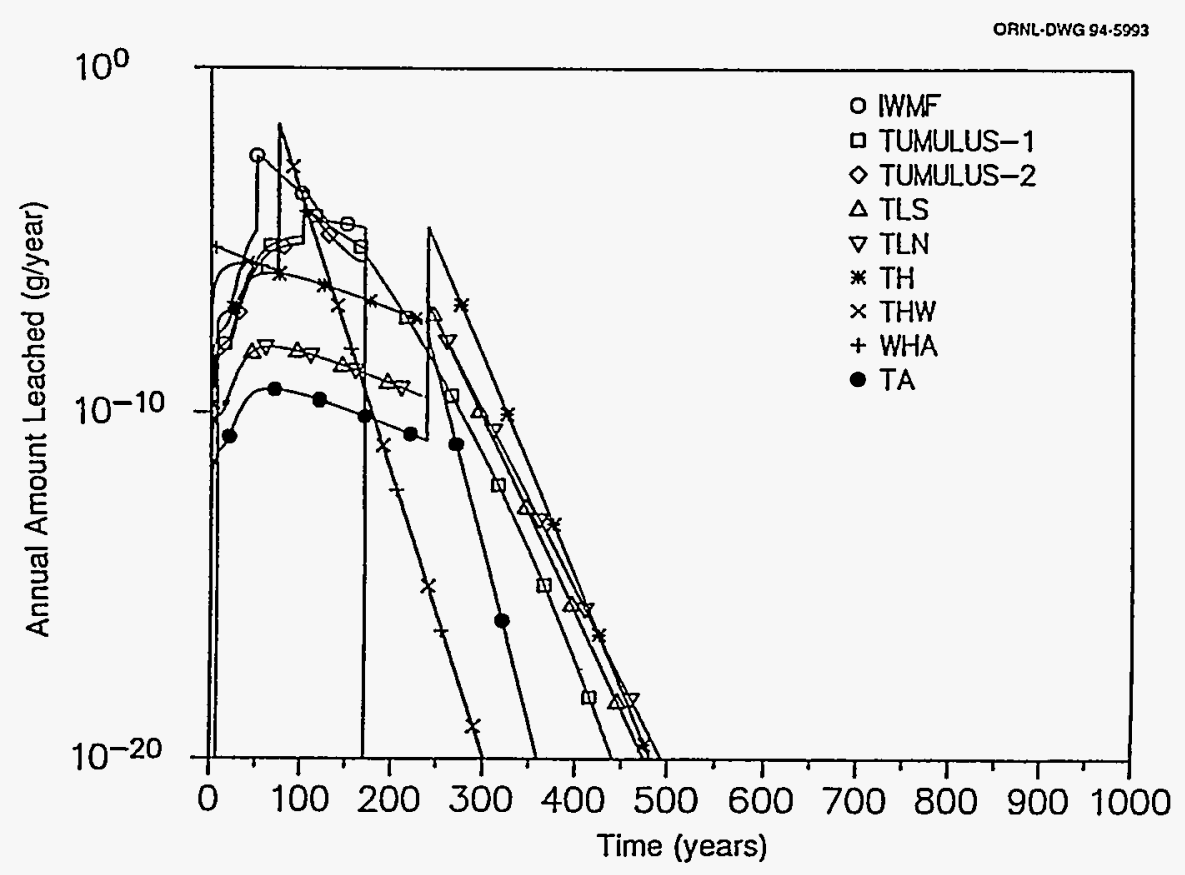

(a) $\operatorname{Sr}-90$

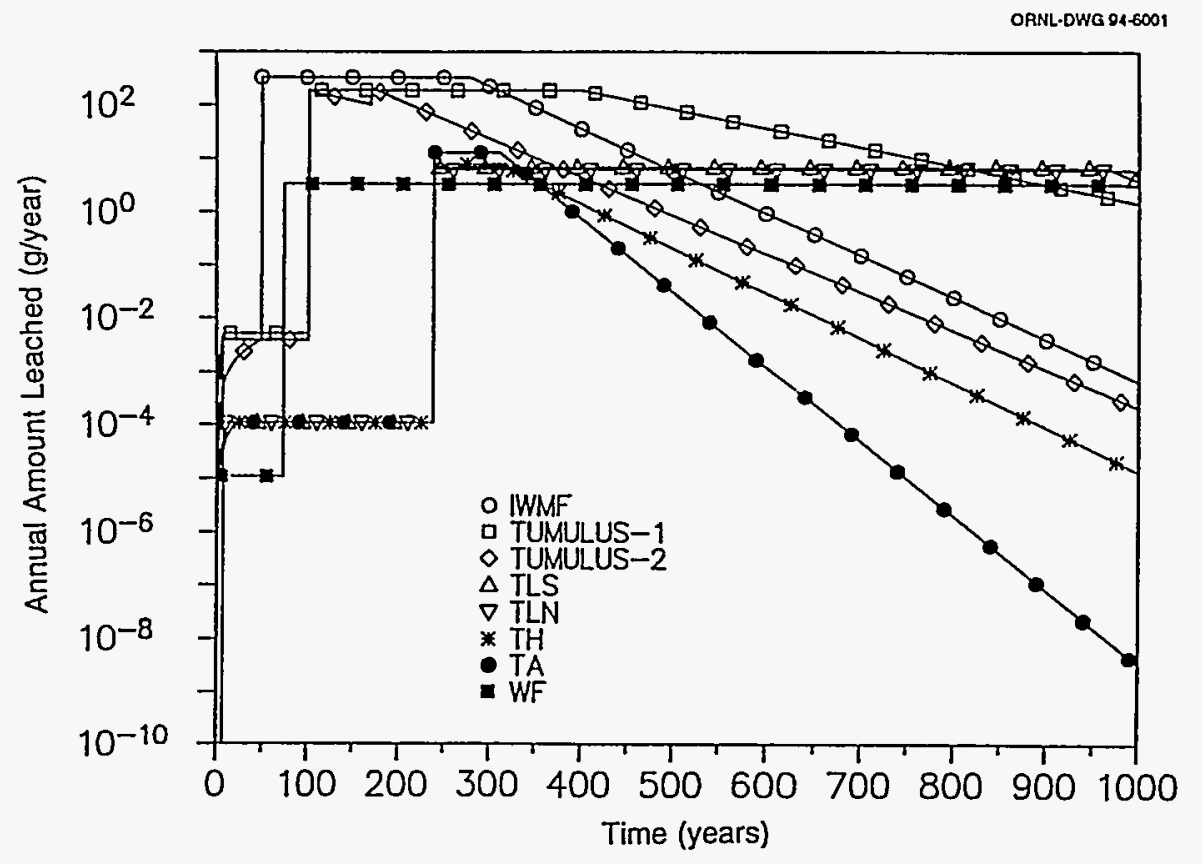

(b) U-238

Figure ORR-1. Calculated release rates of (a) Sr-90 and (b) U-238 (modified from ORNL, 1994, Appendix F). 


\section{A.3.1.2.1 Vadose Zone}

The concentration attenuation provided by the vadose zone, $C R F_{V}$, in the SWSA 6 PA is based on the application of Equations ORR-1 through ORR-3 as described in the SWSA 6 PA (ORNL, 1994, Appendix D). An independent implementation of the vadose zone sorption model has been developed to ensure proper understanding of the results and to extend the results to continuous source terms. This implementation has been performed by application of Equations ORR-1 through ORR-3 using the following steps:

1. Approximations of the source term profiles in Appendix F of the SWSA 6 PA (ORNL, 1994) were used as the input to the model.

2. Equations ORR-1 through ORR-3 were solved with an annual time step. The added leachate mass was added to the adsorbed and dissolved masses from the previous time step to determine the new dissolved nuclide concentration (DNC). Table ORR-3 shows the data used to solve the equation.

3. The quotient of the maximum leachate concentration from step 1 and the maximum DNC from step 2 was calculated as $C R F_{V}$.

Table ORR-3. Data Used in the Vadose Zone Sorption Model Development and Analysis

\begin{tabular}{|l|l|l|}
\hline \multicolumn{1}{|c|}{ Parameter } & \multicolumn{1}{c|}{ Value } & \multicolumn{1}{c|}{ Reference } \\
\hline distribution coefficient, $K_{d}$ & See Table ORR-4 & ORNL, 1994, p. 3-32 \\
\hline bulk density, $\rho_{b}$ & $1.35 \mathrm{~g} / \mathrm{cc}$ & ORNL, 1994, p. E-3 \\
\hline porosity, $n$ & 0.39 & ORNL, 1994, p. D-4 \\
\hline field capacity, $\theta_{f c}$ & 0.305 & ORNL, 1994, p. D-4 \\
\hline thickness of vadose, $I$ & $2 \mathrm{~m}$ & ORNL, 1994, p. 3-15 \\
\hline IWMF pad area, $A$ & $356 \mathrm{~m}^{2}$ & ORNL, 1994, p. 3-29 \\
\hline rate of water flowing through IWMF, $q_{f}$ & Function of time & ORNL, 1994, p. E-9 \\
\hline natural recharge through local soils, $i$ & $0.183 \mathrm{~m} / \mathrm{y}$ & ORNL, 1994, p. F-1 \\
\hline
\end{tabular}

Figure ORR-2 shows an example of the time dependency of the DNC for (a) the release profile for U-233 ( $K_{d}=40 \mathrm{~mL} / \mathrm{g}$ ) (ORNL, 1994, Figure F.8) and (b) an assumed continuous release for the same radionuclide. This figure illustrates that (1) for a finite-duration release, the DNC peaks at a value lower than the maximum leachate concentration, and (2) for a continuous release, the $\mathrm{DNC}$ increases to the leachate concentration with time, as the $C R F_{V}$ approaches unity. This figure illustrates that the ORR PE vadose zone assumption (i.e., no vadose zone concentration attenuation results from a continuous source) will also apply when a vadose zone sorption model is used. The time required to reach equilibrium is a function of the $K_{d}$ value assumed for the radionuclide. 


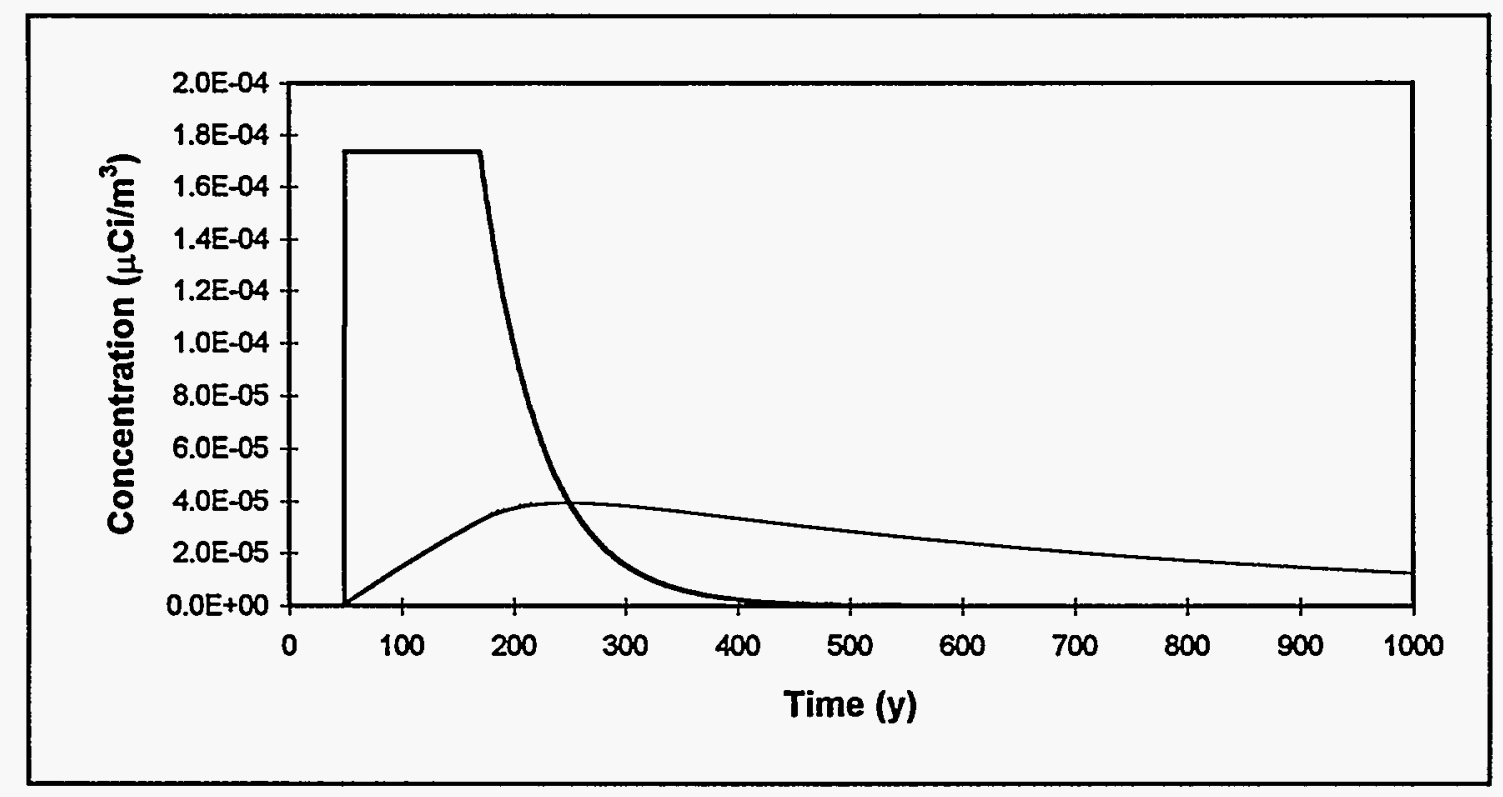

(a) U-233

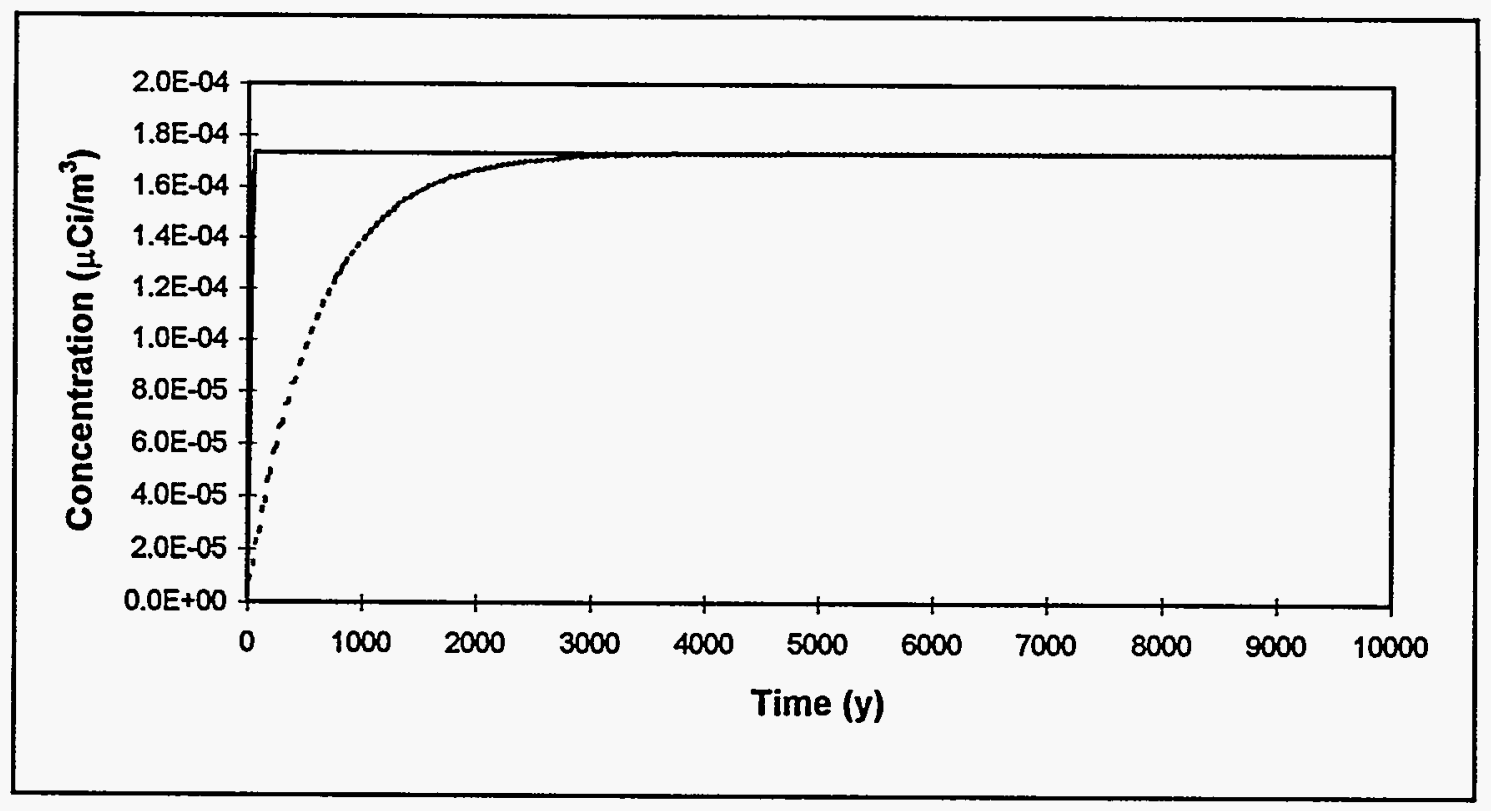

(b) Continuous Release

Figure ORR-2. Dissolved nuclide concentration exiting the vadose zone for U-233 $\left(K_{d}=40 \mathrm{~mL} / \mathrm{g}\right.$ ) for (a) the release profile used in the SWSA 6 PA (ORNL, 1994, Figure F.8) and (b) a continuous release. 
A comparison of the $C R F_{V}$ values for the IWMF at SWSA 6 based on intermediate SWSA $6 \mathrm{PA}$ results, the independent implementation of the vadose zone sorption zone model, and the ORR PE results applied to the IWMF location are shown in Table ORR-4. The results in column "PA Calculated $C R F_{V}$ " are based on the intermediate PA results presented in Table ORR-4. The results in column "PA Modeled $C R F_{V}$ " are based on the independent implementation of the vadose zone sorption model described above.

The PA-calculated $C R F_{V}$ values based on the intermediate-PA results match well with the PA-modeled $C R F_{V}$ values from the independent implementation of the vadose zone sorption model; all are within a factor of two except U-238. The $C R F_{V}$ values for Cs-137 $\left(K_{d}=3000\right.$ $\mathrm{mL} / \mathrm{g}$ ) are three orders of magnitude higher than the $C R F_{V}$ values for the radionuclides with lower $K_{d}$ values for both the calculated and modeled PA results. This result illustrates the effect of the vadose zone sorption model used in the SWSA 6 PA for a high- $K_{d}$, short-duration release radionuclide. The calculated $C R F_{V}$ value for U-238 is less than one, indicating a higher concentration entering the groundwater than released from the disposal facility. As discussed in Section A.3.1.3, the U-238 results in the SWSA 6 PA are based on an analytical extension of the groundwater transport code used for the other radionuclide results in this table. These anomalous intermediate results for U-238 are likely due to this reason.

The PA $C R F_{V}$ results (both calculated and modeled) are generally four times higher than the $\mathrm{PE} C R F_{V}$ results, both for the zero $K_{d}$ radionuclides with short durations of release (H-3, C-14, and Tc-99) and the intermediate-range $K_{d}$ radionuclides with longer durations of release (Th-232, U-233, Pu-239, Am-241, and Am-243). Larger differences result from Sr-90 (intermediate-range $K_{d}$, short duration of release) and Cs-137 (high $K_{d}$, short duration of release). The other radionuclides with high $K_{d}$ values in the IWMF (Al-26, Ni-63, and Eu-152) are expected to exhibit high $C R F_{V}$ values similar to Cs-137 when the vadose zone sorption model and short-duration releases are used.

\section{A.3.1.2.2 Saturated Zone Analyses}

The results of the SWSA 6 PA and ORR PE $C R F_{\text {Sat }}$ analyses are presented in Table ORR-5. All but the last column in Table ORR-5 pertain to the intermediate results in the SWSA 6 PA (ORNL, 1994). The SWSA 6 PA results are generally five times larger than the ORR PE results for radionuclides with low $K_{d}$ values (H-3, C-14, Cl-36, and Tc-99) and ten times larger for radionuclides with intermediate-range $K_{d}$ values (U-233, Pu-239, and Am-243). Intermediate results from the SWSA 6 PA for the high- $K_{d}$ radionuclides are not available. 


\begin{tabular}{|c|c|c|c|c|c|c|c|c|c|}
\hline Nuclide & $\begin{array}{c}\text { Assumed } \\
K_{d} \\
(\mathrm{~m} \sqcup \mathrm{g})^{n}\end{array}$ & $\begin{array}{c}\text { Undecayed } \\
\text { Concentration } \\
\text { in Leachate } \\
(\mu \mathrm{Ci} / L)^{b}\end{array}$ & $\begin{array}{c}\text { Duration } \\
\text { of Release } \\
(y)^{c}\end{array}$ & \begin{tabular}{|c|} 
Maximum \\
Recharge \\
Rate to \\
Groundwater \\
$(\mathrm{g} / \mathrm{y})^{\mathrm{d}}$
\end{tabular} & $\begin{array}{c}\text { Arrival } \\
\text { Time } \\
(y)^{d}\end{array}$ & $\begin{array}{c}\text { Approximate } \\
\text { Undecayed } \\
\text { Concentration to } \\
\text { Groundwater } \\
(\mu \mathrm{Ci} / \mathrm{L})^{\circ}\end{array}$ & $\begin{array}{c}\text { PA } \\
\text { Calculated } \\
\text { CRFV } \\
\text { (dimensionless) }\end{array}$ & $\begin{array}{c}\text { PA } \\
\text { Modeled } \\
C R F_{V} \\
\text { (dimensionless) }^{g} \\
\end{array}$ & $\begin{array}{c}\text { PE } \\
\text { Estimated } \\
\text { CRFV } \\
\text { (dimensionless) }^{h}\end{array}$ \\
\hline Al-26 & 3000 & - & - & - & - & - & - & - & 1 \\
\hline $\mathrm{Cl}-36$ & 0 & - & - & $9.78 \mathrm{E}+00$ & 18 & 5.9E-01 & - & - & 1 \\
\hline $\mathrm{Ni}-63$ & 2000 & - & - & - & - & - & - & - & 1 \\
\hline Sr-90 & 30 & 1.7E-01 & 120 & 4.49E-06 & 75 & $6.9 \mathrm{E}-03$ & 25 & 30 & 1 \\
\hline Tc-99 & 0 & 6.3E-02 & 20 & 5.93E-01 & 54 & $1.8 \mathrm{E}-02$ & 3.5 & 2.7 & 1 \\
\hline U-238 & 40 & 1.2E-05 & 360 & 4.35E+01 & 341 & 2.7E-05 & 0.4 & 2.9 & 1 \\
\hline Pu-239 & 40. & 4.6E-04 & 230 & 8.58E-04 & 262 & $1.0 \mathrm{E}-04$ & 4.6 & 4.4 & 1 \\
\hline Am-241 & 40 & 4.6E-05 & 250 & 1.54E-06 & 221 & $1.4 \mathrm{E}-05$ & 3.3 & 4.5 & 1 \\
\hline Am-243 & 40 & 2.5E-05 & 250 & 1.48E-05 & 259 & 5.5E-06 & 4.5 & 4.4 & 1 \\
\hline
\end{tabular}

a Values taken from Table 3.7 (ORNL, 1994).

b Values copied from Table ORR-2.

c Values estimated from leach rate figures in Appendix F for the IWMF (ORNL, 1994); duration of release to 10\% of peak release.

d Values taken from Table 4.3 (ORNL, 1994).

e Half-lives and specific activities from Table 3.7 ; recharge based on $5.8 \times 10-7 \mathrm{~cm} / \mathrm{s}$ groundwater recharge rate based on monthly recharge estimates summarized from hourly precipitation estimates (ORNL, 1994).

f Quotient of "Undecayed Concentration in Leachate" and "Undecayed Concentration to Groundwater" columns.

g Values based on independent implementation of vadose zone sorption model described in Appendix D (ORNL, 1994).

$h$ Values based on equilibrium resulting from continuous source assumption. 
Table ORR-5. Calculated $C R F_{\text {sat }}$ Based on IWMF PA Results and PE Method

\begin{tabular}{|c|c|c|c|c|c|}
\hline Nuclide & $\begin{array}{c}\text { Assumed } \\
K_{d} \\
(\mathrm{~m} \sqcup \mathrm{g})^{\mathrm{a}}\end{array}$ & $\begin{array}{c}\text { Undecayed } \\
\text { Concentration } \\
\text { to Groundwater } \\
(\mu \mathrm{Ci} / \mathrm{L})^{\mathrm{b}}\end{array}$ & $\begin{array}{c}\text { Undecayed } \\
\text { Concentration } \\
\text { in Groundwater } \\
@ 100 \mathrm{~m} \\
(\mu \mathrm{Ci} / \mathrm{L})^{c} \\
\end{array}$ & $\begin{array}{c}\text { PA } \\
\text { Calculated } \\
\text { CRF }_{\text {Set }} \\
\text { (dimensionless) }^{\mathrm{d}}\end{array}$ & $\begin{array}{c}P E \\
\text { Estimated } \\
C R F_{\text {Sat }} \\
\text { (dimensionless) }^{c}\end{array}$ \\
\hline $\mathrm{H}-3$ & 0.2 & $1.1 \mathrm{E}+01$ & $1.0 E+00$ & 11 & 2.2 \\
\hline C-14 & 0.2 & $2.1 \mathrm{E}+00$ & $1.4 \mathrm{E}-01$ & 15 & 2.2 \\
\hline Al-26 & 3000 & - & - & - & 2.2 \\
\hline $\mathrm{Cl}-36$ & 0.2 & $5.9 \mathrm{E}-01$ & $6.8 \mathrm{E}-02$ & 8.7 & 2.2 \\
\hline $\mathrm{Ni}-63$ & 2000 & - & - & - & 2.2 \\
\hline Sr-90 & 30 & $6.9 \mathrm{E}-03$ & - & - & 2.2 \\
\hline TC-99 & 0.2 & $1.8 \mathrm{E}-02$ & $1.6 \mathrm{E}-03$ & .11 & 2.2 \\
\hline Cs-137 & 3000 & $8.5 \mathrm{E}-05$ & - & - & 2.2 \\
\hline Eu-152 & 3000 & - & - & - & 2.2 \\
\hline Th-232 & 40 & $7.6 \mathrm{E}-08$ & - & - & 2.2 \\
\hline U-233 & 40 & $2.0 \mathrm{E}-04$ & $9.0 \mathrm{E}-06$ & 22 & 2.2 \\
\hline U-238 & 40 & 2.7E-05 & 2.1E-08 & - & 2.2 \\
\hline Pu-239 & 40 & $1.0 \mathrm{E}-04$ & 4.5E-06 & 22 & 2.2 \\
\hline Am-241 & 40 & $1.4 \mathrm{E}-05$ & - & - & 2.2 \\
\hline Am-243 & 40 & $5.5 \mathrm{E}-06$ & 2.6E-07 & 21 & 2.2 \\
\hline
\end{tabular}

a Values taken from Table 3.7 (ORNL, 1994).

b Values copied from Table ORR-4.

c Values copled from Table ORR-2.

d Quotient of "Undecayed Concentration to Groundwater" and "Undecayed Conc in Groundwater @ $100 \mathrm{~m}$ " columns.

The ORR PE results are based solely on dilution of leachate with groundwater, while the SWSA 6 PA results are based on dilution of leachate with groundwater, dilution of contaminated groundwater due to regional recharge, and dispersion in the groundwater. The effects of dilution due to regional recharge can be estimated by treating the saturated zone down-gradient of the disposal facility as a mixing cell (Figure ORR-3) and estimating the dilution by the relative flows of clean recharge water and contaminated groundwater. Using the values from Figure ORR-3, a CRF for dilution due to regional recharge is calculated as 3.1. Concentration reduction due to regional recharge is applicable to the continuous-source assumption used in the ORR PE and the finite-duration source assumption used in the SWSA 6 PA. 


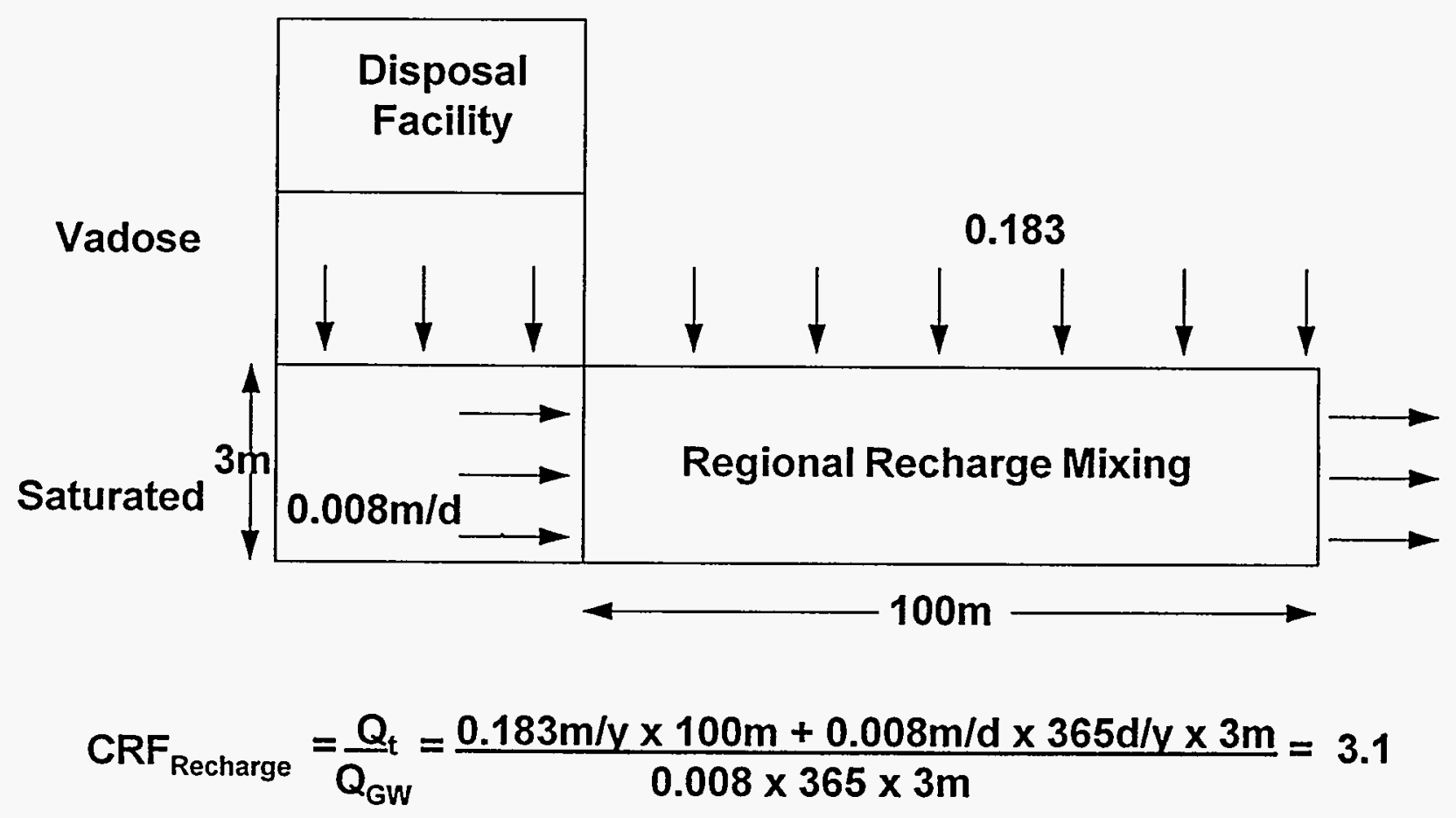

Figure ORR-3. Schematic diagram of the regional recharge dilution CRF, $C R F_{\text {Recharge }}$

A concentration reduction due to dispersion is only important for finite-duration sources with well-defined peaks (applicable only to some SWSA 6 PA radionuclides). It is not applicable to a continuous source because dispersion will only affect the shape of the contaminant front (see Appendix B of Volume 2 of this report). The concentration reduction effects of dispersion included in the SWSA 6 PA can be estimated by dividing the $C R F_{\text {Sat }}$ by the effects of leachate dilution in groundwater, $C R F_{\text {Dilution, }}$ and dilution by regional recharge, $C R F_{\text {Recharge. }}$ It is assumed here that the concentration reduction due to dilution of leachate with groundwater is the same for the ORR PE and the SWSA 6 PA results. The results are shown in Table ORR-6.

These results show that the $C R F_{\text {Disperse }}$ in the saturated zone are about 1.6 or about $23 \%$ of $C R F_{\text {Sat }}$ for low- $K_{d}$ radionuclides and about 3.2 or about $37 \%$ of $C R F_{\text {Sat }}$ for intermediate-value $K_{d}$ radionuclides. These results show that a continuous release source assumption provides conservatism. 
Table ORR-6. Components of the SWSA 6 PA CRF $F_{\text {Sat }}$

\begin{tabular}{|c|c|c|c|c|c|}
\hline Nuclide & $\begin{array}{c}\text { Assumed } \\
K_{d} \\
(\mathrm{~mL} / \mathrm{g})^{a}\end{array}$ & $\begin{array}{c}\mathrm{PA} \\
\mathrm{CRF}_{\text {Sat }} \\
\text { (dimensionless) }^{\mathrm{b}}\end{array}$ & $\begin{array}{c}\text { PA } \\
\text { CRF }_{\text {Dllution }} \\
\text { (dimensionless) }^{c}\end{array}$ & $\begin{array}{c}\text { PA } \\
\mathrm{CRF}_{\text {Recharge }} \\
\text { (dimensionless) }^{\mathrm{d}}\end{array}$ & $\begin{array}{c}\text { PA } \\
\text { CRF }_{\text {Disperse }} \\
\text { (dimensionless) }^{e}\end{array}$ \\
\hline $\mathrm{H}-3$ & 0.2 & 11 & 2.2 & 3.1 & 1.6 \\
\hline C-14 & 0.2 & 15 & 2.2 & 3.1 & 2.2 \\
\hline Al-26 & 3000 & - & 2.2 & 3.1 & - \\
\hline $\mathrm{Cl}-36$ & 0.2 & 8.7 & 2.2 & 3.1 & 1.3 \\
\hline Ni-63 & 2000 & - & 2.2 & 3.1 & - \\
\hline Sr-90 & 30 & - & 2.2 & 3.1 & - \\
\hline TC-99 & 0.2 & 11 & 2.2 & 3.1 & 1.6 \\
\hline Cs-137 & 3000 & - & 2.2 & 3.1 & - \\
\hline Eu-152 & 3000 & - & 2.2 & 3.1 & - \\
\hline Th-232 & 40 & - & 2.2 & 3.1 & - \\
\hline U-233 & 40 & 22 & 2.2 & 3.1 & 3.2 \\
\hline U-238 & 40 & - & 2.2 & 3.1 & - \\
\hline Pu-239 & 40 & 22 & 2.2 & 3.1 & 3.2 \\
\hline Am-241 & 40 & - & 2.2 & 3.1 & - \\
\hline Am-243 & 40 & 21 & 2.2 & 3.1 & 3.1 \\
\hline
\end{tabular}

a Values taken from Table 3.7 (ORNL, 1994).

b Values copied from Table ORR-5.

c Values copled from Table ORR-5 (PE Estimated CRF water). $_{\text {. }}$

d Values result from dilution due to regional recharge using values from Figure ORR-2.

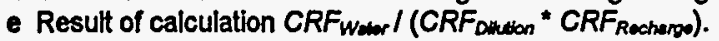

\section{A.3.1.3 Discussion of Effect of the Additional Transport Assumptions}

A summary of the effects of the different transport mechanisms used in the SWSA 6 PA compared with the effects used in the ORR PE is shown in Table ORR-7. The $C R F_{\nu}$ effects are most pronounced for radionuclides with high $K_{d}$ values and short to medium durations of release (Cs-137). The effect disappears for long durations of release. The $C R F_{\text {Disperse }}$ provides a relatively minor effect for all radionuclides. This effect is minimized for long-duration releases, for which dispersion only affects the shape of the contamination front. By definition, the $C R F_{\text {Dilute }}$ equals the $C R F_{\text {Water }}$ used in the ORR PE. The $C R F_{\text {Recharge }}$ provides additional concentration reduction in the saturated zone, an effect which will also occur with a continuous source assumption and which is not currently accounted for in the ORR PE. The products of the four PA concentration reduction factors in Table ORR-7 equal the PA $C R F_{\text {Water }}$ values. These PA $C R F_{\text {Water }}$ values in Table ORR-7 match the PA calculated $C R F_{\text {Water }}$ values presented in Table ORR-2 (within round-off error), which demonstrates that all concentration reductions are accounted for in the SWSA 6 PA analysis. 
Table ORR-7. Comparison of the Individual Impacts of the SWSA 6 PA and ORR PE Transport Assumptions

\begin{tabular}{|c|c|c|c|c|c|c|c|c|}
\hline Nuclide & $\begin{array}{c}\text { Assumed } \\
\text { Vadose / } \\
\text { Saturated } \\
\text { Zone } K_{d} \\
(\mathrm{~m} \cup \mathrm{g})^{\mathrm{a}}\end{array}$ & $\begin{array}{c}\text { Duration } \\
\text { of Release } \\
(y)^{b}\end{array}$ & $\begin{array}{c}\mathrm{PA} \\
\mathrm{CRF} \\
\text { (dimensionless) }\end{array}$ & $\begin{array}{c}\text { PA } \\
\text { CRF Dllution } \\
\text { (dimensionless) }\end{array}$ & $\begin{array}{c}\text { PA } \\
\text { CRF }_{\text {Recharge }} \\
\text { (dimensionless) }\end{array}$ & $\begin{array}{c}\mathrm{PA} \\
\mathrm{CRF}_{\text {Disperse }} \\
\text { (dimensionless) }^{\mathrm{d}}\end{array}$ & $\begin{array}{c}\mathrm{PA} \\
\mathrm{CR} F_{\text {Water }} \\
\text { (dimensionless) }\end{array}$ & $\begin{array}{c}\text { PE } \\
\text { CRF Water }_{\text {(dimensionless) }}\end{array}$ \\
\hline $\mathrm{H}-3$ & $0 / 0.2$ & 10 & 3.6 & 2.2 & 3.1 & 1.6 & 39 & 2.2 \\
\hline C-14 & $0 / 0.2$ & 10 & 4.8 & 2.2 & 3.1 & 2.2 & 72 & 2.2 \\
\hline Al-26 & 3000 & - & - & 2.2 & 3.1 & - & - & 2.2 \\
\hline $\mathrm{Cl}-36$ & $0 / 0.2$ & - & - & 2.2 & 3.1 & 1.3 & - & 2.2 \\
\hline $\mathrm{Ni}-63$ & 2000 & - & - & 2.2 & 3.1 & - & - & 2.2 \\
\hline Sr-90 & 30 & 120 & 25 & 2.2 & 3.1 & - & - & 2.2 \\
\hline TC-99 & $0 / 0.2$ & 20 & 3.5 & 2.2 & 3.1 & 1.6 & 38 & 2.2 \\
\hline Cs-137 & 3000 & 90 & 1600 & 2.2 & 3.1 & - & - & 2.2 \\
\hline Eu-152 & 3000 & - & - & 2.2 & 3.1 & - & - & 2.2 \\
\hline Th-232 & 40 & 210 & 3.6 & 2.2 & 3.1 & - & - & 2.2 \\
\hline U-233 & 40 & 230 & 6.0 & 2.2 & 3.1 & 3.2 & 131 & 2.2 \\
\hline U-238 & 40 & 360 & 0.4 & 2.2 & 3.1 & - & - & 2.2 \\
\hline Pu-239 & 40 & 230 & 4.6 & 2.2 & 3.1 & 3.2 & 100 & 2.2 \\
\hline Am-241 & 40 & 250 & 3.3 & 2.2 & 3.1 & - & - & 2.2 \\
\hline Am-243 & 40 & 250 & 4.5 & 2.2 & 3.1 & 3.1 & 95 & 2.2 \\
\hline
\end{tabular}

a Values taken from Table 3.7 and E.2 (ORNL, 1994).

b Values estimated from leach rate figures in Appendix F for the IWMF (ORNL, 1994); duration of release to 10\% of peak release.

c Values copied from Table ORR-4.

d Values copied from Table ORR-6.

e Product of the four component PA CRF values in this table.

f Values copied from Table ORR-2. 
A discussion of three topics concludes this section: (1) an analysis of the "continuous release" assumption used in the ORR PE, (2) a discussion of the effects of regional recharge, and (3) a discussion of the groundwater model for U-238 in the SWSA 6 PA.

\section{Continuous Release Assumption Used in the ORR PE}

The continuous release assumption was used in all site $\mathrm{PE}$ analyses because the inventory of the disposal facilities was unknown in the PE process and a continuous release assumption is conservative relative to a finite duration release. The general impact of this assumption is the neglect of the concentration reduction provided by dispersion on a finite source. This effect has been shown to be relatively minor in the SWSA 6 PA (Table ORR-7).

Using a vadose zone sorption model like the one used in the SWSA 6 PA can make the effects of the continuous source assumption more dramatic. High- $K_{d}$ radionuclides are affected most, although all radionuclides are impacted to some degree, as shown in Table ORR-7.

Each radionuclide has a duration of release for which the vadose zone sorption model reaches equilibrium (i.e., $C R F_{V}=1$ ). This duration of release depends on the assumed $K_{d}$. Figure ORR-4 shows the relationship between duration of release and assumed $K_{d}$.

The resulting curve is linear, with a slope of $69 \mathrm{~g}-\mathrm{y} / \mathrm{mL}$ and an intercept equal to the water travel time through the vadose zone. For all radionuclides with $K_{d}$ less than $145 \mathrm{~mL} / \mathrm{g}$, the minimum duration source term required to achieve a $C R F_{V}=1$ is less than $10,000 \mathrm{y}$. For the radionuclides with $K_{d}=40 \mathrm{~mL} / \mathrm{g}$ (i.e., $\mathrm{Th}, \mathrm{U}, \mathrm{Np}, \mathrm{Pu}, \mathrm{Am}, \mathrm{Cm}, \mathrm{Cf}$ ), the minimum duration source term required to achieve a $C R F_{V}=1$ is approximately $2700 \mathrm{y}$.

A radionuclide with a duration of release less than the minimum time for its $K_{d}$ value given in Figure ORR-4 results in a $C R F_{V}$ greater than 1, with increasing $C R F_{V}$ values resulting from decreasing durations of release. A radionuclide with a duration of release longer than the minimum time given in Figure ORR-4 results in the vadose zone model reaching equilibrium with no concentration reduction occurring. Therefore, the indicated durations of release in Figure ORR-4 provide some context for the definition of a "continuous release". For example, for a radionuclide with a $K_{d}=5 \mathrm{~mL} / \mathrm{g}$, a duration of release greater than about 350 y can be considered a continuous release because the vadose zone has reached equilibrium; for a radionuclide with a $K_{d}=40 \mathrm{~mL} / \mathrm{g}$, a duration of release greater than $2800 \mathrm{y}$ can be considered continuous. Therefore, a finite release of sufficient duration can be considered equivalent to a continuous release with respect to the effect of the vadose zone sorption model.

The peak leach rate durations used in the SWSA 6 PA for the IWMF are all less than 400 $y$ (measured to $10 \%$ of peak fluxes) (Table ORR-7), and all durations of release used in the SWSA 6 PA are less than their respective minimum durations of release required to be considered a continuous source. Therefore, all $C R F_{V}$ used in the PA are expected to be greater than one, the result shown in Table ORR-7. 


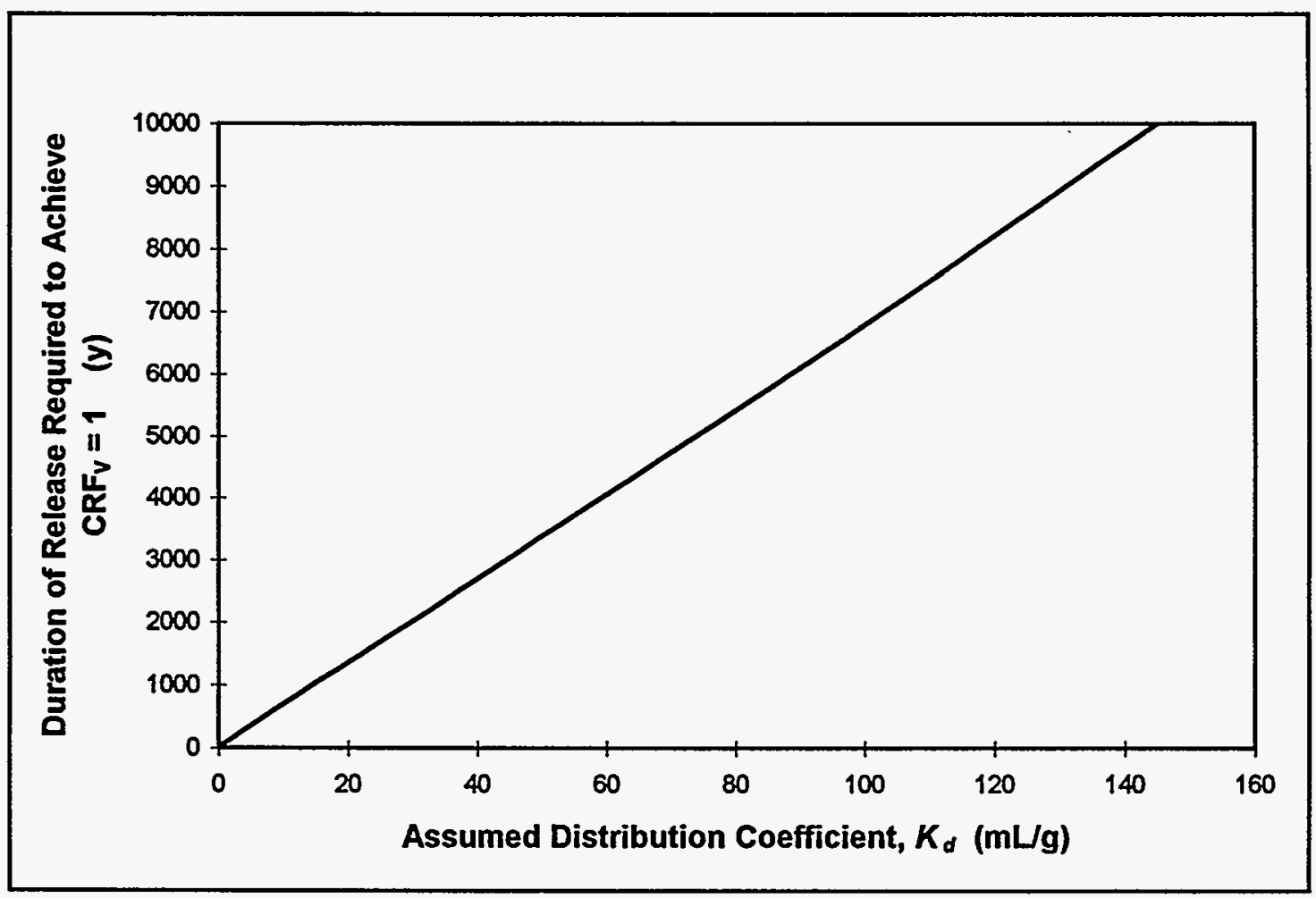

Figure ORR-4. Minimum duration of release required to achieve $C R F_{V}=1$ versus $K_{d \text {. }}$

Because the generic facilities assumed in the ORR PE will have some finite inventory (i.e., the product of the plan area, assumed height, mixing fraction, and limiting concentration), the durations-of-release until exhaustion can be calculated by using the capacity of the disposal facility and the most restrictive waste concentration limit calculated by the ORR PE. This result can be used to estimate a $C R F_{V}$ based on the vadose zone sorption model. This analysis has been done for a group of indicator radionuclides and the results are presented in Table ORR-8. The duration of release is determined by the following equation:

$$
\text { Duration of Release }=\frac{\text { Total Inventory }}{\frac{\text { Permissible Waste Conc. }}{C R F_{\text {sarce }}} \times \text { Plan Area } \times \text { Recharge }}
$$

This constant duration of release begins at the failure of the engineered barriers, assumed to occur at $300 \mathrm{y}$. Prior to that time, low infiltration rates will result in only minor releases from the facility. A plan area of $2500 \mathrm{~m}^{2}$, a facility height of $6 \mathrm{~m}$, and a recharge through the facility of 2.7 $\mathrm{m} / \mathrm{y}$ are used in these calculations. 
Table ORR-8. $C R F_{V}$ Resulting from Finite Inventory in the Generic Tumulus Facility for the ORR PE for Several Indicator Radionuclides

\begin{tabular}{|l|c|c|c|c|c|c|c|}
\hline Nuclide & $\begin{array}{c}C_{w} \\
\left(\mu \mathrm{Ci} / \mathrm{m}^{3}\right)\end{array}$ & $\begin{array}{c}\text { Controlling } \\
\text { Pathway }\end{array}$ & $\begin{array}{c}\text { Total } \\
\text { Inventory } \\
(\mu \mathrm{Ci})\end{array}$ & $C F_{\text {Source }}$ & $\begin{array}{c}\text { Soil } \boldsymbol{K}_{d} \\
(\mathrm{~mL} / \mathrm{g})\end{array}$ & $\begin{array}{c}\text { Time until } \\
\text { Exhaustion } \\
(\mathrm{y})\end{array}$ & $\begin{array}{c}\text { Resulting } \\
C_{R} F_{v}\end{array}$ \\
\hline $\mathrm{H}-3$ & $2,000,000$ & Water & $1.0 \mathrm{E}+10$ & 0.90 & 0 & 1 & 2.4 \\
\hline $\mathrm{C}-14$ & 200 & Water & $1.0 \mathrm{E}+06$ & 54 & 0 & 40 & 1.0 \\
\hline Sr-90 & 200,000 & Intrusion & $1.0 \mathrm{E}+09$ & 540 & 30 & 400 & 1.7 \\
\hline Tc-99 & 40 & Water & $2.0 \mathrm{E}+05$ & 6.2 & 0 & 5 & 1.2 \\
\hline Cs-137 & 200,000 & Intrusion & $1.0 \mathrm{E}+09$ & 54 & 3000 & 40 & 1100. \\
\hline U-238 & 20 & Water & $1.0 \mathrm{E}+05$ & 540 & 40 & 400 & 2.0 \\
\hline Pu-239 & 1 & Water & $5.0 \mathrm{E}+03$ & 540 & 40 & 400 & 2.0 \\
\hline Am-241 & 200 & Water & $1.0 \mathrm{E}+06$ & 540 & 40 & 400 & 2.0 \\
\hline
\end{tabular}

Of the eight indicator radionuclides evaluated, only Cs-137, with a soil $K_{d}=3000 \mathrm{~mL} / \mathrm{g}$, provides a $C R F_{V}$ much greater than one. The concentration of this radionuclide is limited by intrusion, not drinking water, indicating that additional credit from vadose zone sorption is not necessary. For the remaining radionuclides, the continuous source assumption does not produce a $C R F_{V}$ much greater than one, indicating that the continuous source is not an unreasonable assumption for these indicator radionuclides.

In summary, the continuous source assumption is a significant factor only for sites with radionuclides having high $K_{d}$ values and soils that can be represented with a vadose zone sorption mechanism. Radionuclides with low or medium $K_{d}$ values will not result in concentration reductions in the vadose zone much greater than one, so the vadose zone sorption mechanism can be ignored with minor conservatism. Additionally, radionuclides with high $K_{d}$ values are likely to have limiting concentrations based on intrusion because the high retardation values may cause the radionuclide to reach the $100-\mathrm{m}$ performance boundary beyond $10,000 \mathrm{y}$.

\section{Effects of Dilution Due to Regional Recharge}

Dilution in the saturated zone due to regional recharge results in a concentration reduction of approximately 3.1. Ignoring this effect will result in concentrations in the ORR PE approximately three times lower than if the effect were included. While ignoring individual concentration reduction mechanisms generally causes relatively small differences in results, the combined effect of ignoring several mechanisms results in much larger differences in calculated concentration reductions. This effect needs to be considered in viewing the results of the PE. 
The groundwater pathway analysis in the SWSA 6 PA was performed for each individual radionuclide, combining the effects of all eleven disposal sites at the SWSA 6. As discussed in the SWSA 6 PA (ORNL, 1994, p. 4-15), a simple analytical solution was used in lieu of the numerical groundwater model, USGS MOC, in instances where the concentration at observation nodes for one or more disposal facilities did not reach a maximum value (i.e., cases with long durations of release). This is most evident in the case of U-238, which has continuous and constant leach rates for several disposal facilities at SWSA 6 beyond 1000 y (see Fig. ORR-1b).

A slightly increasing flux to groundwater for these facilities results in a slightly increasing concentration at the observation nodes, which prevents a peak groundwater concentration to be calculated for U-238 using USGS MOC even for $5000 \mathrm{y}$ of simulations (discussed on p. 4-15 of ORNL, 1994). As demonstrated above, this slightly increasing flux to groundwater is largely the result of the vadose zone sorption model, which provides an effluent concentration that asymptotically approaches the influent concentration for a long-duration source term. The effect of solubility constraints also likely affect these results.

In summary, long durations of release, which approximate continuous releases, can occur with finite inventories. The impact of the vadose zone sorption model on concentration is minimized for these cases.

\section{A.3.2 ATMOSPHERIC PATHWAY ANALYSIS}

A comparison of the results of the atmospheric pathway analysis based on the ORR PE with the results of an ORNL analysis done subsequent to the SWSA 6 PA is presented below. No atmospheric transport analyses were included in the SWSA $6 \mathrm{PA}$, but atmospheric analyses were performed subsequent to that document in response to reviewer comments (Lombardi and Socolof, 1994).

The methodologies of the post-SWSA 6 PA and ORR PE analyses are identical in that volatile and vapor diffusion mechanisms are used to transport $\mathrm{H}-3$ and $\mathrm{C}-14$ to the soil surface and Gaussian dispersion is used to transport the radionuclide to the $100-\mathrm{m}$ performance boundary. However, the differences in the geometry of the disposal facilities assumed in the two analyses result in different atmospheric dispersion values. The comparison of the results from the two analyses are shown in Table ORR-9. 
Table ORR-9. Comparison of the Results of the ORR PE with the Post-SWSA 6 PA Analysis for the Atmospheric Pathway at the ORR

\begin{tabular}{|c|c|c|c|c|c|c|}
\hline Nuclide & \multicolumn{2}{|c|}{ Total CRF } & \multicolumn{2}{c|}{$\begin{array}{c}\text { Time of Arrival } \\
(y)\end{array}$} & \multicolumn{2}{c|}{$\begin{array}{c}\text { Permissible Waste } \\
\text { Concentration, } C_{W-A t m} \\
\left(\mu C^{\prime} / m^{3}\right)\end{array}$} \\
\cline { 2 - 7 } & PA & PE & PA & PE & PA & PE \\
\hline$H-3$ & $3 E+12$ & $2 E+09$ & 100 & 100 & $1 E+13$ & $5 E+09$ \\
\hline$C-14$ & $3 E+08$ & $6 E+07$ & 100 & 100 & $4 E+04$ & $2 E+03$ \\
\hline
\end{tabular}

The ORR PE permissible waste concentrations are 2000 and 20 times larger than those provided by the post-SWSA 6 PA analysis for H-3 and C-14, respectively. These differences in results are due solely to the assumed atmospheric dispersion parameters, $A_{D}$, used in the two analyses. As shown in Table ORR-10, the ratios of the ORR PE and post-SWSA 6 PA analysis $A_{D}$ values are the same (within round-off error) as the ratios of the permissible waste concentrations shown in Table ORR-9.

Table ORR-10. Comparison of the Atmospheric Dispersion Parameter Values Calculated with the ORR PE and the Post-SWSA 6 PA Analysis at the ORR

\begin{tabular}{|c|c|c|c|}
\hline $\begin{array}{c}\text { Atmospheric Dispersion } \\
\text { Parameter, } A_{D}\end{array}$ & ORR PE & $\begin{array}{c}\text { Post-SWSA 6 } \\
\text { PA }\end{array}$ & Ratio PE : PA \\
\hline $\mathrm{H}-3$ & 2.1 & 0.00087 & 2400 \\
\hline $\mathrm{C}-14$ & 2.1 & 0.14 & 16 \\
\hline
\end{tabular}

The differences between the $A_{D}$ values used in the two analyses are due to the assumed geometry of the disposal facilities used in the two analyses. The disposal facility geometry for the generic tumulus and trench used in the ORR PE analysis is shown in Figure ORR-5a. The facility is assumed to be square surrounded by a $100-\mathrm{m}$ performance boundary. The disposal facility geometry used in the post-SWSA 6 PA analysis is shown in Figure ORR-5b, with the 100-m performance boundary shown as a dotted line around the perimeter of all disposal facilities. The disposal facilities at SWSA 6 result in separate emissions sources surrounded by non-emission source areas. The complex source geometry used in the post-SWSA 6 PA analysis results in increased dispersion and lower $A_{D}$ values when compared with the ORR PE. In addition, the potential receptors at the 100-m performance boundary in the post-SWSA 6 PA analysis are generally located much further than $100 \mathrm{~m}$ from most facilities, further lowering the $A_{D}$ values. 


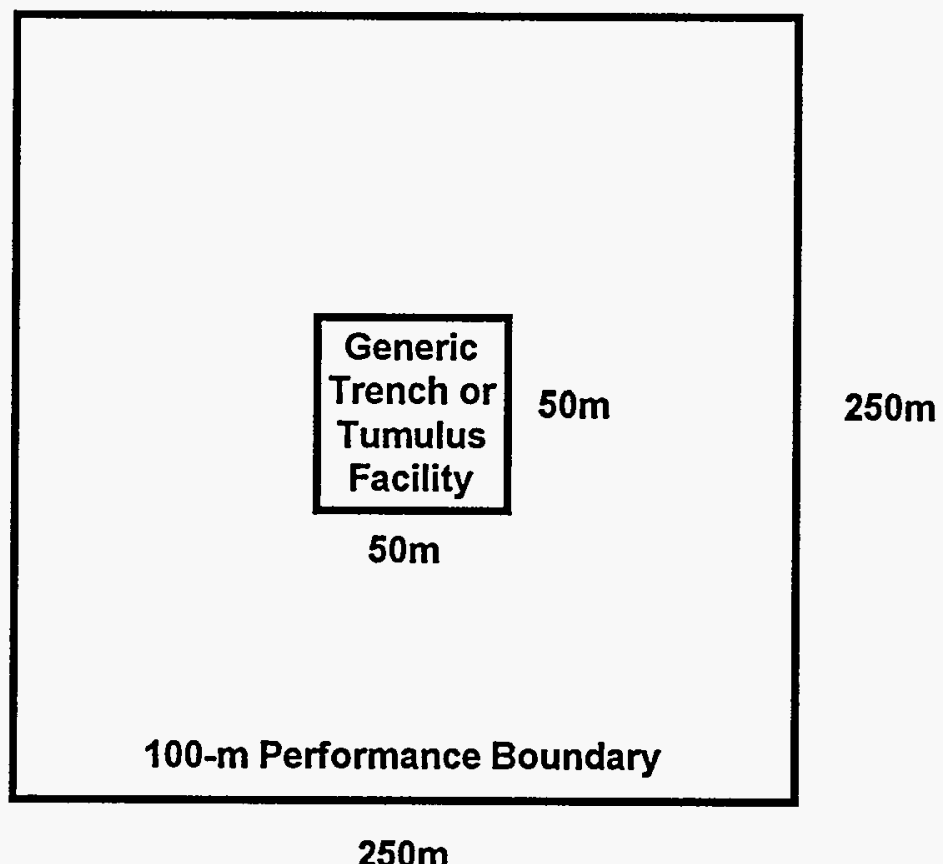

(a) Generic PE disposal facility and performance boundary.

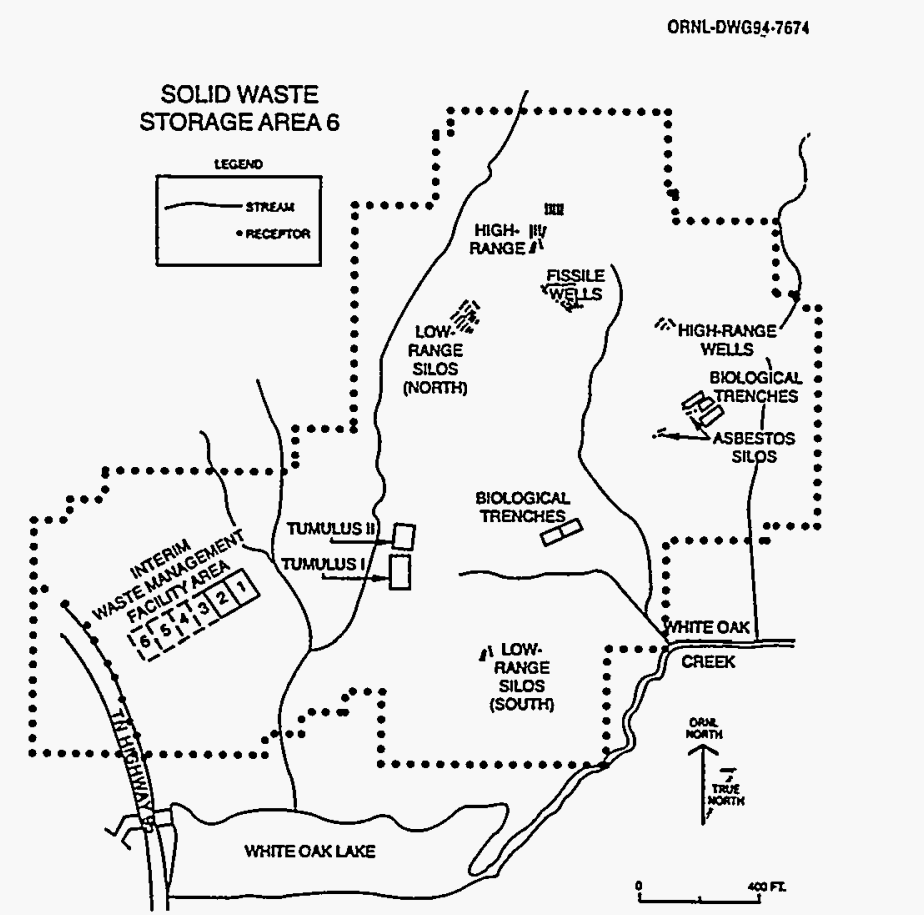

(b) SWSA 6 disposal facilities and performance boundary.

Figure ORR-5. Geometry of the performance boundary for the generic ORR PE disposal facility and the SWSA 6 disposal facilities. 
The difference in the $A_{D}$ values for $\mathrm{H}-3$ and $\mathrm{C}-14$ in the post-SWSA $6 \mathrm{PA}$ analysis is due to the distance to the performance boundary from the disposal facilities containing the principal fraction of these wastes. The Low Range Silos contain approximately $72 \%$ of the C-14 waste at the SWSA 6, which concentrates the emissions from the SWSA 6, resulting in less atmospheric dispersion and a higher $A_{D}$ value. Conversely, the $85 \%$ of the H-3 waste at the SWSA 6 is distributed between the Low Range Silos, High Range Silos, and the IWMF. This wider distribution of emissions sources results in more atmospheric dispersion and a lower $A_{D}$ value.

While the atmospheric analyses of the post-SWSA 6 PA and the ORR PE produce different permissible waste concentrations, the differences are due solely to the geometry of the disposal facilities assumed for the two analyses. The distributed emission sources from the facilities in the post-SWSA 6 PA analysis and the varying distances from the emission sources to the performance boundary provide greater atmospheric dispersion than provided by the simple geometry used in the ORR PE analysis.

\section{A.3.3 INADVERTENT INTRUDER ANALYSIS}

The IWMF at SWSA 6 was selected as the most appropriate basis for comparison of the PE method to published SWSA 6 PA results. The IWMF design is similar to that of the aboveground tumulus as used in this ORR PE. Because the PE methodology for intrusion scenarios (see Volume 2, Appendix D of this report for details) is patterned after that used in the performance assessments for SWSA 6 (ORNL, 1994) and the SRS E-Area Vault (MMES, 1994), agreement between the ORR PE method and the SWSA 6 PA published values is expected to be good.

The SWSA 6 PA assumes that the presence of concrete barriers in the IWMF will preclude the agriculture scenario for $300 \mathrm{y}$ after disposal, and the post-drilling scenario is assumed to occur at $100 \mathrm{y}$ after disposal. For the purposes of comparing SWSA 6 PA and ORR PE results, the ORR PE results were modified to reflect homesteader intrusion at $300 \mathrm{y}$. The ORR $\mathrm{PE}$ post-drilling intrusion scenario remains unchanged at $100 \mathrm{y}$.

The geometry factor, $f_{g}$, is specified in the SWSA 6 PA as 0.4 for the homesteader intrusion scenario and 1.0 for the post-drilling scenario. These values were incorporated into the ORR PE method for comparison.

Tables ORR-11 and ORR-12 show the comparative results of the intrusion scenarios for the IWMF at Oak Ridge. The columns in these two tables labeled "PA Data" contain values extracted directly from the performance assessment for the IWMF. The scenario dose conversion factors (SCDFs) were obtained from Table 4.12 in the SWSA 6 PA (ORNL, 1994) for the agricultural (homesteader) scenario and from Table 4.15 for the post-drilling scenario. The waste limits were also extracted directly from tables in the SWSA 6 PA. Table 4.20 of the SWSA 6 PA was used for the homesteader scenario, and Table 4.23 was used for the post-drilling scenario. The columns in Tables ORR-11 and ORR-12 labeled "PE Method" contain values computed with the ORR PE method as described in Volume 2, Appendix D of this report modified as discussed above. 
Table ORR-11. Intrusion Scenario Dose Conversion Factors (SDCF) for the IWMF at ORR for the SWSA 6 PA and ORR PE

\begin{tabular}{|c|c|c|c|c|c|c|c|c|c|}
\hline \multirow[t]{2}{*}{ Nuclide" } & \multirow[t]{2}{*}{$\begin{array}{c}\text { Half-Life } \\
\text { (y) }\end{array}$} & \multicolumn{3}{|c|}{$\begin{array}{l}\text { Homesteader Scenario } \\
\text { "Undecayed" Dose } \\
\text { Conversion Factor } \\
\text { (rem/y per } \mu \mathrm{Ci} / \mathrm{m}^{3} \text { ) }\end{array}$} & \multirow[t]{2}{*}{$\begin{array}{c}\text { Time of } \\
\text { Intrusion } \\
\text { (y) }\end{array}$} & \multicolumn{3}{|c|}{$\begin{array}{l}\text { Post-Drilling Scenario } \\
\text { "Undecayed" Dose } \\
\text { Conversion Factor } \\
\text { (rem/y per } \mu \mathrm{Ci} / \mathrm{m}^{3} \text { ) }\end{array}$} & \multirow[t]{2}{*}{$\begin{array}{l}\text { Time of } \\
\text { Intrusion } \\
\text { (y) }\end{array}$} \\
\hline & & PA Data & $\begin{array}{c}\text { PE } \\
\text { Method }^{c}\end{array}$ & \begin{tabular}{|c|} 
Ratio \\
PE : PA \\
Value \\
\end{tabular} & & PA Data ${ }^{d}$ & $\begin{array}{c}\text { PE } \\
\text { Method }^{c}\end{array}$ & $\begin{array}{c}\text { Ratio } \\
\text { PE : PA } \\
\text { Value }\end{array}$ & \\
\hline $\mathrm{H}-3$ & $1.23 \mathrm{E}+01$ & $3.9 \mathrm{E}-06$ & 4.0E-06 & 1.01 & 300 & $3.9 \mathrm{E}-07$ & 4.0E-07 & 1.01 & 100 \\
\hline C-14 & $5.73 E+03$ & $1.5 \mathrm{E}-05$ & 1.5E-05 & 1.00 & 300 & $1.5 \mathrm{E}-06$ & 1.5E-06 & 1.00 & 100 \\
\hline Al-26 & $7.30 \mathrm{E}+05$ & 4.9E-03 & $3.8 \mathrm{E}-03$ & 0.78 & 300 & $2.2 E-06$ & 1.8E-06 & 0.83 & 100 \\
\hline $\mathrm{Cl}-36$ & $3.01 E+05$ & $1.2 E-03$ & 1.2E-03 & 0.97 & 300 & 1.2E-04 & $1.2 E-04$ & 0.97 & 100 \\
\hline$K-40$ & $1.28 \mathrm{E}+09$ & $3.4 \mathrm{E}-04$ & $2.9 \mathrm{E}-04$ & 0.84 & 300 & $6.0 \mathrm{E}-06$ & 5.8E-06 & 0.96 & 100 \\
\hline Co-60 & $5.27 \mathrm{E}+00$ & 4.6E-03 & 3.6E-03 & 0.77 & 300 & 2.1E-06 & 1.8E-06 & 0.86 & 100 \\
\hline $\mathrm{Ni}-63$ & $1.00 \mathrm{E}+02$ & $1.8 \mathrm{E}-07$ & 1.9E-07 & 1.08 & 300 & 1.8E-08 & 1.9E-08 & 1.08 & 100 \\
\hline$S r-90+d$ & $2.91 \mathrm{E}+01$ & 1.8E-04 & 2.0E-04 & 1.10 & 300 & $1.8 \mathrm{E}-05$ & 2.0E-05 & 1.10 & 100 \\
\hline Tc-99 & $2.13 E+05$ & 1.1E-05 & 1.2E-05 & 1.10 & 300 & 1.1E-06 & 1.2E-06 & 1.10 & 100 \\
\hline Cd-113m & $1.41 E+01$ & 1.3E-04 & 1.3E-04 & 1.03 & 300 & 1.3E-05 & 1.3E-05 & 1.03 & 100 \\
\hline Cs-137+d & $3.02 E+01$ & 1.0E-03 & 7.6E-04 & 0.76 & 300 & 1.3E-06 & 1.2E-06 & 0.95 & 100 \\
\hline Eu-152 & 1.35E+01 & $2.0 E-03$ & 1.5E-03 & 0.77 & 300 & 9.4E-07 & 7.7E-07 & 0.82 & 100 \\
\hline Eu-154 & $8.59 E+00$ & $2.2 E-03$ & 1.7E-03 & 0.77 & 300 & 1.0E-06 & $8.5 E-07$ & 0.85 & 100 \\
\hline $\mathrm{Pb}-210+\mathrm{d}$ & $2.23 E+01$ & $3.0 \mathrm{E}-04$ & 3.1E-04 & 1.03 & 300 & $3.0 \mathrm{E}-05$ & 3.1E-05 & 1.03 & 100 \\
\hline Ra-226 + d & $1.60 \mathrm{E}+03$ & $3.4 \mathrm{E}-03$ & $2.8 \mathrm{E}-03$ & 0.82 & 300 & 3.3E-05 & 3.4E-05 & 1.03 & 100 \\
\hline Th-229 + d & 7.30E+03 & $5.2 \mathrm{E}-04$ & 4.3E-04 & 0.82 & 300 & $3.0 \mathrm{E}-06$ & 3.0E-06 & 1.01 & 100 \\
\hline Th-230 & $7.54 \mathrm{E}+04$ & 1.1E-05 & 1.1E-05 & 0.99 & 300 & $3.4 E-07$ & 3.5E-07 & 1.02 & 100 \\
\hline Th-232 + d & 1.40E+10 & 4.3E-03 & 3.6E-03 & 0.85 & 300 & $6.2 E-06$ & 6.3E-06 & 1.02 & 100 \\
\hline$U-232+d$ & $7.00 \mathrm{E}+01$ & 2.7E-03 & $2.3 \mathrm{E}-03$ & 0.85 & 300 & 5.7E-06 & 5.7E-06 & 1.00 & 100 \\
\hline U-233 & $1.59 \mathrm{E}+05$ & 1.1E-05 & 1.2E-05 & 1.08 & 300 & $7.5 E-07$ & 8.1E-07 & 1.08 & 100 \\
\hline U-234 & $2.46 \mathrm{E}+05$ & 1.1E-05 & $1.2 \mathrm{E}-05$ & 1.06 & 300 & 7.3E-07 & 7.9E-07 & 1.08 & 100 \\
\hline$U-235+d$ & $7.04 E+08$ & $1.9 \mathrm{E}-04$ & 1.8E-04 & 0.94 & 300 & $7.9 \mathrm{E}-07$ & 8.4E-07 & 1.06 & 100 \\
\hline U-236 & $2.34 \mathrm{E}+07$ & $1.0 \mathrm{E}-05$ & 1.1E-05 & 1.11 & 300 & $6.9 \mathrm{E}-07$ & $7.5 \mathrm{E}-07$ & 1.09 & 100 \\
\hline$U-238+d$ & $4.47 E+09$ & $4.0 E-05$ & 4.0E-05 & 0.99 & 300 & $6.6 \mathrm{E}-07$ & 7.3E-07 & 1.11 & 100 \\
\hline $\mathrm{Np}-237+\mathrm{d}$ & $2.14 E+06$ & $5.8 \mathrm{E}-04$ & 5.3E-04 & 0.91 & 300 & $2.4 E-05$ & 2.7E-05 & 1.13 & 100 \\
\hline Pu-238 & 8.77E+01 & $3.4 \mathrm{E}-05$ & \begin{tabular}{|l|}
$2.9 E-05$ \\
\end{tabular} & 0.86 & 300 & 2.1E-06 & 1.8E-06 & 0.86 & 100 \\
\hline $\mathrm{Pu}-239$ & $2.41 E+04$ & 4.0E-05 & $3.2 \mathrm{E}-05$ & 0.81 & 300 & 2.5E-06 & 2.0E-06 & 0.80 & 100 \\
\hline $\mathrm{Pu}-240$ & $6.56 \mathrm{E}+03$ & 4.0E-05 & 3.2E-05 & 0.81 & 300 & $2.5 E-06$ & 2.0E-06 & 0.80 & 100 \\
\hline $\mathrm{Pu}-242$ & $3.75 \mathrm{E}+05$ & 3.8E-05 & 3.1E-05 & 0.81 & 300 & $2.4 \mathrm{E}-06$ & 1.9E-06 & 0.79 & 100 \\
\hline Am-241 & $4.33 E+02$ & $5.6 \mathrm{E}-05$ & \begin{tabular}{|l|}
$4.7 E-05$ \\
\end{tabular} & 0.84 & 300 & 3.1E-06 & 2.5E-06 & 0.80 & 100 \\
\hline$A m-243+d$ & $7.37 E+03$ & 2.7E-04 & 2.3E-04 & 0.87 & 300 & $3.2 E-06$ & 2.6E-06 & 0.80 & 100 \\
\hline $\mathrm{Cm}-243$ & $2.91 E+01$ & 1.7E-04 & 1.5E-04 & 0.89 & 300 & $1.6 E-06$ & 1.5E-06 & 0.91 & 100 \\
\hline $\mathrm{Cm}-244$ & $1.81 \mathrm{E}+01$ & 2.0E-05 & 1.8E-05 & 0.91 & 300 & 1.3E-06 & 1.1E-06 & 0.86 & 100 \\
\hline Cf-249 & $3.51 \mathrm{E}+02$ & 5.7E-04 & $4.5 E-04$ & 0.79 & 300 & $2.8 E-06$ & 2.8E-06 & 1.01 & 100 \\
\hline
\end{tabular}

a Nuclides analyzed in the intrusion analysis (ORNL, 1994).

VValues taken from Table 4.12 in SWSA 6 PA (ORNL, 1994).

'Values taken from Appendix $D$ of Volume 2 of this report.

- Values taken from Table 4.15 in SWSA 6 PA (ORNL, 1994). 
Table ORR-12. Intrusion Permissible Waste Concentrations $\left(C_{\text {Wr-Int }}\right)$ for the IWMF at ORR for the SWSA 6 PA and ORR PE

\begin{tabular}{|c|c|c|c|c|c|c|c|c|c|c|c|}
\hline \multirow[t]{2}{*}{ Nuclide } & \multirow[t]{2}{*}{$\begin{array}{l}\text { Half-Life } \\
\qquad(y)\end{array}$} & \multicolumn{5}{|c|}{$\begin{array}{l}\text { Homesteader Scenario Waste Limit } \\
\qquad\left(\mu \mathrm{Ci} / \mathrm{m}^{3}\right)\end{array}$} & \multicolumn{5}{|c|}{$\begin{array}{l}\text { Post-Drilling Scenario Waste Limit } \\
\qquad\left(\mu \mathrm{Ci} / \mathrm{m}^{3}\right)\end{array}$} \\
\hline & & PA Data & $\begin{array}{l}\text { Associated } \\
\text { PA Dose } \\
(\mathrm{rem} / \mathrm{y})^{\mathrm{a}}\end{array}$ & $\begin{array}{c}\text { PA Waste } \\
\text { Limit } \\
\text { Prorated } \\
\text { to } 100 \\
\text { mrem/y }\end{array}$ & $\begin{array}{c}\text { Waste } \\
\text { Limit with } \\
\text { PE } \\
\text { Method }^{\text {b }}\end{array}$ & $\begin{array}{l}\text { Ratio } \\
\text { PE:PA } \\
\text { Value }\end{array}$ & PA Data" & $\begin{array}{l}\text { Associated } \\
\text { PA Dose } \\
\text { (rem/y) }^{2}\end{array}$ & $\begin{array}{c}\text { PA Waste } \\
\text { Limit } \\
\text { Prorated } \\
\text { to } 100 \\
\text { rem/y } \\
\end{array}$ & $\begin{array}{c}\text { Waste } \\
\text { Limit with } \\
\text { PE } \\
\text { Method }^{b}\end{array}$ & $\begin{array}{l}\text { Ratio } \\
\text { PE:PA } \\
\text { Value }\end{array}$ \\
\hline C-14 & $5.73 E+03$ & & & & & & 4.1E+04 & $6.2 E-02$ & $6.6 \mathrm{E}+04$ & 6.7E+04 & 1.02 \\
\hline $\mathrm{Cl}-36$ & $3.01 E+05$ & $2.8 \mathrm{E}+03$ & $1.3 E+00$ & $2.2 \mathrm{E}+02$ & $2.1 E+02$ & 0.99 & $2.8 \mathrm{E}+03$ & $3.4 E-01$ & $8.2 E+02$ & $8.6 \mathrm{E}+02$ & 1.04 \\
\hline$S r-90+d$ & $2.91 E+01$ & & & & & & $8.2 E+03$ & $1.3 \mathrm{E}-02$ & $6.3 E+04$ & $5.5 \mathrm{E}+04$ & 0.87 \\
\hline TC-99 & $2.13 E+05$ & $3.9 E+02$ & 2.0E-03 & $2.0 E+04$ & $2.1 \mathrm{E}+04$ & 1.06 & & & & & \\
\hline Cs-137+d & $3.02 E+01$ & $1.4 E+04$ & $6.0 \mathrm{E}-03$ & $2.3 E+05$ & $3.3 \mathrm{E}+05$ & 1.39 & $1.4 E+04$ & $2.0 \mathrm{E}-03$ & $7.0 \mathrm{E}+05$ & 8.1E+05 & 1.15 \\
\hline U-233 & $1.59 E+05$ & $2.4 \mathrm{E}+02$ & 1.0E-03 & $2.4 E+04$ & $1.0 \mathrm{E}+04$ & 0.44 & & & & & \\
\hline$U-238+d$ & 4.47E+09 & 1.5E+02 & 2.0E-03 & $7.5 \mathrm{E}+03$ & $6.3 E+03$ & 0.84 & & & & & \\
\hline Pu-239 & 2.41E+04 & $1.2 E+02$ & $2.0 \mathrm{E}-03$ & $6.0 \mathrm{E}+03$ & $7.8 E+03$ & 1.30 & & & & & \\
\hline
\end{tabular}

- Values taken from Table 4.20 in SWSA 6 PA (ORNL, 1994).

Values taken from Appendix D of Volume 2 of this report. 
The SDCF values presented in Tables 4.12 and 4.15 in the SWSA 6 PA are valid only for the specified parent radionuclides and any progeny in secular equilibrium. The ORR PE values in Table ORR-11 thus presents SDCF data on this same basis: any progeny not in secular equilibrium at the time of intrusion have not been included in the ORR PE SDCF values in Table ORR-11. The waste limits in Table ORR-12 for both the SWSA 6 PA and ORR PE methods were developed by accounting for the parent's radioactive decay as well as ingrowth of any radiologically significant progeny at the time of intrusion.

For the agricultural and post-drilling intrusion scenarios at SWSA 6, Table ORR-11 shows the SWSA 6 PA and ORR PE values for the SDCFs to be in good agreement-all within a factor of two. The slight differences are primarily associated with the ORR PE using EPA dose conversion factors (Eckerman et al., 1988; Eckerman and Ryman, 1993) and the SWSA 6 PA using DOE values (DOE, 1988). These values alone can vary by about $20 \%$.

Agreement between the SWSA 6 PA and ORR PE values for permissible waste concentrations is also good for the agricultural and post-drilling intrusion scenarios. They are also within a factor of two, except for U-233, which is slightly larger.

In summary, the results of intrusion scenarios for the ORR PE match well with the results of the SWSA 6 PA. This good agreement is not unexpected because the PE intrusion scenarios are based largely on the intrusion scenarios developed for the SWSA 6 PA.

\section{A.3.4 REFERENCES}

Eckerman, K. F., A. B. Wohlbarst, and A. C. B. Richardson, 1988. Limiting Values of Radionuclide Intake and Air Concentration and Dose Conversion Factors for Inhalation, Submersion, and Ingestion. Federal Guidance Report No. 11, EPA-520/1-88-020. Washington, DC: U.S. Environmental Protection Agency.

Eckerman, K. F., and J. C. Ryman, 1993. External Exposure to Radionuclides in Air, Water, and Soil. Federal Guidance Report No. 12, EPA 402-R-93-081. Washington, DC: U.S. Environmental Protection Agency.

Lombardi, D.A. and M. L. Socolof, 1994. Atmospheric Pathway Analysis for Potential Emissions of Volatile Radionuclides from Solid Waste Storage Area 6 (SWSA 6). Response to Peer Review Comments of Performance Assessment for Continuing and Future Operations at Solid Waste Storage Area 6, ORNL-6783.

MMES (Martin Marietta Energy Systems, Inc.), EG\&G Idaho, Inc., and Westinghouse Savannah River Company, 1994. Radiological Performance Assessment for the E-Area Vaults Disposal Facility. WSRC-RP-94-218, Rev. 0. Aiken, SC: Westinghouse Savannah River Company.

ORNL (Oak Ridge National Laboratory), 1994. Performance Assessment for Continuing and Future Operations at Solid Waste Storage Area 6. ORNL-6783. Oak Ridge, TN: U.S. Department of Energy, Oak Ridge National Laboratory. 
Appendix A.4: Hanford Site (HAN)

A-HAN-1 


\section{NOMENCLATURE}

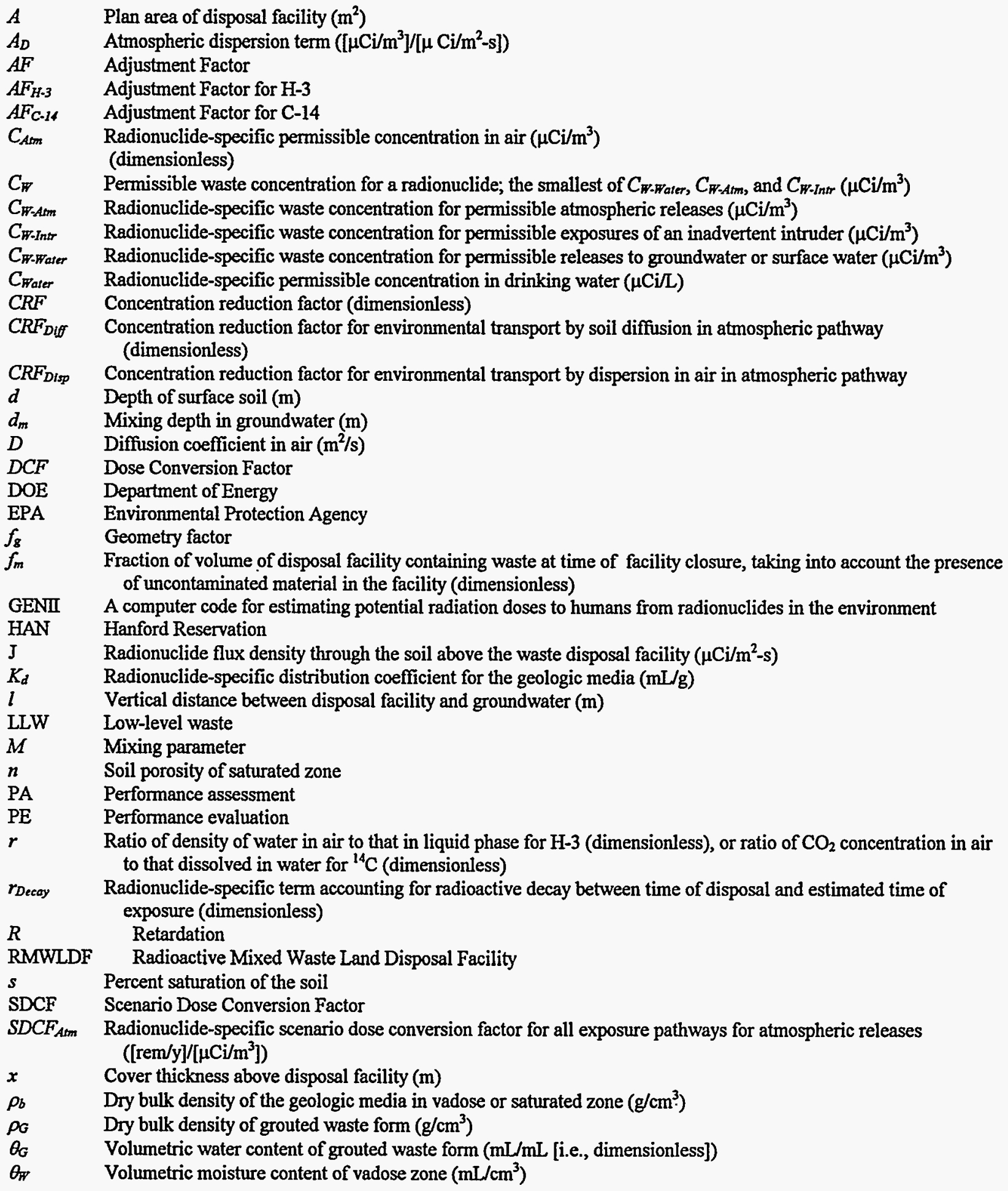




\section{APPENDIX A.4: HANFORD SITE (HS)}

In order to evaluate the applicability of the standard performance evaluation (PE) method to the location of the Radioactive Mixed Waste Land Disposal Facility (RMWLDF) at the Hanford Site, it is appropriate to apply the method to an existing site which has been well studied. The Hanford performance assessment for the 200 West Area Burial Grounds (Wood et al., 1994) considers the release of radionuclides from trenches that were determined to be similar in design to the proposed RMWLDF. The findings of that performance assessment (PA) were used as the basis for comparison of results obtained from implementation of the PE method as documented in Volume 2, Chapter 5 in this report. This appendix discusses the findings of that comparative process (see Section A.4.2) and presents the PE results regarding the permissible waste concentrations for the RMWLDF at Hanford (see Section A.4.3).

\section{A.4.1 OVERVIEW OF THE EXISTING PERFORMANCE ASSESSMENT}

The general type of disposal facility considered in the 200 West Area performance assessment is a shallow, unlined trench of variable width (about 3 to $10 \mathrm{~m}$ ), length (about 50 to $100 \mathrm{~m}$ ), and depth (about 5 to $10 \mathrm{~m}$ ). Waste is typically packaged in containers (drums or boxes) and placed in trenches to within 2 or $3 \mathrm{~m}$ from the surface. Once a trench is filled, a soil cover is placed over the waste.

Two types of disposal facilities are considered in the performance assessment: (1) a Category 1 waste facility, assumed to have no functional barriers and intended to contain very low concentrations and quantities of radionuclides in the inventory and (2) a Category 3 waste facility, assumed to have a cover that controls infiltration to the same degree as the natural soil and vegetation system. One criterion for evaluating two such disposal technologies in the performance assessment is to differentiate those wastes that can be disposed at minimal expense from those wastes that require enhanced isolation at greater cost.

For each type of facility, a set of calculations was completed in the performance assessment to estimate the potential dose to humans resulting from the release of radionuclides from the facility into the surrounding environment. Dose estimates were determined for radionuclide release scenarios that were relevant to the performance objectives stated in DOE Order 5820.2A. A comparison of dose estimates with performance objectives was then used to determine the effectiveness of these facilities in meeting the performance objectives.

The dose calculations in the performance assessment were used to determine with reasonable assurance that compliance with the performance objectives would be satisfied. The calculations were used to develop criteria to ensure that waste accepted for disposal could not result in a potential dose in excess of the performance objectives. The primary waste acceptance criteria are radionuclide-specific concentration limits (in $\mathrm{Ci} / \mathrm{m}^{3}$ ) for isotopes with half-lives greater than $5 \mathrm{y}$ and total activity limits (in $\mathrm{Ci}$ ) for long-lived, environmentally mobile radionuclides. 
The performance assessment employs the following process to calculate a potential dose: (1) identify performance objectives, (2) select radionuclide release scenarios that correspond to each performance objective, (3) quantify a set of parameters controlling radionuclide release and contamination of the environment for each scenario, and (4) estimate the radionuclide-specific doses that can be compared with each performance objective. The performance objectives are interpreted to define two basic types of release scenarios: (1) inadvertent intrusion into the waste and (2) release of radionuclides from the facility by natural phenomena (includes leaching, followed by migration to groundwater).

In the performance assessment, three human activities are considered to potentially result in contact with the buried radioactive waste: (1) construction of a home with a basement, (2) drilling a well for irrigation or drinking water, and (3) farming (i.e., growing crops and raising livestock). Irrigated farming is a major commercial activity in the vicinity of the Hanford Site.

Four intruder scenarios were developed in the performance assessment: two scenarios consider acute exposure and the other two consider chronic exposure. For the Category 1 facility, the performance assessment assumes that all of the intrusion scenarios are credible because the waste could be disposed of at a shallow depth. The scenario that provided the maximum dose was identified as the post-excavation scenario occurring at $100 \mathrm{y}$ after closure of the facility. For the Category 3 facility, an assumed depth of burial greater than $5 \mathrm{~m}$ excludes excavation and post-excavation as a credible means of intrusion. Consequently, the post-drilling scenario-occurring at $500 \mathrm{y}$ after closure —was identified as providing the maximum dose. The GENII code (Version 1.485) is used in the performance assessment to calculate intruder doses; the code includes the contributions of decay products to the calculated dose for the parent.

To address exposures via the groundwater pathway, the performance assessment uses three scenarios:

(1) An all-pathways scenario in which radionuclides are first leached from the disposal facility due to infiltration and then are transported through the vadose zone into the unconfined aquifer. Subsequently, a person drills a well into the aquifer and withdraws contaminated water for drinking, crop irrigation, and livestock watering. Dose is received by direct exposure; inhalation of dust; and ingestion of contaminated crops, water, beef, and milk.

(2) A drinking water scenario in which the movement of radionuclides is identical to that in the all-pathways scenario, but the individual is exposed only by drinking contaminated well water.

(3) A Columbia River scenario in which dose is received in essentially the same manner as in the all-pathways scenario, except that the source of contamination is river water into which contaminated water has discharged from the aquifer. Additional pathways of exposure are immersion (swimming) and eating contaminated fish.

Uranium in a Category 3 facility was found in the performance assessment to be the only radionuclide for which solubility controlled the dose limits. Among the three groundwater 
scenarios considered, the maximum dose relative to the performance objectives occurs for the drinking water scenario.

To complete the discussion of potential exposure pathways, two other means of release are considered in the performance assessment: vapor release and upward diffusion. Vapor release was examined for only three radionuclides: H-3, C-14, and Rn-222. Upward liquid diffusion from the waste facility is considered a possible means of transport for all radionuclides because of the anticipated low recharge rates.

The above analyses for the groundwater pathway, the atmospheric pathway, and the intrusion scenarios yielded waste acceptance criteria (e.g., permissible waste concentrations). The published values for these limits in the performance assessment provide an adequate basis for comparison to the PE method at Hanford.

The final part of the performance assessment analyses was to estimate the potential dose to humans by assuming that the entire projected inventory of LLW at Hanford was ultimately disposed of in the 200 West Area burial grounds. A total inventory was estimated, and doses were forecast based upon the disposed inventory. The performance assessment found that all performance objectives could be satisfied.

\section{A.4.2 COMPARISON OF THE PE METHODOLOGY WITH THE 200 WEST AREA PERFORMANCE ASSESSMENT}

\section{A.4.2.1 Water Pathway}

The performance assessment employs the simple concept that, for exposure at a groundwater well, it is not the concentration of the waste in the facility which is important, but rather the total inventory directly upstream of the well. This idea suggests that an appropriate analysis could simply consider a vertical slice of unit width through the waste and subsurface. The performance assessment uses this approach, with a two-dimensional application of the VAM3D-CG model in a vertical plane, including a trench of unit width with a unit activity of waste, and a slab of the subsurface below the trench and extending to the compliance well. The performance assessment demonstrates that the concentration in the well is insensitive to trench length as long as the same unit inventory is maintained. Other sensitivity analyses were performed as part of the performance assessment to study dependence on recharge, $K_{d}$ values for the natural media, and other factors. The PE comparison was done for the base case, with a $20 \mathrm{~m}$ trench, a recharge of $0.05 \mathrm{~m} / \mathrm{y}$, and subsurface medium $K_{d}$ values of $0,1,10$, and 100, which correspond to the performance assessment simulations $1 \mathrm{a}, 1 \mathrm{~b}, 1 \mathrm{c}$, and $1 \mathrm{k}$, respectively. All waste $K_{d}$ values are assumed to be zero (Wood, 1994). The unit inventory of waste was presumed to be uniformly distributed throughout the trench, and release is presumed to begin at the time of closure. Other values used in the analysis are reported in Table HAN-1. Forty three of the radionuclides included in the PE were addressed in the 200 West Area performance assessment-though only eight of these were deemed to be of concern-providing a basis for comparison between the PE and performance assessment methods. 
Table HAN-1. Parameters and Values Used in the PE Analysis for the 200 West Area Burial Grounds

\begin{tabular}{|c|c|c|}
\hline Parameter & Value & Comments \\
\hline \multicolumn{3}{|l|}{ SOURCE TERM } \\
\hline Initial waste concentration & $\begin{array}{l}11,111 \\
\mu \mathrm{Ci} / \mathrm{m}^{3}\end{array}$ & $\begin{array}{l}\text { A concentration of } 1 \mathrm{Ci} \text { is uniformly distributed in a } \\
\text { trench measuring } 1 \mathrm{~m} \text { wide } \times 20 \mathrm{~m} \text { long } \times 4.5 \mathrm{~m} \\
\text { deep }\left(90 \mathrm{~m}^{3}\right)\end{array}$ \\
\hline $\begin{array}{l}\text { Waste volumetric water } \\
\text { content }\end{array}$ & 0.13 & Wood et al., 1994 \\
\hline Waste bulk density & $1.5 \mathrm{~g} / \mathrm{mL}$ & Wood et al., 1994 \\
\hline Facility length & $20 \mathrm{~m}$ & Wood et al., 1994 \\
\hline Facility width & $1 \mathrm{~m}$ & Wood et al., 1994 \\
\hline Waste area & $20 \mathrm{~m}^{2}$ & $20 \mathrm{~m} \times 1 \mathrm{~m}$ \\
\hline Waste mixing fraction & 1 & None assumed \\
\hline $\begin{array}{l}\text { Annual rate of water flowing } \\
\text { through intact facility }\end{array}$ & $0.05 \mathrm{~m} / \mathrm{y}$ & Wood et al., 1994 \\
\hline $\begin{array}{l}\text { Time to failure of leachate } \\
\text { collection system }\end{array}$ & oy & Wood et al., 1994 \\
\hline Time to failure of facility & $0 y$ & Wood et al., 1994 \\
\hline \multicolumn{3}{|l|}{ UNSATURATED ZONE } \\
\hline Volumetric water content & 0.09 & $\begin{array}{l}\text { Selected by staff as representative of the } \\
\text { unsaturated zone, and used to calibrate subsurface } \\
\text { travel times to the performance assessment; } \\
\text { confirmed by Wood (1995) }\end{array}$ \\
\hline Bulk density & $1.5 \mathrm{~g} / \mathrm{mL}$ & $\begin{array}{l}\text { Selected by staff as representative of the } \\
\text { unsaturated zone, and used to calibrate subsurface } \\
\text { travel times to the performance assessment; } \\
\text { confirmed by Wood (1995) }\end{array}$ \\
\hline $\begin{array}{l}\text { Unsaturated zone thickness } \\
\text { below facility }\end{array}$ & $65 \mathrm{~m}$ & $\begin{array}{l}\text { Cumulative unsaturated sediment thickness is } \\
72 \mathrm{~m} \text { (Wood et al., 1994) and trench bottom is } 7 \mathrm{~m} \\
\text { below ground surface. }\end{array}$ \\
\hline $\begin{array}{l}\text { Natural recharge through local } \\
\text { soils }\end{array}$ & $0.05 \mathrm{~m} / \mathrm{y}$ & Wood et al., 1994 \\
\hline \multicolumn{3}{|l|}{ SATURATED ZONE } \\
\hline Aquifer porosity & 0.31 & Wood et al., 1994 \\
\hline Bulk density & $1.6 \mathrm{~g} / \mathrm{mL}$ & Wood et al., 1994 \\
\hline Mixing depth & $5 \mathrm{~m}$ & Khaleel (1994) \\
\hline Darcy velocity & $22 \mathrm{~m} / \mathrm{y}$ & Khaleel (1994) \\
\hline $\begin{array}{l}\text { Distance to performance } \\
\text { boundary from facility } \\
\text { boundary }\end{array}$ & $100 \mathrm{~m}$ & $\begin{array}{l}\text { Wood et al., 1994; same as for standard PE } \\
\text { method }\end{array}$ \\
\hline
\end{tabular}

\section{A-HAN-6}


The performance assessment transport calculations were performed for various cases in which radionuclides were grouped by $K_{d}$ value. The list of PE radionuclides can be matched to these cases based on the $K_{d}$ values listed in Table HAN-2, using the elements listed in Table 3-5 of the 200 West Area performance assessment, with additional values supplied by site technical personnel (Wood, 1994).

Table HAN-2. Radionuclide Groupings by $K_{d}$ Value

\begin{tabular}{|l|c|l|l|}
\hline $\begin{array}{c}\text { PA Simulation } \\
\text { Case } \\
\text { (Run Number) }\end{array}$ & $\begin{array}{c}\text { Subsurface } \\
K_{d}\end{array}$ & $\begin{array}{c}\text { Elements Listed in the } \\
\text { Hanford Performance } \\
\text { Assessment } \\
\text { (Wood et al.,1994, Table 3-5) }\end{array}$ & $\begin{array}{c}\text { Additional Elements Not in } \\
\text { the Hanford Performance } \\
\text { Assessment }\end{array}$ \\
\hline $1 a, 2 a, \ldots$ & 0 & $\mathrm{C}, \mathrm{I}, \mathrm{Mo}, \mathrm{Re}, \mathrm{Se}, \mathrm{Tc}, \mathrm{U}, \mathrm{H}$ & $\mathrm{Cl}$ \\
\hline $1 \mathrm{~b}, 2 \mathrm{~b}, \ldots$ & 1 & $\mathrm{Ba}, \mathrm{Cd}, \mathrm{Co}, \mathrm{Cs}, \mathrm{Pa}, \mathrm{Sr}$ & $\mathrm{r}$ \\
\hline $1 \mathrm{c}, 2 \mathrm{c}, \ldots$ & 10 & $\mathrm{Ac}, \mathrm{Eu}, \mathrm{K}, \mathrm{Np}, \mathrm{Pd}, \mathrm{Ra}$ & $\mathrm{Al}, \mathrm{Si}, \mathrm{Ag}$ \\
\hline $1 \mathrm{k}, 2 \mathrm{k}, \ldots$ & 100 & $\begin{array}{l}\text { Am, Cm, Gd, Nb, Ni, Pu, } \\
\mathrm{Sm}, \mathrm{Sn}, \mathrm{Th}, \mathrm{Zr}\end{array}$ & $\mathrm{Pb}, \mathrm{Cf}$ \\
\hline
\end{tabular}

Several radionuclides were deemed in the performance assessment to be of no concern for the water pathway for a variety of reasons. Those which have a large decay factor (have gone through a large number of half-lives) include Co-60, Ni-63, Sr-90, Nb-93m, Cd-113m, Sn-121, Ba-133, Cs-137, Sm-151, Eu-152, Eu-154, Ra-228, Pu-241, Ac-227, Pu-238, Am-241, Cm-242, $\mathrm{Cm}-243$, and $\mathrm{Cm}-244$. The following elements were dismissed from further analysis due to their high $K_{d}$ values: $\mathrm{Nb}, \mathrm{K}, \mathrm{Sm}, \mathrm{Ra}, \mathrm{Pu}, \mathrm{Am}, \mathrm{Cm}, \mathrm{Sn}, \mathrm{Zr}, \mathrm{Cs}$, and $\mathrm{Th}$. Although $\mathrm{Np}-237, \mathrm{~Pa}-231$, and Po-209 were also deemed to be of no concern, they do have reported values in the table of inventory limits (see Wood et al., 1994, Table 4-25). The remaining radionuclides of concern are C-14, Cl-36, H-3, Se-79, Mo-93, Tc-99, I-129, Re-187, and U-x (Wood et al., 1994). Of these, the performance evaluation does not examine Mo-93 and Re-187, leaving only C-14, Cl-36, H-3, Se-79, Tc-99, and I-129 for comparison with the PE methodology. The isotopes of uranium were modeled in the PA as solubility limited in an analysis that is beyond the scope of the PE.

The PE method as applied at Hanford involves two modifications to enable it to capture the site-specific behavior more accurately. The standard performance evaluation methodology (as discussed in Volume 2, Chapter 5 of this report) does not account for dispersion or dilution in the unsaturated zone, and hence always results in a concentration reduction factor of 1 between the leachate and the water table. The 200 West Area performance assessment does employ these processes and shows a roughly tenfold reduction in concentration between the leachate and the waters just above the water table (Wood et al., 1994, p. 4-28). This effect is attributed to lateral dispersion and dilution with regionally infiltrating waters (Khaleel, 1995) and so is adopted as a site-specific enhancement to the standard PE method. This modification is implemented by substituting the performance assessment's leachate-to-recharge CRF (equal to 11) for the PE's value of 1 . 
A second modification to the PE method is required to capture the differences resulting from the standard PE's assumed continuous source as compared to the 200 West Area performance assessment's short term pulse. Since the performance assessment assigns a $K_{d}=0$ to all radionuclides in the waste form, the peak release occurs as the finite inventory escapes from the degrading facility (Wood et al., 1994, Figure 4-4). This is nearly a pulse input into the subsurface transport regime where the PE's continuous input will eventually produce concentrations at the compliance well which are the same for all values of $K_{d}$ (and retardation $R$ ); an instantaneous input will produce lesser concentrations by a factor of $R$. Reducing the standard PE's peak concentrations at the well by the $R$ for each radionuclide mimics the behavior of the pulse input used in the performance assessment.

The combined effects of using the performance assessment's leachate-to-recharge CRF and a $1 / R$ source characterization correction enables the $P E$ method to capture the behavior of the 200 West Area Burial Grounds as exhibited in the performance assessment. A comparison of the results between the PA for the 200 West Area Burial Grounds and the modified PE method is shown in Table HAN-3.

A comparison of travel times is presented in Table HAN-4, which shows the PE to be well calibrated in terms of groundwater hydraulics. This level of agreement was achieved by adjusting the unsaturated zone bulk density and volumetric water content within acceptable ranges, a process necessitated by the PE's assumption of uniform material properties for the unsaturated zone.

\section{A.4.2.2 Atmospheric Pathway}

The PE method has been applied to the 200 West Area Burial Grounds to compare the PE atmospheric analysis methodology against the performance assessment findings. Only the two volatile radionuclides, $\mathrm{H}-3$ and $\mathrm{C}-14$, were subjected to atmospheric pathway analyses as part of the $\mathrm{PE}$ methodology. A performance objective of $10 \mathrm{mrem} / \mathrm{y}$ from all pathways was incorporated into the analyses.

Table HAN-5 shows the input for the PE methodology relevant to the comparison of the performance assessment findings for the 200 West Area Burial Grounds. The meteorological data unique to the Hanford Site were obtained from hourly average meteorological readings taken at a height of $10 \mathrm{~m}$ at the meteorological tower in the 200 Area at Hanford for the period 1983 to 1991. These data were used to determine the $M$ and $A_{D}$ values, and thus the CRFs, for mixing and atmospheric dispersion of the radionuclides, once they reached the surface by diffusion.

The total waste area of the 200 West Area Burial Grounds is $100,000 \mathrm{~m}^{2}$ compared to the $20,000 \mathrm{~m}^{2}$ area of the proposed RMWLDF. The waste area is used in calculating the $M$ and $A_{D}$ values shown in Table HAN-5. The other parameters and values used in this comparative analysis are the same as those used to determine CRFs for the proposed RMWLDF. 
Table HAN-3. Comparison of the Results from the Modified PE Method with the Performance Assessment (PA) Findings for the Groundwater Pathway at Hanford (Part 1 of 2)

\begin{tabular}{|c|c|c|c|c|c|c|c|}
\hline \multirow[t]{2}{*}{ Nuclide } & \multirow[t]{2}{*}{$\begin{array}{c}\text { Run } \\
\text { Number }\end{array}$} & \multicolumn{2}{|c|}{$\begin{array}{l}\text { Total CRF } \\
\text { (no decay) }\end{array}$} & \multicolumn{2}{|c|}{$\begin{array}{l}\text { Arrival Time } \\
\text { (y) }\end{array}$} & \multicolumn{2}{|c|}{$\begin{array}{c}\text { Permissible Waste } \\
\text { Concentration, } c_{\text {w-Water }} \\
\left(\mu \mathrm{Ci} / \mathrm{m}^{3}\right)\end{array}$} \\
\hline & & $\overline{P A}$ & PE 2 & PA & PE 2 & PA & PE 2 \\
\hline $\mathrm{H}-3$ & $1 a$ & 1.4E+2 & $1.9 E+2$ & 1.2E+2 & 1.2E+2 & 1.2E+7 & $1.3 \mathrm{E}+7$ \\
\hline C-14 & $1 a$ & 1.4E+2 & $1.9 E+2$ & $1.2 E+2$ & $1.2 E+2$ & $3.7 E+2$ & $5.0 \mathrm{E}+2$ \\
\hline Al-26 & $1 c$ & $2.2 E+4$ & $3.2 \mathrm{E}+4$ & $1.9 \mathrm{E}+4$ & $2.0 \mathrm{E}+4$ & & $1.2 E+4$ \\
\hline Si-32 & $1 c$ & $2.2 E+4$ & $3.2 \mathrm{E}+4$ & $1.9 E+4$ & $2.0 E+4$ & & no limit \\
\hline Cl-36 & $1 a$ & $1.4 E+2$ & $1.9 \mathrm{E}+2$ & $1.2 E+2$ & $1.2 E+2$ & $2.6 E+2$ & $3.4 \mathrm{E}+2$ \\
\hline $\mathrm{K}-40$ & $1 \mathrm{c}$ & $2.2 E+4$ & $3.2 E+4$ & $1.9 \mathrm{E}+4$ & $2.0 \mathrm{E}+4$ & no limit & $9.3 \mathrm{E}+3$ \\
\hline Co-60 & $1 \mathrm{~b}$ & $2.3 E+3$ & $3.3 E+3$ & $2.0 \mathrm{E}+3$ & 2.1E+3 & no limit & no limit \\
\hline $\mathrm{Ni}-59$ & $1 \mathrm{k}$ & $2.2 \mathrm{E}+5$ & $3.1 \mathrm{E}+5$ & $1.9 \mathrm{E}+5$ & $2.0 \mathrm{E}+5$ & & $4.9 E+7$ \\
\hline Ni-63 & $1 k$ & $2.2 E+5$ & $3.1 E+5$ & $1.9 E+5$ & $2.0 E+5$ & no limit & no limit \\
\hline Se-79 & $1 a$ & $1.4 \mathrm{E}+2$ & $1.9 E+2$ & 1.2E+2 & $1.2 E+2$ & $9.4 \mathrm{E}+1$ & $1.2 E+2$ \\
\hline Sr-90 & $1 b$ & $2.3 E+3$ & $3.3 E+3$ & $2.0 \mathrm{E}+3$ & $2.1 E+3$ & no limit & $3.5 \mathrm{E}+23$ \\
\hline Zr-93 & $1 k$ & $2.2 E+5$ & $3.1 \mathrm{E}+5$ & $1.9 \mathrm{E}+5$ & $2.0 \mathrm{E}+5$ & no limit & $8.6 E+5$ \\
\hline $\mathrm{Nb}-93 \mathrm{~m}$ & $1 k$ & $2.2 E+5$ & $3.1 E+5$ & $1.9 E+5$ & $2.0 E+5$ & no limit & no limit \\
\hline $\mathrm{Nb}-94$ & $1 k$ & $2.2 E+5$ & $3.1 E+5$ & $1.9 E+5$ & $2.0 \mathrm{E}+5$ & no limit & $2.1 E+8$ \\
\hline TC-99 & $1 \mathrm{a}$ & $1.4 \mathrm{E}+2$ & $1.9 E+2$ & $1.2 \mathrm{E}+2$ & 1.2E+2 & $5.9 E+2$ & $7.1 \mathrm{E}+2$ \\
\hline Pd-107 & $1 c$ & $2.2 E+4$ & $3.2 E+4$ & $1.9 \mathrm{E}+4$ & $2.0 \mathrm{E}+4$ & & $1.2 E+6$ \\
\hline $\mathrm{Ag}-108 \mathrm{~m}$ & $1 c$ & $2.2 E+4$ & $3.2 \mathrm{E}+4$ & $1.9 \mathrm{E}+4$ & $2.0 \mathrm{E}+4$ & & $9.0 \mathrm{E}+49$ \\
\hline $\mathrm{Cd}-113 \mathrm{~m}$ & $1 k$ & $2.2 E+5$ & $3.1 \mathrm{E}+5$ & $1.9 E+5$ & $2.0 E+5$ & no limit & no limit \\
\hline Sn-121m & $1 \mathrm{k}$ & $2.2 E+5$ & $3.1 E+5$ & $1.9 \mathrm{E}+5$ & $2.0 \mathrm{E}+5$ & no limit & no limit \\
\hline Sn-126 & $1 k$ & $2.2 E+5$ & $3.1 \mathrm{E}+5$ & $1.9 E+5$ & $2.0 \mathrm{E}+5$ & no limit & $3.2 E+5$ \\
\hline $1-129$ & $1 a$ & $1.4 \mathrm{E}+2$ & $1.9 E+2$ & 1.2E+2 & $1.2 \mathrm{E}+2$ & $2.8 E+0$ & $3.7 E+0$ \\
\hline Cs-135 & $1 b$ & $2.3 E+3$ & $3.3 E+3$ & $2.0 \mathrm{E}+3$ & $2.1 E+3$ & no limit & $2.6 \mathrm{E}+3$ \\
\hline Cs-137 & $1 b$ & $2.3 E+3$ & $3.3 E+3$ & $2.0 \mathrm{E}+3$ & $2.1 E+3$ & no limit & $1.9 E+23$ \\
\hline Ba-133 & $1 b$ & $2.3 E+3$ & $3.3 E+3$ & $2.0 E+3$ & $2.1 E+3$ & no limit & no limit \\
\hline Sm-151 & $1 \mathrm{k}$ & $2.2 \mathrm{E}+5$ & $3.1 E+5$ & $1.9 E+5$ & $2.0 E+5$ & no limit & no limit \\
\hline Eu-152 & $1 c$ & $2.2 E+4$ & $3.2 E+4$ & $1.9 \mathrm{E}+4$ & $2.0 \mathrm{E}+4$ & no limit & no limit \\
\hline Eu-154 & $1 c$ & $2.2 E+4$ & $3.2 E+4$ & $1.9 E+4$ & $2.0 E+4$ & no limit & no limit \\
\hline $\mathrm{Pb}-210$ & $1 \mathrm{k}$ & $2.2 E+5$ & $3.1 E+5$ & $1.9 E+5$ & $2.0 \mathrm{E}+5$ & & no limit \\
\hline Ra-226 & $1 c$ & $2.2 \mathrm{E}+4$ & $3.2 E+4$ & $1.9 \mathrm{E}+4$ & $2.0 \mathrm{E}+4$ & no limit & 1.0E+5 \\
\hline Ra-228 & $1 c$ & $2.2 E+4$ & $3.2 E+4$ & $1.9 \mathrm{E}+4$ & $2.0 E+4$ & no limit & no limit \\
\hline Th-229 & $1 k$ & $2.2 \mathrm{E}+5$ & $3.1 E+5$ & $1.9 E+5$ & $2.0 \mathrm{E}+5$ & no limit & $5.1 E+10$ \\
\hline Th-230 & $1 \mathrm{k}$ & $2.2 E+5$ & $3.1 \mathrm{E}+5$ & $1.9 E+5$ & $2.0 \mathrm{E}+5$ & no limit & $2.0 E+2$ \\
\hline Th-232 & $1 \mathrm{k}$ & $2.2 E+5$ & $3.1 E+5$ & $1.9 E+5$ & $2.0 \mathrm{E}+5$ & no limit & $3.5 \mathrm{E}+2$ \\
\hline $\mathrm{Pa} a-231$ & $1 b$ & $2.3 E+3$ & $3.3 E+3$ & $2.0 E+3$ & $2.1 E+3$ & $1.1 E+0$ & $7.5 \mathrm{E}-1$ \\
\hline
\end{tabular}


Table HAN-3. Comparison of the Results from the Modified PE Method with the Performance Assessment (PA) Findings for the Groundwater Pathway at Hanford (Part 2 of 2)

\begin{tabular}{|c|c|c|c|c|c|c|c|}
\hline \multirow[t]{2}{*}{ Nuclide } & \multirow[t]{2}{*}{$\begin{array}{c}\text { Run } \\
\text { Number }\end{array}$} & \multicolumn{2}{|c|}{$\begin{array}{l}\text { Total CRF } \\
\text { (no decay) }\end{array}$} & \multicolumn{2}{|c|}{$\begin{array}{c}\text { Arrival Time } \\
\text { (y) }\end{array}$} & \multicolumn{2}{|c|}{$\begin{array}{c}\text { Permissible Waste } \\
\text { Concentration, } C_{\text {w-Water }} \\
\left(\mu \mathrm{Ci} / \mathrm{m}^{2}\right)\end{array}$} \\
\hline & & PA & PE 2 & PA & PE 2 & PA & PE 2 \\
\hline Np-237 & $1 c$ & $2.2 E+4$ & $3.2 E+4$ & 1.9E+4 & $2.0 \mathrm{E}+4$ & 3.1E+1 & $3.9 \mathrm{E}+1$ \\
\hline Pu-238 & $1 \mathrm{k}$ & $2.2 \mathrm{E}+5$ & $3.1 \mathrm{E}+5$ & $1.9 E+5$ & $2.0 E+5$ & no limit & 1.0E+4 \\
\hline Pu-239 & $1 \mathrm{k}$ & $2.2 \mathrm{E}+5$ & 3.1E+5 & $1.9 \mathrm{E}+5$ & $2.0 E+5$ & no limit & $1.4 E+5$ \\
\hline Pu-240 & $1 \mathrm{k}$ & $2.2 E+5$ & $3.1 E+5$ & $1.9 E+5$ & $2.0 \mathrm{E}+5$ & no limit & $4.7 E+11$ \\
\hline Pu-241 & $1 \mathrm{k}$ & $2.2 E+5$ & $3.1 E+5$ & $1.9 E+5$ & $2.0 E+5$ & no limit & $5.8 E+6$ \\
\hline Pu-242 & $1 \mathrm{k}$ & $2.2 E+5$ & $3.1 \mathrm{E}+5$ & $1.9 \mathrm{E}+5$ & $2.0 \mathrm{E}+5$ & no limit & $7.4 \mathrm{E}+2$ \\
\hline Pu-244 & $1 \mathrm{k}$ & $2.2 E+5$ & $3.1 E+5$ & $1.9 \mathrm{E}+5$ & $2.0 \mathrm{E}+5$ & no limit & $3.1 E+2$ \\
\hline Am-241 & $1 \mathrm{k}$ & $2.2 E+5$ & $3.1 \mathrm{E}+5$ & $1.9 E+5$ & $2.0 \mathrm{E}+5$ & no limit & $1.9 \mathrm{E}+5$ \\
\hline Am-243 & $1 \mathrm{k}$ & $2.2 E+5$ & $3.1 \mathrm{E}+5$ & $1.9 \mathrm{E}+5$ & $2.0 \mathrm{E}+5$ & no limit & $4.7 E+10$ \\
\hline $\mathrm{Cm}-243$ & $1 \mathrm{k}$ & $2.2 E+5$ & $3.1 E+5$ & $1.9 E+5$ & $2.0 E+5$ & no limit & $1.1 \mathrm{E}+8$ \\
\hline $\mathrm{Cm}-244$ & $1 \mathrm{k}$ & $2.2 E+5$ & $3.1 E+5$ & $1.9 E+5$ & $2.0 \mathrm{E}+5$ & no limit & 1.7E+14 \\
\hline Cm-245 & $1 k$ & $2.2 E+5$ & $3.1 \mathrm{E}+5$ & $1.9 E+5$ & $2.0 \mathrm{E}+5$ & no limit & $2.8 \mathrm{E}+2$ \\
\hline $\mathrm{Cm}-246$ & $1 k$ & $2.2 \mathrm{E}+5$ & $3.1 \mathrm{E}+5$ & $1.9 \mathrm{E}+5$ & $2.0 \mathrm{E}+5$ & no limit & 1.1E+15 \\
\hline $\mathrm{Cm}-247$ & $1 \mathrm{k}$ & $2.2 E+5$ & $3.1 E+5$ & $1.9 E+5$ & $2.0 \mathrm{E}+5$ & no limit & $2.9 \mathrm{E}+2$ \\
\hline Cm-248 & $1 \mathrm{k}$ & $2.2 \mathrm{E}+5$ & $3.1 E+5$ & $1.9 E+5$ & $2.0 E+5$ & no limit & $1.9 \mathrm{E}+2$ \\
\hline Cf-249 & $1 \mathrm{k}$ & $2.2 E+5$ & $3.1 \mathrm{E}+5$ & $1.9 \mathrm{E}+5$ & $2.0 \mathrm{E}+5$ & & $6.7 E+3$ \\
\hline Cf-250 & $1 \mathrm{k}$ & $2.2 \mathrm{E}+5$ & $3.1 E+5$ & $1.9 E+5$ & $2.0 E+5$ & & $4.1 E+17$ \\
\hline Cf-251 & $1 \mathrm{k}$ & $2.2 \mathrm{E}+5$ & $3.1 E+5$ & $1.9 \mathrm{E}+5$ & $2.0 \mathrm{E}+5$ & & no limit \\
\hline
\end{tabular}

Table HAN-4. Comparison of Performance Assessment (PA) and PE Travel Times for the Hanford 200 West Area

\begin{tabular}{|c|c|c|c|c|}
\hline $\begin{array}{c}\text { Run } \\
\text { Number }\end{array}$ & $\begin{array}{c}\text { Recharge } \\
(\mathrm{m} / \mathrm{y})\end{array}$ & $\begin{array}{c}K_{\boldsymbol{d}} \\
(\mathrm{mL} / \mathrm{g})\end{array}$ & $\begin{array}{c}\text { PA Time to Peak } \\
\text { at Well } \\
(\mathrm{y})\end{array}$ & $\begin{array}{c}\text { PE Time to Peak } \\
\text { at Well } \\
(\mathrm{y})\end{array}$ \\
\hline $1 \mathrm{a}$ & 0.05 & 0 & 123 & 120 \\
\hline $1 \mathrm{~b}$ & 0.05 & 1 & 2,030 & 2,080 \\
\hline $1 \mathrm{c}$ & 0.05 & 10 & 19,350 & 19,700 \\
\hline $1 \mathbf{k}$ & 0.05 & 100 & 190,000 & 196,000 \\
\hline $2 \mathrm{a}$ & 0.005 & 0 & 995 & 1,040 \\
\hline $2 \mathrm{~b}$ & 0.005 & 1 & 20,100 & 20,500 \\
\hline $2 \mathrm{c}$ & 0.005 & 10 & 190,300 & 196,000 \\
\hline $2 k$ & 0.005 & 100 & $1,870,000$ & $1,950,000$ \\
\hline
\end{tabular}


Table HAN-5. Parameters and Values Used in the PE Method for the Atmospheric Pathway for the Hanford Site 200 West Area Burial Grounds (standard PE method values are discussed in Volume 2, Chapter 5 of this report)

\begin{tabular}{|c|c|c|}
\hline Parameter & Value & Comments \\
\hline $\begin{array}{l}\text { Soil thickness above the disposal } \\
\text { facility, } x\end{array}$ & $3.0 \mathrm{~m}$ & Value is site-specific (Wood et al., 1994) \\
\hline Depth of the soil surface, $d$ & $0.01 \mathrm{~m}$ & $\begin{array}{l}\text { Standard PE method; value is generic } \\
\text { and not site-specific }\end{array}$ \\
\hline Void space in the soil, $n$ & 0.5 & Value is site-specific (Wood et al., 1994) \\
\hline $\begin{array}{l}\text { Moisture content in the soil void } \\
\text { space, } s\end{array}$ & 0.14 & Value is site-specific (Wood et al., 1994) \\
\hline $\begin{array}{l}\text { Ratio of the density of water in air } \\
\text { to that in the liquid phase for } \mathrm{H}-3, r\end{array}$ & $9.20 \mathrm{E}-6$ & $\begin{array}{l}\text { Standard PE method; value is generic } \\
\text { and not site-specific }\end{array}$ \\
\hline $\begin{array}{l}\text { Ratio of the } \mathrm{CO}_{2} \text { concentration in } \\
\text { air to that in dissolved water for } \\
\mathrm{C}-14, r\end{array}$ & $4.25 E-4$ & $\begin{array}{l}\text { Standard PE method; value is generic } \\
\text { and not site-specific }\end{array}$ \\
\hline $\begin{array}{l}\text { Diffusion coefficient in air for } \mathrm{H}-3 \text {, } \\
D\end{array}$ & $\begin{array}{c}2.39 \mathrm{E}-5 \\
\mathrm{~m}^{2} / \mathrm{s}\end{array}$ & $\begin{array}{l}\text { Standard PE method; value is generic } \\
\text { and not site-specific }\end{array}$ \\
\hline $\begin{array}{l}\text { Diffusion coefficient in air for } C-14 \text {, } \\
D\end{array}$ & $\begin{array}{c}1.40 \mathrm{E}-5 \\
\mathrm{~m}^{2} / \mathrm{s}\end{array}$ & $\begin{array}{l}\text { Standard PE method; value is generic } \\
\text { and not site-specific }\end{array}$ \\
\hline Mixing parameter, $\boldsymbol{M}$ & 12.7 & $\begin{array}{l}\text { Value is site-specific and calculated } \\
\text { using the ISCLT2 air dispersion model. } \\
\text { Important model input parameters were } \\
\text { the surface area of the } 200 \text { West Burial } \\
\text { Grounds equal to } 100,000 \mathrm{~m}^{2} \text { and site- } \\
\text { specific meteorological data (see } \\
\text { Chapter } 16.3 .2 \text { in this volume) }\end{array}$ \\
\hline $\begin{array}{l}\text { Atmospheric dispersion parameter, } \\
A_{D}\end{array}$ & 5.07 & $\begin{array}{l}\text { Value is site-specific and calculated } \\
\text { using the ISCLT2 air dispersion model. } \\
\text { Important model input parameters were } \\
\text { the surface area of the } 200 \text { West Burial } \\
\text { Grounds equal to } 100,000 \mathrm{~m}^{2} \text { and site- } \\
\text { specific meteorological data (see } \\
\text { Chapter } 16.3 .2 \text { in this volume) }\end{array}$ \\
\hline $\begin{array}{l}\text { Atmospheric Scenario Dose } \\
\text { Conversion Factor for } \mathrm{H}-3, S D C F\end{array}$ & $\begin{array}{c}\text { 8.33E+2 } \\
\mathrm{mrem} / \mathrm{y} \text { per } \\
\mu \mathrm{Ci} / \mathrm{m}^{3}\end{array}$ & $\begin{array}{l}\text { Standard PE method; value is generic } \\
\text { and not site-specific. Includes "all } \\
\text { pathways" considerations. }\end{array}$ \\
\hline $\begin{array}{l}\text { Atmospheric Scenario Dose } \\
\text { Conversion Factor for C-14, SDCF }\end{array}$ & $\begin{array}{l}2.20 \mathrm{E}+5 \\
\mathrm{mrem} / \mathrm{y} \text { per } \\
\mu \mathrm{Ci} / \mathrm{m}^{3}\end{array}$ & $\begin{array}{l}\text { Standard PE method; value is generic } \\
\text { and not site-specific. Includes "all } \\
\text { pathways" considerations. }\end{array}$ \\
\hline
\end{tabular}


Table HAN-6 shows the results of the atmospheric analysis, including CRF values, the time of arrival, and the permissible waste limits that can be disposed without exceeding the PE performance measure (i.e., a dose of $10 \mathrm{mrem} / \mathrm{y}$ from all pathways). These values are compared to those reported in the 200 West Area performance assessment. Only total CRF values are compared because the performance assessment did not break the CRF into the soil diffusion and atmospheric dispersion terms components as does the PE analyses. Total CRF is calculated as the product of the soil diffusion and atmospheric diffusion CRFs. PE method results are less conservative (i.e., higher permissible waste limit) than performance assessment values for C-14 and more conservative (i.e., lower permissible waste limit) for H-3.

Table HAN-6. Comparison of the Results from the PE Method with the Performance Assessment (PA) Findings for the Atmospheric Pathway for the Hanford Site 200 West Area Burial Grounds

\begin{tabular}{|c|c|c|c|c|c|c|}
\hline \multirow[t]{2}{*}{ Nuclide } & \multicolumn{2}{|c|}{ Total CRF } & \multicolumn{2}{|c|}{$\begin{array}{c}\text { Time of Arrival } \\
(y)\end{array}$} & \multicolumn{2}{|c|}{$\begin{array}{c}\text { Permissible Waste } \\
\text { Concentration, } C_{W \cdot A t m} \\
\left(\mu \mathrm{Ci} / \mathrm{m}^{3}\right)\end{array}$} \\
\hline & PA & PE & PA & PE & PA & $\overline{P E}$ \\
\hline $\mathrm{H}-3$ & $2 \mathrm{E}+10$ & $2 E+08$ & 100 & 100 & $2 E+11$ & $6 E+08$ \\
\hline C-14 & $3 E+07$ & $7 E+06$ & 100 & 100 & $5 E+04$ & $3 E+02$ \\
\hline
\end{tabular}

Total CRF values and permissible waste concentrations are different between the PE method and the performance assessment as shown in Table HAN-6. These differences are due to calculational variations in several parameters as shown in Table HAN-7 and discussed in detail below.

The $A_{D}$ value from the performance assessment is ten, which is about two times higher than the $A_{D}$ value calculated using the PE method. Note that a higher $A_{D}$ indicates higher annual average atmospheric concentrations, and therefore, less atmospheric dispersion. The 200 West Area performance assessment calculated $A_{D}$ based on a performance boundary of $50 \mathrm{~m}$ compared to $100 \mathrm{~m}$ used in the PE method. Additionally, the performance assessment divided the waste area into 36 equal squares to improve model accuracy for receptors at close distances. The PE method divided the waste area into 256 equal squares.

The performance assessment approximates diffusive flux value, $J$, as second-order and non-linear in which the concentration gradient driving the volatile radionuclide decreases as it diffuses upward (Wood et al., 1994, p. 4-55). This approximation differs substantially from the PE method which assumes first-order, linear diffusion in which the concentration gradient is constant as the volatile radionuclide diffuses upward. The parameter $J$ is not explicitly used in the $\mathrm{PE}$ method but is implicitly calculated as part of the soil diffusion and mixing CRFs. In order to compare flux calculations between the performance assessment and the PE method, the radioactive decay component was isolated and removed from the value of $J$ calculated from the performance assessment. After the effect of radioactive decay was removed, the performance assessment's value of $J$ for $\mathrm{H}-3$ was $5.1 \times 10^{-12} \mathrm{Ci} / \mathrm{m}^{2} / \mathrm{s}$ (about 10 times less than the $P E$ value), and for $\mathrm{C}-14$, was $3.9 \times 10^{-9}$ (about 170 times less than the $\mathrm{PE}$ value). 
Table HAN-7. Comparison between Atmospheric Dispersion Parameters Calculated Using the PE Method and the Performance Assessment (PA) Findings for the Hanford 200 West Area Burial Grounds

\begin{tabular}{|c|c|c|c|c|}
\hline Nuclide & Parameter & $\begin{array}{l}\text { Value used in } \\
\text { the PE Method }\end{array}$ & $\begin{array}{l}\text { Value from the } \\
\text { Performance } \\
\text { Assessment } \\
\text { (PA) }\end{array}$ & $\begin{array}{c}\text { Ratio of the PE } \\
\text { Value to the PA } \\
\text { Value }\end{array}$ \\
\hline \multirow[t]{5}{*}{$H-3$} & $\begin{array}{l}\text { Inverse of the atmospheric } \\
\text { dispersion parameter, } 1 / A_{D}{ }^{a} \\
\left(\mu \mathrm{Ci} / \mathrm{m}^{3} \text { per } \mu \mathrm{Ci} / \mathrm{m}^{2} / \mathrm{s}\right)\end{array}$ & 2.0E-01 & 1.0E-01 & $2.0 \mathrm{E}+00$ \\
\hline & $\begin{array}{l}\text { Inverse of the diffusive flux, } \\
1 / J^{a}\left(m^{2}-s / \mu C i\right)\end{array}$ & $2.2 E+10$ & $2.0 E+11$ & 1.1E-01 \\
\hline & $\begin{array}{l}\text { Inverse of the diffusion } \\
\text { coefficient, } 1 / D\left(\mathrm{~s} / \mathrm{m}^{2}\right)\end{array}$ & $4.2 E+04$ & $1 E+06$ & $4.2 E-02$ \\
\hline & $\begin{array}{l}\text { Inverse of the atmospheric } \\
\text { scenario dose conversion } \\
\text { factor, } 1 / S D C F^{a} \\
\left(\mu \mathrm{Ci} / \mathrm{m}^{3} \text { per } \mathrm{mrem} / \mathrm{y}\right)\end{array}$ & 1.2E-03 & 1.3E-03 & 9.6E-01 \\
\hline & \multicolumn{3}{|c|}{ Product of the ratios $=$ adjustment factor for $\mathrm{H}-3, A F_{\mathrm{H}-3}$} & 8.9E-03 \\
\hline \multirow[t]{7}{*}{ C-14 } & $\begin{array}{l}\text { Inverse of the atmospheric } \\
\text { dispersion parameter, } 1 / A_{D}{ }^{a} \\
\left(\mu \mathrm{Ci} / \mathrm{m}^{3} \text { per } \mu \mathrm{Ci} / \mathrm{m}^{2} / \mathrm{s}\right)\end{array}$ & 2.0E-01 & $1.0 \mathrm{E}-01$ & $2.0 \mathrm{E}+00$ \\
\hline & $\begin{array}{l}\text { Inverse of the diffusive flux, } \\
1 / J^{a}\left(m^{2}-s / \mu \mathrm{Ci}\right)\end{array}$ & $1.5 E+06$ & $2.5 E+08$ & 5.8E-03 \\
\hline & $\begin{array}{l}\text { Inverse of the diffusion } \\
\text { coefficient, } 1 / D\left(\mathrm{~s} / \mathrm{m}^{2}\right)\end{array}$ & 7.1E+04 & $1.0 \mathrm{E}+06$ & 7.1E-02 \\
\hline & $\begin{array}{l}\text { Inverse of Henry's Constant, } \\
1 / r^{a}\end{array}$ & $2.4 E+03$ & $1.0 \mathrm{E}+00$ & $2.4 E+03$ \\
\hline & Soil saturation fraction, $s$ & 1.4E-01 & $1.0 E+00$ & 1.4E-01 \\
\hline & $\begin{array}{l}\text { Inverse of the atmospheric } \\
\text { scenario dose conversion } \\
\text { factor, } 1 / \mathrm{SDCF} \\
\left(\mu \mathrm{Ci} / \mathrm{m}^{3} \text { per } \mathrm{mrem} / \mathrm{y}\right)\end{array}$ & 5.6E-05 & 2.4E-06 & $1.3 E+01$ \\
\hline & \multicolumn{3}{|c|}{ Product of the ratios $=$ adjustment factor for $\mathrm{C}-14, A F_{C-14}$} & $3.6 E+00$ \\
\hline
\end{tabular}

- Inverses are reported because these parameters appear in the denominator of the overall calculation of permissible waste concentrations (see Volume 2, Chapter 5 of this report). 
Additionally, the performance assessment assumed that the diffusion coefficient for both H-3 and C-14 are equal to $1.0 \times 10^{-6} \mathrm{~m}^{2} / \mathrm{s}$ (Wood et al., 1994, p. 4-55). This value is about 24 times less than the value used in the PE for $\mathrm{H}-3$ and about 14 times less than the PE value for C-14.

For C-14, the 200 West Area analysis assumed that the entire pore space was filled with gas phase ${ }^{14} \mathrm{CO}_{2}$. This is equivalent to setting the Henry's Constant, $r$, equal to 1 (about 2000 times greater than the $\mathrm{PE}$ value) and the soil saturation fraction, $s$, equal to 1 (about 7 times greater than the PE value).

The performance assessment assumed that the entire annual equivalent dose was received through the inhalation pathway compared to the all-pathways method used in the PE. The inhalation dose conversion factor (DCF) for $\mathrm{H}-3$ is $8 \times 10^{2} \mathrm{mrem} / \mathrm{y}$ per $\mu \mathrm{Ci} / \mathrm{m}^{3}$, which is slightly greater than the PE SDCF. For C-14 the inhalation DCF is $1.8 \times 10^{4}$, which is about 13 times less than the PE SDCF.

For each volatile radionuclide, individual factor differences between the 200 West Area performance assessment and the PE method can be multiplied to yield an overall difference between the two methods. This product is the adjustment factor, $A F$, necessary to reconcile the differences between the PE method and the performance assessment. For $\mathrm{H}-3, A F$ is equal to about 0.009 , indicating that the 200 West Area analysis is about 110 times less restrictive overall than the PE method. For $\mathrm{C}-14, A F$ is equal to 3.6, indicating that the 200 West Area analysis is almost 4 times more restrictive overall than the PE method.

\section{A.4.2.3 Inadvertent Intruder Scenarios}

The 200 West Area performance assessment is used as the basis for comparison of the PE method to site-specific results. Category 1 (shallow burial) and Category 3 (engineered structure) facilities at Hanford were used for the comparison. The performance assessment includes a postexcavation and a post-drilling intruder scenario, both of which are similar to the PE agricultural (homesteader) scenario and the post-drilling scenario, respectively. Both the performance assessment and the PE include the same exposure pathways (e.g., ingestion of vegetables and soil, inhalation of suspended soil in the garden, and external exposure). However, the performance assessment did not include inhalation of suspended particulates while in the home. In the Hanford performance assessment, the post-excavation scenario is assumed to occur at $100 \mathrm{y}$ in Category 1 facilities and the post-drilling at $500 \mathrm{y}$ after closure of Category 3 facilities. 
Tables HAN-8 (post-excavation) and HAN-9 (post-drilling) present the scenario dose conversion factors (SDCFs) and the waste limits extracted from the performance assessment and compare them to results using the PE methodology ${ }^{1}$. That is, the PE method was modified to assume the agricultural scenario occurs at $100 \mathrm{y}$ and the post-drilling at $500 \mathrm{y}$. All other assumptions for the PE methodology are the same as that for the generic PE analysis (see Chapter 5 in Volume 2 of this report). The scenario dose conversion factors (total dose per unit concentration) were tabulated from Tables 4-3 and 4-4 of the Hanford 200 West Area Burial Grounds performance assessment (Wood et al., 1994) for the post-excavation and the postdrilling scenarios, respectively. For comparison with the PE, the "without soil leaching" category was chosen for both scenarios. To quantify the differences between the PE and the performance assessment, the ratio of PE to performance assessment data was calculated (see Tables HAN-8 and HAN-9). The waste limits were also extracted from the performance assessment. Table 4-24 of the performance assessment (Wood et al., 1994) lists concentration limits for the postexcavation and post-drilling scenarios under Category 1 and 3 , respectively.

The agricultural scenarios were in good agreement and varied within approximately an order of magnitude for all radionuclides except one $(\mathrm{H}-3)$. The post-drilling scenarios were also in good agreement and varied within about two orders of magnitude. The Hanford performance assessment used the GENII computer code and an independent spreadsheet methodology to calculate annual doses. The GENII code uses special models for exposure to $\mathrm{H}-3$ and C-14, which may account for the greater deviation for these two nuclides.

In general, the differences between the performance assessment and PE values are likely due to the different parameter values applied to the exposure models. For example, the performance assessment used DOE dose conversion factors and the PE used those from EPA. The parameter values that were farthest apart were the fraction of time spent in the garden $(0.21$ for the performance assessment and 0.01 for the PE) and the intake rate of vegetables. The difference in the fraction of time exposed would result in higher doses (and thus lower and more restrictive waste limits) in the performance assessment for pathways dominated by inhalation and external exposures. The PE assumed a greater intake rate of vegetables than did the performance assessment. This would tend to make the PE waste limits more restrictive for nuclides that have dominant ingestion pathways. Therefore, we can see that the differences between the performance assessment and PE values are likely a result of differing parameter values applied to the models.

For the post-drilling intruder scenarios, nearly all of the performance assessment waste limits were higher (i.e., less restrictive) than the PE limits. This directional bias in the post-drilling case, not seen in the post-excavation case, may be linked to the soil mixing fraction. The mixing fraction $\left(f_{m}\right)$ of waste to garden soil used in the performance assessment was $9.3 \times 10^{-4}$ (Wood et al., 1994, p. 3-5) and in the PE was $2 \times 10^{-2}$. The lower $f_{m}$ in the performance assessment would result in lower exposures and higher (less restrictive) waste limits. For the post-excavation scenario, the $f_{m}$ is the same $(0.5)$ in the performance assessment and PE.

\footnotetext{
${ }^{1}$ The SDCF values presented in the tables do not include progeny not in secular equilibrium at the time of intrusion. The waste limits for both the performance assessment and the PE method, on the other hand, were developed by accounting for the parent's radioactive decay, as well as ingrowth of any radiologically significant progeny at the time of intrusion.
} 
Table HAN-8. Comparison of the Results from the PE Method with the Performance Assessment Findings for the Post-Excavation (Agricultural) Intrusion Scenario at Hanford (Part 1 of 2)

\begin{tabular}{|c|c|c|c|c|c|c|c|}
\hline \multirow[t]{2}{*}{ Nuclide } & \multicolumn{3}{|c|}{$\begin{array}{c}\text { Post-Excavation Scenario } \\
\text { Dose Conversion Factor } \\
\text { (Undecayed) } \\
\text { (rem/y per } \mu \mathrm{C} / \mathrm{m}^{3} \text { ) }\end{array}$} & \multirow[t]{2}{*}{$\begin{array}{c}\text { Time of } \\
\text { Intrusion } \\
\text { (y) }\end{array}$} & \multicolumn{3}{|c|}{$\begin{array}{c}\text { Waste Limit } \\
\left(\mu \mathrm{Ci} / \mathrm{m}^{3}\right)\end{array}$} \\
\hline & PA Data & PE Method & $\begin{array}{l}\text { Ratio } \\
\text { PE : PA } \\
\text { Value }\end{array}$ & & PA Data & PE Method & $\begin{array}{c}\text { Ratio } \\
\text { PE : PA } \\
\text { Value }\end{array}$ \\
\hline $\mathrm{H}-3$ & $3.1 E-10$ & $4.0 \mathrm{E}-06$ & 1.29E+04 & 100 & $9.9 E+10$ & $1.4 \mathrm{E}+07$ & 1.43E-04 \\
\hline$C-14$ & 1.1E-06 & $1.5 \mathrm{E}-05$ & 13.50 & 100 & $9.1 E+04$ & $1.3 E+04$ & 0.15 \\
\hline Al-26 & NA & $3.8 \mathrm{E}-03$ & NA & 100 & NA & $5.2 E+01$ & NA \\
\hline Si-32 & $\mathrm{NA}$ & 1.7E-04 & NA & 100 & NA & $2.3 E+03$ & NA \\
\hline $\mathrm{Cl}-36$ & 1.6E-04 & $1.2 \mathrm{E}-03$ & 7.46 & 100 & $6.4 E+01$ & 1.7E+02 & 2.67 \\
\hline $\mathrm{K}-40$ & 5.6E-05 & $2.9 E-04$ & 5.10 & 100 & $1.8 \mathrm{E}+03$ & $7.0 \mathrm{E}+02$ & 0.39 \\
\hline Co-60 & $6.9 \mathrm{E}-04$ & $3.6 \mathrm{E}-03$ & 5.18 & 100 & $7.5 E+07$ & $2.9 E+07$ & 0.38 \\
\hline Ni-59 & $2.5 E-08$ & 7.1E-08 & 2.78 & 100 & $3.9 E+06$ & $2.8 E+06$ & 0.73 \\
\hline $\mathrm{Ni}-63$ & $3.4 E-08$ & $1.9 \mathrm{E}-07$ & 5.79 & 100 & $5.9 \mathrm{E}+06$ & $2.1 E+06$ & 0.35 \\
\hline Se-79 & $2.0 \mathrm{E}-07$ & $1.2 \mathrm{E}-06$ & 6.30 & 100 & $5.1 E+05$ & $1.6 \mathrm{E}+05$ & 0.31 \\
\hline Sr-90 + d & $7.0 \mathrm{E}-05$ & $2.0 \mathrm{E}-04$ & 2.85 & 100 & $1.6 \mathrm{E}+04$ & $1.1 E+04$ & 0.68 \\
\hline $\mathrm{Zr}-93$ & $4.0 \mathrm{E}-08$ & $4.1 E-08$ & 1.03 & 100 & $2.5 E+06$ & $4.9 E+06$ & 1.95 \\
\hline $\mathrm{Nb}-93 \mathrm{~m}$ & $7.5 E-09$ & $1.8 \mathrm{E}-08$ & 2.41 & 100 & NA & $8.2 E+08$ & NA \\
\hline $\mathrm{Nb}-94$ & 4.6E-04 & $2.1 \mathrm{E}-03$ & 4.67 & 100 & $2.2 E+02$ & $9.4 \mathrm{E}+01$ & 0.43 \\
\hline Tc-99 & $4.3 E-06$ & $1.2 \mathrm{E}-05$ & 2.83 & 100 & $2.3 E+04$ & $1.6 \mathrm{E}+04$ & 0.72 \\
\hline Pd-107 & $6.5 \mathrm{E}-09$ & $3.4 \mathrm{E}-08$ & 5.25 & 100 & $1.5 \mathrm{E}+07$ & $5.8 E+06$ & 0.39 \\
\hline $\mathrm{Ag}-108 \mathrm{~m}$ & NA & $2.1 \mathrm{E}-03$ & NA & 100 & NA & $1.6 E+02$ & NA \\
\hline Cd-113m & $1.8 \mathrm{E}-05$ & 1.3E-04 & 7.46 & 100 & $7.6 \mathrm{E}+05$ & $2.0 \mathrm{E}+05$ & 0.27 \\
\hline Sn-121m & 5.2E- 07 & $5.1 E-07$ & 0.98 & 100 & $6.7 \mathrm{E}+05$ & $1.4 E+06$ & 2.07 \\
\hline Sn-126+d & $6.4 E-04$ & $2.6 \mathrm{E}-03$ & 4.06 & 100 & $1.6 E+02$ & 7.7E+01 & 0.48 \\
\hline I-129 & 1.2E-05 & $8.1 \mathrm{E}-05$ & 6.89 & 100 & $8.5 E+03$ & $2.5 E+03$ & 0.29 \\
\hline Cs-135 & 6.1E-07 & $1.2 E-06$ & 1.99 & 100 & $1.6 \mathrm{E}+05$ & 1.7E+05 & 1.03 \\
\hline Cs-137+d & $1.8 \mathrm{E}-04$ & $7.6 \mathrm{E}-04$ & 4.21 & 100 & $5.5 \mathrm{E}+03$ & $2.6 E+03$ & 0.48 \\
\hline Ba-133 & 1.0E-04 & $4.4 \mathrm{E}-04$ & 4.25 & 100 & $7.1 E+05$ & $3.3 E+05$ & 0.47 \\
\hline Sm-151 & 4.7E-09 & $1.2 E-08$ & 2.44 & 100 & $4.6 \mathrm{E}+07$ & 3.7E+07 & 0.81 \\
\hline Eu-152 & $3.6 \mathrm{E}-04$ & $1.5 \mathrm{E}-03$ & 4.31 & 100 & $4.8 E+04$ & $2.2 E+04$ & 0.46 \\
\hline Eu-154 & 4.2E-04 & 1.7E-03 & 3.97 & 100 & $7.5 \mathrm{E}+05$ & $3.8 E+05$ & 0.50 \\
\hline $\mathrm{Pb}-210+\mathrm{d}$ & $6.0 \mathrm{E}-05$ & $3.1 \mathrm{E}-04$ & 5.15 & 100 & $3.7 E+04$ & $1.4 E+04$ & 0.39 \\
\hline $\mathrm{Ra}-226+\mathrm{d}$ & 6.2E-04 & $2.8 \mathrm{E}-03$ & 4.48 & 100 & 1.7E+02 & $7.5 E+01$ & 0.44 \\
\hline Ra-228 & $9.8 \mathrm{E}-04$ & $3.6 \mathrm{E}-03$ & 3.64 & 100 & $1.7 E+07$ & $9.4 E+06$ & 0.55 \\
\hline Th-229 + d & 2.3E-04 & 4.3E-04 & 1.86 & 100 & $4.4 E+02$ & $4.7 E+02$ & 1.07 \\
\hline Th-230 & $4.8 \mathrm{E}-05$ & 1.1E-05 & 0.23 & 100 & $2.1 E+03$ & $1.6 E+03$ & 0.76 \\
\hline Th-232+d & $9.2 E-04$ & 3.6E-03 & 3.94 & 100 & $1.1 E+02$ & $5.5 E+01$ & 0.50 \\
\hline $\mathrm{Pa}-231$ & 7.1E-04 & $8.3 E-04$ & 1.17 & 100 & $1.4 E+02$ & $2.4 E+02$ & 1.72 \\
\hline
\end{tabular}


Table HAN-8. Comparison of the Results from the PE Method with the Performance Assessment Findings for the Post-Excavation (Agricultural) Intrusion Scenario at Hanford (Part 2 of 2)

\begin{tabular}{|c|c|c|c|c|c|c|c|}
\hline \multirow[t]{2}{*}{ Nuclide } & \multicolumn{3}{|c|}{$\begin{array}{c}\text { Post-Excavation Scenario } \\
\text { Dose Conversion Factor } \\
\text { (Undecayed) } \\
\text { (rem/y per } \mu \mathrm{Ci} / \mathrm{m}^{3} \text { ) }\end{array}$} & \multirow[t]{2}{*}{$\begin{array}{l}\text { Time of } \\
\text { Intrusion } \\
\text { (y) }\end{array}$} & \multicolumn{3}{|c|}{$\begin{array}{c}\text { Waste Limit } \\
\left(\mu \mathrm{Ci} / \mathrm{m}^{3}\right)\end{array}$} \\
\hline & PA Data & PE Method & $\begin{array}{l}\text { Ratio } \\
\text { PE : PA } \\
\text { Value }\end{array}$ & & PA Data & PE Method & $\begin{array}{l}\text { Ratio } \\
\text { PE : PA } \\
\text { Value }\end{array}$ \\
\hline$U-232+d$ & $5.9 \mathrm{E}-04$ & 2.3E-03 & 3.92 & 100 & $4.6 E+02$ & $2.3 E+02$ & 0.51 \\
\hline U-233 & $1.4 E-05$ & 1.2E-05 & 0.88 & 100 & $7.4 E+03$ & $1.3 E+04$ & 1.69 \\
\hline$U-234$ & 1.1E-05 & $1.2 E-05$ & 1.04 & 100 & $8.9 E+03$ & 1.7E+04 & 1.91 \\
\hline$U-235+d$ & 3.6E-05 & 1.8E-04 & 4.89 & 100 & $2.8 E+03$ & $1.1 E+03$ & 0.40 \\
\hline U-236 & 1.1E-05 & $1.1 \mathrm{E}-05$ & 1.06 & 100 & $9.5 E+03$ & $1.8 E+04$ & 1.90 \\
\hline$U-238+d$ & 1.8E-05 & 4.0E-05 & 2.27 & 100 & $5.7 E+03$ & $5.0 E+03$ & 0.88 \\
\hline$N p-237+d$ & $1.5 \mathrm{E}-04$ & $5.3 E-04$ & 3.58 & 100 & $6.8 E+02$ & $3.8 E+02$ & 0.56 \\
\hline $\mathrm{Pu}-238$ & 4.7E-05 & $2.9 \mathrm{E}-05$ & 0.63 & 100 & $4.7 E+03$ & $1.5 \mathrm{E}+04$ & 3.19 \\
\hline Pu-239 & $5.2 E-05$ & $3.2 E-05$ & 0.62 & 100 & $1.9 E+03$ & $6.2 E+03$ & 3.27 \\
\hline Pu-240 & $5.2 E-05$ & $3.2 \mathrm{E}-05$ & 0.62 & 100 & $1.9 E+03$ & $6.3 E+03$ & 3.29 \\
\hline $\mathrm{Pu}-241$ & 2.0E-04 & $6.2 E-07$ & $3.09 E-03$ & 100 & $6.1 E+04$ & $1.5 E+05$ & 2.38 \\
\hline Pu-242 & 5.0E-05 & 3.1E-05 & 0.62 & 100 & $2.0 E+03$ & $6.5 E+03$ & 3.25 \\
\hline$P u-244$ & $1.6 \mathrm{E}-04$ & $3.0 E-05$ & 0.19 & 100 & $6.1 E+02$ & $4.2 E+02$ & 0.69 \\
\hline Am-241 & $5.6 E-05$ & 4.7E-05 & 0.84 & 100 & 2.1E+03 & $5.0 \mathrm{E}+03$ & 2.37 \\
\hline$A m-243+d$ & $9.9 \mathrm{E}-05$ & $2.3 E-04$ & 2.37 & 100 & $1.0 \mathrm{E}+03$ & $8.6 E+02$ & 0.86 \\
\hline $\mathrm{Cm}-243$ & $6.1 E-05$ & 1.5E-04 & 2.48 & 100 & $1.8 E+04$ & 1.5E+04 & 0.84 \\
\hline $\mathrm{Cm}-244$ & 3.4E-05 & $1.8 \mathrm{E}-05$ & 0.54 & 100 & $1.4 E+05$ & $4.1 E+05$ & 2.96 \\
\hline $\mathrm{Cm}-245$ & $7.6 E-05$ & 1.1E-04 & 1.43 & 100 & $1.3 E+03$ & $1.8 E+03$ & 1.35 \\
\hline $\mathrm{Cm}-246$ & $5.5 E-05$ & 3.3E-05 & 0.60 & 100 & $1.8 E+03$ & $6.1 E+03$ & 3.39 \\
\hline $\mathrm{Cm}-247$ & $1.8 \mathrm{E}-04$ & 4.4E-04 & 2.47 & 100 & $5.6 \mathrm{E}+02$ & $4.5 E+02$ & 0.81 \\
\hline $\mathrm{Cm}-248$ & $2.0 \mathrm{E}-04$ & 1.2E-04 & 0.63 & 100 & $5.1 \mathrm{E}+02$ & $1.6 E+03$ & 3.21 \\
\hline Cf-249 & NA & $4.5 E-04$ & NA & 100 & NA & $5.4 E+02$ & NA \\
\hline Cf-250 & NA & $1.9 \mathrm{E}-05$ & NA & 100 & NA & $1.1 E+06$ & NA \\
\hline Cf-251 & NA & 1.6E-04 & NA & 100 & NA & $1.4 E+03$ & NA \\
\hline
\end{tabular}

" $+d^{\prime \prime}$ denotes short-lived decay products that are assumed to be in secular equilibrium with the parent radionuclide. NA indicates that the radionuclide was not subjected to detailed intrusion analyses in the Hanrford 200 West Area performance assessment. 
Table HAN-9. Comparison of the Results from the PE Method with the Performance Assessment Findings for the Post-Drilling Intrusion Scenario at Hanford (Part 1 of 2)

\begin{tabular}{|c|c|c|c|c|c|c|c|}
\hline \multirow[t]{2}{*}{ Nuclide } & \multicolumn{3}{|c|}{$\begin{array}{c}\text { Post-Drilling Scenario } \\
\text { "Undecayed" Dose Conversion } \\
\text { Factor } \\
\left(\text { rem/y per } \mu \mathrm{Ci} / \mathrm{m}^{3}\right)\end{array}$} & \multirow[t]{2}{*}{$\begin{array}{l}\text { Time of } \\
\text { Intrusion } \\
\text { (y) }\end{array}$} & \multicolumn{3}{|c|}{$\begin{array}{c}\text { Waste Limit } \\
\left(\mu \mathrm{Ci} / \mathrm{m}^{3}\right)\end{array}$} \\
\hline & PA Data & PE Method & $\begin{array}{l}\text { Ratio } \\
\text { PE : PA } \\
\text { Value } \\
\end{array}$ & & PA Data & PE Method & $\begin{array}{l}\text { Ratio } \\
\text { PE : PA } \\
\text { Value } \\
\end{array}$ \\
\hline $\mathrm{H}-3$ & $1.4 \mathrm{E}-12$ & 4.0E-07 & 286505.04 & 500 & NO LIMIT & 4.4E+17 & Unknown \\
\hline C-14 & 5.2E-09 & $1.5 \mathrm{E}-06$ & 289.44 & 500 & $2.1 E+07$ & $7.1 E+04$ & 0.00 \\
\hline Al-26 & NA & $1.8 \mathrm{E}-06$ & NA & 500 & NA & $5.5 E+04$ & NA \\
\hline Si-32 & NA & 1.7E-05 & NA & 500 & NA & $1.9 E+05$ & NA \\
\hline $\mathrm{Cl}-36$ & 7.3E-07 & $1.2 \mathrm{E}-04$ & 159.40 & 500 & $1.4 E+05$ & $8.5 E+02$ & 0.01 \\
\hline$K-40$ & 2.6E-07 & 5.8E-06 & 22.09 & 500 & $3.8 E+05$ & 1.7E+04 & 0.05 \\
\hline Co-60 & $3.2 E-06$ & $1.8 \mathrm{E}-06$ & 0.56 & 500 & NO LIMIT & $2.0 E+33$ & Unknown \\
\hline Ni-59 & 1.2E-10 & 7.1E-09 & 59.64 & 500 & $8.5 \mathrm{E}+08$ & $1.4 \mathrm{E}+07$ & 0.02 \\
\hline $\mathrm{Ni}-63$ & $1.6 \mathrm{E}-10$ & $1.9 \mathrm{E}-08$ & 123.55 & 500 & $2.0 \mathrm{E}+10$ & $1.6 \mathrm{E}+0 \mathrm{~B}$ & 0.01 \\
\hline Se-79 & $9.2 \mathrm{E}-10$ & $1.2 E-07$ & 135.20 & 500 & $1.1 E+08$ & $8.1 E+05$ & 0.01 \\
\hline$S r-90+d$ & $2.8 \mathrm{E}-07$ & $2.0 \mathrm{E}-05$ & 71.99 & 500 & $5.4 \mathrm{E}+10$ & $7.5 \mathrm{E}+08$ & 0.01 \\
\hline $\mathrm{Zr}-93$ & $1.9 E-10$ & 3.1E-09 & 16.71 & 500 & $5.4 \mathrm{E}+08$ & $3.2 \mathrm{E}+07$ & 0.06 \\
\hline $\mathrm{Nb}-93 \mathrm{~m}$ & $5.9 \mathrm{E}-12$ & 1.7E-09 & 289.87 & 500 & NA & $1.3 E+17$ & NA \\
\hline $\mathrm{Nb}-94$ & 2.1E-06 & 1.1E-06 & 0.51 & 500 & $4.8 \mathrm{E}+04$ & $9.4 E+04$ & 1.96 \\
\hline Tc-99 & $2.0 \mathrm{E}-08$ & $1.2 \mathrm{E}-06$ & 60.84 & 500 & $5.0 E+06$ & $8.3 E+04$ & 0.02 \\
\hline Pd-107 & 3.0E-11 & 3.4E-09 & 111.38 & 500 & $3.3 E+09$ & $3.0 E+07$ & 0.01 \\
\hline $\mathrm{Ag}-108 \mathrm{~m}$ & NA & 1.5E-06 & NA & 500 & NA & $9.6 E+05$ & NA \\
\hline Cd-113m & 4.7E-08 & 1.3E-05 & 284.58 & 500 & NO LIMIT & $3.5 E+14$ & Unknown \\
\hline Sn-121m & 2.4E-09 & 7.0E-09 & 2.86 & 500 & $2.2 E+10$ & $7.8 E+09$ & 0.35 \\
\hline Sn-126 & 3.0E-06 & $1.4 \mathrm{E}-06$ & 0.48 & 500 & $3.4 E+04$ & 7.1E+04 & 2.08 \\
\hline $1-129$ & 5.5E-08 & $7.8 E-06$ & 142.18 & 500 & $1.8 E+06$ & 1.3E+04 & 0.01 \\
\hline Cs-135 & 2.8E-09 & 1.2E-07 & 42.58 & 500 & $3.5 E+07$ & 8.3E+05 & 0.02 \\
\hline$C s-137+d$ & $8.4 \mathrm{E}-07$ & $1.2 \mathrm{E}-06$ & 1.47 & 500 & $1.2 E+10$ & $7.9 E+09$ & 0.66 \\
\hline Ba-133 & 4.4E-07 & $2.6 \mathrm{E}-07$ & 0.59 & 500 & NO LIMIT & $7.5 E+19$ & Unknown \\
\hline Sm-151 & 2.2E-11 & 1.1E-09 & 48.41 & 500 & $2.1 E+11$ & $4.4 E+09$ & 0.02 \\
\hline Eu-152 & $2.0 \mathrm{E}-06$ & 7.7E-07 & 0.38 & 500 & NO LIMIT & $1.9 E+16$ & Unknown \\
\hline Eu-154 & 4.3E-06 & $8.5 \mathrm{E}-07$ & 0.20 & 500 & NO LIMIT & $3.9 E+22$ & Unknown \\
\hline $\mathrm{Pb}-210+\mathrm{d}$ & 2.7E-07 & $3.1 \mathrm{E}-05$ & 112.93 & 500 & $2.1 E+12$ & $1.8 E+10$ & 0.01 \\
\hline $\mathrm{Ra}-226+\mathrm{d}$ & 2.9E-06 & 3.4E-05 & 11.68 & 500 & $4.3 E+04$ & $3.7 E+03$ & 0.09 \\
\hline Ra-228 & 4.2E-06 & 4.6E-06 & 1.10 & 500 & NO LIMIT & $2.9 E+30$ & Unknown \\
\hline Th-229 + d & 1.1E-06 & $3.0 E-06$ & 2.82 & 500 & $9.8 E+04$ & $3.5 E+04$ & 0.35 \\
\hline Th-230 & 6.7E-07 & $3.5 \mathrm{E}-07$ & 0.52 & 500 & 1.5E+05 & 1.5E+04 & 0.10 \\
\hline Th-232+d & 4.3E-06 & $6.3 \mathrm{E}-06$ & 1.47 & 500 & $2.3 E+04$ & $1.6 \mathrm{E}+04$ & 0.69 \\
\hline $\mathrm{Pa}-231+\mathrm{d}$ & $3.4 \mathrm{E}-06$ & 1.9E-05 & 5.63 & 500 & $3.0 \mathrm{E}+04$ & $5.3 E+03$ & 0.18 \\
\hline
\end{tabular}


Table HAN-9. Comparison of the Results from the PE Method with the Performance Assessment Findings for the Post-Drilling Intrusion Scenario at Hanford (Part 2 of 2)

\begin{tabular}{|c|c|c|c|c|c|c|c|}
\hline \multirow[t]{2}{*}{ Nuclide } & \multicolumn{3}{|c|}{$\begin{array}{c}\text { Post-Drilling Scenario } \\
\text { "Undecayed" Dose Conversion } \\
\text { Factor } \\
\left.\text { (rem/y per } \mu \mathrm{Ci} / \mathrm{m}^{3}\right)\end{array}$} & \multirow[t]{2}{*}{$\begin{array}{l}\text { Time of } \\
\text { Intrusion } \\
\text { (y) }\end{array}$} & \multicolumn{3}{|c|}{$\begin{array}{c}\text { Waste Limit } \\
\left(\mu \mathrm{Ci} / \mathrm{m}^{3}\right)\end{array}$} \\
\hline & PA Data & PE Method & $\begin{array}{l}\text { Ratio } \\
\text { PE : PA } \\
\text { Value }\end{array}$ & & PA Data & PE Method & $\begin{array}{c}\text { Ratio } \\
\text { PE : PA } \\
\text { Value }\end{array}$ \\
\hline$U-232+d$ & 3.1E-06 & 5.7E-06 & 1.87 & 500 & $4.6 \mathrm{E}+06$ & $2.5 E+06$ & 0.54 \\
\hline U-233 & $1.0 \mathrm{E}-07$ & $8.1 \mathrm{E}-07$ & 7.82 & 500 & $9.7 E+05$ & 1.1E+05 & 0.11 \\
\hline$U-234$ & 5.3E-08 & $7.9 \mathrm{E}-07$ & 15.06 & 500 & $1.9 \mathrm{E}+06$ & $1.2 E+05$ & 0.07 \\
\hline$U-235+d$ & 2.0E-07 & $8.4 \mathrm{E}-07$ & 4.22 & 500 & $5.0 \mathrm{E}+05$ & $9.7 E+04$ & 0.19 \\
\hline U-236 & 4.9E-08 & $7.5 \mathrm{E}-07$ & 15.28 & 500 & $2.0 E+06$ & $1.3 E+05$ & 0.07 \\
\hline $\mathrm{U}-238+\mathrm{d}$ & $8.2 E-08$ & $7.3 \mathrm{E}-07$ & 8.97 & 500 & $1.2 E+06$ & $1.4 E+05$ & 0.11 \\
\hline Np-237+d & $6.9 \mathrm{E}-07$ & $2.7 \mathrm{E}-05$ & 39.42 & 500 & $1.5 E+05$ & $3.7 E+03$ & 0.02 \\
\hline Pu-238 & $2.2 E-07$ & $1.8 \mathrm{E}-06$ & 8.29 & 500 & $2.4 E \div 07$ & $2.8 \mathrm{E}+06$ & 0.12 \\
\hline Pu-239 & $2.4 \mathrm{E}-07$ & $2.0 \mathrm{E}-06$ & 8.21 & 500 & $4.2 E+05$ & $5.1 E+04$ & 0.12 \\
\hline Pu-240 & $2.4 \mathrm{E}-07$ & $2.0 \mathrm{E}-06$ & 8.20 & 500 & $4.3 E+05$ & $5.3 E+04$ & 0.12 \\
\hline Pu-241 & $1.1 E+02$ & $3.9 \mathrm{E}-08$ & 0.00 & 500 & $2.5 E+07$ & $2.6 E+06$ & 0.10 \\
\hline Pu-242 & $2.3 E-07$ & 1.9E-06 & 8.24 & 500 & $4.3 E+05$ & $5.3 E+04$ & 0.12 \\
\hline Pu-244 & 7.7E-07 & $1.9 \mathrm{E}-06$ & 2.43 & 500 & 1.3E+05 & $4.7 E+04$ & 0.36 \\
\hline$A m-241$ & $2.6 E-07$ & $2.5 \mathrm{E}-06$ & 9.53 & 500 & $8.5 E+05$ & $9.0 E+04$ & 0.11 \\
\hline$A m-243+d$ & 4.6E-07 & 2.6E-06 & 5.54 & 500 & $2.3 E+05$ & $4.0 E+04$ & 0.18 \\
\hline$C m-243$ & 4.3E-05 & 1.5E-06 & 0.03 & 500 & $3.4 E+08$ & $4.3 E+07$ & 0.13 \\
\hline Cm-244 & 1.3E-01 & 1.1E-06 & 0.00 & 500 & $1.6 E+08$ & $1.9 E+07$ & 0.12 \\
\hline $\mathrm{Cm}-245$ & 4.7E-07 & 2.1E-06 & 4.51 & 500 & $2.2 E+05$ & $3.0 E+04$ & 0.14 \\
\hline $\mathrm{Cm}-246$ & 2.6E-07 & 2.0E-06 & 7.90 & 500 & $4.2 E+05$ & $5.3 E+04$ & 0.13 \\
\hline Cm-247 & $8.4 E-07$ & 2.1E-06 & 2.49 & 500 & $1.2 E+05$ & $4.5 E+04$ & 0.38 \\
\hline $\mathrm{Cm}-248$ & $9.1 \mathrm{E}-07$ & 7.5E-06 & 8.23 & 500 & 1.1E+05 & $1.3 E+04$ & 0.12 \\
\hline Cf-249 & NA & $2.8 \mathrm{E}-06$ & NA & 500 & NA & $8.9 E+04$ & NA \\
\hline$C f-250$ & NA & $1.2 E-06$ & NA & 500 & NA & $1.9 E+07$ & NA \\
\hline Cf-251 & NA & $2.7 \mathrm{E}-06$ & NA & 500 & NA & $5.4 E+04$ & NA \\
\hline
\end{tabular}

" $+d^{\prime \prime}$ denotes short-lived decay products that are assumed to be in secular equilibrium with the parent radionuclide. NA indicates that the radionuclide was not subjected to detailed intrusion analyses in the Hanrford 200 West Area performance assessment. 


\section{A.4.2.4 Discussion of the Results of the Comparative Exercise}

One objective of this comparative exercise is to gain insight into the differences between the scoping methodology of the PE and the more detailed evaluations conducted for the sitespecific performance assessment. Observations regarding this objective is discussed below.

As modeled in Hanford's performance assessment, the effect of lateral dispersion and dilution with infiltrating waters is not captured as part of the PE methodology. In addition, the PE's assumed continuous source poses fundamental differences in regard to the pulse source assumed in the performance assessment. Nevertheless, the general agreement between the findings of the performance assessment and the PE were good after the PE was modified to account for the aforementioned differences.

Only radionuclides ( $\mathrm{H}-3$ and $\mathrm{C}-14)$ were analyzed for the atmospheric pathway with the $\mathrm{PE}$ method. Agreement between the PE results and the performance assessment were reasonably good (i.e., within about two orders of magnitude) for $\mathrm{C}-14$, but were in substantial disagreement for $\mathrm{H}-3$.

The intrusion results for the performance assessment and the PE were in generally excellent agreement (i.e., within about one order of magnitude) for both the homesteader (agricultural) and post-drilling scenarios.

\section{A.4.3 PE CALCULATIONS FOR THE RMWLDF}

Based on the above exercise, it is concluded that application of the PE approach (as modified by the aforementioned additions to the groundwater pathway equations) closely mimics the findings of the performance assessment for the 200 West Area burial grounds. A PE analysis was therefore conducted for the proposed Radioactive Mixed Waste Land Disposal Facility (RMWLDF) at the Hanford Site. As in the Hanford PE for a generic trench and generic tumulus facility (see Chapter 16 in this volume), three pathways were separately analyzed and the individual results combined to discern the most restrictive permissible waste concentration among all three pathways. This section describes the results for each pathway and concludes with a presentation of the overall results for the RMWLDF at Hanford. Details of the PE methodology are contained in Volume 2, Chapter 5 of this report; data used in that methodology are described below.

\section{A.4.3.1 Water Transport for the RMWLDF}

Site-specific values required to perform the water pathway analysis were selected by site technical staff either from site-specific characterizations and reports, from site-specific modeling results, or from the general literature. The values applicable to the RMWLDF in the 200 West Area at Hanford are listed in Table HAN-10, along with the generic values used in the PE. Also indicated in the table is a designation of the type of data represented by the value and its source. The values are representative of one or more of four data types: (A) measurements performed by the site, state, or federal agency; (B) results of a numerical analysis performed by the site, state, or federal agency; (C) general literature values selected by the site; and (D) generic values used in the PE. 
Table HAN-10. Parameters and Values Used in the PE Analysis for the Radioactive Mixed Waste Land Disposal Facility at the Hanford Site

\begin{tabular}{|c|c|c|c|}
\hline Parameter & Value & $\begin{array}{l}\text { Data } \\
\text { Type }\end{array}$ & Comments \\
\hline \multicolumn{4}{|l|}{ SOURCE TERM } \\
\hline Initial waste concentration, $C_{W}$ & $1 \mu \mathrm{Ci} / \mathrm{m}^{3}$ & D & $\begin{array}{l}\text { A unit concentration is part of the standard } \\
\text { PE value }\end{array}$ \\
\hline $\begin{array}{l}\text { Volumetric water content of the } \\
\text { waste, } q_{G}\end{array}$ & 0.3 & D & Standard PE value \\
\hline Bulk density of the waste, $r_{G}$ & $1.76 \mathrm{~g} / \mathrm{mL}$ & $D$ & Standard PE value \\
\hline $\begin{array}{l}\text { Plan area for RMWLDF facility, } \\
A \quad(100 \mathrm{~m} \text { by } 100 \mathrm{~m})\end{array}$ & $10,000 \mathrm{~m}^{2}$ & C & Wood et al., 1994 \\
\hline $\begin{array}{l}\text { Waste mixing fraction for } \\
\text { RMWLDF, } f_{m}\end{array}$ & 0.67 & $\mathbf{D}$ & Standard PE value \\
\hline $\begin{array}{l}\text { Annual rate of water flowing } \\
\text { through intact RMWLDF }\end{array}$ & $0.03 \mathrm{~m} / \mathrm{y}$ & $D$ & Standard PE value \\
\hline $\begin{array}{l}\text { Annual rate of water flowing } \\
\text { through failed facility }\end{array}$ & $0.05 \mathrm{~m} / \mathrm{y}$ & A & Wood et al., 1994 \\
\hline $\begin{array}{l}\text { Time to failure of leachate } \\
\text { collection system }\end{array}$ & $30 y$ & $D$ & Standard PE value \\
\hline $\begin{array}{l}\text { Time to failure of RMWLDF } \\
\text { facility }\end{array}$ & $100 y$ & $D$ & Standard PE value \\
\hline \multicolumn{4}{|l|}{ UNSATURATED ZONE } \\
\hline Volumetric water content, $q_{w}$ & 0.09 & B & $\begin{array}{l}\text { Selected by staff as representative of the } \\
\text { unsaturated zone and used to calibrate } \\
\text { subsurface travel times to the performance } \\
\text { assessment; confirmed by Wood (1995) }\end{array}$ \\
\hline Bulk density, $r_{b}$ & $1.5 \mathrm{~g} / \mathrm{mL}$ & B & $\begin{array}{l}\text { Selected by staff as representative of the } \\
\text { unsaturated zone and used to calibrate } \\
\text { subsurface travel times to the performance } \\
\text { assessment; confirmed by Wood (1995) }\end{array}$ \\
\hline $\begin{array}{l}\text { Thickness between bottom of } \\
\text { RMWLDF and saturated zone, I }\end{array}$ & $65 \mathrm{~m}$ & A & $\begin{array}{l}\text { Cumulative unsaturated sediment thickness } \\
\text { is } 72 \mathrm{~m} \text { (Wood et al., 1994) and bottom of } \\
\text { RMWLDF is } 7 \mathrm{~m} \text { below ground level. }\end{array}$ \\
\hline \multicolumn{4}{|l|}{ SATURATED ZONE } \\
\hline Aquifer porosity, $n$ & 0.31 & A & Wood et al., 1994 \\
\hline Bulk density, $r_{b}$ & $1.6 \mathrm{~g} / \mathrm{mL}$ & A & Wood et al., 1994 \\
\hline Mixing depth, $d_{m}$ & $5 \mathrm{~m}$ & C & Khaleel, 1994 \\
\hline Darcy velocity & $22 \mathrm{~m} / \mathrm{y}$ & C & Khaleel, 1994 \\
\hline $\begin{array}{l}\text { Distance to performance } \\
\text { boundary from facility boundary }\end{array}$ & $100 \mathrm{~m}$ & $D$ & Standard PE value and Wood et al., 1994 \\
\hline
\end{tabular}


The unsaturated zone is represented with uniform properties based on guidance offered by site technical staff. Bulk density and volumetric water content have been adjusted within reasonable ranges to calibrated unsaturated zone travel times to those reported in the performance assessment.

Values for the distribution coefficients ( $K_{d}$ values) are listed in Table HAN-11 for the 58 radionuclides considered in the PE analysis. In addition to the $K_{d}$ values for the geologic media, grout $K_{d}$ values are listed for determining the desorption from the grouted waste form. The $K_{d}$ values for the subsurface flow pathway (both for the unsaturated and saturated zones) are taken from Table 3-5 in the performance assessment for the 200 West Area (Wood et al. 1994). For a specified radionuclide, there is no difference in the $K_{d}$ values at Hanford for the unsaturated and saturated zones. Additional values for radionuclides not included in the performance assessment (i.e., $\mathrm{Cl}, \mathrm{Al}, \mathrm{Si}, \mathrm{Ag}, \mathrm{Pb}$, and $\mathrm{Cf}$ ) were provided by site technical staff at Hanford.

Application of the PE methodology for water transport of the 58 radionuclides considered in the $\mathrm{PE}$ analysis produced the results shown in Table HAN-12. The table shows the permissible waste concentrations based upon transport through the water pathway $\left(C_{\text {W-Water }}\right)$, as well as the values used in calculating the permissible concentrations.

\section{A.4.3.2 Atmospheric Transport for the RMWLDF}

Site-specific data required to perform the atmospheric pathway analysis came from site personnel either as data from site characterizations and reports or from general literature. The site-specific data required for the soil diffusion calculation were identical to those required for the water transport analysis (see Section 16.4.1 in this volume). The values used in the atmospheric dispersion analysis are shown in Table HAN-13. Necessary atmospheric dispersion data include wind speed, wind direction, and stability class, which are discussed in Section 16.3.2.1 of this volume.

Application of the PE methodology for atmospheric transport of the two volatile radionuclides considered in the PE (H-3 and C-14) produced the results shown in Table HAN-14. The table shows permissible waste concentrations based on transport in the atmospheric pathway $\left(C_{W-A t m}\right)$, as well as the values used in calculating the permissible waste concentrations. For both $\mathrm{H}-3$ and $\mathrm{C}-14$, the greatest concentration reduction occurred as the radionuclides diffuse from the top of the disposal facility to the soil surface. 
Table HAN-11. Solid/liquid Distribution Coefficients ( $K_{d}$ values) Used in the PE Analyses for the Radioactive Mixed Waste Land Disposal Facility at Hanford

\begin{tabular}{|l|c|c|}
\hline Element & $\begin{array}{c}K_{d} \text { for } \\
\text { Waste } \\
(\mathbf{m L} \mathbf{g})\end{array}$ & $\begin{array}{c}K_{d} \text { for Saturated } \\
\text { and Unsaturated } \\
\text { Zones (mLg) }\end{array}$ \\
\hline $\mathrm{H}$ & 0 & 0 \\
\hline $\mathrm{C}$ & 10 & 0 \\
\hline $\mathrm{Al}$ & 100 & 10 \\
\hline $\mathrm{Si}$ & 100 & 10 \\
\hline $\mathrm{Cl}$ & 0 & 0 \\
\hline $\mathrm{K}$ & 1 & 10 \\
\hline $\mathrm{Co}$ & 100 & 1 \\
\hline $\mathrm{Ni}$ & 10 & 100 \\
\hline $\mathrm{Se}$ & 1 & 0 \\
\hline $\mathrm{Sr}$ & 100 & 1 \\
\hline $\mathrm{Zr}$ & 10 & 100 \\
\hline $\mathrm{Nb}$ & 10 & 100 \\
\hline $\mathrm{TC}$ & 1 & 0 \\
\hline $\mathrm{Pd}$ & 100 & 10 \\
\hline $\mathrm{Ag}$ & 100 & 10 \\
\hline $\mathrm{Cd}$ & 100 & 100 \\
\hline
\end{tabular}

\begin{tabular}{|l|c|c|}
\hline Element & $\begin{array}{c}K_{d} \text { for } \\
\text { Waste } \\
(\mathrm{mL} / \mathrm{g})\end{array}$ & $\begin{array}{c}\boldsymbol{K}_{\mathrm{d}} \text { for Saturated } \\
\text { and Unsaturated } \\
\text { Zones }(\mathrm{mL})\end{array}$ \\
\hline $\mathrm{Sn}$ & 10 & 100 \\
\hline $\mathrm{I}$ & 1 & 0 \\
\hline $\mathrm{Cs}$ & 10 & 1 \\
\hline $\mathrm{Ba}$ & 10 & 1 \\
\hline $\mathrm{Sm}$ & 10 & 100 \\
\hline $\mathrm{Eu}$ & 10 & 10 \\
\hline $\mathrm{Pb}$ & 100 & 100 \\
\hline $\mathrm{Ra}$ & 10 & 10 \\
\hline $\mathrm{Th}$ & 100 & 100 \\
\hline $\mathrm{Pa}$ & 100 & 1 \\
\hline $\mathrm{U}$ & 100 & 0 \\
\hline $\mathrm{Np}$ & 100 & 10 \\
\hline $\mathrm{Pu}$ & 100 & 100 \\
\hline $\mathrm{Am}$ & 100 & 100 \\
\hline $\mathrm{Cm}$ & 100 & 100 \\
\hline $\mathrm{Cf}$ & 100 & 100 \\
\hline
\end{tabular}

Waste $K_{0}$ values are uniquely applicable to the grouted waste form assumed in this PE. See Chapter 1 of this volume and/or Chapter 5 of Volume 2 for additional detalls. 
Table HAN-12. Results of the PE Water Pathway Calculations for the Radioactive Mixed Waste Land Disposal Facility at the Hanford Site (Part 1 of 2)

\begin{tabular}{|c|c|c|c|c|c|}
\hline Nuclide & $\begin{array}{l}\text { CRF }_{\text {TOTAL }} \\
\text { (no decay) }\end{array}$ & $\begin{array}{c}\text { Arrival Time } \\
(y)\end{array}$ & $r_{\text {Docay }}$ & $\begin{array}{c}C_{\text {whwater }} \\
\left(\mu \mathrm{Ci} / \mathrm{m}^{3}\right)\end{array}$ & Nuclide \\
\hline $\mathrm{H}-3$ & 1.3E+2 & 1.8E+2 & 2.1E+4 & $2.4 E+8$ & $\mathrm{H}-3$ \\
\hline$c-14$ & $8.0 E+3$ & $1.8 \mathrm{E}+2$ & $1.0 \mathrm{E}+0$ & $2.1 E+4$ & C-14 \\
\hline Al-26 & 1.3E+7 & $2.0 \mathrm{E}+4$ & $1.0 \mathrm{E}+0$ & $5.1 E+6$ & Al-26 \\
\hline Si-32 & 1.3E+7 & $2.0 \mathrm{E}+4$ & $2.8 E+59$ & no limit & Si-32 \\
\hline $\mathrm{Cl}-36$ & 1.3E+2 & $1.8 \mathrm{E}+2$ & $1.0 \mathrm{E}+0$ & $2.4 E+2$ & $\mathrm{Cl}-36$ \\
\hline$K-40$ & $1.5 E+5$ & $2.0 E+4$ & $1.0 \mathrm{E}+0$ & $4.5 E+4$ & $K-40$ \\
\hline Co-60 & $1.4 \mathrm{E}+6$ & $2.1 E+3$ & $7.2 E+121$ & no limit & Co-60 \\
\hline Ni-59 & 1.3E+7 & $2.0 \mathrm{E}+5$ & $6.0 \mathrm{E}+0$ & $2.1 E+9$ & Ni-59 \\
\hline $\mathrm{Ni}-63$ & 1.3E+7 & $2.0 \mathrm{E}+5$ & infinity & no limit & Ni-63 \\
\hline Se-79 & $9.2 \mathrm{E}+2$ & 1.8E+2 & $1.0 \mathrm{E}+0$ & $5.8 \mathrm{E}+2$ & Se-79 \\
\hline Sr-90 & $1.4 \mathrm{E}+6$ & 2.1E+3 & $1.2 E+22$ & $5.9 E+26$ & Sr-90 \\
\hline $2 r-93$ & 1.3E+7 & $2.0 \mathrm{E}+5$ & 1.1E+0 & $3.7 E+7$ & Zr-93 \\
\hline $\mathrm{Nb}-93 \mathrm{~m}$ & 1.3E+7 & $2.0 \mathrm{E}+5$ & infinity & no limit & Nb-93m \\
\hline $\mathrm{Nb}-94$ & 1.3E+7 & $2.0 \mathrm{E}+5$ & $8.9 E+2$ & $9.1 E+9$ & Nb-94 \\
\hline Tc-99 & $9.2 E+2$ & $1.8 \mathrm{E}+2$ & $1.0 \mathrm{E}+0$ & $3.5 E+3$ & TC-99 \\
\hline Pd-107 & 1.3E+7 & $2.0 \mathrm{E}+4$ & $1.0 \mathrm{E}+0$ & $4.8 E+8$ & Pd-107 \\
\hline Ag-108m & 1.3E+7 & $2.0 \mathrm{E}+4$ & $5.4 E+45$ & no limit & Ag-108m \\
\hline Cd-113m & 1.3E+8 & $2.0 \mathrm{E}+5$ & infinity & no limit & Cd-113m \\
\hline Sn-121m & 1.3E+7 & $2.0 \mathrm{E}+5$ & infinity & no limit & Sn-121m \\
\hline Sn-126 & 1.3E+7 & $2.0 \mathrm{E}+5$ & $3.9 \mathrm{E}+0$ & $1.4 \mathrm{E}+7$ & Sn-126 \\
\hline I-129 & $9.2 \mathrm{E}+2$ & $1.8 \mathrm{E}+2$ & $1.0 \mathrm{E}+0$ & $1.8 E+1$ & I-129 \\
\hline Cs-135 & $1.4 \mathrm{E}+5$ & $2.1 \mathrm{E}+3$ & $1.0 \mathrm{E}+0$ & $1.1 \mathrm{E}+5$ & Cs-135 \\
\hline Cs-137 & $1.4 E+5$ & $2.1 E+3$ & $1.9 \mathrm{E}+21$ & $3.0 E+25$ & Cs-137 \\
\hline Ba-133 & $1.4 E+5$ & $2.1 \mathrm{E}+3$ & $9.9 E+60$ & no limit & Ba-133 \\
\hline Sm-151 & 1.3E+7 & $2.0 \mathrm{E}+5$ & infinity & no limit & Sm-151 \\
\hline Eu-152 & 1.3E+6 & $2.0 E+4$ & infinity & no limit & Eu-152 \\
\hline Eu-154 & 1.3E+6 & $2.0 \mathrm{E}+4$ & infinity & no limit & Eu-154 \\
\hline $\mathrm{Pb}-210$ & 1.3E+8 & $2.0 \mathrm{E}+5$ & infinity & no limit & $\mathrm{Pb}-210$ \\
\hline Ra-226 & 1.3E+6 & $2.0 \mathrm{E}+4$ & $5.2 E+3$ & $4.4 E+6$ & Ra-226 \\
\hline Ra-228 & 1.3E+6 & $2.0 \mathrm{E}+4$ & infinity & no limit & Ra-228 \\
\hline Th-229 & $1.3 E+8$ & $2.0 E+5$ & $1.2 E+8$ & 2.1E+13 & Th-229 \\
\hline Th-230 & $1.3 E+8$ & $2.0 \mathrm{E}+5$ & case 2 & $8.6 E+4$ & Th-230 \\
\hline Th-232 & $1.3 E+8$ & 2.0E+5 & $1.0 \mathrm{E}+0$ & $1.4 E+5$ & Th-232 \\
\hline $\mathrm{Pa-231}$ & $1.4 E+6$ & $2.1 E+3$ & $1.0 \mathrm{E}+0$ & $3.2 \mathrm{E}+2$ & $\mathrm{~Pa}-231$ \\
\hline
\end{tabular}


Table HAN-12. Results of the PE Water Pathway Calculations for the Radioactive Mixed Waste Land Disposal Facility at the Hanford Site (Part 2 of 2)

\begin{tabular}{|c|c|c|c|c|c|}
\hline Nuclide & $\begin{array}{l}\text { CRF total } \\
\text { (no decay) }\end{array}$ & $\begin{array}{c}\text { Arrival Time } \\
(y) \\
\end{array}$ & $r_{\text {Docay }}$ & $\begin{array}{c}C_{\text {w.water }} \\
\left(\mu \mathrm{Ci} / \mathrm{m}^{2}\right)\end{array}$ & Nuclide \\
\hline $\mathrm{U}-2,32$ & $7.9 E+4$ & $1.8 \mathrm{E}+2$ & $5.7 \mathrm{E}+0$ & $1.2 \mathrm{E}+3$ & U-232 \\
\hline U-233 & $7.9 \mathrm{E}+4$ & $1.8 \mathrm{E}+2$ & case 2 & $1.2 E+3$ & U-233 \\
\hline U-234 & $7.9 E+4$ & $1.8 \mathrm{E}+2$ & case 2 & $1.5 E+3$ & U-234 \\
\hline$U-235$ & $7.9 \mathrm{E}+4$ & $1.8 E+2$ & case 2 & $1.2 E+3$ & U-235 \\
\hline U-236 & $7.9 E+4$ & $1.8 \mathrm{E}+2$ & $1.0 \mathrm{E}+0$ & $1.6 \mathrm{E}+3$ & $\mathrm{U}-236$ \\
\hline U-238 & $7.9 E+4$ & $1.8 \mathrm{E}+2$ & $1.0 \mathrm{E}+0$ & $1.5 \mathrm{E}+3$ & U-238 \\
\hline Np-237 & $1.3 E+7$ & $2.0 E+4$ & $1.0 E+0$ & $1.6 E+4$ & Np-237 \\
\hline Pu-238 & 1.3E+8 & $2.0 E+5$ & infinity & $4.3 E+6$ & $\mathrm{Pu}-238$ \\
\hline Pu-239 & $1.3 E+8$ & $2.0 E+5$ & $2.8 E+2$ & $5.7 E+7$ & Pu-239 \\
\hline Pu-240 & $1.3 E+8$ & $2.0 E+5$ & $9.8 \mathrm{E}+8$ & $2.0 E+14$ & $\mathrm{Pu}-240$ \\
\hline Pu-241 & $1.3 E+8$ & $2.0 \mathrm{E}+5$ & infinity & $2.4 \mathrm{E}+9$ & Pu-241 \\
\hline Pu-242 & 1.3E+8 & $2.0 E+5$ & $1.4 E+0$ & $3.1 E+5$ & $\mathrm{Pu}-242$ \\
\hline Pu-244 & $1.3 E+8$ & $2.0 E+5$ & $1.0 \mathrm{E}+0$ & $1.3 E+5$ & $\mathrm{Pu}-244$ \\
\hline Am-241 & $1.3 E+8$ & $2.0 E+5$ & $2.0 E+136$ & $8.1 \mathrm{E}+7$ & $A m-241$ \\
\hline Am-243 & $1.3 E+8$ & $2.0 E+5$ & $1.0 E+8$ & $2.0 \mathrm{E}+13$ & Am-243 \\
\hline $\mathrm{Cm}-243$ & $1.3 E+8$ & $2.0 E+5$ & infinity & 4.7E+10 & $\mathrm{Cm}-243$ \\
\hline Cm-244 & $1.3 E+8$ & $2.0 \mathrm{E}+5$ & infinity & $7.2 E+16$ & $\mathrm{Cm}-244$ \\
\hline Cm-245 & $1.3 E+8$ & $2.0 E+5$ & $8.7 E+6$ & $1.2 E+5$ & $\mathrm{Cm}-245$ \\
\hline $\mathrm{Cm}-246$ & $1.3 E+8$ & $2.0 E+5$ & $2.5 E+12$ & $4.8 E+17$ & $\mathrm{Cm}-246$ \\
\hline $\mathrm{Cm}-247$ & $1.3 E+8$ & $2.0 E+5$ & $1.0 E+0$ & $1.2 E+5$ & $\mathrm{Cm}-247$ \\
\hline $\mathrm{Cm}-248$ & $1.3 E+8$ & $2.0 E+5$ & $1.5 E+0$ & $7.8 \mathrm{E}+4$ & $\mathrm{Cm}-248$ \\
\hline C $1-249$ & $1.3 E+8$ & $2.0 E+5$ & $1.0 E+168$ & $2.8 E+6$ & Cf-249 \\
\hline Cf-250 & $1.3 E+8$ & $2.0 E+5$ & infinity & $1.7 \mathrm{E}+20$ & Cf-250 \\
\hline Cf-251 & $1.3 E+8$ & $2.0 \mathrm{E}+5$ & $3.4 E+65$ & no limit & Cf-251 \\
\hline
\end{tabular}


Table HAN-13. Parameters and Values Used in the Atmospheric Pathway PE Analysis for the Radioactive Mixed Waste Land Disposal Facility at Hanford

\begin{tabular}{|c|c|c|c|}
\hline Parameter & Value & $\begin{array}{l}\text { Data } \\
\text { Type" }\end{array}$ & Comments \\
\hline $\begin{array}{l}\text { Cover thickness above the disposal } \\
\text { facility, } x\end{array}$ & $3.0 \mathrm{~m}$ & B & $\begin{array}{l}\text { Value is site-specific } \\
\text { (Wood et al. 1994) }\end{array}$ \\
\hline Depth of the soil surface, $d$ & $0.01 \mathrm{~m}$ & D & $\begin{array}{l}\text { Standard PE method; value is generic } \\
\text { and not site-specific }\end{array}$ \\
\hline Void space in the soil, $n$ & 0.5 & A & $\begin{array}{l}\text { Value is site-specific } \\
\text { (Wood et al. 1994) }\end{array}$ \\
\hline $\begin{array}{l}\text { Moisture content in the soil void } \\
\text { space, } s\end{array}$ & 0.14 & A & $\begin{array}{l}\text { Value is site-specific } \\
\text { (Wood et al. 1994) }\end{array}$ \\
\hline $\begin{array}{l}\text { Ratio of the density of water in air } \\
\text { to that in the liquid phase for } \mathrm{H}-3, r\end{array}$ & $9.20 E-6$ & D & Standard PE value \\
\hline $\begin{array}{l}\text { Ratio of the } \mathrm{CO}_{2} \text { concentration in } \\
\text { air to that in dissolved water for } \\
\mathrm{C}-14, r\end{array}$ & $4.25 E-4$ & D & Standard PE value \\
\hline $\begin{array}{l}\text { Diffusion coefficient in air for } \mathrm{H}-3 \text {, } \\
\text { D }\end{array}$ & $\begin{array}{c}2.39 \mathrm{E}-5 \\
\mathrm{~m}^{2} / \mathrm{s}\end{array}$ & D & Standard PE value \\
\hline $\begin{array}{l}\text { Diffusion coefficient in air for C-14, } \\
D\end{array}$ & $\begin{array}{l}1.40 \mathrm{E}-5 \\
\mathrm{~m}^{2} / \mathrm{s}\end{array}$ & D & Standard PE value \\
\hline $\begin{array}{l}\text { Atmospheric dispersion parameter, } \\
A_{D_{1}} \text { for site-specific RMWLDF } \\
\text { design }\end{array}$ & 2.26 & A & $\begin{array}{l}\text { Value is estimated using the Industrial } \\
\text { Source Complex-Version } 2 \text { Long } \\
\text { Term Air Dispersion Model (ISCLT2) } \\
\text { (EPA 1992) based on site-specific } \\
\text { STAR data }\end{array}$ \\
\hline $\begin{array}{l}\text { Atmospheric Scenario Dose } \\
\text { Conversion Factor for } \mathrm{H}-3, \text { SDCF }\end{array}$ & $\begin{array}{c}8.33 \mathrm{E}+2 \\
\mathrm{mrem} / \mathrm{y} \text { per } \\
\mu \mathrm{Ci} / \mathrm{m}^{3}\end{array}$ & D & $\begin{array}{l}\text { Standard PE value; includes "all } \\
\text { pathways" considerations. }\end{array}$ \\
\hline $\begin{array}{l}\text { Atmospheric Scenario Dose } \\
\text { Conversion Factor for C-14, SDCF }\end{array}$ & $\begin{array}{c}2.20 \mathrm{E}+5 \\
\mathrm{mrem} / \mathrm{y} \mathrm{per} \\
\mu \mathrm{Ci} / \mathrm{m}^{3}\end{array}$ & D & $\begin{array}{l}\text { Standard PE value; includes "all } \\
\text { pathways" considerations. }\end{array}$ \\
\hline
\end{tabular}

${ }^{2} A=$ Site measurement; $B=$ Result of site numerical analysis; $C=$ Literature value selected by site; $D=$ Generic PE value 
Table HAN-14. Results of the Atmospheric Pathway Calculations for the Radioactive Mixed Waste Land Disposal Facility at Hanford

\begin{tabular}{|c|c|c|c|c|c|c|}
\hline Nuclide & $\begin{array}{c}S D C F_{A t m} \\
\text { (rem/y.per } \mu \mathrm{CI} / L)\end{array}$ & $\begin{array}{c}\text { CRF } \\
\text { (dimensionless) }\end{array}$ & $\begin{array}{c}\text { CRF } \\
\text { (dimensioniess) }\end{array}$ & $\begin{array}{c}\text { Arrival } \\
\text { Time (y) }\end{array}$ & $\begin{array}{c}r_{\text {Decay }} \\
\text { (dimensionless) }\end{array}$ & $\begin{array}{r}C_{W-A t m} \\
\left(\mu \mathrm{Ci} / \mathrm{m}^{3}\right)\end{array}$ \\
\hline $\mathrm{H}-3$ & $8.33 E+02$ & $2 E+06$ & $2 E+02$ & 100 & 300 & $1 E+9$ \\
\hline C-14 & $2.37 E+05$ & $5 E+04$ & $3 E+02$ & 100 & 1 & $7 E+02$ \\
\hline
\end{tabular}

\section{A.4.3.3 Inadvertent Intruder Exposure for the RMWLDF}

As explained in Section 16.3.3 of this volume, the PE used two standard intrusion scenarios-agricultural (or homesteader) and post-drilling-to describe potential modes of inadvertent intrusion into the waste facility. Both intrusion scenarios are assumed to be credible and applicable for the RMWLDF at Hanford.

The geometry factor, $f_{g}$, for the RMWLDF was assumed to be 0.8 , based upon the large size of the facility. The permissible waste concentrations for the RMWLDF for each of the 58 radionuclides based on the standard PE intrusion scenarios are listed in Table HAN-15.

Values for the radioactive decay term in Table HAN-15 were based on the applicable time of homesteader intrusion into the disposal facility $(3,000 \mathrm{y})$. For six radionuclides in the table (U-233, U-234, U-235, U-238, Pu-244, and Cm-247), the time of homesteader intrusion was changed to $10,000 \mathrm{y}$, the end of the performance period. For these six radionuclides, ingrowth of decay products yields scenario doses that increase over time. The doses at $10,000 \mathrm{y}$, therefore, represent the maximum that could be encountered during the performance period. Also, for Th-230 and Cm-245, ingrowth of decay products likewise produces a scenario dose that increases over time and peaks within the 10,000-y performance period. The times of homesteader intrusion for these two radionuclides (Th-230 and $\mathrm{Cm}-245$ ) were taken as the time of maximum dose, $9,000 \mathrm{y}$ and $1,000 \mathrm{y}$, respectively.

\section{A.4.3.4 PE Results for the RMWLDF at Hanford}

The limiting waste concentrations in the disposed MLLW for the water, atmospheric, and intruder analyses for the RMWLDF are summarized in Table HAN-16. For the RMWLDF design at Hanford, five radionuclides were limited by the water pathway, one radionuclide (C-14) was limited by the atmospheric pathway, and 52 radionuclides were limited by intrusion scenarios.

For the RMWLDF, four waste concentrations were reported for the water pathway analysis as having no limit. The calculated concentrations for those radionuclides reported as NL (No Limit) were above the specific activity of the pure elemental radionuclide, implying that the performance measure of $4 \mathrm{mrem}(0.04 \mathrm{mSv})$ per year would not be reached under the given release and transport assumptions. 
Table HAN-15. Permissible Waste Concentration for the Intrusion Scenarios for the Radioactive Mixed Waste Land Disposal Facility at the Hanford Site (most limiting radionuclide concentration for each facility design is highlighted in bold italic) (Part 1 of 2)

\begin{tabular}{|c|c|c|c|}
\hline \multirow[b]{2}{*}{ Nuclide } & \multicolumn{2}{|c|}{ Hanford RMWLDF (Trench) } & \multirow[b]{2}{*}{ Nuclide } \\
\hline & $\begin{array}{c}C_{\text {W/Antr }} \\
\text { Homesteader } \\
\left(\mu \mathrm{Ci} / \mathrm{m}^{3}\right)\end{array}$ & $\begin{array}{c}C_{W-\ln t r} \\
\text { Post-Drilling } \\
\left(\mu \mathrm{Ci} / \mathrm{m}^{3}\right) \\
\end{array}$ & \\
\hline $\mathrm{H}-3$ & $7 E+11$ & $7 E+07$ & $\mathrm{H}-3$ \\
\hline C-14 & $9 E+03$ & $7 E+04$ & $c-14$ \\
\hline Al-26 & $3 E+01$ & $5 E+04$ & Al-26 \\
\hline Si-32 & $6 E+03$ & $1 E+04$ & Si-32 \\
\hline $\mathrm{Cl}-36$ & $1 E+02$ & $9 E+02$ & Cl-36 \\
\hline$K-40$ & $4 E+02$ & $2 E+04$ & $K-40$ \\
\hline Co-60 & $N L^{b}$ & $3 E+10$ & Co-60 \\
\hline Ni-59 & $2 E+06$ & $1 \mathrm{E}+07$ & Ni-59 \\
\hline $\mathrm{Ni}-63$ & $5 E+06$ & $1 \mathrm{E}+07$ & $\mathrm{Ni}-63$ \\
\hline Se-79 & $1 E+05$ & $8 E+05$ & Se-79 \\
\hline Sr-90 & $8 E+05$ & $5 E+04$ & Sr-90 \\
\hline Zr-93 & $3 E+06$ & $3 E+07$ & $2 r-93$ \\
\hline $\mathrm{Nb}-93 \mathrm{~m}$ & $3 E+12$ & $4 E+09$ & $\mathrm{Nb}-93 \mathrm{~m}$ \\
\hline $\mathrm{Nb}-94$ & $6 E+01$ & $9 \mathrm{E}+04$ & $\mathrm{Nb}-94$ \\
\hline Tc-99 & $1 E+04$ & $8 E+04$ & TC-99 \\
\hline Pd-107 & $4 E+06$ & $3 E+07$ & $P d-107$ \\
\hline $\mathrm{Ag}-108 \mathrm{~m}$ & $3 E+02$ & $1 E+05$ & $\mathrm{Ag}-108 \mathrm{~m}$ \\
\hline $\mathrm{Cd}-113 \mathrm{~m}$ & $2 E+09$ & $1 E+06$ & Cd-113m \\
\hline Sn-121m & $1 E+07$ & $5 E+07$ & Sn-121m \\
\hline Sn-126 & $5 E+01$ & $7 E+04$ & $5 n-126$ \\
\hline $1-129$ & $2 E+03$ & $1 E+04$ & $1-129$ \\
\hline Cs-135 & $1 E+05$ & $8 E+05$ & Cs-135 \\
\hline Cs-137 & $2 E+05$ & $8 E+05$ & Cs-137 \\
\hline Ba-133 & $1 E+11$ & $3 E+08$ & Ba-133 \\
\hline Sm-151 & $1 E+08$ & $2 E+08$ & $S m-151$ \\
\hline Eu-152 & $4 E+08$ & $2 E+07$ & Eu-152 \\
\hline Eu-154 & $2 E+12$ & $4 E+08$ & Eu-154 \\
\hline $\mathrm{Pb}-210$ & $5 E+06$ & $7 E+04$ & $\mathrm{~Pb}-210$ \\
\hline Ra-226 & $5 E+01$ & $3 E+03$ & Ra-226 \\
\hline Ra-228 & $\mathrm{NL}^{\mathrm{b}}$ & $4 E+09$ & Ra-228 \\
\hline Th-229 & $3 E+02$ & $3 E+04$ & Th-229 \\
\hline Th-230 & $5 E+01^{\circ}$ & $7 E+04$ & Th-230 \\
\hline Th-232 & $3 E+01$ & $2 E+04$ & Th-232 \\
\hline $\mathrm{Pa}-231$ & $2 E+02$ & $5 E+03$ & $\mathrm{~Pa}-231$ \\
\hline
\end{tabular}


Table HAN-15. Permissible Waste Concentration for the Intrusion Scenarios for the Radioactive Mixed Waste Land Disposal Facility at the Hanford Site (most limiting radionuclide concentration for each facility design is highlighted in bold italic) (Part 2 of 2)

\begin{tabular}{|c|c|c|c|}
\hline \multirow[b]{2}{*}{ Nuclide } & \multicolumn{2}{|c|}{ Hanford RMWLDF (Trench) } & \multirow[b]{2}{*}{ Nuclide } \\
\hline & $\begin{array}{c}C_{\text {W-Intr }} \\
\text { Homesteader } \\
\left(\mu \mathrm{Cim}^{3}\right)\end{array}$ & $\begin{array}{c}C_{\text {W-Antr }} \\
\text { Post-Drilling } \\
\left.(\mu \mathrm{Cilm})^{3}\right)\end{array}$ & \\
\hline$U-232$ & $1 E+03$ & $5 E+04$ & $\mathrm{U}-232$ \\
\hline $\mathrm{U}-233^{\dagger}$ & $6 E+02^{T}$ & $1 E+05$ & $U-233^{f}$ \\
\hline$U-234^{f}$ & $6 E+02^{f}$ & $1 E+05$ & $U-234^{f}$ \\
\hline$U-235^{f}$ & $4 E+02^{7}$ & $1 E+05$ & $U-235^{f}$ \\
\hline U-236 & $1 E+04$ & $1 E+05$ & U-236 \\
\hline$U-238^{f}$ & $3 E+03^{7}$ & $1 E+05$ & $U-238^{f}$ \\
\hline $\mathrm{Np}-237$ & $2 E+02$ & $4 E+03$ & Np-237 \\
\hline Pu-238 & $5 E+04$ & $1 E+05$ & Pu-238 \\
\hline Pu-239 & $4 E+03$ & $5 E+04$ & Pu-239 \\
\hline Pu-240 & $4 E+03$ & $5 E+04$ & Pu-240 \\
\hline Pu-241 & $1 E+05$ & $1 E+06$ & Pu-241 \\
\hline Pu-242 & $4 E+03$ & $5 E+04$ & Pu-242 \\
\hline Pu-244 & $3 E+02^{f}$ & $5 E+04$ & $\mathrm{Pu}-244^{\mathrm{f}}$ \\
\hline Am-241 & $4 E+03$ & $5 E+04$ & Am-241 \\
\hline Am-243 & $5 E+02$ & $4 E+04$ & Am-243 \\
\hline $\mathrm{Cm}-243$ & $9 \mathrm{E}+05$ & $8 E+05$ & $\mathrm{Cm}-243$ \\
\hline $\mathrm{Cm}-244$ & $1 E+06$ & $3 E+06$ & Cm-244 \\
\hline $\mathrm{Cm}-245^{\circ}$ & $9 E+02^{\circ}$ & $4 E+04$ & $\mathrm{Cm}-245^{8}$ \\
\hline $\mathrm{Cm}-246$ & $4 E+03$ & $5 E+04$ & $\mathrm{~cm}-246$ \\
\hline $\mathrm{Cm}-247^{f}$ & $2 E+02^{f}$ & $5 E+04$ & $\mathrm{Cm}-247^{\mathrm{f}}$ \\
\hline $\mathrm{Cm}-248$ & $1 E+03$ & $1 E+04$ & $\mathrm{Cm}-248$ \\
\hline Cf-249 & $5 E+02$ & $4 E+04$ & Cf-249 \\
\hline Cf -250 & $1 E+06$ & $9 E+06$ & Cf-250 \\
\hline Cf-251 & $1 E+03$ & $4 E+04$ & $C f-251$ \\
\hline
\end{tabular}

a Except as otherwise noted, the time of homesteader intrusion is $300 \mathrm{y}$ after closure of the disposal facility.

b "NL" = No Limit; the estimated permissible concentration exceeds the specific activity of the pure elemental radionuclide.

c The time of post-drilling intrusion is $100 \mathrm{y}$ after closure of the disposal facility.

d Except as otherwise noled, the time of homesteader intrusion is $500 \mathrm{y}$ after closure of the disposal facility.

- Homesteader intrusion is assumed to occur at 9,000 y after closure of the disposal facility, since the ingrowth of decay products for this radionuclide would produce the maximum dose at that time.

i Homesteader intrusion is assumed to occur at 10,000 y after closure of the disposal facility, since the ingrowth of decay products for this radionuclide would produce the maximum dose at that time.

g Homesteader intrusion is assumed to occur at 1,000 y after closure of the disposal facility, since the ingrowth of decay products for this radionuclide would produce the maximum dose at that time. 
Table HAN-16. Permissible Waste Concentrations for the Radioactive Mixed Waste Land Disposal Facility at the Hanford Site (for each radionuclide, the most restrictive concentration among the three pathways is highlighted in bold italics) (Part 1 of 2)

\begin{tabular}{|c|c|c|c|c|}
\hline \multirow[b]{2}{*}{ Nuclide } & \multicolumn{3}{|c|}{ Radioactive Mixed Waste Land Disposal Facility } & \multirow[b]{2}{*}{ Nuclide } \\
\hline & $\begin{array}{c}C_{\text {W.Wator, }} \\
\left(\mu \mathrm{C} / \mathrm{m}^{3}\right)\end{array}$ & $\begin{array}{l}C_{W \cdot A t m}{ }^{c} \\
\left(\mu \mathrm{C} / m^{2}\right)\end{array}$ & $\begin{array}{l}C_{W-\operatorname{lntr}{ }^{\sigma}} \\
\left(\mu \mathrm{Ci} / \mathrm{m}^{3}\right)\end{array}$ & \\
\hline $\mathrm{H}-3$ & $2 E+08$ & $1 E+09$ & $7 E+07$ & $\mathrm{H}-3$ \\
\hline$C-14$ & $2 E+04$ & $7 E+02$ & $9 E+03$ & $c-14$ \\
\hline Al-26 & - & & $3 E+01$ & Al-26 \\
\hline Si-32 & - & & $6 E+03$ & Si-32 \\
\hline $\mathrm{Cl}-36$ & $2 E+02$ & & $1 E+02$ & $\mathrm{Cl}-36$ \\
\hline$K-40$ & - & & $4 E+02$ & $K-40$ \\
\hline Co-60 & $\mathrm{NL}$ & & $3 E+10$ & $c 0-60$ \\
\hline Ni-59 & - & & $2 E+06$ & Ni-59 \\
\hline Ni-63 & - & & $5 E+06$ & Ni-63 \\
\hline$\overline{S e-79}$ & $6 E+02$ & & $1 E+05$ & Se-79 \\
\hline ST-90 & $\mathrm{NL}$ & & $5 E+04$ & Sr-90 \\
\hline Zr-93 & $\overline{-}$ & & $3 E+06$ & $z r-93$ \\
\hline $\mathrm{Nb}-93 \mathrm{~m}$ & - & & $4 E+09$ & $\mathrm{Nb}-93 \mathrm{~m}$ \\
\hline $\mathrm{Nb}-94$ & - & & $6 E+01$ & $\mathrm{Nb}-94$ \\
\hline$T c-99$ & $3 E+03$ & & $1 E+04$ & Tc-99 \\
\hline $\mathrm{Pd}-107$ & - & & $4 E+06$ & $\mathrm{Pd}-107$ \\
\hline $\mathrm{Ag}-108 \mathrm{~m}$ & - & & $3 E+02$ & Ag-108m \\
\hline Cd-113m & - & & $1 E+06$ & $C d-113 m$ \\
\hline Sn-121m & $\overline{-}$ & & $1 E+07$ & Sn-121m \\
\hline $5 n-126$ & $\overline{-}$ & & $5 E+01$ & Sn-126 \\
\hline $1-129$ & $2 E+01$ & & $2 E+03$ & $1-129$ \\
\hline Cs-135 & $1 E+05$ & & $1 E+05$ & Cs-135 \\
\hline Cs-137 & $\mathrm{NL}$ & & $2 E+05$ & Cs-137 \\
\hline Ba-133 & $\mathrm{NL}$ & & $3 E+08$ & Ba-133 \\
\hline$S m-151$ & - & & $1 E+08$ & Sm-151 \\
\hline Eu-152 & - & & $2 E+07$ & Eu-152 \\
\hline Eu-154 & - & & $4 E+08$ & Eu-154 \\
\hline $\mathrm{Pb}-210$ & $\overline{-}$ & & $7 E+04$ & $\mathrm{~Pb}-210$ \\
\hline Ra-226 & - & & $5 E+01$ & Ra-226 \\
\hline Ra-228 & - & & $4 E+09$ & Ra-228 \\
\hline Th-229 & - & & $3 E+02$ & Th-229 \\
\hline Th-230 & - & & $5 E+01$ & Th-230 \\
\hline Th-232 & $=$ & & $3 E+01$ & Th-232 \\
\hline $\mathrm{Pa}-231$ & $3 E+02$ & & $2 E+02$ & Pa-231 \\
\hline
\end{tabular}


Table HAN-16. Permissible Waste Concentrations for the Radioactive Mixed Waste Land Disposal Facility at the Hanford Site (for each radionuclide, the most restrictive concentration among the three pathways is highlighted in bold italics)

(Part 2 of 2)

\begin{tabular}{|c|c|c|c|c|}
\hline \multirow[b]{2}{*}{ Nuclide } & \multicolumn{3}{|c|}{ Radioactive Mixed Waste Land Disposal Facility } & \multirow[b]{2}{*}{ Nuclide } \\
\hline & $\begin{array}{c}C_{\text {w.water }}{ }^{a, b} \\
\left(\mu \mathrm{Ci} / \mathrm{m}^{3}\right) \\
\end{array}$ & $\begin{array}{l}C_{W-A t m}{ }^{c} \\
\left(\mu \mathrm{Ci} / \mathrm{m}^{3}\right)\end{array}$ & $\begin{array}{l}C_{w / n t r}{ }^{d} \\
\left(\mu \mathrm{Ci} / \mathrm{m}^{3}\right)\end{array}$ & \\
\hline $\mathrm{Np}-237$ & - & & $2 E+02$ & Np-237 \\
\hline Pu-238 & - & & $5 E+04$ & $\mathrm{Pu}-238$ \\
\hline Pu-239 & - & & $4 E+03$ & Pu-239 \\
\hline Pu-240 & - & & $4 E+03$ & Pu-240 \\
\hline Pu-241 & - & & $1 E+05$ & Pu-241 \\
\hline Pu-242 & - & & $4 E+03$ & Pu-242 \\
\hline Pu-244 & - & & $3 E+02$ & Pu-244 \\
\hline Am-241 & - & & $4 E+03$ & Am-241 \\
\hline Am-243 & - & & $5 E+02$ & Am-243 \\
\hline $\mathrm{Cm}-243$ & - & & $8 E+05$ & $\mathrm{Cm}-243$ \\
\hline $\mathrm{Cm}-244$ & - & & $1 E+06$ & $\mathrm{Cm}-244$ \\
\hline $\mathrm{Cm}-245$ & - & & $9 E+02$ & $\mathrm{Cm}-245$ \\
\hline $\mathrm{Cm}-246$ & - & & $4 E+03$ & $\mathrm{Cm}-246$ \\
\hline $\mathrm{Cm}_{\mathrm{m}-247}$ & - & & $2 E+02$ & $\mathrm{Cm}-247$ \\
\hline $\mathrm{Cm}-248$ & - & & $1 E+03$ & $\mathrm{Cm}-248$ \\
\hline Cf-249 & - & & $5 E+02$ & Cf-249 \\
\hline Cf-250 & - & & $1 E+06$ & Cf -250 \\
\hline Cf-251 & - & & $1 E+03$ & Cf-251 \\
\hline
\end{tabular}

- "NL" = No Limit; the estimated permissible waste concentration exceeds the specific activity of the pure elemental radionuclide.

b "- Indicates that the waste concentration is based on a groundwater arrival time beyond 10,000 years; for specific values, see Table 16-4 in Chapter 16 of this volume.

- Results presented only for radionclides expected to be volatile under disposal facility conditions.

- Waste concentration is based on the most restrictive intrusion scenario (i.e., homesteader or post-drilling) for the site; soe Table $16-6$ in Chapter 16 of this volume for specific values. 
Also, values for some radionuclides are not reported in Table HAN-16 for the water pathway analysis. Arrival times for these radionuclides were beyond the 10,000-y performance period. For these radionuclides, the estimated waste concentrations are presented in Table HAN-12 for information purposes but are not listed in Table HAN-15. Consistent with the approach used in LLW performance assessments, because arrival times for these radionuclides were beyond $10,000 \mathrm{y}$, these values were not considered in determining the most restrictive disposal limit from among the evaluated pathways.

For the RMWLDF, the radionuclides limited by the water pathway generally tended to be highly mobile (e.g., Tc-99 and I-129). While the some of the uraniums (i.e., U-236 and U-238) are limited by the water pathway at Hanford, none of the radiums, thoriums, or transuranics are limited by the water pathway because their peak arrival times were beyond $10,000 \mathrm{y}$.

\section{A.4.4 REFERENCES}

Wood, M. W., 1995. Personal communication with John Tauxe (ORNL) on December 20, 1994, and January 10, 1995.

Wood, M. W., R. Khaleel, P. D. Rittman, A. H. Lu, S. H. Finfrock, R. J. Serne, K. J. Cantrell, T. H. DeLorenzo, 1994. Performance Assessment for the Disposal of Low-Level Waste in the 200 West Area Burial Grounds, WHC-EP-0645, prepared for the U. S. Department of Energy, Office of Environmental Restoration and Waste Management by Westinghouse Hanford Company, Richland, Wash.

Khaleel, R., 1995. Personal communication with John Tauxe, Oak Ridge National Laboratory, January 1995. 


\section{DISTRIBUTION}

National Governors Association

State Task Force Representatives

John Thomasian

NGA-Natural Resources Policy Studies

444 N. Capitol Street, Suite 267

Washington, DC 20001

Jerry Boese

Ross \& Associates

1218 Third Avenue, Suite 1207

Seattle, WA 98101

Rufus Howell

Chief, Environmental Health Services

Section

Drinking Water and Environmental

Management Div.

California Dept. of Health Services

P. O. Box 942732, MS-216

Sacramento, CA 94234-7320

Jan Radimsky

Acting Assistant Deputy Director

Office of Statewide Planning

CA Dept. of Toxic Substance Control

400 P Street, Box 806

Sacramento, CA 95812-0806

Jacqueline Hernandez-Berardini

Director, Environmental Integration

Group

Colorado Dept. of Public Health \&

Environment

4300 Cherry Creek Drive, South/OE-EIG-

B2

Denver, CO 80222-1530

\section{Doug Young}

Environmental Policy Analyst

Office of the Governor

136 State Capitol Building

Denver, CO 80203
Fred Scheuritzel

Radiation Control Physicist

Air Monitoring and Radiation

CT Department of Environmental

Protection

79 Elm Street, 6th Floor

Hartford, CT 06106-5127

Teresa Hay

Administrator, Waste Management Division

Iowa Department of Natural Resources

Wallace State Office Building

East 9th \& Grand Aveue

Des Moines, IA 50319-0034

Allan Stokes

Administrator, Environmental Protection

Division

Iowa Department of Natural Resources

Wallace State Office Building

East 9th \& Grand Aveue

Des Moines, IA 50319-0034

Brian Monson

Bureau Chief

Division of Environmental Quality

1410 North Hilton

Boise, ID 83706-1290

Jeff Schrade

Special Assistant to the Governor

Office of the Governor

700 West State Street

P. O. Box 83720

Boise, ID 83720-0034

Allen Grosboil

Executive Assistant to the Governor

Office of the Governor

204 Statehouse

Springfield, IL 62706 
Tom Ortciger

Director

Illinois Dept. of Nuclear Safety

1035 Outer Park Drive, 5th Floor

Springfield, IL 62704

Pat Haight

Waste Management Division

KY Dept. of Environmental Protection

14 Reilly Road

Frankfort, KY 40601

Randall McDowell

Supervisor, Waste Legal Section

KY Department of Law

Capitol Plaza Tower, 5th Floor

Frankfort, KY 40601

Joan Jones

Environmental Specialist, Hazardous Materials

Unit

Maine Dept. of Environmental Protection

State House, Station \#17

Augusta, ME 04333

Robert Geller

Section Chief, Federal Facilities

Missouri Department of Natural Resources

P. O. Box 176

Jefferson City, MO 65102

David Shorr

Director

Missouri Department of Natural Resources

205 Jefferson St., 12th Floor

Jefferson City, MO 65102

Ed Kelly

Director, Water and Waste Management

Division

New Mexico Environment Dept.

P. O. Box 26110

1190 St. Francis Drive, Rm. N-4050

Santa Fe, NM 87502
Jim Seubert

RCRA Inspection Group Supervisor

Hazardous \& Radioactive Materials Bureau

P. O. Box 26110

Santa Fe, NM 87502

Paul Liebendorfer

Bureau Chief, Bureau of Federal Facilities

Nevada Division of Environmental Protection

$123 \mathrm{~W}$. Nye Lane

Carson City, NV 89710

John Walker

Research Analyst

Agency for Nuclear Projects

1820 N. Carson Street, Suite 252

Carson City, NV 89710

Roger Murphy

Supervisor, Hazardous Waste Land Disposal

Section

Dept. of Environmental Conservation

50 Wolf Road, Rm. 460

Albany, NY 12233-7252

Mike Savage

Assistant Chief, Hazardous Waste Division

Ohio Environmental Protection Agency

P. O. Box 1049

Columbus, $\mathrm{OH}$ 43216-1049

Tom Winston

Chief, South West District Office

Ohio Environmental Protection Agency

401 East Fifth Street

Dayton, OH 45402

Leon Kuchinski

Chief, Division of Hazardous Waste

Management

Bureau of Waste Management

P. O. Box 8471

400 Market Street, 14 Floor

Harrisburg, PA 17105-8471

Dist-2 
Beth Partlow

\section{Legal Counsel}

Office of the Governor

P. O. Box 11369

Columbia, SC 29211

David Wilson

Assistant Bureau Chief, Hazardous and

Infectious Waste Management

SC Dept. of Health \& Environmental Control

2600 Bull Street

Columbia, SC 29201

Brian Kelly

Assistant to the Governor

Office of the Governor

State Capitol -G7

Nashville, TN 37243

Earl Leming

Director, Oversight Division, Department of

Energy

TN Dept. of Environment \& Conservation

761 Emory Valley Drive

Oak Ridge, TN 37830-7072

Boyd Deaver

Pantex Project Manager

Texas Natural Resource Conservation

Commission

3918 Canyon Drive

Amarillo, TX 79109

Roger Mulder

Director of Special Projects

Office of the Governor

P. O. Box 12428

Austin, TX 78711

Harry Gregori

VA Dept. of Environmental Quality

P. O. Box 10009

629 East Main Street

Richmond, VA 23240-0009
Wladimir Gulevich

Assistant Director, Division of Waste

Operations

VA Dept. of Environmental Quality

P. O. Box 10009

629 East Main Street

Richmond, VA 23240-0009

Jeff Breckel

Washington-Oregon Interstate Liason, Nuclear and Mixed Waste Management Program

Washington Department of Ecology

P. O. Box 47600

Olympia, WA $98504-7600$

Mike Wilson

Nuclear Waste Program Manager, Nuclear and

Waste Management Program

Washington Department of Ecology

P. O. Box 47600

Olympia, WA 98504-7600

Disposal Workgroup

Joel Case

DOE/Idaho

850 Energy Drive, MS 1118

Idaho Falls, ID 8340.1-1563

Martin Letourneau

$\mathrm{DOE} / \mathrm{HQ}$

Trevion II, EM-33

19901 Germantown Road

Germantown, MD 20874-1290

Linda Suttora

DOE/Cloverleaf BIdg.

19901 Germantown Road

Germantown, MD 20874

Lance Mezga

LMES/Oak Ridge

Hwy 58, K-25 Site, Bldg. K-1037

Oak Ridge, TN 37831-7357 
Colleen O'Laughlin

DOE/Nevada

2763 South Highland Drive

Las Vegas, NV 89109

Carol Boghosian

DOE/Oakland Operations Office

1301 Clay Street, 700-N

Oakland, CA 94612-5208

Maurice Ades

WSRC

Bldg. 705-3C

Aiken, SC 29803

Bill Gilbert

DOE/Oak Ridge

200 Administration Road

Oak Ridge, TN 37831-8620

Joanne Steingard (20)

BDM Federal

Bellmeade 3

20300 Century Blvd.

Germantown, MD 20874

Jim Orban

DOE/Albuquerque

P. O. Box 5400

Albuquerque, NM 87185-5400

Tim Sloan

LANL, TA-54 Area L

37 Mesita del Buey Road

Los Alamos, NM 87545

Roger Piscitella

INEL

765 Lindsay Blvd., TSB Bldg.

Idaho Falls, ID 83415

Jeff Kerridge

DOE/RF

Highway 93/Cactus Road, Bldg. T-117A

Golden, CO 80402
John Starmer

ERM

7926 Jones Branch Dr., Suite 210

McLean, VA 22101

Joe Waring

DOE/RL

2355 Stevens Drive, MO 277, 200 E Area

Richland, WA 99352

Ted Eliopoulis

DOE/EM-5, Forrestal Bldg.

1000 Independence Ave., SW

Washington, DC 20585

Senior Review Panel Members

Dade Moeller

Dade Moeller and Associates, Inc.

147 River Island Road

New Bern, NC 28562

Randall Charbeneau

Center for Research in Water Resources

10100 Burnett Road

Austin, TX 78758

William Dornsife

Commonwealth of Pennsylvania

400 Market Street, 13th Floor

Harrisburg, PA 17105

Frank Parker

Vanderbilt University

400 24th Ave., So., CEE-Room 106

Nashville, TN 37235

Vern Rogers

Rogers and Associates Engineering Corp.

515 East, 4500 South

Salt Lake City, UT 84107

Kristin Shrader-Frechette

University of South Florida

Environ. Sc./Policy Prog./ Dept. of Philosophy

107 Cooper Hall

Tampa, FL 33620-5550

Dist-4 
PE Internal Review Team Members

Jim Cook

WSRC

Building 773-43A

Aiken, SC 29874-1290

David Kocher

ORNL

1060 Commerce Park

Oak Ridge, TN 37830-6480

Don Lee

Oak Ridge National Laboratories

Bldg. 4500 N, MS-6185

Bethel Valley Road

Oak Ridge, TN 37831-6185

Rob Shuman

Rogers \& Assoc.

21124 E. Lakeshore Road

Big Fork, MO 59911

Reading Rooms

Nancy Ben

DOE/RF Public Reading Room

3645 West 112th Ave., Front Range CC

Westminster, CO 80030

Janet Fogg

DOE/NV Public Reading Room

$3084 \mathrm{~S}$. Highland Drive

Las Vegas, NV 89109

Kristin Giller/Rose Newman

LLNL Visitors' Center

L-790, Greenville Road, Bldg. 651

Livermore, CA 94550

Diane Leute

DOE/Albuquerque

P. O. Box 5400

Albuquerque, NM 87185-5400
Paul Lewis

University of SC - Aiken

171 University Pkwy, Gregg-Graniteville Lib.

Aiken, SC 29801

Amy Rothrock

DOE Public Reading Room

55 Jefferson Circle, Room 112

Oak Ridge, TN 37831

Gayla Sessoms

DOE Public Reading Room

1000 Independence Ave., SW, Rm. 1E190

HR831

Washington, DC 20525

Terri Traub

DOE Public Reading Room

100 Sprout Road, Room 130 West

Richland, WA 99352

Kim Tully

Center for Environmental Mgmt. Information

470 L'Enfant Plaza East, SW, Ste. 7112

Washington, DC 20024

Gail Wilmore

DOE/ID Public Reading Room

University Place, 1776 Science Center Dr.

Idaho Falls, ID 83415

Mary Wilson

Miamisburg Sr. Adult Cntr. Public Reading Rm.

305 East Central Avenue

Miamisburg, OH 45342 
Policy Coordinating Group

Mona Williams

DOE/Albuquerque Operations Office

P. O. Box 5400

Albuquerque, NM 87185-5400

Mike Klimas

DOE/Chicago Operations

9800 S. Cass Avenue

Argonne, IL 60439

John Sattler

DOE/Fernald

7400 Wiley Road

Cincinnati, $\mathrm{OH}$ 45253-8705

David Osugi

DOE/Oakland

1303 Clay Street, 700-N

Oakland, CA 94612

Joy Sager

DOE/Oak Ridge Operations Office

3 Main Street

Oak Ridge, TN 37830

Bill Prymak

DOE/Rocky Flats Operations Office

Highway 93

Golden, CO 80402

Joe Waring

DOE/Richland

2355 Stevens Drive, MO-277

Richland, WA 99352

Virgil Sauls

DOE/Savannah River Operations Office

Road 1A

Aiken, SC 29808

T. J. Rowland

DOE/West Valley Demonstration Project

10282 Rock Springs Road

West Valley, NY 14171
Rob Rothman

DOE/Miamisburg Area Office

1 Mound Road

Miamisburg, $\mathrm{OH} 45342$

Tom Shadoan

DOE/Paducah

5600 Hobbs Road

Paducah, KY 42001

Melda Rafferty

DOE/Portsmouth

3930 US Route 23, Perimeter Road

Piketon, OH 45661

Site Technical Contacts

Albert Lamarre

LLNL

7000 East Avenue, L-619

Livermore, CA 94550

Mark Wood

WHC-Hanford

2355 Stevens Drive

Richland, WA 99352

Greg Shott

REECo-Nevada Test Site

3271 S. Highland, Suite 702

Las Vegas, NV 89109

Swen Magnuson

EG\&G/INEL

2251 North Blvd.

Idaho Falls, ID 83415

Brandon Williamson

DOE/Rocky Flats

Highway 93

Golden, CO 80402

Dianna Hollis

LANL

CST-14, MS J595

Bikini Road, SM30 Warehouse

Los Alamos, NM 87545

Dist-6 
Dan Ferguson

DOE/Pantex

Hwy 60 at FM 2373

Amarillo, TX 79120

Norbert Golchert

Argonne-East

9700 S. Cass Avenue, Bldg. 214

Argonne, IL 60439

Greg Shaia

Lockheed Martin-Paducah

1410 Hobbs Road

Paducah, KY 42001

Nancy Weatherup

FERMCO-Fernald

7400 Wiley Road

Cincinnati, $\mathrm{OH}$ 45253-8705

James Campbell

Lockheed Martin-Portsmouth

Bldg. X7725

3630 US Route 23 So.

Piketon, OH 45661

Elizabeth Matthews

DOE/West Valley

10282 Rock Springs Road

West Valley, NY 14171

DOE EM-30

Steve Cowan

Deputy Assistant Secretary for Waste

Management

US DOE, EM-30

1000 Independence Avenue, SE

Washington, DC 20585

Gene Schmitt

Associate Deputy

US DOE

EM-30

Germantown, MD 20874
Joseph Coleman

Technical Advisor

US DOE

EM-30

Germantown, MD 20874

Ralph Erickson

Director, EM-32

US DOE

Trevion II

19901 Germantown Road

Germantown, MD 20874

Dick Blaney

Director, EM-33

US DOE

Trevion II

19901 Germantown Road

Germantown, MD 20874

Mark Frei

Director, EM-34

US DOE

Trevion II

19901 Germantown Road

Germantown, MD 20874

Patty Bubar

Director, EM-35

US DOE

Trevion II

19901 Germantown Road

Germantown, MD 20874

Jim Turi

Director, EM-36

US DOE

Trevion II

19901 Germantown Road

Germantown, MD 20874 
Jim Antizzo

Director; EM-37

US DOE

Trevion II

19901 Germantown Road

Germantown, MD 20874

Maureen Hunemuller

Director, EM-38

US DOE

Trevion II

19901 Germantown Road

Germantown, MD 20874

Other

Nick Orlando

US NRC

11545 Rockville Pike

Rockville, MD 20852

Jeanie Foster

23365 Salt Pork Road

Lawrenceburg, IN 47025

Virgil Lowery

DOE/HQ

DOE/Trevion II, EM-33

19901 Germantown Rd.

Germantown, MD 20874-1290

Greg Dugan

DOE/HQ

DOE/Trevion II, EM-33

19901 Germantown Rd.

Germantown, MD 20874-1290

Jay Rhoderick

DOE/HQ

DOE/Trevion II, EM-321

19901 Germantown Rd.

Germantown, MD 20874-1290
Greg Zimmerman (5)

Oak Ridge National Laboratories

Bldg. 4500 N, MS-6200

Bethel Valley Road

Oak Ridge, TN 37831-6200

\section{Internal}

MS 0734 Robert Waters, 6472 (20)

MS 0734 Larry Bustard, 6472

MS 0734 Marilyn Gruebel, 6472

MS 0734 Alva Parsons, 6472

MS 0734 Bruce Thomson, 6472

MS 0734 Maryann Hospelhorn, 6472

MS 1335 Margaret S.Y. Chu, 6801

MS 1303 Maureen Lincoln, 7573

Unclassified Unlimited Release Documents

1 MS 9018 Central Technical Files, 8523-2

50899 Technical Library, 4414

10619 Print Media, 12615

20100 Document Processing, 7613-2 For DOE/OSTI

Dist-8 